\title{
Intellectual property and developing countries : balancing rights and obligations
}

Citation for published version (APA):

Claessens, F. (2009). Intellectual property and developing countries : balancing rights and obligations.

[Doctoral Thesis, Maastricht University]. Wolf Legal Publishers. https://doi.org/10.26481/dis.20091125fc

Document status and date:

Published: 01/01/2009

DOI:

10.26481/dis.20091125fc

Document Version:

Publisher's PDF, also known as Version of record

\section{Please check the document version of this publication:}

- A submitted manuscript is the version of the article upon submission and before peer-review. There can be important differences between the submitted version and the official published version of record.

People interested in the research are advised to contact the author for the final version of the publication, or visit the DOI to the publisher's website.

- The final author version and the galley proof are versions of the publication after peer review.

- The final published version features the final layout of the paper including the volume, issue and page numbers.

Link to publication

\footnotetext{
General rights rights.

- You may freely distribute the URL identifying the publication in the public portal. please follow below link for the End User Agreement:

www.umlib.nl/taverne-license

Take down policy

If you believe that this document breaches copyright please contact us at:

repository@maastrichtuniversity.nl

providing details and we will investigate your claim.
}

Copyright and moral rights for the publications made accessible in the public portal are retained by the authors and/or other copyright owners and it is a condition of accessing publications that users recognise and abide by the legal requirements associated with these

- Users may download and print one copy of any publication from the public portal for the purpose of private study or research.

- You may not further distribute the material or use it for any profit-making activity or commercial gain

If the publication is distributed under the terms of Article $25 \mathrm{fa}$ of the Dutch Copyright Act, indicated by the "Taverne" license above, 
Intellectual Property and Developing Countries:

Balancing Rights and Obligations 
Intellectual Property and Developing Countries:

Balancing Rights and Obligations

F.J.R. Chassiens

ISBN: 978-9(--5850-472-2

Wolf Legal Publishers

POB 31051

6503 CB Nijmegen

ww'w.wolfpublishers.nl

Cover Design: Diego Oyarzun 


\title{
Intellectual Property and Developing Countries: Balancing Rights and Obligations
}

\author{
DISSERTATION \\ to obtain the degree of Doctor \\ at the Maastricht University, \\ on the authority of the Rector Magnificus, \\ Prof. dr. G.P.M.F. Mols \\ in accordance with the decision of the Board of Deans, \\ to be defended in public \\ on Wednesday 25 November 2009, at 14.00 hours \\ by
}

Fleur Jeanne Roxane Claessens 


\section{Supervisors}

Prof. dr. Anselm Kamperman Sanders Phd (Lond.)

Prof. dr. Peter Van den Bossche L.L.M.

\section{Assessment Committee}

Prof. dr. G.R. de Croot (Chairman)

Prof. dr. A.P.M. Coomans

Prof. dr. A.A. Quadvlieg (Radbound University Nijmegen)

Prof. dr. D.J. Gervais (Vanderbilt University Law School, Nashville, Canada) 


\section{Foreword}

And here it is... Writing this book has thought me a lot about intellectual property rights and development issues but it also gave me the opportunity to meet many friends both in professional and private circles. A number of people have been vital during this process and I would like to mention and thank them. First of all, my PhD supervisors Prof. Anselm Kamperman Sanders and Prof. Peter Van den Bossche, they have been involved from the beginning and have shared valuable information which was crucial to shape the content, style and structure of this book. Thank you both for your ongoing support, even whilst I was no longer in Maastricht. Anselm was crucial in facilitating my research at the Queen Mary Intellectual Property Research Institute (QMIPRI), University of London. Many thanks as well to Marjo Mullers for taking care of the layout. I would like to thank Prof. G.R. de Groot, Prof. A.P.M. Coomans Prof. A.A. Quadvlieg and Prof. D.J. Gervais, for their willingness to sit on the assessment committee. Furthermore, 1 would like to extend my thanks to the Department of Private Law and a number of friends at the Faculty of Law, Dorris de Vocht, Mieke Olaerts, Nicole Kornet and Alex van Gans. During my stay at QMIPRI, Prof. Graham Dutfield, Uma Suthersanen and Spyros Maniatis provided useful comments to earlier drafts of chapters contained in this book. Malcolm Langley always knew how to find the latest publications in the library. A special thanks to Rajesh Sagar, Stefan Hochhuth, Nico Tyabji, Els Kini and Barbara Olivaris, for reading parts of my manuscript and for providing comments. Andrea Leary, my special friend in Geneva, I am grateful for her support, her sense of humour and her iron discipline in editing the English text. Merci! Rosalie Gijselaers and Jacques Claessen, I am very happy to have you as my "paranimfen". Bedaank! "The biggest thank you, however, goes to my parents for their support, patience and love. 



\section{Table of Contents}

Foreword v

List of Abbreviations $X V^{\prime}$

Glossary xvii

Introduction 1

\section{Chapter One}

The International Legal Framework for the Protection of Intellectual Property

Introduction.

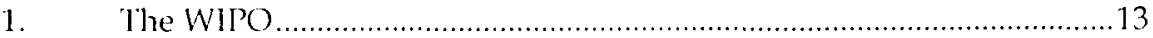

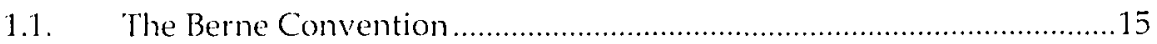

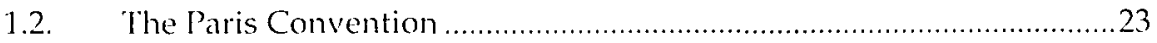

1.3. Shortcomings of the Paris Convention and the Berne Convention .....28

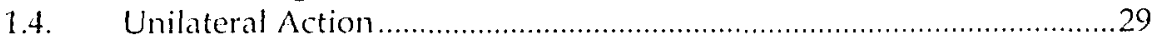

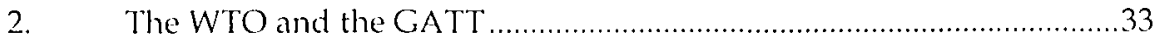

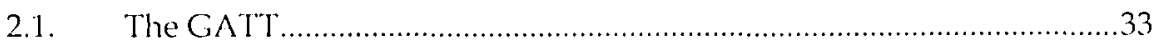

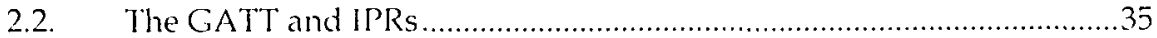

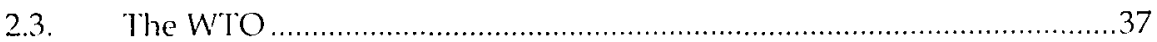

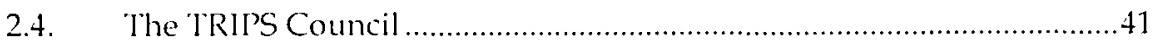

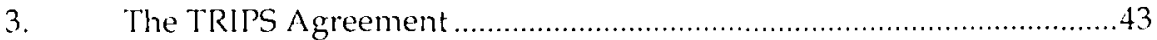

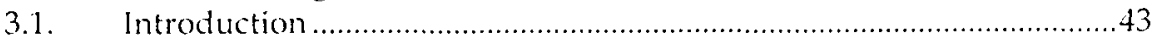

3.2. The Negotiation History of the TRIPS Agreement ...........................44

3.2.1. The 1982 Ministerial Meeting ........................................................ 48

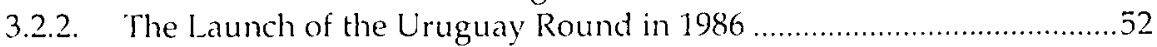

3.2.3. The 1988 Montreal Ministerial Meeting ..................................................55

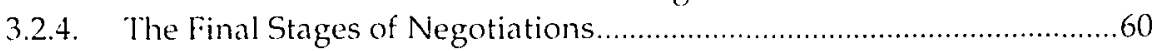

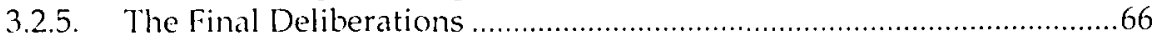

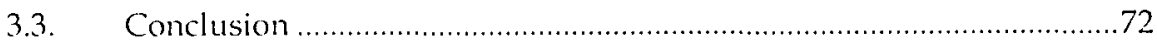

4. Proliferation of Bilateral and Regional Free Trade Agreements ..........77

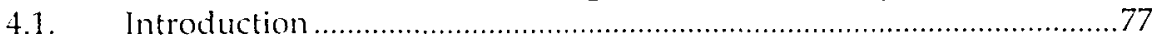

4.2. Implications of Bilateral and Regional Free Trade Agreements ..........79

4.3. The ACP - EC Economic Partnership Agreements ............................82

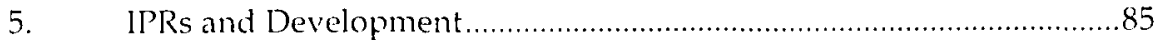

5.1. Rationale and Justifications Underlying IPRs ...................................85

5.2. A Halt to Overprotective Intellectual Property Measures.....................89

5.3. Different Stages of Development and IPRs .....................................91 
5.4. Short and Long Term Benefits of II'R ................................................ 94

5.5. Development and Globalisation ...................................................... 97

6. New Developments: The Wipo Development Agenda and the WTO Doha Declaration .................................................................... 98

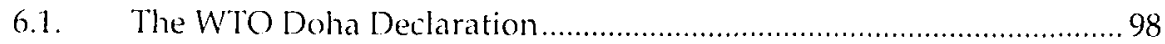

6.2. The WIPO Development Agenda......................................................... 99

6.2.1. Recommendations in Relation to Technical Assistance ...................... 102

6.2.2. Recommendations in Relation to Norm-setting................................ 104

6.2.3. Recommendations in Respect to Technology Transfer, ICT and Access to Knowledge.................................................................. 106

6.2.4. Recommendations in Respect to Assessment, Evaluation and Impact Studies............................................................................... 107

6.2.5. Recommendations in Relation to Institutional Matters Including Mandate and Govemance and Enforcement ..................................... 107

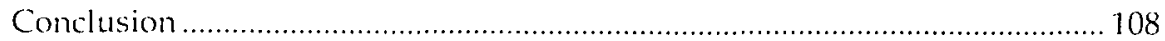

\section{Chapter Two}

\section{Analysis of the TRIPS Agreement Provisions Relevant for Developing Countries}

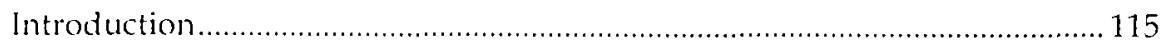

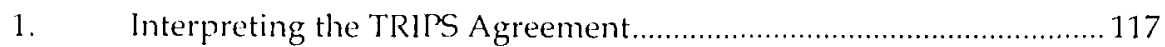

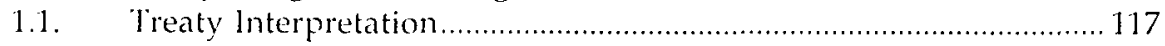

1.2. WTO Case Law on "Legitimate Expectations" ................................. 119

2. General Provisions and Main Principles of the TRIPS Agreement... 122

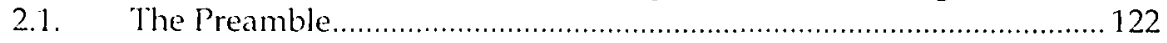

2.2. "Minimum Standards" and "Freedom of Implementation" ............. 125

2.2.1. WTO Case Law on Article 1 ................................................................ 127

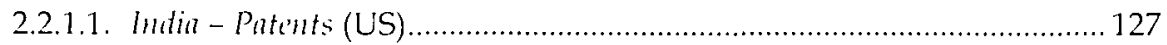

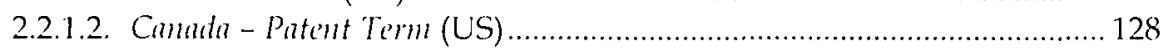

2.3. Definition of Intellectual Property Rights ..................................... 129

2.4. Incorporation of Provisions of Existing Intellectual Property

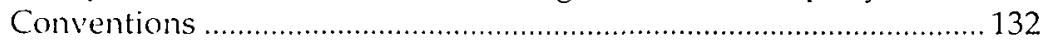

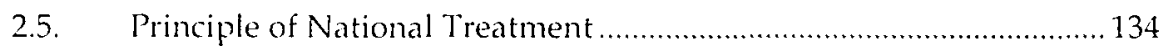

2.5.1. WTO Case Law on Principle of National Treatment .......................... 139

2.6. Principle of Most Favored-Nation Treatment..................................... 140

2.7. Doctrine of Exhaustion ............................................................... 142

2.8. Key Objective and Principle .......................................................... 144

3. Substantive Intellectual Property Rights .......................................... 145

3.1. Limitations and Exceptions to TRIPS Rights ................................. 145

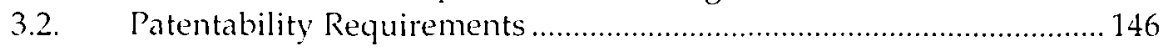

3.2.1. New Developments on Article 27 TRIPS Agreement ......................... 152

3.3. WTO Case Law on TRIPS Patent Provisions .................................... 155

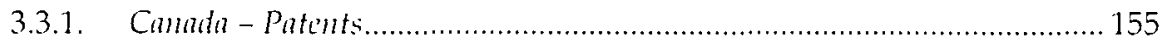

3.3.2. WTO Consultations on "Local Working" Requirement..................... 163 
3.4. Patent Term Duration...................................................................... 165

3.4.1. WTO Case Law on Patent Term Duration..........................................165

3.5. Draft Article 29bis: Disclosure of Origin of Genetic Material ............. 166

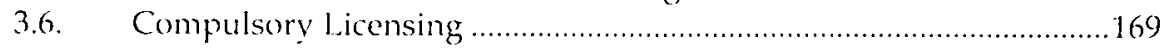

3.6.1. New Developments on Compulsory Licensing ................................176

3.6.2. The Doha Declaration on the TRIPS Agreement and

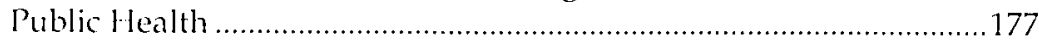

3.6.3. The Waiver Decision: Key to Improving Access to Essential

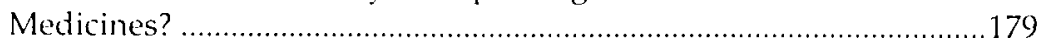

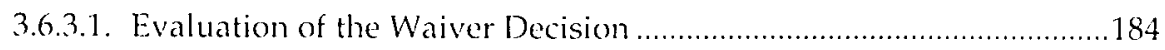

3.6.4. Article 31bis 'TRIPS Agreement: Making the Waiver Permanent .......189

3.6.5. Ratification of the TRIPS Amendment ................................................ 191

3.6.6. Use of the Compulsory Licensing Scheme ......................................... 192

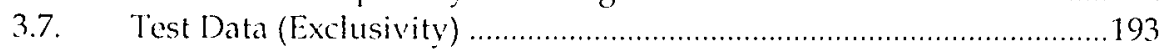

3.8. Initiatives on Access to Medicine Problem ........................................ 196

3.8.1. The World Health Organization and Access to Medicine ................... 198

3.8.2. UN Millennium Development Goal 6 .............................................201

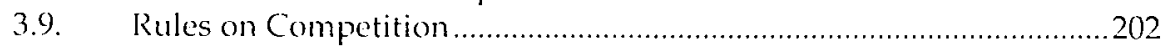

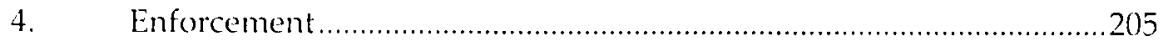

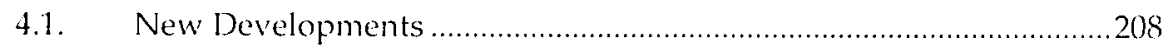

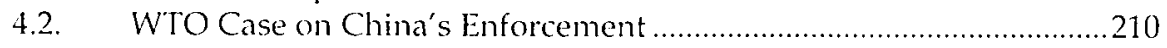

5. Transitional Arrangements and Technical Assistance ........................216

5.1. Transition Periods for Developing Countries ...................................216

5.2. Transition Periods for Least-Developed Country Members ..............218

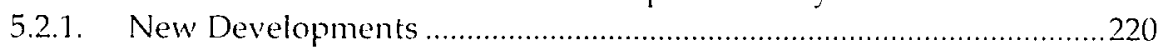

5.2.1.1. The Doha Declaration Development Requests ..............................220

5.2.1.2. The TRIPS Council Decision of 2005 ..............................................221

5.3. Technical Cooperation and Technical Assistance..............................222

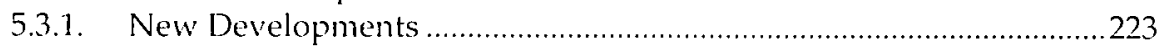

6. Protection of Existing Subject Matter .............................................226

6.1. W'TO Case Law on "Acts Which Occurred Before the Date of

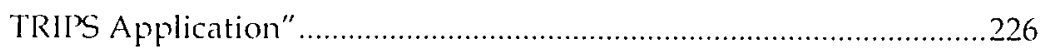

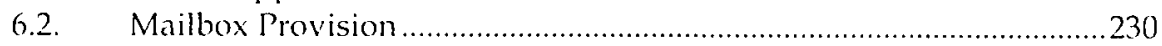

6.2.1. WTO Case Law on Article 70.8 TRIPS Agreement ............................232

6.3. Grant of Exclusive Marketing Rights ...............................................237

6.3.1. WTO Case Law on Article 70.9 TRIPS Agreement ...........................237

6.3.2. New Developments ...................................................................240

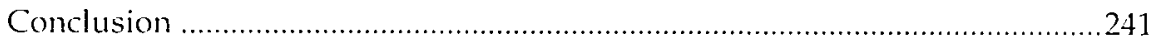

\section{Chapter Three}

\section{Searching for Traditional Knowledge Protection: The Internationalisation of Local Tradition}

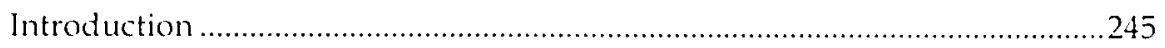

1. Traditional Knowledge: Issues at Stake ...........................................251 


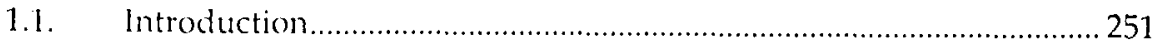

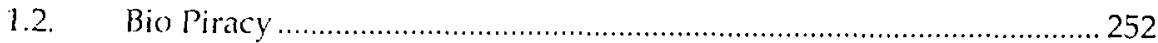

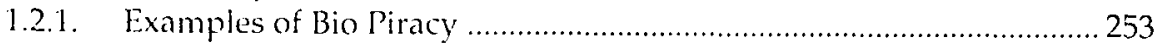

1.3. Problems in Protecting Traditional Knowledge ............................... 255

1.3.1. Why Protect Traditional Knowledge? ............................................. 258

2. Legal Initiatives on Traditional Knowledge Protection, Access to Genetic Material and the Promotion of Technology Transfer .......... 259

2.1. The Convention on Biological Diversity.......................................... 262

2.1.1. The Convention on Biological Diversity and Benefit Sharing........... 265

2.2. The TRIPS Agreement ............................................................... 267

2.3. The Convention on Biological Diversity versus the TRIPS Agreement ........................................................................ 271

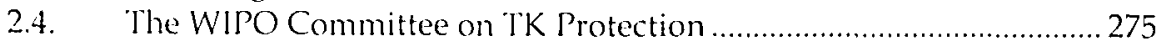

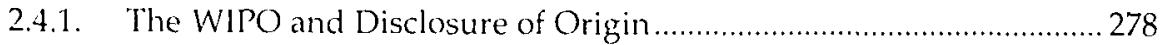

2.4.2. Criticism of the WIPO Committee on TK Protection........................... 280

2.5. The FAO Seed Treaty ........................................................................ 281

2.5.1. Access to Genetic Resources and Rights of Indigenous/ Traditional People .................................................................... 281

2.6. The Convention on Biological Diversity and the Transfer of Technology ................................................................................ 285

2.7. The TRIPS Agreement and Technology Transfer............................... 289

3. Different Modes to Protect and Promote Traditional Knowledge.... 291

3.1. Shaping Traditional Knowledgde Protection ................................... 291

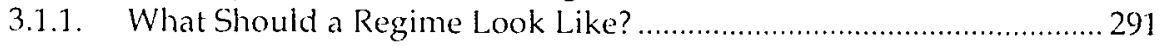

3.1.2. Entitlement to TK Protection............................................................294

3.1.3. TK Term Duration of Protection ........................................................ 294

3.2. Defensive Protection Measures.......................................................... 294

3.2.1. Contractual Agreements for Access to Genetic Resources .................. 297

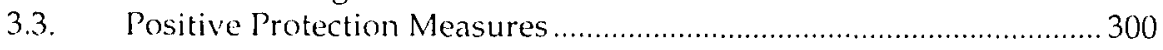

4. Intellectual Property Rights and Traditional Knowledge .....................301

4.1. Arguments Against Using IPRs to Protect Traditional Knowledge .. 301

4.2. Arguments in Favour of Using IPRs to Protect Traditional

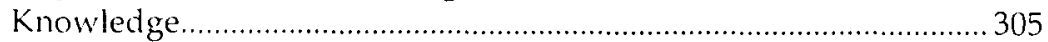

4.3. Correcting Failures in the Patent System ............................................... 306

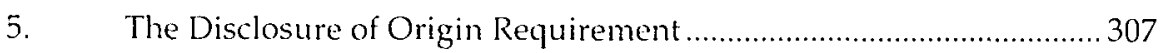

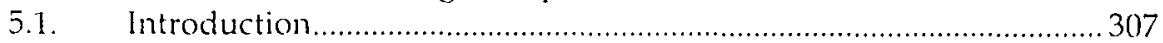

5.2. The Disclosure of Origin Requirement: Why, What, Where, How?.. 309

5.2.1. Rationale Behind a Disclosure of Origin Requirement...................... 309

5.2.2. What Type of Disclosure Requirement? ............................................. 310

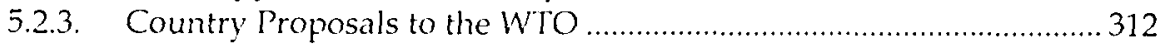

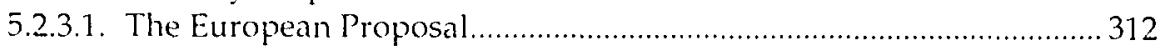

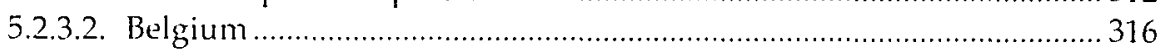

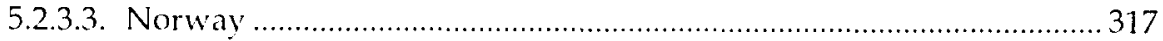

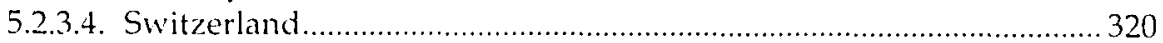


5.2.3.5. Draft Article 29bis Proposal by a Group of Developing Countries

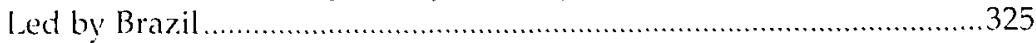

5.2.3.6. Japan

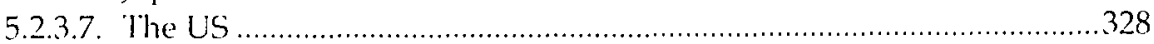

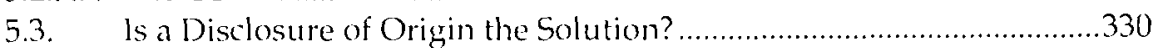

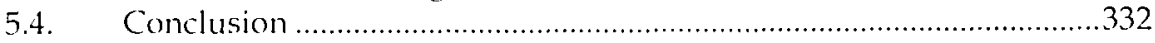

Conclusion - Some Considerations and Recommendations

.334

\section{Chapter Four}

The International Legal Framework for the Protection of Indications of Geographical Origin: Implications for Developing Countries

Introduction

1. International Legal Framework for IGOs: History, Terminology

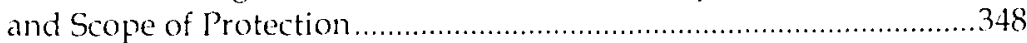

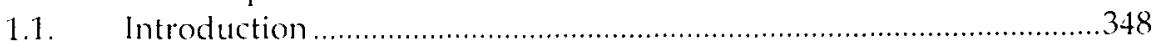

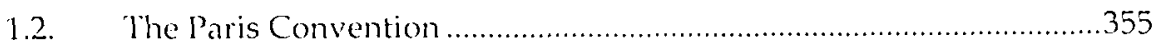

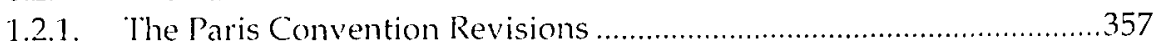

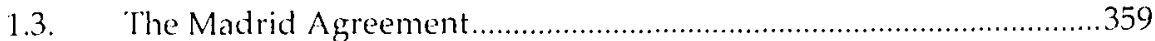

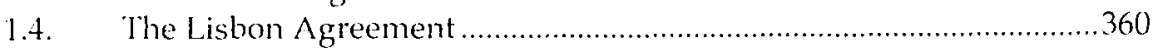

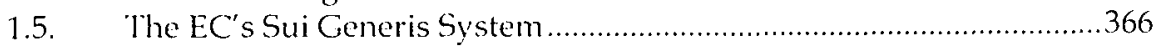

1.5.1. EC Case Law Defining Scope and Boundaries of GI System ..............370

1.6. The EC versus US in Relation to GI Protection .................................374

1.6.1. WrO Case EC - Trademarks and Geographical Indications ..............378

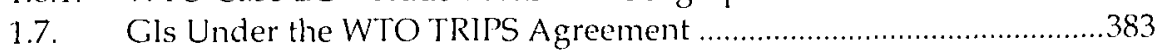

1.8. Role of Bilateral and Regional Free Trade Agreements ......................390

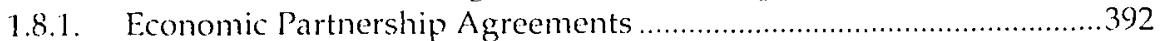

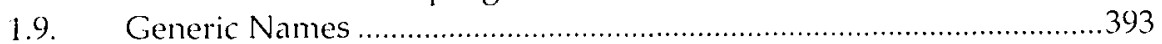

2. Legal and Economic Rationale Underlying GI Protection.................396

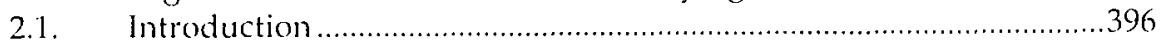

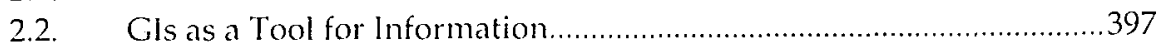

2.3. Gls as a Tool for Protecting Producer and Consumer ........................4 400

2.4. GI as Tool for Agricultural Development .......................................401

2.5. GI as Tool for Development - Redistribution of Wealth ..................402

2.6. Gls as a Tool for Cultural Heritage and Traditional Knowledge

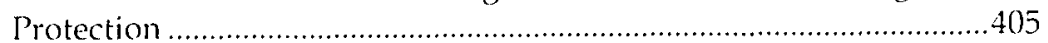

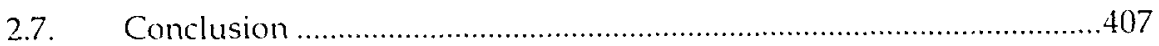

3. Trademarks Versus Indications of Geographical Origin ...................408

3.1. Conflicts Trademarks and Geographical Indications.........................411

3.1.1. Jurisprudence of the EC] on Relationship TMs and GIs ..................413

3.2. Indications of Geographical Origin Versus Collective and Certification Marks ................................................................420

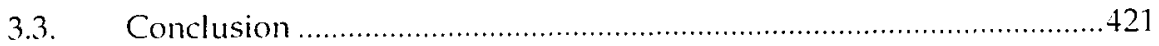

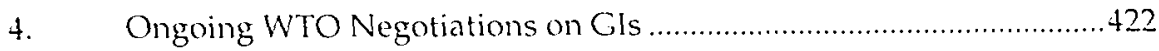


4.1. Extension of "Absolute" Protection to Other Products than

Wines and Spirits.

4.1.1. Discussions on the Manclate to Negotiate Extension......................... 423

4.1.2. Arguments For and Against the Extension of GI Protection .............. 426

4.1.3. Potential and Risks for Gl Protected Products from Developing Countries

4.2. Establishing a Multilateral Register for Wines (and Spirits)............. 430

4.2.1. The Proposal by the EC ................................................................... 433

4.2.2. The So-called Joint Proposal............................................................ 434

4.2.3. The Proposal by Hong Kong ....................................................... 435

4.2.4. Recommendations for Developing Countries on a Multilateral Register.

5. Recommendations for Developing Countries in Establishing IGO

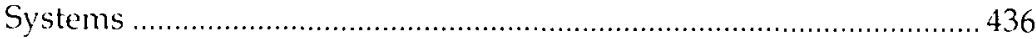

5.1. Examples of Successful GIs in Developing Countries ....................... 440

Conclusion

\section{Chapter Five}

\section{International Technology Transfer and Developing Countries}

Introduction 449

1. Technology Transfer: Characteristics, Scope and Access .................. 451

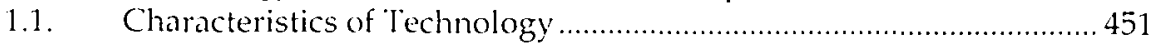

1.1.1. Publicly and Privately Developed Technology .................................. 455

1.2. Characteristics of Technology Transfer ............................................... 457

1.3. Why is Technology Transfer Important?.......................................... 460

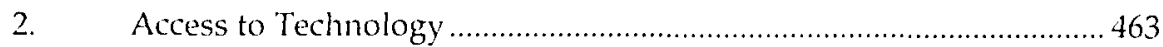

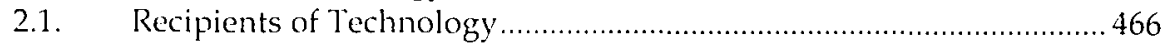

2.2. Recommendations for Developing Countries to Facilitate Technology Transfer ..................................................................... 468

3. The International Legal Framework on Transfer of Technology .......471

3.1. UNCTAD Draft International Code of Conduct on the Transfer

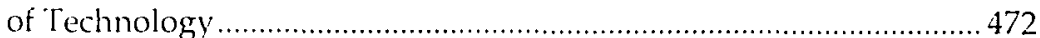

3.2. From the UNCTAD Draft TOT Code to Present ...............................475

3.3. The TRIPS Agreement Provisions on Technology Transfer ...............477

3.3.1. Articles 7 and 8 of the TRIPS Agreement .......................................4 479

3.3.2. Article 66.2 of the TRIPS Agreement ....................................................481

3.4. WTO Working Group on Technology Transfer ..................................482

3.5. The WIPO Development Agenda .....................................................4 484

3.6. Investment Treaties and Technology Transfer ...............................485

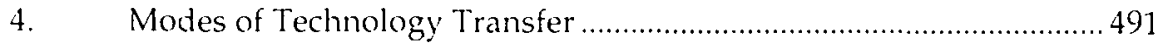

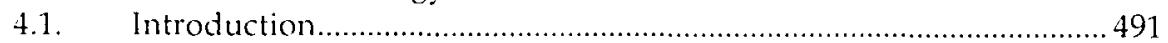

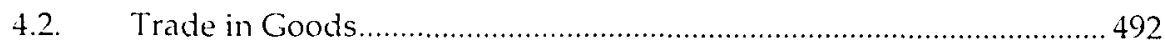

4.3. Foreign Direct Investment..............................................................493 


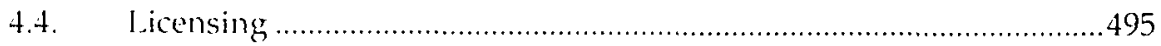

4.5. Labour Movement ...............................................................................4 497

4.6. Non-market Channels of Technology Transfer..................................501

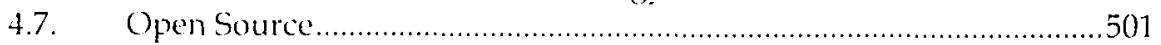

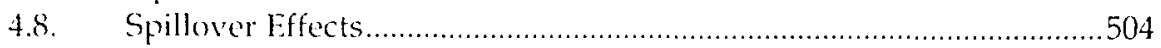

5. IPRs and International Technology Transfer ...................................506

5.1. The Role of IPRs in Facilitating Technology Transfer ........................508

5.2. Sector Specificity of the Role of IPRs ...........................................512

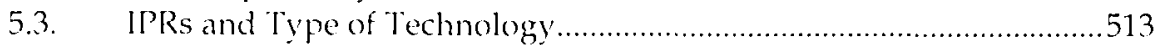

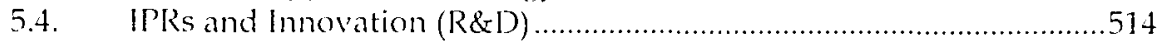

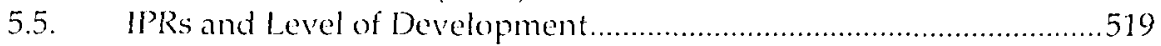

5.5.1. Market Failure Problems...............................................................5 522

5.5.2. IPRs and Development: The Case of Korea ........................................524

5.5.3. II'Rs and Development: The Case of Thailand..................................526

5.6. IIRs and Foreign Direct Investment.............................................529

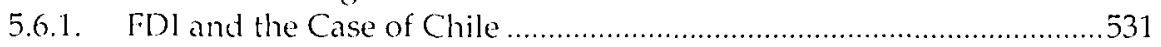

5.7. How Trade-Related are IPRs? What is the Role of IPRs in

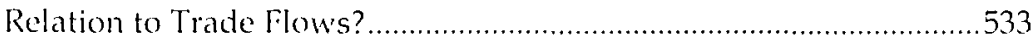

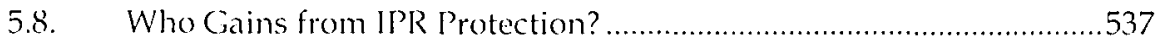

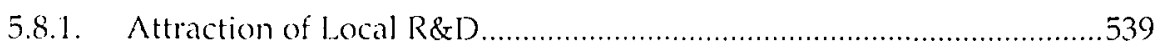

Conclusion and Recommendations for Developing Countries ......................539

\section{Summary and Conclusion}

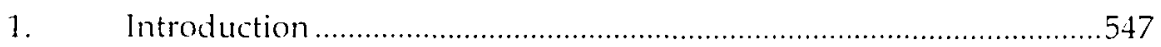

2. Development of International Legal Framework for the Protection of Intellectual Property

3. Balancing Public and Private Rights as well as Rights and

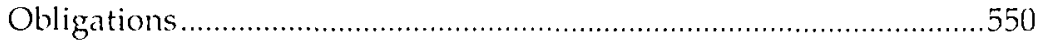

4. Using Flexibilities and Technical Assistance Possibilities ..................554

5. Geographical Indications and Its Potential for Developing Countries

6. The Search for Biodiversity and Traditional Knowledge Protection

7. The Role of IPRs in Technology Transfer .....................................575

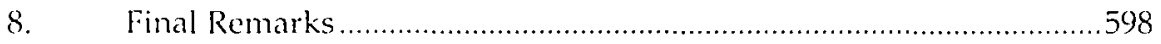

\section{Samenvatting}

1. Introductie. .601

2. De ontwikkeling van het internationale juridisch kader voor de bescherming van intellectuele eigendom 603

3. Rechten en plichten in balans brengen. .606 
4. Inzicht in TRIPS flexibiliteiten en technische bijstandsactiviteiten.... 611

5. Geografische herkomstaanduidingen en potentieel voor ontwikkelingslanden....

6. Zoektocht naar bescherming voor biodiversiteit en traditionele kennis

7. Intellectuele eigendomsrechten en de overdracht van technologie... 634

8. Slotconclusies 656

\section{List of References}

Books / Journals / Reports 659

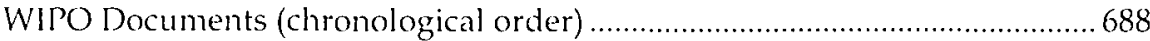

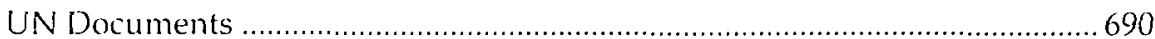

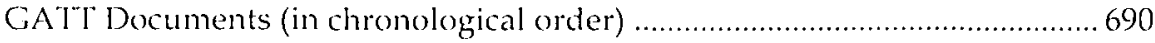

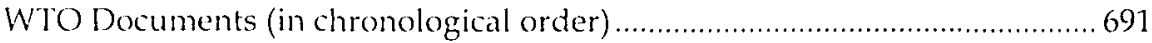

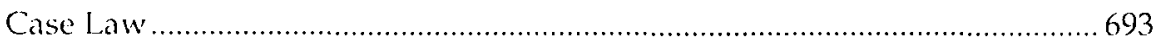

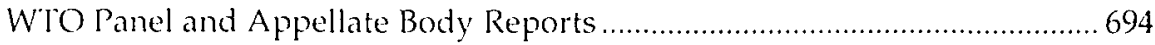

Annex One

Indications of Geographical Origin - Terminology, Concepts and Characteristics

Annex Two

Indications of Geographical Origin - Legal Framework 703

Annex Three

Draft International Code of Conduct on the Transfer of Technology [1985 version] Unctad

Curriculum Vitae 731 


\section{List of Abbreviations}

\begin{tabular}{|c|c|}
\hline$\triangle B S$ & Access and Benefit Sharing \\
\hline $\mathrm{A} \& \mathrm{O}$ & Appellations of Origin \\
\hline$\triangle R I P O$ & African Regional Industrial Property Organization \\
\hline $\mathrm{BC}$ & Beme Convention \\
\hline$C B D$ & Convention on Biodiversity \\
\hline DSS & Dispute Settlement System \\
\hline DSU & Dispute Settlement Understanding \\
\hline EFTA & European Free Trade Area \\
\hline FAO & Food and Agriculture Organization \\
\hline FIA & Free Trade Agreement \\
\hline GAT"' & General Agreement on Tariffs and Trade \\
\hline Gl & Geographical Indication \\
\hline MPMA & $\begin{array}{l}\text { International Federation of Pharmaceuticals Manufacturers' } \\
\text { Association }\end{array}$ \\
\hline IGC & $\begin{array}{l}\text { Intergovernmental Committee on Intellectual Property and } \\
\text { Genetic Resources, Traditional Knowledge and Folklore (WIPO) }\end{array}$ \\
\hline $1 \mathrm{GO}$ & Indication of Geographical Origin \\
\hline IIPA & International Intellectual Property Association \\
\hline IPR & Intellectual Property Right \\
\hline MDG & Millennium Development Goals \\
\hline NAFTA & North American Free Trade Organization \\
\hline OAPl & $\begin{array}{l}\text { Organisation Africaine de la Propriété lntellectuelle / African } \\
\text { Intellectual Property Organization }\end{array}$ \\
\hline OECD & Organisation for Economic Co-operation and Development \\
\hline PC & Paris Convention \\
\hline PDO & Protected Designation of Origin \\
\hline PGI & Protected Geographical Indication \\
\hline PIC & Prior Informed Consent \\
\hline $\mathrm{R} \& \mathrm{D}$ & Research and Development \\
\hline Seed Treaty & $\begin{array}{l}\text { AO International Treaty on Plant Genetic Resources for Food and } \\
\text { Agriculture (FAO) }\end{array}$ \\
\hline TK & Traditional Knowledge \\
\hline TOT & Transfer of Technology \\
\hline TOT Code & $\begin{array}{l}\text { Draft International Code of Conduct for the Transfer of } \\
\text { Technology }\end{array}$ \\
\hline TRIPS & $\begin{array}{l}\text { Trade Related Aspects of Intellectual Property Rights } \\
\text { (Agreement) }\end{array}$ \\
\hline UN & United Nations \\
\hline UNCTAD & United Nations Conference on Trade and Development \\
\hline UPOV & $\begin{array}{l}\text { Uniom International pour la Protection des Obtentions Vegitales / } \\
\text { International Union for the Protection of New Varieties of Plants }\end{array}$ \\
\hline USTR & Office of the United States Trade Representative \\
\hline WIPO & World Intellectual Property Organization \\
\hline
\end{tabular}


LISI OI ABBREVIATIONS

WHO World Health Organization

Wlo World Trade Organization 


\section{Glossary}

Anell Draft: This draft corresponds to the consolidated draft text of the Report to the General Negotiation Group on the status of work in the TRIPS Negotiating Croup, including Trade in Counterfeit Goods of July 23, 1990. Draft is named after the Chairman Lars E.R. Anell. (MTN.GNG/NG11/W/76, 23 July $1990)$.

Appellate Body: An independent body, consisting of seven persons, responsible for the appeal in WTO disputes under the Dispute Settlement System. The Appollate Body reviews the findings in the WTO Panel Reports.

Bernc Coniention for the Protection of literny and Artistic Works: First multilateral convention establishing rules on literary and artistic works (copyright and related rights), established in 1886 and administered by WIPO, last revised at Paris in 1971 and amended in 1979 in Berne.

Bolar cxamption: Experiments made for the purposes of seeking regulatory approval for marketing a product after the expiration of a patent.

Brussels Drnft: This draft corresponds to the Ministerial Text of December 1990 containing the Draft Final Act Embodying the Results of the Uruguay Round of Multilateral Trade Negotiations, Revision, Trade-Related Aspects of Intellectual Property Rights, and Including Trade in Counterfeit Goods. Anell prepared this Draft on his own responsibility and it was said to reflect the results of the negotiations through 22 November 1990. This Draft was submitted to the Brussels Ministerial Conference to be held on 3-7 December 1990. (MTN. TNC/W/35/Rev.1, 3 December1990).

Bio piracy: Bio piracy refers to the misappropriation - generally by means of patents - of genetic resources and associated traditional knowledge.

Compulsory licensing: Article 31 of the TRIPS Agreement provides for "Other use without authorisation of the right holder", i.e. compulsory licensing. A compulsory licensing enables a WTO Member to work a patent (product or process) without the explicit consent of the patent right holder but subject to certain conditions. In the case of a grant of a compulsory license the public interest to access the pharmaceuticals is rated higher than the private interest of the patent right holder.

Contention on Biolugical Dizersity (CBD): Intemational treaty adopted at the Earth Summit in Rio de Janeiro in 1992, having as its main goals the conservation of biological diversity, the sustainable use of its components and the 
promotion of a fair and equitable sharing of benefits arising from genetic resources.

Copyright: Form of IPR, the creator of an original "literary and artistic" work receives exclusive rights for a certain time period in relation to that work, including its publication, distribution, translation and adaptation. After the duration lapses the work is said to enter the public domain.

Connterfiting: A counterfeit goods refers to imitations made usually with the intent to deceptively represent its content or origins, most frequent in relation to trademarks. The counterfeiters try to deceive the consumer into thinking they are purchasing a legitimate item, or convince the consumer that they could deceive others with the imitation. An item which doesn't attempt to deceive, for instance a copy of a DVD with missing or different cover art, is often called a "bootleg" or a "pirated copy" instead. Counterfeiting is very popular, in particular in Asian countries: it is a lucrative business to firms wishing to free ride on well-known brand names. Highly fashionable products such as "Luis Vuitton" bags or "Christian Dior" sunglasses, "Gucci" perfumes are reproduced using cheaper production processes and as a consequence these products are often of an inferior quality but bear the name of the trademark owner or a similar name. Notably, counterfeiting rarely leads to absorption by the rival of new or improved technologies.

Dispute Settl'ment Luderstanding (DSLI): The Understanding on Rules and Procedures Governing the Settlement of Disputes (DSU) is a legal text containing the rules for dispute settlement in the WTO.

Dunkel Draft: Draft named after the GATT Director at that time, who submitted his proposal in December 1991 entitled "Draft Final Act Embodying the Results of the Uruguay Round of Multilateral "Trade Negotiations". (MTN/ TNG/W/FA, 20 December1991).

Exhmustion of IPRs (also referred to as parallel importation): The principle that once a product has been sold on a market, the intellectual property owner no longer has any rights over the further sale of the product. The principle is applicable only when a product made legally (i.e. authorised not pirated or counterfeited) in one country is imported into another country without the permission of the intellectual property right-holder (e.g. the trademark or patent owner). Countries' laws vary as to whether the right continues to be exhausted if the product is imported from one market into another. Countries can choose between international, regional or national exhaustion. For instance, in the European Union the principle of regional exhaustion is applicable. This implies that one may buy cheap pasta in Italy and sell it for a higher price in Germany without interference by the original right holder as its right to sell and distribute are exhausted. Australia applies a policy of international exhaustion, like Australia. The United States apply national exhaustion. A debate among WTO 
Member governments is whether this principle applies to products put on the market under compulsory licences.

Europerm Patent Office: Organ of the European Patent Organization which conducts a centralised patent grant procedure under the European Patent Convention.

Goneral Agre'ment on Tariffs and Trade (GATT): The Bretton Woods Conference acknowledged the need for an international agreement on tariffs and trade as part of a larger plan for economic recovery after World War II - however, attempts to establish the International Trade Organisation (ITO) failed. In 1947 in Geneva the General Agreement on Tariffs and Trade (GATT) was created with the purpose to reduce barriers to international trade by diminishing tariff barriers. 'The functions of the CAIT"l' have been replaced by the WTO in 1994 which was established through the final round of trade negotiations in the early 1990s.

Geogriphical Indications: Indications, such as place names used to identify products (for example, "Champagne", "Tequila" or "Roquefort") which have a particular quality, reputation or other characteristic because they derive from that geographical origin.

IPRs: The legal term intellectual property rights (IPRs) refers to creations of the mind including copyrights, designs, trademarks, patents, geographical indications and related rights. Under intellectual property law, the holder of these rights receives exclusive rights to the creative work, commercial symbol (or trade name), or invention. New forms of IPR include databases, computer programmes and extension of existing rights to the information society.

License: Agreement by which the owner of a patent confers permission to other(s) to carry out an action which, without such permission, would infringe the patent. A license, which can be exclusive or non-exclusive, does not transfer the ownership of the invention to the licensee.

Mailbox system: The term "mailbox system" is used as shorthand for provisions to be put in place which allow for the filing of patent applications for pharmaceutical and agricultural chemical products as required by Article 70.8 of the TRIPS Agreement for countries that make use of the transition period and therefore do not yet provide product patent protection for pharmaceuticals and for agricultural chemical products. For these products they have to create a "means" which allow for the filing of patent applications for pharmaceutical and agricultural chemical products.

Moral right: Right conferred to the creator of a copyright to claim authorship of the work (the right to be named the author) and to object to any distortion, mutilation or other modification of, or other derogatory action in relation to the said work, which would be prejudicial to his honor or reputation. Notably, 
economic rights in a work can be transferred; the moral right stays with the creator.

Most-Farourd-Nation principle: The principle of not discriminating between one's trading partners and as a consequence favours, privileges or immunities granted by a Member to the nationals of any other country shall be accorded immediately and unconditionally to the nationals of all other Members. Within the framework of the WTO it is a key principle.

National tratment principle: Each Member shall accord to the nationals of other Members treatment no less favourable than that it accords to its own nationals with regard to the protection of intellectual property. Within the framework of the WTO it is a key principle.

Paris Coniention for the Protection of Industrial Property: First international convention setting the rules on industrial property rights established on 20 March 1883 and administered by WIPO and subsequently revised. It initiated a system according to which an applicant was granted a right of priority after a first filing, for the filing in other countries.

Pat'nts: Patents protect inventions including methods of making a new substance and/or the process of making that substance. An invention is an idea which permits the practical solution of a specific problem in a field of technology. Its main objective is to encourage innovation: in exchange for public disclosure of an invention, the inventor receives a temporary set of exclusive rights over his invention. After this period of time the invention enters into the public domain. The grant of these exclusive rights is justified on the grounds that due to the work of the inventor who devised and disclosed the improvement, nobody would have been able to use it at that or any other time since it and the manner of producing it may have remained unknown. All patent agreements require a set of conditions to be fulfilled before a patent will be granted protection. The TRIPS Agreement sets out that an invention in order to qualify for a patent (patentability requirements) needs to be new, involve an inventive step and is capable of industrial applicability plus it needs to involve patentable subject matter, i.e. be eligible for patent protection and not contrary to morality or ordre public.

Patent Cooperation Treaty (PCT): The PCT creates a system in which it is possible to seek patent protection in a large number of countries by filing a single international application (PCT application). Treaty dated 19 June 1970 and administered by WIPO.

Patent disclosure: Divulgence of the invention in a manner sufficiently clear and complete for it to be carried out by a person skilled in the art, which an applicant must make in the patent application in return for the possible grant of a patent. 
Patent pooling: Agreement between two or more patent owners in order to cross-license patents relating to a certain technology.

Patentability refuirment: Certain substantive requirements that an invention must meet in order for it to be patentable.

Patent requir'ment - Novelty: A patentability requirement according to which an invention is not patentable if it was already known before the date of filing.

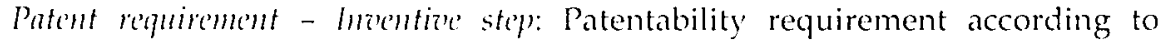
which an invention shall be considered as patentable if having regard to the "state-of- the- art", it is not obvious to a person skilled in the art and it is not part of prior art. The invention should be sufficiently inventive, i.e. nonobvious, in order to be patented.

Patent - Priority date: Priority date is the date of filing of a first patent application in a State party to the Paris Convention. The applicant is entitied to a right of priority starting from this date.

Patent - Prior art: Item of the "state-of-the-art" taken into consideration in deciding whether the invention to which the application relates is new and involves an inventive step. Everything made available to the public by means of a written or oral description, by use, or in any other way, before the date of filing of the patent application.

Patent - Prionity right: The priority right is a right to claim priority from an earlier patent application, i.e. the priority date will count as the date of filing of the subsequent patent applications filed during twelve months following the priority date in respect of the same invention (under the I'CT). Claiming priority gives the later filed application a priority date of the filing date of the earlier application. The Paris Convention introduced this concept.

Piracy: Piracy refers to the unauthorised copying (and thus for commercial purposes) of materials protected by intellectual property rights and unauthorised commercial dealing in copied materials, such as electronic and audiovisual media. It includes trade in computer programmes, and sound recordings (audio and video cassettes providing unauthorised copies of musical performances and films).

Plant patents: In some jurisdictions, notable under US law it is possible to obtain patent protection for distinct and new variety of a plant which is reproduced asexually.

Public domain: Intellectual property for which the term of protection has run out, as well as IP which has been forfeited or unclaimed and goods that are not protected under existing IP legislation. 
Registered design: Exclusive right granted to the author of the outward appearance of a product or part of it which results from the lines, contours, colour, shape, texture, materials and its omamentation.

Rescarch exemption or snfe harbonr exemption under US laze: Limited exception to the rights conferred by a patent allowing third parties to perform purely research based activities with no-commercial implications with regard to the subject matter of a patented invention.

Reverse engine'ring: A method of evaluation of a product in order to understand its functional aspects and underlying ideas. This technique may be used to develop a similar (or even identical) product. Reverse engineering of computer programs under certain conditions is permitted under the copyright rules of the TRIPS Agreement but reverse engineering under patent law is not allowed.

Trade mark: A trademark is a distinctive sign or indicator used by an individual, business or legal entity to identify that the products and or services originate from a unique source of origin and to distinguish them from those of other entities. The legal theory behind providing trade mark protection is that it provides information to consumers to protect the public from confusion over the source of the goods.

Trabitional knowledge/mdigenous knowledge: The knowledge, innovations and practices of indigenous people and local communities passed on from generation to generation. It can comprise, for instance of a culinary recipe, a cultivation technique or medical treatment.

Thrme secret: Undisclosed information which is not generally known or accessible, has commercial value because it is secret, and has been subject to reasonable steps to keep it secret.

Treaties: Classic source of rights and obligations, of importance to the public as a whole and government in particular. For international organisations, treaties are not only one of the most important tools to conduct their operations, but are also their constituent instruments on which their whole existence is build.

TRIPS Agr'ement: Agreement negotiated during the Uruguay Round, adopted as annex $1 C$ to the WTO Agreement outlining minimum standard provisions for the protection of intellectual property rights. The IRIPS Agreement was signed on 15 April 1994, legal effect as of 1 April 1996 for developed countries and 2000 for developing countries and countries in economic transition. Least

1 See Danino Zapato 2006. 
Developed countries obtained an extended transition period till 2013 and 2016 for patent protection for pharmaceutical products.

TRIPS Conncil: WTO Body responsible for the administration and implementation of the TRIPS $A$ greement, regular meetings take place in Geneva.

Urugumy Romud: The Uruguay Round of Multilateral Trade Negotiations launched at Punta del Este, Uruguay in September 1986 and concluded in Geneva in December 1993. The result of these negotiations reflected the $W$ TO Agreement signed by Ministers in Marrakesh, Morocco, on 15 April 1994.

Litility model: Form of IPR also referred to as petty patent or utility innovation. Utility models seek to protect innovations of a rather incremental character which may not meet the patentability criteria. Hence, utility models are easier to acquire as inventive step is usually not required. The duration of protection is shorter than under patent protection.

Wairer: Permission granted by WTO Members allowing a WTO Member not to comply with normal commitments. Waivers have time limits and extensions have to be justified.

WIPO: The World Intellectual Property Organization is a specialised agency of the United Nations, responsible for the administration of various international treaties dealing with different aspects of intellectual property rights protection and is based in Geneva, Switzerland.

WTO: The World Trade Organization is an international organisation dealing with the rules of trade between nations. It is a rules-based, member-driven organisation and the rules are the outcome of negotiations among members. It administers the WTO agreement, is a forum for trade negotiations, handles trade disputes, monitors national trade policies, provides technical assistance to developing countries and cooperates with other international organisations. The Secretariat is based in Geneva, Switzerland.

WTO Agre'ment: The WTO Agreement is also referred to as the "Final Act of the 1986-1994 Uruguay Round of Trade Negotiations" although strictly speaking the Final Act is the first of the Agreements. The WTO Agreement is an umbrella of agreements dealing with trade in goods (including tariffs, sanitary and phytosanitary measures, agriculture, investment, technical barriers to trade, subsidies and countervailing measures, antidumping), services, intellectual property rights, dispute settlement and a number of plurilateral agreements. 



\section{Introduction}

At the multilateral, regional and local level we can identify, in relation to intellectual property rights (IPRs), a trend towards: broadening of the scope of substantive rules; extending of the term duration and removing the limitations and exceptions to rules. As a result, the remaining flexibilities left to the individual countries in how they follow and develop their own IPR strategies, in line with their socio-economic developments needs, diminish, and the public domain shrinks. Do these pursued negotiation strategies do justice to creating a good equilibrium between incentives for creativity and innovation and public policy interests? Intellectual property rights were first given protection in the fifteenth century in Venice. Notably, they were controversial then and have remained so. One of the main reasons for this is the lack of cumulative empirical evidence that IPR protection is essential for innovation and economic growth. The introduction of intellectual property within the framework of the WTO has aroused much controversy, especially amongst developing country members - the focus of this research. This thesis aims to identify available flexibilities in the TRIPS Agreement which could be of use to developing country members and provide recommendations for the pursuit of policies in line with their socio-economic development needs.

There is an on-going debate whether strong(er) intellectual property protection speeds up or slows down technological change and, by implication economic growth. Developed countries welcomed the harmonisation of intellectual property rights at a scale not previously accomplished under the TRIPS Agreement. However, they were not fully satisfied as demonstrated by the ongoing search for bilateral and regional free trade agreements in which increased standards of IPR are sought: hence developing countries have been confronted by an international policy motive almost as a fait accompli.

IPR is an exciting field of public policy and constantly in a state of flux since every year new IP laws are passed at the domestic, regional and international level, treaties are amended, and intellectual property infringement disputes arise. To a large extent this is due to changes in technology that demand an update, restatement or a complete reverse of existing intellectual property laws. Intellectual property has been harmonised at the international level through numerous conventions and treaties, most notably the Paris Convention, the Berne Convention and most recently the WTO Trade Related Aspects of Intellectual Property Rights (TRIPS) Agreement. Unilateral pressure, the limited scope of substantive subject matter and the lack of effective enforcement measures and dispute settlement mechanisms led to the introduction of intellectual property rights in the Uruguay Round of multilateral trade negotiations and were pursuant to the conclusion of the TRIPS Agreement. The 
name of the agreement - trade related aspects of intellectual property rights was an achievement in itself.

\section{Chapter One}

The TRIPS Agreement is a serious attempt to converge intellectual property rights implementation, enforcement and coordination at the international level. The Agreement links a country's access to export markets to its adoption of minimum standards of IPRs. It sets out minimum standards of protection for the main categories of intellectual property, building on the WIPO administered Paris Convention and the Berne Convention, but also adding new substantial subject matter and administrative procedures. It also includes extensive provisions on enforcement of IPRs to combat counterfeiting and piracy and other infringements of intellectual property. The TRIPS Agreements most hailed victory is its link between the agreement and the Dispute Settlement Understanding, which implies that infringement cases can be brought before a WTO panel and in appeal to the Appellate Body of the WTO Dispute Settlement System. In fact, the TRIPS Agreement being subject to the Dispute Settlement System is generally perceived as a major achievement because it gives "teeth" to the protection and enforcement of IPRs. Economic sanctions can be imposed with "cross compliance" consequences which was not possible in previous IP disputes. However, the conclusion of the TRIPS Agreement also restricts countries' freedom to determine IP policies, for instance the areas of non-patentability, the duration of patents and possibilities to provide exceptions and limitations.

The Uruguay Round of negotiations has been criticised for neglecting developing countries' needs and interests. By and large, the developing countries did not really have a choice whether to harmonise intellectual property protection in the framework of the GATT Uruguay Round. There was no real alternative because the TRIPS Agreement is part of a single undertaking - the WTO Agreement in all its facets. To continue insisting on excluding intellectual property would have meant abandoning cumulated market access rights a crucial issue within the WTO framework. The TRIPS Agreement in its final form is the result of continuous lobbying by so-called non-governmental organisations ( $\mathrm{NGO}^{\prime}$ ), although at the time of the UR they were mainly lobbying for private industry. Recently, this has changed and there are now many NGOs supporting the interests of developing countries and stimulating public policy objectives. These organisations are very well informed and contain a lot of expertise and technical knowledge which makes them capable of influencing the decision-making process. Arguably, these efforts have resulted in establishing the WIPO Development Agenda, The Declaration on TRIPS and Public Health, the Declaration of Indigenous Peoples, the TRIPS Amendment in relation to Compulsory Licensing and the large support for a disclosure of origin requirement. All these activities aim to bring back the public interest balance in the international legal framework for intellectual property protection. 
Until the adoption of the TRIPS $A$ greement, multi-national IP agreements had to a great extent been managed at the WIPO, an UN agency. But when IP was linked explicitly to trade in the GATI and the WTO, its status changed fundamentally. With the establishment of the TRIPS Agreement, intellectual property was included into the framework of multinational trade negotiations and so came to the attention of a broader range of policymakers in government and to the public as a whole. Ever since the adoption of the TRIPS Agreement, intellectual property has not only been of interest to inventors, creators, industry, lawyers, and policy makers but also the great potential and risks of intellectual property right protection has come to the attention of environmentalists, anthropologists, indigenous interest groups, social society, non-governmental organisations, trade groups and academia. Intellectual property protection has gone global and it is ubiquitously present in the media and prominently present on the agenda of the WIPO and the WTO TRIPS Council meetings. The history and the negotiation process underlying the international legal framework for IPR protection will be addressed in chapter one of this book as will the rationale and justifications behind granting IPR protection.

\section{Chapter Tien}

The conclusion of the TRIPS Agreement has brought about many challenges for developing countries. Foremost, the complexities of implementing substantive intellectual property provisions into their national legislative system, including the assertion of adequate enforcement mechanisms, such as border control and judicial review possibilities. No doubt, these mandatory changes caused and will continue to raise enormous transaction costs for the developing and least developing countries.

The TRIPS Agreement is comprehensive in coverage, in that it provides differential treatment for developing countries in some areas, transition periods, dispute settlement, and enforcement mechanisms. It is also a truly global endeavour with so many signing Member countries. It is also clear that it is the result of a consensus-building process: all parties have lost and gained during the negotiation process. The preamble of the TRIPS Agreement reflects this compromise. The question however is whether this compromise has set the right balance between the rights of the IPR right-holders and the users? The line between providing an incentive for foreign investment and protecting public interest is a balance that must be struck against a backdrop of local social and economic considerations. Notably, the Preamble recognises that "the provision of effective and appropriate means for the enforcement of trade-related intellectual property rights, [should take] into account differences in national legal systems". However, it is also questionable whether this is a realistic goal considering the prescriptive nature and content of the substantive obligations under the Agreement. Chapter two outlines the rights and obligations and key principles embodied in the TRIPS Agrcement. Chapter two provides an analysis of the key provisions of the TRIPS Agreement and 
includes a study of the presumed negotiation history, the interpretation of the Article in terms of case law and current developments. It scrutinises the principles and objectives underlying the TRIPS Agreement, as well as analysing the substantive provisions and their implications for developing countries. In addition it examines the TRIPS requirements in relation to enforcement. This analysis will include the WTO DSU case law and current developments in the relevant WIPO committees plus the WTO TRIPS Council deliberations as well as free trade agreements. It also adds new developments such as the extension of the transition periods and the TRIPS formal amendment on compulsory licensing.

\section{Chipter Thre'}

Developing countries hold the majority of the world's genetic resources and TK and are concemed about contemporary practices that appropriate biological diversity and associated knowledge. Chapter three of this book sets out the ongoing political debate on the protection of traditional knowledge (TK) and defensive and positive protection measures. TK is manifested in various ways, and could comprise, for instance, a culinary recipe, a cultivation technique or medical treatments. Increasingly, local craftsmanship, knowledge of farming techniques and comprehension of flora is recognised and valued for their ability to protect the environment and its biodiversity and to instigate further scientific development. Interest in the protection of TK at the international level has grown significantly over the last two decades. Currently, the WIPO Intergovernmental Committee on Intellectual Property and Genetic Resources, Traditional Knowledge and Folklore (IGC) is discussing the relationship between IPRs and biodiversity, TK and access to genetic resources. Unfortunately, after eight years of discussions WIPO negotiators remain divided on whether to create a new binding international treaty to protect genetic resources, TK and folklore against misappropriation. Chapter three will look at these issues in more detail. Chapter three will also address the relationship between the TRIPS Agreement and the CBD. Pursuant it will analyse the existing legal framework to protect $T \mathrm{~K}$, its shortcomings and potential.

At first industry's focus was mainly on the potential of genetic resources and associated TK for the development of new pharmaceutical products. But during the 1990s, bio prospecting associated with the plants and resources of indigenous people peaked. Advances in biotechnology resulted in a rapid increase in the patenting of biological material obtained from developing countries but modified and enhanced in industrial country laboratories using state-of-the-art science and techniques. The countries of origin of the genetic resources and the indigenous and local communities, holders of the associated TK, have not been consulted by those that access and use their resources to obtain economic advantages, and they have received limited or no benefit deriving from their use. This essentially raises a question as to how one can control forfeiture of the genetic resources and associated traditional knowledge collected, preserved, conserved and enhanced over countless years by 
local communities or indigenous people. And if one can, what kind of control mechanisms should exist? Should the solution be within the legal framework for IPR protection or are sui generis types of protection more suitable? Discussions within IGC focus on what a legal regime should look like, and who would qualify for protection and for how long. The different modes to protect and promote TK are still under discussion as well as a number of questions such as: "What should a regime look like?", "Who qualifies for protection and for how long?" Should protection be granted for a limited amount of time? Is the existing IPR framework suitable for protecting TK. What are the arguments in favour and against using IPRs to protect TK. These questions are addressed in chapter three.

Solutions could be found within the framework of either defensive forms of protection or positive mechanisms, and may lie within or beyond IPR regimes. Deliberations within the CBD have proposed the development of a certificate of origin. This would serve as a type of passport or permit which would accompany the genetic resource and possibly associated TK along the whole chain of the access and benefit sharing process and could be verified at various points, particularly once the genetic resource has left the provider country. It would therefore accompany the genetic resource from the collection phase until the marketing of a resultant product. The main objective of an internationally recognised system of certificate of origin would be to ensure the traceability of genetic resources from the moment they have been accessed, thereby increasing transparency. Developing countries hope the certificate would aid in combating bio piracy. ${ }^{1}$ Developing countries have proposed an amendment to the TRIPS Agreement stipulating the disclosure of information in the patent specification, including the origin of the genetic resources and the TK associated with them. Hence they want disclosure of origin to be made a condition for granting patents and their validity. In addition, they want evidence that the patent applicant got prior informed consent from the holders of $T K$ in order to ensure the sharing of benefit under the CBD. Other countries, argue that there are many practical problems in identifying the source and geographical origin of genetic resources and hence evidence should not be insisted upon. For them the solution is adequate documentation of genetic resources and associated TK and contractual agreements that deal with material transfer outside the scope of patent applications. Another related issue within this paradigm is the transfer of technology. The developing nations who are custodians of vast biogenetic material and IK view the present situation as a two way process: one as the flow of genetic resources and associated TK from these nations to the industrialised countries; and the other as the flow from the industrialised countries to these nations in the form of the products/resources

1 Bio piracy refers to the misappropriation, generally by means of patents, of indigenous/traditional (biomedical) knowledge by foreign entities (including corporations, universities and governments) without compensatory payment. 
based or made from these genetic resources such as new plant varieties, pharmaceutical products, and other scientific technologies which are crucial for the development of these nations. However, the latter flow can obtain protection from the IP system, while the former is not necessarily seen as a resource that can be protected within the western conception of $1 P$. Thus, how can one secure rights for developing countries for their own resources? More importantly, how can one facilitate technology transfer in areas crucial for the development of these nations, especially where they relate to adding value to the resources of these countries and their indigenous communities? Could the transfer of technology be incorporated into access and benefit sharing agreements as a form of benefit sharing? This chapter addresses these issues, and also scrutinises the potential of the proposed disclosure of origin requirement within the IRIPS Agreement and the IGC and outlines the various country positions.

\section{Chupter Four}

Some intellectual property concepts are more suitable than others in accommodating developing countries' wishes. A geographical indication (GI) is a legal concept that links a product with a particular geographical origin. They serve both the consumer and the producer in the market chain as they inform consumers about the source, quality and characteristics of the product and help to further market visibility for the producer. ${ }^{2}$ GIs have been perceived as a tool to stimulate agricultural policy goals, the protection of traditional knowledge (TK) and cultural traditions as well as facilitating rural socioeconomic development goals. There is, however, no singular and common pattern behind successful GI products and it takes a lot of time, money and effort to build a strong GI. GIs have been at the heart of international trade negotiations since their inclusion in the Uruguay Round that led to the adoption of the TRIPS Agreement. The negotiations subsequently mandated by the Doha work programme, and the outstanding TRIPS implementation issues on the extension of Gl protection to products other than wines and spirits and the notification and registration of GIs for wines and spirits, are analysed in more detail in chapter four. Chapter four also sets out the international legal framework for Gls, analyses the present legal standards and mandates and assesses the possible risks and benefits for developing countries in supporting the extension of GI protection to products other than wines and spirits. It also examines developing country positions on the multilateral system of GI notification and registration. In doing so, it aims to reinforce the negotiating capacity of developing countries by bringing together the different proposals made by various country groupings in the TRIPS Council and in the WTO Committee on Agriculture. Moreover, it compares geographical indica-

2 For instance, the 600 French registered Gl's generate almost 20 billion Euros annually. 
tions with trademarks and highlights their similarities and the potential for improving supply chain management and brand building in developing countries. It ends with a number of recommendations for developing countries which should help determine the political direction on Gls.

\section{Chupter Fin'}

The emphasis during the Uruguay Round placed by industrial countries on strengthening intellectual property protection in order to attract foreign direct investment (FDI), to stimulate the transfer of technology and to boost local creativity, is still up for discussion and is discussed in chapter five of this book. Countries with various levels of development have long sought to use national policies, such as those relating to education, intellectual property rights or tax incentives, to stimulate the sale of goods, and international agreements to stimulate international technology transfer. The TRIPS Agreement is the first multilateral attempt to reach some mutual agreement on the issue of technology transfer after the failure of the UNCTAD Draft TOT Code in the 1970s. The provisions of the TRIPS Agreement which deal with the transfer of technology are analysed and suggestions for their improvement are made in this book, which also explains the concept of international technology transfer and its relationship with intellectual property rights. It endeavours to reach some conclusions as to what extent intellectual property policies can play a role in fostering development and reducing poverty and to what extent the TRIPS Agreement can facilitate the transfer of technology. For these purposes some of the economic, empirical and theoretical research available on the relationship between IPR protection, foreign direct investment and the trade in technology is analysed. In particular, the role IPR protection plays in facilitating international technology transfer is scrutinised. Chapter five furthermore analyses the perceived socio-economic consequences that IPR protection brings about, differentiating between long and short term consequences, by referring to economic research and accompanying statistics. In addition, chapter five explains the different modes in which technology transfer can occur and conclusions are drawn as to what constitutes the most rewarding and efficient way to transfer knowledge and technology, with an emphasis on which ways are best for developing countries. Chapter five also addresses the issues of technology transfer between systems with different levels of development during an era of continuous strengthening of intellectual property regimes.

Unfortunately, a better understanding of what technology transactions are all about has not contributed to enlarge technology transfer flows to developing countries. This chapter provides recommendations, firstly to developing countries which want to use the transfer of technology effectively for their socio-economic development, and secondly, to developed countries that are under the obligation to comply with Article 66.2 of the TRIPS Agreement. 
Hence, this chapter analyses whether the relationship between IPRs and technology transfer is sector specific, if the level of development plays a role and whether the mode of technology transfer is of importance.

The conclusion of this book will summarise the main findings of this research and provide a synthesis of the research. 


\title{
Chapter One
}

\section{The International Legal Framework for the Protection of Intellectual Property}

\author{
"Imagination is more important than knotededge. Knoteledge is limited. \\ Imagination c'ncircles the world" \\ Albert Einstein
}

\section{INTROIULTION}

The principle to give protection to the inventor for his invention was recognised as early as the 15 th century, when the city state of Venice granted the first patents - mainly the result of a policy to attract new technology to venice. Gradually, the underlying reason to provide patent protection was the "natural" right of the inventor to the fruits of his labour, the benefits to society at large, society's compensation (reward) and the incentive this would provide for further innovation. Back then, these rights were already controversial as some argued that granting such exclusive rights imitated prohibitive tariffs (in so far as the protected goods could not be imported) and should not be granted. ${ }^{1}$

In the 19th century, the industrial revolution heralded a new era, when inventors of great inventions, such as the steam engine, were hesitant to expose their inventions at the "International Exhibition" in Vienma in 18732 as they feared their invention would be copied without their prior permission. ${ }^{3}$ The need for an international treaty including substantive provisions to protect the intellectual property of foreigners became apparent. These calls from industry to receive some sort of protection for their inventions within and outside their country of residence resulted in the negotiations for multilateral protection, which eventually led to the Paris Convention (PC).

If we draw a parallel with the contemporary situation we see many similarities. The dissatisfaction with the IPR system - in particular the lack of enforce-

1 See Kanwar and Evenson 2001, p. 2.

2 "International Exhibition", in German Weltansstellung, 1873, held in the then Austrian-Hungarian capital of Vienna. The initial idea was to hold a Welt-Intustrieausstellung (International Industry Exhibition) but the name was changed into International Exhibition to indicate the principal of universalism. See Plan of the Weltausstellung, Vienna 1873, <http://www.lib.umd.edu/ARCH/honr219f/1873 vien.html>.

3 However, arguably in reality the patents held back development in steam engine technology. 
ment - led to the conclusion of the TRIPS Agreement in the last decade of the 20th century. Over time the scope of international agreements to protect intellectual property rights (IPRs) changed according to economic, technological and political demands. The most recent IPR treaties - including the TRIPS Agreement - contain substantially more substantive provisions than the Paris Convention and the Berne Convention (BC), administered by World Intellectual Property Organization (WIPO). Historically, international organisations like WIPO, together with national governments, have shaped the international legal framework for intellectual property protection. ${ }^{+}$It was feared that WIPO had primarily become a forum for industrialised countries endeavouring to expand the minimum standards on IPRs - for instance in relation to raising the level of patent protection." However, 2004 proved to be a year of placing WIPO back at the forefront of intellectual property deliberations as Brazil and Argentina" proposed the establishment of a Development Agenda for WIPO as a countermovement to the Doha (Development) Round within the framework of the WTO:

Intellectual property rights are a bundle of exclusive rights over creations and innovations of the mind, both artistic and commercial. Artistic creations are covered by copyright laws, which protect books, films, music, paintings, photographs, and software, and it provides the author (the copyright holder) an exclusive right to control reproduction, distribution and adaptation of such works for a certain period of time. Traditionally a distinction was made between intellectual (read copyright and related rights) and industrial

- The Convention establishing the World Intellectual Property Organization, signed at Stockholm, July 14, 1967. WIPO administers over 40 treaties and conventions, see <www:wipo.org/treaties/sitemap/a-z.html>. In 1970 the Bureaux internationaux réunis pour la propriete intellectuelle/United International Bureaux for the Protection of Intellectual Property (BIRPI) became the WIPO, and in 1974, the WIPO became a specialised agency of the UN.

5 For instance, the discussions in relation to a substantive patent law treaty (SPLT) within WIPO.

- Resolution proposed by Argentina and Brazil to the WIPO General Assembly in October 2004, asking for the establishment of a "Development Agenda", see WO/GA/31/11, dated 27 August 2004. <http://www.wipo.int/documents/en/ document/govbody/wo_gh_ga/pdf/wo_ga_31_11.pdf.

- The Development Agenda was supported by a number of academics, civil society and IGO's. See for instance Boyle 2004. See also South Centre and Centre for International Environmental Law, "Integrating Development into WIPO Activities and Processes: Strategies for the 2004 WIPO Assemblies", SC/TADP/AN/IP/2, South Centre Analytical Note, Geneva, August 2004. For analytical papers supporting a development agenda see "Towards Development Oriented IP Policy: Setting an Agenda for the Next Five Years", The Bellagio Series on Development and Intellectual Property Policy, ICTSD, 30 October-2 November 2002. For more information go to: <http://ww'w iprsonline.org/unctadictsd/bellagio/dialogue 2002/bellagioparticipants.htm>. 
property but this distinction is no longer upheld in the TRIPS Agreement. Commercial creations relate to industrial property as they are created and used for industrial or commercial purposes. A patent may be granted for a new, novel (and non-obvious invention) subject to industrial applicability and it gives the patent holder a right to prevent others from practicing the invention without a license from the inventor for a certain period of time. In exchange for disclosure of the patent, the patent holder achieves an exclusive right to market the invention and to recoup his investment. A trademark is a distinctive sign which provides the consumer with information about origin of the product. It is used to prevent confusion among products by linking a labelled product with a corporate entity.

Intellectual property rights give creators and innovators exclusive rights to their creations and inventions, thereby providing an incentive for the author or inventor to develop and share the information rather than keep it secret. Intellectual property rights are usually limited to non-rival goods, that is, goods which can be used or enjoyed by many people simultaneously. Because of this nature, IPR protected goods are prone to copying and re verse engineering and reduce the incentive to create such works. Hence, protection for intellectual property rights was established in which right holders are granted exclusive rights for a limited amount of time. However, these exclusive rights may lead to producers charging higher prices and produce less than would be socially desirable. The establishment of intellectual property rights, therefore, represents a trade-off, to balance the interest of society in the creation of nonrival goods (by encouraging their creation and production) with the problems of granting exclusive rights.

$I P R$ is an exciting field of public policy. It is constantly in a state of flux since every year new IP laws are passed at the domestic, regional and international level. Treaties are amended, and intellectual property infringement disputes give rise to litigation in many jurisdictions. To a large extent this is due to changes in technology that demand an update or a complete reverse of existing intellectual property laws." As a rule of thumb amendments to

s With the emergence of the information society' during the 1980s and the 1990s, the diffusion and use of information and knowledge-based goods have exponentially grown. All the new technological developments have put the existing IPR legal system under pressure. Following this trend, digitised information goods have not only become accessible by vast number of users, but are also now widely disseminated. Technological protection mechanisms aim to prohibit the unauthorised reproduction of literary works. Yet, the dissemination and copying of information products is hampered by restrictions on access when those technical measures are widely applied. For example, the digitisation of scientific joumals and the implementation of electronic "gate- keepers" to limit accessibility to subscribers have raised major concerns in academic environment on a potential slowdown in academic research. See David 2000. 
existing laws occur slowly, just as the law is always outrun by technological development. Indeed, the things that we take for granted now for instance email, internet access, search engines, chat rooms, virtual gaming possibilities, rapid downloading of articles and music, copying of literary works and music, television/video on demand, protection mechanisms to be unlocked by keys/ codes, peer-to-peer networks, mp3 files, and biotechnology have all been invented in the last two decades or less. As no sufficient protection mechanisms were in place to protect these inventions, counterfeiters and pirates were able to produce low-cost copies and sell the goods with or without false trade mark logos attached. As a consequence right holders were desperate to find solutions to safeguard their intellectual assets, for instance: lobby groups were established calling for laws to protect new technological developments and to extend IPRs to the internet domain. Copyright holders started so-called "collective societies" in order to receive royalties for the use of their music as well as using digital rights management systems which puts works behind locks. Domain name disputes were subjected to dispute resolution by means of the Internet Corporation for Assigned Names and Numbers (ICANN). " These technological developments were supplemented with an increase in advanced technology products with high technology property (e.g. biotechnological inventions, mp3 players, mobile telephones etcetera.) content entering the market." Domain names are interesting 1PRs for a number of reasons: 1) domain names are registered, maintained and enforced in a different way then "normal" IPRs. Domain names arise through a contract with a registration authority. This registration authority is commonly a private company, representing a number of national or international internet providers, and is in charge of administering a so-called top-level domain. Moreover, 2) the fact that IPRs are territorial are not so self-evident in relation to domain name registrations. This fact gives rise to questions of private international law and uniform domain name dispute resolution mechanisms. ${ }^{12}$

Intellectual property protection has been harmonised to a certain extent through numerous conventions and treaties of which the Paris Convention, the Berne Convention and most recently the TRIPS Agreement have been most significant in the development of the international intellectual property archi-

"Collective societies are organisations that collect fees (royalties) for the use of copyrighted music, which they pass on to their members, i.e. the musicians, performers and the music writers.

111 For more information on ICANN's activities visit the website: <http://www. icann.org/>.

11 For example, US exports with a high IPR content increased from 9.9 per cent in 1947 to 27.4 per cent in 1986 and consequently the US was one of the major initiators of the introduction of IPR subject matter into the Uruguay Multilateral round of trade negotiations to stop the trade in counterfeited products and piracy. See Gadbaw and Richards 1988, p. 4, Chart. 1.1.

12 See Kamperman Sanders 2008, p. 159. 
tecture. However, the international IPR negotiation process has been criticised for neglecting developing countries' needs and interests: For over a century, the path for intellectual property lawmaking in the developing countries has deviated from those normally attributed to sovereign nations. Instead of providing support for the mational economy, political space and cultural and social life, II lawmaking has become a means of appeasing powerful external pressures trained on those nations". ${ }^{3 .}$ Changes in $I P$ policies and laws affect the "bottom-line profitability of Fortune 500 companies" but also affect "poor people in remote parts of the world". ${ }^{1-4}$

The US repeatedly argued that the recognition of intellectual property rights in overseas territories is necessary to safeguard national revenue and to retain international economic competitiveness. Piracy rates have shown major differences between the European Union (EU), the US and China during the 1990s. ${ }^{15}$ China leads with a rate of 95 per cent, the EU follows with 35 per cent and the USA with 25 per cent. ${ }^{\prime \prime}$ 'There are fundamental differences in national and regional legislation, i.e. implementation and enforcement of the established international IP legal rules vary to a great extent. Those differences in legislation led to "forum shopping", i.e. where firms take advantage of weak national IP regimes and operate virtually (have their basis in these countries and hence fall under these jurisdictions) from those nations. ${ }^{17}$ It was this awareness that gave the incentive to bring IPR into the framework of the GATT and onto the Agenda of the Uruguay Round of Multilateral Trade Negotiations. ${ }^{\text {s }}$

\section{THE WIPO}

The last century has shown a rapid increase in the adoption of international conventions on IP, many of which are administered by the WIPO. WIPO is a specialised United Nations agency, located in Geneva. Its objectives are to administer international treaties on intellectual property, to provide assistance to signatories in implementing intellectual property laws, and to seek

13 See Endeshaw 2006, p. 374.

1.4 See Fink and Maskus 2005.

15 Industry sources in 2005 continued to estimate that levels of piracy in China across all lines of copyright business are 85 to 93 per cont, indicating little to no improvement. For example, estimated business software losses fell to $\$ 1.27$ billion in 2005 from $\$ 1.48$ billion in 2004 . Information retrieved from the USTR website: <htlp:// www.ustr.gov/assets/Document_Library/Reports_Publications/2006/2006_Specia 1_301_Review/asset_upload_file353_9337.pdf>.

in See Stolpe 2000.

17 The internet as a global communications platform enables the location of firm's databases in one country and its management "over the border". Hence, the media and service providers may be recognised non-liable in cases of infringements of IPR in one nation would be recognised as wrongful acts in other countries.

is See Evans 1996, p. 149. 
harmonisation of intellectual property laws at the international level. WIPO schedules and hosts meetings in order to implement the various treaties it administers and also to reach consensus on new ones. WIPO Committee that comvene frequently are the WIPO Intergovernmental Committee on Intellectual Property and Genetic Resources, Traditional Knowledge and Folklore, the WIPO Standing Committee on the Law of Patents, the WIPO Copyright Committee and the WIPO Standing Committee on the Law of Trademarks, Industrial Designs and Geographical Indications WIPO plays an active role in facilitating and developing training programs for developing country's members.

WIPO administers two of the prime multilateral intellectual property conventions; the Paris Convention for the Protection of Industrial Property (1883) ${ }^{14}$ and the Berne Convention for the Protection of Literary and Artistic Works (1886). 2) 'These two conventions have laid down the rules on intellectual property protection for over a century. ${ }^{21}$ The conventions set minimum standards on intellectual property protection but are not very detailed in scope. The Paris Convention deals with industrial intellectual property rights, such as trademarks and patents. The Berne Convention protects literary and artistic works i.e. it provides minimum levels of copyright protection; it enhances authors' rights and also formally establishes the principle of national treatment of foreign nationals in respect of their intellectual property (following Article 5 Berne Convention). ${ }^{22}$

A severe blow to the position of WIPO as the leading international organisation for the protection of intellectual property was the inclusion in 1995 of rules on the protection of intellectual property within the WTO framework. For a while it seemed as if WIPO had lost its law-making role to the WTO as a

19 The Paris Convention was signed in 1883. Last revised at Stockholm in 1967 and amended in 1979 in Paris (Paris Union), 164 states are presently party to the Convention, the latest Act of the Convention to which a State is party differs as well, status on 15 October 2003.

2:1 The Berne Convention was signed in September 1886.

21 As well as the Universal Copyright Convention (UCC), signed on 6 September 1952 (administered by UNESCO) and the Rome Convention on protection of performers, broadcasters and sound recordings (jointly administered by the WIPO, the UNESCO and the International Labor Office). The UCC desires that national laws must adhere to the UCC provisions (Art. 10 UCC)), by contrast the PC and the BC merely states that national law must comply with their rules, following Art. 25(2) $P C$ and Art. 36(2) BC. The UCC requires that comestic laws must adhere to the UCC provisions when states join the Convention; art. 10 UCC specifies that in order to access the UCC a State "must be in a position under its domestic law to give effect to the terms of this Convention".

22 For more information on the attempts to revise the Berne Convention sce Dixon and Hansen 1996. 
result of the introduction of the WTO TRIPS Agreement. It seemed that its remaining task would be facilitating training programs in order to help developing countries meet their implementation and enforcement obligations. However, already in 1996 WIPO proved the opposite with the conclusion of two treaties addressing new technological developments: the WIPO Copyright Treaty (WCT) and the WIPO Performances and Phonograms Treaty (WPPT) (collectively the WIPO Internet Treaties). ${ }^{27}$ The WIPO Internet Treaties intend to raise the minimum standards of intellectual property protection around the world by adjusting them to the digital environment, particularly with respect to copyright protection on the internet. They clarify exclusive rights in the online environment and specifically prohibit the devices and services created to circumvent technological protection measures for copyrighted works. ${ }^{2-4}$

Recent discussions in WIPO have centred on various subject-matter: on the one hand discussions centred on developed country demands to harmonise the patent system (in the framework of the Substantive Patent Law Treaty (SPLT)) and on the other, developing country pleas to reform the global iP system towards development - which led to the recently adopted WIPO Development Agenda. The Development Agenda is an initiative to balance the activities of WIPO and to emphasise the particular interests of the developing countries in the IP negotiations. WIPO has also been active in expanding the scope of protection, e.g. the introduction of protection for layout designs of integrated circuits, ${ }^{25}$ as well as applying existing forms of IP to new technologies, e.g. patents to biotechnological inventions and copyright to computer programmes and databases.

\subsection{The Berne Comention}

The need for a uniform copyright system led to the formulation and adoption of the Berne Convention for the Protection of Literary and Artistic Works in September 1886. ${ }^{26}$ The Preamble sets out that the aim of the Berne Convention

23 WIPO Copyright Treaty (WCT) and WIPO Performances and Phonograms Treaty, both adopted in Geneva on 20 December 1996. The WCT has 67 contracting parties as of 23 September 2008; the WPPT has 66 contracting parties as of 23 September 2008. The treaties can be accessed at <http:/ www.wipo.org>.

2.t For more information on the WIPO internet treaties, see Reinbothe and Von Lewinski 2002. The WIPO Internet Treaties have resulted in the EU Information Society Directive. See Directive 2001/29/EC of the EP and of the Council of 22 May 2001 on the Harmonization of Certain Aspects of Copyright and Related Rights in the Information Society, OJ L 167, 22 June 2001.

$\approx$ The Washington Treaty on Intellectual Property in respect of Integrated Circuits of 1989 (the IPIC Treaty).

20 The Berne Convention has been revised several times in order to improve the international system of protection which the Convention provides. Changes have been effected in order to cope with the challenges of accelerating development of technologies in the field of utilisation of author's works, in order to recognise new 
is to protect, "in as effective and uniform a manner as possible, the rights of authors in their literary and artistic works". Article 2(1) of the Berne Convention provides more information as to what is understood by the expression "literary and artistic works":

"It] shall include every production in the literary, scientific and artistic domain, Whatever may be the mode or form of its expression, such as books, pamphlets and other writings; lectures, addresses, sermons and other works of the same nature; dramatic or dramatico-musical works; choreographic works and entertainments in dumb show; musical compositions with or withoul words; cinematographic works to which are assimilated works expressed by a process analogous to cinematography; works of drawing, painting, architecture, sculpture, engraving and lithography; photographic works to which are assimilated works expressed by a process analogous to photography; works of applied art; illustrations, maps, plans, sketches and three-dimensional works relative to geography, topography, architecture or science". (cmphasis added FC)

This list is understood to be non exhaustive and any original production in the literary, scientific and artistic domain, whatever may be the mode or form of its expression qualifies for protection. The Berne Convention leaves it up to the contracting party to determine the level of originality or artistic creativity required for the work to be subject to copyright protection. ${ }^{27}$ Derivative works, that is those based on other pre-existing works, such as translations, adaptations, arrangements of music and other alterations of a literary or artistic work, receive the same protection as original works. ${ }^{2 *}$ Article 2(2) provides an important exception to contracting parties in that:

"[i]t shall, however, be a matter for legislation in the countries of the Union to prescribe that works in general or any specified categories of works shall not be

rights or update existing ones and to take account of the interests of the newly independent developing countries (1971). The first major revision took place in Berlin in 1908, and this was followed by the revisions in Rome in 1928, in Brussels in 1948, in Stockholm in 1967 and Paris in 1971 and amended in 1979 in Berne (Berne Union). Currently 151 States are party to the Convention. Signatories to the Berne Convention are referred to as contracting parties. In 1970 the $\mathrm{BC}$ held 58 contracting parties and 2008 showed 164 contracting parties. Countries that joint recently include Yemen, Andorra, Bhutan, Dibouti, Montenegro and Sudan. For details access: <http://www.wipo.int/treaties/en/statistics/StatsResults.jsp?treaty_idt=15 \&lang=en>. Countries that joint recently include Yemen, Andorra, Bhutan, Djibouti, Montenegro and Sudan.

27 Notably, Art. 14ter of the BC refers to "authors of original works of art and original manuscripts".

2s See Art. 2(3) of the BC. 
protected unless they how be'n fixed in some muterial form". 2" (emphasis added l.c)

The Berne Comvention is the oldest international treaty in the field of copyright and it is open to all States. ${ }^{31}$ Article 1 of the Berne Convention sets out that the "countries to which this Convention applies constitute a Union for the protection of the rights of authors in their literary and artistic works". Article 2(6) of the Berne Convention lays down that protection under the Convention is to operate for the benefit of the author and his successors in title. ${ }^{31}$ Instruments of accession or ratification are deposited with the Director General of the World Intellectual Property Organization (WIPO). Prior to the adoption of the Berne Convention countries did protect their literary works by negotiating bilateral agreements based on mutual recognition of rights but protection was found to be inadequate and not comprehensive enough and it did not provide a uniform solution. 32

The Berne Convention is based on three principles: 1) There is the principle of "national treatment", according to which works originating in one of the member States are to be given the same protection in each of the member States as these grant to works of their own nationals. ${ }^{33}$ 2) There is automatic protection, according to which such national treatment is not dependent on any formality; in other words protection is granted automatically and is not subject to the formality of registration, deposit or the like. ${ }^{3 .+3}$ ) There is independence of protection, according to which enjoyment and exercise of the rights granted is independent of the existence of protection in the country of origin of the work. 35.36

The Berne Convention sets out minimum standards of protection in relation to the rights of authors and the duration of protection. Article 7 lays down a minimum term of protection, which is the life of the author plus 50 years after his death. 7 However, for cinematographic works, the term is 50 years after the

2) For instance, the protection of performances of a theatre play may be dependant on their being fixed in some form.

30 The $B C$ is available online: <http:/ www.wipo.int/treaties/en/ip/berne/trt docs_ wo()(1.html>.

3 For some categories of works, however, such as cinematographic works (Art. 14bis), ownership of copyright is a matter for legislation in the country where protection is claimed.

3 See WIPO 2004, p. 262.

3 See Art $5(1)$ of the $B C$.

34 Ibid.

3 See Art. $5(2)$ of the $B C$.

3. See WIPO 2004, p. 262.

3) This duration is based on the fact that it was deemed to be fair to cover the life of the author and the lifetime of his children. This could also provide the incentive 
work has been made available to the public, or, if not made available, then 50 years after the making of such a work. For photographic works and works of applied art, the minimum term of protection is 25 years from the making of the work. ${ }^{38}$

The exclusive rights granted to authors of literary and artistic works under the Berne Convention include the right of authorising: translation; ${ }^{39}$ the right of reproduction in any manner or form, including any sound or visual recording, the right to perform dramatic, dramatico-musical and musical works and any communication to the public of the performance of their work as well as with respect to translations; "1 the right to broadcast and communicate their works to the public, by wire, rebroadcast (when this communication is made by an organisation other than the original one) or loudspeaker or any other analogous instrument; ${ }^{+2}$ the right of public recitation of their works; ${ }^{+3}$ the right to make adaptations, arrangements or other alterations of their works; ${ }^{4+15}$ and the right to make cinematographic adaptations and reproductions of a work and the distribution of the works thus adapted or reproduced as well as public performances and communication to the public, th the option to grant droit de suite to authors of original works of art and original manuscripts. ${ }^{77}$ ts

necessary to stimulate creativity, and constitute a fair balance between the interests of the authors and the needs of society. Sec WIPO 2004, p. 264.

3 Resp. Arts. 7 par. 2 and $t$ of the $B C$.

3.) See Art. 8 of the BC.

*1) See Art. 9 of the BC.

4 See Art. 11 of the $B C$.

12 See Art. 11 lis of the BC.

4. See Art. 11 ter of the BC.

Hed Art. 12 of the $B C$.

th For instance the author of a book would have to be asked permission before a producer of films could adapt the story of the book into a screenplay.

in See Art. 14 of the BC.

ti See Art. 1tter of the BC.

th. The so-called droit de suite provided for in Art. 14ter (concerning original works of art and original manuscripts) is optional and applicable only if legislation in the country to which the author belongs grants protection. Droit de suit refers to interest in sale after the first transfer of the work by the author: "The author, or after his death the persons or institutions authorised by national legislation, shall, with respect to original works of art and original manuscripts of writers and composers, enjoy the inalienalle right to an interest in any sale of the work subsequent to the first transfer by the author of the work". (Art. 1tter of the BC). In contrast Art. 11 of the TRIPS Agreement requires the recognition of rental rights in some cases. In particular, TRIPS Members are to permit authors and their successors of computer programmes and cinematographic works to authorise or to prohibit the commercial rental to the public of originals or copies of their copyright works - subject to 
An important provision set out in the Berne Convention is the so-called 'moral rights' provision. Independently of the author's economic rights, Article 6lis provides for moral rights. Moral right refers to the right of the author to "claim atthorship of [his/her] work and to object to any distortion, mutilation or other modification of, or other derogatory action in relation to, the said work which would be prejudicial to his honour or reputation". ${ }^{49}$

Note that the US has not formally endorsed the concept of moral rights which derives from the original French concept of "droit d'auteur".

Article 15 (4) is one of the most important provisions of the Berne Convention as it is understood to cover folklore without mentioning the term. Article 15(4) (a) stipulates that any country may give protection to
"unpublished works where the identity of the author is unknown, but where there is every ground to presume that fhe author) is a national of that country of the Union, it shall be a matter for legislation in that country to designate the competent authority which shall represent the author and shall be entitled to protect and enforce his rights in the countries of the Union".

By providing for the bringing of actions by authorities designated by the State, the Berne Convention offers to countries whose folklore is a part of their heritage, a possibility of protecting it. ${ }^{\text {") }}$

The Berne Convention allows for the free use of copyrighted works in special cases. Article 2(8) of the Berne Convention explicitly excludes news and facts having the character of mere items of press information from protection hence countries have no option and have to exclude from copyright protection. It is explicitly mentioned that countries may exclude speeches, lectures, ${ }^{11}$ legislative and administrative texts ${ }^{52}$ or works of folklore ${ }^{53}$ - hence, the protection of these categories of works is optional. In addition, Article 10 of the Berne Convention permits the unrestricted use of protected works in certain special

commercial rental. A Member shall be excepted from this obligation in respect of cinematographic works unless such rental has led to widespread copying of such works which is materially impairing the exclusive right of reproduction conferred on authors and their successors in that Member. Hence, authors of cinematographic works can only request the right to authorise or prohibit the commercial rental of their works if they can prove that otherwise the copying of their work leads to the loss of considerable revenue.

4. See Art Gbis(1) of the BC.

\# See WIPO 200\%, p. 263.

5 See Art. 2bis(2) of the BC.

$\therefore$ See Art. 2(4) of the BC.

5. See Art. $15(4)$ of the $B C$. 
cases: it allows to make quotations from a work that has already legally been made available to the public including quotations from news articles and the use of literary and artistic works for teaching purposes on the condition that such utilisation is compatible with "fair practice". What is entailed by "fair practice" is not defined. In any case "mention shall be made of the source and of the name of the author if it appears thereon". ${ }^{5+}$ What fair practice entails is a matter left to the sovereignty of the contracting party and is not defined by the Berne Convention. Further possible free uses of works are set out in Article 10bis of the Berne Convention which leaves it to the contracting parties to decide whether to permit:

\begin{abstract}
"the reproduction by the press, the broadcasting or the communication to the public by wire of articles published in newspapers or periodicals on current economic, political or religious topics, and of broadcast works of the same character, in cases in which the reproduction, broadcasting or such communication thereof is not expressly reserved".
\end{abstract}

\title{
Article 10bis(2) of the Berne Convention sets out that:
}

\begin{abstract}
"[i]t is also a matter for domestic legislation to determine the conditions under which, for the purpose of reporting of current events by means of photography, cinematography, broadcasting or communication to the public by wire, literary or artistic works seen or heard in the course of the event may, to the extent justified by the informatory purpose, be reproduced and made available to the public".
\end{abstract}

The way in which countries have implemented these free use options in relation to literary and artistic works is a matter of cultural preference and differs from country to country. 55 There are two cases where the Berne Convention provides the possibility of compulsory licenses: under Article 11bis(2), for the right to broadcast and communicate to the public, by wire, rebroadcast or loudspeaker or any other analogous instrument, the broadcast of the work, and under Article 13(1) for the right of recording musical works. The use of compulsory licensing is subject to equitable remuneration to the authors fixed by the competent authority as well as without prejudice to the moral rights of the author.

Special provisions regarding developing countries are included in the appendix. Article 21 states that the appendix is an integral part of the Berne

if See Art. $10(3)$ of the BC.

$\because$ The TRIPS Agreement refers to limitations and exceptions in its Art. 13. Art. 13 reads "Members shall confine limitations and exceptions to exclusive rights to certain special cases which do not conflict with a normal exploitation of the work and do not unreasonably prejudice the legitimate interests of the right holder". 
Convention. "The Berne Convention was developed initially according to the standards and requirements of the industrialised countries in Europe. In the 1960 s when countries gained independence due to the end of the colonisation process they were faced with laws negotiated by developed countries without taking into consideration the special circumstances and needs of developing countries. Developing countries raised awareness for the difficulties they encountered in the process of accessing copyrighted work for educational and technological purposes. At the same time technological advances required a copyright treaty with a large geographical scope in terms of contracting parties. Deliberations at the more recent revision conferences focussed on adapting the systems of international protection of literary and artistic works to the needs of these newly independent developing countries. Developing countries desired an update of the Berne Convention to see their development needs reflected. The question of incorporating into the Convention special provisions for the developing countries bore fruit at an African Copyright Meeting in Brazzaville in 1963. Subsequently, this matter was pursued at the Conference called in Stockholm in 1967 for revision of the Berne Convention, ${ }^{57}$ The Stockholm revision conference added a "protocol regarding developing countries" known as the Stockholm Protocol to the Convention. However this protocol faced protests by the main copyright producing countries and another conference was called in 1971 in Paris to find a solution in order to support the universal nature of the Berne Convention (finding an appropriate balance between reinforcement of rights versus the concems of developing countries).

Article 15(4) dealing with folklore was added during the Paris revisions conference - this provision rendered it possible for developing countries to also protect its folklore abroad. By providing for the bringing of actions by authorities designated by the State, the Berne Convention offers to developing countries, whose folklore is a part of their heritage, a possibility of protecting it.

Moreover, deliberations during the Paris Convention led to the special provisions concerning developing countries that were incorporated in an appendix. ${ }^{5 s}$ According to this Appendix, developing countries may, under certain conditions, depart from the minimum standards of protection provided for in the Convention:

in Please note that Art. 9.1 of the TRIPS Agreement expressly incorporates Arts. 1 to 21 and the Appendix of the BC. Chapter two of this thesis will elaborate more on the TRIPS provisions.

$\Rightarrow$ See WIPO 2004, p. 265.

is See WIPO 2004, p. 265. 
"having regard to its economic situation and its social or cultural needs, does not consider itself immediately in a position to make provision for the protection of all the rights as provided for in [the Berne Convention]".

It concems two rights, the right of translation ${ }^{59}$ and the right of reproduction. ${ }^{60}$ The Appendix enhances the Berne Convention's existing exceptions to the author's exclusive rights, including those of 1) reproduction for use in connection with systematic instructional activities, of works protected under the Convention (Article IIl of the Appendix of the Berne Convention allows to substitute the exclusive right of reproduction provided for in Article 9 with a system of non-exclusive and non-transferable licenses) and 2) translation for the purpose of teaching, scholarship or research (Article Il of the Appendix of the Berne Convention permits to substitute the exclusive right of translation provided for in Article 8 of the Appendix of the Berne Convention with a system of non-exclusive and non-transferable licenses). These licenses may be granted, after the expiry of certain time limits and after compliance with certain procedural steps, by the competent authority of the developing country concerned." They must provide for just compensation in favour of the owner of the right. In other words the payment to be made by the compulsory licensee must be consistent with standards of royalties nomally applicable in respect of licenses freely negotiated between persons in the two countries concerned."2 Article III(6) Appendix of the Berne Convention makes mention of distribution "at a price reasonably related to that normally charged in the country for comparable works". This possibility is subjected to ensuring a correct translation or an accurate reproduction of the work, as the case may be, and to specify the name of the author on all copies of such translations or reproductions. ${ }^{\text {t.3 }}$ Moreover, copies of translations and reproductions made and publication under licenses cannot be exported. ${ }^{\text {int }}$ The applicant for a CL should ask for prior consultations to the right owner to make and publish the translation or to reproduce and publish the edition or proof that after due diligence he was not capable of tracking the right owner ${ }^{65}$ Since the license is nonexclusive, the copyright owner is entitled to bring out and place on the market his own equivalent copies, upon which the power of the licensee to continue making copies under the license would cease. However, in that event, the compulsory licensee's stock can be exhausted. 100

5" See Art. II of the Appendix of the BC.

(w) See Art. III of the Appendix of the BC.

(1) Details are provided for in Arts. II (2)(3) and (4) of the Appendix of the BC.

1.2 See Art. IV(6)(a) of the Appendix of the BC.

6.3 See Resp. Arts. IV (6) and IV (3) of the Appendix of the BC.

in See Art. IV (4) (a) of the Appendix of the BC.

"See Art. IV (1) of the Appendix of the BC.

(t) See Art. I (t) and Art. II (6) of the Appendix of the BC. 
The other possibility provided for is the so-called "ten-year rule" provides for the possibility of reducing the term of protection as far as the exclusive right of translation is concerned. "The "ten year rule" entails that for a period of ten years from the publication of the work the author's consent has to be sought before the right to translate is obtained; after this period the right of translation is in the public domain and translations can be made without prior authorisation. The Berne Convention offers a choice in that a developing country may, when ratifying or acceling to the Paris Act, make a reservation under the socalled "ten-year rule", "which provides for the possibility of reducing the term of protection as far as the exclusive right of translation is concerned or the developing country may avail itself of the compulsory licensing system. Any developing country is allowed to choose between those possibilities but cannot combine them."19

\subsection{The Paris Conantion}

The Paris Convention was the first endeavour to protect industrial property at a multilateral level. The Paris Convention protects patents, trademarks, trade names, industrial designs, appellations of origin, and utility models. ${ }^{71}$ The Paris Convention provides minimum standards of protection on industrial intellectual property rights and it includes limited substantive provisions. ${ }^{71}$ It follows that countries are free to enhance the level of protection on their territories. Key provisions of the Paris Convention are the principle of national treatment and the right of priority in the field of patents. Article 1 of the Paris Convention provides a very loose definition of what contains intellectual property right subject matter. The list is not exclusive and it covers not only patents and trademarks but also service marks, appellations of origin, utility model protection and rules on unfair competition. But, parties to the Convention are under no obligation to protect all the subject-matter indicated by the definition as Article 1 of the Paris Convention sets out "a mere statement of intention as to the object of the Convention - namely, the protection of inciustrial property". "The Revision Conference of "The Hague stresses that the "enumeration of industrial property rights attending the definition of industrial property would not oblige members to legislate on all the specific rights enumerated";

ni See Art. 30(2)(b) of the $B C$.

in Ibicl.

114) See Art. $V$ of the Appendix of the BC.

(1) See Art. 1.2 of the Paris Convention.

it See Art. 2, 24 of the Paris Convention.

22 Revision Conference, Actes de la Haye, 1925, at 410 to 411. Referred to in Evans 1996, p. 153.

is Ibid. 
For the most part the Paris Convention arranges that parties should provide protection for patents, trade marks, designs and utility models, but the Convention did not arrange how the parties should shape or reflect this in their juristictions, and hence it does not set out substantive obligations. For instance, the Paris Convention stipulates that patents need to be protected but it does not set the conditions which make an invention patentable subject matter, hence leaving considerable flexibility to the domestic policy maker to design the national intellectual property framework. As a result, countries remain responsible for setting conditions constituting a patent which provides them with flexibility to design a patent regime in line with their domestic needs. For instance it is up to country's sovereignty to decide what subjectmatter can be patentable (e.g. because patenting certain subject matter is found to be morally unacceptable - the discussion on patenting life); what constitutes novelty (e.g. absolute or relative novelty); the possible provision of a grace period; what constitutes an inventive step (e.g. major step forward and no hindsight, technical in nature), and the choice between first to file or first to invent in relation to grant of patent.

\section{The Principle of National Treatment}

One of the key provisions of the Paris Convention is the principle of national treatment. Article 2 of the Paris Convention stipulates that:

"Nationals of any country of the Union shall, as regards the protection of industrial property, enjoy in all the other countries of the Union the adrantages that their respective laws now grant, or may hereafter grant, to nationals".

Article 2(3) of the Paris Convention provides an important exception to the principle of national treatment:

"The provisions of the law's of each of the countries of the Union relating to judicial and administrative procedure and to jurisdiction, and to the designation of an address for service or the appointment of an agent, which may be required by the laws on industrial property are expressly reserved".

The principal of national treatment should be placed in a historical context. The first treaties on intellectual property were enacted in the 19 th century. They dealt with numerous countries at different levels of economic and cultural development and this made it very difficult to reach consensus on scope and subject matter of protection that would be applicable and enforceable in all countries. Different levels of protection were proposed and discussions were stuck in some kind of deadlock. Therefore the principle of national treatment was introduced. ${ }^{7+}$ Before the Paris Convention was concluded in

it See for a detailed discussion on the principle of national treatment, Evans 1996. 
1883, exporting nations established overseas protection of their products through bilateral agreements based on an exchange of privileges between states. Most states were reluctant to grant unconditional reciprocity, i.e. in intemational relations and treaties, the principle of reciprocity states that favours, benefits, or penalties that are granted by one state to the citizens or legal entities of another, should be retumed in kind. However it was agreed that protection was granted on the basis of national treatment meaning that foreign works received the same rights and protection as national works. Hence, the principle of national treatment implies that foreign right-holders enjoy the same legal rights in other countries than their own than nationals even if they are of a higher standard than is applied by their own (host country). The benefit of the principle of national treatment is that it provides protection to foreigners up to the domestic standard without prejudice to each nation's sovereign right to determine the content of the law. The principle proved to be popular as nearly 70 bilateral agreements including the principle of national treatment were concluded between various European countries in the second half of the 19 th century. ${ }^{-5}$ These agreements were however limited in subject-matter, application and scope. For instance, they were mostly general commercial treaties in which IPR played a limited role and for the most part referred to trade marks and designs. ${ }^{76}$ Hence, a lot of uncertainties remained and as a result the call grew for substantive provisions to give increased effect to the principle of national treatment.

At the time the principle of national treatment was introduced it was a break through. However, currently the principle of national treatment under the Paris Convention is merely a formality since the Convention requires little of the member countries when it comes to substantive requirements. As a result, the level of protection required is low and subsequently the foreign rightholder will derive little benefit from the Convention - but it follows that the foreign right-holder will have the same protection as the national rightholder $"$ However, the principle of national treatment is enhanced by the following actions: 1) The gractual expansion of substantive law in the TRIPS Agreement and some revisions of the WIPO treaties as well as FTAs bolsters the principle of national treatment in that it makes the protection of inventive works on foreign territories more effective, for instance the introduction of the patent priority filing possibility (right of priority) $;{ }^{; 8} 2$ ) It follows from Article 2

: See Evans 1996, p. 150.

in With the exception of the Treaty of Commerce 1881 between Cemmany and AustriaHungary and the Customs Convention 1876 between Austria-Hungary and Liechtenstein which provided for the reciprocal protection of patent rights. See Evans 1996, citing Ladas 1975, p. 47.

$\because$ Sec Evans 1996, p. 154.

is Chapter two of this thesis will discuss in more details some of the key provisions of the TRIPS Agreement and content of FTA negotiations. 
Paris Convention that the principle of national treatment embodies the acquisition, preservation and enforcement of industrial property rights. Hence, the principle of national treatment does not only apply to the IPR granted at the time of the entry into fore of the Paris Comention but also to the IPR that are granted after that date. This implies that also future grant of rights and remedies will be enjoyed by the foreigner intellectual property right holder; 3 ) The growing number of countries that have signed up to the MIPO treaties and the $117 O$ TRIPS Consention extend the application of the principle of national treatment even further.

\section{The Right of Pribitu}

Another important achievement of the Paris Convention is the right of priority as set out in its Article 4 . This system gives the registrant some time to file for multiple patents simultaneously in other countries which are members of the Paris Convention and to claim the priority date in the first country of registration. The right of priority status is given when corresponding applications for patents (and also for designs and trademarks) have already been made in another convention country within the preceding six months. The date of the latter registration will be deemed the same as that of the first registration, implying simultaneous filing in multiple countries. The underlying idea is to prevent discrimination against foreigners by providing the patent applicant some time to prepare foreign patent applications while not losing the priority filing date. This means that norelty will be assessed as of the first date of filing and not the actual filing date in the foreign country. Novelty is one of the patentability requirements according to which an invention is not patentable if it was already known before the date of filing.

\section{Rerison of the Parls Coniontion and the Beme Cone'ntion}

In the beginning of the 1980s, both developed and developing countries favoured a revision of the Paris Convention but for different reasons. The developed countries wanted a revision to combat the trade in counterfeit goods and the developing countries favoured a revision incorporating a more development friendly approach to IPRs."

The deseloping countries based their arguments on a report of the LN Conference on Trade and Deselopment (LNCTAD) on the role of the patent system in the transfer of technology to developing countries. "This document

$\therefore$ In the 1970s a number of developing countries advocated a revision of the PC, at that time it was endeavored to establish a Code of Conduct on Technology transfer, however it was never concluded. See chapter five of this thesis for a discussion.

- "The Role of the Patent Sistem in the Transter of Technology to Developing Countries": Report prepared jointly by the LX Dept of Economic and Social Affairs, the 
recommended a revision of the Paris Convention. It advised preserving the use of compulsory licensing and lowering the amount of royalties payable to the right holders." Revision conferences were hosted in Geneva in 1980, in Nairobi in 1981 and again in Geneva in 1982. Notwithstanding all attempts to reach consensus, a revision of the Paris Convention failed. In 1984 another attempt was made to align the diverging views, but this attempt also ended in deadlock. ${ }^{.2}$ The contrasting viewpoints on the rationale underlying the intellectual property system and the level and scope of protection, in particular in relation to patents, made it impossible to move forward.

Attempts to update the Berne Convention also failed due to incompatible views: on the one hand, the developed countries regarded intellectual property as a private right that needs protection, the same as any tangible property in order to prevent piracy and counterfeiting and on the other hand developing countries were of the opinion that intellectual property is a public good that should create socio-economic development and technological advancement and therefore should be easy accessible to the public. ${ }^{83}$

In a response to its members' concerns, WIPO endeavoured to improve the mechanisms for dispute resolution by developing a treaty on dispute settlement that would be applicable to all their conventions and treaties in $1990 .{ }^{s-1}$

UNCTAD Secretariat and the International Bureau of the WIPO. UNCTAD, TD/B/AC.11/19.Rev.1.

s! US General Accounting Office, "Strengthening Worldwide Protection of Intellectual Property Rights", GAO Doc. No. GAO/NSIAD-87-65, 1987, at p. 26.

:2 The Paris Convention has undergone quite a few revisions at so called revision conferences, namely: Brussels in 1900, Washington in 1911, The Hague 1925, London 1934, Lisbon 1958, and Stockholm 1967. The countries subscribing to the Paris Convention formed a Union to stop unauthorised imitation. The Union for the Protection of Industrialised Property was established in 1883 (effective as of 7 July 1884) by 11 countries: Belgium, Brazil, France, Guatemala, Italy, Portugal, Netherlands, El Salvador, Serbia, Spain and Switzerland.

For a detailed overview of anendments made during these revision processes see Bogsch 1983.

s3 See Stewart 1993, p. 2255. See also May 2000, p. 11 on the balance between public and private ownership, arguing that "intellectual property constructs a balance between public availability and private henefit". Stewart continues that patent laws are diluted by public policies as to ensure that societies needs are taking into consideration - already in the seventeenth century it was argued that "society needed to be able to utilise new methods more widely than a single owner with a monopoly might allow. Patents are therefore an explicit bargain between the idea's originator and the state, balancing ownership and disclosure, allowing both individual reward and social use".

s. The International Bureau of the prepared a document on the principles of a draft treaty for settlement of disputes between States in the field of intellectual property. 
However, negotiators were not able to agree on such a treaty. ${ }^{8.5}$ Developing countries explained that this was essentially because the US wanted to make sure that the WIPO process would not undercut its own efforts in GATT, where it is seeking to set new and enhanced international norms and standards and provide for a dispute settlement mechanism backed by the ultimate sanction of trade retaliation that would be effective against developing countries.

On the other hand, Japan and the US wanted retaliation or sanction for nonimplementation of a recommendation to be provided for in the WIPO dispute settlement mechanism. The US stressed that since international trade had been the source of much of the IPR disputes, its own preference was for dealing with the issue in the GATT and its dispute settlement mechanism, and that the US reserved its position on whether such a treaty and provision was needed in the WIPO. Switzerland, Norway and UK wanted to ensure that WIPO efforts would not undercut or delay the work in this area in the GATT. Brazil, Mexico, Argentina and India also said that a dispute settlement mechanism on IPRs should also contribute to the reduction of inequalities and promotion of symmetry and balance of intellectual property rights and obligations. Such a mechanism should not only monitor compliance with the standards of IPR protection, but instances of excessive or abusive protection. ${ }^{\text {it }}$

\subsection{Shortcomings of the Paris Conantion and the Berme Comention}

Both the Paris Comvention and the Berne Comvention contributed to the harmonisation of intellectual property but they have shortcomings. Firstly, they fail to provide mechanisms to adequately ensure enforcement of rights and a binding and effective dispute settlement mechanism. In addition, the review process to update the conventions to include new subject matter, for instance in relation to internet-related developments, was never completed. Countries do have the option to bring intellectual property infringements before the International Court of Justice but only after negotiation or arbitration has failed (following Article 28.1 Paris Convention). However, none of the parties to the conventions have done so to date. ${ }^{87}$ Most likely this fact is related to Article 28.2 Paris Convention which allows a member country "to declare itself

This mandate came out of the first session of the WIPO "Comnittee of Experts on the Settlement of Intellectual Property Disputes between States" held here from February 19 to 23 1990. The idea of a WIPO mechanism for dispute settlement was adopted by the Governing Bodies of the WIPO at their last meeting in SeptemberOctober 1989, and is on the WIPO work programme.

s. See Gadbaw 1989, p. 223 and 240.

sn See Stewart 1999, p. 552-553.

$\therefore$ See Goldstein 2001, p. 111. 
not bound by the provision of [28.1] in any dispute that may arise between it and another member of the Union". Hence, to a certain extent it renders Article 28.1 of the Paris Convention ineffectual. As a consequence where a right-holder was faced with inadequate IPR laws overseas or laws which discriminate against foreign right-holders, there was no guarantee that remedial possibilities such as injunctions and damages were available and thus foreign trade remained a risky business. Foremost the industrialised countries wanted to change the $P C$ and $B C$ to include more precisely defined provisions (i.e. increase scope of substantive provisions), which would not leave the interpretation of the provisions to the national authorities. The general provisions laid down in the field of patents were especially found to be a thorn in their flesh. As a response of the lack of adequate provisions (read more precisely defined provisions) to protect their intellectual property including enforcement, countries followed the unilateral, bilateral or regional route to resolve a dispute between states. The US especially has often invoked its so-called S. 301 to punish (in their view) inadequate domestic intellectual property protection - often to the distress of developing countries. Unilateral action to combat IPR infringement is discussect below. ${ }^{\text {s. }}$

\subsection{Unilaternl Action}

The US, concerned about its loss of political influence in the international IP policy setting, ${ }^{89}$ was desperately searching for ways to increase its influence on IP related matters and to stop the trade in counterfeited goods and piracy outside of WIPO and other multilateral settings. ${ }^{911}$ "This search was supported by its industries, which believed that their interests were threatened under the existing international IP framework and its minor enforcement possibilities. In an attempt to control goods in overseas territories and to put a halt to piracy

\$s Losses to US industries alone are estimated at $\$ 200-\$ 250$ billion per year. To counteract these developments, "Special 301" provisions of the Trade Act of 1974, as amended, require USTR to identify foreign countries that deny adequate and effective protection of intellectual property rights or fair and equitable market access for U.S. persons that rely on intellectual property protection. Countries that have been placed on the Watch List Argentina, Brazil, China, Egypt, India, Indonesia, Israel, Kuwait, Lebanon, Pakistan, Paraguay, the Philippines, Russia, Turkey, Ukraine and Venezuela. The USTR claims that the economic damage caused by counterfeiting to the legitimate companies whose products are counterfeited is enormous. See 2005 USTR Special 301 Report, <http://www.ustr.gov/as sets/Document_Library/Reports_Publications/2005/2005_Special_301/asset_uploa d_file195_7636.pdf>.

sw The US, although a member of the Universal Copyright Convention administered by UNESCO, had limited means to influence policy making due to its withdrawal from UNESCO plus the fact that it was not a contracting party to the Berne Convention (until accession in 1989).

(1) See the debate on FTAs in section four of this chapter. 
and counterfeiting products the US took a number of unilateral measures. For instance, it introduced mechanisms into domestic legislation, such as "Section 301" of the 1974 US Trade Act, which authorises sanctions against foreign countries, whom the US considers to be in violation of IPR agreements, or even when there are no such violations, when they in one way or another unfairly restrict US foreign trade." The 1988 amendments of the 1974 US Trade Act resulting in the Trade and Competitiveness Act, increased the mandate of the Office of the United States Trade Representative (USTR) over IPR disputes by introducing a new procedure, the so-called "Super 301", which enhanced penalties under the 1974 Act and included the creation of various II' watch and priority lists which could eventually lead to trade sanctions.

91 Section 182 of the US Trade Act of 1974, amended by the Omnibus Trade and Competitiveness Act of 1988 and the Uruguay Round Agreements Act, referred to as "Special 301" sets out that the USTR should indicate countries that do not provide adequate and effective protection for IPR or refuse fair and equitable market access for persons that rely on IP protection. Pursuant, those countries that have the most "onerous or egregious acts, policies, or practices and whose acts, policies, or practices have the greatest adverse impact (actual or potential) on the relevant U.S. products must be designated as "Priority Foreign Countries". Pursuant, "Priority Foreign Countries" may be subjected to an investigation under the Section 301 provisions of the Trade Act of 1974. Priority Foreign Countries are those pursuing the most onerous or egregious policies that have the greatest adverse impact on U.S. right holders or products, and are subject to accelerated investigations and possible sanctions Moreover the USTR has created a "Priority Watch List" and "Watch List" under Special 301 provisions. Countries or economies on the Priority Watch List do not provide an adequate level of IPR protection or enforcement, or market access for persons relying on intellectual property protection. Thirty-four trading partners are placed on the Watch List, meriting bilateral attention to atdress the underlying IPR problems. The investigation concerns information gathering and consultations with the private sector US embassies in the country at stake, the US trading partners, the US Congress, and the National Trade Estimates Report among other sources. If countries are placed on the "Priority Watch List" or "Watch List" it means that particular problems exist in that country' with respect to IPR protection, enforcement or market access. Countries placed on the "Priority Watch List" become the focus of increased bilateral attention concerning the problem areas. In addition, under Section 306 monitoring, the USTR monitors a country's compliance with bilateral IP agreements that are the basis for resolving an investigation under Section 301. China and Paraguay, due to their serious IP-related problems are subject to Section 306 monitoring, because of previous bilateral agreements reached with the United States to address specific problems raised in earlier reports. The USTR may apply sanctions if a country fails to satisfactorily implement an agreement. In 2007 Switzerland was threatened to be put on the list in relation to its biodiversity law and in relation to disclosure of source (origin) requirements. Information retrieved from the USTR website: <http://www.ustr.gov>. 
Although unilateral pressure to enforce certain rules is an instrument used by a number of countries, the US was the most frequent user. ${ }^{92}$ Unilateral trade remedies rest on the assumption that countries have markets with which to retaliate their trade with. Ohviously, the EU, the USA and Japan, strengthened by their power position, have the power to actually impose unilateral actions. Developing countries do not have markets to retaliate with - or if they do, only to a lesser extent than their big counterparts. Over the years, the US has threatened with economic sanctions or the withdrawal of benefits, such as favorable market access terms, if counterfeited trademarked goods and piracy was not reduced." ${ }^{n}$ Despite these unilateral actions, the US still preferred multilateral efforts within the GATT framework to protect IP as multilateral efforts would raise the level of IPR protection at a global level and make the IPR system less territorial in nature. Because of the territorial nature of IPRs US based multinationals faced difficulties with enforcing their rights abroad, such as lower levels of IPR protection including inadequate enforcement measures. Consequently the US adopted a two-tiered approach by continuing to use domestic, unilateral and bilateral actions in addition to multilateral endeavors." The continuing use of and threats to invoke Section 301 of the US Trade Act by the US has caused much controversy and discomfort among other members of the WTO, academia and civil society. 95 'This unease with US' unilateral action endangered the strong EC-US alliance in the negotiations towards the TRIPS Agreement. In fact US unilateralism was the main driving force behind the Uruguay Round negotiations on the WTO dispute settlement system - the US position was that they would continue to resort to unilateral action as long as there was no effective multilateral dispute settlement system. The US, asserted that the existing GATT dispute settlement system, as a result of the consensus requirement, " was too weak to protect US trade interests in

"2 See for instance Carmody on the Canadian situation. However, it should be noted that although the provision is retaliatory in nature, the conditions to call the provision into being are quite distinct from the Section 301 procedure. Besides, Canada would burn its fingers, as its economy depends heavily on US imports and exports if it would use unilateral action. Ait. 559 should therefore be seen as a "piece of reserve legislation". Camody explains that Canada, being an intermediate country, favours a multilateral trading system as it values a rule oriented trading regime. See Carmody 1998, p. 690-694.

43 S. 301 was seen by supporters as a useful tool to open foreign markets and to balance the weaknesses/gaps encountered in the GATT system.

4.4 See Gadbaw 1989, p. 229

"4 See for instance, Bhagwati 1990.

m. When a contracting party to the GATT believed that any benefit accruing to it directly or indirectly under CATT was being nullified or impaired that party could request consultations with the contracting party which it believed to be at fault. If consultations failed, it could request that a panel be established to decide on the matter. Notably, the decision on the establishment of a Panel was to be taken by consensus. A panel report was submitted for adoption to the GATT Council in 
an effective manner. ${ }^{97}$ As a result, the US has put much emphasis on introducing the Dispute Settlement Understanding (DSU) into the WTO system. Some form of consensus was found in the DSU, providing a procedurally tighter dispute settlement system. Consensus decision -making was in the context of the WTO Dispute Settlement System replaced with reversed consensus decision-making, on the establishment of panels, the adoption of panel and Appellate Body reports and the authorisation of retaliation measures. Reverse consensus decision-making means that in practice the decision-making is quasi-automatic. Under this system, recourse to unilateral action is explicitly prohibited (see Article 23 DSU). Through the enactment of the DSU, the need for the US to use Section 301 has been diminished:

\begin{abstract}
"the Uruguay Round agreements and the new DSU have 'multilateralized' S. 301. Under the DSU, the USA is guaranteed an expeditious ruling by a dispute settlement panei on the WTO compatibility of foreign trade restrictions". "4
\end{abstract}

However, the threat of Section 301 has not completely disappeared: If the USA is not happy with the results of future WTO negotiations, Section 301 can still be applied. Countries enjoy great freedom with regards to the implementation of the TRIPS Agreement. It implies that enforcement is left to the sovereignty of each individual Member in conformity with its own legal system. ${ }^{99}$ Perhaps as a result of this enforcement freedom the US has reserved the right to address international legal disputes in the field of IPRs through unilateral actions. However, it is questionable if this unilateral action is permissible as Article 23.2 of the DSU stipulates that WTO Members may not unilaterally decide that a violation of WTO law has occurred and may not take retaliation measures in case of violation of WTO law. ${ }^{100}$ However, Section 301 can still legitimately be used for countries which are not a party to the WTO but the ever-shrinking number of countries that are not yet in the WTO does not give much room in this respect. The Section 301 can also still be used for matters outside of the scope of the TRIPS Agreement and it can (and still is) a useful tool for private parties (mainly US MNEs which have encountered malfunc-

which all contracting parties were represented. Notably, under the GATT system consensus was required. This meant that, the losing party could vote against adoption and by so doing veto it. See Arts. XXII and XXIII of CATT, the Understanding on Notification, Consultation, Dispute Settlement and Surveillance of 28 November 1979 and its Annex "The Agreed Description of the Customary Practise of the GATT in the Field of Dispute Settlement". See Gervais 2003, p. 6.

47 See Van den Bossche 2005, p. 217.

"s See Schaefer 1998, p. 157.

w) For instance, Europe has harmonised to a great extent its enforcement policy in their Enforcement Directives.

1in Art. 3.2 DSU stipulates that it should provide: "a central element in providing security and predictability to the multilateral trading system". 
tioning IPR protection systems overseas) to lobby the USTR to bring a case to the DSU, this has happened with China. "1"1 The USTR has, since the enactment of the WTO Agreement, used the Section 301 in a WTO consistent mamer with the notable exception of the Japanese auto-spare parts market. ${ }^{112}$

\section{THI: WTO ANDTHE GATT'}

\subsection{The GATT}

The predecessor of the WTO is the GATT. Ever since the 'Bretton Woods' conference ${ }^{10.3}$ took place in 1944 - in an attempt to re-build nations after World War 11 - the US was eager to establish a global body that would set the rules on free trade and unlimited access to trade. This body ought to complement the World Bank and the International Monetary Fund and tackle problems relating to trade. The Conference also proposed the creation of an International Trade Organization (1TO) to establish rules and regulations for international trade (to regulate trade as part of a larger plan for economic recovery). The 110 charter was agreed on at the UN Conference on Trade and Employment (held in Havana, Cuba, in March 1948), but was not ratified by the US Senate. ${ }^{1 / 4}$ As a result, the ITO never came into existence. As governments negotiated the [TO, some countries began parallel negotiations for the GATT as a way to attain early tariff reductions and removal of all obstacles coming in the way of free trade. ${ }^{115}$ "The Protocol of Provisional Application of the GATT was signed by a number of countries on 30 October 1947 or shortly thereafter to apply provisionally on and after 1 January 1948. ${ }^{\text {tot }}$ The Protocol of Provisional Application entered into force on 1 January 1948. In the following years - after it became clear that the ITO Chapter would never enter into force and the ITO would therefore not be established - the GATT gradually developed into a de facto international organisation on trade (to fill to gap left

1 1u1 See China Enforcement, Chima - Measures Affecting the Protection and Enforconent of Intellectual Property Rights WTO Case DS 362/363, vide Gervais 2008. For a detailed overview of the Pand's findings see section 4.2 of chapter two of this book.

1 :12 See Schaefer 1998, p. 156-160.

in The Bretton Woods Conference, also referred to as the UN Monetary and Financial Conference, took place from 1-22 July 1944. This Conference established the International Bank for Reconstruction and Development (the "World Bank") and the International Monetary Fund (IMF). It failed in establishing a multilateral trade organisation.

14 The TrO never materialised because the Havana Charter inserted some rules regulating restrictive trade practices which the US could not accept.

105 See Sharma 1994, p.8.

14. See Protocol of Provisional Application of the General Agreement on Tariffs and Trade, 30 October 1947. Published online at: <http:/ /ww.ucc.ic/acad/appsoc/ tmp_store/mia/Library/ history/capitalism/gatt/cht1.htm>. 
by the still-born ITO). ${ }^{1177}$ The GATT"s main objective was to ensure that trade takes place on a non-discriminatory basis ${ }^{118}$ through the reduction of barriers to international trade: i.e. the reduction of tariff barriers, quantitative restrictions and subsidies on trade through a series of agreements. In addition it should provide a platform for political exchange of thoughts on these matters. However, the GAJ'T was a treaty, not an organisation.

The GATT proved to be successful, reflected by a steady expansion of contracting parties: by the end of the Uruguay Round 128 countries had joined the GATT: ${ }^{10}$ Nonetheless, the GATT was never intended to be an organisation, which was reflected in its structure which was flawed. In addition, the GATT Dispute Settlement System was weak."

The GAT"T was originally initiated to lower tariff barriers but over time its role expanded as a result of the drop in tariff levels. As a result, it increasingly came to concentrate on non-tariff trade policies and domestic policies having an impact on trade." ${ }^{11}$ The GAT"I multilateral trade negotiation system produced major tariff reductions, especially on imports of manufactured goods by developed countries. However, it proved less successful in reducing non-tariff barriers, which became greater obstacles to trade as tariffs came down. Examples of non-tariff barriers concemed technical regulations, standards, sanitary

10: On 1 January 1948 the agreement was signed by 23 countries of which 12 were industrial and 11 developing Countries. The founding parties of the GATT were Australia, Belgium, Brazil, Burma, Canada, Ceylon, Chile, China, Cuba, Czechoslovakia, France, India, Lebanon, Luxembourg, the Netherlands, New Zealand, Norway, Pakistan, Southern Rhodesia, Syria, South Africa, the United Kingdom, and the United States. Subsequently China, Lebanon, and Syria withdrew.

10 For an extensive overview of the principles of non-discrimination see Van den Bossche 2005, Chapter four Principles of Non-Discrimination.

$10 \%$ See Van den Bossche 2008, chapter two, section 2.2.1 on the success of the GATT.

111. When a contracting party to the GATT believed that any benefit accruing to it directly or indirectly under GATT was being nullified or impaired that party could request consultations with the contracting party which it believed to be at fault. If consultations failed, it could request that a panel be established to decide on the matter. Notably, the decision on the establishment of a Panel was to be taken by consensus. A panel report was submitted for adoption to the GATT Council in which all contracting parties were represented. Notably, under the GATT system consensus was required. This meant that, the losing party could vote against adoption and by so doing veto it. See Arts. XXII and XXIII of GATT, the Understanding on Notification, Consultation, Dispute Settlement and Surveillance of 28 November 1979 and its Annex "The Agreed Description of the Customary Practice of the GATT in the Field of Dispute Settlement". See Gervais 2003, p. 6.

111 See Hoekman, Mattoo and English 2002, p. 41. 
and phytosanitary measures, health and safety measures, customs formalities and govemment procurement practices. ${ }^{112}$

\subsection{The GATT and IPRS}

The focus and enhanced importance on intellectual property in bodies such as the CATIT is the result of the acknowledgement that intellectual property and international trade are increasingly interwoven. ${ }^{1.3}$ International trade and competition are affected by the protection of intellectual property, in particular by the grant of exclusive rights to the IP right holder. Until the adoption of the TRIPS Agreement, only limited reference to intellectual property was made within the GATT framework: Article IX, addressed marks of origin; Article IX:6 dealt with geographical indications ${ }^{114}$ and; Article XX GATT, predominantly dealt with the general exceptions to the promotion of free trade. Its paragraph (d) stipulated that contracting parties can adopt or enforce measures in relation to the protection of patents, trade marks, copyrights and the prevention of deceptive practises.

Prior to the establishment of the TRIPS Agreement cases including an intellectual property component were sometimes referred to the GATT under the national treatment obligation to bring a case of nullification and impairment of benefits under the Agreement. Once a violation with a GATT provision was found, the possible justification of this violation under Article $X X(d)$ became relevant. Article $X X(d)$ stipulates:

"Subject to the requirement that such measures are not applied in a manner which would constitute a means of arbitrary or unjustifiable discrimination

112 See Van den Bossche 2008, p. 741.

11.3 Stewart explains the inclusion of intellectual property within the CATT as follows "this focus reflected the increasing recognition of the relationship between intellectual property and international trade", see Stewart 1993, p. 2245.

11.4 Art. IX:6 of the GATT stipulates: "The contracting parties shall co-operate with each other with a view to preventing the use of trade names in such manner as to misrepresent the true origin of the a product, to the detriment of such distinctive regional or geographical names of products of the territory of a contracting party as are protected by its legislation. Each contracting party shall accord full and sympathetic consideration to such requests or representations as may be made by' any other contracting party regarding the application of the undertaking set forth in the preceding sentence to names of products which have been communicated to it by the other contracting party". Notably this provision was given a restrictive interpretation in the Panel report on Jupan - Customs Duties, Taxes and Labelling Practices on Imported Wines and Alobolic Beierages. The Panel found that the use of marks such as "Riesling" or "chateau" by Japanese manufacturers had not been shown to be to the detriment of distinctive regional or geographical names of products. L6216, report adopted on 10 November 1987, see BISD 34S/83. See Gervais 2003, p. 6 . 
between countries where the same conditions prevail, or a disguised restriction on international trade, nothing in this Agreement shall be construed to prevent the adoption or enforcement by any contracting party of measures: (d) necessary to secure compliance with laws or regulations which are not inconsistent with the provisions of this Agreement, including those relating to customs enforcement, the enforcement of monopolies operated under paragraph 4 of Article $I 1$ and Article XVII, the protection of patents, trade marks and copyrights, and the prevention of deceptive practices".

Hence, Article $X X(d)$ provides a general exception to the GATT principle of free trade. This provision was invoked in two disputes brought before GATT panels. In the patent infringement case US - Imports of Certain Automotion Spring Assemblie's, 115 the GATT Panel ruled that patent protection was an area in which contracting parties could take measures which otherwise would not be in conformity with their GAT"T obligations. ${ }^{116}$

In the Luited States - Section 337 of the Tariff Act of $1930^{117}$ the Panel held that in the light of Article $X X(d)$ the substantive patent law of a contracting party could probably not be challenged under GATT. The Panel held that contracting parties to the GATI had the obligation to try to enforce their patent legislation in a mamer that was not inconsistent with GATT provisions. ${ }^{118}$ 'The provisions allowing the suspension of the importation of goods allegedly infringing a US patent by the lnternational Trade Commission (ITC) were said to violate GATT. The suspension of the importation of goods clearly violated GAT" but the question was whether this measure was justified under the general exceptions of Article $X X$ and in particular Article $X X(d)$ ? The answer was no, one of the reasons was that the alleged infringer could not benefit from the same procedural rights as the plaintiff (e.g. the right to file a cross complaint).

During the 1970 s and 1980s efforts were made to revise the existing international intellectual property framework - to combat the increasing problems encountered with counterfeited goods. In particular, the enforcement provisions were subject to review, with the US, Canada and the countries of Western Europe at the forefront of this endeavour. These countries considered that due to ineffective and inadequate enforcement regulations, piracy and counterfeiting could flourish. The supporters of revision were in favour of establishing effective enforcement provisions and dispute settlement mechanisms for countries to seek redress against non-compliance with the existing

115 See US-Imports of Certain Automotize Spring Assemblies, L/5333, adopted on May 26, 1983. See BISD 30S/107.

11. See Gervais 2003, p. 6.

11: $\mathrm{L} / 6+39$ adopted on 7 November 1989 , BISD 36S/345.

11. GATT Analytical Index, p. 582-583 Guide to GATT law and Practise (Analytical Index), WTO, Geneva 1995 (2 Vols.). Referred to by Gervais 2003, p. 7. 
international intellectual property conventions and treaties. Pushed by its industries to combat the trade in counterfeit trademark goods and due to the disappointing results under the WIPO framework, the USA government sought revision of the existing intellectual property framework, in the Tokyo Round by building on Article XX(d) of the GAT"T. During the Tokyo Round (which took place from 1973 until 1979) the trade in counterfeited goods had started to emerge as a serious issue. The International Anti-counterfeiting Coalition was established with the participation of 100 multinationals. This coalition aimed to combat counterfeiting by stimulating the international community to enforce the existing framework of intellectual property rights. In 1979 the endeavours of the Coalition bore fruit when they put forward a draft code called "Agreement on Measures to Discourage the Importation of Counterfeit Goods". 1" This code was negotiated between the US and the European Communities (EC) and in the years to come negotiations were undertaken to gather support among other countries. However, this effort did not succeed. ${ }^{12 n}$

\subsection{The WTO}

The Uruguay Round of multilateral trade negotiations started in 1986 and after eight years of cumbersome and at times contentious negotiations Agreement was reached. The World Trade Organization'21 was founded on 1 january 1995, in effect replacing the General Agreement on Tariffs and Trade (GATT) ${ }^{122}$ which for almost 50 years functioned as the de facto international organisation for setting the rules on world trade. The WTO Agreement was established by the Agreement Establishing the World Trade Organization in Marrakesh on 15 April 1994. The Final Act embodying the results of the Uruguay Round of Multilateral Trade Negotiations signed in Marrakesh in 1994 is like a cover note. Everything else is attached to this. Foremost is the Agreement Establishing the WTO (or the WTO Agreement), which serves as

114 Draft Code entitled "Agreement on Measures to Discourage the Importation of Counterfeit Goods", GATT Doc. No. L/4817, July 31, 1979.

120) These negotiations led to a revised text of the Code in 1982, signed by the US, the EC, Japan and Canada. However, attempts to gain support from other countries failed just before the ministerial meeting of 1982 scheduled for the preparations for the fortheoming GATT Round. Another draft was circulated in 1984 under number L5382. See Bradley 1987.

121 The WTO's agreements are also referred to as the Final Act of the 1986-1994 Uruguay Round of trade negotiations. The WTO Agreement was established by the Agreement Establishing the World Trade Organization in Marrakesh on 15 April 1994.

122 The CATT opened for signature on 30 October 1947, 61 Stat. A3, TIAS No. 1700, 55 UNTS 1987, reprinted in 4 General Agreement on Tariffs and Trade, Basic Instruments and Selected Documents [GATT, BISD] (1969) (hereafter referred to as "GATT"). 
an umbrella agreement. Annexed are the agreements on goods, services and intellectual property, dispute settlement, trade policy review mechanism and the plurilateral agreements.

The $\mathrm{WTO}^{123}$ is a Member-driven organisation with a relatively small secretariat: decisions are taken by Members only and as a result the secretariat has no decision-making powers. The Secretariat's main duties are to supply technical and professional support to the various councils and committees; to provide technical assistance to developing countries; to monitor and analyse developments in world trade; to provide information to the public and the media; and to organise the ministerial conferences. ${ }^{24}$ The WTO is mandated to

\begin{abstract}
"facilitate the implementation, administration and operation, and further the objectives, of |the WTOI Agreement"125 and to provide a "forum for negotiations among its Members concerning their multilateral trade relations in matters dealt with under the agreements in the Annexes to this Agreement. It may also provide a framework for the implementation of the results of such negotiations, as may be decided by the Ministerial Conference". ${ }^{2 t}$
\end{abstract}

The Secretariat also provides legal assistance in the dispute settlement process and advises governments wishing to become Members of the WTO in the accession process. ${ }^{12 \pi}$

The WTO is to administer the trade agreements which were negotiated by its Members. These agreements stipulate the rules of trade and are jointly referred to as the multilateral trade agreements. ${ }^{128}$ These agreements cover trade in

123 The WTO's founding charter is titled "The Agreement Establishing the WTO Agreement". Signed at Marrakesh in 1994 and therefore commonly referred to as the Marrakesh Agreement, or the WTO Agreement.

$12+$ See Art. VI of the Agreement Establishing the WTO Agreement regulates the WTO Secretariat.

12: See Art. III.I of the Agreement Establishing the WTO Agreement.

120. See Art. 111.2 of the Agreement Establishing the WTO Agreement.

12: The WTO Secretariat administers the Understanding on Rules and Procedures Governing the Settlement of Disputes (amnex 2 of the WTO Agreement) following Art. III.3 of the Agreement Establishing the WTO Agreement.

12* Art. Il.1 of the Agreement Establishing the World Trade Organization defines the scope of the WTO: "The WTO shall provide the common institutional framework for the conduct of trade relations among its Members in matters related to the agreements and associated legal instruments included in the Armexes to this Agreement". Prof. Van den Bossche distinguishes six groups of basic rules and principles conmonly referred to as the multilateral trading system: 1) the principles of non-discrimination; 2) the rules on market access, including rules on transparency; 3) the rules on unfair trade; 4) the rules on conflicts between trade liberalisation and other societal values and interests; 5) the rules on special and differential treatment for developing countries; 6) a number of key institutional and 
goods (GATT) and related issues such as investment (TRIMS) and phyto and sanitary measures; trade in services (GATS), and intellectual property (the TRIPS Agreement). In comparison its predecessor, the GATT, covered only trade in goods. The Uruguay Round required a "single undertaking approach", implying that one could not pick and choose agreements to meet national interest and needs, but that membership in the WTO entailed accepting all the results of the Round without exception. In other words adhering to the WTO implied accepting a "package deal": all the rules apply to all Members and they are subject to the Dispute Settlement mechanism. This is in contrast to the GAT" which allowed "opt out" possibilities for countries for certain subject matter. ${ }^{129}$

The WTO has now a functioning and binding Dispute Settlement System (DSS) as shown by the frequent use made of the WTO dispute settlement system. All countries, even the most powerful trading nations have to comply with the rulings of the Panel or Appellate Body. The Panel or the Appellate Body may impose trade sanctions or opt for economic sanctions. DSS is of vital importance to developing country Members which need protection of the law, in particular because the smallest and economically less powerful nations face difficulties to retaliate by using trade sanctions. For instance if a small country denies market access to a big nations such as the US because it finds the latter in infringement of WTO law, this measure will probably not harm the US much. In this case the DSS will be able to introduce economic sanctions instead or use cross-retaliation.

Cross retaliation allows countries to retaliate in another area than the area at issue in the dispute - Article 22.3 of the DSU provides the conditions. For instance, it enables countries to withdraw benefits in textiles or agriculture as punitive measure for failing to comply with IPRs obligations. The system has not been used much but it has potential for the future, in particular in disputes between developing countries and considerably larger economic players in international trade.131 In 2000, Ecuador was granted permission to impose cross-retaliatory sanctions worth $\$ 200$ million against the EU for the latter's failure to comply with a WTO ruling against its banana import regime. ${ }^{1.31}$

procedural rules relating to decision-making and dispute settlement, 7) rules on the protection of intellectual property rights. See Van den Bossche 2008.

124 After the conclusion of the WTO Agreement, the "old" GATT received the official legal term GATT 1947. The updated version of the GATT received the official legal term CATT 1994, and forms an integral part of the WTO Agreement, incorporating by reference the provisions of the GATT 1947. The WTO signatories are referred to as WTO Members, whereas the GATT signatories were contracting parties.

1.31) See Gervais 2003, p. 21.

13 See Bridges Weekly Trade News Digest 2005 b. 
However, Ecuador chose not to avail itself of this right to retaliate. Two times the cross-retaliation possibility has been invoked by developing countries in relation to intellectual property rights to induce compliance with WTO rulings: Brazil in the US-Lypland Cotton dispute ${ }^{1.32}$ and Antigua in the USCmmbling dispute ${ }^{133}$ in response to the WTO incompliant measures of the US under the WTO TRIPS Agreement. The WTO arbitrators in the LIS-Gambling decision approved the cross-retaliation proposed by Antigua; ${ }^{13.4}$ the LIS-Cotton dispute is settled. Hence, Antigua had won the right to retaliate against US intellectual property rights and it has been authorised to suspend trade

132 See US Lplaml Cofton, United States - Subsidies on Upland Cotton, WT/DS267/ $A B / R, 3$ March 2005. Recourse to Ait. 21.5 of the DSU by Brazil, ABR, WT/DS 267/ $A B / R W, 2$ June 2008. In respect of the actionable subsidies, with regard to which the reasonable period of time expired on 21 September 2005, on 6 October 2005 Brazil requested the DSB for authorisation to suspend concessions or other obligations under Art. 7.9 of the SCM Agreement and Art. 22.2 of the DSU. In fact, Brazil asked the WTO DSS for permission to suspend obligations under WTO rules on services and intellectual property rights. If granted permission to cross-retaliate, Brazil would have the right lo suspend US patents, which would clear the way for companies in Brazil to make generic copies of medicines. Cross retaliation would also give Brazil much greater leverage in forcing the US to bring its cotton subsidies into compliance with WTO rules.

133 See US-Gombling, United States - Mcasures Affecting the Cross-border Supply of Gambling and Betting Services. Recourse by Antigua and Barbudin to Art. 22.2 of the DSU, WT/DS285/22, 21 June 2007.

1.4 Antigua challenged various US measures relating to gambling and betting services arguing that they were inconsistent with the US obligations under the General Agreement on Trade in Services (CATS). This is a classic David versus Goliath case in terms of the huge difference in the economic, population and geographic size of the two countries. Antigua had issued a complaint against the US because the US had shut its internet gambling market to operators based in Antigua. The US failed to comply with the ruling and the parties' attempts to reach a compensation agreement were unsuccessful. The compensation Antigua searched was based on lost exports - earnings from the gambling's' exports to the US. Notably, internet gambling is Antigua's biggest revenue after tourism. Consequently, the WTO Dispute Settlement Body (DSB) authorised Antigua to suspend concessions and obligations (to retaliate) with respect to the US under the Agreement on TradeRelated Aspects of Intellectual Property Rights (TRIPS Agreement). Ordinarily, Antigua should have suspended concessions and obligations in the services sector in which the dispute arose, failing that, under other sectors of the GATS. But Antigua is not capable of retaliating effectively against the US under the GATS, and under the GATT for that matter. Antigua was authorised to "cross-retaliate" against intellectual property after successfully arguing that confining sanctions to US services companies, or additional duties on US goods (retaliatory tariffs) - the most common form of WTO retaliation - would hurt its own tiny economy and have virtually no effect on the US. However, the case has resulted in a rare withdrawal of commitments under the GATS as the US decided to modify its GATS Schedule to exclude gambling and betting from its market access commitments so it is likely that Antigua is not gaining much in the end. 
concessions or other obligations (including TRIPS obligations) for an amount of 21 million dollars (notably Antigua had sought penalties worth of $\$ 3.443$ billion). Ilowever, little precedent exists for precisely how Antigua, a tiny Caribbean island nation, might go about suspending standard WTO protections for US intellectual property. No government has ever actually suspended intellectual property rights as a result of a WTO dispute. It is difficult to attach a precise amount to different kinds of IP. Quantifying damages, for instance, could prove difficult if the US and Antigua disagree on the financial value of an overridden patent or denied trademark. ${ }^{135}$

The practicalities of making effective use of cross-retaliation measures are unclear: for instance, how does one ensure equivalence between a WTO violation and a punitive measure? This is not so difficult when the retaliation measure takes the form of increased customs duties but it is indeed a problem when retaliation measures are in the form of a suspension of TRIPS obligation. How will intellectual property obligations be suspended and to what extent? I low can there be flexibility in determining what $I P$ will be suspended? What must be done if products produced under legalised piracy are exported to other countries? Other questions relate to determining the economic value of the suspension? Questions also arise as to the relation between the suspension of IRIPS Agreement obligations and obligations under other IPR treaties or investment treaties. ${ }^{13 n}$

\subsection{The TRIPS Conncil}

The TRIPS Council is responsible for the implementation of the TRIPS Agreement. ${ }^{137}$ However, currently the TRIPS Council's meetings focus predominantly on the extension of geographical indication protection and the introduction of a disclosure of origin requirement. ${ }^{138}$ The Doha Development Agenda also provided the mandate for special sessions to be held by for instance the TRIPS Council and the Trade and Development Committee to negotiate IPRs in the context of the Doha Development Agenda.

The objective of the TRIPS Council is to oversee the functioning of the Agreement on Trade-Related Aspects of Intellectual Property Rights. ${ }^{1.39}$ Article

13 See Bridges Weekly Trade News Digest 2007 a.

1.3. Some of these questions are addressed in a recent paper by Grosse Ruse-Khan 2008.

137 Art. IV of the WTO Agreement provides for the establishment of a Council for Trade-Related Aspects of IPRs, answerable to the General Council of the WTO.

is See Council for Trade-Related Aspects of Intellectual Property Rights - Minutes of Meeting, IP/CM/57, 17 June 2008.

134 Art. IV.5 of the Marrakesh Agreement Establishing the World Trade Organization requested the establishment of subsidiary bodies focussing on a specialised area of trade, e.g. the Council for Trade in Goods, the Services Council and the TRIPS 
68 of the TRIPS Agreement sets out that the TRIPS Council shall afford members the opportunity of consulting on matters related to the trade related aspects of IPRs and it shall provide assistance to Members in the context of dispute settlement procedures. The TRIPS Agreement stipulates the rules on institutional arrangements. The intention is that the TRIPS Council operates as a forum for further negotiation ${ }^{1+10}$ and monitors the functioning of the agreement. ${ }^{141}$ It has been said that this monitoring will contribute to prevent or resolve disputes at an early stage. ${ }^{1+2}$ In particular, the Council must review the implementation of the TRIPS Agreement at least every two years following Article 71 of the TRII'S Agreement. ${ }^{1.3}$ To facilitate this process WTO Members are under the obligation to notify the TRIPS Council of all legislation and rulings they have introduced domestically to fulfil the obligations pertaining to TRIPS as a result of the implementation process (following Article 63 TRIPS Agreement).

One of the main objectives of the Agreement is to eliminate trade in goods that infringe intellectual property rights. The establishment of contact points in Members administrations is believed to facilitate exchange of information on trade in goods infringing intellectual copyright. In this regard Member states need to promote the exchange of information and cooperation between customs authorities with regard to trade in counterfeit trademark goods and pirated copyright goods. $1+4$ The TRIIS Council needs to be kept informed on this process and its progress.

The TRIPS Council and the WIPO have concluded a cooperation agreement between them which aims to facilitate the implementation of the TRIPS

Council. Working groups and committees directly falling under the General Council are also established, e.g. the Working group on Trade and Technology Transfer, the WTO Committee on Agriculture and the Committee on Trade and Development. All these working groups address IP related issues.

1.11 Articles on the implementation of the TRIPS Agreement and developing countries: Primo Braga and Fink 1998, p. 537-554; and also Otten 1998, p. 523-536.

$1+1$ See Art. 68 of the TRIPS Agreement.

14: See Stegemann 2000, p. 1260.

1.3. This is of course an immense job, for example the review of the implementation of the TRIPS into the national intellectual property laws of about 30 countries was completed over a time period of two years and dealt with around 20.000 pages of legal texts. To demonstrate that even for industrial countries implementation was not straightforward, it should be noted that thousands of remarks were made related to enforcement of intellectual property provisions. A positive effect of this thorough review is that in the future, countries will most likely draft national laws more carefully. See Stegemann 2000, p. 1259.

14: See Art. 69 of the TRIPS Agreement. 
Agreement. 1.5 This Agreement mainly endeavours the sharing of information and technical cooperation and assistance activities. For instance, both forums are to inform each other on the notification of laws and to provide access to national laws and regulations and translations thereof. In this respect the WIPO Secretariat (atso referred to as the International Bureau) shall provide WTO Members with access to its computerised databases containing national laws and regulations. Moreover the WIPO Secretariat shall help the TRIPS Council in monitoring the operation of the TRIPS Agreement, the promotion of legaltechnical assistance and technical cooperation in implementing the TRIPS Agreement and providing assistance in the context of dispute settlement procedures (following Article 63.2 and 68 of the TRIISS Agreement respectively. ${ }^{140}$

\section{THE TRIPS AGREEMLNI}

\subsection{Introduction}

More than a century after the Paris and Berne Comventions were drafted, the intellectual property regime was expanded by another major treaty: the Agreement on Trade-Related Aspects of Intellectual Property Rights (TRIPS). ${ }^{1.7}$ The TRIPS Agreement was part of the "single undertaking" that resulted from the GATT Uruguay Round negotiations (1986-1994). 1" The TRIPS Agreement has been called: "the most significant milestone in the derelopment of intellectual property in the twentioth century". ${ }^{140}$

The introduction of intellectual property within the framework of the World Trade Organisation (WTO) was remarkable since prior to this WIPO was the main organisation responsible ${ }^{150}$ for international cooperation promoting intellectual property protection around the world and the WTO's predecessor, the GATT, did not have any tradition of work in the area of IPRs. ${ }^{151}$ Despite

145 The Preamble of the TRIPS Agreement sets out that it desires to establish a mutually supportive relationship between the WTO and the WIPO and this statement is repeated in the Preamble of the WTO-WIPO cooperation agreement. See Agreement between the WIPO and the WTO, Geneva, 22 December 1995. Effective as of 1 January 1996.

14 See Arts. 2.5 and 4 of the WTO-WIPO Cooperation Agreement.

1.t Armex $1 \mathrm{c}$ of the Marrakech Agreement establishing the World Trade Organization.

1.4. "Nothing is agreed until everything is agreed" a phrase repeated on various accasions within the negotiation process. "The launching, the conduct and the implementation of the outcome of the negotiations shall be treated as parts of a single undertaking", Punta del Este Declaration, B (ii).

1.40 See Gervais 2003, p. 3.

tin UNESCO also deals with certain aspects of IPR protection.

15 The WTO membership countries account for well over three-fourth off all countries in the world and currently WTO membership is held by 153 countries (status as of 2.3 July 2008 see <http://www.wto.org>). Hence, the vast majority of international 
the existing IPR framework predominantly administered by the WIPO, with the passing of time certain developments demanded an update and restatement of intellectual property rights. Dissatisfaction with the existing IPR regime and especially the lack of effective enforcement measures, in combination with minimal dispute settlement arrangements, and the limited scope of substantive subject matter led to the introduction of the protection of IPRs on the work programme of the Uruguay Round.

The IRIPS Agreement is a serious attempt to harmonise intellectual property protection including its implementation and enforcement at the international level. ${ }^{52}$ In a nutshell the TRIPS Agreement incorporated the basic GATT principles of national treatment and most-favoured-nation treatment, together with the substantive provisions of the Paris and Berne Convention, supplemented with rules on enforcement and border measures. And it made the Agreement subject to the dispute settlement understanding rules to improve enforcement. The scope and width of the TRIPS Agreement is also new as it comprises almost all facets of IPR and is applied globally due to the number of signatories - considerably higher than the number of parties to the WIPO Conventions. The Marrakesh Agreement (including the TRIPS Agreement) was signed by 114 countries, together with the European Communities. Currently more than 150 countries are Members of the WTO Agreement and therefore bound by the provisions of the TRIPS Agreement. The fact that the TRIPS Agreement is negotiated among such a large number broadens the scope of its enforcement and facilitates trade across borders. For an elaborate discussion on the key provisions of the TRIPS Agreement see chapter two of this book.

\subsection{The Negotiation History of the TRIPS Agreement}

The next sections discuss the negotiation process underlying the TRIPS Agreement within the Multilateral Trade Negotiation Rounds, the Uruguay Round. The reconciliation of diverging interests in one legal document proved to be a cumbersome process. Because of this the Agreement has faced severe criticism ever since. An analysis of the history of the foundation of the Agreement will help understand that criticism.

trade is now subject to the WTO rule-based trading system. Recent accessions to the WTO include Cape Verde, Ukraine, Nepal, Cambodia, Saudi Arabia, Vietnam and Tonga. China became a member in 2001. These accessions make the organisation even more universal and strengthen the multilateral trading system governed by the WTO Agreement even further. Russia, Algeria and Kazakhstan, amongst others, are currently in the accession process. Art. XIl of the WTO Agreement lays down the rules on accession.

152 See Evans 1996, p. 159. 
The need for strong, coherent enforcement procedures for the international protection of II'Rs was the main drive behind a multilateral agreement on trade related aspects of intellectual property rights. ${ }^{153}$ The lack of effective enforcement measures within the WIPO administered Berne and Paris Conventions caused developed countries to seek an alternative for enforcement within the GAl"I framework.

Developed countries argued that technological developments including the advance of the information society facilitated the rapid copying and dissemination of material all over the world and required new forms of IPR protection. Furthermore business operated increasingly on a global scale which increased the need for the harmonisation of laws on IPRs. ${ }^{154}$ Hence, industry was pushing for ways to protect IPRs in the digital enviromment as well as measures to stop the trade in counterfeited trademarked goods and piracy products. ${ }^{155}$ Traditional international legal instruments dealing with IPR were not adjusted to the changing needs of the intellectual property community. Attempts to update the Paris and Berne Conventions to address new technological developments and to improve enforcement mechanisms had failed over the years. Mainly as a result of the disappointing outcome of the revision conferences, intellectual property protection was introduced into the CATT framework, which provided the possibility to trade off intellectual property protection with other matters of (trade) interest - something that was not possible if intellectual property was kept within the WIPO framework. For instance, enhanced intellectual property protection could be traded with market access for tropical products and textiles. On top of this an cconomic recession further demonstrated the need for a global trade agreement.

From the begimning, fundamental disagreement existed between the developed and developing countries in the TRIPS Agreement negotiations. The points of contention from a developing country perspective mainly boiled down to

133 See Draft Agreement on the Trade-Related Aspects of IPRs, Communication from the US, GATT Doc. No. MTN.GNG/NG11/W/70, May 11, 1990 (hereinafter US Draft lext), at 14 and Draft Agreement on the Trade-Related Aspects of IPRS, Communication from the EC, GATT Doc. No. MTN.GNG/NG11/W/68, March 29, 1990 (hereinafter EC Draft Text) at 13.

54 The advent of multinationals which transcended the entity of the nation state moved the negotiations further towards a harmonised IPR system under the WTO framework affecting the territorial nature of JPR protection.

15 Gervais sets out the difficulties negotiators had to deal with in attempts to harmonise intellectual property protection: "the evolution of the world trading system, the sky-rocketing importance of intellectual property, and technological changes, in particular generalised computerisation and digital technology, required a serious updating of international intellectual property rules. By the same token, the enormous potential impact of changes to the rules on major industries made it difficult to agree to any such changes". See Gervais 2003, p. 5-10. 
the fact that developing countries do not see the benefit of strengthening IPRs at this stage of their development. Most developing countries can only profit to a limited extent from an extensive intellectual property regime, because of a lack of technological capability and the fact that appropriate judicial and administrative authorities do not exist or are not modern enough to deal with enforcement and implementation obligations. In fact developing countries view themselves as users rather than generators of intellectual property, so protection of intellectual property rights has not been a high priority to them: "reforming intellectual property rights regimes in poor countries is seen as premature - much like adopting Western environmental protection laws". ${ }^{15}$, What would an increase in intellectual property rights protection yield in reality? From their perspective, the balance shifts towards the negative aspects of adopting a far-reaching IPR regime. The costs of installing the judicial and administrative authorities to effectively implement and enforce the intellectual property protection are huge and must be taken into consideration. Additional costs include those incurred in obtaining technology if possibilities to use reverse engineering, imitation and copying are abolished. ${ }^{157}$ Moreover, developing countries argued that WIPO is the platform to deal with the international legal protection of intellectual property. However, if negotiations were going to take place on IP within the framework of the GATT, developing countries were in favour of restricting the scope of intellectual property protection to trade in counterfeit goods and intellectual property issues immediately related to trade. ${ }^{15}$ The developing countries were reluctant towards negotiations on substantive intellectual property issues and norm setting. However, they encouraged the inclusion of policies stimulating technology transfer, accessing new technologies and pharmaceuticals and (in the broader context of the UR negotiations) market access commitments for tropical products, textiles and development policies in general.

The developed countries stated that the existing intellectual property framework had gaps with regards to substantive norm setting, and that existing provisions were not effectively enforced. The developed countries wanted intellectual property protection to stop the trade in counterfeit goods and were searching provisions to stop the import and export of goods, which infringed intellectual property rights by other means, like piracy. ${ }^{159}$ For instance, they

15t) See Luthria 2002, p. 165.

15. See Reichman 1998 and UK CIPR Report 2002. Both articles provide information on how developing countries can implement intellectual property rights in a consistent manner to the TRIPS Agreement but still benefiting from the flexibilities the Agreement provides.

15 See Adede 2001, p. 10.

159) Piracy refers to the unauthorised copying (and thus for commercial purposes) of materials protected by intellectual property rights and unauthorised commercial 
wanted national governments to keep a better eve on the production of pirate audio and videocassettes within their territory, and to take real action on offenders.

The TRIPS Agreement in its final form is the result of continuous lobbying efforts by not only industry but also by non-governmental organisations (NGO's). ${ }^{161}$ These NGO's are often very well informed and have a lot of expertise and technical knowledge which makes them capable of influencing the decision-making process. Two NGOs have been particularly important in influencing international intellectual property law: the International Chamber of Commerce (ICC) $)^{|t|}$ and the International Association for the Protection of Intellectual Property (AIPPI). 16.2 These two NGO's have worked closely together to formulate IPR policies. ${ }^{16.3}$ For a long time they were the only ones visibly present and involved in the international debate on intellectual property from a private industry interest standpoint. Only as from the 1990 s did other NGO's get actively involved in this debate in order to protect the public interest in the international intellectual property system. ${ }^{164}$

dealing in copied materials. It includes trade in audio and video cassettes providing unauthorised copies of musical performances and films.

161) NGO's are broadly defined by the UN Economic and Social Council (ECOSOC) as follows: "Any international organisation which is not established by inter-governmental agreement shall be considered as a non-governmental organisation". See Art. 71 of the UN Charter and the Resolution $288 \times$ (B) of the UN Economic and Social Council (ECOSOC).

1.1 The ICC has been established in 1919 and has been advocating the convergence of trade and intellectual property related matters ever since. Although established after the Paris Convention was concluded according to Penrose there is evidence that national chambers of commerce have influenced the negotiation process of the Paris Convention. See Penrose 1951, p. 48.

112. The abbreviation stems from its French origin: "Association Internationale pour la Protection de la Propricte Industrielle". The AlPPI has been established in 1897and on its website they introduce themselves as being the "world's leading nongovernmental organisation for research into and formulation of policy for, the law relating to the protection of intellectual property". See <http://wwwaippi.org $>$.

In.3 Koury Menescal calls the relationship between the two organisations a "symbiosis of interests and proposals", because influential experts on national and international II issues - inter alia, professors of law, scientists, patent attorneys, directors of patent departments of multinational corporations - were active members of both organisations simultaneously or consecutively. See Koury Menescal 2005, p. 158.

tow Such other Geneva based NGOs include the Centre for International Envirommental Law (CIEL), the International Centre for Trade and Sustainable Development (ICTSD) and KEl international (former CPtech) and intergovernmental organisations such as the South Centre. 
The name of the agreement - trade related aspects of intellectual property rights - was an achievement in itself. ${ }^{1 n^{\circ}}$ Gervais mentions that even the name, "trade related aspects of intellectual property rights" is a political achievement. He questions if there are any issues of intellectual property that are not in one form or another trade related (besides the moral rights provisions). The most plausible explanation for the choice of name is that by using these wordings intellectual property would fall into the traditional GAT" $\Gamma$ subjects. ${ }^{161}$ The name raised all kind of questions such as "How trade related is intellectual property".67 Hence the question was raised of whether the allegations of the trade impacts of trade mark counterfeiting could be quantified. This question will be addressed in more detail in chapter three. The US responded to this question by listing the losses of industry in relation to inadequate IPR protection: annual losses of the video industry were estimated at 6 billion, ${ }^{165}$ and the automotive parts and accessories association claimed losses of 12 billion, ${ }^{10.9}$ and copyright industries announced annual losses of 1.3 billion to the American copyright industries due to ineffective copyright laws in Brazil, Egypt, Indonesia, Malaysia, Nigeria, the Philippines, the Republic of Korea, Singapore, Taiwan and Thailand. ${ }^{171}$

\subsubsection{The 1982 Ministerial Meeting}

From the late 1970s it became apparent to the US and the EC that the counterfeiting of trade marked products was having an adverse impact upon trade revenues. ${ }^{171}$ Pushed by industry lobbies, the USA and the EC to called for

1n5 See Evans for a more elaborated discussion on how trade related IPRs are, "Intellectual Property as a Trade Issue", 1994, 18 World Competition 137.

the See Gervais 2003, p. 11.

16 Koury Menescal explains thoroughly that the adoption of the TRIPS Agreement is not the first occasion in which a linkage has been made between trade and intellectual property rights. She explains that the convergence of trade and intellectual property rights dates back to the beginning of the $20^{\text {th }}$ century and stems from the way the international patent system has been designed focusing on securing the rights of the patent right holders. See Koury Menescal 2005.

10s Possibile Renewal of the Generalysed System of Preferences - Hearing Before the Subcommittee on Trade of the US House of Rep. Comm on Way's and Means, $98^{\text {th }}$ Cong., first Sess., 1983, p. 57.

1tw" Ibid., p. 57.

150 The international Intellectual Property Alliance (IIPA), "Piracy of US Counterfeited Works in Ten Selected Countries", 1985, p. 7.

17 Especially, during the mid eighties, the US government faced heavy pressure from industry to take action against piracy and the trade in counterfeit trademark goods. The International Intellectual Property Alliance (IIPA) conducted a study on Piracy of US Counterfeited Works in Ten Selected Countries. The IIPA estimated that US industry lost over 1.3 billion dollars in these ten countries per year, due to inadequate intellectual property protection and a lack of enforcement provisions. 
adequate enforcement mechanisms concerning civil, administrative and criminal procedures to control and deter piracy and counterfeiting. For instance increasingly forum shopping was used as an instrument to circumvent those jurisdictions which had the strongest protection and legislation. In 1979 the US and the EC had reached agreement on a draft Code "Agreement on Measures to Discourage the Importation of Counterfeit Goods". 172 Endeavours to gain more support for the court lead to a revised draft Anti-Counterfeiting Code. ${ }^{173}$

Most developed countries argued that the existing IPR framework showed gaps, and that in particular the enforcement of IPRs should be improved. During the 1982 Ministerial Meeting the issue of counterfeiting was placed on the Work I'rogramme of the GATT on request of the US. The US, being one of the strongest supporters of the enhancement of intellectual property protection and enforcement suggested further negotiations on trade in counterfeiting goods and proposed adopting the Code as part of the GATI. 17. The United States saw great advantages to include intellectual property rights within the GATT Forum, in particular in relation to applying the new WTO dispute settlement system (which was still to be negotiated) also to TRIPS obligations.

However, the US perspective was not supported by many developing countries, in particular, India and Brazil pointed out that the WIPO hold the mandate to focus on intellectual property and that the GATr was not authorised to do so due to the fact that the GAT'T's mandate related to tangible goods only. In their opinion the inclusion of these topics would not be in favour of developing countries interests. ${ }^{175}$

The opponents of the introduction of intellectual property protection within the GATT framework were to a certain extent successful as the 1982 Ministerial Declaration showed a limited work program focusing on trade in counterfeit goods and it did not include high technology goods - a subject that the US had wished to place on the Work Programme of the GATT as well.1\% The text of the 1982 Ministerial Declaration in relation to intellectual property reads as follows:

172 See Agreement on Measures to Discourage the Importation of Counterfeit Goods, GATT DOC. No. L/4817 31 July 1979.

13.3 See Agreement on Measures to Discourage the Importation of Counterfeit Goods, GATT Doc. No. L/5382 18 October 1982.

17. See Bradley 1987, p. 57.

1;: The developments in negotiations should be placed against the difficult economic situation around the world. The economy was generally in a state of recession and the developed countries were ubiquitously using trade restrictive practices. 1982 was the year, which showed the lowest growth in international trade and in output by the developed countries since World War II. See Croome 1999, p. 11.

15n 1982 Ministerial Declaration. Thirty-eight Session at Ministerial Level Ministerial Declaration, reprinted in GATT, BISD 30"th Supplement, 1983, p. 9. 


\begin{abstract}
"The Contracting larties instruct the Council to examine the question of counterfoit goods with a view to determining the appropriateness of joint action in the GATI Framework on the trade aspects of commercial counterfeiting, and if such joint action is found to be appropriate, the modalities for such action, having full regard to the competence of other international organizations. For the purposes of such examination, the Contracting Parties request the DirectorGeneral to hold consultations with the Director-General of WIPO in order to clarify the legal and institutional aspects involved".177
\end{abstract}

In response to the 1982 Ministerial Declaration a select group of trade experts were asked to study the effects of counterfeit trademarked goods on international trade. ${ }^{178}$ This group of trade experts concluded that joint action by all stakeholders was desirable to stop the trade in counterfeit trademark goods and pirated goods. ${ }^{179}$ The 1985 study ${ }^{180}$ indicated that while all IPRs were affected by counterfeiting and piracy, goods bearing protected trade marks were more directly affected. It was indicated that the Paris Convention was a useful yet insufficient instrument to prevent trade in counterfeit goods, particularly when it came to surveillance and dispute settlement. It was also indicated that any measures taken to prevent the trade in counterfeit goods should not become an obstacle to trade in genuine goods. However, no agreement was reached in the 1985 study on whether the GATT framework was the appropriate framework for negotiations on this issue. It remained difficult to convince developing countries of the need to adopt new additional standards in relation to intellectual property, as they feared they could become an obstacle to legitimate trade. ${ }^{181}$ In contrast, the 1985 study strengthened some industrialised countries in their conviction that not only should counterfeit goods be included in the Work Programme of the GATT but also that the scope should be broadened to cover a whole range of trade-related aspects of intellectual property rights. For them a binding and enforceable international obligation to eliminate trade in counterfeit and pirated goods was becoming a necessity. ${ }^{182}$

17 Ibid., p. 19.

in The group of trade experts received support from WIPO. The mandate to establish the group of trade experts and to conduct the study was provided at the GATT Annual Meeting in November 1984. GATT, GATT Activities in 1984 (1985), p. 9.

120 Counterfeit goods refers to imitations made usually with the intent to deceptively represent its content or origins, most frequent in relation to trademarks. Piracy refers to the unauthorised reproduction and distribution of copyrighted protected goods, such as electronic and audio-visual media, notably sound recordings and computer programmes.

15: The Group of Experts tabled its report on Octoher 9, 1985. L5878. The L refers to general documents published by the GATT Secretariat since 1962.

1 s. See Gervais 1999 , p. 9.

1s2 GATT, GATT Activities in 1985 (1986), p. 20-21. 
These different opinions continued to be voiced in the following years, during which the desirability and the purpose of a new round of multilateral trade negotiations were heavily debated. In a nutshell negotiations were dominated by two contrasting viewpoints. On the one hand the developed countries favoured a rapid start of multilateral trade negotiations (a new GATT Round), ${ }^{183}$ on the other hand 24 developing countries jointly declared that no new round of negotiations could start before "confidence building measures to restore credibility to the trading system" were established. ${ }^{\text {wi }}$ "This urge by industrialised countries to kick off a new round is explained by what they expected to gain from a new round: 1) the further liberalisation of trade in goods, which would stimulate trade and the world economy; 2) the clarification and updating of old trade rules; 3) discussion on new matters such as trade in services and; 4 ) the rebirth of the GATT as an institution of importance. ${ }^{185}$

In an attempt to speed up the negotiation process, the US turned to the highest body within the CATT - the Session of Contracting Parties - to take issues further. ${ }^{1 \text { st }} \wedge$ ided by the global slowdown in economic activity and increased barriers to trade, contracting parties decided to establish a preparatory committee to try to reach agreement on a decision whether to start a round and, if so, on the agenda of the round. 197 This I'reparatory Committee's mandate was rather broad; the only criteria being that sufficient acknowledgement ought to be given to the needs of the developing country members.

1 si Since the April 1985 meeting of the GATT Council, the developed countries were determined to start a new GATI Round as soon as possible, preferably in 1986 as they announced during the May 1985 summit held in Bonn.

1s. India spoke on behalf of 24 developing countries and voiced criticism on the ideas of a new Round. These 24 countries being Argentina, Bangladesh, Brazil, Burma, Cameroon, Colombia, Cote d'Ivoire, Cuba, Cyprus, Egypt, Ghana, India, Jamaica, Nicaragua, Nigeria, Pakistan, Peru, Romania, Sri Lanka, Tanzania, Trinidad and Tobago, Uruguay, Yugoslavia and Zaire. See Croome 1999, p. 17.

in: See Croome 1999, p. 16.

lst, The Secretariat circulated a paper on "The launching and organisation of tracle negotiations in the GATT". The CATT contracting parties were asked to reply - "to decide to conduct, sponsor or support multilateral negotiations". The special session was called and in October 1985 it was decided that a new round would take place and that a start was made on the preparations towards the round.

16: The Preparatory Commission was to lay down the "objective, subject matter, modalities for and participation in the multilateral trade negotiations, taking into account the elements of the 1982 Ministerial work program". Decision of $28 \mathrm{Novem}-$ ber 1985 on Establishment of the Preparatory Committee, GATT Doc. No. L/5925, reprinted in GATT, BISD 32ni supp. (1986), p. 10. See Croome 1999, p. 6. 


\subsubsection{The Launch of the Uruguay Round in 1986}

It took a lot of effort to agree on the agenda of the new Round. The US and Japan submitted proposals to the I'reparatory Committee to cover all intellectual property rights and their enforcement, not just trademark goods. ${ }^{186}$ Proposals by Brazil ${ }^{1,4}$ and Argentina ${ }^{190}$ opposed the inclusion of intellectual property protection in a new Round.

The 24 developing countries, responsible for the developing country statement in 1985 had diminished in number but were still very active and persuasive. They believed intellectual property rights protection should not be negotiated within the GATI framework (nor should services and trade-related investment measures).

Attempts were made to reconcile the opposing views on the jurisdiction of the GAT"I in intellectual property matters by the Swiss and Columbian ambassadors. ${ }^{191}$ After heavy debates, in particular amongst the United States, Brazil and India it was decided to include intellectual property on the Work Programme of the GATl but to separate them from the traditional trade subjects. Another condition was that a deadlock in negotiations on these new subject matters should not stop progress in other areas. The threat by the US to use unilateral or bilateral action if a new round of multilateral trade negotiations did not include intellectual property matters was an important factor in taking up IP within the GATT discussions.

The Swiss-Colombian text served as the basis for the GATT Ministerial Conference in Punta del Este. The list of subjects for negotiation included the item "tracle-related aspects of intellectual property rights, including trade in counterfeited goods".

The new round was launched in Punta del Este, Uruguay in September 1986 when Ministers adopted the Ministerial Declaration on the Uruguay Round. ${ }^{192}$

1s: PREP.COM(86)SR/3, April 11, 1986.

1.: PREP.COM(86)W/H]/Rev.1, July 16, 1986.

1\% PREP.COM(86)W/49, July 29, 1986.

19 PREP.COM(86)W/47/Rev.2, July 30, 1986.

192 Punta del Este, Uruguay was chosen to launch the new round because it was a developing country, which, would demonstrate to the world that the new round was not merely an endeavour of the developed countries. Ministers gathered on 16 September 1986 to negotiate the work plan for a new round. On 20 September the Ministers adopted a new work program and adopted the Ministerial Declaration on the Uruguay Round at a Special Session of the Contracting Parties. GATT Ministerial Conference, Punta del Este, Uruguay, 15-20 September 1986. The Ministerial Declaration of Punta del Este, officially called the Ministerial Declaration on the Uruguay Round, MIN.DEC 20 September 1986. 
The Punta del Este Declaration expressed the goals and the mandate for negotiations. ${ }^{193}$

Pursuant to the Punta del Este Declaration, the negotiations were roughly divided into two parts: trade in goods ${ }^{19.4}$ (part I), by far the largest part, and trade in services (part 11). In addition 15 negotiation groups were established covering the topics mentioned in the Punta del Este Declaration. ${ }^{195}$ The 15 negotiation groups worked independently to implement the negotiation objectives laid down in the Punta del Este Declaration. The objective was to conclude negotiations within four years. Intellectual property rights were mentioned in part I under the heading: "Trade-related aspects of Intellectual Property Rights, including trade in counterfeit goods". The mandate on intellectual property was formulated as follows:

\begin{abstract}
"In order to reduce the distortions and impediments to international trade, and taking into account the need to promote effective and adequate protection of intellectual property rights, and to ensure that measures and procedures to enforce intellectual property rights do not themselves become barriers to legitimate trade, the negotiations shall aim to clarify GATT provisions and elaborate as appropriate new rules and disciplines. Negotiations shall aim to develop a multilateral framework of principles, rules and disciplines dealing with international trade in counterfeit goods, taking into account work already undertaken in the GATT. These negotiations shall be without prejudice to other complementary initiatives that may be taken in the World Intellectual Property Organization and elsewhere to deal with these matters".
\end{abstract}

Hence, the necessity to promote the protection of IPRs was highlighted but it has also emphasised that measures to enforce IPRs should not become barriers to legitimate trade. Some countries were still not convinced that IPRs is subject

193 The overall guidance of the Uruguay Round was in hands of the Trade Negotiations Committee. Depending on the type of negotiations chaired by the Uruguayan foreign minister (ministerial level) or the Director General of the GATT (officiallevel meeting).

14 Part 1 Trade in Goods was steered by the Group of Negotiations on Goods, the chairperson was the Director Gencral of the GATT, Arthur Dunkel, later his successor Peter Sutherland took over.

19: The subject matter covered included: tariffs, non-tariff measures, tropical products, natural resource-based products, textiles and clothing, agriculture, GAT'7 Articles, safeguards, MTN Agreements and Arrangements, subsidies and countervailing measures, dispute settlement, trate-related aspects of intellectual property rights, trade-related investment measures, functioning of the GATT System and trade in scrvices. The 15 negotiations group had their separate moetings to work out how they could best meet the objectives laid down in the Uruguay Declaration, starting from February 1987. See Croome 1999, p. 29.

1.h Ministerial Declaration on the Uruguay Round, Document MIN.DEC of September 20, 1986, p. 7-8. 
matter that should be placed in the context of multilateral trade negotiations and disputed the trade related nature of IPRs. Some argue that intellectual property is all about trade, others argue the opposite, and namely that intellectual property does not relate to trade at all but to creativity. Most developing countries perceived the existing IPR framework administered by WIPO and the proposed new legislation (within the GATT framework) as only supporting the interests of developed countries' society and industry. They expressed their preference for continuing IPR negotiations within the exclusive framework of WIPO, the UN agency dedicated to intellectual property right issues. This conviction was expressed in the last sentence of the mandate that negotiations should be without prejudice to actions undertaken by the WIPO. ${ }^{197}$

If one looks at this mandate, and the final TRIPS Agreement it shows that a lot of work still needed to be done. The only reference to substantive IPR subjectmatter is found in the wording "elaborate as possible new rules and disciplines". The discussion on whether negotiations on substantive matters fall within the competence of the GATT was also not an easy one, as reflected in the Punta del Este Declaration: The wording "as appropriate" describing the mandate's call for negotiations on "new rules and disciplines" made it possible for both proponents and opponents of negotiations to claim that their view was justified. ${ }^{148}$ The focus of the mandate was still very limited, restricted to stopping trade in counterfeited goods. It was decided that the initial phase of the negotiating process would be taken up with gathering relevant factual material and with the tabling of the submission texts of interested countries. ${ }^{199}$

The initial objective was to stop the trade in counterfeit goods but increasingly it was desired to renegotiate the whole intellectual property legal framework. Developed countries wanted to enhance the existing IPR regulations, add new substantive provisions on IPR and replace old ones with more detailed provisions. However, the developed countries were divided on the topic of raising the substantive level of IP protection (within the GATT) and their primary focus was on the enforcement of IPR while ensuring that enforcement measures would not create barriers to legitimate trade. For instance, initially the EC wanted to discuss substantive IPR protection within the framework of

Wi Already in the 1970s a number of developing countries were advocates of a revision of the $P C$, at that time it was endeavored to establish a Code of Conduct on Technology transfer, however it was never concluded. See chapter three of this book.

14s See Croome 1999 , p. 113.

1*x) Negotiation Plan settled by a Decision of January 28, 1987 entitled "Trade-Related Aspects of IPRs, Including Trade in Counterfeit Goods", See Stewart 1993, Vol. III, p. 11. 
the WIPO. ${ }^{2(x)}$ However, it was also understood that the inclusion of new subject matter should not be avoided.211 The US described its view of the TRIPS Agreement and its relation to the other conventions and treaties:

\begin{abstract}
"in regard to standards or norms, the suggestion was to incorporate those elements of established international conventions which provided for the adequate protection of intellectual property, supplementing them were necessary and appropriate".212
\end{abstract}

The developing countries, on the other hand, favoured restricting the scope of IPR subject matter, to the trade in counterfeit goods and intellectual property issues immediately related to trade. Developing countries made it very clear that negotiations should be restricted to trade related matters in order to prevent the protection of intellectual property rights from being a pretext for blocking or distorting trade. In addition they wanted differing national priorities recognised, reflecting differing levels of development and social concerns, meaning that governments could legitimately differ in the protection they were prepared to give to intellectual property - as they also benefited less from IPR protection. ${ }^{203}$ These different perspectives put a heavy burden on negotiations; in fact it caused earlier negotiations on the reform of IPR in the framework of WIPO to fail.

Hence, following from the above the least controversial topic among negotiators was enforcement. There was general agreement that enforcement was an issue to tackle as the Paris Convention and Berne Convention provided inadequate mechanisms to address the treatment of goods crossing national frontiers.

\title{
3.2.3. The 1988 Montreal Ministerial Meeting
}

Between 1987 and 1989 work progressed slowly as the Secretariat of the GATT was identifying the gaps in the existing intellectual property legal framework. Delegations were busy outlining areas where they thought new rules on IPRs would be necessary. This process considerably widened the scope of the negotiations as the background work covered all forms of intellectual property as well as acquisition and enforcement. Delegations were aware of the various opinions and preferences expressed in different statements but did not really

2(k) Guidelines by the European Communities for the Negotiations on Trade Related Aspects of IPRs, GATT Doc. No MTN.GNG/NG11/W17, 20 November 1987.

201 Suggestion by the US for Achieving the Negotiating Objective, GATT Doc. No. MTN.GNG/NG11/W/14, 20 October 1987.

212 Meeting of the Negotiation Group of 28 October 1987, GATT Doc. No. MTN.GNG/NG11/4, November 17, 1987.

211: See Croome 1999, p. 111. 
know how to glue the pieces together. If countries continued to stick to their ideas and remained reluctant to change viewpoints, further progress in the Uruguay Round would not be possible. The US submitted a substantive proposal for the interdiction of the trade in infringing products through the implementation of customs controls and through the promulgation and implementation of legislative norms for the protection of intellectual property rights. ${ }^{20.4}$

However, unsurprisingly it did not gain support from most of the developing countries. They regarded the proposal as too far reaching for the negotiation group's mandate. Some industrialised countries responded by emphasising the importance of abolishing trade obstacles caused by provisions on the enforcement of IPR. In contrast, Japan was the only country that welcomed the proposal in all its facets and thought it could have gone further. 21.5 Although most developing countries did not approve of the US proposal, Korea ${ }^{206}$ and the ASEAN countries moved further and further in the direction of the developed countries to negotiate on substantive subject matter. ${ }^{217}$

The EC proposal suggested that a future agreement should adhere to the basic GAT'F principles of national treatment, non-discrimination, reciprocity and transparency, as well as applying to the new categories of IPR, such as semiconductor layouts, and plant varieties, as well as to the traditional categories, including utility models and appellations of origin. ${ }^{2118}$

To review progress in the Uruguay Round made so far, the Trade Negotiations Committee decided to hold a ministerial meeting in Montreal in December 1988. Many countries doubted the need for this mid-term review because no decisions would be taken in areas of minor importance such as intellectual property protection before agreement was reached in the most sensitive issues of the Round such as agriculture and services. However, the Montreal meeting was found to be important for a number of reasons to further the possible outcome of the Multilateral Trade Negotiations and to abolish unilateral and bilateral trade protectionist actions and threats. ${ }^{2119}$ The negotiations were held

2u Suggestion by the US for Achieving the Negotiating Objective, GATT Doc. No. MTN.GNG/NG11/W/14, 20 October 1987.

211 Submission by Japan, GATT Doc. MTN.GNG.NG11/W/17, November 23, 1987.

2ith Korea argued in favour of compulsory licensing, see GATT Doc. No. MTN.GNG/ NG/11/W48, October 26, 1989, just as Brazil, GATT Doc. No. MTN.GNG/NG/11/ W57, December 11, 1989.

2ur See Croome 1999, p. 114.

2is Guidelines proposed by the European Community for the Negotiations on Trade Related Aspects of IPRs, GATT Doc. No MTN.GNG/NG11/W17, 20 November 1987.

201 See Croome 1999, p. 114. 
according to the so-called "green-room" negotiation system. 210 Developing countries criticised this process for being opaque as they were only made part of the negotiations in an advanced stage which did not allow them to contribute to the negotiation process. ${ }^{211}$ Due to the time pressure, the presence of senior officials and ministers, and the use of green-room sessions and so-called dark-room meetings, ${ }^{212}$ negotiations, advanced rather smoothly in Montreal regarding IPRs.

The Montreal Ministerial Meeting (so-called mid term review') reached agreement on 11 of the 15 topics. The four remaining were, agriculture, textile and clothing, safeguards and intellectual property rights - which were by far the most sensitive and controversial issues. Negotiations on agriculture resulted in a deadlock and caused further negotiations on the other three topics to become stuck as well. The five Latin American members of the Cairns Group objected to further negotiations on the other undecided issues until the deadlock on agriculture was resolved. As a result of this decision it was senseless to continwe the negotiations on intellectual property for the time being. However, the group negotiating $I P$ made some progress in relation to whether to include substantive IP standards on the agenda. ${ }^{213}$ Gradually developing countries

2111 The "green rooms negotiating system" refers to the colour of the room in which deliberations are held within the WTO. First a small group (5 plus 5 ) commits itself to a certain issue and the outcome of the discussions, which should he near to consensus, is then presented to a larger group (10 plus 10). They on their tum do the same and ones consensus has been reached, they present their results to a bigger audience.

211 This procedure has been heavily criticised by developing countries, who, are of the opinion that they get into the picture when the most influential inciustrialised countries have already discussed upon the most essential items. The developing countries do not stand alone in their utterances; criticism also came from another angle, namely the Non Governmental Organizations (NGOs) and Civil Society. These groups were obviously (due to the nature of the green room negotiating system) excluded from taking part in the negotiating process. This is not utterly true because of course the possibility remained to organise symposiums or workshops in which they could express their views and invite key players in the negotiation process. NGOS and Civil Society groups have shown reluctance to the way the WTO is organised and this can explain partly the unsuccessftil meetings of the MTN in Seattle, USA in January 1999 (generally called the Millennium Round) and Cancun in 20013. See also Croome 1999, p. 142.

212 These so-called dark-room meetings proved useful, because it provided a platform in which countries could talk informally and exchange ideas without commitment. This exchange of views and openness on the amount of concessions countries were willing to make, would reassure countries that others would join in as well. The developing countries wanted benefits in return to the concessions they would have to make. On the other hand, the developed countries expected some reciprocity from the developing countries. See Croome 1999, p. 143.

213 See Stewart 1993, p. 2268. 
gave up their reluctance to negotiate on standards of intellectual property rights. However, India and Brazil pointed out that negotiations on standards could only take place if due regard would be given to public interest objectives, in particular health, social and development needs, and access to technology. These prerequisites were regarded by the United States and other industrialised countries as blocks to patent protection for pharmaceuticals. However, there was no further discussion on these issues due to the abrupt end of the Montreal Round.

Press attention grew steadily once the consequences of the round's outcome on national policies, employment and industry became clear. ${ }^{21+}$ As a result the general public became more aware of the importance of the negotiations which led to more interest groups putting pressure on them. The negotiations in Montreal were overshadowed by demonstrations, which showed the sensitivity which surrounded them and their impact on daily life of people worldwide (especially in relation to agriculture and opening of markets).

The Uruguay Round was supposed to finish by the end of 1990; however, a successful closure of the round was depended on consensus so a way out of the deadlock from the Montreal meeting was crucial. The negotiating countries needed to make overtures to one another and make some concessions. Especially the US and the EC needed to give in on their general principles and explicit targets - especially in relation to agriculture. The US realised that it could not continue to pursue its policy of removing all trade-distorting supports to agriculture. And the EC accepted that it made no sense to stop all liberalisation of agriculture, if it wanted the Round to progress further. ${ }^{215}$ The negotiations resumed in April 1989 to review all topics and in particular the four remaining ones. Negotiations regarding IP protection focussed on the applicability of basic GAT"T principles (e.g. national treatment, most-favoured nation) as well as dispute settlement to intellectual property and the provision of adequate standards regarding the availability, scope and use of intellectual property rights. 210

The Trade Negotiations Committee agreed in April 1989 that future negotiations should deal with standards concerning the scope and use of intellectual property rights and the means of enforcing them. It was agreed that a future instrument on intellectual property should embody the following elements:

"(a) the applicability of the basic principles of the GATT and of relevant international intellectual property agreements or conventions; (b) the provision of adequate standards and principles concerning the availability, scope and use

214 See Croome 1999, p. 143.

215 See Croome 1999, p. 147.

210 See Gervais 2003, p. 14-15. 
of trade-related intellectual property rights; (c) the provision of effective and appropriate means for the enforcement of trade-related intellectual property rights, taking into account differences in national legal systems; (d) the provision of effective and expeditious procedures for the multiateral prevention and settlement of disputes between governments, including the applicability of CAlT procedures; (c) and transitional arrangements aiming at the fullest participation in the results of the negotiations".217

Hence, the Montreal Ministerial meeting and subsequent meetings progressed as participants agreed to work on: 1) the application of basic GATI principles, such as national treatment, non-discrimination and transparency; 2) commitments to provide effective and appropriate means for the enforcement of intellectual property rights; 3) the specification of reference points regarding the availability, scope and use of intellectual property rights, in light of the need to reduce trade problems arising from excessive, discriminatory or inadequate protection of intellectual property; 4) effective multilateral procedures for the settlement of disputes between participants, including commitments to bring the use of connected national trade policy instruments under multilateral disciplines. ${ }^{218}$

This text was far from being suitable to treaty language; however, the mandate implied that all substantive norm setting aspects, enforcement and dispute settlement could legitimately be negotiated, subject to appropriate safeguards and limitations. ${ }^{21 "}$ 'The text implicitly refers to the unilateral mechanisms, such as Section 301 of the US Tariff Act. Developing countries were willing to include IPRs on the condition that appropriate safeguards and limitations were built in and in order to avoid the threat of unilateral action.

Ministers declared that public policy objectives of national systems, including developmental and technological objectives would be taken into consideration. In addition ministers agreed that negotiations should contribute "to a mutually supportive relationship between the GATT and WIPO, as well as other relevant international organisations".2211

The Australians submitted a proposal in which they proposed that the standards contained in the principal intellectual property conventions (such as

21: Ministers delivered a short statement concerning TRIPS. Trade Negotiations Committee Meeting at Ministerial Level Montreal, December 1988, contimued in Geneva from April 5 to 8, 1989. MTN.TNC/11, dated 21 April 1989, p. 21.

215 See Stewart 1993, p. 2269.

$21 "$ See Gervais 2003, p. 14.

221) Trade Negotiations Committee Meeting at Ministerial Level Montreal, December 1988, GATT Doc. No. MTN.TNC/7(MIN), 9 December 1988, p. 21-22. 
the Paris Convention and the Berne Convention) should be incorporated by reference in a future GATT Agreement.221

\subsubsection{The Final Stages of Negotiations}

Brazil and India explicitly disputed the authority of the GATT to negotiate on the actual norms or standards of intellectual property protection as this was perceived to be the kind of subject matter that the WIPO should address. The EC submitted a comprehensive legal text on substantive IPR provisions which showed that they had overcome their initial resistance towards the GATT in negotiating substantive IPR protection in March 1990. It decided to support norm setting activities, in particular to accommodate the protection of appellations of origin. ${ }^{222}$ The EC proposal was entitled "Draft Agreement on Trade-Related Aspects of Intellectual Property" and covered all aspects of IPRs as well as their acquisition, enforcement and the application of basic CATT principles such as national treatment and most-favoured nation using treaty language. This proposal marked a significant step forward in the negotiation process. The proposal by the EC was quickly followed by similar proposals on draft legal texts (also in treaty language) by the US,223 Switzerland224 and Japan. 225 The general idea of these proposals was to incorporate a broad spectrum of IPRs including their scope, use and duration and enforcement measures. Developing countries submitted a draft legal text in May 1990; the submission was referred to as the developing countries' proposal. The proPresident, Mr. George Bush senior said at the Uruguay Negotiations in May 1990: "Our direction is to open markets, expanding trade and negotiating a set of clear and enforceable rules to govern world trade. This is the path to prosperity and growth and high employment. My top trade priority for this year is an ambitious multilateral agreement. (...) Our objective is to anchor these countries in the ideal of freedom, cconomic as well as political. And so we're striving for free trade not just because it is good for America, but because it is good for all mankind". Developing nations on the other hand were not keen on opening their economies. As they believed that unlimited access to foreign companies is in the interest of the developed countries only: The opposition of the developed countries became more manifested, through the Multilateral Trade Negotiations Coalition to advance interest in free trade. This Coalition consisted of a broad alliance of multinational enterprises such as IBM, General Electric, Proctor \& Gamble, and committees such as the Intellectual Property Committee and the International Investment Alliance.

224 Submission by Switzerland, GATT doc. MTN.GNG/NG11/W/73, 14 May 1990.

223 
posal was divided in two parts:22" I'art I entitled "Intellectual Property and International Trade" stipulated rules (procedures and remedies) which should be applied with regard to counterfeit and pirated goods while avoiding obstacles in trade in legitimate goods. ${ }^{22}$ Whereas Part II entitled "Standards and Principles Concerning the Avalability, Scope and Use of IPR" stipulated objectives and principles which should form the basis for the Agreement. The underlying reason for the division (in two parts) was to highlight the preference for a strong regime to deal with trade in counterfeited goods but to minimise provisions on the substantive standards on IPR. Developing countries stressed the importance of keeping the balance between public and private rights - as a main justification for the IPR system and said it was in the interests of both consumers and users. In this regard, developing countries put forward that different stages of development demanded different treatments with regards to an effective use of IPR. Developing countries realised the need for intemational legal framework for the protection of IPRs - to reward innovative creations and to provide incentives for such innovations and artistic creations - but they demanded different levels of protection for different levels of economic development. However, excessive protection of IPR should be prevented. In addition, it was stressed that because they do not have much work to protect enhancing the level of IP protection at the international level would impact access to literary works, music, pharmaceutical and agricultural products. ${ }^{22}$ Developing countries highlighted that merely granting transition periods would not solve the problems they faced in making effective use of IPRs and IPR protection and enforcement but it would just postpone the problem. Moreover, the incorporation of IPRs in the framework of the GAT"T remained an issue for some countries. ${ }^{22}$

22" A group of 14 developing countries submitted a proposal. These countries were Argentina, Brazil, Chile, China, Colombia, Cuba, Egypt, India, Nigeria, Peru, Tanzania and Uruguay, later joined by Pakistan and Zimbabwe.

22: Submission by a group of developing countries, so-called "Developing Country' Proposal", GATT. Doc. MTN/GNG/NG 11/W71, 14 May 1990.

22. Developing countries expressed concern about the possible over-protection of IPRs addressed the impact on technology transfer, and increase in cost of accessing agricultural and pharmaceutical products. See submission by Thailand, document MTN.GNG/NG11/W/27, 21 September 1988, Submission by Mexico, Doc. MTNGSG/NG11/W28, 19 October 1988 and Submission by Brazil, Doc. MTN.GNG/NG11/W/30, 31 October 1988.

224 Chile submitted a communication on 14 May 1990 indicating that standards relating to the protection of IPRs should be dealt with in the framework of WIPO. Communication by Chile, MTN.GNG/NG11/W/72. 
In particular, the developed countries demanded that the developing countries upgrade their intellectual property protection. In relation to copyrights, ${ }^{231}$ the developing countries should provide the protection required by the Berne Convention plus protection for software and databases. With regard to patents, developing countries should provide an adequate patent term and product protection for pharmaceutical and chemical compounds as well as provide limits on compulsory licensing. By contrast, developing countries wanted to restrict the scope of the negotiations and were opposed to setting standards of protection or raising the level of protection. However, there were not only so-called North-South issues. For instance the EC challenged areas of difference in the US system and vice versa. The issue of moral rights for instance was an area of difference. A moral right as opposed to an economic right is non transferable, to protect the integrity of the author's literary work. Moral rights include the right to be known as the author of the work and the right to prevent others from making deforming changes.2.31 Draft texts submitted by Japan, the EC, Switzerland and the developing countries provided for the protection of moral rights, however the US text referred to the economic rights provided in the Berme Convention and did not recommend the wholesale adoption of the Berne Convention.232 The Final Draft TRIPS Agreement represented the US proposal as it called for compliance with Articles 1-21 and excluded Article 6bis of the Berne Convention. In relation to patents there were several differences between the countries perspectives. ${ }^{2.33}$ Under US law, patents have been awarded to the individual who invents the product first, not to the individual who first files the invention in order to obtain a legally acknowledged patent. ${ }^{23+4}$ International harmonisation in the area of patent law was definitely not a new issue for the negotiation countries

23i) Copyright law covers the expression of ideas in tangible written form, rather than the ideas themselves. The idea must be the original work of the author. The term of copyright is typically the life of the author plus fifty years.

231 Moral rights are protected under the Berne Convention in Art. 6bis(1). The US is a party to the Berne Convention since 1989 but it has not changed its copyright law on moral rights as it argued that other areas of law were adequate to protect moral rights such as contract law or libel law. See Stewart 1993, p. 2288.

232 US Draft Text, at Art. 1 as referred to by Stewart 1993, p. 2289.

23. "The owner of a patent has the right to prevent other persons from making, using or selling the subject matter of the invention protected by the patent for a given period, usually twenty years from filing. Patents are granted to technological advances that display a significant advance over the prior work of others in technology. A patent may be sold, like other forms of personal property. Under a patent license, the owner of the patent allows a licensee to practice the invention, or some aspect of it, in return for money, typically a percentage of the sales price of the product under the license". See Stewart 1993, p. 2292.

23 The first to invent rule is based on a policy of fairness as opposed to efficiency, the fatter being the goal of the first to file system. The Philippines is the only other country (next to the US) that operates by a first to invent system. See Stewart 1993, p. 2292. 
as the Paris Convention was signed in 1883. The US law gives precedence based on the invention date but limits this to domestic inventors and foreign inventors are held to the foreign priority date based on filing. The first to invent rule has been viewed as raising potential bias in US courts because of the difficulty of compelling discovery in a foreign country. 235 Neither the 1990 Brussels TRIPS Draft nor the 1991 Dunkel Draft contained a requirement that patents be based on a first-to-file system. In addition the patent term duration was a point of concern. Japan favoured limiting the patent term to twenty years from the filing of the earliest patent application in the chain. The US, the EC, the Nordic countries and Switzerland proposed that the term be limited to twenty years from the time of filing. ${ }^{23 x}$ By contrast the developing countries proposed patent terms to be based on national legislation.23: The TRIIS Agreement called for a twenty-year period of patent protection. What may constitute patentable subject matter was an issue of concem. The US, Japan, the Nordic countries and Switzerland urged broad patent coverage without exclusions for plants and living organisms. 23. Protection was sought because patents can protect the research and development efforts of companies, which may amount to ten per cent of total corporate sales. ${ }^{23 \prime}$ By contrast, The EC and developing countries wanted an exception for patents concerning plants and animals. ${ }^{2+11}$ "The 'TRIPS $\Lambda$ greement stated that parties "may" exclude plants and animals from patent protection but that parties shall provide for the protection of plant varieties either by patents of by an effective sui generis system. Another area of difference concerned compulsory licensing provisions. In developing countries it was normal practise to grant a patent holder an exclusive patent right for a number of years, after which the holders must license this right to the local industry in return for compensation. In addition these compulsory licensing provisions could require that a patent be "worked" in the location where the patent was granted within a short period of grant (for

235 See Stewart 1993, p. 2293.

23r Draft EC text, at Art. 25; US Draft Text at Art. 25; Main elements of a legal draft for TRIPs, Communciation from Japan, GATT Doc. No. MTN.GNG/NG/11/74, 15 May 1990. (hereinafter Japan Draft text), at Art. 4 ; Draft Amendment to the General Agreement on Tariffs and Trade on the Protection of Trade-Related lntellectual Property Rights, Communication from Switzerland (hereinafter Switzerland Draft Text) at Art. 231. See Stewart 1993, p. 2293.

23. See Communication from Argentina, Brazil, Chile, China, Colombia, Cuba, Egypt, India, Nigeria, Peru, Tanzania and Uruguay, GATT Doc., No. MTN.GNG/NG11/ W/70, 14 May' 1990 (hereinafter Developing Countries Draft Text), at Art. $4(3)$. See Stewart 1993, p. 2294.

23: US Draft Text, at Art. 23; Japan Draft Text, at Art. 4(3); Proposal by the Nordic countries, at Art. 1(1); Switzerland Draft Text, at Art. 229 as referred to by Stewart 1993, p. 2294.

23. See Stewart 1993, p. 2294.

241 EC Draft Text, at Art. 23; and Developing Countries Draft Text at Art. 4(1)ii. See Stewart 1993, p. 2295. 
instance within three years). The local working requirement implies that the patent holder must manufacture the goods locally and exporting the goods to the foreign country is not sufficient to avoid the compulsory licensing. Hence, patents that cannot be, or are not, developed quickly become subject to compulsory licensing. The US and the EC wanted to limit the use of compulsory licensing. The EC proposed conditions that must be met for compulsory licensing can take effect and the US prohibited compulsory licensing all together except in the case of an antitrust violation or a national emergency. 241 The TRIPS Agreement was in line with the EC Draft Text and recognised the use of patents without authorisation of the patent owner including use by the government upon certain conditions. Such conditions are prior efforts to obtain authorisation from the patent owner, non-exclusive use of the compulsory license and that adequate remuneration should be paid to the patent owner. ${ }^{242}$ Another point of contention concerned process patents, i.e. patents on the invention process rather than on the product itself. The US and the EC wanted a reversul of the burden of proof from the claimant to the defendant when a patent on a process is violated by a product. ${ }^{243}$ The TRIPS Agreement set out that the judicial authorities shall have the authority to order the defendant to prove that the process to obtain an identical product is different from the patented process.

In an attempt to reconcile positions, Chairman Lars Anell24t combined the different proposals into one document, referred to as the "Chairman's draft" or "Composite draft text". This text was circulated in June 1990 and summarised the main proposals and highlighted substantive differences. ${ }^{245}$ The text succeeded in restructuring the individual proposals into one document and push-

2.11 EC Draft lext, at Art. 26; US Draft Text at Art. 27.

2:2 Chapter two, section 3.6 of this thesis addresses the compulsory licensing provision (Art. 31 TRIPS Agreement) in more detail.

24. Art. 34.1 of the TRIPS Agreement reads as follows: "For the purposes of civil proceedings in respect of the infringement of the rights of the owner referred to in paragraph $I(b)$ of Article 28, if the subject matter of a patent is a process for obtaining a product, the judicial authorities shall have the authority to order the defendant to prove that the process to obtain an identical product is different from the patented process. Therefore, Members shall provide, in at least one of the following circumstances, that any identical product when produced without the consent of the patent owner shall, in the absence of proof to the contrasy, be deemed to have been obtained by the patented process: (a) if the product obtained by the patented process is new; (b) if there is a substantial likelihood that the identical product was made by the process and the owner of the patent has been unable through reasonable efforts to determine the process actually used".

$2+4$ Lars Anell, ambassador of Sweden, chairman Negotiating Group on Trade-Related Aspects of Intellectual Property Rights, Including Trade in Counterfeil Goods.

245 The Chairman's draft was distributed on 12 June 1990. Differences among the proposals were indicated with "square brackets". 
ed negotiations further. After informal discussions the draft became a formal document, referred to as the Chairman's report to the Group of Negotiation on Goods. ${ }^{2+1}$ Notably, the document followed the structure of the US and EC proposals. "This approach was referred to as the " $A$ " approach, the purpose of which was to conclude a single agreement covering all IPRs, including their acquisition, and enforcement. The developing country position was referred to as the "B" approach. Developing countries still opposed an all-encompassing agreement and preferred the separation approach as indicated above (one on trade in counterfeit and pirated goods and a second agreement on the availability, scope and use of II'Rs). Future negotiations had to focus on deleting the square brackets (all the issues left unresolved). Hence there were three possibilities "adopt one of the solutions proposed to each of the questions raised, abandon the issue, or find compromise language". $2+2$ Negotiations continued largely in informal sessions involving the principal actors. Developing country delegates remarked that the Punta del Este had been interpreted in a very broad manner, and further negotiations should take due account of developing countries' developmental and technological needs. ${ }^{2+4}$ They said that, in particular, developing countries need to be able to exclude of certain products and processes from patentability on grounds of public interest, health or nutrition reasons. They also asked to keep the local working requirement implying that one of the obligations of the patentee is that the patent should be locally produced in the country of grant. The local working requirement was viewed by developing countries as one of the essential elements upon which the patent system was based and was part of the balance between the interests of patent owners and those of the country undertaking to protect inventions. ${ }^{2+4}$

The Chairman's text was regularly updated and by October 1990 the text contained standards in all fields of IPRs including a provision that the text constituted minimum requirements, i.e. countries are free to adopt higher standards of protection on their territory. 250 It has been argued that it would have been possible to strike a deal on IP at this stage in the negotiations had not negotiations on other issues such as agriculture and services been stuck in stalemate..$^{251}$

2th Chaiman's report to the Croup of Negotiation on Coods, MTNGNG/NG11/W/ 76, 23 July 1990.

24. See Gervais 2003, p. 19.

24s See the Note dated 14 November 1990, document MTN.GNG/NG11/27.

2.4\% See the Note dated November 14, 1990, document MTN.GNG/NG11/27 as quoted in Gervais 2003, p. 20.

27) See Gervais 2003, p. 21.

251 See Gervais 2003, p. 21. 


\subsubsection{The Final Deliberations}

The Trade Negotiations Group of Negotiations on Goods (GNG), of which the TRIPS group formed part, submitted a draft agreement on TRIPS to the Trade Negotiations Committee (TNC) - at the level of Heads of Delegations.252 This text was discussed during the Ministerial Meeting in Brussels, hence the name Brussels text. But the Round was not closed during this meeting. However, five crucial issues surfaced: they were the protection of pharmaceutical products by patents; $; 5.5$ dispute settlement and link to cross retaliation; nature and duration of transitional periods for developing countries; copyright protection; ${ }^{254}$ and the protection of geographical indications.

It relation to dispute settlement countries hoped to effectively replace the unilateral pressures and measures that states had increasingly been using with the multilateral dispute settlement procedures. Negotiations on IPRs had stopped because of a deadlock on trade in agriculture which led to the collapse of the Brussels meeting.

Further draft texts were received by the TRIPS negotiation group during 1991. Korea submitted a proposal in July 199025 on expanding dispute settlement (e.g. with Draft Article 67bis) which would allow private parties negotiating a patent or know-how license agreement to request an opinion from a group of experts on the question of whether such a license would constitute an abuse of an IPR in a given technology or have an adverse effect on trade. ${ }^{25}$ However it was found that such a system could delay transfer of technology or license agreements. The Andean group submitted a proposal to include all the substantive provisions of the Berne Convention. ${ }^{257}$

252 Draft Final Act Embodying the Results of the Uruguay Round of Multilateral Negotiations (Brussels text), Document MTN.TNC/W/35/Rev.1, 3 December 1990.

25.3 The pharmaceutical industry was concerned that developing countries were allowed too long a transitional period to implement appropriate patent laws. See Stewart 1993, p. 2284-2285.

254 The copyright industry faired the problematic protection of computer programmes, absence of coverage of the legal status of videogram producers and direct satellite broadcasting and the concept of theft in relation to cable and satellite communications. See Blakeney 1996, para. 1.14 referring to Oman, "Berne Revision: The Continuing Drama", 1993, 7, World Intell. Prop. Rep. 160-161.

255 Submission by Korea on "Proposal for the Establishment of a Dispute Prevention System in Respect of Transfer of Technologies", MTN.GNG/TRIIS/W/1, 12 July 1990.

25. See Gervais 2003, p. 23.

3 Submission by Colombia on behalf of the Andean Group. Document MTN.GNG/ TRIPS/W/2, 16 October 1991. 
In November 1991 the Director General, Arthur Dunkel issued a progress report which identified twenty IP issues which required resolution. ${ }^{258}$ Negotiations moved to the next level with the drafting of another key document, the Dunkel Draft (named after the GATT Director General Arthur Dunkel) which attempted to settle outstanding difficulties by proposing compromise formulae in December 1991. ${ }^{259}$ 'This document contained no options and deleted all the square brackets. Negotiations resumed in Geneva and while the main focus was on market access of agricultural, industrial products and services countries also addressed issues in the Dunkel Draft which were regarded as requiring revision to the Final Draft TRIIS Agreement. Both India and the US suggested changes. The US, in response to the concerns raised by the pharmaceutical manufactures, proposed that the TRIPS Agreement provide "pipeline" protection for patented drugs which have not been marketed in foreign countries. ${ }^{2(1 i)}$ Moreover, the US requested changes to Article 3 (national treatment) to ensure that US copyright owners would receive benefits in foreign countries from practises such as the French video levy (imposition of a tax). ${ }^{2 t 1}$

India proposed changes but in different areas of the Dunkel Draft. India suggested that the exclusive right to market patented products be omitted from the proposed Agreement. The deletion of this right, in effect, would extend the transition period for developing countries to provide patent protection. In addition, India requested that countries be demanded to establish facilities to work a patent and that absent such facilities, a patent be revoked by a country through compulsory licensing. ${ }^{262}$ Despite of these proposed changes to the Dunkel Draft, the text remained largely unchanged.

235 Progress of Work in Negotiating Groups: Stock Taking, GATT Doc. No. MTN.TNC/ W/89/Add.1, 7 November 1991.

${ }_{254}$ Draft Agreement on Trade-Related Aspects of Intellectual Property Rights, Including Trade in Counterfeit Goods, Dunkel Draft of December 1991, embodied in Document "Draft Final Act Embodying the Results of the Uruguay Round of Multilateral Trade Negotiations", MTN.TNC/W/FA, 20 December 1991.

2 in) The protection of pharmaceutical subject to a patent, but not yet developed or marketed is known as pipeline protection. Most of the developed countries would like to include pipeline protection in the TRIISS Agreement. Protection for pipeline protection would ensure bencfits to pharmaceutical and chemical industries, for instance: if a patent was granted before the TRIPS Agreement (e.g. May 1984) became applicable to a country that previously did not provide protection on 1 January 1994, then that country would have to accept the earlier patent application and provide patent protection for the remaining term of the patent until May 2004. The TRIPS Agreement did not provide for transitional or pipeline protection.

201) See "GATT Negotiations Threatened as US, EC Press for Changes in Draft Text", 10 Inside US Trade, 18 December 1992 at 1, as referenced in Stewart 1993, p. 2286.

2n2 See GATT Negotiations Threatened as US, EC Press for Changes in Draft Text, 10 Inside US Trade, 18 December 1992 at 1, as referenced in Stewart 1993, p. 2286. 
Another issue that was controversial concerned trademark protection. A trademark is a distinctive sign or indicator used by an individual, business or legal entity to identify that the products and or services originate from a unique source of origin and to distinguish them from those of other entities. The legal theory behind providing trade mark protection is that it provides information to consumers to protect the public from confusion over the source of the goods. During the TRIPS negotiations a controversial topic was the "use" requirement. Canada and the US require actual use, or the intention to use, for registration of a trademark. The EC and Japan did not require actual use. The Developing countries wanted individual country flexibility to determine the conditions for the use of a mark as well as the duration of the protection granted. ${ }^{263}$ Article 15.3 of the TRIPS Agreement stated:

\begin{abstract}
"Members may make registrability depend on use. However, actual use of a trademark shall not be a condition for filing an application for registration. An application shall not be refused solely on the ground that intended use has not taken place before the expiry of a period of three years from the date of application".
\end{abstract}

Fundamental disagreement existed between the EC and the US with regards to the protection for "geographical indications". 2n- The EC, from the very beginning of the negotiations expressed its discontent with the inadequacy of existing international protection of appellations of origin and the need for GATT protection. The EC argued that protection under the Paris Convention was not sufficient as the only sanction foreseen is seizure on importation and no general civil or criminal protection has been provided for. ${ }^{265}$ The EC wanted all (not only those related to wine) geographical indications to be protected against any use which constitutes and act of unfair competition, including use which is susceptible to mislead the public as to the true origin of the product. 2 th the US wanted protection only for non-generic appellations of origin for wine by prohibiting their use when such use would mislead the public as to the true geographic origin of the wine. ${ }^{267}$ In addition the EC wanted the US to rollback its list of generic terms in particular in relation to wines. ${ }^{206}$ By contrast the US

20.3 US Draft Text, at Art 11; EC Draft Text, at Art. 11; Japan at section 1(2) and developing countries Draft Text at 17(3) as referenced in Stewart 1993, p. 2287.

2tor For an elaborate discussion on the protection of Gls - including a WrO case between the EU and the US - within the framework of the TRIPS Agreement see chapter four of this thesis.

2n. Submissions from Participants on Trade Problems Encountered in Connection with IPRs, MTN.GNG/NG11/W/7, 29 May 1987, p. 2-3.

20.t EC Draft Text at Art. 20.1.

2 thi US Draft Text at Art. 19.

2 2ns See chapter four of this thesis for more detail on the EC's endeavours to gain back protection for Gls that have become generic in foreign countries. The US for example was not willing to give up common terms, such as champagne. 
wanted to see some type of grandfathering for existing terms (generic terms). The TRIPS Agreement recognised protection for geographical indications and provided for additional protection for wines and spirits "even where the true origin of the goods is indicated or the GI is used in translation or accompanied by expression such as 'kind', 'type', 'style', 'imitation' or the like". However, Article 24 provides exceptions including a grandfathering clause retaining the exception for continuous use for at least ten years or in good faith before implementation of the Agreement (Article 24.4 of the TRIISS Agreement).

Trade secrets were also addressed during the negotiation process - the issue being whether protection for trade secrets should be covered. Trade secrets protection addresses legal protection for certain proprietary information developed by industries. Developing countries did not regard trade secrets as a category of IPRs ${ }^{2(1)}$ and as such argued that it did not come under the negotiating mandate of TRIPS. ${ }^{271}$ Another area of difference regarding the protection of trade secrets was the issue of government regulation, e.g. governments often require submitting proprietary trade secret information as part of government regulation processes. ${ }^{27}$ For instance, governments may demand test data on drugs in order to obtain marketing approval. The final text provided protection for "undisclosed information" in line with Article 10lis of the Paris Convention. ${ }^{272}$

The US, the EC and Switzerland wanted extensive civil, criminal, and administrative enforcement procedures and remedies in the form of damages, injunctions or the forfeiture, destruction or disposal of infringing goods. In addition, the drafts provided for broad provisional and border measures. ${ }^{273}$ By contrast

20,4 Meeting of Negotiating Group of 20 July 1990, Note by the Secretariat, GATT Doc. No. MTN.GNG/NG11/24, 24 August 1990, at 2.

271 Meeting of Negotiating Group of 1 November 1990, Note by Secretariat, CA TT Doc. No. MTN.GNG/NGI1/27, 14 November 1990, at 2.

27 See Stewart 1993, p. 2307.

272 Art. 39.1 of the TRIPS Agreement reads: "In the course of ensuring effective protection against unfair competition as provided in Articte 10bis of the Paris Convention (1967), Members shall protect undisclosed information in accordance with paragraph 2 and data submitted to governments or governmental agencies in accordance with paragraph 3". Art. 39.3 of the TRIPS Agreement states: "Members, when requiring, as a condition of approving the marketing of pharmaceutical or of agricultural chemical products which utilise new chemical entities, the submission of undisclosed test or other data, the origination of which involves a considerable effort, shall protect such data against unfair commercial use. In addition, Members shall protect such data against disclosure, except where necessary to protect the public, or unless steps are taken to ensure that the data are protected against unfair commercial use".

23 US Draft Text, Switzerland Draft Text and EC Draft Text as referenced in Stewart 1993, p. 2309. 
the developing countries wanted simple, effective and adequate enforcement procedures including administrative and civil remedies, and in appropriate cases, penalties under criminal law. Moreover, developing countries wanted enforcement measures in consistence with each Party's legal and judicial systems and traditions and within the limits of its administrative resources and capabilities. ${ }^{27-1}$

The TRIIS Agreement provided a comprehensive section (Part III) on the enforcement of IPRs. Section one set out the general obligations and required parties to provide enforcement procedures under their national laws so as to permit effective action against any act of infringement of intellectual property rights covered by the TRIPS Agreement, decide cases quickly and by written decision and allow for the opportunity for judicial review of final administrative decisions (as set out in Article 41 of the TRIPS Agreement). Section 2 sets out the conditions for civil and administrative procedures, including the right to written notice of civil judicial procedures, the right to damages, the right to indemnification and the right to have infringing goods destroyed. Section three provides for provisional measures in order to permit jucticial authorities to prevent an infringement of any intellectual property right from occurring, and in particular to prevent the entry into the chamnels of commerce in their jurisdiction of goods, including imported goods immediately after customs clearance and to permit to preserve relevant evidence in regard to the alleged infringement (under Article 50.1 (a) and (b)). Section 4 provides for the ability to stop (under Article 51 of the TRIPS Agreement) and even destroy infringing goods at the border (under Article 59 TRIPS Agreement). Section 5 provides for criminal procedures. Article 61 obliges Members to provide for criminal procedures and penalties to be applied at least in cases of wilful trademark counterfeiting or copyright piracy on a commercial scale. Remedies available shall include imprisomment and/or monetary fines sufficient to provide a deterrent.

In order to ensure the uptake of effective enforcement measures, the negotiation parties wanted multilateral consultation and dispute settlement procedures. However, countries differed on the procedure. The EC and the US proposed that in the area of IPRs, contracting parties shall abide by the disputes settlement rules and procedures of the General Agreement and not have recourse in relation to other contracting parties to unilaterally decided economic measures of any kind. 255 Switzerland proposed that disputes be settled on the basis of Article XXII and XXIII of the GATT (1994). ${ }^{27}$ Switzerland, the EC and the US also requested the establishment of a

274 Developing Countries Text, at Art. 17 as referenced in Stewart 1993, p. 2309.

27 EC Draft Text, at Art. 8 and the US Draft Text as quoted by Stewart 1993, p. 2311.

2.t Meeting of the Negotiating Group of 11, 12 and 14 December 1989 as referenced by Stewart 1993, p. 2310. EC Draft Text, at Art. 8 and the US Draft Text. 
Committee on Trade-Related Aspects of IPRs including representatives from each party. The Developing countries included a provision on the settlement of disputes but proposed consultations, conciliation, mediation and arbitration if consultations between the parties did not resolve the dispute but made no mention of abiding by the rules of the GATI. Article 64 sets out that the provisions of Articles XXII and XXIII of GATI 1994 as elaborated and applied by the Dispute Settlement Understanding $2 \%$ shall apply to consultations and the settlement of disputes. Article 68 provides for a council for TRIPS responsible for the monitoring of the operation of this $\Lambda$ greement and, in particular, Members' compliance with their obligations. The TRIPS Council shall also afford Members the opportunity of consulting on matters relating to the trade-related aspects of intellectual property rights and it shall, provide assistance in the context of dispute settlement procedures.

The Uruguay Round ended in Geneva on 15 December 1993, and the Final Act containing the results, was signed in Marrakesh on 15 April 1994. The TRIPS Agreement sets minimum standards of protection and provides rights and obligations in an endeavour to balance the public interest and the private right holder.

The TRIPS Agreement is comprehensive in coverage and provides an updating and supplementing of the relevant WIPO comventions with more detailed provisions on substantive IPRs as well as providing new rules. ${ }^{278}$ In addition, it creates an obligation on Members to have a system in place for the enforcement of the protected IPRs and links them to the binding dispute settlement mechanism of the WTO. However, enhancing the scope and duration of substantive IPRs also led to the deletion of some exceptions and limitations and hence Members have less sovereignty to set IP policies in line with their socio-economic development needs. However the agreement provides for differential treatment for developing countries in some areas, rules on compulsory licensing, leaves exhaustion policies to Members and it provides for transition periods. In addition it is a truly global endeavour with so many signing Member countries. It is also clear that it is the result of a consensus-building process, all parties have lost and gained during the negotiation process - however, some more than others. Importantly the TRIPS Agreement is part of a package deal - the WTO Umbrella Agreement and concessions in agriculture, services or textiles are traded off with intellectual property obligations and vice versa.

I7) Annex two "Understanding on Rules and Procedures Governing the Settement of Disputes" of the WTO Agreement.

27. The Berne Convention is supplemented in the TRIPS Agreement with new rights in relation to the protection of computer programs and compilations of data and related rights of performers and broadcasters. 


\subsection{Conclusion}

Whether to include IPRs within the work programme of the Uruguay Round was a matter of controversy at the beginning of the Round. As set out in this chapter, the negotiating mandate set at Punta del Este was rather limited and the end result clearly exceeds the initial mandate. This negotiation mandate clearly reflects the novelty of IPRs within the GATT framework and the uncertainty of the breadth or depth of coverage any future agreement might entail. ${ }^{27}$ Although the Agreement is perceived as one of the major accomplishments of the Uruguay Round many countries are concerned by the compromise package put together and argue that the TRIPS Agreement is simply a bad starting point for further negotiations.

In the past, as reflected in the Paris and Berne Conventions, industrial property rights (trade marks and patents) were separated from intellectual property rights (copyright). In the TRIPS Agreement this distinction is no longer made. ${ }^{240}$ In the past, these conceptual differences made it possible for countries to pursue their own interests, while signing the conventions e.g. they signed one treaty dealing with certain subject matter of intellectual property but abstained from signing the other. 281 The TRIPS Agreement lays down rules for both intellectual and industrial property protection and for new subjects like, protection for computer software, integrated circuits and databases. From the combination of these different aspects of intellectual property into one multilateral agreement it becomes apparent that countries were not satisfied with the existing IPR legal framework and wanted to harmonise and strengthen the intellectual property provisions by creating a singular, integrated set of interdependent substantive provisions, procedural regulations and enforcement mechanisms. Stewart explains the blur between the once held differentiation between industrial property and intellectual property in the TRIPS Agreement as follows:

27) See Stewart 1993, p. 2313.

2s: Although in the literature the distinction is still made, e.g. Kanagavel who mentions a division into two categories, namely industrial property (including patents, trademarks, industrial designs and geographic indications) and cultural property (including copyright and related rights, including literary and artistic works such as poems, novels, plays, films, photographs, paintings etc.). Kanagavel remarks that it is also an option to divide intellectual property by means of activities, being either intellectual activities or business activities: the former including copyright, patents, industrial designs, layout designs of integrated circuits, utility models, and trade secrets and the latter including trademarks, geographical indications and plant variety protection. See Kanagavel 2003, p. 2.

$2 \times 1$ The US, for instance has been a signatory party to the Paris Convention for a long time but refused to sign the Berne Convention until 1988. This information does not imply that the US did not provide copyright protection; the US preferred its domestic laws and bilateral treaties to multilateral agreements. 


\begin{abstract}
"the broad coverage of the agreement reflects the importance of intellectual property at the current time. By morging the protection of copyright and industrial property in a single mullilateral agreement, the TRIISS negotiations indicated a desire to strengthen the overall protection of intellectual property under international law" ${ }^{252}$
\end{abstract}

The scope of negotiations gradually widened and the country positions were generally deeply opposed. On the one hand the developed countries wanted the developing countries to significantly improve IPRs, on the other hand developing countries sought to restrict the scope of negotiations and opposed setting standards of protection or raising the level of protection. In addition, the developing countries argued that WIPO was the proper forum to discuss IPR. Solving the differences was generally referred to as the North-South debate although numerous areas of disagreement existed among the developed countries.

As negotiations progressed, differences between developed countries became apparent and country submissions challenged these areas of difference. For instance: the strengthening of protection for appellations of origin and geographical indications; coverage of design rights, ${ }^{2}, 3$ breath and coverage of neighbouring rights in relation to copyrights; first to file versus first to invent requirements in case of patent protection; moral rights in relation to copyright; the sharing of technologies, in particular in relation to the transfer of technology; rules on compulsory licensing and local working requirement; rules on exhaustion of rights; the breath of issues to be tackled; the scope of substantive subject matter; and dispute settlement and cross retaliation. The intense debates on the aforementioned topics have shown that, in particular the EC, Japan and the US differed profoundly on the details of intellectual property matter standardisation. Some issues remained unresolved because no consensus could be reached. These included moral rights, first to file require-

23: See Stewart 1993, p. 2246.

243 Design protection remained controversial between the EC and the US: the EC wanted the US to alter its domestic design patent law to expand coverage. In particular the US would not require protection of functional designs such as designs for automobile crash parts. The EC and Japan proposed protection for all industrial designs including functional designs. Under US design patent law, automobile manufacturers cannot obtain design patents on most replacement parts, thus allowing replacement part manufacturers to compete in the market. The issue had not been resolved and the TRIPS Agreement stated in Art. 25.1: "Members shall provide for the protection of independently created industrial designs that are new or original. Members may provide that designs are not new or original if they do not significantly differ from known designs or combinations of known design features. Members may provide that such protection shall not extend to designs dictated essentially hy technical or functional considerations". 
ment versus first to invent, levies on cassettes, rental rights ${ }^{28.4}$ and rules in relation to exhaustion.

Criticism has been directed at the strong supporters of harmonised intellectual property protection, namely the US, Japan and the EC, who are accused of imposing an intellectual property legal framework on developing country members. ${ }^{25}$ Indeed, the major global actors, the USA, the EC and Japan, have put their stamp on the international harmonisation of intellectual property protection. ${ }^{2 x+1}$ It is argued that by following the approach of extending national systems of IPRs to an international level one assumes that cultural values regarding property, effort and rewards are equal around the globe.267 For instance for Colombia and Ecuador the discussion on patenting life was deeply offending.

Supporters traditionally have argued that a strong and harmonised intellectual property rights regime promotes economic growth, foreign direct investment, research and development and the transfer of technology. On the contrary one can argue that a weak intellectual property regime allows (least) developing countries to copy and reverse engineer technologies, books and pharmaceuticals and to learn from other countries' experiences for future local innovation and production. With strong intellectual property rights both on paper and in practice they are deprived of imitation, copying and reverse engineering practices.

From the point of view of industrialised countries the Agreement provides a level playing field as it provides equal rights to all WTO Members to protect inventions and stimulate development, i.e. it reaffirms IPR at the global level, provides for enforcement mechanisms and border control and a dispute settlement system. Developing countries on the other hand are not convinced about this level playing field: does the agreement really give them chances

$2 \times 4$ Japan had difficulties with a proposal to create exclusive long-term rental right on sound recordings. Under Japanese law, rental could be prohibited for a maximum of one year, after which records (CD's) could be rented out, with right holders receiving remuneration administered by a collecting society. On the other hand the Intellectual Property Alliance (IIPA, a US based lobby group representing major US right holders in musical recordings, motion pictures and computer programs) argued that the Japanese rental system contributed to widespread private copying and thus affecting sales. See Gervais 2003, p. 23.

$25:$ Templeman is of the opinion that "at present the enforcement of TRIPS coupled with action against so called unfair exports, and the refusal of investment for political reasons, help to keep developing countries in a state of economic subjection which is no better than the colonial exploitation of the last century". See Templeman 1998, p. 605.

$2 x$, See May 2000, p. 13.

2s: See Gray 1993, p. 5-6. 
equal to those of the industrialised countries? Indeed IPR may help protect books, music and textiles produced on their territory but on the other hand the TRII'S Agrement restricts their access to foreign IPR protected products. However, developing countries are still struggling to set up these industries and at the moment have little to protect. In particular, substantive patent law requires patent protection for pharmaceutical and agricultural products which reduces opportunities to initate copy or reverse engineer. As a result local industries go out of business since they can not legally produce the imitations of IPR protected products. For example, generic producers of medicine are limited in their manufacturing practices and as a result, developing countries are to a certain extent deprived of cheap access to new pharmaceutical products. ${ }^{2 s}$. The enforcement obligations mean trademarked products camnot be imitated and sold under trademarked names. For instance, in Asian countries where counterfeited goods are produced on large scale enforcement measures can result in the loss of jobs. The TRIPS Agreement also restricts access to copyrighted material because copyright owners have a number of exclusive rights at their disposal which may deprive others of accessing information. An additional obstacle is the fact that as well as copyright rules, industry increasingly protects its works by using technological restriction measures, socalled digital rights management (DRM). ${ }^{2 \times 9}$ Technology enables the placement of works behind coded websites which only permits access with a pin code or payment. As a consequence the "limitations and exceptions" of copyright as set out in Article 13 of the TRIPS Agreement is also restricted implying that accessing literary works for educational or research purposes is restricted. In addition, works that have entered the "public domain" may also put behind coded websites and are still not freely available. ${ }^{2 \cdot 1}$

2xs Although study has shown that only five per cent of essential medicines are still under patent protection. Hence, industries are free to reverse engineer pharmaceutical products that are no longer protected under IPR since the term of patent duration has lapsed and consequently the product has entered the public domain. Moreover it can also be the case that the pharmaceutical company has not applied for a patent in the relevant territory. Since $I P$ rights are territorial rights they are only effective if made effective in a particular country.

2sw The WIPO Copyright Treaty sets out a number of rules that are applicable whilst using digital rights management systems: Rules that need to be applied by the copyright holder and also rules that should be applied by the users of the copyright, for instance the rules in relation to the circumvention of the technology used in the digital rights management system.

20.1 In the UK the Copyright Designs and Patents Act of 1988, under Arts. 29 and 30 , makes mention of the concept of "fair dealing". This concept allow's certain exceptions to the exclusive rights of the copyright owner. These exceptions include the use of a copyright work for research or private study for a non commercial purpose on the condition that sufficient acknowledgement is made. The same exception is made for the purpose of criticism or review. 
By and large, the developing countries did not really have a choice whether or not to opt for harmonised intellectual property protection. There was simply no real alternative as the T'RIPS Agreement is part of a single undertaking the WTO Agreement with all its facets). Hence, to continue insisting on excluding intellectual property would have meant abandoning cumulated market access rights. Furthermore, the decision not to accept the IPR provisions in this context would not have resulted in being freed from any commitments regarding intellectual property. Past examples of the use of Section 301 actions by the US government and other public threats of retaliation for not complying with Western IPR hat proven the contrary. ${ }^{29}$ The consequences of the TRIPS Agreement have been hard on the developing countries. For many the field of intellectual property has been a new one $e^{242}$ and many negotiators lacked the capacity, information and the knowledge to negotiate a treaty that is favourable to their needs. ${ }^{29,3}$ The argument made by industrial countries that strengthening intelfectual property protection will attract foreign direct investment (FDI), stimulate the transfer of technology and boost local creativity is still up for discussion and is discussed more adequately in chapter three of this paper.

Providing an incentive to foreign investment and public interest is a balance to be struck against a backdrop of local social and economic considerations. The preamble of the TRIPS Agreement reflects this compromise (balancing public versus private interests. The question however is whether this compromise has set the right balance between the rights of the IPR right-holders and the users? The Preamble recognises that "the provision of effective and appropriate means for the enforcement of trade-related intellectual property rights, [should take] into account differences in national legal systems". However, it is also questionable whether this is a realistic goal considering the prescriptive mature and content of the substantive obligations under the Agreement. ${ }^{29.4}$ See chapter two, section 2.1 for a more elaborate discussion on the Preamble.

241 See Stegemann 2000, p. 1243.

$2 \% 2$ This is true till a certain extent, because most developing countries have been a party to the Paris and Berne Convention for decades, however, with reservations for c.g. patent protection for pharmaceutical products.

243 A study by the Commission on Intellectual Property Rights has shown that developing countries have comparatively little influence (on the outcome in the international intellectual property standard-setting process), the main reason lies in the continued use of coercion by the US and EC, both of which remain united on the need for strong global standards on intellectual property protection. See Drahos 2002.

20.4 See Evans 1996, p. 160. 


\subsection{Introduction}

The harmonisation efforts in the multilateral context which led to the TRIPS Agreement were regarded as insufficient as shown by the umprecedented proliferation of regional and bilateral free trade agreements during the last ten years (an attempt to strengthen economic relations between the countries involved) including intellectual property rights that go beyond the TRIPS Agreement so-called TRIPS plus obligations. The World Bank counted that the number of agreements in force currently exceeds 250 which implies a six-fold increase in two decades and the WTO counts a triple increase from 130 in 1995 to 385 in $2007 .^{295}$

The TRIPS Agreement sets minimum standards of protection (substantive obligations) but it also includes so-called in-built negotiating mandates. For instance Article 24.1 TRIPS Agreement points out that:

"Members agree to enter into negotiations aimed at increasing the protection of individual geographical indications under Article 23. The provisions of paragraph 4 through 8 below shall not be used by a Member to refuse to conduct negotiations or to conclude bilateral or multilateral agreements". ${ }^{2 k}$

This provision creates a mandate to continue negotiations aimed at increasing the protection of geographical indications, both through bilateral or multilateral trade negotiations. The drafters of this provision made it clear that the exceptions listed in Article 24 ought not to be a hindrance to negotiations to extend the protection of GIs. Surprisingly the drafters leave the matter of negotiations open as both bilateral and multilateral negotiations are explicitly mentioned in the provision. This is unusual in the WTO context of negotiations as most WTO Agreements seek to achieve results at the multilateral level and most regional and bilateral agreements can only be exempted from the MFN clause under certain conditions. For a more elaborate discussion on the MFN principle see chapter two, section 2.6 of this thesis.

FTAs include TRIPS plus issues in the area of patents such as the protection of undisclosed data (in relation to data produced in clinical trials necessary to obtain exclusive marketing approval), compensatory extensions of the patent term (to balance administrative delays, or the time it takes to receive marketing approval), the granting of second use patents (for new uses of

$20-$ World Bank, "Global Economic Perspectives, Trade Regionalism, and Development", The World Bank 2004. See also the WTO website on regional trade agreements: <http://www.wto.org/english/tratop_e/region_e/region_c.htm>.

24 See Art. 24.1 of the TRIPS Agreement. 
chemical entities, i.e. using the drug in treating a different condition than the one described in the original patent application), the patentability criteria (for instance in relation to the protection of business methods), the use of compulsory licensing and the exhaustion of IPRs.

In relation to copyrights it diminishes the use of exceptions and limitations by extending the duration of rights to 70 years, as opposed to the 50 years provided in the TRIISS Agreement and they may also extend the use of digital rights management systems (technical measures) and again reduce the use of exceptions and limitations to IPR protection.

Regarding the relationship between biotechnology and traditional knowledge, FIAs might make reference to the protection of life forms, the relationship and compatibility between the TRIPS Agreement and obligations deriving from the Convention on Biological Diversity (CBD), include disclosure of source, access and benefit sharing arrangements and prior informed consent obligations.

In relation to geographical indication protection it is common to promote the expansion of the higher level of protection (currently granted to wines and spirits under the TRIPS Agreement) to other products including food and agricultural products and handicrafts; to provide rules on the protection of GIs versus the protection of trademarks (for instance, first to come, first in right); the protection of homonymous signs; and increase the existing exceptions provided under Article 24 TRIPS. ${ }^{297}$

In addition FTAs include provisions on the expansion of enforcement and dispute settlement; and provide human and financial assistance in meeting with enforcement requirements. FTAs also make reference to the promotion of technology transfer, access to knowledge, technical assistance in establishing IP framework and the interface between competition policies and IPRs to stop abuses. As well as reiterating commitment to the Doha Declaration on TRIPS and Public Health. ${ }^{298}$

The US, ${ }^{29 y}$ the EC and the European Free Trade Association (EFTA) have been especially active in negotiating bilateral and regional agreements to strengthen IPRs. ${ }^{301}$ These agreements are signed using different names and have different

$2 \%$ For a more elaborate discussion on geographical indications please see chapter four of this thesis. See also Claessens 2008a.

24 See Roffe 2007, p. 6.

20x) The Unite States Trade Representative (USTR) is negotiating a number of new trade agreements under the Trade Promotion Authority.

sti The US has concluded bilateral agreements with fordan (2000), Vietnam (2001), Chile (2003), Singapore (2003), Australia (2004), Bahrain (2004), Morocco (2004), Oman (2006), Peru (2006), and Colombia (2006) and regional agreements with 
emphases on IP issues. In fact, in particular the USA has realised that it can only achieve its desired results whilst negotiating bilateral or regional trade agreements and it made the conclusion of FTAs a major objective within its foreign affairs strategy. Looking at the poor representation of US negotiators present at multilateral for such as WIPO or WTO TRIPS Council, it is clear that the US has turned its focus to the regional and bilateral approach. ${ }^{301}$ Developed countries use FTAs as a means to extend their domestic standards on IPRs to a wider area (and other trade related interests as FTAs rarely involve only the protection of IPRs) to a wider area, hence deepening the harmonisation process kicked off with the TRIPS Agreement.

For the sake of simplicity this thesis makes reference to Free Trade Agreements or Bilateral and Regional Trade Agreements, but in reality all these different agreements adopt different names. If these agreements include sections on IPRs then in most cases they build on the minimum standards of the TIRIPS Agreements and incorporate provisions that go beyond these standards: hence FIAs are characterised as TRIPS-Plus arrangements.

\subsection{Implications of Bilateral and Regional Fre' Trade Agrements}

Developing countries are concemed over how these free trade agreements will impact existing rights and obligations under the TRIPS Agreement, as the new regional or bilateral obligations can go further than rules set out in the TRIPS Agreement, which can lead to inconsistencies in their implementation. In

NAFTA (1992) and CAFTA-DR (2005). Whilst the EC has been even more active and it concluded agreements with Australia (1994), lots of the former Soviet Union states, Eastem European Countries, Jordan (1997), Mexico (1997), Palestinian Authority (1997), South Africa (1999), Chile (2002), Lebanon (2002), Canada (2003), India (2005), some of which are of a general trade nature, others are more specific dealing exclusively with wines and spirits. The $E C$ is currently negotiating the socalled Economic Partnership Agreements (EPAs) with the African Caribbean and Pacific countries. These are regional economic partnership negotiations meant to replace the "Cotonou Agreement" as the waiver is set to lapse by the end of 2007 . See Roffe (2007) for a table of trade agreements concluded within the last two decades (or still under negotiation) including chapters on IP'Rs in which the EC, the USA or EFTA was a negotiation party. The complete text of the agreements can be retrieved from the following websites: <http:/ www ustr.gov>, <http://ec.euro pa.eu/comm/trade/issues/bilateral/index_en.htm>, <http://secretariat.efta.ints, and $\langle$ http://www bilaterals.org $>$.

inl It has been argued that countries who have adopted strong national policy goals and objectives, implying that they only have a small margin of freedom to manoeuve at the multilateral trade negotiation table are more successful at achieving their goals as countries who have not adopt such clear national policy objectives. 
particular, these TRIPS plus obligations have an impact on the use of flexibilities and exceptions for safeguarding certain public interests. Not least because, these enhanced obligations are being introduced at a time when the majority of developing countries are still facing huge challenges to implement the minimum standards of the TRIPS Agreement.

In addition, countries are concluding foreign trade agreements with a number of different other countries and each agreement has its own focus point expressing different interests and policy objectives. The proliferation of FTAs is even more worrisome if one considers obligations under Article 4 of the TRIPS Agreement, its Most-Favoured-Nation clause which implies that any benefit, advantage, privilege or immunity granted to a Member must also be granted immediately and unconditionally to others. Hence, any favours granted to the USA need to be extended to all other WTO Members - which puts developing countries in a particularly difficult position. There is no exception made for regional free trade agreements in the TRIPS Agreement. This means that the EC has been able to free ride on IP provisions that the US has imposed on its trading partners.

However, in respect of the ACP countries, the US has not signed any such agreements, and as a result the $\mathrm{EC}$ will have to seek its own IP deal with these countries. It follows, that any IP provisions that ACP countries sign with the EC will need to be extended to the US and other WTO Members as well. In the case of the TRIPS Agreement, treaties subscribed after 1995 are not exempted from MFN treatment." However, Article 5 TRIPS exempts the treaties concluded under the auspices of the WIPO.

These FTAs also pose a threat to the future of the multilateral trade negotiations in the context of the WIPO and the WTO. Foremost, the prospect of more regional and bilateral FTAs impacts the health and viability of the multilateral trading system, especially at a time when the Doha Round WTO negotiations remain deadlocked.

The EC has concluded quite a few bilateral agreements for the sole purpose of safeguarding its wines and spirits in third countries. For instance it has concluded agreements on wines and spirits with Chile and South Africa (2002), Canada (2003), as well as an agreement on wine with Australia (1994)

:32 Art. 4 of the TRIPS Agreement sets out the obligations Members have under the MFN clause. It also lists four circumstances that are exempted from this rule of which one reads "any advantage, favour, privilege or immunity accorded by a Member deriving from international agreements related to the protection of intellectual property inhich entered into force prior to the entry into force of the WTO Agreement, provided that such agreements are notified to the Council for TRIPS and do not constitute an arbitrary or unjustifiable discrimination against nationals of other Members". (italics added FC) 
and an agreement on spirits with Mexico (1997)..$^{313}$ In these circumstances, the purpose was to achieve reciprocal protection of geographical indications related to wines and/or spirits and the protection of traditional expressions. Also provisions on the protection of "homonymous" signs are included if wine is concerned.

In most cases of which the EC Or EFTA is a party the focus is on reinforcing the existing intemational architecture by committing the parties to become a party to a number of multilateral IPR agreements, in most instance WIPO administered treaties. In most FTAs in which the EC or the EFTA is one of the parties the section on IPRs starts of with the overarching obligation of ensuring "adequate and effective protection to intellectual property rights in accordance with the highest international standards, including effective means of enforcing such rights provided for in international treaties". Hence, the emphasis of the EC was not on strengthening the existing standards set by the international IP architecture but it primarily tries to reinforce them. It wants countries to adequately implement and enforce the standards set by the TRIPS Agreement and the major WIPO administered treaties (as for instance the Patent Cooperation Treaty and the WIPO Internet Treaties of 1996).

The US, besides asking for adherence to the existing intellectual property architecture (TRIPS and major WIPO administered treaties) by promoting accelerated and comprehensive implementation of the TRIPS Agreement focuses strongly on installing effective enforcement measures. ${ }^{304}$ Specifically, the US desires a strong enforcement of IPRs, including through accessible, expeditious and effective, civil, administrative and criminal enforcement mechanisms, including customs and border measures. Moreover, the US stresses great importance to the protection of new and groundbreaking technologies and it favours an IPRs approach that is flexible to the dymamic nature of the IPRs, in that it will ensure that standards of protection and enforcement keep pace with technological developments, and in particular ensuring that right holders have the legal and techmological means to control the use of their works through the internet and other means available in the information society and to prevent the unauthorised use of their works. Just like the EC the US asks for the ratification of a number of WIPO administered conventions -in both cases the coverage of WIPO administered agreements are quite similar setting a detailed time framework when ratification should be accomplished.

3.) The EC has concluded bilateral trade agreements on wines and sprits with Canada in 2003, in South Africa in 2002 and in Chile in 2002. It has concluded an agreement on wine with Australia in 1994 so pre-dating the TRIPS Agreement and it negotiated an agreement on spirits with Mexico in 1997.

$3:$ Although it is very likely that the EU will place enforcement higher on its list of priorities in the very near future, and future FTAs will definitely resemble that shift in policy. 
The EC has in the past been very reluctant in relation to IPRs and its main focus has been on the implementation of the TRIPS Agreement obligations and on improving technical assistance activities and cooperation. However, recently the $\mathrm{EC}$ has become more active in this area, most likely as a result of the slow progress at the multilateral level. The EC has become particularly active in conducting regional negotiations with the ACP countries, the socalled Economic Partnership Agreements (EPAs). Developing countries are often willing to sign these agreements because they are promised market access opportunities in developed countries. Often, these agreements are presented as being supportive of the TRIPS Agreement. However, these agreements should be approached with care as they diminish opportunities to use the flexibilities granted in the TRIPS Agreement - for instance they should not impact on the freedom to determine the appropriate method of implementation (under Article 1 TRIISS Agreement) or request immediate implementation of the TRIPS Agreement impeding the transition periods hence, TRIPS plus.

Both the US and the EC would benefit economically from stronger foreign IPRs as they would lead to an increased flow of royalties or profits in the entertainment and pharmaceutical industries. These industries are lobbying for increased IP protection in overseas territories - the idea being that if strong IPRs cannot be negotiated at the multilateral fora, e.g. WIPO or the WTO, the route of bilateral and regional trade negotiations ought to be followed. 315

\subsection{The $A C P-E C$ Economic Partnership Agreements}

Economic Partnership Agreements (EPAs) are now part of the larger EC trade strategy. ${ }^{316}$ An EC report outlines the importance of market access and IP not only as tools for greater European advancement but also as a means for the general economic development of the EC's partners. ${ }^{317}$ The new trade strategy focuses on regulatory reform allowing EU firms to be treated on as at least an equal footing as those in trading partner countries and in relation to IP to demand standards that approximate those of the EC in particularly on enforcement. ${ }^{315}$ The EPA negotiations replace the Lome Conventions and the Cotonou

3115 Sec Barton 2007.

34, "Global Europe - Competing in the World, European Commission", EC Policy Review, October 4, 2006. Published online at: <http://eceuropa.eu/trade/issues/ sectoral/competitiveness/global_europe_en.htm>.

3it Section 3.2 and 3.2 (iii) of the European Commission report dated October 4, 2006.

31) Section 4.2 (ii) of the European Commission report dated October 4, 2006 stipulates: "FTAs should include stronger provisions for IPR and competition, including for example provisions on enforcement of IP rights along the lines of the EC Enforcement Directive". Section 4.2 (v) sets out that the "EU should seek to strengthen IPIR provisions in future bilateral agreements and the enforcement of existing commit- 
Agreement. ${ }^{3 w}$ The Conventions, of which the Cotonou Agreement was the last iteration, set up a system of non-reciprocal preferences between the $E C$ and the ACP. The objective was to enable the economic development of the ACP country by providing preferential access for their products to European markets over those of other countries. ${ }^{310}$ The Cotonou Agreement was criticised for being WTO incompatible with regard to the CATI Article XXIV exception for regional trade agreements and the WTO Enabling Clause, which allows discrimination in favour of developing countries. To avoid disputes being brought to the Dispute Settlement Understanding the EC negotiated a waiver with other WTO members which lapsed in January 2008.311 In addition the EC viewed the Lome conventions and the Cotonou Agreement as incapable of facilitating economic development in the ACP countries. Hence the EC is demanding a shift towards liberalisation and the opening up of markets in order to achieve economic development. ${ }^{312}$ Notably there is no direct mandate from the Cotonou Agreement for the inclusion of IPRs. The fact that the EC has chosen to include IPRs into the EPA negotiations shows the importance the EC gives to the subject matter. The EC has divided Africa, Caribbean and the Pacific (ACP) into six regional groupings to negotiate the EPAs; these being: the Caribbean, West Africa, Central Africa, Eastern Africa, Southern Africa and the Pacific Region. ${ }^{313}$

ments in order to reduce IPR violations and the production and export of fake goods".

$30 \%$ The Lome Conventions exists of four successive trade agreements stipulating the rules of the trade game between the EU and the ACP from 1975 to 1999. The Cotonou Agrement (2000) is available online at: Lhttp://eceuropa.eu/develop ment/hody/cotonou/agreement_en.htm>.

310 The objectives of the Cotonou Agreement are set out in its A.t. 1 and include sustainable development, poverty eradication and integration of ACP countries into the world economy. The Cotonou Agreement does not request adherence (nor obligation to accede) to the multilateral IP treaties and only stipulates the need to ensure adequate protection of IPRs. Hence countries remain the flexibility to adopt IPR systems in line with their socio-economic development needs in line with TRIPS obligations.

311 See South Centre and CIEL. 2006, p. 2.

312 See Section 4.2, Furopean Commission report dated 4 October 2006.

in In Eastern and Southern Africa the two largest regional configurations COMESA and SADC have ACP members that are in at least two ACP/EC geographical regions. In 2003 COMESA began a consultative process that would see the negotiations evolve into an all Eastern and Southern Africa (ESA) Economic Partnership Agreement (EPA). The rationale for this process was seen in the fact that the development needs of ESA-ACP countries eligible to negotiate EPAs were remarkably similar. Exports from these countries were the same and include: tourism; fish and fish products; horticultural crops and fresh vegetables; tea and coffer; cotton; textiles and apparel; and commodities covered by the protocols 
Priorities for the EC in EPAs include enforcement, the protection of geographical indications (GIs), copyright in the digital enviromment and adherence to existing IPR agreements including the TRIPS Agreement, the WIPO Copyright Treaty and the WIPO Performances and Phonograms Treaty which both extend copyright provisions to the digital environment and contain restrictive standards on access to knowledge and public interest exceptions. Provisions in relation to Gls go far beyond what is required by the TRIPS Agreement and include extending the existing higher level of protection for wines and spirits (under TRIIS). There are the so-called absolute protection-excluding statements indicating origin and using terms such as kind, type or style to all kinds of products. Their ultimate aim is to extend protection to all products that enjoy protection in the EC (claw back approach). ${ }^{31+}$ On the other hand, many ACP countries are seeking to include issues that reflect their own priorities and interests such as traditional knowledge, innovation and transfer of technology. ${ }^{315}$ The CARIFORUM-EPA, for instance, includes a separate chapter on innovation. ${ }^{310}$ The CARIFORUM Agreement is the first full EPA, including a chapter on intellectual property and innovation. The innovation part focussed on the need for support for national and regional imnovation systems in the Caribbean and emphasised the importance of assisting the commercialisation of Caribbean innovations in the EU market. The underlying rational is that IP protection should contribute to establishing a viable technological and innovative base in the country. In addition, the focus on imnovation highlights the fact that the majority of technological innovations in small economies (and i.e. developing or least developed countries) are of an incremental nature reliant on access to information and knowledge to carry out improvements and build on existing imnovations. ${ }^{317}$ The focus on innovation although novel, merely states that the EC will provide technical assistance in this regard (no hard demands are provided for). For instance the EC makes no substantive commitments to transfer of technology other than to provide incentives to transfer

(mainly sugar but also including beef). In 2007 at a Heads of Government Summit in Arusha, the East African Community felt that the COMESA configuration and negotiation of the EPA did not fully address its regional integration and development needs as envisioned in the EAC Treaty and decided that the EPA should be negotiated separately from the ESA grouping in what is now known as the "Seventh EPA" between the East African Community and the European Union.

314 For more information on the EU approach on GIs see chapter four of this thesis.

317 ICTSD has organised two dialogues on EPAs and IP in west and central Africa, respectively in May 2007 and April 2008 which have contributed to formulating a positive agenda for the countries in these regions in the negotiations with the EU. For more information on the Central Africa dialogue see <http:/ www.iprsonline. $\mathrm{org} / \mathrm{ictsd} /$ Dialogues/2008-04-28/2008-04-28_desc.htm>.

3i. See Spence 2008.

31: See South Centre and Centre for International Environmental Law 2006, p. 3. 
technology to LDCs. It remains to be seen how this theory will be translated into concrete practical solutions (i.e. going beyond best endeavour nature).

Intellectual property provisions in El'As raise concerns about the potential impact that IRIPS-plus provisions could have over the use of flexibilities and exceptions for safeguarding certain public interests and advance development objectives. In this regard, EPAs raise many negotiating and implementation challenges in the area of $\mathrm{IP}^{\mathrm{P}}$, regarding policy coherence and maintenance of flexibilities.

\section{IPRS AND DEVILLONANT}

\subsection{Rationale and Justifications Lmderlying IPRS}

Policies of IPR aim at fostering innovation, R\&D and technical change by establishing proprietary rights over know-how as incentives to innovate. IPR policies are influenced by a wide scale of economic and technical phenomena, cultural and economic institutions, domestic markets and by existing IPR regimes.

The TRIPS agreement is based on the assumption that everything under the sun can be patented, trademarked or copyrighted and have private rights appropriated to it and everything is for sale. There is no room for cultural or economic reservations, e.g. against "Macdonaldisation" of national economies: arguably the TRIPS Agreement takes capitalised view of the economy (since it is tailor-made for the US and EU market). However, the perception of information goods as private property or as a "public good being in the public domain" 318 which can be freely duplicated and reproduced, is an important cultural difference between e.g. the EU, the US and China. ${ }^{319}$ Whether policies have promoted innovation and technical know-how (hence benefiting local economies), or on the contrary have led to market inefficiencies is still under discussion. On many issues, e.g. public health there is a clash between economic and social views. The TRIPS Agreement states it serves public interest in granting IP rights, but in reality it does not always do so. For example, the TRIPS Agreement does not provide concrete ways to stop the abuse of intellectual property rights. This problem could be solved if the TRIPS Agreement were complimented with an anti trust code in order to prevent abuses. Furthermore, the TRIPS Agreement has neglected public interest concerns, e.g. it has sufficiently addressed ethical and cultural reservations against appropri-

sis The term public domain refers to intellectual property for which the term of protection has run out, or which has been forfeited or unclaimed and goods that are not protected under existing IPR legislation. See Van Caenegem 2002, p. 324.

31" See Shapiro and Varian 1999. 
ation. However, subsequent rounds of negotiations have focused on its shortcomings.

Traditionally IP protection was justified on the grounds that exclusive rights for a limited period of time (to innovators, authors and artists) were granted in exchange for disclosure of the invention (under patent law) and the benefit for the public at large to receive access to these ideas, designs and literary and musical works. IP protection was regarded as a tool for protecting and promoting new ideas and creativity. The exclusive rights were thus granted as a reward for the creator/inventor and to encourage investment in $R \& D$ and creativity. In addition the disclosure obligation under patent law allowed other researchers and innovators to study patent claims and build on the latest knowledge to develop new inventions. The US Constitution makes reference to "promote the Progress of Science and Useful Arts".321

The protection of the different forms of IPRs is justified on different grounds: for instance, trademarks and geographical indications primarily aim to minimise consumer confusion about the true origins of goods and services. In contrast to patents, copying is not prevented as long as the goods and services are sold under different names. Trademarks and geographical indications have less of a competition-reducing effect, which is reflected in the fact their terms of protection are not limited by time, in contrast to for example patent laws, utility models and designs generally restricted to limited term duration. ${ }^{321}$ The underlying rationale for granting patent protection is to facilitate technological enhancement by providing incentive for research and invention through granting exclusive rights to the right holder to secure either a reward for inventive genius, and/or a return on investment.

With the adoption of the TRIPS Agreement began a new era of debating the justification of intellectual property rights in general especially regarding (least) developing countries.

During the TRIPS Agreement negotiations it was repeatedly emphasised that strengthening IPRs would provide the incentives to support knowledge generation, diffusion and promote techology transfer. However, it is also clear that over-protection of IPRs and IP regimes that do not reflect development needs and public interest can be detrimental to a country's socio-economic development and technology needs: there is no one-size fits all model of IP protection. ${ }^{322}$ Arguably, the interests of the IP holder are favoured and it seems that $I P$ is increasingly being used as a tool for protecting investment and reinforcing market power. In this respect it is important to take into consideration that

32:1 See Art. 1 of the US Constitution, clause 8 on copyrights and patents.

321 See Fink and Maskus 2005, p. 3.

322 See Report UK Commission on Intellectual Property Rights (CIPR), 2002. 
IP negotiations are often conducted between countries with asymmetrical bargaining power.

Kamperman Sanders argues that multilateral and bilateral regimes harmonising IPRs to the highest possible standard has an exclusionary effect especially where it impedes capacity building necessary for the reception and embedding of technology. He argues that:

\begin{abstract}
"[f]rom a development perspective on intellectual property rights this means that capacity-building with an emphasis on effective and iransparent enforcement mechanisms for intellectual property rights may be much more useful than efforts to harmonize and increase substantive rights according to a one-size-fitsall philosophy".
\end{abstract}

Goodenough, discusses ideas and thoughts to enhance IPR enforcement. He is of the opinion that a role for justice is much needed in the IPR framework and argues that we need an IPR system that is not only focussed on economic policy but also on human psychology. Goodenough argues that:

"The intuitively felt duty to respect IP is lacking in our society. Expectations of reciprocity appear to be fundamental building blocks in human psychology and may be part of the justice puzzle". 32.4

A good example of a lacking responsibility to protect copyright is the "Napster" case ${ }^{325}$ which is a prime example of the fact that the ease of infringing hinders enforcement endeavours. Napster was an online platform for users to upload and download music files in a compressed digital format. At its peak Napster was utilised by 26.4 million users. The plaintiffs were major record companies who saw the potential for this technology to impact their sales, and therefore quickly filed suit against Napster as a contributory and vicarious copyright infringer. Napster was held liable for contributory infringement of the plaintiff $(A \& M)$ record company's copyrights. The court also rejected the suggestion that it impose a compulsory licensing arrangement on the plaintiff record company. This was the first major case to address the application of the copyright laws to peer-to-peer file-sharing. Goodenough, considers that the principle of reciprocity helps to create social stability and could function well with regard to IPR where enforcement seems to be most difficult. Exceptions to the IPR system in favour of social benefits could prove to be just as important as the rationale behind the IPR framework. 326 A good example of taking public policy considerations into account is the Eco-Patent

32: See Kamperman Sanders $2007 \mathrm{a}, \mathrm{p} .894$.

324 See Goodenough 2002, p. 291-292.

i25 AEM Recorts, Ini. v. Napster, Inc, 239 F.3d 1004 (US Court of Appeals for the 9th Cir. 2001).

32: See Goodenough 2002, p. 291-292. 
Commons, an initiative to bundle together patents on technology that contribute to protecting the environment. The patents are pledged by companies and other intellectual property rights holders and made available to anyone free of charge. The Commons aims to connect those who have had success with a particular challenge in a way that benefits the environment with those who are facing similar challenges by releasing dozens of innovative, environmentallyresponsible patents into the public domain. 327

IPR protection should contribute to innovation, creativity and technology transfer in the interest of all countries and not only the powerful industrialised ones. Therefore developing countries need to be empowered to better understand II'R concepts and their impact on socio-economic development. A better understanding will also contribute to enhancing negotiation techniques and counter the draft proposals of the EC or US (in multilateral, regional or bilateral negotiation efforts) by allowing developing countries to put forward offensive and defensive strategies in respect of IPRs.

First of all, the adequate level of IP protection in a particular country may vary significantly over time according to productive structures and levels of development. $32 \%$ For instance LDCs are best served by keeping patent protection to a TRIPS-compliant minimum, which will encourage a robust public domain enabling incremental follow-on innovation and technical learning. LDCs should also focus on types of IPR that are most suitable to their needs and promote their domestic imovations, such as utility models, trade secrets, industrial designs and should adopt unfair competition rules. For instance priority is improving the branding of their products by making effective use of trade marks and geographical indications and appellations of origin and supply chain management including export development. However, more advanced developing countries might want to strengthen patent laws to protect their own inventions. As is explained by $\mathrm{Kim}$ in chapter five section 5.5.2 of this thesis, II protection that reflects a country's level of development may contribute to its technological and economic capacity and will increase the necessity of IP over time.

For all countries it is important to establish competition policies and laws to counter abuses of IPRs. IPRs grant exclusive rights and can therefore adversely impact free trade and competition, can stifle innovation and cause high prices for essential drugs. The international legal framework on IPRs should be designed in such a way as to encourage innovation and creation and to limit the negative aspects. This has been addressed in the Doha Declaration on TRIPS and Public Health and the Millennium Development Coals. Also the

327 See "Corporations go Public with Eco-Friendly Patents", published online at: <http://www.whesd.org/templates/TemplateWBCSD5/layout asp?type=p\&Menu $\mathrm{Id}=$ MTQ3NQ\&doOpen $=1 \&$ ClickMenu $=$ LeftMenu> .

32.5 See Lall and Allbaladejo 2003. 
WH IO has recently (24 May 2008) adopted a global strategy aimed at filling the research gap for neglected diseases and facilitating the access to medicine.

Hence it is important to design a global IPR infrastructure that is more balanced and suitable for countries at different stages of development. However, translating the theory into practice - concrete actions- has continued to be a challenge.

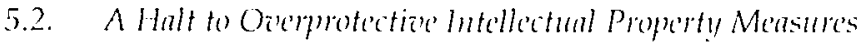

The last decade have been characterised by an unprecedented increase in both scope of coverage and level of II' protection and attempts to harmonise these II' standards at a global level. The negotiation history of the TRIPS Agreement reveals an ongoing struggle between the developed country members' interest to protect the IP right owners and the developing countries perspective to connect IPR with developmental strategies and basic needs. These viewpoints are linked to the fact that present-day economic growth and comparative advantage are proportionate to access to technology, knowledge and invention and not so much to natural resources (see chapter three of this thesis).

There is a lot at stake to protect the intellectual property rights on innovations in order to prevent copying and reverse engineering by others - because of paramount research and development costs. Without such intellectual property protection the possibility to recoup investment costs is lost according to industry perspective. Therefore, industry groups in industrial countries have developed strong networks to lobby with government officials and to stress the importance of intellectual property right protection and enforcement. Governments of the countries in which these lobby groups are active (predominantly the big industrialised countries like the US, the EU and Japan) are generally sensitive to that strong industry lobby pressure. It often results in policies that enhance national or even worldwide protection of intellectual property subject matters as demonstrated by the US industry lobby behind the introduction of IPR within the UR of multilateral trade negotiations. The over extension of IPR protection should be avoided. For instance, Jaffe and Lerner have argued that:

"although patent protection is crucial for the innovative process, it is not the case that making patents stronger or easier to get necessarily improves incentives for innovation. Creating good incentives for innovation requires balancing the need for patents to protect innovators, against the inherent risk that strong patents for some will prevent or hinder others from innovating".32"

320 See Jaffe and Lerner 2004, p. 18. 
For instance it is important to avoid granting patents too easily, for instance the US patent office has been heavily criticised for granting patents based on umnecessarily broad claims - hence obstructing further research. Moreover socalled "evergreening" of patents, i.e. the originator manufacturer simply keeps adding patents to the product should also be avoided. One form of "evergreening" occurs when the pharmaceutical company spreads out the filing of patents by obtaining separate 20 -year patents on multiple attributes of a single product. ${ }^{331}$ Hence, generic producers that produce the pharmaceuticals at lower cost need to wait for the entire patent to expire before launching generics on the market. ${ }^{331}$

Philosopher John Locke places restrictions on the property system which work equally well for the intellectual property system.

"As much as any one can make use of to any advantage of life before it spoils; so much he mey by his labor fix a Property in. Whatever is beyond this, is more than his fair share, and belongs to others". 332

3i) Drug patent "evergreening" is the most important strategy that multinational pharmaceutical companies have been using since the 1980 s to retain profits from blockbuster (high sales volume) drugs for as long as possible. When the original patent over the active compound of a brand-name drug is due to expire, these drug companies often claim large numbers of complex and often highly speculative patents.

In the 1980s the list of a drug's properties eligible for patenting was relatively limited. They included: primary uses, processes and intermediates, bulk forms, simple formulations and composition of matter. During the 1990s the catalogue (1) grew to 18, nearly four times the amount of a decade earlier, to include patents on such additional aspeets as: expansive numbers of uses, methods of treatment, mechanism of action, packaging, delivery profiles, dosing regimen, dosing range, dosing route, combinations, screening Methods, chemistry Methods, biological Target and field of use. See website of the European Generic Medicines Association: <http://www.egagenerics.com/gen-evergrn.htm>.

331 FTAs increasingly contain provisions on "evergreening" and obtaining marketing approval. For instance, the "evergreening" article in the Australia-US FTA (Art. 17.10.4) links the operations of the Australian Therapeutic Drug Adninistration (the drug safety and efficacy body) with supervising patent law. In that it "requires that TGA drug marketing approval be 'prevented' indefinitely (not for the 30-month and 24-month periods as in the US and Canada) whenever any type of patent (including a speculative 'evergreening' patent) is merely 'clamed'". The Generic Medicines Industry Association of Australia, in its submission to the Senate inquiry on the FTA, stated that this "evergreening" provision could lead to long delays or generic equivalents not reaching the market. See Thomas Faunce, "The awful truth about "evergreening", 7 August 2004, posted online at <http://www.theage.com.au/ar ticles/2004/08/06/1091732084185.html>.

332 See Locke 1988 [1690]:290 as quoted in May 2000, p. 25. 
Thus, accorting to Locke, there should be a limit to the rights of the property holder. The question is where to place the limit. If the legal framework of intellectual property is objected to this theory it is possible to argue that stretching the term of copyright protection from e.g. 50 to 70 years, might be beyond reason. To use Locke's words have his property rights not been "spoiled"?

It is doubtful whether the extension of the copyright protection from 50 to 70 years after the death of the author really provides incentives for creation. This kind of extension benefits company profits only. ${ }^{33}$ In the case of patents - how much reward does not exceed your fair share? The same can be said about the acquisition of property, what used to be accessible for everybody is no longer freely available. $\wedge$ shift has taken place from public to privately owned property; in just the same way as genetic material and traditional knowledge is now widely used in pharmaceuticals. ${ }^{33.4}$

The ongoing harmonisation processes of IPR standard setting impacts on the flexibility and policy options for IPRs use in socio-economic development strategies and demand a thorough rebalancing of the justifications underlying IPR protection.

\subsection{Different Stage's of Deredopment and IPRS}

Over the last century intellectual property rights have been expanded which is evident from the steady increase of international treaties. This will have profound implications on innovation, technology transfer, competition and economic development. Maskus and Reichman question the ability of states to provide their citizens with critical public goods, such as public health, education, and environmental protection in the future, since increasingly

333 Mickey Mouse and other famous Disney figures were set to enter the public domain in 2004 if it would not have been for the CTEA. The US Copyright Term Extension Act (CIEA) of 1998 - alternatively known as the Sonny Bono Copyright Term Extension Act, Sonny Bono Act, or pejoratively as the Mickey Mouse Protection Act extended copyright terms in the United States by 20 years. Before the Act (under the Copyright Act of 1976), copyright would last for the life of the author plus 50 years, or 75 years for a work of corporate authorship; the Act extended these terms to life of the author plus 70 years and for works of corporate authorship to 120 years after creation or 95 years after publication, whichever endpoint is earlier. Eric Eldred, a bibliophile in New Hampshire who wanted to put digitised editions of old books online protested the extension of copyright protection. See Supreme Court Case Eric Eldred, if al., petitioners v. folm D. Ashloroft, Atlorney General, Supreme Court, 537 US, 2003 See <http://www lessig.org/blog/archives/01-6180.pdf> and US official copyright website: <http://www.copyright.gov/circs/circ1.html\#hlc>.

334 See chapter three of this thesis for a more elaborated discussion on TK. 
governments depend on the private enterprises to gain access to new technological inventions. ${ }^{335}$

The reality is the conclusion of the agreement does not end with the negotiation process, but instead heralds the complex process of implementation. Not only is there a need to reform domestic legislation to incorporate the new provisions, countries also must become a party to various existing IPR treaties in line with the agreed time frames for implementation. When the implementation process is concluded, countries are subject to the constant monitoring of their implementation and enforcement obligations by the annual review of the USTR and by the industry interested groups (such as the international intellectual property alliance (IIPA), the business software association (BSA) and the pharmaceutical research and manufacturers of America (PHRMA). ${ }^{3,3}$

The global requirements that countries expand and strengthen their IPR systems are both new and complex. Developing countries, in particular, are struggling to enforce the TRIPS Agreement and the obligations deriving from FlAs as few of their policy makers have sufficient experience, expertise and knowledge to understand the potential effects of this change.

A prerequisite for effective implementation is the existence of an appropriate institutional and administrative framework, as well as good governance, health, infrastructure, ${ }^{337}$ transparency and policing. For countries that are for the most part net importers and purchasers of intellectual property the benefits of a far reaching IPR Agreement strengthening the rights of IPR rightholders are not immediately apparent. Nevertheless most of the industrialised countries are convinced that a harmonised IPR system is a precondition to creating, using and encouraging investment in new technology, which in turn fosters economic grow'th as shown by the TRIPS and FTA negotiations. ${ }^{3.35}$ With respect to industrial and techmological policies, the relevance of IPRs to a particular country will largely depend on the type of goods and services that it produces, and particularly on the nature of the innovations that it generates. But, in terms of competition and consumer protection policies, most or all

3i5 See Maskus and Reichman 2004a, p. 275.

33. See Roffe 2007, p. 6.

33 That infrastructure is a neglected area in the developing world proof the figures of the World Bank that describe two-fifth of the country's motorways as "pre-modern" and considers in general that the roads and railways are poor, the ports are clogged and precarious electricity supply. It argues that the public sector in Latin America is not spending enough on transport, electricity and water but nor is it allowing private investors to help out. In addition there is not sufficient access to potable water and sewerage as well as access to electricity. Latin America is far behind China in all of these issues. See "Slow! Government Obstacles alhead", The Economist, 17 june 2006.

is See Evans 1996, p. 159. 
areas may be important, depending on the extent to which protected goods and services of foreign origin are sold within the national territory. Hence, developing countries face many challenges when implementing intellectual property rights. However, these challenges and problems will, vary among developing countries. One can assume that relatively advanced countries (measured by socio-economic status and technological advancement) are likely to benefit more from IPRs. On the other hand, LDCs, in particular when implementing international IP rules, are confronted with short term financial loss which is not compensated with economical or social gains in the immediate future. ${ }^{339}$

An additional difficulty in negotiating IPRs derives from the cross cutting nature of IPRs and public policy considerations, e.g. in the field of health, environment, climate change and food security, developing countries are targeted from many different directions. In addition, developing countries are also forced to negotiate simultaneously at different for a (international, regional and bilateral). There are a number of institutions dealing with IP related issues. Moreover, there are the main international IP fora such as the WTO and WIPO, and increasingly a number of intergovernmental bodies such as the WHO, UNESCO, FAO, CBD, OECD, Interpol and LN organisations such as UNCTAD, UNDP who have all included IP matters on their Work Programmes. Each focuses on various IP concepts in relation to the nature of their mandate as an organisation, touching upon food security, public health, biodiversity, technology dissemination and transfer, innovation, research and development and education. The multitude of organisations dealing with IP makes it difficult to come to terms with conflicting interests and to keep track of ongoing negotiations and implementation processes.

Ostergard distinguishes three groups of countries all in demand of different levels of IP protection in line with their domestic level of development: least developed, newly developing or moderately developed and developed countries.

In relation to intellectual property protection, Ostergard characterises LDCs as:

"states [that] have no incentive to adopt strong IPR protection or to spend the resources needed for enforcing it. Industrial interest groups, particularly those involved in high technology products, either have not formed or are not powerful enough to pressure the government to adopt stronger protection. The government pursues weak protection policies to acquire needed technology that cannot be developed indigenously. Domestic markets are underdeveloped and there is negligible trade with other states. Hence, international pressure to

33. See Bellmann, Dutfield and Melendez-Ortiz 2003 and UK CIPR Report 2002. 
enhance IPR protection is limited, if it exists at all. IPR laws are generally the remnants of colonial laws with some minor enhancements".3in

Newly developing or moderately developed countries are marked as:

\begin{abstract}
"states (that) are entering a stronger economic stage of growth and development characterized by emerging markets and low to moderate technological capacity. They are developing key industries for growth through a combination of targeted trade to enhance revenues and protectionist measures to protect the industries' domestic market. Industries may not seek IPR protection until they' become producers of new technology instead of "free-riding" consumers of existing technology. Because of the growth rates or the potential untapped consumer markets, foreign investment and trade seck to exploit new business opportunities. The origins of pressure to expand IPR protection begin here". ${ }^{3+1}$
\end{abstract}

Finally Ostergard determines developed countries as:

"states [that) have fully developed technological capacities and are on the cutting edge of industrial research and production. They implement the strongest IPR protection and adapts it to accommodate new technologies and processes. Consumer markets are fully developed and oftentimes saturated with products, forcing businesses to explore alternative markets. Governments work closely with business to ensure strong IPR protection in foreign markets. Strong domestic pressure to maintain and to update IPR protection is present, as well as pressures to promote such protection in international markets". 3.92

\title{
5.4. Short and Long Term Benefits of IPR
}

The price that developing countries have to pay for the much wanted opening of developed country markets is high. In particular the implementation and enforcement costs to obey to the TRIPS Agreement are enormous. The exact costs related to introducing such an intellectual property protection system depends on each country's unique economic circumstances - such as the level of development, education system, infrastructure, level of corruption etcetera. ${ }^{3+3}$

341 See Ostergard 2000, p. 349-360.

$3-1$ See Ostergard 2000, p. 349-360.

32 See Ostergard 2000, p. 349-360.

its The compliance costs will be high, for instance, in large countries with substantial markets for newly protected pharmaceuticals and agricultural products (like Brazil, India and South Africa), enforcement of patents will increase prices for drugs, seeds, and fertilisers. The same counts for countries were bootleg music, films and software is ubiquitously present. The effects of the introduction of an intellectual property regime will also be directly noticeable in developing countries that use and produce counterfeit products and consequently (through the compliance with the TRIPS Agreement) should use only authentic trademarked goods. In a worse case 
The lack of visible and tangible long- and short-term benefits of adopting IPR protection make it difficult to appreciate the rationale for IPR, $3+4$ especially from the point of view of the developing country WTO Members. Short-term benefits of the TRIPS Agreement are access to the developed country WTO Members' markets and the transition periods especially devised for developing and least developed country members. A study has shown that some developing countries are likely to lose from the Uruguay Round as a whole in the short-run. But, the study indicated that in the long run nearly all countries will gain. ${ }^{35}$ Long long-term benefits likely to rise from the existence of IPR protection are the promotion of technology transfer, domestic innovation and economic growth. ${ }^{3 \text { th }}$

Other long-term benefits include flexibility in how substantive norms are implemented by nations, especially the provision on compulsory licensing and the exemptions, as provided for in Article 27 TRIPS Agreement. ${ }^{3.47}$ Besides IPR protection, complementary policies are necessary, like educational reform, market liberalisation and competition enforcement. ${ }^{3+8}$ For instance Markus argues that IPR protection functions optimally in an "environment of open competition, risk taking, and adequate engineering and entrepreneurial skills". Furthermore, public policies have to focus on supplying incentives for inven-

scenario intellectual property protection can lead to the close down of industries, which depend heavily on the production of goods protected by forcign intellectual property in case the developing country sees to significant manufacturing capacities producing mainly protected phamaccuticals or e.g. bootlegged music and films. See Heald 2003, p. 1.

34 See also Reinhardt 2003. Reinhardt does think that intellectual property protection have many benefits for developing countries, hut these are contingent upon a number of other things that developing countries can not always control. Futhermore he argues that in the area of AIDS, TRIPS is not the key problem but poverty is.

3.5 Harrison founds that the world as a whole gains substantially from the changes of the UR, about $\$ 96$ billion amnally, however the profit is uncqually divided among the globe, thece major players, the US, the EU and Japan reap the profits, because they reduce distortions the most. Developing countries will be net losers form the UR in the short-run; these losses are to be explained by mainly 2 reasons: (1) the reduction of agriculture subsidies in the US, EU and EFTA, which results in termsof trade losses for some net food importing countries; and (2) the Multi-Fibre Arrangement (MFA) liberalisation induces losses for some developing countries. See Harrison, Rutherford and Tarr 1997, p. 1022-1062.

3. See Maskus 2000.

3.) See Goldstein 2001, p. 113.

3.5 The study of Leesti and Pengelly points out that institutional capacity for intellectual property policy making, administration and enforcement is seriously lacking in poor countries. See Leesti and Pengelly 2001. 
tion and innovation which cannot be dealt with solely by IPR. ${ }^{3.44}$ In addition developed countries should contribute to these major reforms in developing country Members by supplying financial and technical support. Hence, it is necessary to invest in education and $R \& D$ so a country is able to benefit from IPR protection as well as FDI.

There are a number of costs, in particular if right holders are predominantly of foreign origin. For instance, there are costs stemming from higher prices for intermediate and final goods, ranging from pharmaceuticals to computer software as well as the loss of jobs in generic/copying industries. Fink and Maskus explain that it is important to
"quantify potential price effects when designing complementary policies and regulations that seek to soften the effect on firms and consumers. It is also important to quantify the potential employment effects is important when predicting possible fiscal implications and developing labor market policies that would facilitate job transition".3개

It is questionable whether the traditional intellectual property instruments that were developed in the industrial world are adequate for stimulating innovative and artistic activity in poorer countries.

\begin{abstract}
"Although the fundamental incentives posed by patents, trademarks, and copyrights should be the same around the world, developing countries differ from their industrial counterparts in their innovative potential, the education of their work force, the structure and funding of research and development (R\&D), the management of technological assets, and the existence of complementary intellectual property institutions, such as collection agencies and technology'-transfer offices". 31
\end{abstract}

It should not be forgotten that trade policies are an important means for development, but development is not an end goal of trade facilitation. Trade policies raise expectations that trade camnot fulfil, however trade negotiations can certainly help movement in the right direction but will not achieve a development goal quickly. Reaching developing goals requires additional prerequisites, like capacity building and setting up of institutions. Thus, one can argue that different levels of development of industrialised and developing countries call for different approaches to intellectual property protection. In particular, developing countries need strategies and rules which encourage building upon existing stocks of knowledge. This also demands adequate technical assistance for understanding IPR concepts and utilising them for their own socio-economic development. The current technical assistance practices

3.14 See Maskus 2000, p. 200-205.

ini See Fink and Maskus 2005, p. 5.

3 See Fink and Maskus 2005, p. 5 . 
have been criticised for being too focused on implementing IPR obligations and improving including enforcement, i.e. building the right mechanisms and legal and administrative institutional framework rather then on capacity building, building own technical strengths and technology transfer activities. This type of technical assistance does not primarily address the needs of developing countries who would gain more from assistance relating to building innovative and creative capacity, such as assistance in understanding the flexibilities under the TRIPS Agreement, e.g. research and education exemptions, freedom of implementation, flexibilities under patent law, transition periods, setting up an IPR system in line with domestic needs as well as using compulsory licensing. This would help them to benefit from the $I P$ legal framework in the long-run. At the moment the less advanced countries bear high costs while not enjoying any benefits (at least not in the short and mid term). This creates a strong case for amending the IPR framework to meet particular socio-economic development needs in less privileged countries. Taking this into consideration one could argue that the name Doha Development Round is not appropriate, since improving trade is not the panacea for development. ${ }^{35 ?}$

\subsection{Decelopment and Globalisation}

The meetings of the WTO and UN (including the IMF and the World Bank) are now in conflict and turmoil - although to a lesser extent in recent years as negotiations have shifted to FTA's. ${ }^{3.3}$ Why has globalisation become so controversial? Indeed, opening up to international trade has helped many countries grow far more quickly than they would otherwise have done. Trading across borders facilitates economic development when a country's exports drive its economic growth. In fact, export-led growth policies and subsequent legislation have enriched much of Asia. Stiglitz argues that:

\footnotetext{
"globalization has reduced the sense of isolation felt in much of the developing world and has given many people in the developing countries access to knowledge well beyond the reach of even the wealthiest in any country a century ago (...) I believe that globalization - the removal of barriers to free trade and the closer integration of national economies - can be a force for good and that it has the potential to enrich everyone in the world, particularly the poor". 35
}

$3: 2$ Lecture Prof. Pierre Sauve, Trade Academy Forum, Macau, 9 July 2004.

353 Heavy protests took place at the Seattle meeting of the WTO in 1999, and in Genoa in the summer of 2001 one anti-capitalism protester was shot dead and hundreds more injured as demonstrators battled with police in "the war against globalisation" during the G8 Summit meeting.

ist See Stiglitz 2002, p. 4. 
Nevertheless, Stiglitz argues that in order for this potential to be realised one should rethink the way globalisation as well as international trade agreements are managed. He believes that:

"it is important to view problems in a dispassionate way, to put aside ideology and to look at the evidence before making a decision about what is the best course of action".

Nevertheless, in reality he has seen that decisions were often made because of ideology and politics that fit the people in power. He supports the view of the French intellectual Pierre Bourdieu who has written about:

\footnotetext{
"the need for politicians to behave more like scholars and to engage in scientific debate, based on hard facts and evidence. Care should be taken that academics involved in making policy recommendations become politicized and start to bend the evidence to fit the ideas of those in charge". 35
}

\section{NEW DEVELOPMENTS: THE WIPO DEVELOIMENT AGENDA AND THE WTO DOHA DECLARATION}

\subsection{The WTO Dohn Declaration}

Currently, there are many ongoing multilateral, regional and bilateral negotiations on intellectual property issues - many of which aim to expand IP protection. ${ }^{35}$ As we have seen in the previous section regional and bilateral trade and investment negotiations are mushrooming including provisions on intellectual property and expanding the scope of the TRIPS Agreement. At the multilateral level, negotiations are conducted under the auspices of the WIPO, such as the implementation of the recently adopted WIPO Development Agenda, and ongoing deliberations on the Substantive Patent Law Treaty, the Broadcasting Treaty, ${ }^{357}$ and traditional knowledge, folklore and genetic resources within the WIPO Intergovernmental Committee on Traditional Knowledge, Folklore and Genetic Resources (IGC).

Negotiations are also conducted within the framework of the WTO, in particular the in-built negotiating provisions of the TRIPS Agreement and the outstanding implementation issues emerging from the Doha Development Agenda. The in-built negotiating provisions relate to the extension of the

\footnotetext{
355 See Stiglit $\angle 2002$, p. 4.

3is It has been argued that the harmonisation process is further enhanced by technical cooperation and assistance activities that aim at not only national legislation more uniform but also to make the highest IP standards the least common denominator for all countries. See Kostecki 2006.

35 Although it seems that negotiations are stalled since September 2007.
} 
higher level of protection for geographical indications (Article 24.1 TRIPS of the TRIPS Agreement), ${ }^{35}$ the establishment of a multilateral system of notification and registration for wines and spirits (Article 23.4 of the TRIPS Agreement), and review of Article 27.3(b) on exclusions from patentability. ${ }^{309}$ The implementation issues deriving from the Doha Development Agenda refer to public health, ${ }^{3+1}$ geographical indications, the relationship between the CBD and the TRIPS Agreement and extending increased technical cooperation efforts to LDCs (which could increase their participation in the discussions). On request of the least developed countries the transition periods of L.DCs have been extended by the TRIPS Council Decision of 29 November $2005 .{ }^{361}$

In relation to the transition periods, how is the TRIPS Council helping LDCs take advantage of the extensions to the transitional period for the implementation of the TRII'S Agreement so they can build a sound and viable technological base?

Negotiations are ongoing but progress is slow, mainly because countries have different interests and lack of evidenced-based inputs such as cost-benefit analyses which could promote greater understanding of the issues at stake. Progress in norm-setting activities is dependent on consensus and the views of developing countries and other stakeholders (such as NGOS) are increasingly affecting the direction and content of various negotiations processes - in contrast to five to ten years ago.

\subsection{The WIPO De'elopment Agenda}

In an attempt to counterbalance the process of deep harmonisation and to highlight that current trends do not take due account of the development needs and the flexibilities covered under TRIPS, a group of developing countries led by Brazil and Argentina called upon the WIPO General Assembly to consider the integration of a development agenda into the work of the WIPO and to emphasise that WIPO's role is not limited to the promotion of intellectual property rights. Since the WIPO is a member of the United Nations it is incumbent upom them "to be fully guided by the broad development goals that the UN has set for itself, in particular the Millennium Development

sis See for a more elaborate discussion on geographical indications, their implications for developing countries and the various country positions on extension of protection and the establishment of a multilateral system of registration and notification chapter four of this book.

374 See for a more elaborate discussion chapter three and four of this book.

3 wn For more information on the Doha Declaration on Public Health see chapter two, section 3.6.2.

int See Doha Declaration on Public Health and TRIPS Council Decision of 29 November 2005 . 
Goals".3.2 Basically the Development Agenda is about "reforming the way business is done in WIPO".31.3 and "placing development concerns at the heart of the institution's work". "int is an agenda for the reform of WIPO to ensure that the organisation, in all its programmes and activities, including normsetting, supports the development goals of its developing country Member States and the public interest generally in all the Member States.

Argentina and Brazil proposed the development agenda to bridge the "knowledge gap" and the "digital divide", which restricts developing nations to catch up with the developed countries. The proposal stressed that intellectual property should not be seen as an end in itself and hence the strengthening of intellectual property laws irrespective of levels of development should be stopped. They therefore stress that intellectual property policies should be made while taking into account the particular circumstances of developing countries: the proposal refers to a "case by case" approach. Despite the fact that WIPO is already "mandated to take into account the broader development-related commitments and resolutions of the UN system as a whole", the ultimate aim of the proposal is to uptake the development issues into the WIPO Convention (1967). By doing so the proposal drafters believe it will be clear to everyone that "the development dimension forms an essential part of WIPO's work program and will strengthen the credibility of the IP system and encourage its wider acceptance as an important tool for the promotion of innovation, creativity and development". ${ }^{365}$

The proposal reconfirms the promises made in the Doha Ministerial Declaration under paragraph 19 which sets a mandate for the TRIPS Council to take fully into account the development dimension and in the Doha Declaration on the TRIPS Agreement and Public Health in which it is mentioned that the provisions within the TRIPS Agreement should work supportive of and not run counter to the public health objectives of all countries.

Foremost, the implementation of the Agenda should result in "discernible qualitative reform" - in that the implementation of each of the recommendations takes us one step closer to a WIPO that has development and the public

362 Proposal by Argentina and Brazil for the Establishment of a Development Agenda for WIPO to theWIPO General Assembly, 31: Session, Geneva, 27 September to 5 October 200. The development proposal was distributed and added to the agenda of the $31^{\text {-t }}$ session of the WIPO General Assembly, pursuant to the Rule $5(4)$ of the WIPO General Rules of Procedure.

363 Interview with Sisule Musungu, independent IP consultant and co-director IQsensato, conducted by the author, March 2008.

3 See Bridges Weekly Trade News Digest 20086.

ins See Proposal by Argentina and Brazil for the Establishment of a Development Agenda for WIPO. WO/GA/31/11, appendix. 
interest as an integral part of its strategic vision, programmes and activities. ${ }^{3(t)}$ For this to happen it is important that the reforms/improvements which are expected to occur in WIPO are understood by the Geneva based negotiators. ${ }^{367}$

To begin the reform of WIPO, it was decided to establish the Provisional Committee on Proposals Related to a WIPO Development Agenda (PCDA) so that there could be further discussions on the 111 proposals contained in the agenda. The PCDA has convened four meetings in which the proposals were narrowed down, in order to ensure that there is no duplication or repetition; and so that proposals which are actionable were separated, from those which are declarations of general principles and objectives; so that proposals could be linked to existing activities in WIPO and new proposed activities identified. ${ }^{36 s}$ After deliberations the $P C D A$ decided to make the following recommendations to the 2007 WIPO General Assembly: to adopt the recommendations negotiated in the PCD ; to establish a committee on development and IP; to develop a work-programme for implementing the adopted recommendations; to monitor, assess and report on the implementation of all recommendations adopted, and to coordinate with relevant WIPO bodies accordingly. ${ }^{309}$ The WII'O General Assembly - the highest decision-making body of the WIPO decided to adopt the recommendations for action on the $45^{3 \pi 11}$ agreed proposals, and to immediately implement the 19 proposals 31 identified by the Chair of the PCDA. For the additional 26 proposals a work programme had to be prepared. As a result the WIPO Development Agenda was adopted after three years of negotiations. The General Assembly also decided to establish a

3n WIPO Development Agenda Implementation, Commentary on the Preliminary Implementation Report in Respect of 19 Proposals, Ideas in Development. See IQSensato, think thank based in Geneva. Published online at: <hitp://www.igsen sato.org>.

$36 \%$ The report of IQSensato tries to fill the gap by supplementing the Secretariat Report with 1) the expectations from each recommendation - what change do we want to see at the end of the day and 2) it also provides a brief commentary on whether the reported activities by WIPO can promote the intended reforms or whether there are important gaps in the implementation approach currently followed by the Secretariat. See WIPO Development Agenda Implementation, Commentary on the Preliminary Implementation Report in Respect of 19 Proposals, Ideas in Development. Published online at: <http://www.iqsensato.org >.

ins Report of the Provisional Committee on Proposals Related to a WIPO Development Agenda (PCDA), Assemblies of the Member States of WIPO, Forty-Third Series of Meelings, A/43/13 Rev., 17 September 2007.

3 in lbid.

in Intial Working Document for the Implementation of the Agreed Proposals, Annex $B$ of WIPO Document $A / 43 / 16$.

B Preliminary Implementation Report in Respect of 19 proposals, Annex $A$ of WIPO Document $A / 43 / 16$. The 19 proposals were separated because no additional funding is necessary in order to implement these proposals. 
Committee on Development and IP (CDIP). ${ }^{372}$ The 45 proposals were divided into six clusters: cluster $A$ on teclmical assistance and capacity building; cluster $B$ on norm-setting, flexibilities, public policy and public domain; cluster $C$ on technology transfer, information and communication technologies and access to knowledge; cluster D on assessment, evaluation and impact studies; cluster $\mathrm{E}$ on institutional matters including mandate and governance; cluster $\mathrm{F}$ on other issues. ${ }^{.73}$

The review and consideration of the 19 , plus 26 , proposals currently undertaken by the CDIP should be the development of a comprehensive work programme for the implementation of the WIPO Development Agenda. Obviously it is important to establish an implementation programme first before monitoring, assessment and reporting can take place. ${ }^{37.4}$

\subsubsection{Recommendations in Relation to Technical Assistance}

Some important recommendations deriving from the WIPO Development Agenda are listed below.

Recommendation 14 of the WIPO Development Agenda requests that:

"within the framework of the agreement between WIPO and the WTO, WIPO shall make available advice to developing countries and LDCs, on the implementation and operation of the rights and obligations and the understanding and use of flexibilities contained in the T'RIPS Agreement".35

37. The WIPO General Assembly mandated that the committee hold two meetings of five days this year. The first session of CDIP was held in March 2007 in Geneva at the WIPC head quarters, the main goal was to develop a work programme for the implementation of the 45 adopled recommendations.

33 The WIPO Secretariat has prepared a Preliminary Report on the implementation of the 19 recommendations and a more detailed report is excepled to be presented at the July CDIP Session. The Secretariat Report has been criticised for mainly stating information on activities that have been undertaken or are planned. It is not a qualitative analysis of the implementation of the recommendations. Sisule Musungu has criticised this as an important shortcoming. In his view merely stating the list of activities makes it difficult to connect the purpose of the recommendation and the activities undertaken. Foremost it makes it hinders to assess if reform has taken place or is underway because of the activities that are being implemented in the name of the Development Agenda. Interview with Sisule Musungu conducted by the author in April 2008.

sit The first meeting of the WIPO Committee on Development and IP (CDIP) took place from 3-7 March 2008 aimed at implementing the WIPO Development Agenda proposals. So far little progress has been made as only six of 45 proposals were discussed.

35 See WIPO Development Agenda, Recommendation 14. 
Hence this recommendation requires reform and improvements to legislative advice given by WIPO to developing governments and relevant institutions and administrations, with respect to the implementation of the TRIPS Agreement. In particular this advice should uphold the rights of Member States in terms of policy space, as well as their obligations, and comprise a thorough understanding of the available TRIPS flexibilities to address socio-economic development needs. In this respect it is important that WIPO builds on the extensive work undertaken in this area by various NGOs, experts, academia and other UN agencies, like UNCTAD. It is also crucial that TRIPS flexibilities are not limited to the Doha Declaration on the TRIPS Agreement and Public Health but that they also look at the possibilities for developing and least developed countries to build sound and viable technological bases and to develop IP systems in line with their needs.

Recommendation 12 stipulates to "further mainstream development considerations into WIPO's substantive and technical assistance activities and debates". What is mainly expected from this recommendation is that technical assistance activities undertaken by WIPO focus on the benefits, costs and impacts of IP on development. Recommendation one sets out that:

\begin{abstract}
"WIPO technical assistance shall be, inter alia, development-oriented, demand driven and transparent, taking into account the priorities and the special needs of developing countries, especially LDCs, as well as the different levels of development of Member States and activities should include time frames for completion". 37 .
\end{abstract}

The key expected improvement here is that technical assistance should include advice, strategies and ideas on how IP or other rules and policies should support development by encouraging relevant innovation and access. Most importantly, technical assistance activities need to be demand-driven and transparent. Demand-driven means the recipient country predominantly defines the needs, priorities and implementation programme. Being transparent means the technical assistance projects is transparent in terms of identifying recipient countries, subject coverage, timeframe, costs and outcomes. It has not yet been worked out how WIPO is going to assess country-specific needs in relation to IP protection. ${ }^{3 / 7}$ Recommendation three relates to generating greater public awareness on $I P$ and education, in particular introducing intellectual property, at different academic levels. Recommendation four requires a greater focus on the needs of SMEs and institutions dealing with

37. See WIPO Development Agenda, Recommendation 1.

37 Notably ICTSD has developed in cooperation with Saana Consulting a diagnostic toolkit on assessing the Needs for Financial and Technical Cooperation of Least Developed Countries in Implementing the TRIPS Agreement. For more information visit the integrated project website: <http://www.iprsonline.org/ictsd/LDC needs. htm>. 
scientific research and cultural industries plus helping Member States set up appropriate national strategies in the field of JP. It is desired that technical assistance in this respect will not only focus on possible uses of IP but also how they can overcome IP barriers to their business and activities. ${ }^{378}$ Furthermore, recommendation seven refers to providing technical cooperation to developing and Least Developed Countries to better understand the interrelationship between IP and anti-competitive practices. Recommendation five requests that $W I P O$ provides general information on all technical assistance activities on its website and, on request from Member States, more detailed information on the activities in question.

\title{
6.2.2. Recommendations in Relation to Norm-setting
}

Recommendation 15 of the WIPO Development Agenda sets out that:

\begin{abstract}
"norm-setting activities shall be inclusive and member driven; take into account different levels of development; take into consideration a balance between costs and benefits; be a participatory process, which takes into consideration the interests and priorities of all WIPO Member States and the viewpoints of other stakeholders, including accredited inter-governmental organizations and nongovernmental organizations; and be in line with the principle of neutrality of the WIPO Secretariat".37y
\end{abstract}

This recommendation requires that the views and interests of developing countries and other stakeholders, particularly public interest groups are taken into account. It also requires paying more attention so that the substantive content of norms and standards reflect cost and benefit analyses. It also requires that differential treatment for developing countries and LDCs is included. Recommendation 16 requests that the public domain within WIPO's normative processes is preserved and that the analysis of the implications and benefits of a rich and accessible public domain is researched more deeply. Recommendation 17 stipulates that norm-setting processes should take into account the flexibilities in international IP agreements, especially those which are of interest to developing countries and LDCs.

Regarding work carried out in the IGC, recommendation 18 repeats the mandate provided in the WIPO General Assembly, to:

3\% See WIPO Development Agenda Implementation, Commentary on the Preliminary Implementation Report in Respect of 19 Proposals, Iteas in Development. Published online at: <http://wwwiqsensato.org>.

3" See WIPO Development Agenda, Recommendation 15. 
"accelerate the process on the protection of genelic resources, traditional knowledge and folklore, without prejudice to any outcome including the possible develepment of an international instrument or instruments". ${ }^{\text {sil }}$

Hence, this recommendation demands reform in the pace of work in the IGC. However, it is not spelt out how this process should be speeded up and so it is crucial to regularly check how much progress is being made towards concluding the process in the IGC.

Recommendation 19 stipulates the desire to:

"initiate discussions on how, within WIPO's mandate, to further facilitate access to knowledge and technology for developing countries and LDCs to foster creativity and innovation and to strengthen such existing activities within WIPO", in!

Recommendation 21 creates a new mandatory procedure on norm-setting:

"WIPO shall conduct informal, open and balanced consultations, as appropriate, prior to any new norm-setting activities, through a member driven process, promoting the participation of experts from Member States, particularly' developing countries and LDCs". 3is

Hence this recommendation demands reform in norm-setting processes, in particular, increasing the level of stakeholder participation; but also in how new activities should be initiated.

Recommendation 22 demands that:

"WII'O's nom-setting activities should be supportive of the development goals agreed within the UN system, including those contained in the Millennium Declaration. The WIPO Secretariat, without prejudice to the outcome of Member States considerations, should address in its working documents for norm-setting activities, as appropriate and as directed by Member States, issues such as: a) safeguarding national implementation of intellectual property rukes b) links between IP and competition c) IP related transfer of technology d) potential flexililities, exceptions and limitations for Member States and e) the possibility of additional special provisions for developing countries and LDCs". iks

Hence, this recommendation desires to see changes in norm-setting activities to reflect a range of public interest and development considerations. It also

\footnotetext{
3.w See WIPO Development Agenda, Recommendation 18.

3 See WIPO Development Agenda, Recommendation 19.

$3 \$ 2$ See WIPO Development Agenda, Recommendation 21.

3.33 See WIPO Development Agenda, Recommendation 22.
} 
wants to see improvement in the level of alignment between the objectives of IP instruments and development goals. ${ }^{3 k+}$

\subsubsection{Recommendations in Respect to Technology Transfer, IC $T$ and Access to Knowledge}

In relation to cluster $\mathrm{C}$ (technology transfer, $\mathrm{ICT}$ and access to knowledge) WIPO is requested to: bridge the digital divide; ${ }^{385}$ to explore IP-related policies and initiatives necessary to promote the transfer and dissemination of technology, to the benefit of developing countries and to take appropriate measures to enable developing countries to understand and utilise the flexibilities provided for in the international agreements to promote the transfer of technology (this relates, for instance, to research exemption in patent law's); ${ }^{36 \text { to }}$ to strengthen cooperation between research and scientific institutions in developed and developing countries; ${ }^{367}$ to explore supportive IP-related policies and measures which Member States, especially developed countries, could adopt for promoting the transfer and dissemination of technology to developing countries; 3 is to provide a platform for discussions on technology transfer issues within the mandate of an appropriate WIPO body; ${ }^{369}$ and to undertake activities contributing to the transfer of technology to developing countries, such as improving access to publicly available patent information. The debate on all these issues should also focus on why the implementation of Article 66.2 has proven to be so difficult. ${ }^{3 \%}$ In addition, most of the recommendations are focused on technical assistance, whereas it would be useful to focus on normsetting to strengthen the proposals. ${ }^{301}$

ist See WIPO Development Agenda implementation, Commentary on the Initial Working Document for the Implementation of Agreed Proposals, Ideas in Development. Published online at: <http://wwwiqsensato.org>.

345. See WIPO Development Agenda, Recommendation 24.

ist See WIPO Development Agenda, Recommendation 25.

3 See WIPO Development Agenda, Recommendation 26.

iss See WIPO Development Agenda, Recommendation 28.

is See WIPO Development Agenda, Recommendation 29.

3.6) See chapter three of this thesis for more information.

sil WIPO Development Agenda Implementation, Commentary on the Initial Working Document for the Implementation of Agreed Proposals, Ideas in Development. Published online at: <http://www.iqsensato.org >. 


\title{
6.2.4. Recommendations in Respect to Assessment, Evaluation and Impact Studies
}

Recommendation 35 of the WIPO Development Agenda requests:

\begin{abstract}
"WIPO to undertake, upon request of Member States, new studies to assess the economic, social and cultural impact of the use of intellectual property sy'stems in these States". ${ }^{302}$
\end{abstract}

However, it is desirable that these studies focus not only on the economic impact of IPRs on development but also on the social and cultural aspects. In addition, it is important to build on existing studies in this area and that resources are not allocated to re-invent the wheel.

Recommendation 38 aims to strengthen WIPO's capacity to perform objective assessments on the impact of the organisation's activities on development. It is crucial that the evaluation/monitoring system that is contemplated evaluates all activities that impact development and not just the development agenda activities. Hence, WIPO as a whole, and all the activities undertaken within the numerous committees, should be in line with the WIPO Development Agenda objectives.

\subsubsection{Recommendations in Relation to Institutional Matters Including Mandate and Governance and Enforcement}

In respect to cluster $\mathrm{E}$ a number of recommendations have been proposed to initiate studies on the brain drain phenomenon particularly from Africa ${ }^{363}$ and to improve cooperation between WIPO, other UN agencies and the WTO in IP related issues. ${ }^{3,4}$

Cluster $F$ desires IP enforcement in the context of broader societal interests and development-oriented concerns, in particular, in relation to balancing rights and obligations as set out in the objective underlying the TRIPS Agreement (in its Article 7 TRIPS Agreement). Hence the reform which is anticipated in this regard is that enforcement concerns are not only directed at right holders' perspectives and interests but also that the needs of consumers, competitors and the general public are taken into account as well. Hence, there is an urgent need for a balanced approach to IP enforcement. ${ }^{365}$

\footnotetext{
342 See WIPO Development Agenda, Recommendation 35.

343 See WIPO Development Agenda, Recommendation 39.

34.4 See WIPO Development Agenda, Recommendation 40.

345 See WIPO Development Agenda Recommendation 45 (cluster F).
} 
When faced with regulatory diversity there are generally three options: mutual recognition; to make an effort to harmonise all its obstacles; or to use the principle of national treatment (treat foreigners the same as nationals). ${ }^{396}$ In the case of a hamonisation process cultural differences become political differences. For example, people do not want to agree as there is a natural rejection to adopt other people's legislation and to give up national sovereignty. Although it is normal practice that in a harmonisation process one country's standard will become that of all countries, it is very difficult to find an optimal regime. The fact is that over the last century intellectual property rights have been expanded domestically and certainly the number of international treaties and agreements has steadily increased too. ${ }^{397}$

The effective implementation of the Agreement depends on a number of conditions: knowledge of IP concepts and awareness, infrastructure, good governance practices, communication and transparency between various governmental departments and the public at large, cooperation between police, customs authorities and governments, stability, absence of violence, and financial and technical cooperation and assistance. Foremost it is important to understand the basic principles and concepts of intellectual property. For countries that are for the most part net importers and purchasers of intellectual property, the benefits and interests of a harmonised IPR Agreement strengthening the rights of IPR right-holders is not immediately present.

The Uruguay Round of Multilateral Trade Negotiations introduced new rules on trade in goods and included intellectual property rights on the agenda. ${ }^{34 s}$

3\% The route of national treatment is not always desired, for instance there are cases that people do not want to be treated equally. For example a doctor from Taiwan does not want to be treated in the same way as a doctor in the Netherlands, he does not want to do another medical exam but he simply wants recognition of this diploma. In the area of services, their principle of national treatment is not applicable, because countries are not willing to open up their markets, one size does not fit all.

s. The result of this movement is "a globalised regime of private rights in information and of the foundations for a rudimentary transnational system of innovation". Subsequently "this new system will have profound implications for the nature of such basic processes as innovation, technology transfer, competition, and economic development". Maskus and Reichman raise questions as to the ability of governments to provide their citizens with critical public goods (including public health, education, environmental protection) since they are more and more depending on "the exercise of private rights over technical inputs". See Maskus and Reichman $2004 a$, p. 275.

31) Art. II.2 states that the agreements and associated legal instruments included in Annexes 1, 2 and 3 are integral parts of this Agreement, binding on all Members. 
Although a number of contracting parties argued its aim was not to displace the existing international legal intellectual property framework, the inclusion of the subject matter within the Uruguay Declaration can be explained by "at least some discontent with the existing intemational conventions". 399

Clearly the current approach of nations worldwide for resolution to current IPR conflicts was and still is through harmonisation. Along with the process of globalisation, which has exponentially grown in the last decade, policy makers aspire to formulate a global framework for legislation of intellectual property rights. The $W I P O$ and the WTO try to create a uniform legislative regime, across borders, cultures, levels of development and different economic and technological markets. How Hover, many scholars doubt whether a uniform approach can accommodate the unique requirements of local industries and cultures.

The TRIIS Agreement is the most comprehensive international agreement on intellectual property; it also remains an incomplete agreement. As explained in this chapter, the TRIPS Agreement provisions laid down are a compromise, the best possible deal after a long negotiation process in which it was hard to achieve consensus. As such it is a bad starting point for further negotiations.

The imposing of minimum standards of protection including a systematic set of minimum standards on enforcement of IPRs implied reforms in domestic legal systems. In particular developing countries had to substantially transform their national legislation, replacing old laws with new ones, adding sections on new areas of law, or introducing for the first time a domestic legislative framework in the area of intellectual property law. Quite often the new legislation had to be implemented before the country in question had had the chance to establish its own national policy objectives on IPRs in line with their own socio-economic development goals. Before the conclusion of the TRIPS Agreement countries had considerably more sovereignty to frame their national legislative framework on IPRs to their own development needs, conditions and interests. This bottom up approach in the pre-TRIPS era allowed countries, both developing and industrialised, to differentiate between industrial sectors and for instance exclude certain areas from patent protection, like pharmaceutical or food products. A top down approach deprives countries to pursue IPR policies in coherent with socio-economic development goals. Developing countries are late comers in a market in which the rules on IPRs are long set. The ongoing IPR negotiations within the framework of the WIPO and WTO to harmonise IPR even further is criticised by many developing countries as being too much for their fragile economies to handle. In their view, the drive towards strengthening IPRs does not take thorough account of

\footnotetext{
3us See Stewart 1993, p. 2246.

the See Panitchpakdi $2001, \mathrm{p}, 3-13$.
} 
the varying economic, historical, cultural backgrounds and differences but instead imposes a Western-oriented view of property and ownership on the developing countries.

In addition, the TRIPS Agreement has not only brought about major changes in the domestic intellectual property rights legislative framework of all its Members as a result of the standardisation process, but it has also opened the door to a new generation of bilateral or regional trade agreements that include chapters on II and deepen the process of harmonisation initiated by the TRIPS Agreement. ${ }^{4111}$ These regional or bilateral agreements all vary in scope, depth, purpose depending on the countries interest and objectives. However, all these FTAs quite often entail sections or chapters on the protection of IPRs and these can go way beyond the standards set in the TRIPS Agreement. Foremost, the US pursues FIAs to strengthen enforcement levels across the globe. The ECs main interest in negotiating these FTAs is to protect its agricultural and food products imposing its own domestic policies in these areas on third countries. ${ }^{412}$ The EC did not succeed at the multilateral level in reducing the exceptions to the geographical indications protection regime so it now tries to do so following the bilateral and regional route. Increased intellectual property protection provisions in FIAs are seen as a trade-off for market concessions in other areas perceived as more important for developing countries needs. Although FIAs differ in wording, scope and coverage they have some common features. FIAs, in which the US or the EC are parties, promote adequate and effective protection of IPRs in general, however the ones signed by the US tend to be more expansive and detailed in IP subject-matter and scope. However, this is changing with the current EPA negotiations between the EC and the ACP countries. In addition, the ultimate objective is to extend the local level of protection (in the US and the EC) across the world to receive protection for their products (protected by IPRs - be they innovative or creative in nature) at the national and international level.

To a large extent the controversy on the IPR Agreement derives from the immense unequal distribution of wealth across the globe and the different levels of technological development and innovation. The controversy can also be explained by looking at the amount of benefit one is likely to gain from the Agreement i.e. higher standards of intellectual property protection. Only few countries produce and invent technologies and goods which enter the global markets. Research has shown that the use of IPRs is above all sector specific: in particular the chemical, transport, pharmaceutical, biotechnology, software and broadcasting organisations depend on IPR to widen and warrant their market positions. What do developing countries gain in respect to harmonised IPRs, in particular patent protection? The traditional answer was that it

thit See Roffe 2007, p. 1.

tir See Roffe 2007, p. 3. 
provides them access to foreign markets, access to search patent and trademark databases and the expertise of foreign registration offices, as well as access to training programmes organised by the international organisations including information on the establishment of an industrial property system. However, reality has shown that IPRs have not brought the desired results. Developing countries have pleaded for more sensitivity towards their needs and request that developed countries give content and body to articles 7,438 and $66.2^{40.4}$ of the TRIPS Agreement. Currently, TRIPS toes not provide concrete solutions and suggestions towards promoting the transfer of technology, as Article 66.2 is phrased in very general terms. ${ }^{45}$

Hence, focus in all future negotiations should be on the implementation and enforcement of existing IPRs before another relentless move towards even stronger IPR protection which can not be kept up with. More information on the effects of IPR, the benefits and the like, is very necessary and should be provided. tho 'The ethical, legal, regulatory and policy frameworks needs to be in place to support the IPR regime, in order to make it function. Other possibilities would be to adopt a different IPR system for different countries, taking into account different stages of development, various cultural backgrounds, conceptions of property and needs. Besides, the Western world's constant promotion of stronger IPR protection needs to be backed with full support in order for it to work properly. This support is still lacking and so an opposite effect is occurring. $417 \%$

4013 Art. 7 of the TRIISS Agreement stipulates that "The protection and enforcement of intellectual property rights should contribute to the promotion of techological immoration and to the transfer and disemination of techmology, to the muthal ationtage of protucers and users of fedmological knozeledge and in a manner conducive to social and economic welfare, and to a balance of rights and obligations". (italics added FC)

the Art. 66.2 sets out that "Developed country Members shall provide incentives to enterprises and institutions in their territories for the purpose of promoting and encouraging technology transfer to least-developed country Members in order to enable them to create a sount and inable technological base". (italics added FC)

4h Arts. 7,8 and 66.2 will be discussed in greater detail in chapter five of this thesis.

the See UNCTAD Trade and Development Report 2007 - regional cooperation for development, chapter III, section 5, published online at: <http://www.unctad.org/ Templates $/$ webflyer.asp?docid $=8951$ \&int Item $I D=4330 \& l a n g=1 \&$ mode $=t o c>$. Sec also an older report by UNDP, Human Development Report 1999.

111: According to Hamilton, people have to believe in the Western version of the IT? regulatory system in order to obey to it. This involves the acceptance of the following understandings: 1) individual creative effort is valuable; 2) reward has to do with quality and not merely with effort. Hamilton considers the TRIISS framework as being some sort of imperialism: in that developing countries have to obey with an IPR framework in a very short amount of time, whereas the developed countries had build an IPR legal framework over decades, carefully using 
Negotiations within the context of the WTO TRIPS Council and the WTO have been dominated by public policy concerns and whether IPRs conflict with the development needs of poor countries. Not only have there been calls to extend the transition periods; there have been equally stressed concerns about the disproportionate benefits for the industrial countries and the need to support the interests of the developing countries. Disquietude has come over the majority of developing countries in relation to their expectations on technology transfer and the increased flows of foreign direct investment being fulfilled; hence they are trying to redress the IPR balance (promotion of IPR and equal care of development objectives). One can argue that the rationale behind IPR protection has shifted too much in the direction of strong patent protection at the expense of the "public good". Harmonisation of rules regardless of living circumstances and regardless of what type of industry is flourishing can be detrimental to a country's economic growth possibilities since governments will be less able to regulate domestic activities to address local socio-economic development needs and deal with market failure. Developing countries lack the resources to absorb IPRs, install and operate competition policies and train custom authorities. They need financial support, co-operation and training programmes on how to establish the institutional framework to administer, implement and enforce the provisions. Such an approach would also help developed countries, as their IPRs would be more efficiently protected from misappropriation and duplication.

With increased focus on regulating enforcement more efficiently (at the TRIPS Council, the WIPO and within FГAs) and outside these fora's, deliberations on the Anti-Counterfeiting Trade Agreement code, ${ }^{+118}$ within the WIPO and within FTAs), national legal systems, traditions and different starting positions - in terms of infrastructure, governance, institutional framework, capacity, knowledge of IPR concepts - should not be overlooked nor should the multidisciplinary nature of the topics involved. Ensuring compliance to the TRIPS Agreement obligations (just like the negotiation process that preceded it) is not going smoothly due to different development circumstances, costs and lack of institutional capacity. But compliance is also affected by local interests and the simple fact that a provision can be very profitable for one party and very unfavourable for another. States may act in multilateral deliberations and reach consensus (freely or under coercion) but it is difficult to really change behaviour in practice. The adoption of a treaty will not remove constraints and

intellectual property concepts when it would be of importance and discharge it when it would not come in handy. See Hamilton 1997, chapter nine.

whe The C8 called for finalising negotiations of the Anti-Counterfeiting Trade Agreement (ACTA) by the end of the year and in addition declared patent harmonisation a topic of high importance, asking for "accelerated discussions of the Substantive Patent Law Treaty (SPLT)". See Erbert 2008. 
challenges in developing countries. This makes enforcement the most difficult task in the hamonisation process. It is a lot easier to change legislation (on paper) than to obey that legislation. For this to happen a change of mindset is needed in that, countries must be convinced by the merits of the new legislation and policies. measures will be addressed in more detail in chapter two, section four of this thesis.

Currently, developing countries regard the existing international legal framework for IP'R protection as disrespecting their needs because they saw so little support from the developed countries in the negotiation process. This was particularly the case in relation to the much anticipated protection for traditional knowledge, genetic resources and folklore and to the promises made in relation to the transfer of technology - there is still no international TK regime and technology transfer promises have not been materialised. These issues will be addressed in chapter five and three respectively. Developing countries are under huge pressure from developed countries to implement the IPR regimes, but lack adequate technical assistance from the developed countries, and have not been provided with easier access to technology nor the facilitation and promotion of technology transfer. In the short term there is a huge gap between the benefits enjoyed by the developed countries and the sacrifices that developing countries have to make. ${ }^{+10}$ In the short term developing countries are carrying the heaviest burden from the demand to increase IP protection, as they are required to make the most extensive changes in their domestic systems. "They are faced with many difficult questions, for instance they need to work out how to define their respective national intellectual property strategy, legal framework, and institutional and administrative reform. The cost of implementing and enforcing the provisions is likely to outweigh the benefits in the short term. Abbott has argued that:

\footnotetext{
"the role of intellectual property is context-sensitive, depending on the particular characteristics of countries in which intellectual property rights systems are intreduced, and depending on the specific industries in which these intellectual property rights are employed"."12
}

Because of this "context-sensitive role" flexible rules on implementing the TRIPS Agreement which take due account of the specific interests of the developing countries should be prioritised in WTO deliberations. In addition, other organisations such as the World Bank and UNCTAD should enhance

4in: See Sell 1998, p. 218.

401 Presentation by Reichman 1999.

+11 For instance, Watal 2001 and UNCTAD- ICTSD [Resource hook] 2005.

412 See Abbott 1998, p. 497. 
technology capacity building. ${ }^{413}$ Foremost, the WIPO Development Agenda momentum should be build upon.

At the international level, deliberations have intensified to harmonise intellectual property, so far with limited results where it comes to a developmentoriented $I P$ policy, although this is about to change. A number of recent developments have increasingly focused on bringing a better balance between private rights and public interests, such as the adoption of the WIPO Development Agenda and the Doha Declaration on TRIPS and Public Health, as well as the WHO reports. There has also been the TRIPS amendment in relation to compulsory licensing (Article 31bis), the large support for the disclosure of origin proposal and the increased attention to Article 66.2, and technical assistance activities. Each of these shows that developing countries' efforts to bring more balance into the IP system are not without results. However, the implementation of the WIPO Development Agenda is stuck. What will be the pay-off to get it moving? Most likely, the EC and the US will want something in return, e.g. TRIPS plus provisions. This issue is likely to be the highlight of the coming WIPO deliberations. The cross-cutting nature of IPR issues and the number of institutions addressing IPR related issues poses policy coherence challenges which demand increased cooperation between country delegates and institutions. These successes will be discussed in the following chapters of this thesis.

413 See Abbott 1998, p. 498 and 520. 


\section{Chapter Two}

\section{Analysis of the TRIPS Agreement Provisions Relevant for Developing Countries}

"Fifte'n thousand people dying needlessly ere'ry day from AIDS, TB, and malaria.

This is Africa's crisis. That it's not on the vightly newes, that ale do not treat this as an emergency, that's our corisis. We con dhoose to shift the responsibility, or a'e can doose to shift the paradigm".

Bono:

\section{INTRODLCTION}

The final outcome of multilateral trade negotiations or any other convention is always based on consensus. As a result of this consolidation process, laws may use peculiar wording to accommodate wishes and demands of country negotiators. They may also include flexibilities to deal with sensitive areas. Hence, after the adoption of a treaty the real work starts namely the implementation and interpretation of the treaty provisions, both at the domestic and at the intermational level. Hence, "[I]n the diplomatic solutions of yesterday lie the shortcomings of tomorrow". 2

The idea behind the TRIPS Agreement was to follow the existing intellectual property conventions as closely as possible, but to supplement it with new provisions that would bring the existing international legal framework up-todate and ensure enforcement and dispute resolution. The TRIPS agreement is perceived as a Berne and Paris plus agreement as it incorporated these and other existing intellectual property conventions but it also introduced enhanced protection in the field of patents, trade secrets, geographical indications and enforcement measures. The TRIPS Agreement is, however, sparse on new developments in technology. The main new focus is, however, on enforcement and dispute settlement, in line with the priorities of the Uruguay Round work programme on intellectual property rights to stop trade in counterfeit goods.

The TRIIS Agreement is divided in seven parts. Part I deals with the general provisions and basic principles, such as the principle of national treatment and most-favored nation treatment. In respect of industrial property, Part 11 of the TRIPS Agreement sets minimum standards for the availability, scope and use

1 See foreword by Bono in Sachs 2005.

2 See Evans 1996, p. 153.

; The WIPO Conventions on Copyright and Performances also referred to as the Internet treaties have to a certain extent achieved progress on these matters. 
of copyrights, patents, trade marks, geographical indications and industrial designs. Part Il, section tw'o concerning trade marks, for example, not only prescribes the appropriate subject-matter for a trade mark but lays down rules for their validity, rights of ownership and commercial exploitation. Trademarks are not discussed in this chapter but they are compared with geographical indication protection in chapter four of this book. Part III of the TRIPS Agreement stipulates the obligations of Member countries to provide procedures and remedies under their domestic law to ensure that intellectual property rights can be effectively enforced by foreign right holders and nationals alike. Part IV stipulates the rules on acquisition and maintenance of IPRs and importantly it provides that Members may require that these procedures and formalities to register e.g. trade marks or patents are "reasonable". In particular, if examination procedures are applicable they should be carried out within a reasomable period of time. It also stipulates that final administrative decisions shall be subject to review. Part $V$ of the TRIPS Agreement deals with dispute prevention and settlement. In this regard Members are requested to publish law's and final judicial decisions pertaining to the TRIPS Agreement to allow other Members to become familiar with them. It also sets out that the rules of the Dispute Settlement Understanding shall apply to consultations and the settlement of disputes under the TRIPS Agreement. Part VI of the TRIPS Agreement stipulates the rules on transition periods permitted to developing countries in order to implement the rights and obligations under the TRIPS into their own domestic legal frameworks. It also provides that developing countries should receive technical and financial cooperation and assistance on the implementation of the TRIPS Agreement and on the role of intellectual property offices. Part VIl sets the rules on institutional requirements, such as the task of the Council of TRIPS, and it requests international cooperation between members to stop the trade in goods infringing IPRs. In particular customs organisations should cooperate to stop the trade in counterfeit trade mark goods and pirated copyright goods.

This chapter provides an overview of the TRIPS Agreement provisions which have the biggest impact on developing countries. It aims to highlight the key provisions for developing countries and provide some assistance as to how the TRIPS article should be interpreted in relation to its use, negotiation history and WTO case law. It, hopefully, provides developing countries with an overview of the rights and obligations they can derive from the Agreement. In particular, it highlights the remaining flexibilities. Flexibilities, in this context, are understood to mean the freedom left to the national sovereignty of individual countries to address intellectual property rights in a manner constructive to their socio-economic circumstances and needs. In addition this chapter will also discuss new developments as a result of the Doha Development Round, or other negotiation efforts within the TRIPS Council as well as in regional and bilateral free trade agreements. The TRIPS Agreement is not static but on the contrary is of a dynamic nature since it is subject to review under its Article 71. That this review mechanism does not merely exist on paper but that the TRIPS Agreement really is subject to change is proven by 
the recent amendment to Article 31 with the supplement of Article 31 bis dealing with the specificities on compulsory licensing in particular when a country is deprived of manufacturing capacities to produce drugs locally. Another TRIPS amendment in the pipeline is a proposal to incorporate a "disclosure of origin" obligation (Draft Article 29lis) into the TRIPS Agreement. It has gained support from 77 countries and it is aimed at building this political momentum and strategically expanding support for the proposal.

\section{INTERI'RETING THE TRIPS AGREEMENT}

\subsection{Triaty Interpretation}

Treaty interpretation requires a search for the intention and rationale behind certain articles. Treaties are always the result of a negotiation process reconciling diverging positions. Often negotiators agree to a general text that can be understood in more than one way to accommodate the demands of different constituencies and to cover a multitude of individual cases. As a result the interpretation of legal provisions, in particular at the international level, is not an easy task.

It is the task of the Panel and subsequently the Appellate Body-together they form the WTO Dispute Settlement System (DSS) to identify the precise scope of the rights and obligations contained in the WTO Agreement and to interpret and enforce the TRIPS Agreement obligations. They can ask assistance from the Secretariat or from one of the many committees such as the TRIPS Council.

The DSS applies the rules stipulated in the Dispute Settlement Understanding (DSU). ${ }^{4}$ The system aims to provide security and predictability in the multilateral trading system. Most disputes $^{5}$ evolve around the question of

4 The DSU, constituting annex 2 of the WTO Agreement sets out the procedures and rules of the WTO dispute settlement sy'stem. It replaces the GATT Dispute Settlement System. To a large extent, the current dispute settlement system is the result of the evolution of rules, procedures and practices developed under the GATT 1947. The procedure is as follow's: a "Panel" and pursuant the Appellate Body' (in a higher instance) are composed on written request - through the filing of a complaint under. Art. 6 DSU) - by a WTO member who asserts non-compliance of the TRIPS Agreenent obligations by another WTO Member. The findings of the Panel and the Appellate Body are subsequently published in a report. The DSU is considered to be one of the major achievements of the Uruguay Round of Multilateral Trade Negotiations and the WTO Secretariat website refers to the system as being the "backbone of today's multilateral trading regime". See Van den Bossche 2005 for a detailed overview of the rules and their application of the dispute settlement understanding:

$=$ See Art. 3.2 of the DSU. 
whether a violation of a particular treaty provision has taken place through the act or omission of another WTO Member Country. For instance, in the case of the TRIPS Agreement, most disputes address whether a provision has been adequately implemented into domestic legislation. In some cases the flexibilities have been tested.

Nevertheless, it should be remembered that the DSU mandate to clarify WTO rules does not prejudice the rights of Members to seek authoritative interpretations from the Ministerial Conference and the General Council of the WTO, which both have the "exclusive authority to adopt interpretations" of the WTO Agreement." The difference is that only the Ministerial Council and the General Council have the "exclusive authority" to adopt interpretations that are of gonchl validity for all WTO Members. As a consequence, interpretations by Panels and the Appellate Body are applicable only to the parties concerned and limited to the subject matter of a particular dispute.

The DSU explicitly mentions that the dispute settlement system is intended to clarify the provisions of the WTO Agreement "in accordance with customary rules of interpretation of public international law". "Customary public international law is mostly unwritten, but the Vienna Convention on the Law of the Treaties (Vienna Convention) has codified some of these customary rules of interpretation, and these are mainly incorporated in Articles 31, 32 and 33 of the Vienna Convention. "These provisions highlight that treaty interpretation needs to be according to the ordinary meaning of the words in the relevant provision, viewed in their context and in light of the aim and purpose of the agreement." The Appellate Body has ruled that these articles can "serve as a point of reference for discerning the applicable customary rules". I?

"In total, over 340 disputes on various trade related issues have been brought to the WTO Dispute Settlement Body since its creation in January 1995.

7 Interpretation of the WTO provisions is a task left to the WTO Dispute Settlement Body consisting of the Appellate Body and the Panels. In their interpretation and clarification efforts they make use of the negotiation history of the TRIPS Agreement to familiarise themselves with the intentions of the negotiation parties. This is cumbersome since no official negotiating history record tranax preparatoires for the UR has been released. The negotiation history is merely viewed as a supplementary means of interpretation under Art. 32 of the Vienna Convention on the Law of Treaties.

" See Art. IX:2 of the WTO Agreement and Art. 3.9 of the DSU.

"See Art. 3.2 of the DSU.

11) The Vienna Convention on the Law of the Treaties of 23 May 1969 provides the basis of the interpretation of the formulation of the TRIPS Agreement provisions.

"The ordinary meaning of a term in a provision is to be discerned on the basis of the plain text. The definitions given to this term in a dictionary can be of assistance in 


\subsection{WTO Case Late on "Legitimate Expectations"}

In the WTO case Imlin - Patents, the Panel referred to "certain standards" it considered applicable in interpreting the TRIPS Agrement. Firstly, it referred to the customary rules of interpretation of public intemational law, in particular Article 31(1) of the Vienna Convention, saying that "a treaty shall be interpreted in good faith in accordance with the ordinary meaning to be given to the terms of the treaty in their context and in the light of its object and purpose". The Panel clarified that in their opinion "good faith interpretation requires the protection of legitimate expectations derived from the protection of intellectual property rights provided for in the Agreement". "Moreover, the Panel relied on the GATI acquis by mentioning the GATT principle of "the protection of legitimate expectations of Members regarding the conditions of

that purpose. "Context" refers to the kinds of conclusions that can be drawn on the basis of, for example, the structure, content or terminolog! in other provisions belonging to the same agreement, particularly the ones preceding and following the rule subject to interpretation. The "object and purpose" refers to the explicit or implicit objective of the rule in question or the agreement as a whole. In practise, Panels and the Appollate Body seem to rely more on the ordinary meaning and on the context than on the object and purpose of the provisions to be interpreted. This is in line with Art. 32 of the Vienna Convention which stipulates that the negotiating history of the agreement is merely a subsidiary tool of interpretation. This tool is to be used only as confirmation of the interpretation according to the ordinary meaning, context and object and purpose or if that interpretative result is ambiguous, obscure, manifestly absurd or unreasonable. One of the corollaries of the rules on interpretation is that meaning and effect must be given to all terms of the agreement, rather than reducing whole parts of an agreement to redundancy or inutility. According to the Report of the Appellate Body, US Gasoline at p. 23, see United States - Standards for Reformulated and Conventional Gasoline, $A B R$, WT/DS2/AB/R, 29 April 1996. Conversely', the process of interpretation does not permit reading words into an agreement that are not there. According to the Report of the Appellate Body, EC Computer Equipment, para. 83, see European Communities - Customs Classification of Certain Computer Equipment, $A B R, W T / D S 62 / A B / R$, WT/DS67/AB/R, WT/DS68/AB/R, 5 June 1998. Moreover, Art. 3 DSU sets out that in interpreting provisions the customary principles of interpretation of public international law should be followed. Applying the principles of interpretation as set out in the Vienna Convention is being understood as to give words their ordinary meaning in their context and in the light of the object and purpose of the treaty as a whole.

12 Report of the Appellate Body in the US Gonoline and the Japan - Aloololic Berernges II, IS Gasoline at P23, Report of the Appellate Body, Janm - Alcololic Berernges II, WT/DS8/AB/R, WT/DS10, AB/R, WT/DS11/AB/R, 1 November 1996, at p. 104. See Van den Bossche 2008 for an elaborate discussion on treaty interpretation.

1. See para. 7.18 of the Intia - Patents, see India-Patent Protection for Plarmaceutical and Agricultural Chemical Products, WT/DS 50/R, 5 September 1997. 
competition"." The Panel considered that the protection of legitimate expectations is "central to creating security and predictability in the multilateral trading system"15 and falls within the objective and purpose of the TRIPS Agreement. Because of these rationales, the Panel considered the concept "legitimate expectations" to be just as applicable in the TRIPS context as it is in the CATT context. "The Panel had found in India - Patents:

\begin{abstract}
"when interpreting the text of the TRIPS Agreement, the legitimate expectations of WTO Members concerning the TRIPS Agreement must be taken into account, as well as standards of interpretation developed in past panel reports in the GATT framework, in particular those laying down the principle of the protection of conditions of competition flowing from multilateral trade agrecments". 1 r
\end{abstract}

However, this view was contested and reversed by the Appellate Body. The Appellate Body dealt with the interpretation of the TRIPS Agreement on request of India that challenged the Panel's reference to the protection of "legitimate expectations" as a general principle of interpretation of the TRIPS Agreement.

The Appellate Body reversed the conclusion reached by the Panel for the following reasons: Firstly, it disagreed with the Panel that the protection of "legitimate expectations" is used in GATT practice as a fundamental principle of interpretation. Secondly, it found that the reliance on Article 31 of the Vienna Convention for its "legitimate expectations" interpretation was ill chosen. The Appellate Body considered in Paragraph 45 that:

\footnotetext{
"The Panel misapplies Article 37 of the Vienna Convention. The Panel misunderstands the concept of legitimate expectations in the context of the customary rules of interpretation of public international law. The legitimate expectations of the parties to a treaty are reflected in the language of the treaty itself. The duly of a treaty interpreter is to examine the words of the treaty to delermine the intentions of the parties. This should be done in accordance with the principles of treaty interpretation set out in Article 31 of the Viema Convention. But these principles of interpretation neither require nor condone the imputation into a treaty of words that are not there or the importation into a treaty of concepts that were not intended". is
}

14 Which derives in part from Art. XXIIl, the basic basic dispute settlement provisions of the GATT and the WTO. See paras. 7.20 of the India - Patents (PR).

15 See para. 7.21 of the limilia - Patents (PR).

"th See para. 7.22 of the India - Patents (US) (PR).

1: lbid.

1s See para. 30 of the India - Patents (US) (ABR), WT/DS50/AB/R, 19 December 1997. 
The Appellate Body referred to its decision Lmited States - Stmulards for Refommlated and Conicntional Gasoline, ${ }^{14}$ in which the proper approach was set out for interpreting the WTO Agreement in accordance with the rules set out in Article 31 of the Vienna Convention. It stressed that "these rules must be respected and applied in interpreting the 'TRIPS Agreement or any other covered agreement". It found that the Panel had created "its own interpretative principle, which is consistent with neither the customary rules of interpretation of public international law nor established GATT/WTO practice". 211 It considered that:

"|Bjoth panels and the Appellate Body must be guided by the rules of treaty interpretation set out in the Vienna Convention, and must not add to or diminish rights and obligations provided in the WTO Agreement".21

The Appellate Body supported its view on Article 3.2 of the DSU which sets forth that the dispute settlement system:

\begin{abstract}
"serves to preserve the rights and obligations of the Members under the covered agreements, and to clarify the existing provisions of those agreements in accordance with customary rules of interpretation of pullic international law. Recommendations and rulings of the DSB cannot add to or diminish the rights and obligations provided in the covered agreements".22
\end{abstract}

Furthermore, Article 19.2 of the DSU expresses that:

"[i]n accordance with paragraph 2 of Article 3 , in their findings and recommendations, the panel and Appellate Body cannot add to or diminish the rights and obligations provided in the covered agreements".?3

For the above mentioned reasons, the Appellate Body reversed the Panel's findings that the legitimate expectations of Members and private rights holders must always be taken into account in interpreting the TRIPS Agreement. ${ }^{2-1}$

Linited States - Stmutards for Reformulated and Conientional Gotsoline, WT/DS2/AB/R, Adopted $20 \mathrm{May} 1996$.

21) See para. 31 of the Indin - Patents (US) (ABR).

21 lbid.

22 See Art. 3.2 of the DSU.

23 See Art. 19.2 of the DSU setting out the panel and appellate body recommendations.

24 See para. 31 of the Intin-Patents (US) (ABR). 


\subsection{The Premmble}

The Preamble to the TRIPS Agreement states that:

"Members,

Desiring to reduce distortions and impediments to international trade, and laking into account the need to promote effective and adequate protection of intellectual property rights, and to ensure that measures and procedures to enforce intellectual property rights do not themselves become barriers to legitimate trade;

Recognizing, to this end, the need for new rules and disciplines concerning: (a) the applicability of the basic principles of GATT 1994 and of relevant international intellectual property agreements or conventions;

(b) the provision of adequate standards and principles conceming the availability, scope and use of trade-related intellectual property rights;

(c) the provision of effective and appropriate means for the enforcement of trade-related intellectual property rights, taking into account differences in national legal systems;

(d) the provision of effective and expeditious procedures for the multilateral prevention and settlement of disputes between governments; and

(e) transitional arrangements aiming at the fullest participation in the results of the negotiations;

Recognizing the need for a multilateral framework of principles, rules and disciplines dealing with international trade in counterfeit goods;

Recognizing that intellectual property rights are private rights;

Recognizing the underlying public policy objectives of national systems for the protection of inlellectual property, including developmental and technological objectives;

Recognizing also the special needs of the least-developed country Members in respect of maximum flexibility in the domestic implementation of laws and regulations in order to enable them to create a sound and viable technological base;

Emphasizing the importance of reducing tensions by reaching strengthened commitments to resolve disputes on trade-related intellectual property issues through multilateral procedures;

Desiring to establish a mutually supportive relationship between the WTO and the World Intellectual Property Organization (referred to in this Agreement as "WIPO") as well as other relevant international organizations".

The Preamble recognises that "the provision of effective and appropriate means for the enforcement of trade-related intellectual property rights, [should take] into account differences in national legal systems". ${ }^{25}$ It is questionable whether this is a realistic goal considering the prescriptive nature and content of the substantive obligations under the Agreement.

See Preamble to the TRIPS Agreement under (c). 
The Preamble resembles the two Ministerial Declarations, which preceded the Brussels meeting of the Uruguay Round, i.e. the Punta del Este Declaration and the Mid-term Review Decision of April 1989 in Montreal. It reflects the difficult negotiation process in which contravening points of view and different backgrounds and perspectives hindered rapid consensus building. It also lays down the intention and reasoning behind the TRIPS Agreement and, together with the footnotes, the preamble forms an integral part of the TRIISS Agreement. This implies that the WYO Panels and Appellate Body can turn to the Preamble when the wording of a provision is not sufficiently clear or is "susceptible to divergent interpretations".26 Hence, the Preamble provides government officials and magistrates a source of interpretative guiciance useful in the implementation process and dispute settlement. The Preamble is not aimed at the creation of specific rights or obligations but rather a "preamble is designed to establish a definitive record of the intention or purpose of the parties in entering into the Agreement".?"

Also the Vienna Convention, the so-called "treaty on treaties" confirms that the Preamble (and annexes) forms part of the Treaty text for the purposes of interpretation. ${ }^{26}$ For this reason the Preamble should be distinguished from the negotiation history of the treaty, which is a supplementary means of interpretation, used when the express terms are ambiguous or to confirm an interpretation. ${ }^{29}$

The intention or main objective of the Agreement is set out in the first paragraph of the Preamble to the TRIPS Agreement. Members wish to:

"reduce distortions and impediments to international trade, and taking into account the need to promote effective and adequate protection of intellectual

2t. See Gervais 2003, p. 80 .

27 See UNCTAD-ICTSD [Resource Book] 2005, p. 2.

2* Art. 31 of the Viema Comention on the Law of Treaties (Viema Convention), paragraph 1 and 2 stipulate that: 1) a treaty shall be interpreted in good faith in accordance with the ordinary meaning to be given to the terms of the treaty in their context and in the light of its objective and purpose; 2) the context for the purpose of the interpretation of a treaty shall comprise, in addition to the text, including its memmlle and amexes. The Vienna Convention provides the basis of the interpretation of the formulation of the TRIPS Agreement provisions.

24 Art. 32 Vienna Convention on supplementary means of interpretation states: Recourse may be had to supplementary means of interpretation, including the preparatory work of the treaty and the circumstances of its conclusion, in order to confirm the meaning resulting from the application of Art. 31, or to determine the meaning when the interpretation according to Art. 31: a) leaves the meaning ambiguous or obscure; or b) leads to a result which is manifestly absurd or unreasonable. 
property rights, and to ensure that measures and procedures to enforce intellectual property rights do not themselves become barriers to legitimate trade"3u

Following from this abstract, the contracting parties (to the GATI) endeavoured to remove obstacles to free trade such as market access restrictions, ${ }^{31}$ but at the same time they wanted to introduce IPR protection into the multilateral trade agreement. The wording of the objective seems to be a clear paradox; as it seems impossible to achieve both goals. IPRs grant exclusive rights to the rights owners and create obligations and as a result hinder the free flow of trade across national borders. Although the content of IPRs is the information as such, in principal IPRs are exercised generally as exclusive rights for products that embody the protected information. For example, with respect to patents, ${ }^{32}$ the owner of a patent can prevent the manufacture, use or sale of the protected product in countries where the patent has been applied for and registered (obtained). These exclusive rights of the patent holder (the IPRs rights holder) explain why IPRs may have a direct and substantial impact on industry and trade. It is the same case for intangible goods - through the enforcement of such rights, the rights holder may regulate the use of the creation (e.g. a musical work) and the commercialisation of the product (e.g. a CD or a DVD). The underlying idea of the first paragraph of the Preamble is that insufficient protection of intellectual property protection will lead to distortions, but that excessive protection could have a comparable effect on trade. Finding the right equilibrium in balancing private and public interests to diminish the negative consequences of IPR protection is not an easy task. The first paragraph of the Preamble also reflects the reasoning behind the introduction of intellectual property rights within the framework of the GATT. That is, to find a solution to the manifest trade in counterfeit goods, and to establish more efficient enforcement provisions.

A lot has been said on the presumed paradox between on the one hand the protection of intellectual property (the creation of exclusive rights causing obstacles to free trade) and on the other the general objective of the WTO - the liberalisation of trade and the opening of markets. The history of IPR rule-

3 See Preambe to the TRIPS Agreement, first paragraph.

31 Particularly, in the area of agriculture developing countries wanted market access barriers removed or diminished. Negotiations resulted in the conversion of nontariff measures to equivalent bound tariffs. According to Art. 4, paras. 1 and 2 of the Uruguay' Round Agreement - Agreement on Agriculture: "market access concessions (...) relate to bindings and reductions of tariffs, and to other market access commitments. Members shall not maintain, resort to, or revert to any measures of the kind which have been required to be converted into ordinary customs. (...) These measures include quantitative import restrictions, variable import levies, minimum import prices (etc.)".

32 The term patents derives from the Latin plarase litterne patentes and means "open letters". See Davenport 1979. 
setting has been largely preoccupied with determining the balance between, on the one hand, private rights to reward and to recoup the investment made and, on the other, public gain of access to useful information and knowledge. Another balance needs to be sought between the granting of IPRs to stimulate further innovation and creation and exclusive ownership, and right-holders abusing these rights. ${ }^{33}$ Fquilibrium is sought by setting time limits on IPRs, and variations between different forms of intellectual property. ${ }^{3+}$ it is also important to find the right balance between free trade and intellectual property protection ${ }^{35}$ and the right level of $I P R$ protection equally suited to highly industrialised nations and developing countries.

The Preamble also refers to "the importance of reducing tensions by reaching strengthened commitments to resolve disputes on trade-related intellectual property issues through multilateral procedures". In particular, the treaty endeavours to remove the tension caused by the use of unilateral retaliatory measures, such as the use of Special 301 by the US against countries who, in their view, do not adequately protect IIRR.

\title{
2.2. "Minimum Standards" and "Frecdom of Implementation"
}

Article 1.1 TRIPS Agreement states the nature and scope of obligations:

\begin{abstract}
"Members shall give effect to the provisions of this Agreement. Members may, but shall not be obliged to, implement in their law more extensive protection than is required by this Agreement, provided that such protection does not contravene the provisions of this Agreement. Members shall be free to determine the appropriate method of implementing the provisions of this Agreement within their own legal system and practice".
\end{abstract}

Paragraph 1 of Article 1 opens with "Members shall give effect to the provisions of this Agreement". This wording reflects that the TRIPS Agreement is not a self-executing treaty. For provisions to have effect they need to be implemented into the domestic legislation of each Member. Hence, Members need to take concrete action to make TRIPS Agreement provisions effective within their domestic legislation. The TRIPS Agreement asks its Members to adopt domestic legislation to confirm with the Agreement, but differs from the existing IPR framework under the Paris Convention and the Berne Convention in that the TRIPS Agreement imposes detailed minimum standards which put constraints on what can be legislated at the national level. Thus the freedom

is See Gervais 2003, p. 81 .

is See May 2003.

3 Note that before the realisation of the TRIPS Agteement, or more preciscly before the beginning of the Uruguay Round intellectual property was viewed as an exception to free trade, according to Art. $X X(d)$ of the GATT. 
provided under article 1.1 and 8 of the TRIPS Agreement to adopt a national system in line with national needs and objectives is somewhat restricted because some provisions do not leave much scope for manoeuvre. The adoption of the TRIPS Agreement has increased the level and scope of intellectual property in all the WTO Member countries and thus the rights of the intellectual property rights-holder are increased and strengthened since more rules are available in his country and in all countries who are signatories to the TRIPS Agreement. It is clear that exporters of goods bearing an intellectual property constituent will be beneficiaries of the TRIPS Agreement as they encounter higher levels of IPR at an almost world-wide level.

With the arrival of a new generation of bilateral and regional trade agreements the flexibility countries have in determining terms of implementation is diminishing even further. For instance the US-CAFTA-DR agreement, the implementation bill passed by the US Congress, sets out the conditions countries

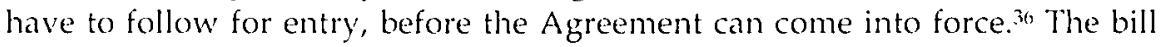
determines that it is the President of the USA who ultimately decides if the other party has taken the necessary steps to implement effectively the provisions of the FTA. This aspect of the implementation process, known in some quarters as the "certification act", commits the other party to adopt, the necessary implementation legislation that meets the expectations of the USA prior to the entry into force of the agremont, as opposed to, for instance, the TRIPS Agreement that comes into force upon atoption. ${ }^{37}$

The second sentence of the Article 1.1 continues:

\begin{abstract}
"Members may, but shall not be obliged to, implement in their law more extensive protection than is required by this Agreement, provided that such protection does not contravene the provisions of this Agreement".
\end{abstract}

Thus this paragraph contains some important direction on the status of the Agreement and implementation requirements. In fact the text implies a TRIPS plus approach since it allows Members to adopt higher standards of protection within their domestic legal system on the condition that extra protection does not undermine the effect of the TRIPS Agreement. ${ }^{38}$ "The choice of the wording - "may, but shall not be obliged to" - shows that the TRIPS Agreement defines the minimum standards of intellectual property protection. This positive formulation, "may, but shall not obliged to", instead of a negative wording "nothing shall prevent parties from" - shows that not all requests by countries

3" Dominican Republic-Central American-United States Free Trade Agreement Implementation Act, Pub. L. 109-53, 109:h Cong., first session. (2005), as referred to in Roffe 2007, p. 9.

:- See Roffe 2007, p. 9.

3* See Worthy 1994, p. 196. 
finally made it to the Agreement. In order to meet these wishes, especially from developed country Members, Members are permitted to adopt higher protection than is required under the TRIPS Agreement.

The third sentence of Article 1.1 stipulates that Members are "free to determine the appropriate method of implementing the provisions of the TRIPS Agreement within their own legal system and practice". Thus negotiators deliberately provide flexibility to each of the Members. It is left to the sovereignty of each Member to decide, in line with their own specific development and technology objectives and socio-economic circumstances, how to make the Agreement part of their domestic legislation. The rationale behind this freedom is to avoid problems of implementation as some countries have common law jurisdictions and others use civil law systems. Moreover this solution keeps as much sovereignty as possible for the individual nations. Critics believe that allowing countries to develop their own laws and policies can result in divergent interpretations of the provisions laid down in the TRIPS Agreement and results in uncertainty. ${ }^{39}$

\subsubsection{WTO Case Law on Article 1}

\subsubsection{Intin - Patents (US)}

Article 1, paragraph 1 of the TRIPS Agreement has been referred to numerous times in the Panel and Appellate Body Reports. However, it was never the primary focus of any dispute. In Indin - Patents, India was accused by the US of not providing "a sound legal basis to preseree nowelty and priority" of certain patent applications (i.e. pharmaceutical patents) in relation to Article 70.8 of the TRIPS Agreement. The Panel and the Appellate Body confirmed in IndinPatents that India was entitled to choose "the appropriate method of implementing" the TRIPS Agreement as provided under Article 1.1. "(1) The Panel concluded that:

"the mere fact that India relies on an administrative practice to receive mailbox applications without legislative changes does not in itself constitute a violation of India's obligations. The lapse of the Patents (Amendment) Ordinance 1994, which was promulgated for the purpose of specifically addressing these

See Gervais 2003, p. 87.

411 The referral to the Preamble was only of secondary importance as the primary focus of the case was on Art. 70.8, the so-called "mailbox" provision, the main issue being "what precisely is the "means" for filing mailbox applications that is contemplated and required by Art. 70.8(a)". See lutin-Patents, para. 54 (ABR) (US). 
obligations, does not automatically mean the lack of a "means" for filing patent applications for pharmaceutical and agricultural chemical products in lndia".+1

The Panel did not agree to the request of the United States in India - Patents (US) that India should implement its obligations under paragraph 8 and 9 of Article 70 in a manner similar to the way in which Pakistan had indicated it was implementing these obligations, as reflected in document. 22 The Panel argued that such a suggestion was not appropriate "since it would impair India's right to choose how to implement the TRIPS Agreement pursuant to its Article $1.1^{\prime \prime}$."

However, the absence of a formal mechanism in the legislation of India was a key element in the Panel's decision. The presence of a de fncto administrative mechanism was viewed as insufficient. The decision thus demands from Members to modify their legislation (in written form) in accordance with the TRIPS Agreement obligations. More on this ruling by the Panel and Appellate Body in section 6.2.1 of this chapter.

\subsubsection{Camada - Patent Term (LIS)}

The WTO Panel also dealt with the freedom of implementation in the case Cannda - Patent Term. ${ }^{44}$ Canada provided for patent term duration of 17 years starting from the patent grant date, whereas the TRIPS Agreement obliges Members to impose patent protection for a minimum duration of 20 years. ${ }^{45}$ The Panel mentioned the discretion given to Members under Article 1.1 which allows them to determine the appropriate method of implementing the rights and obligations under the TRIPS Agreement, but stressed that such discretion did not extend to choosing which obligation to comply with. The Panel referred to Article 33 and 66.2 of the TRIPS Agreement and noted that Article 1.1 gives Members a certain amount of freedom of implementation in relation to these two specific requirements "but not to ignore either requirement in order to implement another putative obligation concerning the length of

4 See para. 7.33 of the lntin- Patents (PR) (US).

42 Pakistan and the US had agreed a mutual solution and therefore have agreed to terminate consultations. "Pakistan - Patent Protection for Pharmaceutical and Agricultural Chemical Products", notification of a mutually agreed solution, WT/DS36/4, IP/D/2/Add.1, 7 March 1997.

t3 See para. 7.36 of the Litin - Patents (PR) (US).

4. Cammila Patent Term, see Canada - Term of Patent Protection, WT/DS/170/R, 5 May 2000 .

45 See Arts. 33 and 70 of the TRIPS Agreement. 
effective protection". 46 The case Canada -. Patent Tem (LS) will be addressed more in detail in section 3.3 of this chapter.

\subsection{Definition of Intellectunl Property Rights}

Intellectual property refers to creations of the human mind, embodied in creative or inventive works. There are plenty of definitions available in the literature on what constitutes IPRs. Intellectual property law's refer to the acquisition and use of a range of rights covering different types of creations, including creations of an aesthetic character (e.g. artistic works and industrial designs), technologies (e.g. patents) as well as information and signs of a purely commercial value (e.g. trademarks). However, it is hard to pinpoint IPRs, as they are in a constant state of flux. Developments are rapidly taking place bringing on board new types of $I \Gamma$. The term intellectual property rights incorporate a bundle of subject matter and rights. Each right is different in scope and duration and with a different purpose and effect. Nevertheless, they have common features as they all exclude third parties for a certain duration of time from exploiting protected subject matter without explicit authorisation of the right holder. This enables IPR owners to use or disclose their creations without fear of loss of control over their use, which facilitates in their dissemination. ${ }^{77}$ As we have seen earlier we can identify different categories of IPRs. These different types can be important to different sectors and (industrial, creative) processes and activities. For instance, trademarks can be of use through all sectors of production and industry; patents have a strong impact on chemicals, pharmaceutical products and electronics; whereas geographical indications are of most use to wines, spirits, food products and tobacco, and in future, maybe for handicrafts. Some categories of IPRs apply to very specific fields, for instance utility model protection is mostly used in the mechanical industry, toy manufacturing, clock and watch making, optics and micro technology and micro mechanics. ${ }^{48}$

For the purpose of the TRIPS Agreement, the term intellectual property refers to all categories of intellectual property that are the subject of Sections one through seven of Part II as follows from Article 1 paragraph 2 . Hence, it includes copyright and related rights, trademarks, geographical indications, industrial designs, patents, plant varieties, layout designs (topographies) of integrated circuits, and undisclosed information (trade secrets). Copyrights also protect computer programs and compilations of data. This definition is not all-embracing, since it simply refers to the subject-matter covered in the Agreement.

\footnotetext{
4t. See para. 7.36 of the Camain - Patent Term (US).

17 See Watal 2001, p. 1.

4. See Suthersanen 2006 , p. 8.
} 
Over the years hundreds of definitions on intellectual property have been written recorded. One formal definition stems from the Convention Establishing the WIPO't" which set out that intellectual property shall include the rights relating to:

\begin{abstract}
"literary, artistic and scientific works, performances of performing artists, phonograms, and broadcasts, inventions in all fields of human endeavor, scientific discoveries, industrial designs, trademarks, service marks, and commercial names and designations, protection against unfair competition, and all other rights resulting from intellectual activity in the industrial, scientific, literary or artistic fielcts". 51
\end{abstract}

Nevertheless, this definition provided by the WIPO is not very up-to-date, since it does not make reference to a number of topics considered falling under the category of intellectual property subject matter. For instance it does not make reference to traditional knowledge, databases, layout-designs of integrated circuits, trade secrets and confidential information, plant varieties, folklore, geographical indications and appellations of origins. The definition laid down in the TRIPS Agreement is more up-to-date although it also does not cover all the existing intellectual property subject matter. For example it does not make reference to traditional knowledge protection, utility model protection or breeders' rights. However, it is questionable if breeders' rights and traditional knowledge protection fall under the category of intellectual property rights. ${ }^{51}$ The reason for not including these topics may be explained by the lack of interest by industrial countries and the absence of an industrial lobby. ${ }^{52}$

As mentioned the level of technical and economic development of one specific country will have an impact on the relevance of each category of IPRs. For instance, providing utility model protection can be of interest for developing countries, since utility models protect so-called minor innovations that predominate in the innovative process in less developed countries. ${ }^{53}$ Utility models protect innovations of a rather "incremental character" or inventions

The Convention establishing the World Intellectual Property Organization, signed at Stockholm on July 14, 1967, and as amended on 28 September 1979.

5. See Art. 2, para. viii of the Convention Establishing the WIPO.

SSee chapter three of this book.

52 Industry lobbies were the main force behind the negotiation process leading up to the TRIPS Agreement and during the Uruguay Round negotiations. The main industries actively promoted certain categories of IPRs amongst their governments. Since two-thirds of all conducted trade is in the hands of the globally operating multinational companies one can fairly say that multinationals to a large extend rule the world.

53 Information derived from the WIPO website. See <http://www.wipo.int/sme/en/ ip_business/utility_models/utility_models.htm>. 
that are less technologically sophisticated than inventions which require patents. The idea behind utility model protection is to bridge the gap between patent and design protection. in comparison to patents utility model protection is much cheaper and easier to obtain because applications for it need far less stringent criteria. For instance, the registration process is less costly since applications as to substance prior to registration are seldom examined. In most jurisdictions the novelty criteria needs to be fulfilled but the inventive step requirement (or non-obviousness) may be low or absent. It should be noted that there are very few technological inventions in developing countries qualifying as inventions under the patent law. Most utility models are sought for inventions which would not fulfil the criteria for patents. Utility models are not only useful for developing countries but are also particularly relevant for small and medium sized enterprises that have relatively small R\&D capabilities. Some countries allow utility model protection only for certain categories of technological products and exclude processes. A disadvantage of utility models is the shorter term of duration, on average between six and ten years. The R\&D figures show that developing countries hold very few patents filed under the PCT regime, even within their own domestic boundaries, since most of the patents filed belong to foreign companies. " Utility model protection and its potential for developing countries is an area which should be explored more in detail. ${ }^{5}$ Not all countries provide for utility model protection, among the countries that do not provide for utility model protection are the United States, the United Kingdom, Canada and India. ${ }^{57}$

There is little economic research on developing countries (at the country level) that directly links the IPR regime to domestic innovation and socio-economic development. It was common practice in Germany, and the East Asian countries (including China) to use utility model protection (or petty patents). These are characterised by how easy they are to obtain, combined with a lower standard of inventiveness, and by registration rather than examination, and by a shorter protection period. Back in 1891, when this type of protection was

$\because$ See Blakeney 1989, p. 8.

$\because$ See New 2008b.

in Only under certain circumstances is it in the benefit of developing countries to initiate utility model protection. See for an analysis Suthersanen 2006.

5) Litity model protection can be acquired in the following countries and regions: Australia, Argentina, Armenia, Austria, the African Regional Industrial Property Organization (ARIPO), Belarus, Belgium, Brazil, Bulgaria, China, Colombia, Costa Rica, Czech Republic, Denmark, Estonia, Ethiopia, Finland, France, Georgia, Germany, Greece, Guatemala, Hungary, Ireland, Italy, Japan, Kazakhstan, Kenya, Kyrgyzstan, Malaysia, Mexico, Netherlands, the African Intellectual Property Organization (OAPI), Peru, Philippines, Poland, Portugal, Republic of Korea, Republic of Moldova, Russian Federation, Slovakia, Spain, Tajikistan, Trinidad \& Tohago, Turkey, Ukraine, Uruguay and Uzbekistan. See <http://www.wipo.int/ $\mathrm{sme} / \mathrm{en} / \mathrm{ip}$ business/utility_models/where.htm>. 
introduced in Germany it gave three years' protection (renewable for a further three years). By the 1930s, twice as many utility patents as examined patents were granted. ${ }^{58}$ Equally, studies of Japan's patent system in the period 19601993 have suggested that utility models were more important than patents in stimulating productivity growth:

"In Japan, the evidence suggests that a system of "weak" protection based on
utility models and industrial designs facilitated incremental innovation by small
enterprises, and the absorption and diffusion of technology. This was associated,
as in Taiwan and Korea, with an absence of patent protection for chemical and
pharmaceutical products. Japan introduced protection for the latter only in
1976 ".

Spain introduced patent protection for these products even later, in 1992.

In sum utility models, in contrast to patents, protect inventions 1) which are less technologically advanced, 2) which are easy to obtain, in comparison to patents, since the requirements are less stringent, and 3) which have a limited scope and duration. These characteristics make utility models particularly important to developing countries, where inevitably the inventive capacity and activity, will produce inventions which do not contribute much to existing technology. Statistics have shown that in countries that introduced utility model protection, the overwhelming majority of applicants are either nationals or residents." These characteristics mean that utility model protection is particularly suited to developing countries as an incentive to invention.

Just as the relevance of different categories of IPRs differs among countries, so we can also see that there are differences across sectors of industry, which have different levels of R\&D intensity and different rates and types of imnovative activities.

\subsection{Inompontion of Prowisions of Existing Intellectual Property Conoentions}

The IPR standards set by the Paris and Berne Convention formed the basis of the TRIPS negotiation Work Programme." Large parts of the existing intellectual property conventions are incorporated into the TRIPS Agreement. Article 2.1 of the TRIPS Agreement provides that:

5. See UK CIPR 2002, chapter one.

37 See UK CIPR 2002, chapter one, referring to Maskus and McDaniel 1999.

(ii) See Blakeney 1989, p. 8 referring to UNCTAD 1975, para. 40.

in See chapter one of this book for an overview of the key provisions of the PC and the $B C$. 
"In respect of Parts II, III and IV of this Agreement, Members shall comply with Articles 1 through 12, and Article 19, of the Paris Comvention (1967)". IIts paragraph 2 stipulates that] "Nothing in Parts I to IV of this Agreement shall derogate from existing obligations that Members may have to each other under. the Paris Comvention, the Berne Convention, the Rome Convention'2 and the Treaty on Intellectual Property in Respect of Integrated Circuits"."

It follows that Article 2 incorporates several substantive provisions of the Paris Convention as Article 1 through 12 and Article 19 of the Paris Convention are built-in the TRIIS Agreement. ${ }^{\text {th }}$ Also, the provisions 1 until 21 of the Berne Convention and its Appendix have been incorporated into the TRIPS Agreement by virtue of Article 9 TRIPS Agreement. Article 9.1 reads as follow's:

\begin{abstract}
"Mombers shall comply with Articles 1 through 21 of the Berne Convention (1971) and the Appendix thereto. However, Members shall not have rights or obligations under this agreement in respect of the rights conferred under Article bbis of that Convention or of the rights cerived therefrom".
\end{abstract}

Consequently in the field of copyright Members of the WTO are required to comply with the provisions on copyright as set out in the Berne Convention. There is the notable exception of moral rights. Consensus has not been achieved on the moral right provision, as the US is a fervent opponent of this right and lobbied its case well." As a result, article blis on moral rights of the Berne Convention is not integrated into the TRIPS Agreement as follows from its Article 9.1. Nevertheless, moral rights or droit moml, as the French counterpart is called, are recognised in many countries including in the EU.

Article 12 of the Paris Comvention obliges each country of the Paris Union to "establish a special industrial property service and a central office for the communication to the public of patents, utility models, industrial designs and trade marks". Implementing this obligation is particularly cumbersome for developing comtries that do not have the financial means to finance such institution. Further study into the role of patent offices is greatly desired. This study should allow developing countries to learn from the role that patent

12 Rome Convention for the Protection of Performers, Producers of Phonograms and Broadcasting Organisations, 1961. The Convention secures protection in performances of performers, phonograms of producers of phonograms and broadcasts of broadcasting organisations.

1.5 This treaty has not entered into force yet.

on Industrial property is a term used to identify patents, utility models, industrial designs, trademarks, service marks, trade names, indications of source or appellations of origin, and the repression of unfair competition. The term is used to identify: industrial property rights. In contrast to literary and artistic works which traditionally belong to intellectual property rights. Currently, these groups of rights are collectively known as intellectual property rights.

ise Stewart 1993, p. 2288. 
offices play in other countries and avoid the shortcomings. Ideally, intellectual property offices in developing countries should not only register and examine patent applications but also advice citizens on basic principles and concepts of intellectual property and provide valuable information on the role that IPR can play in stimulating local creative and inmovative processes.

The protection granted under the Paris Convention to utility models (also referred to as petty patents or utility innovations) and unfair competition protection is extended to the TRIPS Agreement by means of its Article 2.

\subsection{Principle of National Treatment}

Article 3 lays down the rules on the national treatment principle:

1. Each Member shall accord to the nationals of other Members treatment no less favourable than that it accords to its own nationals with regard to the protection (footnote 3) of intellectual property, subject to the exceptions already provided in, respectively, the Paris Convention (1967), the Berne Convention (1971), the Rome Convention or the Treaty on Intellectual Property in Respect of Integrated Circuits. In respect of performers, producers of phonograns and broadcasting organizations, this obligation only applies in respect of the rights provided under this Agreement. Any Member availing itself of the possibilities provided in Article 6 of the Berne Comvention (1971) or paragraph 1(b) of Article 16 of the Rome Convention shall make a notification as foreseen in those provisions to the Council for TRIPS.

2. Members may avail themselves of the exceptions permitted under paragraph 1 in relation to judicial and administrative procedures, including the designation of an address for service or the appointment of an agent within the jurisdiction of a Member, only where such exceptions are necessary to secure compliance with laws and regulations which are not inconsistent with the provisions of this Agreement and where such practices are not applied in a manner which would constitute a disguised restriction on trade.

In footnote to this provision:

Footnote 3: For the purposes of Articles 3 and 4, "protection" shall include matters affecting the availability, acquisition, scope, maintenance and enforcement of intellectual property rights as well as those matters affecting the use of intellectual property rights specifically addressed in this Agreement.

The principle of national treatment, as set out in Article 3, implies that each member should treat nationals of their own and of other WTO countries alike, providing them with the same treatment. The national treatment principle provictes a means of ensuring 1) that intellectual property rights of foreigners will be protected within foreign countries to the level of domestic IPR legisla- 
tion (which might apply different rules on intellectual property) and 2) that foreigners will not be discriminated against.tit

The reference to the wording "protection of intellectual property" stipulates that national treatment applies to all categories of intellectual property, subject to the TRIPS Agreement, including the provisions of the existing IPR conventions incorporated into the TRIPS Agreement ${ }^{1-}$. The principle is bolstered by Article 1 of the TRIIS Agreement which states that the TRIPS Agreement sets out minimum standards of protection on the creation and enforcement of intellectual property rights with which all Members need to comply and implement into their domestic legislation. As a result of the adoption of TRIPS, on the condition that the implementation process is carried out successfully, the level of IPR is increased on the domestic level which assures that rightholders can secure their rights overseas at least to the level guaranteed by the Agreement. The national treatment principle replaces the notion of formal reciprocity."s

Different legal jurisdictions in various countries result in different policies and rules on intellectual property, although serving similar economic functions. If goods are exported to other countries, the adequate protection of one's intellectual property depends on the willingness of the country receiving the goods (bearing the intellectual property right) to recognise and enforce the intellectual property rights of foreigners. The intellectual property framework does, however, hold some shared concepts and principles that are of key importance and are applied in most jurisdictions, such as the principle of national treatment and the principle of most favoured national treatment. These basic principles of the international IPR system, unlike customary international law or general principles of law are grounded in treaty law and are part of positive law.".) It is common that basic principles evolve into customary international law; however, this has not happened yet. ${ }^{71}$ The principle of national treatment was invented to facilitate trade without potential loss of value due to ignorance about intellectual property overseas.

The principle of national treatment is not new as it is embodied in the first endeavours to harmonise intellectual property internationally, e.g. the Paris

See Evans 1996, p. 149.

See definition of intellectual property under Art. 1.2 of the TRIPS Agreement.

See chapter one of this book for more elaboration on the history of the principle of national treatment.

See Abbott, Cottier and Gurry 1999, p. 587.

Although, the principles might be called (quasi-) universal principles of the international IPRs system. See Abbott, Cottier and Gurry 1999, p. 587. 
Convention and the Berne Convention.71 The principle is mentioned in the predecessor to the WTO, the GATT, concerning international tracte in goods. The principle has traditionally been applied in the context of intellectual property. In fact, it is one of the oldest principles in international trade law. It was at the heart of (bilateral) agreements signed in the nineteenth century. However, during the last 50 years the principle has increased in importance. Due to the internationalisation of trade (partly because the use of non-tariff barriers has increased) and the growth in trade of high-technology goods (strongly depending on IP rights), the principle has become crucial in enabling adequate harmonisation of intellectual property laws.

What is new for both the principle of national treatment and the most-favoured nation (MFN) is that by their inclusion in the TRIPS Agreement they can now be compelled (made effective) by means of the dispute settlement system and by their applicability to a large number of countries. Some countries with high piracy rates, like India, Taiwan, South Korea and Singapore, were not members to the WIPO administered treaties. But even countries that were parties, for example China, did not observe these principles. Foremost, the enforcement of these principles was and still is difficult to achieve because of the lack of effective enforcement mechanisms.

The TRIPS Agreement enshrined the principle of national treatment in Article 3 and so far its description of the principle is the most comprehensive. ${ }^{2}$ However, the TRIPS Agreement's definition of national treatment resembles the Article 11I(4) GATT definition as both Agreements speak of "treatment no less favourable". They differ, however, profoundly on who is the beneficiary of protection: the TRIPS Agreement refers to "the nationals of other Members", whereas GATT speaks of "the products of the territory of any contracting party imported into the territory of any other contracting party".

Exceptions to the principle are limited to the exceptions provided for under the Paris Convention, the Berne Convention, the Rome Convention and the

i1 Arts. 2 and 3 of the Paris Convention referred to the principle of national treatment and from then onwards it has been part of all multilateral agreements involving intellectual property.

72 Before the TRIPS Agreement was concluded, the GATT more or less filled the gap of not having adequate international intellectual property protection, it contains the following statement on national treatment Art. III(4) GATT: The products of the territory of any contracting party imported into the territory of any other contracting party shall be accorded treatment no less favourable than that accorded to like products of national origin in respect of all laws, regulations and requirements affecting their internal sale, offering for sale, purchase, transportation, distribution or use. However, Art. XX (d) of the GATT limited the general exception in respect of patents, trade marks and copyrights. See Evans 1996, p. 155. 
Treaty on Intellectual Property in Respect of Integrated Circuits following Article 3.1. A notable exception is the reservation made for

\begin{abstract}
"The Provisions of the laws of each of the countries of the Union relating to judicial and administrative procedure and to jurisdiction, and to the designation of an address for service or the appointment of an agent, which may be required by the laws on industrial property".;
\end{abstract}

This exception is narrowed down in the TRIPS Agreement by only permitting exceptions relating to judicial and administrative procedures where such exceptions are necessary to secure compliance with laws and regulations that are not inconsistent with the provisions of the TRIPS Agreement, and where these practices do not constitute a restriction on trade in any possible way.

An example of an exception provided for in the Berne Convention addresses the duration of copyright. Article 12 of the TRIPS Agreement sets a minimum copyright duration of 50 years after the death of the author. However, in some jurisdictions, notably the EU and the US the term is stretched to 70 years. it if the principle of national treatment were applicable, then nationals of other countries would also benefit from the longer term of protection as the principle of national treatment would not allow the country with the longer term to accord the shorter term only to other Member's nationals. However, the Berne Convention stipulates in its Article 7 that foreigners need only be given their homc coumtry's copyright duration. In case both countries are parties to the Berne Convention, then according to Article 3 TRIPS Agreement, the provision laid down in Article 7 Berne Convention applies. In the case of copyright law, policies of reciprocity have prevailed over the principle of national treatment.

The Paris Convention adopts in Article 3 the concept of "equal treatment", whereas the TRIPS Agreement talks about "treatment no less favourable". The wording is different but it is questionable whether the substance of this na-

3 See Art. 3.2 of the Paris Convention.

it Council Directive 93/98/EFC of 29 October 1993 harmonising the term of protection of copyright and certain related rights, OJ No. L290 of 24 November 1993. Published online at: <http://eur-lex.europa.eu/LexUriServ/LexUriServ'do?uri=CEL_EX:31993 Lo098:EN:HTML> and Supreme Court Case Eric Eldred, ef al., petitioners v. Jolm D. Astcroft, Attomey Gencral, Supreme Cont, 537 U S, 2003 See <http:/www.les sig.org/blog/archives/01-6180.pdf> and US official copyright website: <http:// www.copyright.gov/circs/circl.html\#hles. See also Section 1.1 of chapter one of this book.

-5 Reciprocity is a legal concept underlying that rights and obligations on a certain topic be formally or informally equivalent. The principle of national treatment does not require formal or informal equivalence. See Abbott, Cottier and Curry 1999, p. 590 . 
tional treatment obligation differs between the two Agreements. ${ }^{70}$ Under WTO standards, national treatment does not automatically refer to equal treatment of a Member's own nationals. In theory the WTO notion of national treatment, like these of the GATT and GATS Agreement, grants some privileges to foreign nationals. In practice, however, it is unlikely that countries will treat foreigners in a more favourable manner than their own nationals. The Paris Convention seems to exclucte this possibility because it refers to the requirement of "equal treatment". Nevertheless, the Paris Convention points to equal treatment of foreigners and this does not automatically entail that own nationals have to be treated the same. 7

Since, the harmonisation of rules is a long and difficult process; the national treatment principle can serve as a substitute to international harmonisation in the meantime. Through this principle Members can benefit from "improved standards in municipal law or regional law introduced mainly for the welfare (and at the request of) the domestic right holders". "7x According to Evans, the principle of national treatment is the "linchpin of the TRIPS Agreement, providing the means of raising the level of international protection" amongst the growing number of Members. ${ }^{79}$ In this increasingly "borderless" time derived from the increased use of non-tariff barriers, ${ }^{, 11}$ increased trade in high technology goods and the globalisation and "multinationalisation" 81 of the trade industry - manufacturers and traders wish to be able to control their products in overseas markets. However, IPRs are territorial rights restricting the impact of local laws to the boundaries of the specific country. As a consequence the IPR right holder can not secure his rights outside the borders of his territory which makes trading goods risky. The principle of national treatment can be of assistance in this regard. For instance, the trader can make himself familiar with local IPR traditions and carefully select the country where he wants to continue his business activities as the principle of national treatment should protect his rights and not discriminate him against nationals. However, even with the principle in operation, the problem remains that if the level of local IPR protection is low, national treatment is not going to protect your (high technology) goods nor provide for more legal certainty in business.

See Abboll, Cottier and Gurry 1999, p. 590.

See Abbott, Cottier and Gurry 1999, p. 590.

See Abbott, Cottier and Gurry 1999, p. 588.

See Evans 1996, p. 149

Non-tariff barriers relate to health and safety measures in order to protect the consumer.

In the sense that conducting business has increasingly become transnational and that trade is dominated by these multinationals that set the standard in production and play a large role in international policy making. 


\subsubsection{WTO Case Law on Principle of National Treatment}

The principle of National treatment was addressed by the WTO Panel in the

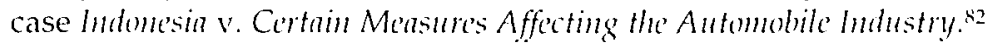

However, Article 3 was not the main issue in this case, as focus was on some GAT"l and some subsidies and countervailing (SCM) provisions. Indonesia had set up the "1996 National Car Program" in order to boost its national car industry. This "1996 National Car Program" contains three measures. The first measure gives Indonesian motor vehicle companies the status of pioneer (i.e. National Car company) if they meet specific requirements on ownership of facilities, use of trademarks, and techmology. These conditions require that the motor vehicles: 1) be produced domestically at production facilities owned by Indonesian enterprises; 2) use a brand name owned by lndonesian citizens; 3 ) be developed with technology, construction, design and engineering based on national capability. The benefits provided are exemption from luxury tax on sales of National Cars, and exemption from import duties on parts and components. ${ }^{83}$ Furthermore, the second measure "The June 1996 Program" guarantees that cars manufactured in a foreign country by Indonesian nationals and which fulfil the local content requirements have the same status as qualifying cars produced in Indonesia i.e. exempt from import duties and luxury tax. ${ }^{\text {it }}$ The US argued that Indonesia "1996 National Car Program" was in violation of its obligations under Article 3 of the TRIPS Agreement. The US is of the opinion that the National Car Program has provisions that discriminate against nationals of other WTO Members in respect to the acquisition and maintenance of trademarks, and in relation to the use of trademarks in Article $20 .{ }^{55}$ Article 20 of the TRIPS Agreement stipulates that the

"use of a trademark in the course of trade shall not be unjustifiably encumbered by special requirements, such as use with another trademark, use in a special form or use in a manner detrimental to is capability to distinguish the goods or services of one undertaking from those other undertakings".

The arguments made by the US were rejected by the Panel. It held that no evidence had been put forward to show that the treatment given to foreign nationals regarding the acquisition, maintenance or use of trademarks did not

:2 See Panel Report Indonesia - Certain Mensures Affecting the Aufomblile Intustry, WT/DS54, 55, 59, 64/R, 23 July 1998.

s3 See para. 2.16 of the Intonesia - Certuin Mensures Affecting the Automotile Industry (PR).

s. See para. 2.17 of the Intonesia - Cortain Measures Affecting the Automobile Intustry (PR).

sis See para. 3.4 (f) of the Indonesio - Certain Mensures Affecting the Automobile Intustry (PIR). 
meet the requirements of Article $3 .{ }^{86}$ Besides, the Panel was not convinced that the operation of the subsidy program would fall under the "requirements" mentioned in Article 20 of the TRIPS Agreement because companies that participate in the subsidy program do so on a voluntary basis.

Another argument raised by the US addressed Article 65.5 of the TRIPS Agreement entailing that changes in domestic law's, regulation and practice during the transition period "do not result in a lesser degree of consistency with the provisions of this Agreement". The US argued that Indonesia is in violation of its obligations deriving from Article 65.5 because the provisions of the National Car Program (issued during Indonesia's transition period under the TRIPS Agreement) put special requirements on nationals of other WTO Members regarding use of trademarks which are inconsistent with the provisions of Article 20. ${ }^{.7}$ This argument was rejected for the same reasons. ${ }^{\text {si }}$

More on the principle of national treatment, its history and applicability in chapter one, section 1.2 of this book.

\subsection{Principle of Most Facored-Nation Treatment}

Article 4 on the Most-Favored-Nation Treatment principle states that:

"With regard to the protection of intellectual property, any advantage, favour, privilege or immunity granted by a Member to the nationals of any other country shall be accorded immediately and unconditionally to the nationals of all other Members. Exempted from this obligation are any advantage, favour, privilege or immunity accorded by a Member:

(a) deriving from international agreenents on judicial assistance or law enforcement of a general nature and not particularly confined to the protection of intellectual property;

(b) granted in accordance with the provisions of the Berne Convention (1971) or the Rome Convention authorizing that the treatment accorded be a function not of national treatment but of the treatment accorded in another country;

(c) in respect of the rights of performers, producers of phonograms and broadcasting organizations not provided under this Agreement;

(d) deriving from international agreements related to the protection of intellectual property which entered into force prior to the entry into force of the WTO Agreement, provided that such agreements are notified to the Council for TRIPS and do not constitute an arbitrary or unjustifiable discrimination against nationals of other Members".

sut See para. $9 \mathrm{~J}$ of the Indonesin - Certain Mensures Affecting the Automobile Industry (PR).

si See para. 3.t(f) of the Indonesia - Cirtain Mersures Affecting the Automobile industry (PR).

ss See para. 9 J of the Intonesin - Certain Mensures Affecting line Automblile Industry (PR). 
The first paragraph of Article 4 sets out that:

"With regard to the protection of intellectual property, any advantage, favour, privilege or immunity granted by a Member to the nationals of any other country shall be accorded immediately and unconditionally to the nationals of all other Members".

The Most-Favoured-Nation principle was a new addition within the intellectual property framework, but it was not a new concept in multilateral trade architecture. The Most-Favoured-Nation Treatment principle stipulates that a benefit (advantage) given to another country (i.e. even non WTO members) shall be granted to the nationals of all members. This implies that all countries have to be approached in the same way and no preferences can be made which are not extended to other Members as well (i.e. non-discrimination approach). Remarkably, this is one of the few principles which directly gives rights to nationals. Most of these "advantages" are granted through bilateral and regional trade agreements which as a result of this Article are "multilateralised". There are a number of exceptions to this principle as set out in paragraphs a, b, c and d of Article 4. Paragraph d assures that exempted from this principal are benefits derived from "international agreements related to the protection of intellectual property which entered into force prior to the entry into force of the WTO Agreement" on the condition that these intermational agreements were notified to the TRIPS Council. An example of a multilateral agreement that is excluded from the principle of national treatment and MFN is the Patent Cooperation Treaty (PCI). ${ }^{s 9}$ This Treaty does not harmonise the granting of international patents but endeavours to reduce costs and accelerate the patent application process by allowing multi-country applications. In order for a country to benefit from this Treaty the country has to be a party to the PCT to ensure that its patent office participates in the PCT system. ${ }^{911}$

Other exceptions to these principles relate to judicial assistance and law enforcement agreements following Article 4(a). The rationale behind this exception is the bilateral nature of judicial assistance agreements, which are not defined to deal with intellectual property rights in particular.

The principle of MFN intends to ensure uniformity within the multilateral trade arena. However, it is questionable whether this principle, which has

sir The Patent Cooperation Treaty (PCT), signed in 1970 under the aegis of the WIPO, facilitates the international filing of patents on the basis of the Paris Convention and the rules on priority described therein. The PCT provides for an intemational search report ( 8 months) and a preliminary examination (12 months), the search is carried out by certain patent offices.

(ii) See Gervais 2003, p. 111. 
worked well in avoiding discrimination in tariffs in the GATT framework, is also suitable for intellectual property legal systems."

The principle is not applicable to multilateral agreements which are signed and administered by the WIPO as explicitly declared in Article 5 of the TRIPS Agreement. Article 5 sets out that obligations derived from the principles of national treatment and MFN are not applicable to "procedures provided in multilateral agreements concluded under the auspices of WIPO relating to the acquisition or maintenance of intellectual property rights".

The principle also implies that, if countries are "forced" into signing TRIPS plus bilateral and regional trade agreements, the rights and obligations signed under these agreements need to be extended to all other countries, implying that these rules reach beyond the parties round the negotiation table. Hence, if rules are adopted on data exclusivity, detrimental to the interests of developing countries, these rights need also to be granted to other foreign countries. This is particularly dangerous for the interests of developing countries that already face difficulties in adequately protecting and implementing IPR obligations under the TRIPS Agreement.

\title{
2.7. Doctrine of Exhumstion
}

Article 6 TRIPS Agreement on exhaustion provides that:

\begin{abstract}
"for the purposes of dispute settlement under this Agreement, subject to the provisions of Articles 3 and 4 nothing in this Agreement shall be used to address the issue of the exhaustion of intellectual property rights".
\end{abstract}

TRIPS leaves it open to the WTO members to decide on what exhaustion rule to adopt on the condition that the rule has to be applied on a non-discriminatory basis (i.e. both national treatment and most-favoured-nation treatment is applicable).

A special facet of IPR policy is the extent to which right holders retain control over the distribution of protected goods once they have been placed on a national market for initial sale. In circumstances where such goods vary in price between countries, parallel traders, could profit by buying the goods in the cheaper location and selling them in the dearer location. An interesting and central question is whether parallel traders should be allowed to take advantage of this business opportunity. The legality of parallel importation is

"It is argued that in the field of agriculture developing countries benefit from the right to Most-Favoured-Nation treatment, because through this right it comes by more favourable terms than are possible through bilateral negotiations. See Sharma 1994, p. 8 . 
determined by the "exhaustion" rule relating to patents, copyrights, and trademarks. Rules on IPR exhaustion determine the extent to which firms can segment national markets.

The system of international exhaustion determines that once a product has been launched on the market in any location with the consent of the right holder, the rights - in respect to that product - are exhausted, i.e. firms lose control over further distribution, leaving markets open to parallel importation from foreign territories." Whereas, under a rule of national exhaustion, after the first sale, firms lose the right to prevent further resale of their goods within a country's territory (the domestic market) but are allowed to prevent parallel importation of their goods from outside the territory, i.e. the right-holder is still authorised to arrange resale or distribution of the goods outside the country of first sale.

The desirability of allowing parallel importation depends, among other things, on the causes of parallel trade:

"One possibility is that IPRs confer market power to firms, which allows them to
set prices according to demand elasticities in national markets. The resulting
price differences create incentives for arbitrage by parallel traders. Another
explanation has centered on the possibility that parallel trades buy goods
cheaply in the wholesale market and free ride on the promotional and sales
support activities of retailers. Empirical research is necessary to determine
whether and for whom the permissibility of parallel trade is welfare
chlancing"."3

It is hard to reconcile conflicting viewpoints on the issue of exhaustion. Switzerland and the US are supporters of a limited scope of exhaustion (i.e. national exhaustion) whereas Australia, Brazil, Hong Kong, India and New Zealand are advocators of an international exhaustion regime. The EC applies a rule of regional exhaustion implying that after first sale traders lose the right to prevent further resale but only in the EU region, outside the territory of the EU it is still possible for traders to regain control over distribution and resale of the goods.

Article 6 explicitly leaves the issue of international exhaustion open, implying that each country is free to decide the issue of international exhaustion under domestic law. This solution is remarkable since in an agreement favouring free trade one would expect a rule on this issue.

"2 See Fink and Maskus 2005, p. 4.

$" 1.3$ See Fink and Maskus 2005, p. 5. 
To emphasise that this issue is left to the discretion of individual countries, Article 6 stipulates that the issue of the exhaustion of intellectual property rights is excluded from dispute settlement, meaning that countries cannot raise this issue in front of the Dispute Settlement Body.

\subsection{Key Objectioe and Principle}

Article 7 sets out the objectives underlying the TRIPS Agreement:

"The protection and enforcement of intellectual property rights should contrib-
wte to the promotion of technological imnovation and to the transfer and
dissemination of technology, to the mutual advantage of producers and users of
technological knowledge and in a mamner conducive to social and economic
welfare, and to a balance of rights and obligations".

This objective, initiated in draft proposals by developing countries, could be used to serve the interests of developing countries, and will hopefully be frequently invoked in dispute settlement cases where provisions enforcing or protecting intellectual property rights to not contribute to the promotion of technological innovation and/or transfer or dissemination of technology. The importance of this provision is not to be underestimated since it is placed in the Agreement text itself and not just in the preamble. Nonetheless, the objective contains a "should" requirement, instead of a "shall" requirement to strengthen it.

The IPR system has been criticised for favouring mainly big multinational players, such as Bill Gates' Microsoft and that the IP infrastructure needs reframing for a well functioning IP system for the mutual benefit of both right holders and users.

Article 7 stipulates that the protection and enforcement of intellectual property rules should be conducive to socio-economic welfare and to a balance of rights and obligations. An infringement of this can be the right holder exercising his rights but not paying attention to his obligations, i.e. he fails to participate in socio-economic development and this subsequently could justify exceptions to his exclusive rights, for instance the use of compulsory licensing." Developing country representatives during the Doha Round negotiation hinted at the interests of developing countries with regard to patent protection for pharmaceuticals. ${ }^{15}$

4.4 See Gervais 2003, p. 116.

"Various academics supported the developing countries in this reasoning, e.g. Correa 1991, p. 56. 
Article 8 stipulates the principles underlying the TRIPS Agreement:

"1. Members may, in formulating or amending their law's and regulations, adopt measures necessary to protect public heolth and mutrition, and to promote the public interest in sectors of itital importance to their socio-conomic and techological derelopment, provided that such mensures are consistent with the provisions of this Agreement.

2. Appropriate measures, prosided that they are comsistent with the provisions of this Agreement, may be needed to prevent the abuse of intellectual property rights by right holders or the resort to practices which unreasonably restrain trade or aiversely affect the international transfer of technology". (emphasis added FC)

The effect of this provision is however diminished by the second part which requires that such measures need to be "consistent with the provisions of the TRIPS Agreement". This provision raises a number of questions such as what constitutes "appropriate measures".

The discemed tensions between Article 8 of the TRIPS Agreement with other provisions can be paradoxical. On the one hand Article 8 provides flexibilities such as the freedom it gives to WTO members to adopt measures to protect public health and the promotion of their public interest in sectors of importance to their development and appropriate measures to prevent abuse of intellectual property. On the other hand it also allows provisions like Article 27 that require that pharmaceutical products should be subject to patent protection.

For a more elaborate discussion on Articles 7 and 8 see chapter five of this book.

\section{Slbstantive intellectlal. Promerty Rights}

\subsection{Limitations and Exceptions to TRIPS Rights}

The general limitations and exceptions provision (copy of the Berne three step test) is fixed in Article 13 of TRIPS. WTO members are only allowed to curtail:

"limitations and exceptions to exclusive rights to certain specinl cases which do not conflict with a nomal exploitation of the work and do not wherasonably prejulice the legitimate interests of the right holder". (emphasis added FC)

Article 30 TRIPS Agreement provides limitations and exceptions in relation to patents:

"Members may provide limited exceptions to the exclusive rights conferred by a patent, provided that such exceptions do not umerasonably comflict with a normal exploitation of the patent and do not umensomably prejudice the legitimate interests of the patent owner, taking account of the legitimate interests of third parties". 
Questions remain as to what constitutes limited exceptions to the exclusive rights of the patent owner? What is meant by exceptions do not unreasonably conflict with a normal exploitation of the patent? What is meant by exceptions do not unreasonably prejudice the legitimate interests of the patent owner?

Deliberations on exceptions and limitations are ongoing, especially in relation to copyright and patents. In relation to copyright a WIPO Committee, titled Standing Committee on Copyright and Related Rights (SCCR) meets regularly, including in its plan of action is a debate on establishing and identifying multilateral rules (e.g. a recommendation adopted by the WIPO General Assembly) limitations and exceptions to copyright. ${ }^{\%}$ Countries vary consider ably on what limitations and exceptions to copyright are permitted within their various laws. Preserving the fundamental notion of balance between the public interest and the interests of property rights holders was particularly important for developing countries. Clearly defined exceptions and limitations on copyright protection are important for improved access to knowledge in particular for libraries and educational institutions and for people with disabilities such as the visually impaired. ${ }^{97}$

\subsection{Patentability Requirentents}

Section 5 of the TRIPS Agreement addresses patent protection. Negotiations on what could qualify as patentable subject matter and exemptions thereto have been subject of long and passionate debates. Article 27 of the TRIPS Agreement defines the substantive subject matter of patentability. Article 27.1 stipulates that:

\footnotetext{
"subject to the provisions of paragraphs 2 and 3 , patents shall be available for any inventions, whether products or processes, in all fields of technology, provided that they are new, involve an inventive step and are capable of industrial application".
}

In footnote it is explained that the terms "inventive step" and "capable of industrial application' are interchangeable with "non-obvious" and "useful" respectively. The latter two refer to the terminology used in the US. The EC uses the TRIPS terminology.

Article 27.1 sets out that in principle all inventions are patentable if they at least fulfil the basic three requirements: novelty, involve an inventive step and be suitable for industrial applicability. In addition the invention needs to be patentable subject matter in that the invention is permitted under Article 27.2.

the Seridges Weekly Trade News Digest 2008c.

" See Hugenholtz and Okediji 2008.

"s See Art. 27.1 of the TRIPS Agreement. 
The exemptions to patentability are laid down in Article 27.2, which provides that Members:

\begin{abstract}
"Members may exclude from patentability inventions, the prevention within their territory of the commercial exploitation of which is necessary to protect ordre public or morality, including to protect human, animal or plant life or health or to avoid serious prejudice to the enviromment, provided that such exclusion is not made merely because the exploitation is prohibited by their law"."
\end{abstract}

From the wording of the paragraph it follows that Members may exclude from patentability (at their own discretion), within their own jurisdiction, inventions from patentability if they go against morally accepted considerations. Such exclusions are mainly seen as a victory for the EC, Japan and the developing countries' who had asked for exclusions on "ordre public and morality". Of huge controversy were the discussions as to whether grant patents for life forms should be permitted and whether stem cell research should be allowed. Prudence is shown in the last bit of this paragraph in which it states that the exclusions cannot merely be based on prohibitions in domestic law. This will outlaw exclusions existing in national legal systems which have not been based upon the exclusions mentioned in Article 27.2.

Article 27.1 (last paragraph) continues that:

"Is]ubject to paragraph 4 of Article 65, paragraph 8 of Article 70 and paragraph 3 of this Article, patents shall be available and patent rights enjoyable without discrimination as to the place of incention, the fich of fedmology and whether products are inported or locally produced". "le: (emphasis added FC)

This implies that the grant of patent protection may not be based on the type of technology involved, meaning that inventions in the bio technology or chemical (including pharmaceutical substances) section should be granted patents. Article 27 is generally regarded as one of the major concessions given by the developing country members. Developing country members agreed to adopt these laws which were in fact diametrically opposed to their existing legislation at the time of entry into the negotiations and presumably counter to their socio-economic development needs. To meet the wishes of developing countries, the article makes reference to the transition periods arranged for them, in particular Articles 65.4 and 70.8. ${ }^{\text {in: }}$ The introduction of patent protection for pharmaceuticals involves tremendous reform in developing countries. Nevertheless, the lack of patent protection for pharmaceuticals was not in the

we See Art. 27.2 of the TRIPS Agreement.

100 See Art. 27.1 of the TRIPS Agreement.

101 For an elaborate discussion on the use of transition periods, see section five of this chapter. 
interests of the countries (mostly developed country members) in favour of a stronger intellectual property regime. It is of note that at the start of the negotiations on the Agreement, approximately 50 countries did not think pharmaceuticals were patentable subject-matter and subsequently did not provide patent protections for them. Developed countries such as Spain and Switzerland introduced patent protection for pharmaceuticals only in 1992.

Article 27.3(a) of the TRIPS Agreement continues the list of exceptions to patentability and stipulates that members may also exclude "diagnostic, therapeutic and surgical methods for the treatment of humans or animals". Next, Article 27.3(b) outlines that members may exclude from patentability

\begin{abstract}
"plants or animals other than non-biological and microbiological processes. However, Members shall provide for the protection of plant varieties either by patents or by an effective sui generis system or by any combination thereof. The provisions of this subparagraph shall be reviewed four years after the date of entry into force of the WTO Agreement". 11:
\end{abstract}

Hence, Members do not need to provide patent protection for plants and animals, with the notable exception of micro-organisms (which are living in nature occurring things) which can not be excluded. Essentially biological processes for the production of plants and animals are exempted from patent protection but non-biological and microbiological processes are not. The European Directive on Biotechnology also requires patent protection for microbiological processes. ${ }^{113}$ But, the exception to the exception for non-biological processes is a new notion. It is questionable how a certain process can produce a plant or an animal, which is not totally or in part biological? ${ }^{114}$

Notably, prior to the TRIPS Agreement plant varieties were not patentable in the EU, whereas this was already possible in the US and Japan.

Article 27.3(b) is subject to review and most proposals for revision have focused on warranting that naturally found elements are not patentable. Proposals from the developing country Members demand recognition for the protection of traditional knowledge of their indigenous communities. 1115 Recently the EC has given up its strict prohibition of patenting life forms as in many EC countries the laws are looser. For instance, in Germany and in the

112 See Art. 27.3(b) of the TRIPS Agreement.

1113. See Art. 4.3 Directive 98/44/EC of the European Parliament and of the Council of 6 July 1998 on the legal protection of biotechnological inventions, OJ (L/213), 30/07/1998, P. 0013-0021.

1.4 See Verma 2004.

165 See chapter three of this book for a more claborate discussion. 
UK stem cell research is allowed to research cancer treatments. Recently also Brazil has given its approval to research involving embryonic stem cells. 10h

Criticism has been raised on the indistinct content of the provision; the criteria, which should determine what, can and what cannot be excluded, are unclear. Due to the controversy of the subject matters involved, the wording of the last subparagraph is rather blurred. This explains why differences in national systems still occur.

Further review will most likely also touch upon the fact that Article $27.3(\mathrm{~b})$ talks about the possibility to exempt plants and animals from patent protection but no further subdivisions have been made, such as varieties or species. "int

During the Uruguay Round; it became clear that introduction of living matter into the IPR system is an issue that will not be solved easily. As a compromise it was agreed to review Article 27.3(b) four years after it became part of the WTO Agreement. This is remarkable; it is the only provision which is subject to review at such an early date (even before the transition period of the developing countries has lapsed). But no real progress on revision has so far been made. On the contrary, it is argued to wait with review in order for the developing country Members to establish the prerequisites of the implementation of this provision.

Article 27 of the TRIPS Agreement has been criticised in the Indigenous Peoples' Seattle Declaration for facilitating bio piracy. ${ }^{108}$ In this Declaration the TRIPS Agreement is attacked for allowing the patenting of life-forms and artificially distinguishes between plants, animals, and micro-organisms. Furthermore, the distinction between "essentially biological" and "nonbiological" and "microbiological" processes is criticised for being erroneous. It

Whe The Brazilian Biosafety Law (Law 11.105/05) of 2005 contains an article allowing the use in scientific research and therapy of embryonic stem cells obtained from human embryos produced through in vitro fertilisation and frozen for more than three years. However this provision was challenged by the former Attorney General for being in breach of the right to life of the embryo. However the Brazilian Supreme Court ruled approved research involving embryonic stem cells. In Brazil, the stem cell cannot be patented, as Arts. 10 and 18 from the Industrial Property Law (Law. $9.279 / 06)$ state that the country does not recognise patents on life. However, Brazil accepts patents on processes for obtaining stem colls and other things such as proliferation, differentiation, and patient treatment, with the patent examination authority (INPI) requiring novelty, inventive step, industrial application and other tests. See Saez 2008.

107 See Correa 1994a.

Ins Indigenous Peoples' Seattle Declaration, submitted on the Third Ministerial Meeting of the WTO, November 30-December 3, 1999. The perseverance and unity of the Developing Countries led to the failure of this Ministerial Mecting. 
also sets out that all life-forms and life-creating processes are sacred and should not become the subject of private property ownership. Furthermore, the prohibition of the patenting of natural processes is advocated. Moreover, the IPR system is viewed as being based on western values and principles and unsuitable for the wishes and interests of indigenous communities for which alternative forms of protection are deemed necessary. Suggestions for the review process of the TRIPS Agreement have been made. It is proposed that the patenting life-forms should be abolished, be it micro-organisms, plants or animals, including all their parts, whether they are genes, gene sequences, cells, cell lines, proteins, or seeds. Alternative forms of protection should protect the knowledge, innovations and practices in agriculture, health care, and conservation of biodiversity. These should also build upon indigenous methods and customary laws protecting knowledge, heritage and biological resources in accordance with the CBD, in particular Articles 8(j), 10(c), 17(2) and $18(4)$ of the $C B D$ and the relevant provisions provided for in the International Undertaking on Plant Genetic Resources. In addition farmers' rights ought to be protected and prior informed consent should always be sought before the use of the genetic material. ${ }^{109}$ The Declaration ends with the belief that the global, export-oriented development model which is active now should be transformed into a model taking into account, justice, equity and sustainability, through the sustainable lifestyles, and cultures, traditional knowledge, cosmologies, spirituality, values of collectivity, reciprocity, respect

10 An interview with VEDCO Uganda highlighted the importance the substantive farmers in Uganda attach to farmers rights. Mrs. Agnes Kabaiky a indicated that the importance of safeguarding farmers rights to harvest, save, store, reuse, exchange and replant seeds without restrictions and at the same time protect local seed varicties that are being threatened with extinction. 1) In Africa "seeds are perceived as a gift of nature of the past generation and diverse cultures. As such it is our inherent duty and responsibility to protect them and to pass them on to the future generations; 2) Seeds have been a community resource that has always been shared among the communities and it is a component of food security in most African countries"; 3) The free exchange from seed among farmers has been the basis for maintaining diversity as well as food security; 4) This freedom goes beyond the mere exchange of seed: it also involves the sharing and exchange of ideas and knowledge of cultural and heritage. Interview conducted with Interview conducted with Mrs Agnes Kabaikya (Kirabo), Communications and advocacy officer Volunteer Efforts for Development Concerns (VEDCO). VEDCO is an indigenous non governmental organisation established in 1986 in response to the challenges of poverty that resulted from the social and economic disruptions caused by the military conflicts of 1980-1986 in Luweero - Uganda. It addresses the low levels of food security, agricultural productivity and low incomes among rural farmers. It strives to empower farmers and to make their voices heard in policy processes on issues that affect their agricultural productivity and marketing. Interview conducted by the author with Mrs Agnes Kabaikya (Kirabo), VEDCO on 25 July 2007 in Kampala, Uganda. 
and reverence for Mother Earth. "10 Thus in sum indigenous people are anxious to receive intemational recognised protection for their biological diversity and cultural heritage:

\begin{abstract}
"Seed is a gift of nature and a source of livelihood. Seeds are very critical farm inputs in the agricultural sector. However, new property rights and technologies theaten the freedom of seeds and that of farmers. In addition, the rapid extinction of diverse crops and crop varieties of non-renewable seeds threatens the future of seeds". 111
\end{abstract}

This view is supported by Khor ${ }^{112}$ who also demands clarification for the distinctions made in Article 27.3(b) between plants and animals and microorganisms and between biological and microbiological processes and for the seeming contradiction to be resolved. In his opinion it should be clarified that all naturally occurring living organisms are not patentable. See for a more elaborate discussion chapter three of this book.

The TRIPS Agreement states that all WTO member countries must protect plant varieties either by patents, or by an effective sui goneris system or a combination. The limits for a sui generis system and the meaning of an "effective" sui g'neris system have not been explicitly defined. UPOV has advocated that the most effective way to comply with the provision of an effective sui generis system is to follow the model of the UPOV Convention. ${ }^{113}$ The objective of the Convention is the protection of new varieties of plants by an intellectual property right. UPOV was established by the International Convention for the Protection of New Varieties of Plants. The Convention was adopted in Paris in 1961 and it was revised in 1972, 1978 and 1991. The 1991 UPOV Act has been subject to criticism. There are crucial differences between the 1978 and the 1991 Acts of UPOV with regard to coverage, period, scope and exemptions. For instance, the 1978 Act covers plant varieties of nationally

111 See Indigenous Peoples' Seattle Declaration.

111 Interview conducted by the author with Mrs Agnes Kabaikya (Kirabo), VEDCO on 25 July 2007 in Kampala, Uganda.

112 Khor is the Executive Director of South Centre, an intergovernmental organisation of developing countries based in Geneva, Switzerland, former Director of the NGO Third World Network (IWN) based in Penang, Malay'sia. See Khor 2002.

113 The International Union for the Protection of New Varieties of Plants (UPOV) is an intergovernmental organisation with headquarters in Geneva (Switzerland). The UPOV Convention was adopted in 1961 to ensure that member states acknowledge the achievements of breeders of new plant varieties by making available to them exclusive property rights for a given period of time. Instead of using the patent sy'stem, there was a need to develop a system that was more adapted to the needs of plant breeders, i.e. continued access to plant varieties for breeding purposes. Therefore it allowed wide exemptions from the property rights for breeders and also for farmers. 
defined species or genera, whereas the 1991 Act covers plant varieties of all genera and species. The protection period is extended from minimum 15 years under the 1978 Act to minimum 20 years under the 1991 Act. Breeders are free to use a protected variety to develop a new variety under the 1978 Act, but not if it requires repeated use of that variety. Under the 1991 Act this exemption is restricted and, among other provisions, it is not allowed to produce varieties which are essentially derived from a protected variety or which are not distinguishable from such a variety. The key change relates to farmers rights. Under the 1978 Act farmers are free to use their harvested material from a protected variety for any purpose. Under the 1991 Act, national governments are entitled to decide whether farmers shall be allowed - within reasonable limits and safeguarding the legitimate interests of the rights holder - to reuse the harvest of protected varieties on their own land holdings without the authorisation of the rights holder. It would not be allowed to exchunge or sell such material. Pursuant, farmers would have to buy propagating material for each season or pay royalties each time (with exceptions for small-scale farmers with regard to some crop species). UPOV Act 1978 was closed to further membership in 1998. New members may only join the Union based on UPOV 1991. Countries seeking to implement the provisions of the TRIPS Agreement pertaining to plant variety protection may therefore use UPOV 1978 as a model, but it will not entitle them to membership of UPOV.

One of the US's goals is to remove the patent exceptions for plants and animals and to arrange that plant varieties are sufficiently protected by the UPOV Convention. The US favours including the most relevant provisions of the UPOV in the TRIPS Agreement, i.e. make UPOV the standard. ${ }^{114}$ However, it is in the interest of developing countries to keep their freedom to design their owm plant variety systems (in order to address local concerns) instead of being bound by the UPOV measures regarding a sui generis regime. Plant varieties are a totally new issue to most developing countries and some of them have already agreed to a UPOV style system before analysing the local consequences. The French African intellectual property organisation (OAPI) 115 has agreed to adopt UPOV 1991 which is more restricted than 1978.

\subsubsection{New Developments on Article 27 TRIPS Agreement}

The current focus of the TRIPS Council's deliberations is limited to GI extension and the introduction of a GI register and the amendment of the TRIPS Agreement in relation to disclosure of origin principle and hence, discussions

11.4 "Preparations for the 1999 Ministerial Conference - General Council Discussion on Mandated Negotiations and the Built-In Agenda", Communication from the United States, WT/GC/W/115, 19 November 1998.

115 The acronym derives from the French version "Organisation Africaine de la Propriété Intellectuelle". 
on Article 27.3(b) have been stalled. The EC is a strong supporter of sharpening the rules on GI, whereas developing countries stress the importance of introducing a disclosure of origin requirement in relation to genetic material used in patent inventions. ${ }^{116}$. The Doha Round ${ }^{117}$ is currently in an impasse: it has been argued that progress in the agricultural negotiations cannot be made if no progress is made in the field of GIs and the disclosure of origin requirement. ${ }^{118}$ The $\mathrm{EC}$ is willing to make concessions on the disclosure requirement, but agreeing to prior informed consent and access and benefit sharing seems out of the question.

The Doha WTO Ministerial Declaration referred to Article 27.3(b), paragraph 19, in which the TRIPS Council is requested to study the relationship between the TRIPS Agreement and the Convention on Biological Diversity (CBD), the protection of traditional knowledge and folklore, and other relevant new developments (raised by Members) pursuant to Article 71.1 in pursuit of their work programme. The TRIPS Council is also requested to review Article 27.3(b), review of the implementation of the TRIPS Agreement under Article 71.1 and the work deriving from paragraph 12 of the Doha Declaration. ${ }^{19}$

Whereas the use of biotechnology has brought many new inventions to the world, societies differ in their acceptance of the use of genetically modified organisms (GMO's) e.g. in food production and scientific research in general. The US government does not view it as a big problem, and they regard the EC's protest and suspicion towards the use of GMO's in food as protectionism, with the exception of the UK who now allows the use of GMO's for stem cell research. This is, however, a question of cultural values and interests and about levels of societal tolerance. ${ }^{121}$

The emergence of a globalised intellectual property regime has caused great concern and has been criticised; one of the criticisms is that "providing more monopoly power to multinational corporate incumbent patent holders will lead to rent extraction from poor developing countries". 121 Why would one want to strengthen intellectual property rights, and in particular patent protection? One of the main reasons for the extension of patent rights is that supporters of stronger intellectual property regimes think that by strengthening these regimes local innovation by domestic firms will be stimulated and

II" See chapter three of this book for a more elaborated discussion.

117 This book addresses progress in the Doha Round until summer 2008.

11s Interview conducted with Alejandro Neyra, first secretary, Permanent Mission of Peru by the author, April 2008.

114 See WTO Doha Ministerial Declaration.

120 As explained by Prof. Pierre Sauve (World Trade Institute Berne, Switzerland) during the Trade Academy (summer school) in Macau 2004.

121 As mentioned in Branstetter 2004, referring to Stillwell and Monagle 2000. 
improved. It can even "improve prospects for information trade by encouraging invention and resolving failures in technology markets". 122 However, this arguably is only a valid deliberation in relation to industrialised countries economies. However, more empirical and economic research is necessary to justify this way of thinking. Branstetter ${ }^{123}$ is of the opinion that there is no sufficient evidence that stronger local patent rights can bring such results. He analysed a number of empirical studies on the impact of stronger patents on local innovation and found that local patent laws did not lead to more local innovation as measured by domestic patent applications. However, stronger patents did lead to more foreigners filing patents in a reforming country. It should, however, be noted that the TRIPS Agreement is not yet implemented in all countries due to the existing transition periods for developing and least developing countries. Studies on "cumulative innovation" (i.e. that innovation leads to more innovation, based on patent claim disclosure) ${ }^{124}$ have shown that excessively broad patent rights can actually retard the pace of innovation. This can occur due to broad patent claims which can lead to patent holders blocking the necessary "follow on" research necessary in a particular field of techmology, which can in turn lead to lower prices and improved quality of the product (which can become a commonly used good). ${ }^{125}$ One of the reasons why patent reform does not really lead to a change in more local innovation is that

"many or most domestic innovating agents also sell their innovative products on global markets, as well as in the domestic market, then IPR regimes abroad may malter even more than IPR regimes at home. (...) If the IPR regime in the larger foreign market is already strong, strengthening the local regime may have a marginal impact on local agents incentives to invest". 2 th

Studies even show welfare losses in developing countries as a result of a reform to stronger patent regime. ${ }^{127}$ Furthermore it is argued that a globalised intellectual property system can distort competition and the access of public goods. ${ }^{124}$

However, assessing the real impact of intellectual property reform on local innovation and international technology transfer can only be done when all countries have implemented the TRIPS Agreement. ${ }^{29}$ Implementation refers to the adoption of the necessary laws and enforcement. See chapter five on the role of IPRs on local innovation and technology transfer.

122 See Maskus and Reichman 2004a, p. 275.

123. See Branstetter 2004.

124 See Branstetter 2004, p. 361, referring to Bessen and Maskin 2000.

125 See Branstetter 2004, p. 361.

126. See Branstetter 2004, p. 362, referring to Grossman and Lai 2002.

127 See McCalman 2001, p. 55.

12. See Maskus and Reichman 2004a, p. 275.

12." Maskus and Reichman 2004a. 


\subsection{WTO Caso Lan on TRIPS Patent Pronisions}

\subsubsection{Canada-Patents}

The European Commission requested a WTO Panel to examine the Canadian Patent Act in 1998. According to the European Commission certain sections of this Act were in violation of Articles 28.1, 27.1 and 33 of the TRIPS Agreement. ${ }^{130}$

The provisions of the Canadian Act at issue were Section 55.2(1) and 55.2(2). Section 55.2(1) 131 of the Canadian Patent Act, the so-called "regulatory review provision", which allows generic producers of pharmaceuticals to complete the time-consuming marketing approval process prior to the patent expiry since the Section permits them to "make the patented invention" for uses related to the "development and submission of information". The benefit is that the generic manufacturer can try to obtain marketing approval while the patent is still valid, so upon the patent's expiry, the generic producer can immediately start selling its generic product. This way they can gain one to two and a half years of sales - the time it normally takes to obtain marketing approval.

Section 55.2(2), , $^{32}$ the so-called "stockpiling provision", permits generic manufacturers to "make" (i.e. produce) pharmaceuticals and to put them in "storage" (i.e. stockpile) them six months before the expiration of the patent. In this way, generic producers can have the (patented) drugs in storage during the patent period, so by the time the patent has lapsed they can start selling immediately. This provision is only available to those who have also invoked the regulatory review provision.

The Panel examined if these provisions from the Canadian Patent Act were in violation of the TRIPS Agreement. The Panel remarked that in order to

13: Cannda - Patents (PR) (EC), Canada - Patent Protection of Pharmaceutical Products, Request for the establishment of a Panel by the European Communities, WT/DS 114/5, 12 November 1998.

1.3 Canadian Patent Act, Section 55.2(1): "It is not an infringenent of a patent for any person to make, construct, use or sell the patented invention solely for uses reasonably related to the development and submission of information required under any law of Canada, a province or a country other than Canada that regulates the manufacture, construction, use or sale of any product".

132 Canadian Patent Act, Section 55.2(2): "It is not an infringement of a patent for any person who makes, constructs, uses or sells a patented invention in accordance with subsection (1) to make, construct or use the invention, during the applicable period provided for by the regulations, for the manufacture and storage of articles intended for sale after the date on which the term of the patent expires". 
interpret the provisions of the TRIPS Agreement it needed to go beyond the negotiation history of the TRIPS Agreement and also examine the intellectual property agreements, which are incorporated into the TRIPS Agreement following the interpretive guidance of Articles 31 and 32 of the Vienna Convention. ${ }^{133}$ For this specific case, the Panel deemed it necessary to examine Article 9(2) of the Berne Convention for the Protection of Literary and Artistic Works (1971). ${ }^{1 . i 4}$

The Panel started off with an important notion that Canada had assumed that its provisions had violated the TRIPS Agreement following Canada's reliance on Article 30 of the TRIPS. Consequently, Canada believed the Sections of the Canadian Patent Act qualified as exceptions under patent law. Article 30 provides for exceptions under the TRIPS Agreement. The Panel argued that Canada could have rebutted to Article 28.1 of the TRIPS Agreement instead.

Therefore the Panel argued that Canada needed to prove that its relevant Sections were not in violation of the TRIPS Agreement but instead complied with the criteria set out in Article 30.

\section{The Stockpiling Proaision}

The Panel looked at the substantive issues subject to analysis: the EC claim that the Sections were in breach of Article 28.1 and Canada's justification that the provisions were permitted because they formed an exception under Article 30 of the TRIPS Agreement.

The panel held that the stockpiling provision, Section 55.2(2) was in violation of Article 28.1 of the TRIPS Agreement. Article 28.1(a) reads:

"A patent shall confer on its owner the following exclusive rights:

Where the subject-matter of a patent is a product, to prevent third parties not having the owner's consent from the acts of making, using, offering for sale, selling, or importing for these purposes that product".

Thus, this provision provides the patent holder a number of exclusive rights: the right to making, using, offering for sale, selling and importing. It was obvious that the stockpiling provision infringed upon these rights but the question remained whether there was justification under Article 30 of the TRIPS Agreement. After Article 28.1, Article 30 of the TRIPS Agreement came under scrutiny by the Panel. Article 30 reads:

133 See chapter one of this book for more information on TRIPS Agreement interpretation by DSS.

134 See paras. 7.13-15 of the Canata - Patents (EC) (PR). 


\begin{abstract}
"Members may provide limited exception to the exclusive rights conferred by a patent, provided that such exceptions do not unreasonably conflict with the normal exploitation of the patent and do not unreasonably prejudice the legitimate interests of the patent owner, laking account of the legitimate interests of third parties".
\end{abstract}

The Panel argued that there are three cumulative criteria stemming from Article 30 that must be met in order for an exception to be allowed: 1) the exception must be "limited"; 2) the exception must not "unreasonably conflict with the normal exploitation of the patent"; 3) the exception must not "umreasonably prejudice the legitimate interests of the patent owner, taking account of the legitimate interests of third parties" 135

The Panel in its analysis followed the arguments raised by the parties: Canada raised Article 7 and 8 of the TRIPS Agreement as relevant to the objective and purpose of Article 30.130 Canada considered that these provisions jointly

\begin{abstract}
"call for a liberal interpretation of the three conditions stated in Article 30 of the Agreement, so that governments would have the necessary flexibility to adjust patent rights to maintain the desired balance with other important national policies". 1 it
\end{abstract}

The EC used as a counterargument that Articles 7 and 8 allow for a balancing which had been negotiated extensively at the TRIPS Agreement deliberations and subsequently it was clear that it was not up to individual countries to renegotiate the vierall balance. The Panel took the view of the EC and argued that the overall context of the Articles 7 and 8 should be taken into account but that the conditions stemming from Article 30 did not allow for a re-negotiation of the basic balance of the TRIPS Agreement. ${ }^{138}$

Subsequently, the Panel made an interpretive analysis of the three conditions of Article 30 TRIPS Agreement. It noted that the first criteria "the exception must be limited" implied that only a "narrow" exception - "one which makes only a small diminution of the rights in question" could be permitted. ${ }^{139}$

The Panel took over the view of the EC namely that the term "limited" is to be "measured by the extent to which the exclusive rights of the patent owner have been curtailed". ${ }^{\text {t11 }}$ Thus, the legal rights of the patent owner should be considered more important than the economic consequences of a provision.

13.3 See para. 7.19 of the Cimatu-Patents (EC) (PR).

1.3n See para. 7.23 of the Conada-Patents (EC) (PR).

13.7 Ibid.

135 See paras. 7.23-26 of the Cannta - Patents (EC) (PIR).

1.34 See pora. 7.30 of the Comuda - Patents (EC) (PR).

1 iti See paras. 7.31-33 of the Canata - Patents (EC) (PR). 
The Panel held that an action - even the smallest one - could potentially violate all the rights that Article 28.1 TRIPS Agreement has set out. The Panel, therefore, rejects Canada's argument that the focus should be on the infringement of the right to "sell". It makes clear that the rights to "make" and to "use" are also crucial rights conferred to the patent holder. ${ }^{1+1}$

The Panel reached the conclusion that Section 55.2(2) is in breach of Article 30's "limited exception" criterion. In its reasoning the Panel explained that it had difficulties with the fact that there was no limit on the production of products intended for stockpiling. Notably, the Panel was of the opinion that a patent right contains a corollary right to a "short period of extended market exclusivity after the patent expires". ${ }^{1+2}$ And if others are allowed to make or use the patented invention during the patent period it would diminish the patent holders' right to this extended market exclusivity. The Panel does not say what level of curtailment would be disqualifying under the limited exception standard but it does mention that "an exception which results in a substantial curtailment of this dimension cannot be considered a 'limited exception'".1.3. (emphasis added FC)

For these reasons the Panel held that the stockpiling provision of Canada's Patent Act did not constitute a "limited exception" under Article 30 of the TRIPS Agreement. The Panel concluded that the stockpiling provision formed a "substantial curtailment of the exclusionary rights" of the conferred rights to patent holders under Article 28.1 and as a result Section 55.2(2) of the Canadian Patent Act is in violation of TRIPS. As the criteria in Article 30 are perceived to be cumulative the Panel did not find it necessary to analyse the other two criteria.

\section{The Regulatory Revieu Provision}

Once again, the issue was not whether Section 55.2(2) violated Article 28.1 but whether the provision fell within the exceptions of Article 30 of the TRIPS Agreement. ${ }^{4+4}$ The Panel started its analysis with the first criterion of Article 30, the "limited exception" criterion and found that the same arguments to constitute a limited exception as noted by the Panel under the stockpiling provision - that the exception should only make a "narrow curtailment" of the legal rights of the patent holder - were also applicable in this case. 14.5 The Panel held that Canada's regulatory review provision met this criterion:

$1+1$ Ibid.

$1 .+2$ See paras. $7.34-37$ of the Canada-Patents (EC) (PR).

$1+3$ lbid.

1.4. See para. 7.39 of the Canada - Patents (EC) (PR).

145 See paras. 7.44-45 of the Caunda-Patents (EC) (PR). 
"as long as the exception is confined to conduct needed to comply with the requirements of the regulatory review process, the extent of the acts unauthorized by the right holder that are permitted by it will be small and narrowly bounded". 1.th

Next, the Panel went on to examine the second criterion of Article 30, which does not allow for exceptions that "unreasonably conflict with a normal exploitation of the patent". It was agreed by both parties that exploitation could be interpreted as including "the extraction of commercial value from the patent by 'working' the patent". This could be done either by selling the product or by licensing third parties to sell it. The difficulty concerned the meaning of the term "normal". 1.t; The Panel noted that the term "normal" has two possible meanings, either: 1) "empirical conclusion" as to what is normal/ common within a society or 2) "nomative standard" referring to the concept of "entitlement". The Panel made clear that the normal practice of exploitation by patent holders is to "exclude all forms of competition that could detract significantly from the economic returns anticipated from a patent's grant of market exclusivity". Wh "This anticipation is of course subject to changes in competition as a result of technological development and changes in marketing practices.

The Panel found that there was nothing abnormal about the period of market exclusivity in favour of the former patent holder that occurs after the patent period has lapsed. But this was contested by Canada. However, the Panel agreed with Canada that when - as in this case, the post-expiration market exclusivity was the result of a government's regulatory process - then a right to this type of protection did not fall within the bounds of nomal.

For these reasons the Panel is of the opinion that Section 55.2(1) - the regulatory review provision - did not conflict with a "normal" exploitation of patents under the second criterion of Article 30 TRIPS Agreement.

The Panel then turned to the third criterion of Article 30, which prohibits exceptions that "unreasonably prejudice the legitimate interests of the patent owner, taking into account the legitimate interests of third parties". The Panel examined whether (former) patent holders could assert a "legitimate interest" in economic benefits resulting from an additional period of post-expiration exclusivity. The question was whether the regulatory review provision "unreasonably prejudices" that legitimate interest. 149 The Panel decided that the term "legitimate" must be interpreted in a manner in which it is often used in

\footnotetext{
1.4t See para. 7.45 of the Camada - Patents (EC) (PR).

1.7 See para. 7.51 of the Camin - Patents (EC) (PIR).

14.4 See paras. 7.54-56 of the Cannda - Patents (EC) (PR).

1.49 See paras. 7.60-61 of the Canala-Patents (EC) (PR).
} 
legal discourse "as a normative claim calling for protection of interests that are 'justifiable' in the sense that they are supported by relevant public policies or other social norms". 131)

Furthermore, the Panel had to look at an argument (normative claim) raised by the EC namely that it was not desirable that generic producers are given an advantage over the patent holders in relation to product development time. The EC refers to the fact that patent holders lose one-half of the patent period when obtaining the necessary marketing approval for the drug, while under the regulatory review provision, the generic manufacturers can already start with the process of gaining marketing approval prior to the lapse of the patent term. As a result, generic producers do not lose time as they can immediately start marketing (i.e. enter the market) the drug after the patent period has lapsed. ${ }^{151}$ The Panel did not take the view - that the above mentioned issue constitutes a "legitimate interest" for the patent owners - of the European Communities for the following reasons: 1) it held that this interest was not so widely recognised or compelling to form a "policy norm" that falls within Article 30 of the TRIPS Agreement, and moreover; 2) at the time of negotiations the concerns about the regulatory review provisions were apparently not compelling enough to be listed in the recorded agenda of the TRIPS negotiations, and in addition; 3) it did not want to use concept of the exceptions mentioned in Article 30 of the TRIPS Agreement to settle on a nomative policy issue, more suited to political debate (which is already ongoing).$^{152}$

The Panel reached the conclusion that Canada had successfully shown that Section 55.2(1) did not prejudice the "legitimate interests" of affected patent owners in the context of Article 30 TRIPS Agreement. And since all three criteria laid down in Article 30 of the TRIPS Agreement are met by Canada's regulatory review provision, the Panel concluded that Section 55.2(1) of the Canadian Patent Act did not violate Canada's obligations under Article 28.1 of the TRIPS Agreement.

However, the Panel had to examine one more claim brought forward by the EC, that Canada's Patent Act violates Article 27.1 of the TRIPS Agreement. ${ }^{153}$

Article 27.1 states that:

"Subject to the provisions of paragraphs 2 and 3, patents shall be available for any inventions, whether products or processes, in all fields of technology', provided that they are new, involve an inventive step and are capable of

150 Ibid.

151 See paras. 7.74-78 of the Comada - Patents (EC) (PR).

152 See para. 7.82 of the Canada - Patents (EC) (PR).

153 See para. 7.85 of the Camada - Patents (EC) (PR). 
industrial application. Subject to paragraph 4 of Article 65, paragraph 8 of Art. 70 and paragraph 3 of this Article, patents shall be available and patent rights enjoyable without discrimination as to the place of invention, the field of technology and whether products are imported or locally produced".

The EC claimed that Canada's Section on regulatory review discriminated on grounds of the "field of technology" - against pharmaceutical products - "in both a de jur' manner, based on the legislative history of the provision, and a de finto manner, in that the measure is effectively limited to pharmaceuticals" 151

The Panel rejected the above mentioned claims by the EC, and it also rejected Canada's counter argument that Article 27.1 did not apply to exceptions provided for under Article 30 of the TRIPS Agreement. The Panel held that nothing in Article 30 pointed out that rules addressing non-discrimination rules are exempted. The Panel elucidated, "[a] discriminatory exception that takes away enjoyment of a patent right is discrimination as much as is discrimination in the basic rights themselves". The Panel further noted that the exceptions mentioned in Article 31 of the TRIPS Agreement on compulsory licenses and government uses are "understood to be subject to the nondiscrimination rule of Article 27.1 of the TRII'S Agreement" ${ }^{155}$

Subsequently the Panel went on to scrutinise whether Canada's section on the regulatory review provision discriminated as to the field of technology. While interpreting the term "discrimination", the Panel acknowledged that this term is 'normative' in nature and "pejorative" in connotation, and that it extended beyond the concept of "differential treatment". The Panel agreed with Canada that discrimination can occur due to

"explicitly different tratment (de jure discrimination), or from the application of formally identical treatment, which, due to differences in circumstances, produces differentially disadvantageous effects (de facto discrimination)". $15 \mathrm{n}$

The EC, while addressing de jur' discrimination underlined that only pharmaceutical products occurred in the negotiation process prior to the enactment of the regulatory review provision in Canada's Patent Act. The Panel, however, found, this reasoning insufficient and put more value on the wording of the provision, which does not discriminate based on technology or product. Furthermore, Canada represented to the Panel that the "meaning" or the regulatory review provision is not limited to pharmaceutical products. The Panel concluded that the provision did not constitute de jure discrimination

13 See paras. 7.86, 7.95-96 of the Canatn - Patents (EC) (PR).

157 See paras. 7.88-91 of the Comatin-Patents (EC) (PR).

15n See para. 7.94 of the Comadn - Patents (EC) (PR). 
against pharmaceuticals. ${ }^{157}$ However, in Indin - Patents (LIS) the Panel refused the interpretations made by the Indian government, with regard to the functioning of the patent system, and commitments made by the government, to implement a patent system in compliance with its obligations under the TRIPS Agreement.

The Panel moved on to look at the EC claims regarding de facto discrimination. They found that there are two elements leading to a de facto discrimination: discriminatory effect and discriminatory purpose (but based on the objective characteristics of the measure and not on subjective purposes defined by government officials). The Panel did not explain why it viewed de facto discrimination the way it did. This case was not dealt with under the Appellate Body so unfortunately we do not know their thoughts on how de facto discrimination under Article 27.1 TRIPS Agreement should be judged.

The Panel rejected the reasoning by the EC regarding de facto discrimination against pharmaceutical products. The Panel held that the EC did not bring forward sufficient evidence that the regulatory review provision had had a "discriminatory effect" against pharmaceutical products because it did not offer knowledge on the various industries that make use of the regulatory review provision in order to show the impact of the provision under a de facto analysis. The Panel also argued that even if at the time of the legislative negotiations the focus was on pharmaceutical products, this does not imply that its intention was to discriminate against pharmaceuticals. The Panel, therefore, concluded that there was no evidence to constitute a de facto discrimination against pharmaceutical products. ${ }^{15 *}$

The regulatory review provisions allowing generic producers to complete the time-consuming marketing approval process prior to patent expiry is in Canada (and in academic writing) referred to as the "Bolar exception".

15. See paras. 7.96-99 of the Contatu - Patents (EC) (PR).

$15 \mathrm{~s}$ See paras. 7.102-104 of the Camata - Patents (EC) (PR). 


\subsubsection{WTO Consultations on "Local Working" Requirement}

The US requested consultations ${ }^{154}$ with Brazil on 30 May 2000 regarding some of the provisions in Brazil's 1996 industrial property law. Brazilian law demanded a "local working" requirement in order for goods to enjoy exclusive patent rights. ${ }^{(t)}$ Brazil's "local working" requirement stipulates that a patent shall be subject to compulsory licensing if the subject matter of the patent is not "worked" in the territory of Brazil, i.e. if the products are not manufactured in Brazil. Brazil then explicitly defines "failure to be worked" as "failure to manufacture or incomplete manufacture of the product", or "failure to make full use of the patented process". "th The US asserts that this "local working" requirement implies that products need to be locally produced in order to qualify for patent protection, which implies that importing the product does not qualify. According to the US these aspects of Brazilian law are inconsistent with Articles 27.1 and 28.1 of the TRIPS Agreement.

Following the request for consultations, Brazil and the US exchanged letters on the matter and held meetings in an attempt to solve the dispute. However, it was not solved so the US requested the establishment of a Panel in which it rephrased its request for consultation. " 62 The US asserted that Article 68 of the Brazil's 1996 Industrial Patent Law is incompatible with the TRIPS Agreement under Article 27.1 which stipulates that discrimination regarding the availability of patents and the enjoyment of patent rights, on the basis of whether products are imported or locally produced is prohibited. Yet, Brazil requires a "local working" of the patent, that is to say that exclusive patent rights under Article 68 of the Brazil Patent Act are granted on condition that the patent is locally produced. What is more - the local working requirement "stipulates that a patent shall be subject to compulsory licensing if the subject matter of

154 Request for Consultations by the United States concerning Brazil - Mensures Affecting Patent Protetion, 8 June 2000 . The European Communities requested to join consultations because of their substantial trade interest pursuant to Art. 4.11 DSU, Request $t o$ Join Consultations concerning Brazil - Measures Affecting Patent Protection, Communication from the European Communities, 20 June 2000. Consultations precede the request for the establishment of a Panel. The procedural requirements for the request of consultations are set out in Art. 4 of the DSU, Art. XXII of GATT 1994 and Art. 64 of the TRIPS Agreement to the extent that it incorporates by reference Art. XXII of GATT 1994.

len Brazil's 1996 Industrial Property Law, Law No. 9,279 of 14 May 1996; effective as from May 1997.

(o) Request for Consultations by the United States concerning Brazil - Mensures Affecting Patent Protection, 8 June 2000.

11.2 A Panel may be requested pursuant to Art. 6.2 of the DSU and Art. 64 to the extent that it incorporates by reference Art. XXII of the GATT 1994. Request for the Establishment of a Panel by the United States concerning Bmzil - Measures Affecting Patent Protection, 9 January 2001. 
the patent is not "worked" in the territory of Brazil". As a result, if the patented invention is not produced in Brazil, or if the patented process is not used in Brazil, a compulsory license can be granted. Furthermore if the patent owner decides to exploit his patent through importing goods instead of manufacturing them on Brazilian ground, Article 68 permits "others to import either the patented product or the product obtained from the patented process". Thus Brazil is of the opinion that the mere supply of the patent product by the foreign owner of a Brazilian patent is not sufficient but that the product needs to be produced on the territory of Brazil. According to the US this requirement discriminates against US owners of Brazilian patents whose products are imported into, but not locally produced in, Brazil and in addition they believe Article 68 reduces the exclusive rights of patent owners.

A few months later Brazil and the US did reach a mutually satisfactory solution and on 5 July 2001 they circulated a communication notifying this. 16.3 Although Brazil was of the opinion that Article 68 of its Brazil's 1996 Industrial Property Law is fully compatible with the TRIPS Agreement they proposed that if the US withdrew the WTO Panel against Brazil concerning the interpretation of Article 68, the Brazilian Government would agree, when necessary to apply Article 68 to grant compulsory licenses on patents held by the US companies, to hold prior talks on the matter with the US government. These talks would be held within the scope of the US- Brazil consultative mechanism, in a special session scheduled to discuss the subject. ${ }^{104}$ The US responded that under those circumstances set out in the letter by Brazil it would agree to terminate the WTO Panel, proceeding without prejudice concerning the interpretation of Article 68 Brazil's 1996 Industrial Iroperty law. This solution was agreed upon, taking into consideration that the US had real concerns about the potential use of Article 68. But in fact this provision to grant a compulsory license has never been used by Brazil to grant a compulsory license. The US, however, has agreed to terminate on the condition that Brazil does not proceed with further dispute settlement action regarding sections 204 and 209 of the US Patent Act (the scope of which is linked to Section 2 of the Small Business Act (Public Law 85-536) that provides that the Federal Government aid and assist small business to increase their ability to compete in international markets) which require the local working of patents obtained with federal assistance. 15.5 Therefore if the Panel had found against Brazil an

1m.3 Notification of Mutually Agreed Solution, Brazil - Measures Affecting Patent Protection, WT/DS199/4, 19 July 2001.

10t Letter from Brazil to the US, dated 19 June 2001, as referred to in Notification of Mutually Agread Solution, Brazil - Measures Affecting Patent Protection, WT/DS199/4, 19 July 2001.

los Letter from the US to Brazil, dated 25 June 2001, as referred to in Notification of Mutually Agreed Solution, Brazil - Measures Affecting Patent Protection, WT/DS199/4, 19 July 2001. 
eventual amendment of the Brazil Patent Act would be minimal and although the scope of the US Patent Act was narrower it probably would have been inconsistent with the TRIPS Agreement as well. Therefore, if one country lost one dispute, the other was fated to lose the other (and vice versa). ${ }^{\text {the }}$

\subsection{Patent Tomm Duration}

Article 33 of the 'TRIPS Agreement stipulates the patent duration:

"The term of protection available shall not end before the expiration of a period of wenty years counted from the filing date". ent

Before the TRIPS Agreement fixed the patent term duration to 20 years, it varied enormously from country to country. This provision endeavours to harmonise these different practices to bring more security to the international patent system. This fixed time duration should provide an adequate balance between public and private rights, in that the disclosure of the invention by the right holder grants exclusive protection to the right holder for a limited period of time (not renewable) allowing him to enjoy the fruits of his invention and to recoup his investment and after this period the invention enters the public domain implying that everyone can use the invention. Countries are allowed to permit longer periods of extension. For instance the US - Korea FIA provides for a patent duration of 25 years.

Recently the term duration has been criticised for not allowing ample time to recoup investment. The pharmaceutical industry has argued that it can take up to eight years before a patent is granted because of a long examination period and with pharmaceutical products this period is supplemented by the time it takes to conduct clinical trials (to secure health safety) to achieve exclusive marketing approval. This can take on average between three to five years. As a result it can take up to 12 years before a pharmaceutical product is allowed to enter the market, thus, providing the inventor with little time to recoup the costs of the invention.

\subsubsection{WTO Case Law on Patent Term Duration}

The term of patent duration in the Dispute Settlement Understanding was the subject of a dispute settlement case: Canada - Term of Patent Protection (Canada Patents). ${ }^{16 s}$ The US requested consultations with Canada (on 6 May 1999) in

Jis See Pires de Carvalho 2005, p. 202 and 203.

Ini In footnote 8 to this provision: "It is understood that those Members which do not have a system of original grant may provide that the term of protection shall be computed from the filing date in the system of original grant".

lus See Canada-Patents (US). 
respect of the length of protection granted to patents that were filed in Canada before 1 October 1989. The US found Canada in violation of Article 33 of the TRIPS Agreement, which according to the US, requires WTO members to grant a term of protection for patents of at least 20 years after the filing date of the underlying protection, and requires each Member to grant this minimum term to all patents existing as of the date of the application of the TRIPS Agreement to that Member. The US alleged that under the Canadian Patent Act, the term granted to patents issued on the basis of applications filed before 1 October 1989 is only 17 years from the date on which the patent is issued. The US contended that this situation is inconsistent with Articles 33, 65 and 70 of the TRIPS Agreement.

The US and Canada could not agree on what constitutes a reasonable period of time required for the implementation of those recommendations and rulings following from the Appellate Body Report (ABR). Both parties turned to the binding arbitration mechanism of the WTO DSU, which had to juxtapose the view of Canada with the view of the US. In the view of the US this period should be six months maximum from the date of adoption of the Panel and the Appellate Body Reports. Canada, for its part favoured a 14 month period, which would allow them to amend its Patent Act. The Arbitrator (Mr. Ehlermann) detemined that a "reasonable period of time" should be the shortest period possible within the legal system of the Member and that it does not require a Member to utilise an extraordinary legislative procedure. He also decided to grant a ten month period to implement the decision of the ABR. ${ }^{10^{6}}$

\subsection{Draft Article 29bis: Disclosure of Origin of Genetic Material}

A group of developing countries have proposed to amend the TRIPS Agreement with Article 29bis titled Disclosure of Origin of Biological Resonrces and/or. Associated Traditional Knowledge. ${ }^{17}$ Article 29 bis aims to supplement Article 29 by the introduction of a number of extra conditions on patent applications. ${ }^{171}$ The communication was directed to the WTO General Council and Trade Negotiations Committee in relation to the Doha Work Programme and addressed more specifically the outstanding implementation issue on the relationship between the TRIPS Agreement and the Convention on Biological Diversity (CBD). The proposal is submitted on 29 May 2006 prior to the TRIIS Council meeting of 12-15 June 2006. The proposal was also in advance of the

121 Communication from Brazil, India, Pakistan, Peru, Thailand and Tanzania titled Doha Work Programme - The Outstanding Implementation Issue on the Relationship between the TRIPS Agreement and the Convention on Biological Diversity. WTO, WT/GC/W/564, TN/C/W/41, 31 May 2006.

17) The Belgium Patent Act was the first to introduce such a disclosure of origin requirement. See chapter three, section 5.2.3.2 of this book. See also Van Overwalle 2001 and 2002 . 
31 July WTO deadline when the "General Council was to review progress and take any appropriate action". ${ }^{172}$ In the meantime the Director General was required to undertake consultations and to report back to the General Council and the Trade Negotiations Committee. This communication refers to the Doha Ministerial Declaration in which Ministers (the highest decision making body) agreed that negotiations on outstanding implementation issues would be an integral part of the Work Programme they had established. The relationship between the TRIPS Agreement and the Convention on Biological Diversity (CBD) was such an outstanding implementation issue. These outstanding implementation issues have been subject to many formal and informal discussions. In the context of the relationship between the TRIPS Agreement and the CBD, discussions primarily focused on the introduction into the TRIPS Agreement of a mandatory requirement for the disclosure of origin of biological resources, and/or associated traditional knowledge used in inventions for which intellectual property rights are applied for. The proposal by the six developing countries was an attempt to move towards text based negotiations in order to take appropriate action by 31 July 2006. According to these six the text presents a proposal of how the disclosure of origin requirement should be put into practice taking into account the questions, comments and concems raised by various Members in the negotiations so far. As indicated in chapter three on traditional knowledge the proposal has gained political momentum with the support of 77 other Member Countries and consensus on such a requirement could end the bottleneck bringing a successful closure of the Doha Round. The huge support puts pressure on the negotiations but fervent opponents remain, like the US and Japan. For a more elaborate discussion on the disclosure of origin proposal and the various country positions see chapter three of this book.

\section{Content of Disclosure of Origin Proposal}

As previously stated the proposed article 29 bis aims to establish a mutually supportive relationship between the TRIPS Agreement and the CBD (paragraph 1 of the proposal). Paragraph 2 of the proposed Article sets out the obligations the patent applicant should fulfil in order to meet the disclosure of origin requirement. In summary this paragraph requires that when an invention is based on biological resources and/or associated traditional knowledge, the patent application shall disclose the country providing the biological material and from who in that country the material was obtained from. In addition, Members are required to provide information and evidence on their compliance with the applicable legal requirements in the providing country, showing proper informed consent for access and fair and equitable benefitsharing, arising from the commercial or other utilisation of the material.

172 According to Art. 39 of the Hong Kong WTO Ministerial Declaration from December 2005. 
Paragraph 3 contains the obligation to amend the information including evidence provided under paragraph 2 in light of new information of which they become aware. Paragraph 4 is of an administrative nature and paragraph 5 asks Members to install effective enforcement procedures to ensure compliance with paragraph 2 and 3 . Article 5 also stipulates that:

"Members shall ensure that administrative and/or judicial authorities have the authority to prevent the further processing of an application or the grant of a patent and to revole, subject to the provisions of Article 32 of this Agreement, or render unenforceable, a patent when the applicant has, knowingly failed to comply with the obligations in paragraph 2 and $3(\ldots)$ or provided false or fraudulent information".

In case the patent has already been granted, the new information should be published without undue delay.

Thus to summarise, if the proposal gets adopted in the form proposed, anyone applying for a patent based on genetic resources or traditional knowledge would have to disclose what country or region they got the material from and show that they have permission from the owners of the material to use it and that appropriate sharing of the benefits is acknowledged. So when a pharmaceutical company manufacturers a new medicine based on/or containing a genetic resource and/or traditional knowledge found in a developing country, the latter would have a means to control use of the material.

Over the course of time it will be interesting to see how far the proposal will be supported by others and how quickly negotiations will move forward. As this proposal is of particular importance to developing countries - since they hold the earth's richest source of biological diversity - it is to be expected that the proposal will most likely be backed further by developing countries. As previously indicated the $\mathrm{EC}$ is likely to partly sponsor the agreement, i.e. disclosure of origin requirement in exchange for concessions in relation to GIs but not be willing to accept PIC and ABS requirement. China has co-sponsored the agreement as it has a special interest in a disclosure of origin obligation (with an eye on their traditional medicine). More countries are likely to follow. With the public support of China, the three largest developing countries in size and population, India, Brazil and China, back the proposal. Most recently the African group and the LDC group have joined. This has already put more pressure on the negotiations.

Some developing countries' representatives have expressed their sadness that more than ten years have passed since the adoption of the TRIPS Agreement and that their request to include rules on genetic resources and traditional knowledge into the TRIPS Agreement has still to be accommodated. In spring 2006 it was believed that the disclosure obligation could possibly be traded off with the request for digital rights in the area of copyrights and broadcasting, under discussion in the WIPO and favoured by many developed countries. However the broadcasting treaty has died early. 
Europe, United States, Canada and Australia have responded negatively to the Draft proposal by arguing that it did not contain any new information and that they had not changed their positions. They generally hold the view that it is premature to consider an amendment to the TRIPS Agreement to address concerns about misappropriation of genetic resources and traditional knowledge and regard the proposed amendment as too broad. ${ }^{173}$

There is a question mark over whether an approach to prevent misappropriation through contracts is effective, or whether the WTO or the WIPO should be the appropriate framework to discuss this matter. Developed countries have submitted their own proposals. These proposals are addressed in chapter three of this book. The differences that stand out between the EC proposal and the Article 29 bis proposal relate to the wording of the text to define the terminology used. For instance the EC speaks of "genetic resources", whereas the developing countries' proposal uses the term "biological resources". In addition the EC prefers a narrower scope in that the EC prefers to mark out the disclosure of origin obligation to genetic material directly used in the invention, in contrast to the developing countries' proposal that asks for disclosure when the subject-matter is derived from or developed with biological resources and/or associated traditional knowledge - and thus refers to a disclosure argument that is much broader in scope. Switzerland expressed its preference to enclose "disclosure of source" (the Swiss prefers to refer to "disclosure of source" in contrast to "disclosure of origin") this matter in the ongoing negotiations on the WIPO Patent Cooperation Treaty (PCT). Please see chapter five for a thorough overview of the different country proposals. ${ }^{17 t}$

\subsection{Compulsory Licensing}

Article 31 of the TRIPS Agreement has received the title "other use without authorisation of the Right holder" but is generally referred to as the 'compulsory licensing' provision:

"Where the law of a Member allows for other use (7) of the subject malter of a patent without the authorization of the right holder, including use by the government or third parties authorized by the government, the following provisions shall be respected:

(a) authorization of such use shall be considered on its individual merits;

(b) such use may only be permitted if, prior to such use, the proposed user has made efforts to obtain authorization from the right holder on reasonable commercial terms and conditions and that such efforts have not been suc-

173 Intellectual Property Watch 2006b. Consultations on the outstanding implementation issue on the relationship between the TRIPS Agreement and the CBD are ongoing.

17. See also Claessens 2008b. 
cessful within a reasonable period of time. This requirement may be waived by a Member in the case of a national emergency or other circumstances of extreme urgency or in cases of public non-commercial use. In situations of national emergency or other circumstances of extreme urgency, the right holder shall, nevertheless, be notified as soon as reasonably practicable. In the case of public non-commercial use, where the govemment or contractor, without making a palent search, knows or has demonstrable grounds to know that a valid patent is or will be used by or for the government, the right holder shall be informed promptly;

(c) the scope and duration of such use shall be limited to the purpose for which it was authorized, and in the case of semi-conductor technology shall only be for public non-commercial use or to remedy' a practice determined after judicial or administrative process to be anti-competitive;

(d) such use shall be non-exclusive;

(e) such use shall be non-assignable, except with that part of the enterprise or goodwill which enjoys such use;

(f) any such use shall be authorized predominantly for the supply of the domestic market of the Member authorizing such use;

(g) authorization for such use shall be liable, subject to adequate protection of the legitimate interests of the persons so authorized, to be terminated if and when the circumstances which led to it cease to exist and are unlikely to recur. The competent authority shall have the authority to review, upon motivated request, the continued existence of these circumstances;

(h) the right holder shall be paid adequate remuneration in the circumstances of each case, taking into account the economic value of the authorization;

(i) the legal validity of any decision relating to the authorization of such use shall be subject to judicial review or other independent review by a distinct higher authority in that Member;

(j) any decision relating to the remuneration provided in respect of such use shall be subject to judicial review or other independent review by a distinct higher authority in that Member;

(k) Members are not obliged to apply the conditions set forth in subparagraphs (b) and $(f)$ where such use is permitted to remedy a practice determined after judicial or administrative process to be anti-competitive. The need to correct anti-competitive practices may be taken into account in determining the amount of remuneration in such cases. Competent authorities shatl have the authority to refuse termination of authorization if and when the conditions which led to such authorization are likely to recur;

(l) where such use is authorized to permit the exploitation of a patent ("the second patent") which cannot be exploited without infringing another patent ("the first patent"), the following additional conditions shall apply:

(i) the invention claimed in the second patent shall involve an important technical advance of considerable economic significance in relation to the invention claimed in the first patent;

(ii) the owner of the first patent shall be entitled to a cross-licence on reasonable terms to use the invention claimed in the second patent; and 
(iii) the use authorized in respect of the first patent shall be non-assignable except with the assignment of the second patent".

This provision allow's an exception to the exclusive rights assigned to patentees different from the exceptions mentioned in Article 30 TRIPS Agreement. The compulsory licensing scheme permits to work a patent (product or process) without authorisation of the patent right holder albeit subject to certain conditions. Article 31 sets out that only governments can authorise such use. Article 31 of the TRITS Agreement provides the legal basis for such use, subject to a number of conditions provided in the paragraphs - to safeguard some of the rights of the patent holder. This provision embodies one of the key flexibilities provided under the TRIPS Agreement as it gives priority to the public interest in that accessing patented pharmaceutical products is rated higher than the private interest of the patent right holder in case of a national emergency. However, although the compulsory licensing scheme is often referred to in combination with pharmaceuticals, the system is not exclusively established to provide access to medicines. For instance it may also be invoked involving different technologies than (bio) chemical technologies. It is important to investigate other possible uses (outside the field of pharmaceutical patents) for compulsory licensing. For instance, the option to amend the TRIPS Agrement to allow for the compulsory licensing of enviromentally necessary technologies ${ }^{17}$ to reduce the burdens on climate change, such as power

175 In footnote 7 to Art. 31 of the TRIPS Agreement: "Other use" refers to use other than that allowed under Art. 30.

17. Chinese officials, currently resisting heavy pressure from some industrialised nations to accept binding caps on greenhouse gas emissions, have increasingly been arguing that intellectual property protections are putting energy-saving technologies out of the reach of developing countries. However, the key barriers encountered by developing countries to access envirommentally friendly technology may not be related to intellectual property protection, but to trade barriors and there is an urgency to stop anti-competitive practice. For instance, Barton found that in the cases he had studied, intellectual property-related obstacles to technology transfer were relatively smaller. In these sectors, intellectual property was generally accessible either through competitively priced products, or through modest rovalty fees. He suspected that the real problem in some instances might lie more in the realm of anti-competitive practices than that of intellectual property. Barton indicated that there is a difference between the renewable energy sector (solar, photo-voltaic, biofuels, and wind) and the pharmaceutical sector, the classic example of how compulsory licenses have been used to create cheaper drugs and expand access to medicine. In the pharmaceutical sector, patents and the associated monopoly rights often have a substantial upward impact on price, as there may be no substitutes for a new medicine. In contrast, in the renewable energy sector, patent protections have long expired on the basic technologies used. Thus, only specific improvements or features tend to be patented. As a result, several competing patented products exist - and the competition usually brings prices down compared what might be charged 
generation, transport and industrial energy use. ${ }^{177}$ It has been argued that it could be a useful tool to make environmentally friendly necessary technologies more available. ${ }^{1 \% \pi}$

There is also potential to use compulsory licenses in the electronic or automobile industries, particularly in relation to the production of spare parts.

Article 31(a) mentions that "authorisation of such use shall be considered on its individual merits", implying that the granting of a compulsory license should be decided on a case by case basis, providing countries with considerable flexibility on whether it is desirable to authorise such use.

Article 31(b) is important as it stipulates that before a compulsory license can be granted efforts have to be made to obtain authorisation from the right holder on reasonable commercial terms and conditions, and that such efforts have been unsuccessful within a reasonable period of time. This requirement may be anivel by a Member in the case of national emergency, or other circumstances of 'xtr'me' urge'mcy, or in cases of public non-commercial use. On the condition that the right holder shall be notified as soon as "reasonably practicable", and in case of public non-commercial use this notification has to be done "promptly". These terms are not further specified. It has also not been elaborated on what constitutes "efforts" to obtain authorisation from the right holder or what constitutes "on reasonable commercial terms and conditions". This gives governments' considerable flexibility to determine compulsory licenses. Just, as a government solely decides if there is a national emergency or other circumstance of extreme urgency that justifies the granting of a compulsory license. Even if there is no such circumstance the government may issue a compulsory license on the basis of "public non-commercial use". The compulsory license is normally used in relation to health and access to crucial medicines such as HIV/AIDS, tuberculosis or cancer treatment. However,

under a monopoly. Interview with Prof. Barton conducted by the author on $3^{\text {rat }}$ of May 2007.

17 The European Parliament adopted a resolution on 29 November addressed to the need to develop production, consumption and trade patterns that mitigate climate change and its economic impact to assist the clean development mechanism, being the main Kyoto Protocol system for technology transfer. In this resolution the European Parliament urged the European Commission, which negotiates trade agreements on behalf of EU members, to push for removing tariff and non-tariff barriers that "prevent or slow the dissemination of low carbon technologies". See Bridges Weekly Trade News Digest 2007h. The European Parliament's resolution on trade and climate change is available online at $<$ http:/ wwwetroparleuropa. eu/sides/getDoc.do? Type=TA\&Reference=P6-TA-2007-0576\&language=EN $>$.

17s As well as removing tariff and non-tariff barriers to accelerate the spread of low carbon technologies. 
Article 31 is not exclusively drafted to address health concerns and it may be used to address other needs as well.

Article 31 (c) curtails the duration of the compulsory license stipulating that the patent's use last only as long as the purpose for which the compulsory license was authorised. In other words if the use was authorised to respond to an emergency situation and this situation no longer exists the use of the unauthorised patent has to end.

Article $31(\mathrm{~d})$ remarks that "the use of the patent shall be non-exchsive" (emphasis added FC). Thus, it is possible that a compulsory license is granted to more than one company at the same time to respond to an existing urgent need.

Further, Article 31(e) notes that such use is "non-assignable". This implies that a compulsory license is granted to a particular company, which cannot decide to further extend/assign the license to another organisation.

Interestingly, paragraph 30(f) further points out that "any such use shall be authorised fredominantly for the supply of the doncstic market of the Member authorising such use" (emphasis added FC). The use of the term "predominantly" implies that more than 50 per cent of the manufactured products ought to be used to serve the domestic market. This rule is a big obstacle for countries without manufacturing capacities, preventing them from importing the necessary drugs from third countries. This makes them dependent on third countries to produce the products under a compulsory license and to subsequently supply their markets with the remaining 49 per cent of production.

In addition, Article $31(\mathrm{~g})$ stipulates that the authorisation to grant a compulsory license shall be terminated if and when the circumstances which led to it cease to exist.

Next, Article 31(h) states that the right holder shall be paid adequate remuneration in the circumstances of each case, taking into account the economic value of the authorisation. The question remains what constitutes "adequate remuneration" - adequate rated to economic spending power of a particular country?

The policy underlying the patent system is that patents are granted to enhance the level of development. However, if a patent is granted and it is not locally used, then there is no benefit to the public. In that case a compulsory license can be granted. In practice it is not used very often. It is more a threat to producers, in that invoking a compulsory license is used as a threat to pharmaceutical companies to lower prices. But what happens when the market is supplied by imports, is that considered "use"? According to Article 27.1 demanding a local working requirement is forbidden. In principle a country cannot distinguish between local and outside production. If there is no 
(longer) requirement of domestic use, it is sufficient to supply the market by foreign produced products. For the market it does not matter where the product comes from but for the level of local development it does.

The discussion at Doha and Cancun circled around such questions as: must products be available at affordable prices adjusted to the country in question? But what is availability? A product can be available on the market but still the population does not have access to these products due to high prices (and inadequate infrastructure, bad governance and lack of health care etc).

The health systems in developing countries have also been criticised for failing to supply medicine to people that need it: "[t]he issue is not intellectual property, it is government intervention (...) even if medicine were offered for free still the needy would not have access to them". "79 "The international policy network has produced a report which shows how developing counties impose needless barriers - such as taxes - that prevent the poor from receiving medicines. ${ }^{181}$ 'The WHO Report of the Commission on IPRs, Innovation and Public Health 2006 (CIPIH Report) also includes delivery obstacles as part of the access problem, recognising that if innovation (leading to new drugs) does not reach people in need, it is meaningless. ${ }^{161}$

Another question is of a more value-oriented nature: Why should a patentee (e.g. pharmaceutical industry) have a social interest and produce pharmaceuticals at agreeable prices? Other industries, like the car or the electronic devices industry also offer products at prices high above the production cost value and are not required to lower their prices. This might be true but there can be public interests at stake with pharmaceuticals. Hence, there is a need for public intervention. The pharmaceutical industries expenditure on research and development is high, but also the advertisement and marketing expenditures weigh heavily on their spending. In addition, manufacturers spend large sums on lobbying efforts and political campaign contributions because governments make most of the important regulatory and legislative decisions affecting prescription drugs. An article published in the Washington Post mentions that increasingly states pass law's to force the lowering of prescription costs or changes in how drug makers do business. For this reason the pharmaceutical

17) Interview with Philip Stevens, health programme director of the International Policy Network (the network is funded by the pharmaceutical industry). Intellectual Property Watch 2006a.

Isil Bbid.

Isi CIPIH Report "Public Health, Innovation and IPRs, Report of the Commission on IPRs, Innovation and Public Health", WHO, 2006 (hereinafter CIPIH Report 2006). Published online: <http://www.who.int/intellectualproperty/documents/there port/ENPublictlealthReport.pdf>. 
industries' political spending has increased enormously. ${ }^{182}$ To recoup R\&D and marketing costs, these products are sold at a price higher than the cost of production.

However, it is questionable if the developing country market is where pharmaceutical companies should be making their profits or even (getting adequate compensation) to recoup their investment costs. In some of these countries people live below the poverty level and have one or two dollars to spend daily. Thus, even if drugs are offered at one dollar, this is very little for some pharmaceuticals; it even is too high for the people. Developing countries have expressed great concern on the negative effects of the TRIIS Agreement on pharmaceutical pricing and the consequences on their generic production. These discussions have eventually paved the way to the Doha Declaration on Public Health. ${ }^{143}$ Developing Member Countries have expressed concerns on the patent provisions of the TRIPS Agreement and the fact that implementation of these provisions can have an adverse effect on access to pharmaceuticals. They impact on their generic production possibilities.

The compulsory license provision is frequently used by industrialised countries. ${ }^{15-4}$ A well-known example of this is the "anthrax" case in the US. Right before the November 2001 WTO Ministerial Meeting in Doha, the US faced "anthrax" attacks, in which several members of Congress and a journalist were mailed "anthrax". At the time it was feared that it would not stop there and that terrorists might have penicillin-resistant strains of "anthrax". The only medicine that was regulatory approved to treat such a strain was "ciprofloxacin", patented in the United States by Bayer. Nonetheless Bayer could not supply the US government with sufficient supplies of the medicine to meet the stockpiles the medical experts advised. The US and Canadian governments

182 The non-partisan Center for Public Integrity reports that the drug industry spent more than 44 million dollars on lobbying state governments in 2003 and 2004 , and eight million dollars on candidates for office. Of the 44 million dollar spend, 4.5 million dollar derived from the Pharmaceutical Research and Manufacturers of America (PhRMA), being the largest spender. Eli Lilly and Co., GlaxosmithKline Inc., l'fizer Inc, and Johnson and Johnson, each spend over three million dollar in that period. This interest for state capitals is related to the fact that states directly or indirectly pay for 16 per cent of the drugs purchased each year. The National Conference of State Legislatures have reported that since 2003 more than 66 bills were enacted aiming at cutting the costs of drugs. These figures show that money makes policy. Kaufman 2006.

1*.3 The Declaration on the TRIPS Agreement and Public Health, adopted on 14 November 2001. For more information on this Declaration see section 3.6 .2 of this chapter.

1s.t Interview with Prof. Jerry Reichman, who argues that the US, Japan and the EU have used compulsory licensing provisions considerably more than developing countries. Interview conducted by the author in October 2007. 
threatened to override the Bayer patents and buy generic versions of the medicine elsewhere. However in the end an agreement was reached with Bayer. After this event, the US negotiating position in the WTO talks was compromised by its flirting with compulsory license for anthrax and a solution to the 31(f) TRIPS Agreement problem was made possible. "185 The US also considered issuing another compulsory license to supply "Oseltamivir", a drug invented by Gilead and licensed to Roche as "Tamiflu", if a flu pandemic health emergency arose. This drug is regulatory approved to cure a human flu pandemic, including Avian Bird Flu. ${ }^{180}$

\subsubsection{New Developments on Compulsory Licensing}

Much anxiety and indignation has been felt by the developing countries regarding obstacles to access medicines (crucial to protect public health) as a result of the provisions on patent protection for pharmaceuticals, under Article 27 of the TRIPS Agreement. At the time of the Uruguay Negotiations, patent protection for pharmaceuticals was a novel concept for most developing and least developing countries, and therefore their knowledge and experience on providing pharmaceutical patent rights was limited or nil. Negotiations were unbalanced with respect to negotiation power, and lack of information. For example some country Members during the Uruguay Round lacked capacity, both in terms of substantial knowledge and in human capacity. As a result, it was not uncommon that the minister of tourism needed to formulate an opinion on IP matters. NGOs were not very visible in the negotiations and it took a while before world-famous NGOs such as "Oxfam", "Medicine sans Frontiers" came to grips with what exactly pharmaceutical product patent protection really meant for developing and least developed countries. Now, both NGOs and the developing countries are much more aware of the consequences of the provisions of the TRIPS Agreement. Pressure has mounted on WTO Members to amend the TRIPS rules to provide developing countries with access to pharmaceuticals. This pressure has been enhanced by negotiations that simultaneously took place in different fora, such as the World Health Organization (WHO) context and the United Nations Commission on Human Rights on access to medication in the context of pandemics such as HIV/AIDS. ${ }^{157}$ These deliberations have strengthened the call for govermments to take this matter serious.

Lis Love 2005 .

ist Love 2005 .

in: Resolution 2001/33 of the 57th Session of the United Nations Commission on Human Rights. The resolution recognised access to medicines in the context of pandemics as an essential human right and called upon States, at the national level, on a non-discriminatory basis, to: 1) refrain from taking measures which would deny or limit equal access for all persons to preventive, curative or palliative 


\subsubsection{The Doha Declaration on the TRIPS Agreement and Public Health}

During a TTRIPS Council meeting in April 2001 it was agreed to hold a special session of the TRIISS Council to elaborate on the relationship between intellectual property rights and access to pharmaceuticals. ${ }^{195}$ The Doha Ministerial Declaration ${ }^{1 \mathrm{~s} y}$ designed a Work Programme, in an attempt to converge controversial WTO subject matter. The Work programme addressed the TRIPS Agreement in paragraphs 17 to 19 . The concerns on access to medicines are dealt with in paragraph 17:

"we stress the importance we attach to implementation and interpretation of the TRIPS Agreement in a manner supportive of public health, by promoting both access to existing medicines and rescarch and development into new medicines and, in this comnection are adopting a separate declaration". 191

The Declaration on the TRIPS Agreement and Public Health (Declaration on Public Health) adopted in November 2001 recognises the gravity of the public health problems, which had distressed many countries, and stressed that the TRIPS Agreement should not prevent Members from taking measures to protect public health. It re-emphasises and interprets the rights granted under Article 31 of the TRIPS Agreement highlighting the possibilities to invoke a compulsory license and the freedom to determine the grounds upon which such licenses are granted. It also recognised the difficulties faced by some WTO Members to make effective use of the compulsory licensing provision in particular 31(f), affecting those countries that have insufficient or no manufacturing capacities. This section sets out the seven paragraphs of the Declaration on Public Health.

pharmaceuticals or medical technologies used to treat pandemics such as HIV/ AIDS or the most common opportunistic infections that accompany them; 2) adopt legislation or other measures, in accordance with applicable international law, including international agrecments acceded to, to safeguard access to such preventive, curative or palliative pharmaceuticals or medical technologies from any limitations by third parties; 3) adopt all appropriate positive measures to the maximum of the resources allocated for this purpose so as to promote effective access to such preventive, curative or palliative pharmaceuticals or medical technologies.

1ws The need for such a special session of the TRIPS Council was urged by a lawsuit brought by the Pharmaceutical Industry Association against the Government of South Africa, more in particular on the latter compulsory licensing rules following the Medicines and Related Substances Control Amendment Act. The Lawsuit was withdrawn in the end. This case received much media attention, especially through a call from Nelson Mandela bidding the pharmaceutical industry to drop the case.

1.4. See WTO Doha Ministerial Declaration.

(4) Para. 17 of the WTO Doha Ministerial Declaration. 
The Declaration on Public Health acknowledged the concerns of developing and least-developed country Members in its paragraph one:

"We recognize the gravity of the public health problems afflicting many developing and least-developed countries, especially those resulting from HIV/ AlDS, tuberculosis, malaria and other epidenics". ${ }^{191}$

It was also noted that intellectual property alone cannot solve the issue on accessibility of medicine, and therefore in paragraph two of the Public Health Declaration it was emphasised that the TRIPS Agreement should be part of the wider national and international arena to address public health problems, including capacity building in areas such as providing the necessary infrastructure and institutions.

In addition paragraph three of the Declaration on Public Health balances the underlying rationale for IPR protection:

"We recognize that intellectual property protection is important for the development of new medicines. We also recognize the concerns about its effects on prices". 142

Paragraph four of the Declaration on Public Health stipulates that the provisions of the TRIPS Agreement should be interpreted and implemented in favour of protecting public health concerns and promoting access to pharmaceuticals:

"We agree that the TRIPS Agreement does not and should not prevent Members from taking measures to protect public health. Accordingly, while reiterating our commitment to the TRIPS Agreement, we affirm that the Agreement can and should be interpreted and implemented in a manner supportive of WTO Members' right to protect public health and, in particular, to promote access to medicines for all". ${ }^{43}$

Paragraph five highlights some of the flexibilities available in the TRIPS Agreement with regards to public health. The main flexibilities being compulsory licensing, national sovereignty in setting the regime on exhaustion of IPRs and above all developing a national regime in line with the objectives and principles underlying the TRIPS Agreement. The Declaration highlights that:

"In applying the customary rules of interpretation of public international law, each provision of the TRIPS Agreement shall be read in the light of the object

191 Para. 1 of the Declaration on the TRIPS Agreement and Public Health.

102 Para. 3 of the Declaration on the TRIPS Agreement and Public Health.

19.3 Para. 4 of the Declaration on the TIRIISS Agreement and Public Health. 
and purpose of the Agreement as expressed, in particular, in its objectives and principles. Each Member has the right to grant compulsory licences and the freedom to determine the grounds upon which such licences are granted. Each Member has the right to determine what constitutes a national emergency or other circumstances of extreme urgency, it being understood that public health crises, including those relating to HIV/AIDS, tuberculosis, malaria and other epidemics, can represent a national emergency or other circumstances of extreme urgency. The effect of the provisions in the TRIPS Agreement that are relevant to the exhaustion of intedlectual property rights is to leave each Member free to establish its own regime for such exhaustion without challenge, subject to the MFN and national treatment provisions of Articles 3 and $4^{\prime \prime} .^{19 \cdot 1}$

Hence, it explicitly refers to HIV/AIDS, tuberculosis, malaria and other epidemics as constituting a national emergency.

Paragraph six addressed the difficulties of WTO Members with limited pharmaceutical production capacity have in making effective use of the compulsory licensing:

\begin{abstract}
"We recognize that WTO Members with insufficient or no manufacturing capacities in the pharmaceutical sector could face difficulties in making effective use of compulsory licensing under the TRIPS Agreement. We instruct the Council for TRIPS to find an expeditious solution to this problem and to report to the General Council before the end of 2002".
\end{abstract}

\title{
3.6.3. The Waiver Decision: Key to Improving Access to Essential Medicines?
}

As explained above the biggest upheaval was caused by Article 30(f) TRIPS Agreement, which requires that "any such use [of compulsory license] shall be authorised predominantly for the supply of the domestic market of the Member authorising such use". This provision has constituted the biggest obstacle for countries without manufacturing capacities, as it stops them from importing necessary drugs from other countries that are equipped with facilities to produce generic drugs. As a result the compulsory licensing provisions were of little use to the Members which do not have pharmaceutical manufacturing capabilities, as they were only allowed to import small amounts from other countries and on the condition that the other country had also invoked a compulsory license. The TRIPS Council was designated to find a solution to this obstacle and presumed injustice under paragraph six of the Declaration of Public Health.

However, paragraph six of the Doha Declaration proved too complex and controversial and the initial deadline of 2002 to reach a solution was not

14 See para. 5 of the Declaration on the TRIPS Agreement and Public Health. 
reached. ${ }^{195}$ The most contentious points were: which countries would be eligible to export the generic medicine (e.g. the US was in favour of only allowing the developing countries); the limited scope of the disenses being allowed for compulsory licensing (e.g. the US was in favour of limiting the diseases to a selected group of identified life threatening illnesses) and; anti-diversion measures to preant parallel import of medicines to other countries rather than the intended beneficiary. Eventually, the WTO Member govermments broke the deacllock ${ }^{1 \%}$ on 30 August 2003 and made a decision entitled "Implementation of paragraph six of the Doha Declaration on the TRIPS Agreement and Public Health (generally known as the Waiver Decision)". ${ }^{197}$ It waives, under exceptional circumstances, countries obligations set out in paragraphs $(f)$ and $(h)$ of Article 31 of the TRIPS Agreement with respect to pharmaceutical products. The Decision sets out that the waiver will last until the TRIPS Article is altered by virtue of a permament amendment. ws

The waiver Decision lays down the conditions and procedural requirements under which a waiver is permitted. ${ }^{(x)}$ Paragraph two stipulates that

"the obligations of an exporting Member under Article 31(f) of the TRIPS Agreement shall be waived with respect to the grant by it of a compulsory license to the extent necessary for the purposes of production of a phamaceutical product(s) and its export to an eligible importing Member(s)".2th)

This implies that the requirement of Article 31(f) (that the use of the compulsory license ought to be predominantly for the supply of the domestic market of the country authorising the compulsory license) can be bypassed to supply the country not in possession of manufacturing capacities. Certain conditions are applicable, namely that the eligible importing Member has to notify the

145. The TRIISS Council was requested to solve the remaining difficulty at the latest by 31 December 2002. Although the intention was to solve the remaining issue, before the end of 2002, this deadline was not met. For a certain time it seemed that it was impossible to achieve an arrangement.

$1 \mathrm{~m}$ Negotiation strategies reflect certain interests and they may change if situations change. For instance the US was known for being a fervent opponent of the use of compulsory licensing schemes. However, it rapidly introduced ways to circumvent patent laws to respond to the anthrax threats in 2001.

14: Implementation of paragraph six of the Doha Declaration on the TRIPS Agreement and Public Health, Decision of the General Council of 30 August 2003, General Council, WT/L/540 and Corr. 1, 1 September 2003, referred to as the Waiver Decision (hereinafter Waiver Decision).

14 Para. 11 of the Waiver Decision stipulates that the waivers granted in it shall terminate for each Member on the date on which an amendment to the TRIIS Agreement replacing its provisions takes effect for that Member. It was envisaged that the work should finish by the end of 2003 / beginning of 2004 .

1'w See paras. 1, 3, and 4 of Art. IX of the Waiver Decision.

2uil See para. 2of the Waiver Decision. 
TRIPS Council. 211 The notification needs to specify the names and quantity of the product needed, and confirms that the importing Member has established that it has insufficient or no pharmaceutical manufacturing capacities and that it has the intention to grant a compulsory license. In addition, the compulsory license needs to fulfil the following conditions by the exporting Member:

"(i) only the amount necessary to meet the needs of the eligible importing Member(s) may be manufactured under the license and the entirety of this production shall be exported to the Member(s) which has notified its needs to the Council for TRIPS;

(ii) products produced under the license shall be clearly identified as being produced under the system set out in this Decision through specific labelling or marking. Suppliers should distinguish such products through special packaging and/or special colouring/shaping of the products themselses, provided that such distinction is feasible and does not have a significant impact on price; and (iii) before shipment begins, the licensee shall post on a website the following information:

- the quantities being supplied to each destination as referred to in indent (i) above; and

- the distinguishing features of the product(s) referred to in indent (ii) ahove".202

Paragraph three of the Waiver Decision, makes reference to the obligation mentioned in Article 31(h) of the TRIPS Agreement. In that the right holder shall be paid adequate remuneration. It stipulates that in case a compulsory license is granted both by an exporting country (the country with the manufacturing capabilities), and an eligible importing Member, the latter is freed from its obligation to pay compensation to the right holder for those products for which the exporting country has paid remuneration. Nevertheless, it is possible that the exporting country calculates these costs into their sale price. Paragraph three reads:

"Where a compulsory license is granted by an exporting Member under the system set out in this Decision, adequate remuneration pursuant to Article 31(h) of the TRIPS Agreement shall be paid in that Member taking into account the conomic value to the importing Member of the use that has been authorized in the exporting Member. Where a compulsory license is granted for the same products in the eligible importing Member, the obligation of that Member under Article $31(h)$ shall be waived in respect of those protucts for which remuneration in accordance with the first sentence of this paragraph is paid in the exporting Member".21:3

2:11 Least developing countries are excluded from this obligation as it is believed not to have manufacturing capacities.

2:12 See para. 2(b) of the Waiver Decision.

20,3 See para. 3 of the Waiver Decision. 
The risk of parallel importation has caused much controversy. It has been feared that the products made under the compulsory licensing system were not reaching their target, that they were not providing countries without manufacturing capacities with the necessary drugs to benefit public health. But instead the generics were being resold to countries at dump prices in contrast to the normal price for the "real" pharmaceuticals. To prevent the leaking of the drugs into the "wrong" hands paragraph four demands that anti-diversion measures are installed to prevent the re-sale of the imported generic products under the compulsory licensing system. Paragraph 4 is directed at the eligible importing Member. Paragraph four reads:
"In order to ensure that the products imported under the system set out in this Decision are used for the public health purposes underlying their importation, eligible importing Members shall take reasomable metasure's within their means, proportionate to their atministration capacities and to the risk of trate diversion to prevent re-exportation of the products that have actually been imported into their territories under the system. In the event that an eligible importing Member that is a developing country Member or a least-developed country Member experiences difficulty in implementing this provision, developed coun- try Members shall provide, on request and on mutually agreed terms and condi- tions, technical and financial cooperation in order to facilitate its implementa- tion".2114 (emphasis added FC)

No indication is provided as to what constitutes "proportionate to their administrative capacities" to prevent re-exportation of the products in question. It is also not clear to what extend developed country Members should provide technical and financial cooperation to establish the anti-diversion measures.

The whole issue of drugs reappearing on the exporting countries is also addressed by paragraph four of the decision which declares that imported products under the system should only be used for the public health purposes for which they were intended. It requires that "reasonable measures" are taken to prevent the risk of trade diversion but does not specify what reasonable measures are. Developed country Members were asked to provide financial and technical support to developing countries to fulfil this obligation. Even developed countries - see NHS example $e^{205}$ - could use a little help on this matter. Hence, Members have to install effective legal means (border controls etcetera) to prevent the importation into, and subsequent sale, into their territory in accordance with paragraph five.

Paragraph five addresses all WTO Members in general to install all the legal measures to prevent and/or put a halt to the importation and sale of the

204 See para. 4 of the Waiver Decision.

215 BBC news, 24 April 2005, "NHS bought Africa's Aids drugs", <http://news.bbe.co. $\mathrm{uk} / 1 / \mathrm{hi} /$ health/4477921.stm>. Further explained in section 3.6.3.1 of this chapter. 
generic goods which are not intended for their markets. Paragraph five stipulates:

\begin{abstract}
"Members shall ensure the availability of effective legal means to prevent the importation into, and sale in, their territories of products produced under the system set out in this Decision and diverted to their markets inconsistently with its provisions, using the means already required to be available under the TRIPS Agreement. If any Member considers that such measures are proving insufficient for this purpose, the matter may be reviewed in the Council for TRIPS at the request of that Member".20u"
\end{abstract}

The General Council Chairperson's Statement, ${ }^{2 n-}$ drafted to compliment the Waiver Decision, can probably be seen as a sort of Preamble to the Decision. It was partially intended to reassure those who feared that the decision might be abused and undermine patent protection. It emphasised that the system should be used in good fnith to potect molic henlth and not to pursue industrial or commerial policy objoctives. It stresses that Members are to take all "reasonable measures" to prevent the diversion of products - including formulated pharmaceuticals, active ingredients or finished products. It is understood that the reference "reasonable measures" points to spocinl lablling, colouring, shaping and sizing to differentiate products supplied through tonor or discounted pricing programmes from those supplied to other markets.

The importance of promoting local investment in producing pharmaceutical drugs by building capacity and stimulating the transfer of tochology (i.e. to be self sufficient in future) into the developing country territories in the pharmaceutical sector is acknowledged in paragraph seven:

\begin{abstract}
"Members recognize the desirability of promoting the transfer of technology and capacity building in the pharmaceutical sector in order to overcome the problem identified in paragraph 6 of the Declaration. To this end, eligible importing Members and exporting Members are encouraged to use the system set out in this Decision in a way which wouk promote this objective. Members undertake to cooperate in paying special attention to the transfer of technology: and capacity building in the pharmaceutical sector in the work to be undertaken purstant to Article 66.2 of the TRIPS Agreement, paragraph 7 of the Declaration and any other relevant work of the Council for TRIPS".2115
\end{abstract}

2ith See para. 5 of the Waiver Decision.

217. The General Council Chairperson's statement, 30 August 2003, New's Item available on the WTO website. See <http:/ wto.org - Press/350/Rev.1 - 30 August 2003>.

2 is see para. 7 of the Waiver Decision. 


\subsubsection{Evaluation of the Waiver Decision}

The Agreement was praised by many, for instance, former WTO DirectorGeneral Supachai Panitchpakdizik called it

"a historic moment for the WTO, [in that] it proves once and for all that the organization can handle humanitarian as well as trade concerns. (...) The fact that WTO members have managed to find a compromise in such a complex issue bears testimony to their goodwill".211

Elucidation on paragraph six was necessary for WTO members with insufficient or no manufacturing capacities in the pharmaceutical sector to enable them to use the compulsory licensing arrangements provided for in the TRIPS Agreement. Equally, the WTO Member countries with the possibility of exporting generic drugs wanted to know the state of affairs.

But does the Waiver Decision really improve access to essential medicines in developing countries? Notwithstanding the waivers from paragraph ( $f$ ) and to a lesser extent (h) of Article 31, even with the Decision in place, the importing Member is still dependent on at least two factors before benefiting from the compulsory licensing scheme: firstly on the willingness of mother commtry to produce the pharmaceuticals and secondly the grant of a compulsory license by the exporting country.

Furthermore the cost of obtaining generics from the exporting country, supplemented with the reasonable remuneration costs to be paid to the patent holder can still be too high for the least developing countries. The question remains as to what amounts for a reasonable remuneration. The only reference in the Waiver Decision to remuneration is made in paragraph three which states that adequate remuneration pursuant to Article 31(h): "shall be paid taking into account the economic value to the importing Member of the use that has been authorized by the exporting Member". ${ }^{211}$

This sophistication towards the original paragraph (h) could be seen as favourable to developing countries, since it recognises different economic markets. What is more worrying is that the additional cost to differentiate the pharmaceuticals may have a detrimental effect on the availability of medicines as pharmaceutical companies might find it less cost-efficient to make these adjusted or modified medical products. The permanent amendment, as discussed below, withdraws this argument. Besides, the right holder does have the

z(N) Mr. Panitchpakdi is currently the Secretary-General of UNCTAD.

211 The General Council Chairperson's statement, 30 August 2003, News Item available on the WTO website. See <http://wto.org - Press/350/Rev.1 - 30 August 2003>.

211 See para. 3 of the Waiver Decision. 
option of legal remedy under Article 31(i) (in which the legal validity of the grant of a compulsory license is subjected to judicial review) so it remains an uncertain situation for (least) developing countries. Apart from this, paragraph three states that in case a compulsory license is granted both by an exporting country (the country with the manufacturing capabilities), and an eligible importing Member, the latter is freed from its obligation to pay compensation to the right holder in respect of those products for which the exporting country has paid remuneration.

In addition, a note of concern relates to the large admimistratio' burden of procedural arrangements that is imposed on the importing country as set out in paragraph two of the decision. 212 'The notification should include details on the wish to use the system, what product is needed, its quantity and how the country has established that it has insufficient capacities to produce this particular medicine and that the compulsory licence (will) conform with the conditions set out in Article 31 of the TRIPS Agreement. The exporting country, for its part, needs to issue a compulsory license and is entitled to produce only the required quantity which it shall export in its entirety to the member which has made a notification to the TRIPS Council. An additional requirement is that the products need to be distinguishable as products made especially for this system through specific labelling or marking, packaging and/or colouring/shaping without significantly enhancing the cost of the product. The exporting Member is obliged to notify the TRIPS Council on the grant of license and its specific content (under paragraph 2(c) of the Waiver Decision).

It should be noted that the Members' obligation to make a notification is not a permission request in disguise, but is intended for review purposes and transparency (implying a new role for the TRIPS Council). ${ }^{21.3}$ Nevertheless the notification request can involve a lengthy process, depriving countries in the meantime from the pharmaceuticals.

212 Greg Perry, Director General of the European Generic Medicines Association and Rachel Kiddel-Monroe, Chair of the Board, Universities Allied for Essential Medicines, Former MSF Access to Essential Medicines Campaign Canada Coordinator have expressed that the WTO created system does not work in reality. The process to obtain medicines is too long, too constrained with bureaucratic bustle and therefore has only been used once. See "Five years from the Decision to Action: Is the2003 August Decision the 'expeditious' solution for access to medicines we need?", WTO Public Forum "Trading into the Future", 24-25 September 2008, <http://www.wto.org/english/forums_e/public_forum08_e/programme_e.htm>.

21: As commented by Roger Kampf, Counselor, Intellectual Property Division, WTO Secretariat at the WTO Public Forum. See "Five years from the Decision to Action: Is the2003 August Decision the 'expeditious' solution for access to medicines we need?", WTO Public Forum "Trading into the Future", 24-25 September 2008, <http://www.wto.org/english/forums_e/public_forum08_e/programme_e.htm>. 
A victory for the developing countries is that the number of diseases to which this system is applicable is not limited as was previously envisaged in proposals by the US.2lt Instead the decision follows the list set out in the Declaration. 215 Apart from this, the notification obligation further mandates Member countries to notify if they will use the system in whole or in a limited way. Notably countries have expressed different attitudes towards the proposed system. A number of Members declared that, if they use the system, it will only be in situations of national emergency or other circumstances of extreme urgency. ${ }^{210}$ This implies that other Members may use the system with large flexibility as regards self determination and use the system in situations other than in conditions of national emergency or other circumstances of extreme urgency. ${ }^{21-}$

The political decision to adopt the Waiver Decision is not the only achievement: All the tumult and publicity let to an increased awareness of the every day struggle of developing countries to survive in economical terms and address their health care concerns. A moral obligation of people in wealthier parts of the world to act, served as a stimulus for policy alternatives. Examples of these policy alternatives (as opposed to the Doha-based solution) include the following: 1) An increase in pharmaceutical companies donating medicine free of charge or for non profit prices. ${ }^{21 s} 2$ ) Improvement of local development to break the dependency culture on foreign medicine and to stimulate R\&D as opposed to generics. Therefore, capacity building is needed to improve manufacturing productivity. 3) $\ln$ this respect an international treaty to promote research and innovation may be one way forward.2" 4) Public private partnerships are installed to develop medicine specifically tailored to the needs of the developing world; the Clobal Fund to fight aids, tuberculosis and malaria

214 As follows from a news report: "By' early' 2002 USTR officials were complaining that the Bush White House was intensively supervising their negotiations on the "para. 6" issue. Meanwhile, big [pharmaceutical] companies reportedly raised some \$30 million for Karl Rove that was used very effectively in swing states to keep the republicans in control of the House and Senate. From this point on, the White House was micromanaging the negotiations on the export issue. During a dramatic period near Christmas 2002, USTR claimed that it was sometimes receiving hourly calls from the White House, who were pushing unsuccessfully to limit the waiver of the export restriction to a handful of diseases, which was the position preferred by [pharmaceutical company] Pfizer", Love 2005.

215 See WTO Doha Ministerial Decharation.

210 See WTO Doha Ministerial Declaration, footnote 3.

21. See Matthews 2004, p. 95.

21s The back side being that the supply of medicine is not guaranteed as the pharmaceutical industry can decide to withdraw their contribution as they see appropriate.

$21^{19}$ As proposed by Barton 2007. 
(WHO initiative) gathers funds and these donations are used to acquire medicine for developing countries.220

An example to show that anti-diversion measures are not always effective is revealed by the NHS example. The BBC came up with information that the shipments of anti-retrovirals (provided free or not for profit prices by Glaxo Smith Cline) earmarked for developing countries ended up in NHS health service. The investigation proved that shipments did actually reach the Senegal but never left the airport since they were resold to a French company by aid of corrupt charity and government officials. Thereafter the drugs were bought by a Swiss company and sold to a hospital in the UK. As a result, the NHS obtained anti-retrovirals to treat Aids, which were illegally diverted from Africa for the benefit of the tax payer in the UK.221

This example shows that also developed countries have problems with preventing drugs from missing its destination and to stop the lucrative practice of corrupt businessmen. In the above mentioned case the pharmaceutical company had not taken the necessary precautions; since the same package and license number was used for the French speaking part of Europe. For instance, diversion can be prevented by using unique (outer) packaging and labelling, batch numbers, a different colour coating, different markings/imprints on capsules, different trademark names and codes, shapes. ${ }^{222}$ Another possibility, in a bid to prevent diversion, is for producers to contractually regulate the distribution of the products as to guarantee shipment to the intended market. Moreover, improved information to customs control and caution by buyers can contribute to stop this unfair parallel trade. In the presented example, developed countries failed to implement anti-diversion measure which shows

220 However, in some cases it is better to avoid too much interference of donors on policy making. Examples: Draft Bill (USAID) and Abstain campaign by the US Government which resulted in condoms being three months out of stock. Interview with Mrs Rosette Mutambi - coordinator Coalition for Health Promotion and Social Development (HEPS) Uganda. HEPS is active in the field of consumer rights, health sector (including access to medicine project), health policy adrocacy (acts on misbehaviour in the health sector, provides counselling). It also lobbies governments, primarily on increasing government spending on pharmaceuticals and health sector as a whole. Biggest success is a tax reduction on medicine. Interview conducted by the author July 2007.

221 BBC new's, 24 April 2005, "NHS bought Africa's Aids drugs", <http://news.bbc.co. uk/1/hi/health/4477921.stm>.

222 The General Council Chairperson's statement provides a best practices guidelines in attach with examples of differentiating measures taken by pharmaceutical companies. The General Council Chairperson's statement, 30 August 2003, News Item avalable on the WTO website. See <http://wto.org-Press/350/Rev.1-30August $2003>$. 
that amongst others, the trouble is border control and adequate supply of information.

The August 30 waiver decision provided the mandate to the TRIPS Council to begin negotiations on a permanent amendment to the TRIPS Agreement. The permanent decision the procedures and safeguards ought to be simplified as to remove the administrative burden on developing countries and parallel trade and reference pricing need to be further scrutinised to address concerns of the pharmaceutical industry as to continue their incentive to invest and develop. Matthews regards the EC Council Regulation to Avoid Trade Diversion into the European Union of Certain Key Medicines, ${ }^{223}$ which benefits from the EU doctrine of regional exhaustion, as a good example to avoid trade diversion in low-cost essential medicines. ${ }^{22.4}$ The Regulation aims to establish a global tiered pricing system for key pharmaceuticals for the prevention, diagnosis and treatment of HIV/AIDS, TB and malaria and related diseases for the poorest developing countries and to prevent product diversion of these products to other markets by ensuring that effective safeguards were in place. ${ }^{225}$ Paragraph five of this EC Regulation reads:

"Price segmentation between developed country markets and the poorest developing country markets is necessary' to ensure that the poorest developing countries are supplied with essential pharmaceutical products at heavily reduced prices. Therefore, these heavily reduced prices cannot be understood as a reference for the price to be paid for the same products in developed country markets".

This Regulation serves the purpose of preventing tiered priced products from being imported into the European Community and sets out conditions under which customs authorities should take action and measures which should be taken by designated authorities in the EU Member States to prevent tiered priced products from being imported into the Community.

The whole debate led to the recognition that it is not just patented drugs that impede developing countries from accessing the essential drugs. Other factors such as poverty, tariffs and sales taxes and inadequate international funding,

223 EC Council Regulation to Avoid Trade Diversion into the European Union of Certain Key Medicines, of 26 May 2003, No 953/2003, published online at: <http:// trade.ec.europa.cu/antitradediversion_html/en.pdf>. Para. 7 sets out that "There is a need to encourage the pharmaceutical producers to make pharmaceutical products available at heavily reduced prices in significantly increased volumes by ensuring through this Regulation that these products remain on those markets".

224 See Mathews 2004, p. 106-107.

225 See para. 1 of the EC Council Regulation to Avoid Trade Diversion into the European Union of Certain Key Medicines. 
just as, improved infrastructure and good governance are also significant. ${ }^{220}$ The whole discussion around the waiver discussion provided insight into a much-forgotten part of the globe and has raised awareness of the difficult positions they found themselves. It does allow them to import generics from countries in the possession of manufacturing capacities even though under very strict conditions and administrative burdens as set out above. Most importantly the whole debate embarked on a new area of political discourse and moral duties to help countries such as Africa in need. It shows that the Dohabased solution is only part of the solution to improve access to medicines and that there are multiple policy options to improve access to medicine and standards of health care in the developing world. Foremost, it is important to have political support for the Waiver. In addition, the low take-up of donated pharmaceuticals is also a point of concern because of bad governance (e.g. governments that stockpile the donated medicines), taxes, bad infrastructure or unstable regions. ${ }^{22}$

\subsubsection{Article 31bis TRIPS Agreement: Making the Waiver Permanent}

Article 31 bis TRIPS228 Agreement provides the long awaited permanent solution to the waiver. Article 31 bis is the first amendment made to the TRIPS Agreement since its adoption. Article 31 bis reads as follows:

"1. The obligations of an exporting Member under Article 31 (f) shall not apply" with respect to the grant by it of a compulsory licence to the extent necessary for the purposes of production of a pharmaceutical product(s) and its export to an cligible importing Member(s) in accordance with the terms set out in paragraph 2 of the Annex to this Agreement.

2. Where a compulsory licence is granted by an exporting Member under the system set out in this Article and the Annex to this Agreement, adequate remuneration purstant to Article 31(h) shall be paid in that Member taking into account the economic value to the importing Member of the use that has been authorized in the exporting Member. Where a compulsory licence is granted for the same products in the eligible importing Member, the obligation of that Member under Article 31 (h) shall not apply in respect of those products for which remuneration in accordance with the first sentence of this paragraph is paid in the exporting Member.

3. With a view to harnessing economies of scale for the purposes of enhancing purchasing power for, and facilitating the local production of, pharmaceutical products: where a developing or least-developed country WTO Member is a

22t See Matthews 2004, p. 75.

227 This may be due to bureaucracy on the side of the donor company, or refer to lacking political commitment by developing country govermments, infrastructure deficiencies stopping distribution, inadequate health care sy'stems and skepticism against drugs, Matthews 2004, p. 98.

22. TRITS Amendment, Annex to the Protocol amending the TRIPS Agreement, WTO, Decision of 6 December 2005, WT/L/641, 8 December 2005. 
party to a regional trade agreement within the meaning of Article XXIV of the GATT 1994 and the Decision of 28 November 1979 on Differential and More Favourable Treatment Reciprocity and Fuller Participation of Developing Countries (L/4903), at least half of the current membership of which is made up of countries presently on the United Nations list of least-developed countries, the obligation of that Member under Article $31(f)$ shall not apply to the extent necessary to enable a pharmaceutical product produced or imported under a compulsory licence in that Member to be exported to the markets of those other developing or least-developed country parties to the regional trade agreement that share the health problem in question. It is understood that this will not prejudice the territorial nature of the patent rights in question.

4. Members shall not challenge any measures taken in conformity with the provisions of this Article and the Annex to this Agreement under subparagraphs $1(b)$ and $1(c)$ of Article XXIII of GATT 1994.

5 . This Article and the Annex to this Agreement are without prejudice to the rights, obligations and flexibilities that Members have under the provisions of this Agreement other than paragraphs (f) and $(h)$ of Article 31, including those reaffirmed by the Declaration on the TRIPS Agreement and Public Health (WT/MIN(01)/DEC/2), and to their interpretation. They are also without prejudice to the extent to which pharmaceutical products produced under a compulsory licence can be exported under the provisions of Article 31(f)".

The waiver solution was made permanent on 6 December 2005, allowing countries with inadequate production facilities to import medicines produced under compulsory license in third countries. ${ }^{22}$

The new Article 31 bis and the annex to the TRIPS Agreement are copied from the Waiver Decision with only few differences. The order of the paragraphs has changed. Where the Waiver started with an enumeration of definitions, Article 31 bis comes straight to the core and all definitions and clarifications are explained in an Annex. Also, the list of countries that have explicitly expressed that they will not use the system as importing Members has been enlarged due to the enlargement of the European Union to a total number of 27.

The Waiver Decision and the annex to the TRIPS Agreement define a pharmaceutical product, an eligible importing member and an exporting member as follow's:

"A pharmaceutical product means any patented product, or product manufactured through a patented process, of the pharmaceutical sector needed to address the public health problems as recognized in paragraph 1 of the Declaration on the TRIPS Agreement and public health. It is understood that active ingredients necessary for its manufacture and diagnostic kits needed for its use would be included. Eligible importing Member refers to any least-developed country Member, and any other Member that has made a notification to the

23.) See TRIPS Amendment. 
Conncil for TRIPS of its intention to use the system as an importer, it being understood that a Member may notify at any time that it will use the system in whole or in a limited way, for example only in the case of a national emergency or other circumstances of extreme urgency or in cases of public non-commercial use (...). Exporting Member refers to a Member using the system set out in this Decision to produce pharmaceutical products for, and export them $t o$, an cligible importing Member".2?

It establishes a system by which eligible importing Members must notify the TRIIS Council about pharmaceuticals needed and by which a compulsory license will be granted if the drug is patent-protected in the exporting country's territory. Meanwhile, the exporting country must issue a compulsory license and notify the TRIISS Council of the existence and terms of the licence. Eligible importing countries must take reasonable measures to prevent pharmaceuticals produced under the compulsory licence scheme from leaking out of their territories and being resold in other countries. All members must employ effective legal means to prevent the importation into, and sale in, their territories products produced under the system and diverted to their markets. The system is to be reviewed ammually.

The Appendix to the Annex sets out that least-developed country Members are deemed to have insufficient or no manufacturing capacities in the pharmaceutical sector. Other eligible importing Members need to proof insufficient or no manufacturing capacities for the product in question through 1) establishing that it has no manufacturing capacity in the pharmaceutical sector, or, 2) where the Member has some manufacturing capacity in this sector, through examining and concluding that its production is insufficient for the purposes of meeting its needs.

\subsubsection{Ratification of the TRIPS Amendment}

In order for the TRIPS amendment to take effect WTO Members need to ratify the agreement in their domestic legislation. It was decided in December 2005 when the amendment was adopted that it needed to be ratified by two-third of WTO Members by the end of 2007 (around 100 Members). This deadline was missed as only 11 Members had ratified the amendment by the end of 2007 . The European Union (27 countries) and China followed which extends the number of ratifying countries to 39 .

The TRIPS Council session extended by two years (hence, till the end of 2009) the deadline for Members to ratify an amendment to TRIPS rules aimed at facilitating poor countries' ability to import affordable medicines. ${ }^{231}$ If it enters into force, the amendment will make permanent the August 2003 Waiver

23i) Ibid.

231 See TRIPS Council meeting of 23-24 October 2007 in Geneva. 
procedure spelling out the conditions under which WTO Members can legally suspend drug patents for the production and export of cheap generic medicines to poor countries unable to manufacture them.

\subsubsection{Use of the Compulsory Licensing Scheme}

It is one thing having such a written declaration - first the waiver and then the permanent amendment, however, it is equally important to have political support from the powerful nations for the Declaration. Thailand, a country that has invoked the compulsory licensing scheme a number of times has received much criticism from the manufacturing industry and from country governments on these practises. ${ }^{232}$ The same goes for Brazil. This tumult has made developing countries afraid that industry will stop investing in their countries if they use the compulsory licensing system (or receive political pressure from the brand name company).

As explained the compulsory licensing scheme has been criticised for being to administratively complex to be effective at improving access to medicines. The little use made of the system so far has strengthened this belief.

However, the TRIPS Council saw the first (and only) notification by Member governments of an attempt to use the waiver. Namely, Rwanda $2 \$ 3$ and Canada ${ }^{23}$ have informed the WTO TRIPS Council of their plan to authorise a Canadian company to produce a generic combination of three patented HIV/

232 As commented by Inthira Yamalhai, Researcher, Health Intervention and Technology Assessment Program, Bureau of Policy and Strategy-MOPH in Thailand. See "Five years from the Decision to Action: Is the2003 August Decision the expeditious' solution for access to medicines we need?", WTO Public Forum "Trading into the Future", 24-25 September 2008, <http://www.wto.org/english/forums_e/ public_forum08_e/programme_e.htm>.

23.3 Notification by Rwanda to the TRIPS Council, IP/N/9/RWA/1, 19 July 2007. The procedure is as follows: Rwanda government notifies to the WTO, the generic company in Canada negotiates a voluntary license with the pharmaceutical company (the patent right holder) and negotiates royalty fees. If they cannot reach agreement on this voluntary license within 30 days, the generic producer may ask its govermment (in this case Canada) to issue a compulsory license and determine rovalty fees. Pursuant, the generic company needs to create a website indicating the quantity of medicines being supplied to Rwanda as well as details on the distinguishing characteristics - packaging, shaping, colouring - aimed at differentiating the generic products from the original brand name version of the product and at avoiding the illegal diversion of the generic produced product into markets where they might displace the full priced brand name version of the product. Canada needs to inform the WTO of its intention to export the products to Rwanda, detailing information about the license, the quantity, and the two-year duration. After all these steps the generic pharmaceuticals can be exported to Rwanda.

234 See Bridges Weekly 'Trade New's Digest 2007 d. 
AIDS drugs for export to Rwanda. ${ }^{235}$ On 25 September 2008 Rwanda received the much awated medicine from India because that turned out to be cheaper. 230

\title{
3.7. Test Datn (Exclusinity)
}

Article 39.3 of the TRIPS Agreement stipulates that:

\begin{abstract}
"Mombers, when requiring, as a condition of approving the marketing of pharmaceutical or of agricultumal chemical products which utilize new chemical entities, the submission of undisclosed test or other data, the origination of which involves a considerable effort, shall protect such data against unfair commercial use. In addition, Members shall protect such data against disclosure, except where necessary to protect the public, or unless steps are taken to ensure that the data are protected against unfair commercial use".
\end{abstract}

Article 39.1 of the TRIPS Agreement sets out that:

"In the course of ensuring effective protection against unfair competition as provided in Article 10bis of the Paris Convention (1967), Members shall protect undisclosed information in accordance with paragraph 2 and data submitted to governments or governmental agencies in accordance with paragraph $3^{\prime \prime} .{ }^{27}$

Article 39 of the TRIPS Agreement imposes obligations on undisclosed information and data in order to ensure effective protection against unfair competition. Article 39.2 establishes the main rule on undisclosed information. Article 39 subparagraph 3 requires protection against unfair commercial use of undisclosed test or other data (this data is derived from the clinical trial period and will provide information whether a product fulfils health and safety measures), necessary to obtain marketing approval for the pharmaceutical or of agricultural chemical products. Article 39.3 stipulates that the data shall be protected against disclosure on the condition that 1) the product utilises new chemical entities (and hence, new uses of existing/known products are excluded) and 2) considerable effort was involved to produce the data. Disclosure is allowed where necessary to protect the public (e.g. to allow a compulsory license) or if steps are taken to protect the data against unfair commercial use. This provision does not apply when it is not necessary to submit such

235 See Bridges Weekly Trade News Digest $2007 \mathrm{c}$.

23, Rachel Kiddel-Monroe, Chair of the Board, Universities Allied for Essential Medicines, Former MSF Access to Essential Medicines Campaign Canada Coordinator. See "Five years from the Decision to Action: Is the 2003 August Decision the 'expeditious' solution for access to medicines we need?", WTO Public Forum "Trading into the Future", 24-25 September 2008, <http://www.wto.org/english/forums_ e/public_forum(18_e/programme_e.htm>.

23 See Art. 39.1 of the TRIPS Agreement. 
data as a condition to receive marketing approval for pharmaceutical or agrochemical products. This is for instance the case when, marketing approval is granted by the national authority relying on prior registration elsewhere - in other words, the national authority does not request test data but takes decisions on the basis of registration granted in a foreign country. In contrast to patents, test data is not the result of creative of innovative processes but is created following established protocols; it is in written form and details the results of scientific health and safety testing of drugs and agrochemicals, in relation to human, animal and plant health, impact on the environment and efficacy of use. ${ }^{23 x}$ In addition,

\begin{abstract}
"the market power of data exclusivity is, in theory, less restrictive, mainly because it does not legally prevent other companies from generating their own registration data. However, in practice, the vast financial resources and extended time required for gathering and generating pharmaceutical registration data for a new drug create a market barrier that is too high for generic based companies".234
\end{abstract}

The national authority is for instance the US Food and Drug administration (FDA) or the European Agency for evaluation of medicinal products (EMEA).

There is controversy among the legal experts whether Article 39.3 of the TRIPS Agreement obigates Members to provide the original applicant with a temporary right of data exclusivity. The Brussels text had proposed the establishment of a reasonable period of time - (generally no less than five years) of data exclusivity, "commensurate with the efforts involved in the origination of the data, their nature, and the expenditure involved in their preparation".2-10 This approach would imply that test data submitted to obtain marketing approval could not be relied upon for the marketing approval of competing (often generic) products for a reasonable period of time, normally no less than five years. If the Brussels text would have been approved this would have meant that WTO Members had to grant the originator of the data an exclusive right in the produced data. And hence, during the exclusivity period national authorities (receiving the test data to grant market approval) would not be

23* See UNCTAD-ICTSD [Resource Book] 2005, p. 530.

230. According to Pugatch, the underlying logic of data exclusivity suggests that it is an expression of trade secrets and that as such data exclusivity should be independent of patents. Meir Perez Pugatch, "Intellectual Property and Pharmaceutical Data Exclusivity in the Context of Innovation and Market Access", Third UNCTADICTSD Dialogue on Development and Intellectual Property, 12-16 October 2004, Bellagio, Italy. Available at: <http://www.iprsonline.org/unctadictsd/bellagio/ dialogue2004/bell3_documents.htm>.

$2+11$ Draft Final Act Embodying the Results of the UR of Multilateral Trade Negotiations, Revision, TRIPS, Including Trade in Counterfeit Goods, MTN.TNC/W/35/Rev. 1, 3 Dec. 1990 under para. 4 a. 
allowed to rely on this data to assess subsequent applications for the registration of similar products. However in the TRIPS version no reference as to time duration is made according to which Members arguably are not obligated to provide the originator of the data with exclusive property rights but protection should be provided in the framework of unfair competition rules. According to the UNCTAD-ICISD Resource Book:

\begin{abstract}
"Article 39 is based on the concept of unfair competition rules. According to this approach, data originators may prevent third parties from using their data only in the event that the third party has acquired the data through dishonest commercial practices. This enhances the possibility of using existing data for the market entry of competing pharmaceutical products".241
\end{abstract}

The TRIPS Agreement was the first multilateral convention introducing obligations in relation to undisclosed information, including trade secrets and test data. Differences in pre-existing national laws where large regarding the protection of test data relating to phamaceutical and agrochemicals. In fact only a few countries had adopted domestic legislation on the matter before the adoption of the TRIPS Agreement - the US provided test data protection since 1984 and the EU since 1987. The underlying reason for granting protection to data submitted by pharmaceutical companies to regulatory authorities is to protect and safeguard pharmaceutical registration files. ${ }^{242}$ It has been argued that competitors gain an economic advantage if they can free ride on the information gathered by the competing phamaceutical company as they do not have to go through the lengthy and costly process of clinical trials to obtain the data necessary for marketing approval. On the other hand, providing data exclusivity can delay bringing competing (cheaper products) on the market and requires a repetition of clinical trials (a waste of time and money). Not granting data exclusivity might restrain pharmaceutical companies from marketing their products on these territories. Data exclusivity is becoming increasingly dominant as an additional $1 P$ layer of protection. However, the extent to which the term duration of data exclusivity extends beyond the term of patent protection is not clear and more empirical research is necessary. Countries have adopted different approaches to the protection of data, the US type of protection is based on the concept of trade secrets, protection in the $E U$ is based on exclusive rights, and the TRIPS Agreement bases protection on unfair competition (protection against unfair commercial use).

$2+1$ See UNCTAD-ICTSD [Resource Book] 2005, p. 526.

242 Test data is expensive to obtain and can easily cost several million dollars to produce - allowing other companies to use this data gives them an economic advantage as they can avoid these costs. India has established a lucrative market for carrying out the clinical trials necessary to obtain test data. 
Increasingly test data protection has been introduced in bilateral and regional free trade agreements which narrows down the TRIPS flexibilities accorded to the WTO Members. Initially, the EC had been friendlier towards development concerns in its regional and bilateral agreements - merely asking for adequate and effective implementation of the existing IP treaties (in particular WIPO administered treaties and the TRIPS Agreement) but it has recently moved away from this stance by introducing TRIPS plus provisions. For instance, the FTA signed between EFTA and the Republic of Korea expanded the protection in the case of pharmaceutical products to data provided to national authorities on the safety and efficacy of those products. The FTA signed between EFTA and the Republic of Korea in 2005 makes reference to Article 39.3 TRIPS. The provision reads as follows:

"The Parties shall protect undisclosed information in accordance with Article 39 of the TRIPS Agreement. The parties shall prevent applicants for marketing approval for pharmaceutical and agricultural chemical products from relying on undisclosed test or other undisclosed data, the origin of which involves a considerable efforl, submitted by the first applicant to the competent authority for maketing approval for pharmaceutical and agricultural chemical products, utilizing new chemical entities, for an adequate number of years from the date of approval, exeept where approval is sought for original products. Any Party may instead allow in their national legislation applicants to rely on such data if he first applicant is adequately compensated".2.3

The NAFTA Agreement also contains a specific provision on the matter (Article 1711) although it differs from the TRIPS Agreement in that it is based on the concept of trade secrets rather than undisclosed information. It also adds a TRIPS plus element in that it requests a minimum five-year period.

\subsection{Initiatioes on Access to Medicine Problem}

Intellectual property rights are only one of the puzzle pieces necessary to facilitate access to medicines. ${ }^{2+4}$ Other important factors are improving supply

24: Korea-European Free Trade Association (EFTA) FTA, signed on 15 December 2005, entered into force on 1 September 2006.

24 Health campaigners view the patent system as inadequate to address the need for R\&D in neglected discases. They argue that the patent system encourage high prices since patent right holders only have limited time to recoup their R\&D expenditure as well as marketing costs and costs related to unsuccessful inventions. In addition, they argue that the patent system does not encourage R\&D into "neglected diseases", when the main market for a new medicine would be poor people who cannot afford to pay high prices. See Bridges Weekly Trade News Digest 2007g. However, these health campaigners, such as MSF and Oxfam, have been criticised for sending the wrong message to the debate, in that they argue to eliminate patent protection in order to facilitate access to medicines. Benedetto Della Vedova, member of the Italian Chamber of Deputies and a former member of the European 
chain infrastructure to distribute the pharmaceuticals - this involves good governance, transport mechanisms, customs authorities and open economies, education, culture and training of doctor's and nurses and tax burdens on medicines. One of the other great threats to world health is poverty. To a large extent (almost 50 per cent of the cases) the cause of the disease is related to poor nutrition, water quality, air pollution and lack of proper sanitation. Poverty also impedes access to pharmaceuticals but not necessarily because of prices as indicated above there are many factors impacting on accessing pharmaceuticals. Hence, the real threat to access to medicines is the fragility of health systems, such as the absence of supply chains and infrastructure. ${ }^{245}$

It is advisable that governments provide incentives to research and development into neglected diseases. The US Orphan Drug Act, enacted in 1983, provides tax credits and market exclusivity for developing treatment for rare diseases. As a result, the annual creation of new treatments for rare diseases was 12 times greater in the 16 years following the passage of the Orphan Drug Act than in the previous decade. The success of the legislation has led to similar models in Japan and the European Union. ${ }^{2+4}$

Other initiatives that could contribute to providing an incentive to the development into neglected diseases are price funds or a voucher system. For instance, the Federal Drug Administration (FDA) have introduced a voucher system in the Federal Drug Administration Amendments Act 2007. This system would reward companies that develop new treatments for neglected diseases with vouchers for a FDA "priority review" of any other drug. The system seeks to provide new types of incentive to improve research into 'tropical diseases' (synonym for neglected diseases) as defined by US regulations. A company that registers a drug aimed at these diseases with the FDA could be eligible for what is called a Priority Review Voucher. The voucher could be valuable, because it can be used by the owner to gain a fast-track approval for other drugs it might want to register in the future. This could reduce the average registration time from ten to six months. The idea behind the system is that shorter approval times are worth a lot of money to many

Parliament, argues that the "[d]evelopment of pharmaceuticals is among the most expensive and risky business propositions in the world. Only 0.2 per cent of chemical compounds tested by a pharmaceutical company will ever go to market. Each drug takes ten years to develop and costs about $\$ 1$ billion. And of the few medicines that do eventually reach consumers, 70 per cent will never be profitable". See Della Vedova 2008.

2i: See Della Vedova 2008.

2.th The EC $7^{\text {th }}$ research framework programme (FP7), 2007 with an expanded scope on international research cooperation also aims at strengthening and increasing the impact of EU funded international collaborative research on the control of neglected infectious diseases (NIDs). 
pharmaceutical manufacturers, who may want to bring commercially valuable products, such as blockbuster drugs, on to the market as quickly as possible. The system hopes to accommodate these manufacturers that has shelved research into a tropical disease product, because of its limited commercial returns, will be given incentives to make that product available, in return for help bringing a drug with more chance of commercial success to the market.247 The idea comes from Duke University researchers. ${ }^{2+4}$ it is calculated that the vouchers could be worth up to $\$ 300$ million to a pharmaceutical company that wants to bring a product to the market before its competitors.

\subsubsection{The World Health Organization and Access to Medicine}

The TRIPS Council and the various WIPO committees are not alone in their efforts to find solutions to the access to essential medicines problem. The World Health Organisation (WHO) addresses the relationship between intellectual property and public health in its working group on Public Health, Innovation and Intellectual Property (ICWG).2:49 Prior to the enactment of this working group, the WHO Commission on Intellectual Property Rights, Innovation and Public Health (CIPIH Commission) produced a report on the relationship between intellectual property rights and research and development (R\&D) into diseases disproportionately affecting developing countries. ${ }^{250}$ It makes about 50 recommendations on how to improve the situation but it does not ask for substantive changes to the existing patent system as wanted by health campaigners. ${ }^{251}$ Hence, the report does not deal with whether patent rights hindered access to medicines yet it advises on measures to gain access to

247 See "FDA offers new incentive for development of drugs for neglected diseases", Global Network, Neglected Tropical Diseases. Published online at: <http://www. globalnetwork.org/press/article/2008/9/29/fda-offers-new-incentive-developmen t- drugs-neglected-diseases $>$.

24: See Ridley and Crabowski 2006, p. 313-324.

$2+4$ The issue of better access to healthare products for poor populations has been the subjecl of many. World Health Assembly resolutions. In May 2006, at the Fifty-ninth World Health Assembly, Member States established an Intergovernmental Working Group on Public Health, Innovation and Intellectual Property (IGWG). The Working Group's mandate is to prepare a glohal strategy and plan of action on public health, innovation and intellectual property to address conditions disproportionately affecting developing countries.

271 See WHO CIPIH Report 2006.

251 For instance, health campaigners (such as MSF, OXFAM and KEI) view the patent system as inadequate to address the need for R\&D in neglected diseases. They argue that the patent system encourage high prices since patent right holders only have limited time to recoup their $R \& D$ expenditure as well as marketing costs and costs related to unsuccessful inventions. In addition, they argue that the patent system does not encourage $R \& D$ into "neglected diseases", when the main market for a new medicine would be poor people who cannot afford to pay high prices. 
medicines. The report calls for: 1) national govemments to undertake measures at the national level to improve the access to medicines including generating capacities in pharmaceutical R\&D and improving infrastructure;252 2) the need for more partnerships and funding;23.3) companies to take more responsibility in providing medicines to the poor; ${ }^{25.4} 4$ ) the WHO to play a greater role in coordination; 255 5) consideration of numerous alternative approaches to the current $R \& D$ raised in recent years; ${ }^{25} 6$ 6) countries entering into negotiations for bilateral free trade agreements to be cautious in particular in relation with provisions on data exclusivity; $; 97$ and the importance of having research and development exemptions in patent laws in order to boost local research.255 Furthermore, the report highlights a number of areas in which the WHO could increase its involvement in IPR issues. For instance, the WHO, in collaboration with the WIPO, could promote patent pools for upstream technologies, or develop a database of information about patents. In addition, the WHO should assist countries in implementing the rights and obligations under the TRIPS agreement indicating the available flexibilities. ${ }^{259}$ Furthermore, the report suggests that the WHO help strengthen the clinical trial and regulatory infrastructure in developing countries, and bring together partners in a "standing forum" to coordinate drug discovery efforts. ${ }^{2}(1)$

The WHO report also provided recommendations on the implementation of the TRIPS Agreement and it called for caution with regard to free trade agreements (FTA's). Notably, the US has included IP provisions including data exclusivity requirements, in its bilateral free trade agreements. The report is fearful of how countries are being pushed in bilateral negotiations beyond TRIPS. The report stated,

"[a] public health justification should be required for data protection rules going beyond what is required by the TRIPS agreement," adding that "(..) developing countries should not impose restrictions for the use of or reliance on such data in ways that would exclude fair competition or impede the use of flexibilities built into TRIPS".201

It explicitly states that bilateral trade agreements should not seek to include TRIPS-plus requirements that may impede access to medicines, in particular

\footnotetext{
252 See WHO CIPIH Report 2006, p. 150.

25. Ibid., p. 150.

294 lbid., p. 179.

$2=5$ Ibid., p. 127.

25. Ibid., p. 151.

25 Ibid., p. 126.

$25:$ Ibid., p. 153.

$2 \sqrt{4}$ Ibid., p. 126.

2ine Ibid., p. 155.

$2 t+1$ Ibid., p. 126.
} 
the request for data exclusivity. It is the commission's view that generic medicines should not be hindered from obtaining market access immediately after patent expiry so as to allow rapid access to drugs. The report reaffirmed that data exclusivity is not required under the TRIPS Agreement but that it constitutes an additional (TRIPS plus) requirement. Moreover, the WHO report reinforced the Doha Declaration, which itself reinforced countries' rights to use the flexibilities built into the TRIPS agreement. 262

The WHO has recently (24 May 2008) adopted a resolution endorsing a global strategy $y^{20.3}$ on intellectual property, health and innovation aimed at filling the research gap for neglected diseases and facilitate access to medicine.20-4

This document titled "W11O Global Strategy and Plan of Action on Public Health, Innovation and Intellectual Property" 26,5 has been referred to as "the most important document since the Doha Declaration on Public Health". 266 The Global Strategy was the result of deliberations within the WHO Working Group on Public Health, Innovation and Intellectual Property (IGWG) in which it was felt necessary to draft a strategy to promote new thinking in

20.2 Ellen 't Hoen from Medecins Sans Frontieres praised the report's finding that there is no evidence that the TRIPS agreement had significantly boosted R\&D, as pharmaceutical industry expenditure has increased but innovation has decreased. In addition, 't Hoen argued that the CIPIH report shows that IPR is irrelevant in stimulating innovation for many of the diseases affecting people in developing countries, where patients have limited purchasing power. Sisule Musungu, a Geneva based IP expert and President, IQsensato questions how far the CIPIH report has gone bevond the UK CII'R report and if it has fulfilled the expectations of member countries who called for such a report. However, he welcomed the expressed concerns on the proliferation of FTAs including TRIPS plus provisions and the pro-active role the WHO intends to make and the plan for global action. Interview with Ellen 't Hoen, MSF and Sisule Musungu, IQsensato conducted by' the author in May 2007.

$2 n .3$ "Global Strategy' and Plan of Action on Public Health, Innovation and Intellectual Property", Sixty-first World Health Assembly, WHA61.21, 24 May 2008. Published online at: <http://www.who.int/gb/ebwha/pdf_files/A61/A61_R21-en.pdf>.

2nt Para. 15 of the Global Strategy, stipulates that the "WHO shall play a strategic and central role in the relationship between public health and inmovation and intellectual property within its mandates, capacities and constitutional objectives, bearing in mind those of other relevant intergovernmental organisations". See also Bridges Weekly Trade News Digest 2008d.

$2 n$ The Global Strategy is the result of work carried out by the Intergovernmental Working Group on Public Health Innovation and IP (IGWG). It was felt necessary to draft a strategy on IP and health after deliberations within this working group had shown that incentives are lacking for industry to invest in diseases that predominantly affect the developing world (so-called neglecting diseases). The WHO General Assembly (19-24 May 2008) marked the end of the two-year mandate of this committee.

2m. As said by a negotiator from the permanent mission of Brazil in Geneva. See Bridges Weekly riade News Digest 2008d. 
imnovation and access to medicines, encouraging "need driven" instead of "market driven" R\&D to target neglected diseases. 2hi The global strategy: reaffirms TRIPS flexibilities; touches upon the prevention of intellectual property abuse by means of competition policies and it aims to promote R\&D on diseases that disproportionately affect people in developing countries; improve R\&D capacity in developing countries; improve access to health products; boost the transfer of technology as well as secure sustainable financing for R\&D in developing countries. It also highlighted the need for a global (bio) medical R\&D Treaty, the collective management of IPRs and the use of new mechanisms, like prizes to provide innovative incentives not linked to product prices, which would provide rewards for phamaceutical innovation; "advance market commitments", which guarantee future purchases of a health product to be developed at an agreed upon price. 20.6 The resolution created an expert working group to develop new and innovative sources of funding to stimulate research and development to address developing country health needs. A progress report on the implementation of the Global Strategy and Plan of Action is to be presented to the 2010 World Health Assembly. 20.9 The adoption of the resolution endorsing the global strategy shows commitment to advance a public-health oriented needs agenda, it emphasises the important role for the $\mathrm{WHO}$ in this respect and it recalls the importance to use the flexibilities to ensure access to health. However it is now time to move forward on concrete activities to implement the global strategy.

\subsubsection{UN Millennium Development Goal 6}

The importance of research into and access to medicines has also been addressed in the UN Millennium Development Goals (MDG), in particular in MDG 6 titled "Combat HIV/AIDS, malaria and other diseases". This goal contains the commitment of governments to halt and reverse the spread of HIV/ AIDS and malaria and other major diseases by $2015,{ }^{270}$ Indicators provided to measure the successful implementation of MDG 6 are identified: 1) HIV prevalence among 15-to24-year-old pregnant women; 2) contraceptive prevalence rate; 3) number of children orphaned by HIV/AIDS; 4) prevalence and death rates associated with malaria; 5) proportion of population in malaria risk areas using effective malaria prevention and treatment measures; 6) prevalence and death rates associated with tuberculosis, proportion of tuberculosis cases detected and cured under directly observed treatment short courses. ${ }^{27}$

2tor See New 2008a.

2,4 As said by a leading developing country negotiator (not further specified) and reported in IP Watch. See New 2008a.

$2 n$ See Bridges Weekly Trade News Digest 2008d.

2a1 Target 7 and 8 of the UN Million Development Goals 6.

271 Ibid. 


\subsection{Rules on Commetition}

Article 40 is the only provision in the TRIPS Agreement dealing with competition. It stipulates that:

"1. Members agree that some licensing practices or conditions pertaining to intellectual property rights which restrain competition may have adverse effects on trade and may impede the transfer and dissemination of technology:

2. Nothing in this Agreement shall prevent Members from specifying in their legislation licensing practices or conditions that may in particular cases constitute an abuse of intellectual property rights having an adverse effect on competition in the relevant market. As provided above, a Member may adopt, consistently with the other provisions of this Agreement, appropriate measures to prevent or control such practices, which may include for example exclusive grantback conditions, conditions preventing challenges to validity and coercive package licensing, in the light of the relevant laws and regulations of that Member.

3. Each Member shall enter, upon request, into consultations with any other Member which has cause to believe that an intellectual property right owner that is a national or domiciliary of the Member to which the request for consultations has been addressed is undertaking practices in violation of the requesting Member's laws and regulations on the subject matter of this Section, and which wishes to secure compliance with such legislation, without prejudice to any action under the law and to the full freedom of an ultimate decision of either Member. The Member addressed shall accord full and sympathetic consideration to, and shall afford adequate opportunity for, consultations with the requesting Member, and shall cooperate through supply of publicly available non-confidential information of relevance to the matter in guestion and of other information available to the Member, subject to domestic law and to the conclusion of mutually satisfactory agreements concerning the safeguarding of its confidentiality by the requesting Member.

4. A Member whose nationals or domiciliaries are subject to proceedings in another Member conceming alleged violation of that other Member's law's and regulations on the subject matter of this Section shall, upon request, be granted an opportunity for consultations by the other Member under the same conditions as those foreseen in paragraph $3^{\prime \prime} .22$

Intellectual property protection grant exclusive rights - which in some cases can look like monopoly rights - something that antitrust laws and policies (competition law) attempts to avoid. IPR is to a certain extent an important exception to the rules of antitrust permitted for a certain amount of time to provide incentives and reward to creation and innovation..$^{273}$

272 See Art. 40 of the TRIPS Agreement.

$2 \pi$ In the context of the EPA (free trade agreements between the ACP and the EC) negotiations the EC argues that low IP protection, together with other trade-related measures, constitutes unnecessary barriers to trade, which is opposed to the tradi- 
The law of intellectual property subjects intellectual assets to the exclusive control of right owners. Whereas competition law seeks to avoid market barriers and benefit consumers by ensuring that a multiplicity of suppliers of goods, services, and technologies may effectively compete against each other. The relationship between these two areas of law poses policy makers challenges, particularly in developing countries, the majority of which has little or no tradition in the application of competition law and policies. ${ }^{2 \pi+4}$ Anti competitive behaviour may be caused by low standards of patentability and shortcomings in patent examination may lead to the grant of "poor quality" patents, as well as patent pools. Moreover there are cases in which IPRs play an important role and where actions taken by governments decisively shape competitive relations. This is for instance, the case of regulations determining the requirements for marketing approval of pharmaceutical and agrochemica! products. 255 Developing a domestic legal instrument may be useful to ensure a pro-competitive use of IPRs. Since there are no international rules ${ }^{2 \pi}$ (with the exception of Article 40 of the TRIPS Agreement) that constrain the capacity of such countries to discipline IP-related anti-competitive behaviour developing countries can follow their own policy strategies about competition law and IPRs. Defining the right balance between competition and IPRs is an objective to be achieved through a diversity of policies and regimes. Some recommendations in this respect are to: 1) strengthen competition laws to avoid abuses from the acquisition or exercise of IPRs, 2) examine the competition implications of policies that influence market entry such as marketing approval of pharmaceutical and agrochemical products, 3) use the available TRIPS flexibilities to determine the grounds for granting compulsory licenses to remedy anti-competitive practices in relation to IPRs including granting of licenses in

tional view that IP, hy definition restrains competition and creates artificial scarcity of groods. See South Centre and CIEL, p. 3.

27. For a thorough expose on the interface between IP and competition law in relation to developing countries see Correa who reviewed country experiences in developing countries and explored the policy options that various stakeholders could taken into account when designing or implementing their own national competition law policies to supplement their intellectual property legal framework. See Correa 2007.

$2 \pi$ See Correa 2007, p. xi.

27. It was endeavoured to conclude a treaty on competition law within the framework of the WTO addressing the interface between competition and international trade but this was never materialised. In July 2004 the General Council of the WTO decided that the "interaction between trade and competition policy" would no longer be part of the Work Programme within the WTO during the Doha Round. See Doha Work Programme under (g), Decision adopted by the General Council on 1 August, WT/L/579, 2 August 200.4. 
cases of refusal to deal; 4) adopt guidelines for use at the patent office to improve quality of patents and avoid overly broad patent claims.27\%

Article 40 provides important rights to all countries, but in particular to developing countries as it allows Members to adopt legislation to stop "licensing practices or conditions pertaining to intellectual property rights which restrain competition may have adverse effects on trade and may impede the transfer and dissemination of technology" that "constitute an abuse" of IPRs. Licensing practises that may constitute such an abuse may include (not exclusively) "exclusive grantback conditions, conditions preventing challenges to validity and coercive package licensing". 2 -

Developing countries are in a difficult position to address unfair competition practises conducted by multinational enterprises on their territories. It is expensive and it takes thorough investigation before a claim can be raised against another country Member. In this regard it would be advisable if developed country Members would provide expertise and financial assistance to tackle actions by multinational enterprises that "constitute an abuse of intellectual property rights having an adverse effect on competition in the relevant market". However, it is not easy to convince developed countries to investigate unfair business practises conducted by multinational enterprises on foreign territories.

Barton has brilliantly set out the difficult relationship and tensions between granting exclusive rights (as under the intellectual property framework) and antitrust policies. He explains why IPRs are a temporarily exception to antitrust principles but that developing countries are benefited by differentiating rules:

"IP has two important economic aspects. On the one hand, it is designed to permit a firm to define a form of market exclusivity and thus to gain a higher price for a product based upon the firm's research. Thus, the static effect is to maintain prices at a non-competitive level, exactly the opposite of the standard goal of antitrust policy, which is to push prices to a competitive level at which price equals marginal cost. But, on the other hand, if the IP system is well designed, this static effect will be balanced by second implication: a dynamic effect under which new research is encouraged. The consumer will lose in the short term from the higher prices and gain in the long term from the moresophisticated and higher quality product. There is a special point for developing

27 Recommendations derived from Correa 2007, p. ix-xi.

2s See for an elaborated discussion on international technology transfer and licensing chapter five of this book. 
nations: especially for the poorer nations, the balance between immediate cost and long-term product quality may look different than for the more wealthy".2an

\section{ENIORCENIENT}

The TRIPS sets minimum standards of protection in each of the IP categories dealt with by TRIPS such as trademarks and copyright among others. The TRIPS was the first time in an international agreement on intellectual property that a systematic set of minimum standards on enforcement was included. The inclusion of these provisions on enforcement show that it was not enough to establish a certain level of minimum protection for each of the Members but that it was necessary to also adopt measures to ensure that those rights are effectively applied and protected in each country. ${ }^{2.11}$ The problem with the existing $I P R$ conventions, like the $P C$ and the $B C$, is that no adequate enforcement mechanisms were available. Member states could have gone to the International Court of Justice (ICJ), but strikingly none of the Member States have conducted a case by this means. ${ }^{2}{ }^{2}$ The TRIPS Agreement was a possibility for reform.

I'art III of the 'TRII'S Agreement stipulates the rules on enforcement of IPR incorporating Articles 41 to 61. General obligations are listed in Article 41 and the civil and administrative procedures and remedies in Articles 42 to 49: 1) Article 41.1 requires WTO Members to ensure that enforcement procedures and remedies are available in their national system and to authorise effective action against any act of infringement of IPR. There is the possibility for review. However, it is explicitly mentioned that, there shall be no obligation to provide an opportunity for review of acquittals in criminal cases. 2) Articles 41.2 and 41.4 indicate that the principles of due process shall be applicable. 3) However, and this is an important flexibility, the Agreement does not ask for the establishment of a specific judicial system dealing with IPR matters only as long as an adequate system to deal with law enforcement issues is available. ${ }^{2.2}$ 4) Article 42 sets out that a civil judicial procedure should exist to be used by right holders to enforce their IPRs. 5) Article 43 stipulates that the evidence of proof lies with the opposing party. Article 44 allows for injunction measures:

"judicial authorities can order a party to desist from an infringement, inter alia to prevent the entry into the channels of commetce in their jurisdiction of imported goods that involve the infringement of an intellectual property right, immediately after customs clearance of such goods".

27) See Barton 2007, p. 3.

$2 \mathrm{x} 1 \mathrm{Sec}$ Roffe 2007.

$2 s 1$ See Goldstein 2001, p. 111.

252 It does not ask to discriminate or to give preference to the enforcement of IPRs in comparison to enforcement of law in general. See Art. 41.5 of the TRIPS Agreement. 
6) Article 45 requests for damages to be paid by the infringer to the right holder to compensate for the losses caused by an infringement of his IPR including for the lawsuit costs. 7) Article 45 stipulates that the infringer can be ordered to pay the right holder damages to compensate for the injury the right holder has suffered on the condition that the infringer "knowingly, or with reasonable grounds to know, engaged in infringing activity". 8) Furthermore, in Articles 46 and 59 it is arranged that judicial authorities have the right to destroy infringing goods they have found on the market subject to the need for proportionality between the seriousness of the infringement and the remedies ordered.

At the time of the TRIPS negotiations it was believed that the WTO Dispute Settlement System, to which the enforcement provisions are subjected, would further strengthen enforcement. Furthermore, Article 45.2 stipulates that in "appropriate cases" the judicial authorities can proceed to "order recovery of profits and/or payment of pre-established damages" even if the infringer did not deliberately engage in infringing activity. The judicial authority is mandated to order the infringer to pay the right holders expenses, including attorney's fees under Article 48.1.

Furthermore Part IIl of the TRIPS Agreement lays down the terms under which this judicial procedure is to take place: It stipulates that 1) defendants have the right to written notice, 2.3 .3 2) the right to independent legal council; 28.4 3) overly burdensome requirements like personal appearances are not allowed; 2.55 4) all parties are entitled to substantiate their claims and to present all relevant evidence $2 s i($ and; 5) confidential information is to be protected; 2576 ) procedures for intellectual property rights enforcement shall be fair and equitable, not unnecessarily costly or unreasonably slow; 2887 ) administrative sanctions have to be open to judicial review; $28 \% 8$ ) there is no obligation to train judges or to publish the decisions. Hence, the system endeavours to avoid burdensome requirements as much as possible.

Further power to the judicial authorities is provided for in Article 46 to "create an effective deterrent to infringement". It sets out that the judicial authorities can proceed to destroy or put outside channels of commerce, goods that are found to be infringing - subject to "the need for proportionality between the seriousness of the infringement and the remedies ordered as well as the

\footnotetext{
283. See Art. 42 of the TRIPS Agreement.

2his Ibid.

$25=$ Ibick.

2sen Ibicl.

25. Ibid.

2ks See Art. 41.2 of the TRIPS Agreement.

2 so See Art. 41.4 of the TRIPS Agreement.
} 
interests of third parties". ${ }^{2}$ "It It continues that "in regard to counterfeit trademark goods, the simple removal of the trademark unlawfully affixed shall not be sufficient, other than in exceptional cases, to permit release of the goods into the channels of commerce".24! By saying this it is clear that the intention of the TRIPS Agreement was to make a strong defence against the trade in counterfeit trademark goods. In addition, article 47 states that the judicial authorities have the right "to order the infringer to inform the right holder of the identity of third persons involved in the production and distribution of the infringing goods or services and of their channels of distribution" - also subject to the need for proportionality.

Article 51 of the TRIPS Agreement sets out the rules on suspension of release by customs authorities:

\begin{abstract}
"Members shall, in conformity with the provisions set out below, adopt procedures to enable a right holder, who has valid grounds for suspecting that the importation of counlerfeit tratemark or pirated copyright goods may take place, to lodge an application in writing with competent authorities, administrative of judicial, for the suspension by the customs authorities of the release into free circulation of such goods". (emphasis added FC)
\end{abstract}

Footnote 14 indicates that for the purposes of the TRIPS Agreement:

\begin{abstract}
"(a) "counterfeit trademark goods" shall mean any goods, including packaging, bearing without authorization a trademark which is identical to the trademark validly registered in respect of such goods, or which cannot be distinguished in its essential aspects from such a trademark, and which thereby infringes the rights of the owner of the trademark in question under the law of the country of importation;

(b) "pirated copyright goods" shall mean any goods which are copies made without the consent of the right holder or person duly authorized by the right holder in the country of production and which are made directly or indirectly from an article where the making of that copy would have constituted an infringement of a copyright or a related right under the law of the country of importation".
\end{abstract}

Article 57 of the TRIPS Agreement sets out the right of inspection and information:

"Members shall provide the competent authorities the authority to give the right holder sufficient opportunity to have any goods detained by the customs authorities inspected in order to substantiate the right holder's claims".

2 nee Art. 46 of the TRIPS Agreement.

$2 \because$ Ibid. 
Article 60 provides an exception for De' Minimis imports:

\begin{abstract}
"Members may exclute from the application of the above provisions small quantities of goods of a non-commercial nature contained in travellers' personal luggage or sent in small consignments".
\end{abstract}

As well as judicial and administrative procedures the TRIPS Agreement also addresses criminal procedures. Article 61 stipulates that members shall provide for criminal procedures and penalties in cases of wilful trademark counterfeiting or copyright piracy on a commercial scale. Remedies shall include imprisonment and/or monetary fines sufficient to provide a deterrent consistently with the level of penalties applied for crimes with a corresponding gravity. If appropriate, remedies shall also include seizure, forfeiture and destruction of the infringing goods. Criminal procedures and penalties may be provided in other cases of infringement of IPRs, in particular where they are committed wilfully and on a commercial scale.

In order to facilitate the enforcement of IPRs, Article 69 of the TRIPS Agreement calls for international cooperation in particular to halt counterfeiting and piracy. In this regard it asks Members to "cooperate with each other with a view to eliminating international trade in goods infringing intellectual property rights". To enhance this cooperation Members are requested to "establish and notify contact points in their administrations and be ready to exchange information on trade in infringing goods. They shall, in particular, promote the exchange of information and cooperation between customs authorities with regard to trade in counterfeit trademark goods and pirated copyright goods"? 242

\title{
4.1. New Dewelopments
}

There is increased attention for enforcement in the TRIPS Council meetings. Both the US and the EC have submitted documents emphasising the importance of installing adequate enforcement mechanisms. ${ }^{293}$ The issue is controversial with the US, the EC and Japan in favour of placing enforcement as a permanent agenda item for the TRIS'S Council meeting. However, developing

202 Art. 69 of the TRIPS Agreement.

24:3 Communication from the United States, "Council for Trade-Related Aspects of Intellectual Property Rights - Enforcement of Intellectual Property Rights (Part 111 of the TRIPS Agreement): Experiences of Border Enforcement", IP/C/W/488 of 30 January 2007; Communication from the EU, Japan, Switzerland and US, Council for Trade-Related Aspects of Intellectual Property Rights - Enforcement of Intellectual Property Rights - Joint Communication from the European Communities, Switzerland, Japan and the United States IP/C/W/485 of 2 Novenber 2006; and two from the EU, IP/C/W/468 of 10 March 2006 and IP/C/W/448 of 9 June 2005. 
countries, such as Brazil, China, India, South Africa and Argentina, strongly oppose initiatives proposing stronger enforcement regulations and regard them as outside the TRIPS Council mandate and being TRIPS plus requirements. ${ }^{24.4}$

In addition, the EC trade strategy stipulates that:

"FlAs should include stronger provisions for IPR and competition, including for example provisions on enforcement of IP rights along the lines of the EC Enforcement Directive".2.5

This is new in the EC policy strategy as the EC had not previously demanded to implement legislation at the same level and scope as the EC itself (other than prospective member states). The EC Enforcement Directive goes bevond the TRIPS Agreement as it covers wider subject matter and requires administrative as well as criminal sanctions. ${ }^{206}$ "The EC has also adopted a "strategy for the enforcement of IP rights in third countries". 247 The fact that enforcement has taken on a higher profile is also demonstrated by other initiatives to strengthen enforcement such as the EC and the US joint Strategy for the Enforcement of IPRs; ${ }^{218}$ and the objective of the US to seek a binding Anti Counterfeiting Trade agreement (ACTA). ${ }^{2(4)}$ Recently the US has asked to establish a WTO Panel as it believes China to be TRIPS incompliant for setting too low a bar for prosecuting counterfeit DVD's, CD's, music and other copyrighted material. ${ }^{3 m}$

In a recent meeting developed country negotiators, custom authorities and international organisations called for greater cooperation in efforts to combat

20.4 See TRIIS Council meeting of 23-24 October 2007, see Bridges Weckly Trade New's Digest $2007 \mathrm{k}$.

$2 "$ Section 4.2 (ii), "Global Europe - Competing in the World, European Commission", EC Policy Review, October 4, 2006. Published online at: <http://eceuropa.eu/ trade/issues/sectoral/competitiveness/global_curope_en.htm>.

2"in The EC Directive on the Enforcement of IPRs, Directive 2004/48/EC of the European Parliament and of the Council of 29 April 2004 is availatle at: <http://eur lex.europa.eu/LexUriServ/LexUriServ'do?uri=CELEX:32004L_0048R(01):EN:NOT>.

2 2.7 See "Strategy for the Enforcement of IPRs in Third Countries", Official Journal of the European Union, 2005/C 129/03.

2 'ws .The EC and the US joint Strategy' for the Enforcement of IPRs. This document does however stress the importance of adopting an approach that is flexible and that takes due account of various needs and levels of development. See <http:/ trate. ec.europe.eu/dodib/docs/2006/june/tradoc_129013.pdf>.

$2 * 47$ As announced by the US Trade Representative Susan Schwab. See Bridges Weekly Trade News Digest 2008a.

(a) See WTO Case Chima - Mensures Affecting the Protection and Enforcement of IPRs. 
counterfeiting and piracy. ${ }^{3 / 1}$ However negotiations aiming at enhancing enforcement of IPR protection need to maintain legitimate balances between the IPR right holders and the public interest and therefore highlight the flexibilities available in the multilateral $I P$ framework. There is a need to clarify concepts, definitions, and obligations of the enforcement of IPRs to avoid misunderstanding in relation to the enforcement debate. ${ }^{312}$

Technical assistance provided to developing countries in relation to enforcement need to focus on: 1) Alteration and modernisation of laws to facilitate work of the enforcement agencies to intercept/seize counterfeit and pirated products (for instance to allow formal prosecution). 2) Strengthening of regulatory framework and public/private institutions responsible for enforcing IPRs, such as custom authorities, police officers, judiciary as well as private sector bodies such as artists associations, collective management societies. This includes improvement of cooperation and information sharing between the relevant agencies and training of customs offices and judiciary as most custom officers and policy officials are not aware of IPRs.

\subsection{WTO Case on Chima's Enforcement}

The US requested consultations with China with respect to certain measures pertaining to the protection and enforcement of 1PRs in China. When these consultations (7-8 June 2007) did not lead to a resolution of the dispute, the US requested the establishment of a Panel (13 December 2007). ${ }^{303}$ The report of the Panel was submitted to the parties on 13 November $2008 .^{314}$ The case focuses on a number of issues, namely:

301 The Fourth Global Congress on Combating Counterfeiting and Piracy (3-5 February 2008 in Dubai) organised by the World Customs Organisation (WCO), Dubai Customs, Interpol, the World Intellectual Property Organisation (WIPO), and the International Chamber of Commerce (ICC) among others looked at the health and safely aspects of counterfeit products, as well as their economic and social effects.

3.2 See Bridges Weekly Trade New's Digest 2008a.

313 The Final report was issued on 26 January 2009. Please note that the Panel took much longer than the time periods (from composition of the Panel to a final report is on average six months) allocated in the DSU - see also Art. 64 TRIPS Agreement. Appendix 3 of the DSL entitled "Panel working procedures" under section 12 indicates that the proposed time table of the Panel is between 23 and 34 weeks in total.

3in China Enforcement, Clina - Merasurs Affecting the Protection and Enforcement of Intellectual Property Rights. WT/DS362/R, 26 January 2009. Third parties: Argentina, Australia, Brazil, Canada, European Communities, Japan, Korea, Mexico, Chinese Taipei, Thailand and Turkey. 
1) The thresholds that must be met in order for certain acts of trademark counterfeiting or copyright piracy on a commercial scale to be subject to criminal procedures and penalties in China. ${ }^{313}$

2) Whether China's measures for disposing of confiscated goods that infringe II'Rs by customs authorities are consistent with obligations under the TRIIS Agreement. 306,

3) The denial of copyright and related rights protection and enforcement to creative works of authorship, sound recordings and performances that have not been authorised for publication or distribution within China. ${ }^{307}$

As per point one - thresholds under which criminal prosecution is possible in China. The US claims that China has not provided for criminal procedures and penalties to be applied in cases of wilful trademark counterfeiting or copyright piracy on a commercial scale that fail to meet certain thresholds. The Panel did not found the thresholds as set by China (initially 1000 copies, reduced to 500 copies in April 2007) " ' $'$ s' incompatible with the TRIPS Agreement. The key finding of the Panel was that that the US had not proven that China had violated its obligation under Article 61 (first sentence) of the TRIPS Agreement to impose criminal penalties in case of "wilful trademark counterfeiting or copyright piracy on a commercial scale". "3us Hence, the Panel did find that the US had not displayed enough evidence to support its view. This is a crucial finding, as it implies that the application by Panels of the enforcement section obligations of the TRIPS Agreement is subject to prowiding sufficiont eidence for an infringent'nt of the TRIPS Agre'ment. ${ }^{311^{\prime \prime}}$ The US is not precluded from filing a new request for consultations and pursuant requesting establishment of a Panel with evidence of incompatibility of the threshold and commercial use.

A per point two - Custom measures - disposal of goods that infringe IPRs following removal of infringing features. The US claims that China's measures for disposing of confiscated goods that infringe IPRs are inconsistent with China's obligations under the TRIPS Agreement. The Panels findings are that regular auctions as they are practised (by the border authorities) in China do not seem to fit the "exceptional case" requirement as set out in Article 46 of the TRIPS Agreement. ${ }^{311}$ The Chinese law does provide for the disposal of infring-

3.5 See para. 2.2 of the Chima - Mersures Affecting the Protection and Enforcencent of Intellectual Property Rights (PR).

Sth See para. 2.3 of the China - Measures Affecting the Protection and Enforcement of butellittual Property Rights (PR).

3us See para. 2.4. of the China - Measures Affecting the Protection and Enforcement of Intellectual Property Rights (PR).

3is See Art. 61 of the TRIPS Agreement, first sentence.

3 See also Daniel Gervais 2008 , stop press.

311) See paras. 7.391 and 7.394 of the Chim - Measures Affecting the Protetion and Enforcement of Intellectual Property Rights (PR). The Panel concluded that "there may be cases that the simple removal of the trademark prior to the release of the goods into 
ing goods which have been confiscated by custom authorities: it sets out that confiscated goods which infringe IPRs can be used for social public welfare undertakings or be bought by the IPR right holder. In case the goods cannot be disposed of in such a way but the infringing features can be eradicated, they shall be auctioned off. ${ }^{31}$ Hence, the preferred option is to use the goods for social public welfare purposes or to auction off the goods (proceeds go to state treasury) and only in last instance (if these possibilities are not feasible/available) shall the goods be destroyed. The US claimed that the competent Chinese authorities lack the scope of authority to order the destruction or disposal of infringing goods required by Article 59 of the TRIPS Agreement. ${ }^{312}$ According to the US, the reality' is that the Chinese customs authorities cannot exercise their discretion to destroy the goods sand therefore must give priority to disposal options that allow infringing goods to enter the channels of commerce or otherwise cause harm to the right holder. ${ }^{313}$. The US argues the following: 1) donation to social welfare bodies can be harmful to a right holder as no precautionary measures are installed to prevent such bodies from selling the infringing goods on the market; 2) the option of sale to the IPR right holder is harmful in the sense that the right holder pays for the infringing goods, 3) auction does not constitute disposal outside the channels of commerce and, absent this consent, may harm the right holder; and 4) only if option 1, 2 and 3 are not available may authorities order destruction of the infringing goods. ${ }^{31.4}$ China disputed the claims made by the US and argued that donation to social welfare bodies and sale the right holder constitute disposal outside the channel of commerce in such a way as to avoid harm to the right holder. ${ }^{315}$ Moreover, it argued that the China customs had chosen to destroy 58 per cent of the total value of infringing goods between 2005 and 2007 despite of the putative hierarchy of disposition options. ${ }^{310}$ Moreover China argues that the obligation

the channels of commerce would not lead to further infringement" but these cases "must be narrowly circumscribed, application of the relevant provisions must be rare, lest the so-called exception become the rule, or at least ordinary". See para. 7.391 .

311 See Art. 27 of the Chinese Customs IPR Regulations and Art. 30 of the Chinese Implementing measures. Paras. 7.193 and 7.194 of the China - Merasures Affecting the Protection and Enforcement of Intellectual Property Rights (PR).

312 See para. 7.197 of the Chima - Measures Affecting the Protection and Enforcement of Intellectual Property Rights (PR).

313 See para. 7.197 of the Chima - Mersures Affecting the Protection and Enforcement of Intellectial Property Rights (PR) and US' first written submission, paras. 56-57 and 172.

314 Ibid., paras. 179-192.

315 See para. 7.198 of the Chinu - Measures Affecting the Protection and Enforcenent of Intellectual Property Rights (PR) and China's first written submission, para. 182.

31. Ibid., para. 194. 
in Article 59 does not entail the obligation to order destruction of infringing goods in all circumstances. ${ }^{31-}$

Article 59 of the TRIPS Agreement stipulates that:

"competent authorities shall have the authority to order the destruction or disposal of infringing goods in accordance with the principles sel out in Article $46^{\prime \prime}$.

In addition Article 46 (fourth sentence) of the TRIPS Agreement stipulates:

"In regard to counterfeit trademark goods, the simple removal of the trademark unlawfully affixed shall not be sufficient, other than in exceptional cases, to permit release of the goods into the channels of commerce".

Hence, the text does not prohibit the release of the goods into the channels of commerce per si. The removal of a counterfeit trademark would ensure that the goods do not infringe the exclusive rights set out in Article 16 of the TRIPS Agreement. The fourth sentence of Article 46 of the TRIPS Agreement sets out that it is not sufficient other than in "exceptional" cases. For instance, where the counterfeit trademark is removed, the goods may still resemble the genuine good to such an extent that there is a high risk of further infringement by means of re-affixation of a counterfeit trademark (an identical trademark can be produced or imported separately). ${ }^{318}$ The Panel considers that the phrase "other than in exceptional cases" must be interpreted in light of the objective of Article 46, namely to "create an effective deterrent to infringement". ${ }^{31 \%}$ "The Panel does not consider that exceptional cases may simply be demonstrated by a low rate of cases in which simple removal of the trademark is treated as sufficient to permit release of goods into the channel of commerce. ${ }^{320}$ The Panel findings may help to shed light on what constitutes "simple removal" and "channels of commerce".321 For instance, the Panel concluded that:

"viewed in light of the objective, the "simple" removal of the trademark is principally a reference to the fact that the state of the goods is not altered in any other way so that the absence of the trademark is not an effective deterrent to

37 Ibid., para. 196.

$31 \mathrm{~s}$ See para. 7.374 of the China - Mensures Affecting the Protection and Enforcoment of lintellectual Property Rights (PR).

$31^{4}$ See para. 7.391 of the Chinn - Merasures Affecting the Protection and Enforcement of Intellectual Property Rights (PR).

320 See para. 7.39 .2 of the China - Measures Affecting the Protection and Enforcement of lutellectual Property Rights (PR).

321 See para. 7.369 of the China - Mersures Affecting the Protection and Enforcement of lutellectunl Property Rights (PR). 
further infringement. Removal of the trademark is not "simple" if the state of the goods is altered sufficiently to deter further infringement".322

China argued that "right-holders have a legal right to protection from goods that infringe their intellectual property, but not from unmarked goods that do not".323 The Panel argued that the wording of Article 46 of the TRIPS Agreement "is not limited to an action to render goods non-infringing, which the simple removal of the trademark would achieve" but that the fourth sentence of Article 46 "imposes an additional requirement beyond rendering the goods non-infringing in order to deter further acts of infringement with those goods".324 Hence, China's customs measures are inconsistent with Article 59 of the TRIPS Agreement as it incorporates the principle set out in the fourth sentence of Article 46 of the TRIPS Agreement. ${ }^{325}$

A per point three - the denial of copyright law. The US claims that China is acting inconsistently with its obligations under the TRIPS Agreement by denying the protection of its Copyright Law to creative works of authorship that have not been authorised for, or are otherwise prohibited from, publication or distribution within China. The Panel found that denying copyright protection as a result of or during a determination of whether a work may be distributed in the country (this may be referred to as censorship) constituted a violation of Article 5(1) of the Berne Convention and, therefore, of the TRIPS Agreement which incorporates a number of provisions of the Berne Convention by its Article 9.1.320 The Berne Convention provides for automatic copyright protection - as soon as an original literary or artistic work has been created - and neither the existence nor its exercise may be subjected to mandatory formalities. ${ }^{327}$ In particular the negotiation history of Article 5 of the Berne Convention prohibits mandatory formalities imposed by the government, such as

322 See para. 7.375 of the Chima - Mensures Affecting the Protection and Enforcement of Intellectual Property Rights (PR).

32.3 See para. 7.378 of the China - Measures Affecting the Protection and Enforcenent of Intellectwal Property Rights (PR) and China's rebuttal submission, para. 195.

324 See para. 7.379 of the China - Metrumes Affecting the Protection and Enforcenent of Intellectual Property Rights (PR).

325 See para. 7.394 of the Chima - Measures Affecting the Protection and Enforcement of Intellectual Property Rights (PR).

321 See para. 7.139 of the Chima - Mensure's Affecting the Protection and Enforcement of Intellectual Property Rights (PR). in which the Panel concludes that Art. 4, first sentence of the Chinese Copyright Law is inconsistent with Art. 5(1) of the Berne Convention, as incorporated by Art. 9.1 of the TRIPS Agreement. Art. 5(1) reads: "Authors shall enjoy, in respect of works for which they are protected under this Convention, in countries of the Union other than the country of origin, the rights which their respective laws do now or may hereafter grant to their nationals, as well as the rights specially granted by this Convention".

32. See Art. 5(2) of the Berne Convention. 
deposit, registration etcetera. The Panels findings also refer to Article 41.1 of the TRIPS Agreement which provicles that Members must "ensure that enforcement procedures" for an infringement of TRIPS, "constitute a deterrent to further infringements". ${ }^{28}$ Members must ensure that these procedures do not block "legitimate trade" and "provide for safeguards against abuse". The Panel concluded that the Chinese Copyright Law, specifically the first sentence of Article 4, is inconsistent with China's obligations under Article 41.1 of the TRIIS Agreement. ${ }^{21}$

China draws the Panel's attention to the WIPO Guide to the Berne Convention provides the following information in relation to Article 17 of the Berne Convention:

"It covers the right of governments to take the necessary steps to maintain public order. On this point, the sovereignty of member countries is not affected by the rights given by the Convention. Authors may exercise their rights only if that exercise does not conflict with public order. The former must give way to the latter. The Article therefore gives Union countries certain powers to control". . . 3 .

The Panel agrees with this interpretation but argues that there is no reason to suppose that censorship will eliminate those rights entirely with respect to a particular work.

With respect to those rights granted by the Berne Convention, China is unable to explain why Article 4(1) of its Copyright Law provides for the complete denial of their protection with respect to particular works. China argues that such copyright protection is a legal and material nullity as economic rights are pre-empted by public prohibition. It argues that copyright enforcement is meaningless in this context. ${ }^{331}$ The Panel also noted that copyright and government censorship address different rights and interests. Copyright protects private rights, as reflected in the fourth recital of the preamble to the TRIPS Agreement, whilst government censorship addresses public interests. ${ }^{332}$ The

32s See Art. 41.1 of the TRIPS Agreement.

32. See para. 7.181 of the Clima - Measures Affecting the Protection and Enforcement of Intellectual Property Rights (PR). Art. 4, first sentence of the Chinese Copyright Jaw reads as follows: "Works the publication and/or dissemination of which are prohibited by law shall not be protected by this Law". See para. 7.1 of the Chinn - Measures Affecting the Protection and Enforcentent of Intellectual Property Rights (PR).

3.4 See para. 7.131 of the Chinn - Mensures Affecting the Protection and Enforcencut of lntellettual Property Rights (PR) referring to the WIPO Guide to the Berne Comvention.

33. China's first written submission, para. 280 as repeated in para. 7.134 of the ClimnMe'rsures Afficting the Protection and Enforcement of lntellectual Property Rights (PR).

$3: 2$ See para. 7.135 of the China - Measures Affecting the Protection and Enforcoment of Intellectum Property Rights (PR). 
Panel notes that these assertions are relevant but are not substantiated. The Panel found that China has not explained why censorship interferes with copyright owners' rights to prevent third parties from exploiting prohibited works. ${ }^{3.3}$ Hence, the Panel concludes that, notwithstanding China's rights recognised in Article 17 of the Berne Convention, Article 4(1) of the Chinese Copyright Law is inconsistent with Article 5(1) of the Berne Convention as incorporated in Article 9(1) of the TRIPS Agreement.

The Panel repeatedly recalled that its terms of reference are limited to the matters set out in the US $^{\prime}$ request for establishment of a Panel. In this dispute, the Panel's task was not to ascertain the existence or the level of trademark counterfeiting and copyright piracy in China in general nor to review the desirability of strict IPR enforcement but it was to address three specific alleged deficiencies in China's IPR legal system in relation to certain provisions of the TRIPS Agreement. ${ }^{3.4}$ However, the Neither parties have appealed ${ }^{35}$ any of the findings yet, but is possible that China will appeal the findings on the copyright denial and disposal of goods issue or that the US will appeal of the findings on the commercial scale test for criminal remedies.

Notably both the US and China claim victory of the dispute. The US claims it won two and a half points out of three, whereas China argues that the US has not been able to provide enough evidence to state its claims.

\section{Trangitional ARRANGEMEnts and TECHNICAL ASSISTANCE}

\subsection{Transition Periots for Developing Countries}

Article 65 sets the rules on transitional arrangements:

"1. Subject to the provisions of paragraphs 2, 3 and 4, no Member shall be obliged to apply the provisions of this Agreement before the expiry of a general period of one year following the date of entry into force of the WTO Agreement. 2. A developing country Member is entitled to delay for a further period of four years the date of application, as defined in paragraph 1 , of the provisions of this Agreement other than Articles 3,4 and 5 .

3. Any other Member which is in the process of transformation from a centrallyplanned into a market, free-enterprise economy and which is undertaking structural reform of its intellectual property system and facing special problems

33 See para. 7.133 of the Chinn - Merasures Affecting the Protection and Enforcentent of Lntellechull Property Rights (PR).

34 See para. 8.5 of the Chima - Measues Affecting the Protection and Enforcement of Lintellectuinl Property Rights (PR).

35 Please note that Appeal is only possible on issues of law and legal interpretations developed by the Panel. 
in the preparation and implementation of intellectual property laws and regulations, may also benefit from a period of delay as foreseen in paragraph 2.

4. To the extent that a developing country Member is obliged by this Agreement to extend product patent protection to areas of technology not so protectable in its territory on the general date of application of this $A$ greement for that $M \mathrm{~cm}-$ ber, as defined in paragraph 2, it may delay the application of the provisions on product patents of Section 5 of Part 11 to such areas of technology for an additional period of five years.

5. A Member availing itself of a transitional period under paragraphs $1,2,3$ or 4 shall ensure that any changes in its laws, regulations and practice made during that period do not result in a lesser degree of consistency with the provisions of this Agreement".

All WTO Members had received a one year transition period following the date of entry into force of the WTO Agreement. During this year they were not required to fulfil the TRIPS obligations. Instead countries needed to comply with the provisions of the TRIPS Agreement as per 1 January 1996. 'This year's transition period was provided so as to give time to implement the TRIPS Agreement in their domestic legislation and to install the necessary enforcement measures.

Developing countries and countries in transition were allowed an additional four years before they were required to conform with the TRIPS Agreement. However, the requirements under Articles 3,4 and 5 of the TRIPS Agreement - national treatment and most-favoured-nation treatment - do not fall under this extension period and have to be obeyed immediately. As a result, developing countries had to install the necessary implementation and enforcement requirements before 1 January 2005. This process involved bringing their domestic laws on copyright, patents, trademarks and other areas of intellectual property in line with the provisions under the TRIPS Agreement and providing adequate enforcement mechanisms to combat counterfeiting and piracy, and other forms of intellectual property infringements.

Most of the developing countries had a hard time meeting the 2000 deadline because of the complexities of intellectual property laws and their enforcement. In 1998 The WIPO and the WTO joined forces to provide technical cooperation for developing countries in order to help them to meet the 1 January 2000 deadline. However, as with most of the technical assistance possibilities provided by the WTO, developing countries needed to request this assistance. The aim was to maximise use of available resources by improved planning and coordination of technical activities. The technical cooperation gave assistance in preparing legislation to conform with the TRIPS Agreement, intellec-

3in See Art. 65 of the TRIPS Agreement.

337 See Art. 65.2 of the TRIP'S Agreement. 
tual property training, institution-building, and updating or introducing intellectual property systems and enforcement. ${ }^{33}$

Article 65.4 of the TRIPS Agreement stipulates an additional flexibility for developing countries. They are exempted from meeting the obligations of TRIPS with regards to product patent protection in areas of technology not so protectable in its territory on the general date of application of this Agreement for that Member for an additional period of five years. For instance, if a country did not provide for patent protection for pharmaceutical or agricultural chemical patents at the time the TRIIS Agreement came into being they could delay compliance with the TRIPS provisions for an additional five years - till 1 January 2000.

Article 65 TRIPS is subject to a clause provided for in its paragraph 5 outlining that any changes in domestic laws made during the duration of the transition period shall not result in a lesser degree of consistency with the TRIPS Agreement.

\title{
5.2. Transition Periods for Least-Dereloped Country Members
}

Article 66 TRIPS Agreement acknowledges the special needs and interests of least-developed country members. Paragraph 1 expresses the extended transition period:

\begin{abstract}
"1. In view of the special needs and requirements of Ieast-developed country Members, their economic, financial and administrative constraints, and their need for flexibility to create a viable technological base, such Members shall not be reguired to apply the provisions of this Agreement, other than Articles 3, 4 and 5 , for a period of 10 years from the date of application as defined under paragraph 1 of Article 65 . The Council for TRIPS shall, upon duly motivated request by a least-developed country Member, accord extensions of this period". $3: 34$
\end{abstract}

Article 66.1 allows least-developing countries a transition period of one plus ten years and consequently they need to confirm with the TRIPS Agreement as from 1 January 2006.

More than three-quarters of WTO'S Members have self-selected the status of being a developing country, ${ }^{3+1}$ thirty-two of these are least-developed. The

sin See WTO News, "WTO and WIPO Join Forces To Help Developing Countries Meet Year - 2000 Commitments on Intellectual Property", Press/108, 21 July 1998.

33 See Art. 66.1 of the TRIPS Agreement.

311 The fact that a Member announces itself as a developing country Member is not automatically accepted in all the WTO bodies. For instance, it does not involve that the country at stake will benefit from the unilateral preference schemes of some of 
WT'O makes a distinction between "developing countries" and "least-developed countries" but it does not provide clarification as to what constitutes a developing country. It is up to self-selection - developing countries are self declared developing countries - however, other Members can challenge the decision of a Member to make use of provisions only available to developing countries.

The WTO recognised the United Nations list ${ }^{3+1}$ to accord least-developed country Member status. The Economic and Social Council of the United Nations has set down a number of criteria to measure a country's state of development in order to determine if the country qualifies as a least-developing country. 32

Fifty countries have been identified, among these are thirty-two least-developing country Members of the WTO: Angola, Bangladesh, Benin, Burkina Faso, Burundi, Cambodia, Central African Republic, Chad, Democratic Republic of Congo, Djibouti, Gambia, Guinea, Guinea Bissau, Haiti, Lesotho, Madagascar, Malawi, Maldives, Mali, Mauritania, Mozambique, Myanmar, Nepal, Niger, Rwanda, Senegal, Sierra Leone, Solomon Islands, Tanzania, logo, Uganda and Mozambique. Currently eight least-developed country Members are in the process of accession to the WTO: Bhutan, Cape Verde, Fthiopia, Laos, Samoa, Sudan, Vanuatu and Yemen. Equatorial Guinea and Sao Tome \& Principe are WTO observers.

the developed country Members such as the Generalized System of Preferences (GSP). Normally the country providing the preference decides on the list of developing countries that can benefit from the preferences.

The list is available on: <http:/ / www.un.org/special-rep/ohrlls/ldc/list.htm>.

Qualification of a least-developed country: 1) a low-income criterion, based on a three-year average estimate of the gross domestic product per capita (under $\$ 750$ for inclusion, above $\$ 900$ for graduation); 2) a human resource weakness criterion, involving a composite Augmented Physical Quality of Life Index (APQLI) based on indicators of: (a) nutrition; (b) health; (c) education; and (d) adult literacy; and 3 ) an economic vulnerability criterion, involving a composite Economic Vulnerability Index (EVI) based on indicators of: (a) the instability of agricultural production; (b) the instability of exports of goods and services; (c) the economic importance of nontraditional activities (share of manufacturing and modern services in GDP); (d) merchandise export concentration; and (c) the handicap of economic smallness (as measured through the poptation in logarithm); and the percentage of population displaced by natural disasters. Report of the Committee for Development Policy on its Sixth Session, UN Economic and Social Council, 29 March - 2 April 2004, E/2004/33. Published online at: <http://www.un.org/esa/policy/devplan/cdp publications/2004ctpreport.pdf>. 


\title{
5.2.1. New Developments
}

\subsubsection{The Doha Declaration Development Requests}

Least-developing countries had requested an extension of the transition period under Article 66.1 TRIISS Agreement and attention to their special socioeconomic needs. This call resulted in the Doha TRIPS Declaration on the TRIPS Agreement and Public Health, of which paragraph 7 of the Declaration on Public Health reaffirmed technology transfer obligations and extended the transition period for least-developed country Members to ten years, with regards to pharmaceutical products, so these countries can delay patent protection for these products until 1 January 2016 :

\begin{abstract}
"We also agree that the least-developed country Members will not be obliged, with respect to pharmaceutical products, to implement or apply Sections 5 and 7 of Part II of the TRIIS Agreement or to enforce rights provided for under these Sections until 1 January 2016, without prejudice to the right of least-developed country Members to seek other extensions of the transition periods as provided for in Article 66.1 of the TRIPS Agreement. We instruct the Council for TRII'S to take the necessary action to give effect to this pursuant to Article 66.1 of the TRII'S Agreement". 3,
\end{abstract}

The instruction contained in the above paragraph was followed up by the TRIPS Council and on 27 June 2002 a decision was approved (using almost the exact wording of paragraph 7) extending until 2016 the transition period during which least-developed countries do not have to provide patent protection for pharmaceuticals. ${ }^{3+1}$. This decision implemented and formalised part of paragraph 7 Declaration on TRIPS and Public Health and is in line with the overall objective of this Declaration to ensure that intellectual property protection supports, not obstructs poorer countries' interests to solve public health problems affecting their people:

"We recognise the gravity of the public health problems afflicting many developing and least-developed countries, especially those resulting from HIV/ AIDS, tuberculosis, malaria and other epidemics".3.5

34 Para. 7of the TRIPS Declaration on the TRIPS Agreement and Public Health, Doha, Qatar, 14 November 2001 , WT/MIN $(01) /$ DEC $/ 2$.

3.4 "Extension of The Transition Period Under Article 66.1 of the TRIPS Agreement for Least-Developed Country Members for Certain Obligations with Respect to Pharmaceutical Products", Decision of the Council for TRIPS of 27 June 2002.

35. The Ministerial Declaration's opening statements in the "TRIPS Declaration on the TRIPS Agreement and Public Health", Doha, Qatar, 14 November 2001, WT/MIN (0I)/DEC/ 2 . 


\subsubsection{The TRIPS Council Decision of 2005}

The Decision of the Council for TRIPS of 29 November 2005 called 'Extension of the Transition Period Under Article 66.1 For Least-Developed Country Members' provides under paragraph 1 that:

"Lcast-developed country Members shall not be required to apply the provisions of the Agreement, other than Articles 3, 4 and 5, until 1 July 2013, or until such a date on which they cease to be a least-developed country Member, whichever date is earlier".

The last sentence of Article 66.1 of the TRIIS Agreement provides for the possibility to extend the transition period for least-developed country Members on duly motivated request. Recently, least-developed countries have been given an extension until 1 July 2013 allowing them more time to implement the TRIPS Agreement, following a decision reached by member governments on 29 November 2005 - just before the Hong Kong Ministerial Conference.3:Pascal Lamy W'TO Director-General applauds the decision:

\footnotetext{
"Members have shown that they are ready to ensure that the world's poorest countries have the flexibility that they need in order to meet their WrO obligations in a way that serves their development needs".3.s
}

According to Article 66.1 the transition period granted to least-developed countries was due to expire on 1 January 2006, exactly 11 years after the TRIPS Agreement came into force. Following the TRIPS Council Decision ${ }^{3+4}$ the transition period has been extended by seven and a half years, unless they graduate from being least-developed. The transition period for patents for pharmaceutical products until 1 January 2016, ${ }^{350}$ will not be affected, nor will the right of least-developed country Members to seek further extensions of the period provided for in Article 66.1 (paragraph 6 of the Decision). Nonetheless, if developing countries voluntarily provide intellectual property protection, they have to observe TRIPS provisions on non-discrimination (Articles 3 and 4

3.th Extension of the Transition Period under Art. 66.1 For Least-Developed Country Members, Decision of the Council for TRIPS of 29 November 2005.

3. Least-developed countries asked for an extension of their transition period under Art. 66.1 TRIIPS Agreement on 13 October 2005, IP/C/W/457.

3.: "Poorest countries given more time to apply intellectual property rules", WTO, Press/424, 29 November 2005.

34" Extension of the Transition Period under Art. 66.1 For Least-Developed Country Members, Decision of the Council for TRIPS of 29 November 2005.

3in See the Decision of the TRIPS Council of 27 June $2002, \mathrm{IP} / \mathrm{C} / 25$ giving effect to para. 7 of the Declaration on TRIPS and Public Health. In this Decision countries approved a waiver that would exempt LDCs from having to provide exclusive marketing rights for any new drugs in the period when they do not provide patent protection. 
TRIPS Agreement). If they already provide some kinds of intellectual property protection, they may not reduce or withdraw the current voluntarily protection that they provide. ${ }^{351}$ In addition paragraph 5 of the Decision demands that least-developed countries will not make any changes in their laws, regulations and practice during the transition period which results in a lesser degree of consistency with the provisions of the TRIPS Agreement.

The TRIPS Council Decision recognised "the continuing needs of least-developed country Members for technical and financial cooperation so as to enable them to realise the cultural, social, technological and other developmental objectives of intellectual property protection" as one of the reasons the extension period is granted. 352 The transition periods being one of the main flexibilities granted to LDCS - how is the TRIPS Council assisting LDCs take advantage of the extensions to the transitional period for the implementation of the IRIPS Agreement to build a sound and viable technological base?

\title{
5.3. Tedmical Coperation and Tédmical Assistance
}

\section{Article 67 TRIPS Agreement stipulates that:}

\begin{abstract}
"In order to facilitate the implementation of this Agreement, developed country" Members shall provide, on request and on mutually agreed terms and conditions, technical and financial cooperation in favour of developing and leastdeveloped country Members". 35
\end{abstract}

The wording implies that developing countries need specifically ask for such help to the developed country members.

It stipulates that such cooperation shall include:

\begin{abstract}
"assistance in the preparation of law's and regulations on the protection and enforcement of intellectual property rights as well as on the prevention of their abuse, and shall include support regarding the establishment or reinforcement of domestic offices and agencies relevant to these matters, including the training of personnel". 35.
\end{abstract}

This includes providing assistance in setting up or enhancing the functions of local intellectual property institutions by training and so forth. The provision is subject to review by the TRIPS Council, who on a regular basis inquires into

51 "Poorest countries given more time to apply intellectual property rules", WTO, Press/424, 29 November 2005.

352 Extension of the Transition Peried under Art. 66.1 For Least-Developed Country Members, Decision of the Council for TRIPS of 29 November 2005.

si See Art. 67 of the TRIPS Agreement.

3is Ibid. 
the matter. It is advisable that in future deliberations - perhaps within the TRIPS Council or in FTA negotiations - the provision of technical assistance should be mandatory rather than a best endeavour practise.

\subsubsection{New Developments}

The Doha Declaration ${ }^{35}$ reconfirmed that technical cooperation and capacity building are core elements of the development dimension of the multilateral trading system.

In February 2001, a Technical Co-operation Unit was established. 35 "This unit is responsible for constant monitoring and evaluation of all technical assistance provided by the W'IO. This unit is set up to control the financial and human investment in WTO-administered technical assistance programmes.

The Doha Ministerial Declaration declares that the WTO technical assistance should focus on assisting developing countries to implement existing WTO obligations as well as on increasing their capacity to participate more effectively in future multilateral trade negotiations. ${ }^{357}$ It considered that - since the majority of the WTO Members are developing countries - it is crucial to make sure that developing countries take part in the increase in world trade, taking into consideration the specific needs of their economic development as addressed in the Marrakech, Singapore and Geneva meetings. In order to achieve these goals, the following factors were considered to be of importance: enhanced market access, balanced rules, financial assistance and capacity building programmes. ${ }^{358}$ Despite of the Doha Declaration, developing countries still face enormous difficulties implementing the TRIPS Agreement as they lack the financial means to install administrative authorities and enforcement bodies. In addition the technical assistance provided is often more focused on implementation of TRIPS obligations and less focused on highlighting TRIPS flexibilities. It is crucial that technical assistance is more directed to building a viable technical base by improving the creative and innovative capabilities of a country to ensure that in future these countries will be able to benefit themselves from IPRs. An often heard criticism among the developing country negotiators based in Geneva is that technical assistance provided by industrialised countries equals enforcement building activities and that so-

155 See WTO Doha Ministerial Declaration.

35 See WTO Annual report 2001, p. 121.

5 SeeWroDoha Ministerial Decharation, p. 8.

35 lbid., p. 1. 
called initiatives in relation to stimulating technology transfer (under Article 66.2 ) are in reality technical assistance. ${ }^{354}$

The Decision of the Council for TRIPS of 29 November 2005 called "Extension of the Transition Period Under Article 66.1 For Least-Developed Country Members' under Section 2 reiterates developed countries" commitments on technical and financial assistance to help least-developed countries implement the Agreement. Section 2 indicates that the least-developed countries should provide a list of their individual priority needs for technical and financial cooperation. This list should help the developed countries in their endeavour to help them most adequately. Section 2 stipulates:

\begin{abstract}
"With a view to facilitating targeted technical and financial cooperation programmes, all the lenst-developed country Members will provide to the Council for TRIPS, preferably by 1 January 2008 , as much information as possible on their individual priority needs for technical and financial cooperation in order to assist them taking steps necessary to implement the TRIPS Agreement". int
\end{abstract}

Section 3 stipulates that the technical and financial cooperation will be provided in accordance with Article 67 of the TRIPS Agreement in order to effectively address the needs identified in section 2 of the Decision. Further, section 4 sets out that in order to make the list as required under paragraph 2, and with the view to making technical assistance and capacity building as effective and operational as possible, the WTO must enhance its cooperation with the WIPO and other relevant institutions.

The only countries which have followed up this request are Sierra Leone and Uganda. Both have submitted communications ${ }^{3.12}$ to the WTO TRIPS Council, titled "Priority Needs for Technical and Financial Cooperation". These submissions provide an overview of the needs of both countries in terms of policy, legislation and administrative reform taking into account the development context of each country. Their submissions stress the importance of allowing ample time to develop national strategy on intellectual property, and using intellectual property as a tool for development. They set out the importance of establishing a national scientific and technological infrastructure to meet the needs of local industry and society at large with a focus on building a

5in Interview with Dyebo Shabalala, Director of the IPR and Sustainable Development Programme, Center for International Envirommental Law (CIEL), conducted by the author July 2008.

(t) Section 2 of the "Extension of the Transition Period under Art. 66.1 For LeastDeveloped Country Members", Decision of the Council for TIRIPS of 29 November 2005.

3nt Communication by Sierra Leone to the TRIPS Council, IP/C/W/499, 3 October 2007 and Communication by Uganda to the TRIPS Council, IP/C/W/500, 9 October 2007. 
scientific, technological and creative base, including technology transfer using intellectual property for their socio-economic development. ${ }^{362}$

The needs assessment carried out in Uganda showed a need for:

1) Determining what are the long and short term goals in the updating/ modernising of; 1) IP policy and regulatory framework; 2) IP administration and infrastructure; 3) development of IPR curriculum, e.g. training and education in (using) basic IPR concepts (and underlying justifications and reasoning); 4) use IPRs to support development/ set a positive lPlk agenda.

2) Building viable own creative and innovative capacity and industry ('create a viable lechnological base' as stipulated in Article 66.1). This includes the formalisation of the music industry - provide formal outlets to sell and distribute $\left(D^{\prime}\right.$ 's and DVD's.

3) Promotion/valorisation of traditional knowledgens and cultural expressions. In this regard one could explore the opportunities to establish national institutions, e.g. national galleries, national concert hall or theatre to increase awareness of domestic creativity.

4) Modernisation of $I P R$ administration: 1) invest in office infrastructure; 2) computerise records: patents/TMs/copyright/PVI? 3) update legislation; 4) increase role of civil society in legislative process. The digitisation of patent and trade mark records will help in information exchange and increase access to and transfer of foreign technologies to Uganda. Establish an IP office in order to disseminate patent/tade mark information and to provide services to the public.

3.2 KTSD has assisted Uganda and Sierra Leone with their preparations and has undertaken tailor made needs assessment exercises. $A$ diagnostic toolkit to assess technical assistance needs has been developed. The toolkit and more information on the project is published online at: <http://www.iprsonline.org/ictsd/LDCneds. htm>.

3n.3 The need for adequate protection against bio piracy (c.g. the stealing of local traditional knowledge and genetic resources without sharing in the benefits) shows the following example: Intention was to enter into a joint project between NARO and researchers from South Africa to study the possibility of using a special varicty' of banana occurring in Uganda for producing liquid drinks (alleged sponsor NEPAD fund). The added value of this particular banana plant is that it consists of fibres that are sweeter and of a more distinct taste than others (in between apple and banana taste). The South African researchers came to explore opportunities, information exchange with NARO researchers and left with the genetic material and associated traditional knowledge. Project never took off. Story told to author in interview conducted with Mr Paul Njoki, research officer, National Agriculture Research Organization Uganda (NARO) on 25 July 2008. NARO is responsible for conducting research in adding value to food products of existing plants and seeds and subsequently to publish results; inform and educate farmers of new research findings; provide information to relevant ministries. One successful project concerned "sorghum". Examination resulted in a type that is more nutritious and sweeter. NARO is also in charge of the botanical gardens and gene bank located in Enteble, Uganda. 
5) Improvement of cooperation and information exchange among different government departments and stakeholders.

6) Enforcement: 1) train policy and judiciary in IPR concepts; 2) modernise laws to allow for prosecution to halt trade in counterfeit products; 3) improve cooperation between customs, police and government institutions.

7) Avoid reinventing the wheel insteat adopt existing technologies to local needs and take experiences from other countries and bring in locally.

8) Provide management services for SMEs and cultural industries to use petty patents, TMs, copyright and Gls to establish value-addition in domestic and exports markets.

9) Concentrating (n product branding and marketing efforts to increase markets and reduce poverty

10) Establishment of formal music industry including the setting up of 'collective societies' to boost the copyright industry.

Furthermore the needs assessment has shown that "specialisation is the need for civilisation" - one need to focus on the comparative advantage of the country. ${ }^{365}$ At the moment Uganda faces competition from China, in particular in relation to the textile industry: For instance African designs are copied in China and subsequently mass production provides the country with cheap textile from China ruining the local industry. This again shows how important local copyright and design laws are. Foremost, in order to improve the domestic IP infrastructure in terms of policy making, legal and administrative framework and enforcement adequate financial resources need to be provided preferably provided in the form of long term sustainable projects that gradually take Uganda to the next phase of development. It is important to establish positive IPR agenda focusing on domestic socio-economic needs and building a viable technological base.

\subsection{WrO Case Lane on "Acts Which Occurred Before the Date of TRIPS Application"}

Article 70 TRIPS Agreement deals with the protection of existing subject matter and stipulates that:

3it Recommendations follow from the interviews conducted with Kampala-Uganda based of ficials dealing with IPR matters by the author in July 2007.

$3 n=$ As said by Mr. Ggagawala Wambuzi, Minister of Tourism, Ministry of Tourism, Trade and Industry, Uganda during a speech, 24 July, Kampala, Uganda. Assessing the Needs for Financial and Technical Cooperation of Least Developed Countries in Implementing the TRIPS Agreement National Stakeholder Consultations, Organised by ICTSD in cooperation with the Ministry of Tourism, Trade and Industry of Uganda and Saana Consulting Kampala, Uganda, 18-27 July 2007. <http://www. iprsonline.org/ictsd/Dialogues/2007-07-24/2007-07-24_desc.htm>. 
Paragraph 1: "|t |his Agreement does not give rise to obligations in respect of acts which occured before the date of application of the Agreement for the Member in question" and paragraph 2: "[e]xcept as otherwise provided for in this Agreement, this Agreement gives rise to obligations in respect of all subiect matter existing at the date of applicution of this Agreement for the Member in question, and which is protected in that Member on the said date, or which meets or comes subsequently to meet the criteria for protection under the terms of this Agreement.ito

The WTO Dispute Settlement Board dealt with the relationship between paragraph 1 and 2 of Article 70 in Canada - Patent Tom. 3h The US argued that Camada is in breach of its TRIPS Agreement obligations under Article 3.3 which requests a patent term of a minimum duration of 20 years. Under the Canadian Patent Act a patent is granted with term duration of 17 years. The US brought the dispute to the ISSS. The focus point of dispute concerned the meaning of "acts which occurred before the date of application" of the TRIPS Agreement and how these acts need to be distinguished from "subject matter existing at the date of application". In Canath - Patent Tim, Canada considered that the length of the patent term falls within the scope of the term act contained in Article 70.1 of the TRIPS Agreement because in their view the grant of a patent term is an integral part of the act granting the patent in question - which occurred before the entry into force of the TRIPS Agreement. Hence, Canada argued that Article 33 did not apply. With respect to the relationship between Articles 70.1 and 70.2 , Canada argued that the phrase "except as otherwise provided for in this Agreement" demonstrates that Article 70.2 does not apply in this instance and that Article 70.1 takes precedence over Article 70.2. The Appellate Body rejected this argument with the following reasoning:

"Like the Panel, we see Articles 70.1 and 70.2 as dealing with two distinct and separate matters. The former deals with past 'acts', while the latter deals with 'subject-malter' existing on the applicable date of the TRIPS Agreement. Article' 70.1 of the TRIPS Agreement operates only to exclude obligations in respect of 'acts which occurred' before the date of application of the TRIPS Agreement, but does not cxolude rights and obligations in respect of contimuing sifuations. On the contrary, 'subject matter existing ... which is protected' is clearly a continuing situation, whether viewed as protected inventions, or as the patent rights attached to them. 'Subject matter existing ... which is protected' is not within the scope of Article 70.1, and, therefore, the 'le]xeept as otherwise provided for' clause in Article 70.2 can have no application to it. Thus, for the sake of argument, even if there is a relationship between Article 70.1 and the opening proviso in Article 70.2, Canada's argument with respect to Old Act potents fails nonetheless, as we have concluded that the continuing rights relating to Old Act patents do not fall within the scope of Article 70.1. We wish to point out that our

3it See Art. 70 of the TRIPS Agreement.

son See Canala-Patent Term. 
interpretation of Article 70 does not lead to a 'retroactive' application of the TRIPS Agreement. Article 70.1 alone addresses 'retronctive' circumstances, and it excludes them generally from the scope of the Agreement. The application of Article 33 to inventions protected under Old Act patents is justified under Article 70.2, not Article 70.1. A treaty applies to existing rights, even when those rights result from 'acts which occurred' before the treaty entered into force" ${ }^{36 \text { s. }^{3}}$

The Appellate Body also analyzed the term "acts which occurred before the date of application of the Agreement" in order to distinguish this term with the term 'subject-matter' under Article 70.2:

\begin{abstract}
"We are of the view that the term 'acts' has been used in Article 70.1 in its normal or ordinary semse of 'things done', 'deeds', 'actions' or 'operations'. In the context of 'acts' falling within the domain of intellectual property rights, the term 'acts' in Article 70.1 may, therefore, encompass the 'acts' of public authorities (that is, governments as well as their regulatory and administrative authorities) as well as the 'acts' of private or third parties. Examples of the 'acts' of public authorities may include, in the field of patents, the examination of patent applications, the grant or rejection of a patent, the revocation or forfeiture of a patent, the grant of a compulsory licence, the impounding by customs authorities of goods alleged to infringe the intellectual property rights of a holder, and the like. Examples of 'acts' of private or third parties may include 'acts' such as the filing of a patent application, infringement or other unauthorised use of a patent, unfair competition, or abuse of patent rights". ${ }^{3,4}$
\end{abstract}

\title{
Following this reasoning the Appellate Body concluded that
}

"Article 70.1 of the TRIPS Agreement cannot be interpreted to exclude existing rights, such as patent rights, even if such rights arose through acts which occurred before the date of application of the TRIPS Agreement for a Member. We, therefore, confirm the finding of the Panel that Article 70.1 does not exclude from the scope of the TRIPS Agreement Old Act patents [i.e. Canadian patents granted on the basis of patent applications filed before 1 October 1989] that existed on the date of application of the TRIPS Agreement for Canada",371

In reaching the previous conclusion, the Appellate Body relied both on the worting of Article 70.1 as well as on the object and purpose of the TRIPS Agreement:

"The ordinary meaning of the term 'acts' suggests that the answer to this question must be no. An 'act' is something that is 'done', and the use of the phrase 'acts which occurred' suggests that what was done is now complete or ended. This excludes situations, including existing rights and obligations, that have not ended. Indeed, the title of Article 70, Protection of Existing Subject

Stw See paras. 69-70 of the Canuda - Patent Term (ABR).

sin See para. 54 of the Cintada - Patent Term (ABR).

30 See para. 60 of the Comada - Patent Term (ABR). 
Matter', confirms contextually that the focus of Article 70 is on bringing within the scope of the TRIPS Agreement 'subject matter' which, on the date of the application of the Agreement for a Member, is existing and which meets the relevant criteria for protection under the Agreement. A contrary interpretation would seriously erode the scope of the other provisions of Article 70 , especially the explicit provisions of Articte 70.2. Almost any existing situation or right can be said to have arisen from one or more past acts'. For example, virtually all contractual and property rights could be said to arise from 'acts which occurred' in the past. If the phrase acts which occurred' were interpreted to cover all continuing situations involving patents which were granted before the date of application of the TRIPS Agrement for a Member, including such rights as those under Old Act patents, then Article 70.1 would preclude the application of virtually the whole of the IRIPS Agreement to rights conferred by the patents arising from such 'acts'. This is not consistent with the object and purpose of the TRIPS Agreement, as reflected in the Preamble of the Agreement". 31

In addition the Appellate Body interpreted the term "subject matter existing at the date of application of this Agreement" enclosed in Article 70.2 - in its reasoning the Appellate Body relied, inter alin, on the use of the term in other provisions of the TRIIS Agreement:

"We agree with the Panel's reasoning that 'subject matter' in Article 70.2 refers, in the case of patents, to inventions. The ordinary meaning of the term 'subjectmatter' is a 'topic deall with or the subject represented in a debate, exposition, or work of art'. Useful context is provided by the qualification of the term 'subject matter', in the same sentence of Article 70.2, by the word 'protected', as well as by the phrase 'meet the criteria for protection under the terms of this Agreement' appearing later in the same sentence. As noted earlier, the title to Article 70 also uses the words 'Protection of Existing Subject Matter'. We can deduce, therefore, that the 'subject matter', for purposes of Article 70.2, is that which is 'protected', or 'meets the criteria for protection', under the terms of the TRIPS Agrement. As, in the present case, patents are the means of protection, then whatever patents protect must be the 'subject matter' to which Article 70.2 refers. Articles 27, 28, 31 and 34 of the TRIPS Agreement also use the words 'subject-matter' with respect to patents and provide an equally useful context for interpretation. Article 27, entitled 'Patentable Subject-matter', states: 'patents shall be available for any inventions' (...) This Article identifies the criteria that an invention must fulfil in order to be cligible to receive a patent, and it also identifies the types of inventions that may be excluded from patentability even if they meet those criteria. On the other hand, in Atticles 28, 31 and 34 , the words 'subject-matter' relate to patents that are granted pursuant to the criteria in Article 27; that is to say, these Articles relate to inventions that are protected by patents granted, as distinguished from the 'patentable' inventions to which Article 27 refers. These Articles confirm the conclusion that inventions are the relevant 'subject-matter' in the case of patents, and that the 'subject-matter' in Article 70.2 means, in the case of patents, patentable or patented inventions. Article 70.2 thus gives rise to obligations in respect of all such inventions 
existing on the date of application of the TRIPS Agrecment for a Member. In the appeal before us, where the measme in dispule is Section 45 of Canada's Patent Act, which applies to Old Act patents, the word 'subject-matter' means the inventions that were protected by those patents. We, therefore, confirm the conclusion of the Panel in this regard". 372

\subsection{Mailbox Proarision}

Article 70.8 stipulates that:

"[w]here a Member does not make available as of the date of entry into force of the WTO Agreement patent protection for phamaceutical and agricultural chemical products commensurate with its obligations under Article 27, that Member shall: a) nolwithstanding the provisions of Part VI, provide as from the date of entry into force of the WTO Agreement a means by ablich applications for putents for such inoentions can be filed". 3ri (emphasis added FC)

Despite the transition period arrangements allowing developing countries more time to implement the TRIPS Agreement, the agreement itself still requires certain limited obligations with respect to pharmaceutical and chemical agricultural products, to which all countries must adhere as of the date the WTO Agreement entered into force, i.e. 1, January 1994. Article 70.8(a) refers to obligations that have to be met by Members while availing themselves of the transitional arrangements. If a Member does not provide for patent protection for pharmaceutical and agricultural chemical products under Article 27, because it avails itself of the granted transition periods, it still needs to make available "a means by which patent applications for such inventions can be filed", following Article 70.8(a). Notably, WTO country Members needs to provide a means for filing applications but not for granting them.

A "means" refers to a mechanism to file patent applications which can be understood to serve as a mailbox. The applications are kept in the mailbox until the country can no longer claim that they are in the transition period. Article $70.8(b)$ stipulates that after this period applications need to be examined according to:

"the criteria for patentability as laid down in this Agreement as if those criteria were being applied on the date of filing in that Member or, where priority is available and chamed, the priority date of the application". 35

37 See paras. $65-66$ of the Canatin - Patents Tirm (ABR).

3 See Art. 70.8 of the TRIPS Agreement.

3it See Art. 70.8(b) of the TRIPS Agreement. 
Pursuant under Article 70.8(c) Members shall:

\begin{abstract}
"provide patent protection in accordance with this Agreement as from the grant of the patent and for the remainder of the patent term, counted from the filing date in accordance with Article 33 of this Agreement, for those of these applications that meet the criteria for protection referred to in subparagraph (b) [of Article 70.8 TRIIS]", 3.
\end{abstract}

1 lence, Article $70.8(a)$ obliges Members to establish a filing mechanism, known as the "mailbox rule" because the patent application is given a date stating when it was received in the Patent office. Applications filed under the mailbox rule are not examined until the transition period lapses. However, the mailbox rule takes into consideration the filing date guaranteeing it as a priority date. Thus, novelty will be examined as of the date of application and not the later date of expiry of transition period.

The TRIPS Agreement requires countries, under Section five, to establish a patent system available to all inventions that meet certain conditions. Nonetheless this provision is subject to a number of exceptions. For example under Article 65.2 developing countries are entitled to a transitional period that allows them to delay the obligations under the TRIPS Agreement for five years from the date of entry into force of the WTO Agreement, i.e., until January 1 , 2000. In addition, Article 65.4 sets forth that developing country Members may delay "product patent protection in areas of technology not so protectable in its territory on the general date of application of this Agreement" for an additional five years.

For example, India did not provide patent protection for pharmaceutical and agricultural chemical products at the time the TRIPS Agreement took effect in its territory (for developing countries like India, on 1 January 2000) and was permitted to invoke the additional five-year transition period for those products. As a result, it was entitled to delay patent protection for pharmaceutical and agricultural chemical products until after the expiry of the additional transitional period which occurred on 1 January 2005.

The Panel and the Appellate Body considered in India - Patents that the term 'means' can not merely be explained by looking at the ordinary meaning of the word but, that in considering what sort of means is required, one needs to look at the context of the subparagraph (a). Therefore the Panel looked at subparagraph (a) along with subparagraph (b) and (c) of Article 70.8 TRIPS Agreement. The next paragraph will discuss the interpretation given to Article 70.8 subparagraphs (a), (b) and (c) by the Panel and the Appellate Body in the lintia - Patents case.

35 See Art. $70.8(\mathrm{c})$ of the TRIPS Agreement. 
In Indin - Patchts, the Panel and the Appellate Body also examined Article 70.9 since the US claimed that India was also in violation of its obligations under 70.9. Article 70.9 stipulates that "where a product is the subject of a patent application in a Member in accordance with paragraph 8(a), exclusive marketing rights shall be granted". 370 "Thus for products falling under Article 70.8(a) Article 70.9 is applicable. This Article requires that Members grant exclusive marketing rights for five years after the product receives marketing approval in the territory of that Member or until a product patent is granted or rejected, whichever period is shorter. This additional obligation applies only if a patent application has been filed and a patent granted for that product and subsequently marketing approval has been obtained in the territory of that other Member.

\subsubsection{WTO Case Law on Article 70.8 TRIPS Agreement}

\section{The Fints}

Article 70.8 was discussed in a case requested by the United States versus India. ${ }^{\prime}$ This was the first dispute concerning the provisions of the TRIPS Agreement solved within the Dispute Settlement System. The US, lobbied by its agitated pharmaceutical industry, requested a Panel and claimed that India did not meet its obligations under Articles 70.8 and 70.9 of the TRIPS Agreement. According to the US, India had not created a valid system for receiving "mailbox" applications that adequately preserved novelty and priority in respect of applications for product patents for pharmaceutical and agricultural chemical inventions. Hence, the issue at stake was whether India had undertaken the action necessary to implement its obligations under subparagraph (a) of Article $70.8 .3 \%$

To meet its obligations under Article 70 TRIPS Agreement, India's president promulgated the Patents Ordinance 1994, which amended the Patent's Act of 1970. The Ordinance was brought to the attention of the TRIPS Council under Article 63.2. The characteristics of the Indian legislature require that the Ordinance be made permanent by Parliament. In order to do this, a Patents Bill 1995 was initiated in the Indian Parliament. Unfortunately, the Parliament was dissolved before the Patents Bill was passed. However, the Indian executive authorities instructed the Indian patent offices to continue to receive the applications and to store them separately for processing at an appropriate stage. According to India, these "administrative instructions" were legally valid in Indian law, as they are reflected in the Minister's Statement to Par-

\footnotetext{
376 See Art. 70.9 of the TRIPS Agreement.

37 Panel Report hitin - Patents, India - Patent Protection for Pharmaceutical and Agricultural Chemical Products, Complaint by the US, WT/DS50/R, DSR 1998: I, 41.

3is See para. 7.23 of the India - Patents (US) (PR).
} 
liament of 2 August 1996. Nonetheless, India did not show a record of these particular "administrative instructions" to the WTO Panel, nor had the patent authorities received any administrative guidelines, nor had a public notice of the administrative decision been made. In addition, the TRIPS Council had not been notified by India on their decision as is required under Article 63 . Furthermore, the Indian law was silent on granting exclusive marketing rights, hence the Indian executive authorities had neither any legal authority to award these marketing rights, nor was there a system in place to grant these rights.

\section{Substantioe losues}

The Panel held that Article 70.8 (a) applied to India, meaning that the effective "date of entry into force of the WTO Agreement", was 1 January 1995. Obligations under subparagraphs (b) and (c) will become binding on India only "as of the date of application of this Agreement", which in this particular instance means no later than 1 January 2005 by virtue of the provisions of paragraphs 2 and 4 of Article 65 of the TRII'S Agreement - entitling India to make use of the transition period under Article 65 TRIPS. "Therefore, the question before the Panel was whether India had taken the necessary action to implement its obligations under subparagraph (a) of Article 70.8 .

The Panel examined the requirement embodied in Article 70.8, which sets forth that Members are to provide "a means" by which applications can be filed. It is not specified what qualifies as "a means". In paragraph 7.24 the Panel considered that:

\footnotetext{
"Subparagraph (a) of Article 70.8, like all other provisions of the covered agreements, must be interpreted in good faith in light of (i) the ordinary meaning of its terms; (ii) the context; and (iii) its object and purpose, following the rules set out in Article 31(1) of the Vienna Convention". ine
}

The Panel remarked - following a textual analysis - that the formulation of subparagraph (a) starts with "notwithstanding the provisions of Part VI" which indicates that this provision is an exception to the transitional arrangements contained in Part VI of the TRIPS Agreement. ${ }^{381}$ However, this was not the issue at stake between the parties. Rather, the issue was the type of 'means' required by this subparagraph. Since, the ordinary tem does not clarify what sort of means is required the Panel reasoned that the wording can only be clarified by looking at the context of this subparagraph (a), thus, by looking at the other subparagraphs (b) and (c). These subparagraphs require Members to

3. See para. 7.23 of the India - Patents (US) (PR).
sil See para. 7.34 of the Intia - Patents (US) (PR).
s. See para. 7.25 of the India - Patents (US) (PR). 
examine the applications after the lapse of the transition period and to grant patent protection to those products that meet certain criteria. In addition the Panel noted that the obligation embodied in Article 70.9 is also applicable to countries during the transitional period. $\$ \$ 2$

The Panel continues that:

"a filing must entitle the applicant to claim priority on the basis of an earlier filing in respect of the claimed invention over applications with subsequent filing or priority dales (...) Without legally sound filing and priority dates, the mechanism to be established on the basis of Article 70.8 will be rendered inoperational. Thus, in order to prevent the loss of the novelty of an invention in this sense, filing and priority dates need to have a sound legal basis if the provisions of Article 70.8 are 10 fulfil their purpose (...) to provicte for effective future patent protection after examination of the applications". $3 \$ 3$

This, according to the Panel "is the central object and purpose of Article 70.8(a) [and] a special obligation imposed on those Members benefiting from the transitional arrangements". $3 .+$ Next, the Pand affirmed that these are confirmed by the negotiating history of the TRIPS Agreement. And finally the Panel recalled that:

"one of the precepts developed under GATT 1947 is that rules and disciplines governing the multilateral trading system serve to protect legitimate expectations of Members as to the competitive relationship between their products and those of the other Members". Moreover "Ip|redictability in the intellectual property regime is indeed essential for the nationals of WTO Members when they make trade and investment decisions in the course of their businesses". 3 .

Hence, in an assessment to explore if India implemented Article 70.8 in confirmation with the TRIPS Agreement obligation the Panel asked itself the following:

"[can the] current Indian sy'stem for the receipt of mailbox applications sufficiently protec the legitimate expectations of other WTO Members as to the competitive relationship between their nationals and those of other Members, by ensuring the preservation of novelty and priority in respect of products which were the subject of mailbox applications". 3 int

352 See para. 7.26 of the India - Patents (US) (PR).

is. See para. 7.28 of the Intia - Patents (PR).

s.t Ibid.

in: See para. 7.30 of the India-Patents (PR).

ist See para. 7.31 of the Indin - Patents (PR) Foremost, the Panel considered Art. 70.8 to set two obligations: 1) to provide a means as to allow for the right to file patent applications and the allocation of filing and priority dates to them, and 2) to provide 


\title{
Conclusions
}

The Panel examined India's system and found that India's Patents Act 1970 embodied certain mandatory provisions which required Indian patent examiners to refuse applications for pharmaceutical and agricultural chemical products. The Panel considered that these mandatory provisions laid down in India's Patent Act resulted in legal insecurity for economic operators since the Indian Patent Act 1970 contradicts India's administrative practice of accepting these applications for mailbox purposes. ${ }^{3 s ;}$

Para. 7.36 Panel Report continued:

\begin{abstract}
"This legal insecurity is further compounded by the lapse of the Patents (Amendment) Ordinance 1994, which formally and publicly established legal procetures for the receipt of mailbox applications. This is a particular problem according to the United Stales because a group of Indian patent law experts advised the Indian Government that a formal legal basis for mailbox applications was required to give them legitimacy under Indian law. Although India counters that the group issued no specific report on this issue and that the group contained patent law and not constitutional law experts, a press note issued at the time of the promulgation of the Ordinance indicates that the Ordinance was based in part on the group's recommendations". $3 \mathrm{si}$
\end{abstract}

India suggested that it would amend its patent law in the remaining time of the transition period but the Panel refused explaining that:

"despite India's commitment to seek legislative changes before the expiry of the
transitional period available to it, without a sufficient legal basis now for
preserving novelty and priority, there would remain doubt during the transi-
tional period regarding the eligibility of these products for future patent protec-
tion. As a result, the legal status of patent applications in respect of these
products would remain insecure and unpredictable for a possibly' long period,
which could last until 1 January $2\left(05^{5}\right.$.36")

In this way, inventors and traders remained uncertain whether their applications would be accepted. Moreover, even if Indian Patent Office officials accepted mailbox applications, there was a possibility that a competitor could seek a judicial order to force India's patent office officials to reject the applications. India put forward that 125 applications had already been received and filed pursuant to the Ordinance procedures in India. The Panel

a sound legal basis to preserve novelty and priority as of the filing date so as to eliminate any reasonable doubts. See para. 7.31 of the lindin - Patents (US)(PR).

3 is See para. 7.35 of the Intia - Patents (US) (PR).

3is See para. 7.36 of the lutio - Patents (US) (PR).

3.6. See para. 7.38 of the lindia - Patents (US) (PR). 
rejected this argument and was of the opinion that many other applications might have been filed, had a proper system been in place.

The Panel concluded its analysis by questioning whether unpublicised administrative practices can be regarded as 'a means':

"There must be a guarantee that the public - including interested nationals of other WTO Members - is adequately informed. For potential applicants from other WTO Members to be adequately informed, it is arguable that they must not only have information about the existence of a system for the filing of patent applications for pharmaceutical and agricultural chemical products, but also be informed of the purpose of such a system, i.e., to protect the novelty of the inventions in question and the priority of the applications claiming their protection so that the applications concerned are capable of Ieading to the grant of a patent under the conditions of subparagraphs (b) and (c) of Article 70.8, and to lead to the grant of exclusive marketing rights under the conditions set out in Article 70.9 even during the transitional period. Otherwise, the security and predictability necessary for the operation of the TRIPS Agreement would be lost, and legitimate expectations of interested nationals of other WTO Members would not be protected". . w

The Panel concluded that the US had presented a prima facie case of violation, unsuccessfully rebutted by india:

"India] failed to take the action necessary to implement its obligations under subparagraph (a) of Article 70.8 because of the lack of legal security regarding the status of product patent applications in respect of pharmaceutical and agricultural chemical products under the system it presently operates". ${ }^{301}$

When paragraph 7 of the Doha Declaration on the TRIPS Agreement and Public Health was negotiated, least-developed Members raised concerns that the requirement to accept the filing of mailbox applications, and subsequently to grant patents based upon them, (for example, after 1 January 2016), would possibly reduce incentives to start manufacturing drugs within their territories. However, this request - to waive the obligation on LDC Members to accept mailbox applications or to grant patents based on such applications following the entry into force (meaning the day patents need to be enforced) of patent protection - was not followed up by the General Council. ${ }^{392}$ However, the obligation to provide exclusive marketing rights under Article 70.9 was waived for L.DCs. ${ }^{393}$

3\%) See para. 7.42 of the ludia - Patents (US) (PR).

3 See para. 7.43 of the India - Patents (US) (PR).

3"2 See UNCTAD- ICTSD [Resource Book] 2005, p. 772.

393 "Least-developed country Members - Obligations under Article 70.9 of the TRIPS Agreement with respect to pharmaceutical products, Draft Waiver", TRIPS Council 


\title{
6.3. Grant of Exclusion Marketing Rights
}

Article 70.9 sets out that:

\begin{abstract}
"Where a product is the subject of a patent application in a Member in accordance with paragraph 8(a), exclusive marketing rights shall be granted, notwithstanding the provisions of Part VI, for a period of five years after obtaining marketing approval in that Member or until a product patent is granted or rejected in that Member, whichever period is shorter, provided that, subsequent to the entry into force of the WTO Agreement, a patent application has been filed and a patent granted for that product in another Member and marketing approval obtained in such other Member". ${ }^{3}$.4
\end{abstract}

The term 'exclusive marketing rights' was new for the TRIPS Agreement and a term not previously used in the IP context. It was designed to find a compromise between countries asking for immediate applicability of patent protection for pharmaceutical products and other countries favouring such protection only after the lapse of the full transition periods. Article 70.9 applies only with respect to patent applications filed in a Member under Article 70.8(a). It is important to bear in mind that no definition or scope of "pharmaceutical product" and "agricultural chemical" has been provided for and therefore there may be questions regarding the inventions which qualify for coverage under Article 70.8 and, by extension, Article 70.9 .

Article 70.9 requires that if a product is in the process of obtaining a patent, exclusive marketing rights are granted. Exclusive marketing rights are granted for a period of five years after obtaining marketing approval or until a product patent is granted or rejected in that country, whichever period is shorter. Countries availing themselves of a transition period under Part Vl of the TRIPS Agreement also have to grant exclusive marketing rights following from Article 70.9 and re-affirmed in the WTO ABR in respect to its interpretation of Article 70.9 in the WTO case Indin-Patents. However, in 2002 a waiver was adopted which exempts LDCs from the obligation from Article 70.9 relating to pharmaceutical products.

\subsubsection{WTO Case Law on Article 70.9 TRIPS Agreement}

The Exclusive marketing rights rule embodied in Article 70.9 was part of the dispute in the India - Patents (US) case brought before the WTO Dispute Settlement Body. The US argued that India was obliged (as of the date of entry into

Decision of 27 June 2002. Published online at: <http://www.wto.org/english/news _c/pres(12_e/pr301_e.htm>.

30.4 See Art. 70.9 of the TRIPS Agreement. 
force of the WTO Agreement, i.e. January 1, 1995) to establish an exclusive marketing rights system on their territory. According to the US, India had not established such a system and that as a result India was not in compliance with obligations under Article 70.9 of the TRIPS Agreement. There is no dispute as to whether India had installed such a marketing rights system: both parties agree that such a system did not exist in India. ${ }^{345}$. However, India rejected the reasoning of the US and believed it was under no obligation to have such an exclusive marketing system, because no application for exclusive marketing rights had so far been filed. ${ }^{3 \%}$

The Panel regarded the issue to be one of timing: at what point in time should India have such a system in place? In relation to this question the Panel formulated two sub questions:

"(a) Is India in breach of the TRIPS Agreement if, at the appropriate time, its executive authorities do not have the legal authority to grant exclusive marketing rights, even if the grant of such rights has not yet been refused to an eligille product?; b) If the answer is yes, what is the appropriate time by which such legal authority must be provided?" 3 ?

The Panel argued that:

"the TRIPS Agreement is different from other covered agreements in that most of its provisions require Members to take positive action; in this particular case to grant exclusive marketing rights pursuant to Article $70.9^{\prime \prime}$.

Failure to do so will constitute a breach with the agreement and the absence of legislation "frustrates legitimate expectations regarding the conditions of competition". 3 .

The Panel considered the wording of Article 70.9 and found that under the ordinary terms of this provision, the transitional exemption rules of Article 65 did not apply to Article 70.9. As a result the obligation contained in Article 70.9 was effective as of the date of entry into force of the WTO Agreement, which was January 1, 1995.tmu

India disagreed with the above for two reasons: Firstly it stated that Article 70.9 did not contain similar wording as Article 70.8 that is to say "provide as from the date of entry into force of the WTO Agreement". Secondly, India believed that Article 70.9 required the grant of exclusive marketing rights and

\footnotetext{
345 See para. 7.51 of the Indin - Patents (US) (PR).

swe See para. 7.52 of the Indin - Patents (US) (PR)

34 See para. 7.53 of the Intia - Patents (US) (PR)

3 sis Ibid.

3,4 lbid.

4hi) See para. 7.54 of the lndial - Patents (US) (PR).
} 
that it did not require that a mechanism for the grant of exclusive marketing rights be available. India argued under Article 27:

\begin{abstract}
"that the obligations under Article 70.9 should be distinguished from those under other provisions of the TRIPS Agreement because it uses the term exclusive marketing rights shall be granted. According to India, there is a material difference between this expression and such other expressions as patents shall be available"
\end{abstract}

With regards to the first statement the Panel held this argument to be insignificant according to the fact that Article 70.9 is directly tied to Article $70.8(\mathrm{a})$. $^{\mathrm{ith}}$ In relation to the second, the Panel was not persuaded and argued that the terms "shall be available" and "shall be granted" could almost be used interchangeably. +12 The Panel found that an analysis of the context and objective and purpose of Article 70.9 supported its interpretation, largely because the provision intended to give a particular right to economic operators from which Members should not be deprived. As with Article 70.8, the Panel also noted that the lack of a mechanism in India's current system created insecurity and was likely to discourage economic operators from filing applications to obtain exclusive marketing rights. ${ }^{* 13}$ As a result, the Panel concluded that India had failed to implement its obligations under Article 70.9 of the TRIPS Agreement. ${ }^{11 .+1}$

The case was next referred to the Appellate Body 115 for reviewing the Panel's finding that the patent law of India was in violation of Article 70.9. The Appellate Body addressed the relationship between Article 70.8(a) and 70.9. It argued that the wording of Article 70.9 made it only applicable where a product patent application was filed under Article 70.8(a):

"Illike Article 70,8(a), Article 70.9 applies 'notwithstanding the provisions of Part VI'. Article 70.9 specifically refers to Article 70.8(a), and they operate in tandem to provide a package of rights and obligations that apply during the transitional periods contemplated in Article 65. It is obvious, therefore, that both Article $70.8(\mathrm{a})$ and Article 70.9 are intended to apply as from the date of entry into force of the WTO Agreement". tht

min lbid.

w2 See para. 7.56 of the Indin - Patents (US) (PR). This view was upheld in lntin Patents (EC) (PR).

tw.3 See para. 7.54-62 of the Intia - Patents (US) (PR).

thit See para. 7.63-64 of the Indin - Patents (US) (PR).

W15 India appealed to the Appellate Body on October 15, 1997 the Appellate Body report was adopted on January 16, 1998. Appellate Body Report India - Patent Protection for Pharmaceutical and Agricultural Chemical Products, Complaint by the US, $W T / D S 50 / A B / R$.

whe See para. 82 of the lindia - Palents, ABR. 
The Panel's view was upheld in the Appellate Body. Hence, the ABR also concluded that a request-based system of rights cannot operate effectively unless there is a mechanism in place that establishes general availability and enables such requests to be made.

\subsubsection{New Developments}

On 27 June 2002, simultaneously with the grant of extension of the transition period for least-developing countries, a waiver was approved that exempted LDCs from having to provide exclusive marketing rights for any new drugs in the period when they do not provide patent protection (hereinafter referred to as waiver 2002). Hence, as long as LDCs are permitted to avail themselves of the transition period they also are under no obligation to grant exclusive marketing rights. It was agreed that exceptional circumstances existed to justify a waiver which exempts least developing countries from the obligation to give these exclusive marketing rights in light of paragraph 7 of the Declaration of TRIPS Agreement and Public Health. ${ }^{418}$

Developing countries - which are not LDCs - do have to provide exclusive marketing rights during the time of the transition period (as was challenged by India in India - Patents). As of 1 January 2005, the additional transition period for developing countries lapsed, implying that they now have to conform with all the provisions of the TRIPS Agreement including establishing product patent protection for pharmaceutical products.

The waiver 2002 stipulated that:

"The obligations of least-developed country Members under paragraph 9 of Article 70 of the TRIPS Agreement shall be waived with respect to pharmaceutical products until 1 January 2016; 2) This waiver shall be reviewed by the Ministerial Conference not later than one year after it is granted, and thereafter annually until the waiver terminates, in accordance with the provisions of paragraph 4 of Article IX of the WTO Agreement".t(n)

As said, the waiver 2002 was drafted at the same time as the TRIPS Council reached the Decision to extend the transition period under Article 66.1 for least developing countries for certain obligations with respect to pharmaceutical

waiver was drafted in accordance with Art. IX titled "Decision Making", paragraph 1, 3 and 4 of the Marrakesh Agreement Establishing the WTO which lays down the conditions under which a waiver is permitted and the procedural requirements to obtain such a waiver. The Decision of the Council for TRIPS of 27 June $2002, I P / C / 25$. 
products. Hence, the objective of the waiver is twofold: 1) accommodating the special interests of least developing countries by providing them extra time to implement The TRIPS Agreement obligations into their own jurisdiction and 2) exempting these countries from having to give exclusive marketing rights.

Developing countries availing themselves of the transition period are allowed extra time before compliance to the TRIPS Agreement provisions but these countries still need to make it possible for inventors to submit patent applications during this period under Article 70.8 - the mailbox provision. In that if a country's health authority approves a new drug for sale, the patent applicant has to be given exclusive marketing rights for a period of five years after obtaining marketing approval in that Member or until a product patent is granted or rejected in that Member, whichever period is shorter even though there is no patent under Article 70.9.

\section{CONCLLSION}

This chapter sets out the key provisions important for developing countries. They provide rights and obligations in relation to intellectual property protection and embody flexibilities countries have in developing their own policy and legislative framework regarding IP. Some of these flexibilities are easy distinguishable other provisions require a more thorough analysis before the flexibility surfaces. Most of the provisions embodied in the TRIPS Agreement, including the provisions incorporated from the Paris Convention and the Berne Convention, are rather broadly defined as a result of the tedious negotiation process.

The TRIPS Agreement sets out the minimum level of IPR protection which Member countries are obliged to provide within their domestic legal framework of protection. These rules aim to provide some predictability for consumers and businesses if business is conducted across borders. TRIPS, contains, by way of counterbalance, a number of provisions that address possible abusive, anti-competitive practices by right holders which may "unreasonably restrain trade or adversely affect the international transfer of technology". The need for this is generally addressed in Article 8 which stipulates that the Agreement should:
"reduce distortions and impediments to international trade, and taking into account the need to promote effective and adequate protection of intellectual property rights, and to ensure that measures and procedures to enforce intellectual property rights do not themselves become barriers to legitimate trade".

Furthermore, Article 40 of the TRIPS Agreement allows members to legislate against particular licensing practices or conditions that may "constitute an abuse of intellectual property rights having an adverse effect on competition in the relevant market", including "grantback conditions, conditions preventing challenges to validity and coercive package licensing". Also, Article 67 of the 
TRIPS Agreement requires developed country members to assist developing countries with the implementation of the TRIPS Agreement. It is explicitly mentioned that cooperation and assistance shall include the "preparation of laws and regulations on the protection and enforcement of intellectual property rights as well as on the prevention of their abuse". Furthermore, TRIPS aims to balance public and private rights and obligations as is set out in Article 7:

\footnotetext{
"the protection and enforcement of technological innovation and to the transfer and dissemination of technology, to the mutual advantage of producers and users of technological knowledge and in a manner conducive to social and economic welfare, and to a balance of rights and obligations".
}

The negotiation history points out that this provision has throughout the negotiation process provided the mandate to negotiate a treaty on intellectual property rights. In addition, the need to take account of differences in levels of development is recognised in the Preamble "the provision of effective and appropriate means for the enforcement of trade-related intellectual property rights, [should takel into account differences in national legal systems". However, one can contest the viability of this endeavour, considering the prescriptive nature and content of the substantive obligations under the Agreement.

The TRIPS Agreement grants Members a number of rights besides imposing obligations and duties. Foremost, the international standardisation of intellectual property rights has an indirect impact on domestic intellectual property rights systems because the enacted provisions of the TRIPS Agreement have to be implemented within the national jurisdiction. The TRIPS Agreement lays down minimum standards of protection. As a result, the Agreement does offer some aiggle rom allowing developing countries to pursue pro-competitive strategies and adopt subsequent policies, while still acting consistently with the TRIPS Agreement requirements. ${ }^{40}$ Developing countries have to manage their rights and obligations well to make optimum use of the flexibilities inherent in the TRIPS Agreement as well as meeting its minimum requirements. The TRIPS Agreement embodies a number of flexibilities. These are the result of left open territory from the negotiation-making process, never finalised for various reasons: 1 ) either because no consensus could be achieved on this particular field of intellectual property; 2 ) or simply because this subject matter was not negotiated; 3) or because only the general framework was set out deliberately leaving the details to the individual countries; 4 ) or because there was no agreement on whether this topic belonged to the field of intellectual property or should be dealt with outside its sphere.

411) See Reichman 1998, p. 585. 
The most prominent flexibility of the TRIPS Agreement is found in Article 1 of the Agreement, which stipulates that the Agreement provides minimum stanitords of protiction. This article includes a certain paradox as; on the one hand, countries are free to enter into bilateral, regional or international agreements to enhance the level of national intellectual property protection. This might be detrimental for socio-economic development as such agreements may further diminish policy flexibility to adopt IPR policies which support their needs and interests. On the other hand, Article 1 provides countries the freedom to choose how to employ the TRIPS provisions in their own domestic legislation supporting socio-economic interests.

Most flexibilities are, however, not as visible as the Article 1 example, and require a more thorough analysis. There are flexibilities in areas where the TRIPS Agreement has remained silent, e.g. competition law, utility model protection or trade secrets, and the substantive scope and level of trademarks and patents, and the possibility to use research exemptions and other exceptions and limitations. Flexibilities also remain where the Agreement has remained indecisive: for example Article 6 deliberately says that the TRIPS Agreement leaves it up to Members to decide which policies to adopt in relation to the doctrine of exhaustion (parallel importation). Another example is Article 27.3 which allows flexibility on the protection of plant varieties e.g. through patents or by establishing sui generis systems.

It is only if Members can benefit from intellectual property rights for their own innovative and creative processes that effective implementation and enforcement will occur. In other words it requires a mind shift. In this regard it is important to develop the necessary conditions in which countries can produce goods that can benefit from intellectual property protection.

Technical assistance should therefore not only be directed at the implementation of the TRIPS Agreement substantive rules. It should also highlight the available flexibilities existing in the TRIPS Agreement and it should provide access to technologies useful for developing countries to build a creative and technological base. Enforcement endeavours should recognise not only the obligations deriving from the implementation process of the TRIPS Agreement but focus on the rights and flexibilities as well. It is high time to bring some balance into the enforcement debate and take more account of various domestic needs and circumstances. 


\title{
Chapter Three
}

\section{Searching for Traditional Knowledge Protection: The Internationalisation of Local Tradition}

\author{
"Nature has given us the seeds of knoweledge, but not knowlodge itsolf" \\ Seneca
}

\section{INTRODLCTION}

Over the past decade, the misappropriation of genetic resources' and traditional knowledge has emerged as an issue of global concern. Yet gaining international recognition for the need to effectively address such misappropriation and adequately protect traditional knowledge remains a major challenge for developing countries, which hold the majority of the world's genetic resources and traditional knowledge. The WTO Doha Ministerial Declaration (2001) requested the TRIPS Council to address the relationship between the Convention on Biological Diversity (CDB) and the WTO TRIPS Agreement. Since then, a debate has ensued over whether the TRIPS Agreement conflicts with the CBD, and whether a disclosure of origin requirement should be introduced into the former. These issues will be addressed in this chapter. Many developing countries, including Brazil, Pakistan, Thailand, Peru, India, the African Group and the group of least-developed countries (LDCs) have proposed amending the TRIPS Agreement to require patent applications to disclose the origin of genetic resources and associated traditional knowledge in inventions, as well as to provide evidence of prior informed consent and benefit sharing with communities with a view to combating bio piracy.2 Their proposed amendment recognises the sovereign rights of states over their natural resources, and includes forfeiture of patent rights as a penalty for noncompliance. However, many industrialised countries question the need for such amendment. Some consider the World Intellectual Property Organisation (WIPO) the appropriate forum to deal with these issues, particularly the WIPO Intergovernmental Committee on Intellectual Property and Genetic Resources, Traditional Knowledge and Folklore (IGC) established in 2001. Japan and the US - which is not a party to the CBD - do not regard the CBD and the TRIIPS Agreement to be in conflict with each other, but understand both Agreements

1 Art. 2 of the CBD provites the following definition of genetic resources: "Genetic resources" means genetic material of actual or potential value.

2 Bio piracy refers to the misappropriation, generally by means of patents, of indigenous/traditional (biomedical) knowledge by foreign entities (including corporations, universities and governments) without compensatory payment. 
to deal with separate issues. In contrast, the EC, Norway and Switzerland are supportive of establishing disclosure of origin requirements at the international level, but not necessarily in the framework of the WTO. Norway was the first developed nation to favour the incorporation of a disclosure requirement in the TRIPS Agreement, yet it differs from developing countries on the legal consequences of the lack of disclosure, considering that non-compliance should not lead to the revocation of the patent.

The search for new pharmaceutical, biotechnological or agricultural applications based on genetic resources has emerged over the last decades and subsequently intellectual property rights (IPRs) have been applied to protect innovations based on genetic resources. ${ }^{3}$ Hence, genetic resources and associated traditional knowledge have economic significance. These practises (the patenting of biogenetic resources) have raised debates at multilateral fora in part because of the (perceived) potential for exploitation of biogenetic resources for biotechnology $y^{4}$ as well as for neglecting the contribution of indigenous communities to the identification of the therapeutic properties of native plants. Indigenous communities that have identified therapeutic properties of native plants and have contributed to their conservation and preservation express concerns about the accessing and exploitation of their biogenetic resources without their consent. ${ }^{5}$ Moreover, they have not been compensated for the use of their genetic resources, nor have they shared in the benefits from the

See Van Overwalle 2002, p. 233.

4 Art. 2 of the CBD provides the following definition: "Biotechnology" means any technological application that uses biological systems, living organisms, or derivatives thereof, to make or modify.

; Indigenous groups believe that frequently genes are appropriated by IPRs that arise from their territories, lands and waters; and hence the knowledge related to those genes is theirs. As a result, any decision making about the rules to regulate the buying and selling of those genes and traditional (indigenous) knowledge must include their right to make their own decisions about what will be the best path for their future generations based on our own cultural and spiritual beliefs and related customary and/or codified laws. This view has been expressed by Le'a Malia Kanehe legal advisor for the Indigenous Peoples Council on Biocolonialims. Interview conducted by the author in February 2008. German Report "The 40 Shades of Technology Transfer" provides the following definition: "Biotechnologies are technologies that capitalise on the attributes of cells, such as their manufacturing capabilities, and put biological molecules, such as DNA and proteins, to work for us. They comprise any technological application that uses biological systems, living organisms, or derivatives thereof, to make or modify". Published online at: $<$ http:// www.cbd.int/doc/case-studies/ttc/tttc-00038-en.pdf $>$. 
exploitation. As a consequence, interest in the protection of traditional knowledge (TK) has grown significantly over the last two decades."

The patenting of inventions based on biogenetic resources is permitted under the TRIPS Agreement. The TRIPS Agreement allows patent protection for all new products and processes generated using any field of technology under Article 27. Article $27.3($ b) provides that plants and animals may be protected by patents subject to the sovereignty of the Member. It stipulates that plant varieties neril to be protected, either by a patent or a sui generis type of protection. During the Uruguay Round negotiations and in the TRIPS Agreement implementing process developing countries have raised many problems in this regard. In their view Article 27 of the TRIPS Agreement conflicts with the provisions and rationale of the Convention on Biological Diversity (CBD). In particular with Article $8 \mathrm{j}$ of the CBD that sets out that CBD Contracting Parties shall

"respect, preserve and maintain knowledge, innovations and practices of indigenous and local communities (...) and promote their arider application with the "uproen and ineotement of the holders of such knowledge, innovations and practices and encournge the equitable shoring of the bentefis arising from the utilization of such knowledge, innovations and practices". (emphasis added FC)

Moreover the CBD demands that:

"developing countries, which provide genetic resources, are provided access to and transfer of teclunology which makes use of those resources, on mutually agreed terms, including technology protected by patents and other intellectual property rights".?

At first the industry's focus was mainly on the potential of genetic resources and associated TK for the development of new pharmaceutical products. But during the 1990s, bio prospecting associated with the plants and resources of indigenous people peaked and scope widened to hybrid plants and plant varieties. "The advances in biotechnology" resulted in a rapid increase in the

"For the history and origin underlying the search for TK protection see RAFI Communique 1994b, and Green College Centre for Environmental Policy and Understanding, 1993 .

- See Art. 16.3 of the CBD.

- See Tobin 2004.

" Biotechnology has been defined as: "Any technique that uses living organisms to make or modify products, to improve plants or animals, or to develop microorganisms for specific uses". See Office of Technology Assessment, 1984. The CBD provides the following definition in its Art. 2: "any technological application that uses biological sy'stems, living organisms, or derivatives thereof, to make or modify". 
patenting of biological material obtained from developing countries but modified and enhanced in industrial country laboratories using state-of-the-art science and techniques. "As a result, genetic resources stand at the basis of the improvement of agricultural crops and medicines with economic significance. The combined annual global markets for the products derived from genetic resources in these sectors lies between 500 and 800 billion US dollars, which is comparable to the world petrochemical and information technology markets. " This development was a direct result of broadening the scope of property right claims over the biological material. Critics have described it as a contrast between the knowledge acquired by indigenous people (in the form of collective ownership passed on from generation to generation) versus "the West's new 'frontier' in (...) the last great resource rush"12 or refer to bio colonisation. ${ }^{13}$

The countries of origin of the genetic resources and the indigenous and local communities - the holders of the associated TK - have not been consulted by those that use their resources to obtain economic advantages, and have received limited or no benefit deriving from their use. Alarmed by these developments, indigenous people have sought recognition of their contribution to and rights over their $1 \mathrm{~K}$ and biogenetic resources. ${ }^{14}$ In their search for justice, they have been supported by numerous civil society groups who, since the late 1980s, have been active in advocating indigenous people's rights and pointing out the injustice meted out to them by profit focussed industries. ${ }^{15}$

Pursuant, the misappropriation of genetic resources and TK has emerged, in the past decade, as an issue of global concern which has been addressed in a number of international fora, such as the Convention on Biological Diversity

II Genetic resources, plant varieties or cultural expressions have over the years been collected and taken overseas by missionaries, anthropologists, tourists, entrepreneurs and field researchers.

11 See Kate and Laird 1999.

12 Cultural Survival Quarterly, Summer 1991, p. 3, as cited in Greaves 1994, p. v. See also Mead 1994, p. $4-7$.

13 See Nair 2000. The paper provides a perspective from India's pharmaceutical industry on the revocation of the neem patent and how to reconcile TRIPS with CBD. Published online at: <http://www indiaserver.com/thehindu/2000/05/17/ stories/0617 000a.htm>.

1.4 Access to genetic resources has to be guaranted to enable preservation and sustainable development of the resources, especially as communities show signs of disintegration. See Heald 2003.

is Voices of the Earth, World Wild Fund for Nature (WWF), GRAIN, RAFI Communique, the Center for International Environmental Law (CIEL) and the Internationa! Union for Conservation of Nature (IUCN), all showed an early interest in conservation. Government interests were perceived much later (1996) within the framework of the WTO. 
(CBD), the World Trade Organisation (WTO) and the World Intellectual Property Organisation (WIPO). These for a have addressed questions such as:

"What can really be done when traditional, local knowledge, resources, or locally produced (manufactured) goods are disseminated outside the control of the local administrative or juridical authorities - either through trade or misappropriation - and are commercialised without the consent of the provider communities and without their sharing in the benefits?"

It is important in this respect that those countries that are searching for a solution to legally protect TK in some form should ultimately achieve some consensus on what the objectives of an international legal framework for TK protection should be and provide guidance as to the implementation and enforcement of the proposed rules. The various fora and players dealing with TK protection at the multilateral level both complicate and facilitate this consensus finding process. ${ }^{16}$ "This equally applies to national regimes of protection - without clear objectives it is unlikely that policies, laws or sui generis systems will be effective. However, opportunities arise from the fact that provisions are being drafted at the WIPO IGC and supported by many countries and that gradually more countries are being convinced that some sort of protection should be available. A long term vision is an absolute must. Moreover, the recent adoption of the UN Declaration on the Rights of Indigenous Peoples by the UN General Assembly is a success in terms of the recognition of indigenous rights." The Declaration concerns respecting the rights of indigenous peoples. It emphasises that indigenous peoples have the right to self-determination - by that right they can freely determine their political status and pursue their economic, social and cultural development. ${ }^{18}$ For the purpose of this chapter, Article 31 of the Declaration is most interesting as it provides for the right of indigenous peoples to protect their TK and to protect and control the intellectual property (IP) over their cultural heritage and $T K$.

1e. The enormous volume of papers and country submissions in circulation which lack focus, common ground and are sometimes even contradictory (government representatives can express conflicting viewpoints on the same topic in different forums). For example, India's differing position in CBD and WTO fora.

17 The UN Declaration on the Rights of Indigenous Peoples (UN General Assembly 2007), adopted by the General Assembly on 13 September 2007, is a comprehensive statement addressing the rights of indigenous peoples. The Declaration has been under negotiation for more than two centuries. It recognises the rights of indigenous people to maintain and strengthen their own institutions, cultures and traditions and to pursue their development in keeping with their own needs and aspirations. Indigenous peoples have the right to fully enjoy as a collective or as individuals all human rights and fundamental freedoms as recognised in the UN Charter, the Universal Declaration of Human Rights and international human rights law including the right to education, the right to their traditions and the right to land.

is There are an estimated 370 million indigenous people and the Declaration will help them to combat discrimination and marginalisation. 
Article 31 of the UN Declaration on the Rights of Indigenous Peoples provides that:

"1. Indigenous peoples have the right to maintain, control, protect and develop their cultural heritage, traditional knowledge and traditional cultural expressions, as well as the manifestations of their sciences, technologies and cultures, including human and genetic resources, seeds, medicines, knowledge of the properties of fauna and flora, oral traditions, literatures, designs, sports and traditional games and visual and performing arts. They also have the right to maintain, control, protect and develop their intellectual property oeer such cultural leritage, tratitional knowledge, and traditional cultural expersions.

2. In conjunction with indigenous peoples, States shall take effective measures to recognise and protect the exercise of these rights". (emphasis added FC)

NGOs supporting indigenous rights and believes want this Declaration to be acknowledged by the CBD as the minimum standard. ${ }^{19}$

At the same time, the needs of the science and biotechnology based industries could not be overlooked while devising these measures for indigenous people. The use of their resources and $\mathrm{l} K \mathrm{~K}$ has the potential to open new frontiers in science and medical treatments for mankind. For this to happen, it is essential that both the ancient intellectual legacy and the scientific industry work together rather than being in conflict with each other. ${ }^{20}$

Another related issue within this paradigm is the transfer of technology. The developing nations who are custodians of the vast biogenetic material and TK view the present situation as a two way process: one as the flow of genetic resources and associated TK from these nations to the industrialised countries; and the other as the flow from the industrialised countries to these nations in the form of the products/resources based or made from these genetic resources such as new plant varieties, pharmaceutical products, and other scientific technologies which are crucial for the development of these nations. The latter flow can obtain protection from the IP system, while the former is not necessarily seen as a resource that can be protected within the western conception of IP. Thus, how can one secure similar rights for developing countries for their own resources? More importantly, how can one facilitate technology transfer in the areas crucial for the development of these nations, especially where they relate to adding value to the resources of these countries and their indigenous communities? Could the transfer of technology be incorporated into access and benefit sharing agreements as a form of benefit

19 As expressed by By Le' a Malia Kanche, legal advisor for the Indigenous Peoples Council on Biocolonialim as well as by Dyebo Shabalala, Director of IP and Sustainable Development Programme, CIEL, interview conducted by the author in February 2008. 
sharing? This chapter will address these issues, and also scrutinise the potential of the proposed disclosure of origin requirement within the TRIPS Agreement.

\section{TRADITIONAL KNOWLLIGE: ISSLES AT STAKE}

\subsection{Introduction}

Traditional knowledge is manifested in various ways, and could comprise, for instance, a culinary recipe, a cultivation technique or medical treatments. Increasingly, local craftsmanship, knowledge of farming techniques and comprehension of flora is recognised and valued for constituting relevant tools to protect the environment and its biodiversity and to instigate further scientific development. ${ }^{21}$ Although folklore is of relevance to the cultural heritage of every nation, developing countries in particular attach great value to folklore and appreciate the latter as a means of self-expression and social identity. The significance of folklore and T' $\mathrm{K}$ to developing countries is easily understood when one understands that in these countries, "folklore is truly a living and still developing tradition, rather than just a memory of the past".22 But in this chapter the focus is essentially on TK rather than on folklore, and in particular the TK associated with genetic resources rather than the general conception of TK.

The WHO reveals that 80 per cent of the population in developing countries relies on traditional medicine for their primary needs and TK is the primary means for securing their health, food, clothing, and housing. ${ }^{23}$ Moreover, knowledge of the healing properties of plants have been the basis of many modern pharmaceuticals ${ }^{24}$ - about 25 per cent are descended from plants first used traditionally. ${ }^{25}$ It is estimated that the world market for herbal medicines has reached, 43 billion, with anmual growth rates of between 5 and 15 per cent. For instance, in China, the WHO estimated that, traditional medicine generated income of about $\$ 5$ billion from the international and $\$ 1$ billion from the domestic market. The European market was estimated at almost $\$ 12$ billion. In addition, many regular pharmaceuticals are based on, or consist of, biogenetic

See Tolin 2004.

See Ficsor 1997.

Traditional medicines based on medicinal plants are ubiquitously used in countries such as India, China, Bhutan, Japan Thailand, Japan and Indonesia. See WHO 2002. See Pearce and Puroshothaman 1995, p. 128.

See Farnsworth 1988. 
resources (especially on plants). ${ }^{26}$ Apart from these obvious uses, TK runs in the very rubric of the culture of these indigenous communities. ${ }^{2-}$

\subsection{Bio Piracy}

Developing countries hold the majority of the world's genetic resources and TK $\mathrm{K}$ and are concerned about contemporary practices that appropriate biological diversity ${ }^{23}$ and associated knowledge. The use of traditional (indigenous) knowledge may help researchers, pharmaceutical and biotechnological companies finding plants with potentially interesting therapeutic (medicinal) features - and save them money as it puts them on the right track. ${ }^{29}$ The contribution of indigenous communities to the identification of the therapeutio properties of native plants has been neglected, they have not been compensated for the exploitation of their traditional knowledge and hence this exploitation is referred to as bio-prospecting, bio-piracy or bio-colonism. ${ }^{31}$ In order to put a halt to the misappropriation of their resources and to minimise the granting of bad or erroneous patents, incorporating naturally-occurring genetic resources without due recognition or compensation, several countries and regions have applied disclosure of origin measures in relation to patent applications for inventions derived from genetic resources. Such certification of origin essentially functions as a tracing mechanism enabling compensation, royalties, the transfer of technology as well as the preservation of natural resources, local knowledge and traditions, and culture.

The misappropriation of genetic resources and T'K has emerged, in the past decade, as an issue of global concern which has been addressed in a number of international fora, such as the Convention on Biological Diversity (CBD), the WTO and the WIPO.

The appropriation of genetic material can have severe consequences for indigenous people in terms of economic losses and access restrictions, which might

2n See Correa 1999, p. 3 referring to WHO "Strategy for Traditional Medicine 20002003", 2000.

I7 In Brazil, it is estimated that around 2 million species can be found in its six biomes (Amazon, Altrantic Forest, Cerrado, Caatinga, Pampa and Pantanal) and the coastal and marine zone. More than 225 indigenous ethnic groups and various local communities derive TK from this biodiversity. Brazil has implemented the CBD and it recognises the rights of indigenous peoples and local communities over their TK and genetic resources for conservation and sustainable development. See Brazil's Provisional Act 2. 186-16, 23 August 2001.

2* Art. 2 of the CBD provides the following definition: "Biological diversity" means the variability among living organisms from all sources including, inter alia, terrestrial, marine and other aquatic ecosystems and the ecological complexes of which they are part; this includes diversity within species, between species and of ecosystems.

29) See Van Overwalle 2001, p. 164

3it See Van Overwalle 2001, p. 164. 
stifle the preservation of culture and biodiversity and the further development of 'TK. The term bio piracy relates to:

\begin{abstract}
"the appropriation of the knowledge and genetic resources of farming and indigenous communities by individuals or institutions seeking exclusive monopoly control (usually patents or plant breders' rights) over these resources and knowledge".
\end{abstract}

The term "bio piracy" is based on the term "piracy", a concept in the IP system that addresses the free downloading of copyrighted material from the internet; while the term "bio" signifies the relationship with biological resources. Although no official definition of bio piracy has been documented, it does not exist in abstract. The legal basis for the concept can be found in the CBD. The CBD provides for mational sovereign rights over genetic resources and thus using genetic resources without authorisation (prior informed consent) amounts to bio piracy.

\title{
1.2.1. Examples of Bio Piracy
}

Despite the CBD, patents have been allocated to products containing genetic resources without previous consultation with and the consent of the indigenous peoples, who have discovered, preserved and nurtured these resources. Their TK relating to these resources acted as a direct pre-cursor to the scientific endeavours that resulted in patents for exploitation in western markets. ${ }^{32}$ However, no benefits or acknowledgement were given to them when the patent applications were filed. Moreover, the resulting benefits derived from commercial exploitation of the patents were never shared with these communities. Examples are numerous: for example the Indian cases of turmeric, ${ }^{33}$ neem tree ${ }^{34}$ and basmati rice - some of these patents were actually applied for by Indians. ${ }^{35}$ In some situations, genetic resources have been appropriated without any further improvement or alteration through scientific endeavours. See for example the US patents granted on quinoa (a very nutritious seed,

3 Definition provided by The Action Group on Erosion, Technology and Concentration (ETC Group), as quoted in the UK CIPR Report 2002, p. 168.

32 See RAFI Communique 1994a.

ii Turmeric was patented for its wound healing properties.

is Products made from neem have proven medicinal properties, being anthelmintic, antifungal, antidiabetic, antibacterial, antiviral, anti-fertility, and sedative. It is considered a major component in Ayurvedic medicine and is particularly prescribed for skin disease. The neem tree is noted for its drought resistance.

$\because$ Turmeric, US patent No. 5,401,5041 and Neem, EPO patent No 436257, were reexamined and consequently revoked on the basis of lack of novelty. See Dutfield 2000a. See also India's communication to the WTO TRIPS Council: "Protection of Biodiversity and Traditional Knowledge", WTO document IP/C/W/198, 14 July 2000 . 
protein source, pseudocereal originating in the Andean region) ${ }^{36}$ and Ayahuasca (a sacred and medicinal plant of the Amazone). ${ }^{37}$

Another famous example of bio piracy was the patenting of Hoodia. The San people of the Kalahari Desert eat the Hoodia cactus to reduce the need to drink or eat. Scientists at the South African Council for Scientific and Industrial Research have used the cactus in an appetite-suppressing drug, which they have patented without acknowledging its origin or giving any benefits to the community from which the knowledge and resources were taken. It is only through the pressure applied by civil society groups and academics that the South African Council relented and reached a mutually acceptable agreement in which it agreed to share future royalties with the San people. Further instances abound, such as the large quantities of the "Maytenus buchanaii" plant retrieved in Kenya, which was researched and used by the US National Cancer Institute without the consent or acknowledgement of its source. ${ }^{3}$ Or the "Devils Claw", 39 genetic material endemic only to Botswana and Namibia - in the Kalahari Desert - which contains medicinal value for the treatment of rheumatism and cancerous tumours and has been patented by a Cerman pharmaceutical company. The plant's large tuberous roots are used medicinally by local people to reduce pain and fever, and to stimulate digestion. European colonists brought Devil's Claw home where it was used to treat arthritis.

In the cases where patents were found to have been granted as a result of bio piracy not all of them have been revoked or fully revoked. Even in the case of basmati rice, the Indian government did not succeed in overturning all the claims made by the patentee. This is believed to have resulted in losses to Indian exports of rice, ") though the loss is hard to quantify as the patent holder, "Rice tech", had been selling other varieties of rice before it obtained the patent." Notably, India invested a lot of time, money (a disproportional

is US patent No. 5,304,718.

3 US plant patent No. 5,751.

34 See Quinn 2002, p. 291.

34 The inventors claim to have found a novel use for Devil's Claw (Harpagophytum Procumbens) root extracts in the treatment of endometriosis. The applicant for international patent application number PCT/EP2006/061831, international filing date 26 April 2006, is German pharmaceutical company Riemser Arzneimittel A.G.

41) US based Rice Tech. Inc. was granted a US patent on 20 broad patent claims. Although the USPTO eventually revoked 15 of those claims, Rice Tech. Inc still holds patents on 5 claims and does business under the name "Basmati" after developing its novel lines named BAS-867, RT-117 and RT-112. As a result the Indian Agricultural Research Institute is forced to do business under the name "aromatic rice" $^{\prime \prime}$ This also causes problems in other IP areas, since the geographical indication of origin, "Basmati", cannot now be used to indicate Indian rice.

41 For more information on the Basmati case, see Lightbourne 2003. 
amount of the annual budget of the Indian patent office) and effort into contesting this case. ${ }^{12}$

These cases also raise other important questions as to what constitutes a community. Local situations differ greatly: for instance in the cases concerning India there was no single group or community which was perceived to be the victim as they concemed a more general TK. There are other cases, such as that of the San people and the Ayahuasca case, in which particular indigenous groups were deprived of their resources ahead of the country, Peru or South Africa, as a whole.t3

In addition, "yoga" postures and techniques and "ayurveda" have been patented in the US (notably by Indians). ${ }^{4}$ Please note that in the US the principle of "relative novelty" is applied meaning that if the knowledge has not been documented (but passed on orally) it is not included in prior art search and hence does not impact novelty. The US relative novelty requirement permitted granting of patents involving knowledge developed and used for many vears by local and indigenous communities. Hence, to counteract these practises countries started to publish/document communities' knowledge thus destroying novelty for the purpose of patentability. Also, the Indian govermment has started to document TK about yoga postures and thousands of remedies in lndian medicinal systems from ancient books. ${ }^{5}$ Once documented and published, they will be in the public domain. Hence, one cannot claim copyright and allege infringement by others who practise these ancient techniques - thus the documentation is a mechanism to protect it from misappropriation. ${ }^{45}$ However, documentation will not ensure benefit sharing with the holders of such knowledge. It may even be dangerous to document the knowledge as it is deemed part of the prior art (under the IPR system).

\subsection{Problens in Protecting Tralitional Knoweledge}

The introduction of an international protection regime has been hindered by a number of factors. Foremost, similar to the problems in protecting geographical indications (GIs), there is a problem with protecting TK under a regime of

12 See Lightbourne 2003.

43 For an overview of many bio piracy cases see McGown 2006, Khor 2002, and CIPR Report 2002, p. 79.

it Ayurveda relates to an old Indian system of medicine, which was codified in Sanskrit as long ago as the $12^{\text {th }}$ century $B C$.

t5 The Indian Health and Family Welfare Ministry will preserve the details of yoga postures in a multi-media digital library called the Traditional Knowledge Digital Library (TKDL). See Mathew 2002. The data will be made available in five international languages and 11 countries, including the US, Britain, Japan and China.

th. Sec Mathew 2002. 
IPR protection, which is preservation versus inmovation. Innovation lies at the heart of the IPR system and the protection of TK is hard to reconcile.

Second, although TK is a hot topic, there is no singular definition of traditional knowledge, and no agreement on the scope of TK protection; all this can unduly restrict further negotiations. However, one may argue whether we really need a standardised definition of $T K$, since we have been able to do without an exact definition of what constitutes a patentable "invention". There are countries that believe that the WIPO IGC should focus its discussions on establishing definitions of traditional knowledge and cultural expressions and the objectives to be achieved by their protection. ${ }^{47}$ Others, for instance Nigeria, argued that, just like classical intellectual property, there is no need for a consensus definition of TK; indeed, a single definition ma be inadequate, and that a convergence on what constitutes T'K would be enough. ${ }^{\text {th }}$

Third, TK, its promotion, preservation, protection and exploitation is not only of interest to local communities. TK is associated with multiple stakeholders and touches upon various areas: health, food, agriculture and biodiversity, folklore, access to knowledge, education, the biotechnology industry and the environment. Due to the contrasting interests in and the complexity of TK it is hard to find a compromise.

Fourth, it is difficult to protect TK at an international level, since there is a lack of protection within the countries most interested in that protection themselves. It might even be that the indigenous community is not recognised in the country itself and it does not receive support from the national government. International debates should identify commonalities amongst indigenous groups in order to help developing countries set up an adequate system of protection. This is difficult since many developed countries are reluctant to protect $T K$, since it is not beneficial to their national interest and is not a priority on their political agenda. Currently the lack of national protection is obstructing progress at the multilateral level to move towards an international protection of TK - many developed countries raise the argument that TK should first be adequately protected at the national level.49

47 As expressed during the plenary session by Portugal on behalf of the European Communities during the WIPO Intergovernmental Committee on Intellectual Property and Genetic Resources, Traditional Knowledge and Folklore, $1^{\text {th }}$ Session 3 July to 12 July 2007 (Geneva, Switzerland).

ts As expressed during the plenary session by Nigeria during the WIPO Intergovernmental Committee on Intellectual Property and Genetic Resources, Traditional

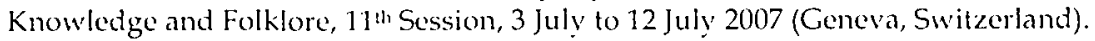

f" However, India did amend its national patent laws to include a "disclosure of origin" requirement. 
Fifth, some local knowledge used among indigenous/local communities frequently does not stop at the border but encompasses various geographical borders. One can argue that the concept of "community" extends beyond a historical, geographical connection. What defines a community and how can this cross border issue be dealt with within a legal framework?

Sixth, protection is impeded by the existence of different legal, historical, socio-economic and cultural traditions in the protection of works. These factors have influenced national policies to result in (customary) local laws which often do not coexist with intellectual property rights (IPRs). From the listed problem areas it follows that in order to understand the problems encompassed with the introduction of TK protection one needs to look at the different cultural backgrounds that have influenced governmental policy objectives and legislation.

Seventh, another cultural difference, not to be underestimated, relates to the value indigenous people attach to their land and spiritual and religious beliefs. ${ }^{50}$ The whole spectrum of land rights, involving issues of sovereignty, customary law, and traditional norms and customs, form a complex social dialogue.51 Le'a Malia Kanehe 52 from the Indigenous Peoples Council on Biocolonialism points out that it is "states" that hold sovereignty over genetic resources within their boundaries: the CBD regime must vest states with the right to determine access to such resources according to Article 3 of the CBD. ${ }^{53}$ This is cumbersome for many indigenous communities and states:

"This issue is of particular importance to the Pacific region where many countries' legal systems recognise customary title or collective land ownership by Indigenous peoples. A 2004 United Nations University study reports that in the Pacific region ... upwards of $80 \%$ of land and a significant portion of coastal and

50 Indigenous peoples see an intrinsic connection between the land and the people: "to destroy one is to destroy the other". See Varese 1996, chapter 6. Central to those indigenous traditions was land and, therefore, land tenure systems and rights were essential to the people's welfare in many respects - in particular, land as a major economic asset, an instrument of inheritance, and a symbol of social status. But land was also sacred and essential to people's spiritual development.

51 See Foreword by Alfredo Sfeir-Younis in Ortega 2004, p. vi-vii.

32 Le'a Malia Kanehe is Kanaka Maoli (Native Hawaiian). She works as legal analyst for the Indigenous Peoples Council on Biocolonialism, an Indigenous non-profit organisation based on the Pyramid Lake Paiute Tribe Reservation in Nevada (USA). See <http://www.ipcb.org>.

53 Art. 3 of the CBD states: "States have, in accordance with the Charter of the United Nations and the principles of international law, the sovereign right to exploit their own resources pursuant to their own environmental policies, and the responsibility to ensure that activities within their jurisdiction or control do not cause damage to the environment of other States or of areas beyond the limits of national jurisdiction". 
marine areas are subject to traditional tenure rights. Likewise, in this region, rights over both biological and genetic resources are subject to customary law rights. It can be seen, therefore that under such circumstances ABS issues must be governed with due respect for and compliance with customary law'".5-

Indigenous peoples live from their land and are closely related to their land; "land is a source of social power and social self-worth. In many societies, part of the land has sacred meaning and great spiritual value" .55 It is an arduous task to reconcile these interests, since they build on different views of society: cultural versus economic goals; community interests/common good versus individual ownership/proprietary good; and the reductionist western scientific tradition versus the holistic use of TK by indigenous communities. ${ }^{56}$ Indigenous peoples are not one singular group but embrace many different understandings, and there is no common understanding as to how TK should be protected.

\subsubsection{Why Protect Traditional Knowledge?}

Just as the optimum level of IP protection depends on a number of factors, such as what a country's level of industrial and technical development and domestic inventive activity, the optimum level of TK protection also depends on what the underlying objectives for such a regime are. The lack of clarity about the rationale for protection stems from the different meanings given to the concept of protection. ${ }^{57}$ We can identify several reasons for granting protection to TK; some of them are closely related.

Firstly, in the context of IPRs, protection implies excluding the unauthorised use by third parties. Secondly, the primary argument in favour of the protection of TK is that it can prevent bio piracy and thus stop ind ustries from reaping the benefits from what they have not sown - hence to avoid bio piracy, misappropriation and unjust enrichment. Thirdly, further justification is in the wealth distribution argument that TK protection should benefit indigenous communities and even improve their livelihoods - equity considerations. For instance, farmers conserve and use plant genetic resources, and add value to them by preserving and enhancing their utilisation for planting, seed production, and by continuously selecting the best farmers' varieties. Traditional farmers are not paid for the value they deliver, since breeders and seed companies are not charged a price for the samples they obtain, and neither is there any later compensation or sharing of the benefits with the

See <http://www.inwent.org/ez/articles/070203/index.en.shtml>.

See Foreword by Alfredo Sfeir-Younis in Ortega 2004, p. vii.

See Dutfield $2000 b$.

See Correa 2001, p. 5. 
farmers. ${ }^{58}$ All these practises contribute to biodiversity and further development of plant genetic resources. Currently, TK generates value that, due to the system of appropriation through the granting of IPR protection, is not adequately recognised and compensated. This could occur through benefitsharing agreements or "royalties" in exchange for access to be collected by a bio-collecting agency. Similarly we can argue that protection favours public policy interests: namely the continuation of the preservation and maintenance of biodiversity requires that adequate protection should be given to traditional knowledge, practices and culture. Hence, protection contributes to the preservation of traditional lifestyles. ${ }^{59}$ Fifthly, safeguarding TK and indigenous people could provide major help in the conservation of the environment and avoid loss of biodiversity. ${ }^{(1)}$ Solutions could be found within the framework of either positive forms of protection or defensive mechanisms, and may lie within or beyond IPR regimes. These concepts will be explained in more detail below.

\section{Legal initiatives on Tradtional KnOWledge Protection, Access to Genetic Material and tile Promotion of Teghnology TransteEr}

In the 1990s, the relationship between IPRs and sustainable development gained prominence in international environmental law and policy making, especially in the CBD and the TRIPS Agreement. IPRs and the commercial marketing of products are relevant in providing incentives to bio prospecting and related sampling, research and product development processes for pharmaceuticals, neutraceuticals (nutritional supplements) and cosmetics. IPRs are increasingly seen as a useful instrument in facilitating benefit-sharing that should be covered by agreements on access to genetic resources. Moreover, IPRs, and in particular the process for granting patents, might form a support mechanism for tracking the flow of genetic resources and providing the opportunity to assure that genetic resources are not misappropriated and have been obtained in accordance with domestic laws on ABS and prior

See Correa 2001, p. 6.

5.)

Dutfield argues that "The knowledge, innovations and practices of indigenous peoples and local communities are manifestations of their cultures. Protecting a peoples' culture means maintaining those conditions that allow a culture to thrive and develop further (...) Therefore, protecting a peoples' cultural heritage involves infer alia maintaining the link between a people and natural features of the landscape and naturally occurring species of plants and animals". See Dutfield 1999 , p. 514.

tol Dutficld sees three reasons to protect TK: 1) moral/equity considerations; 2) legal to comply with international legal obligations such as the Universal Declaration of Human Rights, International Undertaking on Plant Genetic Resources (referred to as the "Seed Treaty") and the CBD; and 3) utilitarian rights. See Dutfield 2000 b. 
informed consent. ${ }^{(1)}$ As a result IPRs are intrinsically linked to access to genetic resources, and requirements of equitably benefit sharing. At the centre of these discussions was the question of developing an in-built mechanism as part of the patent filing system to prevent the misappropriation of genetic resources and associated traditional knowledge. While many WTO Members recognised the need to reconcile and ensure mutual supportiveness between both international instruments, no consensus has yet been achieved on how to realise this in practice. Since the patent system does not seem to accommodate the wishes of the indigenous communities and traditional rights holders the focus shifts to the CBD. The CBD does not offer a regime which is tailored to the IPR needs of indigenous countries but it established an important principle: the equitable sharing principle. ${ }^{62}$ The role of the patent system in dealing with the implementation of CBD objectives and misappropriation issues remains highly controversial. The CBD envisages three principal obligations for Contracting Parties under its Article 1:1) conservation of biological diversity; 2) sustainable use of biological diversity; and 3) fair and equitable sharing of benefits arising out of the utilisation of genetic resources (including appropriate access to genetic resources and transfer of relevant technologies). In order to fulfil these obligations, countries are entitled to sovereign rights over biological resources occurring within their territories. ${ }^{63}$ At the heart of the debate is the question of how a mechanism should be developed to diminish the misappropriation of genetic resources and associated traditional knowledge. The viewpoints range from the incorporation of a requirement to disclose the origin of genetic resources and TK used in an invention, and evidence of prior informed consent $(\mathrm{PIC})$ and benefit-sharing in patent applications, to developing a sui generis system to cover these issues outside the patent system. Some WTO Members think the rights of indigenous communities are adequately protected within the existing legal IPR rules. ${ }^{1-t}$ If the patent system does need to be altered, on the other hand, the question becomes whether amendments should be made within the framework of the TRIPS Agreement, or rather within the WIPO context.

The fact that TK and is now being discussed in so many different international fora - the CBD, TRIPS Council, WIPO IGC, Food and Agriculture Organisation - means there are both opportunities and challenges. Opportunities arise from the fact that these topics are now the subject of substantive proposals in

"1. "ABS" stands for access and benefit sharing, and is shorthand for access to genetic resources and the fair and equitable sharing of the benefits arising out of their utilisation.

1.2 See Van Overwalle 2001, p. 165.

0.3 See Art. 15 of the CBD.

of As expressed during the plenary session by the US during the WIPO Intergovernmental Committee on Intellectual Property and Genetic Resources, Traditional Knowledge and Folklore, $11^{\text {th }}$ Session, 3 July to 12 July 2007 (Geneva, Switzerland). 
various forums which have the broad support of many countries; the WIPO IGC has even drafted provisions for the Protection of Traditional Knowledge. ${ }^{65}$ On the other hand, the number of forums addressing TK and the numerous proposals and submissions made can also obstruct the process as countries are inconsistent in their proposals and, as countries change their diplomats regularly, the continuity in discussing the matter can be hindered. There is a need for one common position on the protection of TK amongst the proponents of 'TK protection identifying clear, realistic and achievable goals based on an informed, well-founded analysis of what is necessary and feasible. ${ }^{\text {th }}$

There is intense debate over whether the CBD conflicts with the TRIPS Agreement and, if so, how any such conflict can best be resolved. "ir There is a strong perception among many NGOs and also many country officials that there are tensions or even conflicts between the objectives, the rights of different stakeholders and the potential effects of the various international treaties - the TRIPS Agreement, the CBD and the FAO International Treaty. ${ }^{6.8}$ The debate is obstructed by the reality that if one side decides that there is no conflict it does not examine the matter any further. ${ }^{69}$

The debate therefore has become polarised; the two constituencies are unwilling to, or incapable of, communicating. The reality, however, is that none of the treaties are likely to disappear in the near future, and that a way needs to be found to stop the misappropriation of unauthorised access to genetic resources and traditional knowledge.

The CBD was not the first international organisation to recognise the obligation that "procedures be developed to compensate native peoples for the utilisation of their knowledge and their biological resources". In fact, this state-

6.5 See WIPO 2005, annex.

on See Dutfield 2006.

wP Para. 19 of the WTO Doha Ministerial Declaration explicitly refers to the relationship between the CBD and the TRIPS Agreement as an outstanding implementation issuc: "We instruct the Council for TRIPS, in pursuing its work programme including under the review of Article 27.3(b), the review of the implementation of the TRIPS Agreement under Articie 71.1 and the work foreseen pursuant to paragraph 12 of this declaration, to examine, inter alia, the relationship between the TIRIPS Agreement and the Convention on Biological Diversity, the protection of traditional knowledge and folklore, and other relevant new developments raised by members pursuant to Article 71.1. In undertaking this work, the TRIPS Council shail be guided by the objectives and principles set out in Articles 7 and 8 of the TRIPS Agreement and shall take fully into account the development dimension".

tis. See Khor 2002.

(i.) See Claessens 2008b, p. 268. 
ment is from the Declaration of Belem, ${ }^{70}$ which outlined the responsibilities consultation, compensation, sharing of research results, promotion of the exchange of information - of scientists and environmentalists in their contacts with local/indigenous communities.

Other achievements in the 1990s included the WIPO Copyright and Performances Treaties ${ }^{71}$ and the UNESCO-WIPO World Forum on the Protection of Folklore. ${ }^{2}$. WIPO's work programme for the 1998-1999 biennium included nine fact-finding missions on "Identifying the Intellectual Property Needs and Expectations of Traditional Knowledge Holders" to sample the expectations of the holders of indigenous knowledge and innovations and the possibilities of using IPR protection to protect TK. ${ }^{73}$ This section will set out the different players active in finding solutions to the TK problem and the results achieved so far.

\subsection{The Convention on Biological Diversity}

The $\mathrm{CBD}^{\text {it }}$ is the first international treaty concerned with bio prospecting that focuses on the inequities in the international biotechnology industry. It was established as a response to the crisis of rapid biodiversity loss. Its objective is to 1) promote the conservation of biodiversity and the wider use and application of indigenous knowledge, and 2) to promote equitable sharing of benefits arising out of the utilisation of genetic resources, making sure that access is provided and the transfer of relevant technologies takes place. ${ }^{75}$ It acknowledges the threats faced by indigenous knowledge systems and the recognition of the tangible and intangible rights of indigenous groups (sovereign rights). ${ }^{76}$

The contracting parties to the CBD are looking for ways to respond to the call from the World Summit on Sustainable Development ${ }^{77}$ to negotiate an inter-

70 The Declaration was established during the First International Congress of Ethnobiology in Bolem, Brazil, 1988.

$\therefore$ WIPO PPT, 20 December 1996, recognises expressions of folklore in its Art. 2(a).

i2 UNESCO-WIPO World Forum on the Protection of Folklore, Phuket, Thailand, April 8-10, 1997. See UNESCO 1998.

33 A draft report on all the fact finding missions is available at: <http://www.wipo. int/traditionalknowledge/report 2000>.

it The CBD was established in 1992 in Rio de Janeiro, Brazil. It is a legally binding treaty. In 2002 the Bonn Guidelines were adopted to facilitate access and benefit sharing.

is However, the CBD has been criticised by civil society for being "a vehicle for commodification instead of conservation". For a critical view of the Seed Treaty see GRAIN 2005.

7t See IUCN, "Indigenous Peoples and Sustainability - Cases and Actions", 1997.

"The World Summit on Sustainable Development took place from 26 August till 4 September 2002 in Johannes Burg, South Africa. The Summit was mandated by the 
national regime to promote and safeguard the fair and equitable sharing of benefits arising from the utilisation of genetic resources. Article 16 of the CBD calls for IPRs to support the objectives of the CBD, but there is controversy on how to bring this about. The starting point of the discussion lies in the two key provisions of the $C B D$ : Articles 15 and $8(j)$. Article 15 creates a regime for access to genetic resources and benefit sharing, based on the principles of national sovereignty over genetic resources, prior informed consent over access to genetic resources, and the need for mutually agreed terms in any access agreements and contracts. ${ }^{7 k}$ In addition, Article 8(j) calls for indigenous and local knowledge to be respected, preserved, and maintained. Article 15.1 of the CBD recognises the sovereign rights of States over their natural resources and as a consequence the authority to determine access to genetic resources rests with the national governments and is subject to national legislation. In order to prevent bio piracy the CBD makes access to genetic resources subject to prior informed consent and on mutually agreed terms (Article 15.4-5). ${ }^{79}$

Article 16.5 of the CBD refers directly to the relationship with IPR protection:

"Contracting parties, recognising that patents and other intellectual property rights may have an influence on the implementation of this Convention, shall cooperate in this regard subject to national legislation and international law in order to ensure that such rights are supportive of and do not run counter to its objectives".

The term "shall" refers to a powerful obligation to cooperate; however, the clause "subject to national legislation and international law", e.g. the TRIPS Agreement, severely limits the clause.

Deliberations within the CBD have proposed the development of a certificate of origin. This would serve as a type of passport or permit which would accompany the genetic resource along the whole chain of the access and benefit sharing $(A B S)$ process and could be verified at various points, particularly once the genetic resource has left the provider country. It would therefore accompany the genetic resource from the collection phase until the marketing of a resultant product. The main objective of an internationally recognised system of certificate of origin would be to ensure the traceability of genetic resources from the moment they have been accessed, thereby increasing trans-

UN General Assembly to respond to the little progress made since the 1992 Earth Summit (resulting in the CBD) with poverty deepening and the environmental degradation.

is See Claessens 2008b, p. 272.

7. For a review of the regional implementation of Art. 15 of the CBD see Van Overwalle 2002, and Sagar 2005. 
parency. Developing countries hope the certificate would aid in combating bio piracy.

The discussions within the CBD resulted in the adoption of the Bonn Guidelines, which brought disclosure requirements into the patent application process. ${ }^{\text {it }}$ The Bonn Guidelines are an attempt to implement the CBD provisions on access to genetic resources and benefit sharing. The Bom Guidelines advocate the adoption of "a legally recognised certification of origin system as evidence of prior informed consent and mutually agreed terms". This soft law instrument endeavours to harmonise the various proposals and to make the disclosure requirement operate effectively. For instance, it proposes the development of a standardised international certificate of origin that could be used and recognised by patent offices around the world. In this context the recent adoption of the UN Declaration on the Rights of Indigenous Peoples by the UN General Assembly in September 2007 might contribute to strengthening developing countries' appeal to pursue their sovereign rights over access to their genetic resources. ${ }^{81}$ The UN Declaration of Indigenous Peoples boosts the demands made by indigenous groups in the ABS negotiations.

Although the $C B D$ advocates the preservation of TK by using mechanisms such as $A B S$, prior informed consent and disclosure of origin, some shortcomings remain. Since the convention only has an impact on genetic resources obtained after its adoption in 1992, the CBD's effectiveness is significantly reduced. In particular, botanical gardens and seed banks have gathered up to one third of the world's plant species, but remarkably the CBD does not demand that these banks adopt policies of prior obtained approval from the country of origin. As a result, these genetic resources can be subjected to further use and subsequent commercialisation without the requirement to share benefits with the source country. ${ }^{82}$ Moreover, the refusal of the US to ratify the convention could be identified as detrimental to the successful operation of the CBD. The US refused for the following reasons: 1) the vagueness of the language used, which can result in different interpretations; 2) the lack of clear provisions on techmology transfer; 3 ) the large sovereignty left to

sar The Bonn Guidelines on Access to Genetic Resources and Fair and Equitable Sharing of the Benefits Arising out of their Utilisation were adopted at the $6^{\text {th }}$ CBD Conference of the Parties (COP), The Hague, April 2002. See COP 6 Decision, The Hague, 7-19 April 2002, available at: <http://www.cbdint/decisions/? $m=c o p-$ $06 \& d=24>$.

s1 The Declaration sets out the individual and collective rights of indigenous peoples, recognises their rights to land and other resources, calls for the maintenance and strengthening of their cultural identities, and emphasises their right to pursue development in keeping with their own needs and aspirations. It also prohibits discrimination against indigenous peoples and promotes their full and effective participation in all matters that concern them.

s2 See Dove 1998, p. 1273, as cited in Watal 2001. See also Claessens 2008c. 
the CBD; ${ }^{\text {i }}$ and 4) the lack of credible enforcement mechanisms to solve interpretation matters." Despite these weaknesses, the adoption of the CBD showed the willingness of 188 parties to protect biodiversity and to value and reward the participation of indigenous people. Implementation has nevertheless been neglected and is currently a focus of attention. It is advisable that the CBD uses its strength (in terms of members) to promote access and benefit sharing agreements combined with technology transfer arrangements. ${ }^{\text {s: }}$

\subsubsection{The Convention on Biological Diversity and Benefit Sharing}

The CBD can be regarded as an instrument to promote the equitable exchange, on mutually agreed terms, of access to genetic resources and associated knowledge in return for finance, technology and the opportunity to participate in research. This exchange, which is at the heart of the convention, has been referred to as the "grand bargain". it The concept of "benefit" addresses the range of benefits that result from the commercialisation of genetic resources at different stages in the research and commercialisation process. It can take different forms: financial compensation through royalty ranges or fees per used sample; stakes in equity or profit sharing; commercial partnerships like joint ventures, local employment possibilities; scientific, social and environmental benefits; or non-monetary benefits. The concept of benefit sharing gained official recognition with the establishment of the CBD. Its main components are on the one hand the exchange of information, transfer of technology and capacity building (non-monetary benefits), and on the other hand the sharing of commercial benefits (monetary benefits)..$^{87}$

Monetary benefits, arising from implementation of the $\mathrm{CBD}$ or the Treaty will never suffice to meet the needs of developing countries. Capacity building is important and more resources are needed, for example for training and equipment.

Non-monetary benefits are likely to be more useful than monetary benefits as they are more promising for the future in that they can contribute to improving national scientific and technological capacities. It is argued that $A B S$ should be part of national policies on sustainable development. ${ }^{\text {s }}$ Notably, the right granted to TK is not exclusive: the same knowledge is simultaneously

s.3 See "open letter to the United States Senate", 19 September 1994. Published online at: <http://www.sovereignity.net/p/land/biolet.htm>.

$\therefore$ See Watal 2001 , p. 172.

s. See Dyebo Shabalala and David Vivas, interviews conducted by the author, summer 2007.

st See Gollin 1993.

$s$ See <http://www seed.org $>$

si See Seiler and Dutfield 2002. 
held and shared by a number of indigenous peoples. This should be taken into consideration in the formulation of decisions on authorisation and benefit sharing.

Arguably, the best route could be to focus on non-monetary benefits, as the exploitation of genetic resources is a long and uncertain process and there is no guarantee that the commercialisation of the genetic resource will be successful. Non-monetary benefits can take the form of sharing research results, technology transfer and local training and capacity building. These forms are inherently interlinked.

Two closely related subsidiary bodies of the CBD, negotiating key elements to facilitate the implementation of the CBD, are the Ad Hoc Open-ended Working Group on Access and Benefit-Sharing and the Ad Hoc Open-ended Working Group on Article 8(j), dealing with Traditional Knowledge and Related Provisions. The Working group on Access and Benefit-Sharing is exploring possibilities to realise in practice an internationally recognised "certificate of origin" to comply with CBD requirements on access and benefit-sharing and the promotion of the wider use of indigenous knowledge and equitable benefit-sharing. Amongst proposals discussed was a codification system (comparable to a patent registration coding system) linking a code to the certificate enabling easier recognition. The code would be used to track the provider, the source, the use of the genetic resource, transfer to third parties, the limitations etcetera. The Working Group got the mandate to establish a "Group of Technical Experts on an Internationally Recognised Certificate of Origin/Source/ Legal Provenance" at COP-8 VIII/4 C.

Notably, discussions within the CBD focus on establishing a "certificate of origin" and not on a "disclosure of origin requirement". ${ }^{89} \mathrm{~A}$ certificate of origin requires that ABS and PIC rules are complied with. Two different checkpoints were identified by the Working Croup on $A B S$ as likely to be most effective to verify if the certificate of origin's conditions have been complied with: 1) at the patent office simultaneously when patent registration takes place; 2) at the point of marketing approval assessment. The latter option would be suitable to indicate the commercial benefits the genetic resource might generate and to cover genetic resources which are not patented. Participants in the working group agreed that transaction costs and bureaucracy should be minimal. For this reason it was felt that it was important to find one single competent authority. Participants also addressed the practicality and feasibility of the different options, in particular for developing countries lacking technology and in need of financial support and capacity building."

$\therefore$ See also Claessens 2008c.

4: See Bridges Trade BioRes 2007a. 
The TRIPS Agreement contains no reference to TK protection nor does it include provisions on the prevention of acts of bio piracy, acknowledgement of the country of origin, prior informed consent, or access and benefit sharing with the contracting party providing the genetic resources. Moreover the TRIPS Agreement does not refer to the obligations deriving from the CBD.

The TRIIS Agreement expressly declares that no discrimination can be made as to the technology used when examining patent applications (see Article 27.1). Consequently, patents can be obtained in all fields of technology including biotechnology. For the purpose of this paper Article 27.3 is most important since it refers to the patentability of biological inventions and states that human life forms, plants and animals mmy be exempted from patent protection. Thus genetic resources and biochemical resources are not explicitly excluded from patent protection. The wording "may" was a compromise resulting from tricky negotiations: on the one hand the US and Japan advocated having as few exceptions as possible incorporated into the TRIPS Agreement, while on the other hand the developing countries and the $E^{\prime 1}$ wanted to exclude patent protection for plants and animals."2 As a result of this debate, it is left to each member's discretion to decide whether to allow patenting of biological inventions or not. The exclusions have been criticised for being broad and unspecified. ${ }^{93}$ Developing countries argue that the theft and patenting of their biogenetic resources is facilitated by this TRIPS provision. ${ }^{9.4}$

The TRIPS Agreement sets out that, exceptions can be made for the protection of plants and animals and essentially biological processes for producing plants and animals. However, no exemptions can be made for micro-organisms. This provision is controversial, because no definition is provided for a plant variety, a micro-organism or an essentially biological process. Clarity is however, desirable since this vagueness gives rise to legal complexities. But at the

"The language used in Art. 27.3 is similar to the European Patent Convention which implies that the EC is keen on keeping the exceptions therein.

$" 2$ See Stewart 1993, p. 2295.

"It is argued that "without a narrowing interpretation or interpretative statement" the exclusion could be understood as "allowing the continued exclusion of certain pharmaceutical products and processes from patentability", Matthews 2002, p. 59.

"14 The Coordinating Body for the Indigenous Organizations of the Amazon Basin (COICA) issued a very critical statement in which they declared that the "IP system reflects a conception and practice that is colonialist, in that the instruments of the developed countries are imposed in order to appropriate the resources of indigenous peoples; racist, in that it belittles and minimises the value of our knowledge systems; usurpatory, in that it is essentially a practice of theft". As quoted in Blakeney 1994. 
same time, the lack of definition does provide the flexibility to adopt a narrow definition: for example, a strict definition of micro-organisms could exclude genes and cells. In any case, determining exactly what constitutes an invention in relation to genetic material is problematic. Only a thin line exists between what is patentable and what is un-patentable material. For instance, should genetic material identified in nature be patentable because it has been subject to isolation and purification processes? ${ }^{45}$ At present it is up to each individual Member to decide how to shape the substantive patent law requirements.

In addition, Article 27.3 of TRIPS requires that plant varieties be protected, either through the use of patents or a sui gencris system or a combination of both. In contrast to the IRIPS Agreement the CBD ascribes sovereign rights to states over their biodiversity and its exploitation. ${ }^{\%}$ Furthermore, it can be argued that Article 27 of TRIPS conflicts with Article 15.7 of the CBD, which requires that the results of research and development and the commercial and other utilisation of genetic resources be fairly shared between the parties. Moreover, Article 16.5 of the $C B D$, as explained in the section above, requires that IPRs should be supportive of the objectives of the CBD.

Article 27.3 of the TRIPS Agreement sets out that plant varieties need to be protected, through either patents or a sui generis system, but allows Members the flexibility to adopt a system compatible with their culture and traditional practises. This could also protect the diverse knowledge systems related to plant and other genetic resources. Developing countries are free to set up a sui generis system of protection for plant varieties which gives recognition to the immovations of indigenous peoples and local communities and which is compatible with their social and cultural values and ethos. ${ }^{17}$ Hence, under the TRIPS Agreement, Members are free to provide for additional IPRs or any other rights such as farmers' rights and indigenous rights which are not covered by the agreement, as long as they do not conflict with any obligations the agreement poses to other IPRs. Developing countries thus have options with regards to plant variety protection and the legal handling of TK. Countries have chosen different ways to implement such a system. The EC, for instance, provides protection through a UPOV based sui generis system, as do many other developed countries. India developed a sui generis system that differs from UPOV, while the US chose to protect plant varieties via patents.

1) Interview with Prof. Dutfield in October 2007 conducted by the author.

\%h See Arts. 3 and 15.1 of the CBD.

47 According to Nyar, such a protective system could adopt a definition of invention that refers to inventive input done collectively, accretionally, intergenerationally and over time in relation to genetic resources. One could adopt rules so that the innovation would be subject to protection even if the innovation is not intended for trade, fulfils a social purpose and serves the common good. See Nyar 1996. 
Increasingly, alternative ways of protection are applied, such as through technological means, or by natural forms of protection. For instance, crops such as commercial hybrid maize camot be reused if hybrid yedd and vignur are to be maintained. Hybrid forms of common crops such as rice, com and wheat have also been developed. Special techniques make it possible to control the actions of gene's in plants in various ways. These controlling mechanisms are called Cenetic Lise Restriction Technologies (CLRTS). These forms of protection different from II protection - are effective by being both self-efficient and cheap.

Cenctic Lse Restriction Technologies (CL'RTS) provide additional technical protection where legal protection is deemed inadeguate. Terminator technologies are designed to remder the seeds sterile so that it is not physically possible to grow a second crop. Terminator technologies can also change crops characteristics either for agronomic or commercial reasons. "Note that both IJ'Rs and CLRTS allow control over the use of genetic materials, albeit with differing modes of control. The former provide legal control over the use of genetic material whereas the latter provide technological control. Most WTO Members, particularly the developing countries, had to rethink and adjust their IPR regimes in response to the TRIIS Agreement. This has coincided with the development of new technologies such as GLRTS that have demanded changes in domestic laws for the protection of new inventions. The scarcity of human and resource capacity in both If and the emerging technologies has impacted has impacted on the ability of developing countries to fully assess and respond to their socio-conomic development needs in these areas.

Countries have the opportunity to use both legal and technological controls to protect innovations. In light of the lack of technological capacity in most developing countries, particularly the least developed countries (I.DCS), the most appropriate means of control is legal,

Article 27.3(b) has been subject to review for many years now following the build-in review to the IRIIS Agreement), but it still proves difficult to reconcile viewpoints that are diametrically opposed to each other. ${ }^{\text {li: }}$ Some

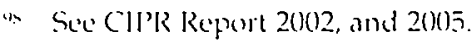

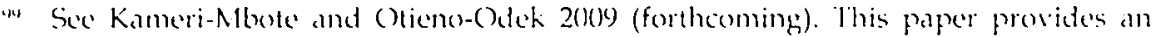
excellent overview of the interface between (ELRTS and IPRs on sustamathe use of agro biofiversity and food sceurity. As well as strutinising the role of IJRs in development, the arguments for and against GLRTS are examined, and proposils suggested which East African countries can consider to mitigate the potential adverse impacts of IPRs and CURTS on agriculture in the region.

1::: See for instance the lndigenous l'eoples' Seattle Declaration, submitted at the Third Ministerial Mecting of the $W^{\prime} 70,30$ November - 3 December 1999. The persederance and unity of developing countries in standing up for their boliefs and interests, among others to remore the patentability of living organisms from the HTO agenda, led to the failure of the Ministerial Mection. 
developing countries wish to revise the entire provision itself, whereas developed countries have held that it is a review limited to implementation. Most developing countries favour an expansion of the scope of exclusions to patentability to inciude all living organisms. Developing countries argue that this option substitutes the need to defend their genetic resources and know-how through litigation. ${ }^{1111}$ In contrast, countries with strong biotechnology industries advocate the removal of the exception and making the UPOV 1991 system mandatory. UPOV Convention stands for the International Union for the Protection of New Plant Varieties of Plants adopted in 1961, and revised in 1972, 1978 and 1991. The UPOV 1978 provides for more flexibility and is more catered to the need of developing countries as it grants farmers' privilege. UI'OV 1991 makes it optional to allow for the farmers' privilege. Notably, farmers' rights (ITPGR) should be distinguished from the farmers' privilege (UPOV and most Plant Variety Protection laws) in that the latter is an exception to the breeders' exclusive right. "Farmers' rights" is not an IPR as such but is frequently invoked to function as a principle that could be implemented as a compensation or benefit-sharing mechanism. ${ }^{1102}$

It is recommended that developing countries make adequate use of the existing flexibility to choose their own sui generis regime (the UPOV Convention 113 is not mandatory as sometimes assumed) and adopt a system which is carefully tailored to their own public interest needs and in line with their development goals. These may include, for instance, accommodating the supply of seed and traditional farming practises, or taking into account their traditional systems of innovation and knowledge sharing, as in the case of India.

One can argue that using the patent system to protect living organisms and biological materials is not an appropriate reward system for innovations in the area of living organisms and leads to distortions of the patent system: most of all because the patent system was established to protect mechanical inventions, which require different rules and conditions. ${ }^{114}$

Currently the discussions on biodiversity within the TRIPS Council focus predominantly on introducing a disclosure of origin requirement into the TRIPS Agreement. A group of developing countries, including Brazil, Ecuador, and India, have proposed amending the TRIPS Agreement to make patent applications require disclosure of the origin of genetic resources and associated traditional knowledge used in an invention, as well as evidence of prior

Iin) See Correa 1999a, p. 8.

102 See Mulvany 1999.

In: See Dutfield 2004.

10.4 See Khor 2002, p. 86. 
informed consent and benefit sharing. ${ }^{105}$ Many industrialised countries have questioned the necessity of such a requirement, with the notable exception of Norway. The discussions on a disclosure of origin requirement and the various country positions are explained in more detail in section five of this chapter.

\subsection{The Contention on Biological Diensity aresus the TRIPS Agrement}

Are the TRIPS $\wedge$ greement and the CBD subject to severe inherent tensions and conflicts? Most developed countries argue that there is no conflict, many developing countries see a need to reconcile the two treaties and favour an alteration of the TRIPS $\wedge$ greement. ${ }^{117}$

The TRIPS Agreement was negotiated within the Uruguay Round of trade negotiations over eight years, with meetings taking place in various countries

115 See Bridges Weckly Trade News Digest 2007b.

whe See US Communication on Review of the Provisions of Art. $27.3(b), I P / C / W / 209,3$ October 2000 and Australian Communication $\mathrm{IP} / \mathrm{C} / \mathrm{W} / 301$ to the WTO TRIPS Council, 2 October 2001. Australia and the US do not see any explicit conflict between the CBD and the TRIPS Agreement and they believe more analysis needs to be undertaken into the most effective way of ensuring access of ensuring that access to material that is subsequently the subject of a patent application was sourced in compliance with the provisions of the CBD. It is certainly not clear that an amendment to the TRIPS Agreement is required in order to achieve this goal, where improved documentation and information sharing procedures could prove sufficient. See paras. 7-15 of the Australian proposal and paras. 5-7 of the US proposal. The US stipulates that the CBD and the TRIPS Agreement are widely disparate, and most of the provisions of the two agrements are unrelated in any way. (para. 5 of the US proposal). In addition, the US regard contract law prior to accessing the resources as the most useful way to ensure access and bencfit sharing (para. 6 of the US proposal).

10: See the Communication from Cuba, Dominican Republic, Egypt, El Salvador, Honduras, India, Indonesia, Malaysia, Nigeria, Pakistan, Sri Lanka and Uganda aimed at harmonising the TRIPS Agreement with the CBD in WT/GC/W/354 of 11 October 1999 and the Indian Proposal in WT/CC/W/225, 2 July 1999 aimed at making the TRIPS Agreement more compatible with Multilateral Environmental Agreements such as the Convention on Biological Diversity. Para. 4 of the Indian proposal reads: "It is widely agreed that the TRIPS Agreement is incompatible with the Comvention on Bio-Diversity. There is first need therefore to incorporate a provision that patents inconsistent with Art. 15 of the CBD must not be granted". In addition it is proposed that Art. $27.3(b)$ be amended to provide additional conditions for patentability, namely: (a) the identification of the source of the genetic material; (b) the related traditional knowledge used to obtain that material; (c) evidence of fair and equitable benefit sharing; and (d) evidence of prior informed consent from the Government or the traditional community for the exploitation of the subject-matter of the patent. 
making it harder for developing countries to participate as properly informed negotiation partners. Developing countries hindered by logistical, financial and capacity constraints were not fully aware of the consequences of the agreements they were negotiating. Moreover, TRIPS was part of a much larger multilateral framework of trade negotiations and developing countries committed to adhere to harmonised IPR rules in exchange for trade-offs in other areas, such as market access for tropical products and cotton. lus

In various discussions related to the inherent tensions between the CBD and the TRIPS Agreement, the conflict arose as to which agreement takes precedence. Under international law, the issue of precedence only occurs when treaties address the same subject matter and, according to the principle of lex posterior dorogat priori, the latest treaty overrules an inconsistent earlier law. However, this rule obviously does not apply when the two laws address different subject matters. The CBD and IRIPS were negotiated and established for different reasons: on the one hand the TRIPS Agreement was deemed necessary to halt the trade in counterfeited and pirated goods and to set minimum standards for IPRs, and provides enforcement measures; on the other hand the CBD was established to conserve biodiversity' and recognise the role and rights of TK and local communities in the conservation, preservation and use of biodiversity. Its members are committed to protect biological and genetic resources and, in providing access to them, to ensure mechanisms are in place to secure fair and equitable remuneration for their genetic resources.

At the heart of the conflict between the two regimes lies the nature of the formation of the two agreements. At the time of the treaties' negotiation there was a tendency to prioritise short-term trade benefits above long-term environmental benefits, including the conservation of biodiversity. TRIPS, being part of the GATT-WTO system, was regarded mainly as a trade issue of obvious interest for intellectual property offices and multinational companies. ${ }^{104}$ The CBD was perceived to be an environmental issue. This categorisation determined the participation of the type of officials involved, i.e. the TRIPS Agreement negotiations were attended predominantly by trade ministry officials and IPR experts; the CBD by environment ministry officials and environmental activists. At the time of the negotiations most parties therefore failed to recognise the connections between the two fora. Most Non-governmental Organisations (NGOs) and Intergovernmental Organisations (IGOs) became active at the international level after the adoption of the WTO Agreement. Both IGOs and NGOs have an important role to play in adequately addressing the relationship between $I P R$ and environmental agreements, and in ensuring that the WrO, the CBD and relevant $U N$ agencies improve their communication on this matter to move the debate forward.

wis See chapter one of this thesis.

16: See Lettington 1999, p. 3. 
According to CBD Article 16.5, the CBD and IPR agreements need to be mutually supportive. Nonetheless, IPRs are often granted without respecting CBD obligations pertaining to legal access, and currently TRIPS does not contain safeguards against the misappropriation of genetic resources. In part, this is because the treaties have different objectives and associated structures. Thus, TRIPS first and foremost protects inventions, creations and signs (trade marks). It grants exclusive and private rights to the right holders, including a right to remuneration. It also endeavours to promote innovation and technology transfer. 111' The CBD protects genetic resources and traditional knowledge, safeguarding national sovereign rights. It provides for public good and collective rights. It sets out detailed rules on access and benefits sharing and the conservation and sustainable use of genetic resources.

The $C B D$ is the first international treaty concerned with bio prospecting and it addresses the inequities of the international biotechnology industry. Arguably, the TRIPS Agreement does enable and facilitate the appropriation/protection of biological resources and living organisms through IPRs. In contrast to the CBD, the TRIPS Agreement allocates ownership over created knowledge embedied in an invention - an IPR is a private right. The CBD refers to ownership in a more indirect way but allocation of ownership and appropriation is not its main objective as it focuses on the "transmission, diffusions, and sharing of knowledge, innovations, and environmental practices rather than upon their protection"."1" And this is where the CBD and IRIPS clash: the CBD recognises sovereign rights over biological resources and sets out rules for their conservation and preservation; the TRIPS Agreement allows proprietary rights over innovations based on biological resources.

IPRs in the context of access to genetic resources have been high on the intemational agenda ever since the adoption of the TRIPS Agreement and the CBD. A multitude of IGOs and NGOs ${ }^{112}$ have addressed the interconnection between IPRs and access to genetic resources and associated traditional knowledge, and have also explored benefit-sharing and innovative disclosure options in this context. ${ }^{113}$

WTO Members have addressed these issues in the TRIPS Council in the context of the review of Article 27.3(b) of the TRIPS Agreement and the Doha Round negotiations. The relationship between TRIPS and the CBD is an out-

1111 Arts. 7,8 and 66.2 of the TRIPS Agreement.

111 See lettington, p. 3.

112 The International Union for the Conservation of Nature and Natural Resources (IUCN), for instance, has carried out a number of projects on IPRs and ABS. See <http://wwwiucnorgs.

113 For an overview of the compatibility of the TRIPS Agreement and the CBD see l.ettington 1999, p. 3. 
standing implementation issue following the WTO Doha Declaration ${ }^{114}$ and a prominent item on the agenda of TRIPS Council meetings. ${ }^{115}$ Although the review of TRIISS Article 27.3 comprises several issues, the current discussion is focused on the introduction of a mandatory disclosure requirement of the source and origin of biological resources and traditional knowledge.

$A$ step forward in reconciling the CBD and TRIPS was the recognition of the necessity of more coherence between the TRIPS Agreement and the provisions within the CBD in the Doha Declaration. The Doha Declaration acknowledges that the review of the IRIPS Agreement, and in particular Article 27.3(b),

"should also look at: the relationship between the TRIPS Agreement and the UN Convention on Biological Diversity [and] the protection of traditional knowledge and folklore. (...) In undertaking this work, the TRIIS Council shall be guided by the objectives and principles set out in Articles 7 and 8 of the TRIPS Agreement and shall take fully into account the development dimension".

The process of convergence between environmental concerns on preservation of biodiversity and intellectual property protection should not only focus on inter-governmental relations but also, crucially, at the private sector since most R\&D is undertaken by the private sector and technologies are privately owned." Only with the participation of industry, indigenous people, civil society and government authorities in the negotiation process of access and benefit laws will the legislation be mutually supported. In this respect it is important to raise awareness of the dangers faced by biodiversity and the

11. The fourth WTO Ministerial Conference in Doha, Qatar addressed the problems of developing countries in implementing the TRIPS Agreement. Deliberations of the highest-level hody of the WTO resulted in the Doha Declaration which provides a mandate for further deliberations on a number of issues, including IP and the relationship with the CBD. See the WTO Doha Ministerial Declaration, 14 November 2001, WT/MIN(01)/DEC/1.

115 This follows paragraph 19 of the WTO Doha Ministerial Declaration, which reads: "We instruct the Council for TRIPS, in pursuing its work programme including under the review of Art. 27.3(b), the review of the implementation of the TRIPS Agreement under Art. 71.1 and the work foreseen pursuant to para. 12 of this declaration, to examine, inter alin, the relationship between the TRIPS Agreement and the Convention on Biological Diversity, the protection of traditional knowledge and folklore, and other relevant new developments raised by members pursuant to Art. 71.1. In undertaking this work, the TRIPS Council shall be guided by the objectives and principles set out in Arts. 7 and 8 of the TRIPS Agreement and shall take fully into account the development dimension".

i1. See Jeffery 2005. 
importance of conservation and sustainable development of the resources for all parties. ${ }^{117}$

In my view, there are no real legal clashes between the provisions of the CBD and the TRIPS Agreement, since most of the CBD provisions and clauses contain conditioning terms severely restricting their impact in favour of the intellectual property provisions. ${ }^{118}$ However, that said about the legal situation, it is obvious that there is a clash in the intention of both agreements: their objectives and principles differ tremendously. The main overlapping and conflicting areas in the CBD and the TRIPS Agreement are over the ownership, protection and access to biological and genetic resources on the one hand and access to technology in biological inventions on the other hand. "The CBD is indeed a

"big step forward in the recognition of the contributions of indigenous knowledge. But it does not do anything to build a bridge between indigenous knowledge and IPRs. These two remain, as before, worlds apart". 121

Due to the lack of progress in establishing some sort of international TK protection, it has been proposed (by GRAIN, developing countries) that the debate should be housed within the UN's Permanent Forum on Indigenous Issues, since in their view it is better equipped to deal with the cross-cutting issues - TK, genetic resources and cultural heritage - than WIPO, which they repeatedly criticise for having a narrow IPR focus. However, shifting forums might cause more delay rather than any more positive outcome.

\subsection{The WIPO Committe' WIPO Conmitte' on TK Protection}

The WIPO Intergovernmental Committee on Intellectual Property and Genetic Resources, Traditional Knowledge and Folklore (IGC) has also discussed the relationship between IPRs and biodiversity, TK and access to genetic resources. The IGC was set up in 2000 by the WIPO General Assembly to work towards a shared intemational understanding of how best to protect $T K$ and traditional cultural expressions against misappropriation and misuse. The committee was based on two premises: that the existing II'R framework offers poor protection for 'TK, and that this has contributed to the misappropriation

11: There is evidence that industries choose not to work in countries that have established access and benefit-sharing laws without consulting industry first. This shows the relevance of participation of all stakeholders in developing workable legislation. Kate and Lair 1999, p. 292-312.

11. See also Cameron and Makuch 1995, who reach the conclusion that the objectives of the CBD are not undermined by the TRIISS Agreement.

$110)$ See Verma 2005.

120 See Patel 1996, p. 318. 
of TK. A key aspiration of the ICC was to find ways for holders and custodians of TK and traditional cultural expressions to exercise greater authority over how these central elements of their cultural identity are used, and to strengthen the legal aspects of respect, sovereignty and recognition. Views on how to facilitate the protection of TK differ greatly, from incorporating the protection of IKK within the existing framework of IPRs to establishing new binding sui generis legislation to protect against the misappropriation of genetic material, including associated traditional knowledge. ${ }^{121}$

It is important to scrutinise the implications of different measures for protecting TK. If a sui generis system is adopted, should one aim for a single regime or are the indigenous and local communities better served by multiple regimes for well defined components of TK, such as for artistic creations including expressions of folklore; plant genetic resources for food and agriculture and associated knowledge; and traditional medicine?

In addition to the different modes of TK protection mentioned above, which are currently being applied at a national level or are in the process of being negotiated at the international level, the WIPO IGC has developed a list of policy objectives which should be taken into consideration in the search for appropriate TK protection mechanisms. ${ }^{122}$

The objectives are complemented by principles, which serve to promote the objectives of protection. Two of these guiding principles are: 1) responsiveness to the needs and expectations of TK holders; and 2) recognition of the rights of traditional TK holders to the effective protection of their knowledge against misuse and misappropriation. ${ }^{123}$

After eight years of discussions WIPO remains divided on whether to create a new binding international treaty to protect genetic resources, TK and folklore against misappropriation. The 2007 WIPO General Assembly agreed to expand the mandate of the IGC for two years and has invited the working group "to accelerate its work and to present a progress report to the [2008] General Assembly". This renewed mandate also underlines that "no outcome of its work is excluded, including the possible development of an international instrument or instruments". ${ }^{12.4}$

121 See CIEL 2007.

i22 See WIPO document WIPO/GRTKF/IC/7/5, annex 1, 20 August 2004 p. 1-2.

123 See WIPO document WIPO/GRTKF/IC/7/5, annex 1, 20 August 2004, p. 3-4, amended in 2005.

12t The WIPO General assembly gathered from 24 September to 3 October 2007 at the Geneva headquarters. 
Notably, substantial amounts of time at the bianmual IC,C meetings are spent wrangling over the wording of a decision on future work to renew the committee's mandate again. 125 The debate within the formal sessions and, according to delegates, behind the scenes, has been broadly broken down along classic North-South lines since the KCC's inception in 2001. Several biodiversity-rich developing countries want an intemational legally binding instrument to address misappropriation, whereas industrialised countries such as the US, Japan, and Canada favour a non-binding recommendation. ${ }^{12}$ Negotiations on the future work of the IC.C saw a similar divide. Where developing countries had sought a commitment to "work towards a common position", for instance, developed countries, particularly the US and Canada, were careful to avoid language that might expand the mandate, said Peruvian delegate Alejandro Neyra. They ensured the final text calis rather tamely for "work towards further convergence of views". ${ }^{127}$

Despite the divisions, there was a growing consensus that the main goal of any protection regime should be the prevention of misappropriation, such as the granting of patents incorporating genetic resources or TK without benefitsharing and the prior consent of the communities to which they belong. Delegates did move to substantive issues and discussed definitional issues, such as the objectives and beneficiaries of the protection of genetic resources, TK and cultural expressions, and the form, extent, and duration of such protection..$^{12 k}$

Complicating the debate on TK is the fact that it involves no fewer than $11 \mathrm{UN}$ bodies which are currently looking at issues from rule making to capacity building. ${ }^{129}$ The UN Permanent Forum on Indigenous Issues has therefore called for improved cooperation and information sharing, particularly between the UN Educational, Scientific, and Cultural Organisation (UNESCO), the CBD, and the Food and Agriculture Organisation (FAO). ${ }^{1301}$

Countries have frequently indicated during IGC meetings that they want the regime to incorporate certain exceptions. Most international trade and IP agreements include exceptions from standard obligations under certain cir-

12: The $11^{\text {th }}$ session of the IGC, held from 3-12 July 2007, was largely taken up by informal negotiations and what delegates called "informal informals" meetings between the Africa Group, Australia, Brazil, Canada, Japan and the US. Agreement on how to proceed was only reached late in the final plenary session.

12n See Bridges Trade BioRes 2007b, and Intellectual Property Watch 2007.

127 Interview conducted by the author with Alejandro Neyra, Permanent Mission of Peru to the UN in Geneva, July 2007.

12w The decisions of IGC 11 are available at: <http:/www.iprsonline.org/resources/ docs/igcl1_decisions.pdf>.

12.) See Intellectual Property. Watch 2007.

1.01 See Intellectual Property Watch 2007. 
cumstances. With regards to the proposed legal instrument for protecting genetic resources, TK and folklore, most countries seem to broadly agree that such a regime should provide for exceptions and limitations for education, public health, research, science and criticism. Some industrialised countries, including Japan, Canada, and the US, assert that entering into such discussions is premature however.

The current IGC Chair, Ambassador Puja of Indonesia, explained that the purpose of the discussion was to find a "common denominator" for further deliberations. Developing countries are becoming impatient with the process, saying that it is high time to start more targeted negotiations on a protection regime for genetic resources, IK $\mathrm{K}$ and traditional cultural expressions. $A$ handful of developed country governments, notably Canada, Japan, Australia, and the US say that more time is needed to grasp the issues and determine how best to proceed. Mexico described this as a pretext for obstruction; Brazil added that the industrialised countries were simply twisting the clearly articulated views of developing nations, saying "they do not want to understand us", 1.31

Developing countries representing their indigenous communities need to clarify some issues including: their expectations, objectives and needs in relation to TK protection. They also need to find agreement on concepts and definitions, especially what it is they are trying to protect. What capacity building is needed and the forms of partnership that would be appropriate.

\subsubsection{The WIPO and Disclosure of Origin}

WIPO is also discussing a disclosure requirement in the context of reforming the Patent Cooperation Treaty (PCT), ${ }^{132}$ where it has been proposed that such a disclosure could be required in international patent applications. ${ }^{133}$ The PCT facilitates the international filing of patents (application process). Introducing the disclosure of origin (source) into this instrument would imply adding an administrative requirement to the filing of patents, as opposed to a substantive

131 Views expressed at the ICC Geneva, 3-12 July 2007 (WIPO IGC attended by author).

132 The PCI makes it possible to seek patent protection for an invention simultaneously in each of a large number of countries by filing a single "international" patent application instead of filing several separate national or regional patent applications. The granting of patents remains under the control of the national or regional patent offices in what is called the "national phase". It carries out an international search as to prior art and can do the preliminary examination as to the patentability of the invention. The PCT is administered by WIPO, enacted in 1970, amended in 1979, and subsequently modified in 1984 and 2001.

1: The PCT currently holds 139 members, status as of 4 August 2008. See <http:// www.wipo.int/export/sites/www/pet/en/texts/pdf/pct_paris_wto.pdf>. 
requirement, as the grant of the patent is left to the national or regional patent offices. Non-compliance with the disclosure requirement will be regarded as not fulfilling the administrative requirements and the applicant will be asked to file the required correction. A disclosure requirement is also being discussed in the context of further international harmonisation of the patent system under the draft Substantive Patent Law Treaty (SPLI). ${ }^{1.4}$ It is likely that, with the adoption of the WIIOO Development Agenda, ${ }^{135}$ the debate on a disclosure requirement will increase in momentum. For instance, the WIPO Development Agenda ${ }^{1,30}$ makes note of promoting

"work on any initiative intended to facilitate the implementation of technologyrelated provisions of multilateral environmental agrements (MEAs), so as to ensure that countries where biological, traditional or other environmental resources originate from, participate in the process of research and development".137

The recently adopted WIPO Development Agenda also contains references to the protection of $\mathrm{T} K$ and genetic resources: it urges the

13. The proposed SPLT aims at going far beyond the formalities as set out in the WIPO Patent Law Treaty (2001) to harmonise substantive requirements such as novelty, inventive step and non-obviousness, industrial applicability and utility, as woll as sufficient disclosure or claim drafting and interpretation.

137 The Development Agenda negotiations started in September 2004, and have been pushed by the "friends of development" (FoD), a group of fifteen developing countries (led by Brazil and Argentina) calling for considerations about the impact of IP on developing economies to be incorporated into every aspect of WIPO's activities. The Fol questioned whether or not the organisation is fulfilling its "development mandate" as a specialised agency of the UN. Firstly, the FoD called, for a review of the mandate and governance of WIPO; secondly, it seeks the promotion of prodevelopment norm-setting in WIPO; thirdly, it proposes principles and guidelines for the provision and evaluation of WIPO's technical assistance; and finally, it suggests guidelines for future work on the transfer and dissemination of technolog: and related competition policies. The Development Agenda was adopted during the 2007 WIPO General Assembly consisting of a series of recommendations to enhance the development dimension of the organisation's activities.

1in The Development Agenda was adopted during the 2007 WIPO General Assembly and consists of a series of recommendations to enhance the development dimension of the organisation's activities. The recommendations include a set of 45 agreed proposals covering six clusters of activities, including: Technical Assistance and Capacity Building; Norm-setting, Flexibilities, Public Policy and Public Knowledge; Technology Transfer, Information and Communication Technology (ICT) and Access to Knowledge; Assessments, Evaluation and Impact Studies; Institutional Matters including Mandate and Governance.

is See WIPO Provisional Committe for the Development Agenda (PCDA), Annex B proposal 4.4 . 
"IGC to accelerate the process on the protection of genetic resources, traditional knowledge and folklore without prejudice to any outcome, including the possible development of an international instrument or instruments". $13 \mathrm{k}$

\subsubsection{Criticism of the WIPO Committee on l'K Protection}

Despite its success in providing a negotiation platform and the production of many studies, criticism has been directed at the functioning of WIPO IC.C. First, and principally, it has been condemned for not acting as a UN organisation in that it is obliged to promote and protect II'Rs in all parts of the world and therefore should also address the interests of indigenous people in international treaties. Second, it has been accused of partiality: for instance, GRAIN13" has claimed that the "IGC suffers from an IP'R bias". Indeed, the UK CIPR Report has called on WIPO to integrate development objectives into its approach to the promotion of IP and has suggested that WIPO

"should give explicit recognition to both the benefits and costs of IP protection and the corresponding need to adjust domestic regimes in developing countries to ensure that the costs do not outweigh the benefits". 1:in

Third, another weakness is in the "analysis overkill". The IGC, for instance, produces multiple documents, but their complexity and lack of structure makes them difficult to digest. Indeed, the ICG has been very diplomatic in avoiding the exclusion of any subject matter in order not to choose sides in the debate; but this has led to the distribution of contradictory information. Fourth, developing countries have expressed concerns that the WIPO IGC should shift from being mainly exploratory in nature, for gathering information and providing a forum for discourse, towards being a norm-setting forum, especially on the enhanced protection of TK. Another problem is that developing countries are eager to set up such a system but remain vague on how best to establish it, and furthermore do not voice a common message. Another drawback is that agreements under WIPO IGC process will be more difficult to enforce since it has no effective powers of sanction.

To sum up, in order to take concrete action, Argentina and Brazil initiated the WIPO Development Agenda, in which they argue that since the WIPO is a UN

Bis See WIPO Provisional Committee for the Development Agenda (PCDA), Annex B proposal.

13 See GRAIN 2004.

wi: See UK CIPR Report 2002, p. 159. For more on WIPO's mandate as a specialised agency of the LN, see Musungu and Dutfield 2003, chapter 5 . 
body it should act to support development and the interests of all participants, not just the dominant Western players. ${ }^{1+1}$

\subsection{The MOS Sed Trenty}

\subsubsection{Access to Genetic Resources and Rights of Indigenous/Traditional People}

The key issues driving the debate on who owns the genetic resources addressed problems like the rapid extinction of farmers' indigenous seeds, often called genetic erosion, and the increasing privatisation of the planting material for the world's food supply through patents and plant breeders' rights. Farmers' rights have been a controversial issue ever since. Governments agreed that farmers should be recognised for the historic and ongoing role they have played as developers, conservers and guardians of the incredible diversity of potatoes, tomatoes, barley, maize and bananas that plant breeders rely on today. Hence, this implies safeguarding

\footnotetext{
"the rights of farmers to work with, and live from, farming systems based on diversity, in the face of expanding monocultures and uniform seeds. It also meant trying to channel some of the profits of the seed industry into conservation of the resource base that it exploits". 142
}

The concept of Farmer's' Rights (see also domestic laws, e.g. in India) was introduced by the Food and Agriculture Organisation (FAO) in 1983 in its International Undertaking on Plant Genetic Resources (International Undertaking), followed by the establishment of the CBD in 1992 which gave a new impetus to the promotion and preservation of TK together with the establishment of a regime on access to resources and benefit sharing.

The International Undertaking was the first comprehensive international agreement dealing with plant genetic resources for food and agriculture. It was adopted by the FAO Conference in 1983, as an instrument to promote intemational harmony in matters regarding access to plant genetic resources for food and agriculture. ${ }^{1.3}$

1.4 WIPO General Assembly, Thity-First (15:th Extraordinary) Session, Genera, 27 September to 5 October 2004, WIPO document WO/GA/31/12.

142 See GRAIN 2005.

1.1 Resolution 8/83, 22nd Session of the FAO Conference, International Lindertaking on Plant Genetic Resources, Rome 1983. Available on the internet at: <itp://ftp.fao. org/ag/cgrfa/iu/iutextE.pdf>. 
Article 1 sets out the objective underlying the International Undertaking:

"to ensure that plant genetic resources of economic and/or social interest, particularly for agriculture, will be explored, preserved, evaluated and made available for plant breeding and scientific purposes. This Undertaking is based on the universally accepted principle that plant genetic resources are a heritage of mankind and conseyuently should be available without restriction".

Moreover, Article $6(a)$ asserts that international cooperation will be directed to

\begin{abstract}
"establishing or strengthening the capabilities of developing countries, where appropriate on a national or sub-regional basis, with respect to plant genetic resources activities, including plant survey and identification, plant breeding and seed multiplication and distribution, with the aim of enabing all countries to make full use of plant genetic resources for the benefit of their agricultural development".
\end{abstract}

This Undertaking is a multilateral framework to facilitate access to the plant genetic resources of major crops, and benefit sharing. It has also promoted the concept of farmers' rights in that it recognises

"the enormous contribution that farmers of all regions have made to the
conservation and development of plant genetic resources, which constitute the
basis of plant production throughout the world, and which form the basis for
the concept of Farmers' Rights". 1 .

The Undertaking defines the best way to implement the concept of Farmers' Rights as:

"to ensure the conservation, management and use of plant genctic resources, for the benefit of present and future generations of farmers. This could be achieved through appropriate means, monitored by the Commission on Plant Genetic Resources, including in particular the International Fund for Plant Genetic Resources, already established by FAO. To reflect the responsibility of those countries which have benefited most from the use of germplasm, the fund would benefit from being supplemented by further contributions from adhering governments, on a basis to be agreed upon, in order to ensure for the Fund a sound and recurring basis. The International Fund should be used to support plant genetic conservation, management and utilisation programmes, particularIy within developing countries, and those which are important sources of plant genetic material. Special priority should be placed on intensified educational programmes for biotechnology specialists, and strengthening the capabilities of

144 See Annex 1, Resolution 4/89, Agreed Interpretation of the International Undertaking, para. 4 . 
develeping countries in genetic resource conservation and management, as well as the improvement of plant breeding and seed production". 14

Annex 2 introduces the concept of farmers' rights. It considers the following:

\begin{abstract}
"(a) in the history of mankind, unnumbered generations of formers have con-

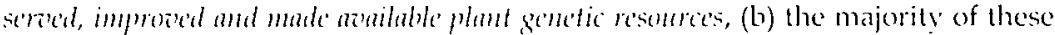
plant genetic resources come from developing countries, the contribulion of whose

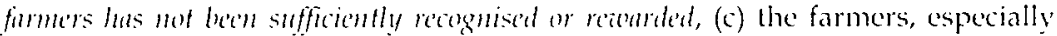
those in developing countries, should benefit fully from the improied and

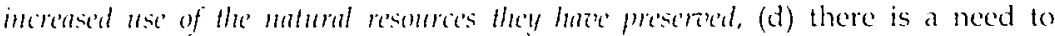
contime the comseration (in situ and ex situ), development and use of the plant genetic resources in all countries, and to strengthen the capabilities of developing countries in these areas, Endorses the concept of Farmers' Rights (Farmers' Rights mean rights arising from the past, present and future contributions of farmers in conserving, improving, and making available plant genetic resources, particularly those in the centres of origin/diversity. These rights are vested in the International Community, as trustee for present and future generations of farmers, for the purpose of ensuring full benefits to farmers, and supporting the contimution of their contributions, as well as the attainment of the overall purposes of the International Undertaking) in order to: (a) ensure that the need for conservation is globally recognised and that sufficient funds for these purposes will be available; (b) assist farmers and farming communities, in all regions of the world, but especially in the areas of origin/diversity of plant genetic resources, in the protection and conservation of their plant genetic resources, and of the natural biosphere; (c) allow farmers, their communities, and countries in all regions, to participate fully in the benefits derived, at present and in the future, from the improesed ase of plant genetic resoures, through plant breeding and other scientific methols". "H" (emphasis added FC)
\end{abstract}

Hence it follows that farmers should share fairly in the benefits arising from the enhanced use of their genetic resources.

The FAO Commission on Genetic Resources for Food and Agriculture revised its International Undertaking on Plant Genetic Resources resulting in the International Treaty on Plant Genetic Resources for Food and Agriculture referred to as the "Seed Treaty". 1.t It was adopted by UN Food and Agriculture Organisation (FAO) member states in 2001 and came into force in 2004 (hereinafter Seed Treaty). It aims at guaranteeing food security through the conservation, exchange and sustainable use of the world's plant genetic resources for food and agriculture, as well as the fair and equitable benefit

itis Ibid.

1.th See Annex two, Resolution 5/89, Farmers' rights.

147 The revision was necessary to bring the International Undertaking in line with the CBD. The international Undertaking was reliant on the principle of genetic resources being the common heritage of humanity. The CBD brought genetic resources under the jurisdiction and sovereignty of national governments. 
sharing arising from its use. Its purpose is the creation of a multilateral system of access and benefit sharing over a range of listed plant genetic resources for food and agricultural purposes. Parties that ratify the international treaty open up their agricultural plant genetic resources to access via a standard Material 'Transfer Agreement (MIA). It recognises farmers' rights, the protection of TK relevant to plant genetic resources for food and agriculture, ABS - and thus equitable participation in the sharing of benefits derived from the utilisation of plant genetic resources, including recognition of the right to participate in negotiations at the national level. As it only recently came into force it is premature to predict the full impact of its rules. ${ }^{1.48}$

The Seed Treaty is basically an agreement on how to implement the ABS rules of the CBD in the field of food and agriculture. Under the $C B D$, nation states have the sovereign right to control all access to biodiversity within their jurisdiction, and to claim a share of the benefits derived from the biodiversity they have granted access to. However, governments have to negotiate individwal bilateral contracts for each and every transaction, including the exact rate and form of benefit sharing. This approach often leads to contracts which are difficult to negotiate and subsequently the commodification of genetic resources, i.e. the privatisation of genetic resources by IPRs whereby benefit sharing does not occur. The Seed Treaty takes a different approach. It is based on a multilateral system: "countries contribute what they have to the global larder, and in an open-access system, they get access to the diversity everyone else has provided while retaining their own". 149 The idea is that parties to the agreement can use their national sovereignty not to regulate every transfer of genetic material individually, but to jointly create a multilateral system that gives everyone access on equal terms to the whole set of resources covered. This has two advantages. First, it recognises that access itself is the main benefit to be shared, and aims to facilitate it rather than limit it by exclusive contracts and patents. Second, any monetary benefits generated through the system are to be pooled and used to support conservation and sustainable use efforts, rather than enrich any single provider. Hence, it provides an alterna-

1.t Many countries have adopted a "wait and see" approach whilst the parties to the FAO International Treaty resolve the implementation issues. For instance, from Asia only Bangladesh, Bhutan and India have ratified the Treaty. For a critical view of the International Treaty see GRAIN 2005. The article argues that developed country governments resisted anything that would limit the right of corporations to continue privatising genetic resources, and in particular the right to patent them. On the other side, a number of developing countries were equally eager to limit the scope and coverage of the Treaty in order to preserve their perceived business opportunities as providers of individual genes on the global market.

14" See GRAIN 2005. 
tive to implementation of the $C B D$ as it does not lock all international seed exchanges into a web of bilateral contracts. ${ }^{151}$

Unfortunately, several important species, such as soybean, cotton and tomato are not covered by the "L.ist of crops covered under the multilateral system" 151

Article 10 of the Seed Treaty deals with a multilateral system of access and benefit sharing.

\begin{abstract}
"In their relationships with other States, the Contracting Parties recognise the sovereign rights of Stales over their own plant genetic resources for food and agriculture, including that the authority to determine access to those resources rests with national governments and is subject to national legislation. ${ }^{\text {ing }}$

In the exercise of their sovereign rights, the Contracting Parties agree to establish a multilateral system, which is efficient, effective, and transparent, both to facilitate access to plant genetic resources for food and agriculture, and to share, in a fair and equitable way, the benefits arising from the utilisation of these resources, on a complementary and mutually reinforcing basis". 1.3
\end{abstract}

Hence, one can argue that under the FAO Seed Treaty plant genetic resources for food and agriculture are no longer the "common heritage of mankind" but subject to the sovereign right of States over their natural resources. ${ }^{154}$

\title{
2.6. The Comerention on Biological Dizersity and the Transfer of Tedmology
}

Essential to the achievement of the objectives of the CBD is the access to and transfer of technology among contracting parties. ${ }^{155}$ Therefore, contracting parties are requested to provide and/or facilitate access to and the transfer of techmologies to other contracting parties that are relevant to the conservation and sustainable use of biological diversity or making use of genetic resources. The transfer of technology is a complex and costly process of learning from others. The objective is not achieved until the transferee understands and can lastingly utilise and finance the technology. ${ }^{150}$

15) SeE GRAIN 2005.

1il See Ammex 1 of the Seed Treaty.

152 See Art 10.1 of the Seed Treaty.

15: See Art. 10.2 of the Seed Treaty.

in See Art. 10.1 of the Seed Treaty and Art. 3 of the CBD.

is: The CBD Programme of Work on Technology Transfer and Scientific Cooperation is avaibble online: <http:/ /wwwebd.int/doc/publications/ttc-brochure-01-en.palf . The CBD has also developed a database on technology transfer and cooperation information. See <http://www.chd.int/programmes/cross-cutting/technolog:/ search aspx>.

15n "Ten Cases of Technology Transfer", Global Enviromment Facility (CEF). Junc 2000. 
This section provides an analysis of the relevant provisions of the CBD in this respect.

The Global Environment Facility (GEF) provides a very useful definition of technology transfer:

\begin{abstract}
"technology transfer means that local capabilities to understand, develop, produce, and use technologies are enhanced. This definition includes, for example, manufacturing joint ventures, technology licensing, joint research programs, university programs, personel exchanges and training, service personnel and infrastructure, consumer understanding, policymaker familiarity, and so on. Going even further, one could say that technology transfer means anything that facilitates the adoption, adaptation, diffusion, and dissemination of new technologies within a given country".157
\end{abstract}

Article 16.2 of the CBD sets out that the access and transfer of technology to developing countries:

"shall be provided under fair and most finourable terms. However in the case of technology subject to patents and other intellectual property rights, such access and transfer shall be provided on terms which recognise and are comsistent with the adequate and effection protection of intellectual property rights". (cmphasis added FC)

Again, the transfer of technology is limited by the incorporation of the clause that, in the case that technology is subject to IPR provisions, such protection should be duly taken into account. Article 16.3 requires the contracting parties to take measures to provide access to and the transfer of technologies based on genetic resources to the countries that provided those genetic resources, especially developing countries. Nonetheless, the fact that the access and transfer agreements have to be agreed on mutually-acceptable terms by both parties diminishes the advantage this might give developing countries, as in most cases their bargaining power is limited.

Article 15.7 of the $C B D$ requires parties to take the necessary measures to share in a "fair and equitable" way, the results of R\&D and the benefits arising from commercial and other utilisation of genetic resources with the contracting party that provided such resources. It is not clear what should constitute "fair and equitable" here, the only indication provided being that the terms have to be agreed mutually. A definition has not been given and no international adjudication mechanism has been installed to provide an interpretation. Article 16.6 intends to promote scientific research based on the genetic resources

15: "Ten Cases of Technology Transfer", Global Environment Facility (GEF). June 2000. The Global Environment Facility is an independent multilateral financial mechanism that assists developing countries to protect the global enviromment in four areas: biodiversity, climate change, international waters, and ozone layer depletion. 
provided by other $C B D$ contracting parties with their full participation, where possible in the research itself. Hence, joint and (on the ground) in-country research is considered an important approach for the development of technological capacity in the parties providing the genetic resources.

There is a clear difference between Article 15 and 16 of the CBD:

\begin{abstract}
"Article 15 discusses the requirements which have to be fulfilled when parties Want to use genetic resonfe's from other parties, whereas Article 16 sums up the conditions which should be fulfilled when parties want to make use of fechnolegie's from other parties". ${ }^{154}$
\end{abstract}

The recently adopted Bonn guidelines - intended to help implement the CBD objectives - recognise the transfer of technology as a benefit-sharing option. ${ }^{154}$ Work on improving the transfer of technology is ongoing, particularly in the context of the CBD Subsidiary Body on Scientific, Technical and Technological Advice, ${ }^{1(s)}$

Although the transfer of technology is supported in all paragraphs of CBD Article 16, conditioning terms like "subject to national legislation and international haw" and "mutually agreed terms" diminish the effect of the requirement to help establish coherence between the objectives of the CBD and IPR provisions.

In the context of the CBD, relevant technologies related to biodiversity are amongst others: techniques for in-situ conservation ${ }^{j 61}$ such as integrated pesticides management; technologies for ex-situ conservation ${ }^{162}$ such as preservation and storage technologies used in gene banks; technologies concerning the sustainable management of biodiversity resources; monitoring technologies for the generation of accurate biodiversity information. Focus of developing countries negotiators should be on what further categories of technology are relevant to the conservation and sustainable use of biological diversity,

15: See Van Overwalle $2(001, \mathrm{p} .173$.

15y See Appendix 2, Bonn guidelines on Access to Genetic Resources and Fair and Eytuitable Sharing of Benefits Arising out of their Litilisation.

leit Sec annex to CBD document UNEP/CBD/SBSITA/9/7/Add.2.

1.1 Art. 2 of the CBD provides the following definition: "In-situ conservation" means the conservation of ecosystems and natural habitats and the maintemance and recovery of viable populations of species in their natural surroundings and, in the case of domesticated or cultivated species, in the surroundings where they have developed their distinctive properties.

len2 Art. 2 of the CBD provides the following definition: "Ex-situ conservation" means the conservation of components of biological diversity outside their natural habitats. 
making use of genetic resources while not causing significant damage to the environment. ${ }^{1 ! 3}$

It is argued that the clearing-house mechanism (i.e. a collaborating network of partners facilitating scientific and technical cooperation) ${ }^{\text {lot }}$ should be the key facilitating mechanism for technology transfer, technology cooperation and the exchange of technology information under the CBD. ${ }^{16}$ ' The Clearing-House Mechanism aims to: 1) promote and facilitate technical and scientific cooperation; 2) promote and facilitate information exchange among CBD Contracting Parties, other Governments and stakeholders and 3) a fully operational mechanism with participation of all Contracting Parties and an expanded network of partners. in

The German study provides the following recommendations: The CHM should work following a Socratic mode, i.e.: to facilitate partners to identify their real needs, to enable them to choose the "right" technologies, and to facilitate the matchmaking with key offers; In addition, the CHM information should be provided about institutions that provide assistance in a cost saving access to technologies that are protected by IPRs by, inter alia, coordinating technology holders and demanders; Moreover, the CHM should facilitate access to information on the assessment and certification of technologies, inter alia by providing a data source. ${ }^{16 r}$

Some developing countries have introduced public policy rules towards attracting foreign direct investment and increasingly try to invest in research and development (R\&D) themselves. For example, Korea, Taiwan and Singapore, India, Mexico, Cuba, Brazil, and China have made substantive investments through the public sector to encourage $R \& D$ and growth of the biotechnology industry, and have also revised their IPR policies. These countries will be more likely to enter into collaborative arrangements with multinationals and to attract foreign investors. ${ }^{\text {tix }}$ Both the TRIPS Agreement and the

this The CBD initiated a joint technical study to further explore the role of IPRs and technology transfer in the CBD context and to identify options to increase technology transfer, with an analysis of costs and benefits. CBD 2004, p. 11. See also CBD 1996, and Crespi and Straus 1996.

1n. Art. 18.3 of the CBD sets out that "The Conference of the Parties, at its first meeting, shall determine how to establish a clearing-house mechanism to promote and facilitate technical and scientific cooperation / to promote international technical and scientific cooperation in the field of conservation and sustainable use of biological diversity, where necessary, through the appropriate international and national institutions]".

${ }_{14}=$ See Institute for Biodiversity 2004.

1we Information retrieved from the CBD website: <http://www.cbd.int/chm/>.

in: Ibid.

ins See Watal 2001, p. 130 and Office of Technology Assessment 1984, p. 13. 
CBD have incorporated provisions on the transfer of technology. The receipt of benefits within the benefit-sharing agreements could be seen as a form of technology transfer in that one flow of knowledge - the biodiversity rich countries' flow of genetic resources to the industrialised countries - can be compensated for by the sharing of research results and access to new technologies based on their genetic resources. Preferably, industry would consult the indigenous knowledge holders from the very beginning and let them participate in the development process in order to establish flows of knowledge and learning. This cooperation could be established through joint ventures and research collaborations, which also have the beneficial side effect of stimulating local employment opportunities. Another technology transfer opportunity would be to let industry provide assistance (by bringing in their knowledge and human capacity) to conservation projects in the field, or to invest in local infrastructure or provide medical assistance.

Industry has a big role to play in effective benefit sharing agreements; their cooperation depends on their view of the CBD, and the nature of the commercial partnership will inform the manner in which benefits are shared. Besides,

"the monitoring and enforcement of access legislation and contractual agreements is difficult, since it involves identifying the source and data collection of specimens and tracking a product's trough the discovery and development pipeline".

In addition, this process is hindered by the absence of laws on access and enforcement mechanisms, which lack support in the user countries. Presumably the participation in scientific research conducted by industry and the transfer of technology developed by the private sector are amongst the most effective ways to share benefits. 17

\subsection{The TRIPS Agrement and Techmology Transfer}

Article 7 sets out the general objective of the TRIPS Agreement. It stipulates out that the protection and promotion of IIPs should

"contribute to the promotion of technological imovation and the transfer and dissemination of technology, to the mutual advantage of producers and users of technological knowledge and in a manner conducive to social and economic welfare, and to the balance of rights and obligations". 17

11, See Kate and Laird 1999, p. 5.

170 See Kate and Laird 1999, p. 5.

17 See Art. 7 of the TRIPS Agreement. 
More specifically, Article 66.2 requests that developed country Members

"shall provide incentives to enterprises and institutions in their territories for the purpose of promoting and encouraging techology transfer to least-developed country Members in order to enable them to create a sound and viable base". 1:2

Thus, developed country governments are requested to stimulate the transfer of technology, for instance by introducing tax incentives or by providing favourable terms to enterprises that share technologies with LDCs. These provisions have been criticised for being unnecessarily limited to l_DCs, and most importantly for not being put into practise. To emphasise the importance of these provisions, the Doha Declaration reaffirmed the mandatory nature of Article 66.2 and envisaged the establishment of a WTO-administered working group on technology transfer in which countries could exchange experience on the practical implementation of the TRIPS requirement. ${ }^{173}$ Countries were also asked to submit annual reports indicating their technology transfer activities. ${ }^{17 . t}$

The reports on the implementation of Article 66.2 shall, subject to the protection of commercially confidential information, provide, inter alia, the following information:

"(a) an overview of the incentives regime put in place to fulfil the obligations of Article 66.2, including any specific legislative, policy and regulatory framework;

(b) identification of the type of incentive and the government agency or other entity making it available;

(c) eligible enterprises and other institutions in the territory of the Member providing the incentives; and

(d) any information available on the functioning in practice of these incentives, such as:

- statistical and/or other information on the use of the incentives in question by the eligible enterprises and institutions;

- the type of technology that has been transferred by these enterprises and institutions and the terms on which it has been transferred;

- the mode of technology transfer;

172 See Art. 60.2 of the TRIPS Agreement.

17: Chapter thee of this thesis will address the functioning of the Working Group on Technology Transfer in more detail.

1.4 Countries "shall submit annually reports on actions taken or planned in pursuance of their commitments under Article 66.2". See WTO document IP/C/28 on the Implementation of the TRIPS Agreement, Decision of the Council of TRIPS of 19 February 2003. 
- least-devedoped countries to which these enterprises and institutions have transferred technology and the extent to which the incentives are specific to least-developed countries; and

- any additional information available that would help assess the effects of the measures in promoting and encouraging technology transfer to least-developed country Members in order to enable them to create a sound and viable technological base"

Nonetheless, the TRIPS Council's Working Group on Technology Transfer has been criticised for being ineffectual and lacking political support, and developing countries have criticised other Members' reports as providing technical information in an unclear or incomprehensible manner.

The IPR regime is in a constant state of flux as a result of a number of developments, such as the growth of the information society, the advancement of high-tech technologies and biotechnologies and, as a consequence, the expansion of the scope of protection of inventions based on such technologies. ${ }^{17}$

Different objectives and rationale behind the search for a TK regime also require different forms of protection. ${ }^{178}$ This section will set out some of the options available to protect genetic resources and associated TK. These protection measures can be classified in two major categories: positive and negative protection measures. Discussions in the different international forums are currently addressing what a legal regime should look like, and who would qualify for protection and for how long.

\subsection{Shaping Traditional Knozuledga Protection}

\subsubsection{What Should a Regime Look Like?}

Developing countries argue that although national laws and regional measures help protect genetic resources, TK and folkiore at the domestic level, they must additionally be supported by effective (binding) international rules. At

15 See Art. 3 of the WTO document IP/C/28 on the Implementation of the TRIPS Agreement, Decision of the Council of TRIPS of 19 February 2003.

12. Interview with WTO officials conducted by the author.

1-: "Thhe recent expansion of intellectual property has come to be more an end in itself than a means to the end of stimulating desirable innovation". Vaver 2003, p. 621637. More on the pros and cons of IPRs in The World Bank, World Bank 1999, chapter 2. May 2000, argues that the balance in international IPRs is absent resulting in an over-stretching of IP protection.

12 See Conea 2001, p. 2. 
the $11^{\text {th }}$ meeting of the IC,C in 2007, India reiterated its call for an international, legally binding instrument, citing recent patents granted to yoga accessories in many countries as an example of growing misappropriation. Pakistan also advocated the negotiation of a legally binding international instrument, including a sili grenerts regime - beyond simple patents, trademarks, and copyrights - for traditional knowledge and traditional cultural expressions. It argues that patents, with their standard tests of "novelty" and "inventiveness", cannot reflect longstanding communal practices. The African Group, too, supports a new legally binding treaty on genetic resources and TK. ${ }^{174}$

The EC told the 2007 IGC that it would be willing to consider sui generis protection models but that they would have to be non-binding. In contrast, the US argued that traditional IP tools may be used or adapted to address the economic as well as moral concerns related to traditional knowledge, a view shared by Japan. ${ }^{13 i}$ Several indigenous people's organisations have expressed frustration with the lack of progress towards an agreement on TK and cultural expressions within the framework of the IGC. ${ }^{181}$ Indigenous communities are home to substantial amounts of both genetic resources and TK, and are particularly vulnerable to misappropriation. ${ }^{132}$

Currently some 25 mations have adopted sui generis systems to protect traditional knowledge, traditional cultural expressions, and genetic resources, although many struggle with the implementation of these laws, in part due to financial constraints. For instance Brazil, Panama, Portugal and Peru have reported to the IGC that they have introduced a sti gemeris IP regime for the protection of TK. However, due to financial and practical constraints the implementation and the enforcement of the sui generis system is lacking. A

174 Country positions submitted to the $11^{\text {th }}$ ICC meeting held from 3-12 July 2007 in Geneva at the WIPO Headquarters.

(s): Ibid.

1s A Maori group, the Hokotehi Moriori Trust, said that the IGC was suffering from a lack of political will and a lack of commitment by national governments to protect the rights of indigenous communities. It stressed that the distinction between TK and traditional cultural expressions had not been created by indigenous peoples, but was rather a device to accommodate them within the IP system. It said that traditional cultural expressions, such as music or names, are inextricably linked to $T K$, and are integral to the maintenance of indigenous cultures. This view was expressed during the $11^{\text {th }}$ IGC meeting.

1.22 Views expressed during the $11^{\text {th }}$ IGC meeting, Geneva 3-12 July 2007. For instance, the International Indian Treaty Council, a coalition of indigenous people from the western hemisphere and the Pacific, brought attention at the $11^{\text {it }}$ IGC to the recently concluded UN Declaration on the Rights of Indigenous Peoples, and emphasised the self-determination provisions which empower indigenous groups to determine how TK would be defined and protected, a point that had earlier been made by the group of Latin American countries. 
Peruvian official explained that her country, despite being one of the first to establish a sui generis system over two decades ago, would benefit greatly from an international solution. ${ }^{\text {s.3. }}$

The Brazilian law regulating the use of genetic resources is up to date and adequately protects genetic resources from misappropriation. ${ }^{i s-1}$ Nonetheless, the Brazilian govermment claims that the law is not obeyed, especially by foreigners, and that an international regime regulating the use of genetic material is a necessity. At present there is still no guarantee against companies patenting genetic resources outside the country from which the genetic resources are derived. For instance, in the US the rules established by the Andean Community or in Brazil, Costa Rica and India, do not apply and thus can be avoided. Under US law a patent can be obtained without needing to satisfy any legal requirements from the provider country. Brazil, with its abundant sources of biological diversity, is advocating at the international level for some form of protection for its natural resources. It argues that patent claims made by companies both in and outside Brazil is unfair exploitation. ${ }^{185}$

The African Regional Intellectual Property Organisation (ARIPO) has adopted a Draft Legal Instrument on the Protection of Traditional Knowledge and Expressions of Folklore. It provides a broad definition of traditional knowledge:

"any knowledge originating from a local or traditional community that is the result of intellectual activity and insight in a traditional context, including know-how, skills, innovations, practices and learning, where the knowledge is embodied in the traditional lifestyle of a community, or contained in the codified knowledge systems passed on from one generation to another. The term shall not be limited to a specific field, and may include agricultural, environmental or medical knowledge associated with genetic resources". ist

The purpose of the Draft law is "to protect traditional knowledge holders against any infringement of their rights as recognised by this instrument". ${ }^{\prime \prime}$

1.3. Interview conducted by author with Alejandro Neyra, representative of the Permanent Mission of Peru to the UN in Geneva, March 2008.

sw In Brazilian haw, Provisional Act 2. 186-16, 23 August 2001, established a national regime to regulate access to genetic resources and associated $\mathrm{TK}$, as well as to ensure prior informed consent and benefit-sharing from their use. This legislation is complemented by "degrees" 2.945/01, 4.946/03, 5.459/05 and 6.159/07.

145 As argued by the Mission of Brazil during 11th KGC meeting, Geneva 3-12 July 2007.

1w, Draft Legal Instrument on the Protedion of TK and Expressions of Folklore, ARIPC), 30 th Session, Maputo, Mozambique, 20-24 November 2006.

is Art.1, ARIPO Draft Legal Instrument on the Protection of Traditional Knowledge and Expressions of Folklore. 


\subsubsection{Entitlement to TK Protection}

Several practical questions arise as to who is entitled to qualify for protection. Should only indigenous communities receive protection? ${ }^{\text {ss }}$. Who defines what constitutes an indigenous community? What is a community? What if indigenous communities exist across country borders, as occurs in many parts of Africa and amongst Andean countries. It has often been expressed that the case for receiving international protection for indigenous knowledge would be encouraged if indigenous groups would speak with on woice - have clear ideas on what the scope and objectives of such a regime should be. This has proved unforthcoming, as indigenous groups are so unique and have not been able to adopt a common position. For instance, when "turmeric" or yoga practices were patented in the US, the whole of India was affronted as a nation, regarding it as a disgrace to their cultural expressions and customs. In the Andean communities, however, the practises of indigenous groups are very differently perceived - often the indigenous groups have to "fight" for their rights and for recognition within their own country. Indigenous groups are often not part of country delegations that speak and make decisions at the multilateral fora and often they are not consulted before the start of such negotiations.

\subsubsection{TK Term Duration of Protection}

IPRs are normally granted for a limited period of time. However, trade marks and geographical indications may be extended, subject to certain conditions, for an undefined period of time. Should TK protection be granted for a limited amount of time? The country perspectives vary. The EC wants the protection period to be limited, as opposed to the absence of constraints sought by China and Nigeria who believe that attaching time limits goes against the vary nature of indigenous knowledge. Japan has also expressed that putting a fixed duration on protection would mean that only certain generations could benefit. Others, for instance the US, Canada, Russia, and Australia, argue that discussing time limits was premature, since the scope of rights had not yet been clarified. ${ }^{\text {sit }}$

\subsection{Defensine Protection Measures}

A distinction can be made between the defensive protection and positive protection of traditional knowledge. Defensive protection primarily concerns the prevention of bio piracy through misappropriation (grant of patents),

ins Italy said it has many local communities that have their own cultural expressions, even though they are not indigenous. It argued that these deserved protection too. Submission to the $11^{\text {th }}$ IGC meeting, 2007.

18. Opinions expressed during the $11^{\text {th }}$ IGC meeting, Geneva 3-12 July 2007. 
misuse or illegal access. Examples of defensive protection mechanisms are the use of TK databases and registers (documentation), the obligation to disclose the origin of genetic resources, and the prevention of misappropriation. Databases can help trace prior art to identify unjustified patent claims and documented TK to foreign companies and patent examination authorities. ${ }^{191} \wedge$ growing number of initiatives seek to use databases and registries to conserve and protect TK and genetic resources. Other examples of defensive protection measures are setting TK patent examination guidelines, providing access to databases of TK (providing prior art) to patent examiners, or establishing genetic resources guidelines for equitable benefit sharing. ${ }^{\mid 9]} \wedge$ rguably, a disclosure of origin obligation may contribute to simplifying the task of searching through databases on traditional knowledge. ${ }^{192}$

WIPO issued a questionnaire on the use of 'TK and genetic resources databases and registries, and has developed a data specification concerning 'TK databases and registries. ${ }^{143}$. The questiomnaire aimed to collect information on legal and practical issues conceming the recognition of TK and genetic resource in the examination of patent applications. The questionnaire sought to ascertain whether databases and registries were considered appropriate mechanisms for the preservation and protection of TK and genetic resources and, if so, for which objectives and with which functions they might be useful. Defensive protection may undermine the interests of TK holders, particularly when this involves giving the public access to TK which is otherwise undisclosed, secret or inaccessible. Thus, in the absence of positive rights, public disclosure of TK may actually facilitate the unauthorised use of TK which the (indigenous) local

$1 \%$ However, attempts to set up databases of TK are coming under attack from the very groups they are intended to benefit. Indigenous groups are concerned that an adverse consequence of these databases is that their knowledge is made publicly available.

1\%1 Practical mechanisms for defensive protection are gathered in document WIPO/ GRTKF/IC/6/8. Defensive protection strategies focused on the patent system have a legal and a practical aspect. The WIPO doc sets out that the legal aspect entails ensuring that information is documented in such a way as to meet the legal criteria to be counted as prior art in the jurisdiction concerned. For instance, this requires a clear date of publication, and that the disclostre enables the reader to put the technology into effect. The practical aspect entails ensuring that the information is available to search autherities and patent examiners, and is effectively accessible to patent authorities (such as being indexed or classified) so that it is more likely to be found in a search for relevant prior art. See WIPO/GRTKF/IC/5/6.

"2 See Utkarsh 2003; Khor 2002 (chapter 3; and proposal by Switzerland to the TRIPS Council, WTO document IP/C/W/400, 28 May 2003, para. 9.

${ }^{103}$ Questionnaire on Recognition of Traditional Knowledge and Genetic Resources in the Patent System, IGC, July 2004, Annex to WIPO/GRTKF/IC/7/8, WIPO/GRT $\mathrm{KF} / \mathrm{IC} / \mathrm{Q} .5$. 
community wishes to protect. ${ }^{19-4}$ However, WIPO has repeatedly emphasised that the purpose of the databases and registries is not to put undisclosed TK and genetic resources into the public domain but should advance the IPrelated interests of custodians of TK and genetic resources. WIPO argues that because of these weaknesses indigenous communities need to consider fully the consequences of documenting their ITK and provide prior informed consent before publishing. ${ }^{195}$

A weakness to this measure could be that initiating, updating and maintaining databases may involve an increase in the cost of R\&D. ${ }^{1 \%}$ Notably the unstructured nature of TK is an obstacle to building databases. It is important to establish that the documentation of 'TK and genetic resources complies with overall objectives. WIPO has developed a TK toolkit setting out how to handle TK during documentation. It has also established TK data standards including recording requirements on appropriate handling of TK (e.g. customary law constraints)." Defensive protection only aims to prevent other parties from gaining IP rights, and it does not in itself prevent others from using this material.

Initiatives have been undertaken to codify TK and cultural expressions of folklore which should facilitate access to information. Notably, UNESCO is collecting large amounts of data, and information databases are being set up at the national level to preserve national cultural heritage, such as the traditional Chinese Medicine Patents ${ }^{198}$ database in China, and the Health Heritage Test and a digital library of TK relating to Ayurveda in India. In the US the Tulalip Tribes in Washington State are compiling a database of their traditional environmental knowledge named "Story Base". .

In India the Honey Bee network/project was set up to stop the "unfair and unethical" ways in which poor peoples' knowledge is taken away from them without any "attribution, accountability or reciprocity".2010 The project established "supporting platforms" to strengthen the indigenous peoples' and local communities' problem-solving capabilities. The network's major achievement has been the establishment and constant updating of a database of thou-

14.4 Ibid., p. 2.

$1 "$ Ibid.

14h See Maskus and Reichman 2004b, p. 302.

1w: "Report on the Toolkit for Managing Intellectual Property When Documenting Traditional Knowledge and Genetic Resources", WIPO/GRTKF/IC/5/5, April 20013.

lith See Bacluner 2005 and Antons 2005.

1w See "Update on Technical Standards and Issues Concerning Recorded or Registered Traditional Knowledge", IGC WIPO/GRTKF/IC/8/7, May' 2005.

zin See: <http:/ www.honeybecorg>. 
sands of innovations and TK, all with the name and addresses of the knowledge providers. Next to providing recognition and documentation of people's knowledge they have also tried to commercialise some of that knowledge and ensure that the benefits are widely shared among the community. In addition, the Grassroots Innovation Augmentation Network (CIAN) was founded. Its objective was to link local innovators to formal systems of marketing, technical and financial services, and to search for and support entrepreneurs who could convert the innovations into enterprise. GIAN cooperates with the National Innovation Foundation (NIF) converting indigenous innovations into products and enterprises. Nonetheless, it has not been able to set up as many new enterprises as it foresaw due to limited financial resources and a lack of substantial risk capital support. ${ }^{201}$

Other international initiatives to codify l'K have been made by the world Bank, which initiated an indigenous knowledge database. ${ }^{212}$ The Consultative Group on Intemational Agricultural Research (CGIAR) set up an information network for genetic resources called the System-wide Information Network for Genetic Resources (SINGER). SINGER makes information about the diversity of plants available to everyone. It provides a gateway to the knowledge that makes collections of crop diversity more useful to farmers, plant breeders and researchers. ${ }^{213}$ Furthermore, the WIPO IGC set up a Portal of online databases and registries of TK and genetic resources during its third session. The Portal is linked to the Clearing House Mechanism of the CBD. ${ }^{2(n)}$

\subsubsection{Contractual Agreements for Access to Genetic Resources}

Other initiatives currently being undertaken to protect TK are access agreements or contracts for genetic resources, such as material transfer agreements (MTAs) within the framework of the Seed Treaty. Contracts are ways to arrange benefit sharing between indigenous communities and research groups and knowledge collectors. Examples of these contracts are research protocols made by indigenous communities to regulate access to and use of their knowledge. ${ }^{205}$ In these arrangements the user country usually pays a lump sum for the right to access and research indigenous material from plant and animal origin, as well as a royalty for the benefits derived from this material. ${ }^{21 t}$ The US National Institute of Health coordinates the International Collaborative Biodiversity Group Program (ICBG) which funds collaborative bio prospecting

201 See: <http://www.nif.org.in/> and <http:/ www.nifindia.org/secondaward/secl. html.

20 See: <http://wwwt.worldbank.org/afr/ikdb/search.cfm>.

213. See: <http://singer.grinfo.net>.

2in See WIPO/GRTKF/IC/3/6 and WIPO/GRTKF/IC/3/17.

2in See also Laird 2002, Laird and Nocjovich 2002 and Collin 1993.

zim See Van Overwalle 2001, p. 179. 
arrangements in different parts of the world. One of the objectives of the ICBG is to promote its collection of genetic resources with traditional uses for the development of new medicinal products.

An example of an ICBC agreement was that negotiated with Peru in the mid 1990), concerning the collection of plant samples in collaboration with the Aguaruna communities. ${ }^{217}$. The contract was comprised of a complex set of agreements including a biological collecting agreement, a license option agreement and a know-how license, in addition to an overarching bio prospecting agreement. The agreement sets rules regarding equitable benefit sharing, and establishes precedents to redefine the nature of property rights over knowledge which should not compromise the morals of the indigenous people in question. There were weaknesses, however, in the absence of effective enforcement mechanisms, a lack of transparency and the insufficient involvement of indigenous communities' representatives in the negotiation process. This exercise shows that only with the full participation of both parties and mutual consent can foundations be laid for true cooperation and subsequently a willingness to accept the contract. It is crucial to balance the different stakeholder's' interests. ${ }^{2115}$

The Australian government liaised with "Amrad", an Australian pharmaceutical company, to develop an anti-Aids drug on the basis of "Smokebush" (biological name Conospermum stoechchadis) - Amrad paid 1.5 million Australian dollars to access and analyse the plant and if it were to come up with a marketable drug it would pay the Australian government royalties. This plant has traditionally been used by Aboriginal peoples for therapeutic purposes and it was discovered that the plant contains "Conocurvone" which destroys the HIV virus in low concentrations. ${ }^{204}$ No arrangement has been made to remunerate the Aboriginal people who identified the therapeutic properties of "Smokebush".

Another well-known example was the agreement between US based pharmaceutical company Merck and Costa Rica's Institute of Biodiversity (INBio). Merck paid 1 million US dollars for the right to analyse indigenous plant and animal extracts for possible pharmaceutical drugs or other use. The agreement was that if Merck were to come up with a marketable (commercial) product based on the genetic material retrieved it would have the right to the intellectual property (patents) on the condition that INBio would receive a royalty between one and three per cent. As well as ten per cent of the down payment

20:- For a thorough assessment of the agreement see Greene 2004, and Rosenthal 1997, p. $281-301$.

20) See Tobin 2004 .

2w See Van Overwalk 2001, p. 162 referencing a study by Blakeney 1997, p. 298-303. 
and 50 per cent of the INBio share in royalties would be invested in conservation projects in Costa Rica. ${ }^{211}$

A successful example of a benefit sharing agreement/initiative outside IPR protection is an agreement reached in Peru over indigenous communities' rights to potato strains. ${ }^{21}$ Notably, Peru has the largest diversity of potatoes in the world. A pact has been signed by six Peruvian indigenous communities with the International Potato Center (IPC). Under the agreement, the IPC gene bank returns the genetic resources and knowledge associated with the potato strains to the six communities, which have established a "potato park" in a large conservation area to grow and manage the potato plants. The agreement is drafted in such a way that the information is made public, so as to prevent third companies from patenting the potato strains and associated TK. This way it recognises the rights of indigenous communities over their developments. The reason why the community has decided not to patent the strains is of an ideological/cultural nature and devoted to the perception of the community that the potato strains should not become subject to IPRs. ${ }^{212}$ Hence it is a form of defensive protection measure for TK.

WIPO has set up a database of contracts ${ }^{21.3}$ (including both existing and model contracts) to facilitate the use of contracts among its members. However, unsurprising its emphasis is on the IPR aspects of agreements.

The problem with contractual agreement is that they are on a voluntary basis as the $C B D$ does not make such arrangements mandatory. Moreover the beneficiaries of those contracts are often government institutions of the provider country and not the indigenous communities themselves. ${ }^{21+4}$

211 See Van Overwalle 2001, p. 179.

211 The potato case is a good example of identifying products and potential products that indigenous people have. The project uses indigenous names to label/brand the products grown in the park. In addition green/eco tourism is promoted. The project establishes various products that link culture of the local indigenous people as well as promoting biodiversity and protecting the environment. It is now expanding its activities: for example designing medicinal plants, ecological products, functional foodstuffs, rumning a restaurant (Parque de la Papa) that serves healthy meals based on a variety of potatoes that are grown locally. For more information see: <http:// www. Parquedelapapa.org>.

212 See Bridges Weekly Trade News Digest 2005a; as well as Suri 2005.

213 See: <http://www.wipo.int/TK/en/databases/contracts>.

214 See Van Overwalle 2001, p. 179. 


\subsection{Positiog Protection Ménsures}

Positive measures of ITK protection relates to the active assertion of rights and to prevent undesirable use of TK (prevent others from using this material).

T'K positive protection measures focus on the promotion and protection of TK in a rights-based recognition system, i.e. by recognising and granting economic or moral rights. This can be achieved via the application of existing IPRs, or by the development of sui generis forms. Suigeneris literally means a right of its own: therefore, it can accommodate certain specific needs or circumstances and can therefore tailor existing IPR laws to the specific interests of the indigenous community. A careful examination of policy options and legal mechanisms is necessary.

One could argue that such a sui generis regime should be based on the authority of a community distinct from IP rules. The Western-based IP system (based on private property rights and monopolies) is not appropriate to fully satisfy indigenous people in that it

"will continue to override and overlook the way in which biological and technological resources are related to the cultural expression, knowledge, or practice that facilitates the cohesion and integrity of a particular group". 215

Hence, the legal recognition of a community, rather than focussing on the individual, is a prerequisite.

Positive protection could also be achieved through the use of database rights or through the establishment of a global "bio collecting" society (GBS) to reach contractual arrangements between indigenous peoples and industry. A GBS could be comparable to the common concept of collecting societies in the copyright field. However, rather than having societies at the national level it would be better to have one global GBS since this would increase transparency; it has also been argued that international organisations are better equipped to serve the needs of indigenous peoples than individual states. The GBS would be intended to serve the purposes of the CBD and the FAO International Treaty. ${ }^{216}$

Questions that developing country delegates to the IGC might consider are the following:

"What is the best mode to protect TK?"; "What are the main components of a defensive protection scheme that suit the interests of indigenous communities?"; "What are the main components of a positive protection scheme that suit the interests of indigenous communities?"; "If the sui generis route is adopted,

215 See Gibson 2004.

21" See Drahos 2000. 
should one aim for a single regime or are indigenous communities better served by multiple regimes for well-defined components of $T \mathrm{~K}$, such as for artistic creations including expressions of folklore; plant genetic resources for food and agriculture and associated knowledge; and tratitional medicine"; and "What elements should be included in the design of a sui generis regime?"

Its establishment poses conceptual and practical issues such as: 1) the definition of the subject matter of protection; 2) the requirements for protection; 3 ) the extent of rights to be conferred (rights to exclude, to obtain a remuneration, to avoid misappropriation); 4) the title-holders (individuals/communities); 5) the modes of acquisition, including registration; 6) the term duration; and 7) enforcement measures.

It is necessary to develop a comprehensive policy framework and a holistic, consultative approach to capacity building for indigenous communities.

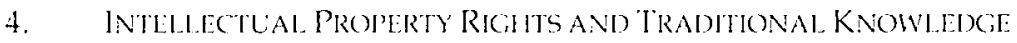

IPRs are public policy instruments and a number of justifications underlay the granting of protection: For instance, firstly, contemporary justifications concern the promotion of knowledge dissemination; secondly, ethical justifications relate to the natural or moral right of an author or inventor to profit from his own creations; and thirdly utilitarian justifications concern economic incentives for the production of creative work for the potential benefit of society as a whole. In exchange for a temporary monopoly given to the inventor, the inventor in return discloses the invention to society - a quid pro quo which is often termed as a social contract between the inventor and society.217 Chapter one of this thesis addresses the justifications underlying IPR protection in more detail.

\subsection{Arguments Against Using IPRs to Protect Traditional Knowledge}

It is often argued that the IP system is not suitable for protecting TK, as there are some inherent problems with its application in this respect. ${ }^{214}$ Indigenous communities are not familiar with IP systems and often to not associate their knowledge with private property. Often indigenous communities regard IPRs

217 See Brush 1996, p. 155-156. Yen argues that considerations of justice and fairness should complement the conomic theory. See Yen 1992, p. 423-437.

21. See Cleveland and Murray 1997. See also Brush who opts for a system of farmers' rights that would acknowledge "our common heritage and common obligation to future generations", something he argues cannot be achieved by privatisation and compensation through IP mechanisms. See Brush 1996, p. 143. 
as a threat to their knowledge and well-being. ${ }^{219}$ The IPR system has its own set of rules that need to be followed in order to obtain protection: for example, the grant of a patent is subject to novelty, inventive step and industrial applicability requirements and hence this system is only suitable for protecting a certain type of knowledge. In Europe, for instance, the inventive step is determined by the "technical effect" achieved by the invention.201 Notably, the TRIPS Agreement does not give any indication on the determination of "inventorship", hence leaving some flexibility to the individual country. Nevertheless it constitutes a basic element in patent law.

There are a number of characteristics of the collective knowledge of indigenous people221 that do not convene with the existing dominant conception of IPR regimes. Indigenous people have been defined as:

"native or original including all those people who were native to the lands where indigenous knowledge, as contrasted to modern or technological knowledge originated".

Some of the problems that occur when trying to protect TK with IPRs are:

1) TK and novelty: The problem with applying the justifications underlying the IPR system to "TK protection is that IPRs arc "forward-looking" in that they are meant to stimulate immorion. To be patentable an invention needs to be novel, involves an inventive step and be industrially applicable. Novelty is assessed by reference to the prior technological art and is considered to be destroyed by prior publication. Knowledge might well be considered to be in the public domain and hence unprotectable. However, not all indigenous knowledge is communally shared and not all of it is considered to be in the public domain. ${ }^{222}$ It might also be the case that ethno botany experts who study the use of plants have published some of their research. It is questionable if this argument holds for knowledge created by indigenous people since the information already exists and is not novel plus above all it involves the preservation and conservation of bio genetic resources; 22.3

21" See Axt et al. 1993. The authors reach the conclusion that the most promising avenues for compensating indigenous peoples while promoting hiodiversity conservation are not through IPRs but through contracts between such peoples and companies and research organisations. See also Posey 1995.

221 See T 1173/97, IBM Case, EPO Board of Appeal, I July 1998 and T 935/97 EPO Board of Appeal, 4 February 1999.

22 See Patel 1996, p. 308.

22 See Van Overwalle 2001, p. 168.

223. This goes without saying the patents are not cheap. It takes time and money to acquire and defend them. 
2) The commodification of TK: Whether or not to assign IPRs to the knowledge of indigenous peoples is related to cultural perceptions, particularly as to whether the commodification of IK is regarded as a good development or on the contrary counters with moral values. The appropriation of genetic resources - wealth maximisation sought in Western countries may therefore not be suitable for all parts of the developing world. However, the preservation of genetic resources is perhaps also a form of wealth maximisation, it is merely a different type of wealth. However one can raise the question if economic interests can truly be guaranteed? The protection of TK does not automatically mean that economic benefits will be gained. Applying the existing IPR system for the protection of TK involves the commodification of indigenous peoples' knowledge, since a shift would take place from sharing the knowledge to licensing or selling the knowledge. 22 This could be detrimental to the existence of indigenous cultures. Indigenous peoples do not view their heritage in terms of property but in contrast they view it in term of community and individual responsibility. Indigenous peoples are not automatically concemed about the economic value but the greatest value might be the cultural identity or sacred significance. 225 However, indigenous communities are diverse and it is likely that diverging views exist on the value of knowledge in these communities. Some authors argue against granting IPRs because the contributions of indigenous knowledge and all scientific discoveries have throughout the ages remained the common heritage of humankind. In contrast, technological inventions and innovations, built upon the very foundations of the genetic resources and associated TK of indigenous groups, have been made subject to the monopolistic granting of IPRs;22,

3) TK and the public domain: The public domain generally includes any information not subject to IPR or for which the rights have expired. Thus, to the extent that TK is not covered under any of the IJR modalities, it would belong to the public domain and be freely exploited.227 However, this technically correct view ignores the fact that TK may be deemed subject to customary laws that recognise other forms of ownership or possession of rights. ${ }^{22 s}$

22. For an explanation of the concept of common heritage see Brush 1996.

$22:$ See Van Overwalle $2001, \mathrm{p} .167$.

22n See Quinn 2002, p. 295 and Patel 1996, p. 318.

22- The same problems are encountered in copyright law whereby a large challenge is to redefine the scope of the public domain in the face of seemingly ever-expanding copyright, software protection and database rights. See Elkin-Koren and Netanel 2002.

22x See Dutfield $2000 k$, p. 285. 
4) The community as holder of 'TK: With respect to TK it might be difficult to attribute rights to a sole inventor or right holder since it is the commumity as "whole who holds the howoledge. Since the TRIPS Agreement is mainly influenced by "Western" concepts of IP it naturally follows that the IPR regime is characterised by the fact that rights are individualised: the TRIPS Agreement grants private individual rights (exclusive rights). For this reason it is difficult to embrace rights belonging to a community within the TRIPS Agreement. A solution to this would perhaps be to give corporate identity to a community, on the same basis that allows a company to hold IPRs;

5) TK and cultural obligations and customs: There is a cultural obligation for indigenous peoples to pass on knowledge to future generations in order to preserve, develop and manage their collectioe knowledge for their ow benefit and for the b'nefit of future generations. Thus, indigenous peoples are the custodians of the collective knowledge they possess. The knowledge forms part of the cultural heritage of indigenous peoples, the admission of which implies recognition of special rights over their knowledge. ${ }^{229}$ Jeffery regards the limited recognition and protection of IP as problematic "as it fails to acknowledge systems of knowledge that have evolved over time, as scientific knowledge does, but whose evolution has not taken place in a laboratory".231

6) TK is regarded by indigenous people as being perpetual, dynamic and non transferable: The TK is part of their cultural heritage and as the custodians; indigenous peoples cannot transfer or prescribe their collective knowledge to others but can permit licenses to use it. In contrast it is common practise in the IPR framework to transfer economic rights. Similarly, it is also not possible to grant legal protection that is limited in time since the collective knowledge is a legacy of past generations to future generations. ${ }^{23 i}$ IPRs are only of a limited duration and such a restriction does constitute an obstacle since most TK has been used for centuries and has been built upon from generation to generation. A major drawback with applying IPRs to TK and folklore is that they are territorial in nature, implying that the granted legal protection only has effect within the domestic territory as currently there is no international legal binding instrument available.

7) Diversity of TK: "Indigenous knowledge differs from scientific knowledge in being moral, ethically-based, spiritual, intuitive and holistic; it has a large social context. Social relations are not separated from relations between humans and non-human entities. The individual self-identity is

22: See Berkes, Folke and Gadgil 1995.

23:) See Jeffery 2005.

$2: 1$ See Jeffery 2005. 
not distinct from the surrounding world".232 A possible solution to keep TK within the framework of I[Rs might be to grant corporate personality (and identifying assets) to a local/indigenous community. Custodians of TK within the community would thus be "directors of the company".

\subsection{Arguments in Fandur of Lsing IPRs to Proted Traditional Knoaledge}

How can we justify the quest for IK protection by using IPRs? First, we can argue that indigenous people are entitled to have property rights to their ideas and knowledge as products of their labour - an argument based on the political philosophy of Thomas Locke. Second, since the IPR system is used amongst the developed countries, it follows that it is only fair that this system should be available to people in other societies as well (equity justification). ${ }^{233}$

Despite the inherent problems between TK and IP protection which are explained above, it might be possible to protect some forms of TK by using conventional systems of IPR protection. ${ }^{234}$ For instance, patents, trade secrets and the law of confidentiality can protect $7 \mathrm{~K}$ against unauthorised disclosure and use. Patents and trade secrets might be used to protect TK where the information leading to the invention is kept a closely guarded secret within the community; 235 otherwise problems occur with regards to novelty. Copyright, performers' rights and design rights can perhaps be suitable for protecting cultural expressions of folklore, to some extent. ${ }^{236}$ Trademarks, geographical indications and certification and collective marks can protect distinctive signs, symbols or indications holding reputation and special qualities. ${ }^{237}$

Perhaps the problems with the IPR novelty requirement can be overcome as one twists the definition to include knowledge and folklore. For example, academics have suggested that the term

\footnotetext{
"tradition' should not mean 'old' but refer to 'the manner of producing such knowledge and not to the date on which the knowledge was produced'. For instance we can define TK as being knowledge that has been developed based on the traditions of a certain community or nation. Following such a definition,
}

232 See Berkes, Folke and Gad gil 1995, p. 283.

21 See Brush 1996.

23.4 See Blakency 2000, p. $251-252$.

235 TK exists that has never been revealed and has always been kept as a closely guarded secret. As a consequence, any future invention based on it can very well qualify as appropriate subject matter for patenting.

23. Developments are also taking place in the field of trademarks, as, for example, in New Zealand, where a law has been drafted to halt the registration of a trademark if it is likely to offend a significant section of the communty, including the Maori. See Gray 2005.

3 For a comprehensive overview of TK and IPRs, see Posey and Dutficld 1996. 
IK and folkfore would not necessarily be barred on the grounds of a lack of novelty".2.3s

Thirdly, the difficulties encountered with prior art/source retrieval of TK could perhaps be overcome by using databases and registers in which countries codify the genetic resources and associated TK existing on their territories. A disclosure requirement could also be helpful in this regard.

\subsection{Comecting Failures in the Patent System}

Patent examination authorities should avoid the granting of "wrong" patents inventions that are either not novel or not inventive due to prior TK. For instance, oversights through a lack or access to knowledge should be avoided. In addition patenting standards are too low: for instance, patents are obtained on inventions which amount to little more than discoveries. Moreover, substantive patent rules differ: for example, in the US the principle of relative novelty is applicable. This implies that on US territory prior art, whether relayed by oral or written information, is by all means novelty-destructive on US territory. However, outside the US prior art is only recognised if documented (written) and thus some forms of public disclosure of TK as prior art are excluded. This can be detrimental to the interests of the indigenous people who are accustomed to passing on their knowledge verbally from generation to generation. Furthermore, patent authorities have been criticised for not working consistently and inadequately examining patentability criteria. For instance, a study has shown that in a third of the cases the patent claims did not match the legal requirement of a patent (novelty and non-obviousness). ${ }^{239}$ In particular, criticism has been directed at the US' dysfunctional patent authority, where the alleged inexperience of patent examiners has led to the quality of examinations on the grounds of novelty and inventive step being questioned.

Another failure is that even if the patent represents a genuine invention - no matter how the patent claim is defined - often no arrangements have been made to obtain the prior informed consent of the communities providing the knowledge or resource, and for sharing the benefits of commercialisation to reward them appropriately in accordance with the principles of the CBD.

23 See Weeraworawit 2003, p. 159.

2:4 See Maskus and Reichman 2004b, p. 300 and the Economist, "Owning the body and the soul", 10 March 2005 . The latter makes reference to a sludy published in Science by J. Paradise, Illinois Institute of Technology, stating that in more than a third of the cases they found that the claims did not mateh the legal requirement of a patent (novelty and non-obrious). 
The WIPC Standing Committee on the Law of Patents is negotiating a Substantive Patent law Treaty with the objective of harmonising the criteria and procedure for granting patents and ultimately to lead to enhanced international patent quality. ${ }^{2+41}$ Arguably an intemational definition of what constitutes prior art would contribute to the discussion on the protection of TK.

\section{THI: DISCLOSURE OF ORICIN REQUIREMENT}

\subsection{Introduction}

In order to combat the misappropriation of their resources and to minimise the granting of erroneous patents, several countries and regions apply disclosure of origin measures for patent applications for inventions derived from genetic resources at the national level. Here, there are two separate but related issues: the disclosure of origin certificate, and the disclosure requirement. A certificatc of origin would serve as a type of passport or permit that would accompany the genetic resource along the whole chain of the access and benefit sharing $(A B S)$ process. It could be verified at various points, particularly once the said resource left the provider country, ensuring the traceability of the genetic resources. A certificate of origin would be a practical way to implement the disclosure of origin requirement, but it would not have the same legal consequences as an official amendment to the TRIPS Agreement, making it a much looser and less effective measure.

In contrast, an amendment incorporating a disclosure of origin requirement would strengthen implementation and enforcement significantly as it would be linked to the W'TO dispute settlement system. It would strengthen the process of verifying whether genetic resources were collected in accordance with national rules requiring consent, and whether the conditions for such consent were met. A disclosure of origin requirement has the potential to function as a bridge between national and international legislation as well as between the providers and users of resources to monitor trade and movement of resources in endeavours to protect and promote TK.

Discussions under the CBD have led to a process for adopting a certificate of origin system that would make the disclosure requirement operate effectively.

A disclosure of origin requirement is part of a broader system of measures to safeguard and protect TK, of which access and benefit sharing (ABS) embodies an important component. The concept of ABS was further crystallised by the CBD. It addresses the range of benefits that result from the commercialisation of genetic resources at different stages. These benefits can take various forms including: 1) financial compensation through royalties or fees; 2) stakes in equity or profit sharing; 3) commercial partnerships such as joint ventures; 4)

2411 WIPO 2004, Annex p. 2, document reference WO/GA/31/9 from WIPO General Assembly, Thirty-First Session, Geneva, 27 September to 5 October 2004. 
scientific, social and/or environmental benefits; and/or 5) non-monetary benefits such as the sharing of research results or technology transfer. All these different modes of benefits are intrinsically linked. ${ }^{2+1}$

A disclosure of origin requirement was originally demanded by civil society organisations and has been taken up mostly by developing countries. Interestingly, more and more developed countries are introducing some form of a disclosure regime in their policy and legislative framework - albeit differing in approach as to the justification, scope, concepts and terminology used, and the legal effect of the requirement and consequences of non-compliance. It has been argued that for a disclosure of origin requirement to be effective it needs to be embraced at the international level to ensure uniform compliance. Therefore, analogous with the development of domestic policy and legal frameworks, a number of countries have also made proposals for introducing some sort of disclosure of origin requirement internationally. ${ }^{2+2}$ A group of developing countries ${ }^{243}$ and Norway have suggested amending the TRIPS Agreement to include a disclosure of origin requirement. ${ }^{24}$ Others, in particular Switzerland, have identified the WIPO as the appropriate body to deal with these issues and submitted proposals to amend the Patent Co-operation Treaty ( $\mathrm{PCT}$ ) and to introduce this into a future Substantive Patent Law Treaty (SPLT), both administered by the WIPO International Bureau.

241 See Claessens 20086 .

2.2 Introducing some sort of a Certificate of Origin is not a new phenomenon: as early as 1923 the Geneva Convention relating to the Simplification of Customs Formalities was estahlished referring to a document (Art. 11) that is used in the international trade to prove that goods in a particular export shipment are wholly obtained, produced, manufactured or processed in a particular country (the country of origin). In fact it is normal practice that countries (custom borders authorities) consider the origin of imported goods when determining what duty will be imposed on the goods or, in some cases, whether the goods may be legally imported at all. In most cases it is the local chamber of commerce that issues the certificate. The International Chamber of Commerce cautions that it is best to avoid confusion with existing systems like this one. See "Issues for Consideration by the Group of Technical Experts Concerning a Cerlificate Relating to Genetic Resources" by the International Chamber of Commerce, available at: <http:/ / www.iccwbo.org>.

2.t. Several indigenous groups have also expressed an interest in a disclosure of origin requirement. For instance the Maori group, the Hokotehi Moriori Trust, stated at the $11^{\text {th }}$ meeting of the WIPO IGC that "indigenous people search for an appropriate mechanism to recognise and respect their knowledge - a requirement for prior informed consent would warrant against suppression of traditional knowledge and stop the culturally offensive use of certain material".

$2+4$ Argentina, Canada, Korea, Japan and New Zealand said that calls for an amendment of the TRIPS Agreement are premature and argue that changing WTO IP rules was not necessary to pursue the objective. See Bridges Weekly Trade News Digest $2007 \mathrm{~b}$. 
The disclosure of information is, however, not a new concept: for example, the PCI already demands that applicants disclose known prior art. ${ }^{25}$ Current discussions within the multilateral framework on the disclosure of origin are outlined below.

The disclosure of origin requirement refers to an obligation for patent applicants to provide certain information when an invention involves, or is based on, either genetic resources and/or TK. The requirement is intended to help realise fair and equitable benefit sharing as required by the CBD. 2th it is designed to verify that the resources, and possibly associated TK, were acquired in accordance with biodiversity access and benefit-sharing regulations, including prior informed consent in the provider countries, and other provisions of the $C B D$ relating to national sovereignty, technology transfer and the knowledge and practices of indigenous and local communities embodying traditional lifestyles. ${ }^{247}$

The following section focuses on the issue of the mandatory disclosure requirement within the WTO TRIPS Council, and seeks to identify the main issues pertaining to these discussions. It focuses on the positions held by key actors, with a special emphasis on the European proposals submitted by Norway, Switzerland and the European Commission. After analysing these proposals to the TRIPS Council, it concludes that Europe is gradually moving to embrace a disclosure requirement at the international level. Nonetheless, countries differ on how this requirement should be implemented and what legal effects it should have. Many implementation challenges remain, due to the different options available for a disclosure of origin requirement. For instance, questions arise as to the feasibility of introducing a new system and its associated costs and benefits. These deliberations are not addressed in detail in this paper. Rather, the aim is to give an overview of the disclosure measures that have been proposed at the international level and contrast the approaches of different European countries.

\subsection{The Disclosure of Origin Requirement: Why, What, Where, How?}

\subsubsection{Rationale Behind a Disclosure of Origin Requirement}

If one supports the effective implementation of rules established under the CBD, it follows that it is necessary to facilitate the effective implementation of fair and equitable benefit-sharing from the exploitation of genetic resources -

245 See Art. 5.1 (a)(ii) of the Patent Cooperation Treaty.

24t The overall objective of the $\mathrm{CBD}$ is to guarantee the sustainable use of genetic resources.

247 See Queen Mary IP Research Institute 2004. 
one of the key objectives of the CBD. It has been proposed that this could be done by reviewing patent applications to ensure that any genetic resources and TK used in an invention have been obtained in compliance with biodiversity access and $A B S$ regulations, including rules on prior informed consent in the provider countries' domestic legislation. A disclosure obligation would smooth the process of verifying whether genetic resources have been collected in accordance with national rules requiring consent, and whether the conditions for such consent have been met. The disclosure obligation would also make patent applicants aware of the importance of complying with the CBD, as adopted by 190 parties. ${ }^{245}$ The same would also apply where states have rules requiring consent for the exploitation of TK independent of the CBD.

One can argue that a disclosure of origin requirement would also facilitate determining whether the patentability requirements in the TRIPS Agreement have been met and, for instance, help prevent patenting where, for example, the novelty or inventive step requirements have not been met. For example, a disclosure of origin obligation would contribute in simplifying database searches on $7 \mathrm{~K}$ by providing an additional basis for such an attack on validity of patent. ${ }^{249}$ A disclosure obligation would, therefore, also be useful in ensuring that patents are not granted contrary to the fundamental principles of patent law.

\subsubsection{What Type of Disclosure Requirement?}

The disclosure requirement raises a number of questions that remain openended. For instance, there is no agreement as to what the ideal disclosure of origin requirement should look like, the necessity of having such a regime, in what form, with what objective, legal consequences and so forth. Therefore, proposals submitted to the international organisations differ in scope and in the terminology used.

For instance, the information required may be:

i evidence of prior informed consent for access and utilisation of genetic resources;

ii evidence of fair and equitable benefit-sharing agreements;

24s 180 parties ratified the Convention rapidly after the time of CBD adoption in 1992 , entry into force on 29 December 1993. The Convention was born at the Rio Earth Summit in 1992, the UNEP Governing Council provided the mandate for negotiation - Decision 14/26 of 1987. The CBD holds 191 Contracting Parties, status as of 3 December 2008. See <http:/ www.chdint/convention/parties/list/>.

24.) See Utkarsh 2003. 
iii reference to geographical origin, provenance or source of the genetic resources and/or traditional knowledge.2n

As to the legal effect and practical consequences, the disclosure could be mandatory or voluntary; and the materialisation of the requirement could lead to the adding of a fourth requirement to the patent system ${ }^{251}$ (as in the Belgian domestic legislation) or the requirement could be part of the grant procedure (as in the Swiss proposal). 22 Proposals included various options as for the consequences of non-compliance, e.g. revocation of the patent or punishment outside the patent system. As mentioned above, the use of specific terms have different legal and practical consequences. For instance, the terminology used to define the role of the genetic resource in an invention relates to the extent to which a genetic resource, or 'TK, is involved in an invention. And the need for a disclosure of origin or PIC could also depend on the extent to which a genetic resource, or TK, is involved in an invention. The use and definition of terms is the subject of ongoing debate.

Dispute remains as to whether or not incorporating a disclosure requirement is compatible with the TRIPS Agreement, as it may add a new condition for patentability (the position of the US). For advocates of a disclosure of origin obligation, the TRIPS Agreement is commonly understood to permit Members to introduce such a requirement in their national legislation. That reasoning comes from the fact that TRIPS provides minimum standards, allowing members flexibility with regard to the implementation of their obligations, and thus permitting them to incorporate additional requirements into their domestic legislation. Nonetheless, in order to oblige Members to introduce a mandatory disclosure obligation, the TRIPS Agreement would need to be amended.

Enforcement is another issue of contention: there are countries that suggest using civil penalties or criminal sanctions outside the patent system to punish non-compliance (e.g. Norway), whilst others propose revoking the patent if it becomes apparent that the applicant has given incorrect or incomplete in-

251 For instance, current legislation and proposals refer to: a) Country of origin; providing country; geographical origin; source; b) Genetic resources, genetic material, biological material of plant or animal origin; components of biodiversity; c) Traditional knowledge of indigenous and/or local communities; collective knowledge; and d) lnventions that are: "obtained from..."; "obtained or developed on the basis of..."; "use samples or components of..."; "concern or use..."; "whose subject matler is..."; or are "directly based on..."; e.g. genetic resources. See Hoare 2006.

$2 \pi 1$ The three patent criteria set out in the TRIPS Agreement are: novelty, inventive step and industrial applicability.

252 These proposals will be discussed in more detail below. 
formation (e.g. Brazil and the group of developing countries proposing Article 29lis).

One can broadly identify three forms of disclosure with differing legal conseyuences for non-compliance:

1) voluntary measure - disclosure would be encouraged and recommended but failure to do so would not affect the patent;

2) mandatory regime - failure to comply would have consequences within the patent system or lead to civil or administrative sanctions outside the patent system;

3) going beyond a disclosure requirement in patent applications to require adherence to domestic or regional legislation on access and benefit-sharing and prior informed consent. ${ }^{25.3}$

The legal basis of disclosure requirements may lie within the patent system, adding another substantive requirement or introducing disclosure into the grant of patent phase. The legal basis may also be found outside patent law mechanisms, for instance in enviromment/conservation law's relating to access and benefit-sharing

\title{
5.2.3. Country Proposals to the WTO
}

\subsubsection{The European Proposal}

Some form of "weak" disclosure was adopted by the EC through the 1998 Biotech Directive. ${ }^{25.4}$ Recital 27 states:

\begin{abstract}
"Whereas if an invention is based on biological material of plant or animal origin or if it uses such material, the patent application should, where appropriate, include information on the geographical origin of such material, if known; whereas this is without prejudice to the processing of patent applications or the validity of rights arising from granted patents".25i
\end{abstract}

Hence, under the Biotech Directive, disclosure of geographical origin is encouraged, but not mandatory, and failure to comply does not affect the granting of patents. ${ }^{250}$ In particular, the Biotech Directive does not refer to the term "disclosure of origin".

25. See Queen Mary IP Research Institute 2004.

25. See EC Biotech Directive.

25 See Recital 27, EC Biolech Directive.

25n Legal opinions differ as to the legal effect of "recitals" of EU Directives. In any event, one can argue that the use of the word "should" rather than "shall" implies 
The EC has expressed its willingness to discuss and examine the introduction of "a system" that would allow states to keep track, at a global level, of all patent applications which make use of genetic resources, within proposals to the WIPO IGC, the (BD and to the TRIPS Council.257 According to the EC, such a requirement should be applied to all patent applications and "be implemented in a legally binding and universal manner".27.8 In its view

\begin{abstract}
"[al global and compulsory system creates a level playing field for industry and the commercial exploitation of patents, and also facilitates the possibilities under Article 15.7 of the CBD for the sharing of the benefits arising from the use of genetic rescutres".
\end{abstract}

The EC believes that such a system should be related to the existing international legal framework for patents. In order to achieve such a binding disclosure requirement, amendment of the PLT, the PCT and regional agreements such as the European Patent Convention will be necessary. Only then will the disclosure requirement apply to all international, regional and national patent applications at the earliest stage possible.

The applicant should be required to declare the country of origin of genetic resources, but only "if he is aware of it" and "[no] additional research on his part would be required".259

If applicants are not capable of indicating the country of origin, they may refer to a broader notion of "source". Hence, if the country of origin is unknown, the applicant should declare the source of the specific genetic resource to which the inventor has had physical access, and which is still known to him.

the absence of an absolute legal requirement. In addition, Recital 27 resulted from a compromise between Denmark, which had originally proposed that such an "information disclosure" become part of the Directive, and other member states that considered that this would add another substantive condition for patentability, and would therefore violate the TRIPS Agreement. See Queen Mary IP Research Institute 2004.

25: Communication submitled by the European Communities and its Member States to the TRIPS Council, WTO document $\mathrm{IP} / \mathrm{C} / \mathrm{W} / 383,17$ October 2002. Document submitted by the Secretariat of the Comvention on Biological Diversity, WIPO/ GRTKF/IC/6/13, 15 March 2004.

2:- Proposal by the European Community and its Member States to WIPO, entitled "Disclosure of origin or source of genetic resources and associated traditional knowledge in patent applications", received 16 December 2004 in response to an invitation by WIPO to submit comments and proposals towards collaboration between WIPO and the CBD, see WIPO document DOC WO/GA/31/8, hereinafter: Proposal by the EC. Published on the internet at: <http:/www.wipo.int/tk/en/ genetic/proposals>.

27 lbid. 
According to the EC, the term "source" refers to any source from which the applicant has acquired the genetic resource, other than the country of origin, such as a research centre, gene bank or botanical garden. The EC links its proposal with the multilateral system as established under the FAO Seed Treaty, indicating that the source can include the "Multilateral System" as a source of genetic resources belonging to crops included in the Annex 1 of the FAO Seed Treaty.2(1)1

As regards to relationship between genetic material and inventions, the EC sets out that the applicant must have used the genetic resources in the claimed invention. More particularly, the EC proposes that the invention must be directly based on the specific genetic resource in that the invention must make immediate use of the genetic resource and be dependent on the specific propcrties of this resource. The EC takes the position that there is good reason for an obligation to disclose that an invention is directly based on TK associated with the use of genetic resources: This is because it would facilitate implementation of Article 8(j) of the CBD, which sets out that there is a commitment to respect, preserve and maintain TK. The EC proposes that the introduction of a disclosure system should be "organised in a non-bureaucratic and cost-efficient manner". ${ }^{2 n}$ it points out that "[a]n overwhelming majority of patent applicants do not base their inventions on genetic resources and/or associated traditional knowledge and for them the burden should be limited to an absolute minimum". ${ }^{262}$ Hence, the patent authorities should not make an assessment of the contents of the submitted information, nor should they be obliged to keep track of whether the patent applicant has obtained the relevant material in a way compatible with benefit-sharing and PIC provisions. On the contrary, their role should be limited to checking whether the formal requirements have been complied with. The EC argue that for reasons of legal certainty, the submission of incorrect or incomplete information should not have any effect on the validity of the granted patent or on its enforceability against patent infringers. However, the EC leaves it to the national sovereignty to determine "the character and the level of these sanctions, in accordance with domestic legal practices and respecting general principles of law". 26.3

The EC does favour the introduction of a simple notification procedure to be followed by the patent offices every time they receive a declaration. It identifies the Clearing House Mechanism of the CBD as the central body that

2n) According to Art. 12.3 (b) of the Seed Treaty, "access shall be accorded expeditiousIy, without the need to track individual accessions". The Multilateral System is in fact the source of the genetic resources, as well as the beneficiary of the sharing of profits from their commercialisation.

201 Proposal by the EC, WIPO document DOC WO/GA/31/8, 16 December 2004 .

2n:2 Ibid.

20.3 Proposal by the EC, WIPO/GRTKF/1C/8/11, 17 May 2005. 
all patent offices should notify about granted patents that make use of genetic resources or TK.

The EC also supports a system that would ensure transparency, and allow the authorities of countries granting access to their resources to keep track of patent applications linked to the use of these resources. Under such a system, the information to be provided by patent applicants should be limited to information on the geographic origin of genctic resources or TK used in the invention, but such a disclosure requirement should not act, de facto or de jure, as an additional formal or substantial patentability criterion. The legal consequences of non-compliance should lie outside the realm of patent law, e.g. in civil law (through a claim for compensation), or in administrative law (with a fine for refusing to submit information or for submitting the wrong information). The EC proposes that problems arising from genetic resources originating from more than one country should be dealt with through arrangements between the source countries, and/or in the context of the CBD.2nt

The EC sets out that in cases where TK is used as a basis for further innovations, then it can be patented. In such cases, applicants should disclose the source of the TK, but as with genetic resources, this should not determine the patentability of the invention. In this regard, the EC supports further work on the development of an international sui generis system for the protection of TK within the IGC.

Similarly, the EC is of the opinion that Article 29 of the TRIPS Agreement does not prevent members from requiring the patent applicant to disclose the source of origin or to provide evidence that $A B S$ rules have been respected, as long as such requirements do not constitute a patentability criterion or invoke the validity of the patent, i.e. no revocation. Hence the introduction of such a system at the national level is permitted.

The EC wanted the IGC to be the body to respond to an invitation from the CBD (7"li Conference of the Parties, 2004) to address the inter-relation of access to genetic resources and disclosure requirements in IP applications, as in its view it is "the only body with a legitimate mandate to discuss these issues". The EC was content with Switzerland's proposal to amend the PCT to allow enhanced disclosure. ${ }^{265}$

2tw See Queen Mary IP Research Institute 2004.

2n: See Bridges Trade Bioles $2004 b$. 
It is questionably whether Recitals are legally enforceable.206 Five European countries have adopted some sort of a disclosure of origin requirement in their domestic legishation (Belgium, Denmark, Germany, Norway and Sweden), and one other (Switzerland) has draft legislation, currently being considered by its parliament. None of the countries introduced a disclosure of origin requirement for evidence of fair and equitable ABS. This was either simply not considered (the case in Belgium and Denmark) or it was not thought to be feasible (in Norway and Switzerland).

\subsubsection{Belgium}

Belgium was the first European Country to take immediate action to implement the origin indication condition mentioned in Recital 27 of the EC Biotech Directive in its patent law. ${ }^{267}$ Belgian legislators have argued that the exploitation of inventions which were developed in violation of the third CBD objective run counter to ordre public and morality. Proposed Article 4, section 4 of the Belgian Patent Act stipulated that the exploitation of an invention is contrary to ordre public and morality, when the invention is developed on the basis of biological material that was collected or exported in breach of Articles $3,8 j, 15$ and 16 of the CBD. 2tw This "original" approach, of linking compliance with $C B D$ to ordre pullic and morality requirements, has been criticised on the basis of both legality and practicality. 200 271 However, this was not adopted, apparently because the legislation never made it through parliament due to changes in government. Instead, Belgium introduced a simple formal requirement in May 2005:

2tw The opinions vary whether recitals are legally binding: it is argued that if Recitals are not duplicated as an Article they are not legally binding, others argue that they are legally binding on national authorities, unless there are valid reasons by EC law for not implementing them. See Van Overwalle 2002, p. 233.

2n- See Van Overwalle 2002 and Van Overwalle 2001 for a detailed description of the various legal proposals and their implications.

2es In 2000, a draft proposal to modify Art. 4(4) of the 1984 Belgian Patent Act (Patents, Law, (Brewets, Loi) BE_031, 28/3/84) (Loi sur lis breats d'ineution) was prepared stipulating "that the exploitation of an invention is contrary to ordre public and morality when the invention is developed on the basis of biological material that was collected or exported in breach of articles $3,8(j), 15$ and 16 of the CBD". Moreover, "a patent application should contain, not only a formal request, a description, one or more claims, drawings and an abstract, but also the geographical origin of the plant or animal material on the basis of which the invention was developed". See Van Overwalle 2002, p. 234-235.

2 2n. See Van Overwalke 2002, p. 235 and Van Overwalle 2001, p. 178.

2ro With respect to legality, it has been argued that the legal basis for such an application of the ortre public and morality concepts is weak, and that there is no precedent for stretching these concepts so broadly. See Dutfield 2003, p. 34. 
"Article 5 of the new law modifies Article 5 of the country's patent law. 27 Under this new legislation, disclosure is repuired of the geographic origin of biological malter of plant or animal origin from which inventions have been developed, where this is known. This is a formal requirement, non-compliance with which could result in the patent application not being processed". $2 ; 2$

Under this legislation, non-compliance could, in theory, result in a patent application not being processed, although this would seem an unlikely event given that the patent office does not check compliance. ${ }^{273}$

\subsubsection{Norway}

Norway was one of the first advocates of a disclosure requirement at both the domestic and the international level. ${ }^{27 t}$ The Norwegian Patent Act stipulates that:

"If an invention concerns or uses biological material, the inventor shall disclose the patent application the country providing such material. If national legislation in the providing country requires prior informed consent before providing such material, the application shall include information on whether such consent has been sought.

In cases where the providing country is different from the country of origin of the biological material, the country of origin shall also be disclosed. Country of origin is defined as the country from where the material is accessed in in situ conditions. In cases where national legislation in the country of origin requires prior informed consent before providing such material, the application shall include information on whether such consent has been sought. If the applicant does not know the country of origin or whether prior informed consent is required, the applicant shall state this fact in the application.

These obligations are applicable even if the inventor has changed the structure of the material. They do not concern human material. Violations of the requirement to disclose information is punishable under paragraph 166 of the

271 No. 2005/11224. Loi modifiant la loi du 28 mars 1984 sur les brevets d'invention, en ce qui concerne la brevetabilité des inventions biotechnologiques, Published in Belgisch Staatsblad/Moniteur Belge 13/05/2005, 22852. Published online at: <http:// www.just.fgov.be/index_fr.htm>.

272 See Hoare and Tarasofsky $2006, p .33$.

73 A quick survey of patent applications in Belgium have shown that in the 6 months since implementation of Belgium's disclosure requirement (from May to October 2005 there had been just six national applications concerning pharmaceuticals, although it was unknown whether these used biological matter. Hence the introduction of the requirement has not significantly impacted on the work of the patent offices. See Hoare and Tarasofsky 2006, p. 8.

27. An amended Norwegian Patent Act was adopted by Parliament in December 2003. It came into force for patent applications submitted from 1 February 2004. 
Penal Code. The requirement to disclose information does not affect that handling of a patent application or the validty of a patent".25

The Norwegian Patent Act sets out that these measures are not applicable to international applications received through the PCT, as this would be contrary to the obligations under the PCT.270 Notably, penalties for non-compliance could be the imposition of a fine or up to two years in prison. ${ }^{27}$

\section{The Rationale}

Norway argues that a disclosure requirement is necessary to enhance the interaction between the CBD and the TRIPS Agreement, because an obligation under the TRIPS Agreement to disclose the origin of genetic resources when applying for patent protection would ensure transparency with regards to the origin of biological materials that are to be patented. ${ }^{278}$ In Norway's view, this would facilitate the effectiveness of the CBD, as a disclosure obligation would make it casier to verify whether genetic resources have been collected in accordance with national rules requiring PIC, and whether the conditions for such consent have been met. In addition, it would allow parties to enforce their rights to their own genetic resources when they form part of a patent application. In particular it would support the CBD in securing an equitable sharing of the benefits of exploiting genetic resources. Norway argues that a disclosure obligation would contribute towards giving effect to Article 16.5 of the CBD, which sets out that the Contracting Parties should cooperate to ensure that IPRs are supportive of and do not run counter to the objectives of the CBD. In addition to facilitating the implementation of the CBD, Norway believes that a disclosure requirement serves the IPR system, as in its view "it would ensure that novelty criteria are met, which accords with the basic intentions and principles of the patent system and increases its credibility". ${ }^{29}$ In Norway's view a general obligation to disclose any TK upon which an invention is based would help to prevent patents being erroneously granted.

Disclosure requirements would hence allow the original TK holders to become aware of patents granted for inventions based on their knowledge and

275 Para. 8(b) of the Norwegian Patent Act. This is an unofficial translation taken from the Queen Mary IP Research Institute Study, available at: <http://trade.eceuropa. eu/doclib/docs/2005/june/tradoc_123533.pdf> [last accessed March 2007].

2in Para. 33 of the amended Norwegian Patent Act.

27- Para. 166 of the Norwegian General Civil Penal Code.

27 See Norway's WTO communication dated 14 June 2006 on "The Relationship between the TRIPS Agreement, the Comvention on Biological Diversity and the Protection of Traditional Knowledge - Amending the TRIPS Agreement to Introduce an Obligation to Disclose the Origin of Genetic Resources and Traditional Knowledge in Patent Applications", WTO document IP/C/W 473, 2006.

$2 \pi$ Ibid. 
resources and to take appropriate action. Therefore, Norway argues that a disclosure requirement should apply to all patent applications; the Patent Cooperation Treaty (ICT) and Patent Law Treaty (PLI'T) shouk be amended, as well as the 'TRII'S Agreement. ${ }^{260}$

\section{Soupe and legal Effect at the International le'ed}

Norway favours the incorporation of a disclosure requirement in the TRIPS Agreement. It suggests amending the TRIPS Agreement to incorporate a mandatory obligation to disclose the origin of genetic resources and TK in patent applications. In Norway's view, the disclosure obligation should be introduced in a new Article 29 bis and should provide that patent applications should not be processed unless the required information has been submitted. However, with regards to enforcement it proposes that non-compliance with the disclosure obligation, discovered post-grant, should not affect the validity of the patent.

Norway favours a disclosure obligation based on the following elements: A binding international obligation should be introduced to include information on the supplier country and the country of origin, if known and different, of genetic resources and TK in patent applications. It should obey national rules (in the supplier country or country of origin) for access to genetic resources or TK and the disclosure obligation must also encompass a duty to make reference to whether such consent has been given. It should specify if the country of origin is unknown; The disclosure obligation should apply to all patent applications whether they are international, regional and/or national; It should set out that the provisions of the disclosure obligation are compatible with the International Treaty on Plant Genetic Resources for Food and Agriculture (International Treaty); If the patent applicant is unable to provide information or refuses to do so, the application should not be allowed to proceed; $A$ breach of the disclosure obligation should be treated as a formal error, i.e. the application should not be processed until the required information has been submitted. Where appropriate, the application could eventually be rejected; If it is discovered that incorrect or incomplete information has been given after the grant of patent, this should not affect the validity of the granted patent, but there should be a penalty in an effective and proportionate way outside the patent system, e.g. by criminal or administrative sanctions. Upholding post-grant patent protection, despite non-compliance with the disclosure obligation, is important to avoid creating unnecessary uncertainty in the patent system. If the applicant has acted in good faith, the fact that incorrect or incomplete information has been given may have no consequence

2wil See WTO document $1 \mathrm{P} / \mathrm{C} / \mathrm{W} / 491$ of 7 May 2007 in which Norway replies to questions posed by Switzerland in the TRIPS Council of 25-26 October 2006, WTO document $\mathrm{IP} / \mathrm{C} / \mathrm{M} / 52$. 
at all; $A$ notification system should be introduced, under which patent offices send all declarations of origin they receive to the CBD Clearing House Mechanism.2s?

Norway argues that revoking a patent as a consequence of non-compliance with the disclosure obligation would not be in the interest of those who consider themselves entitled to a share of the benefits of the invention. This means that, once patent protection is revoked, there are no exclusive rights from which benefits could be derived. However, Norway provides an exception to this rule: if a patent does not differ from TK to the degree required to constitute a patentable invention, in this particular case the patent can be revoked. In such a case the substantive patentability criteria have not been met, but it is the lack of novelty or an inventive step that constitutes the reason for invalidity, and not the breach of the disclosure obligation.

In Norway's view the TRIPS Agreement is commonly understood to permit Members to introduce disclosure of origin obligations in their national legislation. Nonetheless, in order to oblige Members to introduce a mandatory disclosure obligation, the TRIISS Agreement would need to be amended. The disclosure of origin obligation is linked to the patent application, but does not constitute a substantive patent criterion. In Norway's view, it would therefore be most appropriate to introduce a new provision in the TRIPS Agreement immediately following Article 29, which contains provisions on the disclosure of information related to the invention.

In summary: Norway supports the amendment of the TRIPS Agreement to introduce a disclosure of origin requirement.

\subsubsection{Switzerland}

Switzerland has taken a leading position in the field of bridging the relationship between IPR agreements and the CBD, and has been active in the relevant international deliberations on these issues. It has submitted proposals on the disclosure of the sonrce of genetic resources and TK in patent applications to the WIPO Working Group of the PCT.282 It has also pursued the same line in the

2n An international clearing house mechanism refers to an international database capable of functioning as a referral point for genetic resource or TK holders to track the use of their resources. It would function as a measure of transparency'. Thus, the moment the certificate is issued its record will go into an international database.

2:2 Communication from Switzerland to the WIPO PCT, PCT/R/WG/4/13, 5 May' 2003. 
WIPO IGC, in the TRIPS Council and to the Ad Hoc Open-Ended Working Group on $A$ coess and Benefit-sharing of the CBD.2.3.

\section{The' Rationale}

The Swiss view is that including the disclosure of source of genetic resources enhances transparency, traceability, technical prior art and mutual trust. ${ }^{2 s+}$ In addition, it would also support the determination of prior art with regards to TK, as it would simplify searching the TK databases that are increasingly being established at the local and national levels.

It has presented various communications to the IRIISS Council and within the WIPO Working Group on PCI Reform on its proposals for the declaration of the source. Switzerland proposes to amend the regulations under the I'CT' explicitly to enable the national patent legislation to require the declaration of the source of genetic resources and $T^{\top} \mathrm{K}$ in patent applications if the invention is directly based on such resources or knowledge. ${ }^{255}$ Based on the reference to the PCT contained in Article 6.1 of the WIPO administered PLT, the proposed amendment to the PCT would also apply to the PI.T. If made effective, these proposals would enable the national patent legislation to require patent applicants to declare the source of genetic resources and TK in patent applications, if an invention is directly based on these resources or this knowledge. The proposals would also grant applicants the possibility of satisfying this requirement at the time of filing an international patent application, or later during the international phase. The declaration of source would be included in the publication of the intemational patent application in order to render it accessible to the public at the earliest possible stage. ${ }^{28 n}$ In contrast, according to the Swiss, any amendment of the TRIPS Agreement would not apply to international patent applications, and would thus not bring the same results as an amendment to the PCT. Moreover, Switzerland believes that the relevant TRIPS Agreement provisions (e.g. Articles 27.1, 29.1 and 62.1) provide for adequate flexibility regarding source disclosure requirements, so there is no need to amend the TRIPS Agreement. In addition it believes that it will take considerably more time to alter the TRIPS Agreement then amending the PCT regulations. ${ }^{25}$ An amendment of the TRIPS Agreement is also politically sensitive and difficulty, in the context of the Doha negotiations.

26.3 Communication from Switzerland to the TRIPS Council, IP/C/W/400 of $28 \mathrm{May}$ 2003, IP/C/W/423 of 14 June $2004, \mathrm{IP} / \mathrm{C} / \mathrm{W} / 433$ of 25 November $2004, \mathrm{IP} / \mathrm{C} /$ W466, 30 May 2006; WIPO GRTKF/IC/11/10,6 June 2006.

2 is Ibid., and sec Addor 2005.

2s: Proposed Rule 51 bis 1 (g) of the PCT.

2ki. See Addor and Girsberger 2005.

24 See Addor and Girsberger 2005. 
Switzerland has opted to "explicitly enable" the national legislator to introduce a disclosure requirement but which does not make this mandatory. In Switzerland's view a mandatory regime would not be in the interest of the developing countries, and it would be difficult to achieve consensus at international level. In addition, it would allow national governments time to get used to the disclosure concept without prejudicing further international efforts. 2 is

According to Switzerland, the proposed disclosure of the source achieves four policy objectives, namely transparency, traceability, technical prior art and mutual trust:

Transparency: with a requirement in mational and international patent applications to disclose the source, the patent system would increase transparency in access and benefit-sharing with regard to genetic resources and TK;

Traceability: disclosing the source in patent applications would allow the providers of genetic resources and $T K$ to keep track of the use of their resources or knowledge in $R \& D$ resulting in patentable inventions;

Technical prior art: disclosing the source of genetic resources and TK in patent applications would assist patent examiners and judges in the establishment of prior art with regard to inventions that somehow relate to these resources or this knowledge. In particular, it may facilitate the establishment of prior public use as well as the finding of lack of novelty or inventive step, as was the case with the so-called "neem tree oil" patent (European Patent 0436 257). This applies in particular to prior art regarding 'TK, as disclosing the source would simplify the search of TK databases that are increasingly being established at the local, regional and national level;

Mutual trust: the disclosure of the source would increase mutual trust among the various stakeholders involved in access and benefit-sharing, including among developing and developed countries, indigenous and local communities, and private companies and research institutions. All of these stakeholders may be providers and/or users of genetic resources and TK. Accordingly, disclosing the source would build mutual trust in the North-South relationship. Moreover, it would strengthen the mutual supportiveness between the access and benefit-sharing system and the patent system. ${ }^{269}$

\section{Scope and Legal Effect at the International Lewel}

Article 49 a of the Draft Swiss Federal Patent Law states that:

"For inventions based on genetic resources or traditional knowledge the patent application must contain information concerning the source: a) of the genetic

2.w. See Addor and Girsberger 2005.

2sin See Addor and Girsberger 2005. 
resource to which the inventor or the applicant had access, when the invention is based directly on that resource; $b$ ) of the traditional knowledge of indigenous or local communities related to the genetic resources to which the inventor or applicant had aceess, when the invention is based directly on that knowledge.

If the source is not known to either the inventor or the applicant, the applicant must confirm this in writing".

Switzerland has repeatedly expressed that it is not a demamtem of a disclosure of origin requirement in patent applications, but that it has submitted supportive proposals because it is interested both in balanced patent protection (for biotechnological inventions) in the interest of all involved, and in finding solutions that take account of the various other interests at stake. ${ }^{291}$ The Draft Swiss Federal Patent Act has received its approval from parliament, and it is now up to the Swiss Federal Council (the executive body) to determine when the revised law will come into force. This is expected to be in the summer of 2008 . Once the new patent act comes into force, the disclosure of source requirement will become part of the formal administrative obligations that need to be complied with before a patent application can be processed. Article 81a of the Draft Swiss Federal Patent Act provides that an applicant can state it does not know where the genetic material originates from. If, however, it later becomes clear that the applicant has lied about this lack of knowledge, the patent will not be invalidated. But fines are foreseen under criminal law (ex officio offence) that can be quite severe, up to 100,000 Swiss Francs for intentionally withholding essential information. A further sanction is the publication of the court ruling, condemning the patent applicant for making an intentionally false declaration about the source of the biological material used.

Applicants have the possibility of satisfying this requirement at the time of filing an international patent application or later during the international phase. In case an international patent application does not contain the required declaration, national law may see that in the national phase the application is not processed any further until the patent applicant has furnished the required declaration.

In relation to the terminology used, Switzerland has chosen to refer to disclosure of "source" instead of "origin". The reason behind this terminology is that in Switzerland's view "origin" is too limited, as most of the genetic resources are derived from ex situ sources, such as botanical gardens, gene banks or databases. In the view of Switzerland, "source" goes beyond "origin"

2w Switzerland is not part of the group of mega diverse countries (CBD working group) also referred to as the demantims of a disclosure requirement. The demandewrs propose a mandatory requirement, whereas Switzerland would explicitly enable the national legislator to introduce the disclosure requirement at the national level.

291 Ser Addor 2005. 
as it comprises not only the country of origin but in addition communities or regions within the country. The reference to "source" as opposed to "origin" enhances the interests of particular indigenous communities or regions within a particular country or region. The Swiss proposals deliberately use the terms "genetic resources" and "traditional knowledge related to genetic resources" to ensure consistency with the CBD, the Bonn Guidelines and the International lreaty. It explains that source should be understood in its broadest sense referring to genetic resources and associated TK. The Swiss amendment does not deal with the issues of access and benefit-sharing or PIC, which in its view are important questions currently under discussion within the CBD. Switzerland believes the disclosure of source requirement would function as a "gatekeeper" in order for PIC/ABS to work. Switzerland believes that benefitsharing is an element that should be addressed later in the process - after the grant of the patent. Moreover, as most countries do not have domestic ABS systems in place yet, it would be unfeasible and of no added value at this point to ask for adherence to ABS rules in the country of origin/source as part of patent applications. ${ }^{212}$ According to Switzerland, patent authorities are not in a position to determine whether the sharing of benefits is "fair and equitable". Moreover, at the time of filing patent applications, no monetary benefits have yet arisen, and the commercial success of the invention is generally unknown hence making it very difficult for patent applicants to provide the required evidence of "fair and equitable" benefit-sharing when filing a patent application..$^{293}$ However, Switzerland emphasises that its proposal on disclosure of source would allow parties to contract on access and benefit-sharing and to verify whether the other contracting party is complying with its obligations.

Under Swiss proposals, it would be mandatory for patent applicants to disclose the source at the national level (e.g. in Switzerland itself) and non-compliance would lead to sanctions currently allowed under the PCT and the PLT, as well as sanctions outside of the patent system. Notably, through reference, the proposals would also apply to the PLT and thus to national and regional patent applications.

In contrast, the Directive 98/44/EC on the Legal Protection of Biotechnological Inventions (Biotech Directive) ${ }^{29.4}$ refers to disclosure of origin which does not

242 Examples of countries that have detailed domestic or regional rules on ABS in place are the Andean Community and India. See, for instance, Sagar 2005, p. 383-4(00. Sagar points out that the Indian Act makes substantial differentiation between people and organisations of Indian origin and foreign nationals and organisations, as the duties and procedures for foreigners are more onerous as compared to those applied to Indians. This differentiation is most notable in obtaining the following aspects: access to biological resources, research activities and benefit-sharing.

213 See Addor and Girsberger 2005.

zot See EC Directive 98/44/EC, [1998] O] L213/13 (EC Biotech Directive). 
necessarily refer to the pre-existing rights that holders of traditional knowledge might have over the genetic resources. The Swiss draft amendment is more comprchensive than the Biotech Directive. Firstly, it requires disclosure not only of resources related to plant and animals but also to micro-organisms, plus disclosure of traditional knowledge of indigenous and local communities associated with the inventions. Secondly, it states that lack of declaration of source can result in the non-granting of the patent. Thirdly, an intentionally erroneous declaration, known to the inventor or patent applicant, is subject to criminal sanctions. ${ }^{205}$

In its I'CI submissions, Switzerland has proposed to establish some sort of notification system to facilitate the transparency of the patent system and to trace genetic resources (this is not part of the draft revised Swiss patent law). This would imply that the IP institute (authority receiving the patent applications) would inform/notify the competent authority in the country of source about the received patent application and its specificities. In order for this process to work efficiently, countries of source would need to identify focal points in their territories to deal with these matters, which is a rather standard approach in many international environmental treaties, and, hence, feasible.

\subsubsection{Draft Article 29lis Proposal by a Group of Developing Countries Led by Brazil}

In May 2006, Brazil, India, Pakistan, Peru, Thailand and Tanzania submitted a draft text ${ }^{2 \%}$ to the WIO to speed up negotiations on the disclosure of origin. This proposal is now co-sponsored by China, Colombia, Cuba, Ecuador, Paraguay, South Africa, Venezuela, the WTO African Group and the WTO LDC Group. This potential addition of a disclosure of origin requirement to multilateral trade rules has been championed by Peru, ${ }^{217}$ one of the most vocal critics of the misappropriation of biological resources and $T K$ through patents without adequate recompense ("bio-piracy"). The Peruvian delegation presented to the TRIPS Council a document on the country's experience with "bad" patents - those that failed to involve proof of consent or benefit-sharing. The delegation reiterated that a formal TRIPS amendment was necessary to combat bio-piracy:

245 See Bridges Trade Biokes 2007c.

2un Communication from Brazil, India, Pakistan, Peru, Thailand and Tanzania, "Doha Work Programme - The Outstanding Implementation Issue on the Relationship between the TRIPS Agreement and the Convention on Biological Diversity", $\mathrm{WT} / \mathrm{GC} / \mathrm{W} / 564$ and TN/C/W/41, 31 May 2006.

2w: Communication from Peru, "Analy'sis of Potential Cases of Biopiracy", $[\mathrm{P} / \mathrm{C} / \mathrm{W} /$ 458, 7 November 2005, WTO document IP/C/W/458. 


\begin{abstract}
"The patent system works only if the rights of those who made the invention possible are acknowledged. The system does not work (or at least does not work as it should) if it acknowledges only the rights of those who have achieved an invention using the materials developed by others, thereby infringing their rights. There is an urgent need to rethink the patent system and to consider how to make it more balanced". 2"w
\end{abstract}

The session of the TRIPS Council on 23-24 October 2007 also saw the group of 32 LDCs support a proposal to amend TRIPS so as to require patent applicants to disclose the origin of genetic resources or TK used in their inventions. The African Group had already done this earlier the same year. The addition of both of these groups creates a supermajority of countries supporting the proposal. The issue of disclosure is of crucial interest to LDCs, as they want crossborder misappropriation of biological resources to end, and in their view an international disclosure of origin requirement is the only way to ensure transparent and fair tracking of the use and misuse of LDC biological resources and associated $T \mathrm{~K}$. In addition, an intemational disclosure of origin is necessary to enable the proper functioning and enforcement of national $\triangle B S$ systems. The L.DC group seeks not only to prevent misappropriation, but wishes to relaim the resomres so that the rightful owners of biological resources and associated TK can exercise their rights - introducing a CBD plus measure. ${ }^{24}$ The LDC Group indicated that they might want to discuss a possible trade-off between disclosure and $G$ extension/register. This is something that has been proposed informally also by Brazil.

The proposed Article 29bis entitled "Disclosure of Origin of Biological Resources and/or Associated "raditional Knowledge" sets out that:

"[w]here the subject matter of a patent application concerns, is derived from or developed with biological resources and/or associated traditional knowledge, Members shall require applicants to disclose the country providing the resources and/or associated traditional knowledge, from whom in the providing country they were obtained, and, as known after reasonable inquiry, the country of origin. Members shall also require that applicants provide information including evidence of compliance with the applicable legal requirements in the prosiding country for prior informed consent for access and fair and

204 Document submilted by Peru to the eleventh session of the Intergovernmental Committee on Intellectual Property and Genetic Resources, Traditional Knowledge and Folklore "Combating Biopiracy - The Peruvian Experience", WIPO/GRTKF/ IC/11/13, 9 July 2007.

2 (w) Other countries, including Switzerland, think that the law should not be retroactive. Interview conducted with Martin Girsberger by the author, February 2008. 
equitable bencfit-sharing arising from the commercial or other utilisation of such resources and/or associated traditional knowledge". im

The article proposes that this information should be published jointly with the application or grant of the patent.

The proposed text requires that countries provide the legal and administrative means to stop the application for or the grant of a patent and to revoke the patent if the disclosure requirement has not been complied with. ${ }^{311}$ This implies that developing countries have chosen a mandatory disclosure of origin. However, it provides some flexibility as to the legal effect of non-compliance, as it is left to the country in question to decide how to act in cases of noncompliance. The legal and administrative means to act should be available, but it does not set out that a country must act on them.

\subsubsection{Japan}

Japan believes that the CBD and the patent system are not in conflict. ${ }^{312}$ In Japan's view the treaties have different objectives - the protection of IPRs and the conservation of biological diversity - therefore the objectives, content and subject matter of the CBD differ from treaties relating to IP. In its view, the patent system ma complement the CBD in facilitating the benefit-sharing or technological transfer specified in the CBD. Japan does not support the addition of new obligations to the TRIPS Agreement, such as disclosure requirements, as proposed by Brazil and others. Japan would leave it to countries' discretion to decide whether to incorporate disclosure of origin requirements.

3m Communication from Brazil, India, Pakistan, Peru, Thailand and Tanzania, "Doha Work Programme - The Outstanding Implementation Issue on the Relationship between the TRIPS Agreement and the Convention on Biological Diversity", WT/GC/W/564 and TN/C/W/41, 31 May 2006.

3a1 Members need to put in place enforcement mechanisms to ensure compliance. In particular, Members "shall ensure that administrative and/or judicial authorities have the authority to prevent the further processing of an application or the grant of a patent and to revoke, subject to the provisions of Art. 32 of this Agreement, or render unenforceable a patent when the applicant has, knowingly or with reasonable grounds to know, failed to comply with the obligations in paragraphs 2 and 3 of this article or provided false or fraudulent information". See proposed Art. $29 \mathrm{bis}$ (3).

312 Communication to the TRIPS Council by Japan, WTO document $I P / C / W / 472,13$ June 2006. This document is taken from an annex to a document at the 9:h session of IGC in April 2006. Japan bases that decision on Art. 22.1 CBD that reads: "The provisions of this Convention shall not affect the rights and obligations of any Contracting Party deriving from any existing international agreement, except where the exercise of those rights and obligations would cause a serious damage or threat to biological diversity". 
Japan submitted a proposal for the creation of (worldwide accessible) restricted-access databases that would enable patent examiners to determine whether inventions used TK or genetic resources, and could thus avoid erroneously granting patents. ${ }^{3113}$ The paper, which was identical to the one Japan had already submitted to WIPO, urged WTO Members to consider the work being done on this at WIPO. Japan does not accept that

\begin{abstract}
"the risk of erroneously granted patents is reduced by disclosing the country of origin/ providing country/source, evidence of prior informed consent, and evidence of benefit-sharing in patent applications, because such disclosure provides additional information which patent examiners can use when they conduct prior art search". int
\end{abstract}

This rejection is because Japan believes that country of origin evidence of I'IC and benefit sharing are irrelevant to the judgement of novelty and inventive step. Japan rejects this because it believes that evidence of PIC and benefitsharing are irrelevant to the judgement of novelty and inventive steps. In its view "even if a genetic resource collected in a specific place has its own specific characteristics, this does not sufficiently explain the necessity of imposing the new obligations of disclosure". Japan, along with the US, wants discussion of these issues to take place within the WIPO IGC, rather than in the TRIPS Council. 305

\title{
5.2.3.7. The US
}

The US does not see any conflict between the CBD and TRIPS. ${ }^{3116}$ It notes that the $C B D$ does not require or discuss patent disclosure requirements, and points out that it is not a contracting party to the CBD. In the view of the US:

"li]t is not the lack of safeguards in TRIPS, but lack of clearly defined national sy'stems directly regulating the use of genetic resources that creates "erroneous" treatment of relevant sources. The national ABS systems are directed to the goals of providing appropriate access and equitable benefit-sharing. And a searchable database with disclosed information and a post-grant opposition/re-examination procedure will handle bad patents. The most appropriate solution for any

30.3 Communication from Japan, WTO document IP/C/W/504, 17 October 2007.

See "The Patent System and Genetic Resources", Document submitted by Japan, WIPO/GRTKF/IC/9/13, 20 April 2006. The document WIPO/GRTKF/IC/9/13 was submitted to the TRIPS Council as document IP/C/W/472, dated 13 june 2006. See Bridges Trade Biokes 2004a.

3it Communications from the United States on "Article 27.3(B), Relationship between the TRIPS Agreement and the CBD, and the Protection of Traditional Knowledge and Folklore", IP/C/W/434, 26 November 2004 and IP/C/W/449, 10 June 2005, and $I P / C / W / 469,13$ March 2006. 
kind of misappropriation is to strengthen national regimes. Palenting in and of itsclf does not amount to misappropriation". 37

Hence the US does not believe that a disclosure requirement would establish certainty in the patent system. It does not regard the patent system to be in crisis: although overloaded, the system works well. According to the US, a national $A B S$ system must be established in a majority of the member states before supplementary requirements can be developed. In its view, any attempt to single out applications involving genetic material or based on TK and deal with them through a new patent disclosure requirement may negatively affect technological development. According to the US, it would be more appropriate to strengthen a comprehensive and holistic national regime outside the patent system to address the effect of commercialisation on TK. Further, the US holds that additional disclosure requirements would violate the principle within T'RIIS of non-discrimination between fields of technology. ${ }^{3118}$ The LS believes the IC,C to be the most appropriate forum to discuss these matters.

The US argues that although the TRIPS Agreement does not include provisions to protect genetic resources from misappropriation and theft, such an absence does not indicate that there is a conflict between the CBD and TRIPS. ${ }^{3(4)}$ The US believes those acts fall outside the purview of the TRIPS Agreement, and argues that countries should focus on establishing their own ABS regimes, including provisions on PIC. It argues that bio piracy should be prevented with the help of a "searchable, organised database, disclosure of information material to patentability and the use of post-grant opposition and/or reexamination systems as an alternative to litigation". Other countries also opposing an amendment to the TRIPS Agreement on this issue are Korea and Canada. Some countries (including New Zealand and Canada) responded that it was too early to discuss these issues or they were of the opinion that the TRIPS Council was not the appropriate place to discuss issues like bio piracy and disclosure of origin requirements, and found WIPO a more suitable place to pursue these discussions.

3i: Communication by the US to the TRIPS Council, WTO document IP/C/W/469, 13 March 2006.

wix Communication by the US to the TRIPS Council, WTO document $I P / C / W / 40,3,28$ May 2003, paras. 10-11.

Sin Communication by the US to the TRIPS Council, WTO document IP/C/W/469, 13 March 2006. 
As indicated above, other countries counter the US arguments by referring to Article 16.5 CBD, which obliges countries to cooperate to ensure IPRs do not compromise the objectives of the CBD. ${ }^{310}$

\subsection{Is a Disclosure of Origin the Solution?}

Some countries have high expectations about the introduction of a disclosure of origin requirement. But can the introduction of a disclosure requirement realise its potential in putting a halt to the misappropriation of genetic resources and associated IK? The introduction of a disclosure of origin requirement certainly brings about many practical problems. For instance, even an operational disclosure requirement will not change the fact that so many resources and IKK relevant to an invention being patented can be acquired or learned without visiting any of the countries of origin or source. Thus the measure will only be applicable to a small number of patents. It is therefore questionable if a disclosure requirement will improve patent quality, and put a halt to the misappropriation of genetic resources (biodiversity). In addition, the important question remains as to what extent the genetic resources and/or associated TK contribute to the patent. In many cases, knowledge, information and material relevant to an invention are manifold. Hence, various sources and material may have contributed to the ultimate invention. In that case, is it feasible to ask whether all sources of knowledge and material should be remunerated, no matter how far-flung and peripheral to the invention? This brings with it the additional difficulty of tracing all countries of origin. Indeed, how would one deal with several countries that could all legitimately claim to be countries of origin of the same resource? ${ }^{311} \mathrm{~A}$ solution to this problem could be found in the establishment of community funds. ${ }^{312}$

311 Art. 16.5 CBD reads "The Contracting Parties, recognising that patents and other intellectual property rights may have an influence on the implementation of this Convention, shall cooperate in this regard subject to national legislation and international law in order to ensure that such rights are supportive of and do not run counter to its objectives".

i1 The legal ownership of genetic resources can be in many different hands because of wide diffusion through the course of history. Most of the genetic resources used in beeding currently commercialised varieties were almost all obtained before the CBD came into forces, when the free exchange of such resources was customary. Increases in trade and globalisation has made the world a smaller place and genetic resources that used to be found only in a particular geographical areas may now be widely available from many countries through common trate channels. See Dutfiedd 2005.

312 For example, under Peruvian law in order to access genetic material for the purposes of commercial or industrial application a license agreement must be signed ensuring that due reward for the access and the equitable distribution of the benefits 
It is estimated that the ammal market for products derived from genetic resources is between US $\$ 500$ billion and US $\$ 800$ billion. This figure is based on statistics from the following sectors which depend in varying degrees on biogenetic resources, namely pharmaceuticals, botanical medicines, agricultural produce (including agricultural seed), omamental horticultural products, crop protection products, biotechnologies in fields other than healthoare and agriculture, and personal care and cosmetics products. ${ }^{313}$ Of these, the pharmaceutical and agricultural seed sectors are the most dependent on biogenetic resources.

But one caveat applies: although it is clear that industry depended heavily on biogenetic resources and $\mathrm{T} K \mathrm{~K}$ in the past, this does not necessarily mean that in the future they will equally depend on resources and knowledge that are currently undiscovered. ${ }^{31-4}$

\footnotetext{
"The failure of Shaman Pharmaceuticals, which sought to develop new drugs from etho-botanical information provided by indigenous communities, is sometimes cited to demonstrate that traditional knowledge provides no shortcuts for the industry in its costly search for profitable new cures". 315
}

Kate and Laird argue that "natural products are likely to remain an important, although minor, component of drug discovery" but that the "techniques of molecular biology and genetic engineering are likely to become the dominating factor in drug, discovery, design and development". 316, However, "TK is widely used, especially in the botanical medicine industry, as the basis for determining safety and efficacy, to develop agronomic practices for the cultivation of materials, and to guide the development of new products. ${ }^{317}$

The International Chamber of Commerce (ICC) believes that it is premature to consider amending the TRIPS Agreement to provide for special disclosure requirements in patent applications. The ICC is of the opinion that:

deriving from it is guaranteed. A percentage of the revenue resulting from the commercialisation and marketing of goods developed on the basis of collective knowledge goes to the Fund of the Development of Indigenous Peoples.

3 See Kate and Laird 1999.

it The WIPO 2008 Report shows that in 2005 there was a modest increase in pharmaceuticals filings (1.7 per cent) but a decrease in biotechnology filings $(-2.7$ per cent). See WIPO World Patent Report A Statistical Review, 2008 Edition.

315 See Queen Mary IP Research Institute 2004.

31e See Kate and Laird 1999, p. 57.

3: See Kate and Laird 1999. 
"patent disclosure proposals should take into account the broader context of access and benefit-sharing and the specific implications of such proposals for the patent system and innovation". 318

With certainty, one can deduce that the disclosure requirement would provide only part of the solution to ensure that patents are granted in such a way that they further key objectives for the conservation of biological diversity, sustainable use of its components and the achievement of social equity.

\subsection{Conclusion}

In the past decade, the misappropriation of genetic resources and TK has emerged as an important issue of global concern, and has been addressed in a number of international fora such as the CBD, the WTO and WIPO. National proposals, academic literature, as well as civil society organisations, provide for the building blocks of an effective disclosure mechanism, i.e. which addresses concerns over misappropriation and potential burdens on the patent sy'stem.

Whether special patent disclosure requirements are a desirable objective is contentious, however, and key terms are still to be defined. While some countries strongly support these requirements, others vigorously contest them in all multilateral fora addressing the issue, arguing that a disclosure of origin requirement will not advance the aims of $A B S$. However, recent TRIPS Council meetings have show'n a tendency to start fact-based dialogues, and a willingness to continue technical discussions.

The US and Japan are sceptical of claims that a mandatory disclosure requirement in the TRIPS Agreement is necessary. They argue that bio-piracy should be addressed by other means. ${ }^{314}$ Both countries favour government databases (documenting TK, to help avoid bio-piracy), as opposed to patent applicants taking responsibility for the disclosure of the use of biological resources and TK.

The EU and Switzerland support the introduction of some form of a disclosure requirement, but have expressed concerns over the introduction of a mandatory requirement and the legal consequences of non-compliance. Both countries prefer WIPO to be the appropriate platform to deal with these issues. There are some developing countries (including Chile) that have not yet joined the Article 29 his proposal for fear of parallel developments on geographical

ils "TRIPS Should Not be Re-opened to Mandate Special Disclosure Requirements. In Patent Applications", Prepared by the Commission on Intellectual Property and the Commission on Biosociety, International Chamber of Commerce, 19 October 2005. si" Ibid. 
indications. Norway agrees with the mandatory mature of the requirement, but does not support the revocation of the patent as a sanction for non-compliance.

Because the developing countries and the US are so divided on the topic, the EC might act as a bridge-maker between the two in resolving the question of whether a requirement should be introduced in the TRIPS Agreement. Meanwhile, Brazil and the LDCs believe that governments should consider potential trade-offs between geographical indications (multilateral register for wines and spirits) and disclosure requirements.

A number of recommendations follow that could direct the debate in a positive direction.

First, countries should be allowed ample time to develop their own policies, and enact domestic legislation that is supportive of IP protection and CBD objectives, including a detailed disclosure mechanism. It is important that the issues are well considered before any renegotiation of TRIPS. This includes the development of national systems of disclosure and access, and benefit-sharing agreements. An established domestic administrative and legal regime, supportive of $A B S$ of genetic resources, will strengthen international claims and proposals for such a regime, including the disclosure of origin. It is important that countries that have not done so already, in particular most developing countries set in motion processes to create ABS rules, including a disclosure of origin requirement implemented in their domestic legislation. Arguably, an increasing number of significant bio-rich developing countries have adopted domestic legislation to that effect, see e.g. India, the Andean countries, ARIPO and OAPI and Brazil.

Second, it is best that countries should actively participate in FAO, WHO, CBD and other fora aimed at establishing an ABS regime for national and international applications.

Third, the impact of special patent disclosure requirements, already introduced in national law's on the use of bio-prospecting and ABS, is worth studying, as is the extent to which patent applicants already provide source information in their applications when it is materially relevant to the application.

Fourth, more solid consensus should be achieved in international fora on what the disclosure requirement should look like, and how it should work in practice, e.g. its scope, nature, key elements and objectives. This requires the commissioning of more technical work to facilitate this process.

The majority of developing countries and I.DCs favour an amendment of the TRIPS Agreement to introduce a disclosure requirement in their laws. However, most developed WTO members either oppose such a requirement, or favour WIPO as the competent forum to address this issue. Nonetheless, a 
movement towards some form of a disclosure of origin/source requirement is discernable amongst European countries. As detailed above, Norway, Switzerland and the EC have expressed support for such a requirement both at the national, regional and international level, and have suggested various proposals to realise this in practice.

\section{CONCILSION - SOME CONSIIERATIONS ANI RECOMMENDATIONS}

Over the past decade, the (mis)appropriation of genetic resources and traditional knowledge has emerged as an issue of global concern. Yet gaining international recognition for the need to effectively address the use of genetic resources and associated traditional knowledge in patents and adequately protect traditional knowledge remains a major challenge for developing countries, which hold the majority of the world's genetic resources and traditional knowledge. The WTO Doha Ministerial Declaration (2001) requested the TRIPS Council to address the relationship between the CDB and the WTO TRIISS Agreement. Since then, a debate has ensued over whether the TRIPS Agreement conflicts with the CBD, and whether a disclosure of origin requirement should be introduced into the former. Having ongoing parallel discussions on the protection of traditional knowledge within the WTO TRIPS Council, the WIPO IGC, the FAO International Treaty on Plant Genetic Resources for Food and Agriculture (Seed Treaty), and the CBD raises further questions of coherence between deliberations in these different fora and adds to the complexity of this technical debate. The discussions also reflect the highly political nature of the issue.

The transfer of technology is a topic of fundamental importance for the implementation of the CBD. The CBD does not provide a definition of technology transfer. However, Article 16 of the CBD stipulates that "access to and transfer of technology among Contracting Parties are essential elements for the attainment of the objectives of this Convention", Moreover, the CBD sets out that technologies "are relevant to the conservation and sustainable use of biological diversity or make use of genetic resources and do not cause significant damage to the environment". However, it is unclear how the provisions of the CBD are materialised and implemented in practice. Further research is required as to how the objectives of the $C B D$ are implemented at the local level. More information is available on the sharing of environmentally sound (friendly) technologies. For instance study has shown that activities are undertaken to introduce wind power in India and China, high efficiency 
boilers in China, solar water heaters in Morocco, energy efficient building technologies in West Africa, energy efficient lighting in Poland. ${ }^{201}$

The CBD sets out that benefits that arise from the use of the genetic resources must be shared on mutually agreed terms. This brings with it the difficulty to identify the relevant stakeholders involved. As often remarked benefits are not only understood in commercial terms but participation in research are also considered benefits. As a consequence, developing countries that provide access to genetic resources must in turn be given access to the technologies needed to make use of these resources, even where such technology is subject to patents and other intellectual property rights. However, many issues remain unresolved, for instance, it is still unclear who is to be given such access. Indigenous communities, represented by their spoke persons have been very active in the negotiation process (TRIPS Council, CBD Working groups and IGC), but in the end, decisions will be made by the national governments (states).

In 2001, the CBD ABS working group, produced a set of voluntary guidelines for "establishing legislative, administrative and policy measures on $A B S^{\prime}$. These non-binding provisions are called the "Bonn Guidelines". In 2002 (26 August-4 September) at the World Summit on Sustainable Development (WSSD) in Johannesburg, participating countries lifted ABS to a matter for international resolution. They agreed to negotiate "an international regime to promote and safeguard the fair and equitable sharing of benefits arising out of the utilisation of genetic resources".\$21

The CBD Contracting Parties gave themselves until 2010 to comply with the WSSD mandate; but to date, very little progress has been made. For the most part, the parties have lined up along the same North-South divide that existed in 1992. On the one hand developed-country Contracting Parties are leaning toward a non-binding regime, emphasising the principles of intellectualproperty and contract. Developing country Contracting Parties, on the other hand, stress that the regime consist of a legally-binding internationally agreed protocol, which includes provision for a comprehensive monitoring system. ${ }^{322}$

Difficulty is that in the ABS negotiations in the ABS Working Group and also within the WIPO IGC much more is at stake than resolving benefit sharing in terms of money and influence between sovereign states. Key issues addressed within the negotiations are: 1) the rights of indigenous peoples over genetic

321) See "Ten Cases of Technology Transfer", Global Environment Facility (CEF). June 2000. C.FF is the financial mechanism of the UN Framework Convention on Climate Change.

321 See information retrieved from the website: <http://www.un.org/events/wssd/>.

322 Ibid. 
material and associated knowledge sourced from their traditional lands (i.e. the CBD talks about sovereign rights of States and thereby neglecting indigenous peoples interest); 2) the question of whether genetic resources and associated traditional knowledge can be patented and thus privately owned; and 3) the practicality of developing a global framework for regulating access to genetic resources and benefit sharing, taking into account different categories of genetic resources with different uses.

As per point 3) it is difficult to trace the true origin of genetic resources and to monitor their trajectory from source to ultimate utilisation. This requires a high level of technical sophistication and coordination and hence is not easy to implement. It remains to be seen whether a regulatory regime that must define at a given point in time its nature, scope and objectives can be flexible enough to keep up with the rapidity of technological change.

The search for new pharmaceutical, biotechnological or agricultural applications based on genetic resources has emerged over the last decades and subsequently intellectual property rights (IPRs) have been applied to protect innovations based on genetic resources. The patenting of biogenetic resources have caused much tumult at multilateral for in part because of the (perceived) potential for exploitation of biogenetic resources for biotechnology as well as for neglecting the contribution of indigenous communities to the identification of the therapeutic properties of native plants. As a consequence, interest in the protection of traditional knowledge (TK) has grown significantly over the last two decades. ${ }^{333}$ Concerns are not only of an economic nature but more frequently address respect for traditions and local cultural, sovereignty over their bio genetic resources and associated TK. For instance, the Maori group, the Hokotehi Moriori Trust says that the use of their particular symbols and names is an offensive to their spiritual believes. In addition, the Indigenous Peoples Council on Bio colonialism ${ }^{324}$ has frequently expressed that it should be left to the indigenous communities sovereignty whether or not they exploit their genetic resources and associated $T K$ and folklore. They advocate the right of self determination and sovereignty. For instance, in many cases the commercialisation is goes against believes of indigenous communities and is an offensive to their integrity.

23 For the history and origin underlying the search for TK protection see RAFI Communique 1994b and Green College Centre for Environmental Policy and Understanding 1993.

32t "Biocolonialism" stands for the extension of the forces of colonisation to the biological resources that Indigenous peoples have nurtured over millemia. As expressed by By Le'a Malia Kanche, legal advisor for the Indigenous Peoples Council on Biocolonialim. 
Solutions could be found within the framework of either positive forms of protection or defensive mechanisms, and may lie within or beyond IPR regimes.

The protection of TK within a multilateral framework would give the legal possibility of asserting rights outside the domestic territory and would show recognition of TK within the international community. The inclusion of discussions on the protection of T'K within the framework of the WTO TRIPS Council, the WIPO IGC and the CBD committees has made the protection of TK a political matter, as policy-makers need to balance the expected benefits of introducing international TK protection against their costs. Indigenous communities, with the help of NCOS and scholars, are gradually reaching a greater audience to help express the concerns of the indigenous peoples. However, they are facing a difficult task to see some of their interests reflected in the TRIPS Agreement. It is, therefore, unlikely that in the near future any spectacular results will be achieved, as implementing the WTO "Doha Round" of negotiations has proved cumbersome.

In finding an international legal framework for TK protection a distinction can be made between the defensive protection and positive protection of traditional knowledge. Defensive protection primarily concerns the prevention of bio piracy through misappropriation (grant of patents), misuse or illegal access. Examples of defensive protection mechanisms are the use of TK databases and registers (documentation), the obligation to disclose the origin of genetic resources, and the prevention of misappropriation. Positive measures of TK protection relates to the active assertion of rights and to prevent undesirable use of TK (prevent others from using this material).

TK positive protection measures focus on the promotion and protection of TK in a rights-based recognition system, i.e. by recognising and granting economic or moral rights. This can be achieved via the application of existing IPRs, or by the development of suigeneris forms.

In order to combat the misappropriation of their resources and to minimise the granting of erroneous patents, several countries and regions apply disclosure of origin measures for patent applications for inventions derived from genetic resources at the national level. Here, there are two separate but related issues: the disclosure of origin certificate, and the disclosure requirement. A certificate of origin would serve as a type of passport or permit that would accompany the genetic resource along the whole chain of the access and benefit sharing (ABS) process. It could be verified at various points, particularly once the said resource left the provider country, ensuring the traceability of the genetic resources. A certificate of origin would be a practical way to implement the disclosure of origin requirement, but it would not have the same legal consequences as an official amendment to the TRIPS Agreement, making it a much looser and less effective measure. In contrast, an amendment incorporating a disclosure of origin requirement would strengthen implementation and enforcement significantly as it would be linked to the WTO dispute settlement system. It would strengthen the process of verifying whether genetic resources 
were collected in accordance with national rules requiring consent, and whether the conditions for such consent were met. A disclosure of origin requirement has the potential to function as a bridge between national and international legislation as well as between the providers and users of resources to monitor trade and movement of resources in endeavours to protect and promote TK. However, to date, there is no agreement as to the form of an ideal disclosure of origin requirement, the necessity of such a regime, its form, objectives, and whether it should be adopted within the framework of WTO, CBD or WIPO. Views vary as to the legal effect and practical consequences, whether disclosure should be mandatory or voluntary; and whether its materialisation could lead to an additional requirement to patentability, or if the requirement could be inserted as part of the grant/administrative procedure. Proposals have also included various options as to the consequences of non-compliance from revocation of the patent to sanctions outside the patent system. Further, practical problems may arise in the implementation of a disclosure of origin requirement. How will national regimes be brought into compliance on prior informed consent and $A B S$ on mutually agreed terms? How can patent officers be trained to deal with patentability issues in this area? Is it feasible to ask that all sources of knowledge and material be remunerated, no matter how minor and peripheral to the invention? This brings with it the additional difficulty of tracing all countries of origin. Indeed, how would one deal with several nations that could all legitimately claim to be countries of origin of the same resource? In addition, a disclosure requirement will not change the fact that so many resources and TK relevant to a patented invention can be acquired or learned without visiting any of the countries of origin or source. It follows that the measure will only be applicable to a small number of inventions. A disclosure requirement, in the end, is only part of the solution to ensure that patents are granted in such a way that the invention furthers key objectives for the conservation of biological diversity, sustainable use of its components, and the achievement of social equity.

Another issue to take into consideration is the possibility that, the pharmaceutical and agricultural seed industries will not depend heavily on biogenetic resources and TK in the future, this does not mean that they will equally rely on such resources and knowledge in the future. Arguably, molecular biology and genetic engineering technologies will overtake natural products in drug, discovery, design, and development activities. At the same, TK is widely used, especially in the botanical medicine industry, as the basis for determining safety and efficacy, to develop agronomic practices for the cultivation of materials, and to guide the development of new products. Studies have shown that the majority of the population in developing countries relies on traditional medicine for their primary needs and TK is the primary means for securing their health, food, clothing, and housing.

IPRs, as a legal tool to protect TK, may be appropriate and efficient under certain circumstances, but inadequate or ineffective in others. Therefore, one should be careful not to rush into a (new) (legal) protection regime. It is in the 
countries' interest to examine whether or not it is beneficial to their domestic interests and needs. Moreover, ample time should be provided to create an understanding of differences in culture and respect for knowledge differently developed and captured than in the Westem custom prevalent in II' concepts. llowever, time is running against developing countries and some developed countries such as the US woukd be more than happy to grant such time; hence a status quo should be avoided. Developing countries can benefit profoundly from smart drafting of their IP policies. A moratorium on adopting stronger IPRs would be advisable. Instead developing countries should explore options such as open and collaborative projects, which can guarantee better access to information in certain fields, as has been demonstrated by the potato project in Peru. Moreover, focusing on the possible legal modes of protection should not disregard other relevant topics, such as access to land and the preservation of the communities' lifestyles, since these are prerequisites for the conservation, promotion and further development of traditional knowledge. ${ }^{325}$

As shown, there are many different ways of protecting $T K$ and little agreement on what an international TK protection regime should look like. Opinions differ on what are the objectives of a regime of TK protection. Arguably, there are three key elements: 1) control over the use of knowledge; 2) compensation for its use, and; 3) and maintenance of TK.23. Arguably, a certificate of origin has the potential to function as a bridge between national and international juristictions as well as between the providers and users of resources to monitor trade and movement of resources. ${ }^{32}$ It might be too early for an international standard setting effort, and for the time being the solution might be to focus on a "misappropriation regime". Arguably, "defensive protection" is the most effective and feasible path to follow because such measures are "basically enhancements to or modifications of existing IJ'R".32n On the other hand, positive protection measures demand the establishment of new rules which will be hard to accomplish since their success depends on the willingness and participation of the governments. Some scholars have been creative in finding solutions to the difficulties in protecting TK and propose to alter the definition of IPR. For instance, Yinliang Liu introduces the concept of "new TK" in order to break the deadlock over whether or not TK should be subject to IPR

32: The Lnited Nations Permanent Forum on Indigenous Issues supports the recognition of customary law in the development of an international legal sy'stem, in particular when I'IC concepts are addressed. See WIPO ICG Report of the Sixth Session, WIPO document WIPO/GRTKT/IC/6/14, April 14 2004, para. 20.

3in See Ruiz 2003, p. 244.

32: See Tobin 1997, and Louafi and Tobin 2005.

i2: See Dutfield 2003, p. 27. 
protection. 32" By this definition, TK does not automatically have to be "old and inferior", but can also be "new and productive".,3.1

The CBD has shown great potential for providing a platform for public discourse in which NGOs (including those representing indigenous people and communities) have a voice in negotiations, even though their decisions and proposals are not legally binding. Nevertheless, the adoption off the convention and the ongoing work within the countries demonstrates the commitment of the contracting parties, which may prove valuable in future negotiations in other forums. However, the CBD is a framework agreement, its provisions are written in terms of overall goals and policies than precise rights and obligations which are easy to implement. This raises all kind of questions as how to implement the equitable sharing arrangements and technology transfer. Also the TRIPS Agreement provisions on technology transfer are of a best endeavour nature. However various routes are proposed (in and outside the IPR system) to facilitate equitable sharing of benefits, trough contractual arrangements (private or semi private), access regulation schemes (Seed Treaty), trough using IPRs in particular to introduce an origin requirement within the framework of the TRIPS Agreement. Other possibilities are being discussed within the framework of the IGC with the proposal for the establishment of a suigeneris protection system.

Indigenous rights holders attach great value to TK and folklore, but can the same be said of their governments? It cannot automatically be assumed since often indigenous people are minorities in the countries in which they are located; therefore it is important to support indigenous knowledge groups directly and to enable them to participate in negotiating fora. Although the WIPO Fund for indigenous groups' participation is a good start, WIPO should further increase access for non-governmental stakeholders in the IGC negotiation process. Overall, for the IPR system to work favourably for indigenous peoples it is important to have "smooth connections" with the access regime and, vice versa, a system to protect indigenous peoples' knowledge will have to be connected to the access regime and to the IPR system. ${ }^{33 i}$ One of the lessons to be learned from the Peruvian experience is that consulting indigenous communities and ensuring they participate in the realisation of the law and contractual models will contribute to future support of the law. Only if indigenous peoples feel that they are a part of the dialogue and they have some stake in the system will they support it rather than undermine it. ${ }^{32}$ Hence, the participation of the indigenous peoples through civil society and

32" See liu 2003.

3.30 See Liu 2003, p. 194.

$\therefore$ See Ruiz 2003, p. 245.

$3: 2$ Geoffrey Yu, Former Deputy. Director General of the WIPO, quoted in Coombe 2001, p. 275. 
representative groups needs stimulation. This requires adequate funding and capacity building and the willingness of states to take indigenous people as government delegations to the negotiations (Peru and New Zealand have frequently done this). Moreover, it is necessary not to see TK protection as an end in itself but rather as part of a "wider process to develop a new philosophy to guide the relationship between cultures and with the enviromment based upon mutual respect, reciprocity and responsibility". 33 Hence, the active participation of all parties in the various multilateral fora is crucial to building support and acceptance. IPRs are regarded as public policy tools to increase social, economic and cultural development. At present the system needs to be balanced to take into account all global players, not only the dominant players. It is important to scrutinise customary laws and regulatory systems that apply to TK in local and traditional communities. In addition, attention should be given to the lack of indigenous peoples' understanding of property rights, to the concept of community and the collectivity of creation, innovation and ownership. ${ }^{3+4}$ Moreover, customary laws should be taken into consideration and, importantly, indigenous people should be able to assert their difference as a community.

Both indigenous people, seeking to receive recognition and equitable benefit sharing for the use of their genetic resources, and industry, seeking to appropriate, research and technologically enhance the biological resources, can mutually benefit from the IPR regime. However, without further awareness and recognition by governments and industry of indigenous peoples' contribution through some form of benefit sharing, it might not be possible to enjoy the fruits of that knowledge in the future. ${ }^{3.35}$ Therefore, industry needs to realise the importance of conservation and sustainable development for biodiversity, and be willing to share some of their profits through access and benefit sharing agreements - which could be in the form of technology transfer arrangements - even if these agreements are (for the time being) outside the scope of the TRIPS Agreement/IPR framework. A step forward is the international recognition of the need for enhanced cooperation between TRIPS and the CBD in the Doha Declaration. The interaction and differences between the two different knowledge systems should be acknowledged in the process of establishing a multilateral protection regime. . $^{3 . t}$

3 See Tobin 2004, p. 4.

34 See WIPO document WO/GA/26/6, a communication on "Matters Concerning Intellectual Property and Genetic Resources, Traditional Knowledge and Folklore"

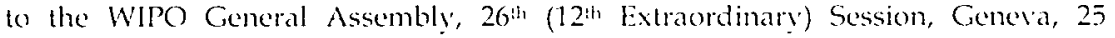
September to 3 October 2000.

$3:$ See Coombe 2001, p. 276.

3in See Gopalakrishnan, Nair and Babu 2007, p. 12. 
Notably, WIPO has recently adopted the WIPO Development Agenda, which incorporates aims relating to TK.

Countries generally agree that the misappropriation of genetic material can have severe conseyuences for indigenous people in terms of economic losses and access restrictions, which could stifle the preservation of culture and biodiversity. An international system of protection would give the legal possibility of asserting rights outside the domestic territory and would also ensure the recognition of $\mathrm{IK}$ within the international community.

Taking the current situation into account, it is arguably most feasible and realistic to focus on protection within the IPR system. In the long term the whole mindset has to be changed. Until perhaps appropriate forms of protection have been established, indigenous people should have access to the existing forms of $\mathrm{IP}^{\mathrm{P}}$ protection. In this context new standards (sui grueris regimes) to protect TK should be developed - for forms of TK not protected by existing IP tools. The ultimate aim is a multilateral framework for TK protection, and the development of a system of "community" or "collective" rights to protect $T K$. There is a great need for information-sharing and capacity-building with regards to existing II'Rs: if indigenous people are informed about the IPR system, they can choose to access it to enforce their rights. Since the development of an international protection regime for TK is a slow process it is important to implement defensive protection mechanisms such as databases documenting TK and to make them available to IP offices that can use them to search for prior art.

Countries advocating the protection of TK should ideally work together to cooperate and act strategically as a group. They could start by agreeing on harmonised standards and apply the principle of reciprocity so that the rules agreed only apply to the members of the union/group. This would provide a good starting point that would allow other countries to follow in due course. Whatever form of protection is adopted, the system should not be too rigid, as developing countries and indigenous groups are so unique, with different needs, customs and traditions, that there should be enough flexibility left to accommodate the traditional and cultural diversity of all involved: a one size fits all approach is not likely to work. It is essential in the negotiation process for countries to include indigenous group representatives within the negotiations. The establishment of the WIPO Fund for indigenous groups' representatives is helping to facilitate their increased participation but it should be emphasised that countries themselves should increase their efforts to include indigenous group representatives in their own delegations.

It is important to start adopting local laws on the protection of TK and avoiding the appropriation of and access to genetic resources without PIC. Of course, such a domestic regime of protection will not have extra-territorial effect and the TK right holders will not be able to secure similar protection abroad, so that exploitative behaviour will not be stopped. However, having 
an effective domestic regime in place will show that TK protection is a matter of serious national concern, which will strengthen the negotiating position at the international level. National efforts also provide insights into the mechanisms and procedures that work well, which will inform and facilitate the establishment of an international regime. In addition, the impact of special patent disclosure requirements, already introduced in national laws on the use of bio-prospecting and $\triangle B S$, should be fully studied, as is the extent to which patent applicants already provide sources of information in their applications when materially relevant. Arguably, an increasing number of significant biorich developing countries have adopted domestic legislation to that effect, see e.g. India, the Andean countries, ARIPO and OAPI and Brazil. Peru indicates that the legal work has been done but that implementation is lacking due to financial constraints and practical problems with enforcement. Moreover, countries should actively participate in FAO, WHO, CBD and other fora aimed at establishing an $A B S$ regime for national and international applications. It is advisable, to study the impact of special patent disclosure requirements, already introduced in national laws on the use of bio-prospecting and ABS, as is the extent to which patent applicants already provide source information in their applications when it is materially relevant to the application.

A number of concerns have led to the outery for protecting indigenous peoples' cultural heritage. IPR protection has been expanded to such an extent that it seems that everything on the planet can be patented from the human genome to biodiversity. Developing countries should explore options, such as local collaborative projects, to promote collection and use of genetic resources with traditional uses. The "T"ikapapa" potato project in Peru, which brings together different sectors of society to promote the commercialisation of native potatoes, can serve as a good example.

As this chapter has pointed out many issues remain unresolved, however the large intemational attention drawn to the complicities of TK protection stem hopeful for the future. 



\title{
Chapter Four
}

\section{The International Legal Framework for the Protection of Indications of Geographical Origin: Implications for Developing Countries}

\author{
"Dis-moi co que tu manges, je te dirai co que tul es" \\ Anthelme Brillat-Savarin
}

INTROI)LCTION

Indications of geographical origin such as geographical indications (GIs) are useful tools for accommodating the consumer's demand for premium products, as they link the product with a particular geographical origin. They serve both the consumer and the producer in the market chain as they inform consumers about the source, quality and characteristics of the product and help to further market visibility for the producer. ${ }^{2}$ Lately other functions have been added to the rationale behind GI protection. For instance, policy makers started using GIs as a tool for furthering agricultural policy goals, the protection of traditional knowledge (TK) and cultural traditions and for facilitating socio-economic development goals (so-called "wealth distribution argument"). Geographical indications facilitate 1) price differentiation, 2) bundling of local knowledge, 3) local organisation of production, 4) local control over a brand, and 5) strong enforcement in developed country export market. Due to these characteristics geographical indications are increasingly perceived as useful intellectual property rights (IPRs) for developing countries. To a large extent this is due to their potential to "localise economic control", promote rural socio-economic development and to provide revenue to TK holders. ${ }^{3}$ Although one should carefully bear in mind that IPRs intend to stimulate innovation and knowledge development and therefore GIs that are promoted to stimulate innovation (hence, farmers are free to include new and other details, materials and components) are more suitable to qualify for IPR protection than Gls that are meant to preserve rural and traditional customs (hence no freedion to include or amend specifications of local production methods). For the latter IPRs are likely not the best way of protection and $s u$ generis types are probably more suitable.

1 The preamble to EC Regulation 2081/92 recital 3 refers to the growing importance attached by consuners to the quality rather than quantity of foodstuffs, and how this preference is leating to a "growing demand for agricultural products or foodstuffs with an identifiable geographical origin" (EC, 1992, recital 3).

2 For instance, the 600 French registered Gl's gencrate almost 620 billion annually.

3 See Ragnekar, forthooming 2009. 
Food quality and product diversity are highly valued among consumers in an increasingly globalised and standardised world. ${ }^{t}$ Of the latter, for instance, it is estimated that ten multinational corporations own approximately 50 per cent of the world seed market (even more after recent take-overs). But a growing niche of the public is willing to pay a higher price for quality products and attach value to goods that are produced using pure, organic production ${ }^{5}$ to reassure them that their products are free of preservatives, stabilisers, flavourings or genetically modified organisms (GMOs). " Consumers are increasingly buying more environmentally-friendly products and opting for more sustain-

+ Globalisation - despite bringing different cultures and their products closer to a global market - has also ushered in an increasingly uniform world in which standardisation and norm-setting may threaten diversity. Indeed, they raise all kinds of questions in relation to food safety and health concerns, the protection of cultural diversity and so forth. The fact that 50 per cent of all seed supply derives from ten multinational corporations is alarming, especially considering the need for a healthy varied diet. However, it goes too far for the purpose of this thesis to assess the political economy of globalisation and its impact on biodiversity. Starbucks, for instance, is becoming aware of the drawbacks of global expansion. The company began life in Seattle in the 1970s as a local coffee bar run by coffee enthusiasts, and expanded to become a global multibillion-profit enterprise (growing from 1,000 outlets to 13,000 within a decade). That expansion does not add to the quality of the product and may lead to the loss of quality in the product. This is an established fact, as demonstrated by a survey (conducted by Consumer Reports, an American magazine that publishes review's of consumer products) in which American consumers rated MicDonald's coffee ahead of Starbucks'. Furthermore, cultural concerns about the impact of Starbucks' expansion were raised by a Chinese television news anchor, which led to the collection of more than half a million signatures petitioning for the closure of a Starbucks store in the heart of China's UNESCO World Heritage-listed Forbidden City. See Herbert 2007.

- Examples of seals/indications referring to certain quality, ecology or humanitarian standards are the "Soil Association organic symbol holder", which verifies to the public that a certain product meets the Soil Association's standard for organic food and farming in the UK. For example "Green and Black's Organic chocolate" is a holder of the Soil Association organic symbol. Another example is "Rainforest Alliance Certified Coffee" bearing the Rainforest Alliance Certified Seal, which guaranteres that the farms where the coffee is produced meet demanding social and emvironmental standards: workers are treated with respect and paid fairly, are properly equipped for their work, and are given access to education and medical care; forests, rivers and soil are protected; and wildlife and rare plants are conserved for future generations. Unilever, the world's largest tea company, has announced its plan to source its entire tea supply sustainably, starting with the certification of its tea producers in East Africa to Rainforest Alliance standards. Rainforest Alliance certification involves a holistic approach, treating enviromment, ethics and economics equally. Coffee farms in Ethiopia and cocoa and banana farms in Cote d'lvoire are already benefiting from Rainforest Alliance certification.

" A consumer survey in the EU in 1999 found that 40 per cent of consumers would pay a ten per cent premium for origin-guaranteed products. 
ably-produced meat, eggs and dairy. The numbers of farmers' markets are rejuvenating alongside the organic food market. They represent products that are more expensive but of a higher quality.' This shows an effort to produce products away from Monsanto's influence.

For many years, protection has been provided, through various legal doctrines, to goods which are of a superior quality due to natural geographic advantages, such as climate, soil or elevation (e.g. "Burgundy" wines from France or "Pisco" from Peru), local knowledge of particular recipes and food processing skills (e.g. "Frankfurter sausages" or "Spreewalder Gurken" from Germany, "Ceylon tea" from Sri l.anka, "Cacao" from Venezuela or "Havana cigars" from (uba), or local techniques and indigenous manufacturing skills (e.g. "Delft Blue" porcelain from The Netherlands, or "Kancheepuram silk" from India).

Laws dealing with IGOs are traditionally justified by the idea of terroir: that a particular land is a key input for a particular product. Terroir is the idea of an essential land/qualitie's mexus: "the local producers are entitled to exclusive use of a product name because no one outside the locale can truly make the same product". "If the geographic name is well known and reputed, exclusive control brings economic benefits to the local producers.

Gls have been at the heart of international trade negotiations since their inclusion in the Uruguay Round that led to the adoption of the TRIPS Agreement. The negotiations subsequently mandated by the Doha work programme, and the outstanding TRIPS implementation issues on the extension of Gl protection to products other than wines and spirits and the notification and registration of Gis for wines and spirits, have proven to be complex and controversial. Indeed, many countries hold diametrically opposed positions on crucial issues, which makes consensus in the near future somewhat unlikely. It should be noted that, unlike the discussions on a number of other IP issues, the discussions on Gls within the framework of the WTO and in other negotiating fora (including informal negotiations) have not seen a North-South divide, but on the contrary have involved different groups of countries - made up of developed and developing countries alike - holding different positions on various crucial (determining) issues. ${ }^{10}$

- See Bittman 2008 .

$\therefore$ See lughes 2006, p. 301.

"In fact the divide is between the so-called "new" world versus the "old" world countries. See Cortes Martin 2004.

1:1 Some Geneva-based trade negotiators argue that Gls should not be regarded as a "developing country" issue, as they have been divisive among developing countries. 
The objective of this chapter is to set out the international legal framework for Gis, to analyse the present varying legal standards and mandates and assess the possible risks and benefits for developing countries in supporting the extension of GI protection to products other than wines and spirits. It will also examine various country positions on the multilateral system of Gl notification and registration. In doing so, it aims to reinforce the negotiating capacity of developing countries by bringing together the different proposals made by various country groupings in the TRIPS Council and in the WTO Committee on Agriculture. Hence, the negotiations on GIs go beyond the IPR debate and they take place in the context of long-standing, high-stakes negotiations over trade in agricultural goods."

This chapter is structured as follows. First, it briefly introduces the terminology and international legal framework for the protection of GIs, including the main TRIPS obligations under the GI section. It will analyse the EC system of protection and relevant case law and it will set out the approaches of the EU in regional and bilateral trade agreements. Second, it sets out the different justifications for Gl protection and their purpose as a tool for wealth distribution and agricultural development. Third, GI protection is contrasted to the protection offered by trademarks. Fourth, it explains the main issues and contentions in the ongoing negotiations on GIs in the TRIPS Council. Fifth, it will also focus on the questions that developing countries should be asking to determine whether or not to support the extension of GI protection. It will also provide recommendations for the steps that need to be taken to actualise the potential in Gl protection for developing countries. The chapter will conclude with recommendations designed for developing countries to take into consideration while drafting their own Gl policies and legal frameworks. Table one, in annex provides an overview of all the different indications of origin terminology, concepts and characteristics.

\section{INTERNATIONAL L,FGAL FRAMEWORK FOR IGOS: HISTORY, TERMINOLOGY AND SCOIE OI: PROTECTION}

\subsection{Introtuction}

Marks indicating the geographical origins of goods were the earliest types of trademarks. ${ }^{12}$ Until the Industrial Revolution in the $19^{\text {th }}$ Century, industrial production was small-scale and international trade was limited to agriculture and simple manufacturing products. Goods were branded to take advantage

11 See Hughes 2006, p. 302.

12 On the history of trademarks and Gls see Schechter 1925. For an overview of the development of appellations of origin protection in France, see Conrad 1996, for Gis in general see Vivas-Eugui and Spenmemann 2006. 
of the local reputation of certain products, with names indicating their place of origin. Gls were historically developed in continental Europe, specifically in France, Italy and Spain. Before the 1970s they were mostly unknown in the rest of the world, especially in countries of a common law tradition.

The current struggle and perseverance of the EC to (re)gain some control over European Gils around the world can be traced back to a process that began at a more local level.13 For instance, in the 18 th century, it was recognised that where soil quality was poor, cultivating vines was often one of the few options available, and thus wine production became a form of rural development, encouraged by the government provision of special privileges. Just as the contemporary debate on the extension of GIs is controversial, at that time the wine privileges granted to the Bordeaux region were under scrutiny. In order to maintain and justify their privileges, the Bordeaux wine producers shifted their policy arguments from safeguarding the authenticity of their vintages to protecting them from foreign competition. In addition, they invoked a rural policy argument, claiming that the region's land was not suitable for other crops and that therefore the growing of vintages should be stimulated. It should be noted that the arguments in favour of abolishing these privileges derived from the desire to grow wheat to feed the population. Rather cleverly, the Bordeaux wine producers shifted this concern to their own advantage by arguing that granting special privileges to the Bordeaux region would stimulate others to grow other crops, including wheat. ${ }^{.4}$

Wine regions have been protected in France since the Middle Ages, especially in the Southwest of the country, with the sale and consumption of wine from other regions prohibited there. In the beginning of the $20^{\text {th }}$ century the Model Appellation d'Origine Controléc (AOC) was introduced as a system of regulation and control. ${ }^{15}$

13 This paragraph is based on Van Caencgem 20036, which gives a short overview of some aspects of the historical development of Gis in France. Van Caenegem refers to Richard, A., De la protection des appellations dorigine matiere ainicile, lmprimeries Gennouilhon, Bordeaux, 1918.

1. See Van Cacnegem 2003b, p. 864.

15 Until the French Revolution in 1789 (privileges were abolished during the Revolutionary period), the wine producing Bordeaux region benefited from two other privileges: the right to use the river-prisilege de la descente (the main means of transport at the time) - and the right to use barrels of a special form and dimension (for instance made from better wood) - mivilige de la burique. The use of a certain type of barrel can be seen as an "early manifestation of the use of such marks to prevent confusion between wines from different regions". Both privileges were introduced with protectionist motives and effects. The use of such barrels can be seen as the first use of some kind of protection of appellations of origin in relation to wines, as essentially it amounted to a true mark of origin. As it was difficult to trace 
Over the years different legal concepts have been invented to protect goods with a product/geographical link. The international legal framework for the protection of IPRs covers indications of source, trademarks, GIs and appellations of origin as distinguishing signs that serve both the consumer and the producer. " They can all be used to acknowledge the relation between a product and its geographical origin. There is no unique terminology to protect indications of geographical origin in legal doctrine or in different legal instruments. For instance, terminology used to identify indications of geographical origin in the TRIPS Agreement does not correspond with the definitions used in the Paris Convention, ${ }^{17}$ Madrid Treaty ${ }^{18}$ and Lisbon Agreement. ${ }^{19}$ Since many agreements are based on different legal concepts, it is important to consider the terminology used in each treaty at issue to understand its scope of protection. Besides these particulars, there are some common characteristics. For instance, an agreement normally provides information on: who is entitled to utilise the indication; which conditions have to be complied with; the definition, scope, legal means and exceptions; and, if applicable relevant aspects of other ongoing negotiations. It is interesting to note that Gl's belong to the legal categories that define IPRs, however normally IPRs protect innovation but GIs protect tradition.

As will be discussed in more detail below, there are different varieties of indicators of geographical origin. ${ }^{21}$ Indications of origin merely provide infor-

illicit use of the barrique (barrels), an additional requirement was proposed: a red brand indicating the name of the dealer and origin. The wine producers in Bordeaux opposed this initiative as in their view the measure would encourage fraud: nothing would prevent dishonest traders from sending poor wine in casks with the most desirable brands and trading them for real. See Van Caenegem 2003b, p. 862-863 and p. 864. Notably, this occurred during a time when chemical analysis and testing was not available to detect dishonest traders.

I" The notion "appellation" covers names, whereas "indication" also comprises drawings, photographs, national emblems, flags, or even symbolism.

17 The Paris Convention uses two notions: indications of source or appellations of origin, which are further defined by the 1891 Madrid Agreement and the 1958 Lisbon Agreement.

1s The Madrid Agreement indicates that "indications of source" denote that a product or service originates from a certain area, country, region or locality.

1" The Lisbon Agreement indicates that an "appellation of origin" covers a "geographical name of a country, region, or locality, which serves to designate a product originating therein, the quality and characteristics of which are due exclusively or essentially to the geographical environment, including natural and human factors".

21) Gevers distinguishes five calegories of geographical names and signs: 1) Names and signs which have a direct geographical association, such as the name of a country, city or a region, island, sca or river, 2) Names and signs with an indirect geographical association, such as associating a perfume with Paris by using the name "Eiffel Tower". An example from the Netherlands is the use of the name "The Australian" 
mation about the origin of the product, for instance a label in a shirt showing that it was made in Peru. ${ }^{21}$

Indications of source refer to any expression or sign used to indicate that a product or a service originates in a country, region or specific place. In principle, an indication of source does not provide information on the quality or other characteristics of the product, but only on its ultimate geographical origin. Certain countries, however, have built a reputation for certain quality goods, such as Switzerland for its watches and clocks, or Peru for its textiles and silverware.22 Gls go one step further than indications of origin and source because they provide information on the product quality, reputation or other special characteristics attributable to the specific origin. The most extensive information given to the consumer is provided by an appellation of origin, which informs them about a special tie between a product and its origin. This asserts that production, processing and preparation take place within the geographical area specified and that its qualities and characteristics are due exclusively or predominantly to its particular geographical environment, including both natural (e.g. soil, climate) and human factors (labour, special techniques/skills used).

for an ice cream chain marketed with images of aboriginal signs; 3) Allusive geographical marks, for example the use of a Swiss mountain image on a chocolate bar for chocolate originating from England, 4) Geographical names that serve as fantasy names, like "Quetchua" for sportswear and bags, or "Chiemsee" for sports clothing; 5) Geographical names which have become generic names for a certain type of good, such as Eau de Cologne for a certain kind of perfume (originally manufactured in Cologne, Germany, its fragrance is meant to be refreshing and relieve symptoms of headache), Cheddar cheese (originally produced in the UK) or Champagne, a kind of sparkling wine which is protected in a number of EU countries but is generic in the US. See Gevers 1990, p. 286.

21 The indication "wol from Peru" refers to an indication of source; it merely implies that the wool originates from Peru. But use of the term "Alpaca wool from Peru" (certification mark protected) provides more information, implying that the wool originates from Peru and from a particular type of animal. In Peru, Alpaca wool is branded through a certification mark that provides the consumer with information as well as identifying the reputation of a particular product. The consumer associates the name with a high quality type of wool; hence the certification mark informs the consumer and makes it easier to choose between products. Here you have source versus origin in that source refers to "first supply" and origin to "coming into being" where it was first developed.

22 The term "made in Switzerland" has a general reputation for quality and durability, for instance. Conversely, the term "made in China" is under scrutiny as health and safety concerns have led to the withdrawal of millions of Chinese products from the market over the last couple of y'ears. 
The WTO TRIPS Agreement provides protection to Gls. ${ }^{23}$ Hence the most universal applied protection for indications of geographical is Gls. However as indicated in Article 1 of the TRIPS Agreement countries are free to determine the implementation process and hence countries have applied various instruments to locally protect GIs, such as sui generis protection systems and by using trademark system. This flexibility is provided because definitional problems arose (TRIPS, Lisbon, PC and Madrid all use different terminology and countries have signed up to different treaties). Gis are names linked with products of a certain nature and quality that consumers favour and are willing to pay a premium price for. Hence, market differentiation is an intangible asset for producers.

In implementing the TRIPS GI provisions, legal drafters are faced with a lot of cross cutting issues, such as conservation use, plant genetic resources and rural development issues. Within the limitations provided by the international legal framework a country should establish a system that furthers the priorities and objectives of its socio-economic development goals. It is important for developing countries to take the protection of traditional and established products into consideration, as well as the importance of supporting rural areas in line with development goals, securing returns for the holders of traditional and/or indigenous knowledge, and the costs of establishing such a protection system.

The WTO undertook a survey of how the TRIPS Agreement provisions on GIs were implemented in domestic regimes. Countries have generally chosen one of three options to protect GIs domestically: laws focussing on business practises, trademarks including collective trademarks and sui groneris systems of protection. ${ }^{24}$ The WTO survey revealed that where countries adopted a si generis system, it tended to incorporate an explicit ex ante registration system

23 It seems that Gls have arisen for processed products: "(a) with a single dominant ingredient; (b) where the processing was done in roughly the same location as the ingredient was produced before processing; (c) where the dominant ingredient had multiple producers (at the farming level) that are citizens of the polity creating the protection, and (d) where the processing made the product transportable to distant markets". See Hughes 2006 , p. 355.

24 The WTO Secretariat following the mandate provided in Art. 24.2 invited countries to fill out a checklist of questions concerning national regimes for the protection of GIs which indicated the three main choices: business practises, trademarks and special measures (sui generis protection schemes). Although, the survey outcome provides merely an indication as mode of protection as only 37 countries have returned the checklist of questions of which, besides from a few "countries in transition", all respondents were developed countries. See WTO "Review under Article 24.2 of the application of the provisions of the section of the TRIPS Agreement on geographical indications: Summary of the responses to the checklist of questions", note by the Secretariat See IP/C/13 and add. 1 as well as IP/W/253. 
(i.e. requirement for prior registration), either formally or through an administrative mechanism.

The survey shows the differences in central elements of the system protecting indications of geographical origin, for instance some systems require registration in a notification register and there are variations in the measures that seek to ensure the link between the product, its quality and the designated area of origin. For instance, these variations include differences in the treatment of geographical units, which vary from political and administrative units (e.g. region, country, village, canton etc) to sui generis geographical areas (e.g. specified wine growing area or small locality). In addition, domestic systems differ in how far-reaching the link between the good and its geographical area should go. Measures of the link between the good and its geographical area of origin vary from demands for all or some stages of production to occur in the designated area, to a requirement for waw material to originate in the designated geographical area. 2520

As a general rule, any person who meets the specifications defining the indication of geographical origin is entitled to use the indication and join the association of the protected GI. One can only be part of the association if the rules of adherence are fulfilled to the product specifications. Monitoring of the system is carried out by quasi-public or public authorities that represent the different interested parties producing the indication of geographical origin. These bodies are mandated to ensure compliance with the specifications defining the indication of geographical origin, and to enforce the rights.

The WTO survey reached the conclusion that protection conferred by special means of protection (sui generis systems) is stronger due to the explicit expression of unauthorised uses, for instance Article 13 in the EC Directive on Gls. The EU has a very detailed and efficient sui goneris system of GI protection but it is not the only example of a regional protection regime in this field. For instance, the Andean Community has also established such a system. By virtue of Article 212 of Decision 486 Andean Community, there is no limitation as to

25 This is often seen in the case of wine, for instance in Australia 80 per cent of wine must originate from grapes in the designated area. In Furope this should be 100 per cent. Van Caenegem argues that GIs, especial!y the ones where all facets of production need to take place within the geographical territory and under strict process control mechanisms can hinder genuine attempts at maintaining consistent quality and supply of wine the imposition of rigid regional delimitations and the resulting impossibility of dealing flexibly with varying levels of production within the area of demarcation or, more generally, to meet demand while effectively maintaining quality is a problem faced by GI owners. For inslance, in a bad grape year the Gl can act as a break on growing genuine attempts at maintaining consistent quality of wine. See Van Caenegem 20036, p. 863.

2" Soc Ragnekar, forthcoming 2009, p. 7. 
the type of product for which appellations of origin can be protected, whether natural, agricultural, handicraft or industrial. ${ }^{27}$ India ${ }^{28}$ also has established a sui generis system and is within the group of demandeurs for GI extension. This is due to, for instance, India having a number of registered and potential GIs, such as "Darjeeling" (tea), "Basmati" (rice), "Alphonso" (mango) and "Malabar" (pepper) amongst others. India adopted the Geographical Indications of Goods (Registration and Protection) Act in 1999 in light of its TRIPS implementation obligations. Under the purview of this Act, the central government has established a "Geographical Indications Registry", where right holders can register their GIs. Unlike the TRIPS Agreement, the Indian Act does not restrict itself only to wines and spirits but takes a flexible approach, leaving it to the discretion of the central government to decide which products should be accorded such higher levels of protection. The establishment of a national system of registration is an important step forward in the protection of Indian GIs, not least because domestic protection is necessary before international protection can be received. The Indian Gl Registry has received around 100 applications, all from India, of which 30 have already been registered." These include Gls like "Darjeeling Tea", "Pochampalli Ikat" (textiles) and "Kashmir Pashmina" (shawls). Significantly, "Basmati" has not yet been registered, due to problems selecting the right varieties and due to problems with the demarcation of the geographical area relevant, as this type of rice is grown both in India and in Pakistan. ${ }^{30}$

Why is the protection of GIs important? Given the commercial potential of indicators of geographical origin, the legal protection of this type of $\mathrm{Gl}$ is of importance. Without some sort of protection, competitors might free ride on the reputation of the GI. These unfair business practises may result in a huge loss of revenue for the right holder of the Gl, mislead the consumer and eventually hamper the goodwill and reputation associated with the GI.31 Avoiding false or unauthorised use of the Gl prevents their products' reputation from being damaged by products of lower quality or different characteristics, and consequently allows them to protect and strengthen their market share and a price differential in comparison with other products in the same category.

27 Decision 486 of the Andean Community concerning a common intellectual property regime of 1 December 2000.

2.x For an overview of the Indian domestic situation see Das 2007.

24 In total 94 applications had been received by the Indian Gl Registry till 15 May 2007. See Das 2007.

31) Scientists have developed many varieties of rice, calling them "Basmati", although many of these aromatic rice varieties do not contain any parental line of the traditional "Basmati". This has given problems as to the authenticity of different varieties of "Basmati". It was opted to file for joint application for the registration of "Basmati". Pakistan has lost to India in the segment in the European markets. One reason for this is that India's export is free from aflatoxin problems. See Das, (2007).

il See Das 2007. 
Geographical indications, furthermore, have economic impacts for producers and suppliers. Because of their role in distinguishing goods and services, they are also significant building blocks of the market identity of these goods and services.

Before the conclusion of the TRIPS Agreement, the protection of Gls in the international arena was limited to three international instruments under the patronage of WIPO, namely the Paris Convention, 32 the Madrid Agreement ${ }^{33}$ and the Lisbon Agreement. It was the Uruguay Round that introduced negotiations on trade in intangibles for the first time in multilateral trade negotiations, which led to the adoption of Annex $C$, the TRIPS Agreement, in the treaty that created the WTO, ${ }^{37}$ The TRIISS Agreement is different to the other three conventions in that it is a truly multilateral effort, acceded to by over 150 different countries, and it contains enforcement measures, subject to the WTO dispute settlement understanding in the event of any differences or conflicts of interest.

This chapter will set out the different international legal instruments used to protect indications of geographical origin and the different terminology, concepts and characteristics applicable. It will briefly outline the history of this protection and elaborate in more detail on the provisions of the TRIPS Agreement and contemporary debates within the WTO and other international fora. It will also examine in more detail the sui generis system of protection which has been developed in the EC for a good number of years. Moreover, it will highlight the differences in protection between the EC and the US. In addition it will cover the bilateral and regional trade negotiations that are emerging to protect indications of geographical origin across regions.

\subsection{The Paris Conoention}

International protection for indications of geographical origin dates back to the last century as the Paris Convention acknowledges, in Article 1.2, that "indications of source" and "appellations of origin" fall within the realm of IPRs:

32 "The Paris Convention for the Protection of Industrial Property" of 1883, administered by WIPO and last revised in 1979.

3 "The Madrid Agreement for the Repression of False or Deceptive Indications of Source of Coods", adopted in 1891 administered by WIPO.

it "The Liston Agreement for the Protection of Appellations of Origin and their international Registration" of 1958 , administered by WIPO).

3 "Final Act Embodying the Results of the Uruguay Round of Multilateral Trade Negotiations and the Marrakesh Agreement Establishing the World Trade Organisation", signed at the Marrakesh Ministerial meeting in April 1994. 
"The protection of industrial property has as its object patents, utility models, industrial designs, trademarks, service marks, trade names, indications of source or appellations of origin, and the repression of unfair competition". 3t

Article 1.3 continues that:

"Industrial property shall be understood in the broadest sense and shall apply not only to industry and commerce proper, but likewise to agricultural and extractive industries and to all manufactured or natural products, for example, wines, grain, tobacco leaf, fruit, cattle, minerals, mineral waters, beer, flowers, and flour".

The Paris Convention obliges signatories to act against the misleading use of indications, requesting that they provide for protection against unfair competition. Article 30 bis sets out that:

"any act of competition contrary to honest practices in industrial or commercial matlers constitutes an act of unfair competition". ${ }^{3 *}$

In particular, the following is prohibited:

"indications or allegations the use of which in the course of trade is liable to mislead the public as to the nature, the manufacturing process, the characteristics, the suitability for their purpose, or the quantity, of the goods". ${ }^{34}$

Article 10 of the Paris Convention sets out that signatories must protect GIs under unfair competition law provisions and make available border measures for the seizure upon importation of goods bearing false indications of the source of goods or the identity of the producer. The Paris Convention provides protection through unfair competition provisions to prohibit the use of false indications of source. It does not, however, deal with the use of an indication of source that is literally true but may still be misleading or deceptive, i.e. socalled deceptive use. This may occur, for instance, where a geographical name exists in more than one country, but was used as an indication of source only for products originating from that place in 1 country. The use of the indication

in The Paris Convention for the Protection of Industrial Property, adopted in 1883, last revised in 1979, Art. 1.2.

$\therefore$ See Art 1.3 of the Paris Convention.

$3 *$ See Art. 10bis of the Paris Convention.

(3) Ibid. 
of source in the other country does not qualify as a false indication of source but could nevertheless deceive the consumers."

The main shortcoming of the Paris Convention provisions is that the Articles 9 , 10 and lobis are only applicable in case the use of the false indication of source misleads the public. Thus, if the consumer is not misled there is nothing the producer or merchant can do to stop the sale of goods bearing similar or identical names to their protected name. Furthermore scope and substantive subject matter is not specified as it does not provide a definition of what entails an indication of source or appellation of origin.

\subsubsection{The Paris Convention Revisions}

In the 1970s, negotiations led to two developments that seemed very promising and significant for developing countries. WIPO gathered together a Committee of Experts on the international protection of appellations of origin and other indications of source in 1974-75 to lay the foundations for a new worldwide treaty, aming to improve on the limited scope of the Paris Convention and the limited acceptance of the Lisbon Agreement."1 Pursuant, a WIPO multilateral draft treaty on the protection of GIs was prepared, which included protection for both appellations of origin and GIs. In addition, a WIPO Model Law on GIs was proposed in 1975 for adoption by developing countries. Both the law and the treaty aimed to establish a system for the registration of appellations of origin, under which developing countries could register up to 200 names and take care of their domestic laws and scope of protection later - in principle offering some form of a transition period. Significantly this draft treaty did not require signatories to have domestic laws for the protection of GIs and appellations of origin in place. This was favourable to developing countries still struggling to introduce domestic laws and an effective institutional framework. ${ }^{2}$ In addition it included an optional provision permitting national courts to determine whether particular terms are generic as opposed to the country were protection was sought. ${ }^{+3}$

Work on this draft treaty was postponed with the prospect of the possible revision of the Paris Convention. Indeed, the draft became part of the basic proposal for the revision of the Paris Convention. The objective of the treaty was to merge the pre-existing notions of indications of source and appellations

411 See "Possible Solutions for Conflicts Between Trademarks and Geographical Indications and for Conflicts Between Homonymous Geographical Indications", WIPO SCT $/ 5 / 3$, June 2000 , p. 8 .

4 The Lishon Agreement is discussed in more details in section 1.4 .

12 In 1990 WIPO issued a memorandum in which it expressed the continuing need for a treaty on Gis. See WIPO SCT/6/3, 2001, para. 71, p. 19.

4. Soe WIIPO SCT/6/3, para. 71, p. 19. 
of origin within a new notion of Gls. The revision of the Paris Convention started in the late 1970s. Negotiations in the context of the Paris Convention led to the proposal of Draft Article 10 quater on the protection of appellations of origin and indications of source.

"The purpose of the new article of the Paris Convention, which was provisionally numbered Article 10 ghater, was twofold. First, the article would ensure more extensive protection of appellations of origin and indications of source against their use as trademarks. In that it would set out a system that included the international registration of false and deceptive Cisf Second, a special provision in favour of developing countries would be included, which would allow those countries to reserve a certain number of potential geographical indications for the future so that, even if they were not yet used as geographical indications, they could not be used as trademarks fHence, this would function as a safeguard mechanism for developing countries]". 1 th

Draft Paragraph 3 contained an additional provision with respect to GIs which had acquired a reputation in relation to goods originating in a country, region or locality, provided that such a reputation was generally known in the country where protection was sought by persons engaged in the production of goods of the same kind or in the trade of such goods. This additional provision would have established a reinforced protection for certain generally known GIs without the requirement of misleading use. Finally, draft Paragraph 7 provided that each developing country could notify WIPO of up to 200 geographical names denominating the country itself, or a region or a locality in its territory; WIPO would then notify all Paris Union member states, and oblige them to prohibit the registration or use of trademarks containing or consisting of the notified names. The effect of this notification would last for 20 years. During this period, any developing country that had made a notification would have the chance to make known and protect the Gl as referring to a geographical area in its territory from which certain goods originated, so that subsequently the general provisions on protection of Gls would apply. The diplomatic conference for the revision of the Paris Convention was never concluded and the draft provisions remained draft. 45

In 1990 the group of experts (GEO/CE/1/2) again tried to establish a worldwide treaty on Cls. It was proposed to replace the concepts of "appellation of origin" and "indication of source" by the notion of "geographical indication". It was felt that the notion of CIs could cover all existing concepts of protection. The Committee of Experts discussed three groups of issues pertinent to the establishment of a new treaty, namely:

th See Höpperger 2003.

t5 See WIPO SCT $/ 6 / 3,2001$, para. 80, p. 21. 
"What should be the sulpect matter of protection? What should be the general principles of protection, including the conditions of protection, its contents, and the mechanisms for its enforcement and for setting disputes arising under the new Treaty? Should there be a system of international registration and, if so, what should it consist of?" + *

In addition, they advocated establishing a new international registration system, which would be more widely acceptable than the Lisbon Agreement:

"To that end, a basic principle was that Contracting larties should be free to choose the manner of prolection of a geographical indication in its country of origin, ather than requiring a specific form of protection. In addition, the new treaty should provide for effective protection of geographical indications against degeneration into generic terms, and ensure effective enforcement of protection". 17

The Committee did not reach a common position on those questions. Reservations concerned, in particular, whether the new treaty should provide for a registration system or for the establishment of lists of Gis protected by Contracting Parties. ${ }^{4}$

\subsection{The Madrid Agre'ment}

The 1891 Madrid Agreement for the Repression of False or Deceptive Indications of Source of Goods touches upon the protection of indications of geographical origin as it provides for protection for goods bearing a misleading, false or deceptive indication. The Madrid Agreement refers to "indications of source" as per Article 1.1:

"Goods bearing a false or deceptive indication by which one of the countries to which this Agreement applies, or a place situated therein, is directly or indirectly indicated as being the country or place of origin shall be seized upon importation into any of the said countries". ${ }^{11}$

The use of indications of source which are "deceptive", i.e. literally true but nevertheless misleading is prohibited. This provision was implemented to supplement the Paris Convention, which merely addresses false use. The Madrid Agreement is only of use for producers or users of the Gl if the false or deceptive indication of source is misleading the public. If the consumer is not misled no legal action can be pursued under this regime. For example if a

See CEO/CE/1/2, para. 64 as referred to in WIPO/SCT 6/3, 2001, para. 83, p. 21. See WIPO SCT $/ 6 / 3,2001$, para. 82, p. 21.

See WIPO SCT/6/3, 2001, para. 84, p. 21.

The Madrid Agreement for the Repression of False or Deceptive Indications of Source of Goods, adopted in 1891, Art. 1.1. 
particular cheese is labelled "type of parmesan cheese" the consumer is not misled as it is clear that the cheese does not originate from the specific region of Italy but from elsewhere. Moreover, the Agreement - just like the PC - does not address the issue of homonymous indications.

Generics - i.e. a common name representing a certain type of product - can be excluded from its purview by the national courts according to Article 4 , with the exemption of "products of the vine"; hence no exception can be made for wines. Article 4 of the Madrid Agreement provides that

\begin{abstract}
"the courts of each country shall decide what appellations, on account of their generic character, do not fall within the provisions of this Agreement, regional appellations concerning the source of products of the vine being, however, excluded from the reservation specified by this Article". 3)
\end{abstract}

A threshold problem with this agreement and with subsequent revisions was the inability of nations to find a solution to the generic use of indications of geographical origin, as it is left to the sovereign decision of each individual country. Notably, contemporary discussions in the TRIPS Council are grappling with what to do with products that are protected under some sort of indication of geographical origin in one particular territory but under generic protection in others.

The implementation and effectiveness of the Madrid Agreement was not very successful as, amongst others, the USA, Germany and ltaly did not accede to it. Countries tried to update the Paris Convention and the Madrid Agreement to introduce protection for the use of names that are indeed not misleading but nonetheless free riding or diluting the reputation of the right holder. Negotiations to solve this matter failed, however, during the revisions conferences. But countries were successful in introducing a new Agreement to protect so-called "appellations of origin" - a particular type of indication of geographical origin - as will be explained in more detail in the following section.

\title{
1.4. The Lisbon Agrement
}

The Lisbon Agreement for the Protection of Appellations of Origin and their International Registration ${ }^{51}$ was concluded to respond to the need for an international system that would facilitate the protection of a special category of GIs, i.e. appellations of origin, in countries other than their country of origin. Hence, countries were searching for ways to extend effectively the

i) Ibid., Art. 4 .

$\$$ The Lisbon Agreement for the Protection of Appellations of Origin and their international Registration, adopted in 1958, as revised at Stockholm on 14 July 1967, and amended on 28 September 1979. 
protection of their indications of geographical origin to third countries. After half a decade of negotiations, the Lisbon Agreement was established in 1958 to facilitate the international protection of appellations of origin. The system offers the possibility of obtaining the protection of appellation of origin in (currently) 26 Contracting Parties to the Lisbon Agreement (i.e., excluding the country of origin) by using one single registration procedure. 52

Article 2.1 of the Agreement provides the following definition for appellation of origin:

"In this agreement, "appellation of origin" means the geographical name of a country, region, of locality, which serves to designate a product originating therein, the quality and characteristics of which are due exclusively or essentially to the geographical environment, including natural and human factors".

The Agreement grants protection to all kinds of products regardless of whether it is an agricultural, food, industrial or handicraft product. It must, however, meet the condition that the product is produced according to the production methods set out in the registration and fulfils certain requirements to qualify as an "appellation of origin" in accordance with the terms of the Agreement. Examples of appellations of origin are "Habanos" (cigars) from Cuba, "lequila" (liquor) from Mexico and "Champagne" (sparkling wine) from France.

The definition in Article 2.1 elucidates that an appellation of origin aims to: 1) designate the product by means of a geographical appellation; 2) identify the geographical origin; 3) link the quality of the product to the geographical environment and human factors; and indirectly 4) prevent the appellation of origin from becoming generic. Natural factors include the climate, temperature, humidity, elevation above sea level, characteristics of the soil etcetera. Human factors, on the other hand, take account of traditions, specialisation in a particular art or occupation, and the use of special production processes etcetera. ${ }^{5+4}$

Article 1.2 of the Lisbon Agreement sets out that appellations need to be domestically recognised and registered in order to obtain protection under the Agreement:

"They' undertake to protect on their territories, in accordance with the terms of this Agreement, the appellations of origin of products of the other countries of

32 For a list of the contracting parties see: <http://www.wipo.int/treaties/en/Show Results.jsp?lang=en\&treaty_id $=10>$.

$\because$ See Art. 2.1 of the Lishon Agreement.

i. See Rodriguez Cisneros 2001. 
the Special Union, recognised and protected as such in the combry of origin and registered at the International Bureau of Intellectual Property (hereinafter designated as "the International Bureau" or "the Bureau") referred to in the Convention establishing the Workt Intellectual Property Organisation".55 (emphasis added $\mathrm{l} C$ )

The scope of protection excludes goods with a given reputation attributable to its geographical origin: even if that reputation is established and extensive it is not in itself sufficient to allow for appellation of origin protection. Moreover, there is also a tie between the condition that the appellation of origin must be recognised in the country of origin and the requirement that the product must have a reputation that it owes to its appellation of origin. Once the reputation is established, the basis for the required recognition of the appellation of origin can be considered achieved. The subsequent formal recognition by the country of origin will complete the second requirement of Article 1.2, i.e. that it itself protects the appellation of origin. Geuze has indicated that a mistake occurred in the translation of the original French (official) version of the Lisbon Agreement into English - as erroneously both quality and reputation are referred to as being cumulative requirements. The French version asks for either reputation or quality. ${ }^{\text {.7 }}$

Whilst the Lisbon Agreement establishes an international system of protection for appellations of origin, it only applies to products which are already protected and recognised under the national law of one of the states party to the agreement - as follows from the wording "recognised and protected". The terminology "as such" signifies that countries are free to adopt their own system of protecting designated appellations of origin, either by judicial or administrative processes, or both. However, signatories are obliged to put a specific system in place that offers protection either through GIs or appellations of origin - which could impose an additional burden to developing countries. Once registered under the Lisbon register, a geographic indication is protected in other countries of the Special Union, as detailed in Article 7 of the Agreement.

According to Article 2.2 of the Agreement, the "country of origin" is defined as:

"the country whose name, or the country in which is situated the region or locality whose name, constitutes the appellation of origin that has given the product its reputation".

55 See Art. 1.2 of the Lisbon Agrement.

3. See Geuze 2007 p. 4.

5 Interview with Geuze conducted by the author, November 2007.

5* See Art. 2.2. of the Lisbon Agreement. 
From this definition it follows that there needs to be a strong link between the characteristics and quality of the product and its geographical origin.

Article 6 sets out that, as long as an appellation of origin is protected in the country of origin, it cannot become generic:

\begin{abstract}
"An appellation which has been granted protection in one of the combries of the Special Union pursuant to the procedure under Article 5 cannot, in that country, be deemed to have become generic, as long as it is protected as an appellation of origin in the country of origin".
\end{abstract}

Hence, the validity of the protection given to an appellation of origin is determined by the continuing existence of the conditions that gave rise to it, i.e. protection of the appellation will continue as long as the conditions that generated it also continue.

In order to qualify for protection under the Agreement the indications have to be registered with the WIPO International Bureau by the designated competent national authority of the country of origin. Currently, there are 882 appellations of origin recorded in the International Register, of which 808 are currently in force." After the registration of an indication for a so-called "application for intermational registration" with WIPO, other parties to the Lisbon Union have a year from the date they receive the notification to protest with a so-called "declaration of refusal", specifying their grounds for refusal. If WIPO receive no such declaration from a competent authority within the relevant time limit, the protection of the appellation of origin takes effect from the date of international registration.'2 Accordingly, members of the Lisbon

See Art. 6 of the Lisbon Agreement.

(14) A recent case concerned an appellation of origin of Israeli origin: "Jaffa" for citrus products. Jaffa is the first and only $A \& O$ in Isracl and has a world-wide reputation. Jaffa represented by the Israel Citrus Marketing Board wanted to renew its registration at the national level but the registration office refused its renewal arguing that Jaffa had ceased to be an $\triangle \& O$ as it permitted use of the $A \& O$ for citrus growing in Africa. However, the Israelian Court argued that the validity of a registration of an $A \& O$ is not impaired by the licensed use of the designation as a trademark in non-I. isbon Agrement countries where the fruits grown are similar in quality to those produced in the A\&O countries. The Court stated that the right to the $A \& O$ cannot be undermined in countries whereby the laws of $A \& O$ are inapplicable. Such an outcome would defeat the right of an owner in his IPR. See the Citrus Division of the Plant Production and Marketing Bourd v. Israel Commissioner of Patents and Tratemarks Appeal Board, Jerusalem, 1011/05, 12 July 2007.

i1 Figures correct as of July 2007.

"2 See Lisbon system for the international registration of appellations of origin website: <http://www.wipo.int/lisbon/en/index.html>. 
Union have the obligation to ensure protection once registration has successfully been completed at the WIPO International Bureau. ${ }^{63}$

"In this regard, the records of the Diplomatic Conference in 1958, which adopted the Lisbon Agreement, confirm that such a refusal can be based on any factual or legal situation (in the authentic French text, "toute situation de fait ou de droit") and mention as examples the existence of a geographical homonym and a denomination that has become generic. They also explain that the grounds for refusal constitule a basis for discussions between the country of origin and the refusing country for the purpose of arriving at an agrecment and that the outcome of such discussions, apart from withdrawal of the refusal or maintenance thereof, could be anything in between. In practice, such discussions have taken place in respect of many Lisbon registrations and have, notably in recent years, resulted in partial refusals and partial or total withdrawals of refusals" "nt

For instance, an interesting case in which many countries filed a declaration of refusal was with regards to Peru's application for "Pisco". Peru registered its famous liquor on 19 May 2005 in order to obtain appellation of origin protection under the Lisbon Agreement. Subsequently, the EC and Mexico submitted "declarations of refusal" expressing that they had made prior bilateral agreements with Chile to protect the name "Pisco" for a similar type of liquor. ${ }^{5 .}$ "The Lisbon Agreement does not specify the rules on dual existence but its negotiation history points out that there was no intention to exclude dual protection." The name "Pisco" now represents the coexistence of homonymous appella-

1.3 See Art. 7 of the Liston Agreement.

at See Geuze 2007, p. 9.

".7. There is a growing trade dispute between Peru and Chile over who has the right to use the name "Pisco". There is a region in Peru called "Pisco", whereas no such region exists in Chile (though in recent years the government of Chile has renamed a region "Pisco"). This dispute goes further than trade interests as Peruvians hold a deep-seated national pride in "Pisco" and any Peruvian celebration is accompanied by a "Pisco sour", a cocktail made with a shot of Pisco, sugar, egg white and lime juice. The liquor has been part of Peruvian culture for over 400 years, with its recipe having been passed from generation to generation. The government promotes "Pisco" as being Peruvian, using the slogan Pisco es permuna ("Pisco is Peruvian"). While hoth countries claim a historical legacy to Pisco, the underlying cause of the dispute is over exports and control of the international market. Peru, however, has been constrained by economic and political turmoil, water pollution and technical drawbacks, and unable to capture an export market for its Pisco. Chile, on the other hand, has established a small export market for its Pisco, mainly to the US and Europe. More information is available at: <http://www.american.edu/ted/pisco. htm>

(1) See Geuze 2007, p. 9. 
tions of origin, with both the "Pisco" from Peru and the one from Chile warranting protection. ${ }^{17}$

The product pursuant to a successful application obtains so-called "absolute" protection as set out in Article 3 :

"protection shall be ensured against any usurpation or initation, even if the true origin of the product is indicated or if the appolation is used in translated form or accompanied by terms such as "kind", "type", "make", "imitation" or the like".

Protection under the l.isbon Agreement goes further than under the PC or the Madrid Agreement as "absolute" protection implies that even if the public is not misled as to the origin of the product, it still deserves protection. The problem of free riding on the reputation of indications is effectively resolved in the Lisbon Agreement. This was achieved by ensuring protection against any usurpation or imitation, even if the true origin of the product is indicated or the appellation is used in translated form or accompanied by terms such as "kind", "like", "type" or "imitation"." "This also prevents the registration of trademarks of such names in member countries.

A major weakness of the Lisbon Agreement is, however, that accession was confined to those nations that protected appellations of origin "as such", thus in principle excluding states that protected them under collective or certification trademarks, unfair competition or consumer protection laws. Another shortcoming is that the Lisbon Agreement did not provide an exception for Gls that had already become generic in member states. Another drawback was the failure to attract signatories: parties included mainly transition economies, developing countries and the major agricultural-producer countries in Europe. Although the number of member states is still small (26), a renewed interest in the Agreement has been witnessed by new accessions in recent years: Moldova, Mexico, The Democratic People's Republic of Korea, Peru, Iran and Nicaragua all recently joined the Lisbon Union."in Indeed, they have registered some of their products on the International Register; for example, Peru has registered "Pisco" 71 and "Maiz Blanco Gigante Cusco" iz

17. Notably Peru is not in favour of coexistence; Chile has been more flexible in this regard.

1.i. See Art. 3 of the Lisbon Agreement.

(14) Ibid.

71) See WIPO website: <hltp://www.wipo.int/treaties/en/statistics/StatsResults.jsp? treaty_id $=10 \&$ lang $=$ en>.

3 Peru categorises "Pisco" as an alcoholic beverage: "Pisco is a liquor of grape, obtained by distilling fresh must of recently fermented grapes in accordance with traditional methods established in the production areas previously recognised and 


\subsection{The EC's Sui Generis Systom}

The next paragraph will set out the EC sui generis system of protection of indications of geographical origin. The scope of protection is illustrated by examples derived from case law. ${ }^{3}$

The EC values the availability of high quality food products and endeavours to enhance the quality of products within the framework of the common agricultural policy. ${ }^{7-4}$ Therefore it promotes and encourages producers through the use of a dual system of legal protection for indications of geographical origin (or as the EC calls them "geographical denominations") the protected designations of origin (I'DO) and protected geographical origin (PGI) legal framework. A common feature of both protected designations of origin (PDO) and protected geographical indications (PGI) is that protection is granted because of the particular link between the geographical origin of the product and its characteristics.; The feature common to PDOs and PGIs is that food products must use the name of the region or specific place, or even country where the product originates from, and thus are given direct geographical

classified as such in the nomative rules contained in the Peruvian Technical Standard 211-011:2002". See Lisbon system for the international registration of appellations of origin website: <htp://www.wipo.int/lisbon/en/index.html>.

$\therefore$ Notably, Spain is not a member of the Lisbon Union as it could not reach an agreement on the protection of "Talavera" porcelain. Talavero refers to a city in both Mexico and Spain. Mexico has protected Talavera porcelain since July 1998; it is registered as number 883 in the Lisbon Register.

$\therefore$ For a short overview of the theoretical issues underlying registration systems for geographical indications (GIs) See Van Caenegem 2003a, Ragneker 2004, VivasSpennemann 2006. For present regulatory structures of GI registration in Europe and Australia, Van Caenegem 2003b. For present regulatory structures of Gl registration in Europe and the Andean community' see Vivas 2001.

it See EC Regulation (old).

7 The EU protects GIs through three separate regulations: the Council Regulation No. $510 / 2006$ on the protection of geographical indications and designations of origin for agricultural products and foodsfuffs (O) L93/12, 31 March 2006) replacing Regulation 2081/92 (OJ L208/1, July 14, 1992); the Council Regulation No 1493/ 1999 on the common organisation of the market in aine (Of L 179, 14 July 1999, p. 1); The Council Regulation No 1576/89 of 29 May 1989 laying down general rules on the definition, description and presentation of spirit drinks (OJ L160, 12 June 1989, p. 1). At the moment there are more than 600 names of different cheeses, meats, fruits and vegetables registered in the EC: see <http//europecu.inl> and search under "Commission", "agriculture" or "quality products". "Cafe de Colombia" has recently been registered as a $\mathrm{Gl}$. 
indications. ${ }^{\circ}$ If names have become generic for a particular type of product, then those names cannot be registered.

Examples of a registered $P D O$ are "Altenburger Ziegenkäse" (goat cheese from Altenburg, Thüringen), "Blue Stilton" cheese and, for a PGI, "Newcastle Brown Ale"," "Bayerisches Bier" (beer from Bavaria), "Lübecker Marzipan" (Marzipan from Lübeck), "Schwarzwälder Schinken" (ham from the Black Forest region), "Nürnberger Rostbratwürste" (a particular kind sausage from Nurnberg) or "Aachener Printen" (a German Christmas delicacy). The regulations sets out that, names registered as IDOS and PGIs may not be used in a manner that misleads the consumer as to the true geographical origin of the product. Moreover, it goes one step further in that such protected names must not be used in forms such as "like" or "imitation", which equates them to the higher protection granted for wines and spirits under the TRIPS Agreement. This form of protection is referred to as the "absolute" protection, as the use of the name is prohibited even though the consumer is not misled about the true origin of the product.

Protected designations of origin (PDO) and appellations of origin are more limited in scope than the rules set out under Article 22 (basic protection) of the TRIPS Agreement; it resembles more the definition of "appellation of origin" under the Lisbon Agreement. ${ }^{78}$ It requires a very strong link between the product and the geographical area: quality and characteristics must be "essentially or exclusively" due to the geographical area, including natural and human factors. In order to fulfil PDO requirements, the designated product must not only be produced, processed and prepared in the respective area, but also that the ingrodients of the protected product hawe to originate in that area. Hence, a product may only be registered as a PDO if it fulfils certain specifications laid down by European Community or national law. The Sprewnlder Gurken case-" clearly illustrates the essential distinction between a PDO and a PGI. In this particular case the Advocate General opined that the Spreewalder gherkins (Gurken) were known to consumers to originate from the Spreewald area (North-East of Germany) and therefore have certain qualities which entitled them to the PDO qualification as opposed to a I'GI qualification, which would

$\therefore$ As opposed to indirect geographical indications, in this case the actual name of the place is not used, or an abbreviation or a slang form of the name is used, nometheless consumers still understand this name to indicate the geographical origin of the product. For instance Basmati, there is no such region or place basmati but still people regard the term to indicated the geographical origin of a certain type of rice.

in Interestingly the name "New Castle Brown Ale" has also been registered as UK and Community Trademarks.

is The PDO category equates to the earlier established AOC system for wines in France.

"Com Kuhnc GmbH \& Co. v. Jutro Konserumburik GmbH \& Co. KG, Case C-269 of 5 April 2001. 
have been appropriate had the term been regarded by consumers as merely referring to the style of processing or recipe of the gherkins. ${ }^{80}$ PGIs protect food products with a "specific quality, reputation or other characteristics which are attributable to that geographical origin". It has, for instance, been argued that "Parma Ham" could not qualify for PDO registration as the pigs used for its production are not always from the designated ltalian area but occasionally originate from the Netherlands or other Northern European countries. Thus, the essential difference between the two categories of protection is that, for a PDO, all the production, processing, and preparation must occur within the designated area." For a ['GI the list is not cumulative: only one of these elements must take place within the designated area.

PCIs resemble the protection granted in Article 22 of the TRIPS Agreement and hence is wider in scope than the protection granted under the PDO system: the link between the product and the geographical area may be less close than in the case of a PDO, and may simply consist of the reputation of the area for the production of certain foods. It does require that the production of the product takes place within the designated area but its ingredients do mot necessarily have to originate from that area. A registered Gl cannot be used in relation to products that do not comply with the specification, implying that products within the designated area are thus compelled to adhere to the specified production requirements.

In July 1993, the EC Council Regulation 2081/92 of July 14, 1992, on the Protection of Geographical Indications and Designations of Origin for Agricultural Foodstuffs, came into force. ${ }^{.2}$ This regulation offers far-reaching protection for "geographical denominations" of foodstuffs by prohibiting:

1) Any direct or indirect commercial use of the protected name on comparable products (e.g. use of the name "feta" for any cheese other than that authorised to do so) and also in relation to unrelated products, if using the name exploits the reputation of the protected GI;

2) Any misuse, imitation or evoking (e.g. evoking "Tetilla" cheese by giving a cheese the peculiar shape of this type of cheese), even if the true origin of the product is indicated; or if the protected name is translated (c.g. "Parmesan") or

sul See the Opinion of the A-G in the Sprewaliter Gurken case.

*t Exceptions are provided for in Art. 2.t of EC Regulation 2081: for instance if the raw material comes from a different area but a defined area and production there takes place under special controlled conditions than the product is entitled to a PDO.

$\therefore$ See EC Regulation 2081/92 used to set out the legal framework of geographical denominations of origin for the EC but it was replaced by Council regulation on the protection of geographical indications and designations of origin for agricultural products and foodstuffs, No. 510/2006 in March 2006 to respond to the WTO Panel Report that ruled that Regulation 2081/92 was not completely TRIPS compliant. 
accompanied by an expression such as "style", "type", "method", "as produced in", "imitation", or "similar" (c.g. type of l'arma Ham):43

3) Any other false or misleading indication as to the provenance, origin, nature or essential qualities of the product on the inner or outer packaging, advertising material or documents relating to the product concerned, and the packing of the product in a container liable to convey a false impression as to its origin;

4) Any other practise liable to mislead the public as to the true origin of the product (e.g. any other use that misleads the public, such as the imitation of a particular smoll);

5) Where a registered name contains within it the name of an agricultural product or foodstuff which is considered generic, the use of that generic name on the appropriate agricultural producl or foodstuff shall not be considered to be contrary to 1) and 2). However, Member States are allowed to invoke a transition period of not more than five years for national measures authorising the use of the expressions referred to under 2) subjected to the following conditions: a) the products have been marketed legally using such expressions for at least five years before the date of publication of this Regulation; and b) the labelling clearly indicates the true origin of the product. The EC Regulation mentions that any exception "may not lead to the marketing of products freely on the territory of a Member State where such expressions are prohibited" which implies that the transition period is mainly suitable for the third-country domestic market.

6) Protected names may not become generic as long as the conditions for protection are fulfilled. ${ }^{\text {s: }}$

Under the EC Regulation, eligibility for a (PDO) or (PGI) an agricultural product or foodstuff is granted on compliance with certain "specification" requirements outlining detailed information of the agricultural product/foodstuff involved. ${ }^{55}$ For instance, the EC Regulation requires member states to put

.3 The scope of protection of a registered name was under discussion in the ECJ case Gomzola v. Cambozla. It was found that the phonetic and visual similarity between the two terms would amount to a mental association in the minds of the consumers, given the similarity of the products. It was not necessary to establish a likelihood of confusion. Gorgonzola v. Combozola, ECJ, ECR 1, 130, 4 March 1999.

s.t See Art. 13 of the EC Regulation (old).

si See Art. 4 EC Regulation (new and old) sets out that the specification needs to include the following information: 1) Name of the agricultural product or foodstuffs, including the designation of origin or the geographical indication; 2) A description of the agricultural product or foodstuff including the row materials, if appropriate, and principal physical, chemical, microbiological and/or organoleptic characteristics of the product or the foodstuff; 3) Definition of the geographical area; 4) Evidence that the agricultural product or the foodstuff originates in the geographical area; 5) Description of the method of obtaining the agricultural product or foodstuff and, if appropriate, the authentic and unvarying local methods; 6) Details outlining the link with the geographical enviromment or the geographical origin within the meaning; 7) Details of the inspection structures; and 8) Specific labelling details relating to the indication PDO or PGI, whichever is applicable, or the equivalent traditional mational indications. 
in place "inspection structures" - a kind of verification mechanism - to ensure that agricultural products and foodstuffs bearing a protected name meet the requirements laid down in the specifications. ${ }^{\text {st }}$

Arguably, the scope of protection under EC Regulation 2081/92 is very broad. Once registered under the system, a whole spectrum of rights is available to the right holders of the registered Gl. One would expect the threshold for registration to be very high, but this is only partly the case as the requirements for obtaining a PG1 are significantly less stringent than for PDOs. ${ }^{s 7}$

The EC Regulation sets out a protection regime that goes beyond the minimum standards set in the TRIPS Agreement as it sets out a protection regime of "absolute protection" for products other than wines and spirits.

\subsection{EC Case Law Defining Scope and Boundaries of GI System}

The question of whether a name had entered generic usage was considered by the European Court of Justice over the name "Feta". sh "The EC), after a long

st. Art. 10 EC Regulation (old) sets out that an inspection structure may comprise one or more designated inspection authorities or private bodies. These designated inspection authorities must offer adecuate guarantees of objectivity and impartiality with regard to all producers or processors, and need to be equipped with qualified staff and the resources necessary to carry out inspections of agricultural products and foodstuffs bearing a protected name. Member states need to inform the European Commission on the choice of bodies for this purpose. Subsequently these details will be published in the Official Journal of the European Communities.

s) See Van Caenegem 2003b, p. 872.

his See cases C-289/96, C-293/96 and C-299/96, joined Cases C-465/02 and C-466/02.

". Feta is a curd cheese in brine. It is traditionally made from goat and/or sheep milk but may be substituted by' cow's milk. After a long legal battle with Denmark which challenged the 2002 protected designation of origin registration of the term feta, which produced a similar cheese under the same name, but used artificially blanched cow's milk, the term "feta" is now a PDO, which limits the term within the $\mathrm{EU}$ to Greek feta. For the registration see <http://ec.europa.eu/agriculture/qual/ en/1210_en.htm>. The European Court of Justice upholds the name "feta" as a protected designation of origin for Greece; see Judgment of the Court of Justice in Joined Cases C-465/02 and C-466/02; Federal Republic of Germany and Kingdom of Dinmark v. Commisston of the Europran Commminties. The judgement expresses that "In order to be registered as a PDO, a traditional name such as 'feta', which is not the name of a region, place or country, must refer to an agricultural product or a foodstuff from a defined geographical environment with specific natural and human factors which is capable of conferring on that product or foodstuff its specific characteristics. Moreover, the name cannot have become generic. In the Commission's view, those conditions are fulfilled. The name 'feta' has not become the common name for an agricultural product or a foodstuff and, therefore, has not become generic. The geographical area defined by the Greek legislation covers only 
debate, finally did recognise Feta as a registered $G$, thereby rejecting arguments that the term was a generic identifier of a particular type of white cheese. As a result of the recognition, the term "Feta" may only be used by producers in certain areas in Greece in accordance with strict product standards set out in the specification. Other well-established cheese producers who previously employed the denomination "Feta" as a generic have been forced to label their products with new names." Notably, following the EC Council Regulation 1829/20)2, producers in other States of the EC have a five-year transition period before they have to change the name of their product or cease production, subject to the fulfilment of certain conditions."

Interestingly, the EC regulation protects "direct" GIs but not "indirect" GIs, such as translations of geographical names. Translations of registered names appear to be protected under Article 13(1)(b). The Court ruled in the Dante Bigi case" that it was far from clear whether the designation "Parmesan" had become generic. The court stressed that it was contended by all the governments and the European Commission which had submitted written observations in this case that the French designation "Parmesan" is the correct translation of the Italian EC registered PDO "Parmigiano Reggiano". The European Court of Justice ruled that according to Article 13.3 of Regulation 2081/92 the name "Parmesan" may not become generic.

\section{"Gran Padano" and "Pama ham" Cases}

The European Court of Justice defined the scope and boundaries of the legal protection for geographical denominations in the Gran Padano and Parma ham cases. ${ }^{93}$ Both cases addressed the protection of geographical designations of origin in the packaging of foodstuffs. The cases examined the compatibility

the territory of mainland Greece and the department of Lesbos. Extensive grazing and transhumance, central to the method of keeping the ewes and goats used to provide the raw material for making Feta cheese, are the result of an ancestral tradition allowing adaptation to climate changes and their impact on the available vegetation".

wh When needed to describe a feta-like cheese that is not Greek feta, names such as "salad cheese" and "Greek-style cheese" are used.

"This case show's how cumbersome it can be to implement the introduction of new levels of GI protection across various countries with disparate jurisdictions and the disruption to well-established practices that can result.

'2 See Dante Bigi, C-66/00, ECJ, 25 June 2002.

$"$ See Case C-469/00 Rail S.t.r.l. v. Bellom lmport S.t.r.l. and Binghi SpA, [2003] ECR I-5053 of $20 \mathrm{May} 2003$ and; Case C-108/01 Consorzio del Prosiutto di Parmu and Silumificio S. Ritn SpA $x$. Asila Stores L.td. and Hygrate Foods Lth., [2003] ECR 1-5121 of 20 May 2003. Grana Padano and Parma Ham were registered PDO's as of 21 June 1996, under Regulation 1107/96. 
(balance) between the right of free movement of goods under Article 29 of the EC Treaty and rights under EC Regulation 2081/92, as well as the scope of protection given to protected GIs under EC law. More in particular, the EC) examined the question of whether national rules requiring locally produced foodstuffs to be prepared and packaged in their region of production amounted to quantitative restrictions on the exportation of those products, contrary to the EC Treaty Article 29, and whether these restrictions could be objectively justified.

\section{Background Luformation}

Gran Padano was registered as a PDO and the name Gran Padano protected under Italian law, which set out the conditions required for the PDO to be applied to cheese. This information was entered into the EC register of PDOs. ${ }^{14}$ The specifics of the Gran Padano cheese as registered set out that grated Gran Padano had to be grated in the region of production and under certain specified conditions.

Prosciutto di Parma was also a PDO. Its name was protected under Italian law, which set out the conditions required for the PDO to be applied to ham and subsequently put in the register as kept by the EC. One of the conditions relating to the PDO for Parma ham under Italian law was that pre-sliced and pre-packaged Parma ham had to be sliced and packaged in the Parma region.

In the dispute regarding Gran Padano (C-469/00), a French company called "Ravil" imported whole cheeses from Italy, and subsequently grated and distributed them in France. In the Prosciutto di Parma case (C-108/01), an English company called "Asda Stores" obtained ham from Hygrade Foods Ltd, also based in the UK. Hygrade acquired the ham from Cesare Fiorucci SpA, an Italian company belonging to the association Consorzio del Prosciutto. The ham was imported as a whole where it was then sliced and packaged by Hygrade. Subsequently Asda sold the packages of ham labelled as "Genume Parma Ham". Both these cases were brought to the ECJ seeking to stop the retailers from continuing their business practices by the Italian government.

\section{The Ruling of the ECJ}

The findings of the ECJ were as follows: firstly, it found that the product specification determined the extent of the uniform protection conferred by EC Regulation 2081/92 within the EC. The ECJ pointed out that the regulation did

4. Commission Regulation 1107/96 of 12 June 1996 on the registration of geographical indications and designations of origin under the procedure laid down in Art. 17 of Regulation 2081/92 (1996 OJ LJ48/1). 
not exclude the determination of special technical rules applicable to operations leading to different presentations on the market of the same product, in order to satisfy the criteria of quality and guarantee an identifiable geographical origin. Thus, the regulation allowed rules that set out that the grating or slicing and packaging could be conditional on those operations taking place in the region of production, where the corresponding conditions were laid down in the product specification. In the opinion of the ECJ, those conditions restricted the pattems of exports of goods bearing these PDOs and those conditions constituted measures equivalent to a quantitative restriction on exports, which are prohibited by Article 29 of the EC Treaty. Nonetheless, such restrictions on the free movement of goods could be justified under the EC Treaty for reasons, for instance, relating to the protection of industrial and commercial property or to enhance the quality of products within the framework of the common agricultural policy. The ECJ held that the conditions laid down by the specifications for goods were consistent with EC laws as long as they were necessary and proportionute for the purpose of protecting the releant PDOs. It ruled that the grating and packaging of Gran Padano, and the slicing and packaging of Parma Ham, were important operations capable of damaging the quality and authenticity of those products, and therefore the reputation of the PDOs, if they were not complied with. The Court ruled that the consumers would not be appropriately protected if operators outside the region of production were merely obliged to inform consumers with appropriate labelling that grating, or slicing, and packaging had taken place outside that region of origin. Hence, there were no alternative, less restrictive measures to attain the objective pursued. The ECJ did not, however, want to set a precedent for all PDOs as they explicitly stressed that the protection conferred by a PDO did not nommlly (xt'nd to operations such as grating, slicing and packaging. Only if these operations were expressly laid down in the specification and brought to the attention of their attention by adequate publicity in EC legislation could those entitled to the PDO prohibit third parties from doing so.

Notably the Advocate General Alber differentiated from the Court's opinion in his view that ham is purchased by consumers either sliced or by the piece or even as a whole ham, and that therefore the slicing of ham does not have a significance comparable to the bottling of wine. He made reference to the Rioja Case, ${ }^{95}$ in which the ECJ ruled that the bottling of wine in the region of production is a justified restriction on the free movement of goods since it that was the best means of guaranteeing the quality of the bottled wine. The AG admitted that the bottling of the wine in the region of production constitutes a commercially material characteristic, since consumers primarily purchase wine in bottles." However, in the case of ham the AG opined that the place

is Belgium v. Spain, ECJ, C-388/95, E.C.R. I-3123, 16 Mav 2000.

"th Although increasingly wine originating in South Africa and Australia is shipped in large barrels and bottled in the destination country. 
where slicing took place would have no influence on consumer choice and that therefore slicing in the region of production does not involve a commercially material characteristic. Nonetheless, the same could be said about the bottling of wine, as there is no specific link between the geographical place and bottling, except the fact that bottling in the place of production ensures and guarantees the quality of the product.

The AC also took a different view from the Court in the Gran Padano case: in his opinion, the requirement for grating and packaging in the region of production makes export of the cheese more difficult, more expensive and therefore, not rational. Hence, he reaches the conclusion that these measures were having an equivalent effect to a quantitative restriction on exports within the meaning of Article 29 of the EC Treaty. ${ }^{y 7}$

In summary, the ECJ has held that the maintenance of the quality and reputation of Gran Padano cheese justified the rule that the product had to be grated and packaged in its region of production, and that similar concerns with respect to Parma ham justified the rule that that product must be sliced and packaged in its region of origin.

\subsection{The EC arersus LS in Relation to Gl Protection}

Cis were traditionally used in Europe to protect certain industries, especially to strengthen the position of local farmers and to ensure the reputation of local products. In addition, granting exclusive rights to producers to use a geographical term, associated with particular goods within a certain region, served to limit competition, especially from producers outside that region. ${ }^{\prime \prime}$ In the US, on the other hand, such use was prohibited and indications of origin function to protect the consumer against being misled. Thus, in principle, in the US "there are no rights in a term or sign until that term or sign has become distinctive in the minds of the relevant consumer as an indicator of source". This difference in rationale behind the allocation of protection explains the roots of the current conflict on stronger GI protection in the WTO. ${ }^{100}$

The TRIPS Agreement leaves it up to the Members to choose the legal framework to implement the TRIPS provisions following Article 1 of the TRIPS Agreement, but it reiterates this freedom for GIs in Article 22.1. This provision indicates that Members are under the obligation to "provide the legal means" for the protection of GIs to be available for "interested parties" to prevent the "use of any means in the designation or presentation of a good that indicates or suggests that the good in question originates in a geographical area other

4. See O'Comnor and Kireeva 2004.

wh See Haight Farley 2000.

(x) See Haight Farley 2000, p. 1.

19: Se fHughes 2006 for a GI discussion from an American point of view. 
than the true place of origin in a manner which misleads the public as to the geographical origin of the good" and to prevent "any use which constitutes an act of unfair competition within the meaning of Article 10bis of the Paris Convention". 101 Nonetheless, this freedom to choose the legal mode for implementing the provisions is subject to remaining consistent with the Agreement; in case of any disputes here, the WTO Dispute Settlement Understanding will oversee the resolution of the conflict. It follows that the Agreement does not specify the preferred legal means, nor does it provide a set of legal options. ${ }^{102}$ Implementation of Section 3 of the TRIPS $\wedge$ greement has therefore occurred in various modes, e.g. the law of "passing off" (in common law countries), protection based under the doctrines of unfair competition (in civil law countries), tort law, collective and certification marks, administrative measures, appellations of origin or GI sui generis regimes. ${ }^{10: 4}$ Nonetheless, GIs fall within a broadly defined concept of IP (under the TRIPS Agreement) and therefore the general principles such as minimum standards, national treatment and MostFavoured Nation are applicable. 115 These principles stood at the basis of the WTO dispute EC - Trademarks and Goographical lndications. (This case will be discussed in section 1.6.1).

The inclusion of GI protection in the TRIPS Agreement was a key demand of European negotiators during the Uruguay Round of the GATT. Whe The competing positions were divided into those of the EC and Switzerland, which

111 Notably the fundamental difference between Arts. 22 and 23 is in terms of the scope of protection and not in terms of the obligation in respect of legal means. The Paris Convention defines the term "interested parties" in its Art. 10(2). The UNCTADICTSD [Resource Book] 2005 elaborates on the term.

112 The conclusion of the TRIPS Agreement in 1994 required legal and administrative reforms for introducing GI prolection into domestic legislation, including in major market economies such as the US and Canada. Nonetheless, as the implementation of the TRIPS Agreement is, following Art. 1, somewhat flexible, most countries simply altered their trademark laws so as to accommodate the new TRIPS obligations. Even countries with extensive laws on the protection of Gls had to reform their regimes to meet the stricter enforcement standards set by the TRIPS Agreement. This occurred, for instance, in the Andean countries in South America. The implementation of these obligations is subject to review in the TRIPS Council following the same procedure as applicable to other TRIPS Agreement provisions; implying that as soon as the transition period has expired the Council may undertake a review. Art. 24(2) and 71(1) TRIPS Agreement lay down the procedures for review.

1in For instance, the protection against wrongful appropriation of geographical indications is found in English tort of passing-off.

114 For more details on the different ways of protecting GI under national laws see UNCTAD-ICTSD [Resource Book] 2005, Chapter 15, Section 2.1.

1115 See Escudero 2001.

10m For a history of the TRIPS negotiations under the Uruguay Round see Gervais 2003 and Stewart 1993 and chapter 1 of this thesis. 
proposed a French-style of protection, and the US, which favoured the protection of GIs through a certification mark system. Prior to and during negotiations on the TRIPS Agreement, the concept of GIs was unsettled, with the EC at the forefront of seeking domestic legal protection. ${ }^{107}$ The controversy can be seen as an extension of the linkage between GIs and agricultural products. The EC's interest in GIs was and still is associated with the important role they can play in its commom agricultural policy. ${ }^{108}$ The negotiations within the Uruguay Round proved controversial. Progress was possible only because the TRIPS Agreement is part of a package deal: in exchange for favours in the field of agriculture and textiles, IP was moved into the WTO Agreement. GIs proved to be a particularly controversial topic on which, in particular, the EC and US were diametrically opposed. Section 3 of the TRIPS Agreement is therefore a compromise, reflecting the arduous nature of the debate. The last few decades have shown great upheaval in relation to agriculture, with, in particular, both EC and US subsidy practices hindering progress during the Uruguay Round extensively - in that countries are requested to severely cut their subsidies to the agricultural sector but that they are reluctant to do so. Gls do not necessarily relate to agricultural products since cultural and handicraft goods are also covered: nonetheless, Gis are mainly used to protect basic and processed agricultural products. ${ }^{\mid m}$ The limitations to the protection of Gls (see section 1.8 on generic names) for wines and spirits indicate that strengthening the protection of GIs applies to future rather than to past practises. The EC, aware of these limitations but still determined to obtain "absolute" protection for its GIs has therefore proposed its so-called "claw back" proposal to the WTO Agricultural Committee involving a list of 41 names. ${ }^{131}$ "This implies that of the listed GIs (generic or grandfathered GIs), should be protected retrospectively regardless of their generic use elsewhere. The TRIPS Council discussions on the Gl register will depend on the move in agriculture.

The controversy between the US and the EC, and their differing interests attached to Gls, became apparent from the very start of the negotiations under the Uruguay Round with US proposals and submissions making no mention

wi: The extensive European jurisdiction on indications of origin include Council Regulation No. 2081/92 of 14 July 1992 on the protection of geographical indications of origin for agricultural products and foodstuffs and Council Regulation No. 1493/ 1999 of 17 May 1999 on the common organisation of the market in wine. In addition the EU has been very active in negotiating bilateral agreements (e.g. with Australia, Chile, Mexico and South Africa) and thereby extending its laws and regulations to third countries.

ux See UNCTAD-ICTSD [Resource Book] 2005, p. 279.

Itk See UNCTAD-ICTSD [Resource Book] 2005, p. 317.

110 EC Proposal in WTO Agricultural Committee for "claw back" of 41 GIs. See annex $W$ of WTO documents JOB (03)/ 12 and JOB (03)12/add. 1. 
of Gl protection." 11 On the other hand, the EU included detailed provisions on the protection of Cis from the very beginning of the Uruguay Round, which later formed the basis of Section 3 of the TRIPS Agreement. ${ }^{112}$ The extensive EU proposal made reference to a link between quality and geographical territory and provides for extensive protection - even when the consumer is not misled as to the real source of the good - is granted for all types of Gls. All the other proposals referred only to products originating in a certain territory and not necessarily to quality. In addition, it advocated an international register for protected indications for all products (not confined to wines and spirits) ${ }^{113}$ and the need for appropriate measures to avoid Gls developing into generic designations. The Swiss proposal was similar to that of the EC, but it additionally proposed extending the reach of GIs to services in addition to goods. The US proposal, meanwhile, took a fairly limited approach and suggested protecting Gls by means of collective and certification marks, with protection only being granted in the event that the indication was not generically used within the country. ${ }^{114}$ Surprisingly, India ${ }^{115}$ macie no mention of Gl protection in its proposal. A group of developing countries proposed protecting GIs under unfair competition rules."

The Brusids Act distinguished standard protection for all goods (i.e. use of the term "goods" implies that services are not included) and an additional protection for wines; this was supplemented by protection for spirits in the Dunkel Draft. The Brusisls Draft differed from the final TRIPS Agreement in that the latter recognises that reputation itself can constitute a characteristic of the good, by which it distinguishes GI protection from the protection given to appellations of origin under the Lisbon Agreement.

11 Suggestion by the US for Achieving the Negotiation Objectives, MTN.GNG/NG11/ W/14, 20 October 1987.

112 Guidelines and Objectives Proposed by the European Community for the Negotiations on Trade Related Aspects of Substantive Standards of IPRs, MTN.GNG/ NCi11/W/26, 7 July 1988.

113 This route was followed up under the Brussels Draft but was limited to wines in the subsequent Dtukel Draft. Draft Final Act Embodying the Results of The Uruguay Round of Multilateral Trade Negotiations, Revision, TRIPS including Trade in Counterfeit Goods, MTN.TNC/W/35/Rev. 1, 3 December 1990.

114 The US was accommodated by the insertion of text to the effect that Members should put in place the legil mems to protect Gls, hence leaving it to Members' discretion to choose the legal mode, for instance through collective and certification marks.

11 Standards and Principles Concerning the Availability, Scope and Use of TradeRelated Intellectual Property Rights, Communication from India, MTN.GNG/ NG11/W/37, 10 July 1989.

11" Communication from Argentina, Brazil, Chile, China, Colombia, Cuba, Egypt, India, Nigeria, Peru, Tanzania and Uruguay, MTN.GNG/NG11/W/71, 14 May 1990. 
Subsequently, during review sessions of the TRIPS Agreement within the TRIPS Council and framework of the WIPO Standing Committee, the involvement and awareness of developing country Members has steadily increased, which has revealed a division amongst developing countries with regards to the protection of GIs.

\subsubsection{WTO Case EC - Trademarks and Geographical Indications}

The Gl case was initiated when the European Commission published a list of 41 wines, cheeses and other regional products that it sought to protect under WTO rules to the WTO Agriculture Committee. The US and Australia claimed that the EC was not affording enough protection to their products, since the EC did not protect imported goods bearing Gls. Presumed inconsistencies between the EC's domestic system for the protection of GIs and the provisions in the TRIPS Agreement have led Australiali7 and the US ${ }^{115}$ to invoke the WTO Dispute Settlement Understanding concerning the EC's domestic system refers to EC Council Regulation No. 2081/92 of 14 July 1992 on the protection of GIs of origin for geographical products and foodstuffs (hereinafter the EC GI Regulation). "1" Australia and the US disputed the possibility of coexistence of trademarks and Gis, which is permitted under the EU Regulation. However, the core of the dispute addressed the EC's reciprocity requirements - implying that $\mathrm{C}$ i protection will only be granted in the EC if the third-country provides identical CI protection for European GIs on their territories and that local GIs (i.e. in countries other than the ECU) are protected in similar ways, as set out in the EC GI Regulation. This requirement has resulted in well-known US GIs (protected through certification marks in the US) such as "Idaho Potatoes" and "Florida Oranges" being denied protection in the EC. The EC Regulation requires that third countries protect registered European GIs in order for them to enjoy reciprocal protection of those countries' brand names in the EC. ${ }^{121}$ The

117 EC-Tratemarks and Geographical Indications, European Communities - Protection of Trademarks and Geographica! Indications for Agricultural Products and Foodstuffs, WT/DS290/18 of 19 August 2003 - Australian complaint. Reports are almost identical as they were essentially based on the same claims.

11. EC-Trademarks and Geographical Intications, European Communities - Protection of Trademarks and Geographical Indications for Agricultural Products and Foodstuffs, WT/DS17.4/20 of 19 August 2003 - US complaint.

11" On 18 August 2003, the US and Australia requested separately the establishment of a pancl. The DSB established a single panel at its meeting on 2 October 2003. The DSB adopted the Panel report on 20 April 2005.

120 The US addressed the conditions of the regulation with respect to the principle of national treatment Art. 3(1) of the TRIPS Agreement: 1) the equivalence and reciprocity conditions, as applicable to the avalability of protection for geographical indications; 2) the application procedures, insofar as they require examination and transmission of applications by governments; 3 ) the objection procedures, insofar as they require verification and transmission of objections by governments; and t) the 
US and Australia argued that the EC GI Regulation did not provide national treatment and most-favoured-nation treatment with respect to geographical indications and does not provide sufficient protection to pre-existing trademarks that are similar or identical to a geographical indication. In particular it was argued that the EC GI Regulation did not seem to accord immediately and unconditionally to the nationals and/or products of each WTO Member any advantage, favour, privilege of immunity granted to the nationals and/or like products of any other WTO Member. The EC GI Regulation also did not seem to accord to the nationals and/or products of each WTO Member treatment no less favourable that that it accords to its own nationals. The US and Australia argued that the EC situation was inconsistent with the obligations under the TRIPS Agreement, in particular, Articles 2, 3, 16, 22, 24, 63 and 65 of the TRIPS Agreement. According to the US and Australia, the EC GI Regulation limits the Gls that he EC will protect and limits the access of national of other Members to the EC set GI procedures and protection under the EC GI Regulation. The EC GI Regulation sets out that geographical names of agricultural products or foodstuffs from non-EU (third) countries may be registered as European GIs only if the European Commission approves the respective thirdcountry as providing $G I$ protection to EU products in an equivalent fashion as that is available in the EC as follows from Article 12(3) of the Regulation. Differences remain mainly in the different policy arguments underlying protection: the US has a system for protecting GIs, primarily through rights provided to private rights holders under the US trademark system, by using certification marks. In contrast, the $\mathrm{EC}$ has a special sui gencris regulatory regime for GIs, which is separate from its trademark system and which depends to a significant extent on government intervention.

Australia added, Article 1, 41, and 42 of the TRIPS Agreement. In particular it argued that the EC GI Regulation is not consistent with the obligation under the TRIPS Agreement to provide the legal means for interested parties to prevent misleading use of a GI or any use which constitutes an act of unfair competition within the meaning of Article 10bis of the PC. Moreover Australia argued that the $\mathrm{EC}$ may not have met its transparency obligations and that the EC GI Regulation was more trade-restrictive than necessary.

The main provision under dispute was Article 12 of the EC GI Regulation which sets out the conditions under which agricultural products from third countries will be protected. Article 12 stipulates that:

requirements of government participation in the inspection structures under Art. 10 of the EC GI Regulation (old), and the provision of the declaration by governments under Art. $12 \mathrm{a}(2)(\mathrm{b})$ of the EC GI Regulation (old). 
1) The third-country is able to give guarantees identical or equivalent to the specifications set under the EU Regulation; ${ }^{21}$

2) The third-country concerned has inspection arrangements equivalent to thuse laid down in the EC GI Regulation; ${ }^{122}$

3) The third-country concerned is prepared to provide protection equivalent to that avalable in the European Community to corresponding agricultural products for foodstuffs coming from the Community;

4) If a protected name of a third-country is identical to a Community protected name, registration shall be granted with due regard for local and traditional usage and the practical risks of confusion. Use of such names shall be authorised on the condition that the country of origin of the product is clearly and visibly indicated on the label.

The US fears that their industry will incur severe losses if what they consider to be generic names like "Chablis", "Feta" and "Parmesan" (are forced to) become protected names within the US. Therefore, the US has requested that the EC bring its measures into conformity with its obligations under the TRIPS Agreement. In addition, the complainants claim that the coexistence of trademarks and Gls jeopardises the exclusivity of a prior registered trademark and defeats the trademark owner's expectations under Article 16.1 of the TRIIPS Agreement. The US has argued that trademarks can incorporate certain geographical elements and, if subsequently that geographical name obtains GI protection under the EC GI Regulation, it will inhibit the ability of the trademark owner from preventing unauthorised confusing use. The US argued that Article 14.3 of the EC Regulation, which addresses the confusing use of registered GIs vis-à-vis trademarks, does not satisfy the obligations under Article 16.1 of TRIPS, because it does not ensure that a trademark owner may prevent uses of Gls which result in a likelihood of confusion with a prior trademark and thus in their view limit the rights of the trademark owner, ${ }^{123}$. The US raised the example of the three Czech beer GIs (registered under the EC Regulation) "Budejovické pivo", "Ceskobudejovické" and "Budęjovický méšt anský var" which could result in a likelihood of confusion with the "prior" trademarks "Budweiser" and "Bud", also registered for beer (and which are hence identical products). ${ }^{124}$

The EC refuted these accusations and argued that the risk of registering a GI which is confusingly similar to a prior trademark is very small given the registration criteria for trademarks as applied under EC law; and secondly that

121 Specifications are set out in Art. 4 of the EC GI Regulation (old).

122 Inspection arrangements are set out in Art. 10 of the EC GI Regulation (old).

123 See US, first written submission, para. 170, WT/DS174.

124 In addition the US alleges that the GI "Bayerisches Bier" might result in a likelihood of confusion with the prior registered trademark "Bavaria". Sec "Bayerische Bier" Case 178/84 Commission v. Germumy [1987] E.C.R. 1227. See also section 3.1.1 of this chapter. 
Article 14.3 is sufficient to prevent the registration of any confusing GI as it prevents the registration of a $G$ whose use would result in a likelihood of confusion with a prior trademark. ${ }^{125}$ Thus, a priori the registration criteria for trademarks limit the possibility of conflicts between GIs and earlier trademarks. Moreover, the EC continued that Gls are primarily non-distinctive but descriptive and, as such, are not suitable for registration as trademarks. In addition, the use of GIs on trademarks may also be deceptive insofar as they are used for goods that do not originate in the location that they designate. Thus, under EC Regulation 2081/92, Gis may only be registered as trademarks where (1) the geographical name is not currently associated with the product concerned, and where it can reasonably be assumed that it will not be associated in the future; (2) or where the name has acquired distinctiveness through use. ${ }^{2}$. The EC asserted that the TRIPS Agreement does not confer superiority to trademarks over Gis. It argued that it is not Article 16.1 TRIPS that defines the boundaries between GIs and trademarks but rather Article 24.5 TRIPS which provides for coexistence with earlier trademarks.

\section{Ruling of the WIO Panel}

The claims raised by the US and Australia predominantly concerned the TRIPS rules on national treatment and the relationship between trademarks and GIs; other issues were also raised in the complaints such as the TRIPS requirements on the Most Favoured Nation clause and on minimum standards of GI protection. $^{127}$

The WTO Panel issued two separate but almost identical reports - one for Australia and one for the US - because the complaints were essentially based on the same claims. The WTO panel firstly clarified that the EC GI regulation could protect GI names only as registered and not foreign translations or linguistic variations of the registered name. ${ }^{128}$

127 See EC first written submission, para. 292.

12. See EC first written submission, paras. 278-285. This particular issue was also under discussion in the Chiomsec case.

12: Although it woukd have been fascinating to hear the Panels view on these claims, the Pancl did not comment on these claims, it either rejected or refused to examine them.

12s The scope of Gls is limited to the extent that the right of coexistence applies for Cls only as they appear in the EU register and not to any signs, combination of signs, or translations of the indication (e.g. in the Butuetiser case). The Panel also indicated that such registration grants the right to use the indications only to goods that conform to the product specifications. 
In addition, the Panel ruled that Article 24.5 of the TRIPS Agreement provides for the coexistence ${ }^{129}$ of Gls and prior trademarks and that Article 24.3 requires the EC to maintain coexistence. Thirdly, it stated that Article 14.3 of the EC Regulation would be justified as a limited exception under Article 17 of the TRIPS Agreement. ${ }^{130}$ Fourthly, the next question addressed was whether the TRIPS Agreement requires Members to make available to trademarks owners rights against the use of GIs. The Panel reached the conclusion that the EC has not asserted the US' prima facie case that Article 14.3 of the Regulation cannot prevent all situations from occurring in which a trademark would be subject to Article 14.2 and, hence, in which the EC CI Regulation would limit the rights of the owner of such a trademark. The Panel held that the EC GI Regulation is inconsistent with Article 16.1 of TRIPS Agreement with respect to the coexistence of Gls with prior trademarks, however, taken into account the evidence presented by the EC to the Panel, this is justified by Article 17 of the TRIPS Agreement, which allows for limited "fair use" exceptions to the protection of trademarks. The Panel declared Articles 24.3 and 24.5 of the TRIPS Agreement as inapplicable in such situations. Fifthly, the Panel argued that it was a national treatment violation to make the availability of Gl protection dependent on the existence of inspection bodies. ${ }^{31}$ In the WTO Panel's view the principle of national treatment puts Members under the obligation to ensure "effective equality of opportunities" between own nationals and other Members' nationals. ${ }^{132}$ The Panel agreed with the US and Australia that the EC GI Regulation does not provide national treatment (i.e. by according less favourable treatment to non-EU Members) to other WTO Members' right holders and products for the following reasons: 1) registration of a GI outside the EC is dependant on the government of that country adopting a system of $\mathrm{Gl}$ protection equivalent to the EC system; and 2) the EC GI Regulation's procedures require applications and objections from WTO Members governments to be examined and transmitted by the govermments of those Members, and require those governments to operate systems of product inspection like nationals living in the EU. Hence, foreign governments do not have guaranteed access to the EC's system for their Cls, unlike nationals of the EC.

12: In this case, the term coexistence refers to a legal regime under which a GI and a TM can both be used concurrently to some extent even though the use of one or both of them would otherwise infringe the rights conferred by the other.

1:il See EC first written submission, paras. 268-273.

1.31 In response to this decision, the new EC Regulation does not make the availability of Gl protection dependent on the existence of inspection bodies in the thirdcountry. However, the new EC legislation demands the existence of such inspection structures for the murketing in the EU of a product bearing a GI, both for EU products and third-country products which seems contradicting.

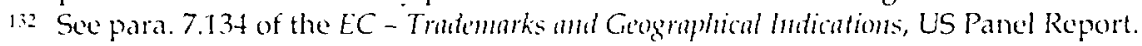


In reacting to the Panel decision, the EC replaced regulation 2081/92 with Regulation 510/2006 on "the Protection of Geographical Indications and Designations of Origin for Agricultural Products and Foodstuffs" on 20 March 2006. To comply with the instructions of the Panel the EC changed the GI protection for third-country producers in two respects: 1) the availability of GI protection; and 2) the application and objection procedure. The new regulation no longer differentiates between EC-based producers and producers based in third countries. Following Article 5.9 of the new EC regulation, in order to obtain a GI application third-country producers have to contain the same information as those by EU based producers, next to evidence that the respective name already enjoys protection in its country of origin. The new regulation no longer requires European approval of third-country Gl protection being equivalent to that in the $\mathrm{EC}$. In addition the new regulation does not require thirdcountry authorities to participate in the EC application and objection procedures, but instead they can send their Gl application directly to the European Commission and, furthermore, they may lodge their objection to Gl registration directly with the Commission.

Remarkably, both the US ${ }^{133}$ and the EC 1.34 have claimed victory in this dispute. They each emphasised different issues: the US' focus being on the national treatment principle, as the US required access to the EC system to submit applications for GI protection to the EC registry. The EC views the decision as a confirmation that the EC domestic system allow's for the coexistence of GIs with prior trademarks (under certain circumstances) as being fully justified.

\subsection{Gls Linder the WTO TRIPS Agreenent}

The predecessor of the WTO, the GAT" was enacted in 1947 and makes notion of "marks of origin" in Article IX. ${ }^{135}$ This article asks contracting parties to "co-

13 Sec <http://usinfo.state.gov/ci/Archive/2005/Mar/15-158946.html>.

13 See "WTO Panel Upholds EU System of Protection of 'Geographical Indications", FU Focus 2005 Case Comment, EUF 2005, 163, 3.

135 Art. IX of the GAIT deals with "marks of origin":

"1. Each contracting party shall accord to the products of the territories of other contracting parties treatment with regard to marking requirements no less favourable than the treatment accorded to like products of any third-country; 2 . The contracting parties recognise that, in adopting and enforcing law's and regulations relating to marks of origin, the difficulties and inconveniences which such measures may cause to the commerce and industry of exporting countries should be reduced to a minimum, due regard being had to the necessity of protecting consumers against fraudulent or misleading indications; 3 . Whenever it is administratively practicable to do so, contracting parties should permit required marks of origin to be affixed at the time of importation; 4. The law's and regulations of contracting parties relating to the marking of imported products shall be such as to permit compliance without seriously damaging the products, or materially reducing their 
operate" to prevent the use of trade names in such a manner that they misrepresent the true origin of a product to the detriment of distinctive geographical names. This provision did not entail a strict obligation but was viewed more as a form of cooperation to prevent misappropriation. ${ }^{3.36}$

The term "geographical indications" was coined by WIPO ${ }^{137}$ and defined by the TRIPS Agreement in Article 22.1 as:

"indications which identify a good as originating in the territory of a Member, or a region or locality in that territory, where a given quality, reputation, or other characteristic of the good is essentially attributable to its geographical origin". lin

This definition tells us that, for the purpose of the TRIPS Agreement, GIs: 1) address goods but they do not apply to services; 2) are a tool to identify and differentiate products in the market; 3 ) must be identified by a geographical name; 4) correspond to a territory, region or locality and the geographical origin has to exist in reality or has to identify its origin; and 5) must involve a link between the origin and the quality, reputation or special characteristics of the good. ${ }^{134}$ Following the definition of the latter, the requirements of quality, reputation or special characteristics of the good are not cumulative, implying that it is not necessary to fulfil all of them to qualify for protection. ${ }^{1+11}$ Rather,

value, or unreasonably increasing their cost; 5 . As a general rule, no special duty or penalty should be imposed by any contracting party for failure to comply with marking requirements prior to importation unless corrective marking is unreasonably delayed or deceptive marks have been affixed or the required marking has been intentionally omitted; 6 . The contracting parties shall co-operate with each other with a view to preventing the use of trade names in such manner as to misrepresent the true origin of a product, to the detriment of such distinctive regional or geographical names of protucts of the territory of a contracting party as are protected by its legislation. Each contracting party shall accord full and sympathetic consideration to such requests or representations as may be made by any other contracting party regarding the application of the undertaking set forth in the preceding sentence to names of products which have been communicated to it by the other contracting party".

5in See UNCTAD-ICTSD [Resource Book] 2005, p. 272.

13. In 197.4 WIPO's Committee of Experts developed a draft treaty for the international protection of geographical indications and coined the name geographical indications.

13: See Art. 22.1 of the TRIPS Agreement.

13.) See Vivas Eugui 2001, p. 704-705.

14t In both the TRIPS Agreement and the Lisbon Agreement, countries retain a lot of flexibility for the implementation of the provisions. Neither agreement gives an explanation as to the scope of the expression that "the quality, reputation or other characteristics of the goods must be essentially attributable to geographical origin" 
proof of one would be sufficient. Following case law, the expression "other characteristics of the good" relates to goods having distinguishable features like colour, texture, and fragrance that differentiate them from similar related products. ${ }^{1+1}$ There has to be a link between the designated product's characteristics and its place of origin. The notion of quality appears to refer to some objectively measurable, physical characteristics. The notion of reputation makes it clear that indications may qualify for protection even where the link between the designated good and its geographical origin does not result in any objectively measurable characteristics, but merely creates certain goodwill or reputation associations with consumers. In particular, the reputation of a product that traditionally belongs to a geographical area is closely linked with its continued use by production, distribution or recognition by the public in that area. In this respect, GI protection differs from an appellation of origin as the latter requires both quality and characteristics to be linked to the geographical origin and mere reputation is not sufficient to qualify for protection.

Following from the definition given in the TRIPS Agreement we can draw the conclusion that it is not the name of the geographical area but the significance of the geographical area to the name of the product that must be established to qualify for protection. For this reason, products that are not named after a geographical place name can qualify for GI protection, such as in the Basmati rici case. Basmati is not a geographical name but if it is perceived by the public to indicate rice originating from particular geographical areas in India and Pakistan, then it could in principle qualify for Gl protection. Thus, it is sufficient if a word eokes a certain territory, without itself being the name of the territory. Hence, the notion of GIs under the TRIPS Agreement is wider than its notion of appellation of origin, which requires the name of the product and the geographical name to be identical.

The WTO TRIPS Agreement sets out two different levels of protection: the basic level of protection accorded to any $G 1$ under Article 22, and a higher level of protection under Article 23 (the lex specialis) accorded specifically to GIs for wines and spirits. The special protection granted to wines and spirits basically derives from the fact that they have to be protected even if misuse of the name would not cause the public to be misled.

(as TRIPS puts it). Similar flexibility is evident in the Lisbon Agrecment, where the quality and characteristics of the products must be due "exclusively or essentially to the geographical enviromment, including natural and human factors". Just as in the TRIPS context, no test or definition was laid dow'n to determine the meaning of these terms. Moran argues that the triple connection between product, place of origin and quality remains difficult to define as quality is socio-culturally configured. See Moran 1993.

141 See UNCTAD-ICTSD [Resource Book] 2005, p. 290. 
The essential difference between the protection provided by Article 22 and that required by Article 23 is that unlike Article 22, Article 23 does not require evidence of the public being misled or the presence of an act of unfair competition in order to prevent the use of a geographical indication in respect of a product from a place other than the indicated region. Further, the use of accompanying expressions such as "style", "type", "kind", "imitation" or the like are prohibited, and protection is also provided when the indication is used in translated form.

This hierarchy in protection does not have a rational or legal foundation but is the result of trade-offs made in the Uruguay round. 12 The distinction was a compromise between the EU and the US at the end of the Uruguay Round. At that time, in the early 1990s, the EU only provided protection for wines and spirits but it wanted to expand protection for all types of Gls. This hierarchy mainly reflected the narrow vested interests of the $E U$ wines and spirits industry. The US, on the other hand, did not wish to protect GIs as such but favoured affording them protection under ordinary trademark law. Hence they came to a compromise, agreeing to give wines and spirits special protection. It is not clear how many WTO members make this distinction in practice. Some countries, including many Asian countries, the European Union, the Andean community and Egypt, have raised additional GI protection to include other products than wines and spirits in their territories. It is also difficult to examine the shortcomings of this two-track protection system since there has been no court case on failed attempts to protect GIs. In the GI extension debate, supporters of strengthening GI protection have claimed that the low standards of protection offered by Article 22 allows for "free-riding" on the reputation; thus subsequently rendering the indication "generic".143

The protection provided for in Article 22 will also be applicable against a GI that, although literally true as to the territory, region or locality from which the good originates, falsely presents to the public that the goods originate from another territory. For instance, where producers in one area " $X$ " adopt a GI for the purpose of free-riding on the reputation built by an identical GI in region " $Y$ " (i.e. a deceptive indication), Article 22.4 obligates WTO Members to make available the "legal means" for producers of a protected GI in region $Y$ to prevent the use of their GI, but only when use by producer $X$ misleads the public about the geographical origin of the product or constitutes an act of

14. See Rangnekar, fortheoming 2009.

143 Communication from Bulgaria, Cuba, Cyprus, The Czech Republic, The European Communities and their member States, Georgia, Hungary, Iceland, India, Kenya, Liechtenstein, Malta, Mauritius, Pakistan, Romania, The Slovak Republic, Slovenia, Sri Lanka, Switzerland, Thailand and Turkey on the extension of the additional protection for Gls to products other than wines and spirits, WTO IP/C/W/353, 24 June 2002. 
unfair competition (following Article 22 (a) en (b)). Producer $X$ is allowed to use the name, provided that they indicate the exact origin of the product on the label.

The TRIISS Agreement sets out an important condition in its Article 24.9, providing that Gis aill only be cligible for international protection if annestic legal protection in the country of origin is alrealy provided for. If national protection is absent or if the Gl ceases or falls into disuse in the country of origin, other WTO Members are under no obligation to protect them. This clause must be acknowledged by developing countries where in reality many potential Gis are used in the normal course of trade but are not defined as such under the domestic legishative framework or have not been registered. ${ }^{1+4}$ Hence, they cannot obtain protection at the multilateral level. If a multilateral register is introduced in the future it will be of utmost importance for them to provide domestic protection in order to make use of it. In this case, developing countries should ask for a transition period - they could, for instance, submit a list of potential Gls that deserve protection at the national, regional and multilateral level and make arrangements for domestic protection later. This way developing countries could gain time to examine the best possible ways for them to protect GIs - e.g. in relation to legislation, administrative requirements and modes of protection - on their territories in line with their socio-economic development interests.

As follows from Article 22.2(a) of the TRIIS Agreement, the G1 right holder has to prove that a third party, by designating or presenting a good, misleads the public into believing that the third party's goods originate from the same place as the protected GI - the burden of proof rests with the GI holder. The TRIPS Agreement does not define what constitutes the public or the degree of confusion required to oblige to protection of the Gl. Hence, the Members have quite some flexibility to implement Article 22 in their domestic legislation.

With respect to Article 22.2(b), the burden of proof is on the side of the GI right holder, who has to prove that the use of an indication by a third party constitutes an act of unfair competition within the meaning of Article 10bis of the Paris Comvention. The TRIPS Agreement prohibits any use which "constitutes an act of unfair competition under Article 10bis of the Paris Convention", and it extends the focus of Article 10bis of the Paris Convention to a GI "which although true as to a territory, region of locality in which the goods originate,

1 it Is significant to note that so far, not one member of the OAPI benefits from a national or regional geographical indication. However, countries recognise some "informal" Gis, which contribute to the socio-economic development of the region, by creating labour opportunities and local revenue. One example is I.e Violet de Galmi from Niger, a purple coloured onion with a special spicy flavour. 
falsely represents to the public that the goods originate in another territory", i.e. that amounts to a deceptive indication (referred to as a homonymous GI).

The burden of proof is made easier when the GI concerns wines or spirits, as in this case third parties may not use a protected GI for the designation of their own products, even where the consumer is not misled as to the true origin of the third party product. This makes it easier for the Gl holder to prove an infringement, as it is sufficient to show that the third party product using the protected GI does not originate in the indicated region. The GI holder does not have to prove consumer confusion or an act of unfair competition, which becomes a much more complex endeavour. Article 23, the lex specinlis for wines and spirits, is also subject to some exceptions, so its protection is far from absolute. For instance, it is subject to the grandfathering clause which permits the continuing use of names registered and protected before the enactment of the TRIPS Agreement. The EU pursues a global policy of eliminating these exceptions as much as possible in its bilateral and regional agreement negotiations. The lex specinlis is also subject to the same limitations/exceptions as the basic protection of GIs. Hence the exceptions for the generic names, the personal names and the obligation to obtain national protection first are also applicable to the wines and spirits legal protection scheme.

Vivas and Spennemann argue that TRIPS Article 22.2(b), in conjunction with Article 10 bis (3) of the Paris Convention, extends the protection available under TRIPS Article 22.2(a):
"while the latter covers cases of consumer confusion about the origin of the indicated good, the former addresses cases where the public is aware of the true origin, but is misled with respect to the good's nature, manufacturing process or characteristics". 1.4

They provide the example of "Californian Chablis", whereby consumers realise that the wine does not originate in France but might nevertheless associate it with, or expect the product to contain certain characteristics typical of, the famous French "Chablis". ${ }^{1+4 t}$

The pitfall under the TRIPS regime and other international treaties is that the users of generic terms and owners of prior JPRs will have to bring opposition proceedings in all the countries were their rights are jeopardised by GI registrations. There is no international tribunal or arbitrage committee to reach a (consensus) decision. Obviously, govermments are reluctant to spend their scarce resources for the cause of third-country nationals wishing to defend either a prior right or their export market where they wish to continue the use

14. See Vivas-Spennemann 2006, p. 9.

1th See Rangnekar 2003, p. 14. 
of a generic term. Table two, in annex, sets out the legal framework for indications of origin.

Members have the flexibility to implement the rights and obligations deriving from the TRIPS Agreement in a manner most appropriate to their individual legal system and practice as indicated in Article 1 of the TRIPS Agreement, and it reiterates this freadom for Cls in Article 22.2.1.7 1.t5 This provision indicates that Members are under the obligation to "provide the legal means" for the protection of Gls to be available for "interested parties" to prevent the "use of any means in the designation or presentation of a good that indicates or suggests that the good in question originates in a geographical area other than the true place of origin in a manner which misleads the public as to the geographical origin of the good" and to prevent "any use which constitutes an act of unfair competition within the meaning of Article 10bis of the Paris Comvention". 1.4" Article $23.1^{151}$ goes a step further as indicated by also providing protection even if the consumer is not misled. Members' governments are not themselves directly obliged under Article 23 to enforce protection for geographical indications, but simply to ensure that the legal means to do so are available. Therefore, even under Article 23 producers wishing to enforce protection of a certain geographical indication would do so via recourse to the available legal and/or administrative mechanism rather than necessarily relying on the government of another Member to take action on their behalf.

However, FTAs addressing Gl protection increasingly ask to provide "positive protection" of GI which goes further than the TRIPS Agreement wording "providing the legal means".

Art. 22.2 of the TRIPS Agreement reads as follows: "In respect of geographical indications, Members shall provide the legal means for interested parties to prevent: (a) the use of any means in the designation or presentation of a good that indicates or suggests that the good in question originates in a geographical area other than the true place of origin in a manner which misleads the public as to the geographical origin of the good; (b) any use which constitutes an act of unfair competition within the meaning of Article lobis of the Paris Convention (1967)".

1.4. For instance, "Darjecling" (India) for tea; "Stilton" (Great Britain) for cheese; "Swiss" (Switzerland) for chocolate; and "Roquefort" (France) for cheese are protected by the United States as registered certification marks.

1.44 Notably the fundamental difference between Arts. 22 and 23 is in terms of the scope of protection and not in terms of the obligation in respect of legal means.

150) Art. 23.1 of the TRIPS Agreement stipulates: "Each Member shall provide the legal means for interested parties to prevent use of a geographical indication identifying wines for wines not originating in the place indicated by the geographical indication in question or identifying spirits for spirits not originating in the place indicated by the geographical indication in question, even where the true origin of the goods is indicated or the geographical indication is used in translation or accompanied by expressions such as "kind", "type", "style", "imitation" or the like". 


\subsection{Role of Bilateral and Regional Free Trade Agrecments}

Next to these international (multilateral) treaties, bilateral and regional free trade agreements have been concluded in which two or more states accord to protect each other's GIs. These agreements are referred to in numerous ways, most frequent the following names are used: free trade agreements, foreign trade agreements or trade and investment agreements. ${ }^{151}$ These trade agreements will challenge ACP countries if they result in an additional layer of intellectual property rights (IPRs) legislation.

The EU has been particularly active in negotiating these foreign trade agreements to protect its Gis as it facilitates its policy strategy to export (some would say impose) its (I protection regime to other parts of the world. It is common practice to complement such an agreement with an annex listing the existing Gls within the contracting parties - which should be mutually recognised and protected. Due to the EC's large economic bargaining power, the bilateral and regional route is quicker and probably more effective than the current multilateral route for ensuring a similar level of protection for indications of geographical origin.

Most of the recently concluded regional or bilateral FTAs to which the EC or the US are one of the signatory parties include detailed IP chapters, including rules on Gls and rules on market access-related issues. Regional agreements that include a subsection on GIs are the North American Free Trade Agreement (NAFTA), the Andean Decision 486 and the Economic Partnership Agreements (EPAS) currently under negotiation between the EU and the African, Caribbean and Pacific (ACP) countries. An example of a regional agreement to protect indications of geographical origin is NAFTA, signed in 1994. Annex 313 of NAFTA states that Canada and the US shall recognise "Iequila" and "Mezcal" (spirit made of agave) as products originating from Mexico and, consequently, shall not permit the sale of any product as "Tequila" and/or "Mezcal" unless they have been prepared in Mexico, in accordance with the laws and regulations there. In return, Mexico recognises "Bourbon whiskey" and "Tennessee whiskey" as American spirits. Mexico has signed a bilateral agreement with the $E U$ that addresses the mutual recognition and protection of appellations of origin in the spirits sector (signed on 27 May 1997). Mexico signed this agreement for the following reasons: a) to increase the consumption of "Tequila" and "Mezcal"; b) to stop the marketing

(5) Art. 24.1 TRIIS Agreement creates a mandate to continue negotiations aimed at increasing the protection of GIs both through bilateral and multilateral trade negotiations. The drafters of this provision made it clear that the exceptions listed in Art. 24 ought not to be a hindrance to entering into negotiations to extend the protection of Gls. Surprisinglv, the drafters leave the matter of negotiations open, as both bilateral and multilateral negotiations are explicitly mentioned in the provision. 
of drinks with the false appellations of "Tequila" and "Mezcal"; and c) to stop the lack of recognition of its appellations of origin in EU countries that are not party to the Lisbon Agreement.

Over the past decade numerous bilateral agreements have been signed between the EC on the one side and e.g. Australia, Chile, Jordan and Mexico on the other; or between the US and Australia, CAFIA DR, Chile, Jordan, Morocco and Singapore. Almost all these agreements entail provisions on the definition of Gls, wider scope, registration, relationship with trademarks and mutual recognition of each other's Gls. These agreements can be restricted to a certain area of goods. For example, the FU-Australia Wine Agreement of 1994, in which $\wedge$ ustralia agreed to stop using, among others, the terms "Beaujolais", "Cava", "Chianti", "Madeira" and "White Bordeaux". In addition Australia agreed eventually to stop using "Burgundy", "Chablis", "Champagne", "Port", "Sherry" and "White Burgundy". See also, the EU-South Africa Wine Agreement of 2002 in which South Africa agrees to phase out use of the terms "Port" and "Sherry". This agreement contains an annex which is an 82 page long list of forbidden terms. In addition agreements have been signed on food products such as cheese and olive oil: for instance, the International Convention on the Use of Appellations of Origin and Denominations of Cheeses of 1951 (Stresa Convention) or the plurilateral Olive Oil Agreement of 1963 signed by 13 olive oil producing countries. Bilateral and regional forms of protection - to the extent that they establish protection for producers from two or more countries - may prevent third-country producers from challenging the decision to confer protection for certain type of products. For instance, "Pisco" is fabricated in Peru and in Chile. Chile has been most active in securing rights abroad by entering into bilateral negotiations with many European countries and Mexico. Peru has to a certain extent been sidelined by these actions. Consequently, bilateral protection agreements can undermine the WTO Most Favoured Nation principle by conferring more extensive protections to some Members than others. ${ }^{52}$ Moreover, these bilateral agreements often link the protection of Gls to market access. Countries should be aware of this and include it in the TRIPS review negotiations within the TRIPS Council.

Countries in the process of negotiating an FTA with the EC that includes provisions on GIs should carefully assess whether or not they will arrange for Article 23-type protection for all categories of GIs. Such strengthening of protection may possibly help them secure better protection for third-country products in EU markets, although it is likely to be more advantageous for the EU. This is because the number of GIs in the EU is significantly higher, but also because many of the European GIs already have an established reputation

152 See UNCTAD-ICTSD [Resource Book] 2005, p. 315. 
in the international market, in contrast to many developing country GIs that have to start from scratch.

In its encounters with foreign countries in the process of negotiating bilateral or regional trade agreements, the EC is seeking to achieve a level of GI protection comparable to its domestic system. Especially with regards to the ongoing pressure within the wider WTO context, where the EC is committed to lowering its export subsidies, the EC has been forced to alter its agricultural policies and adopt new strategies to maintain European market shares throughout the world - it seems that it has chosen GIs to be at the heart of that new approach. ${ }^{15.3}$ The $\mathrm{EC}$ has identified three major negotiating objectives: 1) the establishment of a multilateral register for GIs; 2) the extension of the lex specinlis to other products than wines and spirits; and 3) multilateral acceptance and enforcement of a list of selected Gls. This would involve the removal of previously conflicting trademarks and provide protection to European GIs whose name had become generic in that particular country. These measures establish a de facto removal of the exemptions listed in Article 24 paragraphs 4 , 5 and 6 of the TRIPS Agreement. The first two goals are mainly pursued at the multilateral level in the context of the TRIPS Agreement, but objective number 3 is the key drive behind the EC's bilateral and regional trade agreement negotiations.

\subsubsection{Economic Partnership Agreements}

The $\mathrm{EU}$ is currently negotiating regional free trade agreements with the ACP countries to replace the Cotonou Agreement, the so-called Economic Partnership Agreements (EPAs). To date, only the Caribbean region ${ }^{154}$ has signed a full EPA with the EU, comprising IPRs in its scope. The rest have all "initialled" so-called interim agreements covering trade in goods - with a commitment to negotiate and agree IPRs within a year. Within the chapters on intellectual property rights, the draft EU texts enclose detailed provisions on geographical indications (GIs).

Looking at the text that was initialled between the EC and CARIFORUM, the only ACP group to sign a comprehensive EPA, the following preliminary observations can be made: 1) The starting point for GI negotiations is a commitment by both parties to ensure an adequate and effective implementation of the international treaties dealing with intellectual property - in particular to the WIPO administered treaties on intellectual property and the TRIPS

15: See the ECs note titled "Why do Geographical Indications matter to us?", 30 July 2003 available on the EU website at <http://europacu.int/comm./trade/issues/ sectoral/intell_property/argu_en.htm>.

1:4 The Caribbean Forum of African, Caribbean and Pacific (ACP) States (CARIFORUM). 
Agreement. 2) Provisions that go beyond the minimum standards set in the TRIPS Agreement, so-called IRIPS plus provisions, have also been included in the text, For example, there is an extension of the higher level of protection granted to wines and spirits under the TRIPS Agreement to all kinds of products (including agricultural, food products, and handicrafts products);

3) The text contains a clear mandate to protect Gls, hence it proposes to upgrade the obligation set out under the TRIPS Agreement to provide "the legal means for interested parties to prevent use of geographic indications" to a positive obligation to protect geographic indications; 4) The text contains responsibilities in relation to the use of Gis on the internet and; 5) Both parties shall aim to negotiate an agreement on the protection of geographical indications. The EC proposed to include a list of terms, annexed to the text, which according to the $\mathrm{EC}$ do not constitute terms customary in common language. In other words, the EC is demanding exclusive use for EC producers of certain commonly used terms as part of a so-called "claw back" agenda. ${ }^{15}$

In contrast, $\triangle$ frican countries need to focus on the identification of $G$ I products that could qualify for protection. ${ }^{150}$

\subsection{Generic Nome's}

Where two geographical areas in two different countries bear the same name and, subsequently use identical Gls for the marketing of a similar type of product, a collision of interests may occur.

An increasingly globalised market requires multilateral law making, which brings with it new kinds of problems. The biggest difficulty in regulating GIs across borders is probably that which arises from the applied principle of territoriality in IPR systems. This relates to the fact that IPRs are in principle territorial in nature, in that they are protected only in the country where registration was obtained. Due to the territorial nature of trade names and indications of geographical origin, it is possible that an indication is a term customary in common language as the common name for such goods: a socalled "generic" expression for a kind of product in one country and a protected (and registered) GI in the other. For instance, "Parmesan" cheese is a protected Gl in Europe, denoting a cheese that comes from a particular area in Italy, but in the US and India it is the common or generic name for a type of cheese and is no longer understood to refer to the original area of production. In the US the use of "semi-generic names", such as "Champagne", "Burgundy" and "Chablis" - which are registered appellations of origin in

15 See Claessens 2008a.

the See section 4.3 of chapter one of this book. 
France but generic terms in the US - is permitted subject to notification of the real place of origin in direct conjunction to the name.

\title{
Article 24.6 of the TRIPS Agreement reads:
}

\begin{abstract}
"Nothing in this Section shall require a Member to apply its provisions in respect of a geographical indication of any other Member with respect to goods or services for which the relevant indication is identical with the ferm customary' in common language as the common name for such goods or services in the terrilory of that Member. Nothing in this Section shall require a Member to apply its provisions in respect of a geographical indication of any other Member with respect to products of the vine for which the relevant indication is identical with the customary name of a grape variety existing in the territory of that Member as of the date of entry into force of the WTO Agreement".
\end{abstract}

Article 24.6 of the TRIPS Agreement allows the continued use of terms/names customary in common language as the common name for products in trade even if that product is protected as a $\mathrm{Gl}$ in a third-country. Hence, it allows countries to exempt these terms from CI protection, it does so in order not to limit the use of words that have become part of their everyday language. A famous example of the problems that occur with names that are perceived to be generic in some countries but protected in others is the Basmati case, ${ }^{157}$ which started in 1997 when a company in the US obtained several patents on rice lines (although some claims have been revoked for lack of novelty). In addition, the American company tried to obtain a trademark claiming that Basmati was a generic term; though it failed to so in the US, the name is nevertheless regarded as a generic term. ${ }^{15}$ However, countries, which are a member to the Lisbon Union do have to provide reciprocal protection for names that are registered under the Lisbon Agreement. The Lisbon Agreement provides that, as long as an appellation of origin is protected in the country of origin it cannot become generic (Article 6 Lisbon Agreement) in one of the countries of the Lisbon Union.

15: Basmati refers to long grain aromatic rice from the Northern regions of India and Pakistan. Its characteristics are due to a complex combination of soil, climate, agricultural practices and the genetics of the Basmati variety.

155 The problem with the name Basmati is also due to neglected government practices; why did India and Pakistan not interfere earlier against the gradual adoption of generic status over the last 20 years? For more information on the Basmati case, see Lightbourne 2003. 
Article 24.4 of the TRIPS Agreement 150 contains a "grandfathering clause" that allow's countries to continue using particular Gils that have been used for at least 10 years prior to the adoption of the TRIIS Agreement and which have resulted in identical Gls originating in different parts of the world ${ }^{\text {tal }}$ Immigrants from Europe that brought their traditions with them during periods of colonisation have led to the introduction of certain production techniques and/or using imported seeds and using similar names for similar or identical products. Homonymous Gls relate to the use of names by the European immigrants that have taken the names along with the methods for making certain products to their new homelands and have been using them in good faith. An example is Rioja wine, which derives from a wine region in Spain but also from a wine region in Argentina. In fact it was the Spaniards bringing their wine grapes to Argentina a couple of centuries ago that introduced the wine manufacturing technique and skills to Argentina. The name is protected by an appellation of origin for wine in Europe. The National Wine Institute of Argentina, on the other hand, has insisted on the validity of the appellation of origin, given that the regions are homonymous and that any risk of confusion is avoided by the additional indication of Argentina as the origin of the wine. When the use is in good faith (bonn fide $)^{\text {lnd }}$ both indications may be maintained following Article 23.3 (so-called homonymous GIs). Notably, this provision is limited to wine. In the Rioja case both parties are allowed to use the name but

Iaw Art. 24.t of the TRIPS Agreement reads: "Nothing in this Section shall require a Member to prevent continued and similar use of a particular geographical indication of another Member identifying wines or spirits in comnection with goods or scrvices by any of its nationals or domiciliaries who have used that geographical indication in a continuous manner with regard to the same or related goods or services in the territory of that Member either (a) for at least 10 years preceding 15 April 1994 or (b) in good faith preceding that date".

lew For example, the name "Parma" was registered by a Canadian citizen before the TRIPS Agreement entered into force implies that Italian producers of "Prosciutto di Pama" have to resort to expensive litigation and re-label their product as the "No. 1 ham" on the Canadian market and compete with the locally produced "Parma" which is chimed to be of an inferior quality. The European Commission estimates that the losses are some 3 million euro per year. "Parma Ham" faces a similar situation in Mexico and Argentina. Similarly, GIs that have become generic in third countries or have been used in good faith ten years prior to the TRIPS Agreement do not need to be protected under WTO rules. The European Commission argues that the grandfathering clause "discourages export and promotion efforts as the reputation of a GI has been so severely eroded that is no longer worth it to make the effort of entering those markets". See <http://ec.europa.eu/trade/issues/sectoral/ intell_property/argu_en.him>.

inl Art. 22.4 of the TRIPS Agreement stipulates that: "The protection under paragraphs 1, 2 and 3 [of GIs] shall be applicable against a geographical indication which, although litemally true as to the territory, region or locality in which the goods originate, falsely represents to the public that the goods originate in another territory". 
it follows from Article 23.3 that Members are to determine the practical conditions under which the homonymous indications in question will be differentiated from each other, taking into account the need to ensure equitable treatment of the producers concerned and that the consumers are not misled. ${ }^{162}$ Hence, Members are allowed considerable flexibility in the implementation of this provision. In this case the producers can fulfil the TRIPS requirements with precise labelling that provides both the name of the region and the country. One could argue that the procedure laid down for homonymous trademarks lowers the level of protection given to wines to the basic level of protection, where consumer confusion may be avoided by precise labelling.

Article 24.5 of the TRIPS Agreement recognises that trademarks which have been "applied for or registered in good faith" or where the rights to a trademark "have been acquired through use in good faith", either before the implementation of the TRIPS Agreement or before the establishment of GI protection in the country of origin, may continue to exist. ${ }^{16.3}$ This recognition of prior trademark rights is limited to a notification period (to show proof of registration or use of a prior trademark right) of five years after the adverse use of the protected indication has become generally known in that Member (following Article 24.7).

\section{Lligal and ECONOMIC Rationale Underlying GI PrOTECTION}

\subsection{Introduction}

It should be recalled that goods bearing a GI are not produced to serve a wide market: they are not "designed to be sold as commodity goods or to have a hegemonic preponderance in the market" but in most cases represent luxury or high quality (mainly agricultural food) goods. ${ }^{164}$ Consumers are willing to pay premium prices for high quality goods in order to buy into their reputation and quality. In order to accommodate this demand, the public needs to be informed on the quality and characteristics of the product in question by using labels, trade names etcetera. When there is a specific geography-product link, associations of producers use indicators of geographic origin such as GIs, appellations of origin, collective marks and certification marks on their products.

162 Art. 23.3 of the TRIISS Agreement address homonymous Gis: "In the case of homonymous geographical indications for wines, protection shall be accorded to each indication, subject to the provisions of paragraph 4 of Article 22. Each Member shall determine the practical conditions under which the homonymous indications in question will be differentiated from each other, taking into account the need to ensure equitable treatment of the producers concermed and that consumers are not misled".

1h: See Art. 24.5 of the TRIPS Agreement.

1m. See Vivas Eugui 2001, p. 705. 
These indications give the consumer confidence in the origin of the good, which is synonymous with a particular quality and/or special characteristics. Gis are most frequently used in the production of wine, licuors and agricultural products, although the potential of Gl protection is increasingly being explored by the producers of special handicrafts, fumiture, textiles and industrial and mining products. ${ }^{165}$

Gradually more countries have recognised GI protection; this paragraph seeks to address the underlying policy changes in this respect. Why have these changes occurred? Various policy arguments underlie the introduction of GI protection: for example, to safeguard the producer's position against a loss of reputation due to competitors' practices (traditionally the justification behind European CI policy); or to protect the consumer from being misled as to the real source of the products (the approach traditionally taken by the US). Increasingly, Gls are also being used as a tool for development and the distribution of wealth, as, for example, in India.

Since indications of geographical origin link production to the territory from which they originate, they can play an important economic role in serving to protect intangible assets constituted by market differentiation, reputation and quality standards. ${ }^{16 t}$ 'The following sections attempt to set out why protection is granted to indications of geographical origin. The rationale or justification for allowing the establishment of a legal framework of protection has evolved over time. Initially, both the protection of the producer and the consumer were at the forefront of attention - i.e. to provide information. But more and more indications of geographical origin are being used to protect other interests, such as those of the agriculture sector; to safeguard cultural traditions, traditional knowledge and production methods; and recently also to stimulate the socio-economic development of the poorest regions of the world ("a wealth distribution argument"). What is the underlying rationale to protect indications of geographical origin? Innovation (IPRs) or the preservation of (agricultural) rural production and cultural artesian practises.

\subsection{Gls as a Tool for Information}

Distinctive signs such as indications of origin can be instrumental in resolving market failures that derive from the asymmetry of information. ${ }^{167}$ Without a geographical name indication consumers might be misled as to the quality,

1" Register of the Lisbon Agrcement, available at: <lettp://www.wipo.org>.

twe See Vivas Eugui 2001, p. 705.

wi Indeed, the preamble to EC regulation 2081/92 emphasises that "in view of the wide variety of products marketed and of the abundance of information concerning them provided, consumers must, in order to be able to make the best chose, be given clear and succinct information regarding the origin of the product" (recital 4). 
origin and properties of the product. In addition, imitation of the product in question (or the sale of inferior products at the same price) can severely damage the producer's reputation and may leat to a loss of future business. This is why manufacturers safeguard their rights and take action against counterfeiting in the case of trademarks, the risk of becoming generic (e.g. parmesan cheese, protected in Italy but the common name for a type of cheese in the US without regard for where it has been produced) and turning mainstrenm (i.e. not associated with luxurious products or high quality products).

Product information is crucial to consumers to enable them to choose between multitudes of competing goods of varying qualities. As detailed below, indications of origin, next to trademarks, can fulfil an important purpose in the provision of information. Economists look at the use of distinctive signs such as indications of geographical origin and trade marks as part of the information theory, for instance using Shapiro'sits model on reputation and Akerlof $s^{\prime \prime 164}$ model of lemons". 171

From an information theory perspective, it flows that market failure is caused by an asymmetry of information between the producer and the consumer. This asymmetry results from the fact that the producer is in a better position to judge the product's properties, and thus consumers are in a disadvantaged situation. Nelson ${ }^{171}$ identifies three categories of goods (in relation to agrofood products) that are distinguished by the information perception of customers:

1) Search goods - consumers can ascertain quality before buying them;

2) Experience goods - consumers can ascertain quality afler buying and using them;

3) Credence goods - consumers cannot ascertain quality even after using them. ${ }^{122}$

Nelson states that consumers often do not have access to information such as quality, price offers, origin or characteristics and that this information is essen-

lew See Shapiro 1982.

(ni") See Akerlof 1970.

17 Lemons is a term coined in the US to refer to second hand cars.

17 See Nelson 1970.

172 Ragnekar exemplifies this by arguing that a bag of coffee beans could be considered a search good for those consumers who are mainly interested in the price rather than other product attributes. If the consumer valued other attributes, such as the flavour and aroma, as well as the price it would be classified as an experience good. The same coffee bag would be classified as a credence good if the consumer is interested in the production process, for instance the salary of the worker, the use of child labour or environmental circumstances. See Ragnekar 2004, p. 10. 
tial to making a well-considered choice. ${ }^{1 / 3}$ Only in the case of experience goods and credence goods can we speak of market distortion due to information asymmetry. By definition, search goods do not represent an information asymmetry between buyers and sellers.

$\wedge$ kerlof sets out that asymmetrical information can be detrimental to quality standards. The producer is the only one who is truly informed about the product's ingredients and recipe and hence can misrepresent its quality. It is this practice of dishonesty that involves costs for consumers, competitors and at the end even the dishonest trader. Quality uncertainty consequently leads to losses for:

1) the cheated consumer;

2) competing businesses who are driven out of existence;

3) the trust undermined in the marketplace. 17.

To counteract these effects of quality uncertainty, concepts such as warrantees, trade marks, indications of geographical origin, and the grant of licenses to practitioners (such as lawyers and doctors) have been developed. In addition, trust is an important factor in this economic theory. Akerlof points out that, especially in developing countries, dishonest practises result in business difficulties for both consumers and producers. Such practices lead to greater variations in quality and consequently the need for quality control and improved consumer awareness and education. ${ }^{175}$

Shapiro refers to the quality of a company's output and interest in reputation as indicators of consumer perception, and argues that consumers' expectations about product quality form the reputation of a company. Essential to Shapiro's theory is the supply of information to consumers:

"The sooner the consumer perceives a product's true quality, the smaller the differential between its marginal cost and the premium price. This differential, which causes a reduction in well-being as compared to a situation of perfect information, should not be considered a market failure, but rather as a cost stemming from the fact that information is imperfect: costs arising from a lack of information are just as real as production costs. It follows that while there are advantages in terms of overall well being to improve the level of consumer information, informational programmes incur a significant cost; it is therefore necessary to strike a balance between these two elements".

173 See OECD $2000, p .7$.

17 See Akerlof 1970.

175 See Akerlof 1970.

17. See OECD 2000, p. 33 referring to Shapiro's model. 
Consequently, to increase consumer information, producers invest in building a reputation by producing high quality goods and through labelling, advertising, trademarks, signs indicating the origin or certificates of guarantee. Furthermore, governments and agencies regulate consumer information through labelling, which contains information on production methods, packaging, product origin, the presence of genetically modified organisms, etcetera. These activities are not without costs, on the contrary marketing expenditures are extremely high and hence it provides market value and hence this also explains the push for extended protection in the TRIPS Council negotiations and in regional and bilateral deliberations. See section 4.1 of this chapter for more information on the extension debate currently taken place in the TRIIS Council.

\subsection{Clsas a Tool for Protecting Producerand Consumer}

Gls as a tool for information is closely linked with GIs as a tool for the protection of producer and consumer. Product differentiation is an important aspect of building competition position on the market place. It benefits the consumers since they are offered more choices with more information about product quality. On the other hand it also benefits producers, who are able to develop quality products and can worry less about unfair or misleading competition in export markets if protection is international. Increased competition helps to differentiate prices and offering lower prices to the consumer.

The introduction of protection for geographical names (firstly under competition law) was a direct result of damages endured by businesses from a false representation by a competitor that its product originated from the same source. In order to support a claim of unfaimess under a competition regime, one needs to show that the public perceives the good and the geographical name to be intrinsically associated and that the public was misled by the use of the name. ${ }^{17}$

177 The misuse of GIs in trade gives rise to various legal remedies. For instance, depending on the jurisdiction concerned, legal actions could be taken for misrepresentation, unfair competition, or for misleading and deceptive conduct in trade. On the other hand, misuse that involves trademarks incorporating a geographical term, for instance wherely a competitor started selling chocolate labelled Cote $\mathrm{d}^{\prime} \mathrm{Or}$, can be remedied by an action of trademark infringement. Hence, if the use of the term falsely implies something to the consumer about the geographical origin of the good the remedy lies in the realm of an action for misrepresentation. Arguably an action for misrepresentation is not a sufficient remedy to protect GIs, as in most cases they indicate so much more than the geographical origin, for instance assuring a certain quality or characteristics since they are usually subject to product standards and control mechanisms. 
Unfairness is comprised of two elements from the perspective of the producer:

1) Free riding on the reputation of the injured party;

2) Loss of reputation that results from goods placed on the market that are of inferior quality but traded as the original product (counterfeiting).

From a consumer perspective, unfairness derives from the deception and misleading of customers as to the real provenance and quality of the goods, and thus a failure to meet the expected quality. ${ }^{178}$

\subsection{Gl as Tool for Agricultural Development}

Distinctive signs, such as Gls and trademarks, are also potential tools to promote the recognition of biological products. The function of Gls, as a tool for agricultural development and as a tool for the redistribution of wealth (discussed in next section) respectively, are very much intertwined as developing countries are agricultural societies and agricultural development is an important aspect of socio-economic development.

Since agricultural subsidies are slowly disappearing, due to the growing protest against protectionism and the call for the opening of markets, other ways are being sought to support vulnerable agricultural markets. The EC, forced to change its agricultural policies, has opted to fill this gap by introducing new legislation on the protection of GIs and now advocates quality rather than quality. ${ }^{179}$ Hence, with the continuing pressure to end subsidies, Gls are seen as a new tool to facilitate agricultural policies and advance on product differentiation by predominantly European countries. ${ }^{180}$ However from a development point of view, protection can also help avoid the (subsidy-dependent farming sector) standardisation and homogenisation of (agricultural) production currently rapidly taking over the local traditional production practices of small-scale farmers. It is clear that there are opportunities

17 The EU's experience has been that the introduction of registered designations of origin on their territory (protected designations of origin (PDOs)) "have proved successful with producers, who have secured higher incomes in return for a genuine effort to improve quality, and with consumers, who can purchase high quality products with guarantees as to the method of production and origin". EC Regulation 2081/92, recital 6 .

17) See <http:/ / ec.europa.eu/trade/issues/sectoral/intell_property/argu_en.htm>.

180 The Preamble to the EC Regulation 2081/92 reads: "Whereas, as part of the adjustment of the common agricultural policy the diversification of agricultural production should be encouraged so as to achieve a better balance between supply and demand on the markets; whereas the promotion of products having certain characteristics could be of considerable benefit to the rural economy, in particular to lessfavoured or remote areas, by improving the incomes of farmers and by retaining the rural population in these areas". 
for developing countries to use GIs as a tool for poverty alleviation in rural areas - especially for handicrafts, artisan items, rice, coffee (comparable to connoisseur wine producers), tea etcetera. In addition, the protection and promotion of GIs can help to promote the region of origin. For instance, the relationship between product and place (which is at the basis of protection) could furthermore be beneficial to the attraction of local tourism, as is demonstrated by the Peruvian potato project in Cuzco, the attraction of numerous tourists to the Napa Valley in California and the Champagne region in France.

These are various issues to take into consideration in evaluating the viability of GIs as an instrument to support specific biological trade products. They are most effective when the product reputation and consumer preference are already established in national and international markets. Indeed, a significant demand or niche should already exist for the product based on its distinctive origin and characteristics. Generally, this is more likely to be the case in relation to products purchased directly by consumers, as opposed to raw materials.

Next to the EC, some developing countries, especially the ones with large agricultural industries, have realised the potential of GIs as a tool for strengthening their sustainable development and economic growth policies and strategies. For instance, developing countries are benefiting from the Gl protection of products such as "Basmati", "Darjeeling", "Tequila", and "Pisco".

Developing countries should explore and identify potential GI products in the areas of agriculture, fisheries, crafts and artisan works, as these sectors provide livelihood for a large part of the population (e.g. in Uganda approximately 70 per cent of the population is dependent on subsistence farming). Another question of concern is whether GIs contribute to preserving biodiversity and the environment (for instance in relation to promoting endemic species and avoiding indigenous seeds from going extinct) or whether they lead to uniformity (as in the Tequila case). Is the contribution of GIs to local resources and the environment linked to the economic impact of the GI? However as interesting as these issues may be they are outside the scope of this chapter but may be suitable for further research projects.

\subsection{Gl as Tool for Development - Redistribution of Wealth}

IPRs are a public policy instrument and hence, if used correctly, the introduction of indications of origin protection can be used to promote sustainable development. Because of the collective nature of GI protection and its focus on traditional ways of production, it holds particular potential for indigenous groups and communities. Although indications of geographical origin fall 
within intellectual property, they can be distinguished from other types of IPRs included in the TRIPS Agreement by their shared character, ${ }^{181}$ in that a GI is normally not owned by a single entity but is rather an identifier that is used by producers in a particular place. ${ }^{182} \mathrm{~A}$ GI is therefore more than a collective monopoly right since it is open to all producers within a designated region that meet its product specifications. In particular, they protect and promote the interests of smaller producer groups that continue to practise long-standing production techniques. GIs can refer to different concepts, cultures and tradition (as is shown by the "Pisco" and "Darjeeling" examples). They facilitate market development by protecting the market share and reputation of commodities in addition to identifying an explicit quality associated with valuable know-how. Protection for GIs may transform cultural values into economic value and reorganises supply chains. ${ }^{183}$

Next to the specific characteristics of the natural environment, it can be essential to achieve a certain quality human input. ${ }^{18.4}$

In the Parma ham case Advocate-General Alber noted the "general tendency of legislation to bring out the quality of products within the framework of the common (EC) agricultural policy, in order to promote their reputation". ${ }^{185}$ The means used for this purpose include designations of origin. This underlying common agricultural policy argument to EC Regulation 2081/92 concerned not only the protection of the quality of agricultural products but also matters of structural policy which encourages the diversification of agricultural production "so as to achieve a better balance between supply and demand on the

181 See Ribeiro de Almeida 2005: in his view geographical indications are IPRs but the contents of such rights are not entirely private, rather belonging to a very unique public sphere.

152 See UNCTAD-ICTSD [Resource Book] 2005, p. 270.

18.3 For instance "Nuoc Mam" from Phu Quoc has tripled in price since it was granted Gl protection in 2001. See "Ceographical Indications: A business opportunity and a rural development tool" <http://info.worldbank.org/etools/docs/library/55547/ geoindications/geoindications/pdf/Gleconomics.pdf $>$. Also, the European Commission website reports that GIs are important for their producers and exports as they have increased product value: "GIs provide added value to our producers. French GI cheeses are sold at a premium of $€ 2$. Italian "Toscano" oil is sold at a premium of 20 per cent since it has been registered as a GI in 1998. Many of these products whose names are protected, are exported. 85 per cent of French wine exports use GIs. 80 per cent of EU exported spirits use GIs. Gls are the lifeline for 138,000 farms in France and 300,000 Italian employees". See <http://ec.europa.eu/ trade/issues/sectoral/intell_property/argu_en.htm>.

1s An example of the importance of human input is the cacao of "Chuao" Cacao varieties are found on the Venezuclan coast but subsequently produced under particular climatic conditions and use is made of traditional drying and fermentation procedures of the Afro-American communities residing in this area. The "Chuao" cacao is protected by a geographical indication.

is: See Ravil v. Bellon import Srl and Biraghi SPA, C-469/00, 20 May 2003. 
markets; whereas the promotion of products having certain characteristics could be of considerable benefit to the rural community, in particular to lessfavoured or remote areas, by improving the incomes of farmers and by retaining the rural population in these areas".186 These underlying wealth distribution arguments could be beneficial to developing countries as well: in order for that to be so, smart legal drafting and thoroughly considered policies should be introduced to stimulate (agricultural) development in rural areas, which would even be beneficial to socio-economic disparities within a country.

To make efficient use of GIs in promoting and stimulating socio economic growth, not only should the laws to protect them be in place but also adequate enforcement mechanisms, GI registers, methods of production, mechanisms to ensure quality control and access to markets. Nevertheless, stronger GI protection alone will not make a major change in economic development since other barriers to trade still exist and need to be complied with. Currently, high tariffs, quantative measures, product quality requirements and hygiene standards on agricultural products make it difficult to enter foreign markets. Developing countries would benefit from the increased opening of Western markets, and in particular a reduction in the tariff lines applying to traditionally made products or those manufactured by indigenous and local communicates. In addition the re-valorisation of bio-products, should contribute to making developing countries part of the globalisation of economic activities. ${ }^{187}$ For these reasons, Gls can be regarded as a promising policy instrument for

18t See EC Council Regulation 2081/92, recital 2, 1992. In other cases, protected designs of origin and other newly created rights like GIs have been used to compensate for the lost national statutory protection from competition, e.g. in the Bayerische Bier case, Case 178/84, Commission v. Germany [1987] E.C.R. 1227.

ist Globalisation, despite bringing different cultures and their products closer to a global marketplace, also involves an increasingly uniform world in which standardisation and norm setting come with risks as well as opportunities. In fact, they raise all kinds of questions in relation to food safety and health concerns, the protection of cultural diversity and so forth. Moreover, rapid globalisation and standardisation has resulted in the product-origin link disappearing. In response, a growing trend has emerged for returning to "the basics", to natural and local products. Consumers are more conscious of food production, not least through popular culture, such as the recent films "Darwin's Nightmare" (documentary film by Hupert Sauper 2004) and "Super Size me" (film directed by Morgan Spurlock 2004) which brought the consequences of mass production for animals, the environment and development to the attention of the global masses. Fair trade campaigns by OXFAM and other civil society organisations have raised awareness about the often arduous conditions faced by farmers in developing countries, e.g. long working hours, low wages, the involvement of child labour and the position of woman. As a result, development-friendly products labelled with the "Max Havelaar Hallmark" and other fair trade insignia, or products produced under environmentally-friendly production methods, have gained support and a niche in the market. 
developing countries on the condition that supply chain management, constant quality is guaranteed and infrastructure is improved.

The discussion on GIs was partly moved (initiative of the EC) from the TRIPS Council to the WTO Agricultural Committee partly due to the linkages between enhanced GI protection on market access for agricultural products. ${ }^{188}$ Stronger GI protection has an impact on market access for agricultural products (which serves to justify the shift to the WTO Committee on Agriculture) in that product differentiation is an important feature of competition. Many developing countries are exporters of agriculture (mainly raw) products, including Chile, Kenya, Tanzania, Ghana, South Africa and Thailand. These countries face market access difficulties due to high tariffs and strict technical regulations set by many developed countries, particularly in the EC. ${ }^{189}$ Thus it would be advisable for developing countries to link negotiations on strengthening international GI protection with increased liberalisation and market access in the agricultural sector otherwise extended protection for GIs is useless as there are no markets to pursue business. ${ }^{190}$

This shift has been criticised on the grounds that agricultural negotiations focus on food products, whereas the TRIPS Agreement covers all types of products like cultural goods, including handicrafts. Moreover, the TRIPS Council is perceived to be better equipped to deal with this topic since it has a deeper pool of knowledge in the area and can treat the subject more fully. Currently the TRIPS Council deliberations are of a very short nature: countries are supposed to gather for two full days but nowadays meetings seem to come to a close before lunch break on the first day. ${ }^{191}$

\subsection{Gls as a Tool for Cultural Heritage and Traditional Knowledge Protection}

Traditional methods of production relate, in principle, only to agriculture products. As is set out in Chapter three on traditional knowledge, developing countries in particular have a very rich variety in biological diversity. Cultural practices and customs play an important role in contextualising and shaping

158 Initiated by the EU, see "EC's proposal for modalities in the WTO Agricultural negotiations of 28 November $2003^{\prime \prime}$.

189 The tariff structure employed by the EU shows that, particularly for food products, tariffs are exorbitantly high: tariffs above 200 per cent are levied against dairy products, garlic, bovine and pork meat, bananas, processed cereal grains, mushrooms, wine and starch. Tariffs over 100 per cent are raised against rice, olive oil, sugar and prepared vegetables.

19) There may be an interesting link between the TRIPS Agreement and technical barriers to trade (TBT) which I have not further addressed in this chapter.

(19) This seems to be the case for TRIPS Council Meetings that were scheduled in 2007 and 2008. 
Gl products in many ways, for instance in terms of the origin of the product, authenticity, traditions and good farming practices. ${ }^{192}$

Gls are not necessarily held by one single right holder but may be used by all producers in the indicated area, which makes them suitable for the protection of community interests. ${ }^{143}$ They cannot be assigned or licensed to other producers outside the indicated area.

With regards to the scope of protection, Article 22.1 of the TRIPS Agreement sets out that its subject matter of protection is "goods", thereby excluding "services" from its scope of protection. Nonetheless, it does not limit protection to a particular category of goods, so all kind of goods, from agricultural products to handicrafts, can be protected under the GI regime.

In some jurisdictions there are deeply embedded traditions within which the products are located and hence the need to protect them:

"[t]his protection constitutes a legitimate safeguard of rights acquired by" generations of producers of a region who have imposed on themselves a certain number of rules and disciplines". 194

For example, in the Feta cheese case, the Advocate-General Colomer in his pleadings referred to a culture-related argument about food characteristics. Colomer argued that the quality and the characteristics of production within the Greek environment contribute to the colour, texture, smell and taste of the cheese. But in addition also the cultural environment of the Greek region and the traditional means of production contributed to the special characteristics of the cheese. ${ }^{195}$

The emphasis on the relationship between the product and quality or characteristics derived from its geographical environment is also indicative of the intention to protect the interests of the producer (or community). The incorporation of both natural and human factors belonging to the geographical environment in the definition of appellations of origin or GIs looks promising for developing countries that are looking for ways to protect their traditional knowledge. Traditional knowledge embodied in the stages of production,

192 See Ragnekar, forthcoming 2009, p. 15.

143. Unlike conventional trademarks, which are in principle owned by one particular owner (with the exception of collective trademarks, which do involve shared ownership but, unlike GIs, are available to all producers in the region; a collective trademark is typically limited to a pre-defined group of owners). See UNCTAD-ICTSD [Resource Book] 2005, Chapter 15, Section 1.

194 Institut national des appellations d'origine, the French regulatory body quoted in Moran 1993.

145 Reasoning 193 and 197 of the FETA case; joined cases C $-465 / 02$ and C $-466 / 02$. 
preparation or processing could to some extent be protected through the framework of appellations of origin protection. Nonetheless, GIs can only protect traditional knowledge to a certain extent as they do not protect the actual knowledge embodied within the good and/or the associated production process. As a result, GI protection does not guarantee against the misappropriation of TK (i.e. bio piracy). Despite these shortcomings, GI protection can be used as a legal tool to develop, market and protect a certain indication of geographical origin, especially for products based on distinctive methods of production that have been preserved and nurtured over time and passed on from generation to generation within communities belonging to a certain region. ${ }^{196}$

Certain IP concepts are considered to be more suitable for the protection of TK than others. GIs seem to be suitable for protecting TK as they are, unlike other instruments of IP, more accommodating of the customary practices of indigenous communities. Their distinguishing features for this purpose are that: 1) knowledge remains in the public domain (no institution or individual exercises exclusive monopoly control over the knowledge); 2) rights are in principle held in perpetuity (as long as the product-place link is maintained and the indication has not been rendered generic); and 3) the result of protection is to limit the number of people (to a particular designated community) who may use the protected indication and fulfil the set production requirements (and as a result one cannot assign the rights to a third party, as is possible under patent law or trademark law).

Indications of geographical origin have already been effectively used in a number of developing countries to recognise, protect and reward traditional (established) practices. Cncno de Chuno, for example, is the appellation of origin given to the native cacao varieties found in the Chuao locality of Venezuela and produced using the traditional drying and fermentation procedures of the Afro-American communities living within this region. The appellation of origin resulted from the joint efforts of the local community, local, national and regional authorities, and R\&D institutions. The Cacao de Chuno is highly regarded for its aroma and flavour and is currently exported to high-quality chocolate producers in Europe.

\subsection{Conclusion}

This section, and the above exposition of the characteristics of indications of geographical origin, has shown that distinctive signs, by protecting the identity and quality standards of biological products, can preserve agricultural practices and traditions, add value to product, and increase their reputation

196. See Das 2007. 
and market share. Moreover, by recognising the physical and environmental factors as well as traditional practices linked to the product, Gls have a particularly important potential to protect and promote the sustainable use of biodiversity and related TK and more equitable sharing of benefits deriving from biodiversity (genetic resources), practices and customs. Hence, GIs are well recognised as a tool for marketing and consumer protection, and may have a direct impact on local development and the promotion of traditional customary practices. Nonetheless, GIs, as well as other distinctive signs, have costs and limitations that must also be considered in order to determine their most useful application in relation to biological products. It is also important to recognise that the use of GIs does not in itself guarantee market access or commercial success. Constant development of and investment in promotion and communication strategies is crucial to effectuate the potential benefits of product differentiation. It is important to note that GIs do not prevent producers from other regions from marketing the same kind of product, but do prohibit them from selling these products under the same reference or label. Products protected with GIs must therefore remain competitive in their market category and keep consistent quality.

\section{TRADEMARKS VERSUS INDICATIONS OF GEOGRAPHICAL ORIGIN}

Geographical indications and trademarks both function as source identifiers except that GIs link the product with a specific geographical location instead of a particular enterprise. Both GIs and trademarks distinguish goods and services and protect against consumer confusion. ${ }^{197}$ Trademarks need to be fanciful and distinctive in order to differentiate products. A trademark functions as an indicator of the enterprise manufacturing the product and acts as an information channel to consumers - and therefore to some extent addresses the information asymmetry (as addressed in more detail in section 2.2). The key economic rationale underlying trademark protection relates to the activities (and expenditure) undertaken by the enterprise to develop a brand name and associated reputation. In particular, brand development demands investments in maintaining certain quality standards and advertising and promoting distinctive signs, names and logos. All these efforts are undertaken to make it easier for consumers to identify and differentiate the brand products from

197 Art. 15.1 of the TRIPS Agreement sets out what may constitute a trademark: "Any sign, or any combination of signs, capable of distinguishing the goods or services of one undertaking from those of other undertakings, shall be capable of constituting a trademark. Such signs, in particular words including personal names, letters, numerals, figurative elements and combinations of colours as well as any combination of such signs, shall be eligible for registration as trademarks. Where signs are not inherently capable of distinguishing the relevant goods or services, Members may make registrability depend on distinctiveness acquired through use. Members may require, as a condition of registration, that signs be visually perceptible". 
similar types of products. In effect, another economic rationale underlying the legal protection given to trademarks is to provide incentives to enterprises to continue making investments in maintaining a minimum level of quality and brand development. This is all quite similar in the case of GIs, although GIs derive their quality from their geographical origin rather than industrial practice.

Indications of geographical origin cannot be registered as ordinary trademarks because they are descriptive rather than distinctive: they are not fanciful but descriptive as the name tells something about the goods. ${ }^{198}$ In fact, they need to be descriptive; otherwise it would not qualify for protection under indications of geographical origin legislative framework. Gls fulfil two purposes: 1) to guarantee the geographical origin of the good; and 2) to ensure certain qualities, characteristics or the reputation of the good. In contrast, if the trademark informs the consumer about the qualities of the labelled good, it does this in an indirect way, not because of the descriptive meaning of the term (trademark) or link between geographic origin and product but rather because consumers have come to associate certain qualities with an identifiable trade source. A registered trademark incorporating a geographical term can distinguish the goods of one trader from those of another, rather than the goods from one region from the goods from another. Broadly speaking, the trader is the registered owner of the registered trademark. Again, that the use of the term is fanciful does not mean it is without meaning; the trade origin of goods can indirectly signal the characteristics of the goods to consumers who have learned by experience that goods with the mark have certain consistent qualities. But the trademark does not in itself, and does not necessarily by implication, indicate anything about the quality or characteristics of the good. Trademarks can be assigned from one company to the other. In contrast, an indication of geographical origin cannot be assigned to another owner as only producers within the region who fulfil the set production methods may use the name, it does indicate quality and its name is descriptive. Both GIs and trademarks can in principle be perpetual, as long as the required fees are paid and the requirements for protection are still met. ${ }^{199}$ appellations of origin and trademarks. The Court held that: "a trademark is arbitrary, of fantasy and not necessary; that it does not indicate the essential quality of the product, that it is the object of private property and owned exclusively by he who had adopted it; and it can be assigned independently from the enterprise and finally that, as it is privately owned, it can [in principle, subject to certain conditions, be perpetual]". See Cour de Cassation, 1 December 1987, France, dispute between the appellation of origin "Romanée-Conti" for wine, which had also been filed as a trademark, and the trademark "Vicomte Bernard de Romanet". 
As indicated above, the main function of trademarks is to distinguish the marked products from other products; and in order to do so they need to be distinctive. ${ }^{2(1)}$ In contrast, indications of geographical origin are descriptive, or deceptive, by nature and for this reason in many trademark laws it is explicitly indicated that geographical terms are excluded from trademark protection. Nevertheless, a geographical term may be used as a trademark where that trademark, despite being originally descriptive, has acquired distinctive character (e.g. "Chiemsee" Windsurfing sports wear) ${ }^{201}$ or secondary meaning through use (e.g. "Oxford University Press" for an academic publisher) ${ }^{202}$ or where its use is fanciful (e.g. "Mont Blanc" pens or "Côte d'Or" chocolate) and therefore does not deceive the public as to the origin of the goods. ${ }^{203}$ In these cases the use of the term does not intend to indicate or guarantee the geographical origin, but the commercial origin of the goods, i.e. the manufacturer.

The law on trademarks occasionally refers to indications of geographical origin such as GIs, although indirectly: for instance, Article 6 quinquies B(2) of the Paris Convention sets out that excluded from trademark protection are:

"signs or indications which may serve, in trade, to designate the kind, quality, quantity, intended purpose, value, place of origin, of the goods, or the time of production, or have become customary in the current language". ${ }^{21 \mathrm{H}}$

Moreover, Article 6 quinquies $B(3)$ of the Paris Convention excludes "trademarks of such a nature as to deceive the public". ${ }^{205}$ For example, in the Benelux Convention on IP of $2005^{206}$ and in Italy and France, it is, under certain

21:1 Art. 3.1(b) EU Trademark Directive sets out that trade marks which are devoid of any distinctive character shall not be registered or if registered shall be liable to be declared invalid.

201 As happened in the Windsurfing Chiemsee case, ECJ Judgment of 4 May 1999 in joined cases C-108/97 and C-109/97 (reference for a preliminary ruling from the Landgericht München I (Germany)): Windswing Chiemsee Produktions- und Vertricbs GmbH (WSC) v. Boots- und Segelzubehör Walter Huber (C-108/97) and Franz Attenberger (C-109/97).

202 Oxford University Press (1988), 15 IPR 646.

2113 See "Possible Solutions for Conflicts between Trademarks and Geographical Indications and for Conflicts between Homonymous Geographical Indications", WIPO $\mathrm{SCT} / 5 / 3,2000$, p. 13.

20.4 See Art. 6 quimquies $B(2)$ of the Paris Convention. Art. The EU Trade Mark Directive contains a similar provision, Art. 1 (c).

2115 See Art. 6 quinquies B(3)of the Paris Convention.

20th Replacing the Benelux Convention on TMs, and the Benelux Convention on designs and the Benelux Trademark Act and the Benelux Designs Act. Art. 1 in combination with Art. 4(2) of the Benelux Trademark Convention. Geographical names can be protected as long as the public is not misled as to the origin of the product. Furthermore, Art. 4(7) holds that names concerning GIs for wines and spiritualities 
conditions, possible to register a geographical name as a trademark. In the UK, Germany and the Scandinavian countries, geographical names cannot, in principle, be registered as trademarks. ${ }^{207}$

Under the Lisbon Agreement the members guarantee the protection of Gls that are protected as such in other member countries. Gls are registered in the "Lisbon Register" administered by the WIPO. This means that the validity of the "appellation of origin" (terminology used by the Lisbon Agreement) is determined by recognition in the home country. This is what currently is at stake at the TRIPS negotiations on the notification register - if such a register was established countries had to guarantee protection of Gls that are protected as such in other TRIIS Member countries. In this respect GIs and appellations of origin differ from trademarks in the sense that trade marks are valid only in the jurisdiction where they are registered in a national office for industrial property/trademark office.

\subsection{Conflicts Trademarks and Geographical Indications}

Conflicts between TMs and indications of geographical origin as to the right to the exclusive use of a distinctive sign usually arise where there are different parties claiming entitlement to such use. The (legal) principle of territoriality implies that identical or similar trademarks used for identical goods and services can coexist in different territories. ${ }^{208}$ However, erosion of territoriality has occurred as a result of the rapid evolution of the information society (in particular domain names), globalisation of trade and the harmonisation of IP laws. ${ }^{2010}$

Resolution of conflicts between GIs and trademarks also differ from that of normal trademark law. In trademark law disputes are normally solved on the basis of the priority principle. As indicated above under trade mark law a trade mark should not be registered if it exclusively consists of signs or indications that may serve, in trade, to designate the place of origin of the goods. This constitutes an absolute ground of refusal by the trade mark office:

are excluded unless they were protected by a prior trademark before the registration of the Gl.

207 See Gevers 1990, p. 285.

$21 \mathrm{~s}$ The principle of territoriality implies that both trademarks and GIs give protection for a certain legally defined territory which makes them subject to national laws, although these laws can be extended across borders through bilateral, regional and international agreements.

2019) See "Possible Solutions for Conflicts between Trademarks and Geographical Indications and for Conflicts between Homonymous Geographical Indications", WIPO $\mathrm{SCT} / 5 / 3,2000$. 


\begin{abstract}
"this is because the geographical element may be deemed descriptive of characteristics of the categories of the goods concerned and that it is the public interest that the geographical sign remains available for other competitors in the same place of origin to use".210
\end{abstract}

In addition, misleading geographical signs are excluded from trademark registration, meaning that the public should not be mislead as to the true geographical origin of the goods. This forms the basis for a challenge to the validity of registered trademarks comprising GIs.

As indicated, in case of conflicting claims to trademark rights it is normal practice that the prior trademark in time prevails. This principle of priority is only exempted by prior registrations obtained in bad faith. In principle an earlier Gl, when registered takes precedence over a later trademark. Priority issues over earlier trademarks and GIs are solved according to different rules. For example, under Article 5(6) of the Lisbon Agreement an appellation of origin that has been registered takes precedence over a prior trademark use by third parties. What happens in cases of conflict between trademarks and indications of geographical origin - can they coexist? From a theoretical point of view, GIs and trademarks are different concepts serving different purposes, and thus theoretically camnot coexist. The use of geographical names as trademarks varies in different jurisdictions. In most countries with a common law tradition, such as the US and Australia, the exclusivity of prior trademarks is the favoured rule, in contrast to the EC where prior trademarks and GIs are permitted to coexist (as follows from EU Council Regulation 2081-92). In some countries, such as France, a dual system of protection - i.e. protection through both trademarks and GIs - is not permitted.211

The TRIPS Agreement does not explicitly deal with coexistence. However, it is arguable 212 that the TRIPS Agreement deals with coexistence in Article 24.5 which sets out that: when a trademark has been acquired or registered in good faith before the date of application of the Agreement in that country or before the GI was protected in its country of origin, measures adopted to implement Section 3 (section of the TRIPS Agreement dealing with GIs) shall not prejudice eligibility for or the validity of the registration of a trademark or the right to use a trademark, on the basis that the trademark in question is identical or similar to a certain Gl. Hence, this would imply that prior trademarks and GIs can coexist.

210 See Kamperman Sanders 2007b, p. 434. See also the Windsurfing Chiemsee case as discussed in section 3.1.1 of this chapter.

211 As follows from the Rommene-Conti and Budteiser decisions by the French Court of Appeal, respectively decided on 1 December 1987 and on 22 April 1986.

212 As argued by the EU in EC - Trademarks and Geographical Mudications. 
Article 22.3 of the TRIPS Agreement demands that the registration of a trademark be refused or invalidated in case a trademark consists of a GI with respect to goods not originating in the territory indicated, provided that use of the indication as a trademark for such goods would mislead the public as to the true place of origin. If, for example, it is clear that the product does not derive a special reputation or its characteristics are not related to the indication of geographical origin, as in the Chiemsee sporfwear case, use of the sign as a trademark is permitted. ${ }^{213}$

\subsubsection{Jurisprudence of the ECJ on Relationship TMs and GIs}

\section{Budweiser}

The ECJ has been drawn, on numerous occasions, into an ongoing battle over the name "Bud Beer", which is protected by a trademark in some countries and by a GI in others. The Czech brewer Budejovicky Budvar, is involved in a complex trademark battle with its rival - the largest brewer in the US Anheuser Busch. They have been at loggerheads over the exclusive rights to the Budweiser name for over a century. Currently they are involved in some 40 lawsuits worldwide. Budejovicky Budvar was founded in 1895 in Ceske Budejovice - called Budweis by the German-speaking people that populated the area at the time. Beer has been brewed there since 1265. The founders of Anheuser-Busch used the name Budweiser for their product because it was well-known in their German homeland. The St. Louis brewery got its start in 1852. It began producing Budweiser, America's first national beer brand, in 1876. Problems arose when Anheuser-Busch started exploring the European markets for its well-known beer Budweiser. The American firm claims it has the right to the name as it first started brewing Budweiser in 1876, 19 years before Budejovicky Budvar was founded in 1895. In addition, Anheuser-Busch argues that Budvar is simply trying to profit from the reputation of one of the world's biggest selling beer brands. Yet Budejovicky Budvar counters that its Budweiser is simply named after its hometown of Ceske Budejovice, which is called Budweis in German and hence it has the right to use the name. ${ }^{214}$ Budejovicky Budvar has obtained a GI over the use of the name Budvar in Europe. Budvar is now strengthened by the EC - Czech Republic Accession Agreement in which a list of Gl protected names are provided strong protection on EU territory.

21.3 But signs like "Quetchua" (used for sportswear and bags), which is not the name of a particular place of origin but the name of an indigenous language (in the Andean), cannot be treated this way, and indeed raises more questions - the use of the name could be perceived offensive to cultural traditions and beliefs.

214 See "Budweiser to appeal Court verdict", BBC, 3 March 2006, <http://news.bbc.co. $\mathrm{uk} / 2 / \mathrm{hi} /$ business/4771674.stm>. 
Anheuser-Busch sought trademark protection for the Budweiser name under property rights guaranteed by the 1950 European Convention on Human Rights. ${ }^{215}$ Anheuser-Busch cannot sell beer under the brand name Budweiser in Portugal, the European Court of Human Rights (ECHR) ruled. 216 Anheuser had been appealing a 2001 decision by Portugal's Supreme Court, which ruled that Czech brewer Budejovicky Budvar (Budvar) had the right to use the name under a 1986 treaty between the Czech Republic and Portugal. ${ }^{217}$ AnheuserBusch argued the 2001 decision by Portugal violated its rights to the "peaceful enjoyment" of the trademark and lodged a complaint with the European Court of Human Rights (ECHR). It said the Portuguese ruling infringed Article 1, first Protocol of the European Convention on Human Rights, which guarantees individuals and companies protection of property. Anheuser-Busch claims that the name Budweis is property in the sense of Article 1 and that it has been deprived of the name because of the application of a 1986 treaty. A treaty that went into effect years later after the 19 May 1989 request for registration of the name Budweiser in the Portuguese national institute for industrial property by Anheuser-Busch. Hence, according to Anheuser-Busch a disappropriation occurred which was not in the interest of the public as a whole. However, the ECHR holds that Budweiser could not invoke protection of Protocol No. 1 in suit against Portugal for rejecting its trade mark application since mark had never become its possession: it was merely a request for registration of a trademark with the hope to obtain a trademark but it was not a legitimate expectation. Hence, the way the Portuguese Supreme Court applied the 1986 treaty could not infringe on a right of the claimant. 218

The Anhususr-Busch v. Portugal dispute reflects the vast economic interests for two beer breweries competing on the global beer market. Both companies claim rights to the name "Budweiser", "Budweis" or "Bud". The Czech company bases its claim on a protectable GI, Anheuser-Busch on trade mark rights. However, national recognition of a right to industrial property, sometimes further determined by international obligations, essentially determines the validity of the claims to priority. This is where the arguments between the two parties becomes part of a larger question, namely the way in which recognition

215 The Strasbourg court has competence because all forms of appeal have been exhausted in Portugal, ECHR, Grand Chamber No. 73049/01, 11 January 2007.

211. Anheuser-Busch had first applied to register Budweiser as a trademark in Portugal in 1981. Subsequently, the trademark was registered, however this was reversed on appeal, and the trademark was given to Budvar in the 2001 decision based on a 1986 treaty between Czechoslovakia and Portugal treaty. Budvar claimed that the name "Budweiser Bier" was registered since 1968 as indication of origin.

21. See Lisbon's Court of Appeal's Decision of 10 May 2001. See International Herald Tribune, "Czech brewer says it has registered 'Budweiser Budvar' trademark registered in Portugal", 9 November 2006, see <http://www.iht.com/articles/ap/ 2006/11/09/business/EU_FIN_Czech_Portugal_Budvar.php?pass=true $>$.

21. ECHR, 11 January 2007, No. 73049/01 
of CIs as inclustrial property rights is awarded in various jurisdictions. ${ }^{219}$ The definition of what constitutes a GI is not uniform. The fundamental difference in outlook between US and the EC in relation to the protection of GIs makes the Budweiser sage a complicated one. The EC protects GIs under a Council Regulation (2081/92 as amended 692/2003), whereas the US chose to protect GIs as trade, collective or certification marks. In addition the EC is a member to the Lisbon Agreement, the US is not. Under the Lisbon Agreement the use of a GI in translated form may be prohibited. 221

Outcome of court cases differed, for instance, the House of Lords, Britain's highest court, allowed Budvar to continue to use the trademark "Bud" name making the UK the only country where both Anheuser-Busch and Budvar can sell their beer products using the Budweiser brand.221 However, Anheuser Busch had successfully prevented Budvar, which exports a large part of its production, from using or registering the name Budweiser in Argentina, Australia, Brazil, Denmark, Finland, New Zealand, Italy, Hungary and Spain. ${ }^{222}$ Budvar won in Lithuania, Switzerland, Portugal and Austria.

\section{Gerolsteiner Brummen}

In the European Court of Justice Gerolsteiner Brumnen Case, ${ }^{223}$ the validity of a GI was disputed against an earlier trademark. The conflict at stake concerned the sign "Kerry Spring", which refers to the geographical origin of the water used in the manufacture of its products versus "Gerri", a prior registered word mark for non-alcoholic drinks in general. In this case the ECJ held that where there existed a likelihood of aural confusion between a word mark registered in one Member State and a GI of origin of a product originating in another, the owner of the trade mark could prevent the use of the indication of origin only if that use was not in accordance with honest practices in industrial or commercial matters. In its decision the ECJ acknowledged the size of the EC and its linguistic diversity, which makes the possibility of phonetic similarity between a registered trademark in one country and a GI in another very likely.

214 See Kamperman Sanders 2007b, p. 433.

221 See Art. 3 of the Lisbon Agreement.

221 See "Czechs win battle over 'Bud' name", 17 February 2003, <http://news.bbc.co. uk/2/hi/business/2772205.stm>.

222 See Corte-Real 2005.

223 See Gerolsteiner Brummen GmbH \& Cov. Putsch GmbH, C-100/02, 2004, ECJ. 


\section{Chiemser}

The Chiemsee case, deals with trademarks involving an indication of geographical origin.224 Questions were raised in two sets of proceedings between Windsurfing Chiemsee Produktions- und Vertriebs $\mathrm{GmbH}$ (hereinafter "Windsurfing Chiemsee"), on the one hand, and Boots- und Segelzubehör Walter Huber (hereinafter "Huber") and Franz Attenberger, on the other, relating to the use by Huber and Mr Attenberger of the designation "Chiemsee" for the sale of sportswear. ${ }^{225}$

Windsurfing Chiemsee, which is based near the shores of the Chiemsee, sells sports fashion clothing, shoes and other sports goods which are designed by a sister company based in the same place, but are manufactured elsewhere. The goods bear the designation Chiemsee. Between 1992 and 1994, Windsurfing Chiemsee registered that designation in Germany as a "picture mark" in the form of various graphic designs, in some cases with additional features or words such as "Chiemsee Jeans" and "Windsurfing Chiemsee Active Wear".226 Apparently, there is no German trade mark by which the word "Chiemsee" as such is protected:

"The German registration authorities have hitherto regarded the word 'Chiemsee' as an indication which may serve to designate geographical origin and which is consequently incapable of registration as a trade mark. However, they have allowed the various particular graphic representations of the word Chiemsee and the additional accompanying features to be registered as picture marks". ${ }^{227}$

Huber has been selling sports clothing such as T-shirts and sweat-shirts since 1995 in a town situated near the shores of the Chiemsee. The clothing bears the

224 See Windsurfing Chiemsee Produktions-und Vertriebs GmbH v. Boots-und Segelzubehor Walter Lher and Fromz Attenterger, C-108/97 and C-109/97, 4 May 1999, ECJ.

225 The Chiemsee is the largest lake in Bavaria, with an area of $80 \mathrm{~km} 2$. It is a tourist destination and surfing is one of the activities carried on there. The surrounding area, called the "Chiemgau", is primarily agricultural. See paragraph 9 of the Chiemser case.

22n See para. 10 of the Chiemsec case.

22: See para. 11 of the Chiemsec case. The German Law on Trade Marks (Markengesetz), which has been applicable since 1 January 1995, transposed the Directive into German law. Under Section 8(2)(2) of the Markengesetz, trade marks "which consist exclusively of ... indications which may serve in trade to designate the ... geographical origin ... or other characteristics of the goods" are to be refused registration. See para. 7 of the Chiemser case. Pursuant to Section 8(3) of the Markengesetz, Section 8(2)(2) does not apply "if the mark, before the time of the decision on registration, as a result of its use for the goods ... in respect of which registration has been applied for, has gained acceptance among the relevant class of persons". See para. 8 of the Chicmse' case. 
designation Chiemsee, but this is depicted in a different graphic form from that of the trade marks which identify Windsurfing Chiemsee's products. Mr Attenberger sells the same type of sports clothing in the Chiemsee area, also bearing the designation Chiemsee, but using different graphic forms and, for certain products, additional features different from those of Windsurfing Chiemsee. ${ }^{228}$ In the main proceedings, Windsurfing Chiemsee challenges the use by Huber and $\mathrm{Mr}$ Attenberger of the name Chiemsee, claiming that, notwithstanding the differences in graphic representation of the marks on the products in question, there is a likelihood of confusion with its designation "Chiemsee" with which, it claims, the public is familiar and which has in any case been in use since 1990. The defendants (Huber and Mr Attenberger) in the main proceedings, on the other hand, contend that, since the word "Chiemsee" is an indication which designates geographical origin and must consequently remain available, it is not capable of protection, and that using it in a different graphic form from that used by Windsurfing "Chiemsee" cannot create any likelihood of confusion. 221)

The ECJ had to address a number of questions raised under the preliminary ruling 230 possibility by the "Landgericht" Munich which addressed the interpretation of the EC Trademark Directive in particular 3(1)(c) and 3(3). Article $3(3)$ provides an exception to the general rule in Article 3(1)(c) which stipulates that the following shall not be registered or if registered shall be liable to be declared invalid:

"trademarks which consist exclusively of signs or indications which may serve, in trade, to designate the kind, quality, quantity, intended purpose, value, geographical origin, or the time of production of the goods or of rendering of the service, or other characteristics of the goods". 231

Question was if the descriptive geographical name "Chiemsee" had acquired distinctive character and could therefore qualify for TM protection under Article 3(3) TM Directive. Article 3(3) reads as follows

"[a] trademark shall not be refused registration or be declared invalid in accordance with paragraph 1 (b), (c) or (d) if, before the date of application for registration and following the use which has been made of it, it has acquired a distinctive character. Any Member State may in addition provide that this

22 See paras. 12 and 13 of the Chiemsee case.

224 See paras. 14 and 15 of the Chiemsic case.

23:) Following Art. 234 EU Treaty - former Art. 177 of the EU Treaty.

231 Art. 3 EU Trademark Directive deals with the grounds for refusal or invalidity for trademarks. 
provision shall also apply where the distinctive character was acquired after the date of application for registration or after the date of registration". 232

In particular, the ECJ addressed the following questions concerning Article $3(1)(c): 1)$ If the application of Article 3(1)(c) depends on whether there is a real, current or serious need to leave the geographical sign or indication free; and 2) what connection there must be between the geographical location and the goods in respect of which registration of the geographical name for that location as a trade mark is applied for. ${ }^{233}$ The ECJ ruled that if the competent authority finds that a significant proportion of the relevant class of persons identify goods as originating from a particular undertaking because of the TM, it must hold the requirement for registration to be satisfied. It precludes differentiation as regards distinctiveness by reference to the perceived importance of keeping the geographical name available for use by other undertakings. It does not prohibit the registration of geographical names as TMs if, in the mind of the public, the goods are associated with the designated place. ${ }^{23.4}$ If this is the case, it must hold the requirement for registering the mark to be satisfied. The ECJ argued that it cannot be ruled out that the name of a lake may serve to designate geographical origin within the meaning of Article $3(1)(\mathrm{c})$, even for goods such as those in the main proceedings. Importantly, the ECJ held that it is not necessary for goods to be manufactured in the geographical location in order for them to be associated with it. ${ }^{2.35}$

In relation to Article $3(3)$ the $\mathrm{ECJ}$ considers the core of the problem what requirements must be met, for the purposes of the first sentence of Article 3(3) of the Directive, in order for a mark to have acquired distinctive character

232 See Art. 3.3 EU Trade Mark Directive.

233 See para. 19 of the Chientse decision.

234 When assessing whether the geographical name is capable, in the mind of the relevant class of persons, of designating the origin of the category of goods in question, regard must be had more particularly to the degree of familiarity amongst such persons with that name, with the characteristics of the place designated by the name, and with the category of goods concerned. (See para. 32) In that connection, Art. $3(1)(c)$ of the Directive does not in principle preclude the registration of geographical names which are unknown to the relevant class of persons - or at least unknown as the designation of a geographical location - or of names in respect of which, because of the type of place they designate (say, a mountain or lake), such persons are unlikely to believe that the category of goods concerned originates there. (See para, 33) However, it cannot be ruled out that the name of a lake may serve to designate geographical origin within the meaning of Art. 3(1)(c), even for goods such as those in the main proceedings, provided that the name could be understood by the relevant class of persons to include the shores of the lake or the surrounding area. (See para. 34) It follows from the foregoing that the application of Art. 3(1)(c) of the Directive does not depend on there being a real, current or serious need to leave a sign or indication free. (See para. 35 of the Chiemsee decision).

235 See para. 37 of the Chiemse' decision. 
through use. In particular, whether those requirements differ according to the extent of the need to keep the mark free, and whether that provision lays down any requirements as to how distinctive character acquired through use is to be assessed. ${ }^{236}$ The ECJ argued that the first point to note is that Article $3(3)$ of the Directive provides that a sign may, through use, acquire a distinctive character which it initially lacked and thus be registered as a trade mark. It is therefore through the use made of it that the sign acquires the distinctive character which is a prerequisite for its registration. ${ }^{2.37}$ Article 3(3) therefore constitutes an important exception to the rule laid down in Articles 3(1)(b), (c) and (d), whereby registration is to be refused in relation to trade marks which are devoid of any distinctive character, descriptive marks, and marks which consist exclusively of indications which have become customary in the current language or in the bonn fitc and established practices of the trade. ${ }^{238}$ The ECJ argued that just as distinctive character is one of the general conditions for registering a trade mark under Article 3(1)(b), distinctive character acquired through use means that the mark must serve to identify the product in respect of which registration is applied for as originating from a particular undertaking, and thus to distinguish that product from goods of other undertakings. ${ }^{239}$ Hence, it follows that a geographical name may be registered as a trade mark if, following the use which has been made of it, it has come to identify the product in respect of which registration is applied for as originating from a particular undertaking and thus to distinguish that product from goods of other undertakings. Where that is the case, the geographical designation has gained a new significance and its connotation, no longer purely descriptive, justifies its registration as a trade mark. ${ }^{241}$ In case of very well known geographical name "acquired distinctive character" can only be obtained if there has been a long-standing and intensive use of the mark by the undertaking applying for registration. ${ }^{2+1}$ The Court ruled that in order to asses distinctiveness the competent authority must make an overall assessment of the evidence that the mark has come to identify the product concerned as originating from a particular undertaking, and thus to distinguish that product from goods of other undertakings. ${ }^{2+2}$ If the competent local authority finds that

236 See para. 38 of the Chiemsec decision.

237 See para. 44 of the Cliemser decision.

23. See para. 45 of the Chiemser decision.

23.4 See para. 46 of the Chiemsee decision.

241 See para. 47 of the Chiemse' decision.

241 See para. 50 of the Chiemsee decision.

242 The ECJ argued that "In assessing the distinctive character of a mark in respect of which registration has been applied for, the following may also be taken into account: the market share held by the mark; how intensive, geographically widespread and long-standing use of the mark has been; the amount invested by the undertaking in promoting the mark; the proportion of the relevant class of persons who, because of the mark, identify goods as originating from a particular under- 
a significant proportion of the relevant class of persons identify goods as originating from a particular undertaking because of the trade mark, it must hold the requirement for registering the mark to be satisfied. ${ }^{2+3}$

\subsection{Indications of Geographical Origin Versus Collective and Certification Marks}

An alternative to GI protection is provided by a specific type of trademark protection: collective and certification marks. Both collective and certification marks are found in common law jurisdictions, for instance, the US has opted to provide protection to indications of geographical origin through this type of protection. Certification marks are legal signs which indicate that the goods or services on which they are used have specific qualities and possibly of certain geographical origin. As a general rule the owner of a certification mark does not use the mark but licenses it to other enterprises and certifies that the goods or services carrying the mark are of a certain quality. Collective marks are quite similar to certification marks. These are owned by a collective body (like a trade association) and serve to indicate that goods or services displaying the mark are produced by an enterprise that is a member of the collective body. As membership to the association entails some qualifying standards, the collective mark is a distinctive sign conveying the said standards of the trade association. ${ }^{2+4}$

GIs are public/collective rights while collective trademarks (CTMs) tend to be private (or at times collective rights). The property and its administration belong to one or various producers. Also the protection offered is different: in the case of CIs, all parties within the geographical area are protected against misappropriation of the indication. But only the owner and licensee of a CTM are protected. Certification marks must be renewed periodically, but the duration of GI protection is as long as its specific conditions are maintained. GIs have a strong link with the origin, whereas the link between certification marks and the origin is not a necessary condition. GIs can neither be transferred between owners nor licensed to producers outside the designated geographical area. In contrast, the owner essentially licenses CTMs to users. On the other hand, a collective trademark permits licensing that is not restricted by production taking place in a designated geographical area. For instance, the Gl "Honduran Bananas" can only apply to bananas from Honduras, whereas the CTM "Chiquita Bananas" can be used on any banana. ${ }^{245}$

taking; and statements from chambers of commerce and industry or other trade and professional associations". See reasoning 51 of the Chiemsec case.

243 See para. 55 of the Chiemser case.

244 See OECD 2000, p. 9 and 10.

245 Example taken from Addor and Grazioli 2002. 
It is important to note that there is an essential difference between trademarks and collective and certification marks with regards to the conditions for application. Trademarks that entail descriptive geographical terms are as a rule excluded from protection, whereas geographical terms are normally expressly permitted to qualify for collective and certification marks..$^{24 h}$

It can be a valuable tool to obtain a collective or certification mark on an indication of geographical origin since strong, widely applicable and enforceable trademark law will become available to enforce the indication. This is something that developing countries should consider, as it could be more costeffective to install a collective/certification system than a GI sui generis system of protection. However, trademarks are territorial (they are only protected in the jurisdiction where they are registered), hence multiple registrations are required. Whereas, in principle, GIs under the Lisbon Agreement (and potentially under the TRIPS Agreement when the notification register is introduced) the members guarantee the protection of GIs that are recognised as such in other members to the agreement.

Question is to what extent can collective and certification marks satisfy TRIPS obligations?

\subsection{Conchusion}

The whole trademark versus $G$ l debate raises more questions than it provides answers. In the case of conflict between a GI and a prior registered trademark there are a number of possibilities/scenarios: 1) following the concept of "first in time, first in right"; or 2) arguing that the earlier trademark and the GI are allowed to coexist; or 3) taking the view that the Gl should take precedence over the prior trademark. An interesting question is the relationship between an earlier GI and a later trademark, and whether the earlier Gl should take precedence and maintain exclusivity ahead of the later trademark.

For reasons relating to legal certainty and securing a good investment climate, it is best to establish clear rules on the relationship between a trademark and a GI: does allowing a later GI to coexist with a prior trademark reduce the certainty that trademark owners enjoy? Does it mean that an existing trademark, no matter how long it has been used or registered, would ever be safe from usurpation by a later Gl? At present this still very much depends on national legislation and the interpretation of international laws, since the TRIPS Agreement is not very precise. Neither has the outcome of the WTO EC

2th See "Possible Solutions for Conflicts between Trademarks and Geographical Indications and for Conflicts between Homonymous Geographical Indications", WIPO $\mathrm{SCT} / 5 / 3,2000, \mathrm{p} .13$. 
- Trademaks and Goographical Indications case presented a more clear-cut ruling on which should take precedence.

\section{ONGOING; WTO NEGOTIATIONSON GIS}

\subsection{Extension of "Absolute" Protection to Other Products than Wines and Sprivits}

As explained above, the TRIPS Agreement contains a two-tier level of GI protection. This hierarchy in protection is the subject of much debate within TRIPS Council negotiations. The final provisions on GIs are the result of a compromise achieved in the Uruguay Round; this history is also behind the current debate on whether or not to extend the special protection. The proposals for review reveal two divergent groups: there are domandeur countries pleading for higher standards of protection for more types of GIs, who believe stronger GI protection has the potential to promote rural development and generate economic returns to otherwise disadvantaged areas, mainly because it addresses agricultural food products or handicrafts produced by small- and medium-size enterprises; ${ }^{247}$ and others who wish to keep the status quo as they are not convinced that stronger Gls will result in economic benefits.

Supporters of expanding the special protection given to wines and spirits to other Gls believe it will, amongst others, facilitate the export of products of interest to all members, guarantee better consumer protection and promote rural development. Supporters of extension consider extension to improve the marketing of their products by differentiating them more effectively from their competitors. Many countries called for the protection already granted by Article 23 of the TRIPS Agreement to wines and spirits to be extended to other products and expressed their concern that having two different levels of protection did not reflect their commercial interests. Many developing countries, for instance, are not big producers of wines and spirits (not to mention Muslim countries, where domestic alcoholic production is almost zero) and would benefit from extended Gl protection, in particular to products such as tea, rice, coffee, cacao, corn, tropical fruits and handicrafts. ${ }^{2+8}$ Some developing countries support the proposal for higher protection because of the potential they see for increasing the value of "flagship" products such as "Thai silk" and "Kenyan coffee". On the other hand, opponents of extension argue that: 1) the existing level of protection under TRIPS Article 22 is adequate and that extension would be redundant and no credible evidence has been presented that

24: This demantew group includes Bulgaria, Cuba, the Czech Republic, Georgia, Hungary, Iceland, the Kyrgyz Republic, Liechtenstein, Moldova, Nigeria, Pakistan, Slovenia, Sri Lanka, Turkey, India, Kenya, Switzerland, Bangladesh and Jamaica. See WTO document IP/C/W/308/Rev.1, 2 October 2001.

See Vivas-Spennemann 2006, p. 3. 
this protection is inadequate; 2 ) enhanced protection would be a financial and administrative burden and would disrupt existing legitimate marketing practices; 3) concerns about limited access to export markets as a direct consequence of additional protection; 4) increases in costs due to product labelling requirements (and eco-labelling) and the administrative burden necessitated by competent authorities to protect and enforce Gls. Hence, opponents take the view that the costs of Gl extension would far outweigh any perceived benefits.

There is a lack of empirical evidence and studies to support either side of the debate. Economic studies as to the potential of GIs to facilitate sustainable development could provide an impetus to the current negotiating deadlock.

Numerous developing countries including Colombia, the Dominic Republic, El Salvador, Honduras, Paraguay and the Philippines have expressed in TRIPS Council Meetings that they have faced problems in the implementation of the TRIPS provisions and hence adopting new rules on IPRs would be adding to their obligations.

The different perspectives are to a great extent due to the different historical backgrounds of the so-called "new" and "old" world. Members of the "old world" traditionally take a protectionist stance on their agricultural markets and food products, and GIs constitute a significant part of their domestic agriculture policies. The "new world" does not have the same kind of tradition linking culture and food production, and it acknowledges the superiority of trademark protection which works on a "first come first served principle". In this regime GIs are normally protected through certification marks. Interestingly, member countries opposing the demand for GI extension agree that there is no legal or other rationale for the basis of a hierarchy in the level of protection under Section 3 TRIPS Agreement: "If the extension discussion were purely one of intellectual property policy, it would make sense to treat all products in the same manner legally". ${ }^{249}$ As such, the problem is about revisiting the Uruguay Round bargain and re-configuring the balance of obligations. ${ }^{250}$

\subsubsection{Discussions on the Mandate to Negotiate Extension}

The TRIPS Council has agreed to continue the "consultative process" on issues related to the extension of the protection of Gls provided for in Article 23 of the TRIPS Agreement to other products than wines and spirits. The TRIPS

2.44 See WTO, "Implications of Article 23 Extension. Communication from Argentina, Australia, Canada, Chile, the Dominican Republic, El Salvador, Guatemala, New' Zealand, Paraguay, the Philippines, Chinese Taipei and the United States", WTO document $\mathrm{IP} / \mathrm{C} / \mathrm{W} / 386,8$ November 2002.

231 Ibid. 
Agreement contains provisions that require member states to continue negotiations on certain issues, the so-called inbuilt provisions. For instance Article 24.1 of the TRIPS Agreement points out that:

\footnotetext{
"Members agree to enter into negotiations aimed at increasing the protection of individual geographical indications under Article 23. The provisions of paragraph 4 through 8 below shall not be used by a Member to refuse to conduct negotiations or to conclude bilateral or multilateral agreements".251
}

Hence, Article 24.1 of the TRIPS Agreement provides the mandate to continue negotiations aimed at increasing the protection of GIs both through bilateral and multilateral trade negotiations. This provision mirrors the discussion under the Uruguay Round where the hierarchy of protection was seen as discriminatory. ${ }^{252}$ Nonetheless, members differ over the exact interpretation of Article 24 and opponents of extension argue that the wording "individual geographical indications" refers to the goods covered by Article 23, i.e. covering wines and spirits. 253 According to this view, there is no mandate for negotiations on the extension of the higher protection to other products, and negotiations on this extension would be convened without any legal basis. ${ }^{254}$ In their view Article 24.1 requests Members to enter into negotiations to abolish some of the exceptions currently applicable to wines and spirits protection, for instance to abolish the exemption set out in Article 24.4 (the flexibility to keep using GIs on goods which were in use before TRIPS entered into force). ${ }^{25.5}$

Members favouring extension of the special protection to all products argue that the wording of Article 24.1 should be interpreted as referring to all products, and that the reference made to Article 23 does not relate to products contained therein (wines and spirits) but to a means of granting the additional protection to other products. ${ }^{25}$. They refer to Article 24.2 to strengthen their

251 TRIPS Agreement, Art. 24.1. The drafters of this provision emphasised that the exceptions listed in Art. 24 ought not to be a hindrance to entering into negotiations to extend the protection of Gls. Surprisingly, the drafters left the form of negotiations open, as both bilateral and multilateral negotiations are explicitly mentioned in the provision.

272 See Rangnekar, forthcoming 2009.

$25 ;$ TRIPS Council Minutes of Meeting, 6 March 2001, WTO document IP/C/M/29, point $G$.

25 This reasoning was set out in a Communication submitted by Argentina, Australia, Canada, Chile, Guatemala, New Zealand, Paraguay and the US, WTO document $\mathrm{IP} / \mathrm{C} / \mathrm{W} / 289,29$ June 2001 , para. 3.

255 This reasoning was set out in a Communication submitted by New Zealand, WTO document $I P / C / W / 205$, para. 23.

271. This reasoning was set out in the Communication submitted by Bulgaria, the Czech Republic, Egypt, Iceland, India, Kenya, Liechtenstein, Pakistan, Slovenia, Sri Lanka, Switzerland and Turkey on 18 September 2000, WTO document IP/C/W/204, para. 12. 
argument, which mandates the TRIPS Council to keep under review the application of the provisions on Cis. In accordance with this mandate, the TRIPS Council explicitly expressed that inputs from parties on the issue of scope were permitted. 25 Supporters of extension regard this notion of the TRIPS Council as supporting its claims for negotiations on an extension of protection.

Next to the inbuilt provision (Article 24.1), the Doha Ministerial Declaration also instructed Members to solve certain outstanding implementation issues within the TRIPS Council meetings. These "outstanding implementation issues" were a legacy from the Uruguay Round negotiations, namely those issues on which the Uruguay Round failed to reach agreement. One of the outstanding implementation issues addresses the extension of the higher level of protection provided under Article 23 of the Agreement to other products. It provides the mandate for parties to the TRIPS Agreement to enter into "negotiations to extend protection of geographical indications to other products than wines and spirits".27s

The extension of GI protection to other products has for long figured on the agenda of the TRIPS Council but so far without a concrete result. Diplomats based in Geneva presenting their country positions in the TRIPS Council take different viewpoints over the mandate: the EC and many developing countries view the so-called implementation issues as already part of the negotiations. Others argue that these issues can only become negotiating subjects if the Trade Negotiation Committee decides to include them in the talks.

Thus both the TRIPS inbuilt provision and the Doha Declaration provide a mandate to enter into negotiations to increase the protection of Gls, although these two measures use different language. The TRIPS provisions require "increasing the protection of individual geographical indications under Article 23 " whereas the Doha Declaration speaks of "extend[ing] protection of geographical indications to other products than wines and spirits". The issue of the content of the mandate for negotiations on Gl extension has not been solved yet.

25. TRIPS Council in its submission to the 1996 Singapore Ministerial, 1996 Report of the TRIPS Council, 6 November 1996, WTO document IP/C/8, para. 34.

25 See paras. 12 and 18 of the Doha Declaration. See Decision on Implementation Issues and Concerns (WTO document WT/Min(01)/W/10, 14 November 2001) and List of Outstanding Implementation Issues (WTO document JOB(01)/152/Rev.1, 27 October 2001). 


\subsubsection{Arguments For and Against the Extension of GI Protection}

While some countries would like to see the imbalance between wines and spirits and other goods removed, there are others who do not expect to see any benefit from extended protection. The main arguments raised against broadening the scope of protection are cost related. Many countries believe - although there is a lack of empirical evidence and studies - that extension of the scope to other goods than wines and spirits would involve high financial costs and raise the administrative load, especially for developing countries.

A number of proposals on the extension of protection issue have been submitted to the WTO TRIPS Council. ${ }^{254}$ A number of countries have openly expressed their wish to extend the special protection to other products than wines and spirits. Supporters of extension are, amongst others: Bulgaria, the EC and its member states, Guinea, India, Jamaica, Kenya, Madagascar, Mauritius, Morocco, Pakistan, Romania, Sri Lanka, Switzerland, Thailand, Tunisia and Turkey. ${ }^{20 \prime \prime}$ Opponents of extension, are amongst others: Argentina, Australia, Canada, Chile, Colombia, the Dominican Republic, Ecuador, El Salvador, Guatemala, Japan, Honduras, New Zealand, Panama, Paraguay, The Philippines, Chinese Taipei, South Africa and the US.

The EC ${ }^{261}$ favours a TRIPS amendment in order to provide for the eligibility of all products for the higher level of protection, subject to some exceptions similar to the ones listed in Article 23. The EC strongly links the extension of GIs with agricultural development. In its view progress made in the Gl negotiations will facilitate the burdensome agriculture negotiations within the context of the WTO. The EC proposed in the WTO Agriculture Committee negotiating the protection of specified names linked to specific agricultural products as part of the agricultural negotiations: the so-called "claw back proposal", covering 41 European Gls.

259 See "Issues related to the extension of the protection of GIs provided for in Article 23 of the TRIPS Agreement to products other than wines and spirits - compilations of issues raised and view's expressed", note prepared by the WTO Secretariat, WTO document WT/GC/W/546, TN/C/W/25, 18 May 2005.

2tit Switzerland submitted a proposal on behalf of 20 countries on undertaking extension of GI protection to other products than wines and spirits: WTO, "The Extension of the Additional Protection for Geographical Indications to Products other than Wines and Spirits. Communication from Bulgaria, Cuba, Cyprus, the Czech Republic, the European Communities and their Member States, Georgia, Hungary, lceland, India, Kenya, Liechtenstein, Malta, Mauritius, Pakistan, Romania, the Slovak Republic, Slovenia, Sri Lanka, Switzerland, Thailand and Turkey". WTO document IP/C/W/353, 24 June 2002.

$2 n$ See WTO document TN/IP/W/11, Communication from the European Communities on geographical indications, 14 June 2005. 
As most of the GIs are related to agriculture and fond stuffs, we can draw the conclusion that developing countries whose main economic activity is related to agriculture are more likely to benefit from strengthening the protection of Gls. If this is not the case it is most likely that increased consumer costs for protected goods will be the consequence. While some developing country and other developed country producers may possibly benefit from increased GI protection for one or two products, the major beneficiary of extension would be Europe, which has almost 700 products registered as Gls within its own territory. ${ }^{262}$ On the other hand, the costs of extension would fall overwhelmingly on non-European countries that would have to protect all of Europe's Gls whilst gaining little in return. Gl extension would not in itself, for example, guarantee access to export markets. The negative impact of Gl extension is likely to be felt most acutely by new world agricultural producers such as Australia, which produces a range of food products that Europe claims as its own, such as "feta" and "parmesan" cheese, despite the fact that Australia, as an immigrant nation, has been producing and trading these products for decades. The costs of GI extension are also likely to fall heavily on developing countries that do not necessarily have the legal and administrative capacity to provide the increased level of protection for Gls sought by the EC.

There are roughly three choices regarding the hierarchy in the level of protection that WTO members can choose from. For instance WTO members can opt to: 1) Continue the hierarchy in protection and continue to grant spirits and wines additional protection; 2) Make the additional level of protection of Article 23 applicable to all goods irrespective of their product category; 3 ) Allow for a flexible hierarchy in protection, implying that the hierarchy remains in existence but with the removal of the Article 23 restrictions on a higher level of protection being applicable only to wines and spirits. This would allow countries to provide the higher level of protection to other products, such as agricultural (tropical) products. ${ }^{26.3}$

For instance, Brazil has opted to remove the hierarchy, India has chosen a flexible hierarchy and Sri Lanka provides a higher level of protection to agricultural products only.

These three choices need to be scrutinised accordingly and in this respect countries should take due account of a number of factors, the foremost of which is the potential benefit that could be derived domestically from enhanced GI protection. In order to determine whether or not countries are likely to benefit from a Gl protection system a cost-benefit analysis should be carried

21.2 See the EU Database of Origin and Registration (DOOR) for registered PDOS and PGIs: <http://ec.europa.eu/agriculture/quality/door/browse.html;jsessionid=Cls 2)rMSHhBRyYRyvBb2F11VGywK3pd1f2JQL zS2ttyN5fJ7nHSL!670835221?display >. 2th: See Ragnekar, forthcoming 2009. 
out. This examination should balance potential benefits from granting GI protection with the costs related to the establishment of a legal and administrative system (including the surrender of generically used names) that it would require.

\subsubsection{Potential and Risks for GI Protected Products from Developing Countries}

Developing countries do hold Gis that could be valuable on the global market. Developing countries should adopt government policies to facilitate markets that increase product differentiation on the basis of locally produced products. 2 (n.t

One should also consider the socio-economic differences within a country: a great variety of experiences may exist as developing countries in transition like China and India are divided into rural agricultural parts and increasingly high-tech metropolises. The industrialised areas to not trade in agricultural products and would therefore presumably benefit less from an extension of protection since it will increase prices. In addition, a country normally focuses on one or a few particular foodstuffs and is therefore dependent on imports. Therefore, gains acquired from extensive protection on some of their own export products need to be balanced against the increased cost of imported agricultural goods. Because most countries have diverse production profiles, none would be assured of only being on the winning side of an extension of Article 23. ${ }^{265}$ For instance, India may gain exclusive use of "Basmati" rice but lose it right to sell "mozzarella" cheese and other dairy products as they have to surrender the generic use of certain names. Furthermore, developing countries should take a more active approach to protecting their products in third countries and make more use of the available measures to protect their products, as well as improving the supply chain of products.

It is of importance for developing countries to prepare their own position on the importance they attach to the protection of Gls, and act from the basis of that domestic position at the international level. It is advisable for all negotiators, particularly developing countries, to undertake a cost-benefit analysis on the added value of introducing a GI system of protection on their territories. This analysis could provide the deciding factor as to whether or not the administrative and financial costs coupled with the extension would outweigh the benefits derived from extension for individual governments. ${ }^{206}$ Another

2on See Ragnekar, forthcoming 2009.

$2 n=$ See Williams 2002.

2to The UK government's CIPR report states that developing countries should consider carefully the potential costs and benefits for their individual situations before taking up a new IP-related obligation. See UK CIPR, Report 2002. 
objective of such a cost-benefit analysis is to identify (potential) GIs within the country. This cost-benefit analysis will set out the short- and long-term benefits of extended GI protection and its contribution to socio-economic development. This analysis needs to take into consideration the implications for market access, i.e. the upgrading of safety and consumer standards, including sanitary issues, required for access to foreign markets. For instance, mineral water sourced in Africa had difficulties entering the EU market, as it did not meet the high standards set by the EC.

It would also be wise to ask for a cap on the number of GIs that developed countries can register. This may help to mitigate the risk of severe unbalance in who can benefit from the system: the EU has more than 700 protected GIs (of which 80 per cent are wines and spirits), whereas there only a handful of GIs in Africa. In fact, of all the Gls currently receiving protection, it is estimated that 80 per cent address wines and spirits, another ten per cent relate to cheese and meat, and the last ten per cent include all the rest, such as nuts, oils, textiles, cigars and coffee. Identifiable Gl benefits in African and Latin American countries are at present mostly potential. Hence it is the EU which holds most claims to GIs and as a consequence, in a "static economic sense, wider acceptance of these claims is likely to result in increased IP-rent payments from developing countries to Europe, at least in the short and medium term".2hr

Developing and least developed countries should carefully analyse the consequences of stronger GIs before taking any sides in the extension debate, as the issue will most likely be balanced by concessions in other areas as a result of the WTO negotiation framework. Hence, the short-term benefits of enhanced protection are for the countries holding the GIs, and it will take time for developing countries to catch up.

Developing countries need to analyse the market for their potential GI products, domestically as well as regionally or internationally. Much like trademarks, GIs are intrinsically linked with buying and selling. While in some instances the markets might be international, in the first instance it could be worthwhile to examine the local and regional market potential. According to Ragnekar, part of the examination should address the possibilities of future strategic alliances (e.g. tie-ups with other producer groups and retailers), policy options (e.g. bilateral agreements, market access agreements) and marketing routes (e.g. use of socially constructed labels like "organic" and "fair trade") that might enable superior marketing. In this respect, European case 
studies suggest that marketing is the weakest link in the product's supply chain. $26 s$

Before taking a stance in the international debate, developing countries should decide on their domestic situation (at the policy and legal level) regarding the importance they attach to the protection of GIs, and the form of protection they want to offer (i.e. a GI sui generis regime or collective trademarks). In order to safeguard intemational protection, it is necessary for the relevant body administering the GI or CIM (e.g. trade association, producer group or regional authority) to secure protection in key foreign jurisdictions. Multiple registrations will without doubt cause problems for developing countries, as this process will be very costly.2(19)

Establishing a legal and administrative infrastructure to protect and enforce GIs is only part of creating socio and economic benefits from GI protection; in order to supply markets a system is needed to manage the supply chain, including marketing strategies. ${ }^{270}$ The associations administering the GI are faced with varying levels of competency of different participants in the supply chain which makes establishing and amending commercial and distribution channels of production a long process.

In summary, developing countries need to: 1) undertake a tailor made cost/ benefit analysis of the GI system as it applies to their domestic situation; 2) produce an inventory of potential GIs; and 3) assess their technical needs for instigating national frameworks on CIs and protecting national products. Developing countries should consult with the supporters of Gl extension, e.g. the EC and Switzerland, and international NGOs and civil society to commission such studies and to provide technical assistance in setting up local GI systems of protection. Finally, developing countries should coordinate among themselves: for instance, it is advisable that the African Group within the WTO establishes a common position, as this would strengthen its negotiating position.

\subsection{Establishing a Multilateral Register for Wines (and Spirits)}

In addition to the extension of GI protection, the debate has been focusing on the introduction of a multilateral system for the notification and registration of

2ns See Ragnekar, forthcoming 2009, referring to Ragnekar 2004.

2ny As Ragnekar rightly observes: "[T]he problems with internationalising a sui generis system tend to be less theoretical and more practical and (at times, insurmountably) political. Here, deliberations concerning the multilateral register for wines and spirits and GI-extension stand testimony to these practical and political problems". See Ragnekar, forthcoming 2009.

27i) See Ragnekar, forthcoming 2009. 
wines (and spirits) as envisaged in Article 23.4 of the TRIPS Agreement. The objective of a multilateral register is to facilitate the protection of Gls for wines and spirits. There were many aspects of the Lruguay Round negotiations that could not be concluded and a number of these areas became part of the socalled "built-in agenda" of the WTO that forms part of the work programme for the Doha Development Round. ${ }^{271}$ One of these outstanding implementation issues was set out in Article 23.4, calling for negotiations for the
"establishment of a multilateral system of notification and registration of geo- graphical indications for wines eligible for protection in those Member countries participating in the system".272

Thus, the TRIPS Agreement not only sets minimum standards but also requires further negotiations. The scope of the mandate is limited, as it only requires negotiations to set up a system for the registration of wines. Its wording and narrow scope derives from the negotiations of the "Dunkel Draft" in the Uruguay Round, in which the US and EC were diametrically opposed on the matter of GIs and the final mandate was the result of trade-offs between the EC and US. Section three of the TRIPS Agreement on dealing with Gls are the result of long negotiations and represent a final compromise which makes it a bad starting point for further negotiations.

Negotiations to set up a multilateral system of notification and registration of Gls for wines began in 1995 and have so far not resulted in an outcome. The negotiations were influenced by the Report of the Council for TRIPS to the Singapore Ministerial Conference, where Members called for preliminary work to include spirits in the multilateral register for wines as described in Article 23.4. The purpose behind this addition was to gain more supporters for the negotiation process, as negotiating a register for just one type of product proved difficult.

The progress of the negotiations on the establishment of such a system has been hindered by negotiations on other issues. $2 * 3$. The first is the mandated

2i) The Doha Development Round took up the issue in para. 18 of the Doha Ministerial Declaration, which reads that Member's have agreed to "negotiations for the establishment of a multilateral sy'stem of notification and registration of geographical indications by the Fifth Session of the Ministerial Conference". Hence it was anticipated to reach a solution to this outstanding implementation issue in Cancun (fifth ministerial conference) held from 10-14 September 2003 but this deadline was not met.

2:2 See Art. 23.4 of the TRIPS Agreement.

273 The WTO Secretariat prepared an overview of different proposals in WTO document TN/IP/W/12 of + September 2005. The latest version is WTO document TN/IP/W/12/add. 1 of 4 May 2007, plus WTO document TN/IP/W/12/Add.1/ Corr. 1 of 10 May 2007. 
review of the chapter in TRIPS on Gis, where many developing countries and countries in transition want to expand the scope of the future register to include other products such as agricultural (food) and handicraft products. The second factor that obstructs the advance of such a register are the ongoing negotiations on agriculture: these negotiations have caused TRIPS issues to be linked with food quality, GMOs, health concerns, the use of biotechnology and plant varieties.

At the heart of the debate is what legal effect, if any, the multilateral register would have within Member states: options vary between a voluntary or mandatory system. Article 23.4 calls for a system that "facilitates protection of GIs for wines". ${ }^{274}$ Members remain divided over various aspects of the system including: a) the type of system to be established and procedures applicable; b) the form of participation; c) whether or not it should be subject to examination procedures; d) whether or not opposition procedures should be available; and e) the legal effects, i.e. whether it should be a voluntary or binding system. ${ }^{275}$

Opinions vary greatly on the scope of protection of such a register: some countries support the case that the multilateral system should not be limited to wines only, while others think that an extension of subject matter would be outside the given mandate and that it is therefore not an issue that should be discussed. It has also been proposed to replace the reference to wines and spirits with "products protected under Article 23 of the TRIPS Agreement". The rationale behind this being that if the multilateral register were introduced, it would automatically be applicable to other products should GI extension become a reality. 270

Furthermore opinions differ as to the form of protection prescribed: should the register be of a voluntary nature and seen more as a database of existing Gls or should it be mandatory?277 The EC, Bulgaria, Switzerland and Sri Lanka have

27: A number of delegations have emphasised (during the discussions in the TRIPS Council under Art. 23.t prior to the Doha Ministerial Conference and in the Special Sessions of the TRIPS Council held since then) that the purpose of any system estabished under Art. 23.4 is to "facilitate" the protection of geographical indications rather than to ensure protection for particular indications - reiterating Art. 23.4 which reads: "In order to facilitate the protection of geographical indications for wines, negotiations shall be undertaken in the Council for TRIPS concerning the establishment of a multilateral system of notification and registration of geographical indications for wines eligible for protection in those Members participating in the sy'stem".

25 See Vivas and Spennemann 2006, p. 4.

27n Interview with Christoph Spennemann, UNCTAD legal expert, june 2007, conducted by the author.

$2 \pi$ In addition to stronger $\mathrm{Gl}$ protection and the establishment of a multilateral register, the whole of Section 3 is subject to review as indicated in Art. 24.2. 
submitted proposals in which they advocate that Members should be required to protect the GIs listed on the register, and thus advocate a mandatory register. On the other hand, Australia, Canada, Japan and the US envisage that the register should mainly function as a database and that protection of the registered terms should be voluntary. 278

Below the main proposals submitted to the TRIIS Council are set out in greater detail.

\subsubsection{The Proposal by the EC}

The EC has submitted a number of proposals over the years ${ }^{27}$ in which it sets out its approach to such a register. Its position includes the following elements:

1) Official ame'ndme'nt of the TRIPS Agrement in the form of an annex to the Agreement to incorporate a register into the Agreement;

2) Members should be required to protect the Gls listed in the register;

3) Scope of the system: favouring a system of notification and registration of Gis, with the focus on foodstuff products;

4) Participation in the register is optional but it also has effect ocer nonparticinants, as the registration of a GI would establish "reputable presumption" that the term is protected in other WTO members, except for countries that made a reservation to certain names. Opposition procedure is envisaged which sets out that any Member may, within 18 months from the date on which the notification was published and circulated, lodge a reservation with the administering body which could consider the GI not to be eligible for protection, for instance for not meeting Article 22.1 (the definition of a GI), for confusion under Article 22.4 (falsely representing to the public that goods originate in its territory) or for generics and grapes names as dealt with in Article 24.6. Opposition for other exceptions are not available;

5) Substantive examination in light of Article 22 of the TRIPS Agreement is applicable;

6) Legal effects on participating Members: each WTO Member may elect to participate by submitting GIs into the multilateral system of notification and registration of Gls. Members that do not notify GIs will be deemed to be non-participating;

7) Legal effects on non-participating Members: WTO Members aho have not lotged a rescriation in respect to a notified GI within the 18 month period (the

$2-6$ The WTO secretariat compiled the various positions in WTO document TN/IP/W/ 7,18 February 2003.

$2 \pi$ See communications from the European Communities on the protection of GIs: $\mathrm{W} / \mathrm{GC} / 5+7, \mathrm{TN} / \mathrm{C} / \mathrm{W} / 26, \mathrm{TN} / \mathrm{IP} / \mathrm{W} / 11,14$ June 2005. 
opposition period) shall (a) not refuse protection of the GI and (b) not notify the administering body of any applications for trademark registration that comtain or consists of a Gl that has been registered or applied for. It is needless to say that the request (under seven) for action is cumbersome for developing countries as it requires active action.

\subsubsection{The So-called Joint Proposal}

A diverse group of countries existing of Argentina, Australia, Canada, Chile, Costa Rica, Dominican Republic, Ecuador, EI Salvador, Guatemala, Honduras, Japan, Korea, Mexico, New Zealand, Nicaragua, Paraguay, the Separate Customs 'Territory of Taiwan, Penghu, Kinmen and Matsu, South Africa and the United States have submitted a proposal known by the term of "the joint proposal". 2al "They take the following viewpoints:

1) Scope of system: both notification and database should be on a voluntary basis;

2) Objectives of the system/form of participation: the joint proposal favours a voluntary system where notified Gls would be registered in a database (which in their view is consistent with the mandate under Article 23.4 as it reads "in those Members participating in the system". Hence, it does not support a TRIPS Amondment;

3) Legal effect: participation in the system should be ioluntary. Members should express their intention to participate in the system by means of a written notification to the WTO Secretariat and they need to consult the database when taking decisions on protection in their own countries. Members who choose not to participate are inconraged but not obliged to consult the database in making decisions under their domestic law that involve the registration or protection of trademarks and GIs for wines and spirits. Each member is free to determine the appropriate method of implementing the provisions of that agreement within its own legal system and practise. The submission stresses that systems for protecting Gls include: trademark law, including collective, guarantee or certification marks, specific protection systems for Gls and other relevant laws like unfair competition laws and consumer protection laws and hence these delegations recognise the need for a system that accommotates the various systems currently used by WTO Members to protect geographical indications. The underlying reason for this proposal is the recognition that not all WTO Members produce wines and spirits for export and hence these delegations are of the opinion

$2 \times 1$ See document TN/IP/W/5 of 23 October 2002 and TN/IP/W/10 of 1 April 2005. A recent draft legal text based on document TN/IP/W/10 is produced in TN/IP/W/ 10/Rev.2 of 24 July 2008 titled "proposed draft trips council decision on the establishment of a multilateral system of notification and registration of geographical indications for wines and spirits". 
that the system developed by the TRIPS Council should not create new obligations or otherwise alter the rights and obligations of Members under Section 3 of Part II of the TRIIS Agreement. They further believe that the system of notification and registration should not impose undue burdens or costs on the WTO Secretariat. Finally, recognising in particular the needs of developing and least-developed countries, they believe that any system of notification and registration for geographical indications must be nonburdensome for the WTO Members choosing to participate.

\subsubsection{The Proposal by Hong Kong}

The proposal by llong Kong, ${ }^{2 * 1}$ China endeavours to form a compromise between the EC and the "joint proposal". ${ }^{262}$ Its position includes the following elements:

1) Scope of system: both notification and registration but only applicable to abines and spirits;

2) Legal effect: participation in the system should be voluntary. The obligation to give legal effect to registrations under the system will only be binding upon Mimbers choosing to participate in the systom. The registered terms would enjoy a more limited "presumption" than under the EC proposal;

3) Examination procedure: after receiving notifications from participating members, the administering body shall undertake a "formality examination" of the notifications only, thereby not examining their substance.

\subsubsection{Recommendations for Developing Countries on a Multilateral Register}

The three proposals briefly summarised above have not been examined as to their likely consequences for the integration of developing countries products into the global economy. However, it is advisable that before taking any decisions at the multilateral level, developing countries first decide on their domestic position, including on the mandatory elements in notifications. This analysis should focus on costs and benefits, particularly whether the administrative and financial costs of setting up such a system would outweigh its potential benefits in the long-term. In addition, the decision to support such a system should be strongly linked with the decision by developing countries on whether or not they demand extension of special protection to products other than wines and spirits. For developing countries it is important that obliga-

24 Hong Kong is part of the Chinese Separate Customs Territories see Art. XI WTO Agreement.

$2 \times 2$ See "Multilateral System of Notification and Registration of Geographical Indications Under Art. 23.4 of the TRIPS Agreement", Communication from Hong Kong, $\mathrm{TN} / \mathrm{IP} / \mathrm{W} / 8$ of 23 April 2003. 
tions relating to such a register are coupled with technical and financial assistance in the establishment and administration of such a system.

\section{RECOMMENIAATIONS HOR DEVELOPING COLNTRIES IN ESTABLISHING IGO SYSTEMS}

As discussed above the protection of GIs at the international level is subject to prior protection at the national level. Many developing countries have the potential for protecting Gls on a national, regional or even global market scale, and most likely some already function as GIs in practise but governments have failed to provide the national legal frameworks of protection. This said, it is obvious that developing countries need time to familiarise themselves with the concept of indications of geographical origin. It would be wise for developing countries to ask for a transition period within the context of the multilateral WTO negotiations. This transition period 283 would allow them to search, examine and make an inventory of potential Gls and to register them, but to install the necessary administrative framework later (hence acting as a kind of moratorium).

When deciding what kind of legal system to adopt the cost element plays an important factor, for instance policy makers should take the following elements into account: 1) expense of setting up the necessary infrastructure and institutions; 2) the running costs of the system including the costs to acquire and enforce the rights; and 3) the diversity of potential sectors where GIs might be of importance (in particular the rural, agriculture and agriculturalfood processing and handicraft industries and small scale industries).

All these factors make it difficult to design a domestic regime. As per element 1 , it is of utmost importance to determine the mode of production. As per element 3 , if one takes into consideration that for developing countries agricultural and rural based products are important industries, it would be best to start the identification of products suitable for GI protection amongst these sectors followed by the handicraft industries.

A number of other measures may be pursued in the process of establishing domestic Gl protection, including the following:

25. Unlike some subject matter covered under the TRIPS Agreement, the provisions for Gls do not give allowances for an extension to the implementation period. This implies that the provisions on Gls had to be adhered to as of 1 January 2000 for developing countries and as of 1 January 2006 for least developed countries (as detailed in TRIPS Arts. 65.2 and 65.3 and Art. 66.1 respectively). Requesting some sort of transition period might be an option. 
1) Convene stakeholder meetings on how to establish the legal framework, the quality control and registration procedures of the Gis. Stakeholders should include the private industry, farmer organisations, the traditional producers, traders, policy makers and legal drafters from the relevant ministries of health, agriculture, justice, trade and the intellectual property office. ${ }^{2 s .4}$ The "mode of production" defines the association of GI right holders. First, one determines what kind of raw material is used (land, animal breed, feed, plants and skills). Second, one determines the production and/or processing stage ${ }^{255}$ (distilling, blending, curing, pasteurisations and ripening, harvesting, or handicrafts). The third stage involves the final production, for instance in the labels of authenticity used. $2 \mathrm{son}$

2) Make a list of those Gls that are currently being protected and identify potential GIs in developing countries to visualise the importance or nuisance of $G I$ protection for the country.

3) Request technical cooperation and assistance from the supporters of GI protection for instance the EC; in terms of setting up the system, network of traders and producers, administrative framework, control authorities and supply chain management.

4) Examine the added value of joining the Lisbon Agreement as negotiations in the WTO take many years to conclude, the Lisbon Agreement can

23. The International Trademark Association (INTA) pleads for administering Gl by using similar systems as applied by the Madrid System for the International Registration of marks implying that there is a need for: 1) one search; 2) both national and international registration and publication and; 3) prior right and right to challenge the registration on grounds of the prior right. Unsurprisingly, INTA favours an approach in line with the principles of territoriality, priority and exclusivity. It is convinced that national application should form basis of international registration since they are best equipped to undertake an IPR priority examination, which is demonstrated in the Budweiser cases. For more information see <http://wwwinta.org>.

23i: There is currently an ongoing cooperation programme between the World Intellectual Property Organisation (WIPO), the French authorities and the African Intelleclual Property Organisation (OAPI) to promote the establishment of GIs in some of the 16 francophone OAPl countries. A pilot project was initiated to help farmers set production standards establishing the basis for regulating GI protection. The group, which bases its IPR rules on the legal framework of the revised 1999 Bangui Agreement (see Box 2), has recently protected "Champagne" as its first recognised geographical indication. For further details see: <http//www.oapi.wiponet/en/ OAPl/actualites/indication_geo_champagne.htm>.

2st Information derived from lecture given by Dwijen Rangnekar. "The International Protection of Gls - Regional Dialogue on IPRs, Innovation and Sustainable Development", 8-10 November 2004, Hong Kong. 
protected Gls at an international level provided domestic registration and protection is in place

5) Negotiate a cap (ceiling) on the number of GIs that can be registered and mutually accepted in F'IAs and on a multilateral level.

6) Prepare a list of foreign Gls that are currently generically used in the country. Extension/strengthening of GI protection on their territory might involve the surrender of these generically used names. Implying that one can still use these products but that it is not possible to use the (protected GI) names, for instance Indian manufacturers can not call white cheese made of sheep milk "feta" but they will have to rename these products. ${ }^{2 k 7}$

7) Organise the producers by establishing cooperation's, unions or associations. These associations need to install and implement the applicable method of production in order to guarantee the quality of the specific products.

8) Fxamine the national, regional and international market potential for the GIs. This includes looking at the market access possibilities: "How high are the tariff lines?", "Are there any sanitary and phytosanitary measures that need to applied with?" and "What are the technical standards requirements?"

9) Focus on branding and labelling activities and improving the supply chain management including marketing strategies, e.g. using billboards, radio and information technology mechanisms to promote the Gls.

10) Establish measures to protect an indication from being rendered generic and safeguard its legal rights. The Darjecling case has shown that fighting infringement is costly.

As per measure eight (on market access) mentioned above, currently, many developing countries are exporters of agricultural products but they face problems (market access barriers) accessing the EU markets due to high tariffs, hygiene standards, high safety standards and strict technological regulations imposed on products entering the EU markets that adversely affect export competitiveness and form a barrier to trade. ${ }^{2 x s}$ It would be wise to see if the protection of GI could contribute to accessing foreign markets. Currently, many developing countries are not using the GI system and for them, any con-

25: In Europe a typical white cheese made of a mixture of sheep and goat cheese can only be called Feta if originating from Greece, as a result a lot of Danish cheep cheese had to be renamed. See para. 1.7 of this chapter.

2ns See Zarilli, Jha and Vossenaar 1997. 
cessions made on protecting food specificity are related to increased liberalisation in the agricultural sector. ${ }^{28 \%}$

First and foremost GI protection would help to increase the quality of the product as the product is subject to strict quality control set by the association controlling and safeguarding the specificities of the GI. Nonetheless granting Gl protection does not guarantee market access to export markets or increase in sale.

"[C]losing-off market access opportunities for emerging and future export industries could be a serious and difficult to anticipate consequence of extension"..$^{2 \times 11}$

As the current market barriers, like tariffs and technical regulation, will remain in place and need compliance.

Another problem encountered with the extension of protection relates to the access to foreign markets: if the market is already sufficiently supplied with a particular type of good, it is likely that due to limited shelf space and previous established reputation and client binding (clients are very loyal to daily need goods) it is difficult for other producers to acquire marketing space..$^{291}$

As per measure one, developing countries should remember that countries enjoy flexibility in determining the legal definition of GIs within their domestic jurisdictions. There is no unanimity in this respect. ${ }^{292} \wedge$ s said before the TRIPS Agreement does not specify what constitutes "a given quality", "reputation", or other "characteristic", hence this leaves considerable flexibility to the individual countries as to the mode of interpretation of these requirements. In addition, the TRIPS Agreement does not specify the description of the geographical area: countries are free to use a wide range of geographical units including for instance, political units, restricted wine growing areas etcetera. It might be useful for developing countries to follow a wide concept of geographical origin as a particular geographical circumstance (soil, climate, and elevation level) might not stop to exist at (artificially drawn) borders.

2 sa See Vivas-Fugui 2004.

201 See Vivas-Eugui 2001, p. 17.

201 See UNCTAD-ICTSD [Resource Book] 2005, p. 318.

242 For instance, countries like, Belgium, Bulgaria and Mexico have adopted an "appellations of origin"-type of definition as per the Lisbon Agreement, which requires the denomination to be a direct geographical name. 


\title{
5.1. Examples of Successul GIs in Deotoping Comutries
}

The UNCTAD BioTrade Initiative ${ }^{293}$ is supporting partners in developing countries to consider the feasibility of distinctive signs being used to promote and add value to sustainable BioTrade products. The programme has commissioned case studies to analyse whether the use of geographical indications is appropriate and advisable in concrete cases in particular regions. The programme analysed a couple of cases in Latin America. For instance, in the Borojo case in Colombia, they found that seeking an appellation of origin was premature and that it was advisable to focus on a number of issues first:

\begin{abstract}
"Although all the requirements for an appellation of origin exist, including a strong link between the fruit and the geographical focation in which it is produced, the quality-location connection, for example, has not yet been verified. Another concern raised in discussions was the lack of an organisation with the necessary technical, political, financial and human capacity to control uniform quality throughout the productive chain of Borojo. Strengthening the value chain, organising stakeholders, and consolidating markets were thus identified as necessary initial steps towards an eventual geographical indication". 20,4
\end{abstract}

Other cases were thought to have higher potential for the use of appellations of origin. For instance, "Maca", a plant native to Peru embodying high nutritive and medicinal properties, qualifies for an appellation of origin as it contains particular qualities derived from geographical, natural, and human factors. Moreover, it is considered an advantage that the Peruvian government and various other organisations linked to the production and export of "Maca" are already actively involved in establishing the institutional bases and technical standards needed for the registration and implementation of an appellation of origin. Some outstanding issues remain as to the adequate terminology and the geographical boundaries for the appellation of origin, particularly given that Maca is also cultivated in Bolivia. "Cacao Arriba", which is a type of cocoa with a particular aroma found in Ecuador, is another product identified as having great potential for an appellation of origin given the link between its quality with the natural factors in the region it is cultivated, as well as the TK used in the method of production. In addition, a Consultative Council guards the cocoa value chain, through which national associations of producers, rural workers and exporters have contributed to the national definition of sectoral policies. Areas that need more attention are "increased collaboration in monitoring and controlling production and quality

24:3 Since its launch in 1996, the UNCTAD BioTrade Initiative has been promoting sustainable biotrade in support of the oljectives of the Convention on Biological Diversity. See <http://www.biotrade.org/>.

24 See Oliva 2007, p. 4. 
processes, as well as promotion and marketing of the product". ${ }^{245}$ This also involves establishing domestic legislation that adequately addresses procedures and elements for the implementation of appellations of origin.

Tequila and Darjeeling are examples of success stories which will shortly be described in this section. The story of Tequila tells us that it takes significant efforts to turn a local drink into an international bestseller. Tequila has been produced in Jalisco, Mexico for centuries but until a decade ago it was considered to be cheap liquor which was consumed only by the lower classes of society, in particular in rural areas. The shift of image of Tequila was the result of the protection of the beverage as an appellation of origin in Mexico and by raising production standards and improving labelling and marketing. Although the Official Mexican Standard only requests using 51 per cent pure agave (implying that 49 per cent of sugars from other sources may be used) companies started producing tequila based on 100 per cent pure agave which improved quality and purity. Companies also experimented with introducing different kinds of tequila to meet consumer taste and improved bottles and packaging which added to the value of the product. In addition, the establishment of an administrative body to verify production methods (as stipulated in the Official Mexican Standard for Tequila) and quality, the Tequila Governing Council (CRI) helped to stop the counterfeit products that damaged the image of tequila. Nonetheless due to the uniformity of the ingredients to produce Tequila, it has been mentioned that it had a negative impact on biodiversity in Mexico. It is important that biodiversity and sustainable land use is taken into account before countries decide on the production methods (specifications) underlying the product.

Another success story is of a successful indication of geographical origin is "Darjeeling" Tea. ${ }^{246}$ This particular tea is presumably one of the most wellknown teas in the world and is considered the "Champagne of teas" on account of the unique geographical location, the type of tea plant and its processing method. ${ }^{297}$ The Darjeeling tea producers face a number of problems in terms of safeguarding its protection and economic value retrieval. These problems are not unique to this particular case but could occur in all situations of building up and or strengthening a GI. For instance problems occur with the trade in counterfeit goods: a substantial amount (an estimated 80 per cent) of internationally traded Darjeeling tea is counterfeit, coming from Kenya, Sri Lanka and Nepal. Other problems are due to the variations in price (market

295 Sec Oliva $2007, \mathrm{p} .1$.

2 the paragraph on Darjecling is based on an example given by Ragnekar 2009. See also Tea Board of India <http://www.teaindia.orgs.

2w- For a fairly detailed history of the development of Darjeeling tea and an overview of protection measures undertaken to strengthen the mark, see Ragnekar, forthcoming 2009. 
value). This reflects the underlying structure of the industry and supply chains. In it its initial stage of production the trade in Darjeeling tea was entirely controlled by the British colonialists but at the present time the marketand of the supply chain is controlled by foreign blending and marketing companies implying that a lot of Darjeeling tea is sold under the brand name of the foreign blender and packer. Finally, the association needs to cope with the changing market situation. Changes in the market have had implications for the Darjeeling tea segment. For instance the emergence of new tea exporting countries (Malawi and Kenya), changing consumption patterns (e.g. tea bags or chilled tea)

The Tea Board of India, working together with the Darjeeling Planters' Association and the government of India, has undertaken a number of measures attempting to strengthen the Darjeeling mark. For instance a logo for Darjeeling tea was developed and registered in a number of countries as a trademark and/or collective trademark (in the UK, US, Canada, Japan, Egypt and a number of European countries). In India itself, protection was sought by registering the logo and the word Darjeeling under the Trade and Merchandise Mark Act of 1958 in the 1980s.

The central role of signs and symbols that differentiate products is to lessen information asymmetries faced by consumers and simultaneously to facilitate reputation building for producers. The Darjeling case shows the importance of undertaking measures to guarantee the authenticity and uniqueness of the GI. For instance the Tea (Marketing and Distribution) Control Order of 2000 grants Certificates of Origin for tea exports to ensure the integrity of consignments leaving India. There is a need for the Tea Board to establish mechanisms "to ensure authenticity at the retail end of the supply chain where foreign blenders and marketers dominate". ${ }^{298}$ Next to securing the protection of GI as an IPR, the Tea Board also focused on the enforcement of their rights in overseas territories. For instance, an international watch agency has been hired to detect all uses of the word "Darjeeling". This step was undertaken to retain the reputation of the word and its association with a particular quality of tea from a specific region. Finally, in October 2004, Darjeeling tea was registered as a $\mathrm{Gl}$ in India.

\section{CONCLLSION}

A GI is a designation which identifies certain qualities, characteristics or the reputation of a particular product to a specific geographical locality. It is designed to indicate product quality, highlight brand identity and preserve cultural traditions.

zow See Ragnekar, forthcoming 2009. 
The TRIPS Agreement brought Gls within the framework of IPRs. For Gls, the TRIPS Agreement forged a complex substantive compromise between the EC and the so-called new world countries interests. It provides for a minimum level of Gl protection and provides the mandate to continue discussions and hence the "compromise included an agreement to put off the full battle for another day". ${ }^{20}$ Hence, the TRIPS Agreement provides a bad starting point for further negotiations. If intellectual property protection is seen as a tool to stimulate innovation, then the protection of Gls is somewhat contradictory as they in principle protect goods that already exist: they protect tradition in that they preserve culture and agriculture practices. The protection of Gls was introduced for different purposes and reasons than traditional IPR concepts such as trademarks, and they are different concepts. In my opinion, to have dual-protection coexistence of trademarks and GIs would undermine the foundations of both systems. Nevertheless due to the principle of territoriality it would not be feasible to prevent the coexistence of Gls and trademarks existing prior to the IRIDS Agreement.

As we have seen the protection of Gl cuts across a range of issues, which, besides the prevention of misleading use and dilution of indications touches upon sustainable development, the promotion of agricultural development, consumer protection and the protection of indigenous knowledge. Geographical indications are by essence a collective right. They allow for the protection of existing products and traditional methods of production and knowledge. Due to these characteristics, GIs can play a role in promoting rural development in remote areas. Gls may also contribute to social cohesion, helping local producers work together to solve common problems. They can also positively influence local and national identity by making producers and consumers proud of their unique traditional products. GIs encourage variety and diversity of production and allow for a better redistribution of "added value" in the production chain - from the raw material producer to the manufacturer. They allow producers to market distinct products with specific characteristics that are clearly identifiable. ${ }^{3(k)}$

GIs do facilitate product differentiation as they protect products which evoke quality, special characteristics and traditional methods of production but GIs do not guarantee market access or compliance with safety and consumer standards. In this regard, developing countries should consider trating market access for agriculture and tropical products in exchange for the enhanced protection of GI. They should also raise the awareness for the difficulties they face accessing the EU markets for their products as the labelling and eco labelling regulations set by the EC do not take account of the realities of these countries, i.e. all these rules are difficult to apply for small companies and

ser See Hughes 2006, p. 301
See Claessens 2008a. 
these rules do not consider the type of materials or procedures used by developing countries. ${ }^{301}$ Due to the different interests at stake and highly controversial policies on agriculture, a breakthrough in the current impasse at the WTO TRII'S Council and WTO Agriculture Committee deliberations is unlikely.

More studies are needed on the effectiveness of the regimes used by the WTO members to fulfil Gl obligations. An economic assessment to scrutinise the potential costs-benefits of Gl is necessary; only an empirical study can help developing countries to make a balanced decision of whether the advantages of protecting GIs outweigh the disadvantages and vice versa. As with any other legal and policy instrument, GIs have costs as well as benefits and for Gls to operate successfully, certain commercial and institutional conditions are required, such as costs of establishing a uniform GI system, including a means to follow and verify production methods. Countries need to identify potential products that could qualify for protection as well as decide upon decide upon standards and criteria of protection. ${ }^{312}$ In addition, GIs require consumer recognition of the quality of the labelled products, which in turn will need to be reinforced through marketing and communication strategies (including labelling). Developing countries would need technical assistance and cooperation in this regard. In the future, WTO cases under DSU can shed a light on other countries effectiveness in protection. Especially for developing countries that are in the process of drafting a regime, it might be worthwhile gaining insight into the nature of other countries' regimes and how they function on the market. 313

There could be clear benefits from using GIs in developing countries. However, countries should ask several questions before deciding to enter the complex Gl debate or before committing to obligations: Does the country need GIs? What effects would they have? How do rules on GIs compare with similar areas, such as trademarks or improved labelling and marketing efforts? Most importantly, developing countries must look for products where real commercial value could be gained - or lost - as a consequence of expanding the level of protection. However, developing countries face huge challenges in

301 See Vivas-Eugui 2001, p. 719.

3:12 For instance, the African continent is gifted with diverse areas of agriculture, natural resources, culture and traditions. For centuries communities across the continent have produced goods with a quality associated to a special area and that enjoy a strong reputation with national and international consumers. Possible examples include some Kenyan teas and coffees, shea butter from Burkina Faso, Guinean pineapples, white honey from Cameroon, Nile Perch from Lake Victoria, Tanzania, Kenya and Uganda, Rovilos tea from South Africa, Mamamara vanilla from Madagascar or Korloge fabrics from Wory Coast. See Claessens 2008 a.

in: See World Bank 2002, p. 143-1+4. 
drafting and implementing IPR policies in general and stronger GI protection will add another layer to their obligations. Therefore, it is recommended that developing countries decide upon their domestic strategy first before pursuing a certain path at the multilateral TRIPS Council forum. However, a domestic needs assessment to determine country policy and strategy in relation to GIs is hindered by the pressures of FlAs and bilateral agreements in which particularly the EC broadens its regional scope of protection.

At present it is most likely the countries that have long established GI systems in place will benefit from extension of protection since they have a competitive edge in this particular sector. For products without accomplished tradition trademark protection might be more adequate as it is cheaper and easier to accommodate and realise in practise. Currently, the EU is the only region with long GI history and experience with the concept and protection and enforcement regime. It is rather hypocritical of the EC to slow down multilateral protection of traditional knowledge but to be a fervent supporter of the extension of $G 1$ protection because $G 1$ protection is really about the protection of traditional processes of production applied over centuries in a specific region using particular techniques and human skills. This comes very close to the concept of traditional knowledge for which the EC does not support the establishment of international standards of protection. It is a political ballgame: it all comes down to the socio-economic interests of the players, as there is no consistency in reasoning behind the inclusion of certain subject matter in the negotiations.

The over protection of Gls should be avoided as not to impede market access and trade flows:

\footnotetext{
"It should be borne in mind that, as is the case with trademarks, an unduly high level of protection of geographical indications and designations of origin would impede the integration of national markets by imposing unjustified restrictions on the free flow of goods". 3it
}

The framework as set out in the multilateral framework and on the European domestic system are most suitable for goods for which the entire production chain occurs in the same location, from the production of the raw material to packaging and labelling. This means that products based on geographically diffuse production models can face difficulties in obtaining protection. Countries that do not have the capacity to carry out the whole production chain on their territory will need to find ways to avoid this hindrance. It is a big cha!lenge to introduce coherent, effective and efficient legal protection of Gls. Next to establishing the institutional framework to implement and enforce the policies and legislation needs to be put in place.

3is European Union Advocate General Francis Jacobs, quoted by Hughes 2006, p. 299. 
Still no adequate solution to solve the genericism problem has been agreed on at an international level. The problem of many newcomers to the market is that many welj-known names (like Darjeeling) may already be registered and used by multinational companies. In the long term, if developing countries policies focus on developing, identifying and protecting GI at the domestic market. Cil could be a valuable tool for development and economic growth. Nonetheless, in my view for new products (new in the sense that it has not acquired fame and reputation yet) it would be best to start by adopting a less cumbersome and less expensive trademark or "certification of origin" protection scheme. This would also facilitate regional initiatives, in which countries collaborate in the protection of jointly held special foodstuff. For instance, it would be advisable to set up a regional system of certification of origin protection for peanuts coming from Senegal and The Gambia. Foremost, it is important for developing countries to strengthen the product by improving marketing strategies and building a strong name for the product in question.

GIs have been at the heart of the debate on international trade negotiations since their inclusion in the Uruguay Round and the adoption of the Trade Related Aspects of Intellectual Property Rights (TRIPS) Agreement. GIs have caused particular divisions in the current WTO Doha round of trade liberalisation negotiations. The EC, with support from some Asian countries, wants to create a binding register of protected GIs, whereas the US, Australia, Argentina and a coalition of other countries want a non-binding database (notification system) of other countries' protected designations which could be consulted on a more-or-less voluntary basis. These countries believe EC plans for an international $G I$ register would grant unwarranted protection to European produce. At present, WTO law contains a commitment to ensure that Gls do not mislead consumers on the true origin of a product or cause unfair competition. However, for wines and spirits, a higher level of protection applies. Thus, "Senagalese Champagne" is not a permitted formulation, whereas "Senagalese Gorgonzola", for example, would be allowed. The EC and its allies are essentially pressing for the higher-level protection that currently applies to wines and spirits to be extended to other agricultural and food products. Some question whether a developing country that has no interest in Gls for its own products should seek to oppose GI requests for EC products. What motive would they have without competing products? While there is no obligation for developing countries to support a wider extension of rules, Gls at the multilateral level are here to stay. It would seem better that developing countries try to benefit from them - an unlikely prospect if protection is only given to wines and spirits. In this respect, perhaps developing countries should consider trading agricultural market access and tropical products for better GI protection. Either way, the complete lack of consensus between WTO countries makes the possibility of an agreement on geographical indications for agricultural products in the near future a bleak one. There is speculation that there has been a change in strategy and certain countries are now trying to secure protection for regional products via bilateral deals with individual countries, as a safeguard against possible failure to 
make progress in multilateral negotiations. As such, GI provisions are increasingly being included in regional and bilateral trade agreements - especially those negotiated by the EC and the European Free Trade Association. One recent example is the Economic Partnership Agreements (EPAs) between the $E C$ and the ACP countries. Regional and bilateral trade agreement to which the EC is a party include the following elements: 1) the extension of the higher level of protection for wines and spirits under the TRIPS to all GIs (basically to all products that have protection in the EU); 2) upgrading the obligation of countries from "providing the legal means" for interested parties to prevent the use of Gls (under IRIPS) to a positive obligation to protect GIs; and 3) including a list of terms that do not constitute terms customary in common language as the common name for goods or services in the territory of the parties.

The needs of developing countries that are slowly discovering the market value of Gls must also be taken into account in the TRIPS Council negotiations. They need identify possible products on their territory that would be able to qualify for GI protection. Consequently the domestic legislation needs to be drafted and implemented and the institutional framework to facilitate enforcement needs to be installed. It might therefore be a good idea for developing countries to advocate the WIPO 1975 Draft Treaty which recognises the specific concerns of developing countries and provides the opportunity to register geographical names prior to domestic registration and protection so as to safeguard/reserve these names for the future. It is advisable to developing countries to propose for a cap/ceiling to the amount of registrations in the WIO TRIPS Council negotiations in relation to the establishment of a multilateral register. Likewise developing countries should consider demanding a transition period to allow the introduction of domestic protection. Developing countries could also opt to join the Lisbon Union and receive protection under the Lisbon Agreement. However, this brings the additional burden of registration which is not present under the TRIPS Agreement yet. Developing countries should focus on domestic and regional protection first as it is not easy to protect, register and enforce the GI in foreign territories. For instance it is not easy to apply for GI protection in other countries and fighting legal battles in foreign territories are expensive. Developing countries should focus on finding "niche products" since it is important not to imitate neighbouring countries but to cooperate or to enter the market with a completely new product suitable to the countries climate conditions - comparative advantage. As said it is important to focus on improving the supply chain including marketing and distribution of the product and its branding and promotion. Market access will also be a point of concern, as having Gl protection for domestic products will not necessarily guarantee access for these products to foreign markets - mainly due to high tariffs or unattainable health and safety standards. ACP countries or regions must begin by evaluating the potential benefits GIs could bring to key products such as fish, fruits, textiles and crafts. 
There will never be a win-win situation; GI protection might lead to the surrender of generically used names in certain countries (but will provide protection for local GI products). But in the long term, if developing countries can focus on developing, identifying and protecting Gls on the domestic market, the system could be a valuable tool for sustainable development and economic growth. It will be an endeavour best approached one step at a time. 


\title{
Chapter Five
}

\section{International Technology Transfer and Developing Countries}

\author{
"All animals are e'qual, but some amimals are more e'tual than othe'ss" \\ George Orwell
}

\section{INTROALCTION}

The importance of international technology transfer for economic development is beyond doubt. Both the acquisition of technology and its diffusion foster productivity and growth.' Among others, Kruger (1995) is convinced that there is

"broat evidence that differences in technology, ather than differences in resources, are the most important determinant of the pattern of comparative advantage".?

Countries with various levels of development have long sought to use mutually national policies, such as policies relating to education, intellectual property rights or tax incentives to stimulate the sale of goods as well as international agreements to stimulate international technology transfer.

To encourage the generation and creation of new knowledge and information, industrialised countries have elaborate systems of IPRs in place and they conduct the majority of the world's R\&D. Technologies deriving from such

See Hoekman, Maskus and Saggi 2005, p. 1587.

See Card and Krueger 1995, p. 349.

WII') summarises the evolution of world wide patent filings: "Until 1960, growth in worldwide patent activities was very modest with an average annual growth rate of $1.99 \%$ from 1883 to 1959 . During this period, patenting activity was concentrated in four countries - the United States of America, Germany, the United Kingdom and France. From 1960, usage of the patent system accelerated due to the emergence of users from new States or regions. Filings of patent applications in Japan and inventor's certificates in the Soviet Union increased noticeably during this period. Since 1980, the patent offices of the United States of America followed by the European Patent Office, the Republic of Korea and China have all experienced significant growth rates in filings. At the nine offices shown above, the average annual growth rate from 1960 to 2005 was $3.35 \% "$. See WIPO Patent Report Statistics on Worldwide Patent Activities 2007 Edition, p. 11. 
R\&D spread throughout the world through a multitude of channels as we will see below.

Most of the regulations on technology transfer are of a territorial nature as harmonisation on an international level proved to be difficult at providing flexibilities for developing countries to establish national and regional rules on technology transfer. The most prominent example of the search for international protection and encouragement of technology transfer is the effort made by a group of developing countries in the 1970 s to develop a Code of Conduct to regulate technology transfer under United Nations auspices. Negotiations led to the establishment of a Draft Transfer of Technology Code (Draft TOT Code) but various different perspectives hindered the legal formalisation of the Code and as a consequence it never came into existence.

The TRIPS Agreement is the first multilateral attempt to reach some mutual agreement on the issue of technology transfer after the failure of the Draft TOT Code. The provisions of the TRIPS Agreement dealing with the transfer of technology will be analyzed and suggestions for its improvement will be made in this chapter.

Just as the level of R\&D (innovation) within a country is difficult to determine, the level of technology transfer is equally hard to pinpoint. For the former, a determining factor is the number of patents registered (although limitations exists as not all inventions are patented - alternative IPRs might be used such as trade secrets or marketing strategies; in addition there may be double counting of the same invention due to multi country patent applications in the country or origin and abroad; in addition the R\&D can take place in one country and the patent application in another). ${ }^{5}$ To assess the level of international technology transfer is possibly an even more strenuous task as "technology itself is differentiated and diverse". "The amount of foreign direct investment (FDI) is often used as a parameter to fix to a certain extent the amount of technology transfer taking place.

4 Annex three of this book entails a copy of the UNCTAD Draft International Code of Conduct on the Transfer of Technology', 1985 version.

- According to the WIPO: "Patent statistics are increasingly recognised as useful indicators of inventive activity and of technology flows. Patents are a unique information resource because they contain very detailed, publicly available information about inventions which can be matched with other indicators to provide insight into the evolution of technology (...) [T] The use of the patent system remains highly concentrated with only five patent offices (United States of America, Japan, Republic of Korea, China and the European Patent Office) accounting for 75 per cent of all patent applications and 74 per cent of all patents granted. See WIPO Patent Report, Statistics on Worldwide Patent Activity 1, 4, 2006, p. 9. See also WIPO Patent Report Statistics on Worldwide Patent Activities 2007 Edition, p. 3.

- See May 2003, p. 113. 
Empirical evidence on the role of intellectual property protection in promoting innovation and growth in general and attracting the transfer of technology remains limited and inconclusive. ${ }^{7}$ The role of IPR protection and technology transfer has been the subject of many econometric studies and conclusions are drawn; nevertheless, the drawback is that a lot of these outcomes are to a great extent based on assumptions. In fact, conflicting views persist on the impacts of intellectual property rights in the development prospects. Obviously, the impact of IPR on economic growth and development is of utmost importance for government officials deciding on policy strategies for future (multilateral, regional, plurilateral or bilateral) negotiations in line with and supportive of socio-economic policies. Having a more realistic evidence-based outlook as to how much an IPR legal framework determines the amount of technology transfer developing countries are going to receive will also help to implement the TRIPS Agreement obligations and other international, regional and bilateral agreements that they are committed to.s

This chapter will explain the concept of international technology transfer and its relationship with intellectual property rights. It will endeavour to reach some conclusions as to what extent intellectual property policies can play a role in fostering development and reducing poverty and to what extent the current TRIPS Agreement plays a role at various levels of development in facilitating the transfer of technology. For these purposes some of the economic, empirical and theoretical research available on the relationship between intellectual property, foreign direct investment and the trade in technology will be analysed. It addresses the issues of technology transfer between systems with deviating levels of development in an epoch of continuous strengthening of intellectual property regimes. The different forms of technology transfer will be explained, and conclusions will be drawn as to what constitutes the most rewarding and efficient way to transfer knowledge and technology.

\section{TECHNOLOGY TRANSFER: Characteristics, SCOIE AND ACCESS}

\subsection{Characteristics of Technology}

Technology is seen as "an essential precondition for improving productivity, attaining industrial development and promoting export growth"."

- See Mansfield 1994 and 1995, Park and Lippoldt 2004 and 2008, Ginarte and Park 1997. Saggi 2000, Branstelter, Fisman and Foley 2005, and Maskus 2000.

s See section 5 of this chapter for a discussion on the relationship between IPR and the transfer of technology.

"See UNCTAD 2005b, p. 5. 
The term technology is a term commonly used, but not easy to capture in one simple definition. One definition could only define one or more of the combinations of skills or rights embodied within the notion. ${ }^{10}$ WIPO provides a practical working definition of what constitutes technology in its Licensing Guide for Developing Countries in which it confirms that technology is essential to all stages of a commercial or industrial endeavour and that technology relates to knowledge embodied in different ways:

\begin{abstract}
"Technology means systematic knowledge for the manufacture of a product, the application of a process or the rendering of a service, whether that knowledge be reflected in an invention, an industrial design, a utility model, or a new plant variely, or in technical information or skills, or in the services and assistance provided by experts for the design, installation, operation or maintenance of an industrial plant or for the management of an industrial or commercial enterprise or its activities". "1:
\end{abstract}

Technology can be divided according to its form, for example: 1) a tangible form, such as in plant, machinery, or skilled labour; or 2) in an intangible form, such as managerial knowledge and technical skills; and 3) the knowledge embodied in legal documents, such as patent licenses, know-how agreements or registered designs. 2 'Thus, technology may be codified (e.g., in blueprints) or uncodified (e.g., know-how of engineers).

We have seen that technology can be embodied in different forms, but we can also make a difference between "conventional technology" and "high technology". The former contains technologies used in the textile, spare parts, automobile, ${ }^{13}$ cement and paper industries to name just a few. The "high technology" industries are for instance the pharmaceutical, mobile phone or computer industries, where large sums of money are spent in the R\&D department. Characteristics of these industries are large elements of

"complex patented or non-patented proprietary technology, rapid and continuing technological change, sky-scraping capital needs, and product differentiation". 1.1

11) See Blakeney 1989, p. 1

11 See WIPO, Licensing Guide for Developing Countries, Geneva, 1977, p. 28.

12 For a detailed overview of the aspects of technology transfer, IPRs and developing countries see Blakeney 1989.

13 The automobile industry can be an example of both high and low tech industry: most of the technique is standard and basic but some cars add special functions for instance relating to safety and security measures such as Mercedes or Volvo. For instance, the "Bugatti EB 16.4 Veyron" is called a mobile laboratory.

See Blakeney 1989, p. 2 quoting Chudson 1981, p. 19. 
$\Lambda$ significant characteristic of contemporary economic growth has been the considerable role played by technological change. Of the diverse factors motivating technological change, one factor that has received increasing attention in the recent past has been the role of intellectual property protection which will be discussed in more detail below.

Knowledge and technology are interlinked concepts: technology does not exist without knowledge as knowledge is the basis for the development of new technology and knowledge is necessary to use a certain technology or to operate it. Knowledge is by nature a non-rival good as it can be simultaneously used by two different agents/constituencies. Nonetheless, this fact does not imply that knowledge can be transferred across agents at zero cost. The non-rival nature of knowledge only implies that if two agents are willing to pay the cost of adopting a new idea or a technology, they can do so without interfering with each others decisions. The concept of knowledge is broader than information: "Knowledge, in whatever field, empowers its possessors with the capacity for intellectual or physical action". ${ }^{15}$ Hence, where it is easy to copy information at relatively zero costs, reproducing knowledge is a far more complicated since "cognitive capabilities" are not easy to transfer and depend on training (including watching, listening, imitating). ${ }^{\text {it }}$

Frankel prefers to use the term knowledge rather than information transfer because knowledge focuses on the experience of the recipient of knowledge. Knowledge arises from deliberate seeking, but it also arises from observations incidental on other activities. ${ }^{17}$

Another characteristic of technology and related know-how is that the advantage of a certain new technology is significantly improved if it is widely used

15 See Foray, fortheoming 2009 , p. 12.

1t See Foray, forthooming 2009, p. 12.

17 From his experiences he draws the following conclusion: "legal drafting requires creative policy analysis that cannot be acquired by repetition and drill". Frankel distinguishes between "learning" and "teaching" rather than "training". In his opinion learning focuses on the recipient's active and voluntary acquisition of knowledge, generally by creating and discovering; whereas training is designed to qualify people for a test or provide them with a skill by discipline and repetition. The paper draw's on the author's involvement in a project by the government of China and $U N$ development programs to help the Chinese draft their laws. The project uses both teaching and consulting modes. It compares teaching and consulting with respect to their immediate results and the costs and benefits of teaching and consulting. The author concludes that the mode of knowledge transfer should be carefully examined weighting the costs and benefits of each mode. Moreover, combining both modes of transfer may not achieve optimally the goal of either teaching or consulting in the short-term, the benefits from the combination can outweigh the deficiencies. See Frankel 1995, p. 1-2. 
allowing the interoperability and interconnection of technological equipment: the network effects. The broad and rapid diffusion of new and state-of-the-art knowledge embodied in a product contributes to social wellbeing and welfare. Hence it is important that multiple firms have access and are able to use the newly developed technology which makes rapid technology diffusion a key matter for economic grow th. is

Technology increasingly plays a central role in production input, and the amount of knowledge required in production processes has grown remarkably. Technological knowledge for production includes research and development (R\&D), design, engineering and improvement of the supply chain including effective maintenance, management and marketing. The 1992 OECD study has shown that intangible investments (e.g. R\&D, training, software development, design and engineering) have been mounting at three times the rate of tangible investments since the late 1970s." New technologies like microelectronics, biotechnology and new materials have created new products. ${ }^{21}$ At the same time they have changed the characteristics and performance of many traditional products. ${ }^{21}$ See chapter three for an expose of the search for international (legal) protection for genetic researches and associated traditional knowledge (IK) and concerns in relation to the appropriation of genetic resources through the advance of biotechnology industries. Grossman and Helpman argue that "economic growth centrally relies on technological change through the creation of new products and processes". 22 New products embody novel ideas and international trade can transmit knowledge across borders.

1s For instance, the newly developed Apple iPhone is already the second most popular smartphone after the BlackBerry, with a 28 per cent share of the market, but its inability to communicate with corporate computer systems running Microsoft Exchange has hindered its growth in that market. In order to increase sales, Apple iPhone announced a low cost software development kit that outside programmers can use to create programs for the iPhone as its use was limited as it was only able to run on applications that Apple include. In an attempt to attract corporate customers, Apple has announced that the iPhone would be able to work directly with Microsoft's Exchange software, allowing it to interact closely with corporate networks and e-mail systems in much the way that BlackBerry devices do. See Flym 2008. The $3 G$ iPhone and 2.0 software do have exchange integration which resulted in the sale of 6 million 3G iPhones in 50 days in contrast the first iPhone sold 6 million in one y'ear - a perfect example of network effects.

1. See OECD 1992.

20 See "World Economic and Social Survey 1995", UN, 1995.

21 See UNCTAD 1995.

22 See Grossman and Helpman 1991. 
Hence, barriers to technology adoption are a key determinant of international differences in per-capita income and greater trade openness can increase growth by lowering such barriers. ${ }^{23}$

\subsubsection{Publicly and Privately Developed Technology}

The public sector, including universities, and the private sector are the two main sources of funding for new technologies. Each allocates money in its own sector as well as research in the other, the balance of which varies over time, from country to country, from industry to industry. The development of the computer for instance was heavily subsidised by government, while contemporary research and engineering of computers is funded almost in its totality by the private sector. ${ }^{2 \cdot}$ The public sector supports research in various ways but the most prominent way is the direct funding of research at universities and laboratories. There are also programs to support specific industries for instance to realise a particular goal: For instance where the government is the main purchaser of a product containing the technology, the government will have to pay the price for the R\&D. This occurs frequently in military, space and energy technology and at one time agricultural research was almost entirely funded by the public sector. ${ }^{25}$

The majority of research is financed by the private sector. Governments pursue strategies that provide incentives to encourage research. For instance, research incentives include tax or regulatory advantages, or exceptions from antitrust rules to encourage industrial firms to cooperate with one another in the development of new technologies.

Currently private-public partnerships are responsible for the development of pharmaceuticals and the necessary research and clinical testing before marketing approval is obtained. Currently the research community together with government officials, civil society and the private sector are investigating price fund models to stimulate the research into neglected diseases for Least Developed Countries and developing countries.

Civil society and academia have argued that the collective management of intellectual property rights, including the use of patent pools, can contribute to

23 See Parente and Prescott 1994. The World Bank also underscored the importance of market openness, stronger IPRs and FDI as important channels for acquiring imported knowledge, especially' in developing countries. World Bank, "Knowledge for Development, World Development Report 1998-1999". World Bank 1999, p. 16-56.

2. See Barton 2007.

2 For an overview of the mechanisms of supporting research and trends in publiclydeveloped technology, see Barton 2007, chapter three. 
achieving new innovation and access to medicines. ${ }^{26}$ Civil society has also advocated the use of monetary prizes as an alternative mechanism to stimulate private investments in R\&D. In particular, donors and governments should consider prizes as an alternative to marketing monopolies as the reward for successful investments in R\&D.27 The prize funding mechanism is seen as an altematio' to the patent system. ${ }^{2 x}$ According to James Love from Knowledge Ecology lnternational (KEI):

\begin{abstract}
"What the prizes offer uniquely is an alternative to the marketing monopoly as an incentive for private investment (...) If you can divorce the incentive for innovation from the product's price to consumers, knowled ge goods, including the R\&D for a new medicine, can be placed in the public domain immediately, so that competition among suppliers leads to low prices and greater access to new medical inventions". ${ }^{2 !}$
\end{abstract}

The prize funding mechanism should not be seen as providing the solution on its own but should be complemented with other direct or indirect government funding of basic research, non-profit product development partnerships, clinical trials, and other traditional and non-traditional types of funding for R\&D. The prizes system seems to be useful for solving well-defined problems. This leaves the IP system unaffected and hence, the prize funding model is merely an additional means of providing incentives for innovation.

2n The collective management has been identified as "systems for aggregating and managing intellectual property rights, such as copyrights or patents. By pooling together assets, collective management systems can overcome market inefficiencies, offering lower transaction costs, and ensuring a more effective access to multiple rights. These systems facilitate the legitimate use of works and features to their users, by granting licenses and authorisations. Such arrangements can be made voluntarily or non-voluntarily, and involve a varicty of different policy objectives, as well as legal and management regimes". Patent pools are examples of collective management of IPRs for instance they normally involve an agreement between two or more patent owners to pool their patents and subsequently to license them to one another or to third parties and they usually involve standard licensing terms to licensees and a percentage of the license fees are allocated to the patent owner (royalties). A pool may "involve simple cross-licensing among two or more competitors, in order to share a handful of patents necessary for the manufacture and sale of a particular product, or it may involve a large, industry-wide pool open to anyone, encompassing hundreds of manufacturers and thousands of patents, as well as other intellectual property, such as rights to use data, know-how or trademarks". See Knowledge Ecology Internationally, "iGWG Submission on Collective Management of Intellectual Property -- The Use of Patent Pools to Expand Access to Needed Medical Technologies", 30 September 2007.

27 See Love and Hubbard 2007.

28 The patent system provides the inventor an exclusive right to make market or use an invention for a set amount of time in return for disclosure of his patent. After the lapse of the patent duration the invention enters the public domain.

2* See Love $2007 \mathrm{~b}$, p. 2. 
Many of these alternatives to the traditional patent system to stimulate research and development of pharmaceuticals, in particular for neglected diseases for developing countries, are currently at the forefront of the negotiations within the World Health Organisation (WHO) Intergovernmental Working Group (IGWG) on Public Health, Imnovation and Intellectual Property. ${ }^{30}$

For instance, Gavi Alliance (formerly the Global Alliance for Vaccines and Immunisation) brings together developed country donors, recipient governments, research and technical institutes, civil society organisations, and vaccine industries to partner with international organisations, private sector philanthropists and international financiers to find ways to fund and support immunisation in the world's poorest countries. GAVI Alliance aims to save children's lives and protect people's health by increasing access to immunisation in poor countries by using innovative funding models so as to make financing for national programmes more predictable and sustainable. Gavi developed the so-called "International Finance Facility for Immunisation" (IFFIm), which was proposed to the Group of Seven (G7) countries by the UK government in 2005:

"Donor countries make 10-20 year, legally-binding aid commitments. IFFlm borrows against these pledges on capital markets, raising funds that can be disbursed in an optimal way".31

\subsection{Characteristics of Technology Transfer}

The transfer of technology is regarded as "a key element for enabling developing countries to integrate into and compete in the global economy as well as to meet their development goals". 32 Hence, great expectations for socio-economic development have been attributed to the transfer of teclinology. The promise of attracting technology transfer was also a main drive behind the adoption of the TRIPS Agreement as we will see below.

31) Resolution WHA59.24 noted "the need to promote new thinking on the mechanisms that support innovation" and Resolution WHA60.30 specifically called upon the WHO to address the "linkage" between R\&D costs and prices. Altemative to prize funds are donors acting for humanitarian reasons, for instance, the Bill and Melinda Gates Foundation has become a major founder of research in neglected diseases. Also the Global Fund has committed to addressing HIV/AIDS, tuberculosis and malaria in its work programme.

3 See for more information <http:/www.gavialliance.org/resources/GAV1_Allian ce_Strategy__2007_2010_pdf> and <http://www.gavialliance.org/about/in_finan ce/index.php>.

32 See UNCTAD 2005b, p. 5. 
A clear definition has been provided by Barton:

"The transfer of technology is fundamentally a matter of the flow of human knowledge from one human being to another. This can be through education, the scientific literature, or direct human contact".33

Barton points out that it is not licences dealing with legal rights to use the particular technologies in particular contexts, but it is the human level, that dominates the managerial and economic reality of a successful technology transfer exercise. 1 le highlights that:

"close links between the basic researchers and the manufacturing experts and even marketing personnel contribute to competitiveness and advancement". 34

The transfer of technology relates to any process by which one party gains access to another's technical information and successfully learns and absorbs it into his production process. It may be embodied in products or disembodied in ideas. ${ }^{35}$

The transfer of technology can be governed by explicit contractual arrangements, such as licensing between two different business partners but it can also be managed implicitly through the establishment of subsidiaries and affiliates of multinational enterprises (MNEs) in other countries. ${ }^{36}$

There are always two parties; the suppliers and the recipients of technology. Much technology transfer occurs between partners in voluntary transactions. Thus, it involves mechanisms for moving information across borders and subsequently the diffusion into the recipient country's economy. Hence, technology transfer relates to innovation, the marketing of technology and also its absorption into the recipient country.

The transfer of technology occurs between two parties, normally business parties and is to a great extent outside the scope of governments which limits the possibilities of governments to influence the transfer of technology. Nonetheless this argument should not be raised as an argument not to interfere. There are alternatives as we will be discussing in more detail. For instance, FTAs and FDIAs are used for additional control or security.

Technology transfer transactions are arrangements between parties involving the transfer of technology and may not only include the assignment, sale and

33 See Barton 2007, p. 3.

it See Barton 2007, p. 3.

3 See Maskus 2003, p. 3.

in See Patel, Roffe and Yusuf 2001, p. 4. 
licensing of industrial property, but may also concern the know-how and technical expertise embodied in e.g. models, instructions or guides. In addition, it involves the knowledge necessary for the operation or functioning of a plant and equipment, as well as, the technological knowledge necessary to install and use machinery or materials." Article 1.2 of the Draft TOT Code provides the following definition:

\begin{abstract}
"Transfer of technology under this Code is the transfer of systematic knowledge for the manufacture of a product, for the application of a process or for the rendering of a service and does not extend to the transactions involving the mere sale or mere lease of goods".
\end{abstract}

We can distinguish between non-commercial and commercial technology transactions. The non-commercial transfer of technology occurs, for instance, uncier international cooperation agreements with developing countries. Examples of non-commercial transactions are infrastructure projects relating to education, scientific or agricultural management.

Maskus ${ }^{38}$ provides interesting comments in relation to how the transfer of technology occurs and highlights that a lot of (technical) information is freely available in the public domain for various diverse reasons:

\begin{abstract}
"Markets for information are peculiarly subject to failures and there is justification for addressing these with public policy. However, not all technologies are transferred in private markets between unrelated parties. Much information flows within the boundaries of firms and joint ventures. Further, knowledge about production and management processes may be gained from reverse engineering, reading published materials, training within firms and laboratories, and attending professional conferences. Finally, much information may be in the public domain. Note that the public domain is filled both by public research outcomes and by the decisions of firms not to seek protection or to permit their intellectual property protection to lapse".,34
\end{abstract}

In order to effectively establish the international transfer of technology one needs a multidisciplinary approach covering the disciplines of law, economy, sociology and political science, alongside the setting of trade and investment policies. Since all these different fields can affect the terms of access to knowledge all policy aspects should be taken into consideration. For instance in relation to the legal discipline one cannot look at the concept without looking at intellectual property rights, international trade laws, and competition laws.

$\therefore$ This was acknowledged in Art. 1.3(d) of the Draft TOT Code.

3.* Keith Maskus is Professor of Economics and Associate Dean for Social Sciences at the University of Colorado, Boulder, USA.

* See Maskus 2003, p. 3. 


\subsection{Why is Tedmology Transfer Important?}

In the last two decades some phenomena have changed international trade and social and economic systems in general: 1) The importance of technology in all economic activities, with the swift pace of technological transformation; and 2) The globalisation of all economic and technological activities." Technology is increasingly being exploited and generated globally, often as a result of international collaborations. ${ }^{41}$ Both features are intrinsically interrelated and mutually reinforcing. This is also demonstrated by the increase in patent applications by foreign inventors within a country. On the one hand, the amount of non-resident patenting tells us to what extent a country is impacted by foreign inventions and on the other hand external patents (referring to national inventors patenting abroad, a proxy for the presence of a country's inventions in other countries) have grown at very high rates. ${ }^{+2}$

Hence, the transfer and exchange of technology across countries has increased and is important to socio and economic development. ${ }^{43}$ The interrelation between globalisation and the importance of technology is brilliantly expressed by Pietrobelli:

"[T]he rapid pace of technological change induced by improvements in communications, transportation, information technology, and by new materials, is facilitating the international expansion of economic activities, which in turn further accelerates technological change. The product cycle of technology is getting shorter, and technology may be transmitted more quickly across coun-

11. Research undertaken by the John Hopkins University, has indicated that European consumers (i.e., all Europeans when they are shopping) are big wimers from globalisation, which has delivered cheap imports, held down inflation and kept interest rates low: "Despite the fuss about China and India, the EU's share of world exports rose slightly between 2000 and 2006". This study is referenced in "Globalisation and Europe: Prospering in the New Whirled Order". By Hamilton and Quinlan 2008.

Moreover, two-thirds of Chinese exports involve foreign brands, a good chunk of which are European, nor does a "made in China" tag mean big revenues for Chinese firms. Recently, in a lecture defenting globalisation, the EU trade commissioner, Peter Mandelson, cited a University of California study into who gains when an iPod is sold in America for \$299. However, only $\$ 4$ stays in China with the firms that assemble the devices. $\$ 160$ goes to American companies that design, transport and retail iPods. A similar pattern holds for many European products. Hamilton and Quinlan 2008.

41 For instance international agreements today represent almost 60 per cent of all the registered inter-firm agreements. See Freeman and Hagedoorn 1994, p. 771-780.

t2 See Archibugi and Jammarino 1997.

4. Economic and social development should be seen in this respect as the collective term for issues relating to innovation, competition, market structure, trade, investment and licensing decisions. 
tries. This can result in effective cycles of cumulative causation linking faster technological change to international competitiveness, to improved access to international knowledge, and to further technological changes. Such cycles may enable countries to catch up with lechnological leaders". H

Just as the relationship between technological intensity of production processes and products has augmented one can also identify an increasingly important link between technological change and competitiveness. Hence, having access to technology or not determines to a large extent a company's competitiveness. The critical role of knowledge in development and comparative advantage is beyond doubt. Ricupero describes it as follows:

"the knowledge factor appears to be the most important element in the shaping of the new international economic order, as it alters radically the state of overall equilibrium created by the century-old industrial world and the associated comparative advantage that it has enjoyed".t5

Sideri highlights the importance of technology absorption:

"technology or more specifically the ability to utilise effectively the new technologies and absorb them into the productive process, is increasingly crucial in determining comparative advantages, creating competitiveness, and promoting economic growth and development".t"

New technologies, on the condition that they are successfully incorporated in the production system, can lead to improvements in productivity and result in a higher growth rate. The question for developing countries and least developed countries is how to acciss the technologies produced in the industrialised countries and use them to achieve their sustainable development objectives.

Foray explains that a successful technology transfer goes through a variety of process before one can speak of the "consolidation" of the transfer. These phases are:

"(i) the assimilation and absorption of technological knowledge, (ii) its adaptation to local conditions, (iii) the absorption of subsequent improvements and (iv) the generalisation of the transferred knowledge". tr

Parente and Prescott found that barriers to technology adoption explain the differences in per capita income across countries. The cost of access to technology and knowledge available in the world economy may differ across

4 See Pietrobelli 2000, P. 209.

t5 See Ricupero 1990.

it See Sideri 1994.

it See Foray, forthooming 2009, p. 5. 
countries due to differences in legal, regulatory, political, and social factors. Hence in some countries obtaining technology comes at a higher price and this retards economic growth and development. th

The international exchanges of technological know-how and services have increased support by internal business $R \& D$ expenditure. Moreover, the amount of $R \& D$ carried out by transnational companies in their foreign subsidiaries is slowly increasing. "Some figures on R\&D show that within the large bulk of world R\&D expenditure, the amount spent in developing countries only account for about four per cent of global R\&D expenditures. " Globalisation and the ongoing concentration of knowledge and expertise in multinational corporations caused $R \& D$ expenditure to be limited to a few countries ${ }^{51}$ and firms gradually placing the developing countries out of the playing field. One would expect that globalisation would move some $R \& D$ centres (or at least some R\&D capabilities) to developing countries however decentralisation of R\&D is mainly taking place within the developed countries. ${ }^{52}$

Let us first look at the value of the transfer of technology. The transfer of technology from one country to another assures that a certain technology is not only useful in the country of development but is also of practical utility in foreign territories. It provides access to technologies that otherwise would not be available on their territories. In addition it reduces $R \& D$ expenditure for the developing countries and it is efficient, as the wheel does not have to be invented twice because one can build on existing knowledge and technology.

In principle economic growth and economic theory anticipated convergence across countries and the transfer of technology was thought to be a great facilitator in realising this process. Primarily, this was predicted for reasons relating to the wide applicability of technology transfer (and the price of diffusion being lower than its production). Nonetheless, technology has not been transferred to all remote areas of the world, especially not to the African continent. Technology transfer operations have proved difficult in particular where countries of different development levels have been concerned. Some critical authors have argued that the:

"Inherent interdependence of human societies is used to promote inequalities within and between countries in a globalised world. (...) Elegant intellectualism

\footnotetext{
See Parente and Prescott 1994 and Saggi 2000, p. 6-7.

See Reddy 1997.

See UNDP"Human Development Report 1999", 1999.

"[L]arge firms of developed countries have been able to develop a complex network of cooperation in technology through 'strategic alliances' that further enhance their dominant role in technology generation and use". See Correa 1999a, p. 12.

See Correa 1999a, p. 12.
} 
or self-serving prescriptions took the centre stage, and became tools to serve the objectives of hegemonic power interests. (...)This must change if the promise and hope of the new century is to be realised". "3

There are alternatives and there is recognition that a diversity of situations asks for different approaches and solutions:

"II]ssues of development go beyond the narrow realm of economies and that technology is there to facilitate and not to determine the path to progress (...) [and that the] interdependence of various facets of human experience: social, cultural, economic and political thave to be taken into account combined with a deep sense of humanity, a vision of common human heritage, fortunes and destiny".

The importance of technology transfer is expressed by Maskus in the following paragraph:

\begin{abstract}
"The international flow of technological information and its successful integration into domestic production and management processes are central to the ability of developing countries to compete in the global economy and to narrow the technological gaps they face compared to developed countries. Technological change is a principal source of sustained growth in living standards and is essential for transformation and modernisation of economic structures". .9
\end{abstract}

Hence, to conclude this session, crucial roles in establishing competitive positions on the market are played by technology and know-how. Economic growth relies on technological change through the creation of new products and processes, especially within the knowledge-based economy. ${ }^{\text {th }}$

\title{
2. ACCESSTO TECHINOLOGY
}

All countries desire access to new technologies to improve their competitive position. Nonetheless, technology is unevenly distributed on the globe; in 1974, for example, a study ${ }^{\overline{5}}$ conducted by UNCTAD revealed that nationals of

53 "Critical thinking and analysis should not be an idle intellectual pursuit or a means to craft and impose standard models and prescriptions. Alternatives always exist. This is true both in an historical as well as contemporary context. Yet, the dominant economic thought and analysis of the last thirty years or so ignored this". See foreword written by Yash Tandon, executive director South Centre in Girvan 2005.

it See foreword written by Yash Tandon, executive director South Centre in Girvan 2005.

$\because$ See Maskus 2004, p. 7.

5t See Grossman and Helpman1991, as referred to in Hoekman, Maskus and Saggi 2005, p. 1588.

57 See United Nations Department of Economic and Social Affairs, "The Role of the Patent System in the Transfer of Technology to Developing Countries", 1974. 
industrialised countries like the US, Germany, France, Switzerland, the Netherlands and the UK were the owners of 84 per cent of all patents issued world-wide. Nationals of developing countries, on the other hand, held only one per cent of the patents within their own states. More recent data show very similar results: 76 per cent of all patents applications requests are from either Japan, the US, Republic of Korea, Germany and China. ${ }^{58}$ As a result, only few of all industrialised countries invent and produce technologies and goods that enter the global markets. Some industries depend more on intellectual property rights than others. Classic examples of IPR dependant industries are the pharmaceutical, biotechnology, software and broadcasting companies.

Statistics have shown that trade containing an intellectual property component has severely increased over the last two decades. ${ }^{59}$

A handful of global corporations and powerful economies control the production and dissemination of most new technologies including production technology but also information, communication and biotechnology. Hence, there are only a few multinational firms operating within a few sectors of industry that produce high-technology. For this reason the markets for conventional technology is most of the time more competitive than those for high technology. Evidence has shown that innovative activities today are still concentrated in few industrialised countries. Notably seven countries carry out 80 per cent of the world's innovation activity. Machinery and transport equipment (including aircraft) and to a lesser extent the chemical industry account by far for

is The WIPO 2008 Report shows an increase in patent applications and in the delivery of patents. In 2006,727000 patents have been issued world wide. Approximately 6.1 million patents were in force in 2006 of which nearly 50 per cent were owned by applicants from Japan and the US. Chinese residents increased their share of total worldwide patent filings from $1.8 \%$ to $7.3 \%$ between 2000 and 2006 , mostly due to increases in domestic patent filings. In addition, there has been an increase in the level of patenting activity in emerging countries: "The patent offices of India, Brazil and Mexico all received a large number of filings in 2006 . However, for the majority of the reported emerging countries, non-resident applicants accounted for the largest share of total filings in these countries". See WIPO World Patent Report A Statistical Review, 2008 Edition, p. 7. The WIPO 2007 Report noticed an increase in workload (900.000 patents pending in the US and 800.000 in Japan). The workload is also increased by duplication of efforts as world-wide 38 per cent of the patent applications are by non-resident applicants. For instance, these applications are usually preceded by prior applications in the country of residence of the applicant and, often, by parallel applications in other countries. Hence, each of these applications may be subject to a separate search and examination in each patent office. See WIPO Patent Report Statistics on Worldwide Patent Activities 2007 Edition, p. Ill.

5) For instance, US exports with a high $I P$ content more than doubled from 9.9 per cent in 1947 to 27.4 per cent in 1986, amounting to more than 25 per cent of all its exports. See Gadbaw and Richards 1988, at 4, Chart 1.1. 
the largest amount of $R \& D .^{(n)}$ Study has also indicated that research is carried out by a small group of MNEs. It has also shown that because of high investments the electronics, aircraft and pharmaceutical industries studies are particularly IPR dependant."1

With the technological and economic capabilities of developing countries being rather on the weak side, the developing countries find themselves facing difficulties negotiating transfer of technology contracts with their considerably stronger counter parties - the multinationals of industrialised countries.

Despite the fact that technology is much desired, much empirical evidence also suggests that it is a costly affair to transfer technology across borders."2 How rapidly does technology diffuse within society? As indicated earlier, the majority of the world's technological progress and development takes place in a dozen highly industrialised countries. Subsequently, it is then transferred to other parts of the world through various channels for instance via international trade, cross-border education and foreign direct investment. ${ }^{6.3}$ The producers of the knowledge try to keep control over their technologies produced after large investments in time and money. If some kind of control was not feasible they would have little incentive to create and produce new products in the first place. Thus, inventors do play a role in controlling the rate at which their technologies spread internationally. The last two decades have seen the advent of the MNES and rapid globalisation of trade which on the one hand facilitated the transfer of technology but also hindered it on the other.

(1) According to the National Science Foundation (2002), in 1998 about 80 per cent of world innovation activity was performed by only 7 developed countries. The US accounted for roughly 40 per cent of world R\&D expenditures, spending as much as the rest of the major advanced countries (G7) countries combined. Japan, the second largest R\&D investing country, is responsible for about 18 per cent of world expenditure and the European Union for approximately 30 per cent. In terms of GDP, in 2000 Japan invested about 3 per cent in R\&D. US about 2.7 per cent and the EU around 1.9 per cent. The business sector is the major R\&D performer in each of the leading economies: in 2000 the ind ustrial sector performed more than 70 per cent in the US and Japan, whereas in the European countries above 60 per cent. Within the business sector, manufacturing firms perform more than 90 per cent of industrial R\&D in Japan, more than 80 per cent in EU and almost 70 per cent in US. See National Science Board, Science and Engineering Indicators, Arlington, VA: National Science Foundation, (2002) as referred to by Crispolti and Marconi 2005, p. 7.

"1 A survey undertaken by the OECD in 1970 showed that in the US the eight largest firms accounted for over one-third of total expenditure on R\&D, and the 40 largest firms for 70 per cent. The survey demonstrated that three-quarters of the R\&D expenditure was spent on aircraft, electronic and chemical industries. See OECD, "Gaps in Technology'. Analytical Report", 1970, p. 17 as quoted in Blakeney, p. 4.

1.2 See Saggi 2000, p. 5. See also Mansfield and Romeo 1980.

a. See UNCTAD 2005b, p. 5.

th See Saggi 2000, p. 11. 
Companies are increasingly dependent on various sources to access technology as they come from different disciplines and geographical origins. Companies are not solf-sufficiont but are incrensingly rolying on other companies to acquire and to gather parts of technology - they are then combined in various ways for a multiple of uses. In other words companies are increasingly incapable of supplying all the required technological knowledge to produce a particular product ${ }^{\text {s. For }}$ For instance one mobile phone contains multiple patents. In line with this reasoning it is therefore important to establish linkages in science and technology and in R\&D.

For a country to benefit most efficiently from the intermational transfer of technology they need to invest in enhancing efforts to create and improve technological capabilities, not only to access the technology, but also to absorb the technology and to utilise it to their own socio-economic development needs.

\begin{abstract}
"Technological capabilities may be subdivided into four possible layers of skills sophistication. These include skills to use and operate technology, skills to assimilate the acquired technology, skills to upgrade and reverse-engineer foreign technologies, and skills to designs and develop novel technologies. The first two are basic and almost all firms posses them. However, only' a few firms are able to upgrade and develop novel products. The latter two layers of skills can be built up through learning and accumulation of knowledge over a long period". "tot
\end{abstract}

Technological capacity can be improved via investments in both general and technical education and training and in science and technology (S\&T) and $R \& D$ institutions.

\title{
2.1. Recipients of Technology
}

Most developing countries have comparatively few high-tech industries and depend on the industrialised countries to obtain access to technology, for example, through its transfer. In developed countries large amounts of money are spend on both public sector research and private sector research; nonetheless technology can also be acquired in other ways such as through reverse engineering, personnel movement, ${ }^{67}$ compulsory licensing and imitating. Thus, most developing countries are "import dependent countries" or in other words "net importing countries" of technology. For this reason, developing countries show more reluctance towards strong intellectual property rights

os See Pictrobelli 2000, p. 210.

th See UNCTAD 2005a.

oi For instance, Indian and Taiwanese graduates have learned valuable skills in Silicon Valley during the internet boom and have then gone home to start their own companies. 
protection since they see many possible negative side effects: it undermines their ability to engage in reverse engineering, imitating and copying, it leads to increased prices for pharmaceutical products and it restricts access to information products." Developing countries are by all means eager to gain access to new technologies and existing or established technology in order to increase their knowledge, wealth and competition position. Unsurprisingly, they are interested in obtaining technology and acquiring information at low cost. Some argue that this objective is best realised in practise "by refusing the rights of foreign firms to profit from such transfers, or at least to restrict sharply their exclusive rights to exploit technology". "(i) Developing countries thus favour intellectual property rules supportive of their development needs.

Most technology is developed in a dozen of industrialised countries which implies that many other industrialised countries are also dependent on foreign countries to gain access to new technologies. The problems faced by the developing countries to gain access to technology are also at issue in technology transfer transactions between developed countries. Nevertheless, technology transfer between developed countries falls outside the scope of this chapter. The main difference between industrialised countries and developing countries in search of technologies is that the technological and economic capabilities of the recipient corporations in developed countries are severely stronger than those of the developing countries. The developing countries, on the other hand, find themselves in a rather weak position since they do not have the "quasi-monopolistic power of the transnational corporations of the developed countries" to negotiate transfer of technology contracts. This difference should be taken into consideration in any negotiation concerning the international regulation of the transfer of technology.

The UNCTAD Secretariat has been very active conducting studies in the field of technology transfer and developing countries since the 1970s. These studies have shown the particular problems faced and concerns at the level of recipients of technology in the transfer of technology process. ${ }^{71}$

These include for instance: 1) The large number of limitations imposed by enterprises on the field of technical activity they are willing to transfer and ownership by foreign enterprises; 2) The explicit clauses (such as certain cartels, exclusive grant back clauses and coercive packaging licenses restricting use of competing technologies) in contractual agreements and implicit practices of MNEs which are responsible for the high direct and indirect costs of technology transfer; 3 ) The various limitations and abusive practices (such

is See Maskus 2000, p. $x$.

(1) See Maskus 2004, p. 7.

$\approx$ See Patel, Roffe and Yusuf 2001, p. 4.

$\therefore$ See UNCTAD 1975. 
as reverse engineering) which are either deemed to be illegal or otherwise controlled in the countries which supply the technology, but which are very widely practiced in developing countries; 4) Industrial property regulations and administrative policies which hamper the effective utilisation of the technology acquired; 5) A whole series of implicit and explicit practices followed by enterprises which limit the possibility of the developing countries obtaining access to the right technology for the right product under the right terms and conditions and at the right time.

All these problems adversely affect the development of national scientific and technological capabilities and contribute to lengthening the technological dependence of developing countries.72

Blakeney ${ }^{73}$ argues that the main difficulty faced by developing countries in the acquisition process of technology is the

\footnotetext{
"inappropriateness of much of the available technology for their requirements and the absence or a receptive and skilled work-force able to absorb and apply the available technology" 7
}

\subsection{Recommendations for Deweloping Conntries to Facilitate Techology Transfer}

Host countries ${ }^{75}$ face challenges to improve the local environment for international technology transfer and its subsequent diffusion into the domestic market. An enabling environment to attract technology relates to the improvement of the infrastructure, ${ }^{76}$ transparency and stability in government and the reduction of corruption, as well as a reasonably open trade and investment regime. ${ }^{7}$

UNCTAD ${ }^{78}$ research has shown that tax policies in the technology importing (host) country as well as in the technology-exporting (home) country have implications for the form and mode in which technology transfer takes place. The formulation of a tax policy with respect to the importation of technology

; See Patel, Roffe and Yusuf 2001, p. 4 and Kumar 2002, p. 9.

73 Prof. Michael Blakeney, Queen Mary Intellectual Property Research Institute, London.

it See Blakeney 1989 , p. 105.

-5 Also referred to as importing countries or the recipients of the technology.

it Study has indicated that trade logistics - or the capacity to connect to international markets to ship goods - is critical for developing countries to improve their competitiveness, reap the benefits of globalisation, and fight poverty more effectively in an increasingly integrated work. However, if there are no goods to trade it will not help much. See Arvis et al. 2007.

$\because$ See World Bank 2004.

$\therefore$ See UNCTAD 2005b, p. 41. 
involves the balancing of conflicting objectives. On the one hand, countries wish to facilitate the acquisition of technology: on the other, they wish to derive, in the form of tax revenue, a fair share of the profits that accrue to the foreign owner of that technology by virtue of the transfer. ${ }^{\text {it }}$ The research emphasised that, in general, all tax provisions could be perceived as obstacles to TOT, in that they increase the cost of the transfer or reduce the rate of return. However, most of those provisions are standard features of modern tax systems and do not constitute major deterrents. Formulating an incentives policy to promote technology transfer involves two basic decisions: which enterprises or activities should receive tax advantages (targeting), and what form those tax advantages should take (design).

A number of recent debates have considered whether developed-country tax systems might do more to facilitate and encourage investment in developing countries. Various modifications to existing rules and practices have been proposed or considered, including the adoption of tax-sparing credits, sil the granting of a deemed credit in the amount of tax that would have been paid to the foreign country had it not provided a tax subsidy, or the exemption from tax for business income earned in developing countries, and in particular in sub-Saharan Africa. ${ }^{81}$ nother possible measure would be to extend R\&D incentives to include activities performed in other countries (and especially in developing countries), as in the case of Ireland, rather than restricting them to

7" From a tax perspective, the objectives of technology-exporting countries are in many ways similar to those of technology-importing countries. They encourage their enterprises to develop new technologies and to exploit and to export the technology that they have developed, thereby increasing their ability to earn income. At the same time, they wish to derive tax revenues from what they consider to be a fair proportion of the profits resulting from the export. These two objectives can come into conflict, and tax rules that are designed to protect the domestic tax hase can create disincentives to transfer technology abroad. See UNCTAD 2005h, p. 41.

*i) Countries frequently provide tax incentives to promote and attract inward FDI. "Where the exporting country adopts the tax credit method to provide relief from double taxation, it is evident that a reduction in the amount of tax payable in the source country can simply result in a reduction in the amount of credit that may be claimed in the residence country, with a corresponding increase in the amount of home-country tax payable. There woukt consequently seem to be little point in potential host countries' secking to attract investment by offering tax incentives or generally low tax rates, since the benefit of the tax forgone, or 'spared' would accrue not to the investor but to the investor's home country. One response to this problem is the 'tax-sparing' credit. The effect of a 'tax-sparing provision' is to allow' a home country credit for the host-country tax that is deemed to have been 'spared' as a result of specific incentive measures granted to investors. The credit usually applies to reductions in business profits tax, and often also to reductions in witholding taxes on dividends, interest or royalties granted under specific incentive legislation". See UNCTAD 2005b, p. 38.

s1 See Brown 2002, p. 45 as referenced in UNCTAD 2005b, p. 38. 
activities carried out in the home country, as is usually the case. However, the most effective approach would be to tailor tax policy to facilitating FDI in developing countries generally, in the expectation that increased TOT will be one of the benefits flowing from such investment. A third possible measure to encourage TOT to developing countries would be to grant tax-sparing credits in respect of reduced rates of withholding tax on royalties and professional fees (where this is not already done). 2 However, the UNCTAD study indicated that tax incentives alone are only rarely a major determinant in foreign direct investment decisions. ${ }^{.3}$

In addition, it is important to stimulate local R\&D capacity because this helps to improve the ability to absorb and adapt technology. In this respect, it is important to analyze carefully the current local environment and its laws and policies and determine whether they contribute to the transfer of technology or if, on the contrary, the existing technology policies, capital market regulations, and tax system discourage such investment. If so, they should be altered to support incentives to innovation. In addition as international technology transfer requires sufficient engineering and management skills it is important not only to attract new technology but also to accompany it with the necessary education and training.

The country wishing to acquire technology from a third-country firstly needs to identify its technological needs in the light of its objectives in terms of economic and social development. Often developing countries are benefited most by focusing on what is already out there, free for everyone to use. For instance, because the patent has lapsed or because the patent holder has not patented the technology within their territories.

Countries in need of technology transfer must take some crucial issues into consideration before entering into technology transfer arrangements: 1) It is crucial to determine what information is available on alternative sources of technology; 2) To provide for dialogue between the various stakeholders involved and to map technology discrepancies and needs; 3) It is important to evaluate and select the most appropriate technology in relation to country needs and strategy in terms of socio-economic needs. Focus on what the country is good at making, find a niche/a comparative advantage; 4) Evaluate in terms of suitability, cost and conditions, of the components of technology packages - perhaps focus only on a few essential components; 5) Carefully analyse the terms and conditions of technology transfer contracts. The technol- 
ogy transfer should be accompanied by training sessions in order to transmit knowledge on how to use the technology effectively. ${ }^{\text {s.t }}$

Once the technology has been acquired it is important to absorb and adapt it to local needs and to disseminate it widely to potential technology users. 45

\section{TIIE INTERNATIONAL LEGAL FRAMEWORK ON TRANSFER OF TECHNOLOGY}

Many studies in the 1970 s revealed that the contracts and practices of MNEs were full of clauses and restrictions whose objectives were precisely the opposite of facilitating efficient technology transfer. ${ }^{\text {th }}$

Developing and least developed countries received technology first and foremost from MNEs whose key concern is to make profit and reduce risks (control over the technology), rather than taking account of the interests of the developing countries. As a result of these practices there was a call for substantial changes to the existing methods of technology transfer.

Studies have indicated that the restrictive practices of $M N E s^{k 7}$ had four harmful effects on the recipient companies namely of: 1) prolonging the importation of technology, 2) restricting its assimilation, 3) restricting its adaptation and indigenous creative activity, and 4) magnifying its social cost. ${ }^{s s}$ Other research conducted at the same time found that two-third of the technology agreements contained secrecy and confidentiality clauses, and obligations not to use technology after the expiry of the agreement. In addition, 15 per cent of such agreements had grant back provisions obliging the recipient to hand over technology improvements to the licensor. ${ }^{89}$ As a consequence of these practices, developing countries did not develop local technologies and did not learn how to adopt technologies to their local domestic needs - which are crucial elements of successful transfer of technology operations. Hence, developing countries remain dependent on imported technologies and find themselves caught in a poverty trap. To refer to these arrangements as transfer of techmology is misleading and this fed the calls for a counter movement by the so-called group of 77 developing countries (G 77) for a code of conduct to guide technology transfer transactions. In response to these calls, negotiations

*4 These recommendations are based on the "Licensing Guide for Developing Countries", WIPO 1977, p. 17.

s: See UNCTAD report on Home-Country Measures (HCMs) which shows the results of a survey amongst 41 agencies and programmes in 23 countries that offer HCMs facilitating the transfer of technology. UNCTAD 2004.

sin Sec Patel 1974.

$\therefore$ The terminology multinational enterprises (MNEs) is used intertwined with transnational corporations (TNCS) in this paper.

s. See Odle 1979 as referred to in Girvan 2005.

**) See Arthur 1984 as referred to in Girvan 2005. 
were mandated by the General Assembly of the UN in 1977."11 The negotiations were initiated to adopt a code of conduct intended to bind industrialised countries and their corporations to eliminate such restrictive business practices and to promote the kind of technology transfer that would support development.

The paradigm used in the deliberations during the 1970s focused on technology licensing from a multimational enterprise to either a recipient country (the host country) subsidiary or licensee, manufacturing for the local market. Issues at stake were the high costs involved in the transfer of technology; the restrictive clauses hindering host country use of the technology; and the transfer of inferior technologies. As a response, national technology transfer offices were established at the domestic level to review incoming technology transfers, to prohibit a number of clauses which were written into licensing contracts and to put a ceiling on the price of technology. "The intention was to expand these technology transfer regulating practices at the international level, but these actions failed.

\subsection{LNCTAD Draft Intermational Code of Conduct on the Transfer of Téchology}

This section highlights the endeavours to achieve a multinational code of conduct to guide behaviour in technology transfer transactions and sets out some of its key provisions."2

The United Nations Declaration for the Establishment of a New International Economic Order (NIEO) was adopted in 1974 by the UN General Assembly. It aimed at changing the international economic system in line with developing countries interests, thus replacing the Bretton Woods system. ${ }^{93}$ Negotiations within the framework of UNC ГAD ${ }^{4+4}$ followed on enlarging the participation

(4) See United Nations 1977, General Assembly Resolution 32/188.

") See Bartom 2007.

"2 For a thorough overview of the history of technology transfer see Patel, Roffe and Yusuf 2001.

4.3 The UN Declaration for the Establishment of a New International Economic Order objects to provide developing countries with access to: "the achievements of modern science and technology, and promoting the transfer of technology and the creation of indigenous technology for the benefit of the developing countries in forms and in accordance with procedures which are suited to their economies". General Assembly Resolution 3201 (S-Vl) of 1 May 1974, para. 4(c).

"4 UNCTAD was established in 1964 to complement the Gemeral Agreement on Tariffs and Trade (GATT) which was set up to serve the cause of free trade. UNCTAD's mission was to have trade serve the cause of development. Its work aims to support enhanced market access for the exports of developing countries, for instance the support for commodity price as the exports of developing countries mainly concerned primary commodities. Also, it allocates financial support to developing 
by and benefits to developing countries in the global economy. These negotiations, referred to as the North-South Dialogue, focused on improving terms and conditions for trade in commodity products and also included debtrelated issues. Along with the Declaration of a Programme of Action, a Charter of Economic Rights and Duties of States was adopted.

The origins of the NIEO related to the growing economic and political tensions between developed and developing countries ever since the Havana Conference in 1948. Developing countries favoured: 1) improving their terms of trade; 2) the reduction of tariffs by developed countries; 3 ) the regulation and control of practices of multinational corporations, operating on their territories, including the right to nationalise or expropriate them on their terms; 4) increased transfer of technology, for instance, by reducing licensing costs and providing development assistance. ${ }^{45}$ These efforts led to the adoption of the non-legal, non-binding Restrictive Business Practice Code. ${ }^{1 / 4}$

The UNCTAD Secretariat put forward five basic objectives and principles which could be incorporated into a Code of Conduct. ${ }^{27}$ These were: 1) the need for intemational regulatory action; 2) the encouragement of the transfer of unpackaged technology; 3) the improvement of access to technology at fair and reasonable prices and cost; 4) the effective performance of transfer arrangements; and 5) ensuring the development of technological capabilities of recipients."

countries: Ioans to finance education, health and infrastructure. It concerns the facilitation of international transport for developing countries and it addresses international technology transfer since improved technology is the source of the productivity growth that underlies agricultural and industrial development. Hence UNCTAD searches sustainable solutions to development in all fields.

See Sell 1998, p. 81.

"UN Restrictive Business Practise Code 1979, adopted by the UN General Assembly in 1980 .

'5 Efforts to create a Code of Conduct were supplemented by another movement, namely the negotiation of a Code of Conduct on Transmational Corporations that would demand transnational corporations to be "good corporate citizens" in developing countries by respecting their sovereignty, adherence to their laws, refraining from entering into domestic politics or adding to anti-corruption practices. See Givin 2005, p. 6.

"Packaged foreign technology includes assembly processes, product specifications, production know-how, technical personnel and components and parts.

whese objectives and principles were based on the outcome of negotiations form the Working Group on the Code of Conduct on Transfer of Technology' of the Pugwash Conferences on Science and World Affairs and the decisions made by the General Assembly. See Patel, Roffe and Yusuf 2001, p. 7. 
The rational, principles and objectives underlying the Code of Conduct as developed in the 1970s and 1980s are still highly relevant and topical for the current debate on improving the transfer of technology, for instance, within the framework of the WTO Working Croup on Technology Transfer.

In particular, the Preamble to the UNCTAD Draft International Code of Conduct on the Transfer of Technology ${ }^{100}$ Draft TOT Code provides us with information on the considerations underlying the provisions. For instance, it recognises the "role of science and technology in the socio-economic development of all countries, and in particular, in the acceleration of the development of the developing countries". It adds that mutual benefit sharing of technology is seen as a fundamental right as "technology is key to the progress of mankind and that all peoples have the right to benefit from the advances and developments in science and technology in order to improve their standards of living".

Furthermore, it sets out that the transfer of technology should be facilitated without discrimination as to the level of development. It should be endeavoured to "promote an increase of the international transfer of technology with an equal opportunity for all countries to participate irrespective of their social and economic system and of their level of development". It requires developed countries to provide special treatment for developing countries. Pursuant, it stresses the importance of improving the flow of technological information and choosing "technologies suited to the specific needs of developing countries". Moreover, it underlines that technology transfer agreements are to be concluded "under mutually agreed and advantageous terms to all parties". ${ }^{m !}$

During that time, negotiations primarily focused on the terms and conditions of acquiring technology. Technology was not treated differently from any other product and the process of technology transfer was seen like any other transaction between a seller and a buyer. Hence, local learning of new skills and access to information to absorb newly acquired technology was not given much thought apart from engineering efforts to operate the acquired technology. Information problems were assumed not to exist since firms were assumed to operate with full knowledge of the market for inputs, including technology. In addition it was assumed that technologies were selected according to their utility for local needs. ${ }^{102}$

Negotiations have been drawn out for a decade and although hopes were pinned on successfully completing the code of conduct, this did not happen. It has proven to be very difficult to regulate international technology transfer at an international level for various reasons but at the core of the dispute was the

10in UNCTAD Draft TOT Code, see Annex three of this book.

1 inl Ibid.

1in See Roffe and Tesfachew 2001, p. 381. 
persuasiveness of technology owners not to transfer technology without an adequate financial return and the problem of monitoring compliance of such a code with international regulations. ${ }^{103}$ Developed countries would not agree to key provisions encouraging effective technology transfer. For instance no consensus could be reached on prohibiting restrictive practices and clauses written into technology contracts; provisions demanding technology suppliers to adhere by the laws of developing countries; those relating to the effective enforcement of the code and dispute settlement; and a definition of what constitutes international transfer of technology. ${ }^{\text {ith }}$

The Code of Conduct and the NIFO were overshadowed by the counterrevolution in economic thinking and practice of the 1980 s which can be coined by the Washington Consensus. ${ }^{113}$ Furthermore, in the 1990s the WTO had overtaken UNCTAD as the central negotiating forum on international economic relations.

\subsection{From the UNCTAD Drift TOT Code to Present}

Since the launch of negotiations on the Draft TOT Code in the 1970s major changes have occurred in our society. In particular, globalisation rapidly intensified, making the world a smaller place and changing the way trade takes place. Also, the role of technology increased in every day life, making people more dependent on it. 106 In addition, the way the technology transfer process is perceived by governments and key economic agents has changed over time, from mere access to attention to appropriate absorption of technology. ${ }^{1107}$

Barton los observed that today's world differs from that considered in previous debates because of two key reasons: Firstly, a number of developing countries have becone much more technologically advanced. There are many more

1113 Sec Hockman 2005 , p. 1587.

1th See Girvan 2005, p. 5 .

105 The Washington Consensus was a reaction to the crisis (economic stagnation and hyper inflation) that hit Latin America during the 1980s. A number of policy recommendations were deemed necessary for the recovery of Latin America. The consensus included ten sets of recommendations in the area of tax reform, redirection of government spending to support education, infrastructure and primary health, trade liberalisation, tariff reduction, privatisation of state enterprises, and the legal security of property. See Stiglitz 2002.

16t Oliver Curry, evolutionary theorist of the London School of Fconomics expects that the human race will peak in the year 3000 before a decline due to dependence on technology, Curry 2006.

wi: See Roffe and Tesfachew 2002.

las Prof. John Barton is George E. Osborne Professor of Law, Emeritus, Stanford Law School. 
trained scientists and technologists, the level of science-based inctustry and the magnitude of national scientific research and financing programs has also increased. Notably this change is much bigger for the middle income and largest nations such as Brazil, China and India and much weaker for the poorest nations, such as many in Africa. Nonetheless these changes indicate that there is an enormous potential in the skills of those in the developing world. Secondly, globalisation has caused free trade to spread which has led to many industries favouring production facilities that serve more than one mation. The result has been increasing specialisation and trade, both in components and in finished products that may have origins in a number of nations. Also part of this trend is that production chains are now often spread over a number of nations. Barton gives the example of computer chips that may be designed in one nation, manufactured in the second, diced and tested in a third, assembled into computers in a fourth, with software written in a fifth. ${ }^{109}$

All these developments have resulted in the business climate for indigenous developing world firms changing; they now have to face global competition in contrast to local competition and they have to find a place in an already established and elaborate intemational production structure. What it also means is that not every nation can have firms leading in every area of technology and that naturally a process of crystallisation takes place, because for many areas of technologies there can only be a few centres of excellence anywhere in the world. "1" Countries need to find their "niche" - their competitive advantage. In addition, the world has also become a more regulated place, e.g. the existence of IPRs, which implies that firms have fewer possibilities to learn by imitating existing technologies." 11 Hence, developing countries are late comers in an established market and do not have the same possibilities to learn by trial and error in contrast to the Europeans, Americans and Japanese.

Over time a shift of attention occurred from merely stressing the importance of acquiring (large amounts of) technology transfer to emphasising the importance of adequately absorbing the technology into socicty. In addition the form of technology transfer has changed due to the digitisation of society with the result that most of the technology transfer does not involve tangible goods but intangible goods. Increasingly, focus shifted from acquisition of technology to what happens to the technology once it has been transferred. Hence, attention moved towards the processes of technology adaptation and mastering of the teclmology at the recipient conntry lewe It has been gradually understood that the transfer of technology process involved more than acquisition of a tangible good, like a machine, it also referred to skills and training necessary to operate

Iw See Barton 2007, p. 1.

11i) See Barton 2007, p. 1.

111 See Barton 2007, p. 2. 
it, and other elements like investment climate, country stability and IPRs also played an important role in the transfer process.

This view is supported by figures: the knowledge component of the output of manufacturing goods is measured to have increased from 20 per cent in the 1950s to 70 per cent in 1995.112

\subsection{The TRIPS Agrement Provisions on Technology Transfer}

After the failure of the Draft TOT Code, the issue of technology transfer remained dormant until the Uruguay Round of Multilateral Trade Negotiations. The issue was then re-included in the agenda.

Currently, a number of international agreements make notion of the importance of facilitating the access to and transfer of technologies to developing countries. For example, agreements falling under the umbrella of the WTO Agreement make reference to technology transfer, such as the GATS, the Agreement on Tracte-Related lnvestment Measures (TRIMS), the Agreement on the Application of Sanitary and Phytosanitary Measures (SPS), the Agreement on Technical Barriers to Trade (TBT), the Government Procurement Agreement (GPA) and the TRIPS Agreement. ${ }^{113}$ In addition, outside the scope of the WTO, the Convention on Biological Diversity (CBD) has included provisions on technology transfer and benefit sharing in relation to biodiversity and genetic material. Moreover, bilateral investment treaties (BITS) and various preferential trade areas (PTAS) have an impact on incentives and conditions for the use of technology and the transfer of technology.1.4 These agreements are characterised by common terminology: They acknowledge that technology transfer is important in facilitating the creation of a sound and viable technological base in developing and least developed countries. Further, they recognise that technology transfer is important to enable reintegration of developing countries into the global economy while meeting international obligations and commitments set out in multilateral treaties. ${ }^{1.5}$ However, no concrete solutions have been adopted to follow up on these wise statements and to make a real difference on the ground - soft law type of provisions.

112 See Patel, Roffe and Yusuf 2001, p. 382.

11.3 Sec Maskus 2004, p. 7.

114 See Maskus 2004.

115 For an overview of existing technology-related provisions in international instruments see "Compendium of International Arrangements on technology transfer: Selected Instruments, Relevant Provisions in Selected International Arrangements Pertaining to Transfer of Technology", 2001. 
In general we can say that the existing international rules on international technology transfer are mostly of a best-endenoon nature referring to actions that governments should follow to encourage 17T, in contrast to the rules set on IPR protection or on trade policy rules, which are of a more stringent nature setting out a system of rights and obligations.

As the chapter on the history of the TRIPS Agreement has already indicated, the main reason convincing developing countries to agree with the terms in the TRIPS Agreement was that enhanced intellectual property rights would result in increased technology transfer (including both importing goods and FDI) to developing countries and simultaneously stimulate domestic innovation. Nonetheless, Correa notes that: "[t]he North-South technological gap has continued to grow since the adoption of the Agreement". 116 Many civil society groups, academics and developing countries officials have voiced concerns that the provisions taken up in the TRIPS Agreement will not add to the economic growth of developing countries but will limit the access to technology instead by raising costs. ${ }^{117}$

During the course of the Uruguay Round Negotiations, many developing countries were opposed to accepting multilateral rules on IPR protection at the outset. 11: As such rules would request countries to establish and enforce comprehensive minimum standards of IPR protection and would abolish the possibility of discriminating between domestic and foreign creators, they were not viewed favourably by the South. The very incorporation of IPRs protection within the scope of a trade agreement was new - IP was not seen as traderelated and could easily have remained within the WIPO domain of IPR negotiations only. The reluctance of developing countries to adopt intellectual property rights into the Uruguay Round of Multilateral trade negotiations was to a large extent withdrawn for the following reasons:

11" See Correa 1999a, p. 1. This concern has also been expressed by Argentina and Brazil in 2004 launching the WIPO Development Agenda. The text of their original proposal is available on the internet at: <http://www.wipo.int/documents/en/ document/gowbody/wo_gb_ga/pdf/wo_ga_31_11.pdf>. The debate that followed led to the adoption of the WIPO Development by the WIPO General Assembly on 28 September 2007 approwing a set of reform proposals aimed at placing development concerns at the heart of the institution's work. See BridgesWeekly Trade News Digest $2007 \mathrm{e}$.

11. "TRIPS (...) entrenched the right of [multinational corporations] to engage in the very behaviour that the intermational codes on technology and on transnationals had sought to regulate, while restricting the freedom of governments to regulate this behaviour in order to promote development". See Girvan 2005, p. 6.

11: See Gervais 2003, and Correa 1999a. 
1) Promises with regards to the facilitation of the transfer of technology because the TRIIS Agreement made it a basic objective of the international trading system;

2) Market access. The TRIPS Agreement is part of a package deal and the acceptance of the TRIPS Agreement would lead to concessions such as the opening of markets to agricultural products, tropical fruits and textiles amongst other things;

3) Rules on enforcement and dispute settlement. The TRIPS Agreement is subject to the Dispute Settlement Body which facilitates enforcement at a multilateral level. At the time of the negotiations it was understood by many developing countries as a means that would reduce the fear of unilateral pressure.

With IPRs being subject to dispute settlement and enforcement mechanisms they became easier to negotiate as there was a much wider variety of possible trade-offs with other subject matter available in contrast to leaving it to the exclusive domain of WIPO, which had failed to revise its key agreements, the Paris Comvention and the Berne Convention.

Three Articles in the TRIIS Agreement refer to the transfer of technology of which Article 66.2 makes an explicit request to developed countries and Article 7 elevates the concept of technology transfer to a basic objective of the international trading system. A major shortcoming, however, is that nothing in the TRIPS provides any guidance as to how this objective should be realised in practice.

\subsubsection{Articles 7 and 8 of the TRIPS Agreement}

Article 7 TRIPS Agreement on the objectives underlying the TRIPS Agreement is very promising in terms of promoting innovation and the transfer of technology:

"The protection and enforcement of intellectual property rights should contribute to the promotion of technological innovation and to the transfer and dissemination of technology, to the mutual advantage of producers and users of lechnological knowledge and in a manner conducive to social and economic welfare, and to a balance of rights and obligations".11"

The TRIPS Agreement recognises in Article 7 that the transfer and dissemination of technology is a fundamental objective of the global intellectual property system. Nonetheless, the TRIPS Agreement provisions provide little guidance as how technology transfer should be facilitated. However, the importance of this provision is not to be underestimated since it is placed in the Agreement

11. See Art. 7 of the TRIPS Agreement. 
text itself and not just in the Preamble. Nonetheless, the objective contains a should requirement, where it was also possible to use a different wording, for instance shlll, to strengthen the requirement. Besides referring to a balance of interests between inmovation and the transfer of techology, it also addresses equilibrium between the producers/right holders and users of technological knowledge. This touches upon issues such as an appropriate public domain balance. The advent of the multinational corporation as really big players in the transfer of technology, e.g. Microsoft, has raised questions such as; "Is the traditional IPR system suitable to serve the interests of developing countries?" As, arguably only a few big players earn the cash and benefit from it. It is much desired that Article 7 in the future will be frequently invoked in dispute settlement cases where provisions enforcing or protecting intellectual property rights do not contribute to the promotion of technological innovation and/or transfer or dissemination of technology. Currently, this has not yet been the case. ${ }^{(2: 1)}$

Article 8 TRIPS Agreement lays down the principles underlying the TRIPS Agreement:

"1. Members may, in formulating or amending their laws and regulations, adopt measures necessary to protect public health and nutrition, and to promote the public interest in sectors of vital importance to their socio-economic and technological development, provided that such measures are consistent with the provisions of this Agreement.

2. Appropriate measures, provided that they are consistent with the provisions of this Agreement, may be needed to prevent the abuse of intellectual property rights by right holders or the resort to practices which unreasonably restrain trade or adversely affect the international transfer of technolo$g y^{\prime \prime} .121$

Thus, Article 8 gives Members the right to take "appropriate measures" to prevent practices which "adversely affect the international transfer of technology". However, this provision is severely restricted by the clause that these measures need to be consistent with the provisions of the TRIPS Agreement.

The Ministerial Doha Declaration reconfirmed the importance of Articles 7 and 8 in its paragraph 19. It mentions that the TRIPS Council in undertaking its work programme has "to be guided by" the objectives and principles set out in Articles 7 and 8 of the TRIPS Agreement and "shall fully take into account" the development dimension. The fact that such Articles are taken up in the Doha Declaration could possibly strengthen their position - during the negotiations and in dispute settlement procedures - since these provisions are meant to

121 Until March 2008 Arts. 7 and 8 have not been the subject of dispute settlement cases at the WTO.

121 See Art. 8 of the TRIISS Agreement. 
have an impact on all the provisions laid down in the TRIPS Agreement. In other words, this reconfirmation gives more body to the TRIPS provisions and can contain an important foothold for the developing countries in future dispute settlement cases.

\subsubsection{Article 66.2 of the TRIPS Agreement}

Article 66 is the article that deals most explicitly with the transfer of technology within the TRIPS.

Article 66.2 demands action to facilitate technology transfer flows:

"Developed country Members shall provide incentives to enterprises and institutions in their territories for the purpose of promoting and encouraging technology transfer to least-developed country Members in order to enable them to crente a sound and viable lechonological base".122

Notably, this obligation, imposed on developed country Members is reaffirmed in paragraph 7 of the Declaration on the TRIPS Agreement and Public Health $(2001)$.

Article 7 and Article 66.2 TRIPS reflect the fundamental tensions inherent in protecting technology developers with the aim of inducing more invention and transfer of technology. Arguably, stronger IPR protection may contribute to improving the business climate within which technology markets operate, expanding both innovation and (compensated) diffusion. However, exclusive rights grant the developers and owners of technology the opportunity not to transfer technologies to particular markets and to raise the costs of (uncompensated) imitation. Nonetheless, where a refusal to transfer technology becomes an abuse of II'Rs, countries are empowered to offset this abuse by using compulsory licenses.

There are several interesting aspects to Article 66.2. Firstly, it requires only developed countries to provide such incentives, and only on behalf of the LDCs. No obligations or rights are created for developing countries and economies in transition. Secondly, it is a positive obligation, as affirmed by the Doha Declaration. Thirdly, there is presumably an effectiveness test implicit in this article. Although nothing in the wording requires incentives to actually achieve increases in the transfer of technology, a failure to be effective would reduce the meaningfulness of both Article 66.2 and Article 7. In fact, the last phrase implies that such incentives should be carried out in order to enable LDCs to create a technological base, which makes the effective transfer of technology an expectation. Finally, Article 66.2 does not mention IPRs specifically.

122 See Art. 66.2 of the TRIPS Agreement. 
Thus, developed countries could establish whatever incentives they find appropriate. Such incentives could include limitations on the scope of intellectual property protection that do not otherwise conflict with provisions of TRIPS. ${ }^{223}$

\subsection{WTO Working Gronp on Technology Transfor}

As we have seen a number of provisions make notion of the importance of the transfer of technology between developed and developing nations but it is not clear how this takes place in practice and what specific measures should be installed within the WTO context to encourage flows of technology transfer. To respond to these shortcomings, the implementation of Article 66.2 was readdressed at Doha in paragraph 11.2 of the Doha Decision on Implementation-Related Issues and Concerns. At the Doha Ministerial Conference it was determined that a Working Group on Technology Transfer, ${ }^{24}$ under the auspices of the General Council, should investigate the relationship between trade and the transfer of technology and further the possibilities to increase the flows of technology from developed countries to developing countries. The Working Group is mandated to report progress to the Ministerial Conference. It was decided that developed-country Members should submit, before the end of 2002 (during the fifth Ministerial Conference), a report describing the incentives provided to their enterprises for the transfer of technology, subject to review by the TRIPS Council. ${ }^{125}$ However, the working group has been criticised for progressing too slowly. The reports, that countries must submit on a yearly basis regarding incentives and regulatory measures they are implementing, in order to support and promote technology transfer from the business sector to LDCs, have been criticised for being too technical in nature, incomprehensive and referring to technical assistance activities (official development assistance (ODA)) instead of real technology transfer actions - if reporting takes place at all.

LDCs have complained about the lack of information derived from these reports and how the technical assistance featured in these reports had contributed to actual technology transfer. There is a general frustration that developed countries are not really fulfilling their obligations as set out in Article 66.2.

123 See Maskus 2003.

12.4 At the Doha Ministerial Conference, Ministers agreed to "an examination, in a Working Group under the auspices of the General Council, of the relationship between trade and transfer of technology, and of any possible recommendations on steps that might be taken within the mandate of the WTO to increase flows of technolog! to developing countries". Annual report WTO 2001, p. 78 and WTO, WT/MIN (01)17, p. 7.

125 See Annual report WTO 2001, p. 78 and WTO, WT/MIN (01)17, p. 7. 
Despite the fatigue with the problematic nature of the issue, some interesting proposals have been presented in the Working Group, in particular the proposal made by India, Pakistan and the Philippines. These countries indicate that the "absorptive capacity" of developing countries is lacking to effectively use the technology in their territories. On the other hand most of the provisions in the WIO lack the resources to be properly implemented and monitored. Also technical assistance is lacking. They propose the following:

"In this light, a possible recommendation is to expand teclmical assistance under
the TRIPS Agrecment by linking Article 67 to Articles 66.2 and 7 . As it is, Article
67 does not deal with measures or incentives needed to facilitate technology
transfer. The support built into Article 67 could then be largeted at facilitating
technology transfer to institutions and firms in developing countries, especially
LDCs (...). To facilitate technology transfer, development of clear implemen-
tation and monitoring processes, including fiscal support, may be important.
Such mechanisms as those in multilateral envirommental agreements (e.g. the
Montreal Protocol which mentions transfer of technologies needed to phase out
the use of ozone depleting industrial substance) could serve as models".2t

The proposal also raises attention to the fact that most developing countries and in particular LDCs have

"limited capacity in developing, implementing and managing competition policies relating to technology packaging (e.g. such as certain cartels, exclusive grant back clauses and coercive packaging licenses restricting use of competing technologies, sources of intermediate inputs". 127

To address this problem they propose adopting competition law and policies:

"A possible recommendation is to help developing countries improve or implement competition policies capable of monitoring and discouraging use of restrictive husiness practices by technology owners and by ensuring firms adopt similar or better practices at home and abroad. Alternatively, developed country competition authorities could consider undertaking a commitment to examine practices whose effect is felt only outside their own juristictions, namely in developing countries". 128

We can come to the conclusion that the TRIPS Agreement in many ways attempts to converge the divergent viewpoints and interests WTO members have in IPR protection, but that the issue of technology transfer did not lead to

12n "Steps that might be taken within the mandate of the WTO to increase flows of technology to developing countries", Submission to the Working Group on Trade and Transfer of Technology by India, Pakistan and the Philippines, WT/WGTTT/ W/10, 13 October 2005 .

12: Iltid.

12: Ihid. 
a detailed list of rights and obligations which could provide some guidance as to what expectations are justified. On the contrary, references made to technology transfer in the TRIISS Agreement are of a rather vague character and to the most reflect a best endeavour nature, implying that the negotiations on this topic had been a difficult battle.

Evidently, Geneva-based negotiators believed that simply agreeing to the TRIPS, and even enforcing its provisions, would not suffice to expand information flows to the poorest countries. There seems to be some general understanding that market forces alone will not lead to effective technology transfer and development. ${ }^{129}$

\subsection{The WIPO Derelopment Agenda}

The transfer of technology debate is again at the forefront of attention at the WIPO. The recently adopted WIPO Development Agenda (WIPO General Assembly 2007) is now being discussed by the Committee on Development and Intellectual Property (CDIP) which has the difficult task to implement the 45 recommendations. A couple of recommendations deal with the transfer of technology which are listed below.

Recommendation 23 asks Members to undertake an exercise:

"To encourage Member States, especially developed countries, to urge their research and scientific institutions to enhance cooperation and exchange with research and development institutions in developing countries, especially LDCs".

Likewise recommendation 25 urges research

"To explore IP-related policies and initiatives necessary to promote the transfer and dissemination of technology, to the benefit of developing countries and to take appropriate measures to enable developing countries to fully understand and benefit from different provisions, pertaining to flexibilities provided for in international agreements, as appropriate".

In addition recommendation number 28 sets out that members need

"To explore supportive IP-related policies and measures Member States, especially developed countries, could adopt for promoting transfer and dissemination of technology to developing countries".

124 Moreover, the role of Aid for Trade in the context of capacity building and the development of human capital deserved more attention and the need for new or improved market access commitments in the GATS to stimulate intra-company transferees. 
Furthermore, recommendation 29 sets out that, members need

"To include discussions on IP-related technology transfer issues within the mandate of an appropriate WIPO body".

Moreover, recommendation number 30 sets out that members need:

"To undertake initiatives agreed by Member States, which contribute to transfer of technology to developing countries, such as requesting WipO to facilitate better access to publicly available patent information".

Besides, recommendation 31 indicates that research should be undertaken:

"To undertake initiatives agreed by Member States, which contribute to transfer of technology to developing countries, such as requesting WIPO to facilitate better access to publicly available patent information".

Article 7 of the TRIPS Agreement is reinforced in recommendation 45 which requires members

\begin{abstract}
"To approach intellectual property enforcement in the context of broader societal interests and especially development-oriented concerns, with a view that the protection and enforcement of intellectual property rights should contribute to the promotion of technological innovation and to the transfer and dissemination of technology, to the mutual advantage of producers and users of technological knowledge and in a manner conducive to social and economic welfare, and to a balance of rights and obligations', in accordance with Article 7 of the TRIIS Agreement". 1311
\end{abstract}

Hence, the development Agenda has brought the issue of technology transfer back to the centre of attention at negotiations taking place at the negotiation table. It is now high time to translate the theory into practice.

\title{
3.6. Inoestment Treaties and Technology Transfer
}

Next to the TRIPS Agreement there is a clear proliferation of bilateral investment treaties (BITS) as well as free trade agreements (FTAs) that include explicit obligations for the protection of intellectual property rights as investments.

Developing countries have embraced policies welcoming foreign investments, especially after the failure of attempts to impose some forms of control over the activities of MNEs and the flows of foreign direct investment and

130 See WIPO "Report of the Provisional Committee on Proposals Related to a WIPO Development Agenda" (PCDA), A/43/13 Rev., 17 September 2007. 
technology through the UN Code of Conduct on Transnational Corporations ${ }^{131}$ and the Draft TOT Code during the late 1970s. ${ }^{132}$ Investment agreements are viewed by most developed countries and the followers of the Washington Consensus as an instrument to attract foreign investors.

These investment agreements mainly include provisions for the protection of forcign investers on the basis of MFN ${ }^{133}$ and national treatment principles. ${ }^{134}$ Typically, under these agreements, host countries are required to take on broad obligations for the protection of foreign investments, particularly against expropriation (without compensation) and rivalry. These agreements fall outside the framework of multilateral standard-setting on intellectual property rights, and are being strategically pushed by developed countries to advance their industries' economic interests. Furthermore, bilateral and regional investment agreements can increase the scope and availability of IPR protection beyond the current standards, reduce the flexibilities available to developing countries under international treaties such as TRIPS and limit the sovereignty of countries to set their rules on biodiversity. ${ }^{135}$ On the other hand, many developing countries are seeking to include issues that reflect their own priorities and interests such as improving innovative capacity and receiving transfer of technology. Hopefully, the foreign trade agreement between the European Communities and the Caribbean (the CARIFORUM-EPA) which includes a separate chapter on innovation provides an example for the future. ${ }^{136}$ The innovation part focuses on the need for support for national and regional innovation systems in the Caribbean and emphasises the importance of assisting the commercialisation of Caribbean innovations in the EU market. The underlying rational is that IP protection should contribute to establishing a viable technological and innovative base in the country (in line with Article

1.1 UN Code of Conduct on Transnational Corporations, 23 I.L.M. 626 (1984). The code was never adopted but attempted to provide either mandatory requirements or voluntary guidelines for transnational corporations (TNCs) to follow, by encouraging contribution to the development goals and objectives of the countries in which they operated. The Code also attempted to facilitate co-operation with and among States on issues relating to TNCs; and to alleviate difficulties derived from the international character of such corporations and the resulting diversity of laws and cultures. The development of the United Nations Code of Conduct for Transnational Corporations was a twenty year process and was finally abandoned in 1992.

132 See Annex three of this book.

13.3 Although a common exemption of the most-favoured nation treatment obligation treatment (MFN) from IIAs to avoid that non-members can free ride on special concessions made to members of a regional economic integration agreement, typically in exchange for special concessions made by those members.

13. See chapter two of this book for an explanation of these terms.

15.5 See Correa 2004.

1.t. See Spence 2008. The CARIFORUM EPA is the first full EPA and besides the chapter on imnovation includes a chapter on innovation and IPRs. 
66.2 of the TRIPS Agreement). In addition, the focus on innovation highlights the fact that the majority of technological innovations in small economies (and i.e. developing or least developed countries) are of an incremental nature reliant on access to information and knowledge to carry out improvements and build on existing innovations. ${ }^{137}$ The focus on imovation although novel, merely states that the EC will provide technical assistance in this regard (no hard demands are provided for). For instance the EC makes no substantive commitments to transfer of technology other than to provide incentives to transfer technology to LDCs. It remains to be seen how this theory will be translated into concrete practical solutions (i.e. going beyond best endeavour nature).

Within the last decade international investment agreements (IIA) mushromed at the bilateral, regional and inter-regional levels. ${ }^{138}$ UNCTAD signalled a trend towards IIAs that are more "sophisticated and complex in content, clarifying in greater detail the meaning of certain standard clauses and covering a broader range of issues". In addition, economic development policy is hindered because of the complex web of overlapping commitments arising from IIAs holding a diversity of provisions applicable to the same matters. International investment treaties mushroomed but also the investor-State disputes have significantly grown. All these developments burden countries and industries that have to set out strategies and develop policies within this "increasingly complicated framework of multi-layered and multi-faceted investment rules". 139

The content of $11 \wedge$ s has changed over the last 50 years. In 1959 when the first IIA was concluded IIAs were limited in scope, simply aimed at protecting investments of developed country investors in the territory of the developing countries. From the 1990 s increasingly features such as liberalising access to resources and markets as well as protection for international investment stocks were added. Also it is not as easy to understand the web of IIAs as these agreements have diverse names, such as free trade agreements, regional trade agreements, new-age partnership agreements, closer economic partnership arrangements and also economic integration agreements, amongst others.

In principle one can distinguish between two types of IIAs: The first group consists of bilateral treaties for the promotion and protection of investment (or bilateral investment treaties (BITs)). These BITs are agreements negotiated between two countries to protect and promote investment of investors of one

13 See South Centre and Centre for International Environmental Law 2006, p. 3.

13 The number of concluded BITs raised from 385 at the end of the 1980s to 1857 at the end of the 1990 s while the number of countries involved in bilateral investment treaties reached 173. See Correa 2004, p. 3.

1.34 UNCTAD Report entitled "International Investment Arrangements: Trends and Emerging Issues", 2006, p. I (hereinafter called UNCTAD Report on IIAs). 
party in the territory of another. ${ }^{1.41}$ These treaties have a uniform character and have not changed since their creation - other than including provision on investor-State dispute resolution in the 1960s. The second group is less easy to identify as these refer to investment rules incorporated in larger trade agreements including issues such as trade in goods and services, intellectual property rights, competition policy, govermment procurement, temporary entry for business persons, transparency, the environment, and labour rights. ${ }^{141}$ This group of treaties was mainly negotiated during the 1990s. The increasing number of investor-State dispute resolution have led to a re-evaluation of the content of the traditional investment rules. As a consequence, IIAs conducted in the last decade show greater variation in comparison with the traditional BI'Ts concluded within the first group. Thus, there are new challenges for policy makers since second group IIAs not only limit the regulatory space within which countries can pursue their economic development policies but also touch upon multiple disciplines in a complex and detailed manner of ten creating complex interactions amongst agreements. ${ }^{1+42}$

The key reason for negotiating IIAs is to obtain protection for Foreign Direct Investment (FDI) against expropriation by the host country/recipient country. ${ }^{43}$ Notably developed countries seek to protect the investment of their investors and developing countries desire to attract foreign investment but are also increasingly investing outside their territory. ${ }^{1+4}$

Do these investment treaties take developmental concerns into consideration? Often an IIA contains language on developmental issues such as preserving policy space to pursue developmental objectives for host countries. But one can see a trend towards the inclusion of numerous exceptions, which results in treaties that are very complex and detailed. For instance, exceptions relate to

1.+1) See UNCTAD Report on IIAs, p. 3.

14! See UNCTAD Report on IIAs, p. 10.

142 Both developed and developing countries are active in concluding BITs, Germany is topping the list, Lut rapidly followed by China. Developing countries were one or both parties to 75 per cent of all BITs, as increasingly South-South cooperation on investment takes place, especially among countries in Asia. See UNCTAD Report on IIA, p. 8 and 13 .

14. Investors seck to arrange that expropriation is only lawful if it was "for a public purpose, non-discriminatory [and] consistent with due process, and accompanied hy compensation generally at fair market value". A provision generally included in IIAs concerns the right of investor to "transfer their investment and any returns form their investment into a fredy convertible or fredy usable currency". See UNCTAD Report on IIAs, p. 36 and 38.

$1+4$ See UNCTAD Report on llAs, p. 13. 
"measures necessary to protect health, safety or the environment, to regulate financial services, or to preserve cultural patrimony, industries or diversity". 14

The growing number of exceptions is a sign of the increased awareness of the complexity involved in balancing different policy objectives and the desire of

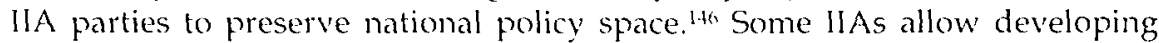
countries transition periods to permit more time in order to adopt obligations. In addition developing countries are often authorised special and differential treatment with respect to the implementation of the substantive obligations of the agreement.

Recipient countries often include provisions on "performance requirements" which are intended to alter the behaviour of investment actions in line with their economic needs. For instance to stimulate employment by requiring the hire of local employees or that inputs are purchased locally, or by mandating export at least a certain percentage of its produce. These requirements

"may distort trade by preventing the importation of goods or services or by requiring the expotation of goods or services, a consequence that could be of concern in negotiating an agreement to liberalise trade", 147

It is questionable if such provisions are still legitimate in the light of the TRIMS Agreement, to the detriment of developing countries interests.

Intellectual property is generally seen as falling within the definition of investment and as a result it is by its nature protected against host country interference. Nonetheless, most recent IIAs made explicit reference to intellectual property rights, normally requiring adherence to international IPR protection agreements or providing for national treatment or non-discrimination. In some investment treaties IPR protection is laid down to go beyond the minimum standards set by the TRIPS Agreement. Recent investment treaties have also endeavoured to exclude intellectual property rights from falling within the rules on expropriation. For example, Article 10.13 of the 2003 Chile-Republic of Korea Free Trade Agreement sets out that the rule on expropriation is not applicable to "the issuance of compulsory licenses granted in relation to intellectual property, or to the revocation, limitation or creation of intellectual property rights, to the extent that such issuance, revocation, limitation or creation is consistent with the TRIPS Agreement". ${ }^{1.45}$

14: Ibid., p. 24.
14. Ibid.
1.t Ibid., p. 40.
1.th Ibid., p. 44. 
Hence, the increase in investment treaties including elaborate provisions on intellectual property rights also includes protection against host country interference. ${ }^{(-4)}$

Because of the network of investment treaties concluded containing a number of provisions applicable to the same matters it becomes increasingly difficult to maintain coherence of a country's economic development policy. IIAs addressed these policy coherence problems and started to require parties to access or adhere to other agreements or to observe obligations under another agreement. ${ }^{151}$

Despite expectations about the impact of BITs on FDI, there is no evidence indicating that the adoption of BITs has actually encouraged foreign direct investment flows to developing countries that have signed up to these agreements.

To a certain extent, FTAs permit developed country partners to influence the domestic political economy of developing countries and advance the interests of their corporations in the latter's markets. Studies comparing FDI flows in the three years after a BIT was signed with the three years prior to it surprising show no significant increase in FDI. ${ }^{151}$

To sum up investment treaties or investment chapters of free trade agreements do extend the existing levels of IPRs set under TRIPS and other IPR treaties, in addition they include the national treatment principle without the exceptions provided for under international treaties. It is unclear to what extent rights granted by investment agreements may be used to substantiate IPR claims trough investment-related disputes. In this respect special attention should be devoted to compulsory licenses since it might be possible for investors to claim an economic loss. 152

144. IIAs can also include provisions that prohibit, or require the parties to prohibit, agreements or concerted practices that may affect trade between the parties and that have as their object or effect the prevention, restriction or distortion of competition. This has especially occurred in IIAs concluded by European countries. But increasingly also non European countries enclose provisions in relation to competition in the line that anti-competitive practices should be addressed. See UNCTAD Report on IIAs, p. 44.

15. For a more detailed overview see chapter three of the UNCTAD Report on IIAs and Correa 2004.

151 See World Bank 2003.

152 In addition the enforcement of disclosure of origin principles to prevent misappropriation of bio piracy may be challenged by investors as incompatible with international law. In addition, biological materials collected under an access permit may be considered the property of the collector who, under a broad definition of investment, may claim protection as an investor with regard to the materials. See Correa 2004, p. 2. 
Although often exempted, if included, the incorporation of the most favoured nation clauses in BIT's and FIAs contribute to a global elevation of IPR standards. For instance, if negotiations on investment were initiated in the framework of the WTO, for instance, pressure to replicate the highest levels of investment protection for IPRs, as currently found in the bilateral treaties, can be expected. 153

\section{MODESOR TECHNOLOCYY TRANSFER}

\subsection{Introduction}

This section sets out how technology can flow from one country to another and the impact the level of IPR protection has on the transfer of technology. It is difficult to measure the impact of existing IPR protection on technology flows as it depends on a number of factors and circumstances but we can draw some conclusions from the nature and determinants of international technology transfer. It should be noted that IPR protection includes not only the level of legal protection in the form of laws (and subject matter, scope, and term duration), but also its implementation and enforcement.

There are different channels through which technology can be transferred across international boundaries. For instance, technology transfer can take place through 1) trade in goods (especially capital goods and technological inputs), 2) foreign direct investment (FDI), 3) licensing of technology (through patents), 4) joint ventures, 5) public/private research/partnerships, and 6) personnel (labour) movements, along with 5) informal means (also referred to as non-market channels of technology transfer), through imitation, reverse engineering, de-compilation of software and technology spillovers.

An IPR holder (i.e. a patent holder) can serve multiple markets in many ways: it can opt to supply a market by exporting its goods, by conducting FDI, licensing or otherwise. Why a firm chooses one method over the other is often analyzed by economists by using the ownership-location-internalisation (OLI) framework. ${ }^{15-4}$ This OLl framework puts forward that firms in the possession of ownership advantages - for instance, in the form of IPRs - would chouse foreign production oar export if the attributes of a particular location (lower wages, proximity to international markets) favour production abroad. The decision whether to choose FDI or licensing to serve a market would depend on what advantages the mode of transfer is likely to bring. For instance, one needs to compare the transaction costs of maintaining an "arm's length relationship" with an independent foreign firm against the costs of establishing a

153 See Correa 2004, p. 2.

1 it See Fink and Maskus 2005 , p. 4. 
wholly owned subsidiary. ${ }^{155}$ It is argued that IPR policies can have an effect on both "location" advantages and "intermalisation" advantages, such that strengthened IPR protection can lead a firm to invest in different places and switch from wholly owned production to licensing. ${ }^{150}$ According to Fink and Maskus the strongest link can be made between strengthened IPR and licensing in that licensing becomes more popular if IPR protection is strengthened:

"the enforceability of licensing contracts relies fundamentally on the security" that these rights provide for a firm's technologies and reputation-enhancing assets". ${ }^{27}$

\subsection{Trade in Goods}

The advantages of international trade for economic growth and development are of major importance. ${ }^{158}$ Imports bring additional competition and variety to domestic markets, thus benefiting consumers. In addition, exports enlarge markets for domestic production, benefiting businesses. They also provide access to the best practices of foreign firms to meet demands of customers and encourage greater efficiency. 159

The international trade in goods brings new products embodying new ideas and knowledge to a country. It furnishes access to new machinery and equipment and provides opportunities for local reverse engineering. ${ }^{160}$ Studies have shown that "foreign R\&D embodied in imported capital goods has a significantly positive impact on total factor productivity on importing countries" 161 and that this effect is enlarged, "the more open countries trade policies are, the

155 See Fink and Maskus 2005.

15, See Fink and Maskus 2005.

15 See Fink and Maskus 2005.

15. The basic idea of product cycle models (for details see Grossman and Helpman 1991 is that new products are invented in the North and due to lower relative Southern wage (endogenous in the model) firms in the South can successfully undercut Northern producers once they succeed in imitating Northern products. A typical good is initially produced in the North till either further innovation (in the quality ladders model) or successful Southern imitation (in both the variety model and the quality ladders model) makes profitable production in the North infeasible. Consequently, either production ceases all together (if product innovation is over) or shifts to the South (if imitated). Thus, prior to imitation, all products are exported by the North whereas post imitation they are imported, thereby completing the cycle. See Saggi 2000, p. 8 .

$15 \%$ See Higino Schneider 2005 , p. 529.

16i) See Hoekman, Maskus and Saggi 2005, p. 1588.

inl See Coe, Helpman and Hoffmaister 1997, as referred to in Hoekman, Maskus and Saggi 2005 , p. 1588. 
more skilled is their labour force, and, in the case of developing countries, the more their trade with developed countries". ${ }^{162}$

Trade gives firms access to improved capital inputs such as machinery which increases productivity and provides new opportunities for growth for developing countries. It is thought that good imports may embody imnovations that are not available in the local economy, and hence local researchers may gain insights from these innovations and improve them for the local situation. Therefore, by providing access to foreign innovations, trade can promote technological diffusion into the recipient country and lead to economic grow th. ${ }^{163}$

\subsection{Foreign Direct lna'stment}

Foreign Direct Investment (FDI) refers to an investment made to obtain longterm interest in enterprises operating outside the economy of the investor. In addition, the investor's purpose is to gain an effective voice in the management of the enterprise. It is suggested that a threshold of ten per cent of equity ownership is needed for an investor to qualify as a foreign direct investor. ${ }^{\text {lit }}$

The foreign investment of multinational corporations involves the transfer of technological information that most likely is newer or more efficient than existing in local firms. In addition, technological spillovers might come about from the retrieved $\mathrm{FDI}$ which can benefit the recipient country.

However, the attraction of FDI must be approached with care as some studies have shown diverse outcomes as results of FDI investment. On the one hand studies suggest that FDI is responsible for substantial technology diffusion. 16.5 This view is supported by an econometric study that found that domestic firms in sectors with a relatively high multinational presences show more productivity. ${ }^{160}$ On the other hand, other studies have concluded that com-

1112 See Schiff, Wong and Olarreaga 2002 as referred to in Hoekman, Maskus and Saggi 2005, p. 1588.

11..3 See Higino Schneider 2005, p. 530.

10. Definition derived from the "Balance of Payments Manual", Fifth Edition, Washington, DC, International Monetary Fund, 1993. The main feature of FDI is taken to be the lasting interest of a direct investor in an enterprise and therefore only capital that is provided by the direct investor either directly or through other enterprises related to the investor should be classified as FDI. For instance, equity capital, the reinvestment of earnings and the provision of long-term and short-term intra-company loans (between parent and affiliate enterprises). See <http://www. unctad.org $>$ on FDI statistics.

sn: See Blomström and Kokko 1997b, referred to by Hockman, Maskus and Saggi 2005 , p. 1588.

1tr See Kokko, Tansini and Zejan 2001, referred to by Hoekman, Maskus and Saggi 2005, p. 1588. 
peting domestic firms do worse as the foreign multinational presence increases. "For instance, the OECD signals a risk that the import of foreign technology may reduce the $R \& D$ efforts of local firms which can be detrimental in the sense that it can lead to a lack of local receptors for future technologies. ins

It is argued that investment by (MNEs) may provide developing countries with more efficient foreign technologies and result in technological spillovers into the domestic market of the recipient country because of labour turnover and vertical linkages of technology. ${ }^{169}$ Econometric studies have shown a diverse picture: some have found that firms in sectors with a relatively high MNE presence tend to be more productive, ${ }^{170}$ while others noted that competing domestic firms do worse when the foreign presence in their industry increases. ${ }^{171}$ For instance, "negative horizontal spillover effects may occur if MNEs siphon off domestic demand or bid away high-quality labour". ${ }^{172}$ In addition, imports of technology may reduce the R\&D efforts of local firms, which may have happened in some sectors in China in the 1990s. ${ }^{133}$ However, multinational presence may also attract other seroices such as banks, schools, shops as it moves more labour to a particular region. ${ }^{174}$

Studies have shown that integrated subsidiaries into the multinational enterprise have a more positive effect on the local economy than mandatory joint ventures:

"a substantial difference in operating characteristics between subsidiaries that are integrated into the international sourcing networks of the parent MNEs and those that are prevented from such integration by policy barriers such as mandatory joint venture and domestic content requirements. These different

w- See Aitken and Harrison 1999, referred to by Hoekman, Maskus and Saggi 2005, p. 1588.

lus. See Hoekman, Maskus and Saggi 2005 p. 1589.

16. See Blomstrom and Kokko 1997b as referred to by Hockman, Maskus and Saggi 2005, p. 1589.

171 See Kokko, Tansini and Zejan 2001, as referred to by Hoekman, Maskus and Saggi 2005 , p. 1589.

in See Aitken and Harrison 1999 as referred to by Hoekman, Maskus and Saggi 2005. p. 1589.

172 See Hoekman, Maskus and Saggi 2005, p. 1589.

17 See Hoekman, Maskus and Saggi 2005.

174 This demonstrated in the UNCTAD Salmon case study. The salmon industry has contributed to the general development of the region. Currently it employs about 45.000 workers directly and indirectly, and has brought about a general improvement in regional infrastructure and services. In that specific region the poverty index decreased from 40 per cent to 13 per cent between 1990 and 2003 while the index of extreme poverty decreased from 24 per cent to 7 per cent. See UNCTAD 2006, p. 2. 
characteristics include size of the plant, proximity of technology and qualitycontrol procedures to global best practices, speed with which production processes are brought to the frontier, and cost of output. Integrated subsidiaries have a more positive impact on the host country, often accompanied by vertical backward linkages and externalities. Isolated affiliates have a less positive, and sometimes negative, impact on the local economy".

Hoekman's studies pointed out that the research which focused on spillovers to local competitors of MNEs missed the fact that the multinational enterprises typically transfer technology to local suppliers. For instance Mexico's "maquiladora" sector ${ }^{17 t}$ is a recent example of vertical international technology transfer. Most "maquiladoras" began as subsidiaries of US firms that shifted labour-intensive assembly operations to Mexico. ${ }^{17}$ However, over time, the "maquiladoras" adopted more sophisticated imported production techniques. $1 \%$

\subsection{Liconsing}

Technology transfer is often linked to patent licensing as an option to legally transfer proprietary-protected information embodied in an invention. The provisions of the license contract define the rights and responsibilities of the two parties. In a typical license agreement, the licensee is normally granted access to an early stage invention that is protected by a patent. In exchange, the licensee makes a commitment to commercialise the invention and pay the agreed fees, and royalty payments when products reach the marketplace. The licensing of technology can be done either within firms or between unrelated firms at arm's-length. In the case of intra firm technology transfer the foreign multinational corporation retains immediate proprietary control of the knowhow. In contrast, in the case of arm's-length transfer a corporation explains its

175 See Hockman, Maskus and Saggi 2005, p. 1589. A recent case study of the effects of Smarzy'nska (2004) examined backward linkages and technology spillovers using data from Lithuanian firms over 1996-2000 and found that productivity is positively' affected by a sector's contacts with multinational enterprises but not by the presence of MNEs in the same industry. Thus, her results supported the existence of vertical spillovers from FDI. See Smarzynska 2004.

17t A "maquiladora" is a factory that imports materials and equipment on a duty free and tariff free basis for assembly or manufacturing and then re-exports the assembled product, usually back to the originating country.

i7 Other examples of vertical spillovers are for instance Intel's investment in Costa Rica by Larrain, Lopez-Calva, and Rodriguez-Clare which have found that local suppliers benefited substantially from Intel's investment. Also in the electronics sector, foreign investors helped their local subcontractors kecp pace with modern technologies by assigning technicians to the suppliers' plants to help set up and supervise automated production and testing procedures. See Larrain, Lopez-Calva and Rodriguez-Clare 2000.

17 See Saggi 2000. 
conditions in a license contract. These contracts contain information on the acquisition of production or distribution of rights and the underlying technical information and know-how. ${ }^{179}$ Most licensing contracts involve the purchase of production or distribution rights, often including intellectual property rights, and the technical information and know-how required to utilise the rights in practise. Thus, patents, trade secrets, copyrights and trademarks serve as direct means of information transfer.

There is great potential for the licensing of technology to developing countries to be an important channel of international technology transfer to them. Nonetheless, this form of technology transfer might be unaffordable to low income countries who can not meet the terms and conditions of the licensor. ${ }^{180}$

Just as for FDI, the deciding factors of multinational enterprises whether to license or not include a number of factors: potential market size, location of country, policy certainty and transparency, compuption and political stability. ${ }^{181}$ Another important factor is the certainty of the licensor that technologies will not leak into the host economy through copying or through actions of personnel. If there is a great risk of imitation or the leakage of technology into the wrong hands a firm will most likely not choose licensing to transfer its technology but will opt for the safer option of FDI instead to pursue its business activities (e.g. producing goods in other countries) or it may transfer technologies which are inferior or older. This way, it can safeguard proprietary control more easily. ${ }^{182}$

The downside of obtaining transfer of technology through licensing contracts or sale contracts might be the clauses introduced by multinational corporations. One should bear in mind that multinationals have gained strong market positions and as a result gained bargaining power allowing them to design contracts including terms more favourable to their business objectives. They wish to make the highest profits possible and keep maximum control even after licensing the technology. Since for many developing countries their principal source of technology comes from these multinational corporations they become vulnerable and dependent to the whims of these corporations.

Another way of accessing technology is by compulsory licensing. This involves unauthorised use of proprietary owned technology under certain prerequisites. ${ }^{\text {is? }}$

174 See Hockman, Maskus and Saggi 2005, p. 1589.

1:it) See Park and Lippoldt 2004.

$1: 1$ See Maskus 2000.

1 s. See Maskus 2000.

1.3. One of the main objectives of the revision process of the Paris Convention was to improve access to proprietary technology by developing countries, for instance by easing the use of compulsory licensing mechanisms. 
Nonetheless the TRIPS Agreement severely restricts the use of compulsory licensing as a means of access to technology and has made it subject to certain stringent conditions. See chapter two, section 3.6 of this book for a more elaborate discussion of the provisions on compulsory licensing in the TRIPS Agreement.

\subsection{Labour Mur'ent'nt}

The role of labour as a channel for lTT has recently been given more attention. ${ }^{13+4}$ Some studies have found that domestic labour turnover from MNEs to local firms is limited while others claimed the opposite. ${ }^{155}$ It is likely that in countries where local firms are not far behind MNEs in technical terms, labour tumover is more likely. Hence, the ability of local firms to absorb new technologies is an important factor if labour turnover is going to be a successful means of diffusion. ${ }^{\text {sho }}$

Human resources are crucial both to the development and to the application of technology. Certainly, some inventions have been made involving little education, training or skills; nonetheless currently most inventions are made by those with considerable education in science and technology. In addition it requires skills to turn inventions into commercial applications which require, besides technological expertise, also business and marketing skills. Hence, simultaneously, if all these skills are necessary for the development into a specific sector in a particular country it follows that many of these skills are also needed for the successful adaptation and application of a particular technology transferred to a third-country. As a result, a certain level of scientific and technological knowledge is a must for a country to play a role in the international technological economy. ${ }^{197}$ Hence, countries and the donor community need to invest in education and providing linkages between universities, public research institutions and private industry. Notably, developing nation govermments find it easier to fund and improve their public sector scientific capability than to similarly improve the private sector. Links need to be established, for instance, through stakeholder meetings to accomplish that university scientists are aware of the needs on the ground amongst the industry players and likewise industry needs to know what technologies are being developed that might be useful. A regular interchange of personnel between industry and academia can improve communication and understanding and awareness of each other's needs. Hence, the learning circle can be improved if scientists and engineers have business experience combined with their technical background.

\footnotetext{
is See for instance, Barton 2007.

15.5 See Rhee as referred to in Hoekman, Maskus and Saggi 2005, p. 1590.

1.t. See Hoekman, Maskus and Saggi 2005, p. 1590.

1s. See Barton 2007, p. 4.
} 
The famous economist Friedman describes in his book "the World is Flat" that the world is increasingly interconnected. He argues that the world is flat as a result of globalisation processes which have changed the economic level playing field and produced equal opportunities for both industrial and emerging economies. Friedman describes ten so-called "flatteners" that level the global playing field and increase global collaboration as well as the power of communities and networks: 1) the collapse of the Berlin wall; 2) the emerge of the information society (netscape and web); 3) workflow software (such as computers that intercomnect); 4) opensource movements (such as opensource computer software, blogs, google and wikipedia); 5) outsourcing (such as companies are cost efficient by splitting activities and subcontracting, for instance service and financial activities take place in a different location than actual manufacturing); 6) offshoring (related to outsourcing - the internal relocation of a company's manufacturing to another foreign country which is more cost efficient); 7) supply chaining (technology is used to arrange for sales, distribution and shipping); 8) insourcing (in which the company's employees perform services (beyond shipping) for another company, Friedman provides the example of UPS that repairs Toshiba computers); 9) in-forming (search engines such as google and yahoo that allow people from all over the world to search and access information in no time); and 10) the steroids (personal digital devices such as iPods, Black Berry's, instant messaging). ${ }^{\text {is }}$ Although the book provides an interesting outlook on globalisation and economic relations it is written from an American point of view.

The Dutch government has provided another type of intemational development assistance for over a quarter of a century by sending senior experts to more than 80 countries in Africa, Asia, the Middle East, Latin America and Central and Eastern Europe. The so-called PUM project ${ }^{159}$ offers, on request, skills and experience to businesses and organisations in developing countries, mostly to small and medium sized enterprises (foreign subsidiaries are excluded). PUM projects provide assistance in every stage of the managerial process: administration, finance, automatisation, production, marketing, and in a wide variety of specialist fields. It has assigned experts to advise firms in just about every sector of industry, including construction, textile, metal and wood processing, chemicals and agriculture. The senior experts work on a voluntary basis and are mostly retired. Since, its establishment in 1978, the PUM project has become Europe's largest "job agency" for professional volunteers who wish to work in developing countries. ${ }^{191}$

1.s. See Friedman 2005, chapter two.

1n: The PUM project refers to Project Llitzending Managers. Freely translated from Dutch into English this would refer to Project Transferring Managers.

1w: For more information on the PUM project see: <https://www.pum.nl/>. Another example of information sharing and tailor made business assistance is The African 
Linking industry and academia can also be established by allowing interns to come and work for a while in start-up companies and also in established companies. NGOs currently face the financial difficulties to welcome trainees from developing countries as the received donor funding does not provide the additional costs such as housing allowance, insurances and travel expenses. It is advisable that the donor community allocates money for this type of capacity building activity that is crucial for the education, training of young professionals coming from developing countries. Another channel of international technology transfer with high potential is the crossing borders of people, e.g. students or workers or the inward movement of foreign citizens. India is a good example of this mode of technology transfer as they have invested a lot in their software and related services industry and this has proven very successful. As a result many foreign countries are interested in hiring these professionals, much needed in their own territory, for instance in Europe or in the US.

Barton points out that, over the last 30 years a significant growth in scientific and technological education and in numbers of engineers and scientists has taken place. The number of people with a college degree has risen in Latin America and in East $\Lambda$ sia, as well as in the US and there are many possibilities to study internationally under a scholarship program. In particular Asian students follow studies overseas, in particular in the US, which currently hosts about 40 per cent of international students. Barton sees an important task for national governments and the intemational donor community is to improve developing-nation education. ${ }^{101}$

However, immigration policies stop people at the border, and in order to stimulate the international movement of labour, governments need to adopt favourable immigration and services policies. For instance, the former Dutch Minister of Development affairs, Mrs. Agnes van Ardenne investigated the possibilities of granting doctors and other medical personnel a temporary visa (for a year) during which they could gain advanced skills which they could, after this period, introduce back in their country of origin. Immigration policies in the European Union and the US focus on attracting highly skilled people who are granted visas more easily. It is necessary to make it easier for students and scientists to access visas. It is advisable to tackle this issue in the

Technology Development Forum (ATDF), which supports small and medium sized enterprises to realise their business aspirations. Business ideas can be submitted and subsequently ATDF selects among these submissions and provides financial, administrative and technical support to the most potential business idea. See <http:// www. atdforum.org/>.

191 See Barton 2007, p. 4. 
context of mode 4 of the General Agreement on Trade in Services whilst addressing the flow of professional services. ${ }^{1 / 2}$

Policies favouring international transfer of personnel have also brought about the phenomenon of "brain drain", implying that many skilled, highly qualified, educated people leave their home countries and do not return. As a result, the countries do not profit from the gained knowledge and experiences abroad. Egypt, Latin American countries and India have frequently complained that the ongoing process of brain drain should be stopped in order for them to develop their own economies. Some countries have initiated a process of reverse brain drain by making it more attractive for intellectuals/business people to return home after gaining experience in foreign countries, for instance, by providing job security or tax benefits in setting up local businesses. Hoekman believes a policy challenge for developing countries is facilitating temporary movement abroad and encouraging returnees to undertake local research and business development. ${ }^{193}$

How can we make sure that the technology introduced into a country will subsequently diffuse throughout the rest of the economy and spill over to other companies? Saggi ${ }^{19.4}$ suggests that since the mobility of labour is hindered at the international level, because of immigration laws, it is most likely that technology diffusion will mainly occur within the territory:

\footnotetext{
"The presence of barriers across countries, as well as international differences in market conditions and policy environments necessarily imply that the techology diffusion within a country may be considerably easier than international transfer of techology. For example, mobility of labour is severely constrained only at the international level (exceptions are contact with consultants, return of foreign educated natives etc.) Thus, labour turnover across firms may be crucial for driving technology diffusion within a country and not play as big a role in international technology transfer". ${ }^{145}$
}

Examples are India that provides financial, technical and administration services at a large scale such as computer programmers, financial accountants and call centre operators to big multinational co-operations that are now to a great extent dependant on India for their supply chain management and administration. Also Ireland has through favourable laws attracted European headquarters of multinationals offering one of the world's most beneficial corporate tax environments.

142 For a more elaborated discussion on visa restrictions, the brain drain phenomenon and remittances and human resources in general, see chapter 2 of Barton 2007.

1\%3. See Hoekman, Maskus and Saggi 2005, p. 1590.

194 Kamal Saggi is a professor of economics in the Department of Economics at the Southem Methodist University.

${ }^{145}$ See Saggi 2000, p. 5. 


\subsection{Non-market Channels of Tedmology Transfor}

Informal ways of acquiring technology occurs through non-market channels of technology transfer. This can be a useful source of new information and technology to developing countries: involving all kinds of circumstances that involve learning processes. This paragraph will shortly describe the most common forms of non-market channels of technology transfer, for instance, imitation through careful product inspection. However, this can be quite costly a process and requiring special knowledge and skills.

Another non-market chamnel of technology transfer is persomnel movement from one firm to another, for example from a multinational enterprise to a local company transferring skills and knowledge. For instance, personnel movement can relate to technical or managerial personnel leaving a firm and setting up a rival firm or starting to work at another rival company. Also the temporary migration of students, scientists, managerial and technical personnel to universities, laboratories, and conferences contribute to in-depth training in various fields notably in science and engineering which forms a longlasting form of international technology transfer.

Another way of learning is to study closely available information about relevant technologies; for instance the granting of patents requires the disclosure of the technology behind the product which can provide access to new technological knowledge if properly described. Thus, we can say that patents play a role both in formal and informal modes of technology transfer, directly through FDI and licensing, and indirectly through inspection of the patent registration. Whether or not patent disclosure provides sufficient information for rival engineers to understand the described technologies remains controversial. ${ }^{9 \%}$

Finally, information might be freely available in the public domain -free for everybody to use - although it is likely that fust as with the understanding of patent claims) even if a technology has entered into the public domain, it might still not be easy to understand or to absorb it at low cost.

\subsection{Open Sonre'}

One can argue that innovation can be stimulated by other means then by granting proprietary rights. Successful attempts like open source software show that innovation can be achieved by other means than by linking proprietary rights/ownership and innovation by focusing on concepts such as sharing, open access and cooperation. Hence, the innovation process itself has

14. See Maskus 2004. 
changed over the last decade: there is a degree of innovation within the process of innovation. ${ }^{147}$ The idea of open source licensing is to keep the discoveries freely available to researchers and producers.

An alternative way to protect intellectual creations and to arrange technology diffusion simultaneously is open source. Open source movements have mushroomed in the last decade mainly to provide an alternative to the Microsoftruled world of computer software and to protect copyrighted software creations in a different way. In the field of software this model has proved to be very successful in generating a high rate of innovation and good functioning products at low cost. However, technological advancement ${ }^{198}$ has successfully extended the use of open source beyond the field of software for example in pharmaceutical discovery research.

How open source works has been clearly described by Hope:

"open source business strategies actively promote innovation by making
technologies available in easily-modified form, at low or no cost, under licensing
terms that allow users to make changes to the technology and to use or dis-
tribute the resulting modified versions as they see fit". ${ }^{109}$

Accordingly, the techmology is available for everyone to use and to advance, in exchange for any improvements made to the technology must remain freely available to all. The underlying rationale is that the "free revealing" may enhance the value of the technology. Hope concludes that open source has two components: 1) Maximising the use value of the technology through free revealing, and 2) Translating increased use value into economic value for the technology owner.

Hope also adequately describes the main objective of the open source strategy:

"The use value of a technology depends on its accessibility. Accessibility is a function of availability and affordability. Open source licenses aim to increase both arailability and affordability by making it possible for anyone at all to become a distributor and by ensuring that anyone who receives the technology has freedom to operate - with the qualification that under a copy left-style license, the licensee is constrained to make any distributed improvements available on the same terms as the original licensed technology".

Wir See Gosh and Soete 2006.

wis The greater size of chemical, biological and medical databases, new software and more powerful computers have facilitated collaboration efforts in order to rapidly developed knowledge and products. See Foray 2008, p. 36.

jin See Hope 2006. 
The use of open source strategies to launch a technology is mainly suitable for "fundamental enabling techologies that are not a source of competitive advantage for the companies involved". An open source strategy is clearly not suitable for high-tech technologies (such as pharmaceuticals) that involve skyscraping R\&D costs and are subjected to a short life period because of competitive follow up technologies. So for which industries might open source be interesting? Open source might be suitable where it "complements proprietary business models by reducing costs, risks and product development time", 200 Hence, open source protection is suitable for creations involving basic technologies and it can facilitate efficiency as one does not need to invent the wheel twice.

For instance in the case of limux $v$. Unixint the value is added by third party software and open source development of the underlying core of open source software. The engine is open source but the shell is proprietary.

In the world of proprietary IP exploitation, one player's R\&D win is another's loss. Consequently the leading company might not be interested in open source strategies since a proprietary business model might be more lucrative but it might be of interest to the second and third comers in the market. For the simple reason that they are interested in supporting any new development that offers to erode the winner's competitive advantage. In addition open source might be a suitable business strategy to: 1) "To leverage the improved use value of an open source technology to enhance the appeal of a complementary product".212 An example would be if a company's prime product is to sell hardware but it gives away freely enabling software such as driver and interface code along with the hardware. Basic economic theory tells us that technology is more valuable the more it is used and the more it becomes the mainstream/the standard; 2) To sell services. "In this model the technology is distributed on an open source basis in order to grow the market for the technology itself and associated offerings. Revenue is generated by selling the technology in a form that is easier or more convenient to use than the freely available version and by providing services such as training, consulting, custom development, and after-sales support or accessories such as user manuals". 2113 An example is the freely available e-mail service provided by "hotmail.com". One can use the programme for free but with limited data

214 See Hope 2006.

201 Linux is a free Unix-type operating system originally created by Linus Torvalds with the assistance of developers around the world. Developed under the GNU General Public License, the source code for Linux is freely avaibble to evervone. IBM supports Linux on all IBM servers. IBM employs 600 developers working on over 100 open source projects.

2in See Hope 2006 .

203 See Hope 2006. 
space but the possibility exists to buy more space in exchange for a money transfer; 3) Open source could function as a market positioner. The open source product may generate little or nothing but by making the technology widely available the product gets more known (and shows the attractiveness of the technology in terms of user-friendliness, quality, affordability or availability) and builds the firm's overall brand and reputation or adds value to conventional products. In addition, it can increase the number of technology developers and users that are familiar with and loyal to the product line as a whole. Hope makes the link between brand licensing and franchising which are business strategies that both depend on "good market positioning". Looking at the open source context, "both involve charging a fee for the right to use brand names and trademarks associated with technology that is itself open source".2(14 Another example falling into category iii would be if Apple were to start promoting its il'od by decreasing the price for the iPod in order to sell its main product, the downloadable "iTunes" for a small charge per download and later on computer software.215

\subsection{Spillower Effects}

Once a technology has been introduced into a country, does it subsequently diffuse throughout the rest of the economy? Research has shown that the role of trade in encouraging growth hinges critically on the geographical scope (national versus international) of knowledge spillovers. Empirical studies have not yet delivered a clear judgement on this issue and the truth may simply be that, for developing countries, spillovers are more likely to be national in scope unlike those for industrialised countries. Thus, as a result it matters for development whether $R \& D$ and high technology production are carried out in close geographical proximity to a country. 206

Barriers between countries, as well as international differences in market conditions and policy enviromments mean that technology diffusion within a country may be considerably easier than the international transfer of technology, with exception of foreign consultants and the return of educated abroad

214 See Hope 2006.

215 See <http://www.opensource.org> for more information on open source. Voluntary licensing standards are employed by the Open Source Initiative - the open source software community's most authoritative standard-setting and conformity assessment body.

2ilu See Saggi 2000, p. 2. 
natives. ${ }^{217}$ This makes labour tumover across firms a crucial factor in technology diffusion within a country. 2118

Local regulations often prohibit FDI, thus forcing foreign firms to choose licensing or joint ventures instead if they want to do business in some countries. Empirical evidence has not shown that this mode of technology transfer leads to increased learning by local firms, hence the jury is still out on this question. ${ }^{209}$ Increasingly governments adopt policies to attract FDI. If the reason for such policies rests on positive spillovers from FDI to domestic firms, then the case may be rather weak. Saggi argues that several recent plant level studies have failed to find positive spillovers from FDI to firms competing directly with subsidiaries of multinationals. In his view these studies need to be approached with care as they treat FDI as exogenous. Second, FDI spillovers may have a oertical nature rather than the horizontal nature assumed in such studies. Despite these shortcomings all such studies find that the subsidiaries of multinationals are more productive than domestic firms. However, regardless of the evidence on the spillover issue, FDI does result in a more effective use of resources in host countries.210

Saggi's study has shown that successful spillovers of the acquired technology into the host country require a certain amount of absorptive capacity to take advantage of increased trade and FDI. Without adequate human capital or investments in R\&D, spillovers from FDI are likely not to occur. This highlights the significance of countries' policies toward open trade policies, education, human capital accumulation and R\&D.2il

Crispolti and Marconi researched two chamnels of international technology transfer - FDI and trade - and scrutinised the extent to which, through these channels, R\&D expenditures, performed by advanced countries affected total factor productivity levels in developing countries over the period 1980-2000. They found that both channels induce technology transfer between countries. In addition each developing country, for a given amount of foreign R\&D, enjoys bigger spillovers the higher its educational level..$^{212}$

The spillover effect of acquired technologies is limited by the fact that developing countries do not engage in $R \& D$, or only to a small extent, resulting in little

\footnotetext{
2n Please note that when the spread of know-how across countries is concerned it is often referred to as international technology transfer and within a country as technology diffusion.

zas See Saggi 2000 , p. 5.

$2(1)$ See Saggi 2000, p. 39.

210 See Saggi 2000, p. 2.

211 See Saggi 2000, p. 39.

212 See Crispolti and Marcomi 2005.
} 
domestic technological capacity. ${ }^{213}$ Hence, developing countries are dependant on foreign technology and are technology followers. However, to really benefit from the newly acquired technology country's ability to adopt and appropriate innovations is crucial.21-4

Notably, the absorption of foreign technology depends upon the capabilities of the host country - the capital stock available to benefit from the technologies and also the level of education. ${ }^{215}$ For these reasons, understanding international technology spillovers becomes crucial in explaining economic development.

One can distinguish passive spillovers from active technological spillovers. The former generally arise through the import of more specialised capital goods from developed countries. Total factor productivity increases simply because a greater variety of specialised inputs are employed in the production process. The latter occur when innovation and learning are primarily "conscious and purposive". Local firms do not only adopt the technology but also possess the technological capability to master and eventually improve upon technologies conceived in other countries, thereby improving domestic production and inventive activity. 216 FDI is generally considered the channel through which active technology spillovers may actually occur. However it is argued that trade may also contribute to active technology spillovers: by exposing domestic firms to new products, it may help foster reverse engineering and induce innovation or imitation by the local competitors. ${ }^{217}$ Research has also show'n that what matters is not only the amount but also the quality of FDI in assessing the possibility of building upon foreign technology for domestic socio and economic advancement. 218

\section{IPRS AND INTERNATIONAL TECHINOLOGY TRANSFER}

Viewpoints on the effects of strengthened IPR on economic development are diverse ranging from outright opposition to reforming IPRs to a strong belief that by doing so innovation and growth will be encouraged. This chapter aims to better understand the relationship between IPRs and technology transfer by analysing a number of empirical and econometric studies. As this chapter will conclude the answer lies somewhere in between these two viewpoints and that the results of stronger IPRs depend on the lew of development, the socio-economic

21. There are some developing countries that perform a relatively significant R\&D expenditure, and these are normally the countries with higher human capital levels.

214 See Grossman and Helpman 1991 as referred to by Crispolti and Marconi 2005.

215 See Saggi 2000.

23" See Crispolti and Marconi 2005.

21: See Grossman and Helpman 1991 as referred to by Crispolti and Marconi 2005.

21. See Crispolti and Marconi 2005, p. 17. 
circumstances, the complementary policies andable and also the type of industry (the scotor) incoled the quality of the tedmology and the mode of tedinology transfer. Moreover it should be noted that this particular area of economic research is a fairly new area and that more empirical analysis is necessary. Economic research is restricted by insufficient or inadequate data and the results are ambiguous. ${ }^{219}$ This type of research may assist policy makers in deciding what strategies to follow in setting IPR and complementary policy reforms that help minimise costs and maximise benefits. It requires the measurement of the existence and strength of IPRs on a consistent international basis. This is difficult, since IPRs are perceived to fall into the category of general rules supporting (or hindering) the legal operation of business, along with competition policies, environmental regulations, and labour standards. And unlike taxes and tarifs, IPRs are not readily measurable. In addition, IPRs interact in complex ways with other policies (i.e. competition and investment policies) in reaching their full effectiveness and thus similar rights in different countries can have different effects because of variations in market structure and preferences.2211

The rush on IPR protection by industrial countries was based on the reasoning that strong II'Rs would contribute to economic growth, because it would: stimulate domestic innovation, enhance flows of FDI and stimulate the transfer of technology. Contesters criticise the hypothesis of the healing effect of IPR protection by expressing that there is not enough proof (economic theory or empirical evidence).221 Sell222 also argues that the industrialised countries simply have assumed a strong relationship between IPR and economic growth since it is beneficial to their own interests (to underline the need for international harmonisation of IPR). ${ }^{223}$ A group of scientists argued in an open letter to the Financial Times that social need rather than priate profits are the main driace belind innowation. In their view history shows that scientific discovery was greatly influenced by curiosity to benefit social society. ${ }^{224}$ For instance, the rapid dissemination of the mobile phone on the African continent was the result of unreliable land line services. Now multiple services are carried out via mobile telephony, including money transfer is popular. Moreover,

$21^{\circ}$ See Maskus and Penubarti 1995 and Fink and Prima Brago (1999) studies encountered the problem that the strength of intellectual property protection may be en endogenous variable. Nevertheless Fink and Primo Braga argue that the degtee of endogeneity may not be too severe if one takes into account that most IPR regimes were established before 1960 s and that the level of protection remained fairly constant until 1989-90, the years of the Fink and Primo Braga estimation. See Fink and Primo Braga 1999, p. 32.

220) See Maskus 2000, p. 87-88.

221 See Abbot 1998, p. 520 .

222 Susan Sell is Professor of Political Science and International Affairs at the Elliot School of International Affairs, George Washington University, USA.

223 See Sell 1998, p. 222.

22.4 As described in Rasiah 2003, p. 25. 
"[a]ssessments of innovation are purely subjective; what is commonplace for one scientist will be extremely novel to another. (...) Most breakthroughs in science take place not through the generation of entirely new ideas, but through the application of concepts from one field to another".2.

This also applies to the needs of developing countries in terms of accessing new technologies; "new" can also apply to technologies that are not novel in developed countries but newly introduced in developing countries.

It is now widely accepted that the stage of development is a determinant factor in whether countries will benefit to some extent from enhanced IPRs.

As discussed in chapter one on the history of IPR, the international IPR framework has undergone significant changes over the last two decades and as a consequence many developing countries were forced to radically change their domestic IPR laws to adhere to the obligations derived from the multilateral trade negotiations and other bilateral and regional trade agreements. Knowledge and resources are required to implement new rules into domestic legislation and also for understanding the potential impact of these IPR policies and rules on socio and economic development. ${ }^{226}$

\subsection{The Role of IPRs in Facilitating Tedmology Transfer}

Foreign inventors have basically three choices: 1) produce a new variety by themselves in the home country and then export it (trade flows);2) produce a new variety in a developing country and sell it in the market and abroad through a wholly owned subsidiary or through a joint venture (FDl); or3) sell the license to a firm owned by residents of a developing country.

It has been frequently argued that weak IPRs protection in a developing country negatively influences investment flows from developed countries. ${ }^{227}$ Particularly, multinational enterprises might not be willing to invest in a country with lax IPRs or only by means of wholly owned subsidiaries, in contrast to joint ventures with local partners. They would also be unwilling to enter into licensing agreements. Perhaps, they might only transfer inferior, more mature technologies. ${ }^{228}$ Differing levels of IPR protection may influence a firm's preferred mode of technology transfer in serving a foreign market: For instance a firm can decide to supply a foreign market by FDI or it may choose licensing

225 See Wiley 2008, p. 33. Published online at: <http://www.the-scientist.com/2008/ $3 / 1 / 33 / 1 />$.

22. See Fink and Maskus 2005, p. 2.

22 See sections $5.2,5.3$ and 5.4 of this chapter.

225 The United Nations, Department of Economic and Social Development, "Intellectual Property Rights and Foreign Direct Investment", NY, 1993. 
its intellectual asset to a foreign firm instead of serving a market by exports (if the level of $I P R$ is perceived as sufficient). Hence, a strong IPR system may have a further negative effect on trade flows if companies choose to serve a market through FDI or licensing.22"

Governments can only to some extent influence the transfer of technology as these transactions take place primarily between private business undertakings. However, governments can create a stimulating business environment, including supportive policies, regulations and incentives, which can facilitate or promote the transfer of technology or at least make it more attractive. It is important to achieve the right equilibrium of IPR protection: on the one hand, IPRs are a necessary tool for innovation creation and the sharing of knowledge, but on the other, they create "monopolies" making it difficult to access technology at low cost as the IPR holders are in strong market negotiation positions able of setting licensing terms and other conditions. On the other hand, strong IPRs would prevent poor countries from converting from commodity-based (agricultural) societies to industrialised once, hence blocking their development.

The patent system is an important means of knowledge creation and learning as one of the prerequisites of patent filing is the disclosure of the invention. This public disclosure of the invention is the patent trade off: in exchange for public disclosure, the inventor achieves an exclusive patent right for a certain period of time. The public disclosure ensures the public availability. A patent holder by means of his exclusive rights granted to him under the IPR framework can prohibit the unauthorised use of his patented technology and thus control (prevent) the technology transfer. Hence, the transfer of technology is hindered by the exclusive rights granted under the patent system. Patents through the obligatory disclosure of their underlying technology bring a source of technological knowledge to society. Patents are designed in such a way that restrict a company from producing a product invented and protected by another firm but not exclude the other party from using the knowledge embodied in the invention. Firms, are thus allowed to study the attributes of the product and to invent around a certain invention and subsequently develop higher quality versions of the same product.23) Hence, as soon as a product is created

224 See Fink and Primo Braga 1999, p. 21 referring to Ferrantino 1993.

$23 i$ See Saggi 2000, p. 7. 


\begin{abstract}
"knowledge needed for its production becomes available to all and such knowledge spillovers ensure that anyone can try to invent a higher quality version of the same product". 231
\end{abstract}

However, the question is whether recipients are capable of mastering the technology without assistance from the innovator. Imitation of a certain technology will not automatically lead to the assimilation and absorption of the technology. ${ }^{232}$

The realisation of smooth and rapid transfer of technology can, to a certain extent, be hindered by monopolistic behaviour of the patent holder. For instance, the patent system can be used in the wrong way, namely if firms merely acquire patents to use them to be able to sue (i.e. eliminate) the actual competitors in the same industry. Moreover, in the current economy firms use tiers of protection. For instance,

"a seed may be protected by patents, by a license contract that prohibits reuse of the harvested crop as seed, and by being a hybrid, implying that biologically it does not breed true to type".?33

A method of evaluation of a product in order to understand its functional aspects and underlying ideas is reverse engineering. This technique may be used to develop a similar (or even identical) product. Reverse engineering of computer programs is permitted under the copyright rules of the TRIPS Agreement (following procedures) but reverse engineering under patent law is not allowed. Reverse engineering is a way of learning about how a product/ technology is build up. For instance, reverse engineering of foreign products leads to lower prices for technology and it helps strengthen bargaining power in acquiring foreign technology. Access to patented technologies is also possible through subsidiaries and licensees. By these means the recipient can make legal use of patents and trademarks.

There is a common understanding that technological change is important for economic growth. Technological change is of course influenced by a number of factors of which intellectual property is one. Given that international trade is an important channel of technology transfer and that the share of knowledge-intensive or high-technology products in world trade has increased it

231 See Saggi 2000, p. 7. The model designed by Grossman and Helpman 1991 explains that firms always have an incentive to improve the quality of products since consumers are willing to pay a premium price for higher quality products. Thus, this model suggests that grow th is sustained by the fact that every successful innovation through the patent disclosure allows all firms to study the attributes of the product and then improve upon it. See Hoekman, Maskus and Saggi 2005, p. 1589-1590.

2.32 See also Fink and Maskus 2005, p. 4.

2.3 .3 Example taken from Barton 2007, p. 21. 
follows that IPRs have had a role in trade. Kanwar and Evenson argue that IPRs have become even more important as it is not the individual but the enterprise that owns the patents:

"Igliven the shift in the ownership distribution of innovations away from individuals towards large corporations in "recent decades", intellectual property protection has arguably become an even more important stimulus than hitherto; for such protection augments both the means and the incentive to undertake expensive inmovation".234

Realistically it is unlikely that firms will voluntary transfer their technology or trade their goods, incorporating their technology, if there is a chance that their products will be copied. Foremost, because products take a good number of years to develop and improve and $R \& D$ investment is high. In addition, the preparation and filing of patent applications (and in the case of pharmaceuticals the clinical trial in order to obtain exclusive marketing approval) is a long and costly process which can add a number of years before a product can be successfully put on the market. Hence, following from this line of reasoning it is unlikely that firms will go about transferring technology and selling products in countries where patent law or enforcement is weak and thus copying more likely. 235

A report issued by the UK Commission on Development 2.36 indicates that firms' investment decisions are contingent on a number of factors. 1) To a large extent developing countries (i.e. the less technologically advanced developing countries) will attract low technology industries and hence IPRs are unlikely to be an important factor in the investment decision. 2) If it is the case that the technologies involved are more sophisticated, but relatively easy to copy, then IPRs may play - though not necessarily - a significant factor in investment decisions, if the recipient country has both the scientific capacity to copy and if there is a sufficiently large market to justify the costs of patenting and enforcement (for instance in the chemical and pharmaceutical industry). 3) Studies have shown that the introduction of IPR protection has been associated with an increase in imports, but has not contributed to the investment in local production, 4) In the case of high technology industries and for countries with sophisticated technological capabilities, technology owners may choose to license their technologies, protected by the intellectual property regime, rather than invest directly in production. 5) Existing IPRs may not really have a large impact on investment flows where it is likely that other factors will play a

23 See Kanwar and Evenson 2001. This claim is supported by the following figures: in the US, the share of all patents issued to individual inventors was 91 per cent in 1901 but by the early' 1980s this had reduced to fewer than 19 per cent. Scherer and Ross (1990) referenced in Kanwar and Evenson 2001.

235 See Branstetter 2005, p. 8 .

23t See the conclusion of the UK CIPR Report 2002. 
larger role (i.e. geographical destination, 2.37 size of country, security, transparency and infrastructure). IPR protection can, however, facilitate technology transfer under licensing and stimulate trade. ${ }^{238}$

\subsection{Sector Specificity of the Role of IPRS}

Mansfield2" studies indicates that in relatively high-technology' industries like chemicals, pharmaceuticals, machinery, and electrical equipment, a country's system of IPR protection often has a significant effect on the amount and kinds of technology transfer and direct investment directed to that country. The study indicates that the type of industry (the sector) matters when deciding what influence IPR protection plays as well as what type of activity (e.g. R\&D, assembly or sales activities). For instance, in the chemical and pharmaceutical industry over 80 per cent of the IPR managers found the strength or weakness of $I P$ protection to be important with regard to investments in $R \& D$ facilities, but only 20 per cent said it was important with regard to sales and distribution outlets. For investment in rudimentary production ${ }^{2+4}$ and assembly facilities about 30 per cent said that such protection was important. For investment in facilities to manufacture components or complete products, about 50 to 60 per cent said it was important. 241 For all types of investments other than in sales and distribution outlets, the chemical industry (including the pharmaceutical industry) has the largest percentage of firms regarding IPR protection as important, followed by the electrical equipment, metals, and machinery indus-

23- Geographical destination is also regarded as important as IP reform in Mexico was seen as more significant to US firms than recent changes in IP law in the Republic of Korea, Taiwan and China. See Mansfield 1994, p. 22.

2is See the UK CIPR Report 2002, p. 23-24.

239) Edwin Mansfield was a Professor of Economics at University of Pennsylvania, USA.

2:0 Rudimentary production and assembly facilities are ones involving basic technologies that are reasonably well known to all firms in the relevant industry.

241 Mansfield study addressed Japanese, US and German firms. See Mansfield 1995 and Mansfield 1994. Mansfield conducted interviews with managers of major companies. A manager of a major Japanese chemical and pharmaceutical company responded to the question if IP protection plays a role in the transfer of high technology goods as follows: "Transfer of top-grade technology is possible only to the subsidiaries on the following three terms and conditions: 1) the majority of which stocks we own; 2) to which we may dispatch key persons and; 3) which may fully control technology of production disclosed and/or transferred by us. However, even in this case we have difficulty in controlling a "trade secret". We are not willing to transfer the top-grade technology to such developing countries as being weak on their system of patent and trade secret protection. Therefore, as an inevitable consequence, the amount of investment by us becomes small and we are obliged to expand our investment little by little while taking in the situation in such countries". See Mansficld 1995, p. 25. 
tries. IPR protection matters the least for the food and transportation equipment industries. ${ }^{2+2}$

\subsection{IPRs and Type of Tedmolog!y}

The research carried out by Mansfield found that the strength or weakness of an $I P R$ regime influences investment in joint ventures where they contributed adranced tedmology, especially in the chemicals and pharmaceutical industries and to a lesser extent in the machinery and electrical equipment industries. In all three countries addressed by Mansfield - US, Germany and Japan - it was found that if IPR levels of protection are perceived as low, they impact business decisions on whether to transfer the newest or most effective technology to wholly-owned subsidiaries. Also, in relation to licensing their technology, firms were reluctant to transfer their newest or most effective technology to unrelated firms in cases where the level of IPR protection was weak. This was true for the chemical and phamaceutical industry but to a much lesser extent for the machinery and electrical equipment sector. Mansfield's studies also indicate that countries laws protect different industries in different ways. In addition the competence and aggressiveness of one country's firms may differ from industry to industry:

"there is often little correlation between one industry's evaluation of the strength or weakness of intellectual property rights protection in a particular country and another industry's evaluation of the same country".2+3

For instance, in some industries, such as metals and transportation equipment, it is relatively difficult to copy a firm's technology without many expensive and complex complementary inputs, while in the pharmaceutical industry it is relatively easy for local firms to imitate an innovator's new products. Mansfield argues that research intensive firms, with products or processes that are relatively easy to imitate, are more reluctant to make substantial investments or transfer advanced technology to countries with weak IP protection. Nonetheless, most of the firms addressed (especially the ones outside the chemical industry), asserted that IP is only one of a number of factors, influencing their investment decision. A firm with limited R\&D investment per-

242 Sec Mansficld 1994, p. 22.

243 For example, in chemicals and pharmaceuticals, US firms are more likely to regard protection in the developing countries addressed too weak to permit FDI and the transfer of their most advanced technology than Japanese firms. However, in the machinery and electrical equipment industry there is hardly any difference between US and Japan in this regard. This can be explained by arguing that Japan is a world leader in machinery and electrical equipment but not as strong in the chemical and pharmaceutical industry. See Mansfield 1995, p. 21. 
ceives IP to be relatively unimportant. 244 IP is regarded as more important in decisions relating to the transfer of advanced technology than in investment decisions. Many chemical industries are reluctant to transfer relatively new or advanced technology to anything other than wholly owned subsidiaries. Hence, for this industry if IPR protection is perceived as weak, it is most likely that investment in wholly owned subsidiaries is devoted to sales and distribution outlets or to rudimentary production and assembly facilities and not too R\&D.

A potential benefit of the strengthening of IPRS is that such protection may induce foreign firms to produce and sell technologically advanced goods in the IPR reforming country. This was reaffirmed in interviews with multinational managers who have expressed that technology transfer within multinational firms is sensitive to the perceived strength of IPR protection. 245 In Lee and Mansfield's research, managers expressed that they generally songht to awoid the transfer of strategially sensition techology to unaffliated parties, regardless of the percioed strength of the IPR regime.2th

\subsection{IPRs and lmontion (RED)}

How can we measure the impact of IPRs on a country's innovation level? One common way of doing this is by looking at the statistics gathered by IP offices on the number of tratemarks and patents filed over a period of time in a country by residents, as opposed to non-residents as well as the effects of IPR reform on these figures. An important limitation is that this approach does not take account of other types of 1PRs, such as copyright, trade secrets, geographical indications, know-how, database or research data compilations. The number of patents registered does however provide a rough indication on the importance attached to innovation and the role local creation and innovation plays within a certain territory. ${ }^{247}$ Statistics on licensing as an activity is another way of measuring the use of IPR but this information is not easy to obtain as licensing is primarily a private activity. The difficulty comes from the fact that patent offices are mainly concerned with the filing and granting of applications and trademark offices register trademarks but do not interfere with, or obtain information on licensing practises.

Although traditionally it has been believed that more patents equates to more innovation this can no longer be presumed. The number of patents has indeed increased but this has not automatically led to an increase in the level of

244 See Mansfield 1994 and Mansfield 1995.

245 For instance Mansfield 1994, and Lee and Mansfield 1996.

24. See Lee and Mansfield 1996.

2ti See Yap 2006, p. 8. See also WIPO Patent Report, Statistics on Worldwide Patent Activity 1, 4 (2006), <http://www.wipo.int/ipstats $>$. 
innovation. 24 Hence the link between strong IPR protection (both in terms of law and enforcement) and innovation and investment has to be approached with care. ${ }^{2+4}$

Kanwar and Evenson (2001) study the factors behind technological change and their prime research question was whether a regime of stronger intellectual property protection encourages innovation. ${ }^{251}$ They concluded that the existence of intellectual property rights provides a stimulus for innovation. Their research looks for an empirical relation between the protection of IPRs (proxied by an index of patent rights) and technological change (proxied by R\&D investment expenditure). They found that the former encourages the latter insofar as II' protection was found to have a strong positive association with R\&D investment. Nonetheless they admit that the results would have been more pronounced if they had had reliable, quantifiable evidence on the implementation of IPR protection across countries, because many developing countries have strong protection of laws on paper, but are weak in enforcement. Their study also shows that relatively educated countries, coteris paribus, invest significantly more in R\&D. They also established that the strength of IPR is positively associated with R\&D. Hence, they found that countries with strong IPR protection tended to have larger proportions of their GDP devoted to $R \& D .{ }^{251}$ They argue that their research results provide some evidence for developing countries that adherence to the TRIPS Agreement, may be important to them in the long rmo. However, they stress that the strengthening of the laws in the statute books should be reflected in practice through effective enforcement. 252

2+4: A report prepared for the Council on Foreign Relations (non-partisan think tank on foreign policy and America's role in the world) called for a reform of the US patent system. The report sets out that although the number of US patents has increased there was no available evidence that enhanced patent protection did stimulate innovation. The report concluded that expect for the pharmaceutical, biotechnology' and machinery industry, inventing firms did not view patents as crucial for their technology investment decisions. See Kamperman Sanders 2007a quoting Maskus, CSR No. 19, "Council on Foreign Relations, Reforming US Patent Policy, Getting the Incentives Right", p. 15-16, available at <http://www.cfrorg/content/publication s/attachments/PatentsCSR.pdt>.

2.4" Fink and Maskus argued that neither strong IPR, nor bilateral investment or free trade agreements automatically yield an increase in technology transfer and FDI. Moreover, countries with weak IPR protection such as China and Brazil have been able to attract more FDI than countries that made IPRs part of their development goals - such as some Sub-Saharan African countries. Maskus 2005.

2ñl To examine this question they use country panel data on R\&D investment, patent protection and other country-specific characteristics. See Kanwar and Evenson 2001.

$2 \pi$ See Kanwar and Evenson 2001, p. 18.

252 See Kanwar and Evenson 2001. 
Higino Schneider ${ }^{253}$ has also examined the role of high-technology trade, IPRs and $\mathrm{FDI}$ in determining a countrys rate of innovation and economic growth. Her study reveals that 1) high-technology imports are relevant in explaining domestic innovation both in developed and developing countries; 2) foreign technology has a stronger impact on per capita CDP growth than domestic technology; 3) IPRs affect the innovation rate, but this impact is more significant for developed countries; 4 ) the results regarding FDI are inconclusive.

Little information is available on the impact of national economic activities or national research priorities on the amount of innovation (or patent filing). However, it is important that governments adopt policies which help companies convert their intellectual assets into financial capital. For instance a government can develop a system in which projects are funded to stimulate a certain segment of industry: for instance the electronic sector. See paragraph 4.5 of this chapter on labour as a mode of technology transfer

Research has prompted the question as to what extent the Southeast Asian nations (ASEAN) $)^{25.4}$ use intellectual property as a tool for development. They found that the majority of countries in ASEAN have only made limited use of intellectual property rights as an economic development tool. The study indicates that

"[t] there is very little, if any use of IP for technology collaboration and development, raising finance, licensing and technology transfer where a lot of the value of IP lies locked up". 255

Myanmar, Cambodia, Laos and, to a lesser extent, Vietnam and Thailand face language barriers which affect communication with potential technology partners (even within ASEAN) and lack of access to IPR information in the local language hinders the utilisation, understanding and development of intellectual property concepts. Some countries do not even have local intellectual property administration systems in place, like Myanmar, Cambodia and Laos. Foremost, the study concludes that ASEAN countries are in need of understanding and awareness (also at inventor/manager level) of IPR concepts and need ample time to adopt these concepts to local development needs. The ASEAN Secretariat in participation with the German Federal government are currently involved in a joint project to increase capacity building for the ASEAN Secretariat in relation to IPRs. In particular the project aims to build up regional institutional capability within the ASEAN Secretariat for effective

25. See Higino Schneider 2005, p. 529-547.

254 ASEAN includes, Brunci Darussalam, Cambodia, Indonesia, Lao PDR, Malaysia, Myanmar, the Philippines, Singapore, Thailand and Vietnam.

255 See Yap 2006, p. 11. 
and timely implementation of the ASEAN Community Blueprint (AEC Blueprint) 25,

Park and Lippoldt (20)8) find that developing country patent applications (by both residents and non-residents) and expenditure on $R \& D$ (as a percentage of GDP) tend to have a positive and significant relationship to the strength of patent rights. Moreover, imports of goods and services and FDI inflows are also significantly and positively associated with non-resident patenting in developing countries. This association suggests that foreign imports and FDI contain patentable technological assets for which non-residents have a vested interest in seeking protection. ${ }^{277}$ Thus, stronger patent rights in developing countries appear to have the potential not only to stimulate international technology transfer but also to provide incentives for foreigners to transfer new technologies.

In the BRIC countries, technology transfer via trade flows and FDI has been one important input (among other factors) into developing local technological capabilities and thus stimulating economic growth. The study qualifies that IPRs do not operate in a vacuum. There are complementary factors that help facilitate technology transfer, such as the quality of infrastructure, government policies and regulations, size of country, market structure, and complementary factors that help facilitate innovation, such as the quality of research institutions and the extent of collaboration among different research organisations. There are complex interactions to account for between innovative or absorptive capacities and intellectual property systems. ${ }^{258}$ This is affirmed by Higino Schneider who concluded that the rate of innovation is determined by market size, high-technology imports from developed countries, the stock of human capital, the level of $R \& D$ expenditure, infrastructure and the level of IPR protection

27n The ASEAN Economic Community Blueprint was endorsed by ASEAN leaders in November 2007, establishing a roadmap for transforming ASEAN into a single market and production base. In November 2004 the ASEAN IPIR Action Plan 20042010 was endorsed placing IPRs in the context of integrated social, economic and technological development. The ASEAN Secretariat has to implement the IPR Action Plan, the Copyright Cooperation Plan and the AEC Blueprint. Aim of the joint project is to explain the nature of EU proposals and provide a range of options to the ASEAN Secretariat with respect to their negotiation and, if desired, possible future implementation. It will further make observations with respect to the negotiations and propose strategies for the future with the ultimate aim to ensure coordination and coherence of AMSs' IP positions in FTA negotiations, taking into account their multilateral negotiations and commitments.

25 See Park and Lippoldt 2008.

2si See Park and Lippoldt p. 5. 
Copyright and trademark protection rights are less strongly associated with technology transfer than patents, and hence strengthening these rights has less of an impact on FDI. Nonetheless in some sectors, in particular the software industry, copyright protection may be more of a decisive factor due to it being the only legal means of protecting an intellectual property asset (e.g. in the EU computer programs are not patentable but may be protected under copyright law's).

Park and Lippoldt (2008) found that the quality of research institutions is important for resident patenting but university-industry collaboration is not a statistically significant determinant. The latter collaboration may be more important in the R\&D stage where firms and academia can collaborate on basic, foundational research. At the patenting stage, firms may want to keep commercial successes proprietarily and rely less on collaboration with academia. In most countries the US Bayh-Dole type of law does not exist (encouraging publicly funded university research to be patentable). ${ }^{259}$

Patent protection is a statistically significant determinant of patent applications filed by residents. Moreover, each of the modes of technology transfer, inward FDI, merchandise imports and service imports, is also a significant determinant of resident patenting when considered individually. Park and Lippoldt (2008) found that when all three modes are considered jointly, merchandise imports dominate. Imports of equipment and materials may help to stimulate $R \& D$, and if increased $R \& D$ results in increased innovative outputs for which local residents file for patent protection, increased resident patenting will be positively associated with merchandise imports. ${ }^{2(6)}$

Research has shown that "foreign technology (measured as the growth of per capita high-technology imports) has a stronger impact on per capita GDP growth than domestic technology". ${ }^{261}$ Different elements play a role to explain innovation in developing countries and developed countries:

\begin{abstract}
"Market size and infrastructure are the dominant factors in explaining innovation in developing countries; while high-technology imports, human capital, and R\&D expenditures appear to have a stronger impact on developed countries. (...) They suggest that IPRs have a stronger impact on domestic innovation for developed countries and might even negatively impact
\end{abstract}

25\% The Bayh-Dole Act or also referred to as University and Small Business Patent Procedures Act has been part of United States legislation from 1980. Among other things, it gave US universities, small businesses and non-profits intellectual property control of their inventions that resulted from federal government-funded research. The act, sponsored by two senators, Birch Bayh of Indiana and Bob Dole of Kansas, was enacted by the United States Congress on 12 December 1980.

2til) See Park and Lippoldt 2008, p. 24.

2n. See Higino Schneider 2005, p. 22. 
innovation in developing countries. These results may be indicative of the fact that most innovation in developing countries may actually be imitation or adaptive in nature. Therefore, providing stronger Iliks protects foreign firms at the expense of local firms. The policy implication here is not to discourage intellectual property protection in developing countries, but to generate incentives for its strengthening |so that IPRs benefit the local economy and not only foreign intermationals]. Innovative activities and IPISs are complementary in nature fone strengthens the other]; thercfore, developed countries would bemefit by supporting R\&D activities in developing countries". $2 n 2$

\subsection{IPRS and level of Dewelopment}

Research has shown that as developing countries get technologically advanced they will also need access to more sophisticated, superior technologies. Developed countries provide stronger IPR protection than developing countries. 20.3 Research by Ginarte and Park has shown that the underlying factors which influence patent protection levels are the country's level of R\&D activity, market environment, and international integration, which are correlated with its level of development. The research demonstrated that $R \& D$ activity influences patent protection levels after a nation's research sector reaches a critical size. An implication of this is that to raise patent protection levels in countries with lax IPRs, it is important to foster a significant research base in those countries and thereby create incentives for protecting patent rights. 20 .

Unsurprisingly, techmology which is still developing and improving is more difficult to obtain than more mature technologies. Calls for more advanced technology, once a country reaches a certain threshold level of development, may result in internal and external pressure to increase levels of IPR protection, especially patent protection. 265 The UNTAD salmon case study2tot has indicated that:

"In the early stages of industrial development, countries can rely on imported technology and simple modifications, but success may depend upon local

2n.2 See Higino Schneider 2005, p. 22.

20.3 Rasiah distinguishes three groups of developing countries:

1) the new industrialised economies (NIEs), in which a high tech infrastructure is at hand to meet the demands of the TRIPS Agreement;

2) the second-tier NIEs, being economies which are slowly going up but the high tech infrastructure has not yet been installed to that extend that they can actively participate in the TRIPS Agreement;

3) the third group exists of the LDC's, including the non-European transitional and communist economies and the poorest developing economies. See Rasiah 2003, p. 44.

2n- See Ginarte and Park 1997, conclusion.

$2 t 5$ See Cortea 1999, p. 12.

2 th See UNCTAD 2006. 
capacity to assimilate foreign technology as well as to upgrade and adapt it to local needs and the focal environment. This may involve 'learning by doing' or 'trial and error'. (...)All countries borrow idteas and information from others that have more advanced knowledge in the field of interest in order to quickly raise their technological standards. Countries use public scientific and technological institutions to acquire, adapt and diffuse technologies in the early stages. As the industry develops, complex relationships develop between knowledge developer, specialised technology suppliers, marketing agents and distributors. At this stage, technology is needed not only to boost productivity but also to meet the demands of distribution channels and international markets". 20 "

According to Fink and Maskus the capacity to absorb technology matters is important in determining how influential the role of IPRs is in establishing economic growth:

\begin{abstract}
"A weak IPR regime might allow domestic firms to imitate foreign technologies and thereby contribute to economy wide productivity and income grow th. That perspective assumes, however, that firms can master all components of new technologies, including both codified knowledge and know-how without the participation of foreign intellectual property holders. If that were not the case, stronger lPRs could be better suited to promoting technology diffusion, by enhancing access to knowledge-intensive foreign inputs and promoting formal technology transfer through joint ventures and licensing agreements". 21,
\end{abstract}

Park and Lippoldt (2008) have shown a positive association between patent rights and technology transfer, and that this association is not qualitatively different across different income groups of countries. ${ }^{269}$

Falvey and Foster argue that in the long run stronger IPR protection can reap rewards in terms of greater domestic innovation and increased technology diffusion in developing countries with sufficient capacity to innovate. However, it has little impact on innovation and diffusion in those developing countries without such capacity and in fact may impose additional costs. There is a considerable incentive, therefore, for countries at different stages of development to use the flexibilities in the TRIPS Agreement to maximise its net benefits for their development. ${ }^{270}$

Hence, the level of development of a particular country should be a factor taken into consideration while deciding on the appropriate level of IPR legislation.

2n: See UNCTAD 2006, p. 3.

2ow See Fink and Maskus 2005, p. 4.

20,4 See Park and Lippoldt 2008.

27i) See Falvey and Foster 2006. 
The impact of IPR protection on growth, innovation and technology diffusion in developing countries is likely to depend upon a number of factors. While stronger IIR protection in the poorest countries is not likely to lead to substantial benefits in terms of innovation or technology diffusion, the administrative cost of developing a patent system and the enforcement of TRIPS, along with the potential abuses of market power in small closed markets suggests that such countries could loose out from TRIPS. Stronger IPR protection in the poorest countries may also inhibit or lengthen the imitative stage of development that seems to be necessary in order to develop innovative capacity in many industries. Policies aimed at improving the business environment and encouraging imports of technology embodied in goods could potentially reduce such costs, though their impact on other development-related goals needs to be carefully weighted. In middle developing countries the potential for bencfits from TRIPS is stronger. Here existing firms engaging in imitation could be encouraged through stronger II'R protection to shift resources towards adaptive innovation, and stronger IPR protection is likely to increase trade and FDI flows into countries with existing initative ability, thus enhancing technology transfer. Policies to enhance the benefits of TRIPS would help develop the domestic innovative sector through encouraging R\&D and investment in education, along with policies aimed at opening markets to foreign imports and encouraging inward FDI.

Mansfield concluded that multinational corporations - in determining whether or not a country's system of IPRs protection is too weak - have a particular interest in three questions: 1) Can the country's laws protect their technology? (For instance, some countries do not allow chemical or drug products to be patented); 2) Is there an adequate legal infrastructure in the country? (many developing countries contain few patent attomeys or other specialists in this area of expertise); 3) Do the relevant government agencies in the country enforce the laws and provide prompt and equitable treatment to foreign firms? $?^{271}$

Foray ${ }^{272}$ argues that in the case of the least developed countries (LDCs):

\footnotetext{
"the number, scale and domains of [technology transfers] cannot be left to depend on general economic operations such as foreign direct investment or infrastructure construction; neither can they take the form of market transactions alone (licenses). In alt these cases, the particular circumstances and
}

271 See Mansfield 1994, p. 12.

2i2 Dominique Foray is Professor of Economics of Innovation, Ecole Polytechnique Federale de Lausame, Switzerland. 
conditions prevailing in LDCs imply a suboptimal level of ftechnology transfer] in relation to the needs of these countries".223

Hence he argues that we can not leave it to general economic operations, such as FDI or infrastructure construction or market transactions such as licenses instead the transfer of technology has to be specifically directed to and tailormade to the needs of these very poor countries. He argues that preferably the focus should be on projects in which the technology transfer is the primary product but entails a very low expected prizate profitability for the ted nology-ononing firm. Clearly this form of technology transfer where commercial returns are small, if at all, requires additional incentioes within the framework of publicprivate partnerships. Hence, the focus should be on projects that are socially beneficial but not very profitable for the firms that own, and are in a position to transfer, technology. In other words attention should be on projects that under general ecomomic operations would not thke place - hence, semi-humanitarian projects. ${ }^{27.4}$

This view is shared by Maskus, who also argues that there are inherent shortcomings in markets for techmology that justify public intervention. ${ }^{275}$ He views intellectual property as one form of intervention which can support international technology transfer but also can create market power. He refers to empirical research that suggests that enforceable patents can increase inward flows of international technology transfer in middle-income and large developing countries but probably have little impact in the least-developed countries. As a consequence, the TRIPS Agreement by itself will have little impact on technology acquisition for poor countries. ${ }^{276}$

Hence, we can conclude that different levels of industrialisation within society have different needs in respect to IPR protection, which in turn leads to different results regarding technology transfer and economic growth.

\subsubsection{Market Failure Problems}

Markets within which international technology transfer takes place are subject to at least three problems. The first is asymmetric information, meaning that, technology suppliers camnot fully reveal their knowledge without destroying the basis for trade, while buyers cannot fully determine the value of the infor-

27. See Foray, fortheoming 2009, p. 52.

$2 \pi$ See Foray, forthcoming 2009, conclusion.

25 See Maskus 2004, p. 15.

$2 \pi$ See section 5.5.1 of this chapter for a discussion on the role of government intervention in establishing successful technology transfer. 
mation before buying it. ${ }^{27}$ This problem can lead to large transaction costs and stifle techmology flows. Moreover, the enforcement of contracts involving parties from different countries will be difficult. In addition, owners of new technologies typically have substantial market power resulting from lead time and IPR. Hence, the price of technology will exceed its marginal cost. A third problem is that

\begin{abstract}
"externalities arise if the costs and benefits of technology exchange are not internalised by participants (Saggi 20(04). A major share of benefits to recipient countries of [international techology transfer] is likely to arise from uncompensated spillovers, wherein technological information is diffused into the wider economy and the technology provider cannot extract the associated economic value". 278
\end{abstract}

Similarly Maskus argues that "markets for exchanging technologies are inherently subject to failure due to appropriability problems, spillovers, asymmetric information, and market power".779 For this reason he sees a strong case for public intervention to provide incentives to private agents to engage in international technology but he also sees the difficulties in achieving this. For instance, technology developers take interest in:

"reducing the costs and uncertainly of making transfers, along with protecting their rights to profit from such transfers (...) [and] argue that effective protection and policy supports for markets are necessary to increase the willingness of innovative firms to provide knowledge of their production processes to firms in developing countries".

But, in contrast, technology importers are interested in

"acquiring knowledge at minimal cost (...) [and it is argued] that this objective is best met by refusing to protect the rights of foreign firms to profit from such transfers, or at least to restrict sharply their exclusive rights to exploit technology".2*io

It is the task of governments to provide supportive policies to limit the effects of market failure and to increase welfare for society at large but Hoekman realises this is a difficult task. He says policies should focus on:

2 See chapter four, section 2.2. of this book on the information theory and market failure.

27s See Hoekman, Maskus and Saggi 2005, p. 1590.

27 See Maskus 2004, p. 1.

2wi) See Maskus 2004, p. 1. 
1) increasing access of local buyers to the existing international stock of knowledge and improving the ability of technology owners to indicate the real value of their inventions to buyers;

2) reducing the costs of acquiring and absorbing existing technologies;

3) increasing incentives for domestic innovation. ${ }^{281}$

\subsubsection{IPRs and Development: The Case of Korea}

It is also evident that an advanced system of IPR protection has a counter effect at the early stages of industrialisation. This is demonstrated by a study carried out by Linsu Kim who verified that under high levels of intellectual property protection, few countries are likely to emerge as newly industrialising economies. ${ }^{282}$

During the 1960s and 1970s Korea was in the mature technology stage in which they acquired, assimilated, and improved generally available mature foreign techmology through duplicative imitntion. The intermediate technology stage was reached in the 1980s and 1990s through aggressive efforts to strengthen technological capabilities focussing on crentioe imitation, possible because of very lax IPRs. As a result of this process Korean firms mastered the manufacturing of low-cost products. The next step was to upgrade their indigenous capabilities and start producing more value-added products enabling the increase in local wages and to respond to emerging competitive threats in the labour intensive production from the second-tier developing countries. Hence the focus shifted from labour-intensive mature technologies to more knowledge-intensive intermediate technologies across all the sectors. Policies were amended to attract foreign technology transfer through formal mechanisms, e.g. the recruitment of foreign personnel to stimulate local $R \& D$ efforts; and the investment in upgrading university research and diversifying research. 28.3

Notably patent right holders were not strict on controlling duplicative imitation of mature technology as this technology was not responsible for their competitive edge. ${ }^{2 s ;}$ In contrast, technologies at the intermediate stage were a lot more complex and difficult to acquire, absorb and adopt. Foreign patent owners did control the technologies in the "intermediate stage" since these technologies still played an important role in expanding their international business activities and ensuring their competitiveness".285 For these reasons Korean corporations could not follow the route of informal mechanisms (such

2si See Hoekman, Maskus and Saggi 2005, p. 1590.

252 See Linsu 2003.

22.3. See Linsu 2003, p. 21.

$28+$ See Linsu 2003, p. 3.

255 See Linsu 2003, p. 3. 
as duplicative imitation) anymore and had to convert to more formal mechanisms to acquire new technologies such as FDI and foreign licensing. ${ }^{25 t}$. This is shown by the patent statistics that show an upwards line, also local patent registration increased enormously.2.27

Over the years $R \& D$ expenditure shifted from the public sector to the private sector due to enlarged international competition and through a supportive policy environment.

Only a few of all the operating multinational corporations have established R\&D centres in Korea. These centres are of a rather small nature and intended mainly fo adapt the foreign products to local maket needs. This is a common practice for most $R \& D$ centres of multinational corporations in developing countries. Also, govermment research institutions played a big role in strengthening the bargaining power of local enterprises in acquiring sophisticated foreign technologies (on favourable terms or through self learning). ${ }^{2 k 8}$

Koreans register extensively patents across borders. Examples of successful Korean firms are Samsung Electronics and LG electronics. The electronics business flourished as did the pharmaceutical industry. Initially small local pharmaceutical firms entered the market as importers/dealers of packaged finished drugs, gradually changing their activities to that of formulating imported raw materials. By applying reverse engineering it was possible to gradually develop into larger sized companies capable of producing chemical compounds. This process was accompanied by adopting a regime of IPRs in line with their socio-economic needs as Korea provided protection only for process patents but not for product patents in the chemical, cosmetics, and pharmaceutical industries. Importantly, these favourable IPR policies allowed local producers to work around patented processes and to produce chemical

2w, The statistics show a booming change in FDI, licensing and capital goods import. For instance, FDl increased from 218 million dollar during 1967-1971 to 1.76 billion dollar in 1982-1986. Moreover, R\&D expenditure increased from 26.6 million dollar in 1971 to 12.2 billion dollar in 2000 making it one of the fastest growing economies in the world.

2s: "Production at this stage is merely an assembly operation of foreign inputs to produce fairly standard, undifferentiated products. Once the acquisition task is accomplished, production and product design technologies are quickly diffused within the country. Increasing competition from new entrants spurs indigenous technical efforts in the assimilation of foreign technologies to produce slightly differentiated products. The relatively successful assimilation of imported technology and increased emphasis upon export promotion, together with the enhanced capability of local scientific and engineering personnel, lead to the gradual improvement of mature technology. Technological emphasis during this stage is duplicative imitation, producing knockoffs and clones". See Linsu 2003, p. 24.

$2 s s$ See Linsu 2003, p. 24. 
and pharmaceutical products. It is argued that without these lax IPRs the pharmaceutical companies could not have reached their current level where they are capable of undertaking $R \& D$ activities and developing new drug compounds. 2 sy

This case study on the development of Korea teaches us the following lessons: 1) strong IPR protection will hinder rather than facilitate technology transfer and indigenous learning in the "early stage of industrialisation" when learning takes place through reverse engineering and duplication imitation of mature foreign products; 2) only after countries have accumulated sufficient indigenous capabilities with extensive science and technology infrastructure to undertake creative imitation does the protection of IPR become an important element in technology transfer and industrial activities; 3) if adequate protection and enforcement of IPRs is genumely intended to enhance development, policy makers should seriously consider differentiation in terms of the level of economic development and industrial sectors; 4) developing countries should cooperate to change current trends towards a standardised all-encompassing multilateral IPR system. They should try to make IPR policies more favourable to them in the short-term. But they should also strengthen their own absorptive capacity for a long-term solution. Focussing on building creative and imovative capability will also make developing countries them less dependent on foreign technologies in the future.

A number of East Asian economies, like Thailand, Malaysia, Indonesia, Vietnam, and the Philippines are at this mature technology stage undertaking duplicative imitation of existing foreign products with cheap labour forces. According to Kim, coastal China and the East European countries will most likely not follow the same route since they already have a history of technological accumulation and had reached the duplicative imitation stage before they opened their economies. So it is likely that they will enter the intermediate technology stage at the outset or alternatively they could move quickly from mature technology stage to the intermediate technology stage. ${ }^{200}$

\subsubsection{IPRs and Development: The Case of Thailand}

Thailand has been successful in building up an internationally competitive electronics industry and in integrating itself into the global economy. Thailand

2ni) See Linsu 2003, p. 5.

2\%) Although one can argue that this is to some extent a wrong thesis: currently a lot of IPR litigation is going on, as China is imitating everything from cars and autobuses to bags and watches. See among others: "Man zieht in China vor Gericht", A. Lorenz, Spiegel Online, 19 October 2006, Peking and "Chinesen kopieren den Smart", Spiegel Online, 12 October 2006. Published online at: <http://www. spiegel.de/wirtschaft/0,1518,443522,00.html>. 
shifted from an "import-substitution" to an "export-oriented" development strategy. ${ }^{201}$ This required liberalisation of the economy to promote trade and investments. The industry has required most of its technology trough foreign direct investment and trade flows. Pro-active government policies to create an enabling environment included low tariffs for imports needed to produce electronic export units, loosening of controls on foreign ownership of firms and provision of essential infrastructure. ${ }^{2 / 2}$ These liberal economic policies, coupled with the availability of a skilled but low-cost labour force, made Thailand an important location for export-oriented production activities of transmational corporations (TNCs). Government Policies induced industries to move production bases to the rural areas through tax incentives and provisions of support infrastructure and into sectors of importance, such as agriculture and electronics. Although being a major exporter of hard disk drives, the industry's activities are largely limited to assembly operations in the field of computers, computer parts and integrated circuits. These are indications of growing manufacturing capabilities, but the design and product development skills remain low. Thai domestic firms are largely subontractors of TNC affiliates. ${ }^{293}$ In an attempt to change this pattern - to move from being a contractor to a original equipment manufacturer - the government has adopted policies to promote the attraction of technology transfer, its diffusion and local innovation in an attempt to upgrade foreign technologies and promoting novel product development: $2^{294}$

"The Thai electronics industry started with the assembly of low-technology" consumer products and has steadily developed into assembly and manufacture of high-technology products. In the early stages, the industry mainly acquired

$2 \times 1$ See UNCTAD 2005a, p. 27.

2"? See UNCTAD 2005a.

24: The UNCTAD study shows that the production of electronic goods may be divided into three major stages that can be performed separately: "design, manufacture and assembly. The design stage requires extensive and intensive technical knowledge, and investment in R\&D to develop novel products and processes, while the manufacturing of components requires capital-intensive investment for mass production. Finally, the assembly of the final products is capital - and labour-intensive and requires lower skills than the other stages of production". UNCTAD 2005a, p. 19.

20.4 For instance, "The Government created several initiatives to promote technology transfer, diffusion and innovation. The National Science and Technology Development Agency (NSTDA) established the Industrial Consultancy Services in 1992 to promote the use of local and foreign technical consultants and facilitate the formation of alliances. NSTDA set up the Software Park Thailand (SPT) to promote innovation and facilitate development of start-up firms. Furthermore the Board of Investment also development the Unit for Industrial Linkage Development (BUILD) programme to encourage the development of support industries, strengthen linkages and help small and medium-sized contract manufacturers improve their productivity and facilitate cooperation between foreign and domestic firms". UNCTAD 2005a, p. 27. 
technology to assemble household consumer products such as radios and television. Since the 1980s, it has required more complex technologies to assemble advanced electronic products such as $\mathrm{PCB}$, microwave isolators, floppy disk drives (FDD) and hard disk drives (HDD). This achievement reflects the fact that the industry has acquired the capacity to source, adapt and operate foreign technologies as well as the capacity to upgrade and improve assembly processes. Manufacture and design capabilities remain limited to a few subsectors. For instance, the HDD sub-sector has acquired strong manufacturing capabilities. Some of the major HDD producers have manufacturing facilities in Thailand. However, the Thai HDD firms have not yet acquired research and product development capabilities. The TNCS perform most of the design and product derelopment actioitie's outside Thailant". ${ }^{20 \%}$ (emphasis added FC)

Policies were also directed to IPRs, especially to meet the wishes of the electronics industry and provide an attractive FDI destination. Thailand enacted its Patent Law in 1979, it introduced protection for the protection of integrated circuits designs in 2000, it revised its copyright laws (in 1995) to meet the demands of the TRIPS Agreement and to protect software. ${ }^{206}$ However, despite these efforts the study indicates that the IPR reform has not brought greater technology development, transfer and diffusion. However, in the case of Thailand, the protection of IPR has probably encouraged enhanced FDI and trade flows. ${ }^{297}$ The UNCTAD study shows that some firms have developed as partners of MNEs as suppliers and/or distributors. This is a point of interest as the Thai electronic firms seem to have in common that they become suppliers of components or provide manufacturing services to MNEs and they do not compete with MNEs but are rather complementary. However, some MNEs provide technical assistance to Thai electronics firms, and obviously this training support would not have been possible if the firms were competing. ${ }^{298}$ In Thailand MNEs have played a major role in the transfer of technologies by setting up facilities to assemble and manufacture electronic products. MNEs have enabled local employees to learn process technologies, mainly how to operate and maintain production equipment. The transferred technologies mainly relate to assembly processes and in some cases to manufacturing. Not many cases of transfer of design and product development skills in Thailand. The technologies and skills transferred largely remained within the production networks of MNEs, with limited diffusion to some

245 See UNCTAD 2005a, p. 19.

2w, For the electronics industry, the need to protect designs of electronic systems is very important, the development of a new layout design of an integrated circuit requires substantial investment but it can casily be copied and built using components that are readily available in the market place. Software development is important in the electronics industry and requires substantial investment, but software is relatively easy to copy and reproduce. See UNCTAD 2005a, p. 27.

207 See UNCTAD 2005a, p. 9.

$24:$ See UNCTAD 2005a, p. 27. 
domestic suppliers and subcontractors. Thailand's electronics industry remained dependent on imports for the majority of high-tech components. ${ }^{299}$

Hence, this study shows the importance of the acquisition and adaptation of foreign technology for competitive advantage and focussing on particular sectors (in this case the electronic industry) instead of being moderate in many. In addition, it is important to adapt domestic policies to align with the rapidly changing trends in the global economy.

\subsection{IPRs and Foreign Direct lnowstment}

In countries with weaker IPRs, there may also be substantinl flow's of FDI, although these tend to be for the purpose of establishing sales and distribution outlets rather than high-value production and research and development (R\&D) facilities. ${ }^{3(1)}$

A recent study by Park and Lippoldt (2008) highlights that between 1995-2005 following the adoption of the TRIPS Agreement the developing and least developed countries, as a group, experienced a greater percentage increase in IIRR strength than did the developed world. In addition, during this period, the developing and least developed countries experienced large growth in inflows of inward FDI, merchandise and service imports, patent applications by foreigners, as well as increases in their R\&D to GDP ratios and patenting by local residents. The empirical analysis in this study centres on evaluation of two hypotheses regarding the experience of the developing world with strengthened IPRs: 1) IPRs stimulate technology transfer, particularly the transfer of technology-intensive goods, services and capital; 2) IPRs can stimulate local innovation both directly and indirectly by stimulating the transfer of technologies that foster innovation. ${ }^{311}$ The hypotheses concern the net empirical effects of 1PRs. ${ }^{302}$ The main empirical results support a positive assessment

$2 *$ See UNCTAD 2005a, p. 27.

3in See Park and Lippoldt 2008, p. 4.

3!1 The Park and Lippoldt study uses recent data (from 1990-2005) thus covering the IPR reform that the TRIPS Agreement brought about. It distinguishes between merchandise imports and services imports as measures of technology transfer via trade, and examining imports and inward FDl by sector, particularly those that are high tech. Service imports includes intangible goods such as communications, computers and royalties. Merchandise imports includes pharmaceuticals, office and telecom equipment, chemicals, optics and precision equipment, chemicals, optics and precision equipment, electronic and electrical equipment and aerospace. The study is published on the internet at: <http://oecd.org/trades.

302 For instance one could also argue that IPRs hinder the transfer of technology transfer, e.g. by increasing the costs of research inputs by creating patent thickets which require costly licensing negotiations to resolve or by blocking important technological components needed by other innovators. See Park and Lippoldt 2008, p. 14. 
of both hypotheses. Importantly the study does not merely focus on patents, but also on trademarks and copyright.

The Park and Lippoldt study has shown that trademark protection in developing countries has been seen as an important step forward for reassuring investors in manufacturing industries that they can combat knock-offs. ${ }^{3113}$

The first empirical evidence on the relationship between the protection of patents and other forms of IPR by developing countries and FDI flows is provided by Mansfield ${ }^{314}$ His findings are as follows:

\footnotetext{
"the strength or weakness of a country's system of intellectual property protection seems to have a substantial effect, particularly in high-technology industries, on the kinds of technology transferred by many US firms to that country. Also this factor seems to influence the composition and extent of US direct investment there, although the size of the effects seems to differ from industry to industry". 305
}

Javorcik Smarzynska confirms that stronger patent rights have a positive and statistically significant effect on the probability of foreign investment in hightechnology sectors and an insignificant effect in other sectors. 316

Park and Lippoldt (2008) found that stronger patent protection in developing countries is associated with a greater expansion of US operations in the chemical, machinery, service, and information industries in developing countries. This reinforces the important role of IPRs in the service industry. However, it is not associated with a greater expansion of US operations in the electronic and computer industries of developing countries. It may be that US FDI in the electronics and computer ind ustries of developing countries is largely for sales and distribution purposes, so that there is less sensitivity to the strength of local patent rights. Nonetheless, IPR enforcement in general does matter to all of these sectors, particularly to protect against piracy and unauthorised sales and distribution but the effect tends to be sector specific. ${ }^{317}$

313 See Park and Lippoldt 2008, p. 8.

:31 Mansficld's research focused on 100 major US firms in six manufacturing industries being chemicals (including drugs), transportation equipment, electrical equipment, machinery, food and metals. The results are reached based on a combination of survey data, interview studies and statistical analysis. See Mansfield 1994.

31 See Mansfield 1994, p. 1.

Sin See Smarzynska 2004, p. 39-62.

3it See Park and Lippoldt 2008, p. 23. 


\title{
5.6.1. FDI and the Case of Chile
}

UNCTAD research has demonstrated that technology transfer has enabled Chile to build a globally competitive and innovative salmon industry over the last two decades. The salmon industry has become one of Chile's main export sectors and a significant contributor to regional development. Chile has actively promoted scientific and technological innovation that adds value to or generates industries based on its natural resource environment ${ }^{3118}$ - hence, stressing the importance of focussing on its competitive advantage. Chile is now a major player in the production and marketing of salmon products: ${ }^{30 \%}$

\begin{abstract}
"Salmon production grew about 17-fold between 1990 and 2002. Chile's share in global production of farmed salmon and trout increased from about $10 \%$ in 1990 to about $35 \%$ within the same period. The industry's exports increased from about $\$ 291$ million in 1993 to about $\$ 1.4$ billion in 2004 . Chilean salmon is $n$. being exported to new markets in Asia and Eastem Europe". 310
\end{abstract}

The research indicated that FDI did not play a major role in the early stages of the industry development but grew steadily over the last two decades. In particular, the entry of large foreign firms has facilitated the introduction of new technologies and the expansion of production, fostered vertical integration and increased the average size of firms. It is estimated that about $\$ 300$ million of FDI was invested in the industry between 1989 and 2003.311

The UNCTAD study demonstrated that the technology is transferred through various channels: "such as technology licensing, foreign direct investment, trade, and participation in technology exhibitions, demonstrations and projects". ${ }^{312}$ Moreover the study shows that:

"[i]rrespective of the channels used, successful transfer of technology involves several innowative processes needed to adapt the technology to local operational conditions. Such activities may' include 'trial and error' steps, imitations, minor

3ik See UNCTAD 2006, p. 1.

in However, the Chilean salmon industry has yet to attain the efficiency and environmental standards of competitor countries such as Norway: "The technologies needed to handle waste, reduce the use of antibiotics and improve the harvesting of fish are just emerging. Similarly, the regulatory agencies have not kept pace with the rapid expansion of the industry. This is important in ensuring that environmental standards are maintained for the future development of the industry". UNCTAD 2006, p. 29.

311 SeC UNCTAD 2006, p. 2.

311 See UNCTAD 2006, p. 2.

il See UNCTAD 2006, p. 3. 
modifications, and upgrade steps needed to improve productivity and efficiency or reduce the cost of the transfer process". 313

The development and expansion of the salmon industry is largely attributed to the central role played by various public and private support institutions. For instance, the government stimulated the industry by the introduction of regulatory agencies at an early stage: for instance in the seventies it created the Office of the Undersecretary for Fisheries and the Fisheries and Protection Divisions (under the Ministry of Agriculture) to strengthen the development and regulation of fisheries and other agencies that link entrepreneurs with government institutions. ${ }^{31+4}$ These agencies focus on data analysis for the fishing industry, such as fish stock assessment and determining the margin of dumping as well as arranging food safety and quality control technologies in the salmon industry and representing the views of the producers. This proved very important in dealing with international disputes, marketing and technology development. 315

Although adaptation and imitation played a role in the emergence of the industry, domestic innovative capacity was needed for it to become competitive in the global market. ${ }^{316}$ Soon the government realised that it takes more than favourable natural conditions to build an industry but that it required increasing the value of the product (improving sanitary standards), investing in developing an innovative capacity in salmon farming and investing in international networks and reduction in production costs in comparison with the other main competitors. 317

Hence, the study has shown that it is important to invest in a friendly regulatory framework (tax exemption on expenditures incurred in training their workers), promotion of standards and international networks, facilitating the emergence of a producer association and enhancing cooperation between technology development institutions and industry. Chilean salmon firms are increasingly developing joint ventures with other international producers. Moreover, the study indicated the beneficial side effects for socio-economic development:

\footnotetext{
11. See UNCTAD 2006, p. 3.

31. See UNCTAD 2006, p. 5.

35 See UNCTAD 2006, p. 5 and 19.

31. See UNCTAD 2006, p. 29.

31: See UNCTAD 2006, p. 19.
} 
"Banks and insurance companies, consultancy and engineering services, research centres and universities have been developed in the region to support the industry [education level has increased as well as road infrastructure]".31:

Significantly, this case study has also shown that technology transfer is not purely a private-sector activity, but that the public sectors of technologyexporting and technology-importing countries can play an important role.

\subsection{How Trude-Related are IPRs? What is the Role of IPRs in Relation to Trade Flowes?}

Literature endorses the common assertion that trade is an engine of growth. A study by Acharya and Keller (2007) demonstrates that imports are an important channel of technology transfer, although the volume of transfer varies by country, being greater in countries with stronger absomptioe capacities (measured by the level of location and R\&D investments). ${ }^{319}$ Eaton \& Kortum support this research and have argued that trade can increase the productivity of importing countries by increasing their access to foreign inputs and technologies. 320 Moreover, studies have shown that international trade flows increase, especially in patcht-sonsition industrics, as a result of enhanced patent rights among middle-income and large developing countries but not among poor countries. ${ }^{321}$

Maskus \& Penubarti focus on the effect of IPR regimes on trade, in particular whether the distribution of bilateral trade among nations depends upon the $I P R$ regimes of importing countries. They found that within the group of large dioloping countries, strong IPR regimes attract larger than expected flows of imports from OECD countries. ${ }^{322}$

Fink and Primo Braga ${ }^{323}$ show that stronger IPRs have a significant positive effect on total trade but that this effect depends on the type of tedmology involved. 'The Fink/Primo Braga study' 1999 looks at two different kinds of

318 See UNCTAD 2006, p. 27.

$31 "$ See Acharya and Keller 2007.

32: See Eaton and Kortum 2002.

321 See Hoekman, Maskus and Saggi 2005 referring to Smith 2001.

322 See Maskus and Penubarti 1995.

323 The study conducted by Fink and Primo Braga 1999 uses a gravity model of bilateral trade flows and estimates the effects of increased protection on a cross section of 89 by 88 countries. Previous study (Maskus and Penubarti 1995) in which they estimate the effect of IPRs (patent protection) on international trade flows using an augmented version of the Helpman-Krugman model of monopolistic competition indicated a positive link between tighter. IPR protection on bilateral manufacturing imports (trade flows) into both small and large developing countries. See Fink and Brimo Braga 1999, p. 23. 
aggregates: total non-fuel trade and high-technology trade. In addition they use the Park and Ginarte Index (1997) to measure the strength of II'R regimes. The Park and Ginarte index grades the national IPR regimes of 110 countries on a scale from zero to five. In order to calculate the country's place on the list, Park and Ginarte created five categories: 1) extent of coverage, 2) membership in international patent agreements, 3) provisions for loss of protection, 4) enforcement mechanisms, and 5) duration protection. ${ }^{32: 4}$ For instance Fink and Primo Braga found that the stringency of a country's patent regime makes no difference to trade in high-technology products. They also found that a system of strong IPRs has a significant positive effect on bilateral trade flows for total non-fuel imports and exports. ${ }^{325}$ The study did not find this same effect on high-technology trade. Fink \& Primo Braga argue that this outcome is somewhat surprising as they would have expected a positive trade effect for knowledge intensive goods. They try to explain their findings in the following way: 1) there is a possibility that strong IPRs cause high-technology firms to serve foreign markets through FDI (substituting foreign trade); or 2) the Park and Ginarte index does not correctly capture the IPR effect; 3) there is a possibility that strong market power effects, in the case of high-technology goods, may offset positive market expansion effects caused by stronger IPR regimes; or 4) some knowledge-intensive goods are insensitive to the destination country's IPR regime and as a result means other than strengthening IPRs may be more important in appropriating investment in $R \& D$ (for instance first mover advantage or rapid movement down the learning curve). ${ }^{326}$

This outcome is in line with studies conducted by Maskus and Penubarti (1995).327 and Smith (1999) which also find a positive link between trade and strong IPR protection but Maskus and Penubarti do not find such a link for very patent sensitive industries and Smith finds no such link in countries that face no threat of imitation. ${ }^{32}$ One may interpret these results in a variety of ways. Firstly, it seems likely that multinational trading firms do not base their export decisions on IPRs in the poorest countries, where local threats of reverse engineering are weaker. Secondly, patent rights are more important in middle-income, large developing countries, where imitation is more likely. As these countries reduce the threat of imitation through stronger patents, foreign firms are more likely to expand their volumes of trade. Thirdly, the products of many high-technology industries are inherently difficult to imitate, so those trade flows are less responsive to IPRs than those in medium-technology or mature-technology sectors. Fourthly, high-technology firms may decide to serve foreign markets through FDI and licensing, so that exports in these

\footnotetext{
324 See Ginarte and Park 1997.

i2s See Fink and Primo Braga 1999, p. 26.

320 See Fink and Primo Braga 1999, p. 28.

.37 See Maskus and Penubarti 1995, p. 227-48.

32.5 See Smith 1999 as referred to by Fink and Maskus 2005, p. 7.
} 
industries may be little affected by variations in the degree of patent protection. ${ }^{329}$

The Fink and Primo Braga (1999) study confirms the outcomes of their previous studies which show that there is a positive link between IPR protection and trade flows for the aggregate of non-fuel trade (imports and exports). Nevertheless, they indicated that II'Rs are not significant for high-technology trade flows (such as trade in chemicals, electrical and office machinery and telecommunications). ${ }^{330}$ Moreover, another reason could be that high-tech technologies have a short life span and hence being first is more important than IPR protection.

In contrast to Primo Braga and Fink (1999), Mansfield (1999 and 1995) ${ }^{331}$ finds that high-technology industries require tighter IPR regimes. This is not so surprising since these industries tend to regard patents as relatively important. In all three countries, the percentage of firms indicating that intellectual property protection has a major effect on their FDI investment decisions depends greatly on the type of investment.

IPRs alone may not stimulate knowledge transfers. Bascavusoglu and Zuniga (2002) examine the exports of French technology services to 19 countries and sectors in 1999. They find that foreign IPRs can enhance such exports if the destination markets have commerial potentinl in terms of large markets and strong techological capacities. Stronger IPRs in low-income countries have an insignificant effect and may even deter knowledge flows in low-technology sectors. ${ }^{332}$

Existing IPRs may have an impact on international trade flows, for instance a company may decide not to export its patented good into a certain foreign market if it is likely that potential pirates can diminish its profitability in that market because of lax IPRs. In line with this reasoning one would expect that an enhancement in patent regulations in one country would result in an increase of imports as "foreign firms face increasing net demand for their products, reflecting the displacement of pirates". On the other hand

"a firm might choose to reduce its sales in a foreign market as a response to stronger IPR protection because of its greater market power in an imitation-safe environment". 333

Thus we can conclude that contesting market expansion and market power effects imply that the overall effect of IPR protection on bilateral trade flows is

\footnotetext{
32.) See Fink and Maskus 2005, p. 7.

33: See Fink and Primo Braga 1999, p. 20.

331 See Mansfield 1995.

$3: 2$ See Bascavusoglu and Zuniga 2001.

333 See Fink and Primo Braga 1999, p. 21.
} 
theoretically ambiguous. ${ }^{334}$ However, the rality is that IPR enforcement, adher'nce to the existing IPR traties and TRIPS plus provisions play an important role in FlAs and FDIAs negotintions.

Maskus and Penubarti (1995) find that the effect of market expansion effect tends to dominate the power of the market so that stronger IPRs on balance expand trade:

"one reason may be that the market power effect of IPRs dominates in hightechnology sectors. The plausibility of this is that firms in technology-intense industries may already possess some market dominance form their technological superiority. Stronger patent protection would then largely raise their rents".35

The case of Hungary has recently been brought into play; a country that adopted higher standards of IP protection to obey to the accession requirements of the EU, and where subsequently most of the locally owned firms in the pharmaceutical industry were taken over by foreign multinationals and the market share of local firms shrank from 70 per cent to 30 per cent. ${ }^{336}$ Another possibility could be that stronger IPRs lead firms to switch between different modes of technology transfer, e.g. from exporting (trade flows) to FDI. However, many studies find that stronger IPRs can stimulate trade in high-tech products. Smith (1999) ${ }^{37}$ finds that the impact of stronger patent protection on trade depends on the importing country's capacity to imitate. In countries with weak capacity to imitate, the weak capacity acts as a de facto form of protection. Firms would not actually need IPRs to appropriate the returns to their innovation. Thus in such circumstances stronger patent rights provide greater market power, which could outweigh any market expansion effects. On the other hand, the empirical results in Smith (1999) confirm that where the capacity for initation is high, a strengthening of IPRs increases the flow of trade. ${ }^{338}$ This is confirmed in Higino Schneider 2005.

Park and Lippoldt (2008) find that stronger levels of patent protection make a significant positive difference to the influx of high-tech products, like pharmaceutical goods, chemicals, aerospace, computer services, information, office and telecom equipment as well as optics and precision equipment. Thus, goods that are technologically-intensive are particularly affected by stronger patent protection in developing countries. For least developed countries, the qualitative and quantitative impacts of patent rights on merchandise imports

3.4 Fink and Primo Braga 1999, referring to Maskus and Penubarti 1995.

335 See Park and Lippoldt 2008, p. 10.

in See Raman 2005.

3.7 See Smith 1999.

is See Smith 1999. 
are weaker. ${ }^{339}$ Patent rights are a dominant influence because service imports are more sensitive to levels of patent protection, holding other variables constant. Most of the control variables (index of free trade, GDP per capitn, IPR enforcement, and legal effectiveness) have a positive effect on service imports. The possibility to engage in free trade positively influences the merchandise imports of developing countries, but may induce substitution effects in developed countries and in least developed countries. That means they, encourage a switch from merchandise imports (trade flows) to inward FDI. Park and Lippoldt (2008) found that in terms of service imports - patent protection and IPR enforcement are positively associated with the importing of communication services, computer services and royalties. Hence, results suggest that stronger IP protection helps attract imports of services that are knowledgerelated or technology-intensive. Imports of equipment and materials may help to stimulate $R \& D$, and to the extent that increased R\&D results in increased innovative outputs for which local residents file for patent protection, increased resident patenting will be positively associated with merchandise imports. ${ }^{341}$

\subsection{Who Gains from IPR Protetion?}

Branstetter' $\mathrm{s}^{3+1}$ study indicates that IPR reform increases royalty paymonts and RED expenditures of LS multinationals affilintes, as well as the level and growth rate of patent filings by non-residents. Hence, it has very positiz' r'sults for tedmology oroners that seek opportunities to explore new markets. The study suggests that these results collectively imply that US multinationals respond to changes in IPR regimes abroad by significantly increasing technology transfer to IPR reforming countries. Nevertheless, these results are not sufficient to show that IPR reform is welfare enhancing for IPR reforming countries. For instance, the study

"does not consider the impact of reforms on locally owned firms that may be displaced after reforms nor does it examine the effects of the reforms on the pace of innovation in non-reforming countries".

There is also limited evidence to what extent $1 P R$ reform impacts on domestic innovation or to what extent newly introduced technologies diffuse to local industry". $3: 2$

3.3. See Park and Lippoldt 2008, p. 22.

$3+1$ See Park and Lippoldt 2008, p. 24.

$3+1$ Lee Branstetter is associate professor of economics and public policy, Carnegie Mellon University, Pittshurgh, USA.

342 See Branstetter, Fisman and Foley 2005, p. 25. 
Thus Branstetter, Fisman and Foley found that stronger IPRs could have both maket expmision effects, enabling the rights holders to exclude imitators and enjoy a larger market for their products, and market poiver iffects increasing royalty payments on technologies by constraining the quantity supplied (through increased prices). Hence, immediate positive results for right holders.

Fink and Primo Braga argue that - from a static partial equilibrium point of view flow of trade from - the host (source) country is likely to benefit from strong IPR protection, because it can capture increased monopoly profits from the sale of goods abroad. 3.43

According to Branstetter, Fisman and Foley the supporters of strong IPR protection believe that IPR reform will induce more innovation and foster rapid economic growth. They argue that if the additional innovation is mostly concentrated in advanced countries, a strengthening of IPR will accelerate the transfer of technology between countries, ensuring that all countries will benefit. ${ }^{3.4}$ Their findings reveal that royalty payments for technology, transferred to affiliates, increase at the time of reforms, as do affiliate R\&D expenditures and total levels of foreign patent applications. Branstetter, Fisman and Foley examined how technology transfer within U.S. multinational firms has changed in response to a series of JPR reforms carried out by 16 developing countries over the 1982-1999 periods. Throughout the 1980s and 1990s multiple countries undertook legal reforms substantially changing their patent laws. Each reform can be classified according to whether or not it expanded or strengthened patent rights along five dimensions: 1) an expansion in the range of goods eligible for patent protection, 2) an expansion in the effective scope of patent protection, 3) an increase in the length of patent protection, 4) an improvement in the enforcement of patent rights, and 5) an improvement in the administration of the patent system. ${ }^{3.45}$ However, the study shows that increases in royalty payments and $R \& D$ expenditures are concentrated among affiliates of parent companies that use US patents extensively prior to reform and are therefore expected to value IPR reform most. Increases in royalty payments exceed 30 per cent. They measured that R\&D spending (viewed as a complementary to technology imports from the parent) increases after IPR reform. In addition non-resident patenting also increases in the post IPR reform period. Neacrtheless, no change in resident patent filings is obseroed.

34: Sec Fink and Primo Braga 1999, p. 21-22.

34 This research used affiliate-level data on U.S. multinational firms and aggregate patent data to test if legal reforms that strengthen IPR increase the transfer of technology to multinational affiliates operating in reforming countries. See Branstetter, Fisman and Foley 2005.

345 See Branstelter, Fisman and Foley 2005, p. 14. 


\subsubsection{Attraction of Local R\&D}

Actditional factors that play a role in the successful transfer of technology are the presence of an R\&D program, domestic research laboratories and universities, and the existence of a sound base of technical skills and human capital. These nominators decrease the costs of imitation, adaptation and follow-on innovation. 34

Research has shown that a successful transfer of technology depends on the "capacity to learn and investments to apply technologies into local production processes". Th "This is proven by the fact that countries in the possession of "substantial engineering skills and R\&D programs for adaption and learning are greater recipients of licensing flows than others" $3: 4$

Normally R\&D conducted in affiliates is devoted to modification and absorption of existing products to meet local market conditions and for this reason is complementary to technology imports from the parent. In contrast the parent's research is designed to advance the technological frontier, as seen in research conducted by US based multinationals. The former method will produce few patents, whereas the latter has the potential to produce many patents. U.S. multinationals do undertake some basic and applied research abroad but mainly in other advanced countries in the possession of a highly accomplished local scientific and engineering community and where the infrastructure for research is well-developed. R\&D activity in developing countries is most of the time focused on the absorption of parnt firm tedmology and on its modification for local markets. ${ }^{3.49}$ Thus, the nature of $R \& D$ at home and abroad is very different in nature and quality.

\section{CONCLLSION AND RECOMMENDATIONS FOR DEVEloping COLNTRIES}

Technology transfer is important for employment creation, export competitiveness and building national innovative capacity. This research addressed whether IPR protection plays a role in attracting technology transfer. Comparing the studies shows that sector-specificity greatly determines whether IPR protection plays a role in attracting technology transfer and establishing economic growth. In addition, the impact of IPR protection on economic grow th is highly sensitive to a country's level of development, depends on business type of activity (e.g. production, assembly, sales or R\&D activity) and is technology-

\footnotetext{
ith See Maskus 2000 and Hoekman, Maskus and Saggi 2005, p. 1588.

3.: See Yang and Maskus 2001.

34. See Yang and Maskus 2001.

3.4 See Branstetter, Fisman and Foley 2005, p. 7.
} 
dependant (e.g. pharmaceutical, engineering or food sector). ${ }^{330}$ For particular industries, like the chemical and pharmaceutical industry and for particular activities, such as FDl, the existence of intellectual property rights may be a significant factor in the decision process of whether companies are willing to invest. Some studies indicate that IP'R protection is crucial in attracting high technologies but other studies contradict this More research is needed on the impact of changes (reform) in IPR regimes in developing countries and the behaviour of multinational enterprises. ${ }^{351}$ In addition, more research is necessary at industry level, to see what impact IPRs have on different types of collaboration, e.g. joint ventures, whole ownership.

Research has also shown that only after countries have accumulated sufficient indigenous capabilities with extensive science and technology infrastructure to undertake creative imitation does the protection of IPR become an important element in technology transfer and industrial activities. Obstacles to efficient international technology transfer flows remain and include little R\&D activities in developing countries, the limited technological base necessary to absorb technology, to amend technology to local needs and subsequently to build on the technology for future inventions.

A number of factors play a role in investment decisions and IPR protection is only one of them. IPR protection is not the sole solution to economic development; nevertheless it can contribute to it. The effects of strengthened IPRs on economic welfare are not easy to determine as having IPR statutes does not guarantee enforcement. The effect of stronger IPRs on innovation and economic development depends on various circumstances within a country. IPR becomes more important over time as income levels grow and increased inventive capacity materialises. In addition, technology transfer is conducted through various channels and some channels might be more suitable in certain situations than others.

IPR protection can have a positive effect on economic growth and attracting technology transfer but only in the long term and only after countries have reached a certain level of industrialisation. The majority of studies indicated that for the poorest countries IPR protection will have counter effects on their socio-economic development needs as it deprives them of reverse engineering and imitation activities. Developing countries are not unanimous. They vary greatly in economy and technology infrastructure and innovation competence.

35 See Lall and Allbaladejo 2003. See also Reichman 1998, p. 585.

35 For instance, how could Hong Kong, South Korea, and Taiwan grow so quickly? Was the economic growth in these countries largely driven by accumulation of resources or improvement in productivity (driven partly through trade)? Economists are still dived on this matter. Another interesting research question would be how imitation affects incentives for imnovation in the more industrialised countrjes? 
The prerequisites of TRIPS do not give enough room for the absorption of the basic technology and knowledge to be able to stimulate capacity building in those countries. ${ }^{352}$ Especially the LDCs are incapable of benefiting from the existing IPR framework as they are still dealing with basic development imperatives such as education, health system, infrastructure, and basic communication systems. It is likely that an obligation to install IPR mechanisms could undermine the fulfilment of these basic needs and utilities. Moreover, without the necessary infrastructure in place it is impossible to achieve adequate enforcement compliance let alone the creativity in the domestic innovative activity. Developing countries ought to make IPR policies more favourable to them in the short-term. But they should also strengthen their own absorptive capacity for a long-term solution. Focussing on building creative and innovative capability will also make developing countries less dependent on foreign technologies in the future. Local governments and entrepreneurs should decide which type of technology transfer is most crucial and pertinent and hence should focus on those goods and services addressing domestic needs through local entrepreneurial activity. 33 . What is probably necessary is a change of "mind" set to address the needs of foreign poor countries and to contribute to socially beneficial projects sparked by a moral obligation rather than by profit. Developing countries should cooperate to change current trends towards a standardised all-encompassing multilateral IPR system as envisaged by the industrialised countries. Initiatives such as the WIPO Development Agenda should be build upon.

The TRIPS Agreement is a serious attempt for the convergence of IPRs, in terms of its implementation, enforcement and coordination. However, in many developing countries the administrative infrastructure is lacking or insufficient to fulfil the requirements of the Agreement. Article 66.2 obliges developed country Members to provide incentives to their enterprises and institutions for the purpose of promoting and encouraging technology transfer to least-developed country Members. However, in contrast to the IPR rights and obligations, Article 66.2 seems to be of a best endeavour nature. Many of the activities listed in the reports presented by developed countries in fulfilment of Article 66.2 do not directly relate to technology transfer actions but amount to training and capacity building activities, which do not necessarily lead to transfer of technology.

Next to the TRIPS Agreement there is a clear proliferation of bilateral investment treaties (BITs) as well as free trade agreements (FTAs) that include explicit obligations for the protection of intellectual property rights as investments. The transfer of technology is to some extent outside the scope of

$\$ 2$ See Rasiah $2003, \mathrm{p} .44$

33 See Foray, forthooming 2009. The UNCTAD case studies of the That electronics industries and the Chilean salmon industry confirm this view. 
governments which limits the possibilities of governments to influence the transfer of technology flows. FIAs and IIAs ${ }^{354}$ are used for additional control and security. Investment agreements mainly include provisions for the protection of foreign investors (and include protection against host country interference) on the basis of MFN and national treatment principles. Intellectual property is generally seen as falling within the definition of investment and as a result it is by its nature protected against host country interference. Although research has indicated that the overall effect of IPR protection on trade flows is ambiguous, IPR reform plays an important role in FTAs and IIAs nevertheless. Most, recent IIAs made explicit reference to intellectual property rights, normally requiring adherence to international IPR protection agreements or providing for national treatment or non-discrimination. Recent investment treaties have also endeavoured to exclude intellectual property rights from falling within the rules on expropriation.

In contrast to the 1970 s (where focus was merely on attracting foreign technology) it is currently understood that successful technology transfer requires 1) the assimilation and absorption of technological knowledge, 2) its adaptation to local conditions, 3) the absorption of subsequent improvements and 4) the generalisation of the transferred knowledge. ${ }^{355}$ Unfortunately, a better understanding of what technology transactions are all about has not contributed to enlarge technology transfer flows to developing countries.

This chapter provides recommendations, firstly to developing countries that want to use the transfer of technology effectively for their socio-economic development, and secondly, to developed countries that are under the obligation to comply with Article 66.2 of the TRIPS Agreement.

Foremost, developing countries need tailor-made solutions and a mere reproduction of what is happening in developed countries will not bring real changes. Times have changed and developing countries will have to look for different ways to switch from being commodity based societies to industrialised ones as the current IPR legislative framework works restrictive on reverse engineering and imitating practises. Moreover, the most important innovation for LDCs are probably not technical but depend on whether a country can find its "niche" or competitive advantage.

As shown, there are many possible strategies for international technology acquisition and local industrial and technological development. It seems that priority should be given to improvement of the local environment for acquiring international technology transfer and for its subsequent diffusion. Both

35. Foreign Direct Invest Agreements (FDIAs) and International Investment Agreements (IIAs) can be used interchangeably.

is See Foray, fortheoming 2009. 
FDI and licensing respond positively to such factors as an effective infrastructure, transparency and stability in government, and a reasonably open trade and investment regime. ${ }^{356}$ Also important is an entrepreneurial environment that attracts skilled workers to return home from developed countries. Given that vertical spillovers are strongest in countries where multinational enterprises work with competitive suppliers, reducing entry barriers for industries to operate on the market can also assist technology transfer. An important determinant of a country's ability to absorb and adapt technology is the return on investment in simple $R \& D$ capacity to reduce the technological gap between local and foreign firms. Local policies should be directed to encourage such R\&D investments (e.g. cost-saving technologies), as well as establishing links between universities and public laboratories with the private sector. It is also important to improve education levels, in particular management and engineering skills, which will allow technology to be deployed for local needs and gradually improved over time. Hence, countries need to work on establishing local R\&D programs, and research capacity at laboratories and universities. Having a solid technological understanding and basis will also help to identify and subsequently attract the most appropriate and necessary technologies and to negotiate better terms and conditions in technology transfer arrangements.

In an increasingly globalised world, knowledge and access to knowledge is crucial for gaining a competitive edge. The role of intellectual property in achieving technology transfer is questionable - most studies argue that other factors, such as investment climate, economic, political and other considerations (i.e. taxation laws, infrastructure, education, corruption, guarantees against expropriation) play a much larger role. 357 Hence, whilst formulating policies, countries need to focus on the overall package whilst trying to build an environment of supporting creative and innovative domestic capacity.

A number of recommendations are as follows:

1) The patent system contains a huge body of technical information in any technical area that can be freely used by anyone looking for information in a certain field of technology. In many cases the patents generating the useful technical information are not patented in developing countries so that not only can the information be used freely, but also the incorporated knowledge can be reproduced and used commercially in developing countries. $A$ patent is only granted for a certain amount of time hence, after the lapse of patent the information should enter the public domain.

in See World Bank 2004.

3 See Kunz-Hallstein 1975, p. 427, and "The role of patents in the Transfer of Technology to Developing Countries, Report of the Secretary General of the United Nations", 1964. 
2) The boosting of local industries does not require high tech or the latest technology to flourish. This can be achieved by improving production processes (and supply chain management). Hence, developing countries should focus on "what is already out there", free for everyone to use. For instance developing countries should attract mature technologies, that are often already in the public domain. If they are still under protection, they might be cheap to obtain. In any case developing countries should avoid signing technology transfer agreements in terms of accessing technologies that are no longer under some sort of IP protection.

3) The TRIPS Agreement provides minimum standards and hence, it leaves developing countries some degree of autonomy. However, countries need to be properly informed and trained in how to apply these flexibilities effectively. In particular countries should focus on using compulsory licensing (available under Article 31 TRIPS).

4) Developed countries often provide technical assistance and techology transfer in areas in which they have an interest, for instance coffee production. This might not always be in the best interests of the receiving country. Uniformity in production should be avoided.

5) There is a role for local intellectual property offices and patent offices not only in administering the registration of patents and trademarks but also in educating and training as to how to make use of IPRs. In particular, how to make use of IPRs in a way that benefits local people.

6) In addition, other flexibilities need to exist, such as the opportunity to be innovative outside the IPR system by the use of open source initiatives.

7) Developing countries should seek a pro-active approach from developed countries to stop unfair business practices by multinational enterprises operating on their territories. Developing countries often lack adequate unfair competition laws. In particular the European Commission has been very active in stopping unfair competition practices (i.e. the Microsoft cases). It would be recommended to extend these efforts to developing countries as well.

8) The fact that technology transfer arrangements are negotiated between unequal negotiating partners (small local firm or government subsidiary versus huge multinational) should be taken into consideration at any negotiation concerning the international regulation of transfer of technology.

9) Joint ventures and collaborative arrangements with multinationals might be beneficial since both parties can cooperate from the initial stage of a project. This way developing countries "collaborate" with the foreign multinational business partners instead of being "confronted" in the process of developing new products and associated technology. By following this 
route, developing countries may increase their chances to share in the benefits of the new found technology ${ }^{35 s}$

10) There should be discussion of a treaty on access to knowledge and technology within the framework of the WTO negotiation framework. ${ }^{359}$

11) The negotiations on a Substantive Patent Law Treaty within the WIPO auspices should be approached with care. Developing countries need sufficient time to balance the benefits of such a treaty. In contrast, it is best to amend patent laws to expand research exemptions and diminish the negative impact of patents on research.

12) There should be further negotiation on the pro-competitive licensing practises with "a view to fostering creativity, innovation and the transfer and dissemination of technology" within the framework of the WIPO Development Agenda. ${ }^{3(x)}$

13) The implementation of the WIPO Development Agenda recommendations in the WIPO Committee on Intellectual Property and Development (CDIP) should be monitored and accelerated and an adequate implementation of the technology transfer provisions should be demanded. ${ }^{361}$

14) Developing countries should consider bringing a number of these recommendations to the agenda of the TRIPS Council and the Working Group on Technology Transfer to make sure that endeavours to make the IP global framework more development friendly within both WIPO and WTO are mutually reinforcing. ${ }^{362}$

35 The developing countries are mostly arailed by the development of competitive skills in research in biotechnology, however, this cannot be achieved overnight, since it is a highly developed, costly industry, which requires skilled personal. Financial and technical assistance will be required to overcome the lechnological gap and research cooperation is one way to start.

35y See Barton 2003.

3et1 Recommendation 23 of the WIPO Development Agenda. See WIPO "Report of the Provisional Committee on Proposals Related to a WIPO Development Agenda (I'CDA). A/43/13 Rev., 17 September 2007.

3 Recommendation 14 of the WIPO Development Agenda stipulates that "within the framework of agrement between WIPO and the WTO, WIPO slaall make available advice to developing countries and LDCs, on the implementation and operation of the rights and obligations and the understanding and use of flexibilities contained in the TRIPS Agreement". A/43/13 Rev., 17 September 2007.

inz See Abdel Latif 2008. 



\section{Summary and Conclusion}

1.

INTRODLCTION

This book discusses current changes in IPR protection: it analyses contemporary trends and challenges in ongoing negotiations by focussing on the diverging view points and interests by the various players at stake. At the multilateral, regional and local level we can identify, in relation to intellectual property rights (IPRs), a trend towards: broadening of the scope of substantive rules; extending of the term duration and removing the limitations and exceptions to rules. As a result, the remaining flexibilities left to the individual countries to develop IPR strategies, in line with their socio-economic developments needs, diminish, and the public domain shrinks. Arguably, changes in IPR protection at the multilateral level lead to a shift in the balance of interests between countries which are at the front of developing state-of-the-art technology and those that fall behind. First, with the swift pace of technological transformation technology has become important in all economic activities. Second, intemational collaborations have led to the globalisation of all economic and technological activities. These two factors are intrinsically interrelated and mutually reinforcing, as demonstrated by the increase in patent applications (and use of IPRs in general) by foreign inventors within a country. Just as the relationship between technological intensity of production processes and products has grown, an increasingly important link between technological change and competitiveness has also appeared. The amount of knowledge required in production processes has grown remarkably; including increased intangible investments such as $R \& D$, training, and software development. Hence in our contemporary society, having access to technology determines a company's and countries' competitiveness. In the long run access and diffusion of technology can make the difference and contribute to social wellbeing and welfare. Hence, developing countries and in particular LDCs need to focus on building a technological and viable base and use technologies available in the public domain in order to develop their technological strength. This will make them less dependent on foreign technologies in the future.

This book focuses on the potential and challenges of developing countries to use the existing IPR agreements to create a viable techmological and artistic base. Chapter one sets out the history and the negotiation process underlying the international legal framework for IPR protection as well as the rationale and justifications behind granting IPR protection. Chapter two discusses in detail the provisions of the TRIPS Agreement and aims to highlight the key provisions for developing countries and provide some assistance as to how the TRIPS article should be interpreted in relation to its use, negotiation history and WTO case law. Chapter three, four and five provide more detail on IP subject matter closest to the interest of developing countries: geographical 
indications, traditional knowledge and the transfer of technology. In each chapter the outstanding negotiation issues are discussed and recommendations are provided for developing countries as how to best pursue their interests at the bilateral and multilateral level of IP policymaking and norm setting.

The book concludes that lately developing countries have been trying hard to regain some of the ground that they lost under the TRIPS Agreement, by the Doha Ministerial Declaration and the Declaration on TRIPS and Public Health. In fact multiple efforts are taking place: they are trying to make TRIPS more development friendly by placing technology transfer back on the WTO negotiation agenda, and to include a development dimension into WIPO activities. The international legal framework on IPRs should be designed in such a way as to encourage innovation and creation and to limit the negative aspects. A number of recent developments have increasingly focused on bringing a better balance between private rights and public interests such as the adoption of the WIPO Development Agenda, the WTO Doha Declaration on TRIPS and Public Health and the Millennium Development Goals. Also the WHO has recently (24 May 2008) adopted a global strategy aimed at filling the research gap for neglected diseases and facilitating access to medicine. There has also been the IRIPS amendment in relation to compulsory licensing (Article 31 bis), the large support for the disclosure of origin proposal (Article 29bis) and the increased attention to technology transfer and technical assistance activities - all of them focused on bringing a better balance between private rights and public interest. It is important that the implementation of the WIPO Development Agenda leads to visible improvements in that the implementation of each of the recommendations takes us one step closer to a WIPO that has development and the public interest as fundamental parts of its strategic vision, normsetting, programmes and activities.

All of these successes have shown that the efforts of developing countries to bring more balance in the IP system are not without results. However, translating the theory into practice - concrete actions-continues to be a challenge.

\section{DEVELOPMENT OF INTERNATIONAL LEGAL FRAMEWORK FOR THE Protection of INTElLectlal. Proteirty}

As a rule of thumb, amendments to existing legal jurisdictions occur slowly, just as the law is always outrun by technological development. Hence, the intellectual property legal infrastructure is in a constant state of flux and it is truly one of the most dynamic areas of international (public) law in which new agreements are being negotiated and adopted at the national, bilateral, regional and international level that build on and strengthen the minimum standards established by the existing intellectual property rights (IPRs) agreements. Over time, the scope of international IPR agreements has changed according to economic, technological and political demands. Mainly, the development of new technologies, especially the information and communica- 
tion technologies and the progress of biotechnology, has contributed to the rapid changes in the protection of intellectual property rights. In particular, since these technologies bring about high research costs and are fairly easy to replicate. IPR protection, in existence for decades and in some jurisdictions even centuries, had been granted for various reasons, but most of the time the underlying idea was to promote social welfare through the stimulation of innovation, research and creativity. However, recent amendments in IPR protection lead to a shift in the balance of interests between countries which are at the front of developing state-of-the-art technology and those that fall behind. Surprisingly, until the last decade of the 20th century, IPRs policy-making and norm-setting had occurred within the domain of legal experts in relative isolation from more general public interest debates and related fields such as protecting public health, food security, education, free trade, industrial policy, traditional and indigenous knowledge, biodiversity, biotechnology, the information society, the entertainment and media industries. IPRs are in principle territorial rights, meaning that they are awarded and enforced within the confines of national policies and legislation. However, over time harmonisation processes have occurred: two organisations that have been at the forefront of international IPR policy making are the WIPO and the WTO. Dissatisfaction with the existing intellectual property rights (IPRs) system led to the WTO TRIPS Agreement in the last decade of the 20"t century. As chapter one has set out in great detail, in contrast to the Berne and the Paris Conventions, the obligations derived from the 1994 TRIPS Agreement and the 1996 WIPO Internet treaties have caused a considerable erosion of national sovereignty since member states lost the freedom to establish criteria for protection. In fact, the TRIPS Agreement is a serious attempt for the convergence of IIRs, in terms of their implementation, enforcement and coordination. However, in many developing countries the administrative infrastructure is lacking or insufficient to fulfil the requirements and to reap benefits from the rights and obligations of the Agreement. Studies have indicated that the capacity to participate in the TRIPS Agreement relies to a great extent on the stage of development of the country concerned. For instance, contemporary IPR agreements enhance the scope and width of IP protection (subject matter is widened and new laws are created to include other forms of IP previously not protected at the international level, such as geographical indications, (pharmaceutical) regulatory data protection as well as adaptations to accommodate the new information society, i.e. domain name protection and database protection), contain substantive rights (new standards being created and extended to the global level), diminish exceptions and limitations, and prolong the duration of protection in line with the laws of technologically advanced countries.

The harmonisation efforts in the multilateral context were clearly not enough as the last decade has been characterised by an unprecedented proliferation of regional and bilateral free trade agreements (in an attempt to strengthen economic/trade relations between the countries involved) including IPRs. Frequently, these IPR provisions go beyond the TRIPS Agreement - so-called TRIPS plus obligations, for instance by demanding the adherence or accession 
to a number of international IPR treaties, expanding substantive rights or bypassing granted transition periods for developing countries. Countries' sovereignty to develop their own regimes on IPRs, in line with socio-economic development needs and objectives, is severely diminished through the TRIPS Agreement and the results of regional and bilateral trade negotiations. The fact that these FIAs may go further than rules set out in the TRIPS Agreement can lead to inconsistencies in the implementation of IPR rights and obligations. In particular, these TRIPS plus obligations may have an impact on the use of flexibilities and exceptions for safeguarding certain public interests and proceeding development objectives. Foremost, these enhanced obligations have been introduced at a time when the majority of developing countries are still facing huge challenges implementing the minimum standards of the TRIPS Agreement. In addition, countries are concluding foreign trade agreements with a number of different countries and each agreement has its own focus on interests and policy objectives. The proliferation of FTAs is even more worrisome if one considers the obligations under Article 4 of the TRIPS Agreement, entailing the Most-Favoured-Nation clause, implying that any benefit, advantage, privilege or immunity granted to a Member shall have to be granted immediately and unconditionally to others. Hence, these regional and bilateral trade agreements should be approached with care so as not to impede flexibilities granted under the TRIPS Agreement, nor hinder multilateral trade negotiations in the context of the WIPO and the WTO, especially at a time when the Doha Round WTO negotiations remain deadlocked.

\section{Balancing Pliblic and Pirivate Rights as well as Riguts and OBLIGATIONS}

Most of the industrialised countries, but not exclusively, take the view that a harmonised IPR system is a precondition to creating, using and encouraging investment in new technology, which in turn fosters economic growth. In reality there can be clashing interests between economic and social interests and needs among countries with different levels of development. During the TRIPS Agreement negotiations, it was repeatedly emphasised that strengthening IPRs would provide incentives to support knowledge generation and promote technology transfer and diffusion. However, over-protection of IPRs does not reflect development goals and in contrast can be detrimental to a country's socio-economic development and technology needs. It is also evident, that most of the benefits derived from the TRIPS Agreement will be of a long-term nature, for instance the promotion of technology transfer, domestic innovation and economic growth. The TRIPS Agreement has its shortcomings. For instance, it does not provide means to stop the abuse of intellectual property rights. Furthermore, arguably, the TRIPS Agreement has neglected public interest, as it has not provided sufficient solutions to ethical and cultural reservations against appropriation. Subsequent rounds of negotiations have focused on these shortcomings. 
The differing needs and interests of private innovators and the public (society as a whole) create public policy concerns, e.g. public health (access to essential pharmaceuticals and food security), access to information in general and for education purposes, and envirommental concerns (biodiversity, including appropriation of genetic resources and associated traditional knowledge). Hence, it has long been recognised that there is no one-size-fits-all model of IP protection as a uniform approach cannot accommodate the unique requirements of local industries and cultures. IPR protection needs to contribute to innovation, creativity and techmology transfer in the interest of all countries and not only the powerful industrialised ones.

Currently, the delicate balance between public benefit and private rights is diminishing: the interests of the IP holder are favoured and it seems that IPRs are increasingly a tool for protecting investment and reinforcing market power. Hence, it is time to bring some balance back into IP policy-making and to recognise the asymmetrical bargaining power in IP negotiations. In order to respond to these needs, three widely documented initiatives, supported by the international community, are worth mentioning: 1) The United Nations adopted the Millennium Development Goals (MDC's) in 2000 which acknowledged the severe problems affecting developing countries and least-developed countries and made firm commitments to combat these problems; 2) the WTO kicked off its Doha Development Round in, Doha, Qatar in November 2001, providing the mandate for negotiations on a range of topics (the Doha Ministerial Declaration). The original mandate was later refined at Cancun, Geneva and Hong Kong. It was envisaged to conclude the Round in 2006, but negotiations in Geneva in 2008 remained deadlocked - the main topics of dispute being the opening of agricultural and industrial markets; 3) The Proposal by Argentina and Brazil for the "Establishment of a Development Agenda for WIPO" drafted in 2004 and formally adopted by the WIPO General Assembly in 2007. The Development Agenda makes explicit reference that WIPO's role is and should not be limited to the promotion of intellectual property protection but ought to be fully guided by the UN's broad development goals, in particular the Millennium Development Goals. The key objective of the WIPO Development Agenda is to reduce the "knowledge gap" and the "digital divide" in order to allow developing nations to catch up with developed ones. It underlined that intellectual property should not be seen as an end in itself and that harmonisation of intellectual property law's should not occur irrespective of countries' levels of development. The agenda reconfirms the promises made in the Doha Ministerial Declaration - both the pledge under paragraph 19, which sets a mandate for the TRIPS Council to take fully into account the development dimension, and the promise in the Declaration on the TRIPS Agreement and Public Health, which mentions that the provisions within the TRIPS Agreement should support and not counteract the public health objectives of all countries. The WIPO Development Agenda also says that a multilateral agreement on access to basic science and technology (ABST) should be established in the framework of the WTO in order to increase technology flows to poor countries. This would involve the placing into the public 
domain, or sharing at little cost, the results of publicly funded research. The idea is to preserve and enhance global science and technology, while setting out a public mechanism for increasing the international flow of technical information, especially to developing countries, without unduly restricting private rights in commercial technologies. This agreement could include provisions advocating increased opportunities for temporary migration of scientific persommel and additional student visas. It would also need to promote access to scientific databases and ensure that intellectual property regulations do not limit access to basic scientific knowledge. However, realisation of the proposals in the WIPO Development Agenda will be a political challenge. It is likely that norm-setting, technical assistance activities and flexibilities will receive the most attention in the deliberations.

At the multilateral level, IP negotiations are ongoing under the auspices of the WIPO and the WTO. Recent discussions in WIPO have centred on divergent subject-matter: on the one hand discussions centred on expanding the scope of protection for instance, developed country demands to harmonise further the patent system (in the framework of the Substantive Patent Law Treaty (SPLT)) and efforts to further regulate broadcasting rights as well as to improve IPR enforcement. On the other, developing countries wishes to reform the global IP system towards development - which led to the recently adopted WIPO Development Agenda and negotiations on the protection of traditional knowledge, genetic resources and folklore. Within the multilateral context but also in FTA negotiations, the developed countries advocate membership of the WIPO Patent Cooperation Treaty (PCT) by noting that it will enhance technology transfer. The PCT has been criticised for being a one-sided system that benefits big industry in developed nations. In this regard, it would be worth exploring the establishment of a special fee for applications through the Patent Cooperation Treaty, the revenues of which would be earmarked for improving IP administrative systems in developing countries. Currently as the primary beneficiaries of stronger patents in the developing world will be firms in developed economies, poor countries have little incentive to fund these institutions. Hence, a special administrative fee at the PCT for developing countries (or other international patent organisations) is sensible and recommendable.

Also, the World Trade Organisation (WTO) tackles IP issues in its ongoing negotiations. Within the framework of the WTO, the current focus of the negotiations is on the so-called in-built negotiating provisions of the TRIPS Agreement and the outstanding implementation issues emerging from the Doha Development Agenda. The in-built negotiating provisions relate to the extension of the higher level of protection for geographical indications (Article 24.1 TRIPS), the establishment of a multilateral system of notification and registration for wines and spirits (Article 23.4 TRIPS), and review of Article 27.3(b) on exclusions from patentability. The implementation issues deriving from the Doha Development Agenda refer to public health, geographical indications, the relationship between the CBD and the TRIPS Agreement, in particular the introduction of a disclosure of origin requirement, and increased technical 
cooperation efforts to LDCs (which could increase their participation in the discussions).

Negotiations are ongoing but progress is slow, mainly because countries have different interests. There is a lack of evidenced-based inputs, such as costbenefit analysis (indicating the advantages and disadvantages of adopting stronger IPR protection) which could promote greater understanding of the issues at stake. Progress in norm-setting activities is dependent on consensusbuilding and careful selection of trade-offs. To a certain extent, developing countries are forced into entering multilateral, regional or bilateral agreements that enhance the set standards in the TRIPS and WIPO Agreements since the big market players like the US set conditions on market access unless they enter into bilateral agreements. However, the views of developing countries and other stakeholders are increasing in number affecting the direction and content of various negotiations processes - in contrast to ten years ago. In particular, the involvement of more specialised think thanks, academics and NGOs has increased the IP knowledge of developing countries and has empowered them to contribute better in the negotiations process, which they had not done before.

For countries that are for the most part net importers and purchasers of intellectual property the benefits and interests of a far-reaching IPR Agreement, strengthening the rights of IPR right-holders, is not immediately present. The cross-cutting nature of IP issues and the number of institutions addressing IP. related issues poses policy coherence challenges which demand increased cooperation between country delegates and institutions. Hence, the price that developing countries have to pay for the much-wanted opening of developed country markets is high, particularly the implementation and enforcement costs to obey to the TRIPS Agreement. Developing countries face many challenges relating to the implementation and enforcement of the rights and obligations derived from the TRIPS Agreement as well as the regional and bilateral trade negotiations including IPRs. Notably, the negotiation process does not end with the conclusion of the agreement. On the contrary, the complex process of implementing these obligations is just about to start. Not only is there the need to reform domestic legislation to incorporate the new provisions, countries also must become party to the various IPR treaties in line with the agreed timeframes. A prerequisite for effective implementation of these rights is the existence of an appropriate institutional and administrative framework, as well as good governance, infrastructure, including cooperation between custom authorities, ministries and police authorities. When the implementation process is concluded, countries are subject to constant monitoring of their implementation and enforcement obligations.

In particular, the enforcement of IPRs has gained prominence in recent years on the global trade and intellectual property agenda. Recently a DSU Panel had to consider China's measures affecting the protection and enforcement of IPRs on request of the US. Lately there has been a huge push by developed 
countries for developing countries to strengthen IPR enforcement. However, there is more discussion about stronger IPR enforcement than there is about data collection on the losses industry suffer through counterfeiting goods and piracy, which is necessary for effective and balanced policy-making. This often one sided debate should be approached with care. It is important not to lose side of the implications and challenges for developing countries in providing IPR protection, while indicating the rights and obligations, including flexibilities they are entitled to under the TRIPS Agreement such as research and education exemptions. As chapter one and five of this book have indicated complementary policies besides IPR protection are needed, such as educational reform, market liberalisation, competition policies and adequate enforcement. Thus, public policies will have to focus on supplying incentives for invention and innovation which camnot be dealt with solely by IPR. Moreover, there is a need for technical assistance activities, focussing on highlighting rights and obligations derived from the existing IPR framework, including a thorough understanding of the available flexibilities.

\section{Using FlexibILITIES and TECh inICAL Assistance Possibilities}

Chapter two of this book gives a detailed overview of the rights and obligations derived from the TRIPS Agreement and the flexibility given to developing countries to support their own technological and socio-economic development needs. Notably, Research exemptions and anti-competitive provisions are two key but under-explored flexibilities in the TRIPS Agreement. Other flexibilities are the use of compulsory licenses (especially in relation to national emergencies situations as discussed in the Doha Declaration), parallel importation, utility models, trade secrets, exhaustion of rights allowing for parallel importation and national emergency that have been discussed by the Doha Declaration. These are all in addition to the country's freedom in implementation and interpretation of rights and obligations, provided in Article 1 of the TRIPS Agreement. Hence, countries can benefit proficiently from smart drafting of domestic IPR regimes.

There is great potential to make further use of the compulsory licensing system. Compulsory licensing effectively allows the production of generic copies in return for payment of a royalty to the patent-holder. The government's decision whether to grant a compulsory license should be carefully scrutinised. The risks of not granting a compulsory license are that technology will be monopolised and priced too high but the risks of granting such a license too readily are that incentives for private research will be decreased and impact on future FDl decisions. For developing countries, it is important to investigate other possible uses (outside the field of pharmaceutical patents) for compulsory licensing. For instance, the option to amend the TRIPS Agreement to allow for the compulsory licensing of environmentally necessary technologies to reduce the burdens on climate change, such as power generation, transport and industrial energy use. There is also potential to use compulsory licenses in 
the electronic or automobile industries, particularly in relation to the production of spare parts.

Innovation represents an important challenge for the regions, not only for competing in intemational markets, but also, and more importantly, for advancing living standards, in particular in the farming sector. In a biologically rich region, inmovation could be increasingly linked to the intelligent use of biodiversity, not only for economic growth and promoting job creation, but also for the conservation of natural resources. As biotechnology is fast becoming an economic growth generator in several parts of the world, the research exemption and anti-competitive provisions in TRIPS could be used to develop local biotechnology sectors in developing countries to counter an over-dependency on essential products like pharmaceuticals from developed countries. Most of all, it is essential that governments and other national actors understand the importance of innovation, technological progress and sustainable development for growth and development. In particular, developing countries should focus on making their small and medium enterprises (SME), more innovative and competitive.

In addition, developing countries are entitled to transition periods which were recently extended. The Decision of the Council of TRIPS of 29 November 2005 entitled "Extension of the Transition Period Under Article 66.1 For LeastDeveloped Country Members" granted LDCs an extension until July 2013 allowing them more time to implement the TRIPS Agreement. Moreover, paragraph 7 of the Doha TRIPS Declaration on the TRIPS Agreement on Public Health extended the transition period for least-developed country Members to ten years, with regards to pharmaceutical products; hence these countries can delay patent protection for these products until 1 January 2016. These periods are meant to provide extra time to developing countries in order to improve the creative and innovative capabilities of a country and to ensure that in future these countries will be able to benefit themselves from IPRs. However, developing countries need help in pursuing these endeavours. The Doha Ministerial Declaration declares that the WTO technical assistance should focus on assisting developing countries to implement existing WTO obligations as well as on increasing their capacity to participate more effectively in future multilateral trade negotiations. ${ }^{1}$ In order to achieve these goals, the following factors were considered to be of importance: enhanced market access, balanced rules, financial assistance and capacity-building programmes. 2 The Decision of the Council for TRIPS of 29 November 2005 under Section 2 reiterates developed countries' commitments on technical and financial assistance to help least-developed countries implement the Agreement. Section 2 indicates that the least-developed countries should provide a list of their individual

See WTO Dota Ministerial Declaration, p. 8.

2 Ibid., p. 1. 
priority needs for technical and financial cooperation. The only countries which have followed up this request are Sierra Leone and Uganda. Both have submitted communications ${ }^{3}$ to the WTO TRIPS Council, titled "Priority Needs for Technical and Financial Cooperation". These initiatives are important and more countries should follow, if only to show at the lapse of the transition periods that technical assistance was requested but not successfully delivered and hence a new extension is desirable.

\section{GEOCRAPHICAI. INDICATIONS AND ITS POTENTIAL FOR DEVELOPINC COLNTRIES}

Chapter four examines the potential of geographical indication (GI) protection for developing countries. As a result of the TRIPS Agreement, Gls are afforded international protection as a separate type of intellectual property, and have simultaneously become one of the most debated issues within the WTO. In fact, the WTO is divided between Europe and the "Old World" in favour of greater protection for GIs, on one side, and the United States and the "New World" opposed to greater protection, on the other side. A GI is a name or sign used on certain products which correspond to a specific geographical location or origin and certify a certain quality or reputation due to its geographical origin. While most often used on food products, geographical indications can be used to identify any product (e.g., Swiss watches, Peruvian silver, Indian scarves) that may be associated with a specific geographic place. Gl protection can be used as a legal tool to develop, market and protect products based on distinctive methods of production that have been preserved and nurtured over time and passed on from generation to generation within communities belonging to a certain region. Hence, Gis are useful tools to indicate product quality, brand identity, as well as to preserve traditional and cultural traditions. The use of geographical indications allows producers to obtain market recognition and often a premium price. Arguably, with the increased internationalisation of food and product markets, GIs have become a key source of niche marketing. Notably, Gls do not prevent producers from other regions from marketing the same kind of product, but do prohibit them from selling these products under the same reference or label. Products protected with Gls must therefore remain competitive in their market category.

Outstanting GI lssues

Chapter four emphasises that there are many outstanding issues - related to Gl protection - that need to be addressed by the international community and

Communication by Sierra Leone to the TRIPS Council, IP/C/W/499, 3 October 2007 and Communication by Uganda to the TRIPS Council, IP/C/W/500, 9 October 2007. 
on a domestic level. These include - and not necessary in this order - the following items:

1) Ensuring domestic profection. These include ensuring that Gls are protected at the national level - a key requirement to obtain protection at the international level.

2) Generic Names. In addition, solving the controversies that exist when names that are GI protected in one region simultaneously have a common use in the other (i.e. generic status - names customary in common language as the common name for such goods). Currently, countries are diametrically opposed on the issue of generic expressions (a famous example being "Basmati"): some argue that these "generic" names should not belong exclusively to a specific group of producers in a specific geographic location as consumers expect these names to identify a class of product that can be produced in one of many locations. On the other hand, others argue that the products associated with the name have a certain quality that derives from the geographic region and specific production process used and hence deserves protection.

3) Homonymous Gls. Furthermore, finding a solution as what to do with the so-called homonymous Gls, that is situations where two geographical regions are identically named and produce identical/similar products based on identical/similar production methods. The issue of homonymous Gls pertains almost exclusively to wines. Notably, in most cases it was the European immigrants that took the names and accompanying production methods to their new fatherlands.

4) Extension of Gl protection. Currently the TRIPS Agreement contains a twotier level of Gl protection: basic legal protection for all products and a higher level for wines and spirits. This hierarchy in protection is the subject of much debate within TRIPS Council negotiations. Advocates of expanding the special protection given to wines and spirits to other GIs believe it will facilitate the export of products of interest to all members, guarantee better consumer protection and improve the marketing of their products by differentiating them more effectively from their competitors plus promote rural development. In addition such expansion would further the commercial interests of many developing countries, as they, are not big producers of wines and spirits (not to mention Muslim countries, where domestic alcoholic production is almost zero) and they would benefit from extended Gl protection, in particular to agricultural and food products such as tea, rice, coffee, cacao, corn, tropical fruits as well as handicrafts. On the other hand, opponents of extension argue that: A) the existing level of protection under TRIPS Article 22 is adequate and that extension would be redundant; B) enhanced protection would be a financial and administrative burden and would disrupt existing legitimate marketing practices. 
5) Introduction of a Gl register. In addition to the extension of Gl protection, the debate has been focusing on the introduction of a multilateral system for the notification and registration of wines (and spirits) as envisaged in Article 23.4 of the TRIPS Agreement. The objective of a multilateral register is to facilitate the protection of GIs for wines and spirits. At the heart of the debate is what legal effect, if any, the multilateral register would have within Member states: options vary between a voluntary or mandatory system. Opinions vary greatly on the scope of protection of such a register: some countries support the case that the multilateral system should not be limited to wines only, while others think that an extension of subject matter would be outside the given mandate and that therefore the issue should not be discussed;

6) Bilateral and Regional Foreign Tradi Agrements. Next to negotiating at the multilateral level (at the WTO and WIPO), a country wishing to strengthen protection may follow a bilateral or regional route to impose protection of products on other countries. These agreements contain extended protection for GIs, including the higher type of protection for all kinds of products. Frequently, a list is included with names that should be mutually recognised and granted protection - a solution to deal with the generic names issue. In this regard the possibility exists to negotiate a cap (ceiling) on the number of Cls that can be registered and mutually accepted in foreign trade agreements (FTAs) and on a multilateral level.

As per point four, unfortunately, there is a lack of empirical evidence and studies to support either side of the GI extension debate. Some developing country and developed country producers may possibly benefit from increased GI protection for one or two products, the major beneficiary of extension would be Europe, which has almost 700 products registered as GIs within its territory. However, the costs of extension would fall overwhelmingly on nonEuropean countries that would have to protect all of Europe's Gls whilst gaining little in return, at least in the short and medium term. Gl extension would not in itself, for example, guarantee access to export markets. Developing countries may consider undertaking a cost/benefit analysis as it applies to their domestic situation in order to determine whether or not countries are likely to benefit from a $\mathrm{Gl}$ protection system. Hence, it is recommended that developing countries examine the following issues before taking position in the GI extension debate: A) Examine the potential benefits from granting GI protection against the costs related to the establishment of the legal and administrative system (including the surrender of generically used names) that it would require; B) Furthermore, developing countries need to analyze the market for their potential Gl products, domestically as well as regionally or internationally; C) Pursuant, developing countries should produce an inventory of potential GIs. Much like trademarks, GIs are intrinsically linked with buying and selling. While in some instances the markets might be international, in the first instance it could be worthwhile examining the local and regional market potential. Hence, it is important to prepare a list of those GIs 
that are currently being protected and identify potential GIs in developing countries to visualise the importance or nuisance of Gl protection for the country. Moreover, a list should be drafted of foreign GIs that are currently generically used in the country as extension/strengthening of Gl protection may involve the surrender of these generically used names; D) Assessment of technical needs for instigating national frameworks (including setting methods of production) on GIs and protecting national products. In this regard developing countries should consult with the proponents of GI extension, e.g. the European Community (EC) and Switzerland, international NGOs and civil society to commission such cost/benefit studies; E) Developing countries should coordinate among themselves: for instance, it is advisable that the African Group within the WTO establishes a common position, as this would strengthen its negotiating position.

As per point four and five, many countries have expressed in TRIPS Council Meetings that they have faced problems in the implementation of TRIPS including the provisions dealing with Gl protection. Opponents of GI extension use this reasoning to support their view points by saying that it is too early to add more obligations and accompanying institutional framework requirements (e.g., establishing legal GI system, setting production methods and enforcement mechanisms).

As per point five, it has also been proposed to replace the reference to wines and spirits with "products protected under Article 23 of the TRIPS Agreement". The rationale behind this is that if the multilateral register were introduced, it would automatically be applicable to other products should GI extension become a reality. It is important that, before taking any decisions at the multilateral level, developing countries first decide on their domestic position, including on the mandatory elements in notifications. This analysis should focus on costs and benefits, particularly whether the administrative and financial costs of setting up such a system would outweigh its potential benefits in the long-term. In addition, the decision to support such a system should be linked with political stance on GI extension.

As per point six, the EC has been particularly active in negotiating bilateral and regional agreements to protect its GIs by putting in place a strategy to export its Gl protection regime to other parts of the world. It is common practice to complement such an agreement with an annex listing the existing Gls within the contracting parties that should be mutually recognised and protected. Due to the EC's large economic bargaining power, the bilateral and regional route is quicker, and probably more effective than the current multilateral route, for imposing the protection of products on other countries and regions. The $\mathrm{EC}$ is seeking to achieve a level of $\mathrm{GI}$ protection comparable to its domestic system. Especially with regards to the ongoing pressure within the wider WTO context, where the EC is committed to lowering its export subsidies, the EC has chosen to alter its agricultural policies and adopt GI strategies to maintain European market share throughout the world. 


\section{Final Remarks on Geographical Indication Protection}

The analysis in chapter four reaches the conclusion that GI protection is most suitable for products that have a "history" because GIs protect certain specific methods of production that have evolved over time as a kind of dynamic improvement process and therefore have acquired a certain reputation, quality or characteristics that justify protection against imitation. If, on the other hand, the product still needs to establish a place in the market, implying that neither the production methods nor their reputation have yet been established, trademark protection might be more appropriate. It could be more cost-effective to install a trademark system allowing for collective or certification marks then a Gl sui generis system of protection. This is easier to acquire - a simple labelling of the product will suffice. However, trademarks - in contrast to GIs - need to be registered which involves administrative procedures and regular payment of a set fee. It is important to note that there is an essential difference between trademarks and collective and certification marks with regards to conditions for application. Trademarks that entail descriptive geographical terms are as a rule excluded from protection, whereas geographical terms are normally expressly permitted for collective and certification marks. Notably, Gls - in contrast to TMs - have important potential to protect and promote the sustainable use and more equitable sharing of benefits deriving from biodiversity and related traditional knowledge, practices and customs. Nonetheless, GIs can only protect traditional knowledge to a certain extent as they do not protect the actual knowledge embodied within the good and/or the associated production process. As a result, Gl protection does not guarantee against the misappropriation of TK (i.e. bio piracy).

Many developing countries have the potential for protecting GIs on a national, regional or even global market scale, and most likely some already function as GIs in practice but governments have failed to provide the national legal frameworks of protection. It would be wise for developing countries to ask for a transition period within the context of the multilateral WTO negotiations. This includes negotiating a cap (ceiling) on the number of GIs that can be registered and mutually accepted in FTAs and on a multilateral level. This would allow them to research, examine and make an inventory of potential Gls and to register them, but they could install the necessary administrative framework later (hence acting as a kind of moratorium). Foremost, developing countries should take ample time to complete the implementation of the current GI provisions of the TRIPS Agreement into national laws. This includes taking the time to get familiar with the concept of GI and conducting an analysis of the old system, its shortcomings and problems and conflicts before rushing into adopting a new registration system and the extension of protection.

When deciding what kind of legal system to adopt the cost element plays an important factor, for instance policy makers should take the following elements into account: 
1) The expense of setting up the necessary infrastructure and institutions. This includes the organisation of producers by establishing co-operations, unions or associations. These associations need to install and implement the applicable method of production in order to guarantee the quality of the specific products;

2) The running costs of the system including the costs to acquire and enforce the rights;

3) The diversity of potential sectors where GIs might be of importance (in particular the rural, agriculture, agricultural-food processing, handicraft industries and small scale industries). All these factors make it difficult to design a domestic regime. As per point 3 , if one takes into consideration that for developing countries agricultural and rural-based products are important industries, it would be best to start the identification of products suitable for Gl protection amongst these sectors followed by the handicraft industries;

4) An examination of the national, regional and international market potential for Gls. Chapter four also recognises that the use of Gis does not in itself guarantee market access or commercial success. The latter requires constant development of and investment in promotion and communication strategies, crucial to effectuate the potential benefits of product differentiation. This includes looking at the market access possibilities: "How high are the tariff lines?", "Are there any sanitary and phytosanitary measures that need to applied?" and "What are the technical standards requirements?" As well as improving the supply chain management including marketing strategies, e.g. using billboards, radio and information technology mechanisms to promote the GIs. However, as indicated GIs are often associated with non-monetary benefits such as the protection of traditional knowledge, community rights and biodiversity conservation and preservation;

5) The establishment of measures to protect local indications from being rendered generic and safeguard its legal rights. The Darjeeling case has shown that fighting infringement is costly; and

6) An examination of the added value of joining the Lisbon Agreement as negotiations in the WTO take many years to conclude. The Lisbon Agreement can protect Gls (i.e. the Lisbon system protects a type of GIs, so-called appellations of origin for which the threshold of protection is higher in line with the extended protection for wines and spirits provided in Article 23 TRIPS) at the international level provided domestic registration and protection is in place.

As we have seen the protection of Gl cuts across a range of issues, which, besides the prevention of misleading use and dilution of indications touches upon sustainable development, the promotion of agricultural development, 
the protection of indigenous knowledge, and consumer as well as producer protection. Due to the different interests at stake and highly controversial policies on agriculture, a breakthrough in the current impasse at the WTO TRIPS Council and WTO Agriculture Committee deliberations is unlikely. Indeed, GIs do facilitate product differentiation as they protect products which evoke quality, special characteristics and traditional methods of production but GIs do not guarantee market access or compliance with safety and consumer standards. In this regard, developing countries should consider trading market access for agriculture and tropical products in exchange for the enhanced protection of GI. They should also raise awareness of the difficulties they face in accessing EC markets for their products as the labelling and eco labelling regulations set by the EC do not take account of the realities of these countries, i.e. all these rules are difficult to apply for small companies and these rules do not consider the type of materials or procedures used by developing countries.

In the long term, developing countries should focus on developing, identifying and protecting GIs at the domestic market. This could help development and economic growth if biodiversity and environmental concerns are also taken into account.

\section{THE SEARCIIFor Biodiversity and TRaditional KNOWLEDGE PROTECTION}

Developing countries hold the majority of the world's genetic resources and TK and are concerned about contemporary practices that appropriate biological diversity and associated traditional knowledge. Chapter three of this thesis looks at the protection of traditional knowledge and the challenges and implications for developing countries to achieve some sort of international protection. The search for new pharmaceutical, biotechnological or agricultural applications based on genetic resources has emerged over the last decades and subsequently IPRs have been applied to protect innovations based on genetic resources. Hence, genetic resources and associated traditional knowledge have economic significance. These practises (the patenting of biogenetic resources) have raised debates at multilateral fora in part because of the (perceived) potential for exploitation of biogenetic resources for biotechnology as well as for neglecting the contribution of indigenous communities to the identification of the therapeutic properties of native plants. Indigenous communities that have identified therapeutic properties of native plants and have contributed to their conservation and preservation express concerns about the accessing and exploitation of their biogenetic resources without their consent. Moreover, they have not been compensated for the use of their genetic resources, nor have they shared in the benefits from the exploitation. The appropriation of genetic material can have severe consequences for indigenous people in terms of economic losses and access restrictions, which might stifle the preservation of culture, biodiversity and the further develop- 
ment of TK. As a consequence, interest in the protection of TK has grown significantly over the last two decades.

The inclusion of discussions on the protection of TK within the framework of the WTO TRIPS Council, the WIPO Intergovernmental Committee on Intellectual Property and Genetic Resources, Traditional Knowledge and Folklore (IGC) and the CBD committees has made the protection of TK a political matter, as policy-makers need to balance the expected benefits of introducing international TK protection against their domestic costs. The protection of TK within a multilateral framework would give the legal possibility of asserting rights outside the domestic territory and would show' recognition of 'TK within the international community. Chapter three discusses four main arguments underlying the granting of TK protection: 1) The primary argument in favour of the protection of TK is that it can prevent bio piracy (misappropriation of genetic resources - generally by means of patents - of genetic resources and associated traditional knowledge); 2) Further justification is in the wealth distribution argument that TK protection should benefit indigenous communities and even improve their livelihoods. This could occur through benefitsharing agreements or "royalties" in exchange for access to be collected by a bio-collecting agency; 3) Similarly we can argue that protection favours public policy interests: mamely the continuation of the preservation and maintenance of biodiversity requires that adequate protection should be given to traditional knowledge; and 4) Safeguarding TK and indigenous people could provide major help in the conservation of the environment.

It is important that countries that are searching for solutions to stop the misappropriation of genetic resources and TK, and promote the protection of TK in some form, should ultimately achieve some consensus on what the objective or objectives should be: a long-term vision is an absolute must. This applies equally to national regimes of protection. Without clear objectives; laws, sui generis systems or policies are unlikely to be effective. The benefits of having an effective domestic regime in place are twofold: Firstly, it will show that TK protection is a matter of serious national concern, which will strengthen the negotiating position at the international level. Secondly, it will also provide insights into the mechanisms and procedures that work well, which will inform and facilitate the establishment of an international regime. Thirdly, due recognition should be given to the fact that TK is not exclusive, as the same knowledge is simultaneously held and shared by a number of indigenous peoples in the formulation of decisions on authorisation and benefit sharing and hence it is important to take a holistic as well as inclusive approach whilst seeking for solutions.

Negotiations within the WIPO IGC have been troublesome and characterised by diametrically opposed viewpoints about TK and its complexity. The introduction of an international protection regime has been hindered by a number of factors. Firstly, the lack of a definition as to what constitutes traditional knowledge as well as the scope of its protection. However, the need for such a 
definition is questionable as the IP system seems to be working without an exact definition of what constitutes a patentable "invention". Secondly, TK is addressed in multiple fora each focussing on different aspects of TK, for instance, its promotion, preservation, protection and exploitation. In addition, TK is associated with multiple stakeholders and touches upon various areas: health, food, agriculture and biodiversity, folklore, access to knowledge, education, the biotechnology industry and the environment. Thirdly, it is difficult to protect TK at the international level, since countries most interested in obtaining such protection lack domestic protection. It might even be that the indigenous community requesting protection are not recognised in the country itself and do not receive support from the national government. Currently a lack of national protection is obstructing progress to move towards an international protection of TK at the multilateral level - as many developed countries argue that TK should first be adequately protected at the national level. Developing countries with an interest in TK protection dispute this point of view, saying that these developed countries avoid discussion on a TK regime of protection as it is not a political priority to them. Fourthly, some local knowledge used among indigenous/local communities does not stop at the border but encompasses various geographical borders. One can argue that the concept of "community" extends beyond a historical, geographical connection. Hence, questions arise as "What defines a community" and "How can this cross border issue be dealt with within a legal framework"? Fifthly, finding a solution to protect TK is impeded by the existence of different legal, historical, socio-economic and cultural traditions in the protection of works. These factors have influenced national policies, resulting in (customary) local laws which often do not coexist with IPRs. Hence, it follows that in order to understand the problems in the introduction of TK protection it is important to address different cultural backgrounds that have influenced governmental policy objectives and legislation. This also includes the value indigenous people attach to their land, spiritual and religious beliefs. This is not an easy task, since these values are based on different views about society: cultural versus economic goals; community interests (common good) versus individual ownership (proprietary good); and the reductionist westem scientific tradition versus the holistic use of TK by indigenous communities.

As per element two, having ongoing parallel discussions on the protection of traditional knowledge within the WTO TRIPS Council, the WIPO IGC, the Food and Agriculture (FAO) International Treaty on Plant Genetic Resources for Food and Agriculture, and the $C B D$ raises further questions of coherence between deliberations in these different fora and adds to the complexity of this technical debate. The discussions also reflect the highly political nature of the issue. The fact that TK is now being discussed in so many different international fora means there are both opportunities and challenges. Opportunities arise from the fact that these topics are being discussed and are the subject of substantive proposals in various fora which have gained the broad support of many countries. For instance, the WIPO IGC has prepared draft provisions for the protection of traditional knowledge. However, chapter three also found 
the number of fora addressing TK, and the numerous proposals and submissions made, can also obstruct the process as countries are inconsistent in their proposals, get trapped in general statements and, as countries change their diplomats regularly, the continuity in discussing the matter can be hindered. Foremost, there is a need for one common position on the protection of TK amongst the supporters of TK protection identifying clear, realistic and achievable goals based on an informed, well-founded analysis of what is necessary and feasible. This has proved unforthcoming, as indigenous groups are unique and have not been able to adopt a common position. Not being one singular group, they embrace many different values, and there is no common understanding as to how TK should be protected.

In addition, within the academic discourse and the Geneva community there is debate over whether the CBD conflicts with the TRIPS Agreement and, if so, how such conflict can best be resolved. There is a strong perception among many NCOs and also many country officials that there are tensions or even conflicts between the objectives and rights of different stakeholders and the potential effects of the various international treaties - the TRIPS Agreement, the $C B D$ and the FAO Seed Treaty. The debate is obstructed by the reality that if one side decides that there is no conflict it does not examine the matter any further and the status quo remains. The debate therefore has become polarised; the two constituencies are unwilling to, or incapable of, communicating.

Some nations, including Brazil, Panama, Portugal and Peru, have adopted sui generis systems to protect traditional knowledge, traditional cultural expressions, and genetic resources. Although they struggle with the implementation of these laws, in part due to financial constraints. However, the need for an international regime is apparent as these sui generis systems are territorial in nature and hence foreign countries are not obliged to satisfy any legal requirements from the genetic resources provider country. Positive protection could also be achieved through the use of database rights or through the establishment of a global bio collecting society (GBS) to reach contractual arrangements between indigenous peoples and industry. A CBS could be comparable to the common concept of collecting societies in the copyright field. It has also been argued that international organisations are better equipped to serve the needs of indigenous peoples than individual states. Other initiatives currently being undertaken to protect TK are access agreements or contracts for genetic resources, such as material transfer agreements (MTAs) under the FAO Seed Treaty. Contracts are a way to arrange benefit sharing between indigenous communities, research groups and knowledge collectors. Examples of these contracts are research protocols made by indigenous communities to regulate access to and use of their knowledge. A successful example of a benefit sharing agreement (initiative) outside IPR protection is an agreement reached in Peru over indigenous communities' rights to potato strains. Under the agreement, the IPC gene bank returns the genetic resources and knowledge associated with the potato strains to the six farmer communities, which have established a "potato park" in a large conservation area to grow and manage 
the potato plants. The agreement is drafted in such a way that the information is made public, so as to prevent third companies from patenting the potato strains and associated TK. The reason why the community has decided not to patent the strains is down to ideology and culture supporting the community's belief that the potato strains should not become subject to IPRs.

\section{Disclosure of Origin Mensures}

In order to halt the misappropriation of their resources and to minimise the granting of bad or erroneous patents, incorporating naturally-occurring genetic resources without due recognition or compensation, several countries and regions have applied disclosure of origin measures in relation to patent applications for inventions derived from genetic resources. Here, there are two separate but related issues: the disclosure of origin certificate, and the disclosure requirement. A certificate of origin would serve as a type of passport or permit that would accompany the genetic resource along the whole chain of the access and benefit sharing ( $A B S$ ) process. It could be verified at various points, particularly once the said resource left the provider country, ensuring the traceability of the genetic resources and increasing transparency. A certificate of origin would be a practical way to implement the disclosure of origin requirement, but it would not have the same legal consequences as an official amendment to the TRIPS Agreement, making it a much looser and less effective measure. In contrast, an amendment incorporating a disclosure of origin requirement would strengthen implementation and enforcement significantly as it would be linked to the WTO dispute settlement system. It would strengthen the process of verifying whether genetic resources were collected in accordance with national rules requiring consent, and whether the conditions for such consent were met. A disclosure of origin requirement has the potential to function as a bridge between national and international legislation as well as between the providers and users of resources to monitor trade and movement of resources in endeavours to protect and promote TK.

Some successes have been achieved, notably; discussions under the CBD have led to a process for adopting a certificate of origin system that would make the disclosure requirement operate effectively. The discussions within the CBD resulted in the adoption of the Bonn Guidelines, which brought disclosure measures into the patent application process. The Bonn Guidelines advocate the adoption of "a legally recognised certification of origin system as evidence of prior informed consent and mutually agreed terms". This soft law instrument endeavours to harmonise the various proposals and to make the disclosure measures operate effectively. It has also gained support in the context of the TRIPS Council negotiations.

Disclosure of origin measures are part of a broader system of measures to safeguard and protect TK of which access and benefit sharing (ABS) embodies an important component. In particular, the concept of ABS gained official recognition with the establishment of the $\mathrm{CBD}$. It addresses the range of 
benefits that result from the commercialisation of genetic resources at different stages in the research and commercialisation process. It can take different forms: financial compensation through royalty ranges or fees per used sample; stakes in equity or profit sharing; commercial partnerships like joint ventures, local employment possibilities; scientific, social and environmental benefits; or non-monetary benefits. Non-monetary benefits can take the form of sharing research results, exchange of information, technology transfer and local training and capacity building. These forms are inherently interlinked. Chapter three indicates that non-monetary benefits are likely to be more useful than monetary benefits as they are more promising for the future in that they can contribute to improving national scientific and technological capacities. Their usefulness is highlighted by the fact that the exploitation of genetic resources is a long and uncertain process and there is no guarantee that the commercialisation of the genetic resource will be successful. It is argued that $A B S$ should form part of national policies on sustainable development as part of the solution to stop misappropriation of 'TK.

In line with the negotiations within the framework of the CBD, the current discussions on biodiversity within the TRIPS Council have focussed predominantly on introducing a disclosure of origin requirement into the TRIPS Agreement. A group of developing countries, including Brazil, Ecuador, and India, have proposed amending the TRIPS Agreement to make patent applications require disclosure of the origin of genetic resources, and associated traditional knowledge used in an invention, as well as evidence of prior informed consent and benefit sharing with communities with a view to combating bio piracy However, many industrialised countries have questioned the need for such a requirement. Some consider the WIPO the appropriate forum to deal with these issues. Japan and the US - which is not a party to the CBD - do not regard the $C B D$ and the TRIPS Agreement to be in conflict with each other, but understand both Agreements to deal with separate issues. In contrast, the EC, Norway and Switzerland are supportive of establishing disclosure of origin requirements at the international level, but not necessarily in the framework of the WTO. Norway was the first developed nation to favour the incorporation of a disclosure requirement in the TRIPS Agreement, yet it differs from developing countries on the legal consequences of the lack of disclosure, considering that non-compliance should not lead to the revocation of the patent.

Chapter three analyses the various proposals on a disclosure requirement in the TRIPS Council and it concludes that Europe is gradually moving to embrace a disclosure requirement at the international level. It is said that a disclosure obligation would smooth the process of verifying whether genetic resources have been collected in accordance with national rules requiring consent, and whether the conditions for such consent have been met. The disclosure obligation would also make patent applicants aware of the importance of complying with the CBD (adopted by 190 parties). It can also be argued that a disclosure of origin requirement would help determine whether the patentability requirements in the TRIPS Agreement have been met and help prevent 
patenting where other requirements have not been met, for example, the novelty or inventive step requirements. For example, a disclosure of origin obligation can contribute to simplifying database searches on TK by providing an additional search field. A disclosure obligation would, therefore, also be useful in ensuring that patents are not granted contrary to the fundamental principles of patent law." However, the disclosure of origin debate raises a number of questions that have not been answered. For instance, there is no agreement as to what the ideal disclosure of origin regime should look like, the necessity of having such a regime, in what form, with what objective, within the framework of WTO, CBD or WIPO, its legal consequences and so forth. Therefore, proposals submitted to the international organisations differ in scope and in the terminology used.

Views differ as to the legal effect and practical consequences, the disclosure measure could be mandatory or voluntary; and whether its materialisation could lead to the addition of a fourth requirement to the patent system (as in the Belgian domestic legislation) or the requirement could be inserted as part of the grant (administrative) procedure (as in the Swiss proposal). Proposals have included various options as to the consequences of non-compliance, e.g. revocation of the patent or sanctions outside the patent system. As mentioned above, the use of specific terms have different legal and practical consequences. One can broadly identify three forms of disclosure with differing legal consequences for non-compliance:

1) voluntary measure - disclosure would be encouraged and recommended but failure to do so would not affect the patent;

2) mandatory regime - failure to comply would have consequences within the patent system or lead to civil or administrative sanctions outside the patent system;

3) going beyond a disclosure requirement in patent applications to require adherence to domestic or regional legislation on access and benefit-sharing and prior informed consent. ${ }^{5}$

The introduction of a disclosure of origin requirement would bring many practical problems. How will national regimes be brought into compliance on prior informed consent and $A B S$ on mutually agreed terms? How can patent officers be trained to deal with patentability issues in this area? For instance, even an operational disclosure requirement will not change the fact that so many resources and TK relevant to an invention being patented can be acquired or learned without visiting any of the countries of origin or source.

4 It is possible to overcome the difficulties of prior art/source retrieval of TK by using databases and registers in which countries codify the genetic resources and associated existing TK in their territories.

; See Queen Mary IP Report 2004. 
Thus the measure will only be applicable to a small number of patents. It is therefore questionable if a disclosure requirement will improve patent quality and stop the misappropriation of genetic resources (biodiversity). In addition, it is very tricky to determine the extent to which genetic resources and/or associated TK contribute to the patent. In many cases various types of knowledge, information and material may have contributed to the ultimate invention. In that case, is it feasible to ask whether all sources of knowledge and material should be remunerated, no matter how minor and peripheral to the invention? This brings with it the additional difficulty of tracing all countries of origin. Indeed, how would one deal with several countries that could all legitimately claim to be countries of origin of the same resource? Perhaps, a solution to this problem could be found in the establishment of community funds." Although the CBD advocates the preservation of TK by using mechanisms such as $\triangle B S$, prior informed consent and disclosure of origin, some shortcomings remain. For instance, plant species collected prior to the conclusion of the CBD fall outside the ambit of the CBD. In particular, botanical gardens and seed banks have gathered up to one third of the world's plant species, but remarkably the CBD does not demand that these banks adopt policies of prior obtained approval from the country of origin. As a result these genetic resources can be made subject to further use and subsequent commercialisation without the requirement to share benefits with the source country. This factor reduces the effectiveness of the CBD since the convention only has an impact on genetic resources obtained after the adoption of the CBD in 1992.

A distinction can be made between the defensive protection and positive protection of traditional knowledge. TK positive protection measures focus on the promotion and protection of $\mathrm{TK}$ in a rights-based recognition system, i.e. by recognising and granting economic or moral rights. This can be achieved via the application of existing IPRs, or by the development of sui generis forms. Defensive protection primarily concerns the prevention of bio piracy through misappropriation (grant of patents), misuse or illegal access. Examples of defensive protection mechanisms are the use of TK databases and registers (documentation), the obligation to disclose the origin of genetic resources, and the prevention of misappropriation. Databases can help trace prior art to identify unjustified patent claims and documented TK to foreign companies and patent examination authorities.' A growing number of initia-

"For example, under Peruvian law in order to access genetic material for the purposes of commercial or industrial application a license agreement must be signed ensuring that due reward for the access and the equitable distribution of the benefits deriving from it is guaranteed. A percentage of the revenue resulting from the commercialisation and marketing of goods developed on the basis of collective knowledge groes to the "Fund of the Development of Indigenous Peoples".

- However, attempts to set up databases of TK are coming under altack from the very groups they are intended to benefit. Indigenous groups are concerned that an 
tives seek to use databases and registries to conserve and protect TK and genetic resources. Other examples of defensive protection measures are setting TK patent examination guidelines, providing access to databases of TK (providing prior art) to patent examiners, or establishing genetic resources guidelines for equitable benefit sharing. Arguably, a disclosure of origin obligation may contribute to simplifying the task of searching through databases on traditional knowledge.

Chapter three concludes that a disclosure requirement, in the end, is only part of the solution to ensure that patents are granted in such a way that the invention furthers key objectives for the conservation of biological diversity, sustainable use of its components, and the achievement of social equity.

\section{Traditional Knoweledge and Existing IPRS}

Despite the inherent problems between TK and IPR protection which are further explained in chapter three of this thesis, it might be possible to protect some forms of TK by using conventional systems of IPR protection. For instance, patents, trade secrets and the law of confidentiality can protect TK against unauthorised disclosure and use. Patents and trade secrets might be used to protect $\mathrm{T} K \mathrm{~K}$ where the information leading to the invention is a closely guarded secret within the community; otherwise problems occur with regards to novelty. Copyright, performers' rights and design rights can perhaps be suitable for protecting cultural expressions of folklore, to some extent. ${ }^{8}$ Trademarks, geographical indications and certification and collective marks can protect distinctive signs, symbols or indications holding reputation and special qualities." The main problem with applying justifications which are the basis of the IPR system to TK protection is that IPRs are "forward-looking" in that they are meant to stimulate innovation. But knowledge created by indigenous people is not innovative since the information already exists and is not novel. Perhaps the problems with the IPR novelty requirement can be overcome if its definition is twisted to include knowledge and folklore. For example, it has been suggested that the term "traditional" should not mean "old" but refer to "the manner of producing such knowledge and not to the date on which the knowledge was produced"." For instance we can define TK as being knowl-

adverse consequence of these databases is that their knowledge is made publicly available.

* Developments are also taking place in the field of trademarks, as, for example, in New Zealand, where a law has been drafted to halt the registration of a trademark if it is likely to offend a significant section of the community, including the Maori. See Gray 2005.

4. See Posey and Dutfield 1996.

"I See Weeraworawit 2003, p. 159. 
edge that has been developed based on the traditions of a certain community or nation. Following such a definition, TK and folklore would not necessarily be barred from this requirement on the grounds of a lack of novelty. On the other hand, IPRs are only of a limited duration which presents a problem since most TK has been used for centuries and has been built upon from generation to generation. A major drawback of applying IPRs to TK and folklore is that they are territorial in nature, implying that the granted legal protection only has effect within the domestic territory. Currently, as indicated, there is no international legally binding instrument.

Chapter three also finds that it is time to improve the examination of patents in order to avoid onerous granting of patents. Oversights through a lack of access to knowledge should be avoided. Patenting standards have been widely criticised for being too low: for instance, patents are obtained on inventions which amount to little more than discoveries. Furthermore, patent authorities have been criticised for not working consistently and inadequately examining patentability criteria. For instance, a study has shown that in a third of the cases the patent claims did not match the legal requirement of a patent (novelty and non-obviousness). Another failure (already touched upon above in the disclosure of origin measure debate) is that even if the patent represents a genuine invention - no matter how the patent claim is defined - often no arrangements have been made to obtain the prior informed consent of the communities providing the knowledge or resource, and for sharing the benefits of commercialisation to reward them appropriately in accordance with the principles of the CBD. Moreover, substantive patent rules differ: for example, in the US the principle of relative novelty is applicable implying that outside the US prior art is only recognised if documented (written). Thus some forms of public disclosure of TK as prior art are excluded - in contrast to legal systems that use the principle of absolute novelty (including written and oral sources as novelty destructive). Notably, this is detrimental to the interests of the indigenous people who are accustomed to passing on their knowledge verbally from generation to generation.

\section{Final Remarks on TK and Disclosure of Origin}

Notably, the pharmaceutical and agricultural seed sectors are the most dependent on biogenetic resources. However, although industry has depended heavily on biogenetic resources and TK in the past, this does not mean that in the future they will equally depend on undiscovered resources and knowledge. Arguably, molecular biology and genetic engineering technologies will overtake natural products in drug discovery, design and development activities. However, TK is widely used, especially in the botanical medicine industry, as the basis for determining safety and efficacy, to develop agronomic 
practices for the cultivation of materials, and to guide the development of new products."

Having a disclosure of origin requirement would only partly ensure that patents are granted in such a way that they further key objectives for the conservation of biological diversity, sustainable use of its components and the achievement of social equity. It is possible that the EC could conceivably act as a bridge-builder between the developing countries on the one hand and the US on the other in resolving the question of whether a requirement should be introduced in the TRIPS Agreement. Meanwhile, Brazil and the LDCs believe that governments should consider potential trade-offs between geographical indications (the introduction of a multilateral register for wines and spirits) and the disclosure requirement - as proposed during the Doha Ministerial Meeting held in Geneva in July 2008.

Following the findings set out in chapter three, the following recommendations can be made:

1) Firstly, the most important (and obvious) consideration is that developing countries should be allowed ample time to develop their own policies, and enact domestic legislation that is supportive of IP protection and CBD objectives, including a detailed disclosure mechanism. It is crucial that the issues are well considered before any renegotiation of TRIPS. This includes the development of national systems of disclosure and access, and benefitsharing agreements. An established domestic administrative and legal regime, supportive of $A B S$ of genetic resources, will strengthen international claims and proposals for such a regime, including the disclosure of origin. It is important that countries that have not done so already, in particular most developing countries set in motion the process of creating access and benefit sharing (ABS) rules, including a disclosure of origin requirement, for their domestic legislation.

2) Secondly, countries should actively participate in FAO, WHO, CBD and other fora aimed at establishing an ABS regime for national and international applications.

3) Thirdly, it is worth studying the impact of special patent disclosure measures, already introduced in national laws, on the use of bio-prospecting and ABS and the extent to which patent applicants already provide source information in their applications when it is materially relevant to the application.

11 See Kate and Lard 1999. 
4) Fourthly, more solid consensus should be achieved in international fora on what the disclosure of origin measure should look like, and how it should work in practice, e.g. its scope, nature, key elements and objectives. It is also important to gain more insight into the implementation of the CBD and the Bonn Guidelines. This requires commissioning more technical work to facilitate this process: NGOs and think- thanks and research institutions could play a more important role in this regard.

5) Fifthly, a holistic approach is advisable - focusing on the possible legal modes of protection should not disregard other relevant topics, such as access to land and the preservation of the communities' lifestyles, since these are prerequisites for the conservation, promotion and further development of traditional knowledge.

6) Sixthly, since the development of an international protection regime for TK is a slow process it is important to establish databases documenting TK and to make them available to IP offices that can use them to search for prior art.

7) Seventhly, positive protection measures demand new rules which will be hard to put in place since their success depends on the willingness and participation of the governments. Probably, focussing on TK, through enhancements to, or modifications of, existing IPRs (defensive protection mechanisms) is the most effective and feasible way forward at this stage as they are the easiest to achieve as they involve no new rules.

8) Eighthly, as shown, there are many different ways of protecting TK and little agreement on what an international TK protection regime should look like. Arguably a disclosure of origin measure has the potential to function as a bridge between national and international jurisdictions as well as between the providers and users of resources to monitor trade and movement of resources. It is important to bear in mind that just as the optimum level of IP protection depends on a number of factors, such as the country's level of industrial and technical development and domestic inventive activity, the optimum level of TK protection also depends on the underlying objectives for such a regime. Hence it is important to analyse what the ultimate goal of TK protection is.

9) Ninthly, developing countries can benefit profoundly from smart drafting of their IP policies. If a sui generis regime is too complicated to establish at this time it is advisable for countries to set a misappropriation regime. A moratorium on adopting stronger IPRs would be also advisable.

10) Tenthly, developing countries should explore options such as open and collaborative projects, which can guarantee better access to information in certain fields, as demonstrated by the potato project in Peru. 
Indigenous rights holders attach great value to TK and folklore, but can the same be said of their governments? It camnot automatically be assumed that they do since indigenous people often are minorities in the countries in which they live; therefore it is important to support indigenous knowledge groups directly and to enable them to participate in negotiating fora. Although the WIPO Fund for indigenous groups' participation is a good start, WIPO should further increase access for non-governmental stakeholders in the IGC negotiation process to increase transparency, capacity building, awareness of IP concepts and participation. The establishment of the WIPO Fund for indigenous groups' representatives is helping to facilitate their increased participation but it should be emphasised that countries themselves should increase their efforts to include indigenous group representatives in their own delegations. Indigenous communities are finding it hard to get their interests reflected in the TRIPS Agreement, even though NGOs and scholars are gradually bringing their concerns to a wider audience. Overall, for the IPR system to work favourably for indigenous peoples it is important that they have "smonth comnections" with the access regime and, vice versa, a system to protect indigenous peoples' knowledge will have to be connected to the access regime and to the IPR system. ${ }^{2}$ One of the lessons to be learned from the Peruvian experience is that consulting indigenous communities and ensuring they participate in the realisation of the law and contractual models will contribute to future support of the law. Only if indigenous peoples feel that they are a part of the dialogue and they have some stake in the system will they support it rather than undermine it. Hence, the participation of the indigenous peoples through civil society and representative groups needs stimulation through adequate funding, capacity building and the willingness of states to include indigenous people in government delegations to the negotiations.

Both indigenous people, seeking to receive recognition and equitable benefit sharing for the use of their genetic resources, and industry, seeking to appropriate, research and technologically enhance biological resources, can mutually benefit from the IPR regime. However, without further awareness and recognition by governments and industry of indigenous peoples' contribution through some form of benefit sharing, the fruits of that indigenous knowledge may not be enjoyed in the future. Moreover, industry needs to realise the importance of conservation and sustainable development for biodiversity, and be willing to share some of their profits through access and benefit sharing agreements - which could be in the form of technology transfer arrangements - even if these agreements are (for the time being) outside the scope of the TRIPS Agreement/IPR framework. It is therefore, time for business culture to change so as to create an understanding of cultural differences and a respect 
for knowledge developed and captured in a way that does not fit with Western IP concepts.

One step forward is the international recognition of the need for enhanced cooperation between TRIPS and the CBD in the Doha Declaration. The interaction and differences between the two different knowledge systems should be acknowledged in the process of establishing a multilateral protection regime. Notably, some successes have been achieved foremost the recent adoption of the UN Declaration on the Rights of Indigenous Peoples by the UN General Assembly is a success in terms of the recognition of indigenous rights. The Declaration is fundamentally about respecting the rights of indigenous peoples. It emphasises that indigenous peoples have the right to self-determination - by that right they can freely determine their political status and pursue their economic, social and cultural development. Notably, this declaration has been negotiated for more than two decades.

In addition, WIPO has recently adopted the WIPO Development Agenda, which basically reinforces the mandate set out in the WIPO IGC and demands acceleration of negotiations. However, the ultimate aim of many indigenous communities is a multilateral framework for TK protection, and the development of a system of "community" or "collective" rights to protect TK.

Countries advocating the protection of TK should ideally work together to cooperate and act strategically as a group. They could start by agreeing on harmonised standards and apply the principle of reciprocity so that the rules agreed apply to the members of the union/group. This would provide a good starting point that would allow other countries to follow suit in due course. Whatever form of protection is adopted, the system should not be too rigid, as developing countries and indigenous groups are unique, with different needs, customs and traditions. There should be enough flexibility to accommodate the traditional and cultural diversity of all involved: a one size fits all approach is not likely to work.

\section{THE ROLE OF IPRS IN TECHNOLOGY TRANSFER}

Chapter five of this book analyses the importance of technology transfer for developing countries and it discusses the various modes through which technology is transferred and it provides an overview of econometric studies on the importance of IPR in stimulating technology transfer. Chapter five indicates that conflicting views remain as to how intellectual property rights protection impact development and it provides recommendations as how technology transfer to developing countries can be improved from both host and home country perspectives. It observes that since the launch of negotiations on the Draft 'Transfer of Technology (ToT) Code major changes have occurred in society with consequences for international trade and social and economic activities. First, with the swift pace of technological transformation technology has become important in all economic activities. Second, inter- 
national collaborations have led to the globalisation of all economic and technological activities. These two factors are intrinsically interrelated and mutually reinforcing, as demonstrated by the increase in patent applications (and use of IPRs in general) by foreign inventors within a country. Just as the relationship between technological intensity of production processes and products has grown, an increasingly important link between technological change and competitiveness has also appeared. The amount of knowledge required in production processes has grown remarkably; including increased intangible investments such as R\&D, training, and software development. Hence in our contemporary society, having access to technology determines to a large extent a company's and countries' competitiveness. In the long run access and diffusion of technology can make the difference and contribute to social wellbeing and welfare.

As having access to technology is crucial therefore, the importance of international technology transfer for economic development is beyond doubt. Transfer of technology refers to the "flow of human knowledge from one human being to another, through education, scientific literature, or direct human contact". "The transfer of technology from one country to another assures that a certain technology is not only useful in the country of development but is also of practical utility in foreign territories. It provides access to technologies that otherwise would not be available on home territories. In addition it reduces $R \& D$ expenditure for developing countries and it is efficient; the wheel does not have to be invented twice because existing knowledge and technology can be built on. It goes that the advantage of a certain new technology is significantly improved if it is widely used allowing the interoperability and interconnection of technological equipment. Hence it is important that multiple firms have access and are able to use newly developed technology enabling rapid technology diffusion and economic growth, which depends on technological change through the creation of new products and processes. ${ }^{1-4}$ Chapter five highlights that new products embody novel ideas and international trade transmits knowledge across borders but that simply having access to new products is not sufficient. A successful transfer of technology depends on both the capacity to learn and investments to apply technologies into local production processes. This is proven by the fact that countries in possession of substantial engineering skills and R\&D programmes for adaptation and learning are greater recipients of licensing flows than others. ${ }^{15}$ Chapter five finds that barriers to technology adoption are a key 
determinant of international differences in per-capita income and greater trade openness can increase growth by lowering such barriers. ${ }^{16}$

Chapter five also finds that the role of intellectual property protection in promoting innovation and growth in general and attracting the transfer of technology is still unclear and research remains limited and inconclusive. The main drawback is that a lot of these outcomes are to a great extent based on assumptions. However, some conclusions and recommendations can be drawn as discussed below. Arguably, the impact of IPR on economic growth and development is of utmost importance for government officials deciding on policy strategies dictating future (multilateral, regional, plurilateral or bilateral) negotiations. Moreover, having a more realistic evidence-based outlook as to how far an IPR legal framework determines the amount of technology transfer a country is going to receive will also help govemments implement the TRIPS Agreement obligations and other intermational, regional and bilateral agreements they are committed to. The number of patents registered provides a rough indication on the importance attached to innovation and the role local creation and innovation plays within a certain territory. "Statistics on licensing as an activity provide another way of measuring the use of IPRs but this information is not easy to obtain as licensing is primarily a private business activity.

Efforts to establish an intermational technology transfer code failed in the $1970 \mathrm{~s}$ and 1980s for a number of reasons including the following: 1) foremost, technology owners did not want to transfer technology without an adequate financial return; 2) lack of consensus on prohibiting restrictive practices and clauses written into technology transfer contracts such as those on making available any new improvements on the technology to the host country; 3 ) reluctance of technology suppliers (home countries) to adhere to the laws of developing countries (host countries); 4) lack of consensus on the effective enforcement and monitoring of the code and dispute settlement; and 5) no agreement on what defines international transfer of technology. ${ }^{1 s}$ However, chapter five indicates that our contemporary society is very different from how it was a couple of decades ago. In particular, globalisation has rapidly intensified, making the world a smaller place and changing the way trade is carried out as well as the increasing role technology plays in every day life, making people more dependent on it. Moreover, globalisation has caused free trade to spread which has led to many industries favouring production facilities that serve more than one nation. All these development have changed the way the technology transfer process is perceived by governments and industry. Generally speaking we can deduct a trend from merely accessing tech-

16. See Parente and Prescott 1994.

17 Sec Yap 2006, p. 8.

is See Girvan 2005, p. 5. 
nology to making sure there is an appropriate absorption of technology and dissemination into society. Moreover, competition has increased because a number of developing countries have become much more technologically advanced (especially the so-called BRIC countries). ${ }^{19}$ There are many more trained scientists and technologists, and science-based industries, which have flourished, as have national scientific research and financing programmes, thus making technological development more complex. The result has been increased specialisation and trade, both in components and in finished products that may have origins in a number of nations. Also part of this trend is that production chains are now often spread over a number of nations. All these developments have resulted in a changed business climate for (indigenous) developing world firms, as they now have to face global competition as well as local competition and they have to find a place in an already established and elaborate international production structure. Increased global trade also means increased specialisation as not every nation can have firms leading in every area of technology. Thus, a natural process of crystallisation takes place, as there is only room for a few centres of quality and highly specialised research and expertise in the world.20 Hence, chapter five emphasises that countries need to find their "niche" - their competitive advantage. In addition, the world has also become more regulated, including the IPR legislative framework, with the result that firms have fewer possibilities to learn by imitating/copying existing technologies or by using reverse engineering techniques. In sum, developing countries are late comers in an established market and do not have the same possibilities to learn by trial and error, whereas the Europeans, Americans and Japanese could pick and choose IPR systems to suit their needs when they were in the process of transforming from agriculture based to industrial based societies.

\section{Recommendations for Deweloping Countries to Obtain Sustainable Technology Trinsfer}

In contrast to the 1970s where the focus was on the attraction of technology, in our contemporary society successful technology transfer requires additional and crucial steps: firstly, the attraction of technology, secondly the assimilation and absorption of technological knowledge, thirdly, its adaptation to local conditions, fourthly, the absorption of subsequent improvements, fifthly, the generalisation of the transferred knowledge and sixthly the diffusion of it to a

1" In 1973 the combined GDP of West Europe and US was six times greater that that of India and China. In 2050, the estimated GDP of India and China will be 1.3 times greater than that of Europe and US and the population of the Asian powers will increase faster than that of the Western ones. Source 'Weltkrieg um Wohlstand', Der Spiegel 37, 2006. Maddison IMF; BIP in Preisen von 1990 bzw. 2005, kaufkraftbereinigt, Prognose Goldman Sachs.

211 See Barton 2007, p. 1. 
wide audience.21 Hence, it is crucial to invest in enhancing efforts to create and improve technological capabilities, not only to access the appropriate technology, but also to absorb and transform the technology and to utilise it for domestic socio-economic development needs. Technological capacity can be improved via investments in general, science and technical education, R\&D institutions as well as international exchanges.

Chapter five recommends that developing countries in search of technology must take some crucial issues into consideration before entering into technology transfer arrangements. Some recommendations for successful international technology transfer are:

1) The country (host country) wishing to acquire technology from a thirdcountry has to identify its technological needs in the light of its economic and social development objectives. This domestic needs assessment about which technology to attract should focus on the suitability, cost and conditions, of the technology packages - perhaps focusing only on a few essential components of them;

2) Moreover, host countries have to ensure an enabling environment to attract technology. This means improving infrastructure, transparency and stability in government and reducing corruption and violence, as well as fostering a reasonably open trade and investment regime. In this respect, it is important to analyze carefully the current local environment and its laws and policies and determine whether they contribute to the transfer of techmology or whether the existing technology policies, capital market regulations, and tax system discourage such activities:

3) Once, the technology has been acquired it is important that it is absorbed and adapted to local needs and disseminated widely to potential technology users. In this regard it is important that countries stimulate local R\&D capacity because this helps to improve the ability to absorb and adapt technology. As intemational technology transfer requires sufficient engineering and management skills it is important not only to attract new technology but also to accompany it with the necessary education and training in order to transmit knowledge on how to use the technology effectively;

4) In addition, it is crucial that a country focuses on what it is good at, finding a niche (a comparative advantage) for itself, while using technology that is free for everyone to use, because the patent has lapsed or because the

21 See Foray 2008, p. 5. 
patent holder has not patented the technology within their territories (avoid paying for technology that is not patented); and

5) Also, the terms and conditions of technology transfer contracts should be carefully analysed to offset any unfair technology packaging (e.g. such as certain cartels, exclusive grant back clauses and coercive packaging licenses restricting the use of competing technologies); ${ }^{2 \cdot}$

6) LDCs have limited capacity in developing and implementing competition policies to offset unfair technology packaging. It is advisable to establish competition authorities and to improve competition policies so that they are capable of monitoring and discouraging the use of restrictive business practices by technology owners. In particular, developed country competition authorities should be helpful in this area as they can provide technical assistance and guidance in identifying and examining unfair business practices conducted by MNEs in foreign territories. As developing countries often do not have the investigation capacity or financial means to stop them;

7) It is advisable for developing countries to push forward a number of recommendations set out in the WIPO Development Agenda, in particular recommendations $23,25,28,29,30$ and 31 , which urge countries to improve technology transfer and dissemination to developing countries, including better access to publicly available patent information. Moreover, these recommendations stress and recall the importance of building a viable and technological base at developing country level. The recommendations also indicate the importance of exploring IP concepts that are most suitable to the interests and needs of developing countries and how they need to understand fully and benefit from different provisions, pertaining to flexibilities, provided in the IP international legal framework;

8) Furthermore, developing countries should look for ways to stimulate innovation other than by granting proprietary rights. For instance, successful attempts like open source software show that innovation can be achieved by other means such as focusing on concepts such as sharing, open access and cooperation. History shows that scientific discovery has been greatly influenced by curiosity and desire. The idea of open source licensing is to keep discoveries freely available to researchers and producers, to build on knowledge and to share future developments. Moreover, informal ways of acquiring technology occurs through non-market channels of technology transfer which can be a useful source of new information and technology to developing countries, involving learning processes. For instance, it can be

22 These recommendations are based on the 'Licensing Guide for Developing Countries', WIPO 1977, p. 17. 
achieved through imitation, gleaned from careful product inspection, examination of patent claims, personnel movement from one firm to another as well as, the temporary migration of students, scientists, managerial and technical personnel to universities, laboratories, and conferences; and

9) In view of the above recommendations it is important that guidelines are established in the form of a toolkit for developing countries. This would serve as a kind of checklist for technology transfer activities, and would mitigate the effects of governments' high personnel turnover, facilitating the sharing of best practices and information. This toolkit should aim at attracting appropriate technology conditional to the interests of both the recipient and the home country. IGOs and NGOs could be helpful in developing such guidelines based on the 1970s UNCTAD report on home country measures. The Draft TOT Code also provides an excellent definition of technology transfer that has received wide support and could be useful in this regard as opinions differ on what is considered to be under technology transfer activities.

\section{The International Legal Frameicurk on Techology Transfer}

Three Articles in the TRIPS Agreement refer to the transfer of technology and technological development: Article 66.2 makes an explicit request to developed conntries to provide incentiaes to their industries to improwe technology transfer to LDC.s. Article 7 elevates the concept of technology transfer to a basic objective of the international trading system by stating that the protection and enforcement of IPRs should comtribute to the promotion of technological immoration and to the transfer and dissemination of techology, as well as to the mutual advantage of producers and users of technological knowledge and in a manner conducive to social and economic welfare, and to a balance of rights and obligations and; Article 8 allows Members to pursue appropriate measures to prevent the abuse of IPRs by right holders or the resort to practices which unreasonably restrain trate or adiersely affect the international transfer of technology. Article 8 , paragraph 1 also provides Members the flexibility to adopt measures to protect public health and nutrition, and to promote public interest in sectors vital to socio-economic and technological development. However, the added clause to Article 8(1) "provided that such measures are consistent with the provisions of the TRIPS Agreement" severely diminish its potential.

These three Articles reflect the fundamental tensions inherent in protecting technology developers while inducing more invention and transfer of technology for the interest of the public at large. Arguably, stronger IPR protection may contribute to improving the business climate within which technology markets operate, expanding both innovation and (compensated) diffusion into society - although the impact of IPRs differ according to countries and sectors as indicated in chapter five. 
In an attempt to stress the importance of stimulating technology transfer to LDCs the Doha Declaration reconfirmed the importance of Articles 7 and 8 of the TRIPS Agreement in its paragraph 19 which stipulates that the TRIPS Council, in undertaking its work programme, has "to be guided by" the objectives and principles set out in resp. Articles 7 and 8 of the TRIPS Agreement and "shall fully take into account" the development dimension. In addition, the Doha TRIPS Declaration on the TRIPS Agreement and Public Health, of which paragraph 7 reaffirmed technology transfer obligations The fact that these Articles are taken up in the Doha Declaration could possibly strengthen the position of developing countries - during the negotiations and in dispute settlement procedures - since Articles 7 and 8 are meant to have an impact on all the provisions laid down in the TRIPS Agreement.

A major shortcoming, however, is that nothing in the TRIPS Agreement provides any guidance as to how the increase in technology transfer should be realised in practice. The international rules on international technology transfer that exist are mostly of a best- endeavour nature and refer to actions that governments may follow to encourage the transfer of technology. In contrast, the rules on IPR protection or on trade policy rules are of a more stringent nature, setting out a system of rights and obligations. To respond to these shortcomings, the implementation of Article 66.2 was readdressed at the Doha Ministerial Conference (in paragraph 37 of the Doha Declaration), where it was determined that a Working Group on Technology Transfer, under the auspices of the General Council, should investigate the relationship between trade and the transfer of technology and provide recommendations to increase the flows of technology from developed countries to developing countries. Countries were requested to report annually on their technology transfer activities to provide more clarity on activities undertaken to implement Article 66.2 and what specific measures should be installed in the WTO context to encourage flows of technology transfer. Unfortunately, this working group has not lived up to its expectations and LDCs have complained about the lack of information derived from these reports, incomprehensive technical reporting, inconsistencies, and whether the technical assistance featured in these reports has contributed to actual technology transfer. There is a general frustration that developed countries are not really fulfilling their obligations under Article 66.2, i.e. incentivising their industries to improve technology transfer to LDCs - and the working group has not contributed to enhancing technology transfer activities to developing countries. As highlighted many of the activities listed in the reports presented by developed countries in fulfilment of Article 66.2 do not directly relate to technology transfer actions, i.e. they do not provide incentives to their enterprises and institutions to promote and encourage technology transfer to LDCs. In fact many of these activities amount to technical assistance, training and capacity building activities, which do not necessarily lead to transfer of technology. Hence, there is an urgent need to improve activities under Article 66.2. 
It is true that governments can only to some extent influence the transfer of technology as these transactions take place primarily between private businesses. However, governments can create a stimulating business environment, including supportive policies (such as tax breaks to MNEs transferring technologies to LDCs), regulations and incentives, which can facilitate or promote the transfer of technology or at least make it more attractive for industry to do so.

\section{Importance of IPRs for Tedmology Transfer Decisions}

Chapter five addresses in detail the different modes of technology transfer as well as the importance of IPR protection for technology transfer decisions. The crucial issue is not whether IPRs promote trade or foreign investment, but how they facilitate or obstruct developing countries to gain access to technologies that are necessary for their development.

In principle, however, foreign inventors have three choices of how they can transfer their technology to foreign markets. They can: 1) produce a new product by themselves in their home country and then export it (trade channel); 2 ) produce a new product in a developing country and sell it on the market and abroad through a wholly owned subsidiary or through a joint venture (FDI); or 3) sell the license to a firm owned by residents of a developing country (licensing). For the developing country the last option is preferable as it allows it to learn from applying the technology and further improvements can be made to meet local needs. However, foreign investors are often reluctant to grant licenses if technology is sensitive and crucial in its business strategy. It has been frequently argued that weak IPRs protection in a developing country negatively influences investment flows from developed countries. Particularly, MNE's can be unwilling to invest in a country with lax IPRs so therefore they only invest in wholly owned subsidiaries or through exporting goods (trade channel), rejecting joint ventures with local partners or entering into licensing agreements. Sometimes, they are only willing to transfer inferior, more mature technologies were risks are low. On the other hand, strong IPRs would prevent poor countries from converting from commodity-based (agricultural) societies to industrialised ones because IPRs may hinder copying/imitating and reverse engineering practices, ${ }^{23}$ hence blocking a country's development. However,

23. A method of evaluation of a product in order to understand its functional aspects and underlying ideas is reverse engineering, i.e. it is a way of learning about how a product/technology is build up. This technique may be used to develop a similar (or even identical) product. Reverse engineering of foreign products leads to lower prices for technology and it helps strengthen bargaining power in acquiring foreign technology. Notably, reverse engineering of computer programs is permitted under the copyright rules of the TRIPS Agreement (following procedures) but reverse engineering under patent law is not allowed. 
studies have also shown that strong IPRs alone are insufficient incentive for firms to invest in particular countries. This is demonstrated by the fact that large developing countries with high grow th rates have received large foreign investment inflows in the past and even now, with weak IPRs and inadequate enforcement. Many of the East Asian and Latin American economies have received the bulk of such flows. Chapter five emphasises that IPRs do not operate in a vacuum. Complementary factors help facilitate technology transfer, such as the quality of infrastructure, government policies and regulations, and market structure. Study has indicated that trade logistics - or the capacity to comnect to international markets to ship goods - is critical for developing countries to improve their competitiveness, reap the benefits of globalisation, and fight poverty more effectively in an increasingly integrated world. Like improving supply chain management, opening up markets is one step in the right direction. However, if there are no goods to trade with, it will not help much. There are also complementary factors that help facilitate innovation, such as the quality of research institutions and the extent of collaboration among different research organisations. Moreover, it is important for developing countries to understand that IPRs interact in complex ways with other policies, such as competition and investment policies to reach their full effectiveness. In fact, chapter five indicates that when making investment decisions IPRs are only one of a whole range of issues to address by MNEs.

It is important to achieve the right equilibrium of IPR protection: on the one hand, IPRs are a necessary tool for innovation creation and the sharing of knowledge, but on the other, they create semi monopolies (exclusive rights) making it difficult to access technology at low cost, as IPR holders are in strong market negotiation positions, capable of setting licensing terms and other conditions in accessing technologies. The realisation of smooth and rapid transfer of technology can, to a certain extent, be hindered by monopolistic behaviour by the patent holder. For instance, the patent system can be abused, namely if firms merely acquire patents to use them to be able to sue (i.e. eliminate) the actual competitors in the same industry. The use of patent pools also hinders easy access and understanding as patents are interrelated and require understanding of multiple patent claims. Moreover, in the current economy climate firms use tiers of patent protection. ${ }^{24}$

Access to patented technologies is also possible through subsidiaries of MNEs (for instance joint ventures) and licensees. By these means the recipient can make legal use of patents and trademarks.

24 For instance, "a seet may be protected by patents, by a license contract that prohibits reuse of the harvested crop as seed, and by being a hybrid, implying that biologically it does not breed true to type". Example taken from Barton 2007, p. 21. 
Exclusive patent rights allow developers and owners of techmology (for a limited period of time) the opportunity not to transfer technologies to particular markets and to raise the costs of (uncompensated) imitation. Nonetheless, where a refusal to transfer technology becomes an abuse of IPRs, countries are, in principle, empowered to offset this abuse by using compulsory licenses.

The patent system is a means of knowledge creation and learning because one of the prerequisites of patent filing is the public disclosure of the invention (within the patent claim). However, it is questionable to what extent recipients are capable of mastering the technology (embodied within the patent) without assistance from the innovator/patent owner. Notably, imitation of a certain technology will not automatically lead to the assimilation and absorption of the technology.

How important are $1 P R$ s in investment decisions by industry? How traderelated are IPRs? Does IPR play a role in economic development? These are all questions addressed in chapter five. There is a common understanding that technological change is important for economic growth. Technological change is influenced by a number of factors of which intellectual property is one. Given that international trade is an important channel of technology transfer and that the share of knowledge-intensive or high-technology products in world trade has increased it follows that IPRs have played a role in trade. Arguably, IPRs have become even more important as increasingly it is not the individual but the enterprise that owns the patents. ${ }^{25}$ Realistically it is unlikely that firms will voluntarily transfer their technology or tracte their goods, incorporating their IPR protected technology, if there is a chance that their products will be copied and possibilities to protect and enforce their rights are insufficient. This is because products take a good number of years to develop and improve and R\&D investment is high. In addition, the preparation and filing of patent applications (and in the case of pharmaceuticals the clinical trials in order to obtain exclusive marketing approval) is a long and costly process which can delay a product being successfully put on the market by a number of years. Hence, following this line of reasoning it is unlikely that firms will transfer technology and sell products in countries where patent law or enforcement is weak and thus copying more likely. ${ }^{26}$. This view is supported by Park and Lippoldt who found that imports of goods and services (trade flow's) and FDI inflows are significantly and positively associated with nonresident patenting in developing countries. ${ }^{27}$ This association suggests that foreign imports and FDl contain patentable technological assets for which non-residents seek protection. This implies that stronger patent rights in developing countries appear to have the potential not only to stimulate inter-

25 Sec Kanwar and Evenson 2001.

20 See Branstetter 2005.

27 See Park and Lippoldt 2008. 
national technology transfer but also to provide incentives for foreigners to transfer new (er) technologies.

The availability of strong IPR protection is less important in the investment decision in the case of low technology industries and products. However, if the technologies involved are more sophisticated, but relatively easy to copy, then IPRs may be - though not necessarily - a significant factor in investment decisions, particularly if the recipient country has both the scientific capacity to copy and if there is a sufficiently large market to justify the costs of patenting and enforcement (for instance in the chemical and pharmaceutical industry). Chapter five indicates that the role of IPR in TT decisions is sector dependant. For instance, in some ind ustries, such as metals and transportation equipment, it is relatively difficult to copy a firm's technology without many expensive and complex complementary inputs (hence IPR protection is less important), while in the pharmaceutical industry, it is relatively easy for local firms to imitate an innovator's new products by using reverse engineering techniques. It follows that research intensive firms, with products or processes that are relatively easy to imitate, are more reluctant to make substantial investments or transfer advanced technology to countries with weak IP protection. However, companies (especially the ones outside the chemical industry) indicated that IP is only one of a number of factors, influencing their investment decision. Firms with limited $R \& D$ investment perceives IP to be relatively unimportant. ${ }^{2 s}$

Park and Lippoldt (2008) found that stronger patent protection in developing countries goes hand-in-hand with a greater expansion of US operations in the chemical, machinery, service, and information industries in developing countries. This reinforces the important role of IPRs in protecting the service industry. However, stronger protection does not coincide with a greater expansion of US operations in the electronic and computer industries of developing countries. It may be that US FDI in the electronics and computer industries of developing countries is largely for sales and distribution purposes, so that there is less concern about the strength of local patent rights. Nonetheless, the 2008 Park and Lippoldt study indicates that IPR enforcement in general does matter to all of these sectors, particularly to protect against piracy and unauthorised sales and distribution. ${ }^{24}$

The type of investment and technology also plays an important factor as to whether IPRs play a role in the investment decision. Studies have shown that in relatively high-technology industries like chemicals, and pharmaceuticals, and also in machinery and electrical equipment, a country's system of intellectual property protection often has a significant effect on the amount and

2s. See Mansfield 1994 and 1995.

20 See Park and Lippoldt 2008. 
kinds of technology transfer and direct investment (in R\&D facilities) directed to that country."31 Therefore, if IP is perceived as weak, it is most likely that investment will take place only to wholly owned subsidiaries and will be devoted to sales and distribution outlets or to rudimentary production and assembly facilities instead of manufacturing components or complete products. Hence the existence of IPR protection may impact on what activity in the production/supply chain will be carried out on a certain territory.

However, research has also shown that companies avoid the transfer of strategically sensitive technolngy to unaffiliated parties, regardless of the perceived strength of the IPR regime. ${ }^{31}$ For instance, many chemical industries are reluctant to transfer relatively new or advanced (or most effective) technology to anything other than wholly owned subsidiaries.

In contrast to Mansfield, Fink and Primo Braga (1999) found that stronger IPRs have a significant positive effect on total trade flows but that this effect depends on the type of technology. For instance they found that the stringency of a country's patent regime makes no difference to trade in high-techology products (such as trade in chemicals, electrical and office machinery and telecommunications). They did find that a system of strong IPRs has a significant positive effect on bilateral trade flows for total non-fuel imports and exports. However, IPRs are not significant for high-technology trade flows. ${ }^{32}$ Fink and Primo Braga argue that this outcome is somewhat surprising as they would have expected a positive trade effect for knowledge intensive goods. However, it is possible that strong IPRs cause high-technology firms to serve foreign markets through FDI (substituting foreign trade). Some knowledge-intensive goods may be insensitive to the destination country's IPR regime and, as a result, factors other than strengthening IPRs may be more important in appropriating investment in $R \& D$ (for instance first mover advantage or rapid movement down the learning curve - short life span and therefore being first is more important than being protected, i.e. mobile phone technology). This is in line with studies conducted by Maskus and Penubarti (1995) and Smith (1999) which also found a positive link between trade flows and strong IPR protection but Maskus and Penubarti do not find such a link for very patent sensitive industries and Smith finds no such link in countries that face no threat of imitation.

Park and Lippoldt (2008) find that stronger levels of patent protection make a significant positive difference to the influx of high-tech products, like pharmaceutical goods, chemicals, aerospace, computer services, information and office and telecom equipment and optics and precision equipment. Thus, they

30

"See Lee and Mansfield 1996. Supported by Javorcik 2004.

i2 See Fink and Primo Braga 1999. 
argue that goods that are technologically-intensive are particularly affected by stronger patent protection in developing countries. For least developed countries, the qualitative and quantitative impacts of patent rights on merchandise imports are weaker, ${ }^{33}$ Patent rights are a dominant influence because service imports are more sensitive to levels of patent protection, if other variables are constant. Most of the control variables (index of free trade, GDP per capita, IPR enforcement, and legal effectiveness) have a positive effect on service imports. The possibility to engage in free trade positively influences the merchandise imports of developing countries, but may induce substitution effects in both developed countries and in least developed countries - that means a switch from merchandise imports to inward FDl. Park and Lippoldt (2008) found that in terms of service imports, patent protection and IPR enforcement are positively associated with the importing of communication services, computer services and royalties. Hence, results suggest that stronger IP protection helps attract imports of services that are knowledge-related or technology-intensive.

Existing IPRs may have an impact on international trade flows, for instance a company may decide not to export its patented good into a certain foreign market if it is likely that potential pirates can diminish its profitability in that market because of lax IPRs. In line with this reasoning one would expect that an enhancement in patent regulations in one country would result in an increase of imports as "foreign firms face increasing net demand for their products, reflecting the displacement of pirates". On the other hand "a firm might choose to reduce its sales in a foreign market as a response to stronger IPR protection because of its greater market power in an imitation-safe environment". Thus we can conclude that the overall effect of IPR protection on bilateral trade flows is theoretically ambiguous when looking at market expansion and market power. ${ }^{34}$ However, Maskus and Penubarti (1995) find that the effect of increased imports tends to dominate the power of the market so that stronger IPRs on balance expand trade: the reason being that the market power effect of IPRs dominates in high-technology sectors. The plausibility of this is that firms in technology-intense industries may already possess some market dominance from their technological superiority and it seems that stronger patent protection would then largely raise their rents. ${ }^{35}$ Another possibility could be that stronger IPR protection lead firms to switch between different modes of transfer, e.g. from exporting (trade flows) to FDI.

See Park and Lippoldt 2008, p. 22.

it See Fink and Primo Braga 1999, p. 21 referring to Maskus and Penubarti 1995.

35 See Park and Lippoldt 2008, p. 10. The case of Hungary has recently been brought into play; a country that adopted higher standards of IP protection to obey to the accession requirements of the EU, and where subsequently most of the locally owned firms in the pharmaceutical industry were taken over by foreign multinationals and the market share of local firms shrank from 70 percent to 30 percent. 
As indicated above, Smith (1999) finds that the impact of stronger patent protection on trade depends on the importing country's capacity to imitate. In countries with weak capacity to imitate, the weak capacity acts as a de facto form of protection. On the other hand, the empirical results in Smith (1999) confirm that where the capacity for imitation is high, a strengthening of IPRs increases the flow of trade.

Research outcomes are divided when it comes to the relationship between IPRs, technology transfer and the level of development. On the one hand, Park and Lippoldt (2008) have shown a positive association between patent rights and technology transfer, for all groups of countries. This view is supported by Mansfield (1994 and 1995) On the other hand; Falvey and Foster (2006) argue that stronger IIPR protection has little impact on innovation and diffusion in developing countries without capacity to innovate.

These results imply that MNEs do not base their export decisions on IPRs in the poorest countries, where local threats of reverse engineering and imitation are weakest. However, patent rights become more important in middleincome, large developing countries, where imitation is more likely. If these countries can reduce the threat of imitation through establishing stronger patents, foreign firms are more likely to expand their volumes of trade. Products of many high-technology industries (excluding pharmaceuticals) are inherently difficult to imitate, so those trade flows are less affected by IPRs than those in medium-technology or mature-technology sectors. It is also possible that high-technology firms may decide to serve foreign markets through FDl and licensing, so exports (trade flows) in these industries may appear to be little affected by variations in the degree of patent protection. ${ }^{36}$

The impact of IPR protection on socio-economic growth, innovation and technology diffusion in developing countries is likely to depend upon a number of factors. While stronger IPR protection in the poorest countries is not likely to lead to substantial benefits in terms of innovation or technology diffusion, the administrative cost of developing a patent system and the enforcement of TRIPS, along with the potential abuses of market power in small closed markets suggests that such countries could lose out from TRIPS. Policies aimed at improving the business environment and encouraging imports of technology embodied in goods could potentially reduce the costs of IPRs, though their impact on other development-related goals needs to be carefully weighted. Foremost, chapter five found that differences amongst developing countries are apparent. Stronger IPR protection in the poorest countries may also hinder or lengthen the imitative stage of development that seems to be necessary in order to develop innovative capacity in many industries. In fact, stronger IPRs in low-income countries have an insignificant

3t. See Fink and Maskus 2005 and Fink and Primo Braga 1999. 
effect and may even deter knowledge flows in low-technology sectors. In contrast, in middle-income and large developing countries the potential for benefits from TRIPS is stronger. Studies have shown that international trade flows increases, especially in patent-sensitioe industries, as a result of enhanced patent rights among middle-income and large developing countries but not among poor countries. ${ }^{37}$ Here existing firms engaging in imitation could be encouraged through stronger IPR protection to shift resources towards adaptive innovation, and stronger IPR protection is likely to increase trade and FDI flows into countries with existing imitative ability, thus enhancing technology transfer. Along with policies aimed at opening markets to foreign imports and encouraging inward FDI. Policies to enhance the benefits of TRIPS would help develop the domestic innovative sector through encouraging $R \& D$ and investment in education. A study by Acharya and Keller demonstrates that imports (trade flows) are an important channel of technology transfer, although the volume of transfer varies by country, being greater in countries with stronger absomptiv' conacitic's (measured by the level of location and R\&D investments). ${ }^{\text {s }}$ Trade flows can increase the productivity of importing countries by increasing their access to foreign inputs and technologies. ${ }^{39}$

Within the group of large deweloping countries, strong IPR regimes attract larger than expected flows of imports from OECD countries. stimulate knowledge transfers. However, IPR protection can enhance such exports if the destination markets have commercial potential in terms of large markets and strong technological capacities. ${ }^{41}$

Chapter five indicates that enhancing technology transfer directed to the poorest countries requires special attention. This is because technology transfer to LDCs needs additional incentives as general economic operations, such as FDI, infrastructure construction or market transactions such as licences are unable to stimulate technology transfer activities in such countries. Instead the transfer of technology has to be specifically directed to and tailor-made to the needs of these very poor countries.

In relation to licensing their technology, in general, firms were reluctant to transfer their newest most effective technology to unrelated firms where the level of IPR protection was weak. ${ }^{42}$

it See Smith 2001 and Schneider 2005.

3 See Acharya and Keller 2007.

3. See Eaton and Kortum 2002.

* See Maskus and Penubarti 1995.

4i See Bascavusoglu and Zumiga 2002.

42 See Fink and Primo Braga 1999. 
In general the existence of IPRs in developing countries is welcomed by investors. For instance, the introduction of trademark protection in developing countries has been seen as an important step forward for reassuring investors in manufacturing industries that they can combat knock-offs. ${ }^{+3}$

\section{IPRs, RED and Tedmology Trmusfer}

Various studies have indicated that different levels of industrialisation within society have different needs from IPR protection, which in turn leads to different results regarding technology transfer and economic growth. Developing countries are not unanimous. They vary greatly in their economies, technology infrastructures and innovation competences. The TRIPS obligations, arguably, do not give enough room for the absorption of the basic technology and knowledge to be able to stimulate capacity building in those countries. Especially the LDCs are incapable of benefiting from the existing IPR framework as they are still dealing with basic development imperatives such as education, health system, infrastructure, and basic communication systems. It is likely that an obligation to install IPR mechanisms could undermine the fulfilment of these basic needs and utilities. Moreover, without the necessary infrastructure in place they cannot achieve adequate enforcement compliance let alone the creativity and inventiveness in the domestic innovative activity.

Research has shown that market size and infrastructure are crucial elements in explaining FDI flows and innovation in developing countries; while in developed countries high-techmology imports, human capital, and R\&D expenditures appear to have a stronger impact. A key finding of chapter five is that the relevance of IPR protection on domestic innovation depends on the level of development. IPRs have stronger impact for developed countries and might even negatively impact innovation in developing countries. This might be explained by the fact that most innovation occurring in developing countries may actually be imitative or adaptive in nature. Hence, requesting the implementation of high levels of IPRs protects foreign firms and may actually be detrimental to local firms' needs. This does not mean that IPRs are bad, however, the over-protection of IPRs should be avoided and the level of development has to be taken into account when IP policies decisions are made. IPRs need to work for developing countries that need to realise the potential of IPRs for building local innovative capacity; hence they need to find domestic incentives in order to justify the strengthening of IPRs. As innovation and IPRs are to a certain extent interlinked and complementary in nature it is important to emphasise the relevance of supporting R\&D activities in developing countries. A developing country's capacity to absorb technology is an important factor in determining how influential the role of IPRs is in establishing 
economic growth. For instance, a weak IPR regime allows domestic firms to imitate foreign technologies which may stimulate productivity and income growth. However, firms may not be able to master all components of new technologies, including both codified knowledge (disclosed in patent claims) and know-how without the participation of foreign intellectual property holders. However, if they cannot do this, it might be better for them to opt for stronger IPRs to enable access to foreign technologies through formal technology transfer activities such as joint ventures and licensing agreements. ${ }^{\text {th }}$

As developing countries get technologically advanced they will also need access to more sophisticated, superior technologies. Simultaneously, calls for more advanced technology, once a country reaches a certain threshold level of development, may result in internal and external pressure to increase levels of $I[R$ protection, especially patent protection. Unsurprisingly, technology which is still developing and improving (so-called advanced technology) is more difficult to obtain than mature technologies. As chapter five has indicated, in our contemporary society the importance of $R \& D$ in product development has increased and product life cycles have shortened. In this liberalised and competitive environment, firms in developing countries can no longer compete on the basis of importing mature technologies from developed countries and producing them behind tariff barriers. LDCs need to focus on building a technological and viable base and use technologies available in the public domain in order to develop their technological strength. This will make them less dependent on foreign technologies in the future. In the short-term developing countries should prioritise improving their sustainable livelihoods by focusing on their immediate needs and indicate niche products for foreign export.

Studies ${ }^{45}$ have shown that having strong $I P R$ protection encourages $R \& D$ and that countries with strong IPR protection tend to have larger proportions of their GDP devoted to R\&D, on the condition that strong laws in the statute books are backed by effective enforcement. Research has shown that patent applications in developing countries (by both residents and non-residents) and expenditure on R\&D (as a percentage of GDP) tend to add strength to patent rights - with the R\&D expenditure percentage increasing with the quality of local R\&D facilities. ${ }^{\text {to }}$ University-industry collaboration may be more important in the R\&D stage where firms and academia can collaborate on basic, foundational research. At the patenting stage, firms may want to keep commercial successes proprietarily and rely less on collaboration with academia. In most countries the US Bayh-Dole type of law does not exist (encouraging publicly funded university research to be patentable) - this system and its opportunities for developing countries could be wider explored.

See Fink and Maskus 2005, p. 4.

See Kanwar and Evenson 2001.

See Park and Lippoldt 2008. 
Little information is available on the impact of national economic activities or national research priorities on the amount of local innovation (or patent filing). However, it is important that govermments adopt policies which help companies convert their intellectual assets into financial capital. In the BRIC countries, technology transfer via trade and FDI has been one important input (among other factors) into developing local technological capabilities. For instance a government can develop a system in which projects are funded to stimulate a certain segment of industry: for instance the electronic or music sector.

As we have seen the impact of strengthened IPRs on economic welfare is not easy to determine. One cannot draw conclusions about the impact of IPRs on economic welfare. Foremost, IPRs are not the sole solution to economic development; nevertheless they can contribute to it. Some modes of technology transfer might be more suitable in certain situations than others. Research has shown that the role of trade in encouraging growth hinges critically on the geographical scope (national versus international) of knowledge spillovers/ diffusion. Empirical studies have not yet delivered a clear judgement on this issue and it is likely that, for developing countries, spillovers are probably going to be national in scope unlike those for industrialised countries whose diffusion is international. Thus, as a result it matters for development whether $R \& D$ and high technology production are carried out in close geographical proximity to a country. ${ }^{+7}$

It is important to keep in mind that many factors play a role in the successful transfer of technology outside the scope of IPRs, in particular the presence of an R\&D programme, domestic research laboratories and universities, and the existence of a sound base of technical skills and human capital. These decrease the costs of imitation, adaptation and follow-on innovation.

Chapter five finds that the nature of $R \& D$ activities varies. Normally $R \& D$ conducted in affiliates is devoted to the modification and absorption of existing products to meet local market conditions and so is complementary to technology imports from the parent, in contrast to research designed to advance the technological frontier, revealed by research conducted by US and European based MNEs. The former method will produce few patents, whereas the latter has the potential to produce many. US and European MNEs do undertake some basic and applied research abroad but mainly in other advanced countries which have highly accomplished local scientific and engineering community and where the infrastructure for research is welldeveloped. R\&D activity in developing countries is most of the time focused on the absorption of parcut firm technology and on its modification for local 
makets.ts Thus, the nature of R\&D at home and abroad is very different in nature and quality. In countries with weaker IPRs, there may also be substantial flows of FDI, although these tend to be for the purpose of establishing sales and distribution outlets rather than high value production and R\&D facilities. ${ }^{49}$

As shown, there are many possible strategies for international technology acquisition and local industrial and technological development. It seems that priority should be given to the improvement of the local environment for acquiring international technology transfer and for its subsequent diffusion. Both FDI and licensing respond positively to such factors as an effective infrastructure, transparency and stability in government, and a reasonably open trade and investment regime. ${ }^{51}$ Also important is an entrepreneurial environment that attracts skilled workers to return home from developed countries. Given that vertical spillovers are strongest in countries where MNEs work with competitive suppliers technology transfer can also be assisted by bringing down the market entry barriers for industries. An important determinant of a country's ability to absorb and adapt techology is the return on investment in simple R\&D capacity. Local policies should be directed to encourage such investments. For instance, policies should aim at reducing the technological gap between local and foreign firms by establishing innovation systems that encourage $R \& D$, transfer knowledge from universities and public laboratories to domestic firms, and promote use of cost-saving technologies. It is also important that management and engineering are improved so as to allow technology to be deployed for local needs and gradually improved over time. Hence, countries need to work on establishing local R\&D programmes, and research capacity at laboratories and universities. Developing countries need to use international networks, such as student exchange programs, fellow ship opportunities (for instance within the Virtual Institute UNCTAD network or WTO online courses). Having a solid technological understanding and basis will also help a country to identify and subsequently attract the most appropriate and necessary technologies and to negotiate better terms and conditions in technology transfer arrangements. Developing countries also need time to get acquainted with IPR concepts and adopt them according to their socioeconomic needs.

Imports of equipment and materials may help to stimulate $R \& D$, and to the extent that increased $R \& D$ results in increased innovative outputs for which

See Branstetter 2005, p. 7.

See Park and Lippoldt 2008, p. 4.

See World Bank 2004. 
local residents file for patent protection, increased resident patenting can be associated with merchandise imports. ${ }^{51}$

\section{Some Recommendations to Facilitnte Tedmology Transfer}

The following are some recommendations for developing countries in search of knowledge and technology (recipients of TT - so-called host country measures):

1) The recognition that the boosting of local industries does not require high tech or the latest technology to flourish. This can be achieved by improving production processes (and supply chain management). Hence, developing countries should focus on "what is already out there", free for everyone to use, i.e. use the patent system and knowledge available in the public domain (especially mature technologies) and avoid signing technology transfer agreements in terms of accessing technologies that are not under some sort of IP protection on their territory. Above all, for a successful technology transfer it is crucial to attract and absorb foreign technology and knowledge and to use and adapt it for domestic needs and innovation processes, thus making the transfer sustainable in the long run and widely accessible. Hence, developing countries need to work on their technological capabilities through education, engineering skills, R\&D, and the development of appropriate institutions, especially since most technology is not easy to read and understand (codified). Hence, it is important that developing countries realise what technologies they need, explore the market for technologies, investigate if the requested technology is protected on their territory. This way they can improve their negotiation capacity in obtaining technology transfer contracts on advantageous terms.

2) The realisation that the TRIPS Agreement provides minimum standards (rights and obligations) and hence, it leaves developing countries some degree of autonomy. However, countries need to be properly informed and trained in how to apply these flexibilities effectively. In particular countries should focus on utilising research and educational exemptions possibilities as well as using compulsory licensing (available under Article 31 TRIPS).

3) The strengthening of local intellectual property offices and patent offices, not only in administering the registration of patents and trademarks but also in how to make use of IPRs, particularly to benefit local people.

4) Focus on IP altematives, such as the opportunity to be innovative outside the IPR system by using open source initiatives or collaborative efforts

51 See Park and Lippoldt 2008, p. 24. 
such as the Peru potato initiative, which brings together different sectors of society to promote the commercialisation of native potatoes.

5) The utilisation of competition law to stop unfair business practices.

6) Approach WIPO negotiations with care. For instance, the ongoing negotiations on a Substantive Patent Law Treaty within the WII'O: developing countries need sufficient time to balance the benefits of such a treaty. Meanwhile, it is best to amend patent laws to expand research exemptions and diminish the negative impact of patents on research.

7) The implementation of the WIPO Development Agenda recommendations in the WIPO Committee on Intellectual Property and Development (CDIP) should be monitored and accelerated and an adequate implementation of the technology transfer provisions should be demanded.

8) Developing countries should consider bringing a number of the WIPO Development recommendations to the agenda of the TRIPS Council and the Working Group on Technology Transfer to make sure that endeavours to make the II global framework more development friendly within both WIPO and WTO are mutually reinforcing.

9) The discussion of a treaty on access to knowledge and technology within the framework of the WIPO and WTO negotiation framework as foreseen in the WIPO Development Agenda.

Some recommendations for developed countries (so-called home country measures) to facilitate technology transfer are as follows.

1) The selection of technical assistance and technology transfer which are in the interest of developing countries so as to avoid uniformity in production. This might not always be in the best interests of the receiving country as it may lead to uniformity in production.

2) Take a pro-active role to stop unfair business practices by MNEs operating on developing country territory - developing countries lack the capacity to stop unfair business practices themselves. In particular the European Commission has been very active in stopping unfair competition practices (i.e. the Microsoft cases). It is recommendable to extend these efforts to developing countries as well.

3) The recognition/realisation that technology transfer arrangements are negotiated between unequal negotiating partners (small local firm or government subsidiary versus huge multinational). For instance, use of joint ventures and collaborative arrangements with multinationals should be encouraged as both parties can cooperate from the initial stage of a project. This way developing countries "collaborate" with the foreign multinational 
business partners instead of being "confronted" in the process of developing new products and associated technology. This also involves the negotiation of pro-competitive licensing practices (following recommendation 23 of the WIPO Development Agenda).

It is also important that the technology transfer has a lasting positive effect on the receiving country. For instance, if a MNE decides to license its technology and production to a local firm instead of establishing manufacturing locally, in principle less foreign investment will have been attracted. However, in the long run this type of technology transfer will be more beneficial to the developing country (the recipient) because it helps build domestic technological capabilities. The import of high technology goods by developing countries also qualifies as transfer of technology. However, the transfer is only sustainable if the domestic economy is capable of absorbing that technology as a basis for further innovation. For the poorest countries it might be more efficient to develop and enhance domestic technological capacity and skills by means of reverse engineering and imitating (which is hindered by the TRIPS obligations). Hence quality and sustainability of the technology transfer is important to have positive development results on the long term.

The main conclusion drawn in chapter five is that the importance of IPRs in investment decisions is sector and type specific and depends on a number of circumstances such as imestment climate, lewel of development and tedmological capability, guarantees against appropriation, the mode of tedmology transfor and the maturity of the technology. In addition, each country's laws protect different industries in different ways and the strength of IPR protection can also differ between different concepts of IPR, e.g. strong copyright protection but lax patent laws. In addition the competence and aggressiveness of a country's firms may differ from industry to industry. In addition, IPRs in the text books need to be accompanied with efficient and adequate enforcement measures.

Further research is needed on the impact of changes (reform) in intellectual property regimes in developing countries and the behaviour of multinational enterprises. In addition, more research is necessary at industry level, to see what impact IPRs have on different types of collaboration, e.g. joint ventures, whole ownership, etcetera.

Generally, the introduction of IPR protection has been associated with an increase in imports (trade flows) and the facilitation of technology transfer under licensing, but has not contributed to investment in local production. Moreover, existing IPR protection may not really have a large impact on investment flows where other factors are likely to play a larger role (i.e. geographical destination, size of country, security, govemance, transparency and infrastructure). However as chapter five has indicated the overall effect of IPR protection on bilateral trade flows and FDI is theoretically ambiguous. However, there is a general perception that strong IPR protection is hamful for the poorest countries and will unlikely affect FDl decisions. However, the reality 
is that IPR enforcement, adherence to the existing IPR treaties and TRIPS plus provisions play an important role in FTAs and FDIAs negotiations.

\section{FINAL RENARKS}

Developing country members are concerned about the constant stretching of the WTO mandate, allowing the TRIPS Agreement to harmonise and control domestic IPR policies and norm setting, as well as the mushrooming of regional and bilateral trade agreements. It is a continuous struggle for developing countries to stay abreast of the various fora on $1 P$ policy making, the increased attention to enforcement and to keep national policies in alignment with international developments in II?

As we have seen in chapter two, IPRs grant exclusive rights and can therefore adversely impact free trade, competition, stifle further innovation and cause high prices for essential drugs. For all countries it is important to establish competition policies and laws to counter abuses of IPRs. Foremost, the adequate level of IP protection in a particular country may vary significantly over time according to productive structures and levels of development. For instance LDCs are best served by keeping patent protection to a TRIPS-compliant minimum, which will encourage an adequate public domain enabling incremental follow-on immovation and technical learning. LDCs should also focus on types of IPR that are most suitable to their needs and promote their domestic innovations, such as utility models, trade secrets and industrial designs. They will also benefit from improving the branding of their products by making effective use of trade marks and geographical indications. However, more advanced developing countries might want to strengthen patent laws to protect their own inventions. IP protection that reflects a country's level of development may contribute to its technological and economic capacity and will increase the necessity of IP over time.

In principle, everyone has the opportunity to take advantage of the TRIPS Agreement including developing countries, SMEs, farmers, artists, musicians and so on. However, the reality is that in the short term it is most likely that the MNEs will benefit from strong IPRs. The extended literature on the role of IPRs in accomplishing economic growth has shown that above all IPRs are context-sensitive and that a case-by-case approach is an absolute must: a one size fits all regime is a utopia. Whether strong IPRs stimulate economic growth, support flows of technology and technology transfer transactions depends on the particular characteristics of a country (its level of development) into which intellectual property rights systems are introduced. Economic growth also depends on the specific industries (pharmaceutical or electronics industries) in which these intellectual property rights are employed and on the type of investment envisaged (joint ventures, licensing or trade exports). This context-sensitivity requires flexible rules in the implementation of the TRIPS Agreement, including both the prioritisation of developing countries' 
interests and needs in WTO reviews and the enhancement of technology capacity building.

Trade policies are an important means for development, but not an end. Trade policies raise expectations that trade cannot fulfil. It goes without saying that pursuing trade negotiations are certainly a step in the right direction but not a quick pace to development objectives. The process of development requires more actions and conditions, such as capacity building and the establishment of institutions as well as liberalisation of markets and special and differential treatment. Thus, the name Doha Development Round is not truly appropriate, since trade is not the panacea for development if not matched with other policies and activities. In changing times and circumstances it might be a logical conclusion to also restate the justifications to IPR and possibly to amend the existing justifications and rationale behind the intellectual property legislation to justify the socio-economic consequences the $I P$ regime has on developing countries and their indigenous communities. This way, the interests and needs of developing countries can be better reflected in the rationale and justifications. After all, intellectual property is an instrument of public policy: too much can be a bat thing, whereas too little protection can cause delay or obstacles in innovation and (sustainable) development. 



\section{Samenvatting}

1. INTRODLCTIE

Dit boek bespreekt actuele veranderingen in de bescherming van het intellectuele eigendomsrecht: het analyseert ontwikkelingen, obstakels en uitdagingen in aan de gang zijnde vrijhandelsonderhandelingen door te kijken naar de uiteenlopende standpunten van de betrokken landen. Op multilateraal, regionaal en lokaal niveau kunnen we, met betrekking tot het intellectuele eigendomsrecht, een tendens warmemen naar: het uitbreiden van het werkingsgebied van regels; het verlengen van de duur van bescherming en het verwijderen van beperkingen en uitzonderingen op regels. Dientengevolge krimpt de resterende flexibiliteit, overgelaten aan de landen zelf, om beleid en strategieën te bepalen inzake het intellectuele eigendomsrecht, bovendien wordt het publieke domein kleiner. Men kan beargumenteren dat de veranderingen in intellectuele eigendomsrechtbescherming op het multilaterale niveau een verschuiving in het saldo van belangen teweeggebracht heeft tussen landen die voorop lopen in het ontwikkelen van "state-of-the-art" technologieèn en landen die achterop raken. Het is duidelijk, dat de belangen en behoeften van landen, die deze nieuwe technologieën ontwikkelen en produceren, verschillen ten opzichte van de landen, die deze snelle ontwikkelingen niet kunnen bijbenen en zich gedwongen zien bescherming te bieden aan buitenlandse producten en creaties, beschermd door intellectuele eigendomsrechten, terwijl zij zelf op dit moment nog niet of niet ten volle van deze rechten kumnen profiteren.

De laatste decennia zijn gekenmerkt door een aantal factoren, die van invloed zijn geweest op de intemationale handel en sociaal-economische ontwikkeling van landen. Een aantal factoren heeft bijgedragen tot het belang van technologie. Ten eerste heeft het snelle tempo van technologische transformatie tot gevolg dat technologie een belangrijke component is geworden in vrijwel alle economische activiteiten. Ten tweede heeft de toegenomen internationale samenwerking geleid tot de globalisering van alle economische en technologische activiteiten.

Deze twee factoren zijn wederzijds versterkend, dit wordt aangetoond door toegenomen octrooiaanvragen door buitenlandse uitvinders (ondernemingen) binnen een land en het gebruik van het intellectuele eigendomsrecht in het algemeen. Net zoals het verband tussen technologische intensiteit van productieprocessen en producten is gegroeid, is ook de link tussen technologische verandering en concurrentievermogen van ondernemingen en landen toegenomen. De hoeveelheid kennis die in productieprocessen wordt vereist is opmerkelijk gegroeid; met inbegrip van verhoogde ontastbare investeringen zoals Resench e'n Devclopment (R \& D), opleidingen en trainingen, en software ontwikkeling. Het gevolg is, dat in onze eigentijdse maatschappij toegang tot 
technologie het concurrentievermogen van bedrijven en van landen bepaalt. Op lange termijn kunnen toegang tot en verspreiding van technologie het verschil maken en bijdragen tot sociaal welzijn en welvaart. Vandaar, dat ontwikkelingslanden en in het bijzonder de minst ontwikkelde landen (LDCs) zich moeten concentreren op het ontwikkelen van een technologische basis en het gebruiken van technologieën, beschikbaar in het openbare domein, om hun technologische kennis te versterken om in de toekomst minder van buitenlandse technologieën afhankelijk te zijn.

Dit boek analyseert hoe ontwikkelingslanden het bestaande bolwerk van intellectuele eigendomsrechten kunnen gebruiken om zelf een technologische, inmovatieve en artistieke basis tot stand te brengen.

Hoofdstuk één bespreekt de geschiedenis van het totstandkomingsproces, dat geleid heeft tot de internationale intellectuele eigendomsverdragen evenals de redenen en rechtvaardigingen achter het verlenen van intellectuele eigendomsrechtbescherming. Hoofdstuk twee bespreekt in detail de bepalingen van het TRIISS Verdrag (Agreme'nt on Trade Related Aspects of Intellectual Property Rights - annex van het Wereld Handels Organisatie (WTO) verdrag), die van belang zijn voor ontwikkelingslanden, en verstrekt informatie over hoe deze bepalingen zouden moeten worden geïmplementeerd, met behulp van de onderhandelingsgeschiedenis en eventuele WTO jurisprudentie.

De hoofdstukken drie, vier en vijf analyseren drie onderwerpen van belang voor ontwikkelingslanden: bescherming van geografische herkomstaanwijzingen (geographical indications), bescherming van traditionele kennis en genetisch materiaal (traditional knowledge) en de toegang tot en overdracht van technologie (techmologie transfer).

In elk hoofdstuk worden de nog te behandelen onderhandelingskwesties besproken en aanbevelingen gedaan hoe ontwikkelingslanden hun belangen ten opzichte van intellectuele eigendom, beleidsvorming en normering op het bilaterale en multilaterale niveau het beste kunnen nastreven.

Dit boek concludeert dat ontwikkelingslanden de laatste jaren hard hebben gewerkt on grond te herwinnen die zij verloren hadden onder het TRIPS Verdrag. Successen zijn geboekt met de totstandkoming van de "WTO Doha Ministerial Declaration", de "WTO Doha Declaration on TRIPS and Public Health" en de "World Intellectual Property Organisation" (WIPO) "Development Agenda". In feite vinden er veelvoudige inspanningen tegelijkertijd plaats, in het bijzonder: de ontwikkelingslanden proberen de overdracht van techmologie weer op een prominente plek in de reguliere WTO TRIPS onderhandelingen te platsen en van WIPO een meer gebalanceerde organisatie te maken die het belang van ontwikkelingslanden niet uit het oog verliest. Het internationale juridische kader van intellectuele eigendomsrechtbescherming

1 Overeenkomst inzake de Handelsaspecten van de Intellectuele Eigendom. 
zou op een zodanige manier moeten worden ontworpen, dat het innovatie en creativiteit bevordert en de negatieve aspecten voor ontwikkelingslanden beperkt. Zoals, al kort aangehaald, een aantal recente ontwikkelingen (op multilateraal onderhandelingsniveau) zijn gericht op het verwezenlijken van een beter evenwicht tussen privé belangen en openbare doeleinden: de WIPO "Development Agenda", de WTO "Doha Declaration", the WTO "Doha Declaration on TRIPS and Public Health" and the VN "Millennium Goals". Ook heeft te Wereld Gezondheids Organisatie (WHO) onlangs (24 Mei 2008) een globale strategie goedgekeurd, gericht op het opvullen van het onderzoekshiaat voor veronachtzaande ziekten en het verbeteren van de toegang tot essentiële medicijnen. Andere belangrijke ontwikkelingen zijn de totstandkoming van een officiële TRIPS wijziging inzake het verlenen van dwang licenties en lokale productie mogelijkheden (het nieuwe Artikel 31 bis IRIPS), de grote steun voor het disclosure of origin (herkomst aanduiding) voorstel (het voorgestelde Artikel 29 bis TRIPS) en de verhoogde aandacht voor de overdracht van technologie en toegenomen technische bijstandactiviteiten allemaal gericht op het brengen van een beter evenwicht tussen privé doelen en het openbaar belang.

Deze successen hebben aangetoond, dat de inspanningen van ontwikkelingslanden om meer balans in het intellectuele eigendomsrecht systeem te brengen niet zonder resultaten zijn. Nochtans, de theorie naar de praktijk vertalen blijft een uitdaging. Bijvoorbeeld, het is belangrijk, dat de implementatie van de WIPO 'Development Agenda' tot zichtbare verbeteringen leidt in die zin, dat de tenuitvoerlegging van elk van de aanbevelingen opgenomen in de Agenda ons een stap dichter bij een WIPO brengt, die de belangen van ontwikkelingslanden en het openbare belang hoog in het vaandel heeft staan in al zijn activiteiten met inbegrip van beleidsvorming en wetgevingsprocessen.

DE ONTIVIKKELING VAN IIET INTERNATIONALEJ JLRIDISCH KADER VOOR DE BESCHIRMING VAN INTELLECTLELE EIGENDOM

Als vuistregel geldt, dat de technologie altijd voorop loopt en het aanpassen van de wet altijd door technologische ontwikkeling wordt overtroffen. Doordat er voortdurend technologische ontwikkelingen plaatsvinden, die van invloed zijn op het intellectuele eigendomsrecht, is het juist om te stellen, dat dit rechtsgebied één van de meest dynamische gebieden van intemationaal publiek recht is, waarin voortdurend over nieuwe overeenkomsten wordt onderhandeld op internationaal, regionaal en bilateraal niveau. Deze onderhandelingen bouwen voort op de minimummormen, die in de bestaande WIPO verdragen en het TRIPS Verdrag zijn vastgelegd. Het toepassingsbereik en de duur van het intellectuele eigendomsrecht zijn vergroot, met name om bescherming uit te breiden naar het internet en andere informatie en communicatie technologie (ICT) ontwikkelingen, maar ook om tegemoet te komen aan de gevolgen van de toenemende internationale handel. Er zijn nieuwe normen gecreëerd, de duur van bescherming is verlengd en bestaande uitzonderingen en beperkingen zijn verminderd om tot een verdergaande internationale 
harmonisatie van het intellectuele eigendomsrecht te komen overeenkomstig de wetten van technologisch gevorderde landen.

Met de tijd veranderde de reikwijdte en het toepassingsgebied van internationale intellectuele eigendomsrecht verdragen om tegemoet te komen aan economische, technologische en politieke veranderingen, behoeften en eisen. De ontwikkeling van nieuwe technologieën, in het bijzonder de informatie- en communicatietechnologie en de vooruitgang van biotechnologie, heeft bijgedragen tot de snelle veranderingen in de bescherming van intellectuele eigendomsrechten. Deze technologieën brengen hoge onderzoekskosten met zich mee, maar zijn vrij gemakkelijk te kopiëren en te herproduceren, vandaar, dat aanpassing van de bestaande rechten gewenst was.

Intellectuele eigendomsrechten worden al decennia lang verleend, in sommige jurisdicties zelfs eeuwenlang, om diverse redenen zoals in hoofdstuk één van dit boek is besproken, maar meestal is het onderliggende idee om matschappelijk welzijn te bevorderen door de stimulatie van innovatie, onderzoek en creativiteit. Nochtans hebben de recente veranderingen in intellectuele eigendomsrechtbescherming (met name het TRIPS verdrag en de WIPO internet verdragen) een grotere kloof teweeggebracht tussen landen die vooroplopen in het ontwikkelen van 'state-of-the-art' technologieën en landen die deze ontwikkelingen niet kunnen bijbenen en afhankelijk zijn van imitatie en kopieer technieken om toegang te hebben tot nieuwe ontwikkelingen.

Tot ver in de 20 e eeuw behoorden de beleidsvorming en wetgevingsprocessen met betrekking tot het intellectuele eigendomsrecht tot het exclusieve domein van juristen. De totstandkoming van beleid en wetgeving inzake het intellectuele eigendomsrecht vond plaats in relatieve isolatie van debatten over de belangen van het publiek in het algemeen en verwante gebieden zoals de bescherming van de volksgezondheid, voedselveiligheid, onderwijs, vrije handel, industrieel beleid, bescherming van traditionele en inheemse kennis, behoud van de biodiversiteit, stimuleren van biotechnologie, de informatiemaatschappij en de media. Bovendien zijn intellectuele eigendomsrechten in principe territoriale rechten, wat betekent, dat zij worden toegekend, geimplementeerd en gehandhaafd binnen nationale grenzen.

De WIPO en de WTO zijn sturende krachten geweest in de harmonisatie van intellectuele eigendomsrechten en beleid op internationaal niveau. De ontevredenheid met het bestaande intellectuele eigendomsrechten systeem leidde tot het TRIPS Verdrag in het laatste decennium van de $20^{\text {st }}$ eeuw.

Hoofdstuk één beschrijft de ontwikkeling van het intellectuele eigendomsrecht in het algemeen en meer in detail de totstandkoming van het TRIPS Verdrag. Het TRIPS Verdrag maar ook de WIPO Internet Verdragen hebben geleid tot een aanzienlijke erosie van nationale soevereiniteit, aangezien de lidstaten tot op zekere hoogte niet meer vrij zijn om zelf tot besluitvorming te komen inzake intellectuele eigendomsrechtbescherming. Het TRIPS Verdrag har- 
moniseert de implementatie, handhaving en coördinatie van intellectuele eigendomsrechten in vergaande mate. Desalniettemin ontbreekt in veel ontwikkelingslanden de administratieve infrastructuur om de verplichtingen te vervullen, die het TRIPS Verdrag met zich mee brengt, maar tegelijkertijd ook om te profiteren van de rechten opgenomen in het Verdrag. Studies hebben uitgewezen, dat het niveau van ontwikkeling van de betreffende landen in sterke mate bepaalt, of een land baat heeft bij het TRIPS Verdrag en de daarin opgenomen intellectuele eigendomsbepalingen.

Maar de harmonisatie inspanningen in de multilaterale TRIPS context waren duidelijk niet genoeg, aangezien het laatste decennium door een ongekende proliferatie van regionale en bilaterale vrijhandelsovereenkomsten (in een poging om economische en handelsbetrekkingen tussen de landen te versterken) met inbegrip van intellectuele eigendomsrechten is gekenmerkt. Vaak gaan de bepalingen in deze vrijhandelsovereenkomsten verder dan het TRIPS Verdrag zoals bijvoorbeeld het vereiste van toetreding tot een aantal internationale intellectuele eigendomsrecht verdragen, het uitbreiden van substantièle bepalingen en het negeren van overgangsperiodes voor ontwikkelingslanden (zogenaamde transition periods).

Als gevolg van deze ontwikkelingen is de vrijheid van landen om beleid en besluitvorming ten aanzien van intellectuele eigendom op te stellen, overeenkomstig sociaal-economische ontwikkelingsbehoeften en doelstellingen, verminderd. Het feit, dat vrijhandelsovereenkomsten vaak TRIPS plus bepalingen omvatten en landen bovendien partij zijn bij verschillende vrijhandelsovereenkomsten, waarvan de reikwijdte en normalisatie sterk verschillen (elke overeenkomst heeft zijn eigen focus, interesses en beleidsdoelstellingen), leidt tot problemen en ontransparante regelgeving. Het kan leiden tot inconsistentie in de implementatie van intellectuele eigendomsrechten en toenemende verplichtingen. Het betekent ook, dat de flexibiliteit en uitzonderingsmogelijkheden voor het beschermen van bepaalde openbare belangen en ontwikkelingsdoelstellingen onder het TRIPS Verdrag afneemt. Met name voor ontwikkelingslanden kan dit grote gevolgen hebben. Deze bijkomstige verplichtingen zijn geintroduceerd op een tijdstip, waarop de meerderheid van ontwikkelingslanden nog voor reusachtige uitdagingen staan om de minimumnomen, voortkomende uit het TRIPS Verdrag, te implementeren en te handhaven. De proliferatie van vrijhandelsovereenkomsten is nog onrustbarenter, als men in ogenschouw neemt, dat één van de principes van het TRIPS Verdrag (vastgelegd in Artikel 4), de zogenaamde clausule van meestbegunstigde natie (mostfawoured nation principlo', impliceert dat om het even welk voordeel, voorrecht of immuniteit, die aan een lidstaat wordt verleend, onmiddellijk en onvoorwaardelijk aan alle andere lidstaten zal moeten worden verleend.

Het is an te raden, dat regionale en bilaterale onderhandelingen met de uiterste voorzichtigheid worden benaderd om de bestaande flexibiliteit, voortkomend uit het TRIPS Verdrag, niet te bekorten, ook ten aanzien van de aan de gang zijnde multilaterale onderhandelingen in de context van WIPO en de 
WTO, vooral op een tijdstip waarop de WTO Doha Ronde in een impasse blijft.

\section{RECIITEN EN I'LICIITEN IN BALANS BRENGIEN}

Tijdens de onderhandelingen van het TRIPS Verdrag werd door geïndustrialiseerde landen herhaaldelijk benadrukt, dat het aanscherpen en harmoniseren van intellectuele eigendomsrechten noodzakelijk is voor het stimuleren en ontwikkelen van nieuwe technologieën, het genereren van kennis en bovendien de overdracht van technologie zou bevorderen. Nochtans, 15 jaar na de totstandkoming van het TRIPS Verdrag blijkt, dat de meeste voordelen, die uit het TRIPS Verdrag kunnen voortvloeien alleen realiseerbaar zijn op de lange termijn, terwijl op korte termijn ontwikkelingslanden wel de rechten en plichten uit het TRIPS Verdrag moeten implementeren en handhaven, terwijl het deze landen op de korte termijn geen direct profijt oplevert en het gebruik van imitatie en rewse engincering technieken sterk vermindert. De realiteit heeft uitgewezen dat de belangen en behoeftes van ontwikkelingslanden inzake intellectuele eigendomsrechten sterk verschillen en afhankelijk zijn van het ontwikkelingsniveau. Overmatige bescherming van intellectuele eigendomsrechten is niet goed voor ontwikkelingsdoelstellingen en kan zelfs schadelijk zijn voor de sociaal-economische ontwikkeling en technologiebehoeften van een land.

Het TRIPS Verdrag heeft zijn tekortkomingen: hoofdstuk vijf bijvoorbeeld gat uitgebreid in op het softe, niet afdwingbare karakter van de bepalingen in relatie tot de overdracht van technologie in vergelijking met de andere TRIPS bepalingen, die veel dwingender van karakter zijn. Een andere belangrijke tekortkoming is dat het TRIPS Verdrag geen specifieke bepalingen heeft om misbruik van intellectuele eigendomsrechten tegen te houden en er slechts melding gemaakt wordt van het feit, dat intellectuele eigendomsrechten en in het bijzonder licentie verplichtingen en voorwaarden opgenomen in clausules (in technologieoverdracht overeenkomsten), de internationale handel en de overdracht van technologie kan hinderen. Artikel 40 van het TRIPS Verdrag heeft bepaald, dat landen zelf stappen kunnen ondernemen om misbruik van intellectuele eigendomsrechten tegen te gaan, vooral als dit een impact heeft op mededinging in de markt, en in relatie tot "packaging" van technologie overdracht overeenkomsten en dwingende clausules die bijvoorbeeld exclusieve "grant back" voorwaarden tot een contractuele vereiste maken. Het is aan te bevelen om de link tussen het intellectuele eigendomsrecht en het mededingingsrecht verder te bestuderen; verder zouden ontwikkelingslanden geassisteerd moeten worden bij het installeren van mededingingsrechten en autoriteiten. Geindustrialiseerde landen zouden bovendien misbruik van marktpositie moeten identificeren in ontwikkelingslanden en lokale overheidsautoriteiten attenderen op ongeoorloofde acties van multinational enterprises (MNEs). Ook heeft het TRIPS Verdrag niet voldoende rekening gehouden met culturele en ethische verschillen in het opstellen van bepalingen met betrekking tot het verstrekken van exclusieve rechten. Hoofdstuk drie zal met name 
aandacht besteden aan de mogelijkheden die landen hebben om bepaalde zaken buiten het octrooirecht te houden; verder komt ook het gecompliceerde vraagstuk aan de orde hoe traditionele kennis en genetisch materiaal het beste kan worden beschermd. Het TRIPS Verdrag is bijzonder zwijgzaam op dit voor ontwikkelingslanden zo belangrijke onderwerp. Geneefse onderhandelingen, zowel binnen de WTO TRIPS Council als de WIPO vergaderingen concentreren zich op deze tekortkomingen.

De verschillende behoeften en interesses van industrieën en het publiek (de maatschappij als geheel) leiden tot beleidsproblemen, bijvoorbeeld ten aanzien van de volksgezondheid (toegang tot essentiële geneesmiddelen en voedselveiligheid), de toegang tot informatie en onderwijsmateriaal (tekstboeken, academische tijdschriften etcetera.), maar ook met betrekking tot milieukwesties (bescherming en behoud van biodiversiteit, en onrechtmatige toe-eigening van traditionele kennis en genetisch materiaal).

Het is al langer een feit, dat er geen on' size fits all model bestaat ten aanzien van de bescherming van intellectuele eigendomsrechten, aangezien een eenvormige benadering niet aan de unieke vereisten van de lokale industrieën en culturen kan voldoen. De bescherming van het intellectuele eigendomsrecht moet innovatie, creativiteit en de overdracht van technologie bewerkstelligen in het belang van alle landen en niet alleen de machtige geïndustrialiseerde landen. Op dit moment is het evenwicht tussen openbaar en privé belang uit balans aan het raken: de belangen van de intellectuele eigendomsrecht houder worden geprefereerd en het lijkt alsof het intellectuele eigendomsrecht steeds meer een hulpmiddel is om investeringen te beschermen en marktpositie te versterken. Vandaar, dat het tijd is om meer gelijkheid aan te brengen in intellectuele eigendomsrecht beleid-en besluitvorming en de asymmetrische onderhandelingspositie van ontwikkelingslanden in intellectuele eigendomsrecht onderhandelingen te erkennen.

Om in deze behoeften te voorzien zijn drie wijd gedocumenteerde initiatieven het vermelden waard:

Ten eerste de Millennium Ontwikkelingsdoelstellingen van de Verenigde Naties (MDG). In 2000 hebben regeringsleiders van 189 landen internationale afspraken gemaakt: vóór 2015 moeten armoede, ziekte en honger ver teruggedrongen zijn. Dit is vertaald in acht concrete doelen. Eén doelstelling is om de verspreiding van ziektes zoals aids en malaria te stoppen en toegang tot medicijnen te bewerkstelligen;

Ten tweede de WTO Doha Ronde: Dit is een onderhandelingsronde tussen verschillende landen, georganiseerd door de WTO met als doel de handelsbarrières in de wereld op te heffen en vrije internationale handel mogelijk te maken. Het mandaat voor de onderhandelingen werd verstrekt in November 2001 in Doha, Qatar (WTO Doha Ministeriële Verklaring). Het originele mandaat werd later verfijnd in Seattle, Cancun, Genève en Hong Kong. De ronde had eigenlijk beëindigd moeten zijn in 2006, maar in de zomer van 2008 zijn de Europese Gemeenschap (EG), de Verenigde Staten, China, India en 
Brazilië het nog niet eens over de opening van de agrarische en industriële markten.

Ten derde de WIPO "Development Agenda": Een door Argentinië en Brazilië ingediend voorstel in 2004 (later gesteund door het merendeel van de ontwikkelingslanden, lid van WIPO) voor de totstandbrenging van een WIPO "Development Agenda" wordt in 2007 formeel aangenomen in WIPO's Algemene Vergadering (ammual Genernl Assembly). Het centrale punt van deze agenda is om te benadrukken dat de rol van WIPO niet beperkt is tot het promoten van intellectuele eigendomsrechten, mar de verder strekkende ontwikkelingstoelstellingen van de Verenigde Naties niet uit het oog mag verliezen. Met andere woorden: deze agenda benadrukt dat het intellectuele eigendom niet als "eind" (doel) op zichzelf mag worden gezien en dat de harmonisatie van intellectuele eigendomwetten niet ongeacht het ontwikkelingsniveau van landen mag plaatsvinden. De agenda herbevestigt de beloften gemaakt in de WTO Doha Ministeriële Verklaring - zowel de belofte in het kader van paragraaf 19, die een mandaat verleent aan de TRIPS Council om volledig rekening te houden met de ontwikkelingsdimensie, als de belofte gemaakt in de "Declaration on the TRIPS Agreement and Public Health", die vermeldt, dat de bepalingen binmen het TRIPS Verdrag de volksgezondheidsdoelstellingen van alle landen moet steunen en zeker niet moet tegengaan.

De recente onderhandelingen in de WIPO zijn op uiteenlopende onderwerpen gericht: enerzijds op het uitbreiden van het werkingsgebied van intellectuele eigendomsrecht bescherming (het aamemen van substantieve normen, bijvoorbeeld in het kader van het harmoniseren van het octrooirecht) en op het verbeteren van de handhaving van rechten, en anderzijds om het globale intellectuele eigendomsrecht systeem te hervormen om tegemoet te komen aan de wensen van ontwikkelingslanden (met name het realiseren van bescherming voor traditionele kennis en de implementatie van de WIPO "Development Agenda").

De WIPO "Development Agenda" tracht de kenniskloof en de digitale onbalans tussen ontwikkelingslanden en geïndustrialiseerde landen te dichten. Nochtans is de implementatie (realisatie) van de aanbevelingen in de WIPO "Development Agenda" een politieke uitdaging zijn. Tijdens de laatste WIPO "Development Agenda" onderhandelingen stonden procedurele issues centraal in tegenstelling tot substantiële kwesties. Overeenstemming is wel bereikt over de vorm van de onderhandelingen: men is voornemens om de aanbevelingen thematisch te bespreken. Het is waarschijnlijk, dat de WIPO wetgevings- (nomm-setting) en technische bijstandsactiviteiten (techical assistmice) de meeste aandacht in de discussies zullen krijgen.

Binnen de multilaterale context, maar ook in FTA onderhandelingen, bepleiten de geïndustrialiseerde landen lidmaatschap van het WIPO "Patent Cooperation Treaty" (PCT) door te benadrukken, dat dit de overdracht van technologie zal vergroten. Nochtans, de PCT is bekritiseerd op gronden dat het vooral de belangen van de geïndustrialiseerde landen ten goede komt. Het is aan te 
bevelen om ontwikkelingslanden een andere prijs te vragen om octrooien te registreren en een gedeelte van de registratie opbrengst te besteden aan het verbeteren en ontwikkelen van intellectuele eigendomsrecht instituten.

Het intellectuele eigendomsrecht behoort ook tot de onderhandelingsportefeuille van de WrO, met name binnen de halfjaarlijkse vergaderingen van de TRIPS Council. De huidige TRIPS Council onderhandelingen zijn gericht op de zogenaande "ingebouwde onderhandelingsbepalingen" (imbuilt n'gotiation prorisions) van het TRIPS Verdrag en de uitstaande implementatie kwesties, voortkomende uit de WTO Doha Ronde. De imbuilt bepalingen hebben betrekking op het uitbreiden van de bestaande bescherming van geografische herkomstaanduidingen (Artikel 24.1 TRIPS Verdrag), het introduceren van een multilateraal systeem van notificatie en registratie van geografische herkomstaanduidingen met betrekking tot wijn en sterke drank (Artikel 23.4 TRIPS Verdrag), en herziening van Artikel 27.3(b), dat betrekking heeft op patenteerbaarheid van uitvindingen op planten, dieren en plantenvariëteiten. Alhoewel, in de praktijk is deze discussie toegespitst op het introduceren van een disclosure of origin requirment als onderdeel van een octrooi aanvraag. Paragraaf 19 van de "Doha Declaration" heeft de discussie verder uitgebreid naar de relatie tussen het TRIPS Verdrag en de "Convention on Biological Diversity" (CBD) met name de bescherming van traditionele kennis en folklore. De "Doha Declaration" verwijst verder ook naar het belang van de toegang tot en het ontwikkelen van nieuwe medicijnen in het belang van de algemene volksgezondheid, en ziet erop toe dat in de onderhandelingen over deze kwesties de "objectives" en "principles" (vastgelegd in respectievelijk Artikel 7 en 8) van het TRIPS Verdrag niet uit het oog worden verloren net zoals de verschillende niveaus van economische ontwikkeling (paragraaf 17-19 Doha Declaration). De vooruitgang in de onderhandelingen is afhankelijk van een zorgvuldige selectie van compromissen en het bereiken van overeenstemming. De onderhandelingen zijn aan de gang, maar progressie is traag, voornamelijk terug te voeren op de wijd uiteenlopende belangen van de verschillende landen. Er is een gebrek aan empirisch en economisch bewijs (wijzend op de voordelen en de nadelen van verdergaande bescherming voor intellectuele eigendom), zoals kosten en baten analyses, die de onderhandelingen diepgang kunnen geven en bijdragen tot een beter begrip van de op het spel staande kwesties. Ontwikkelingslanden hebben vaak geen keuze, aangezien het versterken van de bescherming van intellectuele eigendomsrechten vaak gepaard gaat met markttoegang voor hun producten. Alhoewel, in tegenstelling tot twee decennia geleden zijn ontwikkelingslanden beduidend meer op de hoogte van de Geneefse onderhandelingen, zowel binnen de WIPO als binnen de WTO. De betrokkenheid van non-gouvernementele organisaties (NGOs), gespecialiseerde denktanks en ontwikkelingsorganisaties hebben de onderhandelingsposities van ontwikkelingslanden versterkt door informatie en kennis op het gebied van intellectuele eigendom, de urgente kwesties en bestaande onderhandelingsprocessen op nationaal, regionaal en internationaal niveau te verstrekken en te analyseren. 
Voor landen die grotendeels netto importeurs van intellectuele eigendom zijn, zijn de voordelen van een ver reikende intellectuele eigendomsrechten overeenkomst, die vooral de belangen van de rechthebbende bevordert, niet onmiddellijk aanwezig. Intellectuele eigendomsrechten hebben een impact op verschillende matschappelijke kwesties (bijvoorbeeld de volksgezondheid, het recht, het milieu, biodiversiteit, educatie, en culturele vorming) en in groeiende mate is het onderwerp van discussie in veel internationale onderhandelingsprocessen. Deze factoren maken een zorgvuldige belangenafweging in het beleidsproces tot een uitdaging: beleidscoördinatie, transparantie en samenwerking tussen de verschillende landen vertegenwoordigers en instellingen en organisaties zijn een must. De prijs, die ontwikkelingslanden betalen voor markttoegang, is hoog, in het bijzonder in relatie tot de implementatie en handhaving van de rechten en plichten, voortvloeiende uit het TRIPS Verdrag en de vrijhandelsovereenkomsten. Het is van belang om te realiseren dat het echte werk pas begint na het ondertekenen van de vrijhandelsovereenkomst: namelijk het complexe proces om de voortvloeiende verplichtingen uit te voeren begint dan pas. Binnenlandse wetgeving moet aangepast worden aan de nieuwe internationale verplichtingen en ook dienen landen toe te treden tot diverse intellectuele eigendomsrecht verdragen volgens de overeengekomen tijdsbepalingen. Een eerste vereiste voor efficiënte implementatie van deze rechten is het instellen van een institutioneel en administratief kader, evenals goed bestuur, infrastructuur, met inbegrip van samenwerking tussen douaneautoriteiten, ministeries en politieautoriteiten. Wanneer het implementatieproces wordt afgerond, zijn de landen onderworpen aan constant toezicht op hun implementatie en handhavingsverplichtingen.

De laatste jaren is er toegenomen aandacht voor het bewerkstelligen van efficiënte handhaving van intellectuele eigendom en de nalatigheden hierin worden in de pers breed uitgemeten. Onlangs moest een WTO Panel beoordelen of China's matregelen om intellectuele eigendomsrechten te beschermen conform zijn met het TRIPS Verdrag op verzoek van de VS. Nochtans is er meer bespreking over het aanscherpen van intellectuele eigendomsrecht handhaving dan er concrete en betrouwbare gegevens beschikbaar zijn over de verliezen die de industrie door inbreuken op het intellectuele eigendomsrecht recht lijden (bv. het vervalsen en namaken van goederen en geschriften en piraterij). Deze informatie is echter noodzakelijk voor een efficiënte en evenwichtige beleidsvorming. Op dit moment is de discussie handhaving eenzijdig en volledig gericht op de belangen van industrie en intellectuele eigendomsrecht rechthebbenden. Het is belangrijk om de implicaties en uitdagingen voor ontwikkelingslanden om het intellectuele eigendomsrecht te handhaven en te beschermen niet uit het oog te verliezen en te blijven wijzen op de rechten en plichten, voortvloeiende uit het TRIPS Verdrag, en de hen toebedeelde flexibiliteiten niet te ontzeggen zoals onderzoeks- en onderwijsvrijstellingen. 
Hoofdstuk twee van dit boek geeft een gedetailleerd overzicht van de rechten en plichten, die voortvloeien uit het TRIPS Verdrag, in het bijzonder de bepalingen, die van belang zijn voor ontwikkelingslanden. De nadruk ligt op de flexibiliteiten die landen hebben om technologische en sociaal-economische ontwikkelingsbehoeften te ondersteunen. In het bijzonder zijn de vrijstellingen voor het verrichten van onderzoek en onderwijs twee zeer belangrijke, maar onderbelichte flexibiliteiten, voortkomende uit het TRIPS Verdrag. Verder beschikken landen over de mogelijkheid om dwanglicenties uit te geven in het geval van een nationale noodsituatie, bijvoorbeeld om medicijnen goedkoper te fabriceren. De mogelijkheden om dwanglicenties uit te geven voor andere doelstellingen bieden perspectief, bijvoorbeeld in het kader van ecologische/ milieu doelstellingen om op een milieuvriendelijkere manier met energie om te gaan of in de auto industrie (het fabriceren van auto onderdelen spareparts). Andere flexibiliteiten zijn de vrijheid om een nationaal regime te bepalen op het gebied van parallelle import, utility modols, handelsgeheimen, maar vooral ook de vrijheid om de TRIPS bepalingen te implementeren (Artikel 1 TRIPS Verdrag) in het nationale rechtssysteem. Landen kunnen profiteren door nationale intellectuele eigendomsrecht regimes zo gunstig mogelijk vast te stellen.

Het is essentieel, dat de overheden en andere nationale instellingen het belang van innovatie, technologische vooruitgang en duurzame ontwikkeling voor sociale en economische groei en ontwikkeling begrijpen. Focus zou moeten liggen om het Midden- en Kleinbedrijf (MKB) meer innovatief en concurrerend te maken ten opzichte van grote buitenlandse bedrijven. Technologische vooruitgang betekent een belangrijke uitdaging voor ontwikkelingslanden, niet alleen voor het concurreren in internationale markten, maar vooral voor het verhogen van de lokale levensstandaard en in het bijzonder in de landbouwsector. Met name in een biologisch rijk gebied zou innovatie meer gericht moeten zijn op het intelligente gebruik van biodiversiteit, niet alleen voor de economische groei en het bevorderen van het creëren van arbeidsplaatsen, maar ook voor het behoud van natuurlijke rijkdommen. Aangezien de biotechnologie in toenemende mate een economische groeigenerator in veel landen is, zouden de flexibiliteiten voortkomende uit het TRIPS Verdrag met name de onderzoeksvrijstellingen en de anti concurrerende bepalingen in het TRIPS Verdrag gebruikt kunnen worden om biotechnologiesectoren in ontwikkelingslanden te ontwikkelen om in de toekomst minder afhankelijk te zijn van producten (met name geneesmiddelen) geproduceerd door Westerse multinationals.

Een belangrijke flexibiliteit voortkomende uit het TRIPS Verdrag betreft de overgangsperiodes (zogenaamde transition periods vastgelegd in Artikels 65 en 55). Dit houdt in dat de minst ontwikkelde landen voor een bepaalde periode vrijgesteld zijn van de plichten voortvloeiende uit het TRIPS Verdrag. Het besluit genomen in de TRIPS Council op 29 November 2005 verlengde de 
overgangsperiode voor de minst ontwikkelde landen met zeven en een half jaar tot 1 Juli 2013. Voorts heeft paragraaf 7 van de "Declaration on the TRIPS Agreement and Public Health" bepaald, dat verplichtingen ten aanzien van de bescherming van farmaceutische octrooien opgeschort mogen worden tot 1 Januari 2016 voor de minst ontwikkelde landen. Dit betekent, dat deze landen tot het verstrijken van de overgangsperiode vrij zijn om generieke medicijnen te produceren en de intellectuele eigendomsrechten van de farmaceutische bedrijven mogen negeren.

Deze overgangsperiodes zijn ingesteld om deze landen langer de tijd te geven om de TRIPS bepalingen te implementeren, toe te passen en te handhaven, maar ook om de onderhandelingspositie te vergroten. Aangezien veel van deze landen niet beschikten over lokale intellectuele eigendomsrechten voor de ratificatie van het TRIPS Verdrag was er een groot hiaat tussen de geschapen verwachtingen en de realiteit ten aanziende van de capaciteit van de minst ontwikkelde landen om aan deze verwachtingen te voldoen. De overgangsperiodes zijn bedoeld om het institutionele en administratieve kader op te zetten dat noodzakelijk is om de rechten en plichten uit het TRIPS Verdrag op dusdanige wijze te implementeren, dat het de sociale en economische groei ten goede komt (van alle landen en niet alleen de meest ontwikkelde). Dit houdt ook in, dat de kennis op het gebied van het intellectuele eigendomsrecht moet worden vergroot, met name de mogelijkheden en de consequenties van bescherming, om beter gebruik te maken van het intellectuele eigendomsrecht voor de sociaal-economische ontwikkeling. Ook dient de extra tijd om ruimte te geven voor het creëren van een technologische en creatieve basis door optimaal gebruik te maken van innitatie, kopieer en reverse engineer technieken en vervolgens de opgedane kennis om te zetten in het ontwikkelen van nieuwe, innovatieve technieken en bedrijfsmethodes. Nochtans heeft de realiteit uitgewezen, dat ontwikkelingslanden hulp nodig hebben in het nastreven van bovengenoemde activiteiten. Het is van belang, dat technische bijstandsactiviteiten, gericht op het helpen van ontwikkelingslanden om aan de TRIPS verplichtingen te voldoen, zich focussen op het verhogen van de algemene kemnis van het intellectuele eigendomsrecht, de verschillende concepten en hun consequenties. Niet alleen de rechten en plichten voortvloeiende uit het TRIPS Verdrag moeten aan de orde komen in trainingsprogramma's, maar er moet ook voldoende aandacht gegeven worden aan de aanwezige flexibiliteiten, met name ten aanzien van het verbeteren van de onderhandelingspositie van ontwikkelingslanden. Het besluit van de TRIPS Council genomen op 29 November 2005 wijst opnieuw op de verplichtingen van de ontwikkelde landen inzake het verlenen van technische en financiële bijstandsactiviteiten aan de minst ontwikkelde landen om de TRIPS bepalingen uit te voeren. Van de minst ontwikkelde landen wordt verwacht, dat zij een lijst met hun individuele, urgente behoeften inzake technische en financiële bijstandsactiviteiten verstrekken. Tot nu toe hebben alleen Sierra Leone en Oeganda aan dit verzoek voldaan. Deze initiatieven zijn belangrijk en meer landen zouden dit voorbeeld moeten volgen, - het laat zien dat de kwesties serieus genomen worden en dat er daadwerkelijk actie ondernomen wordt in de minst ontwikkelde landen om aan hun TRIPS verplichtingen te voldoen. Dit kan een 
belangrijk gegeven zijn om in de toekomst weer voor een verlenging van de overgangsperiode in aanmerking te komen.

\section{GEOGRAFISCHE HERKOMSTAANDLIDINGEN LN POTENTIEEL VOOR ONTWIKKEIINGSLANDEN}

Hoofdstuk vier onderzoekt het potentieel van geografische aanwijzing (GI) bescherming voor ontwikkelingslanden. I let TRIPS Verdrag heeft GIs onderdeel gemaakt van het intemationale intellectuele eigendomsrecht systeem en in de huidige TRIPS Council onderhandelingen is het een prominent en controversieel onderwerp van debat geworden. De meningen ten aanzien van het beschermen van Gls zijn sterk verdeeld: het is niet specifiek een kwestie van de ontwikkelingslanden versus de geindustrialiseerde landen maar eerder een tweestrijd tussen de zogenaamde "nieuwe wereld" en de "oude wereld". Een Gl is een naam of een teken dat op bepaalde producten wordt gebruikt waarvan de kwaliteit, kenmerken en/of de reputatie gelinkt is aan een specifieke geografische plaats. GIs worden meestal toegepast op agrarische producten maar in principe kunnen Gls worden gebruikt op allerlei producten (bijvoorbeeld Zwitserse horloges, tabak uit Cuba, rijst uit India, Peruaans zilverwaar en Indische sjaals).

Gls kunnen bijvoorbeeld een handig hulpmiddel zijn om bescherming te bieden aan producten gebaseerd op traditionele kemis, d.w.z. op distinctieve, traditionele productiemethoden, die bewaard zijn gebleven en van generatie op generatie overgedragen zijn binnen een gemeenschap en tot een bepaalde regio behoren.

Bovendien stat het gebruik van geografische aanwijzingen producenten toe om markterkenning en vaak een premieprijs te verkrijgen. Met name in relatie tot de verhoogde internationalisering van voedsel en productmarkten zijn GIs een zeer belangrijke bron van marketing geworden, vooral voor agrarisch georiënteerde landen. Vandaar, dat GIs nuttige hulpmiddelen zijn om producten te onderscheiden op basis van kwaliteit, om herkenbaarheid te vergroten evenals traditionele en culturele tradities te bewaren.

Het labelen met een Gl verhindert andere producenten niet om gelijksoortige producten te produceren en te verhandelen, maar belemmert hen slechts in het verkopen van deze producten onder dezelfde naamsvermelding op het etiket. Dit betekent dat producten beschermd door GIs in hun marktcategorie concurrerend moeten blijven.

\section{Litstande' Gl Kuesties}

Hoofdstuk vier benadrukt dat er nog veel vraagstukken in relatie tot de bescherming van Gls onbeantwoord zijn gebleven, zowel op internationaal als op nationaal niveau. De uitstaande GI kwesties omvatten de volgende punten: 
1) Het berwerkstelligen tan Gl bescherming op nationanl nivenu. Dit is een belangrijk vereiste, aangezien nationale bescherming noodzakelijk is om bescherming op het internationale niveau te verkrijgen;

2) Soortnamin. Controversie ontstaat, wanneer namen gelijktijdig in omloop zijn op producten, die in een bepaald land beschermd zijn door een Gl, maar in een ander land een generieke status hebben verkregen (d.w.z. dat namen/termen gebruikelijk in gemeenschappelijke taal zijn geworden voor dergelijke producten) en dus door een ieder gebruikt mogen worden en niet alleen door de bepaalde producent, die aan de vereisten van de GI voldoet. Beroemde voorbeelden van namen, die bescherming genieten in bepaalde landen maar generiek zijn in andere landen, zijn: "Basmati" en "Champagne". Momenteel zijn de meningen sterk verdeeld ten opzichte van deze kwestie. Sommigen zijn van oordeel, dat consumenten "Champagne" associëren met een bepaald type bruisende witte wijn, niet specifiek gebonden aan een bepaalde groep producenten uit een bepaalde streek, maar anderen zijn van mening, dat consumenten een bepaalde kwaliteit verwachten bij de naam "Champagne" en dat deze kwaliteit alleen gewaarborgd kan zijn als het product geproduceerd wordt in een bepaald geografisch gebied met gebruik van specifieke productie processen, waardoor de specifieke eigenschappen kunnen worden gegarandeerd. De Europese Gemeenschap probeert namen te beschermen door in FTAs lange lijsten op te nemen met namen (nationaal geregistreerd als GIs) die beschermd dienen te worden door beide partijen;

3) Homoniche GIs. Controversie ontstaat wanneer er oorsprongsbenamingen of geografische aanduidingen in omloop zijn die volledig of gedeeltelijk homoniem zijn met een geregistreerde (beschermde) benaming in een ander lant. Deze situatie ontstaat, wanneer twee geografische gebieden identiek worden genoemd en identieke/gelijkaardige producten produceren, die op identieke/gelijkaardige productiemethodes zijn gebaseerd. De kwestie van homonieme Gls behoort bijna uitsluitend toe tot het gebied van de wijn. In de meeste gevallen waren het de Europese immigranten die de namen en de begeleidende productiemethodes meenamen naar hun nieuwe vaderland (overzeese koloniën). Europese wetgeving bevat een bepaling, dat homonieme benamingen, die bij de consument ten onrechte de indruk wekken, dat de producten, die van oorsprong uit een ander gebied zijn, niet geregistreerd hoeven te worden, ook al is de benaming juist wat het grond gebied, de regio of de plaats van oorsprong van de landbouwproducten of de levensmiddelen betreft en is het alleen toegestaan om beide homonieme producten naast elkaar te laten voortbestaan, indien de praktische omstandigheden garanderen, dat de in tweede instantie geregistreerde homonieme benaming zich duidelijk onderscheidt van de 
reeds beschermde benaming, betrokken producenten billijke behandeling krijgen en de consument niet mag worden misleid.2 De TRIPS bepalingen (Artikelen (22.4 en 23.3)) zijn bijna identiek aan de Europese Wetgeving inzake deze kwestie;

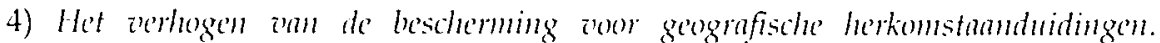
Momented is de GI bescherming voortkomende uit het TRIPS Verdrag tweeledig: een basis rechtsbescherming voor alle producten en een hoger beschermingsniveau voor wijnen en sterke drank. Deze hiërarchie in bescherming is het onderwerp van veel debat binnen de onderhandelingen van de TRIPS Council. De voorstanders van het uitbreiden van de speciale GI bescherming (die momenteel alleen aan wijn en sterke drank wordt verleend) naar andere Gl producten beargumenteren, dat dit de export alsmede de ontwikkeling van plattelandsgebieden zal bevorderen, consumenten bescherming zal warborgen en bovendien de marketing van producten zal verbeteren door grotere product differentiatie t.o.v. concurrenten. Daarnaast zou het verhogen van Cr bescherming ook de commerciële belangen van vele ontwikkelingslanden bevorderen, aangezien zij geen grote producenten van wijn en sterke drank zijn (bijvoorbeeld in Moslimlanden waar de binnenlandse alcoholproductie nihil is). Zij zouden vooral kunnen profiteren van uitgebreide GI bescherming in relatie tot landbouw en voedingsmiddelen zoals thee, rijst, koffie, cacao, graan, olie, tropische vruchten maar ook van ambachten, souvenirs en dergelijke. Aan de andere kant beweren de tegenstanders van uitbreiding, dat: A) de huidige mate van bescheming (in het kader van Artikel 22 TRIPS) adequat is en; B) uitbreiding van $G$ l bescherming hoge financiële en administratieve lasten met zich meebrengen en de in omloop zijnde marketing praktijken hinderen.

5) Het invoren wan e'en notificatic 'n registratic syste'm ioor Gls. Naast de uitbreiding van $G I$ bescherming richt het debat zich vooral op het introduceren van een multilateraal systeem voor de notificatie en de registratie van wijnen (en sterke drank) voortvloeiende uit Artikel 23(4) van het TRIPS Verdrag. De doelstelling van dit systeem is om de bescherming van GIs te vergemakkelijken door hun bekendheid te vergroten. Centraal bij het debat is, welk wettelijk effect het multilaterale register binnen de lidstaten zal hebben: de opties variëren tussen een vrijwillig of een verplicht systeem. De meningen zijn ook verdeeld over het werkingsgebied van zo'n register: sommige landen zijn van mening dat het register niet tot wijnen zou moeten worden beperkt, terwijl andere landen vinden dat een uitbreiding van producten buiten het verleende mandaat valt en niet bespreekbaar is;

2 Artikel 3(3) van de Verordening (EG), No. 510/2006 van de Raad van 20 maart 2006 inzake de bescherming van geografische aanduidingen en oorsprongsbenamingen van landbouwproducten en levensmiddelen. 
6) Bilaterale en Regionale Handelsorere'nkomsten (FTAs). Naast het onderhandelen op het multilaterale niveau (bij WTO en WIPO), kan een land dat GI bescherming wenst te versterken ook kiezen voor een bilaterale of regionale route om GI bescherming af te dwingen. Overeenkomsten, waarbij de Europese Gemeenschap contractpartij is, bevatten vaak gedetailleerde $\mathrm{CI}$ bepalingen, met inbegrip van het hogere type van bescherming voor alle type producten. Vaak is een lijst inbegrepen met namen die wederzijds zouden moeten worden erkend en beschermd - een gemakkelijke manier om de "soortnamen" kwestie te behandelen. In dit verband bestaat de mogelijkheid om een plafond op het aantal van GIs te bespreken dat kan worden geregistreerd in FIAs alsmede op multilateraal niveau.

In relatie tot bovengenoemd punt vier, inzake de uitbreiding van de speciale Gl bescherming voor wijnen en sterke drank naar andere Gl producten, is er helaas een gebrek aan empirisch bewijs en studies om een stellig standpunt in te nemen voor of tegen uitbreiding van GI bescherming. Sommige landen kumnen profiteren van verhoogde Gl bescherming voor één of twee producten, maar het staat buiten kijf, dat Europa het meest gebaat is bij uitbreiding van het Gl beschermingsgebied. Europa heeft rond de 700 producten die als GIs binnen haar grondgebied worden geregistreerd. Nochtans zouden de kosten van uitbreiding overwegend op niet EG landen vallen, aangezien zij de Europese Gls moeten beschermen, terwijl ze zelf op de korte en middellange termijn weinig profijt ervan hebben.

Het installeren van Gl bescherming waarborgt geen markttoegang of commercieel succes. Het is dus aan te bevelen om de uitbreiding van Gl bescherming te linken aan het waarborgen van markttoegang, aangezien op dit moment de tarieven voor het invoeren (bijvoorbeeld in de EG en de VS) van veel agrarische producten extreem hoog zijn. Commercieel succes vereist constante financiële en creatieve investering in de ontwikkeling van promotie en communicatie strategieën, cruciaal om de eventuele voordelen van product differentiatie effectief te genereren. Dit houdt ook in dat gebruik gemaakt dient te worden van marketing strategieën, b.v. het gebruik van aanplakborden, radio en nieuwe communicatie middelen. Verder moet ook gekeken worden naar een aantal kwesties: "Hoe hoog zijn de tarieflijnen om het product in te voeren?"; "Wat zijn de technische standaard vereisten?" en "Zijn er sanitaire en fytosanitaire maatregelen waaraan voldaan dient te worden?". Ook dient voldoende aandacht te worden gegeven aan supply chain management om voldoende productie te garanderen. Nochtans, de opbrengsten gegenereerd door GIs zijn vaak verbonden met niet monetaire voordelen zoals de bescherming van traditionele kennis, gemeenschapsrechten en het behoud van biodiversiteit.

Een kosten/baten analyse kan inzicht geven over het wel of niet invoeren van een Gl systeem op nationaal niveau alvorens een standpunt op multilateraal niveau in te nemen. Zo'n kosten/baten analyse zou de potentiële voordelen van het verlenen van (uitbreiding van) GI bescherming moeten onderzoeken 
in vergelijking met de kosten verbonden met de totstandbrenging van het wettelijke en administratieve systeem (met inbegrip van de overgave van algemeen gebruikte namen, zogenaamde 'soortnamen'), dat uitbreiding van $G$ bescherming met zich meebrengt. De volgende punten zijn van belang met betrekking tot een kosten/baten analyse.

1) In ieder geval moet een kosten/baten analyse de markt voor potentiële GI producten inventariseren, in eigen land evenals op regionaal of internationaal niveau. Net zoals handelsmerken zijn Gls intrinsiek verbonden met het kopen en het verkopen van producten. Alhoewel in sommige gevallen de markten international zouden kunnen zijn, is het logischerwijze aan te bevelen om eerst het lokale en regionale marktpotentieel te onderzoeken. Vervolgens zou er een lijst van potentiële GIs opgesteld moeten worden om inzicht te krijgen in het belang van GIs voor de specifieke nationale context. Er is een grote diversiteit van potentiële sectoren waar Gls van belang kunnen zijn, maar in ogenschouw nemende dat de landbouw sector een prominente rol inneemt in de economie van ontwikkelingslanden is het aan te bevelen om te beginnen met het identificeren van potentiële GIs in deze sector gevolgd door de ambacht sector (hnuticrafts). Bovendien is het noodzakelijk om een lijst van buitenlandse Gls te maken, die momenteel algemeen in gebruik zijn voor soortgelijke goederen (d.w.z. namen die algemeen gebruikt worden in het betreffende land maar beschermd zijn met een geografische herkomst aanduiding in andere landen). Zo'n lijst geeft inzicht in de consequenties van uitbreiding van de standaard TRIPS Gl bescherming naar de verhoogde bescherming, momenteel alleen van toepassing op wijnen en sterke drank. Als de GI uitbreiding doorgaat is het echter niet meer zo eenvoudig on deze namen te blijven voeren op soortgelijke producten.

2) Inventarisatie van technische en administratieve behoeften met inbegrip van het opstellen van productie methoden en werkwijzen om het nationaal kader vorm te geven en de bescherming van GIs in de praktijk te brengen. Dit omvat de organisatie van producenten in de regio om samen tot werkbare productiemethoden te komen die duurzame en constante kwaliteit van producten kunnen garanderen. Het heeft ook betrekking op de constante kosten om een effectief Gl beschermingssysteem draaiende te houden (registratie, administratie en handhavingskosten). In dit verband zouden de ontwikkelingslanden de prominente voorstanders van GI uitbreiding moeten raadplegen, met name de EG en Zwitserland, maar ook de internationale NGOs en belangenorganisaties om kosten-batenstudies uit te voeren en/of te bekostigen.

3) Coördinatie van onderhandelingsposities onder de ontwikkelingslanden. De Afrikaanse groepering en de LDC groep binnen de WTO zouden een gemeenschappelijk standpunt moeten innemen om de onderhandelingsposities te versterken. 
Het is duidelijk dat de implementatie van de huidige GI bepalingen voortvloeiende uit het TRIPS Verdrag al veel problemen met zich meebrengen. Tegenstanders van uitbreiding van GI bescherming gebruiken deze implementatie problemen om hun standpunten te steunen door aan te geven dat het te vroeg is om de GI bescherming uit te breiden, omdat het nog meer verplichtingen met zich meebrengt (t.o.v. institutioneel kader, wettelijk systeem, installatie van productiemethoden en handhaving), die ontwikkelingslanden op dit moment onmogelijk kunnen nakomen.

Inzake punt vijf, de notificatie en registratie van GIs, is voorgesteld om de verwijzing naar wijnen en sterke drank te vervangen door "producten die in het kader van Artikel 23 van het TRIPS Verdrag worden beschermd". De redenering hierachter is, dat, indien het multilaterale register verwezenlijkt wordt, automatisch alle producten, die de speciale (lees meer uitgebreide vorm van) GI bescherming genieten, ook in het register worden opgenomen (bijvoorbeeld als uitbreiding van bescherming ook daadwerkelijk geschiedt). Bovenal moet er pas positie ingenomen worden inzake een notificatie en registratie systeem, als er meer duidelijkheid is voor het nationaal belang van $G$ bescherming en bovendien moet de politieke onderhandelingspositie inzake uitbreiding van Gls gelinkt worden aan zo'n registratie systeem. Het is van belang om inzicht te krijgen of het instellen van zo'n systeem op de lange duur de kosten van installatie en handhaving waard is.

Bovengenoemd punt zes, inzake bilaterale en regionale handelsverdragen, betreft een zeer actuele en belangrijke ontwikkeling inzake de uitbreiding en ontwikkeling van internationale Gl harmonisatie. GI bescherming wordt opgenomen in het grotere doel van de vrijhandelsovereenkomsten (handel en investeringen te bevorderen). Vooral de EG is bijzonder actief in het onderhandelen van vrijhandelsovereenkomsten met inbegrip van GI bepalingen, die verder gaan dan het TRIPS Verdrag vereist (zogenaamde TRIPS plus bepalingen), bijvoorbeeld door het afdwingen van GI bescherming door het opnemen van lijsten met Gls, die door de contractpartijen wederzijds moeten worden erkend en beschermd - dit houdt in, dat de speciale bescherming (op dit moment alleen van toepassing op wijnen en sterke drank) dan ook van toepassing is op alle andere producten, die in de desbetreffende lijsten zijn opgenomen, maar ook door het vereisen van 'positieve' bescherming van Gls, dit in vergelijking met de TRIPS bepalingen, die slechts vragen om Gls te beschermen, maar het aan de nationale soevereiniteit van de lidstaten af laat hangen op welke manier. De EG, als grote economische kracht, heeft zich goed gerealiseerd, dat het sneller is om deze route te bewandelen dan de multilaterale route om een mate van GI bescherming te bereiken vergelijkbaar met zijn binnenlands niveau. De EG geeft agrarische productie, kwaliteit van voeding en differentiatie grote prioriteit. Vooral met het oog op de aan de gang zijnde WTO onderhandelingen, waarin de EG gedwongen wordt om zijn agrarische subsidies te verlagen, is de EG genoodzaakt om zijn landbouwbeleid aan te passen en de bescherming van Gls is een belangrijk speerpunt van deze strategie. 
De analyse in hoofdstuk vier concludeert, dat Gl bescherming het meest geschikt is voor producten, die een bepaalde geschiedenis hebben, omdat GIs bepaalde specifieke productiemethoden beschermt, die door de jaren heen op dynamische wijze zijn verbeterd en geperfectioneerd, gelinkt zijn aan een bepaalde streek met typische geografische kenmerken en als gevolg een bepaalcte reputatie, kwaliteit of kenmerken verworven hebben, die bescherming tegen imitatie rechtvaardigen. Als het product nog een plaats in de markt moet veroveren, implicerend, dat noch de productiemethodes noch hun reputatie zijn gevestigd, dan zou merkenrechtbescherming meer aangewezen kunnen zijn om het betreffende product te beschermen. Het zou rendabeler kunnen zijn om een merkenrechten systeem te installeren dat collectieve en/of certificatie merken bescherming biedt in plaats van een specifiek sui generis systeem of GI bescherming. Deze vorm van juridische bescherming is eenvoudiger te bewerkstelligen - een eenvoudige etikettering van het product zal voldoende zijn. Bovenal zijn er geen voorwaarden in relatie tot productieprocessen gesteld. Nochtans, handelsmerken - in tegenstelling tot GIs (in de huidige TRIPS context) - dienen te worden geregistreerd en dit impliceert administratieve kosten.

In het bijzonder, hebben GIs - in tegenstelling tot het merkenrecht een belangrijk potentieel om het duurzame gebruik en een meer gelijkwaardige verdeling van opbrengsten van genetisch materiaal en de verwante traditionele kennis te beschermen, en om het behoud van biodiversiteit te bevorderen. Desalniettemin kan GI bescherming traditionele kennis alleen in zekere mate beschermen, aangezien zij niet de daadwerkelijke kennis, opgenomen binnen het product en of het bijhorende productieproces kan beschermen. Dientengevolge waarborgt $G l$ bescherming niet tegen de verduistering van traditionele kennis (zoals bio-piraterij).

Veel ontwikkelingslanden hebben potentieel om GIs op de nationale, regionale of zelfs op de globale marktschaal te exploiteren en te beschermen, en hoogstwaarschijnlijk functioneren sommige reeds in de praktijk als GIs maar de overheden zijn er niet in geslaagd om het nationale juridische kader van bescherming te verstrekken.

Het is aan te bevelen, dat ontwikkelingslanden om een overgangsperiode vragen binnen de context van de multilaterale WTO onderhandelingen (naar het voorbeeld van de octrooiuitstelling op medicijnen). Dit omvat het bespreken van een plafond op het aantal GIs dat in FTAs en op multilateraal niveau kan worden geregistreerd en als gevolg wederzijds moet worden erkend en beschermd. Op deze manier kan eerst een kosten/baten analyse plaatsvinden, met inbegrip van een inventaris van potentiële Gls maar het noodzakelijke nationale, administratieve en juridische kader (dat op dit moment een voorwaarde is om internationale bescherming te verkrijgen) kan dan later geïnstalleerd worden - een soort van moratorium. Het is belangrijk dat ontwikkelings- 
landen tijd krijgen om vertrouwd te raken met de huidige verplichtingen ten aanzien van GI bescherming en de tekortkomingen, problemen en potentie, alvorens nieuwe verplichtingen toe te zeggen.

Het is bovendien de moeite waard om te onderzoeken of aansluiting bij het Lissabon Verdrag niet een effectievere optie is dan proberen het TRIIS Verdrag inzake GI bescherming uit te breiden. Het Lissabon Verdrag, geadministreerd door WIPO, beschermt zogenaamde oorsprongsbenamingen (appellations of origin) welke een bescherming geeft gelijk aan de speciale bescherming voor wijnen en sterke drank in het TRIISS Verdrag en bovendien al gebruik maakt van een registratie systeem.

Hoofdstuk vier heeft laten zien, dat de bescherming van GI vele doelstellingen heeft: zowel de preventie van misleidend gebruik en consumenten- en producentenbescherming, maar ook draagt bescherming bij aan duurzame ontwikkeling, bevordering van landbouwproducten en de bescherming van inheemse en traditionele kennis. Maar bovenal bevordert GI bescherming product differentiatie van hoogwaardige kwaliteitsproducten in een tijdperk van globalisering en uniformiteit. Het ziet er niet naar uit, dat de WTO impasse inzake het verlagen van tarieven en agrarische subsidies, maar ook inzake de controversiële GI TRIIS kwesties, snel opgelost zullen worden. Het is aan te bevelen om markttoegang voor tropische- en landbouwproducten te linken aan het vergroten van intellectuele eigendomsrechten en in het bijzonder de uitbreiding van GI bescherming. Bovendien is het van belang om soepelere regels te verkrijgen voor technische, sanitaire en fytosanitaire maatregelen maar ook voor regels inzake etikettering. Het is van belang om de realiteit van veel ontwikkelingslanden niet uit het oog te verliezen: kleine bedrijfjes in ontwikkelingslanden kumnen niet voldoen aan al deze vereisten en standaarden. Ontwikkelingslanden moeten zich concentreren op het ontwikkelen van Gl bescherming op nationaal niveau, op de lange termijn kan dit bijdragen aan economische ontwikkeling en groei als biodiversiteit en milieu kwesties ook in acht worden genomen.

\section{ZOEKTOCHIT NAAR BESCHERMING VOOR BIODIVERSITEIT EN TRADITIONELE KI:NNIS}

Ontwikkelingslanden houden de meerderheid van het genetisch materiaal van de wereld en bijbehorende traditionele kennis en zij zijn bezorgd over hedendaagse praktijken, die het toestaan om biodiversiteit en bijbehorende traditionele kennis toe te eigenen.

Hoofdstuk drie van dit boek kijkt naar de huidige bescherming van traditionele kennis en genetisch materiaal en de uitdagingen en implicaties om tot een internationale vorm van (juridische) bescherming te komen. Het onderzoek naar nieuwe farmaceutische, biotechnologische of landbouwtoepassingen, gebaseerd op genetisch materiaal is in de loop van de laatste decennia explosief gegroeid. Het intellectuele eigendomsrecht wordt gebruikt om innovaties te 
beschermen. Met andere woorden genetisch materiaal en de bijbehorende traditionele kennis hebben economische betekenis gekregen.

Het octrooieren van biogenetisch materiaal leidt tot veel controversie in multilaterale onderhandelingsforums vanwege de veronderstelde potentie van biogenetisch materiaal voor toekomstige innovaties, gebaseerd op biotechnologie maar ook inzake het veronachtzamen van de bijdrage van inheemse gemeenschappen tot de identificatie van de therapeutische eigenschappen van inheemse planten en het behoud van biodiversiteit. Inheemse gemeenschappen uiten hun bezorgdheid over het gebruik van genetisch materiaal (door hen geconserveerd en gë̈dentificeerd als zijnde in het bezit van speciale eigenschappen) zonder hun voorafgaande toestemming. Voorts zijn zij niet gecompenseerd voor het gebruik van hun genetische middelen, noch hebben zij gedeeld in de opbrengsten, die exploitatie heeft opgeleverd. De toe-eigening van genetisch materiaal kan grote consequenties hebben voor inheemse volkeren, het kan bijvoorbeeld leiden tot toegangsbeperkingen, wat weer gevolgen kan hebben voor het behoud van biodiversiteit en traditionele en culturele gewoonten. Toe-eigening kan ook uit religieus, communautair of cultureel oogpunt niet acceptabel zijn. Al deze kwesties hebben bijgedragen aan een groeiende interesse in het vinden van intemationale bescherming van traditionele kennis en genetisch materiaal. Het introduceren van discussies inzake de bescherming van traditionele kennis in de TRIPS Council, de CBD en FAO besprekingen en het WIPO Comité inzake Intellectuele Eigendom en Genetisch Materiaal, Traditionele Kennis en Folklore ("WIPO Intergovernmental Committee on Intellectual Property and Genetic Resources, Traditional Knowledge and Folklore" (IGC)) heeft van de zoektocht naar bescherming van traditionele kennis een politieke kwestie gemaakt, aangezien de beleidsmakers de verwachte voordelen om internationale bescherming te bieden aan TK moeten afwegen tegen de kosten.

De bescherming van TK bimen een multilateraal kader zou de mogelijkheid geven om rechten buiten de nationale grenzen te beschermen en te handhaven en bovendien toont het erkenning van TK binnen de internationale gemeenschap aan.

Hoofdstuk drie bespreekt vier belangrijke argumenten die aan het verlenen van TK bescherming ten grondslag liggen: 1) Het primaire argument ten gunste van het verlenen van TK bescherming is, dat het biopiraterij kan tegengaan (d.w.z. de verduistering van genetisch materiaal - over het algemeen door middel van het octrooieren van genetisch materiaal en bijbehorende traditionele kemnis); 2) Verder is er de opvatting dat TK bescherming kan bijdragen aan de verbetering van de levensomstandigheden van inheemse volkeren (wenlth distribution urgument). Dit kan bewerkstelligd worden door het verstrekken van royalty's in ruil voor toegang tot en gebruik van genetisch materiaal of overeenkomsten gericht op het delen in de opbrengsten van genetisch materiaal (bencfit sharing agrements); 3) Voortbordurend op punt twee kan ook beargumenteerd worden, dat de bescherming een bijdrage levert 
aan openbare beleidsbelangen: namelijk dat het behoud van biodiversiteit sterk verbonden is met de bescherming van traditionele kennis; en 4) Het bieden van TK bescherming kan ook een positieve neerslag hebben op bescherming van het milieu ter voorkoming van klimaatsverandering.

In de zoektocht naar bescherming en promotie van TK is het belangrijk om consensus te bereiken over de doelstelling(en) van TK bescherming: een lange termijn visie is een absolute must om tot een effectieve oplossing te komen.

Ontwikkelingslanden, rijk aan biodiversiteit en genetisch materiaal, moeten ervoor zorgen dat zij beschikken over een efficiënt binnenlands of regionaal regime inzake I'K bescherming. Ten eerste toont dit, dat de bescherming van TK serieus wordt genomen op nationaal niveau met als gevolg dat de intemationale onderhandelingspositie versterkt wordt. Ten tweede geeft het inzicht in de mechanismen en de procedures inzake het bewerkstelligen van TK bescherming, wat de totstandkoming van een internationaal regime zal faciliteren. Ten derde is het noodzakelijk om erkenning te geven aan het feit, dat TK niet exclusief is, aangezien dezelfde kennis gelijktijdig wordt gedeeld door mensen, die tot een bepaalde inheemse groepering behoren (niet gebaseerd op individuele kennis maar op gemeenschappelijke kennis). In het nemen van beslissingen inzake internationale TK bescherming, het autoriseren van toegang tot genetisch materiaal en bijbehorende TK en het aangaan van overeenkomsten gericht op het delen van de opbrengsten is het van belang om voor een holistische en inclusieve benadering te kiezen, openstaand voor verschillende cultureel gebonden overtuigingen.

De onderhandelingen binnen de WIPO IGC zitten vast door totaal verschillende standpunten en behoeften inzake TK maar ook vanwege de complexiteit van het onderwerp: 'Ten eerste, het gebrek aan een definitie van wat traditionele kennis is evenals wat het werkingsgebied van bescherming zou moeten zijn. Nochtans is de behoefte aan zulk een definitie twijfelachtig, aangezien het intellectuele eigendomsrechtsysteem ook functioneert zonder een nauwkeurige definitie van patenteerbare uitvinding. Ten tweede wordt TK bescherming besproken in een veelvoud van multilaterale forums die zich elk richten op? bepaalde aspecten van TK, bijvoorbeeld het bevorderen en promoten van TK, het behoud, bescherming en exploitatie. Bovendien wordt TK geassocieerd met diverse belangenbehartigers en belangenkwesties zoals: volksgezondheid, voedsel, landbouw, biodiversiteit, folklore, toegang tot kennis, onderwijs, de biotechnologie-industrie en het milieu. Ten derde is het moeilijk om TK op het internationale niveau te beschermen aangezien die landen, die het meest geïnteresseerd zijn in TK bescherming, niet beschikken over nationale bescherming. Het zou zelfs zo kunnen zijn, dat de inheemse gemeenschap, die om bescherming verzoekt, in haar eigen land niet worden erkend en geen enkele steun ontvangt in haar zoektocht naar bescherming van de nationale overheid (momenteel is de Peruaanse amazone kwestie zeer actueel). Dit is een heikel punt: tegenstanders van bescherming staken de discussie op internationaal niveau vanwege het gebrek aan nationale bescherming. Voorstanders zien dit als een excuus om onderhandelingen te voeren aangezien het 
voor hen geen prioriteit heeft en er economische belangen op het spel staan, aangezien zij de biotechnologie industrieën in handen hebben. Ten vierde houdt lokale kennis, waarvan door inheemse/lokale gemeenschappen gebruik wordt gemaakt, niet op bij de grens, maar omvat zij vaak diverse geografische grenzen. Men kan betwisten of het concept "gemeenschap" zich uitstrekt tot om het even welke historische of geografische verbinding. Ten vijfde wordt de zoektocht naar een geschikte internationale vorm van GI bescherming gehinderd door de talrijke wettelijke, historische, sociaal-economische en culturele tradities van de verschillende landen inzake eigendom. Al deze factoren hebben nationaal beleid beinvloed, resulterend in (gebruikelijke) lokale wetten inzake eigendom en bescherming van biodiversiteit die vaak niet met intellectuele eigendomsrechten co-existeren.

Rekening houden met culturele achtergronden die nationaal regeringsbeleid hebben beinvloed op internationale onderhandelingsforums is geen gemakkelijke opgave. Aangezien deze waarden op verschillende zienswijzen zijn gebaseerd ten opzichte van de matschappij: culturele tegenover economische doelstellingen; communautaire belangen (gemeenschappelijk goed) tegenover individuele belangen (persoonlijk eigendom); en de reductionist westelijke wetenschappelijke traditie tegenover het holistisch gebruik van TK door inheemse gemeenschappen. Ook moet niet vergeten worden dat inheemse volkeren veel waarde hechten aan hun land en spirituele en religieuze overtuigingen.

Het feit, dat de bescherming van TK nu in zoveel verschillende forums ter discussie gesteld wordt, biedt zowel kansen als uitdagingen. Kansen bestaan uit de wetsvoorstellen, die voorgesteld en gesteund worden, hoewel op dit moment de coördinatie tussen de verschillende forums te wensen overlaat. Vaak zijn landenvertegenwoordigers aan een bepaald forum toegewezen (en zijn zij bovendien voor korte tijd aangesteld) en vindt er onderling weinig coördinatie en informatieoverdracht plats. Dit houdt in, dat landen niet altijd consequent zijn in hun standpunten in de diverse forums en door de jaren heen.

Het is heel belangrijk voor de voorstanders van TK bescherming om tot éen gemeenschappelijk standpunt inzake de bescherming van TK te komen, gebaseerd op duidelijke, realistische en uitvoerbare doelstellingen.

Dit is echter niet gelukt, aangezien inheemse groepen uniek zijn en zij verschillende waarden en opvattingen hebben ten aanzien van TK bescherming. Er zijn bovendien ook spanningen tussen de verschillende bestaande internationale verdragen. Met name tussen de achterliggende doelstellingen en de potentiële gevolgen van het CBD en het TRIPS Verdrag. Het debat wordt echter belemmerd, als één partij vindt, dat er geen conflict is en daarom de kwestie niet verder wil onderzoeken. Het debat wordt dan gepolariseerd. 
Sommige naties, met inbegrip van Brazilië, Panama, Portugal en Peru, hebben sui generis systemen goedgekeurd om traditionele kennis en genetisch materiaal te beschermen. Hoewel zij met de tenuitvoerlegging van deze wetten worstelen, voor een groot deel toe te schrijven aan financiële beperkingen maar er zijn ook praktische implementatie problemen, bijvoorbeeld hoe genetisch materiaal te volgen is - vaak is genetisch materiaal door een eigen burger meegenomen naar het buitenland. Nochtans is de behoefte aan een internationaal regime groot, angezien deze sui gencris systemen territoriaal van aard zijn en ctus in het buitenland niet van toepassing zijn. Positieve TK bescherming kan ook gerealiseerd worden door het gebruik van databanken met uitvoerige informatie over het genetisch materiaal, oorsprong en specifieke kwaliteiten en eigenschappen. Een ander alternatief is de global bio collecting socicty (GBS) om contractuele regelingen tussen inheemse volkeren en de biotechnologische industrie te bewerkstelligen. Zo'n GBS systeem kan vergeleken worden met de collectieve belangen organisaties van muziekauteurs om vergoedingen te incasseren en vervolgens te verdelen inzake het gebruik van auteursrechten (bijvoorbeeld wanneer een muzikaal werk wordt beluisterd, gezongen of vastgelegd). Bovendien zijn internationale organisaties vaak beter uitgerust om de belangen van inheemse volkeren te behartigen dan individucle landen. Andere initiatieven om TK te beschermen zijn ook geïnitieerd, bijvoorbeeld door middel van contracten die toegang tot en het gebruik van genetisch materiaal regelen. Bijvoorbeeld, het FAO Verdrag heeft material transfor agrements geüntroduceerd die toegang tot en gebruik van een 30-tal biologische materialen regelt. Deze contracten zijn een manier om opbrengsten te verdelen tussen de inheemse volkeren, onderzoeksteams en industrie maar ook om toegang tot en gebruik van genetisch materiaal en kennis te regelen. Een succesvol voorbeeld van een overeenkomst inzake het delen in de opbrengst (access and benefit sharing agrement (ABS)) initiatief buiten intellectuele eigendomsrechtbescherming is een overeenkomst in Peru over de rechten van inheemse gemeenschappen op aardappel variëteiten. In het kader van de overeenkomst zijn de gegevens over de aardappelen openbaar gemaakt, zodat ze niet meer geoctrooieerd kumnen worden (door derden) en het genetisch materiaal en de kennis verbonden met hun aanplant, toebehoren aan de zes landbouwersgemeenschappen, die een "aardappel park" op een groot verbouwingsgebied hebben gevestigd om de aardappelplanten te kweken en te laten groeien. De achterliggende reden waarom de gemeenschap heeft besloten om de aardappelvariëteiten niet te patenteren ligt ten grondslag aan ideologische en culturele opvattingen.

\section{Disclosure of Origin Measures}

Om de verduistering van genetisch materiaal te stoppen en de verlening van slechte of onjuiste patenten te verminderen gebaseerd op puur genetisch materiaal zonder gepaste erkenning of compensatie, hebben verscheidene landen disclosure of origin maatregelen geintroduceerd in relatie tot octrooiaanvragen voor uitvindingen gebaseerd op genetisch materiaal. 
Er zijn twee afzonderlijke maar verwante kwesties: het disclosure of origin certificaat, en het disclosure of origin vereiste. Een certificaat van oorsprong zou als soort van paspoort kunnen dienen, dat het genetisch materiaal begeleidt door het hele proces van acc'ss and bonefit sharing. Het is noodzakelijk om het op bepaalde punten te verifiëren voornamelijk wanneer het genetisch materiaal het land heeft verlaten om zo de traceerbaarheid en transparantie van genetisch materiaal te verhogen.

Een certificaat van oorsprong zou een praktische manier kunnen zijn om het disclosure of origin vereiste te implementeren, maar het zou niet de wettelijke gevolgen hebben, die een officieel amendement (vereiste) van het TRIPS Verdrag met zich meebrengt. Dus een certificat is een veel lossere maatregel dan een vereiste. In tegenstelling zou een amendement inzake disclosure of origin vereiste de implementatie en handhaving beduidend versterken aangezien het gelinkt wordt aan het WTO geschillenbeslechtingsysteem (WTO Dispute S'tflement systom). Het zou het proces versterken, om te verifiëren of de genetische middelen overeenkomstig nationale voorschriften zijn verzameld. Een disclosur of origin vereiste kan als brug functioneren tussen nationale en internationale wetgeving evenals tussen de leveranciers en de gebruikers van genetisch materiaal om het gebruik van en de handel in genetisch materiaal te bevorderen in pogingen om TK te beschermen en te promoten.

Sommige successen - in de bredere context om TK te beschermen - zijn bereikt, in het bijzonder: de besprekingen onder de CBD hebben geleid tot een proces om een disclosure of origin certificaat systeem te introduceren om het disclusurc of origin vereiste operationeel te maken. De besprekingen binnen de CBD resulteerden in de goedkeuring van de Richtlijnen van Bonn ("Bonn Guidelines"), die disclosure of origin matregelen onderdeel makten van de octrooi aanvraag. De Richtlijnen van Bonn bepleiten de goedkeuring van een juridisch erkende certificatie van disclosure of origin als bewijsmateriaal van voorafgaande toestemming (prior informed consent (PIC)) en in lijn met wederzijds goedgekeurde werkwijzen. Dit zachte wetsinstrument poogt om de diverse voorstellen inzake disclosure of origin matregelen te harmoniseren en om de maatregelen operatief en effectief te maken. De disclosure of origin maatregelen maken deel uit van een breder systeem om TK te beschermen, waarin toegang tot en delen in de opbrengsten van gebruik (ABS) belangrijke componenten vormen. Met de totstandkoming van de CBD heeft ABS officiële erkenning gekregen. ABS heeft betrekking op het delen in de opbrengsten van het commercialiseren van genetisch materiaal in de diverse stadia van het onderzoek en het op de markt brengen van een product gebaseerd op genetisch materiaal. ABS kan verschillende vormen aannemen: financiële compensatie door middel van vergoedingen voor het gebruik van genetisch materiaal of prijzen per gebruikte steekproef; winstdeling; commerciële vennootschappen zoals gezamenlijke ondernemingen, lokale werkgelegenheidsmogelijkheden; wetenschappelijke, sociale en milieuvoordelen; maar ook niet monetaire voordelen. Niet monetaire voordelen hebben betrekking op het delen van onderzoeksresultaten, uitwisseling van informatie over het gebruik en toepas- 
singsmogelijkheden van het genetisch materiaal, technologieoverdracht en investering in lokale opleiding en de capaciteitsbouw. Deze vormen zijn onderling verbonden en niet exclusief. Hoofdstuk drie wijst erop, dat de niet monetaire voordelen waarschijnlijk nuttiger zullen zijn dan monetaire voordelen, aangezien zij veelbelovend zijn voor de toekomst omdat zij tot het verbeteren van nationale wetenschappelijke en technologische capaciteiten kunnen bijdragen. Hun nut wordt benadrukt door het feit, dat het gebruik van genetische middelen een lang en onzeker proces is en er geen waarborg is, dat commercialisering van het product gebaseerd op het genetisch materiaal succesvol zal zijn.

Overeenkomstig de onderhandelingen in het kader van de CBD, hebben de huidige besprekingen over biodiversiteit binnen de TRIPS Council zich hoofdzakelijk bezig gehouden met het introduceren van een disclosure of origin vereiste. Een groep ontwikkelingslanden, met inbegrip van Brazilië, Equador en India, heeft voorgesteld het TRIPS Verdrag officieel te wijzigen door middel van een TRIPS amendement om het discloswre of origin vereiste onderdeel te maken van de octrooiaanvragen, evenals bewijsmateriaal van voorafgaande toestemming ( $p$ rior informol consent (PIC)) en toegang tot en gebruik van genetisch materiaal in overeenstemming met nationale wetten. Nochtans hebben vele industrielanden de behoefte aan zulk een vereiste betwijfeld. Ook verschillen de meningen over welk forum het meest geschikt is om de kwestie te bespreken (WIPO, CBD of WTO). Japan en de VS (geen partij bij het CBD) zijn van mening dat het $C B D$ en het TRIPS Verdrag niet in conflict met elkaar zijn met als argument dat beide overeenkomsten zich bezig houden met afzonderlijke kwesties. De EG, Noorwegen en Zwitserland steunen daarentegen een bepaalde vorm van disclosture of origin matregelen maar niet noodzakelijk binnen het kader van het TRIPS Verdrag (de EG en Zwitserland prefereren WIPO als het aangewezen platform) en de juridische effecten verschillen ook. Noorwegen was de eerste ontwikkelde natie, die de integratie van een disclosure of origin vereiste in het TRIPS Verdrag wenste. Het voorstel van Noorwegen verschilt echter met het groepsvoorstel van de ontwikkelingslanden inzake de wettelijke gevolgen van het vereiste. Noorwegen is van mening dat gebrek aan conformiteit met het disclosure of origin vereiste niet tot de herroeping van het octrooi zou moeten leiden, maar administratieve gevolgen heeft.

Hoofdstuk drie analyseert de diverse voorstellen betreffende disclosure of origin en komt tot de conclusie, dat Europa steeds positiever stat ten opzichte van een disclosure of origin maatregel. Een vereiste zou het mogelijk maken om te verifiëren dat toegang tot en de voorwaarden inzake het gebruik van genetisch materiaal overeenkomstig nationale/lokale wetten heeft plaatsgevonden.

Het ondersteunen van een disclosure of origin maatregel brengt ook het belang van de doelstellingen en concepten van de CBD (een verdrag, dat door meer dan 190 partijen is ondertekend) tot uiting. Een disclosure of origin vereiste kan een grote rol spelen om te beoordelen of aan de fundamentele voorwaarden 
voor octrooiannvagen (pat'ntability requir(ments) is voldaan en bij het niet verlenen van octrooien, als niet aan de eisen is voldaan (d.w.z. dat de uitvinding nieuw is (nowlty) en uitvindingshoogte heeft (imo'ntize step)). Een disclosure of origin matregel kan bijdragen aan het vereenvoudigen van TK databank radplegingen, ondat het meer onderzoeksgegevens biedt.

Nochtans roept het disclosure of origin debat vragen op die niet eenduidig beantwoord kunnen worden. Er is geen overeenstemming over hoe een ideale disclosure of origin matregel er uit zou moeten zien, de noodzakelijkheid van de maatregel, in welke vorm, met welk doel, binnen welk forum (WIPO, CBD of TRIPS), juridische consequenties, verplichte of vrijwillige maatregel en praktische implementatie. Daarom verschillen de ingediende voorstellen inzake disclosure of origin in grote mate inzake terminologie en werkingsgebied. De verwezenlijking roept problemen op, bijvoorbeeld in sommige landen, zoals in België, is disclosure of origin toegevoegd als een vierde vereiste (d.w.z. van patentability) aan het octrooisysteem, mar in Zwitserland is het onderdeel van de administratieve procedure van de octrooiaanvraag. Ook hebben landen verschillende opties geopperd inzake gebrek an conformiteit met de disclosure of origin matregel: bijvoorbeeld herroeping van het octrooi of sancties buiten het octrooisysteem. Aldus heeft het gebruik van specifieke terminologie verschillende juridische consequenties en praktische gevolgen. Men kan drie vormen van disclesure of origin onderscheiden:

1) vrijwillige maatregel - de onthulling wordt aangemoedigd en geadviseerd maar het nalaten beinvloedt niet het octrooi;

2) verplicht regime - het nalaten heeft gevolgen binnen het octrooisysteem of leidt tot civiele / administratieve sancties buiten het octrooisysteem;

3) een systeem, dat verder gat dan disclosure of origin als onderdeel van de octrooiaanvraag vereisten en dat ook vraagt om conformiteit met lokale wetgeving inzake toegang tot genetisch materiaal en voorwaarden inzake het gebruik ervan en dat ook voorziet in het delen in de opbrengsten van commercialisering.

De introductie van een disclosum of origin vereiste veroorzaakt vele praktische problemen. Bijvoorbeeld, hoe kan de wetgeving van nationale regimes aangepast worden om voorafgaande toestemming (PIC) en het delen in de opbrengsten op wederzijds goedgekeurde voorwaarden te garanderen? En hoe kunnen octrooiambtenaren getraind worden on de nieuwe maatregelen toe te passen? Zelfs een operationeel functionerend disclosure of origin maatregel kan niet veranteren dat veel informatie en kennis over genetisch materiaal en bijbehorende TK verworven kan worden zonder dat het land van oorsprong bezocht dient te worden. Aldus zal de matregel slechts op een klein aantal octrooien van toepassing zijn. Het is daarom twijfelachtig in hoeverre het disclosure of origin vereiste de octrooikwaliteit zal verbeteren en de biopiraterij (ongeoorloofde toe-eigening) van genetisch materiaal tegen zal gaan. 
Bovendien is het zeer netelig om de mate te bepalen waarin de genetische middelen en/ of bijbehorende TKK tot het uiteindelijk octrooi (uitvinding) bijdragen. In veel gevallen kunnen diverse types van kennis, informatie en materiaal tot de uiteindelijke uitvinding hebben bijgedragen. In dat geval kan men de vraag stellen; is het haalbaar om alle bronnen, die inzicht verschaft hebben in kennis en materiaal en toepassingsmogelijkheden, te belonen, hoe klein hun contributie ook was? Ook is er de bijkomstigheid, dat het uiteraard niet eenvoudig is om het land van herkomst te traceren: meerdere landen zouden wettig kunnen claimen om landen van oorsprong te zijn van hetzelfde genetisch materiaal. Én oplossing voor dit probleem zou in de totstandbrenging van communautaire fondsen gevonden kunnen worden.

De CBD heeft ook zijn tekortkomingen: bijvoorbeeld plantspecies, verzameld en gebruikt voor de totstandkoming van het CBD, vallen buiten het werkingsgebied van de CBD - er is geen terugwerkende kracht. Dit is met name interessant, aangezien botanische tuinen en zaadbanken één derde van alle plantspecies in de wereld verzameld hebben, maar het CBD eist niet, dat deze banken vooraf toestemming hebben gevraagd om deze plant variëteiten te verzamelen. Dientengevolge kan van dit genetisch materiaal gebruik gemaakt worden zonder aan de voorwaarden van toegang tot en gebruik van te voldoen (gesteld door inheemse volkeren of land van herkomst) en het kan worden gecommercialiseerd zonder maatregelen te treffen ten aanzien van het delen in de opbrengsten (ABS). Dus de doeltreffendheid van de CBD is twijfelachtig, aangezien de conventie slechts invloed heeft op genetisch materiaal verworven na 1992 (totstandkoming van de CBD).

Een onderscheid dient te worden gemaakt tussen "defensieve" en "positieve" TK bescherming. Positieve TK beschermingsmaatregelen concentreren zich op het promoten en beschermen van TK in een op recht gebaseerd erkenningssysteem, d.w.z. door economische of morele rechten te erkennen en te verlenen. Dit kan via de toepassing van het bestaande intellectuele eigendomsrechtsysteem of door de ontwikkeling van sui generis vormen. Defensieve TK maatregelen hebben met name betrekking op het voorkomen van biopiraterij door de ongeoorloofde toe-eigening van genetisch materiaal, misbruik of onwettige toegang. Voorbeelden van defensieve TK beschermingsmechanismen zijn het gebruik van TK databanken en registers (documentatie), het disclosure of origin vereiste, maar ook richtlijnen inzake octrooionderzoek en toegang tot en het gebruik van genetisch materiaal en ABS. De gegevensbestanden kunnen ertoe bijdragen om "prior art" te traceren en dus om gedocumenteerd TK te identificeren en ongeoorloofde octrooi claims te vermijden (d.w.z. er is dan niet voldaan aan het octrooi vereiste dat de uitvinding nieuw moet zijn).

Hoofdstuk drie concludeert dat een disclosure of origin vereiste, slechts een deel van de oplossing is om ervoor te zorgen, dat octrooien worden verleend op zodanige wijze, dat de uitvinding bijdraagt aan doelstellingen inzake het behoud van biodiversiteit, duurzaam gebruik en sociale gelijkheid. 
Ondanks de inherente problemen tussen de bescherming van TK en intellectuele eigendomsrechten, die in hoofdstuk drie van dit boek aan de orde komen is het mogelijk om bepaalcte vormen van TK te beschemen door conventionele systemen van intellectuele eigendomsrechtbescherming. Octrooien en handelsgeheimen (tradeserets) evenals wetten inzake vertrouwelijke informatie kunnen TK beschermen tegen onbevoegde onthulling en gebruik vooral wanneer de informatie die tot de uitvinding leidt, een streng bewaard geheim binnen de gemeenschap is (zo niet, kunnen er problemen met het octrooivereiste 'nieuw' ontstaan). Het auteursrecht, de rechten van uitvoerders en de ontwerp ("design") rechten kunnen culturele uitdrukkingen van folklore beschermen. Het merkenrecht, geografische herkomstaanduidingen en certificatie en collectieve merken kumen distinctieve tekens, symbolen of aanwijzingen beschermen op producten met een bepaalde reputatie en/of speciale kwaliteit. Administratieve en civiele rechten inzake oneerlijke verrijking kunnen ook ingezet worden om de ongeoorloofde toe-eigening van TK te stoppen.

Het belangrijkste probleem in het toepassen van de intellectuele eigendomsrechtsystemen en hun achterliggende doelstellingen om TK te beschermen is, dat intellectuele eigendom fortord - looking is in zoverre, dat zij innovatie moeten bevorderen. De kennis, die door inheemse mensen wordt gecreëerd en in stand gehouden, is daarentegen niet innovatief, aangezien de informatie reeds bestaat en niet nieuw is. Daarom wordt geopperd om de moeilijkheden inzake het beschermen van TK door middel van het octrooirecht te voorkomen door het "nieuw zijn vereiste" zo te definiëren, dat het kennis en folklore omvat. Bijvoorbeeld door de terminologie "traditioneel" op dusdanige wijze te interpreteren dat het niet verwijst naar "oud" en "bekend" maar naar de mani'r van het ontwikkelen van dergelijke kennis en niet naar de datum wanneer de kennis is ontwikkeld. TK kan worden gedefinieerd als zijnde kennis gebaseerd op de tradities van een bepaalde gemeenschap. Op basis van deze definitie zouden TK en folklore niet noodzakelijk uitgesloten moeten worden wegens een gebrek aan nieuwigheid. Ook worden intellectuele eigendomsrechten maar voor een bepaalde tijd verleend, terwijl TK doorgaans al jaren lang van generatie op generatie wordt overgedragen en geperfectioneerd. Ook het feit, dat intellectuele eigendomsrechten in principe territoriaal van aard zijn, impliceert, dat het juridisch effect alleen binnen de landsgrenzen geldt. Momenteel, zoals vermeld, is er geen internationaal juridisch bindend instrument om TK te beschermen.

Hoofdstuk dric pleit ook voor het verbeteren van de octrooi procedure om te grote octrooi claims te vermijden. De standaarden om een octrooi te bemachtigen zijn te laag, het is nu zelfs mogelijk om een octrooi te verkrijgen op uitvindingen, die weinig meer dan ontctekkingen zijn. Een studie heeft aangetoond, dat in één derde van de octrooi "claims" niet aan de octrooi-eisen (nieuw en niet evident - new and non obious) was voldaan. Het is dus noodzakelijk om de octrooigemachtigden regelmatig te blijven trainen en ver- 
trouwd te maken met TK databanken. En zoals hierboven reeds aangehaald, zelfs als het om een echte uitvinding gat zijn er vaak geen maatregelen getroffen om te voldoen aan de voorwaarden voortvloeiende uit de CBD inzake voorafgaande toestemming om het genetisch materiaal te gebruiken, de wijze waarop er gebruik mag worden gemaakt, en het delen in de opbrengsten. Bovendien verschillen de substantiële octrooivereisten aanzienlijk binnen de verschillende landen. Octrooirechten zijn slechts marginaal gereguleerd op intermationaal niveau. Bijvoorbeeld in de VS is het principe van relative novelty van kracht, hetgeen betekent, dat inzake het uitvoeren van een prior knowledge onderzoek om te bepalen of een uitvinding nieuw is, alleen kennis en informatie wordt meegenomen, die gedocumenteerd is. Met als gevolg dat andere vormen van publieke openbaring (wat dus de nieuwigheid van de uitvinding zou schaden) zijn uitgesloten als zijnde behorende tot "prior art". De meeste landen gebruiken het beginsel van absolute novelty, wat inhoudt, dat alle vormen van publieke openbaring (schriftelijk en mondeling verspreide informatie) inzake kennis en informatie, die in een uitvinding zijn opgenomen, meetellen in het bepalen of de kennis tot de "prior art" behoort. Inheemse volkeren zijn bij een systeem van absolute nowelty gebaat, aangezien het gebruikelijk is om kemis mondeling door te geven aan de volgende generaties.

\section{Slotenchusies inzake de bescherming on TK}

Het belang van TK bescherming moet zeker niet onderschat worden, maar het moet ook niet gezien worden als de oplossing voor alle problemen. In het verleden, zeker in de beginfase van de biotechnologie zijn farmaceutische- en zaadindustrieën sterk afhankelijk geweest van genetisch materiaal. Dit betekent echter niet, dat zij in de toekomst op dezelfde wijze gebruik zullen maken van onontdekte bronnen en kennis. Nochtans wordt TK wijd gebruikt, vooral in de botanische geneeskunde-industrie, als basis om veiligheid en doeltreffendheid van een nieuw product te bepalen, om agronomische werkwijzen voor de cultivering van materiaal te ontwikkelen alsmede nieuwe producten.

Zoals uitgebreid uiteengezet in hoofdstuk drie kan een disclosure of origin vereiste, dat octrooien op eerlijke wijze worden verleend, niet alles oplossen, maar het kan een stap in de juiste richting zijn. Het is mogelijk, dat de Europese Gemeenschap als bruggenbouwer optreedt tussen de VS en de ontwikkelingslanden in het vinden van enige mate van consensus in het disclosure of origin debat. De LDC landen en Brazilië hebben voorgesteld tijdens de Doha Ministeriële Vergadering in Genève in juli 2008 - dat landen de potentiële compromissen (trade offs) tussen geografische herkomstaanduidingen (de introductie van een multilateraal register voor wijnen en sterke drank en uitbreiding van bescherming) en het disclosure of origin vereiste zouden moeten overwegen.

Na de bevindingen, die in hoofdstuk drie worden beschreven, kunnen de volgende aanbevelingen worden gedaan inzake de zoektocht naar mogelijke TK beschermingssystemen: 
1) Ten eerste is de belangrijkste overweging, dat aan de ontwikkelingslanden ruime tijd zou moeten worden toegestaan om hun eigen beleid te ontwikkelen, dat zowel in overeenstemming is met de bescherming van intellectuele eigendomsrechten als met de doelstellingen van de CBD. Dit omvat de ontwikkeling van nationale systemen inzake disclosure of origin, toegang en gebruik van genetisch materiaal en het delen in de opbrengsten van het gebruik (ABS). Een gevestigd binnenlands administratief en wettelijk regime in lijn met ABS zal internationale eisen en voorstellen voor een disclosur of origin vereiste versterken, maar deze aanbeveling is ook gevaarlijk, want het kan ook het bewerkstelligen van internationaal functionerend regime ophouden.

2) Ten tweede, landen zouden actief moeten deelnemen aan de onderhandelingen binnen de WTO, F^O, WHO, WTO en CBD om een internationale oplossing te vinden voor het toepassen van $A B S$ inzake nationale en internationale octrooiaanvragen.

3) Ten derde, het is belangrijk om nationale systemen inzake disclosure of origin matregelen te bestuderen inzake het gebruik van bio-prospecting en $\triangle B S$ alsmede in welke mate octrooiaanvragen al broninformatie verstrekken en wanneer het materieel relevant is voor de aanvraag.

4) Ten vierde zou er grotere consensus moeten zijn over hoe een internationaal regime inzake disclosure of origin er uit zou moeten zien en hoe het in de praktijk zou werken: bijvoorbeeld het toepassingsgebied, aard, belangrijke elementen, doelstellingen en juridische consequenties. Het is ook belangrijk om meer inzicht in de implementatie van CBD en de Richtlijnen van Bonn te verkrijgen. Om dit te faciliteren zijn er commissies van meer technische studies vereist: NGOs en denktanks kunnen hierin een belangrijke rol spelen.

5) Ten vijfde is een holistische benadering raadzaam om relevante en bijkomstige onderwerpen, zoals toegang tot het land en het behoud van traditionele levensstijlen van de inheemse gemeenschappen in acht te nemen, aangezien dit primaire vereisten zijn voor het behoud, de promotie en de verdere ontwikkeling van traditionele kennis.

6) Ten zesde, aangezien de ontwikkeling van een internationaal TK beschermingsregime een langzaam proces is, is het belangrijk om TK te documenteren in databanken en octrooibureaus toegang te geven tot deze informatie.

7) Ten zevende eisen de zogenaamde positieve beschermingsmaatregelen nieuwe regels die moeilijk te initiëren zijn, aangezien het succes afhangt van de bereidheid van landen/overheden om deze regels aan te nemen en te implementeren. Aldus is het waarschijnlijk realistischer om te focussen op oplossingen binnen het bestaande intellectuele eigendomsrecht systeem 
door wijzigingen an te brengen, omdat deze geen nieuwe regels impliceren en dus gemakkelijker uitvoerbaar zijn.

8) Ten achtste, zoals getoond, zijn er vele verschillende manieren om TK te beschermen en is er weinig overeenstemming over hoe een internationaal TK beschermingsregime eruit zou moeten zien. Een disclosure of origin maatregel kan als een brug functioneren tussen nationale en internationale juridische kaders evenals tussen de leveranciers en de gebruikers van genetisch materiaal door de handel in en het gebruik van dit materiaal te controleren. Het is belangrijk om in gedachten te houden dat net zoals een optimaal niveau van intellectuele eigendomsrecht bescherming afhangt van een aantal factoren zoals industriële en technische ontwikkeling en de lokale uitvindingscapaciteit van een land, zo hangt ook de optimale mate van TK bescherming af van de onderliggende doelstellingen voor zulk een regime. Vandaar dat het belangrijk is om een duidelijke doelstelling voor ogen te hebben gedurende de zoektocht naar T`K bescherming.

9) Ten negende kumnen de ontwikkelingslanden profiteren van het slim opstellen van hun intellectuele eigendomsrecht beleid. Als het ontwikkelen van een sui goneris regime op dit moment te hoog gegrepen is, dan is het raadzaam voor landen om zich te concentreren op een civiel regime, dat zich richt op onrechtmatige toe-eigening. Bovendien zou een moratorium op het verhogen van intellectuele eigendomsrechten ook aan te bevelen zijin.

10) Ten tiende zouden de ontwikkelingslanden alternatieve mogelijkheden moeten onderzoeken zoals samenwerkingsprojecten, die betere toegang tot informatie en controle op genetisch materiaal kunnen waarborgen, zoals aangetoond door het aardappelproject in Peru.

Inheemse volkeren hechten grote waarde aan TK en folklore, maar men kan niet automatisch veronderstellen, dat hun overheden hen steunen in het warborgen en beschermen van TK. Inheemse volkeren zijn vaak minderheden in de landen waarin zij leven en zoals de recente beslommeringen in het amazone gebied in Peru duidelijk hebben gemaakt zijn de belangen van overheden vaak verschillend van die van nationale overheden en MNEs. Vandaar dat directe participatie van inheemse volkeren binnen het onderhandelingsproces van groot belang is. WIPO heeft met dit doel een fonds in het leven geroepen om de participatie van inheemse volkeren te stimuleren en te financieren om zo de problematiek onder de aandacht te brengen. Landen zelf zouden ook inheemse groepsvertegenwoordigers aan hun eigen delegaties kunnen toevoegen om zo de participatie en informatie onderling te verhogen. Een intellectuele eigendomregime dient rekening te houden met $A B S$ en vice-versa een systeem, dat de belangen van inheemse volkeren beschermt, dient ook de realiteit van intellectuele eigendomsrechten niet te negeren. Het is van belang om de verschillende belangenbehartigers bij het proces van onderhandelen te betrekken, want participatie, de mogelijkheid om je stem te laten horen, 
onderdeel te zijn van dialoog, zijn allemaal belangrijke factoren om in de toekomst een nieuw regime te ondersteunen.

Inheemse volkeren, op zoek naar erkemning en het eerlijk delen in de opbrengsten van het gebruik van genetisch materiaal, en de industrie, op zoek naar modificatie van genetisch material, commerciële potentie en octrooirechten, kumen wederzijds van het intellectuele eigendomsrecht regime profiteren. Nochtans, zonder de realisatie en erkenning door industrie en overheden van de bijdrage van inheemse volkeren kan in de toekomst misschien niet meer geprofiteerd worden van TK. Het is van groot belang, dat de industrie zich het belang van behoud en duurzame ontwikkeling van biodiversiteit realiseert en bereid is om sommige van hun opbrengsten inzake het gebruik van genetisch materiaal te delen door ABS of in de vorm van technologie overdracht overeenkomsten, ook al is dat buiten het werkingsgebied van het TRIPS Verdrag. Het is daarom tijd om bedrijfscultuur/moraal te veranderen om meer begrip te hebben voor culturele achtergronden en verschillen en respect voor kennis, die op een zodanige manier ontstaan en ontwikkeld is, dat zij niet overeenstemt met intellectuele eigendomstandaarden, die gebruikelijk zijn in Westerse landen.

Één voorwaartse stap in de internationale erkenning om de relatie en samenwerking tussen het TRIPS Verdrag en de CBD te verbeteren is de WTO Doha Verklaring. De interactie en de verschillen tussen te twee verschillende verdragen moet worden meegenomen in de zoektocht naar een oplossing om TK te beschermen. Ook is na twee decennia van onderhandelen de VN Verklaring op de Rechten van Inheemse Volkeren (UN Declarntim on the Rights of Indigrnous Peoples) door de VN Mensenrechten Raad en vervolgens door de Algemene Vergadering van de VN goedgekeurd, een groot succes in termen van erkenning, waardering en welzijn van inheemse rechten. De verklaring is fundamenteel over het eerbiedigen van de rechten van inheemse volkeren. Het benadrukt dat de inheemse volkeren het recht op zelfbeschikking hebben door dat recht kunnen zij hun politieke status vrij bepalen overeenkomstig hun economische, sociale en culturele ontwikkeling en behoeften.

Bovendien is onlangs de WIPO "Development Agenda" goedgekeurd welke opnieuw aandacht vraagt voor TK bescherming en het versnellen van het onderhandelingsproces binnen de IGC. Nochtans is het uiteindelijke doel van vele inheemse gemeenschappen on een multilateraal kader te ontwikkelen voor TK bescherming en een systeem van collectieve gemeenschapsrechten. De landen, die voor de bescherming van TK pleiten, zouden, ideaal gezien, moeten samenwerken om strategisch als groep op te treden. Zij zouden onderling met geharmoniseerde normen akkoord kunnen gaan en het principe van wederkerigheid toepassen, zodat de goedgekeurde regels op de leden van de unie/groep van toepassing zijn. Dit zou een goed uitgangspunt en voorbeeld zijn voor andere landen, die in de toekomst zouden willen volgen. Voor welke vorm van bescherming ook wordt gekozen, in ieder geval dient het systeem niet to rigide te zijn, aangezien inheemse groepen uniek zijn met verschillende 
behoeften, spirituele en religieuze opvattingen en tradities. Er zou genoeg flexibiliteit moeten zijn om de traditionele en culturele diversiteit te accommoderen een: one size fits all approach zal niet werken net als betrokkenheid van alle partijen een voorwaarde is om voorbij het probleem van ready to ink, not rondy to act te komen.

\section{INTELLECTLELEEICIENDOMSRECITEN EN DE OVERDRACITT VAN TECHINOLOGIE}

Hoofdstuk vijf van dit boek analyseert het belang van technologie en de technologieoverdracht voor ontwikkelingslanden en de diverse wijzen waarop technologie kan worden overgebracht. Het bespreekt de rol van intellectuele eigendomsrechten in het bevorderen van de overdracht van technologie aan de hand van economische en empirische studies. Hoofdstuk vijf wijst erop dat er tegenstrijdige meningen blijven over het effect van intellectuele eigendomsrechtenbescherming op groei en ontwikkelingsmogelijkheden van een land en het verstrekt aanbevelingen hoe de technologieoverdracht aan ontwikkelingslanden vanuit zowel host land als home land perspectief kan worden verbeterd.

Sinds de multilaterale onderhandelingen inzake de UNCTAD "Draft Code 'Transfer of Technology" in de jaren '70 en ' 80 van de vorige eeuw zijn belangrijke veranderingen opgetreden in de maatschappij met gevolgen voor intemationale handel en sociale en economische activiteiten. Ten eerste, door het vlugge tempo van technologische transformatie is de technologie belangrijk geworden in vrijwel alle economische activiteiten. Ten tweede heeft internationale samenwerking en de opmars van de informatiemaatschappij geleid tot globalisering van vrijwel alle economische en technologische activiteiten. Deze twee factoren worden intrinsiek met elkaar in verband gebracht en zijn wederzijds versterkend, zoals die door de verhoging van octrooi aanvragen worden aangetoond door buitenlandse uitvinders (en gebruik van intellectuele eigendomsrechten in het algemeen in binnen en buitenland). Net zoals het verband tussen technologische intensiteit van productieprocessen en producten is gegroeid, is er ook een duidelijk verband tussen technologische verandering en het concurrentievermogen opgetreden. De hoeveelheid kennis die in productieprocessen wordt vereist is opmerkelijk gegroeid; met inbegrip van verhoogde ontastbare investeringen zoals $R \& D$, opleiding, en softwareontwikkeling. Het gevolg is dat in onze eigentijdse matschappij het vermogen om toegang te hebben tot technologie voor een groot deel het concurrentievermogen van het bedrijf en van landen bepaald. Uiteindelijk kunnen de toegang tot en de verspreiding van technologie het verschil maken en tot sociaal welzijn en economische groei bijdragen.

Toegang tot technologie is dus essentieel voor economische groei en ontwikkeling. De overdracht van technologie verwijst naar de overdracht van kennis van éen individu naar het andere, door onderwijs, wetenschappelijke literatuur, of direct menselijk contact. De overdracht van technologie van één land naar een ander verzekert, dat een bepaalde technologie niet alleen nuttig is in het land van ontwikkeling, maar ook van praktisch nut is in derde landen, 
het verleent toegang tot technologieën, die anders niet beschikbaar zouden zijn, en het vermindert R\& D uitgaven. Het is bovendien efficiënt ondat het toestaat dat op bestaande kennis en technologie kan worden voortgebouwd, wat impliceert dat het wiel niet opnieuw hoeft te worden uitgevonden.

Bovendien is het voordeel van een bepaalde nieuwe technologie beduidend hoger als de technologie wijd wordt toegepast en de interoperabiliteit en de interconnectie van technologisch materiaal wordt gegarandeerd. Vandaar speelt toegang tot nieuwe technologie een belangrijke factor maar ook het vermogen om van de technologie gebruik te maken om zo een snelle verspreiding van de technologie en economische groei te bewerkstelligen. Hoofdstuk vijf benadrukt dat nieuwe producten nieuwe ideeën opnemen en de internationale handed én vorm is om kemis over meerdere landsgrenzen te introduceren, maar dat toegang alleen tot nieuwe producten niet volstat om over een succesvolle overdracht van technologie te praten. Een succesvolle overdracht van technologie hangt af van de educatieve capaciteit om technologie te gebruiken en toe te passen in lokale productieprocessen. Dit is bewezen door het feit dat landen met wezenlijke techniekvaardigheden en R\&D programma's grotere ontvangers van licenties zijn om een bepaalde techniek te gebruiken dan andere. In hoofdstuk vijf is geconcludeerd, dat de barrières om technologie te absorberen en toe te passen in lokale productieprocessen belangrijke deteminanten zijn in internationale verschillen in inkomen per hoofd en dat grotere handelsopenheid dergelijke barrières kan verminderen.

De conclusie in hoofdstuk vijf is dat de rol van intellectuele eigendomsbescherming in het bevorderen van innovatie en groei in het algemeen en in het aantrekken van technologie overdracht nog onduidelijk is en dat het onderzoek slechts in beperkte mate inzicht heeft gegeven en de bevindingen niet eenduidig en compleet zijn. Het belangrijkste nadeel is, dat veel onderzoeksresultaten grotendeels op veronderstellingen zijn gebaseerd. Nochtans kunnen sommige conclusies en aanbevelingen worden afgeleid. Het effect van intellectuele eigendomsrechten op economische groei en ontwikkeling is van uiterst belang voor overheidsambtenaren, die over beleidsstrategieën beslissen en toekomstige handelsovereenkomsten bepalen. Voorts zal een realistisch beeld over de rol en impact van intellectuele eigendomsrechten op de overdracht van technologie ook meehelpen in het uitzetten van een strategie om de TRIPS verplichtingen te implementeren. Het aantal geregistreerde octrooien verstrekt een ruwe indicatie over hoeveel belang gehecht wordt aan innovatie en lokale creatieve en innovatieve ontwikkeling binnen een bepaald grondgebied. Statistieken over hoeveel licenties verstrekt worden is een andere manier om het belang van innovatie te meten (en het gebruik van intellectuele eigendomsrechten), maar deze informatie is niet gemakkelijk te verkrijgen, aangezien het verlenen van licenties hoofdzakelijk een privé economische activiteit is.

De inspanningen om tot een internationale gedragscode inzake de overdracht van technologie te komen liepen spaak om de volgende redenen: 1) de belang- 
rijkste reden was dat de eigenaars van technologie geen technologie zonder een adequate financiële vergoeding wilden leveren; 2) gebrek aan consensus over het opnemen van verbindende clausules en werkwijzen in technologieoverd racht contracten, bijvoorbeeld, dat elke nieuwe ontwikkeling, modificatie of verbetering moet worden teruggespeeld aan de technologieleverancier; 3) de weigering van technologieleveranciers (home countries) om de wetten van ontwikkelingslanden (host comntries) na te leven; 4) gebrek aan consensus inzake de efficiënte handhaving en het toezicht op de code en geschillenbeslechting; en 5) geen overeenkomst over wat internationale overdracht van technologie inhoudt.

Nochtans wijst hoofdstuk vijf erop, dat onze huidige maatschappij zeer verschilt van een par decemia geleden. In het bijzonder, de toename van globalisatie heeft de wereld een stuk kleiner gemaakt, de manier en de schaal waarop handel plaatsvindt evenals de groeiende rol en afhankelijkheid van technologie in het dagelijks leven.

Globalisering heeft handel international gemaakt en tot een voorkeur geleid voor unificatie van productieprocessen alsmede de mogelijkheid om goederen te produceren die in meerdere landen geleverd kumnen worden. Al deze ontwikkelingen hebben er toe bijgedragen dat de overdracht van technologie op een andere manier wordt benaderd door overheden en industrie. De aandacht is verplaatst van enkel en alleen toegang tot technologie tot absorptie van de technologie en verspreiding in de maatschappij. Voorts is de concurrentie gestegen, ondat een aantal ontwikkelingslanden technologisch zeer geavanceerd zijn geworden (vooral de zogenaamde BRIC landen). Er zijn nu veel meer opgeleide wetenschappers en technologen, en science-based industrieën, evenals nationale wetenschappelijke onderzoeks- en financieringsprogramma's, met als gevolg dat techmologische ontwikkeling veel complexer is geworden. Het resultat is verhoogde specialisatie in de ontwikkeling van producten en handel, zowel in componenten als in eind (volledige) producten. Bovendien kan het ontstaan (design, ontwikkeling, productie, en assemblage) van deze producten over meerdere naties uitgespreid zijn.

Al deze ontwikkelingen hebben geresulteerd in een bedrijfsklimaat waarin firma's lokale en globale concurrentie het hoofd moeten bieden en zij een plaats in een reeds gevestigde orde moeten vinden binnen een gevestigde internationale productiestructuur. De toegenomen globale handel betekent ook verhoogde specialisatie, aangezien niet elke natie industrieën kan hebben, die excelleren op elk gebied van technologie. Aldus vindt er een natuurlijk proces van kristallisatie plaats, aangezien er slechts ruimte is voor een klein aantal onderzoeksinstituten van hoogwaardige kwaliteit en hoogst gespecialiseerd onderzoek en deskundigheid in de wereld. Daarom benadrukt hoofdstuk vijf dat landen hun 'niche' moeten vinden - hun concurrerend voordeel (comparative adoantage). Ook is het juridische kader waarbinnen landen en industrieën moeten opereren drastisch veranderd: de wereld is aan elkaar verbonden door een fijnmazig web van verdragen, overeenkomsten op zowel 
nationaal, regionaal als multilateraal niveau. Ook intellectuele eigendomsrechten zijn geharmoniseerd met als gevolg, dat industrieën minder mogelijkheden hebben om te leren door imitatie, het kopiëren van bestaande technologieën of door rin's' 'ngin'ering technieken te gebruiken. Het komt er op neer dat ontwikkelingslanden laatkomers zijn in reeds bestaande markten, met als gevolg dat zij niet dezelfde mogelijkheden hebben om door vallen en opstaan te leren, zoals de Europeanen, de Amerikanen en de Japanners, die wel intellectuele eigendomsrechten en systemen voor innovatie op mat konden opstellen om aan hun specifieke sociaal-economische behoeften te voldoen, toen zij de switch makten van landbouw naar de industrieel georiënteerde maatschappij.

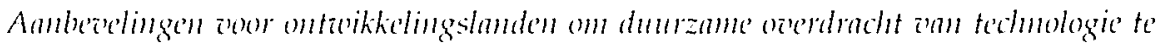
bererkstelligen

In tegenstelling tot de jaren '70 waar de nadruk op het aantrekken van technologie lag, vereist onze huidige matschappij bijkomende en essentiële stappen om over een succesvolle overdracht van technologie te spreken: ten eerste, het aantrekken van de "juiste" technologie; ten tweede de assimilatie en de absorptie van technologische kennis; ten derde, aanpassing aan lokale behoeften en omstandigheden; ten vierde, de absorptie van verdere verbeteringen, ten vijfde, de generalisatie van de overgebrachte kennis om verdere toepassing mogelijk te maken en; ten zesde de verspreiding van de kennis en technologie aan een breed publiek. Het gevolg is, dat het essentieel is om inspanningen te leveren om de zwakke en gelimiteerde capaciteiten alsmede de financiële middelen voor educatie, wetenschap, technologie en innovatie (R\&D) aanzienlijk te verbeteren om niet alleen toegang te hebben tot een bepaalde techniek, mar ook om deze technologie te gebruiken, te absorberen en te benutten voor binnenlandse, sociaal-economische ontwikkelingsbehoeften.

Hoofdstuk vijf adviseert, dat ontwikkelingslanden op zoek naar technologie een aantal essentiële kwesties in overweging moeten nemen alvorens technologieoverdracht overeenkomsten aan te gaan. Sommige aanbevelingen voor succesvolle internationale technologieoverdracht zijn:

1) Het land dat (host comntry) technologie van een derde land wenst te verwerven moet zijn technologische behoeften in het kader van zijn economische en sociale ontwikkelingsdoelstellingen identificeren. Deze binnenlandse behoeften beoordeling inzake het aantrekken van de juiste technologie moet zich richten op de geschiktheid en de kosten van de technologie alsmede de voorwaarden (de opgenomen clausules) voortkomende uit de technologiepakketten (toclmolog! packnges) - misschien dat niet het hele technologie pakket aangekocht dient te worden maar slechts een aantal essentiële componenten);

2) Voorts moeten de host countries zorgen voor een aantrekkelijk investeringsklimat om technologie aan te trekken. Dit impliceert het verbeteren van de 
infrastructuur, transparantie en stabiliteit in overheidsmaatregelen en aangelegenheden, het verminderen van corruptie en geweld, evenals het bevorderen van een redelijk open handel en investeringsregime. Het is ook van belang om het juridische kader en beleid onder de loep te nemen, aan te passen en te zorgen voor wetten, die het aantrekken van technologie promoten. In het bijzonder is het aan te bevelen om te analyseren of het belastingsysteem, markt verordeningen, intellectuele eigendomsrechten en mededingingsrechten aangepast of geintroduceerd dienen te worden;

3) Zodra de technologie is verworven, is het belangrijk, dat het wordt geabsorbeerd en aangepast aan lokale behoeften en productieprocessen en wijd verspreid wordt onder potentiële technologiegebruikers. In dit verband is het belangrijk, dat landen investeren in het bevorderen van lokale R\&D activiteiten, en educatie en training in management en technische vaardigheden, aangezien dit noodzakelijk is om de capaciteit te vergroten om technologie te absorberen en toe te passen;

4) Het is essentieel om activiteiten te concentreren op die gebieden war een land in excelleert, met andere woorden: het is belangrijk om een "niche" te vinden, een comparatioc adiantage om zo in eerste instantie met buurlanden en vervolgens met andere landen te concurreren. Ook moet in eerste instantie gebruik gemaakt worden van technologieën die "vrij" toegankelijk zijn om te gebruiken, bijvoorbeeld oudere technologie die al onderdeel is geworden van het publieke domein, omdat het octrooi al is verstreken of omdat de octrooihouder een bepaalde technologie niet geoctrooieerd heeft binnen een bepaald land;

5) De voorwaarden (clausules) opgenomen in technologieoverdracht contracten moeten zorgvuldig geanalyseerd worden om oneerlijke technologie verpakking te voorkomen, zoals kartelvorming, exclusieve grant-back voorwaarden (dat elke modificatie of verbetering automatisch eigendom wordt van de primaire technologie eigenaar) en dwang clausules, die het gebruik van concurrerende technologieën uitsluiten of beperken;

6) LDC's hebben maar beperkte capaciteit in het ontwikkelen en het uitvoeren van mededingingsbeleid om oneerlijke technologie verpakkingen/contracten te compenseren. Het is raadzaam om mededingingsautoriteiten te vestigen en mededingingsbeleid te verbeteren, zodat zij in staat zijn om restrictieve bedrijfspraktijken door technologie-eigenaars in te perken en te controleren. In het bijzonder zouden de geindustrialiseerde, ontwikkelde landen ertoe bij kunnen dragen om hun mededingingsautoriteiten in te zetten om oneerlijke bedrijfspraktijken (vooral verricht door MNE's) in ontwikkelingslanden te signaleren en te onderzoeken en technische bijstand en raad te verstrekken om problemen aan te pakken, aangezien de ontwikkelingslanden vaak niet de onderzoekscapaciteit of de financiële middelen hebben om deze onderzoeken te verrichten; 
7) Het is raadzaam voor ontwikkelingslanden om een aantal aanbevelingen narr voren te schuiven die in de WIIO "Development Agenda" worden vermeld, in het bijzonder anbevelingen 23, 25, 28, 29, 30 en 31. Deze aanbevelingen hebben betrekking op het aansporen van technologieoverdracht naar ontwikkelingslanden en betere informatie verschaffing over octrooien en technologieën, beschikbaar in het publieke domein, en de flexibiliteit, voortvloeiende uit het TRIPS Verdrag. Voorts beklemtonen deze aanbevelingen ook het belang van het ontwikkelen van een eigen technologische basis op lokaal niveau. De aanbevelingen wijzen ook op het belang om intellectuele eigendomsconcepten te identificeren die het meest geschikt zijn om lokale behoeften te ondersteunen en het belang van het begrijpen van intellectuele eigendomsrecht concepten in het algemeen en de beschikbare flexibiliteit;

8) Voorts zouden ontwikkelingslanden naar manieren moeten zoeken om innovatie te bevorderen buiten het (intellectuele) eigendomsrecht systeem. Bijvoorbeeld, de succesvolle opensource softurme bewegingen hebben laten zien, dat innovatie en vooruitgang ook op andere manieren bereikt kunnen worden, zoals het concentreren op open toegang, samenwerken en het delen van onderzoeksresultaten om verdere innovatic te bewerkstelligen. De geschiedenis toont aan, dat de wetenschappelijke ontdekking niet alleen door eigendomsrechtsystemen is gestimuleerd, maar vooral ook door nieuwsgierigheid en de wens om praktische oplossingen te vinden voor alledaagse problemen (zoals het uitvinden van de mobiele telefoon in Noorwegen om beter te kumen communiceren in de houtindustrie). Het idee van open bron licenties verlening is om onderzoekers en producenten toe te staan om op kemnis voort te bouwen en onderzoeksresultaten te delen. Voorts zijn er ook nog andere informele manieren (zogenaamde nonmarket channels of techulogy transfer) om technologie te verwerven, bijvoorbeeld door imitatie, zorgvuldige product inspectie, onderzoek van octrooi claims, verloop/overstap van personeel van het ene bedrijf naar het andere, tijdelijke migratie van studenten en wetenschappers maar ook van technici en managers;

9) Gezien de bovengenoemde aanbevelingen is het belangrijk, dat richtlijnen in de vorm van toolkit voor ontwikkelingslanden worden ontwikkeld. Dit zou als een soort controlelijst ('checklist') kunnen functioneren inzake best practice's voor technologieoverdracht overeenkomsten.

Het internationale juridische kader inzake de ooerdmath an technologie

Drie Artikelen in het TRIPS Verdrag verwijzen naar de overdracht van technologie en het belang van technologische ontwikkeling. Artikel 66.2 doet een expliciet verzoek aan ontwikkelde landen om hun industrieën aan te sporen de technologieoverdracht aan LDC's te verbeteren; Artikel 7 makt het concept technologieoverdracht een basisdoelstelling van het internationale handelssysteem door te verklaren, dat de bescherming en de handhaving van intellec- 
tuele eigendomsrechten moeten bijdragen tot de bevordering van technologische innovatie en tot de overdracht en de verspreiding van technologie, evenals tot wederzijds voordeel van producenten en gebruikers van technologische kennis en op een manier, die bijdraagt aan sociaal en economisch welzijn, en voor een evenwicht van rechten en plichten en; Artikel 8 staat TRIPS Leden toe om geschikte matregelen na te streven om misbruik van intellectuele eigendomsrechten door rechthebbenden te voorkomen en om maatregelen te nemen tegen gebruiken, die de handel inperken of technologieoverdracht ongunstig beinvloeden. Artikel 8, paragraaf 1, verstrekt Leden de flexibiliteit om matregelen te nemen inzake het belang van de volksgezondheid en voeding, en het openbaar belang te bevorderen in sectoren, essentieel voor sociaal-economische en technologische ontwikkeling. Nochtans, onderstreept de toegevoegde clausule, dat dergelijke maatregelen alleen genomen mogen worden, indien verenigbar met de bepalingen van het TRIPS Verdrag; deze clausule vermindert uiteraard het potentieel van de bovengenoemde bepaling.

Deze drie Artikelen vormen een weerspiegeling van de fundamentele spanningen inherent aan het beschermen van zowel de technologieontwikkelaars op zoek nar nieuwe innovatie als ook de overdracht van technologie voor het publieke belang. Tot op zekere hoogte kunnen intellectuele eigendomsrechten bijdragen aan het verbeteren van het bedrijfsklimaat waarin de markten voor technologie actief zijn; het kan innovatie stimuleren en de verspreiding van gecompenseerde technologie verhogen - hoewel het effect van intellectuele eigendomsrechten sterk afhangt van het ontwikkelingsniveau van landen alsmede de sector van industrie.

Het belang van technologieoverdracht aan LDC's was herbevestigd in de Doha Verklaring: paragraaf 19 bepaalt, dat de TRIPS Council in het uitvoeren van zijn werkprogramma geleid moet worden door de doelstellingen en principes, voortvloeiende uit Artikel 7 en 8 alsmede de ontwikkelingsdimensie in acht moet nemen. Ook de "Doha TRIISS Declaration on the TRIPS Agreement and Public Health" herbevestigt het belang van de overdracht van technologie in paragraaf 7 . Al deze hernieuwde belangstelling voor de problemen van ontwikkelingslanden inzake het implementeren van intellectuele eigendomsrechten en het opzetten van een lokale technische en creatieve basis kunnen de belangen van ontwikkelingslanden ten goede komen in toekomstige onderhandelingsprocessen en in geschillenbeslechting.

Een belangrijke tekortkoming echter is, dat niets in het TRIPS Verdrag inzicht geeft in hoe de technologieoverdracht kan worden verhoogd en verbeterd alsmede praktisch gerealiseerd kan worden. De internationale voorschriften inzake internationale technologieoverdracht zijn vaag geformuleerd en vermelden slechts dat overheden de overdracht van technologie zouden moeten bevorderen en ontstijgen dus niet het niveau van best practices. In tegendeel, de regels inzake intellectuele eigendomsrechten zijn strenger van aard en leggen landen een systeem van rechten en plichten op. Om een oplossing te zoeken 
voor deze tekortkomingen is er een werkgroep opgericht inzake het ten uitvoer leggen van Artikel 66.2 (Doha Ministeriele Verklaring, paragraaf 37) om het verband tussen handel en de overdracht van techmologie te onderzoeken en aanbevelingen te verstrekken om de overdracht van technologie te verhogen. De Leden werden vervolgens opgedragen om jaarlijks te rapporteren om meer duidelijkheid te verschaffen inzake huidige technologieoverdracht praktijken en activiteiten in het kader van Artikel 66.2.

Tot op heden heeft deze werkgroep zijn verwachtingen niet wargemaakt en I.DC's klagen over het gebrek aan informatie, die uit deze rapporten kan worden afgeleid - gecompliceerde technische rapporten, inconsistentie in de jaarverslagen, en bovenal de verwarring van technische bijstands- en capaciteitsactiviteiten met daadwerkelijke technologicoverdracht activiteiten.

Overheden kunnen alleen in zekere mate de overdracht van technologie beïnlocden, aangezien deze transacties hoofdzakelijk tussen privéondernemingen plaatsvinden. Nochtans kumnen de overheden een bevorderend bedrijfsmilieu creëren om de overdracht van technologie antrekkelijker te maken voor bedrijven, bijvoorbeeld door belastingvoordelen te verstrekken aan MNE's, die bereid zijn om technologie projecten an LDC's te ondersteunen en te faciliteren.

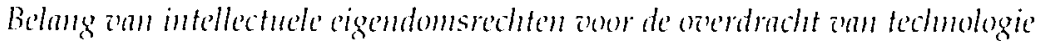

Hoofdstuk vijf beschrijft de verschillende manieren waarop technologieoverdracht kan plaatsvinden evenals de rol, die intellectuele eigendomsrechtbescherming speelt inzake de overdracht van technologie. De essentiële kwestie is niet of intellectuele eigendomsrechten de handel of buitenlandse investering bevorderen, mar in hoeverre zij een rol spelen in de toegang tot nieuwe technologieïn

Buitenlandse investeerders en technologie eigenaren hebben drie opties om hun technologie te introduceren op buitenlandse markten: 1) product zelf produceren op eigen grondgebied en vervolgens via handelskanalen product invoeren in buitenlandse markten; 2) product produceren in een ander (ontwikkelings)land door gebruik te maken van een 'joint venture' of een overzeese vestiging (in eigen eigendom/dochter onderneming); of 3) licentie verstrekken aan een concurrerende firma, die het product vervolgens in eigen beheer produceert. Voor ontwikkelingslanden is de laatste optie te prefereren, aangezien het de mogelijkheid biedt om de technologie zelf toe te passen en modificaties te maken om het product aan te passen aan lokale behoeften. Nochtans aarzelen buitenlandse investeerders vaak om licenties te verlenen, als de betreffende technologie essentieel en cruciaal is in zijn bedrijfsstrategie. Er is vaak over gedebatteerd, dat een laag niveau van intellectuele eigendomsrechtbescherming investeringsstromen negatief beinvloedt. In het bijzonder kunnen MNE's onwillig zijn om in een land met zwakke intellectuele eigendomsrechten te investeren en besluiten om alleen te investeren in dochter- 
ondernemingen (in volledige eigendom) of gebruik te maken van het handelskanaal en opties zoals licenties of joint rentures af te wijzen. Soms zijn zij slechts bereid om inferieure of oudere technologie over te brengen, waar risico's laag zijn. Hoewel, te sterke intellectuele eigendomsrechten landen verhinderen de mogelijkheid om te kopiëren, te imiteren en gebruik te maken van rowe' engine'ring technicken met als gevolg dat de technologische ontwikkeling van een land stagneert. Studies hebben ook aangetoond, dat het hebben van sterke intellectuele eigendomsrechten alleen niet voldoende aansporingen geeft om in een land te investeren. Dit wordt aangetoond door het feit, dat de grote ontwikkelingslanden met hoge groeipercentages veel buitenlandse investeringen ("FDI") hebben ontvangen, zelfs met de wetenschap dat zij zwakke intellectuele eigendomsrechtsystemen en kwakkelende handhavingspraktijken hebben. Hoofdstuk vijf benadrukt, dat het intellectuele eigendomsrecht systeem niet in een vacuüm opereert. Bijkomende factoren vergemakkelijken de technologieoverdracht, met name de kwaliteit van de infrastructuur, overheidsbeleid en marktstructuur. Studies hebben uitgewezen, dat handelslogistiek en vooral de capaciteit om zich te verbinden met internationale markten om goederen te verschepen/te verplaatsen van uiterst belang zijn voor ontwikkelingslanden om hun concurrentiepositie te verbeteren, te profiteren van globalisering en armoede op een effectievere manier te bestrijden in een geintegreerde wereld. Net als het aanbrengen van verbeteringen in supply manngenent activiteiten is het openstellen van markten cruciaal. Maar, bovenal is het belangrijk om goederen te produceren en marketing strategieën te ontwikkelen. Er zijn ook bijkomende factoren die innovatieprocessen faciliteren, zoals de kwaliteit van onderzoeksinstellingen en in hoeverre samenwerking plaats vindt tussen verschillende onderzoeksorganisaties. Voorts is het belangrijk voor ontwikkelingslanden om te begrijpen, dat intellectuele eigendomsrechten op complexe manieren verweven zijn met ander overheidsbeleid, zoals het mededingings- en investeringsbeleid om optimaal te kumen functioneren. Hoofdstuk vijf wijst erop, dat intellectuele eigendomsrechten slechts één van de vele kwesties en aandachtspunten van MNE's zijn in het maken van investeringsbeslissingen.

Het is belangrijk om het juiste evenwicht van intellectuele eigendomsrechtbescherming te bereiken: enerzijds zijn zij een noodzakelijk hulpmiddel om innovatie te verwezenlijken en het delen van kennis te bevorderen, maar anderzijds creëren zij ook semi-monopolies (exclusieve rechten), die het moeilijk maken om technologie tegen lage kosten te verkrijgen, aangezien rechthebbenden een sterke marktpositie hebben en voorwaarden van licenties, productie en marktprijzen bepalen.

De totstandbrenging van vlotte en snelle overdracht van technologie kan door monopolistisch gedrag door de octrooihouder worden belemmerd. Misbruik van het octrooisysteem komt voor, indien firma's slechts octrooien verwerven om de concurrentie in gelijksoortige industrieën juridisch aan te klagen. Het gebruik van patent pools belemmert ook toegang en begrip, aangezien de octrooien van diverse firma's met elkaar verbonden zijn en het kennis van 
veelvoudige octrooi claims vereist. In het huidige economische klimaat gebruiken de firma's voorts rijen van octrooibescherming en andere vormen van intellectuele eigendomsrechtbescherming op één product.

Het octrooisysteem is een middel om kemis te genereren en te leren, omdat én van de eerste vereisten voor het verkrijgen van een octrooi het openbaren van de octrooi claim (de kern van de uitvinding) is. Nochtans is het twijfelachtig in welke mate de ontvangers van de technologie de octrooi claims kunnen begrijpen en kunnen toepassen zonder hulp van de uitvinder/octrooi eigenaar. Imitatie van een bepaalde technologie leidt niet automatisch tot assimilatie en absorptie van de technologie.

Hoe belangrijk zijn intellectuele eigendomsrechten in investeringsbesluiten gemakt door de industrie? Hoe beinvloeden intellectuele eigendomsrechten de internationale handel? Dit zijn vragen die in hoofdstuk vijf worden behandeld. Er is een gemeenschappelijke overtuiging dat technologische verandering belangrijk is om economische groei te bewerkstelligen. Gezien het feit, dat de internationale handel een belangrijk kanaal van technologieoverdracht is en dat het aandeel kennis-intensieve of geavanceerde technische producten in de wereldhandel is gestegen, is het een logisch gevolg, dat intellectuele cigendomstediten e'en grociende rol spelen in de internationale handel. Ook is de opmars van de MNEs een belangrijke factor en het feit dat het niet het individu maar de onderneming is die de intellectuele eigendomsrechten beheert en bezit. Het is onrealistisch, dat firma's vrijwillig hun technologie zullen overdragen aan andere bedrijven of goederen uitvoeren, als er een kans bestaat, dat zij gemakkelijk gekopieerd kumnen worden zonder dat de mogelijkheid aanwezig is om hun rechten te beschermen en juridisch af te dwingen. Dit is omdat de ontwikkeling van producten veel tijd en investering vergen en R\&D kosten vaak een groot onderdeel van de kostempost innemen. Bovendien zijn de voorbereiding en het indienen van octrooiaanvragen een lang en duur proces, dat het op de markt brengen van een product met een flink aantal jaren kan vertragen (en in het geval van geneesmiddelen moet ook voldaan worden aan klinische proeven om exclusieve marketing goedkeuring te verkrijgen). De resultaten van Park en Lippoldt's studie leiden tot de bevinding, dat de (handels)invoer van goederen en diensten en buitenlandse investeringen (FDI) positief geassocieerd zijn met buitenlandse octrooiaanvragen (d.w.z. in het land van de technologie ontvanger). Dit betekent, dat de producten technologische componenten bevatten, die het octrooieren waard zijn. Deze redenering impliceert, dat een hoge octrooibescherming de potentie heeft om de internationale technologieoverdracht te bevorderen, maar ook aanspoort tot het overbrengen van nieuwere technologieën.

De aanwezigheid van sterke intellectuele eigendomsrechten speelt een minder grote rol in investeringshesluiten betreffende de lagere technologie-industrieën en producten. Nochtans, als de technologieën in kwestie verfijnder en hoogwaardig zijn, maar vrij gemakkelijk te kopiëren, dan kunnen intellectuele eigendomsrechten - hoewel niet noodzakelijk - een significante factor in 
investeringsbesluiten zijn, in het bijzonder als het ontvangende land zowel de wetenschappelijke capaciteit heeft om de technologie te kopiëren alsmede een voldoende grote markt om de kosten om te octrooieren en handhaving te rechtvaardigen (bijvoorbeeld in de chemische en farmaceutische industrie). Hoofdstuk vijf wijst erop dat de rol van intellectuele eigendomsrechten in technologieoverdracht besluiten sterk sector aflumkelijk is. Bijvoorbeed, in sommige industrieën, zoals de metaal en transport sector, is het vrij moeilijk om de technologie van een firma te kopiëren zonder vele dure en complexe handelingen (vandaar dat intellectuele eigendomsrechtenbescherming minder belangrijk is), terwijl in de farmaceutische industrie het relatief eenvoudig is voor lokale firma's om nieuwe producten te imiteren door gebruik te maken van rin's' engin'ering technieken. Het gevolg is, dat R\&D intensieve firma's, met producten of productieprocessen, die vrij gemakkelijk te imiteren zijn, aarzelen om wezenlijke investeringen te doen of geavanceerde technologie over te brengen naar landen met zwakke intellectuele eigendomsrechtbescherming. Nochtans wezen de bedrijven (vooral die buiten de chemische industrie) erop, dat de aanwezigheid van intellectuele eigendomsrechtbescherming slechts éen van een aantal factoren is, die hun investeringsbesluit beïnvloeden. Firma's met beperkte $R \& D$ investeringen vinden de aanwezigheid van intellectuele eigendomsrechtbescherming ondergeschikt aan hun investeringsbeslissingen.

Een studie van Park en Lippoldt (2008) heeft uitgewezen, dat het verhogen van octrooibescherming in ontwikkelingslanden de activiteiten (FDI) vergroot van bepaalde sectoren in de VS, met name de chemische industrieën, de productie van machinerieén en de diensten en informatie sector. Nochtans heeft het vergroten van intellectuele eigendomsrechten geen impact op de elektronische en computer industrieën. Een reden hiervoor kan zijn, dat de investeringen gedaan, door de VS in de elektronica en computerindustrieën, in ontwikkelingslanden grotendeels voor verkoop en distributiedoeleinden zijn, zodat er minder bezorgdheid is over de sterkte van lokale octrooirechten. Niettemin wijst de Park en Lippoldt's studie (2008) erop, dat de aanwezigheid van intellectuele eigendomsrechtbescherming en met name de handhaving hiervan belangrijk is voor alle sectoren van industrie met name om piraterij en onbevoegde verkoop en distributie tegen te gaan.

Het type am iniestering en welke soort tedmologie speelt ook een belangrijke factor in het vraagstuk of intellectuele eigendomsrechten een rol spelen in investeringsbesluiten. Studies hebben aangetoond, dat in geavanceerde technische industrieën zoals de chemische en farmaceutische, maar ook in de productie van machines en elektronisch materiaal, de aanwezigheid van intellectuele eigendomsrechtbescherming vaak een significant effect heeft op de hoogte en de wijze waarop technologieoverdracht en directe investering (in R\&D faciliteiten) plaatsvindt (Mansfield (1994)). Als de bescherming van intellectuele eigendomsrechten als zwak wordt waargenomen, dan is het hoogst waarschijnlijk, dat investeringen alleen plaatsvinden door gebruik te maken van overzeese dochterondernemingen (iwholly ozwed subsidiniles) en worden gewijd aan verkoop en afzetkanalen of aan rudimentaire productie en assem- 
blagefaciliteiten in plats van de productie van componenten of volledige producten. Het gevolg is, dat de mate van intellectuele eigendomsrechtbescherming invloed heeft op welke activiteit van het productie-/leveringsproces (production/supply chain mmagement) uitgevoerd zal worden op een bepaald grondgebied.

Onderzoek heeft ook aangetoond, dat bedrijven de overdracht van strategisch gevoclige technologie aan niet geaffilieerde partijen vermijden, ongeacht de waargenomen sterkte van het intellectuele eigendomsrecht regime. Bijvoorbeek, vele chemische industrieen zijn slechts bereid om nieuwe of geavanceerde (of meest efficiënte) technologie naar dochterondememingen over te brengen.

In tegenstelling tot Mansfield vonden Fink en Primo Braga (1999), dat sterkere intellectuele eigendomsrechten een significant positief effect hebben op handelsstromen, maar dat dit effect van het type van technologie afhangt. Bijvoorbeeld vonden zij, dat de starheid van het octrooiregime van het desbetreffende land geen verschil uitmaakt inzake de handel in geavanceerde technische producten (zoals handel in chemische producten, elektronica, kantoormachines en telecommunicatie). Zij vonden echter wel, dat sterke intellectuele eigendomsrechten een significant positief effect hebben op handelsverkeer voor niet brandbare stoffen ( $(n) n-f u c l)$ invoer en export. Nochtans zijn intellectuele eigendomsrechten niet significant voor geavanceerde technische handelsstromen. Fink \& Primo Braga (1999) hadden een positief handelseffect voor kennis intensieve goederen verwacht. Desondanks is het mogelijk, dat sterke intellectuele eigendomsrechten tot gevolg hebben, dat firma's, die geavanceerde technische producten produceren, buitenlandse markten dienen door investeringen (FDI) (en handel dus substitueren). Het kan ook zo zijn, dat sommige kennis intensieve goederen ongevoelig zijn voor het intellectucle eigendomsrechten niveau en dientengevolge kunnen andere factoren een rol spelen in het nemen van besluiten inzake R\&D. Bijvoorbeeld het voordeel om als eerste een nieuw product op de markt te introduceren, of in het geval dat een product een korte levensduur heeft is het belangrijker om de eerste te zijn dan bescherming te verkrijgen (d.w.z. prestige en marketing voordeel). Dit komt vooral veel voor in de mobiele telefoontechnologie.

Dit stemt overeen met studies, die door Maskus en Penubarti (1995) en Smith (1999) werden uitgevoerd en die ook een positief verband tussen handelsstromen en sterke intellectuele eigendomsrechtbescherming vonden, maar Maskus en Penubarti achten een dergelijk verband niet aanwezig voor de octrooi gevoelige industrieën en Smith vindt een dergelijke verband niet in landen, die geen bedreiging inzake imitatie vormen.

Park en Lippoldt (2008) vinden, dat de sterke octrooibescherming de import (handelsstromen) van high-tech producten significant positief beinnvloedt in ontwikkelingslanden, zoals farmaceutische goederen, chemische producten, ruimtevaart, computerdiensten, informatie, kantoor en telecommunicatiemateriaal en optica en precisiemateriaal. Voor de minst ontwikkelde landen 
zijn de kwalitatieve en kwantitatieve effecten van octrooirechten op goederen import veel zwakker. Octrooirechten hebben een dominante invloed, omdat de dienstensector gevoeliger is voor de mate van octrooibescherming, op voorwarde dat andere variabelen constant zijn. De meeste controlevariabelen (index van vrije handel, het bruto nationaal product (BNP) per hoofd, handhaving van intellectuele eigendomsrechten en wettelijke doeltreffendheid) hebben een positief effect op de invoer van diensten. De opening van markten beinvloedt positief de handelsimport van ontwikkelingslanden, maar kan ook substitutie tot gevolg hebben zowel in de geindustrialiseerde als in de armste landen - bijvoorbeeld de overschakeling van goederen import naar FDI. Park en Lippoldt (2008) vonden, dat de import van diensten, octrooibescherming en intellectuele eigendomsrechten handhaving positief geassocieerd wordt met het invoeren van communicatie en computer diensten en vergoedingen (royalty's). Dus de resultaten van de studie zeggen, dat sterkere intellectuele eigendomsrechtbescherming bijdraagt aan het aantrekken van diensten met een kennis of technologie component.

Het bestaan van intellectuele eigendomsrechten kan invloed hebben op internationale handelsstromen, bijvoorbeeld een bedrijf kan besluiten om zijn geoctrooieerde goederen niet te exporteren naar buitenlandse markten war de afwezigheid van of zwakke intellectuele eigendomsrechten de mogelijkheid creëren, dat potentiejle piraten de goederen namaken en winsten te niet gaan. Men zou aldus verwachten, dat een verhoging van octrooirechten in een bepaald land leidt tot een verhoging van import, omdat de netto vraag van buitenlandse firma's naar hun producten stijgt en namaak goederen vervangt. Maar een firma kan ook besluiten om export naar een buitenlandse markt te verminderen als reactie op sterkere intellectuele eigendomsrechtbescherming wegens zijn grotere marktmacht in een imitatie veilig milieu. Aldus kan men concluderen, dat het effect van aangescherpte intellectuele eigendomsrechten op handelsstromen theoretisch dubbelzinnig is ten aanzien van marktuitbreiding en marktmacht (Fink and Prima Braga 1999 in verwijzing naar Maskus en Penubarti 1995). Nochtans vinden Maskus en Penubarti (1995) dat het effect van verhoogde import de marktmacht overheerst, zodat sterkere intellectuele eigendomsrechten per saldo de handelsstromen uitbreiden: de reden is dat de marktmacht van intellectuele eigendomsrechten domineert in de geavanceerde technologische sectoren. De aannemelijkheid hiervan is, dat de firma's in deze technologie-intense industrieën al in het bezit zijn van een bepaalde marktmacht vanwege hun technologische superioriteit en sterkere octrooibescherming zal dan grotendeels hun marktwaarde vergroten. Een andere mogelijkheid zou kunnen zijn, dat sterkere intellectuele eigendomsrechtbescherming firma's laat overschakelen tussen verschillende wijzen van technologieoverdracht, bijvoorbeeld van export (handelsstromen) naar FDI.

Zoals hierboven vermeld vindt Smith (1999), dat het effect van sterkere octrooibescherming op handel afhangt van de imitatie capaciteit van het desbetreffende land. In landen met zwakke imitatie capaciteit doet de zwakke capaciteit dienst als de facto vorm van bescherming. Smith (1999) vindt ook, 
dat, indien de imitatie capaciteit hoog is, het versterken van intellectuele eigendomsrechten de handel verhoogt.

De resultaten van economisch en empirisch onderzoek zijn verdeeld wanneer het over de verhouding tussen intellectuele eigendom, de overdracht van technologic en het niveau van sociaal-economische ontwikkeling gaat. Park en lippoldt (2008) hebben een positieve associatic gevonden tussen sterke octrooirechten en de overdracht van technologie voor alle groepen landen (geïndustrialiseerde landen en ontwikkelingslanden) getoond. Deze mening wordt gesteund door Mansfield (1994 en 1995). In tegenstelling, tot Falvey en Foster (2006) die beargumenteren, dat sterkere intellectuele eigendomsrechtenbescherming minder invloed heeft op innovatie en de verspreiding van technologie in ontwikkelingslanden zonder capaciteiten om te innoveren.

Deze resultaten impliceren dat MNEs hun export beslissingen niet baseren op het niveau van intellectuele eigendomsrechten in de armste landen, waar imitatie en rows' chginering technieken geen reële bedreiging vormen. Nochtans worden octrooirechten belangrijker in grote ontwikkelingslanden met een gemiddeld inkomen, waar de imitatie capaciteit hoger is. Als deze landen de bedreiging van imitatie kumnen inperken door het invoeren van grotere bescherming voor octrooien, zullen de buitenlandse firma's eerder geneigd zijn hun export te vergroten. De producten van vele geavanceerde technische industrieën (exclusief geneesmiddelen) zijn inherent moeilijk te imiteren, zodat handel in deze producten minder beinvloed wordt door de aanwezigheid van intellectuele eigendomsrechten dan de handel in oudere technologieën.

Het effect van intellectuele eigendomsrechtbescherming op sociaal-economische groei, innovatie en de verspreiding van technologie in ontwikkelingslanden hangt van een aantal factoren af. Sterkere intellectuele eigendomsrechtbescherming in de armste landen zal waarschijnlijk geen wezenlijke voordelen opleveren in termen van innovatie of technologieverspreiding, in tegendeel, de administratieve kosten om intellectuele eigendomsrechten te introduceren, te implementeren en te handhaven impliceren dat dergelijke landen op korte termijn geen baat hebben bij het TRIPS Verdrag. Hoofdstuk vijf merkt ook op, dat er grote verschillen tussen ontwikkelingslanden onderling zijn. Sterkere bescherming van intellectuele eigendomsrechten in de armste landen kan het imiterende stadium van ontwikkeling ook belemmeren of verlengen - imitatie is belangrijk om innovatieve capaciteit te ontwikkelen. In de armste landen heeft intellectuele eigendomsrecht bescherming weinig effect en kan het de overdracht van oudere, minder geavanceerde technologie zelfs afschrikken. In ontwikkelingslanden daarentegen met een gemiddeld inkomen en in grotere, is er meer potentie om voordeel uit het TRIPS Verdrag te halen. Studies hebhen aangetoond, dat de internationale handelsstromen, vooral in de octrooi gevoelige industrieën, stijgen, indien ontwikkelingslanden hun octrooirechten aanscherpen. Dit geldt echter alleen voor de ontwikkelingslanden met een gemiddeld inkomen en de grotere ontwikkelingslanden, maar niet voor de 
armste landen. Bestande firma's, die op dit moment vooral opereren door te imiteren, zouden door de aanwezigheid van sterkere intellectuele eigendomsrechten kunnen worden aangemoedigd om middelen in te zetten om oude technologieën te modificeren en te verbeteren om tegemoet te komen aan locale behoeften en aldus hun eigen innovatie capaciteit te ontwikkelen. Tegelijkertijd zouden sterkere intellectuele eigendomsrechten in die landen ook de handel en FDI stromen verhogen. Dit proces zou moeten samenvallen met het openen van markten om buitenlandse export toe te laten en met beleid gericht op het aanmoedigen van investeringen on de lokale innovatieve sector te stimuleren door het anmoedigen van $R \& D$, onderwijs en trainingen. Acharya en Keller (2007) tonen aan, dat import (handelsstromen) een belangrijk kanaal vormt van technologieoverdracht, die, hoewel het volume van overdracht per land varieert, groter is in landen met sterkere absorptiecapaciteiten. Import kan de productiviteit van een land verhogen, doordat het toegang biedt tot buitenlandse input en technologieën.

Binnen de groep grote ontwikkelingslanden trekken aangescherpte intellectuele eigendomsrechtregimes groter dan verwachte import stromen aan van OECD landen (Maskus and Penubarti 1995). Intellectuele eigendomsrechten alleen kunnen de kennis en technologie overdracht niet bevorderen, nochtans kan deze bescherming bijdragen tot een verhoging van de export, indien de bestemmingsmarkten commercieel potentieel hebben in termen van grote markten en sterke technologische capaciteiten.

Hoofdstuk vijf wijst erop, dat het verbeteren en verhogen van technologieoverdracht aan de armste landen speciale aandacht vereist. Dit is, omdat de technologieoverdracht aan LDC extra aansporingen vergt, daar algemene economische operaties, zoals FDI, infrastructuur of markttransacties (zoals licenties), niet in staat zijn om de overdracht van technologie aan deze landen te bevorderen. In plaats daarvan moet de overdracht van techologie specifiek worden gericht en op mat gemaakt om aan de behoeften van de armste landen tegemoet te komen.

Met betrekking tot het verlenen van licenties van hun technologie, in het algemeen, aarzelden firma's om hun nieuwste, meest efficiënte technologie naar niet verwante firma's over te brengen waar de mate van IPR bescherming zwak was (Fink and Primo Braga 1999).

In het algemeen wordt het bestaan van intellectuele eigendomsrechten toegejuicht door investeerders, bijvoorbeeld, de introductie van merkenrechtbescherming in ontwikkelingslanden wordt gezien als een belangrijke stap voorwaarts in het bestrijden van counterfited products (namaak producten van door merk beschermde producten, bijvoorbeeld een namaak Louis Vuiton tas) (Park and Lippoldt 2008). 
Diverse studies hebben erop gewezen, dat de verschillende niveaus van industrialisatie ook verschillende behoeften an intellectuele eigendomsrecht bescherming impliceren, die beurtelings tot verschillende resultaten leiden betreffende technologieoverdracht en de economische groei. Ontwikkelingslanden zijn divers: zij variëren zeer in hun economieën, technologie-infrastructuren en innovatiebekwammeden. De TRIPS bepalingen geven niet genoeg ruimte voor de absorptie van basistechnologieẻn en kennis om capaciteiten te verhogen in ontwikkelingslanden. Vooral L.DCs zijn niet in stat om te profiteren van intellectuele eigendomsrechten, aangezien zij eerst noodzakelijke basis structuren moeten ontwikkelen om sociaal-economische groei te bewerkstelligen zoals onderwijs, gezondheidszorg, infrastructutur, en basis communicatie systemen. Hoogstwaarschijnlijk zal de verplichting om een intellectuele eigendomsrechtsysteem te implementeren en handhaven het installeren van bovengenoemde basisbehoeften ondermijnen. Bovenal, zonder installatie van de noodzakelijke infrastructuur kunnen deze landen ook rechten en plichten niet implementeren en handhaven en evenmin zorgen dat creativiteit en inventiviteit geprikkeld wordt om binnenlandse innovatie te verhogen.

Onderzoek heeft aangetoond dat de marktgrootte en de infrastructuur essentiële elementen zijn in het verklaren van FDI stromen en imnovatie in ontwikkelingslanden, terwijl in de ontwikkelde/geindustrialiseerde landen de import van geavanceerde technologie, menselijk kapitaal, en R\&D uitgaven een sterkere imvloed hebben. Hoofdstuk vijf concludeert, dat de relevantie van de aanwezigheid van een ontwikkeld intellectuele eigendomsrecht beschermingssysteem sterk afhangt van het niveau van sociaal-economische ontwikkeling. Intellectuele eigendomsrecht heeft sterkere invloed voor geindustrialiseerde landen en zou innovatie in ontwikkelingslanden negatief kunnen beïnvloeden. Dit zou kumnen worden verklaard door het feit dat de meeste innovatie die in ontwikkelingslanden voorkomt eigenlijk imiterend of aanpassend (aanpassen aan lokale behoeften) van aard is. Vandaar dat hoge intellectuele eigendomsrechtbescherming schadelijk kan zijn voor de behoeften van lokale firma's (en voornamelijk buitenlandse firma's steunt). Dit betekent niet, dat intellectuele eigendomsrechten geheel verbannen zouden moeten worden, maar dat de overbescherming van intellectuele eigendomsrechten vermeden moet worden en dat toekomstige onderhandelingen veel meer rekening dienen te houden met lokale omstandigheden en behoeften en het niveau van sociaal-economische ontwikkeling. Om een effectief en rechtvaardig intellectuele eigendomsrechtsysteem te garanderen dienen deze rechten ook nut te hebben voor ontwikkelingslanden zelf; alleen als landen potentie zien voor de opbouw van lokale innovatieve capaciteit, kan het versterken van deze rechten gerechtvaardigd worden aan beleidsmakers en het volk. De capaciteit van een ontwikkelingsland om technologie te absorberen is een belangrijke factor in het bepalen van hoe invloedrijk de rol van intellectuele eigendomsrechten zijn in het bewerkstelligen van economische groei. Imitatie is een vorm van technologie 
verkrijging, mar firma's kunnen niet alle componenten van nieuwe technologiein, met inbegrip van zowel vastgelegde kennis (die in octrooi claims worden onthuld) en knwo how zonder de participatie van buitenlandse rechthebbenden, beheersen. Vandaar dat het beter zou kunnen zijn om toch voor een bepaald beschermingsniveau van intellectuele eigendomsrechten te kiezen om toegang te krijgen tot buitenlandse technologie door formele technologieoverdracht activiteiten (handelsstromen, FDI, toelaten van overzeese vestigingen en licenties).

Het spreekt vanzelf, dat, als ontwikkelingslanden technologisch meer geavanceerd zullen worden, zij ook toegang tot verfijndere, superieure technologieën nodig hebben. Tegelijkertijd zullen verzoeken om geavanceerdere technologie de interne en externe druk om de mate van intellectuele eigendomsrechtbescherming te verhogen, doen toenemen. Geavanceerde technologie (onderwerp van constante ontwikkeling en modificatieprocessen) is moeilijker te verkrijgen dan oudere technologieën. In onze huidige maatschappij is het belang van $R \& D$ in productontwikkeling enorm gestegen en de cycli van de levensduur van het product verkort. In deze geliberaliseerde en concurrerende omgeving kunnen firma's in ontwikkelingslanden niet meer op basis van het invoeren van oudere technologieën van geündustrialiseerde landen concurreren en ook niet produceren achter enorme tariefbarrières. Nochtans is het een primaire behoefte van LDCs om bij de realisatie van een technische innovatie en creatieve lokale basis zich eerst te concentreren op technologie, beschikbaar in het openbare domein. Op de lange duur zal dit hen minder van buitenlandse technologieën afhankelijk maken. Op korte termijn zouden ontwikkelingslanden in het duurzaam verbeteren van hun levensonderhoud zich moeten focussen op regionale markten en "niche" productie.

Studies hebben aangetoond, dat het hebben van sterke intellectuele eigendomsrechtbescherming $R \& D$ activiteiten aanmoedigt en dat landen met sterkere bescherming grotere aandelen van hun BBP investeren in R\&D, op voorwarde, dat de sterke, geschreven wetten door efficiënte handhaving worden gesteund. Onderzoek heeft aangetoond, dat octrooiaanvragen in ontwikkelingslanden (door zowel ingezetenen als niet-ingezetenen) en uitgaven op R\& D (als percentage van het BBP) het hebben van sterke octrooirechten promoot. Een samenwerking tussen universiteit en industrie is van belang in het bundelen van $R \& D$ activiteiten wanneer samenwerking gericht is op het onderzoeken van fundamenteel basisonderzoek. Indien er kans is om technologieën te octrooieren zijn industrieën minder geneigd om commerciële successen te delen met academici. In de meeste landen bestaat het VS "Bayh Dole" type van wet niet (deze wet bevortert het octrooieren van uitvindingen, die met publiek geld zijn gefinancierd door middel van universitair onderzoek) - het is aan te bevelen om dit systeem nader te onderzoeken om potentie voor ontwikkelingslanden te onderzoeken.

Weinig informatie is beschikbaar op het effect van nationale economische activiteiten of nationale onderzoeksprioriteiten op de hoeveelheid lokale inno- 
vatie (of octrooianvragen). Nochtans is het belangrijk, dat overheden beleid goedkeuren, dat bedrijven helpt hun intellectuele activa in financieel kapitaal om te zetten. In de BRIC landen is de technologieoverdracht via handel en FDI een belangrijke factor geweest in de ontwikkeling van lokale technologische capaciteiten. Overheden kunnen bijvoorbeeld bepaalde projecten financieel ondersteumen om cen bepaald segment van de industrie te bevorderen: bijvoorbeeld de elektronische of muzieksector.

Zoals hoofdstuk vijf heeft laten zien is het effect van versterkte intellectuele eigendomsrechten op economische groei niet gemakkelijk te bepalen. Intellectuele eigendomsrechten zijn niet de enige oplossing om economische ontwikkeling te bewerkstelligen, niettemin kumnen zij een bijdrage leveren. Sommige manieren van technologieovertracht zijn geschikter dan andere. Onderzoek heeft aangetoond, dat de rol van handel (import) in het aanmoedigen van economische groei sterk afhangt van het geografische werkingsgebied van de overdracht van kennis/verspreiding. De empirische studies hebben nog niet een duidelijk oordeel over deze kwesties uitgesproken en het is waarschijnlijk, dat voor ontwikkelingslanden de verspreiding van kennis eerder nationaal van aard is dan voor geindustrialiseerde landen voor wie de verspreiding internationaal is. Dientengevolge is het voor de sociaal-economische ontwikkeling van belang of R\&D activiteiten en de productie van geavanceerde technische producten platsvinden in de geografische nabijheid van een land (Saggi 2000).

Vele factoren spelen een rol in de succesvolle overdracht van technologie buiten het werkingsgebied van intellectuele eigendomsrechten: in het bijzonder de aanwezigheid van een R\&D programma, binnenlandse onderzoekslaboratoria en universiteiten, en het bestaan van een lokale basis aan technische vaardigheden en menselijk kapitaal. Al deze factoren verminderen de kosten van imitatie, modificatie en vervolg innovatie (innovatie gebaseerd op bestaande uitvindingen).

De conclusie in hoofdstuk vijf luidt, dat de aard van $R \& D$ activiteiten varieert: $R \& D$ in overzeese filialen is normal gesproken toegewijd aan de adoptie, modificatic en absorptie van oudere bestaande producten om aan lokale marktvoorwarden en behoeften te voldoen. Aldus zijn deze R\&D activiteiten complementair aan de technologie invoer van de moederonderneming war onderzoek gericht is op technologische vooruitgang. De eerstgenoemde methode zal weinig octrooien opleveren, terwijl laatstgenoemde het potentieel heeft om er veel te produceren. MNEs doen standaard en toegepast onderzoek in het buitenland, maar hoofdzakelijk in landen met een redelijk gevorderde wetenschappelijke en technische gemeenschap en waar de noodzakelijke onderzoeksinfrastructuur goed ontwikkeld is. Dus de aard van R\& D thuis en in het buitenland is zeer verschillend van aard en kwaliteit. In landen met zwakkere intellectuele eigendomsrechten kan FDI ook plaatsvinden, hoewel deze eerder betrekking hebben op het vestigen van verkoop en distributiekanalen dan hoogwaardige productie en hoogwaardige R\&D activiteiten. 
Zoals aangetoond zijn er vele mogelijke strategieẻn om internationale technologie te verwerven en lokale industriële en technologische ontwikkeling te bewerksteligen. Prioriteit moet gegeven worden aan de verbetering van het lokale milieu om internationale techmologieoverdracht te verwerken en te gebruiken en om verdere verspreiding te bewerkstelligen. Het aantrekken van FDI en licenties hangt ook af van het realiseren van een efficiënte infrastructuur, transparantie en stabiliteit in overheid, en een redelijk open handels- en investeringsregime. Ook belangrijk is de creatie van een aantrekkelijk ondernemersmilieu, dat bewerkstelligt, dat in het buitenland geschoolde arbeiders na verloop van tijd weer huiswaarts keren. Studie heeft aangetoond dat de verticale verspreiding (diffusion) van technologie het grootst is in landen waar MNE's samenwerken met concurrerende ondernemingen, dit betekent, dat beleid erop gericht zou moeten worden om marktbelemmeringen voor buitenlandse ondernemingen op te heffen. Een belangrijke determinant van de capaciteit van een land om technologie te absorberen en aan te passen aan lokale behoeften is het herinvesteren in eenvoudige R\&D capaciteit. Lokaal beleid moet dit aanmoedigen. Naast het versterken van educatie, training en laboratoriumonderzoek is het ook van belang om deel te nemen aan internationale netwerken, zoals studenten en promovendi uitwisselingsprogramma's, followship programma's (bijvoorbeeld binnen de UNCTAD "Virtual Network" of het WTO "Academic Exchange Programme"). Het creëren van technologische basiskennis zal de overdracht van technologie bevorderen door doelgerichter technologie aan te trekken en betere voorwaarden overeen te komen binnen technologieoverdracht contracten. Bovenal hebben ontwikkelingslanden ruim de tijd nodig om intellectuele eigendomsrechten en de gevolgen te implementeren, te begrijpen en toe te passen in lijn met hun sociaal-economische omstandigheden en behoeften.

Het importeren van materiaal kan R\&D bevorderen en in zoverre resulteert R\&D in verhoogde innovatieve output, voor welke ingezetenen octrooien kunnen aanvragen en verhoogde octrooiaanvragen door ingezetenen kan geassocieerd worden met verhoogde import.

Aanbealingen on de ooerdacht an technologie te betorderen

Hoofdstuk vijf heeft geresulteerd in een aantal aanbevelingen voor ontwikkelingslanden op zoek naar kennis en technologie:

1) De erkenning dat het bevorderen van de lokale industrieën geen geavanceerde hoogwaardige nieuwe technologieën vereist. Dit kan worden bereikt door productieprocessen (en supplychain activiteiten) te verbeteren. Vandaar dat ontwikkelingslanden zich zouden moeten concentreren op wat vrij beschikbaar is, d.w.z. gebruik het octrooisysteem en kennis en knowhow beschikbaar in het openbare domein (vooral rijpe technologieën) en vermijd het ondertekenen van technologieoverdrachtovereenkomsten, die te ruim opgezet zijn en de toegang beperken tot vrij beschikbare technologie (niet geoctrooieerde uitvindingen) op hun grondgebied. Ont- 
wikkelingslanden moeten werken aan het creëren van technologische mogelijkheden door te investeren in onderwijs, technische vaardigheden, R\&D en de ontwikkeling van geschikte instellingen, vooral sinds de meeste technologieen niet gemakkelijk te lezen en te begrijpen zijn zonder een bepaalde specifieke kennis. Ontwikkelingslanden dienen hun eigen behoeften te inventariseren: welke technologieën zijn vereist, de markt voor technologieën, en uitzoeken of de benodigde technologie op hun grondgebied beschermd en voorradig is. Op deze manier kunnen zij hun onderhandelingscapaciteit in toekomstige technologieoverdracht contracten versterken door betere voorwaarden te bewerkstelligen.

2) De realisatic dat het TRIPS Verdrag minimum standaarden/normen (rechten en plichten) in het leven roept en door ontwikkelingslanden een zekere vorm van autonomie biedt. Landen moeten echter voldoende geinformeerd en getraind worden om te profiteren van de flexibiliteit van het TRIPS Verdrag. In het bijzonder zouden landen gebruik moeten maken van onderzoeks- en onderwijsvrijstellingen evenals het gebruiken van dwang licenties (Artikel 31 TRIPS).

3) Het versterken van lokale intellectuele eigendomsbureaus en octrooibureaus, niet alleen in het beheer van de registratie van octrooien en handelsmerken, maar ook door informatie te verschaffen over hoe intellectuele eigendomsrechten gebruikt kunnen worden voor lokale behoeften en in het voordeel van de lokale bevolking.

4) Alternatieven onderzoeken buiten het intellectuele eigendomsrecht systeem, zoals open broninitiatieven of samenwerkingsinspanningen zoals het aardappelinitiatief van Peru, dat verschillende sectoren van de matschappij samenbrengt om de introductie op de markt van inheemse aardappel variëteiten te bevorderen.

5) Het ontwikkelen en toepassen van mededingingswetgeving om oneerlijke zakenpraktijken tegen te gaan.

6) Benader WIPO onderhandelingen zorgvuldig. Met name de onderhandelingen inzake de Substantio' Pat'nt Law Treaty moeten voorzichtig benaderd worden om bepalingen in evenwicht te brengen met de behoeften van ontwikkelingslanden. Onderzoeksvrijstellingen binnen het octrooirecht moeten gehandhaafd en zo mogelijk uitgebreid worden en de negatieve impact van octrooirechten op onderzoek moet worden verminderd.

7) De tenuitvoerlegging van de WIPO “Development Agenda" aanbevelingen in het WIPO Comité inzake Intellectuele Eigendom en Ontwikkeling (CDIP) moet worden gecontroleerd en versneld om het internationale intellectuele eigendomsrecht systeem meer in balans te brengen en technologieoverdracht te stimuleren. 
8) Een aantal aanbevelingen voortkomende uit de WIPO "Development Agenda" zou ook gekoppeld kunnen worden aan de onderhandelingen binnen de "TRIPS Council" en de TRIPS Council Werkgroep inzake de Technologieoverdracht om inspamingen te bundelen met betrekking tot een ontwikkelingsvriendelijke benadering van intellectuele eigendomsrechten.

9) Het onderhandelen over een verdrag inzake het faciliteren van toegang tot kennis en technologie zoals voorzien in de WIPO "Development Agenda".

Hier volgen enkele aanbevelingen voor geïndustrialiseerde landen om technologieoverdracht te vergemakkelijken.

1) De selectie van technische bijstandsactiviteiten en technologieoverdracht in het belang van ontwikkelingslanden om uniformiteit in productie (en technologieoverdracht activiteiten) te vermijden en tegemoet te komen aan lokale behoeften.

2) Het aamnemen van een pro-actieve rol om oneerlijke zakenpraktijken door MNEs tegen te gaan, ook op het grondgebied van grondgebied van ontwikkelingslanden.

3) Erkenning voor het feit dat technologieoverdracht overeenkomsten tussen ongelijke onderhandelingspartners worden besproken (kleine lokale firma of overheidstochteronderneming tegenover reusachtige multinationale onderneming). Het is aan te bevelen om samenwerkingsprojecten aan te moedigen door joint ientures aan te gaan of samenwerkingsregelingen met multinationale ondernemingen om beide partijen van begin af aan bij het project te betrekken. Op deze manier kumnen ontwikkelingslanden samenwerken met buitenlandse partners in het ontwikkelen van nieuwe lokale producten en bijpassende techmologie en kennis genereren en delen. Dit impliceert ook onderhandelingen inzake pro-concurrerende licenties en vergunningen (aanbeveling 23 van de WIPO "Development Agenda").

Het is ook belangrijk, dat de technologieoverdracht een duurzaam positief effect op het ontvangende land heeft. Bijvoorbeeld, als een MNE beslist om zijn technologie en productie over te dragen aan een lokale firma door licenties te verstrekken in plaats van het vestigen van een lokale productie unit (in eigen beheer), zal dit in eerste instantie minder buitenlandse investering vergen. Uiteindelijk zal dit type van technologieoverdracht voordeliger zijn voor het ontwikkelingsland (de ontvanger), omdat het helpt om binnenlandse technologische mogelijkheden verder te ontwikkelen. Het importeren van geavanceerde technische goederen door ontwikkelingslanden wordt ook gekwalificeerd als overdracht van technologie. Nochtans is de overdracht slechts duurzaam als de binnenlandse economie die technologie als basis voor verdere innovatie kan absorberen. Voor de armste landen zou het efficiënter kunnen zijn om binnenlandse technologische capaciteit en vaardigheden te 
ontwikkelen en te verbeteren door middel van reverse chginering technieken en imitatie. Vandaar dat de kwaliteit en de duurzaamheid van de technologieoverdracht belangrijk is om positieve ontwikkelingsresultaten op de lange termijn te realiseren.

De belangrijkste conclusie uit hoofdstuk vijf is, dat het belang van intellectuele eigendomsrechten in investeringsbesluiten afhankelijk is van de sector en type van technologie en van een aantal omstandigheden, zoals investeringsklimaat, niveau van ontwikkeling en technologisch vermogen, waarborgen tegen onteigening, de wijze van technologieoverdracht en de rijpheid van de technologie. Bovendien beschermen landen de verschillende industrieën op verschillende manieren en de sterkte van intellectuele eigendomsrechtbescherming kan ook afwijken, bijvoorbeeld sterke auteursrechtbescherming maar zwakke octrooirechten. Daamaast kunnen de bekwaamheid en de agressiviteit van firma's binnen een bepaald land van industrie tot industrie verschillen. Bovendien moet intellectuele eigendomsrecht in de wetboeken met efficiënte en adequate handhavingsmaatregelen worden gecomplementeerd.

Verder onderzoek is nodig op het effect van veranderingen (hervorming) in intellectuele eigendomsregimes in ontwikkelingslanden en het gedrag van multinationale ondememingen - vooral nu veel TRIPS overgangsregelingen ten einde zijn. Bovendien is meer onderzoek noodzakelijk op industrieel niveau, om te zien hoe intellectuele eigendomsrechten verschillende soorten samenwerking, bijvoorbeeld joint icntures, overzeese vestigingen in gehele eigendom, etcetera beïnvloeden.

Over het algemeen is de introductie van IPR bescherming geassocieerd met een stijging van import van goederen (handelsstromen) en het vergemakkelijken van technologieoverdracht in het kader van het verlenen van licenties, maar heeft het niet een wezenlijke verandering gebracht in investering in lokale productie. Hoofdstuk vijf heeft ook uitgewezen, dat intellectuele eigendomsrechtbescherming geen grote invloed heeft op investeringsstromen waar andere factoren hoogstwaarschijnlijk een grotere rol spelen (met name geografische bestemming, grootte van land, veiligheid, bestuur, transparantie en infrastructuur). Nochtans, zoals in hoofdstuk vijf is geconcludeerd, is het algemene effect van intellectuele eigendomsrechtbescherming op tweezijdige handelsstromen en FDI theoretisch dubbelzinnig. Er is evenwel een algemene waarneming dat sterke intellectuele eigendomsrechtbescherming schadelijk is voor de armste landen en het FDI weinig zal beinvloeden. Toch is de werkelijkheid, dat intellectuele eigendomsrechten en handhaving, het nakomen van verplichtingen, voortvloeiende uit de bestaande intellectuele eigendomsrecht verdragen en TRIPS plus bepalingen een belangrijke rol spelen in bilaterale, regionale handels- en investeringsovereenkomsten. 
Landenvertegenwoordigers, afkomstig uit de ontwikkelingslanden, zijn bezorgd over het constante vergroten van het WTO mandaat, het toestaan van het TRIPS Verdrag om binnenlandse intellectuele eigendomsrechten te bepalen, en regionale en bilaterale vrijhandelsverdragen die in toenemende precisie de normen aanscherpen en uitbreiden. Het is een voortdurende strijd om op de hoogte te zijn en te blijven van intellectuele eigendomsbeleidsvorming op lokaal, bilateraal, regionaal en multilateraal niveau en aan de rechten en plichten, voortkomende uit deze overeenkomsten, te voldoen. Hoofdstuk twee heeft laten zien, dat intellectuele eigendomsrechten exclusieve rechten bieden en dat deze invloed hebben op de vrijhandel, de mededinging (zoals de hoge prijzen voor essentiële geneesmiddelen), en toekomstige innovatie zowel positief als negatief kan beïnvloeden. Aldus is het voor alle landen belangrijk om een mededingingsbeleid op te stellen en toezicht te houden om misbruik van intellectuele eigendomsrechten tegen te gaan. Zoals dit boek heeft aangetoond, varieert een adequaat beschermingsniveau van intellectuele eigendomsrechten per land en hangt samen met het niveau van sociaaleconomische ontwikkeling inclusief productie capaciteiten. De LDC landen zijn het meest gediend met een lage octrooibescherming (conform TRIPS minimum), dat een adequaat publiek domein waarborgt en follow up innovatie en technische kennis kan stimuleren. Bovendien moeten LDC landen zich concentreren op die concepten binnen het intellectuele eigendomsrecht systeem, die het meest geschikt zijn om aan hun eigen innovatie behoeften te voldoen met name om lokale uitvindingen en merken te promoten, zoals bijvoorbeeld petty patents, wetten inzake handelsgeheimen, en industriële ontwerpen. $\mathrm{Zij}$ zullen ook profiteren van het verbeteren van merkenrechtbescherming voor hum producten door efficiënt gebruik van handelstekens en geografische herkomstaanduidingen te maken. Nochtans profiteren de meer gevorderde ontwikkelingslanden van een zekere mate van octrooirechtbescherming, ondat dit toestaat om hun eigen uitvindingen te beschermen. Intellectuele eigendomsrecht bescherming op maat (d.w.z. in overeenstemming met het sociaal-economische niveau van ontwikkeling) kan bijdragen aan het verhogen van de technische en economische capaciteit en op den duur de vraag naar hogere bescherming doen toenemen.

In theorie - en op lange termijn - heeft ieder land de mogelijkheid om te profiteren van het TRIPS Verdrag, met inbegrip van ontwikkelingslanden, en met name het midden en klein bedrijf, agrariërs, kunstenaars, musici en wetenschappers. Nochtans, op korte termijn zijn het vooral de MNEs die profiteren van een hoge mate van intellectuele eigendomsrechtbescherming. De uitgebreide literatuur over de rol van intellectuele eigendomsrechten op economische groei en technologieoverdracht laat zien, dat het context afhankelijk is en dat rekening dient te worden gehouden met de specifieke omstandigheden van het land. Naast het niveau van sociaal-economische ontwikkeling spelen ook de sector van industrie, het type van technologie en welke investeringsmogelijkheid is uitverkoren (licenties, joint wentures, handelsverkeer van 
goederen) een belangrijke rol. Deze context-gevoeligheid vereist flexibele regels in de tenuitvoerlegging van de rechten en plichten voortvloeiende uit het TRIPS Verdrag, met inbegrip van prioriteit geven aan de behoeften van ontwikkelingslanden in WTO en WIPO onderhandelingen en de verhoging van lokale creatieve en innovatieve capaciteiten.

Handelsbeleid is een belangrijk middel voor sociaal-economische ontwikkeling, maar niet een doel op zich. Handelsbeleid kan verwachtingen scheppen die handel alleen niet kan vervullen. Het nastreven van handelsovereenkomsten kan zeker een stap in de juiste richting zijn, mar het zal ontwikkelingsdoelstellingen niet snel verwezenlijken. Het sociaal-economische ontwikkelingsproces vereist meer acties en voorwaarden, zoals de capaciteitsopbouw en de totstandbrenging van administratieve en overheidsinstellingen, evenals liberalisering van markten en speciale en differentiële behandeling voor ontwikkelingslanden. Vandaar dat de naam "Doha Development Round" niet geschikt is, aangezien het promoten van handel niet de panacee voor ontwikkeling is, als het niet begeleid wordt met aanvullend beleid en activiteiten. In veranderende tijden en omstandigheden, gekenmerkt door globalisatie en snelle technologische vooruitgang, zou het een logische conclusie kunnen zijn, dat de rechtvaardigingen en beweegredenen achter het intellectuele eigendomsrechtsysteem geherformuleerd dienen te worden om de sociaal-economische gevolgen van intellectuele eigendomsrechten voor inheemse volkeren en ontwikkelingslanden te rechtvaardigen. Op deze manier kunnen de belangen en behoeften van ontwikkelingslanden beter weerspiegeld worden in de achterliggende doelstellingen en rechtvaardigingen inzake het intellectuele eigendomsrechtsysteem.

Bovenal is het intellectuele eigendomsrechtsysteem een instrument van publiek beleid: teveel bescherming is niet goed, terwijl te weinig bescherming de realisatie van duurzame sociaal-economische ontwikkeling afremt. Vandaar dat rechten en plichten op de weegschaal moeten! 



\title{
List of References
}

BOOKS / JOLRNALS / REPORTS

\begin{abstract}
Abbott 1998
Abbott, F., "The Enduring Enigma of Trips. A Challenge for the World Economic System", Special Issue Trade-Related Aspects of Intellectual Property Rights (TRIPS), joumal of International Ecomomic Latio, Vol. 1(4), 1998.
\end{abstract}

\begin{abstract}
Abbott, Cottier and, Gurry 1999
Abbott, F., Cottier, T, and Gurry, F., The Intermational Intellectual Property System: Commentary and Materials, The Hague, London, Beston: Kluwer Law International (2 Vols.), 1999.
\end{abstract}

\section{Abdel Latif 2008}

Abdel Latif, A., "Bringing the WIPO Development Agenda to the TRIPS Council", Iphalth neweletter, March 2008

\section{Acharya and Keller 2007}

Acharya, R. and Keller, W., Technolegy Transfor thromgh lmports, National Bureau of Economic Research (NBER) Working Paper, No. 13086, Cambridge, MA, May 2007.

\section{Addor 2005}

Addor, F., Sicitzerland's Proposals Reganding the Dectaration of the Source of Genetic Resontres and Tratitional Knowledge in Patent Applications and Sicitzerland's Viead on the Dectaration of Eadidence of Prior Informed Comsent and Benefit-sharing in Patent Applications', ICTSD, CIFL, IDDRI, IUCN, QUNO Dialogue on "Disclosure Requirements: Incorporating the CBI Principles in the TRIPS Agreement, On the Road to Hong Kong", WTO Public Symposium, Geneva, Switzerland, 21 April 2005.

\section{Addor and Grazioli 2002}

Addor, F. and Grazioli, A., "Geographical Indications beyond Wines and Spirits: A Roadmap for a Better Protection for Geographical Indications in the WTO/TRIPS Agreement", The fournal of World hitellectual Property, 5(6), 2002, p. 865-896.

\section{Adede 2001}

Adede, A., The Political Economy of the TRIPS Agrement: Origins and History of Negothations, 2001. Published online at: <http://www.ppl.nl/bibliographies/wto/files/12 73.pdf >.

\section{Aitken and Harrison 1999}

Aitken, B. and Harrison, A., "Do Domestic Firms Benefit from Direct Foreign Investment? Evidence from Venezuela", Americin Economic Reriew, Vol. 89(3), June 1999, p. 605-618.

\footnotetext{
Akerlof 1970

Akerlof, G., 'The Market for "Lemons": Quality' Uncertainty and the Market Mechanism', Quarterly Jourmal of Economics, Vol. 84, August 1970, $p$ 488-500.
} 


\section{Antons 2005}

Antons, C, "Traditional Knowledge and Intellectual Property Rights in Australia and Southeast Asia", in: Heath, C. and Kamperman Sanders, A. (Eds.), Nea Frontiers of Intellectual Property, Oxford, Portland: Hart, 2005.

\section{Archibugi and Ianmarino 1997}

Archibugi, D. and Iammarino, S., "Innovation and ghobalization: Evidence and Implications", in: Archibugi, D., and Miclnic, J. (Eds.), Techology, Globalisation and Economic Performance, Cambridge: Cambridge University Press, 1997.

\section{Arthur 1984}

Arthur, ( ). Commerialisation of Tedmology and Dependence in Jamaica, Mona: Institute of Social and Economic Research, University of West Indies, 1984.

\section{Arvis et al. 2007}

Arvis, J., Mustra, Panzer, M., Ojala, L. and Naula, T., Comecting to Compefe - Trate Logistics in the Global Economy: The Logistics Performance Index and its Inticators, World Bank, 2007. Published online at: <http://siteresources.worldbank.org/INTTLF/Resour ces/lpireport.pdf>.

\section{Axt et al. 1993}

Axt, J., Com, M., Lee, M. and Ackerman, D., Biotedmology, Indigenous Peoples and Intellectual Property Rights, Washington DC: Congressional Library Service, Library of Congress, 1993.

\section{Bachner 2005}

Bachner, B., "Back to the Future: Intellectual Property Rights and the Modernisation of Traditional Chinese Medicine", in: Heath, C. and Kamperman Sanders, A. (Eds.), New" Frontiers of Intellectual Property, Oxford, Portland: Hart, 2005.

\section{Barton 2003}

Barton, J., Prescring the Global Sicutific ant Tedmological Commons, ICTSD and UNCIAD, Science and Technology Diplomacy Initiative and the ICTSD-UNCTAD Programme on IPRs and Sustainable Development, Policy Dialogue on a Proposal for an International Science and Technology Treaty, Geneva: Palais de Nations, 11 April 2003.

\section{Barton 2007}

Barton, J., New Trents in Tedhology Transfor: Implications for National and Intemational Policy, ICTSD Programme on IPRs and Sustainable Development, Issue Paper No. 18, Geneva: ICTSD, 2007. Published online at: <http://wwwiprsonline.org/resources/ docs / Barton \%20-\%20New \%20Trends\%20Technology \%20Transfer\%2002 07.pdf>.

\section{Bascavusoglu and Zuniga}

Bascavusoglu, E. and Zuniga, M., Foreign Patent Rights, Technology and Disemboticd Knowledge Transfer Cross Borders: An Empirical Application, Université de Paris I Panthéon Sorbonne, CNRS (no year provided). Published online at: <hitp://wwwecon.kuleu ven.ac.be/smve/abstracts/pj02.pdf>.

\section{Berkes, Folke and Gadgil 1995}

Berkes, F., Folke, C. and Gadgil, M., "Traditional ecological knowledge, biodiversity, resilience and sustainability", in: Perrings, C., Maler, K., Folke, C., Holling, C., and Jansson, B. (Eds.), Biotiousity Conserantion: Problems and Policies, Dordrecht: Kluwer Academic Publishers Group, 1995. 


\section{Bhagwati 1990}

Bhagwati, J., (Ed.), Aggressive Unilateralism: America's 301 Trade Policy and the World Trading System, Ann Harbor: University of Michigan Press, 1990.

\section{Blakeney 1989}

Blakeney, M., Legul Aspects of the Thunser of Tedmology to Dereloping Conntries, Oxford: ESC Publishing Limited, 1989.

\section{Blakeney 1994}

Blakeney, M., "Communal Intellectual Property Rights of Indigenous Peoples in Cultural Expressions", The Journal of World intellectual Property, Vol. 6(6), 1994, p. 985-1002.

\section{Blakeney 1997}

Blakeney, M., "Bioprospecting and the Protection of Traditional Medical Knowledge of Indigenous Peoples: An Australian Perspective", Europrem Intellectual Property Reivieat, 1997 , p. $298-303$.

\section{Blakeney 2000}

Blakency, $M$, "The protection of traditional knowledge under intellectual property law", Europerm Intellectual Property Reriere, Vol. 22(6), 2000, p. 251-261.

\section{Blomström and Kokko 1997}

Blomström, M. and Kokko, A., How forcign inesetment affects host countries, Policy Research Working Paper Series, Working Paper No. 1745, The World Bank, 1997.

\section{Bogsch 1983}

Bogsch, A., "The First Hundred Years of the Paris Convention for the Protection of Industrialised Property 1983", Industrial property, 1983, p. 181- 244.

\section{Van den Bossche 2008}

Van den Bossche, P., The Lne and Policy of the World Trule Organization - Text, Cases and Materials, Cambridge: Cambridge University Press, first print 2005, second print 2008.

\section{Boyle 2004}

Boyle, J., "A Manifesto on WIPO and the Future of Intellectual Property", Duke Lme and Technolegy Recicie, 2004. Published online at: <htpp://www.law.duke.edu/journals/ diltr/articles/2004dltr0009.html>.

\section{Bradley 1987}

Bradley, A., "Intellectual Property Rights, Investment, and Trade in Services in the Unuguay Round: Laving the Foundations", Stanford foumal for Intermationul Lubl, 1987. Vol. 23, p. $57-98$.

\section{Branstetter 2004}

Branstetter, L., "Do Stronger Patents Induce More Local Innovation?", foumal of International Economic Lane, Vol. 7(2), 2004, p. 359-70.

\section{Branstetter, Fisman and Fritz Foley 2005}

Branstetter, L., Fisman, R., Fritz Foley, C., Do Stromger Intellectual Property Rights Increase

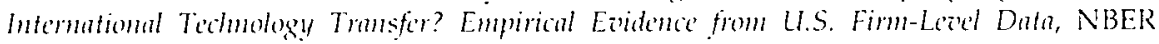
Working Paper Sories, Working Paper 11516, July 2005. Published online at: <http:// www.nber.org/papers/w11516>. 


\section{Bridges Trade BioRes 2004a}

Bridges Trade Bioles, "TRIPS Council: Renewed Calls for Moving Ahead on Biodiversity", Vol. 4, No. 5, 19 March 2004. Published online at: <http:/ictsd.net/i/ news/biores/8883/>.

\section{Bridges Trade BioRes 2004b}

Bridges Trade Biokes, "Disclosure Requirements Remain Divisive in WIPO Patent Reform", Vol. t, No. 10, 28 May 2004. Published online at: <http://ictsd.net/i/news/ biores $/ 9228 />$.

\section{Bridges Trade BioRes 2007a}

Bridges Trade Biokes, "ABS Experts Flesh out Certificate of Origin", Vol. 7, No. 2, 2 February, 2007. P'ublished online at: <http://ictsd.net/i/new's/biores/9321/>.

\section{Bridges Trade BioRes 2007b}

Bridges Trade BioRes, "WIPO Committee Resumes Work On Genetic Resources and TK", Vol. 4, No. 6, 2 April 2007. Published online at: <http://ictsd.net/i/news/biores/ $9221 />$.

\section{Bridges Trade BioRes 2007c}

Bridges Trade Biokes, "Biotech Companies Want Switzerland on IP Walch List", Vol. 7, No. 7, 13 April 2007. Published online at: <http://ictsd.net/i/new's/biores/9507/>.

\section{Bridges Weekly Trade News Digest 2005a}

Bridges Weekly Trade News Digest, "Indigenous Communities' Rights to Potato Strains Recognised", Vol. 9, No, 2, 26 January 2005.

\section{Bridges Weekly Trade News Digest 2005b}

Bridges Weckly Trade News Digest, "Brazil Asks for Cross-Retaliation under TRIPS, GATS in Cotton Dispute With US", Vol. 9, No. 34, 12 October 2005.

\section{Bridges Weekly Trade News Digest 2007a}

Bridges Weekly Trade News Digest, "As Antigua considers Cross-retaliation against US, WIPO Official creates Stir", Vol. 12, No. 2, 23 January 2007. Published online at: <http:// www.ictst.org/weekly/08-01-23/story2.htm>.

\section{Bridges Weekly Trade News Digest 2007b}

Bridges Weekly Trade News Digest, "TRIPS Members Still Divided on Biodiversity, Gl's and Enforcement", Vol. 11, No. 21, 13 June 2007. Published online at: <http:// ictsd.net/i/news/bridgesweekly/7604/>.

\section{Bridges Weekly Trade News Digest 2007c}

Bridges Weekly Trade News Digest, "Rwanda becomes First Country to try to use W'TO Procedure to lmport Patented HIV/AIDS Drugs", Vol. 11, No. 27, 25 July 2007. Published online at: <http://www.ictsd.org/weekly/07-07-25/story2.htm>.

\section{Bridges Weekly Trade News Digest 2007d}

Bridges Weekly Trade News Digest, "Canada Issues Compulsory Licence for HIV/ AIDS Drug Export to Rwanda, in First Test of WTO Procedure", Vol. 11, No. 32, 26 September 2007. Published online at: <http://www.ictsd.org/weekly/07-09-26/story2. htm>. 


\section{Bridges Weekly Trade News Digest 2007e}

Bridges Weckly Trade News Digest, "WIPO Adopts Development Agenda, But Faces Budget Row", 3 October 2007. Published on the internet at: <http://www.ictsd.org/ weekly/07-10-(1)3/storyl htm>.

\section{Bridges Weekly Trade News Digest 2007f}

Bridges Weekly Trade News Digest, "TRIPS Council Extends Public Health Deadline; Discuss Biodiversity, L.DC Aid", Vol. 11, No. 37, 31 October 2007. Published online at: <htip://www. ictst.org/weekly/07-10-31/ story2.htm>.

\section{Bridges Weekly Trade News Digest $2007 \mathrm{~g}$}

Bridges Weekly Trade News Digest, "WHO Committee on Drug Innovation and Prices underway in Geneva", Vol. 11, No, 7, 7 November 2007. Published online at: <http:// www.ictsd.org/weekly/07-11-(17/story2htm>

\section{Bridges Weekly Trade News Digest 2007h}

Bridges Weekly Trade News Digest, "Links between Patent Rules and Access to Green Technology come under Scrutiny", Vol. 11, No. 42, 5 December 2007. Published online at: <http://www ictsd.org/weckly/07-12-(15/storyohthtm.

\section{Bridges Weekly Trade News Digest 2008a}

Bridges Weekly Trade News Digest, "Focus on IP Enforcement at Meeting in Dubai", Vol. 12, No. 5, 13 February 2008, Published online at: <http:/www.ictsd.org/week ly/08-02-13/inbrief.htm>.

\section{Bridges Weekly Trade News Digest 2008b}

Bridges Weekly Trade News Digest, "Sluggish Start to WIPO Talks on Implementing Development Agenda Recommendations", Vol. 12, No. 9, 12 March 2008. Published online at: <http://www.ictst.org/weekly/08-03-12/story2.htm>.

\section{Bridges Weekly Trade News Digest 2008c}

Bridges Weekly Trade News Digest, "Call for Work on Exceptions and Limitations in WIPO Copyright Committee", Vol. 12, No. 10, 19 March 2008. Published online at: <http://www.ictsd.org/weekly/08-03-19/story.3.htm>.

\section{Bridges Weekly Trade News Digest 2008d}

Bridges Weekly Trade News Digest, "WHO Adopts Strategy on Public Health, Innovation and Intellectual Property", Vol. 12, No. 19, 28 May 2008. Posted online at: <htp://www.ictsd.org/weekly/08-05-28/storv6.htm>.

\section{Brown 2002}

Brown, K.B., "Missing Africa: Should US International Tax Rules Accommodate Investment in Developing Countries?", Lniversily of Pemsylianin foumal of Intemational Econumic Law', 2002, Vol. 23(1)p. 45-83.

\section{Brush 1996}

Brush, S., "Is Common Heritage Outmoded", in: Brush, S. and Stabinsky, D. (Eds.), Valuing Local Knowledge'-Indigenous People and IPRs, Washington DC: Island Press, 1996.

\section{Van Caenegem 2002}

Van Caenegem, W., "The Public Domain: Scientia Nullius?", European Intellectual Property Recicis, Vol. 24(6), 2002, p. 324-330. 


\section{Van Caenegem 2003a}

Van Caenegem, W., "Registered Geographical Indications - Between Intellectual Property and Rural l'olicy - I'art l", The fournal of World latellectual Property, Vol. 6(5), 20013, p. $699-719$

\section{Van Caenegem 2003b}

Van Calenegem, W., "Registered Geographical Indications - Between Intellectual Property and Rural Policy - Part II", The foumal of World hitellethal Property, Vol. 6(6), 2003, p. $861-874$.

\section{Cameron and Makuch 1995}

Cameron, J. and Makuch, Z., The LN bivdiversity Conzention and the WTO TRIPS Agrement: Recommendations to movid Conflict and promote Sustainable Development, Gland, Switzerland: World Wide Fund for Nature, 1995.

\section{Card and Krueger 1995}

Cord, D. and Krueger, A., Mylh and Mensurement: The New Ecomomics of the Minimum Wige, New Jersey: Princeton University Press, 1995.

\section{Carmody 1998}

Carmody, C., "Customs Tariff S. 59 (2): A “Canadian 301?", Joumal of Internutional Economic Lnu, Vol. 1(4), 1998, p. 690-694.

\section{Chudson 1981}

Chudson, W. The International Trunsfer of Commercial Techology to Developing Countries, NY UNITAR Research Report, No. 13, 1981.

\section{CIEL 2007}

CIEL, The Cap befween Indigenous Peoples' Demands and WIPO'S Framework on Traditional Knoriledge, Paper Center for International Environmental Law (CIEL), autumn 2007. Published online at: <http://www.ciel.org/Publications/WIPO_Gap_Sept07. pdt>.

\section{Claessens 2008a}

Claessens, F., Gl Rules: Potential and implicutions for African Countries, TNI ICTSD, Vol. 7 , No. 2, March 2008. Published online at: <http://ictsd.net/downloads/tni/tni_en_72.pdif $>$.

\section{Claessens 2008b}

Claessens, F., "The Disclosure of Origin Requirement: Europe Moving Towards ProCBD Implementation", in Etty, T.M.F. and Somsen, H. (Eds.), The Yearbook of Europem Enirommental Lni", Vol. 8, Oxford: Oxford University Press, 2008, p. 265-293.

\section{Claessens 2008c}

Claessens, F., "Negotiations on Disclosure of Origin Requirement under Scrutiny", BioRe's (Juarterly, ICTSD, Vol. 2(3), October 2008. Published online at: <http://ictsd.net/ i/emironment $/ 31514 />$.

\section{Cleveland and Murray 1997}

Cleveland, D. and Murray, S., "The World's Crop Genctic Resources and The Rights of Indigenous Farmers", Cirrent Anthropology Volnme, Vol. 38(4), August-October 1997.

\section{Coe, Helpman and Hoffmaister 1997}

Coe, D., Helpman, E. and Hoffmaister, A., "North-South R\&D Spillovers", Economic Joumal, Vol. 107, 1997, p. 134-149. 


\section{Commission on Intellectual P'roperty Rights 2002}

Commission on Intellectual Property Rights (UK CIPR Report), Integrating Intellectual Properly Rights and Detelopment Policy, London, September 2002. Published online at: <http://www.iprommission.org/graphic/documents/final_report.htm>.

\section{Conrad 1996}

Conrad, A., "The Protection of Geographical Indications in the TRIISS Agreenent", The" Tratematk Reporter, Vol. 36, 1996, p. 11-46.

\section{Coombe 2001}

Coombe, R, "The Recognition of Indigenous Peoples' and Community Traditional Knowledge in International Law", St. Thomas Law Revere, Vol. 14, 2001, p. 275-285.

\section{Correa 1991}

Correa, C., "The Pharmaceutical Industry and Biotechnology": Opportunities and Constraints for Developing Countries", World Competition, Vol. 15(2), December 1991, p. 43-6.3.

\section{Correa 1994}

Correa, C., "The GATT' Agreement on Trade-Related Aspects of Intellectual Property Rights: New Standards for patent protection", European lutellectual Property Reriewe, Vol. $16(8), 1994$, p. 327-335.

\section{Correa 1999}

Correa, C., "Review of the TRIPS Agreenent: Fostering the Transfer of Technology to Developing Countries", Third Worht Netoork, 1999. Published online at: <http://twn side.org.sg/title/foster.htm>.

\section{Correa 2001}

Correa, C., "Traditional Knowiedge and Intellectual Property - Issues and options surrounding the protection of traditional knowledge", QUNO, 2001. Published online at: <http://www quno.org/geneva/pdf/economic/Discussion/Traditional-Knowled ge-l P-English.pdf $>$.

\section{Correa 2004}

Correa, C., "Bilateral Investment Agreements: Agents of New Global Standards for the Protection of Intellectual Property Rights?", GRAIN, 2004. Published online at: <http:// www.grain.orgl.

\section{Correa 2007}

Correa, C., Intellectual Property and Competition Late: Exploring Some Issmes of Releanec to De'eloping Conntries, Programme on lPRs and Sustainable Development, Issue Paper No. 21, Geneva: ICTSD, October 2007.

\section{Corte-Real 2005}

Corte-Real, A., "The Conflict Between Trade Marks and Geographical Indications", in: Heath, C. and Kamperman Sanders, A. (Eds.). Nere Frontiers of Intellectual Property, Oxford, Portland: art Publishing, 2005, p. 149-157.

\section{Cortés Martin 2004}

Cortes Martin, J., "The WTO TRIISS Agreement - The Battle between the Old and the New World over the protection of Geographical Indications", The foumal of World Intellectual Property, Vol. 7, 2004, p. 287-327. 


\section{Crespi and Straus 1996}

Crespi, S. and Straus, J., Intellectwal Property, Tedmology Transfer and Genctic Resonreses an OECD stuly of Current Pratices and Policie's, Paris: OECD, 1996.

\section{Crispolti and Marconi 2005}

Crispolti, V. and Marconi, D., "Technology Transfer and Economic Growth in Developing Countries: an Econometric Analysis", Banca D'ffalia, Temi di Discussone del Servizio Studi, No. 564, November 2005.

\section{Croome 1999}

Croome, J., Re'shuning the World Truding System - a History of the Lruguay, Roumd, Geneva: World Trade Organization, $2^{\text {ind }}$ edition (14 edition 1995), 1999.

\section{Curry 2006}

Cumy, O., "Human Speciess May Split in Two", BBC Nezes, 24 October 2006. Published online at: <http://newsvote.bbc.co.tuks.

\section{Danino Zapato 2006}

Danino Zapato, R., Why Trenties Matter. Speech held at the occasion of the First Annual Conference "Interpretation under the Viemna Convention on the Law of Treaties - 25 Years On", London, 17 January 2006.

Das 2007

Das, K., Protection of Geogrophical Indications - An Overoien of Select lssues anth Particular Refereme' to Imdin, Working Paper No. 8, New Delhi: CENTAD, May 2007.

\section{Davenport 1979}

Davenport, N., The Lnitel Kingitom Patent System: A Brief History, Portsmouth: Kenneth Mason, 1979.

\section{David 2000}

David, P., A Tragedy of the Public Knowledge Commons?, Global Science, Intellectual Property and the Digital Tedmology Boomerang, SIEPR Discussion Paper, No. 00-(2), Stanford Institute for Economic Policy Research, September 2000.

\section{Della Vedova 2008}

Della Vedova, B., "Patents are the Wrong Target", Internutional Herald Tribune, 27 May" 2008. Published online at: <http:/ www.iht.com/articles/2008/05/27/opinion/edved ova.php>.

\section{Dixon 1996}

Dixon, A. and Hansen, M., "The Berne Convention Enters the Digital Age", European Intellectual Property Rericio, Vol. 18(11), 1996, p. 604-612.

\section{Dove 1998}

Dove, A., "Botanical Gardens Cope With Bio-prospecting Loophole", Science, Vol. 281, 28 August 1998, p. 1273.

\section{Drahos 2000}

Drahos, P., "Indigenous knowledge, Intellectual Property and Bio Piracy: is a Global Bio-Collecting Society the Answer?", Europen Intellectwal Property Review, Vol. 22(6), 2000, p. 245-250. 


\section{Drahos 2002}

Drahos, P'., Devetoping Countries and Intermational Intellectual Property Standard-Setfing', Commission on Intellectual Property Rights, Study Paper No. 8, 2002. Published online at: <http://www.ipreommission.org/papers/pdfs/study'_papers/sp8_drahos_study. pdf>.

\section{Drahos and Braithwaite 2002}

Drahos, l'. and Bratthwaite, J., Information Fetulalism: Who (Oens the Knowledge Economy?, London: Earthscan Publishers, 2002.

\section{Dutfield 1999}

Dutfield, G., "Rights, Resources and Responses", in: Posey, D., (Ed.), Cullural and Spiritual Values of Riodiversity, London: Intermediate Technology Publications in association with UNIEP, 1999.

\section{Dutfield 2000a}

Dutfield, G., Intellectuml Property Rights, Trade and Biodicersily - Sects and Plant Varieties, L.onden: Earthscan Publishers, 2000 .

\section{Dutfield 2000b}

Dutfickd, G., Developing ant Implementing National Systems for Protecting Tratitional

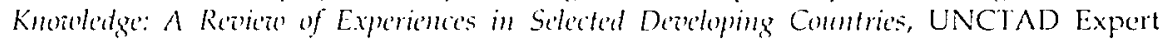
Meeting, Cineva, 30 October- 1 November 2000.

\section{Dutfield 2000c}

Dutfield, G., "The Public and Private Domains. Intellectual Property. Rights in Traditional Knowledge", Science Conmmunication, Vol. 21(3), 2000, p. 274-295.

\section{Dutfield 2003}

Dutfield, G., Protecting Troditional Kuowledge and Folklore - A review progers in diplomacy ant policy formulation', Isste Paper No. 1, ICTSD-UNCTAD Project on IPRs and Sustainable Development, Geneva: ICTSD, 2003. Published online at: <http:// ictsd.net/down loads/2008/06/es_dutfield.pdf>.

\section{Dutfield 2004}

Dutfield, G., Intellectual Property, Biogenetic Resources and Tratitional Knotuledge, London: Earthscan Publishers, 2004.

\section{Dutfield 2005}

Dutficld, G., Thinking Alowd on Disdosure of Origin, Occasional Paper No. 18, Geneva: QUNO, October 2005. Published online at: <http://www.jprsonlinc.org/unctadictsd/ docs/Disclosure__Dutfield.pdf>.

\section{Dutfield 2006}

Dutficld, G., Protecting Traditional Knowleder: Pathways to the Futwe, Programme on IPRs and Sustainable Development, Issue Paper No. 16, Geneva: ICTSD, June 2006.

\section{Elkin-Koren and Netanel 2002}

Elkin-Koren, N. and Netanel, N. (Eds.), The Commodification of Information: Political, Secial, and Cultural Ramificutions, The Hague: Kluwer Law Intemational, 2002.

\section{Eaton and Kortum 2002}

Eaton, J. and Kortum, S., "Technology, Geography, and Trade", Ecomometrica, 2002, No. 70, p. $1741-1779$. 


\section{Endeshaw 2006}

Endeshaw, A., "Free Trade Agreements as Surrogates for TRIPS-Plus", Europeran Intellectual Property Reouciu, Vol. 28(7), 2006, p. 374-380.

\section{EPO 2007}

European Patent Office, Schario's for the Future: How might IP regimes erolve by 2025? What globul legitimucy might such regimes have?', European Patent Organisation, 2007.

\section{Erbert 2008}

Erbert M., "See C8 Governments Want ACTA Finalised This Year, SPLT Talks Accelerated", II Watch. Published online at: <http://www.ip-watch.org/weblog/in dex.php?p=1136>.

\section{Escudero 2001}

Escudero, S., Intermational Protection of Geographical Indications and Deieloping Commeres, T.R.A.D.E. Working Papers, No. 10, Geneva: South Centre, July 2001.

\section{EU focus 2005}

EU focus, WTO Pand Upholts EU System of Protection of "Geogriphical Intications", Brussels, 15 March 2005. Published online at: <http://www.mac-ssiim.com/Docs/200 506/IP-05-298_EN.pdif>.

\section{Evans 1996}

Evans, C., "The Principle of National Treatment and the International Protection of Industrial Property", Europem Intellectual Property Reilew, Vol. 18(3), 1996, p. 149-160.

\section{Falvey and Foster 2006}

Falvey, R. and Foster, N., The Role of Intellectual Properfy Rights in Techology Transfer and Economic Growth: Theory and Evitence', Working Papers Strategic Research and Economics Branch, UNIDO, 2006.

\section{Farnsworth 1988}

Farnsworth, N., "Screening Plants for New Medicines", in: Wilson, E and Peter, F. (Eds.), Biodicersily, Washington DC: National Academy Press, 1988.

\section{Ficsor 1997}

Ficsor, M., Attempts to Provide Intermational Protection for Folklore by Intellectual Property Rights, UNESCO-WIPO World Forum on the Protection of Folklore, April 1997.

\section{Fink and Maskus 2005}

Fink, C. and Maskus, K. (Eds.), Intellectual Property ant Development - Le'sons from Recent Economic Re'search, Washington DC, Oxford: World Bank, Oxford University Press, 2005.

\section{Fink and Primo Braga 1999}

Fink, C. and Primo Braga, C., How Stronger Protection of Intellectual Property Rights Affects International Trak Flezis, World Bank Working Paper, No. 2051, 1999.

\section{Flynn 2008}

Flynn, L., "Apple to Encourage iPhone Programmers", The NY Times, 7 March 2008.

\section{Foray 2009}

Foray, D., "Technology Transfer in the TRIPS Age", in Roffe, P., (Ed.), Develepment Agendas: Diverse View's on Intellectual Property, Geneva: ICTSD, forthcoming, 2009. 


\section{Frankel 1995}

Frankel, T., "Knowledge Transfer: Suggestions for Developing Countries on the Receiving End", Bostom linioersity lntomatiomal Law fommal, Vol. 13, spring 1995, p. 141-162.

\section{Friedman 2005}

Friedman, T., The World is Fht - A Brief Hisfory of the Tuenty-First Century, New York: Farrar, Straus and Ciroux, 2005.

\section{Freeman and Hagedoorn 1994}

Freeman, C. and Hagedoom, J., "Catching up or falling behind: Pattems in international interfirm lechnology partnering", World Deatomment, Vol. 22(5), 1994, p. $771-780$.

\section{Gadbaw 1989}

Gadbaw, "Intellectual Property and International Trade: Merger or Marriage of Convenience?", Vanderbilt. Journal Tramsmational Law, Vol. 22(2), 1989, p. 223-240.

\section{Gadbaw and Richards 1988}

Gadbaw, M. and Richards, T., Intellectual Property Rights: Globul Comscmsus, Global Conflict, Boulder and London: Westriew Press, 1988.

\section{GATT Analytical Index 1995}

GATT Analytical Index, Guide to GATT hae and Practise, (2 Vols.), Geneva: WTO, 1995.

\section{GEF 2000}

Global Environment Facility, Ten Case's of Tedmolog! Transfer, June 2000, Published online at: <http:/ www.chd.int/doc/case-studies/ttc/tttc-00015-en.pdf.>

\section{Gerhardsen 2007}

Gerhardsen, T., WIPO Committee Extends, Adjusts Mandate on Tratitional Knordetge, Folklore, Intellectual Property Watch, 2007. Published online at: <http://www.ip-watch. org/weblog/index.php?p=690>.

\section{Gervais 1999}

Gervais, D., "The TRIPS Agreement Interpretation and Implementation", Europern Intcllectual Property Recical, Vol. 21(3), 1999, p. 156-162.

\section{Gervais 2003/2008}

Gervais, D., The TRIPS Agrement: Drafting History and Analysis, Siect and Maxibell (2nd and $3^{\text {rit }}$ edition), London: Thomson Reuters (Legal) Limited, resp. 2003 and 2008.

\section{Geuze 2007}

Geuze, M., Let's have another look at the Lisbon Agreenent: Its Terms in their Context and in the Light of its Object and Purpose, Document prepared for the International Symposium on Geographical Indications, WIPO and the State Administration for Industry and Commerce (SAIC) of the People's Republic of China, Beijing, 26-28 June 2007. Published online at: <http://www.wipo.int/edocs/mdocs/geoind/en/wipo_geo_bei_07/wipo_ geo_bei_07_www_81756.doc>.

\section{Gevers 1990}

Gevers, F., "Geographical Names and Signs used as Trade Marks", Europerm lntellectual Property Rericu, Vol. 12(8), 1990, p. 285-291. 


\section{Gibson 2004}

Gibson, J., "Intellectual Property Systems, Traditional Knowledge and the Legal Authority of Community", European intellectual Property Reoiew, Vol. 26(7), 2004, p. 280290.

\section{Girvan 2005}

Girvan, N., Lessoms from the Struggle for a Neze Intermational Tedmology Orter, Second Annual Surendra Patel Lecture on Development', South Perspectives, South Centre, 4 November 2005.

\section{Goldstein 2001}

Goldstein, P., Intemational Intellectual Property Lane: Cases and Materials, New York: Foundation l'ress, 2007.

\section{Gollin 1993}

Gollin, M., "An Intellectual Property Rights Framework for Biodiversity Prospecting", in: Reid, W., Laird, S., Meyer, C., Gamez, R., Sittenfeld, A., Janzen, D., Gollin, M. and Juma, C. (Eds.), Biodiaersity Prospecting: Uling Genetic Resources for Sustainable Denelopment, Washington DC: WRI, 1993.

\section{Goodenough 2002}

Goodenough, O., "The future of Intellectual Property, Broadening the Sense of Ought", European Intellectual Property Re'ieio', Vol. 24(6), 2002, p. $291-293$.

\section{Gopalakrishnan, Nair and Babu 2007}

Gopalakrishnan, N., Nair, P. and Babu, A., Exploring the Relationship betaeen Geogrtuhical Indicitions am Tratitional Knowledge: An Analysis of the Legal Tools for the Protection of GIs in Asin', Geneva: ICTSD, 2007. Published online at: <http://wwwiprsonline.org/ictsd/ docs/Gopalctal\%20-\%20GIs\&TK.pdf>.

\section{Gosh and Soete 2006}

Gosh, R. and Soete, L., Information and Intellectual Property, Working Paper UNU-MERIT, No. 29, 2006.

\section{GRAIN 2004}

GRAIN, The Grout Protection raket: Imposing IPRs on tratitional knowletge, 2004. Published online at: <www.grain.org/seedling/seed-04-01-3-en.cfm>.

\section{GRAIN 2005}

GRAIN, The FAO Sed Treaty: From Fumers' Rights to Breders' Privileges, October 2005. Published online at: <http://www.grain.org/ seedling/?id=411>.

\section{Gray 2005}

Gray, E., "Maori Culture and Trade Mark Law in New Zealand", in: Heath, C. and Kamperman Sanders, A. (Eds.), New Frontiers of Intellectual Property, Oxford, Portland: art Publishing, 2005, p. 71-96.

\section{Gray 1993}

Gray, W., "The Challenge of Asian Law", Fortham Intemational Law Joumal, Vol. 19, 1993. Published online at: <http://caselaw.lp.findlaw.com/data/law_reviews/015ford ham_inter_lj/whitgray.htm>. 


\section{Greaves 1994}

Greaves, T. (Ed.), Intellectual Proporty Rights for Indigenous Peoples. A Sourcebook, Oklahoma City, ()K: Society for Applied Anthropology, 1994.

\section{Green College Centre for Environmental Policy and Understanding 1993}

Green College Centre for Envitommental Policy and Understanding, litellectual Preperty Rights, Indigenous Cultures and Biodiarersiby Comserantion', Oxford, 14 May 1993.

\section{Greene 2004}

Greene, S., "Indigenous People Incorporated?", Current Anthropology, Vol. 45(2), April 2004, p. $211-237$.

\section{Grosse Ruse-Khan 2008}

Grosse Ruse-Khan, H., Suspending IP Obligations under TRIPS: A Viable Alternation to Enforce 'reiniling WTO Rulings?', Geneva: CIEL, April 2008.

\section{Grossman and Helpman 1991}

Grossman, G. and Helpman, E., Imoretion and Growth in the Giobal Economy, Cambridge, MA: The MIT Press, 1991.

\section{Grossman and Lai 2002}

Grossman, G. and Lai, E., Intemational Protection of lutellectual Property, NBER Working Paper No, 87()4, $20(02$.

\section{Haight Farley 2000}

Haight Farley, C., "Conflicts Between U.S. Law and International Treaties Concerning Geographical Indications", Whittice Lne Review", Vol. 22(1), 2000, p. 73-88.

\section{Hamilton 1997}

Hamilton, M., "The Trips Agreement: Imperialistic, Outdated, and Overprotective", in Moore, A. (Ed.), Intellectual Properly - Moral, Lecyal and International Dilemma's, Columbus, Ott: Ohio State University Press, 1997, p. 243-264.

\section{Hamilton and Quinlan 2008}

Hamilton, D.S. and Quinlan, J.P., Centre for Transatlantic Relations as referenced in the "Winners and Losers", The Economist, 28 February 2008. Published online at: <http:// www.economist.com/world/europe/['rinterFriendly.cfm?story'_id=10765186>.

\section{Harrison, Rutherford and Tarr 2000}

Harrison, G., Rutherford, T. and Tarr, D., "Quantifying the Uruguay Round", in: Singer, H., Hatti, N. and Tandon, R. (Eds.), TRIPS, The Lruguay Roumi and Third World Interests, (2 Vols.), Delhi: Vedamsbooks, 2000, p. 1022-1062.

\section{Heald 2003}

Heald, P., "The Rhetoric of Biopiracy", Cartozo foumal of International mat Comparation' Lawe, Vol. XI (part 2), 2003, p. 519-546.

\section{Higino Schneider 2005}

Higino Schneider, P., "Intermational Trade, Economic Growth and Intellectual Property Rights: A Panel Data Study of Developed and Developing Countries", Journal of Deiclopment Economics, Vol. 78(2),p. 529-547, 2005. Published online at: <ttp://www: tholyoke.du/ pschneid/images/Schneider_JDEJuly2004.pdf>. 


\section{Hoare 2006}

Hoare, A., Disclosure Reipurements in Patent Applications: the State of the Art of National and Regional Mensures, Background Paper for the Chatham House Workshop "Disclosure Requirements in Patent Applications - Options and Perspectives of Users and Providers of Genetic Resources", London, 9-10 February 2006. Published online at: <http://www. chathamhouse.org.uk.>.

\section{Hoare and Tarasofsky 2006}

Hoare, A. and Tarasofsky, R., Disclosure of Origin in IPR Applications: Options and Perspecives of Leres and Proiders of Genetic Resources, Chatham House, Final Report, May 2006. Published online at: <http://www.jprsonline.org/resources/docs/Hoare $\% 20 \%$ 20Disclosure\%200 \%20origin.pdf $\%$.

\section{Hoekman, Maskus and Saggi 2005}

Hoekman, B., Maskus, K. and Saggi, K., "Transfer of Technology to Developing Countries: Unilateral and Multilateral Policy Options", World Dezelopment, Vol, 33(10), p. 1587-1602, 2005. Published online at: <http://www-wds.worldbank.org/servlet/ WISCContentServer/WDSP/IB/2004/07/29/000160016_20040729155005/Rendered/P

DF/ wps3332.pdf >.

\section{Hope 2006}

Hope, J., Open Sontre Biotedmology: Why amd How?, Draft Paper presented at Fordham IP Conference, New York, April 2006.

\section{Höpperger 2003}

Höpperger, M., Introduction to Geugraphical Indications and Recent Deaslopments in the WIPO, World Wide Symposium on Geographical Indications, WIPO/GEO/SFO/03/1, 12 June 2003.

\section{Hubicki and Sherman 2005}

Hubicki, S. and Sherman, B., "Terminator Genes as 'echnical' Protection Measures for Patents?", in: Heath, C. and Kamperman Sanders, A. (Eds.), Nene Frontier's of litellectual Property, Oxford, Portland: Hart Publishing, 2005.

\section{Hugenholtz and Okediji 2008}

Hugenholtz, B. and Okediji, R., Conceiving an International Instrument on Limitations and Exceptions to Copyright, 6 March 2008. Published online at: <http://www.ivir.nl/publica ties/hugenholtz/finalreport2008.pdf $>$.

\section{Hughes 2006}

Hughes, J., The Spirited Debate ooer Geographic Intications, Paper presented at the $11^{\text {th }}$ Annual Conference on International Intellectual Property Law \& Policy, New York: Fordham University School of Law, 24-25 April 2006.

\section{Institute for Biodiversity 2004}

Institute for Biodiversity (IBN), "Technology Transfer through the Clearing-House Mechanism. An excerpt of a - Study from Germany", Study funded by the German Federal Agency for Nature Conservation (BFN) on behalf of the German Ministry for the Environment, Nature Conservation and Nuclear Safety (BMU), 2004. Published online at: <http://www.cbd.int/doc/casc-studies/tttc/tttc-00038-en.pdf>. 


\section{Intellectual Property Watch 2006a}

Intellectual Property Watch, "Reactions Strong But Mixed to WHO Report on IP and Medicines Access", 4 April 2006. Published on the internet at: <http://www.ip-watch. orgs.

\section{Intellectual Property Watch 2006b}

Intellectual Property Watch, "Biggest Developing Countries Present TRIIS Amendment Proposal", 7 June 2006. Published on the internet at: <http://www.ip-watch.org/web $\log /$ index php? $p=326>$.

\section{Intellectual Property Watch 2007}

Intellectual Property Watch, "WIPO Committee Extends, Adjusts Mandate on Traditional Knowledge, Folklore", 2007. Published on the internet at: <http://ip-watch.org $>$.

\section{IUCN 1997}

IUCN, Indigenous Peoples and Sustumability - Cases and Actions, IUCN Inter-Commission Task Force on Indigenous Peoples, IUCN Indigenous Peoples and Conservation Initiative, International Books, 1997.

\section{QQsensato}

IQsensato, WIPO Derelopment Agenta Implementation, Commentary on the Preliminary Implenentation. Report in Respect of 19 Proposals, Ideas in Development (no year provided). Published on the internet at: $\langle$ http://www.iqsensato.org $>$.

\section{IQsensato}

IQsensato, WIPO Deidopment Agende implementation. Commentary on the Initinl Working Document for the Implententution of Agred Proposals, liters in Derdopment (no year provided). Published on the internet at: $<$ http://www.iqsensato.org>.

\section{Jaffe and Lerner 2004}

Jaffe, A. and Lerner, J., Imoration and Its Discontents: How our broken Patent System is Endangering Imosition and Progerss, and What to Do About It, Princeton, NJ: Princeton University Press, 2004.

\section{Javorcik Smarzynska 2004}

Javorcik Smarzynska, B., "The Composition of Foreign Direct Investment and Protection of Intellectual Property Rights: Evidence from Transition Economies", Europran Economic Reiviow, Vol. 48(1), 2004, p. 39-62.

\section{Jeffery 2005}

Jeffery, M., "Intellectual property rights and biodiversity conservation: reconciling the incompatibilities of the TRIPS Agreement and the Convention on Biological Diversity", in Ong. B. (Ed.), Intellectual Property And Biological Resources: Perspecties On Contempormy Issute, Singapore: Marshall Cavendish Academic, 2005.

\section{Kameri-Mbote and Otieno-Odek 2009}

Kameri-Mbote, P. and Otieno-Odek, J., "The Genetic Use Restriction Technologies, Intellectual Property Rights and Sustainable Development in Eastern and Southern Africa", in: Roffe, P. (Ed.), Deidopment Agendas: Diverse Vieres on litellectual Property, ICTSD, forthooming, 2009.

\section{Kanagavel 2003}

Kanagavel, P., "Intellectual Property Rights: A Comprehensive Overview", Joumal of the Patent and Tratemark Office Society, Vol. 85, August 2003, p. 663-678. 


\section{Kanwar and Evenson 2001}

Kanwar, S. and Evenson, R., Does Intellectual Property Protection Spur Tedmological Chamge?', Center Discussion Paper No. 831, Yale University, Economic Growth Center, Jume 2001. Published online at: <http://www.econ.yale.edu/-egcenter/research.htm> and <http://papers.ssin.com/ paper.taf?abstract_id=275.322>.

\section{Kamperman Sanders 2007a}

Kamperman Sanders, A., "Intellectual Property, Free Trade Agrecments and Economic Development", Georyin State Liniversity Revieze, Vol. 23(4), Paper 36, summer 2007. Published online at: <http://digitalarchive.gsu.edu/colpub_review/336>.

\section{Kamperman Sanders 2007b}

Kamperman Sanders, Europeran Humm Rights Case's, Issue 4, Noot 11 April 2007.

\section{Kamperman Sanders 2008}

Kamperman Sanders, Europenn Homm Rights Case's, lssue 1, Noot 16 January 2008.

\section{Ten Kate and Laird 1999}

Ten Kate, K. and Laird, S., The Commercinl Use Of Biodinersity - Access To Genetic Resumre's Ami Be'nefit-Shring, London: Earthscan, 1999.

\section{Kaufman 2006}

Kaufman, M., "States Get a Big Dose of Drug makers' Cash", The Washington Post, 6 April 2006.

\section{Khor 2002}

Khor, M., Intellectual Property, Biodiversity and Sustumable Development - Resoleing the Difficult lssu's, London: Zed Books in association with TWN, 2002.

\section{Kokko, Zejan and Tansini 2001}

Kokko, A., Zejan, M. and Tansini, R., "Trade regimes and spillover effects of FDI: Evidence from Uruguay", Reviere of World Economics (Weltwirtschaftliches Archiv), Springer, Vol. 137(1), 2001, p. 12-149.

\section{Kostecki 2006}

Kostecki, M., Intellectual Property and Economic Development: What Tedmical Assistance to Redress the Balance in Fatour of Developing Nations?, Issue Paper No. 12, ICTSD Programme on IPRs and Sustainable Development, Geneva: ICTSD, 2006. Published online at: <http:/ / www.jprsonline.org/unctadictsd/docs/Kostecki\%20\%20Final.pdf>.

\section{Koury Menescal 2005}

Koury Menescal, A., "Those behind the TRIPS Agreement: The Influence of the ICC and the AIPPI on International Intellectual Property Decisions", Intellectunl Property (unarterly, No. 2, 2005, p. 155-182.

\section{Kunz-Hallstein 1975}

Kunz-Hallstein, H., "Patent Protection, Transfer of Technology and Developing Countries: A Survey of the Present Situation", Intermationnl Reviea of Intellectual Property and Competition Lno (IKC), Vol. 6(4), 1975, p. 427-455.

\section{Ladas 1975}

Ladas, S., Patents, Trademaks, and Rehated Rights: National and Intermational Protection, Vol. 1, Harvard: Harvard University Press, 1975. 
Laird 2002

Laird, S. (Ed.), Bindiersity and Trutitional Kunaledge: Equitable Partmerships in Practice, London Earthscan, 2002.

\section{Laird and Noejovich 2002}

Laird, S. and Nocjovich, F., "Building Fquitable Research Relationships with Indigenous Peoples and local Communities: Prior Informed Consent and Research Agreements", in: Laird, S. (Fd.), Biodiersity and Traditional Knowletge: Equitable lartnersibs in Practice, London: Earthscan, 20012.

\section{Lall and Allbaladejo 2003}

Lall, S. and Allbaladejo, M., Inticators of the Relntie Importance of IPRs in Dealoping Countrit's, Issue Paper No. 3, UNCTAD-ICTSD Project on IPRs and Sustainable Development, Geneva: ICISD, 2013. Published online at: <http://www.iprsonlineorg/resour

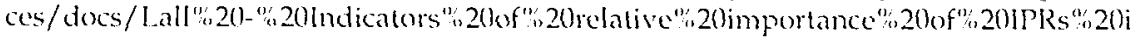
n"\%20DC \%20-\%20Blue \%203.pdf $>$.

\section{Larrain, Lopez-Calva and Rodriguez-Clare 2000}

Larrain B.F, Lopez-Calva, L. and Rodrigues-Clare, A., Intel: A Case Study of Foreign Direct hin'stme'nt in Centrol America, Center for International Development at Harvard University (CID), Working Paper No. 58, December 2000. Published online at: <http:// www.cidharvard.cdu/cidwp/pdf/058.pdfs.

\section{Lee and Mansfield 1996}

Lee, ]. and Mansficld, E., "Intellectual Property Protection and U.S. Foreign Direct Investment", The Rerica of Ecomumics and Statistics, Vol. 78, 1996, p. 181-186.

\section{Leesti and Pengelly 2001}

Leesti, M. and Pengelly, T., Institutional lssues for Developing Countries in Intellectual Property Policymaking, Administration E Enforcement, Study Paper No. 9. Commission on Intellectual Property Rights, 2001.

\section{Lettington 1999}

Lettington, R., The Biodiversity Conention and TRIPS, ICTSD, Regional Trade and Environmental Seminar for Govemments and Civil Society, Harare, Zimbabwe, 10-12 February 1999.

\section{Lightbourne 2003}

Lightboume, M., "Of Rice and Men - An attempt to Assess the Basmati Affair", The Journal of World Intelle'tual Property Law, Vol. 6(6), 2003, p. 875-894.

\section{Linsu 2003}

Linsu, K., Tidmology Transfer E Intellectual Property Rights - The Korean Experience, Issue Paper No. 2, UNCTAD-ICTSD Programme on IPRs and Sustainable Development, Geneva: ICTSD, 2003.

\section{Liu 2003}

Liu, Y., "IPR Protection for New Traditional Knowledge: with a Case Study of Tradiional Chinese Medicine", European Intellecturl Property Reilew, Vol. 25(4), 2003, p. 194 199.

\section{Louafi and Tobin 2005}

Louafi, S. and Tobin, B., User Measures as a Means of Resoling Potential Conflicts betaeen WTO and CRD, WTO Public Symposium, Geneva, 21 April 2005. 


\section{Love 2005}

Love, J., "Preparing for Bird Flu? US waived Right to Import Generic Medicines in Cases of Medical Emergency", Huffington Post, 19 October 2005. Published online at: <http:/ www.huffingtonpost.coms.

\section{Love and Hubbard 2007}

Love, J. and Hubbard, T., The Big lien: Prizes to Stimulate RED for New Medicines, KEI Research Paper, 2007. Published online at: <http://www keionline.org/>.

\section{Luthria 2002}

Luthria, M, "Protecting Intellectual Property: Why, How Much, How?", in: Nabi, I and Luthria, M. (Eds), Building Competitier Firms - Incentie's and Copabilitie's, Washington DC: The World Bank, 2002, chapter 9.

\section{Mansfield 1994}

Mansfield, E., Intellectual Properiy Protection, Forcign Direct mestment, and Tedmology Transfer, Discussion Paper No. 19, International Finance Corporation, 1994.

\section{Mansfield 1995}

Mansfield, E., Intellectual Property Protection, Direct Inoestment, and Technology Transfer Germuny, Japan, and the United States, Discussion Paper No. 27, International Finance Corporation, 1995.

\section{Mansfield and Romeo 1980}

Mansfield, E. and Romeo, A., "Technology Transfer to Overseas Subsidiaries by U.S. based Firms", Quarferly fournal of Economics, Vol. 95, 1980, p. 737-749.

\section{Maskus 2000}

Maskus, K., Intellectual Property Rights in the Globil Economy, Washington DC: Institute for Intermational Economics, 2000.

\section{Maskus 2003}

Maskus, K., Trmefer of Techology and Technological Copacity Building, ICTSD-UNCTAD Dialogue, 2nd Bellagio Series on Development and Intellectual Property, Bellagio-Italy, 18-21 September, 2003. Published online at: <http://www.iprsonline.org/unctadictsd/ bellagio/docs/Maskus_Bellagio2.pdf>.

\section{Maskus 2004}

Maskus, K., Encouraging Intermational Tedmology Trmsfer, Issue Paper No. 7, IP UNCTAD-ICTSD Project on IPRs and Sustainable Development, Geneva: ICTSD, 2004. Published online at: <http://www.iprsonline.org/unctadictsd/docs/CS_Maskus.pdf>.

\section{Maskus 2005}

Maskus, K., "The Role of Intellectual Property Rights in Encouraging Foreign Direct Investment and Technology Transfer", in: Fink, C. and Maskus (Eds.), Intellectual Property and Development - Lessons from Recont Economic Research, Washington DC, Oxford: World Bank, Oxford University Press, 2005, p. 41-73.

\section{Maskus and Penubarti 1995}

Maskus, K. and Penubarti, M., "How Trade Related are Intellectual Property Rights?", Jourmal of International Economics, Vol. 39, 1995, p. 227-248. 
Maskus and Reichman 2004a

Maskus, K. and Reichman, J., "Mini-Symposium: International Public Goods and the Transfer of Technology Under a Globalized Intellectual Property Regime - Introduction to the Symposium", foumal of Intermationnl Ecomomic Lun, Vol. 7(2), 2004, p. 275-278.

\section{Maskus and Reichman 2004b}

Maskus, K. and Reichman, J., "The Globalization of Private Knowledge Goods and the Privatization of Global Public Goods", Jourmol of Inlernational Economic Lawe, Vol. 7(2), 2004, p. 279-320.

\section{Mathew 2002}

Mathew, L., Yogn, Aymredu being Documented to Stop Patent Misuse, NewKarela.com, 2 October 2002. Published online at: <http://www.hvk.org/articles/1005/44.html>.

\section{Matthews 2002}

Matthews, D., Clobalising Intellectual Properly Rights - The TRIIS Agrement, London: Routledge, 2002.

\section{Matthews 2004}

Matthews, D., "WTO Decision on Implementation of Paragraph 6 of the Doha Declaration on the TRIPS Agreement and Public Health: A Solution to the Access to Essential Medicines Problem?", Joumal of International Economic Late, Vol. 7(1), 2004, p. 73-107.

\section{May 2000}

May, C., A Globul Economy of Intellectual Property Rights: The New Enclesures, London: Routledge, 2000.

\section{May 2003}

May, C., "Why IPRs are a Clobal Political Issue", Opinion Europenn Intellectual Property Revicu, Vol. 25(1), 2003, p. 1-5.

\section{McCalman 2001}

McCalman, P., "Reaping what you Sow: An Empirical Analysis of International Patent Harmonization", Joumal of luterintional Economics, Vol. 55(1), 2001, p. 161-186.

\section{McGown 2006}

McGown, J., Out of Africa: Mysterie's of Access and Benefit Sharing, Edmonds Institute in cooperation with African Centre for Biosafety, 2006.

\section{Mead 1994}

Mead, A., Mismplopriation of Intigenous Knordedge: the Next Wane of Colomisation, Otago Biocthics Report, 3(1), 1994.

\section{Mulvany 1999}

Mulvany, P., TRIPS, Biodiaersity and Commonatenlth Conntrits: Conncity Building Prionities for the 1999 Review of TRIPS Article 27.3(b), Commonwealth Secretariat and Quaker Peace and Service, Rugby and London, 1999.

\section{Musungu and Dutfield 2003}

Musungu, S. and Dutfield, G., Multilateral Agreements and a TRIPS-plus anorld: The WIPO. TRIPS Issue Papers No. 3, QUNO and QIAP, 2003. 


\section{Nair 2000}

Nair, M., "Winning the War against Bio-Colonisation". The Hindu, 17 May 2000. Published online at: <http://www.indiaserver.com/thehindu/2000/05/17/stories/06 17000 a.htm>.

\section{Nelson 1970}

Nelson, P., "Information and Consuner Behaviour", Joumal of Political Economy, Vol. 78, March/April 1970, p. 311-329.

\section{New 2008a}

New, W., "WHO Adopts 'Most Important Document Since Doha' on IP and Public Health", IP' Watch, 29 May 2008 l'ublished online at <http://wwwip-watch.org/web $\log /$ index.php?p=1067>

\section{New 2008b}

New, W., "Global Patent Filings Continue Rise But May Level Off; Smaller Nations Slipping", $\mid l$ 'Wath, 5 August 2008. Published online at: <http://wwwip-watch.org/ weblog/index.php?p=1191>

\section{Nyar 1996}

Nyar, G., TRIPS and Biodiversity: the Therat and Responses, Third World Network, 1996.

\section{$\mathrm{O}^{\prime}$ Connor and Kireeva 2004}

O'Connor, B. and Kireeva, 1., "Overview of the EC Case Law Protecting Geographical Indications: The Slicing of Parma Ham and the Grating of Grana Padano Cheese", Case Comment, European Intelletial Property Reriew, Vol. 26(7), 2004, p. 313-318.

\section{Odle 1979}

Odle, M., "Technology Leasing As the Latest Imperialist Phase: A Case Study of Guyana and Trinidad", Social and Economic Studies, 28, 1 March 1979, p. 189-233.

\section{OECD 1970}

OECD, Graps in Tedmology. Analytical Report, Paris, 1970.

\section{OECD 2000}

OECD, Appellations of Origin and Geographical Indications in OECD Member Countries: Economic ant Le'gal Implications, COM/AGR/APM/TD/WP(2000)15/FINAL, 2000.

\section{Office of Technology Assessment 1984}

Office of Technology Assessment, Commercinl Biotechology: an International Analysis, Washington DC, USA: US Government Printing Office, 1984.

\section{Oliva 2007}

Oliva, M, Geographical Indications: Distinguishing the Uniqueness of BioTrate protucts', Technical Update, Issue 10, February 2007. Published online at: <http://www biotrade. org/BTFP/BTFP-docs/Technical_Updates/Issue10/TU_issue10_web.pdf $>$.

\section{Ostergard 2000}

Ostergard, R., "The Measurement of Intellectual Property Rights Protection", Joumal of International Business Studies, Vol. 31(2), June 2000, p. 349-360.

\section{Otten 1998}

Otten, A., "Implementation of the TRIPS Agreement and Prospects for Its Further Development", Jourmal of hiternational Economic Law", Vol. 1(4), 1998, p. 523-536. 


\section{Van Overwalle 2001}

Van Overwalle, G." "Traditional Medicinal Knowledge, Patents and the Convention on Biological Diversity", Re'uce de Droit Intelleduel L'Ingenie'ur-Conse'il, May', June, July, Nos. 5,6 and 7,2001, p. $161-182$.

\section{Van Overwalle 2002}

Van Overwalle, G., "Belgium Goes Its Own Way on Biodiversity and Patents", Europerm Intellectual Property Rights, Vol. 24(5), 20012, p. 233-236.

\section{Panitchpakdi 2001}

Panitchpakdi, S., "The Role of the WTO in Creating Coordination and Coherence in the Global World Economy", Australinn Economic Rivi'u, 2001, p. 3-13.

\section{Parente and Prescott 1994}

Parente, S. and Prescott, E., "Barriers to Technology Adoption and Development", foumal of Political Economy, Vol. 102(2), 1994, p. 298-321.

\section{Park and Lippoldt 2004}

Park, W. and Lippoldt, D., Intermationnl Licensing and the Strengthening of lntellectural Property Rights in Deweloping Comntries', OECD Trade Policy Working Papers, No. 10, OECD Publishing, 2004.

\section{Park and Lippoldt 2008}

Park, W. and Lippoldt, D., Tedmology Trmsfer and the Ecomomic Implications of the Strengthening of Intellectual Property Rights in Developing Combrie's, OECD Trade Policy Working Paper, No. 62, OECD Publishing, 2008. Published online at: <http://www. olis.oced.org/olis/2007doc.nst/LinkTo/NT00005B06/\$FILE/JT03239222.PDF>.

\section{Patel 1974}

Patel, S., "Technological Dependence in Developing Countries", foumal of Modern Africm Sudies, Vol, 12, 1974, p. 1.

\section{Patel 1996}

Patel, S., "Can the Intellectual Property Rights System Serve the Interests of Indigenous Knowledge?", in: Brush, S. and Stabinsky, P. (Eds.), Valuing locol knowledge Mndigenous People and IPRs, Washington DC: Island Press, 1996.

\section{Patel, Roffe and Yusuf 2001}

Patel, S., Roffe, P'. and Yusuf, A. (Eds.), International Tedmology Transfer - The Origins and Aftermath of the Lnited Nations Negotiations on "Draft Cote of Condituct, The Hague, Boston, London: Kluwer Law International, 2001

\section{Pearce and Puroshothaman 1995}

Pearce, D. and Puroshothaman, S., "The Economic Value of Plant-Based Pharmaceuticals", in: Swanson, T. (Ed.), IPRs and Biotiversity Consercotion - An Interdisciplinary Analysis of the Values of Medicinal Plants, Cambridge: Cambridge University Press, 1995.

\section{Penrose 1951}

Penrose, E., 7he Economics of the International Patent System, Baltimore: John Hopkins University Press, 1951. 


\section{Pietrobelli 2000}

Pietrobelli, C., "Technology Transfer for Developing Countries", in: Schroeer, D. and Elena, M. (Eds.), Technology transfer, London, Aldershot: Ashgate Publishing, 2000, p. 209-34.

\section{Pires de Carvalho 2005}

Pires de Carvalho, N., The TRIPS Regime of Patents, The Hague, Boston, London: Kluwer Law International, 2005

\section{P'osey 1995}

l'osey, D., Indigenous Peoples and Traditional Re'source Rights: a Basis for Equitable Relationships?, Oxford, UK: Green College Centre for Environmental Policy and Understanding, 1995.

\section{Posey and Dutfield 1996}

Posey, D. and Dutficld, G., Beyond lntellectual Property - Toward Traditional Resonere Rights for Indigenous Peoples and Local Communitie's, Ottawa: International Development Research Centre, 1996.

\section{Primo Braga and Fink 1997}

Primo Braga, C. and Fink, C., "The Economic Justification for the Grant of IPRs: Patterns of Convergence and Conflict", in: Abbott, F, and Cerber, D. (Eds.) Public Policy and Global Tedmological Inlegration, Dordrecht: Kluwer Academic Publishers, 1997.

\section{Primo Braga and Fink 1998}

Primo Braga, C. and Fink, C., "Reforming Intellectual Property Rights Regimes: Challenges for Developing Countries", Journal of Ihternational Ecomomic Law, 1998, p. 537-554.

\section{Queen Mary II' Research Institute 2004}

Queen Mary IP Research Institute, Report on the Disclosure of Origin in Patent Appliantions, prepared for the European Commission DG-Trade, October 2004.

\section{Quinn 2001}

Quinn, M., "Protection for Indigenous Knowledge: An international Law Analysis", St. Thomes Lat Rericio', 2001, p. 287-313.

\section{RAFI Communique 1994a}

Rafi Communique, The Bencfits of Biodiversity: 100+ Examples of the Contribution by Indigenous and Rural Communities in the South to Deolopment in the North, Vol. 1(1), March 1994.

\section{RAFI Communique 1994b}

Rafi Communique, Bioprospecting-Biopincy and Indigenous Peoples, November 1994.

\section{RAFI Communique 1994c}

Rafi Communique, Consering Indigenous Knowledge - Integrating Tum Systems of Imonation, an independent study commissioned by the UN Development Programme, 1994.

\section{Rangnekar 2003}

Rangnekar, D., Geographical Indications - A Review of Proposals at the TRIPS Conncil: Extending Article 23 to Products other thm Wines and Spirits, Issue Paper No. 4, ICTSDUNCTAD Project on IPRs and Sustainable Development, ICTSD, Geneva, June 2003. Published online at: <http://www.iprsonline.org/resources/docs/Rangnekar\%20-\%20 Gl\%20-\%,20Blue $\% 204 . p d f>$. 


\section{Ragnekar 2004}

Ragnekar, D., The Socio-Ecomomics of Geographical Indications - A Revica of Empirical Eividence from Europe, Issue Paper No. 8, UNCTAD/ICTSD Project on IIRs and Sustainable Development, 2004.

\section{Ragnekar 2009}

Rangnekar, D., "The International Protection of Geographical Indications", in: Roffe, $P$. (Ed.), Deolopment Agemdas: Dienerse Veas on Intellectual Property, Geneva: ICTSD, forthooming, 2009 .

\section{Raman 2005}

Raman, M., Contrasting Vieres Contimue at WIPO Deselomment Seminar, Third World Network Info Service on WTO and Trade Issues, (May 05/08) 11 May 2005. Published on the internet at: <http://www.twnside.org.sg/title2/twninfo215.htm>.

\section{Rasiah 2003}

Rasiah, R., TRIPS and Capubility Building in Developing Economies, The United Nations University, INIECH, Discussion Paper Series, 2003.

\section{Reddy 1997}

Reddy, P., "New Trends in Globalization of Corporate R\&D and Implications for Innovation Capability in Host Countries: A Survey from India", World Development, Vol. 25(11), November 1997, p. 1821-1837.

\section{Reichman 1998}

Reichman, J., "Securing Compliance with the TRIPS Agreement after US v India", joumal of International Economic Law, 1998, p. 585-601.

\section{Reichman 1999}

Reichman, J., The TRIPS Agreement comes of age: conflict or cooperation with the dereloping commtries? Presentation to the World Trade Forum, University of Berne, 29 August 1999.

\section{Reinbothe and Von Lewinski 2002}

Reinbothe, J. and Von Lewinski, S., "The WIPO Treaties 1996: Ready to Come into Force", Europerm Intellectual Property Reriewe, Vol. 24(4), 2002, p. 199-208.

\section{Reinhardt 2003}

Reinhardt, E., "Intellectual Property Protection and Public Health in the Developing World", Emory Intronational Lai Reive', 17(2), 2003, p. 475-489.

\section{Ribeiro de Almeida 2005}

Ribeiro de Almeida, A., "The TRIPS Agreement, the Bilateral Agreements Concerning Geographical Indications and the Philosophy of the WTO", Europem Intellectual Property Reivicu, Vol. 27(t), 2005, p. 150-153.

\section{Ricupero 1990}

Ricupero, R., Trate and Tedmology: Lssu's at Stake for Developing Combries: Tedmology, Trate Policy and the Lirmguay Round, UNCTAD, UN Publication UN Doc. UNCTAD/ $\operatorname{ITP} / 23,1990$.

\section{Rodriguez Cisneros 2001}

Rodriguez Cisneros, E., The Protection of Geographical Indications in Mexico, WIPO/GEO/ MVD/01/7, 5 October 2001. 


\section{Roffe 2007}

Roffe, P., Intellectual Property, Bilateral Agreements and Sustumable Development: The Chatl'nges of Implementution, Intellectual Property, Bilateral Agreements and Sustainable Development Series, No. 1, Geneva: CIEl, January 2007.

\section{Roffe and Tesfachew 2001}

Roffe, I. and Tesfachew, T., "The Unfinished Agenda", in: Patel, S., Roffe, P. and Yusuf, A. (Eds.), Intermational Tedmology Trmsfer, The Hague, Boston, London: Kluwer Law International, 2001, p. 308-406.

\section{Roffe and Tesfachew 2002}

Roffe, P. and Tesfachew, T., Revisiting the Tedmology Transfer Delate: Lessens for the New WTO Working Croup, Bridges Comment, 2002, Published online at: <http://wwwiprs online.org/ictsd/docs/Roffelesfachew BridgesYear6N2February2002.pdf $>$.

\section{Roldán Ortega 2004}

Roldan Ortega, R., Models for Recognizing Indigenous Land Rights in Latin America, Environment Department Papers No. 99, The World Bank, October 2004.

\section{Rosenthal 1997}

Rosenthal, J., "Integrating Drug Discovery, Biodiversity Conservation, and Economic Development: Early lessons form the International Cooperative Biodiversity Groups", in: Grifo, F. and Rosenthal, J. (Eds.), Biodierersity and Human Health, Washington DC: Island Press, 1997, <Published online at: <http://www.fic.nih.gov/programs/lessons. $h t m \mid>$.

\section{Ruiz 2003}

Ruiz, M., "The Andean Community Regimes on Access to Genetic Resources, Intellectual Property, and the Protection of Indigenous Peoples' Knowledge", in: Bellmann, C., Dutficld, G. and Meléndez-Ortiz, R. (Eds.), Trading in Knowledge: Dewelopment Perspetives on TRIPS, Trate Ant Sustainulility, London: Earthscan Publications, 2003, p. 238245 .

\section{Sachs 2005}

Sachs, J., The End of Porerty - The Ecomomic Policies of Our Time, New York: Penguin Books, 2005.

\section{Saez 2008}

Sacz, C., "Brazil Approval of Embryonic Stem Cell Research Could Boost Patenting", IP Watch, 3 June 2008. Published online at: <http://www. ip-watch.org/weblog/index. $\mathrm{php} ? \mathrm{p}=1079>$.

\section{Sagar 2005}

Sagar, R., "Intellectual Property, Benefit-Sharing and Traditional Knowledge - How Effective is the Indian Biological Diversity Act, 2002?", The Journal of World Intellectual Property Law, Vol. 8(3), 2005, p. 383-400.

\section{Saggi 2000}

Saggi, K., Trade, Forcign Direct Inessment, and International Tedmology Transfer: A Survey, Background paper for the World Bank's "Microfoundations of International Technology" Diffusion" research project, 2000. 


\section{Schaefer 1998}

Schacfer, M., "Section 301 and the World Trade Organization: a Largely Peaceful Coexistence to Date", foumal of International Economic Law, Vol. 1(1), 1998, p. 156-160.

\section{Seiler and Dutfield}

Sciler, A. and Dutfield, G., "Regulating Access and Benefit Sharing", Biotedmology and De'ellopment Monitor. No. 49, March 2002, p. 3-7.

\section{Sell 1998}

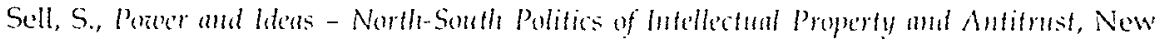
York: State University of New York Press, 1998.

\section{Shapiro 1982}

Shapiro, C., "Consumer Information, Product Quality, and Seller Reputation", Bell Journal of Economics, Vol. 13(1), 1982, p 20-35.

\section{Shapiro and Varian 1999}

Shapiro, C. and Varian, H., Information Rules: A Strategic Guite to the Neterork Economy, Boston MA.: Harvard Business School Press, Boston, 1999.

\section{Sharma 1994}

Sharma, D., GATT and Intia: the Politics of Agriculture, Delhi India: Konark, 1994.

\section{Sideri 1994}

Sideri, S., The Hamonisation of the Protection of Lntellectual Property: Impact on Third World Comntrie's, UNU-INTECH Working Paper, 1994.

\section{Smith 1999}

Smith, P., "Are weak patent rights a barrier to U.S. exports?", Joumal of International Economics, Vol. 48(1), 1999, p. 151-177.

\section{Smith 2001}

Smith, P., "How do foreign patent rights affect U.S. exports, affiliate sales, and licenses?", Joumal of International Economics, Vol. 55, 2001, p. 411-439.

\section{South Centre and Centre for International Environmental Law 2004}

South Centre and Centre for International Envirommental Law (CIEL), Integrating Derelopment into WIPO Actirities and Processes: Strategies for the 2004 WIPO Assemblies', Geneva: South Centre Analytical Note, August 2004.

\section{South Centre and Centre for International Environmental Law 2006}

South Centre and Centre for International Envirommental Law (CIEL). Intellectual Property in Europenn Partmership Agreements arith the African, Caribben and Pacific Group of Comintrie's', South Centre, IP Quarterly Update, fourth quarter 2006.

\section{Spence 2008}

Spence, M, Imovntion and Tedinology Transfer: Lessons from the CARIFORUM EPA Experience. CEMAC Regional Dialogue on EPAs, IPRs, Innovation and Sustainable Development ICTSD and ACDIC 28-29 April 2008. Published on the internet at: <http://ictsd.net/downloads/2008/06/spence_paper2.pdf>. 


\section{Standing Committee on the Law of Trademarks, Industrial Designs and Geographical Indications 2001}

Standing Committee on the Law of Trademarks, Industrial Designs and Geographical Indications, Geographical Indications: Historical Backgroumd, Nature of Rights, Existing Syste'ms for Prolection and Obtaming Protection in other Conntries', Document prepared by the Secretariat, Sixth Session, Geneva, 12-16 March 2001, SCT/6/3, 25 January 2001.

\section{Stegemann 2000}

Stegemam, K., "The Integration of Intellectual Property Rights into the WTO System", The World Economy, Vol. 23(9), September 2000, p. 1237-1267.

\section{Stewart 1993}

Stewart, T. (Ed.), The GATT Urtuguay Round: A Negotiation History (1986-1992), (2 Vols.), Deventer: Kluwer, 1993.

\section{Stewart 1999}

Stewart, T., The CATT: A Negotintion History 1986-1994, The Hague, Boston, London: Kluwer Law International, 1999.

\section{Stiglitz 2002}

Stiglitz, J., Globulization and its Discomtent, London: Allen Lane, an imprint of Penguin Books, Great Britain, 2002.

\section{Stillwell and Monagle}

Stillwell, M. and Monagle, C., Reriew of the TRIPS Agrement under Article 71.1, South Centre Occasional, Paper No. 15, Geneva, December 2000.

\section{Stolpe 2000}

Stolpe, M., "Protecting Against Software Piracy; A Study of Technology Adoption for the Enforcement of Intellectual Property Rights", Economics of Imovation and Neil Techoology, Vol. 9(1), 2000.

\section{Suri 2005}

Suri, S., Potato Capital of the world offers tup new recipe, Inter Press Service, 18 January 2005 , Published online at: <http://www.ipsnews.net/interna.asp?idnews=27069>.

\section{Suthersanen 2006}

Suthersanen, U., Utility models and hmovation in Deicloping Countries, Issue Paper No. 13, UNCTAD-ICISD Project on IPRs and Sustainable Development, Geneva: ICTSD, February 2006, Published online at: <http://www.iprsonlineorg/unctadictsd/dialo gue $/ 2006-03-03 /$ uma $\% 20$ suthersanen $\% 2013 \% 20$ final.pdf $>$.

\section{Swanson 1995}

Swanson, T. (Ed.), IPRs and Bididersity Conscration - An linterdisciplinary Analysis of the Values of Medicinal Plants, Cambridge: Cambridge University Press, 1995.

\section{Templeman 1998}

Templeman, S., "Intellectual Property", Joumal of International Economic Lawe, Vol. 1(4), 1998, p. 603-606.

\section{Tobin 1997}

Tobin, B., "Certificates of origin: a role for IPR regimes in securing prior informed consent", in: Mugabe, J. (Ed.), Access to genetic resources: Strategies for sharing Benefits, Nairobi: ACTS Press, 1997. 
Tobin 2004

Tobin, B., Toinds an Intemational Regime for Protection of Traditional Knoteledge: Reflections on the role of Intellectual lroperty Rights, Draft Paper at the Conference "Bioethical Issues of Intellectual Property in Biotechnology", Tokyo, 6-7 September 2004.

UNCTAD 1975

UNCTAD, The Role of the Patent System in the Tromsfer of Tethology to Dereloping Conmtrit's, Report prepared jointly by the UN Dept of Economic and Social Affairs, the UNCTAD Secretariat and the International Bureau of the WIPO. UNCTAD, TD/B/ AC.11/19.Rev.1, 1975.

\section{UNCTAD 1995}

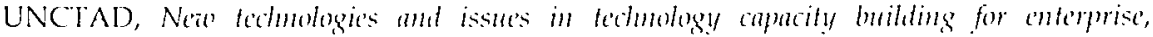
Geneva: Mimeograph, Division for Science and Technology, 1995.

\section{UNCTAD 2001}

UNCTAD, Compendium of Internationnl Arrangements on Transfer of Technologry: Silected Instruments, Releidut Provisions in Solected International Armugements Pertaining to Transfir of Tichology, UNCTAD/ITE/IPC/Misc. 5, United Nations, 2001.

\section{UNCTAD 2004}

UNCIAD, Facilitating Trmifer of Tedmology to Developing Comtries: A Surey of HomeConntry Metsures, 2004. Published online at: <http://www unctad.org/en/docs/iteipe 20045_en.pdf>.

\section{UNCTAD 2005a}

UNCIAD, A Cuse Study of the Electronics Industry in Thailand, UNCTAD's Series on Transfer of Technology for Successful Integration into the Global Economy, NY and Geneva: United Nations, 2005.

\section{UNCTAD 2005b}

UNCTAD, Taxation and Tedmology Transfer: Key lsomes, UNCTAD's series on Transfer of Technology for Integration into the Global Economy, NY and Geneva: United Nations, 2005.

\section{UNCTAD 2006}

UNCTAD, A Cas' Stuly of the Salmon hilustry in Chile, UNCTAD's Series on Transfer of Technology for Successful Integration into the Global Economy, NY and Geneva: United Nations, 2006.

\section{UNCTAD-ICTSD 2005}

UNCTAD-ICTSD, Resource Book on TRIPS and Dewelomment, Cambridge: Cambridge University Press, 2005.

\section{UNDP 1999}

UNDP, Haman Development Report 1999, New York: Oxford University Press, 1999.

\section{US General Accounting Office 1987}

US General Accounting Office, Strengthening Worldatide Protection of Intellectual Property Rights, GAO Doc. No. GAO/NSIAD-87-65, 1987. 


\section{Utkarsh 2003}

Utkarsh, G., "Documentation of traditional knowledge: People's Biodiversity registers", in Bellmann, C., Dutfield, G. and Melendez-Ortiz, R. (Eds.), Trailing in Knornledge: Detulopment Perspective's On TRIPS, Trade And Sustainability, London: Farthscan Publications, 2003, p. 1901-195.

\section{Varese 1996}

Varese, S., "The new Environmentalist movement of Latin American Indigenous People", in: Brush, S. and Stabinsky, P. (Eds.), Voluing locnl knowledge Inilgemons People and lPRs, Washington DC: lsland Press, 1996, p. 122-142.

\section{Vaver 2003}

Vaver, D., "Intellectual property: the State of the Art", Law Quarterly Reaicu, October 2003, p.621-637.

\section{Verma 2004}

Verma, S., Fitting Plant Varicty Protection and Biotedmological lantentions in Agriculture Within the Intellectual Property Frameioork: Clullenges for Developing Comatries, 2004. Published online at: <http://ictsd.net/downloads/2008/09/verma_2004-11-08.pdf>.

\section{Verma 2005}

Verma, S., "Plant Genetic Resources, Biological Inventions and Intellectual Property" Rights: The Case of India", in: Ong, B., (Ed.), Intellectual Property And Biologicul Re'sources: Perspetion's On Contemporury lssue's, Singapore: Marshall Cavendish Academic, 2005.

\section{Visser 2004}

Visser, C., "Making Intellectual Property Laws Work for Traditional Knowledge" (chapter 9), in: Finger, ). and Schuler, P. (Eds.), Poor People's Knowledge - Promoting Intellectual Properiy in Developing Conntries, Washington DC: The World Bank, 2004, p. 207-240.

\section{Vivas Eugui 2001}

Vivas Eugui, D., "Negotiations on Geographical Indications in the TRIPS Council and their Effect on the WTO Agricultural Negotiations - Implications for Developing Countries and the Case of Venezuela", The foumal of World Intellectual Property, Vol. 4(5), September 2001, p. 703-728.

\section{Vivas Eugui and Spennemann 2006}

Vivas Eugui, D. and Spennemann, C., The Trentment of Ceographical Indications in Recent WTO Discussions and in Regional and Bilaternl Agreentents, Geneva: ICTSD, October 2006.

\section{Watal 2001}

Watal, J., (Ed.) Intellectual Property Rights in the WTO and Developing Conntries, The Hague, Boston, London: Kluwer Academic Publishers, 2001.

\section{Weeraworawit 2003}

Weeraworawit, W., "International Legal Protection for Genetic Resources, Traditional Knowledge and Folklore: Challenges for the Intellectual Property System", in: Bellmann, C., Dutfield, G. and Melendez-Ortiz, R. (Eds.), Trading in Knowledge: Development Perspectioes On TRIPS, Trate And Sustainability, London: Earthscan Publications, 2003, p. 157-165. 


\section{Wiley 2008}

Wiley, S., "It's Not Just About Innovation", The Scichtist.com, Vol. 33(3), p. 33. Published online at: <http://www.the-scientist.com/2008/3/1/33/1/>.

\section{Williams 2002}

Williams, D., Extension of Stronger Gi Protection against the Interests of Deweloping Comntrie's, Bridges Monthly, Geneva: ICTSD, May 2002. Published online at: <http://www. iprsonline.org/ictsd/docs/WillamsBridgesYear6N4May2(0)2.pdf>.

\section{WIPO 2004}

WIPO, WIPO Intellectual Property Hanthook: Policy, Lan amd LIse, 2004. Published online at: <http:/ www.wipo.int/about-ip/en/iprm/pdf/chs.pdf\#bernes.

\section{World Bank 1999}

World Bank, Knowledge for Dezelopment, World Development Repont 1998-1999, New York: The World Bank, Oxford University Press, 1999.

\section{World Bank 2002}

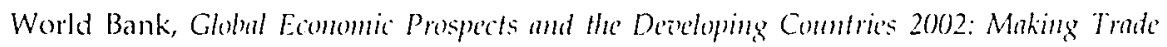
Work for the World's Poor, Washington DC: The World Bank, 2002.

\section{World Bank 2003}

World Bank, Globul Economic Prospects, Washington DC: The World Bank, 2003.

\section{World Bank 2004}

World Bank, Global Economic Perspectioes, Trate Regionalism, and Dere'lopment, Washington DC: The World Bank, 2004.

\section{Worthy 1994}

Worthy, J., "Intellectual Property after GATT", Europern Inlellectual Property Revici,, Vol. $16(5), 1994$, p. 195-198.

\section{Yang and Maskus 2001}

Yang, G. and Maskus, K., "Intellectual Property Rights, Licensing, and Innovation in an Endogenous Product-Cycle Model", Jommal of hiternational Economits, Vol. 53, 2001, p. $169-187$.

\section{Yap 2006}

Yap, A., "IP as a Tool for Economic Growth in ASEAN: Issues, Challenges and the Way" Forward", Recent Dewelopments in Intellectual Propurty Law E Policy in Asin, 2006, p. 1-14.

\section{Yen 1992}

Yen, A., "The Interdisciplinary Future of Copyright Theory", Cardozo Arts and Entertainment Lua Journal, 10(2), 1992, p. 423-437.

\section{Zarilli, Jha and Vossenaar 1997}

Zarilli, S., Jha, V. and Vossenaar, R. (Eds.), Eco-Labelling and Trate, in association with UNCTAD, 1997. 


\section{WIPO DOCLMINTS (CHIRONOLOGICAL ORDER)}

WIPO, Licensing Guide for De'seloping Countries, Geneva, 1977.

Document prepared by the Secretariat, Possible Solutions for Conflicts between Trademarks and Geographical Indications and for Conflicts betweon Homonymous Geographical Indications, Fifth Session Standing Committee on the Law of Trademarks, Industrial Designs and Geographical Indications, Ceneva, 11-15 September 2000, SCT/5/3, June 2000.

Document prepared by the Secretariat, Report on the Toolkit for Manuging Intellectual Property When Documenting Tratitiomal Knowletge and Ge'letic Re'soneres, Fifth Session Intergovernmental Committee on Intellectual Property and Genetic Resources, Traditional Knowledge and Folklore, Geneva, 7-15 July, WIPO/GRTKF/IC/5/5, 1 April 2003.

Proposals by Switzerland Regarding the Deciaration of the Source of Genetic Resources, International Patent Cooperation Union (PCT Union), Working Group on Reform of the Patent Cooperation Treaty (PCГ), Fourth Session, Geneva, 19 to 23 May', 2003 $P C T / R / W G / 4 / 13,5$ May 2003.

Document submitted by the Secretariat of the Convention on Biological Diversity, Certain Decisions of the Seventh Conference of the Parties to the Comaention on Biological Diversity, Sixth Session Intergovernmental Committee on Intellectual Property and Genctic Resources, Traditional Knowledge and Folklore, Geneva, 15-19 March 2004, WIPO/GRTKF/IC/6/13, 15 March 2004.

Document Prepared by the Secretariat, Questionnaire on Recognition of Traditional Knowel-

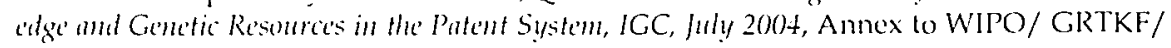
IC/7/8, WIPO/GRIKF/IC/Q.5, Seventh Session intergovernmental Committee on IP and genetic resources, traditional knowledge and folklore, Geneva, 1-5 November 2004 , 23 July 2004.

Document prepared by the Secretariat, Proposal by the United States, Japm and the Europran Patent Office for Establishing a Now Work Plim for the Standing Committer on the Law of Palchts (SCP), WIPO General Assembly, Thirty-First (15 Extraordinary) Session, Geneva, September 27 to Octoher 5, 2004, WO/GA/31/9, 23 July 2004 (WIPO, 2004, annex p. 2).

Document prepared by the Secretariat, Protection of Traditional Knowledge: Oierrieze of Policy Objectioes and Core Principles, Seventh Session Intergovernmental Committee on Intellectual Property and Genetic Resources, Traditional Knowledge and Folklore, Geneva, 1-5 November 2004, WIPO/GRTKF/IC/7/5, 20 August 2004.

Document Prepared by the Secretariat, Proposal by Argentima and Brazil for the Establishment of a Deielopment Agenda for WIPO, WIPO General Assembly, Thirty-First (15 th Extraordinary) Session, Geneva, 27 September to 5 October 2004, WO/GA/31/11, 27 August 2004. Published online at: <http://www.wipo.int/documents/en/document/ govbody/wo_gb_ga/pdf/wo_ga_31_11.pdf>. 
Proposal by the European Community and its Member States to WIPO, entitled

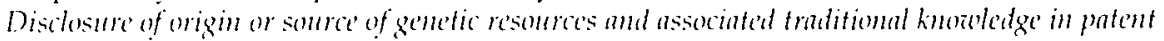
applications, in response to an invitation by WIPO to submit comments and proposals towards collaboration between WIPO and the CBD, WIPO document DOC WO/GA/ $31 / 8,16$ December 2004.

Document prepared by the Secretariat, Uptate on Technical Standards and Isants Comeening Reourded or Registered Traditional knowledge, Eight Session Intergovernmental Commiltee on Intellectual Property and Genetic Resources, Traditional Knowledge and Folklore, Geneva, 6-10 june, 2005, WIPO/CIRTKF/IC/8/7, May 2005.

Proposal of the European Commission and Its Member States, Disclosure of Origin or Source of Genetic Re'sonre's and Associnted Traditional Knowledge in l'atent Applications, Eight Session Intergovernmental Committee on Intellectual Property and Genetic Resources, Traditional Knowledge and Folklore, Geneva, 6-10 June, 20055, WIPO/GRTKF/ IC $/ 8 / 11,17$ May 2005.

Communication from Japan, The P'ntent System and Genetic Resources, Ninth Session Intergovernmental Committee on Intellectual Property and Genetic Resources, Traditional Knowledge and Folklore, Geneva, 24-28 April, 2005, WIPO/GRTKF/IC/9/13, 20 April 2006.

WIPO, WIPO Patent Report, Statistics on Worldaride Patent Actiaity, 2006 Ettition. Published online at: <http://wipo.int/ipstats>.

Proposal by Switzerland, Detarnion of the Sonte of Gentic Resomres and Traditional Knotoledge in Patent Applications: Proposals by Sictizerland, Eleventh Session Intergovernmental Committee on Intellectual Property and Genetic Resources, Traditional Knowiedge and Folklore, Geneva, 3-12 July 2007, WIPO/GRTKF/IC/11/10, 6 June 2007.

Communication from Peru, Combating Biopiracy - The Pertivian Experience, Eleventh session of the Intergovernmental Committee on Intellectual Property and Genctic Resoutces, Traditional Knowledge and Folklore, Geneva, 3-12 July 2007, WIPO/GRTKF/ IC/11/13, 9 July 2007.

Document Prepared by the Secretariat, Repont of the Protisional Committe on Proposals Related to a WVIPO Deielopment Agenda (PCDA). Assemblies of the Member States of WIPO, Forty-Third Series of Mectings, Geneva, 24 September to 3 October 2007, A/43/ 13 Rev., 17 September 2007.

WIPO, WIPO Patent Report Statistics on Worldivide Patent Actioities, 2007 Edition. Published online at: <http://www.wipo.int/export/sites/www/freepublications/en/pa tents/931/wipo_pub_931.pdf>.

WIPO, WIPO World Patent Report a Statistical Reicie, 2008 Etition. Published online at: <http:/wipo.int/export/sites/www/ipstats/en/statistics/patents/pdf/wipo_pub_93 I.pdf $>$. 


\section{UN DOCLMENTS}

Resolution 2001/33 of the 57th Session of the United Nations Commission on Human Rights, Access to Medication in the Context of Dandemics such as HIV/AIDS, 19-27 April 2001 .

UN Ceneral Assembly, UN Dicturation on the rights of Indigenous Peoples, Distr. General, A/Res/61/295, 2 October 2007.

\section{GATT DOCLMINTS (IN CHRONOLOGICAL ORDER)}

Agrement on Mensures to Disconarage the Importation of Connterfeit Goods, GATT Doc. L. 4817,31 July 1979.

Agrement on Menstures to Discotunge the Importation of Comberfat Goods, GATT Doc. $\mathrm{L} / 5382,18$ October 1982.

Ministerial Declaration 1982, Thirty-eight Session at Ministerial Level Ministerial Declaration, reprinted in GATT, BISD 30:h Supplement, 1983.

Communication from the United States, Suggestion by the US for Achieving the Negotiating Objective, GATT Doc. MTN.GNG/NG11/W/14, 20 October 1987.

Communication from the European Communities, Guidelines by the Europem Commmithe's for the' Negotiations on Trade Related Aspects of IPRs', GATT Doc. MTN.GNG/NG11/ W17, 20 November 1987.

Communication from Japan, GATT Doc. MTN.GNG.NG11/W/17, 23 November 1987.

Communication from Thailand, GATT Doc. MTN.GNG/NG11/W/27, 21 September 1988.

Submission from Mexico, GATT Doc. MTN.GNG/NG11/W28, 19 October 1988.

Submission from Brazil, GATT Doc. MTN.GNG/NG11/W/30, 31 October 1988.

Ministerial Declaration on the Uruguay Round, Document MIN.DEC of September 20, 1986.

Trade Negotiations Committee Meeting at Ministerial Level Montreal, December 1988, GATT Doc. MTN.TNC/7(MIN), 9 December 1988.

Communication from Australia, GATT Doc. No. MTN.GNG/NG11/W/35, 10 July 1989.

Communication from Korea, GATT Doc. No. MTN.GNG/NG/11/W48, 26 October 1989.

Communication from Brazil, GATT Doc. No. MTN.GNG/NG/11/W57, 11 December 1989. 
Communication from the European Communities, Draft Agreement on the Trade-Related Aspects of IPRs, GATT Doc. No. MTN.GNG/NG11/W/68, 29 March 1990.

Communication from the United States, Draft Agreement on the Trade-Related Aspects of IPRS, GATT Doc. No. MTN.GNG/NG11/W/70, 11 May 1990.

Communication from Argentina, Brazil, Chile, China, Colombia, Cuba, Egypt, India, Nigeria, Peru, Tanzania and Unuguay, so-called De'eloping Commtry l'ropusal, C,ATT Doc. No. MTN.GNG/NG11/W/71, 14 May 1990.

Communication from Chile, GATT Doc. No. MTN.GNG/NGI1/W/72, 14 May 1990.

Communication from Switzerland, Druft Agreement to the General Agreement on Tariffs and Trute on the protection of trute riated aspects of IPRs, GATT Doc. No. MTNGNG/ NG11/W/73, 14 May 1990.

Communication from Japan, Main Elements of a Le'gal Text for TRIPS, GATT Doc. No. MTN.GNG/NG11/W/74, 15 May 1990.

Chairman's report to the Group of Negotiation on Goods, MTN.GNG/NG11/W/76, 23 July 1990 .

Draft Final Act Embodying the Results of The Uruguay Round of Multilateral Trade Negotiations, Revision, TRIISS including Trade in Counterfeit Goods, MTN.TNC/W/ 35/Rev. 1, 3 December 1990.

\section{WTO DOCLMENTS (IN CIIRONOLOGICAL ORIDER)}

Secretarial Note, Review under Article 24.2 of the application of the provisions of the section of the TRIPS Agrement on Geographical hadications: Summary of the Responses to the Checklist of Questions, IP/C/13, 14 May 1998.

Communication from India, Preparntions for the 1999 Ministerial Conference - Proposals Regarding the TRIPS Agrement in Terms of Paragraph 9(n)(i) of the Genen Ministerint Deciaration, WT/GC/W/225, 2 July 1999.

Communication from Cuba, Dominican Republic, Egypt, El Salvador, Honduras, India, Indonesia, Malaysia, Nigeria, Pakistan, Sri Lanka and Uganda, Preparntions for the 1999 Minsisterial Confirence - Implementation lssues to be addresed Beford At Seatlle, WT/GC/ W/354 of 11 October 1999.

Communication from the United States, Reania of the Provisions of Article 27.3(b) Further Vical's of the United States', IP/C/W/209, 3 October 2000.

The Detaration on the TRIPS Agre'ment and Public Health, adopted on 14 November 2001, Ministerial Conference, Fourth Session, Doha 9-14 November 2001, WT/MIN(01)/ DEC/2, 20 November 2001.

WTO Doha Ministerial Declaration, 14 November 2001, WT/MIN(01)/DEC/1, 20 November 2001. 
Communication from Bulgaria, Cuba, Cyprus, The Czech Republic, The European Communities and their member States, Georgia, Hungary, Iceland, India, Kenya, Liechtenstein, Malta, Mauritius, Pakistan, Romania, The Slovak Republic, Slovenia, Sri Lanka, Switzerland, Thailand and Turkey, "The Extension of the Additional Protection for Geographical Indications to Products other than Wines and Spirits', IP/C/W/353, 24 June 2002.

Extension of the Transition Period under Article 66.1 of the TRIPS Agreement for LeastDeveloper Conumtry Members for Certain Obligations arith Respect to Plarmacentical Products, Decision of the Council for TRIPS of $27 \mathrm{June} 2002, \mathrm{IP} / \mathrm{C} / 25$, I July 2002.

Communication from the European Communities and their Member States, Reviea of Article 27.3(b) of the TRIPS agreement, and the Retationstip between the TRIPS Agreement and the Contention on Biological Diversily (CBD) and the Profection of Tratitional Knoaldedge and Folkhwe, II'/C/W/383, 17 October 2002.

Communication from Switzerland, Article 27.3(b), The Relationship between the TRIPS Agrement and the Contention on Biological Diecrsity, and the Protection of Traditional Knozledgé, IP/C/W/400, 28 Maý 2003.

Implementation of Paragraph 6 of the Doha Dectaration on the TRIPS Agreenent and Public Health, Decision of the General Council of 30 August 2003, General Council, WT/L/540, 2 September 2003.

Communication from Switzerland, Adtitional Comments by Suitzerland on its Proposals Submitted to WIPO regarding the Declarntion of the Source of Genetic Resources and Traditional Knouldedge in Patent Applications, IP/C/W/423, 14 June 2004.

Communication from Switzerland, Further Obserations by Sinitzerland on Its Proposals Regarding the Decturation of the Source of Genetic Resomeces and Traditional Knowledge in Patent Applications, IP/C/W/433, 25 November 2004.

Conmunication from India, Pakistan and the Philippines to the Working Group on Trade and Transfer of Technology by Steps that might be taken within the mandate of the WTO to increase fows of tedmology to developing countries, WT/WGTTT/W/10, 13 October 2005.

Communication from Zambia on behalf of the Least-Developed Country Members, Re'inest for an Extension of the Trmsitional Period under Artick 66.1 of the TRIPS Agreement, $1 \mathrm{P} / \mathrm{C} / \mathrm{W} / 457,21$ October 2005.

Communication from Peru, Analysis of Potential Cases of Biopiracy, $\mathrm{IP} / \mathrm{C} / \mathrm{W} / 458,7$ November 2005.

Extension of the Transition Period Linder Artide 66.1 For Least-Developed Conntry Members, Decision of the Council for TRIPS of 29 November 2005, IP/C/40, 30 November 2005.

Amendment of the TRIPS Agreement, Decision of 6 December 2005, Annex to the Protocol amending the TRIPS Agreement, Article 31bis, WT/L/641, 8 December 2005.

Communication from the United States, Article 27.3(B), Relationship betaeen the TRIPS Agrement and the $\mathrm{CBD}$, and the Protection of Traditional Knoweledge and Folklore, IP/C/ $W / 434,26$ November 2004, IP/C/W/449, 10 June 2005 and IP/C/W/469, 13 March 2006. 
Communication from Brazil, India, Pakistan, Pcru, Thailand and Tanzania, Dolna Work

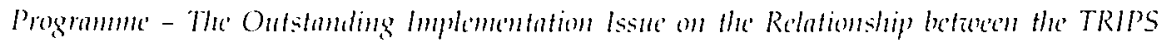
Agrecment and the Comention on Biological Diwersity, WT/G,C/W/564 and TN/C/W/4l, 31 May 2006.

Communication from Japan, The Patent System and Genctic Resources, IP/C/W/472, 13 June 2006.

Communication from Norway, The Relationship betanen the TRIPS Agrement, the

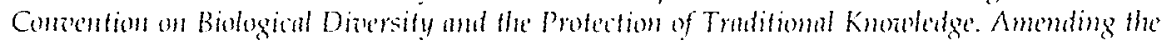
TRIPS Agrement to Introduce an Obligation to Disclose the Origin of Genetio Resonecs and Tratitional Knowledge in Patent Applications, IP/C/W473, 14 June 2006.

Minules of Meeting, TRIISS Council Meeting of 25-26 October $2006, \mathrm{IP} / \mathrm{C} / \mathrm{M} / 52,15$ Jamuary 2007.

Communication from Nomway, The relationship betaen the TRLPS Agrement, the Conerntion on Biological Diversity and the Protection of Thatitional Knoteletge. Anemding the TRIPS Agre'ment to introduce an Obligation to alisclose the Origin of Genetic Resonres and Tratitional Knoaldelge in Patent Applications. Ansaers from Norany to Que'stions posed by Sinitzorlund in the TRIPS Conncil, WT/GC/111, TN/C/W/46,IP/C/W/491, 7 May 2007.

Communication from Sierra Leone to the TRIPS Council, Priority Nerds for Techmical and Finnacial Compration, IP/C/W/499, 3 October 2007.

Communication from Uganda to the TRIPS Council, Priority Nedef for Techrical and Financinl Coupromion, IP/C/W/500, 9 October 2007.

Communication from Japan, The Patent System and Genetic Resources, IP/C/W/504, 17 October 2007.

\section{CASE LAW}

AEM Records, lin. v. Nopster, me. US Court of Appeals for the Ninth Circuil, Case No. 00-16401, 12 February 2001. Published online at: <http://cyber.law harvard.edu/ -wseltrer/napster.html>.

Baverische Bier, Commission of the Europern Commission v. Germany, Purity Requirements for Beer, ECl Case, C-178/84, 1987.

Belgimm v. Sprin, Kingtom of Belgimm v. Kingdom of Spain, ECJ Case, C-388/95, 16 May 2000 .

Budaeiser, ECHR, grand chamber No. 73049/01, 11 January 2007.

Eric Eldrud, ot al., petitioners v. Jolm D. Ashcroft, Attomey General, Supreme Court, 537 US, 15 January 2003. Published online at: <http://www.lessig.org/blog/archives/01$6180 . p d f>$.

Gerolsteiner Brumnen, Gerolsteiner Brumen GmbH \& Cov. Putsch GmbH, ECJ Case, C$100 / 02,2004$. 
Gorgomzola/Cambozola, Consorzio per la tutela del formaggio Gorgonzola v. Käiscrei Champignon Hefmetster GmbH \& Co KG, ECJ Case, C 87/97, 4 March 1999.

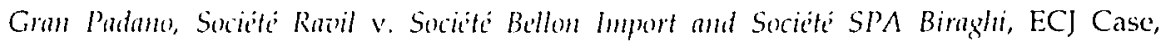
C469/00, 20 May 2003.

IBM Cirse, computer program product/IBM, Board of Appeal of the European Patent Office, T 1173/97, 1 July 1998.

IBM Case, compuler program product 11/IBM, Board of Appeal of the European Patent Office, T 935/97, 4 February 1999.

Oxford Lhiversity Press v. Registrar of Trade Marks, 15 IPR 646, 1988.

Parma Ham, Consorzio del Prosciutto di Parma and Silhmificio S. Rita SPA v. Asta Stores Ltd and Hygrate Foods Lht, EC] Case, C108/01, 20 May 2003.

Spreewalder Gurken, Carl Kuhme GmbH \& Co. v. Jutro Komsenenfabrik GmbH \& Co. KG, EC) Case, C-269/99, 5 April 2001.

Windsurfing Chiemsee, Wimlsurfing Chiemse' Produkfions-und Vertriels Gmblt v. Bootsuni Segelzubluor Walter Uher and Franz Altenberger (C-108/97 and C-109/97), joint ECJ cases, 4 May 1999.

\section{WTO PANEL AND APPELLATE BODY REPORTS}

Cannda - Patents, Canada - Patent Protection of Pharmaceutical Products, 'Request for the establishment of a Panel by the European Communities', WT/DS114/5, 12 November 1998.

Camata - Patents, Canada - Patent Protection of Pharmaceutical Products, 'Complaint by' the European Communities and their Member States - Report of the Panel', WTy DS114/R, 17 March 2000.

Chima Enforcement, China - Measures Affecting the Protection and Enforcement of Intellectual Property Rights, WT/DS362/R, 26 January 2009.

EC-Tradcmarks and Geographical Indications, European Communities - Protection of Trademarks and Geographical Indications for Agricultural Products and Foodstuffs, WT/DS290/18, Australian complaint, 19 August 2003.

EC-Tratemarks and Geographical Indications, European Communities - Protection of Tratemarks and Geographical Indications for Agricultural Products and Foodstuffs, WT/DS174/20, US complaint, 19 August 2003.

India - Patents (PR), India - Panel Protection for Pharmaceutical and Agricultural Chemical Products (US), 'Request for the establishment of a Panel by the United States', WT/DS50/4, 8 November 1996.

Intia - Patents (PR), India - Panel Protection for Pharmaceutical and Agricultural Chemical Products (US), 'Report of the Panel', WT/DS50/R, 5 September 1997. 
Intin - Patents (ABR), India - Panel Protection for Plamaceutical and Agricultural Chemical Products (US), 'Report of the Appellate Body', WT/DS50/AB/R, 19 Decomber 1997.

Intonesin - Cortuin Mensures Affecting the Automobile Industry, Report of the Pand, WT/ DS54/R, WT/DS55/R, WT/DS59/R, WT/DS64/R, 2 July 1998.

Brazil - Merasmes Affecting Patent Protetion (US), 'Notification of Mutually Agreed Solution', WT/DS199/4, 19 July 2001.

Brazil - Measures Affecting Patent Protection (US), 'Request for Consultations by the US', WT/DS199/1, 8 June 2000.

Brazil - Merasucs Affeting Patent Protection (US), 'Request for the Establishment of a Panel by the US', WI/DS199/3, 9 January 2001.

Brozil - Mersures Affecting Patent Protection (US), 'Request to Join Consultations Communication from the European Communities', WT/DS199/2, 20 June 2000.

US - Gasolime, United States - Standards for Reformulated and Conventional Gasoline, 'Report of the Panel', WT/DS2/R, 29 January 1996.

US - Gasolime, United States - Standards for Reformulated and Conventional Gasoline, 'Report of the Appellate Body', WT/DS2/AB/R, 29 April 1996.

Japm - Customs Duties, Taxes and Labelling Practices on Lmponted Wines and Alcoholic Bererrege's, 'Report of the Panel', L6216, see BISD 34S/83, 10 November 1987.

US-Imports of Certain Automotioe Spring Assemblie's, 'Report of the Panel', L/5333, see BISD 30S/107, 26 May 1983.

United States - Section 337 of the Tariff Act of 1930, 'Report of the Panel', L/6439, see BISD $365 / 345,7$ November 1989.

US Lulmol Coffon, United States - Subsidies on Upland Cotton, 'Report of the Appellate Body', WT/DS267/AB/R, 3 March 2005.

US - Gambling Linited States - Measures Affecting the Cross-Border Supply of Gambling and Betting Services - Recourse by Antigua and Barbuda to Article 22.2 of the DSU, WT/DS285/22, 22 June 2007.

Canada - Patent Term, Canada - Term of Patent Protection, 'Report of the Appellate Body', WT/DS170/AB/R, 18 September 2000.

Canndil - Patent Term, Canada - Term of Patent Protection, 'Report of the Panel', WT/DS170/R, 5 May 2000.

EC - Computer Equipment, European Communities - Customs Classification of Certain Computer Equipment, 'Report of the Appellate Body', WT/DS62/AB/R, WT/DS67/ $A B / R, W T / D S 68 / A B / R, 5$ June 1998. 



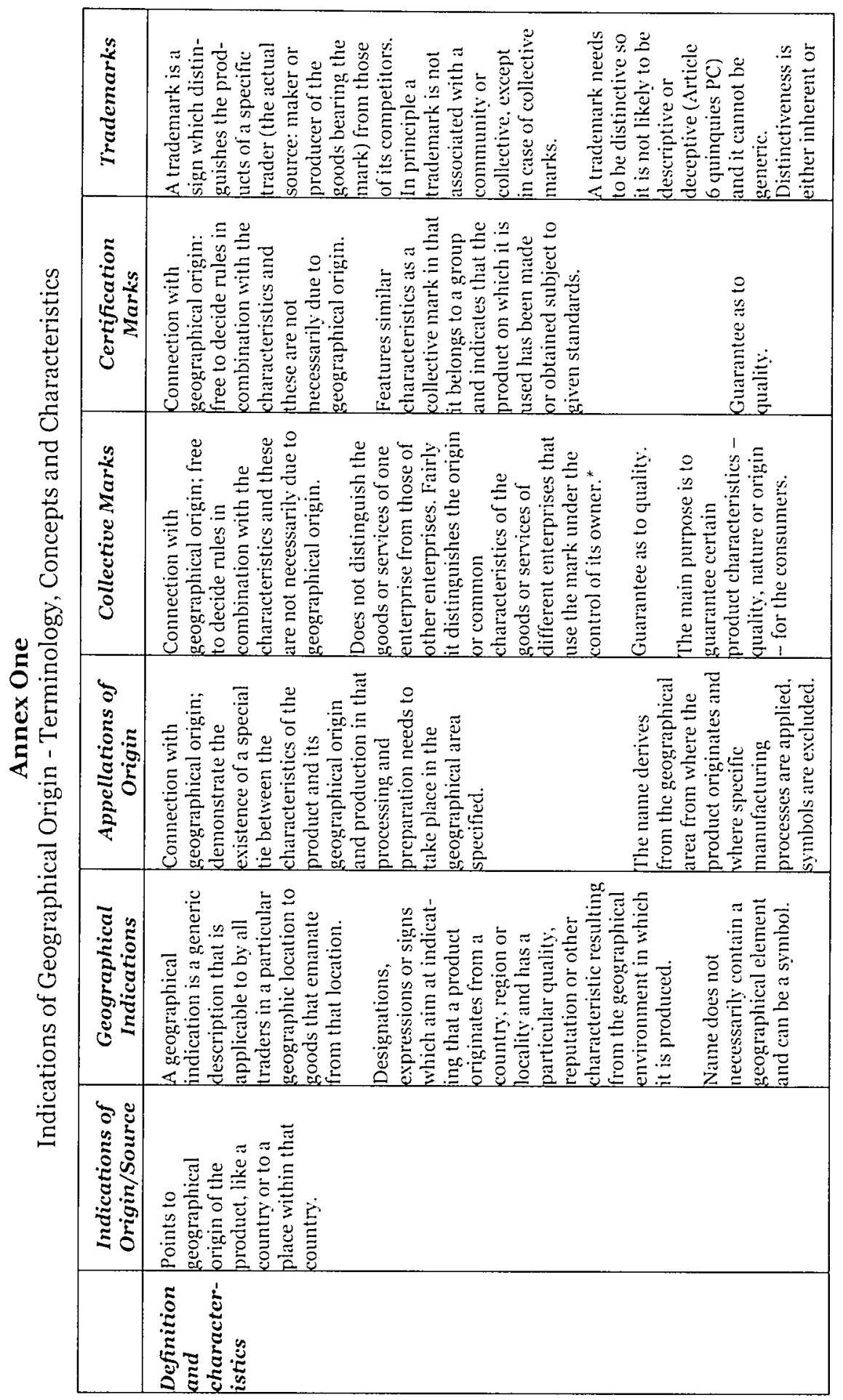




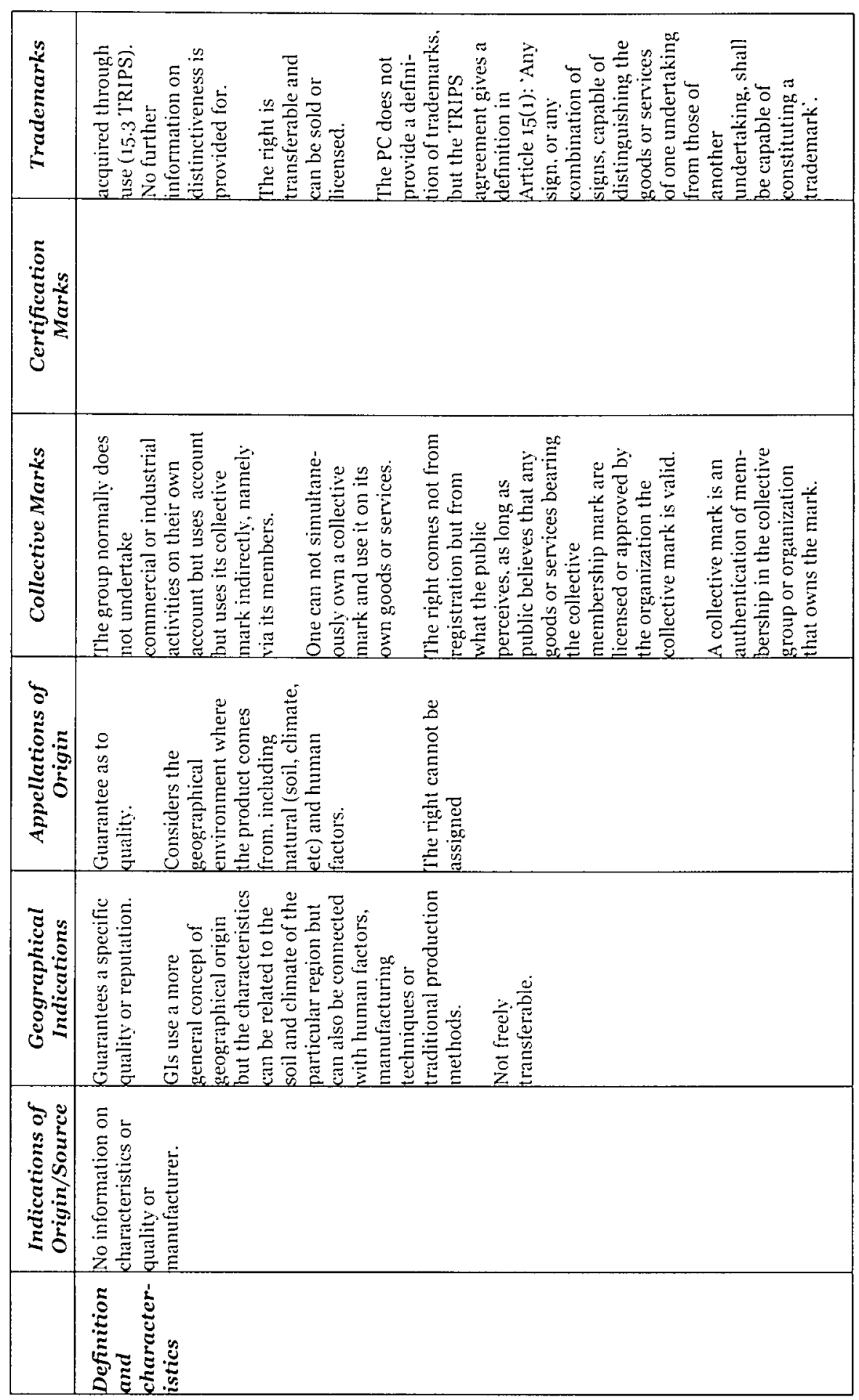




\begin{tabular}{|c|c|c|c|}
\hline 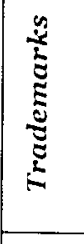 & 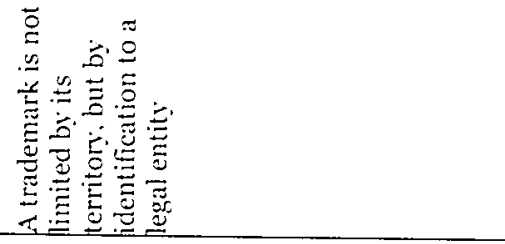 & 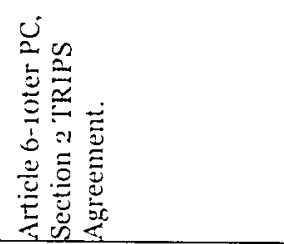 & 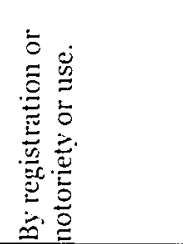 \\
\hline 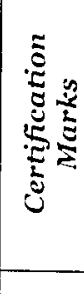 & & 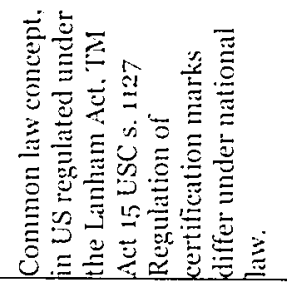 & 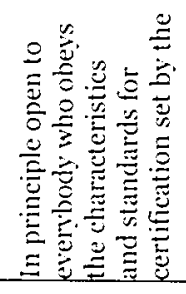 \\
\hline 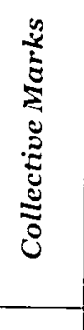 & 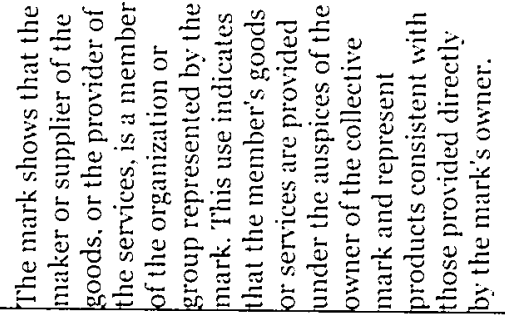 & 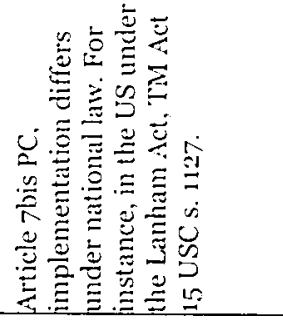 & 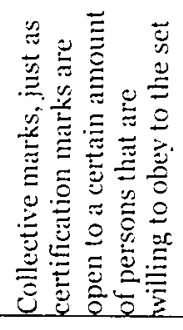 \\
\hline 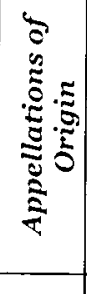 & & & 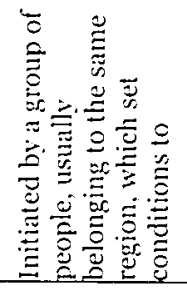 \\
\hline 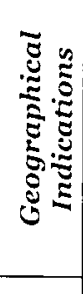 & & 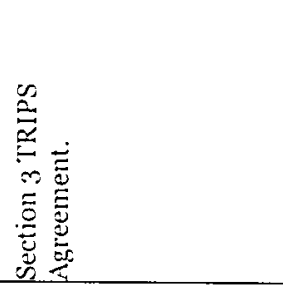 & 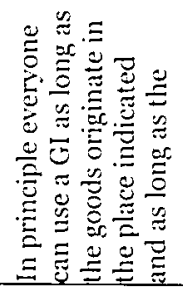 \\
\hline 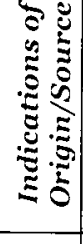 & & 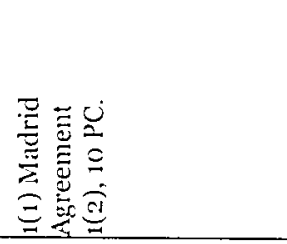 & \\
\hline & 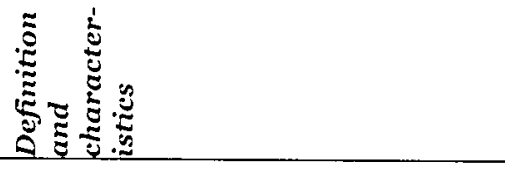 & $\stackrel{\Xi}{\Xi}$ & 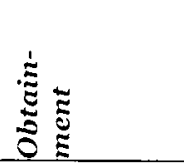 \\
\hline
\end{tabular}




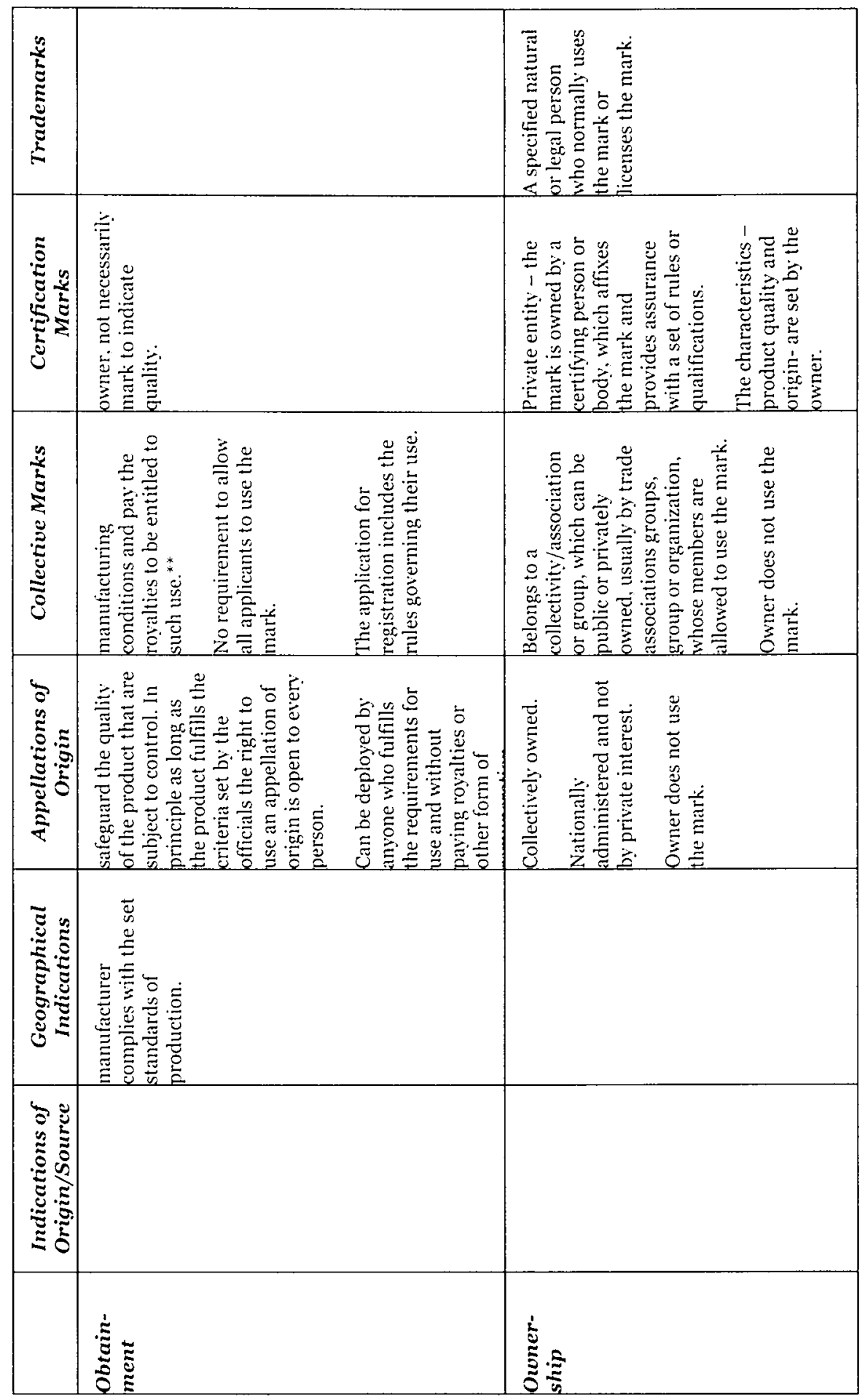




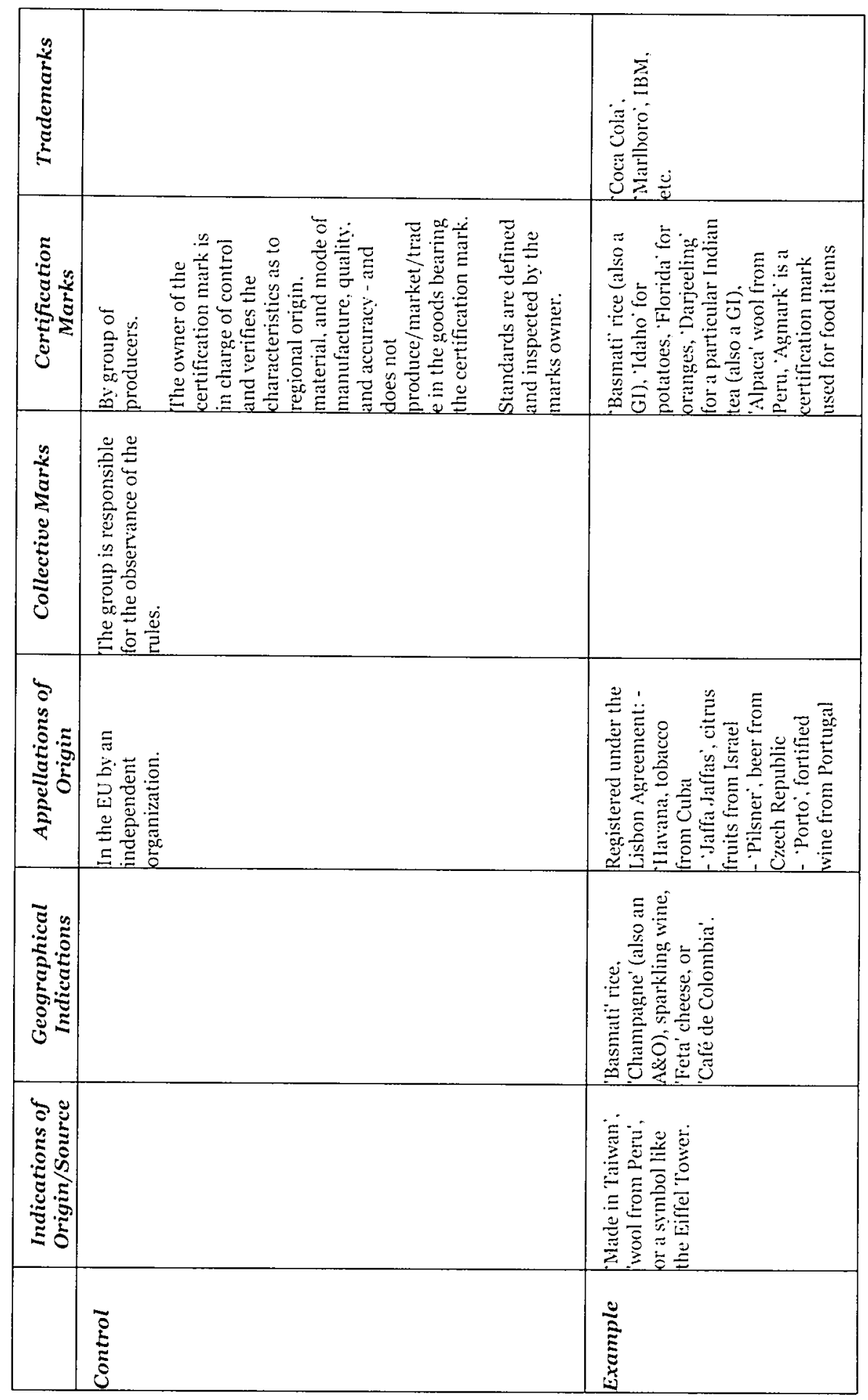




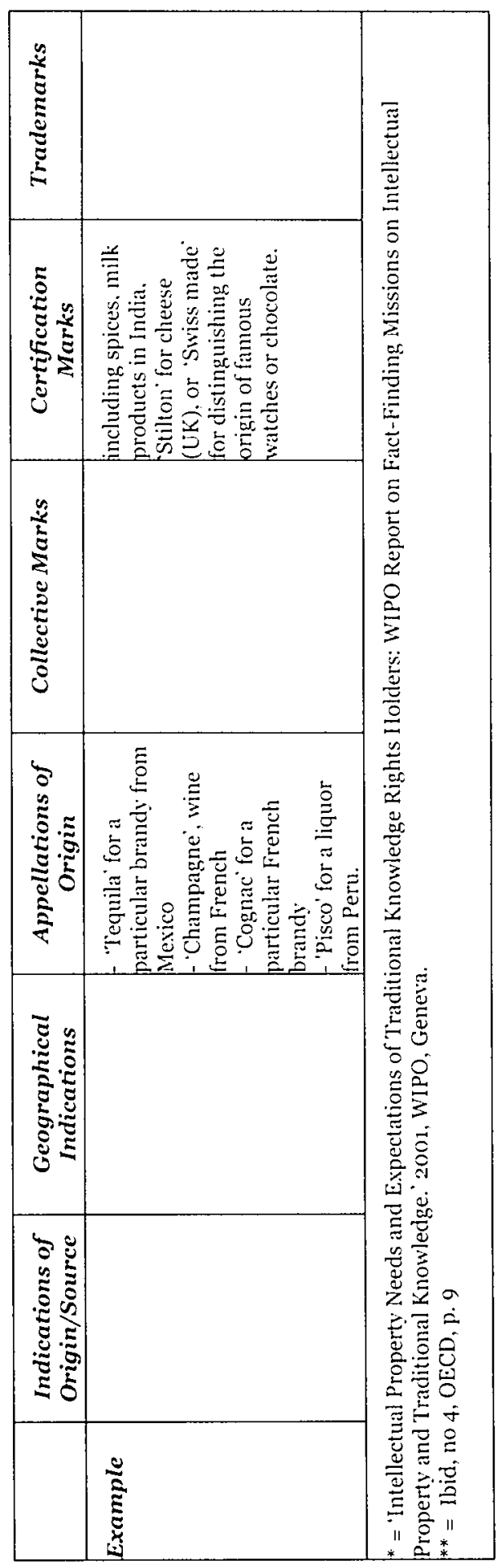




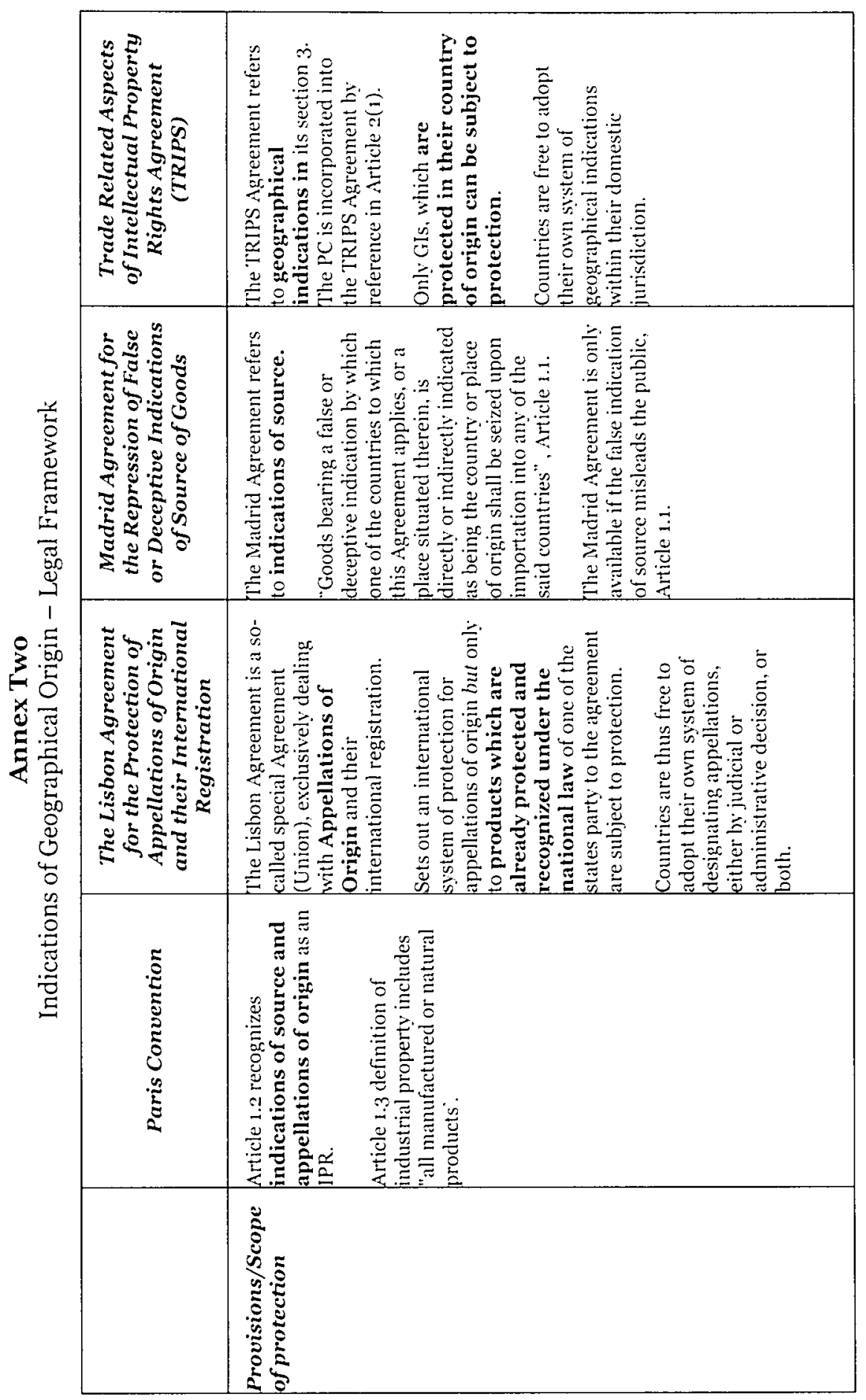




\begin{tabular}{|c|c|c|}
\hline 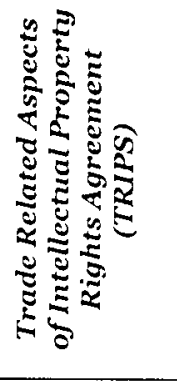 & & 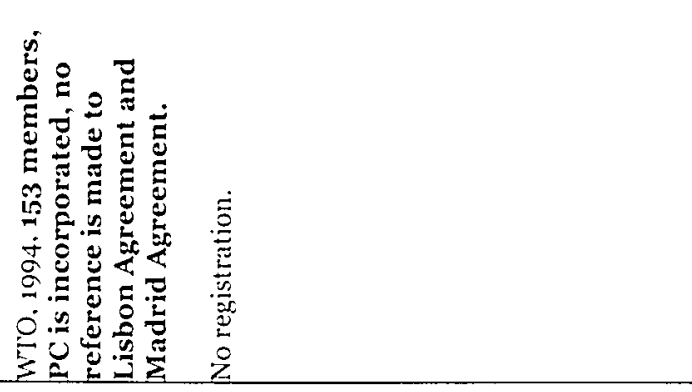 \\
\hline 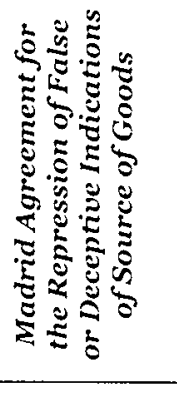 & & 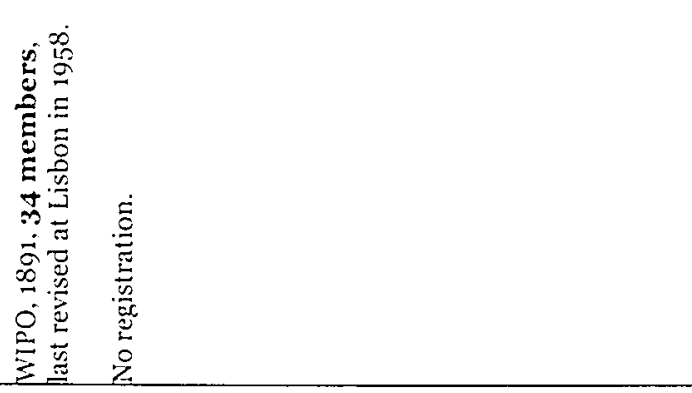 \\
\hline 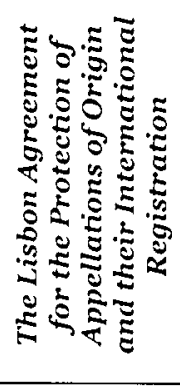 & 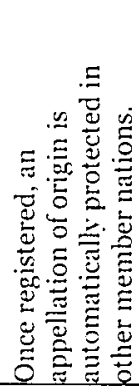 & 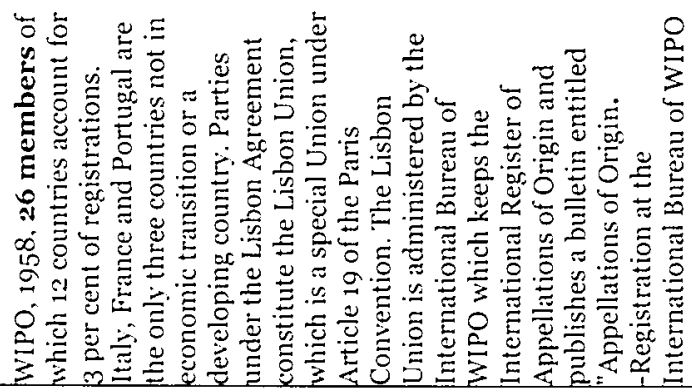 \\
\hline \multirow[t]{2}{*}{ 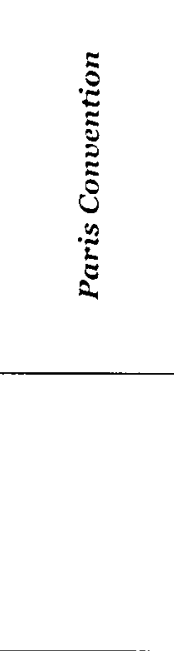 } & & 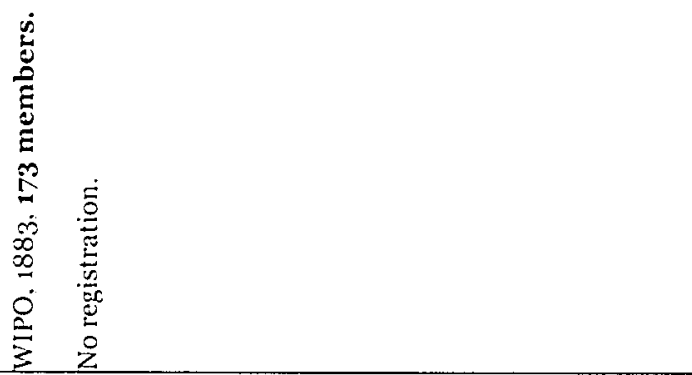 \\
\hline & 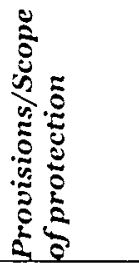 & 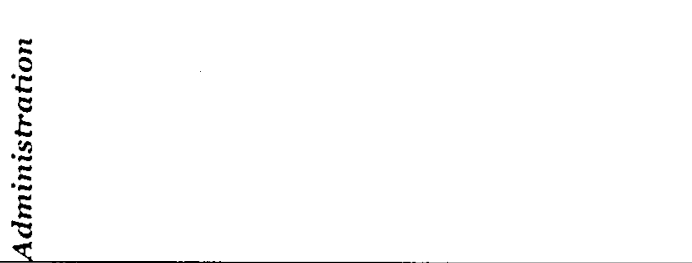 \\
\hline
\end{tabular}




\begin{tabular}{|c|c|c|c|c|}
\hline 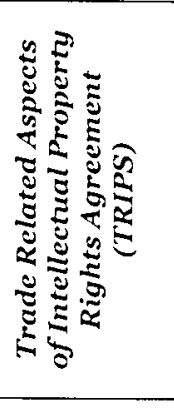 & 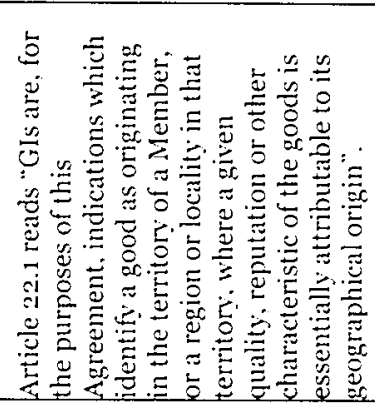 & 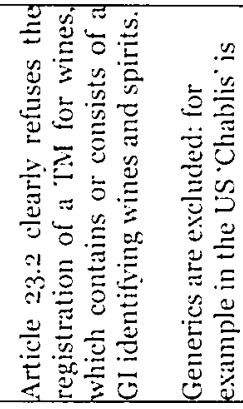 & 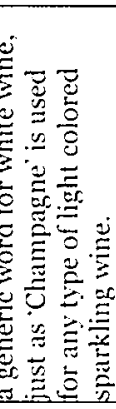 & 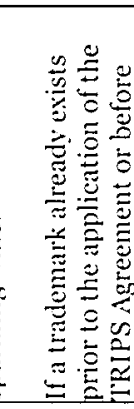 \\
\hline 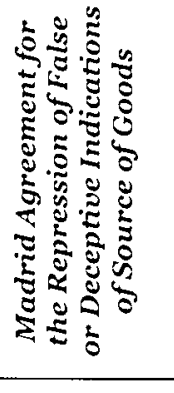 & 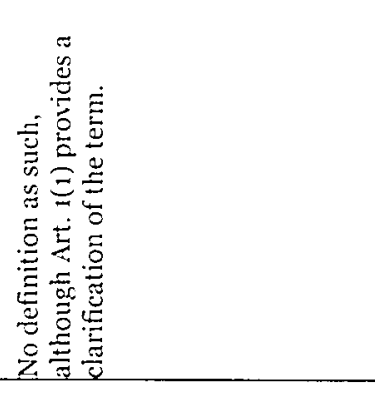 & 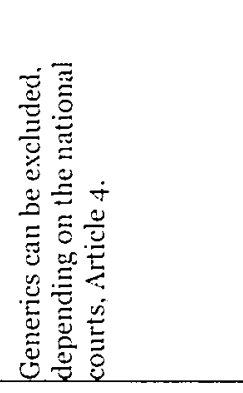 & & \\
\hline 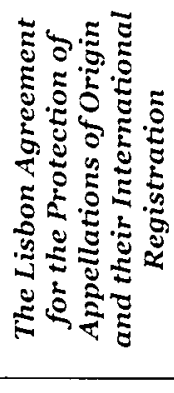 & 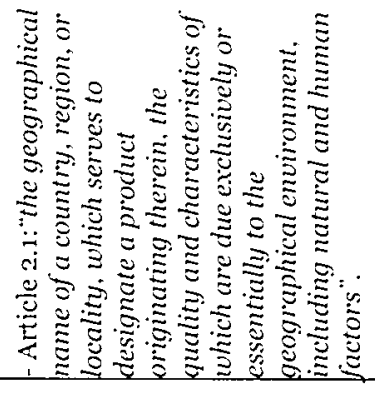 & 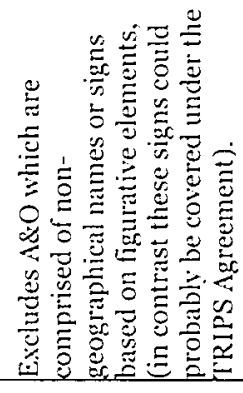 & 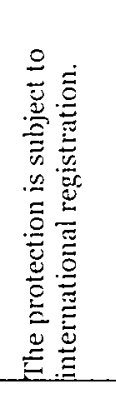 & 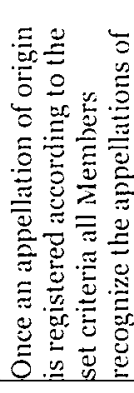 \\
\hline \multirow[t]{2}{*}{ 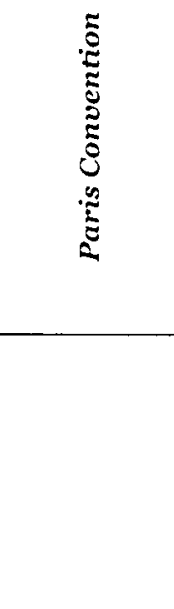 } & 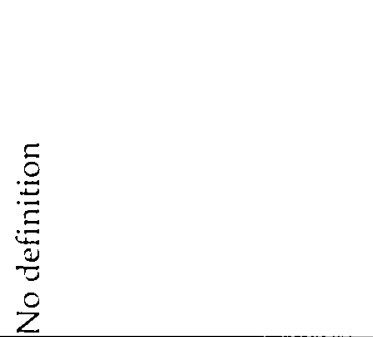 & & & \\
\hline & 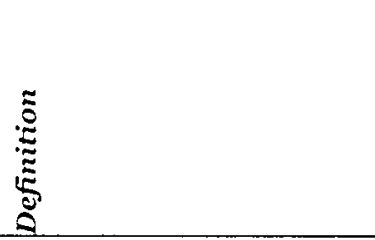 & 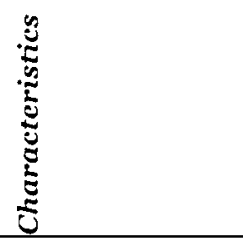 & & \\
\hline
\end{tabular}




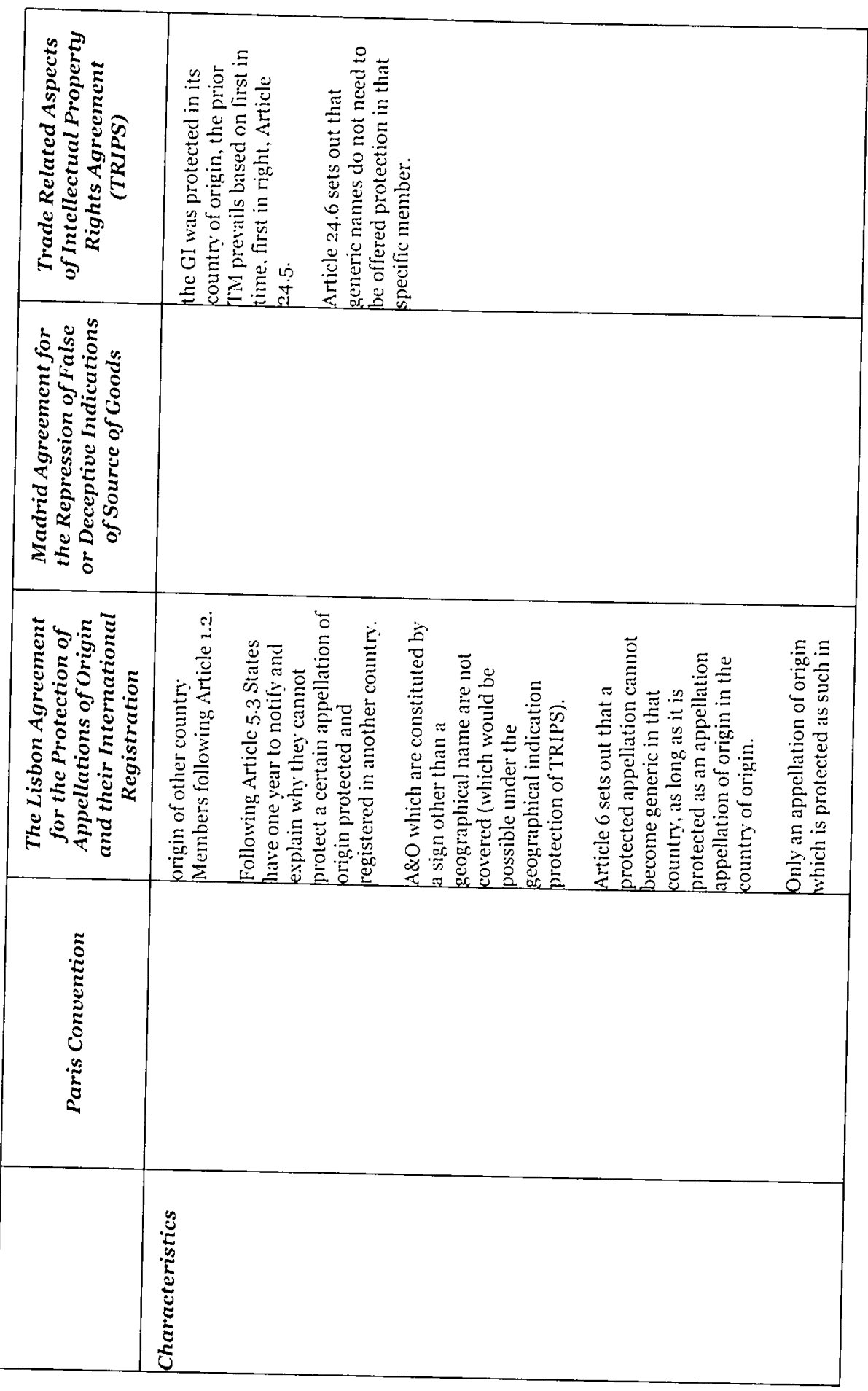




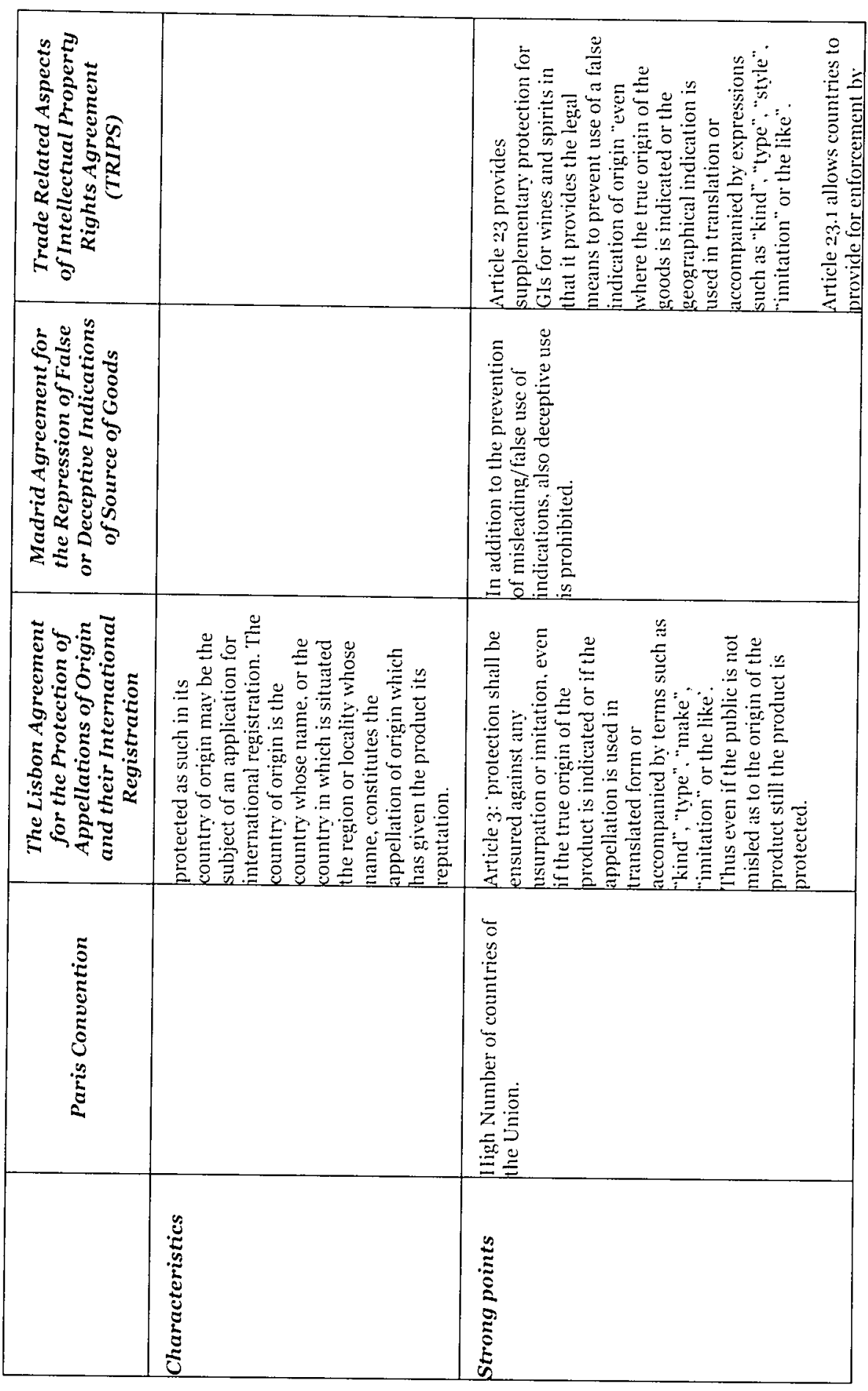




\begin{tabular}{|c|c|c|c|c|}
\hline 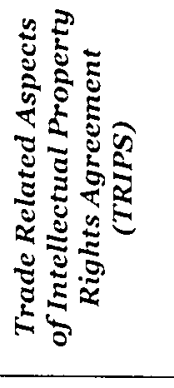 & 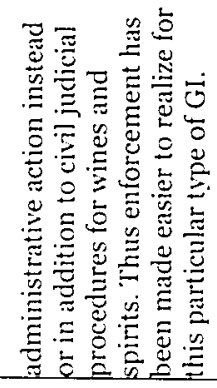 & 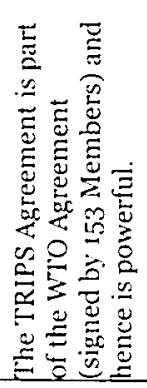 & 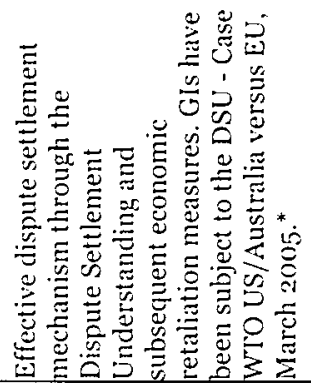 & 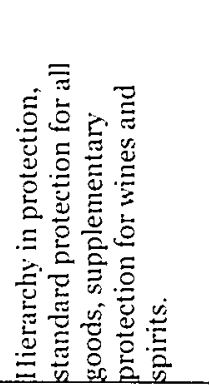 \\
\hline 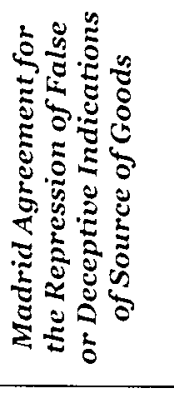 & & & & 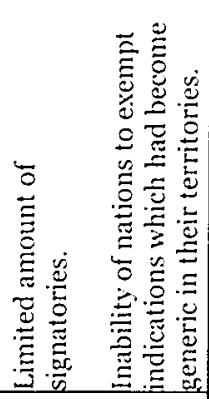 \\
\hline 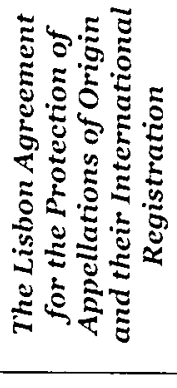 & & & & 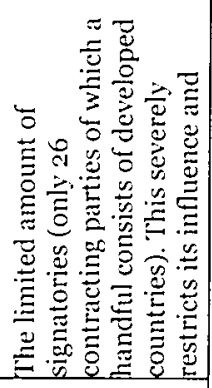 \\
\hline 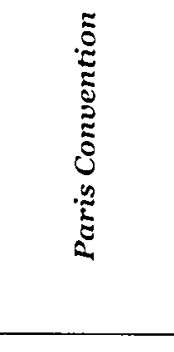 & & & & 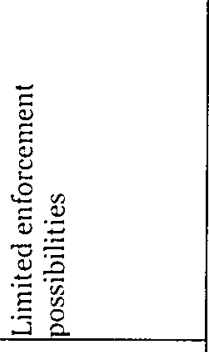 \\
\hline & 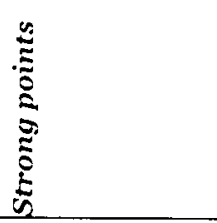 & & & 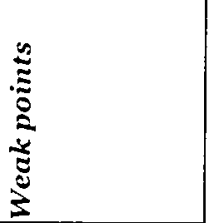 \\
\hline
\end{tabular}




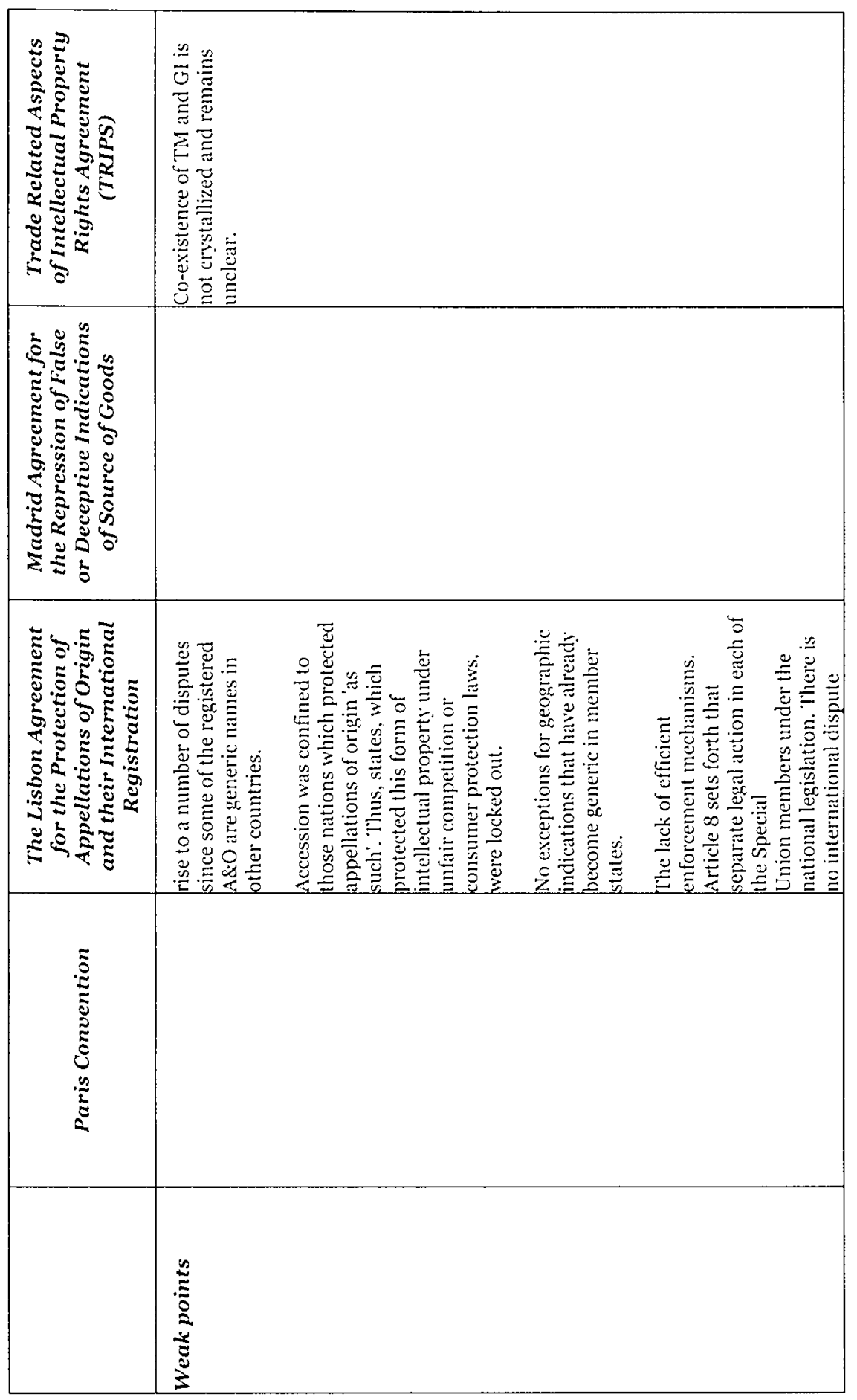




\begin{tabular}{|c|c|c|}
\hline 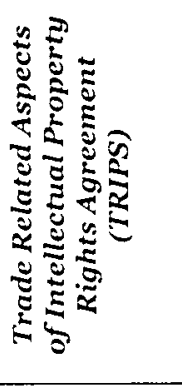 & & 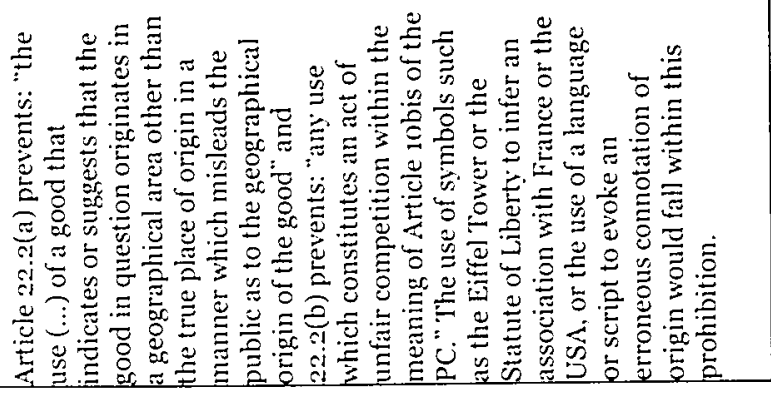 \\
\hline 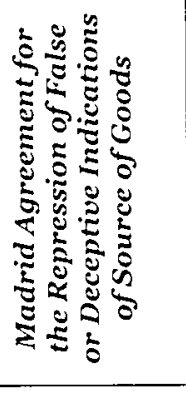 & & 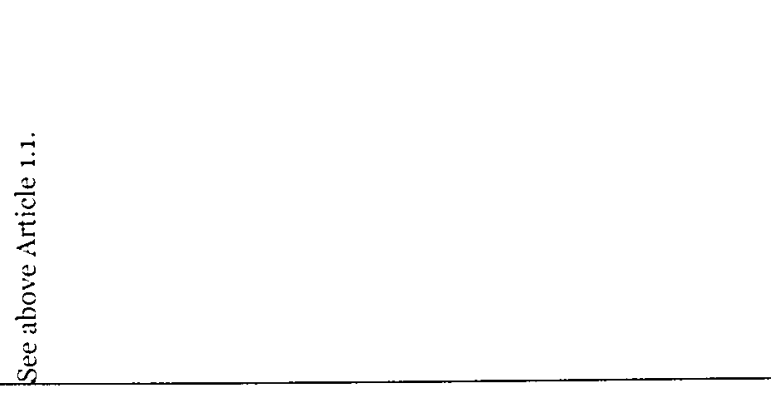 \\
\hline 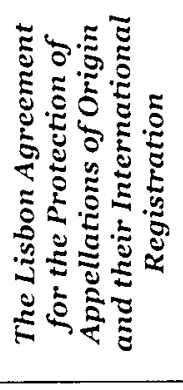 & 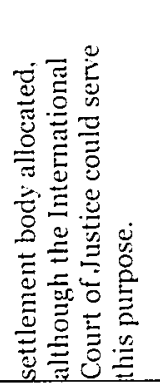 & 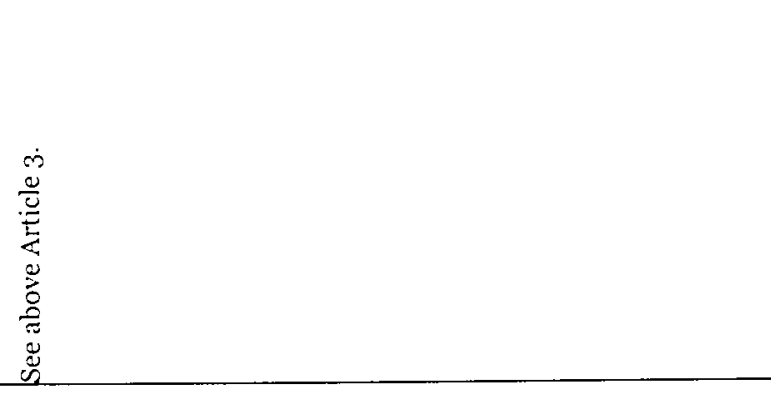 \\
\hline \multirow[t]{2}{*}{ 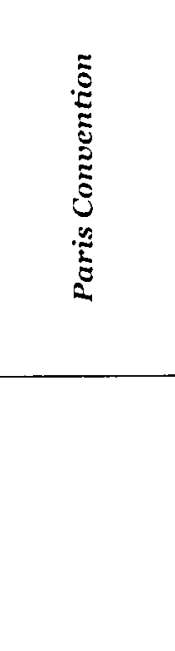 } & & 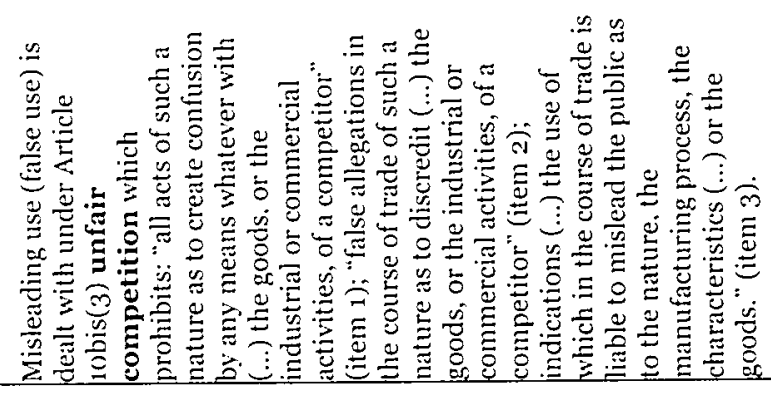 \\
\hline & 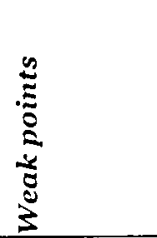 & 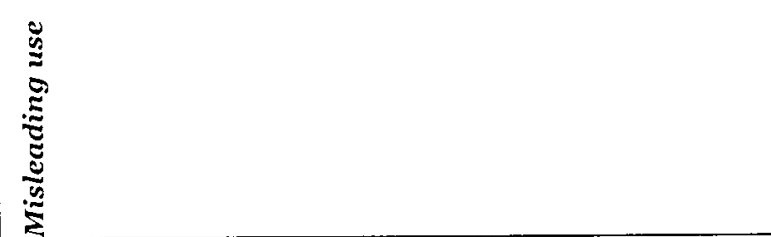 \\
\hline
\end{tabular}




\begin{tabular}{|c|c|c|c|c|}
\hline 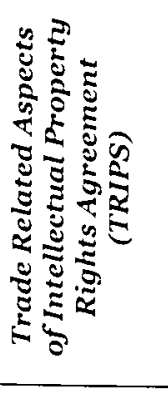 & 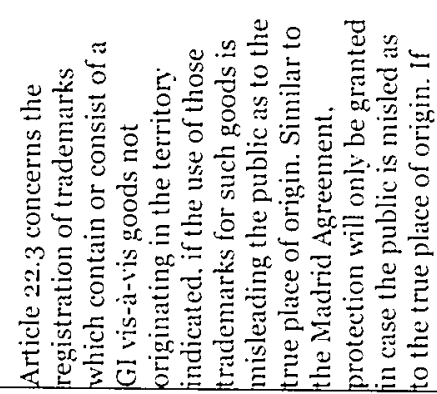 & 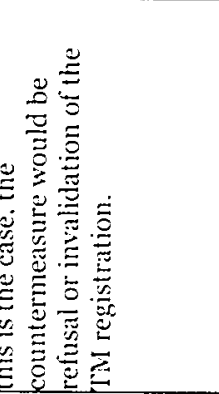 & & 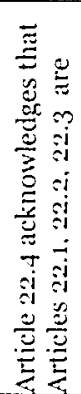 \\
\hline 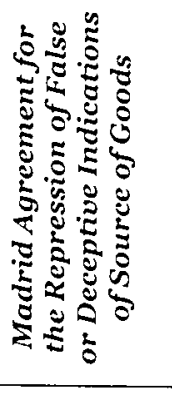 & & & & 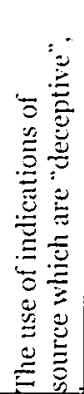 \\
\hline 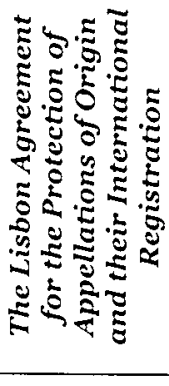 & & & & 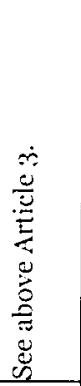 \\
\hline \multirow[t]{2}{*}{ 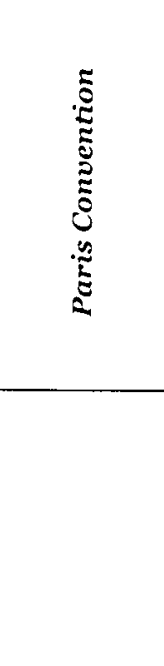 } & 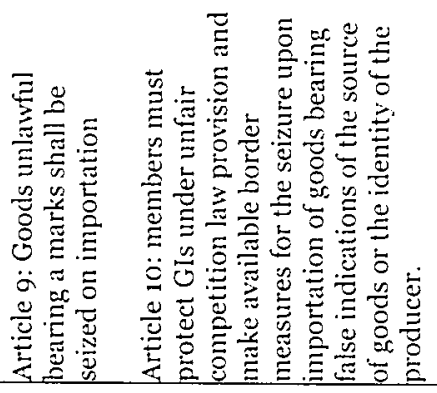 & 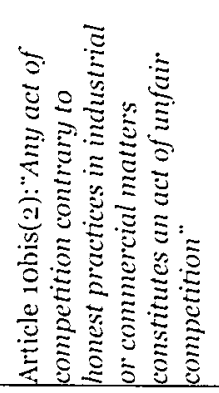 & 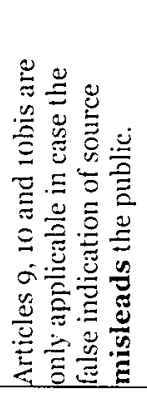 & $x$ \\
\hline & \multicolumn{3}{|l|}{ 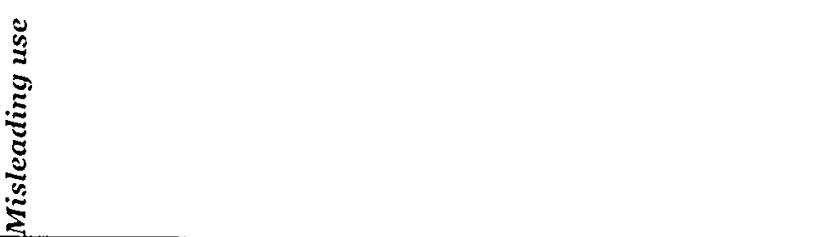 } & 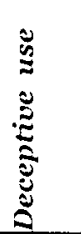 \\
\hline
\end{tabular}


ANNIXTWO

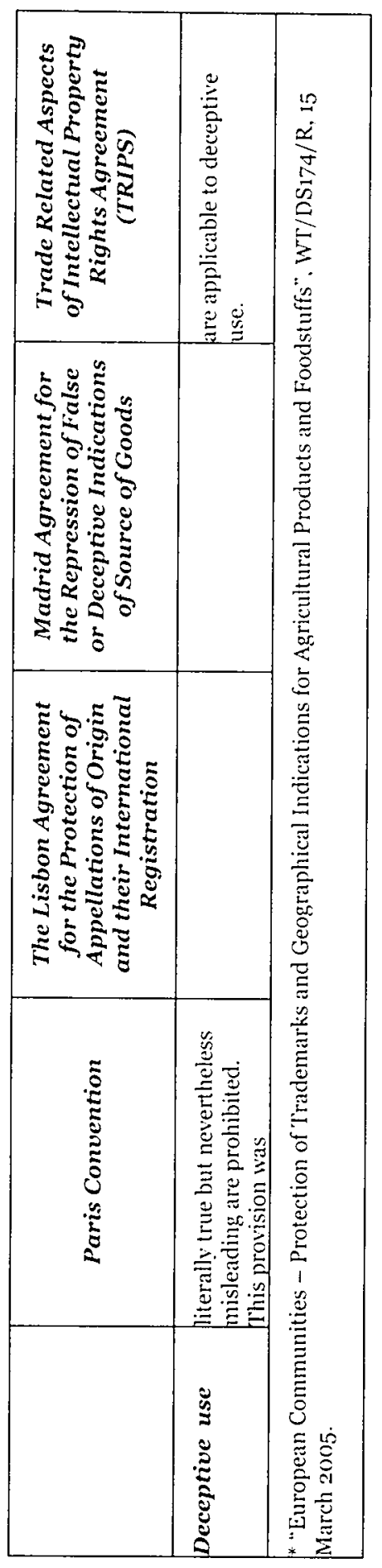




\title{
Annex Three
}

\section{Draft International Code of Conduct on the Transfer of Technology 1}

\author{
[1985 version] Unctad
}

\section{INTRODLICTION}

\section{I'reamble}

The United Nations Conference on an International Code of Conduct on the Transfer of Technology:

1. Recognizing the fundamental role of science and technology in the socio-economic development of all countries, and in particular, in the acceleration of the development of the developing countries;

2. Believing that technology is key to the progress of mankind and that all peoples have the right to benefit from the advances and developments in science and technology in order to improve their standards of living;

3. Bearing in mind relevant decisions of the Ceneral Assembly and other bodies of the United Nations, in particular UNCTAD, on the transfer and development of technology;

4. Recognizing the need to facilitate an adequate transfer and development of technology so as to strengthen the scientific and technological capabilities of all countries, particularly the developing countries, and to co-operate with the developing countries in their own efforts in this field as a decisive step in the progress towards the establishment of a new international economic order;

5. Desirous of promoting international scientific and technological co-operation in the interest of peace, security and national independence and for the benefit of all nations;

6. Striving to promote an increase of the international transfer of technology with an equal opportunity for all countries to participate irrespective of their social and economic system and of their level of economic development;

7. Recognizing the need for developed countries to grant special treatment to the developing countries in the field of the transfer of technology;

8. Drawing attention to the need to improve the flow of technological information, and in particular to promote the widest and fullest flow of information on the availability of alternative techologies, and on the selection of appropriate technologies suited to the specific needs of developing countries;

9. Believing that a Code of Conduct will effectively assist the developing countries in their selection, acquisition and effective use of technologies appropriate to their needs in order to develop improved economic standards and living conditions;

1 Published on the internet at: <http://stdev.unctad.org/compendium/documents/ totcode $\% 20 . h \mathrm{tml}>$. 
10. Believing that a Code of Conduct will help to create conditions conducive to the promotion of the international transfer of technology, under mutually agreed and advantageous terms to all parties; $11.1 /: 12.1 /$

\section{Chapter 1 - Definitions and Scope of Application}

\section{I. For the purposes of the present Code of Conduct:}

(a) "Party" means any person, either natural or juridical, of public or private law, either individual or collective, such as corporations, companies, firms, partnerships and other associations, or any combination thereof, whether created, owned or controlled by States, Government agencies, juridical persons, or individuals, wherever they operate, as well as States, Government agencies and international, regional and subregional organizations, when they engage in an international transfer of technology transaction which is usually considered to be of a commercial nature. The term "party" includes, among the entities enumerated above, incorporated branches, subsidiaries and affiliates, joint ventures or other legal entities regardless of the economic and other relationships between and among them. 2 /

(b) "Acquiring party" means the party which obtains a licence to use or to exploit, purchases or otherwise acquires technology of a proprictary or non-proprietary nature and/or rights related thereto in a transfer of technology.

(c) "Supplying party" means the party which licenses, sells, assigns or otherwise provides technology of a proprietary on non-proprietary nature and/or rights related thereto in a transfer of technology.

1.2. Transfer of technology under this Code is the transfer of systematic knowledge for the manufacture of a product, for the application of a process or for the rendering of a service and does not extend to the transactions involving the mere sale or mere lease of goods.

1.3. Transfer of technology transactions are arrangements between partics involving transfer of technology, as defined in paragraph 1.2 above, particularly in each of the following cases:

(a) The assignment, sale and licensing of all forms of industrial property, except for trade marks, service marks and trade names when they are not part of transfer of technology transactions;

(b) The provision of know-how and technical expertise in the form of feasibility studies, plans, diagrams, models, instructions, guides, formulac, basic or detailed engineering designs, specifications and equipment for training, services involving technical advisory and managerial personnel, and personnel training;

(c) The provision of technological knowledge necessary for the installation, operation and functioning of plant and equipment, and turnkey projects;

(d) The provision of technological knowledge necessary to acquire, install and use machinery, equipment, intermediate goods and/or raw materials which have been acquired by purchase, lease or other means;

(e) The provision of technological contents of industrial and technical co-operation arrangements. 


\subsection{International transfer of technology transactions. $3 /$}

1.5. The Code of Conduct is universally applicable in scope and is addressed to all parties to transfer of technology transactions and to all countries and groups of countries, irrespective of their economic and political systems and their levels of development.

1.6. Regional groupings of States. 4 /

\section{Chapter 2 - Objectives and Principles}

2. The Code of Conduct is based on the following objectives and principles:

\subsection{Objectives}

(i) To establish general and equitable standards on which to base the relationships among parties to transfer of technology transactions and governments concerned, taking into consideration their legitimate interests, and giving due recognition to special needs of developing countries for the fulfilment of their economic and social development objectives.

(ii) To promote mutual confidence between parties as well as their governments.

(iii) To encourage transfer of technology transactions, particularly those involving developing countries, under conditions where bargaining positions of the parties to the transactions are balanced in such a way as to avoid abuses of a stronger position and thereby to achieve mutually satisfactory agreements.

(iv) To facilitate and increase the international flow of technological information, particularly on the availability of alternative technologies, as a prerequisite for the assessment, selection, adaptation, development and use of technologies in all countries, particularly in developing countries.

(v) To facilitate and increase the international flow of proprietary and non-proprietary technology for strengthening the grow th of the scientific and technological capabilities of all countries, in particular developing countries, so as to increase their participation in world production and trade.

(vi) To increase the contributions of technology to the identification and solution of social and economic problems of all countries, particularly the developing countries, including the development of basic sectors of their national economies.

(vii) To facilitate the formulation, adoption and implementation of national policies, laws and regulations on the subject of transfer of technology by setting forth international norms.

(viii) To promote adequate arrangements as regards unpackaging in terms of information concerning the various elements of the technology to be transferred, such as that required for technical, institutional and financial evaluation of the transaction, thus avoiding undue or unnecessary packaging.

(ix) To specify restrictive [business] practices from which parties to technology transfer transactions [shall] [should] refrain. $\underline{5}$ / 
(x) To set forth an appropriate set of responsibilities and obligations of parties to transfer of technology transactions, taking into consideration their legitimate interests as well as differences in their bargaining positions.

\subsection{Principles}

(i) The Code of Conduct is universally applicable in scope.

(ii) States have the right to adopt all appropriate measures for facilitating and regulating the transfer of technology, in a manner consistent with their international obligations, taking into consideration the legitimate interests of all parties concerned, and encouraging transfers of technology under mutually agreed, fair and reasonabie terms and conditions.

(iii) The principles of sovereignty and political independence of States (covering, inter alia, the requirements of foreign policy and national security) and sovereign equality of States, shoukd be recognized in facilitating and regulating transfer of technology transactions.

(iv) States should co-operate in the international transfer of technology in order to promote economic growth throughout the world, especially that of the developing countries. Co-operation in such transfer should be irrespective of any differences in political, economic and social systems; this is one of the important elements in maintaining international peace and security and promoting international conomic stability and progress, the general welfare of nations and international co-operation free from discrimination based on such differences. Nothing in this Code may be construed as impairing or derogating from the provisions of the Charter of the United Nations or actions taken in pursuance thereof. It is understood that special treatment in transfer of technology should be accorded to developing countries in accordance with the provisions in this Code on the subject.

(v) The separate responsibilities of parties to transfer of technology transactions, on the one hand, and those of governments when not acting as parties, on the other, should be clearly distinguished.

(vi) Mutual benefits should accrue to technology supplying and recipient parties in order to maintain and increase the international flow of technology.

(vii) Facilitating and increasing the access to technology, particularly for developing countries, under mutually agreed fair and reasonable terms and conditions, are fundamental elements in the process of technology transfer and development.

(viii) Recognition of the protection of industrial property rights granted under national law.

(ix) Technology supplying partics when operating in an acquiring country should respect the sovereignty and the laws of that country, act with proper regard for that country's declared development policies and priorities and endeavour to contribute substantially to the development of the acquiring country. The freedom of parties to negotiate, conclude and perform agreements for the transfer of technology on mutually acceptable terms and conditions should be based on respect for the foregoing and other principles set forth in this Code. 


\section{Chapter 3 - National Regulation of Transfer of Technology Transactions}

3.1. In adopting, and in the light of evolving circumstances making necessary changes in laws, regulations and rules, and policies with respect to transfer of technology transactions, States have the right to adopt measures such as those listed in paragraph 3.4 of this chapter and should act on the basis that these measures should:

(i) Recognize that a close relationship exists between technology flow's [and] the conditions under which such flows are admitted and treated;

(ii) Promote a favourable and beneficial climate for the international transfer of technology;

(iii) Take into consideration in an equitable manner the legitimate interests of all parties;

(iv) Encourage and facilitate transfers of technology to take place under mutually angeed, fair and reasonable terms and conditions having regard to the principles and objectives of the Code;

(v) Take into account the differing factors characterizing the transactions such as local conditions, the nature of the technology and the scope of the undertaking;

(vi) Be consistent with their international obligations.

3.2. Measures adopted by States including decisions of competent administrative bodies should be applied fairly, equitably, and on the same basis to all parties in accordance with established procedures of law and the principles and objectives of the Code. Laws and regulations should be clearly defined and publicly and readily available. To the extent appropriate, relevant information regarding decisions of competent administrative bodies should be disseminated.

3.3. Each country adopting legislation on the protection of industrial property should have regard to its national needs of economic and social development, and should ensure an effective protection of industrial property rights granted under its national law and other related rights recognized by its mational law.

3.4. Measures on regulation of the flow and effects of transfer of technology, finance and technical aspects of technology transactions and on organizational forms and mechanisms may deal with:

\section{Finance}

(a) Currency regulations of foreign exchange payments and remittances;

(b) Conditions of domestic credit and financing facilitics;

(c) Transferability of payments;

(d) Tax treatment;

(c) Pricing policies; 


\section{Renegotiation}

(f) Terms, conditions and objective criteria for the renegotiation of transfer of fechnology transactions;

\section{Technical aspects}

(g) Technology specifications and standards for the various components of the transfer of technology transactions and their payments;

(h) Analysis and evaluation of transfer of technology transactions to assist parties in their negotiations;

(i) Use of local and imported components;

\section{Organizational forms and mechanisms}

(i) Evaluation, negotiation, and registration of transfer of technology transactions;

(k) Terms, conditions, duration, of transfor of technology transactions;

(1) Loss of ownership and/or control of domestic acquiring enterprises;

(m) Regulation of foreign collaboration arrangements and agreements that could displace national enterprises from the domestic market;

(n) The definition of fields of activity of foreign enterprises and the choice of channels, mechanisms, organizational forms for the transfer of technology and the prior or subsequent approval of transfer of technology transactions and their registration in these fields;

(o) The determination of the legal effect of transactions which are not in conformity with national laws, regulations and administrative decisions on the transfer of technology;

(p) The establishment or strengthening of national administrative mechanisms for the implementation and application of the Code of Conduct and of national laws, regulations and policies on the transfer of technology;

(q) Promotion of appropriate channels for the international exchange of information and experience in the field of the transfer of technology.

\section{Chapter $4 \underline{6} /$}

The regulation of practices and arrangements involving the transfer of technology] [Restrictive business practices] [Exclusion of political discrimination and restrictive business practices] ?/

Section A: (Chapeau) $\underline{8} /$

Section B: (List of practices) 9 /

1. [Exclusive] ${ }^{\star \star}$ Grant-back provisions 10/ 
Requiring the acquiring party to transfer or grant back to the supplying party, or to any' other enterprise designated by the supplying party, improvements arising from the acequired technology, on an exclusive basis [or $]^{*}$ without offsetting consideration or recipreal obligations from the supplying party, or when the practice will constitute an abuse of a dominant market position of the supplying party.

\section{Challenges to validity $10 /$}

[Unreasonably' ** requiring the acquiring party to refrain from challenging the validity of patents and other types of protection for inventions involved in the transfer or the validity of other such grants claimed or obtained by the supplying party, recognizing that any issues concerning the mutual rights and obligations of the parties following such a challenge will be determined by the appropriate applicable law and the terms of the agreement to the extent consistent with that law. 11/

\section{Exclusive dealing}

Restrictions on the freedom of the acquiring party to enter into sales, representation or manufacturing agreements relating $t o$ similar or competing technologies or products or to obtain competing lechnology, when such restrictions are not needed for ensuring the achievement of legitimate interests, particularly including securing the confidentiality of the technology transferred or best effort distribution or promotional obligations.

\section{Restrictions on research $\underline{10 /}$}

[Unreasonably! $]^{\star \star} /^{* \star *}$ restricting the acquiring party either in undertaking research and development directed to absorb and adapt the transferred technology to local conditions or in initiating research and development programmes in connection with new products, processes or equipment.

\section{Restrictions on use of personnel 10/}

[Uneasonably] ** requiring the acquiring party to use personnel designated by the supplying party, except to the extent necessary to ensure the efficient transmission phase for the transfer of technology and putting it to use or thereafter continuing such requirement beyond the time when adequately trained local personnel are available or have been trained; or prejudicing the use of personnel of the technology acquiring country.

\section{Price fixing 10/}

[Unjustifiably. $]^{\star \star}$ imposing regulation of prices to be charged by acquiring parties in the relevant market to which the technology was transferred for products manufactured or services produced using the technology supplied.

\section{Restrictions on adaptations $10 /$}

Restrictions which [unreasonably] ${ }^{\star \star}$ prevent the acquiring party from adapting the imported technology to local conditions or introducing innovations in it, or which oblige the acquiring party to introduce unwanted or unnecessary design or specification changes, if the acquiring party makes adaptations on his own responsibility and without using the technology supplying party's name, trade or service marks or trade names, and except to the extent that this adaptation unsuitably affects those products, or the process for their manufacture, to be supplied to the supplying party, his 
designates, or his other licensees, or to be used as a component or spare part in a product to be supplied to his customers.

\section{Exclusive sales or representation agreements}

Requiring the aceuiring party to grant exclusive sales or representation rights to the supplying party or any person designated by the supplying party, except as to subcontracting or manufacturing arrangements wherein the parties have agreed that all or part of the production under the technology transfer arrangement will be distributed by the supplying party or any person designated by him.

\section{Tying arrangements $10 /$}

[Unduly $]^{\star *}$ imposing acceptance of additional technology, future inventions and improvements, goods or services not wanted by the acquiring party or [unduly] ${ }^{\star *}$ restricting sources of technology, goods or services, as a condition for obtaining the technology required when not required to maintain the quality of the product or service when the supplier's trade or service mark or other identifying item is used by the acquiring party, or to fulfil a specific performance obligation which has been guaranteed, provided further that adequate specification of the ingredients is not feasible or would involve the disclosure of additional technology not covered by the arrangement.

\section{Export restrictions $8 /$}

\section{Patent pool or cross-licensing agreements and other arrangements}

Restrictions on territories, quantities, prices, customers or markets arising out of patent pool or cross-licensing agreements or other international transfer of technology interchange arrangements among technology suppliers which unduly limit access to new technological developments or which would result in an abusive domination of an industry or market with adverse effects on the transfer of technology, except for those restrictions appropriate and ancillary to co-operative arrangements such as co-operative research arrangements.

\section{Restrictions on publicity $10 /$}

Restrictions [unreasonably] ${ }^{\star \star}$ regulating the advertising or publicity by the acquiring party except where restrictions of such publicity may be required to prevent injury to the supplying party's goodwill or reputation where the advertising or publicity makes reference to the supplying party's name, trade or service marks, trade names or other identifying items, or for legitimate reasons of avoiding product liability when the supplying party may be subject to such liability, or where appropriate for safety' purposes or to protect consumers, or when needed to secure the confidentiality of the technology transferred.

\section{Payments and other obligations after expiration of industrial property rights}

Requiring payments or imposing other obligations for continuing the use of industrial property rights which have been invalidated, cancelled or have expired recognizing that any other issue, including other payment obligations for technology, shall be dealt with by the appropriate applicable law and the terms of the agreement to the extent consistent with that law. 11/ 


\section{Restrictions after expiration of arrangement 8 /}

\section{Chapter 5 - Responsibilities and Obligations of Parties}

\section{Common provision on negotiating as well as contractual phase}

5.1. When negotiating and concluding a technology transfer agreement, the parties should, in accordance with this chapter, be responsive to the economic and social development objectives of the respective countries of the parties and particularly of the technology acquiring country, and when negotiating, concluding and performing a technology transfer agreement, the parties should observe fair and honest business practices and take into account the specific circumstances of the individual case and recognition should be given to certain circumstances, mainly the stage of development of technology, the economic and technical capabilities of the parties, the nature and type of the transaction such as any ongoing or continuous flow of technology between the partics.

\section{Negotiating phase}

5.2. In being responsive to the economic and social development objectives mentioned in this chapter each party should take into account the other's request to include in the agreements, to the extent technically and commercially practicable and for adequate consideration, when appropriate, such as the case in which the supplying party incurs additional costs or efforts, items clearly related to the official ecomomic and social development objectives of the country of the requesting party as enunciated by its government. Such items include, inter alia, where applicable:

\section{(a) Use of locally available resources}

(i) specific provisions for the use for the tasks concerned of adequately trained or otherwise suitable local personnel to be designated and subsequently made available by the potential technology recipient including managerial personnel, as well as for the training of suitably skilled local personnel to be designated and subsequently made available by the potential technology recipient;

(ii) specific provisions for the use of locally available materials, technologies, technical skills, consultancy and engineering services and other resources to be indicated and subsequently made arailable by the potential technology recipient;

\section{(b) Rendering of technical services}

Specific provisions for the rendering of technical services in the introduction and operation of the technology to be transferred;

\section{(c) Unpackaging}

Upon request of the potential acquiring party, the potential supplying party should, to the extent practicable, make adequate arrangements as regards unpackaging in terms of information concerning the various elements of the technology to be transferred, such as that required for technical, institutional and financial evaluation of the potential supplying party's offer. 


\subsection{Business negotiating practices}

When negotiating a technology transfer agreement, the parties should observe fair and honest business practices and therefore:

\section{(a) Both potential parties}

\section{(i) Fair and reasonable terms and conditions}

(i) Should negotiate in good faith with the aim of reaching, in a timely manner, an agreement containing fair and reasonable commercial terms and conditions, including agreement on payments such as licence fees, royalties and other considerations;

(ii) The price or consideration to be charged should be fair and reasonable, it should be clearly indicated and, to the extent practicable, specified in such a manner that the acquiring party would be able to appreciate its reasonableness and fairness by comparing it to the price or consideration for other comparable technologies transferred under similar conditions, which may be known to him;

\section{(ii) Relevant information}

Should consider requests to inform each other, to the extent appropriate, about their prior arrangements which may affect the contemplated technology transfer;

\section{(iii) Confidential information}

Should keep secret, in accordance with any obligation, either legal or contractual, all confidential information received from the other party and make use of the confidential information received from a potential party only for the purpose of evaluating this party's offer or request for other purposes agreed upon by the parties;

\section{(iv) Termination of negotiations}

May cease negotiations if, during the negotiations, either party determines that a satisfactory agreement cannot be reached;

\section{(b) The potential acquiring party}

\section{Relevant information}

Should provide the potential technology' supplier in a timely manner with the available specific information concerning the technical conditions and official economic and social development objectives as well as legislation of the acquiring country relevant to the particular transfer and use of the technology under negotiation as far as such information is needed for the supplying party's responsiveness under this chapter;

\section{(c) The potential supplying party}

\section{Relevant information}

(i) Should disclose, in a timely manner, to the potential technology acquiring party any reason actually known to him, on account of which the technology to be supplied, when used in accordance with the terms and conditions of the proposed agreenent, would not meet particular health, safety and environmental requirements in the technology 
acquiring country, already known to him as being relevant in the specific case or which have been specifically drawn to his attention, as well as any serious health, safety and environmental risks known by the supplier associated with the use of the technology and of products to be produced by it;

(ii) Should disclose to the potential lechnology acquiring party, to the actual extent known to him, any limitation, including any pending official procedures or litigation which adversely concerns, in a direct manner, the existence or validity of the rights to be transferred, on his entitlement to grant the rights or render the assistance and services specified in the proposed agreement;

\section{Provision of accessories, spare parts and components}

(iii) Should to the extent feasible, take into account the request of the acquiring party to provide it for a period to be specified with accessories, spare parts and components produced by the supplying party and necessary for using the technology to be transferred, particularly where alternative sources are unavailable.

\section{Contractual phase - Chapeau}

5.4. The technology transfer agreement should, in accordance with 5.1., provide for mutually acceptable contractual obligations, including those relating to payments and, where appropriate, inter alia, the following:

\section{(i) Access to improvements}

Access for a specified period or for the lifetime of the agreement to improvements to the technology transferred under the agreement;

\section{(ii) Confidentiality 12/}

\section{(iii) Dispute settlement and applicable law 12/}

\section{(iv) Description of the technology}

The technology supplier's guarantee that the technology meets the description contained in the technology transfer agreement;

\section{(v) Suitability for use}

The technology supplier's guarantee that the technology, if used in accordance with the supplier's specific instructions given pursuant to the agreement, is suitable for manufacturing of goods or production of services as agreed upon by the parties and stipulated in the agreement;

\section{(vi) Rights to the technology transferred}

The technology supplier's representation that on the date of the signing of the agreement, it is, to the best of its knowledge, not aware of third parties' valid patent rights or similar protection for inventions which would be infringed by the use of the technology when used as specified in the agreement; 


\section{(vii) Quality levels and goodwill}

The technology recipient's commitment to observe quality levels agreed upon in cases where the agreement includes the use of the supplier's trade marks, trade names or similar identification of goodwill, and both parties' commitment to avoid taking actions primarily or deliberately intended to injure the other's goodwill or reputation;

\section{(viii) Performance guarantees}

Specification to technical performance parameters which the supplying party has agreed to guarantee, including specification of requirements for the achievement of such parameters, details of the manner of determining whether the performance has been met and the consequences of failure to meet that performance;

\section{(ix) Transmission of documentation}

The supplying party's commitment that relevant technical documentation and other data required from him for a particular purpose defined in terms directly specified in the agreement will be transferred in a timely manner and as correctly and completely for such purpose as agreed upon;

\section{(x) Training of personnel and provision of accessories, spare parts and components}

Where negotiations under paragraphs 5.2 (a) (i) and 5.5 (c) (iii) have taken place, suitable provisions for training of personnel and supply of accessories, spare parts and components would be made, consistent with the results of the negotiations;

\section{(xi) Liability}

Disposition concerning liability for the non-fulfilment by either party of its responsibilities under the technology transfer agreement including questions of loss, damage or injury.

\section{Chapter 6 - Special Treatment for Developing Countries}

6.1. Taking into consideration the needs and problems of developing countries, particularly' of the least developed countries, governments of developed countries, directly or through appropriate international organizations, in order to facilitate and encourage the initiation and strengthening of the scientific and technological capabilities of developing countries so as to assist and co-operate with them in their efforts to fulfil their economic and social objectives, should take adequate specific measures, inter alia, to:

(i) facilitate access by developing countries to available information regarding the availabilities, description, location and, as far as possible, approximate cost of technologies which might help those countries to attain their economic and social development objectives;

(ii) give developing countries the freest and fullest possible access to technologies whose transfer is not subject to private decisions; $\underline{13}$ /

(iii) facilitate access by developing countries, to the extent practicable, to technologies whose transfer is subject to private decisions; $\underline{13}$ / 
(iv) assist and co-operate with developing countries in the assessment and adaptation of existing technologies and in the development of national technologies by facilitating access, as far as possible, to available scientific and industrial research data;

(v) co-operate in the development of scientific and technological resources in developing countries, including the creation and growth of imnovative capacities;

(vi) assist developing countries in strengthening their technological capacity, especially in the basic sectors of their national economy, through creation of and support for laboralories, experimental facilities and institutes for training and research;

(vii) co-operate in the establishment or strengthening of national, regional and/or international institutions, including technology transfer centres, to help developing countries to develop and obtain the technology and skills required for the establishment, development and enhancement of their technological capabilities including the design, construction and operation of plants;

(viii) encourage the adaptation of research and development, engineering and design to conditions and factor endowments prevailing in developing countries;

(ix) co-operate in measures leading to greater utilization of the managerial, engineering, design and technical experience of the personnel and the institutions of developing countries in specific economic and other development projects undertaken at the bilateral and multilateral levels;

(x) encourage the training of personnel from developing countries.

6.2. Governments of developed countries, directly or through appropriate international organizations, in assisting in the promotion of transfer of technology to developing countries - particularly to the least developed countries - should, as a part of programmes for development assistance and co-operation, take into account requests from developing countries to:

(i) contribute to the development of national technologies in developing countries by providing experts under development assistance and research exchange programmes;

(ii) provide training for research, engineering, design and other personnel from developing countries engaged in the development of national technologies or in the adaptation and use of technologies transferred;

(iii) provide assistance and co-operation in the development and administration of laws and regulations with a view to facilitating the transfer of technology:;

(iv) provide support for projects in developing countries for the development and adaptation of new and existing technologies suitable to the particular needs of developing countries;

(v) grant credits on terms more favourable than the usual commercial terms for financing the acquisition of capital and intermediate goods in the context of approved development projects involving transfer of technology transactions so as to reduce the cost of projects and improve the quality of technology received by the developing countries; 
(vi) provide assistance and co-operation in the development and administration of laws and regulations designed to avoid health, safety and envirommental risks associated with technology' or the products produced by it.

6.3. Governments of developed countries should lake measures in accordance with national policies, laws and regulations to encourage and to endeavour to give incentive to enterprises and institutions in their countries, either individually or in collaboration with enterprises and institutions in developing countries, particularly those in the least developed countries, to make special efforts, inter alia, to:

(i) assist in the development of technological capabilities of the enterprises in developing countries, including special training as required by the recipients;

(ii) undertake the development of technology appropriate to the needs of developing countries;

(iii) undertake $\mathrm{R}$ and $\mathrm{D}$ activity in developing countries of interest to such countries, as well as to improve co-operation between enterprises and scientific and technological institutions of developed and developing countries;

(iv) assist in projects by enterprises and institutions in developing countries for the development and adaptation of new and existing technologies suitable to the particular needs and conditions of developing countries.

6.t. The special treatment accorded to developing countries should be responsive to their economic and social objectives vis-a-vis their relative stage of economic and social development and with particular attention to the special problems and conditions of the least developed countries.

\section{Chapter 7 - International Collaboration}

7.1. The States recognize the need for appropriate international collaboration among governments, intergovernmental bodies, and organs and agencies of the United Nations system, including the international institutional machinery provided for in this Code, with a view to facilitating an expanded international flow of technology for strengthening the technological capabilities of all countries, taking into account the objectives and principles of this Code, and to promoting the effective implementation of its provisions.

7.2. Such international collaboration between governments at the bilateral or multilateral, subregional, regional or interregional levels may include, inter alia, the following measures:

(i) Exchange of available information on the availability and description of technologies and technological alternatives;

(ii) Exchange of available information on experience in seeking solutions to problems relating to the transfer of technology, particularly restrictive [business] $]^{\star \star}$ practices in the transfer of technology; 14 /

(iii) Exchange of information on development of national legislation with respect to the transfer of technology; 
(iv) Promotion of the conclusion of international agreements which should provide equitable treatment for both technology supplying and recipient parties and governments;

(v) Consultations which may lead to greater harmonization, where appropriate, of national legislation and policies with respect to the transfer of teclinology;

(vi) Promotion, where appropriate, of common programmes for searching for, acquiring and disseminating technologies;

(vii) Promotion of programmes for the adaplation and development of technology in the context of development objectives;

(viii) Promotion of the development of scientific and techological resources and capabilities stimulating the development of indigenous technologies;

(ix) Action through international agreements to avoid, as far as possible, imposition of double taxation on earnings and payments arising out of transfer of technology transactions.

\section{Chapter 8 - International Institutional Machinery}

\subsection{Institutional arrangements}

(a) $\underline{15} /$

(b) $\underline{15} /$

(c) States which have accepted the Code of Conduct on the Transfer of Technology should take appropriate steps at the national level to meet their commitment to the code.

\subsection{Functions of the International Institutional Machinery}

8.2.1. The International Institutional Machinery shall have the following functions:

(a) To provide a forum and modalities for consultations, discussion, and exchange of views between States on matters related to the Code, in particular its application and its greater harmonization, and the experience gained in its operations;

(b) To undertake and disseminate periodically studies and research on transfer of technology related to the provisions of the code, with a view to increasing exchange of experience and giving greater effect to the application and implementation of the Code;

(c) To invite and consider relevant studies, documentation and reports from within the United Nations system, particularly from UNIDO and WIPO;

(d) To study matters relating to the Code and which might be characterized by data covering transfer of technology transactions and other relevant information obtained upon request addressed to all States;

(e) To collect and disseminate information on matters relating to the Code, to the overall attainment of its goals and to the appropriate steps States have taken at the national level to promote an effective Code, including its objective and principles; 
(f) To make appropriate reports and recommendations to States on matters within its competence including the application and implementation of the Code;

(g) To organize symposia, workshops and similar meetings concerning the application of the provisions of the Code, subject to the approval of the Trade and Development Board where financing from the regular butget is involved;

(h) To submit reports at least once a year on its work to the Trade and Development Board.

8.2.2. In the performance of its functions, the International Institutional Machinery may not act like a tribunal or otherwise pass judgement on the activities or conduct of individual Covernments or of individual parties in comnection with a specific transfer of technology transaction. The International Institutional Machinery should avoid becoming involved when parties in a specific transfer of technology transaction are in dispute.

8.2.3. The International Institutional Machinery shall establish such procedures as may be necessary to deal with issues related to confidentiality.

\subsection{Review procedure 15/}

\subsection{Secretariat}

The secretariat for the International Institutional Machinery shall be the UNCTAD secretariat. At the request of the Intemational Institutional Machinery the secretariat shall submit relevant studies, documentation and other information to the International Institutional Machinery. It shall consult with and render assistance, by the relevant services, to States, particularly the developing countries, at their request, in the application of the Code at the national level, to the extent that resources are available.

\subsection{General provisions $15 /$}

\section{Chapter 9 - Applicable law and settlement of disputes 16 /}

\section{ENDNOTES}

1/ For texts under consideration, see appendices A and F.

2/ Group 2 accepts inclusion of this sentence subject to agreement to be reached on qualifications relating to the application of the Code to the relations of these entities in relevant parts of the Code.

3/ For texts under consideration, see appendices $A$ and $C$.

4/ Text under consideration. See proposal in appendix $C$.

5/ Text under consideration. See also appendix $\mathrm{A}$.

6/ In view of continuing negotiations on the chapter, no attempt has been made to number the provisions of this chapter consistently with the other chapters.

7/ Title of Chapter 4 under consideration. 
8/ For texts under consideration, see appendices $\mathrm{A}$ and $\mathrm{D}$.

9/ With regard to practices 15 to 20 , see appendix A.I for text of agreed statement for inclusion in the report of the Conference, and for texts under consideration see appendix D.

10/ Text under consideration. See appendix $A$.

11/ The spokesman for the regional groups noted that their acceptance of agreed language which makes reference to the term "applicable law" is conditional upon acceptable resolution of differences in the group texts concerning applicable law and national regulation of this Code.

12/ For text under consideration, see appendix A.

13/ The term "private decision" in the particular context of this chapter should be officially interpreted in the light of the legal order of the respective country.

14/ Text under consideration; see also appendix $\mathrm{A}$.

15/ For texts under consideration, see appendices $A$ and $E$.

16/ For texts under consideration, see appendices $A$ and $F$. 



\section{Curriculum Vitae}

Fleur Claessens was born on the 19 th of July 1976 in Sittard, the Netherlands. She obtained her first Law Degree with a specialisation in European law and languages from the University of Maastricht in 1999. Pursuant, she gained a scholarship to participate in a German academic exchange service (DAAD) programme for young lawyers. After her studies, in 2000, she joined Grolsch as a company lawyer in Enschede, The Netherlands. Pursuant, she joined the Department of Private Law, Faculty of Law at Maastricht University as a junior researcher to work on her doctoral research and to teach IPR courses (2002-2006). She obtained her Masters of Law (Merit) from Queen Mary College, University of London in December 2005. She joined the United Nations Conference on Trade and Development (UNCTAD) in Geneva, Switzerland in October 2008 as an Economics Affairs Officer. Prior to joining the United Nations, Fleur Claessens worked nearly two years for the International Centre for Trade and Sustainable Development (ICTSD) also based in Geneva, as a Programme Officer for the Intellectual Property and Sustainable Development Team. 